\title{
Die Selbstmörderin als Tugendheldin
}

Ein frühneuzeitliches Bildmotiv und seine Rezeptionsgeschichte

\author{
Dissertation \\ zur Erlangung des philosophischen Doktorgrades \\ an der Philosophischen Fakultät \\ der Georg-August-Universität Göttingen \\ vorgelegt von
}

Renate Schrodi-Grimm

aus Ehingen/Donau

Göttingen 2009 
1. Gutachter: Prof. Dr. Werner Schnell

2. Gutachter: Prof. Dr. Carsten-Peter Warncke

3. Gutachter: Prof. Dr. Fidel Rädle

Tag der mündlichen Prüfung: 20. Januar 2009 
Bene mori est libenter mori

Seneca

Meditare mortem: qui hoc dicit, meditari libertatem iubet.

Lipsius

Sed virtus pulchreque necis generosa cupido Vicit vitae ignominiam, insidiasque tiranni, Libertas nam parta nece est, nec vincula sensi, Umbraque tartareas descendi libera ad undas,

Castiglione

[...] una bella e glorïosa morte illustra tutta la passata vita

Trissino

[...] Nichts / als der Tod nur kann

Der Freyheits-Ancker sein

Lohenstein

Morte bramata in ogni etade è cara.

Vivaldi

Wie mutig hat ihr Geist gerungen, Da sie des Todes Arm bezwungen, Noch ehe ihre Brust besiegt.

Gottsched 
Vorwort $\quad 7$

I schönes Sterben` 12

1 Ein slebendes Bildr im Fin de siècle $\quad 12$

2 >Die schöne Toter - ein Motiv des 19. Jahrhunderts 14

3 Der Tod des Helden $\quad 18$

4 >Mourir en philosopher $\quad 20$

5 > Starke Frauen

6 >Exemplum virtutisı 25

II Sterbebildtypen und Todesdarstellung bis zur Frühen Neuzeit 29

1 Die klassizistische Engführung 29

2 Thanatos und Hypnos: Sterben in der antiken Kunst 31

3 Der personifizierte Tod in Spätantike und Mittelalter 33

4 Mittelalterliche Kontingenzerfahrung: Totentanz 34

5 artes moriendi $\quad 35$

6 Der Marientod als Modell des guten Sterbens 36

7 Monumentale Grabmäler $\quad 37$

8 Der Kreuzestod: Vom Triumph zur compassio 39

9 Märtyrer $\quad 41$

10 Erweiterung der Bildthemen im Humanismus und in der Frühen 42 Neuzeit

III Bildthemen exemplarischen Sterbens $\quad 45$

1 Exemplarisches Sterben in der frühneuzeitlichen Historienmalerei $\quad 45$

2 Der Verwandlungstod der Metamorphose $\quad 46$

3 Das nachtridentinische Märtyrerbild $\quad 47$

4 Sterbende Helden $\quad 49$

5 Der Tod des Philosophen 50

6 Die Selbstmörderin als Tugendheldin $\quad 52$

7 Gegenstand der Untersuchung 54

IV Sophonisbe: Liebe, Patriotismus und Selbstbestimmung 57

$\begin{array}{ll}\text { Antike Quellen } & 59\end{array}$

Spätmittelalterliche Rezeption $\quad 63$

Von der Novelle zur Tragödie $\quad 68$

Ikonographische Entwicklung in der Frühen Neuzeit 78

Ikonographie der Historienmalerei $\quad 85$

V Römische Tugendheldinnen in der Ikonographie der Frühen Neuzeit 103

1 Dido: Herrscherin und Liebende $\quad 103$

$\begin{array}{ll}\text { Antike Quellen } & 103\end{array}$

$\begin{array}{ll}\text { Literarische Rezeption } & 104\end{array}$

Ikonographie der Historienmalerei 108

2 Lukretia: Keuschheit, eheliche Treue, politischer Umsturz 118

$\begin{array}{lr}\text { Antike Quellen } & 118\end{array}$

$\begin{array}{lr}\text { Literarische Rezeption } & 119\end{array}$

Ikonographie der Historienmalerei $\quad 123$ 
3 Kleopatra: Tugendheldin oder femme fatale $\quad 139$

Antike Quellen $\quad 139$

Literarische Rezeption $\quad 139$

Ikonographie der Historienmalerei $\quad 145$

4 Porzia: Republikanerin, Ehefrau und Stoikerin $\quad 166$

Antike Quellen $\quad 166$

Literarische Rezeption $\quad 167$

Ikonographie der Historienmalerei 169

VI Der Neustoizismus: Leitphilosophie der Frühen Neuzeit 177

1 Heroische Tugend und Neustoizismus 177

Exkurs: Die moralphilosophische Wendung des frühneuzeitli- $\quad 179$

chen Humanismus

Exkurs: Die Leitfigur des Neustoizismus: Justus Lipsius 181

2 Die meditatio mortis im neustoischen Denken 184

3 gloire und vertu auf der Bühne $\quad 193$

4 Neustoisches Meditationsbild und nachtridentinisches Andachts- 198 bild

VII Posttridentinische Märtyrer und stoische Tugendhelden $\quad 204$

1 Kirchliche Andachts- und profane Meditationsbilder 204

2 Rubens: Christliche compassio und stoische consolatio 212

3 Reni: s Sehnsuchtshalbfiguren als Meditationsbilder 216

4 Tiepolo: Bene mori est libenter mori 222

5 Posttridentinische Andachtsbilder und neustoische Ikonen 227

VIII Tema con variazioni - Bildprogramme 232

1 Bilder im Bild 232

2 Bildprogramme 233

3 Bildfolgen und Galerien 236

4 >La gallerie des femmes fortesi 254

5 Pendants $\quad 259$

IX Von der vertu zum Affekt $\quad 272$

Oper und Kantate $\quad 272$

1 Affektmodellierung und moralischer Diskurs 272

Exkurs: Die Anfänge der Oper 273

2 Tugendheldinnen in der Oper $\quad 274$

3 Didone abbandonata 276

Exkurs: Kammerkantate $\quad 284$

Monodrama und Attitüde $\quad 288$

4 Die Tugendheldin im Monodrama 288

5 Attitüden: die neuen Ausdruckskünste 294

Exkurs: Illuminationen, >lebende Bilderı und Attitüden 295

6 Das Ende eines Motivs $\quad 300$

$X$ Exempla virtutis $\quad 302$

$\begin{array}{ll}\text { Literaturverzeichnis } & 317\end{array}$ 
Inhaltsübersicht

Ausstellungskataloge $\quad 317$

Bestandskataloge $\quad 325$

Quellentexte $\quad 330$

Forschungsliteratur $\quad 337$

$\begin{array}{ll}\text { Bildkatalog } & 370\end{array}$

Index $\quad 435$

Künstlerverzeichnis $\quad 435$

Personen $\quad 441$

$\begin{array}{ll}\text { Forschung } & 458\end{array}$ 


\section{Vorwort}

Am Ausgangspunkt dieser Untersuchung ${ }^{1}$ stand das > schöne Sterben « weiblicher Protagonisten, das als Thema in der Kunst und Literatur des 19. Jahrhunderts in den letzten Jahren unter Perspektiven, die von der Gender-Forschung bis zur Kulturpsychologie reichen, hinreichend Beachtung gefunden hat. Im ersten Kapitel werden mit dem niederländischen Romancier Couperus und der Kleopatra Makarts typische Beispiele für das Fin de siècle angeführt. Die Verbindung von weiblicher Tugend, Selbstmord und sschönem Sterben` erwies sich als so attraktiv, dass sich die gründliche Untersuchung dieses ikonographischen Musters lohnte, die im Folgenden vorgelegt wird.

Die ästhetisierende und erotisch aufgeladene Darstellung weiblicher Selbstmörderinnen im dekadenten Roman und in der Endphase der Historienmalerei, deren literarische oder historische Vorlagen nur noch anzitiert werden, hat eine faszinierende ikonographische Vorgeschichte. Die ästhetische Entschärfung und moralische Überhöhung des schockierenden weiblichen Selbstmords verweist - so meine These - auf einen neustoischen Hintergrund, der im Lauf der Jahrhunderte immer mehr verblasste und in den `Attitüden des 19. Jahrhunderts gänzlich depotenziert ist.

Dabei trat zunächst die Gruppe ıstarker Frauenı in den Gesichtskreis, die über die bekannten Graphikserien des 17. Jahrhunderts einigen der hier untersuchten Bildthemen, die noch in der späten Historienmalerei des 19. Jahrhunderts aufgegriffen wurden, weite Verbreitung verschafft hatte. Über diese ikonographisch recht geschlossene Gruppe biblischer und römischer Tuge ndheldinnen führte der Weg zum frühneuzeitlichen Bildmotiv der Tugendheldin als Selbstmörderin zurück, das seit dem 16. Jahrhundert in einem überraschend stabilen ikonographischen Muster fünf ıstarke Frauen` umfasste: Sophonisbe, Dido, Lukretia, Kleopatra und Porzia. ${ }^{2}$

\footnotetext{
${ }^{1}$ Belege für die Motti: Se ne ca, Ep. mor. 61,2; Lipsius, Manuductio ad stoicam philosophiam II,2; C a stigli on e, Cleopatra; Tris ino, Sofonisba vv. 338f.; Lo he n stein, Sophonisbe, v. 400; Vivaldi, Tito Manlio (Libretto von Matteo Noris), RV 738-A; G o t t s c h e d, Libretto für die Trauerode BWV 198

${ }^{2}$ Zur Schreibweise vgl. Fussnote 27 auf S. 52.
} 


\section{Vorwort}

Bereits die ersten Überlegungen führten in den Bildbereich exemplarischen Sterbens, der sich in der Frühen Neuzeit entwickelt hatte und neben dem uneigentlichen Verwandlungstod der Metamorphose die sterbenden Helden der Historienmalerei ebenso wie das nachtridentinische Märtyrerbild umfasst. Der Philosophentod und die Selbstmörderin als Tugendheldin bilden in diesem Zusammenhang eine gesonderte Gruppe exemplarischen Sterbens, die dadurch auffällt, dass sie den selbstgewählten Tod zum Vorbild erhebt, und dabei gewissermaßen eine profane Variante des Märtyrerbilds gestaltet, die sich allerdings dadurch abhebt, dass sie eine frühe Form individueller Selbstermächtigung darstellt.

In neueren Untersuchungen wird auf den Zusammenhang des Bildmotivs der sstarken Frauen mit der Rolle der Regentinnen im entstehenden frühneuzeitlichen Staat hingewiesen; dieser Zusammenhang mag die Auswahl antiker Herrscherinnen und römisch-republikanischer Aristokratinnen als Tugendheldinnen plausibel machen, erklärt allerdings nicht den Umstand, dass es sich bei den genannten Bildvorwürfen um Selbstmörderinnen handelt, deren selbstgewählter Tod sie mit dem Bildmotiv des Philosophentods verbindet, für den sich eine vergleichbar stabile Bildgruppe antiker Philosophen gefunden hatte.

Hinter dem erotisch-dekadenten Motiv der schön inszenierten und attraktiv dargebotenen weiblichen Körper des 19. Jahrhunderts zeichnete sich so eine ikonographische Semantik ab, die den freiwilligen Tod ganz im Sinn der neustoischen Lehre als äußerste Selbstbestätigung des Individuums gegenüber politischem oder moralischem Zwang verstand. Ohne die neustoische Hintergrundsphilosophie, die für die frühneuzeitliche Historienmalerei und ihr Tugendkonzept ohnehin konstitutiv ist, war die positive Darstellung des Selbstmords als Tugendtod schwer erklärbar, zumal er in evidentem Gegensatz zur negativen Wertung des Selbstmords im Zeitalter der entstehenden Konfessionen stand. Das in der Frühen Neuzeit entstandene Bildmotiv der Selbstmörderin als Tugendheldin setzt einen unter den Prämissen des Konfessionszeitalters so eklatanten Widerspruch in Szene, dass es sich lohnt, dem semantischen Hintergrundssinn nachzugehen, der es Kardinälen erlaubte, das Bildmotiv profaner Selbstmörderinnen neben Märtyrerinnen in ihre Bildersammlungen aufzunehmen.

Neben Parallelen zum Bildmotiv des Philosophentods drängte sich der Zusammenhang mit den Todesdarstellungen der nachtridentinischen Märtyrerbilder auf. Es war zweifellos kein Zufall, dass neustoische Meditationsbilder wie 


\section{Vorwort}

nachtridentinische Andachtsbilder tugendhaftes Sterben in den Mittelpunkt stellten und in der Ausgestaltung oft zu den gleichen ikonographischen Mitteln griffen. Daraus ergab sich eine Ausgangshypothese, die sich nur teilweise bestätigen ließ und die den Selbstmörder als Tugendhelden in bewusster Konkurrenz zum nachtridentinischen Märtyrerbild sah. Gleichwohl rekurrierten die nachtridentinischen ikonographischen Muster auf die gleichen anthropologischen Versatzstücke des Neustoizismus, die auch von der profanen Historienmalerei übernommen und variiert werden konnten.

Die nähere Untersuchung des Bildmaterials verdeutlichte den engen Zusammenhang des Bildtyps der Selbstmörderin als Tugendheldin mit der frühneuzeitlichen Bühne. In allen Fällen ging die dramatische Gestaltung der Entwicklung des Bildmotivs voraus. Dies erklärt auch, warum die hier untersuchte Gruppe einen solch epochalen Erfolg in der Historienmalerei hatte: an ihr ließ sich in bilddramatischer Zuspitzung der Konflikt zwischen Politik und Liebe darstellen, der auf der neuzeitlichen Theater- und Opernbühne in unterschiedlichen Besetzungen die konkurrierende Herausbildung politischer und individueller Normen gestaltete. Die weitere Entwicklung des Bildmotivs folgte der Entwicklung auf der Bühne. Vor allem die Oper griff das Thema auf und verschob allmählich das Interesse des ikonographischen Motivs vom moralischen Hintergrundssinn auf den dargestellten Affekt, eine Umbesetzung, die sich auch in der Entwicklung der Historienmalerei nachvollziehen lässt. In der Attitüde des ausgehenden 18. Jahrhunderts fallen ebenso wie in den slebenden Bildernı des 19. Jahrhunderts bildkünstlerische und dramatische Entwicklungen geradezu zusammen. Dass zu solchen Inszenierungen bereits ein Erklärungsapparat nötig war, verdeutlicht, warum das ikonographische Muster mit der Inszenierung schöner weiblicher Toter im Fin de siècle zu Ende ging. Es ist auf eine zumindest minimale historische Referenz angewiesen.

Aus der Entstehungsgeschichte der Dissertation ergibt es sich, dass mehrere Ge dankengänge parallel verfolgt werden und bewusst nicht eine einzige stringente Konstruktion durchgehalten wird. Die mögliche Entscheidung, die Untersuchung auf eine einzige Heroine, etwa Kleopatra oder Dido, zu konzentrieren, habe ich verworfen, weil sich dann das umfassendere Thema der Selbstmörderin als Tugendheldin nicht hätte darstellen lassen. Dies hatte zur Folge, dass eine - ohnehin 


\section{Vorwort}

nicht erreichbare - Vollständigkeit des Bildmaterials nicht angestrebt wurde, dafür aber möglichst viele Facetten des Bildbereichs aufgegriffen wurden. Einzelne Wiederholungen ließen sich dabei nicht vermeiden, zumal sich historisch angelegte Kapitel mit thematischen Exkursen abwechseln.

Zu diesen Exkursen im weitesten Sinne gehört das Kapitel über »Sterbebildtypen und Todesdarstellungen bis zur Frühen Neuzeit«, das den historischen Hintergrund zusammenfasst, der erst die Erweiterung der Bildthemen exemplarischen Sterbens im Humanismus verdeutlichen kann. Der Winckelmannsche Klassizismus hat im 18. Jahrhundert nicht nur den Zugang zur mittelalterlichen, sondern auch zu frühneuzeitlichen Todesdarstellungen abgeschnitten. Ebenso ist hier der Abschnitt über den Neustoizismus als »Leitphilosophie der Frühen Neuzeit«zu erwähnen. Ohne diesen ausführlichen Exkurs war der Vergleich posttridentinischer Märtyrer und stoischer Tugendhelden nicht durchzuführen. Hier wie anderswo bin ich gelegentlich auch in den Bildprogrammen über die im Mittelpunkt stehende Gruppe weiblicher Tugendheldinnen hinausgegangen. Dass das behandelte Bildthema nicht ohne ständige Beziehung zur literarischen und dramatischen Entwicklung dargestellt werden kann, zeigt sich im Abschnitt »Von der vertu zum Affekt«, der der allmählichen Umbesetzung des Motivs vom moralischen Diskurs zur Affektmodellierung in Oper, Kantate und Attitüde nachgeht.

Die Bildthemen selbst werden für die fünf Tugendheldinnen in gleicher Weise zusammengestellt: ich gehe stets zunächst auf die antiken Quellen und die literarische Rezeption ein, bevor ich die Ikonographie der Historienmalerei exemplarisch darstelle. Dabei erhielt das Bildmotiv der Sophonisbe besondere Beachtung, weil es dem gegenwärtigen kulturellen Horizont am weitesten entrückt ist, aber auf eine beachtliche ikonographische und dramatische Karriere zurückblicken kann. Neben diesen motivkonzentrierten Darstellungen wird das Bildmaterial im Abschnitt »Posttridentinische Märtyrer und stoische Tugendhelden « ebenso wie im Abschnitt »Tema con variazioni - Bildprogramme « exponiert. In beiden Kapiteln geht es um das zeitgenössische Verständnis der profanen Tugendheldinnen und Selbstmörderinnen: der Vergleich christlicher compassio und stoischer consolatio ebenso wie die Einbindung des Themas in komplexe Bildprogramme kann die Funktion der Bildmotive in der höfischen Welt des europäischen Barock verdeutlichen. Das Schlusskapitel über »Exempla virtutis« steht zwischen einem Exkurs und einer Zusammenfassung; die in der Kunstgeschichte beliebte Funktionsbe- 


\section{Vorwort}

schreibung eines Bildtyps als exemplum virtutis bezeichnet nur das rhetorische Verfahren und kann also allenfalls der Ausgangspunkt einer historisch differenzierten Bildinterpretation sein. ${ }^{3}$

${ }^{3}$ Die Übersetzungen sind, wenn nicht anders angegeben, von R. Schrodi-Grimm. Bei Übersetzungen klassischer, mittelalterlicher und frühneuzeitlicher Originaltexte wurde ein freier, aber die Sache präziser treffender Übersetzungsstil gewählt. 


\section{Schönes Sterben`}

\section{I >Schönes Sterbenء}

\section{Ein slebendes Bildk im Fin de siècle}

In Den Haag wurde im Jahre 1889 ein bis dahin wenig beachteter Schriftsteller, Louis Couperus (1863-1923), mit seinem in täglichen Fortsetzungsfolgen veröffentlichten Erstlingsroman schlagartig bekannt. Er hatte mit der Schilderung der großbürgerlichen Gesellschaft des Fin de siècle, vor allem aber mit der einfühlsamen Beschreibung des Schicksals der Hauptperson Eline Vere, die dem Roman auch den Titel gab, den Nerv der Zeit getroffen und ihr gleichzeitig einen Spiegel vorgehalten. Couperus, der seine Jugend in Batavia verbracht hatte und deshalb nach der Rückkehr aus den Kolonien die Haager Gesellschaft mit geschärftem Auge beobachtete, ließ die hypersensible und wankelmütige Eline an einer Gesellschaft scheitern, die unbedingte Anpassung des Einzelnen an die Banalitäten des täglichen Umgangs verlangte.

Louis Couperus lässt sein Werk Eline Vere, den ersten psychologischen Roman der niederländischen Literatur, mit der Schilderung einer großbürgerlichen Geburtstagsgesellschaft beginnen. Vor einem Champagnersouper werden zum Amüsement der Gäste drei >lebende Bilder` inszeniert. Einige der jungen Leute aus der Großfamilie sind damit beschäftigt, sich hinter dem Vorhang in Szeneı zu setzen, während Cousin Paul die Regie führt. Die Protagonistin des stableau vivant ist bereits auf Kissen drapiert und mit Blumen und Schmuck dekoriert, als die beiden anderen Darstellerinnen herbeigerufen werden:

\section{Nu Marie, Lili hier!}

Lili wierp zich op den grond, Marie vlijde zich tegen de bank, met het hoofd aan Frédérique's voeten. Vlug drapeerde Paul beide meisjes in kleurige châles, sluiers, strengelde snoeren om haar armen, in heur haren.

- Marie en Lili, wanhopig kijken! Meer wringen je armen, Lili! In wanhoop, meer in wanhoop! Freddy, jij meer smachten, je oogen omhoog, in je mond iets treurigs. ${ }^{1}$

Der sich drängenden Geburtstagsgesellschaft bietet sich ein erstes Bild:

In den witten gloed van het licht scheen het oude Egypte herschapen te zijn. Tusschen weelderige draperieën zag men iets als eene oaze doorschemeren, een blauwe lucht, een paar pyramiden, een palmengroep. Op haar, door sfinxen ge-

\footnotetext{
${ }^{1}$ Couperus, Louis: Eline Vere, Amsterdam / Antwerpen ${ }^{7} 1991$, S. 9. (`Nun Marie, Lili, hierher! Lili warf sich auf den Boden, Marie schmiegte sich an die Bank, mit dem Kopf an Frédériques Füße. Rasch drapierte Paul die beiden Mädchen in bunte Shawls und Schleier, flocht Schnüre um ihre Arme, in ihre Haare.

- Marie und Lili, verzweifelt schauen! Mehr die Arme winden, Lili! In Verzweiflung, mehr in Verzweiflung! Freddy, du, sehnsüchtiger schauen, deine Augen in die Höhe, in deinem Mund etwas Trauriges!‘)
} 


\section{I schönes Sterben،}

torste, rustbak lag Kleopatra, overgolfd door een vloed van lokken, den dood reeds nabij, terwijl zich een adder om heur arm kronkelde. Twee slavinnen wrongen zich in wanhoop aan haar voeten. De bonte droom eener oriëntalische pracht van enkele seconden, de poëzie der oudheid voor korte wijlen herlevend, onder de blikken eener moderne soirée. ${ }^{2}$

Mit bengalischer Beleuchtung in Grün und Rot wird das Bild noch ein zweites und drittes Mal kurz wiederholt. Der Leser denkt bereits an Makarts ${ }^{3}$ Gemälde als Vorgabe des ılebenden Bildesı und wird in dieser Vermutung bestätigt:

'La mort de Cléopâtreı! las Betsy Van Raat aan mevrouw Van Erlevoort voor, die haar het programma had gereikt. ${ }^{4}$

Besonders die Wiederholungen des inszenierten $>$ Traums $\iota^{5}$ in farblich variierenden Illuminationen animieren die Gesellschaft dazu, die Darstellerinnen zu identifizieren und zu kommentieren, aber auch die Vorlage für das nachgestellte Bild zu erraten:

Was ligt die Freddy stil! En alles zoo rijk en toch niet overladen! lets als een schilderij van Makart! sprak Betsy, haar veêren waaier ontplooiend. ${ }^{6}$

Der Schriftsteller zeigt, mit welchen Mitteln ein stableau vivant gestaltet wird. ${ }^{7} \mathrm{Zu}$ nächst sind zahlreiche und luxuriöse Requisiten nötig, die in diesem Fall durch die Vorgaben in Makarts Ölgemälde ${ }^{8}$ farblich und stofflich genau definiert sind. In der Kulisse scheint das Arrangement aber weit über die Vorgaben des Malers hinauszugehen, spricht Couperus doch von Pyramiden und einer Oase. Der Bildvorlage entsprechend werden den Akteurinnen Positionen abverlangt, die oft unbequem und unnatürlich sind. Das Wichtigste aber ist der Ausdruck der Darstellenden; ihrer Gestik, ihrem Gesichtsausdruck, ihrem Augenaufschlag wird vom Arrangeur größte Bedeutung zugemessen.

${ }^{2}$ Eline Vere, S. 10. (>In der weißen Glut des Feuers schien das alte Ägypten aufs Neue erstanden zu sein. Zwischen üppigen Draperien sah man etwas wie eine Oase durchschimmern, blauen Himmel, ein paar Pyramiden, eine Palmengruppe. Auf ihrem von Sphingen getragenen Ruhebett lag Kleopatra, von Locken überflutet, dem Tode schon ganz nahe, während sich eine Viper um ihren Arm schlängelte. Zu ihren Füßen zeigten zwei Sklavinnen ihre Verzweiflung. Der bunte Traum einer orientalischen Pracht, einige Sekunden andauernd, die Poesie der Antike, unter den Blicken einer modernen Abendgesellschaft für einen kurzen Moment wieder auflebend.८)

${ }^{3}$ Dass Couperus tatsächlich Makarts 1874/75 entstandenen sTod der Kleopatra zum Vorwurf genommen hat, bestätigt sein Biograph: "Graag ook hield hij [= Couperus] zich bezig met het regisseren van tableaux vivants. 'La Mort de Cléopatre in het begin van Eline Vere, gearrangeerd naar Makarts schilderij met het zelfde onderwerp, vormt een goede illustratie van `Paul'sı optreden bij dergeleike gelegenheden. Indien dit tableau vivant werkelijk eens zo is geensceneerd, zou het niet onmogelijk zijn dat Couperus' gedicht Kleopatra er door hem bij is gereciteerd. Het werd in januari 1884 geschreven. « (Bastet, Frédéric: Louis Couperus, Amsterdam 1989, S. 94)

4 , Der Tod der Kleopatra! las Betsy Van Raat Frau Van Erlevoort vor, die ihr das Programm gereicht hatte.ı (Eline Vere, S. 10)

5 "Tweemalen herhaalde zich de droom, eerst in zeegroenen glans, daarna in vuurrooden gloed. (২Zweimal wiederholte sich der Traum, zuerst in seegrünem Glanz, dann in feuerroter Glut.ı) (Eline Vere, S. 10)

${ }^{6}$,"Was liegt diese Freddy still! Und alles so prächtig und doch nicht überladen! Wie ein Gemälde von Makart!“ sagte Betsy und klappte ihren Federfächer auf.ı (Eline Vere, S. 11)

${ }^{7}$ Grundsätzliches unten, S. 295ff.

${ }^{8}$ Heute in Kassel (Kassel, Staatliche Museen, Neue Galerie). Abb. in: Heinz, Marianne (Hrsg.): Bestandskatalog der Gemälde des 19. Jahrhunderts, Kassel 1991, S. 127. 


\section{I /Schönes Sterben`}

Lili und Marie werden im stableau vivant als Dienerinnen Kleopatras eingesetzt, deren eine ihrer Herrin schon im Tod vorangegangen ist, deren andere noch in Verzweiflung und Hoffnungslosigkeit die Hände ringt. Mit der Aufforderung an die Hauptdarstellerin, mehr zu schmachten, die Augen nach oben zu drehen und den Mund von Trauer umspielen zu lassen, fasst der Regisseur die Mittel zusammen, die im 19. Jahrhundert im Theater, in der Oper und im Gemälde eingesetzt wurden, um die Affekte der Trauer und Verzweiflung darzustellen. Couperus lässt seine Leser an der Produktion eines slebenden Bildes` teilnehmen und benennt die dabei eingesetzten ästhetischen Mittel.

Auch die Wirkungen dieses für unseren Geschmack einer Geburtstagsfeier wenig angemessenen Sujets kommen in den Blick: Das Publikum ergeht sich in Ausrufen wie »prachtig « oder »magnifique « ${ }^{9}$ und versucht, die Darstellerinnen zu identifizieren. In den Kostümen werden zur Verfügung gestellte Stoffe und Roben wiedererkannt und die Schwierigkeiten der Posen diskutiert: ১Der Tod der Kleopatrar ist zum gesellschaftlichen Spiel geworden, dem historischen Vorwurf selbst widmet die Geburtstagsgesellschaft kein Wort.

Eine reiche, gesättigte, nach immer neuen Reizen suchende Gesellschaft lässt sich durch ein nachgestelltes Gemälde Makarts, des Malers der römischen Dekadenz par exellence, unterhalten und delektiert sich an den nicht ausgesprochenen, aber deutlich evozierten sexuellen Konnotationen des Themas. Das ıschöne Sterben der Kleopatra interessiert dieses Publikum nicht als historische Szene, sondern als Gelegenheit, einerseits Prunk und Pracht, andererseits Affekte und Emotionen überzogen und im Letzten unernst zu inszenieren.

\section{2 >Die schöne Tote - ein Motiv des 19. Jahrhunderts}

Künstlerische Verfahren, Weiblichkeit und Tod ästhetisch zu verbinden, sind in den letzten Jahren besonders kritisch hinterfragt worden. Die sogenannte Geschlechterforschung $^{10}$ hat die hinter solcher Ästhetisierung stehenden Ängste und Bemächtigungsstrategien herausgearbeitet, die in Poes Satz gipfeln, der Tod einer schönen Frau sei ohne Zweifel das poetischste Thema der Welt ${ }^{11}$, und so einen

\footnotetext{
${ }^{9}$ Eline Vere, S. 10.

${ }^{10}$ Bronfen, Elisabeth: Nur über ihre Leiche, Tod, Weiblichkeit und Ästhetik, München 1996

11 " >Welche Vorstellung wird von der Menschheit im allgemeinen als die trauervollste empfunden? - >Die des Todes`, war die sichere Antwort. ıUnd wann`, forschte ich weiter, ıist diese trauervollste Vorstellung zugleich am poetischsten?` [...] `Dann, wenn sie sich am innigsten mit der Schönheit verbindet. Der Tod einer schönen Frau ist also der poetischste Vorwurf, der überhaupt zu denken ist, und ebenso unzweifelhaft ist der seines
} 


\section{I /Schönes Sterben`}

Schlüssel zum Verständnis der Kunst des 19. Jahrhunderts gefunden. John Everett Millais (1829-1896) schuf mit seiner Ophelia ${ }^{12}$ gewissermaßen ein Emblembild für die schockierende Verbindung von Tod und Schönheit. Ophelia schwebt im Wasser, wobei Haare und Kleidung schon kaum mehr von den sie umgebenden vegetabilen Formen zu unterscheiden sind. Die schöne Tote wird so wieder ein Teil der Natur und verliert ihre angstmachende Sinnlichkeit. ${ }^{13}$ Für unseren Zusammenhang soll als Beispiel der Tod der Kleopatra [Abb. 1] ${ }^{14}$ von Hans Makart (18401884) dienen, das dem niederländischen Autor Couperus die Folie zur Eingangsszene seines ersten großen Romans gab. »Nichts als der sinnlichen Pracht der Farbe zuliebe erfundene, von keinerlei gedanklichem Inhalt beschwerte Festdekorationen« nannte Hans Vollmer die Historienmalerei Makarts ${ }^{15}$. Das vernichtende Urteil, zudem an maßgeblicher Stelle, prägte über viele Jahrzehnte Ansehen und Einord-

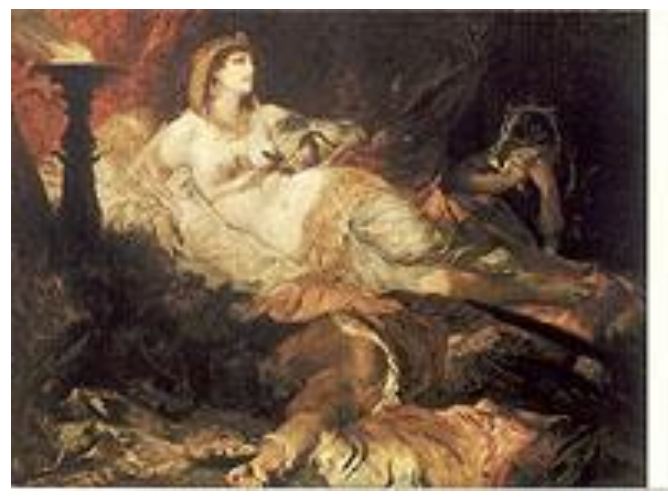

Abb. 1 nung des Historienmalers Makart. Inzwischen ist die historische Distanz zum 19. Jahrhundert gewachsen und ein anderer, leidenschaftsloserer Blick auf Makarts Produktion möglich, der das Spezifische und Zeittypische nüchterner analysiert.

Der zeitgenössischen Begeisterung für orientalische Sujets entsprach Makart schon, bevor er zusammen mit seinem Freund Leopold Carl Müller, dem sogenannten ১Orientmüller`, in den Jahren 1875/76 eine Ägyptenreise unternahm. In der Schaffensperiode vor der Abreise nach Kairo (1874) wurden seine KleopatraBilder ${ }^{16}$ entworfen und ausgeführt, zu denen neben einigen vorbereitenden Ölskizzen Die Nilfahrt der Kleopatra ${ }^{17}$ und zwei sehr unterschiedliche Fassungen des

köstlichsten Schatzes beraubte Liebende der beste Mittler, uns über diesen zu reden.ı (Poe, Edgar Allan: The Philosophy of Composition, in: Essays and Reviews, New York 1984, S. 19; Übersetzung nach: Schumacher, Fritz: Das bauliche Gestalten, Basel 1991, S. 84-94)

12 Das 1852 entstandene Gemälde befindet sich heute in der Tate Gallery in London.

13 Dazu Kindler, Simone: Ophelia. Der Wandel von Frauenbild und Bildmotiv, Berlin 2004. Kindlers kunst-, literatur- und kulturgeschichtliche Aspekte verbindende Untersuchung zeichnet die »Entstehungsgeschichte eines der populärsten Bildmotive der Kunstgeschichte« (S. 213) der besonders im 19. Jahrhundert populären Projektionsfigur nach.

${ }^{14}$ Vgl. Katalog 223. Hier und im Folgenden verweise ich auf meinen Bildkatalog, S. 370ff.

15 Thieme, U. / Becker, F.: Allgemeines Lexikon der bildenden Künstler von der Antike bis zur Gegenwart, München/Leipzig 1992 (ND Leipzig 1929/1930), Bd. 23, S. 583

${ }_{16}$ Dazu Frodl, Gerbert: Hans Makart, Monographie und Werkverzeichnis, Salzburg 1974, Zeittafel S. 65ff.

17 Vgl. Katalog 225. Das Gemälde war ursprünglich als Dekoration eines Festsaales geplant, wurde dann abbestellt und hängt heute in der Staatsgalerie in Stuttgart. 


\section{I /Schönes Sterben`}

Todes der Kleopatra ${ }^{18}$ gehören. Sowohl auf der kleinformatigen Todesdarstellung, die wie ein Ausschnitt aus einer bereits 1865 entstandenen Kleopatra ${ }^{19}$ wirkt, als auch auf dem monumentalen Kasseler Gemälde lieh die Burg-Schauspielerin Charlotte Wolter der Protagonistin ihre Gesichtszüge, um die gar nicht ıorientalischı oder ägyptisch wirkende Königin vorzustellen. Daran wird deutlich, dass der Orientalismus als gesellschaftliches Rollenspiel nicht auf historische 'Korrektheit,, sondern auf überzeugende Wirkungsstrategien angelegt war. Die Mode des Orientalismus hatte mit dem Ägyptenfeldzug Napoleons (1798-1801) begonnen und kulminierte mit der Eröffnung des Suezkanals im Jahre 1869. Erst der Beginn des 19. Jahrhunderts hatte eine Region in greifbare Nähe gerückt, die in der Literatur schon seit der Antike als Bereich des Wunderbaren und Geheimnisvollen dargestellt worden war ${ }^{20}$. In der Romantik wurde der Orient für Literaten, Künstler und Intellektuelle vom imaginären zum realen Reiseziel - es genügt, an die literarisierten Reiseberichte von Chateaubriand, Pückler-Muskau, Lamartine, Flaubert oder Nerval zu erinnern. ${ }^{21}$ Obwohl den Zeitgenossen neben den literarischen Spiegelungen, in denen die europäischen Bildungsreisenden ihre Reiseerfahrungen zu Fiktionen umarbeiteten, auch Reisebeschreibungen von Orientalisten und Grabungsberichte von Archäologen zur Verfügung standen, wurde das im 19. Jahrhundert vorherrschende Orientbild überwiegend durch literarische Projektionen geprägt. So entstanden bizarre, oft sogar morbide Vorstellungen eines Orients, der ein Höchstmaß an Erotik und Exotik, an Wollust und Exzentrizität repräsentierte. ${ }^{22}$

Die heute mit dem Sammelbegriff `Orientalisten` bezeichneten Künstler, zu denen unter anderen Delacroix und Ingres gehören, setzten die mehr fiktiven als realen Vorstellungen vom Morgenland in Bilder um. Vor allem was die Reisenden auf ihrer Orientreise nicht zu sehen bekamen, wurde in Bildern vorgestellt: Harem, Frauenbad und Privatgemächer der Frauen. Dem männlichen Voyeurismus konnte so viel nacktes Fleisch und träge Sinnlichkeit in Kombination mit reichen Stoffen und seltsamen Geräten wie Wasserpfeifen gezeigt werden. Insofern stand Makart

\footnotetext{
${ }^{18}$ Vgl. Katalog 224 und 223.

${ }^{19}$ Vgl. Frodl, a.a.O., S. 292, (Nr. 55). Besitzer und Aufenthaltsort des Gemäldes sind heute unbekannt.

${ }^{20}$ Lemaire, Gerard-George: Orientalismus, das Bild des Morgenlandes in der Malerei, Paris / Köln 2000. Vgl. zum Beispiel Syndram, Karl Ulrich: „Der erfundene Orient in der europäischen Literatur vom 18. bis zum Beginn des 20. Jahrhunderts «, in: Sievernich, G. / Budde, H. (Hrsg.): AK Europa und der Orient, 800 - 1900 , Berlin 1989, S. 324-341. Ebenso Kohl, Karl-Heinz: »Cherchez la femme d'orient«, ebd., S. 356-367.

${ }^{21} \mathrm{Vgl}$. z.B. Wolfzettel, Friedrich: ,Ce désir de vagabondage cosmopoliter, Wege und Entwicklung des französischen Reiseberichts im 19. Jahrhundert, Tübingen 1986.

${ }_{22}$ Mayr-Oehring, Erika / Doppler, Elke (Hrsg.): AK Orientalische Reise, Malerei und Exotik im späten 19. Jahrhundert, Wien 2003
} 


\section{I schönes Sterben`}

mit seinen Kleopatra-Bildern in einer eindeutigen Tradition. Er stellte jedoch nicht einen zeitgenössischen, sondern einen bereits historisch gewordenen Orient dar und beanspruchte mit seinen Kleopatra-Darstellungen durchaus Authentizität. Der Betrachter sollte glauben, dass es so gewesen sein, dass es sich historisch so könnte verhalten haben. Die Orientalisten der ersten Hälfte des 19. Jahrhunderts imaginierten hingegen, ohne Zweifel bewusst, eine zeitlose Präsenz des Morgenlandes. $^{23}$

Bei Makart ruht Kleopatra von üppiger Stoffdekoration hinterfangen und halb aufgerichtet auf einem schräg in den Raum gestellten, mit Kissen und Tüchern überladenen Bett. Die Königin ist unbekleidet bis zu den Hüften, die unter einem breiten Goldgürtel und leichtem Stoff verborgen bleiben. Das aufwendige Goldgeschmeide des Halses wird durch große Ohrgehänge und eine ägyptische Krone ergänzt, die mit den herabhängenden Fittichen der Muttergöttin Mut das bleiche Gesicht der himmelwärts blickenden Herrscherin umrahmen. In ihrer Linken hält sie die Schlange, die sich um ihren Arm ringelt und bereits an ihrer linken Brust züngelt. Mit ihrer Rechten greift die Königin in die Kissen des Lagers. Die marmorne Körperlichkeit Kleopatras wird durch zwei Dienerinnen kontrastiert, deren eine vor dem Lager der Königin hingestreckt liegt, während die andere rechts hinter der Liege ihrer Herrin kauert und das Gesicht in den Händen verbirgt. Inkarnat und Kleidung der Dienerinnen sind in dunklen Beige- und Rottönen gehalten. Am Übergang vom verschatteten Vordergrund zum ausgeleuchteten Zentrum, dem Sterbelager Kleopatras, steht am linken Bildrand ein hoher Leuchter, dessen unruhige Flamme die psychisch aufgewühlte Situation symbolisch illuminiert.

Mit dem kalkulierten Gegeneinandersetzen von Licht und Schatten, von porzellanfarbener Körperlichkeit und dunkler Räumlichkeit schafft Makart Bedeutungsebenen, die im Betrachter zunächst das Klischee der unschuldig Sterbenden evozieren. Der den Blicken preisgegebene Körper erfüllt sexuelle Wünsche, während der Augenaufschlag der Protagonistin ihre Entrückung aus der Welt und den baldigen Tod ausdrückt und damit die mit der femme fatale konnotierte Angst abschwächt. Der Betrachter hat die Gewissheit, dass der von Oktavian und Kleopatra dargestellte Kampf der Geschlechter, der auch als Auseinandersetzung von Okzident und Orient gelesen werden konnte, zugunsten des Mannes (und damit des

\footnotetext{
${ }^{23}$ Dazu Günther, Erika: Die Faszination des Fremden, Der malerische Orientalismus in Deutschland, Münster 1990.
} 


\section{I /Schönes Sterben`}

Okzidents) ausgeht. So darf die strahlende Schönheit Kleopatras gefahrlos betrachtet werden, da sie am Ende Opfer wird und keine Gefahr mehr von ihr ausgeht.

Das historische Vorwissen der Betrachter erlaubte die Inszenierung der ägyptischen Königin als Opfer, ihre /Victimisierung〈, um einen Modebegriff der Genderforschung aufzugreifen. Nur so war ihre sexuelle Attraktivität, deren Reiz durch eine gewisse morbidezza noch erhöht wird, für den Betrachter der Epoche Makarts erträglich. Da die Opferrolle Kleopatras immer gleich mitgedacht wird, darf er ihren Körper betrachten, von dem keine sexuelle Gefahr mehr ausgeht. Schönheit und Attraktivität der Königin lassen den Rezipienten zögern, ob das, was er sieht, überhaupt noch geschaut werden darf, während die Gewissheit, dass Kleopatra im nächsten Moment der erfundenen Bildwirklichkeit tot sein wird, inm diese ungewöhnliche Lizenz erteilt. Der sich in der Viper bereits ankündigende Tod macht den Tabubruch erträglich und stellt den spatriarchalischen، Weltentwurf wieder her. So materialisiert der Künstler unbewusst und stellvertretend für seine zeitgenössischen europäischen Geschlechtsgenossen ${ }^{24}$ im Tod der Kleopatra Ängste und männliche Obsessionen seines Jahrhunderts. Makart bietet - in Abwandlung des eingangs zitierten Urteils von Vollmer - nichts als der Sinnlichkeit (der Betrachter) zuliebe erfundene Dekorationen.

\section{Der Tod des Helden}

Reflektierte der Tod der Kleopatra im ausgehenden 19. Jahrhundert wohl nur noch die Sinnlichkeit des Sujets, geriet in Vergessenheit, dass das Bildmotiv in der Frühen Neuzeit und im Barock durchaus anders akzentuiert war und die >Tugend c der ägyptischen Königin unbeschadet ihrer erotischen Attraktivität betonte. Vor diesem Hintergrund zeigen die Beobachtungen an Makarts Version des Todes der Kleopatra, dass mit der Verbindung von Todesnähe und Sexualität ein charakteristisches Klischee des 19. Jahrhunderts bedient wurde. Die Umbesetzung des Bildmotivs der sterbenden Tugendheldin in der Spätphase der Historienmalerei macht gerade deshalb auf eine Vorgeschichte des ischönen Sterbensı aufmerksam, in der sich erotische Attraktivität und Tugend als Ausdruck der moralischen Selbstbehauptung noch ergänzten.

\footnotetext{
24 „Manet analysierte die Geschlechterbeziehung im Milieu seiner Zeit, Feuerbach greift auf die Mythologie zurück, Makart bezieht den Standpunkt der im wahrsten Sinne des Wortes durchsichtigen historischen Verkleidung. « (Hofmann, Werner: "Hans Makart - Malerei als Inszenierung «, in: Art 7 [1981], S. 40-49, hier S. 41)
} 


\section{I /Schönes Sterben`}

Die ssterbende Tugendheldinı ist allerdings nur ein Sonderfall des exemplum virtutis in der Historienmalerei, wie eine 1987 im Kölner Wallraf-Richartz-Museum präsentierte große Ausstellung mit dem Titel »Triumph und Tod des Helden « ${ }^{25}$ zeigte. Sie betonte die führende Stellung Frankreichs im 17. Jahrhundert, was die Invention möglicher Bildthemen und die theoretische Durchdringung dieser Thematik der Historienmalerei betrifft. ${ }^{26}$ Die gemeinsame Präsentation von Historiengemälden aus nahezu allen Ländern Europas zeigte, wie im 17. und 18. Jahrhundert die Verbindung von Triumph und Tod des Helden als Tugendexempel diente und dass dafür zahlreiche Schlüsselfiguren aus der mythologischen, biblischen und historischen Überlieferung ımobilisiertı wurden. Dass Wertungen ebenso wie aktuelle Bezüge dabei starken Wandlungen unterworfen waren, versteht sich von selbst. ${ }^{27}$ Die Ästhetik des Historiengemäldes brachte es mit sich, dass sterbende oder tote Helden und Heldinnen stets ıschön dargestellt werden. Es gab in Kölner Ausstellung viele Beispiele dafür, dass männliche Helden ihren wahren Triumph erst im Tod feiern und darin eine ganz eigene Vollkommenheit offenbaren.

Frauen blieben in der Ausstellung eigenartig unterrepräsentiert. ${ }^{28}$ Wenn unter den Köln ausgestellten Werken nur wenige Frauen als Protagonisten zeigten, spiegelt dies die historisch gewachsenen Geschlechterrollen wider. Dass aber von den wenigen Exponaten weiblicher Helden mehr als die Hälfte sterbende Frauen zeigten, bedarf weiterer Überlegungen. Heldenhaftes Sterben gehört in der traditionellen Unterscheidung der Geschlechterrollen zum kämpferischen und militärischen, also ımännlichen Bereich, dem Selbstopfer von Frauen stand offensichtlich ein anderer Bedeutungsbereich offen, dem im Folgenden nachgegangen werden soll.

Möglicherweise deutet sich hier ein wichtiger Problemkomplex an, in dem das Motiv des ıschönen Sterbensı über die Darstellung des (männlichen) Heldentodes hinaus in andere semantische Bereiche führt, die sich - so meine Ausgangshypothese - an sterbenden weiblichen Helden sinnfälliger ins Bild setzen

\footnotetext{
${ }^{25}$ Anschließend war die Ausstellung noch in Zürich und Lyon zu sehen. (Mai, Ekkehard / Repp-Eckert, Anke [Hrsg.]: AK Triumph und Tod des Helden, Europäische Historienmalerei von Rubens bis Manet, Köln 1987) Der Ausstellungskatalog dokumentiert Aufbau und Intentionen des Projektes.

${ }^{26}$ Die Entwicklung des Historienbildes in den Niederlanden, Italien, Deutschland, England und Amerika folgte dem französischen Vorbild, wie andere Ausstellungsteile zeigten.

${ }^{27}$ Vgl. Mai, Ekkehard / Repp-Eckert, Anke (Hrsg.): Historienmalerei in Europa, Paradigmen in Form, Funktion und Ideologie, Mainz 1990. Das Kolloquium zur Ausstellung reflektiert in unterschiedlichen Beiträgen Entwicklung, Ideologie und Krise des Historienbildes.

${ }^{28}$ Die Geschlechterproblematik wird auch im Aufsatzband nicht einziges Mal thematisiert. Von 105 ausgestellten Werken stellten nur 15 weiblichen Protagonisten dar, davon acht sterbende Frauen.
} 


\section{I /Schönes Sterben`}

ließen. Ihr ıschönes Sterben verunsicherte das gewohnte Sehen und veranlasste die Betrachter, hinter der ästhetischen eine weitere philosophische oder religiöse Dimension vorauszusetzen. Diese Vermutung wird dadurch verstärkt, dass es in der Historienmalerei eine weitere Gruppe sterbender männlicher Helden gibt, deren Semantik ebensowenig von militärischen Tugenden bestimmt war: sterbende Philosophen.

\section{4 >Mourir en philosopher}

Der sterbende Philosoph war ein erfolgreicher Bildtypus der gesamten aufklärerischen Epoche. Für die Darstellung von Philosophen wie Sokrates, Seneca und Archimedes, aber auch von Politikern wie Cicero oder Cato dem Jüngeren konnte die Historienmalerei auf eine lange Tradition in Literatur, Historiographie, Rhetorik und Philosophie zurückgreifen. Neuere Untersuchungen beschreiben die sich allmählich verändernden semantischen Besetzungen exemplarischen philosophischen Sterbens. ${ }^{29}$

Seit dem Altertum waren diese Figuren Vorbild, Maßstab und Orientierung dafür, dass sIntellektuelle ‘ für ihre Vorstellungen einzustehen und sich zu opfern bereit waren. Spätestens seit Plinius dem Jüngeren ${ }^{30}$ wurde der exemplarische exitus illustrium virorum vergleichend erörtert. Vor allem der Tod des Sokrates war schon in der Antike zum Archetyp philosophischen Sterbens gestaltet worden; seine letzten Worte und seine Haltung angesichts des Todes galten als überzeitlich exemplarisches Verhalten. In den spätantiken Rhetorenschulen wurde der literarische Topos des exitus illustrium virorum häufig zu Ausbildungszwecken traktiert und in zahlreiche Exempla-Sammlungen aufgenommen. Christliche Märtyrerakten übernahmen in Aufbau und Gestaltung die topischen Elemente des exitus illustrium virorum; in der neuen Textgattung wurden Richterrede und Widerrede des Angeklagten aus der platonischen Apologie des Sokrates auf die Befragung unschuldiger Christen durch uneinsichtige heidnische Herrscher übertragen.

Die Historienmalerei der Neuzeit griff die sphilosophische cher Tradition des exitus illustrium virorum auf und transformierte sie in das durch-

\footnotetext{
${ }^{29}$ Oberreuter-Kronabel, Gabriele: Der Tod des Philosophen, Zum Sinngehalt eines Sterbebildtypus der französischen Malerei in der zweiten Hälfte des 18. Jahrhunderts, München 1986; Oberreuter-Kronabel, Gabriele: »Der Philosoph und sein Tod, Beobachtungen zu einem Thema für die Malerei des 18. Jahrhunderts in Frankreich «, in: Historienmalerei in Europa, a.a.O., S. 95-105.

${ }^{30} \mathrm{Vgl}$. Ronconi, A.: Exitus illustrium virorum, in: Reallexikon für Antike und Christentum, hrsg. von Ernst Dassmann u.a., Bd. 6, Stuttgart 1966, Sp. 1258-1268.
} 


\section{I schönes Sterben،}

aus neue Konzept spaganer Märtyrerı. Ohne Todesfurcht, frei von Ängsten, nur von der ratio geleitet, wurde der sterbende Philosoph zum idealen Bildtypus der Aufklärung. Im Sterben konnten die Theoretiker und Vertreter des praxisfernen philosophischen Gesprächs courage und pratique ${ }^{31}$ zeigen, wenn es darum ging, für ihre Ideen einzustehen. Bei Seneca und Cato dem Jüngeren kam noch das willkommene Skandalon des Selbstmords hinzu, der, zu einer Art profaner Selbstermächtigung sublimiert, gegen die kirchliche Moral eingesetzt werden konnte.

Gerade die nachtridentinische Frömmigkeitspraxis hatte der gottgefälligen Inszenierung der Sterbestunde neues Gewicht und geradezu Heilsbedeutung verliehen. Barocke Leichenpredigten versetzten mit übertreibenden Bildern die Gläubigen in Angst und Schrecken, um sie zu einem gottgefälligen Leben anzuleiten. So ist es nicht erstaunlich, wenn die Sterbestunde auch in der profanen Aufklärung eine neue Bedeutung erhielt. Entfielen die Tröstungen der positiven Religion, wurde die Todesstunde zum Prüfstein für das gelebte Leben, das es in den letzten Augenblicken noch einmal in den Blick zu nehmen und zu bewähren galt. Hierin kamen sich die Intentionen der Gegenreformation und der Aufklärung erstaunlich nah. Während jedoch die seelsorgerische Praxis der Kirche dem Gläubigen in seiner letzten Stunde durch die Sterbesakramente Hilfe bot, war die Aufklärung zwar mit der Kirche auffällig in der Gewichtung des letzten Augenblicks einig, überließ die Bewältigung aber jedem Einzelnen. Was den Philosophen Sokrates, Seneca und Cato in ihrem vorbildlichen Sterben gelungen war, die moralische Identität bis zum letzten Augenblick zu bewähren, wurde für das aufgeklärte Publikum ein profanes Exempel der Selbstbehauptung.

So wurde der Philosophentod im 18. Jahrhundert zum Vorwurf von Dramen und Opernlibretti, aber auch zu einem beliebten Sujet der Historienmalerei. Graphische Blätter illustrierten den Text historiographischer Werke. ${ }^{32}$ Das Sterben des Sokrates, der die von seinen Schülern vorbereitete Flucht ausschlägt, um sich selbst treu zu bleiben, avancierte geradezu zum Emblem des siècle philosophique. Mit seiner Mort de Socrate S3 $^{33}$ (1787) fand Jacques-Louis David (1748-1825) wohl

\footnotetext{
${ }^{31}$ In der Encyclopédie wurde so der Tod des Sokrates charakterisiert. Vgl. Diderot, Denis / d'Alembert, Jean le Rond: Encyclopédie ou Dictionnaire raisonné des sciences, des arts et des métiers, par une société de gens de lettres, Paris 1780, Bd. 15, S. 261.

${ }^{32}$ So zum Beispiel Gravelots iSterbestunde des Sokratesı in Rollins Histoire Ancienne (Oberreuter-Kronabel, Der Tod des Philosophen, a.a.O., Abb. 1). Das historische Werk von Charles Rollin erfreute sich im 18. Jahrhundert größter Beliebtheit. Seine zwischen 1738 und 1776 erschienene Geschichte der Antike gehörte zu den geläufigen Informationsmöglichkeiten der Historienmaler.

${ }_{33}^{3}$ Katalog 90. Das Gemälde befindet sich heute in New York (Metropolitan Museum).
} 


\section{I /Schönes Sterben`}

die erfolgreichste Bildidee [Abb. 2] in einer schon langen ikonographischen Traditionskette, die sofort durch Reproduktionsstiche Massards ${ }^{34}$ verbreitet wurde. Obwohl insgesamt dreizehn Personen in der Kerkerszene zu sehen sind, zieht der wie beiläufig mit seiner Rechten nach dem Schierlingsbecher greifende Philosoph alle Blicke auf sich: Mit der rhetorischen Geste des

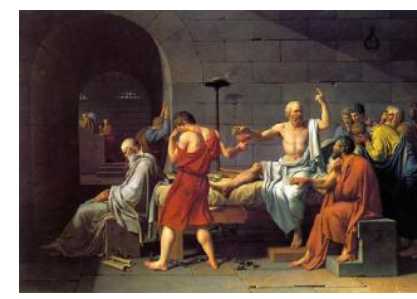

Abb. 2 linken nach oben weisenden Armes setzt Davids Sokrates seine philosophischen Überzeugungen ins Bild und verkörpert mit den Tugenden der Besonnenheit, Gerechtigkeit, Tapferkeit, Großzügigkeit und Wahrheit die im platonischen Phaidon ${ }^{35}$ beschriebene schöne Seele. ${ }^{36}$ Für diese philosophischen Tugenden greift er zum Gift, zu dem inn ein uneinsichtiges Gericht verurteilt hatte, das seine aufklärerischen Unterhaltungen, die vor allem junge Menschen zum Gebrauch des eigenen Verstandes anhielten, für subversiv hielt.

Am Beispiel des erzwungenen Selbstmords Senecas wurde in der Libretto- und Dramenliteratur die Frage erörtert, ob sich die Rolle des Philosophen mit der des Politikers und Fürstenerziehers vereinbaren ließ. Noch die Entscheidung zum Selbstmord war durch den Befehl des Tyrannen moti-

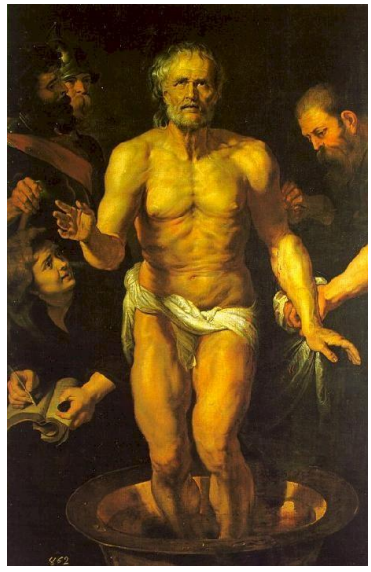

Abb. 3 viert. In der Ikonographie konzentrierte sich die Darstellung auf den letzten Moment, für den Rubens ${ }^{37}$ die geläufige Bildformel [Abb. 3] gefunden hat: Seneca erwartet aufrecht, mit constantia, der stoischen Haupttugend, ausgerüstet, das Wirken des Giftes. Der Selbstmord des jüngeren Cato ist durch den Hinweis auf die vorangehende Lektüre des platonischen Phaidon gleichsam intertextuell mit Sokrates und der von dieser Gestalt ausgehenden Aretalogie verbunden. Andererseits wurde mit Cato Patriotismus und Freiheitsliebe eines Politikers assoziiert, der Rom nicht Cäsar ausgeliefert sehen wollte. Der Selbstmord des Republikaners eröffnete hinreichend aktuelle Bezüge: Cato wurde zur Identifikationsfigur der französischen Republik. Die Akademie machte La mort de Caton d'Utique zum offiziellen Thema ihres Concours von $1797 .{ }^{38}$ Der Themenkreis des ins Bild gesetzten

\footnotetext{
34 Dazu Oberreuter-Kronabel: Der Tod des Philosophen, a.a.O., S. 67.

${ }^{35}$ Platon, Phaidon, 114 e

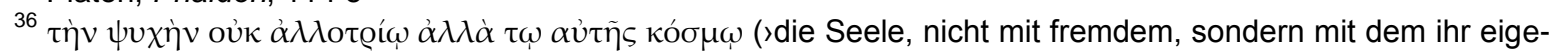
nen Schmuck geschmücktı)

${ }^{37}$ Katalog 354. Das Gemälde befindet sich heute in München (Alte Pinakothek).

${ }^{38}$ Grunchec, Philippe (Hrsg.): Les concours des Prix de Rome, 1797-1863, 2 Bde, Paris 1986
} 


\section{I /Schönes Sterben`}

mourir en philosophe transportierte - durchaus in Konkurrenz zum nachtridentinischen Märtyrerbild ${ }^{39}$ - nicht nur unverbindliche exempla virtutis, sondern zentrale moralische und politische Normen der Aufklärungsepoche. Die Vermutung liegt nicht fern, dass dies bereits für die 'Galeries des femmes fortesı des 16. Jahrhunderts galt, die das weibliche Gegenstück zu den männlichen exempla virtutis bilden könnten.

\section{5)Starke Frauen،}

Schon in der Frühen Neuzeit war in der Tat das Motiv des sexemplarischen Sterbens` nicht auf die Darstellung von militärischen und philosophischen, also ımännlichen` Tugenden beschränkt, sondern erscheint, allerdings eher beiläufig, auch in einem völlig anderen Zusammenhang: in den `Galerien starker Frauen` nämlich, auf die eine Ausstellung im Kunstmuseum Düsseldorf 1995 wieder aufmerksam gemacht hat. ${ }^{40}$

Der ıfeministischı ausgerichtete Ansatz der Düsseldorfer Ausstellung stellte vielleicht den historischen Anlass zu sehr in den Vordergrund, der dem Motiv der sstarken Frauenı in der Kunst der Frühen Neuzeit politische Relevanz gab. Zufällig aufeinander folgende weibliche Regentschaften von Caterina de' Medici (1560), Maria de' Medici (1610) und Anne d'Autriche (1643) führten in Frankreich zu elaborierten Legitimationsstrategien, auch in der bildenden Kunst. ${ }^{41}$ Die Regentinnen versuchten, sich nicht nur juristisch, sondern auch historisch zu legitimieren: Bezüge auf antike Mythologie und Historiographie, aber auch auf Frauengestalten des Alten Testaments dienten diesem Ziel. ${ }^{42}$ So ließ sich Caterina de' Medici als zweite Artemisia darstellen; Rubens führte für Maria de' Medici den bekannten Gemäldezyklus für den Palais du Luxembourg [Abb. 4] aus, in dem Minerva und die Allegorie der Prudentia die Machtübernahme durch eine Frau veranschaulichten. Auch Anne d'Autriche, die Mutter Ludwigs XIV., ließ sich nach dem Tod ihres Mannes (1643) von Vouet in der nunmehr bereits bewährten Ikonographie einer zweiten Artemisia [Abb. 5] darstellen. Die Fortführung der Politik des verstorbenen Herrschers und

\footnotetext{
${ }^{39}$ Vgl. ausführlich unten S. $41 \mathrm{ff}$. und S. $204 \mathrm{ff}$.

${ }^{40}$ Baumgärtel, B. / Neysters, S. (Hrsg.): AK Die Galerie der Starken Frauen, Düsseldorf 1995

${ }^{41}$ Dazu Gaehtgens, Barbara: »Macht-Wechsel oder die Übergabe der Regentschaft«, in: AK Die Galerie der Starken Frauen, a.a.O., S. 64-78.

${ }_{42}$ Garrard, Mary D.: Artemisia Gentileschi, the image of the female hero in Italian Baroque art, Princeton 1989 hat das zweite Kapitel ihrer Monographie (১Historical feminism and female iconography), S. 141-179, ganz diesem Themenkomplex und seiner historischen Entwicklung gewidmet.
} 


\section{I /Schönes Sterben`}

verantwortungsvolle Erziehung des unmündigen Sohnes wurden als wichtige Tugenden weiblicher Regenten in den Vordergrund gestellt. ${ }^{43}$

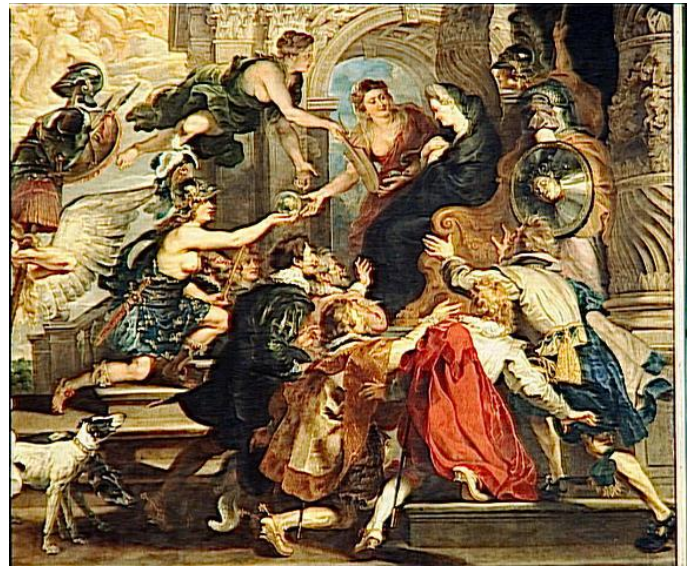

Abb. 4

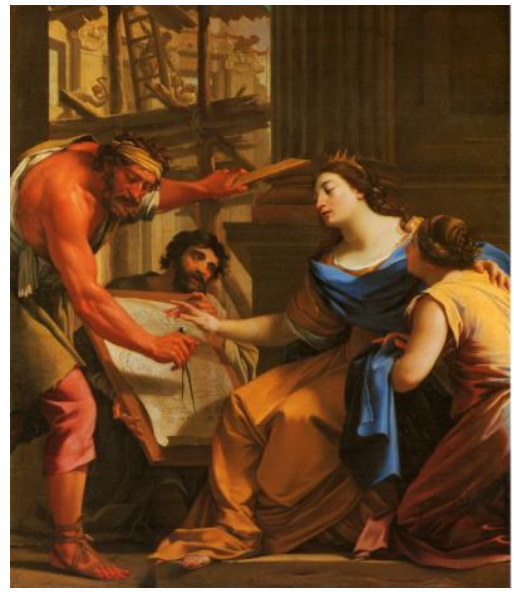

Abb. 5

Für dieses propagandistische Ziel konnten auch die `Galeries des femmes fortesı auf eine lange literarische Tradition zurückgreifen, wie dies wohl schon Giotto tat, der 1333 im neapolitanischen Castel Nuovo eine der ersten Serien von uomini famosi malte und den Anstoß zu weiteren Serien gab. ${ }^{44}$ Die Facta et dicta memorabilia des Valerius Maximus hatten männliche und weibliche Beispiele herausragender >Tugenden` vereint. Diesem Vorbild folgten häufig aufgegriffene, umgeschriebene und ergänzte Sammlungen sberühmter Männerı, etwa Boccaccios De casibus virorum illustrium und Petrarcas De viris illustribus, denen zuerst Bologna-Prozessccaccio auch eine Sammlung literarischer >Gegen-Bilder mit weiblichen Protagonisten, De claris mulieribus, entgegensetzte. Ganz in dieser Tradition entwickelte der eng mit dem französischen Hof verbundene Franziskaner Jacques du Bosc in seiner Schrift La Femme Heroïque (1645) einen Katalog männlicher und weiblicher Helden, der zum Beispiel Debora und Josua, aber auch Lukretia und Cato einander gegenüberstellte. Eine Vielzahl ikonographischer Varianten und Kombinationsmöglichkeiten trug den Legitimationszwängen der Regentinnen Rechnung. ${ }^{45}$ Die folgenreichste Zusammenstellung war wohl die Galerie des femmes fortes (1647) des Jesuiten Pierre Le Moyne.

\footnotetext{
${ }^{43}$ Katalog 359 (Rubens); Katalog 432 (Vouet).

44 Dazu Baumgärtel, Bettina: »Die Tugendheldin als Symbol kirchlicher und staatlicher Macht, Über die Galerie der Starken Frauen in Ausstattungsprogrammen und als Buchillustrationen«, in: AK Die Galerie der Starken Frauen, a.a.O., S. 140-204.

${ }^{45}$ Weiterführend zum Beispiel der Aufsatz von Schlumbohm, Christa: »Der Typus der Amazone und das Frauenideal im 17. Jahrhundert, Zur Selbstdarstellung der Grande Mademoiselle«, in: Romanistisches Jahrbuch 29 (1978), S. 77-99.
} 


\section{I /Schönes Sterben`}

Der Gattungsbegriff der >Galerie ${ }^{46}$ lässt zunächst an eine Bildersammlung denken: Mit einer Serie, die Judith, Esther, Bathseba, Semiramis, Dido, Tomyris, Artemisia, Kleopatra, Sophonisbe und die Frau des Hasdrubal umfasste, ließ in der Tat Anne d'Autriche ihre Räume im Schloss Richelieu ausschmücken. ${ }^{47}$ Verbreitet wurde das Reihungsprinzip der Galerie aber vor allem über Kupferstiche, die die moralistischen Exempelkataloge eines Du Bosc oder Le Moyne illustrierten. Claude Vignons Illustrationen zu Le Moynes Schrift isolieren einzelne femmes fortes und lassen sie monumental und statuarisch in den Vordergrund treten [Abb. 6]. ${ }^{48}$ Neben einer erläuternden subscriptio wird die Heldin mit einem charakteristischen Attribut (einem Dolch bei Lukretia oder Hammer und Pflock bei Jaël) präsentiert; im Hintergrund wird die historia wiedergegeben, in der sich die exemplarische Tugend der Vorgestellten bewährte.

Die Galerien sstarker Frauen sind auf Typisierung angelegt und nehmen neben weiblichen Helden, die durch sstarkes Handelnı auffielen (Cloelia, Judith oder Jaël), auch

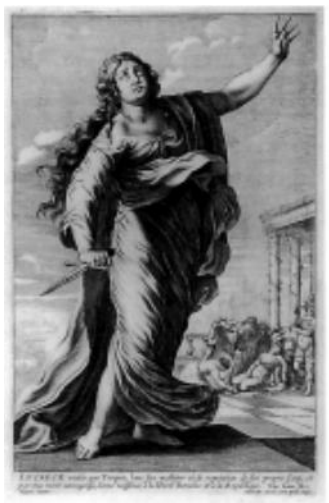

Abb. 6

Figuren auf, die sich dadurch nobilitierten, dass sie durch einen selbst gewählten Tod den Folgen ihrer verletzten Ehre (Lukretia), ihres politischen Scheiterns (Sophonisbe) oder ihrer enttäuschten Liebe (Dido) entgingen. Diese zweite Gruppe ist deshalb besonders interessant, weil sie - offensichtlich allen christlichen Vorbehalten gegenüber dem Selbstmord zum Trotz - den Tugendkatalog auf Selbstmörderinnen erweitert. Die Motivgeschichte der sterbenden Frau als Tugendheldin, der in dieser Untersuchung nachgegangen wird, hat hier einen ihrer Ursprünge.

\section{6 >Exemplum virtutis`}

Das inszenierte Sterben einer mythischen oder historischen Gestalt wird in der Kunstgeschichtsschreibung nicht selten kurzerhand als exemplum virtutis eingeordnet, um so eine vordergründig hinreichende Sinndeutung zu finden ${ }^{49}$, die al-

\footnotetext{
${ }^{46}$ Giovanni Battista Marino hat in die etwa fünfhundert Gedichte seiner Galeria (1619/1620) mit Ausnahme von Sophonisbe alle hier behandelten Tugendheldinnen aufgenommen. In der Gruppe Belle Caste e Magnanime werden Porzia, Lukretia mehrfach (in fünf Gedichten) und Paulina in Madrigalen geschildert. Unter den Belle Impudiche e Scelerate erhalten Dido zwei Madrigale und Kleopatra eine Stanza. (Marino, Giovanni Battista: La Galeria, hrsg. von Marzio Pieri, Padua 1979, 2 Bde, S. 221-235)

${ }^{47}$ Dazu Baumgärtel, Bettina: "Die Tugendheldin als Symbol kirchlicher und staatlicher Macht, Über die Galerie der Starken Frauen in Ausstattungsprogrammen und als Buchillustrationen«, a.a.O., S. 152.

${ }^{48}$ Vgl. Katalog 42.

49 Subsumierungen dieser Art sind in der kunsthistorischen Literatur Legion; ich zitiere nur eine einzige (aus Wolfgang Prohaskas Beschreibung eines Gemäldes von Massimo Stanzione in: Ebert-Schifferer, S. / Emiliani,
} 


\section{I schönes Sterben`}

lerdings gerade davon absieht, der konkreten historischen Funktion des exemplum nachzugehen.

Das ursprünglich in der Rhetorik entwickelte exemplum war bereits im Altertum auch in Skulptur und Malerei übernommen worden. Manche historischen und mythologischen Ereignisse waren in ihrer moralischen Semantisierung schon so zum Allgemeingut geworden, dass sie immer neue >Umbesetzungen zuließen. ${ }^{50}$

Eine Herakles-Statue etwa konnte zum bildhaften Emblem für Ausdauer und Stärke werden und in immer neuen Kontexten erscheinen. ${ }^{51}$ Wenn sich Karl VI. als Herakles abbilden ließ, stellte sich der barocke Herrscher in eine mit Augustus einsetzende Tradition, die über Trajan, Konstantin und Maximilian I. wichtige Herr-

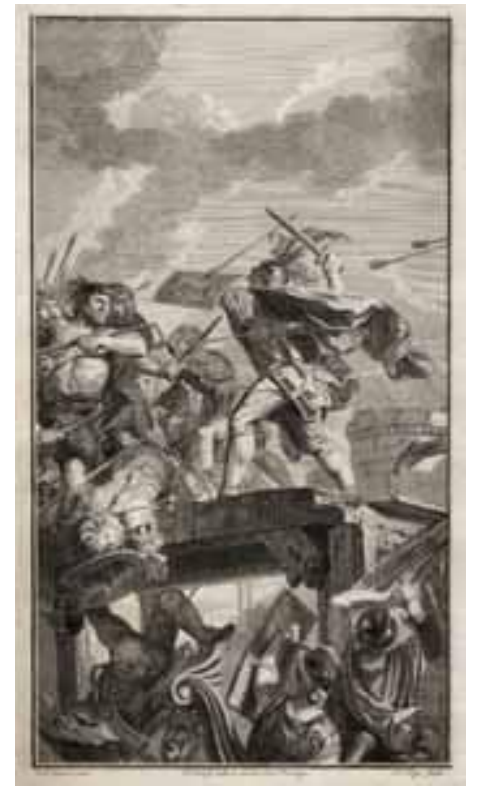

Abb. 7 schertugenden $>$ darstellte ${ }^{52}$

Als Gerard de Lairesse 1688 für den Ratssaal des Stadhouders in Den Haag das Gemälde Horatius Cocles verteidigt allein den Pons Sublicius [Abb. 7] konzipierte, griff er ein exemplum aus der römischen Frühzeit auf. ${ }^{53}$ Die Episode, in der Horatius Cocles allein am vorderen Brückenende gegen die anstürmenden Etrusker so lange Stand hält, bis hinter ihm die Brücke abgerissen ist, war längst zum geläufigen Modell von Operbereitschaft und Einsatz für das Gemeinwesen geworden. ${ }^{54}$ Gleichzeitig hat dieses Historiengemälde als exemplum virtutis aber die konkrete Funktion, die dort versammelten Amtsträger von Holland, Zeeland und West-Vriesland an ihre Verantwortung für den Staat zu erinnern.

\footnotetext{
A. / Schleier, E. (Hrsg.), AK Guido Reni und Europa, Frankfurt/Main 1988, S. 656.): »Das auf Livius (1,57,6$1,60,4)$ zurückgehende, grausam-heroische Geschehen: Lucretia, von Sextus Tarquinius vergewaltigt, gibt sich den Tod, nachdem sie ihren Gatten und ihren Vater hatte Rache schwören lassen, ist besonders im Barock als »exemplum virtutis « unzählige Male dargestellt worden. «

${ }^{50}$ Dazu Fuhrmann, Manfred: »Das Exemplum in der antiken Rhetorik«, in: Koselleck, R. / Stempel, W. (Hrsg.): Geschichte - Ereignis und Erzählung, München 1973 (Poetik und Hermeneutik 5), S. 449-452.

${ }^{51}$ Moos, Peter von: Geschichte als Topik, Das rhetorische Exemplum von der Antike zur Neuzeit und die historiae im `Policraticusı Johanns von Salisbury, Hildesheim / Zürich / New York 1988, S. XI

${ }^{52}$ Zu dieser Tradition die ausführliche Habilitationsschrift von Matsche, Franz: Die Kunst im Dienst der Staatsidee Kaiser Karls VI., 2 Bde, Berlin 1981.

${ }^{53}$ Abbildung bei Roy, Alain: Gérard de Lairesse, 1640-1711, Paris 1992, S. 349 (Nr. P 201). Die Maße des Ölgemäldes sind unbekannt; als Abbildung ist hier der Reproduktionsstich (bei Roy, S. 349, Nr. P 201a) wiedergegeben.

${ }^{54}$ Valerius Maximus: Facta et dicta memorabilia III, 2, hrsg. und übers. von Ursula Blank-Sangmeister, Stuttgart 1991, S. 74-77.
} 


\section{I /Schönes Sterben`}

Der undifferenzierte Gebrauch des Begriffs exemplum virtutis bekommt den konkreten historischen Horizont ikonographischer Innovationen nicht in den Blick. Gewiss sind der Tod der Lukretia oder der Kleopatra in vergleichbarer Weise exempla virtutis. Gleichwohl sind die durch Selbstmord wiederhergestellte moralische Integrität der vergewaltigten Lukretia und der resignative Freitod der betrogenen ägyptischen Königin durchaus verschiedene Sachverhalte, deren moralphilosophische Semantisierung ganz gegensätzlich ausfallen konnte und von unterschiedlicher Reichweite war. Dass Lukretia zum Modell weiblicher Keuschheit wurde, ist trotz der politischen Hintergründe der Episode nicht weiter überraschend. Hingegen ist es durchaus bemerkenswert, dass auch der Selbstmord der Kleopatra als exemplum virtutis dienen und eine Bildinszenierung ${ }^{55}$ als profane Märtyrerin

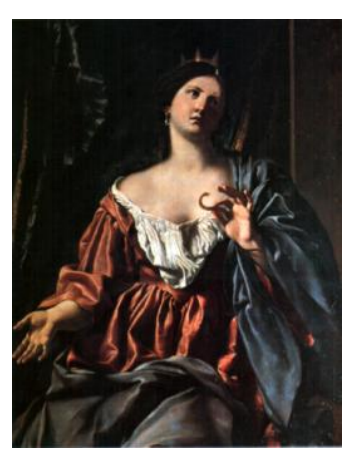

Abb. 8 [Abb. 8] erhalten konnte, obwohl die Königin bereits in der Antike als lasziv und schamlos galt und so auch in der Ikonographie der Frühen Neuzeit des Historiengemäldes tatsächlich auftrat.

Der moralphilosophische Sinn eines exemplum unterliegt im Übrigen historischen Umdeutungen und Umbewertungen. So kritisierte Augustinus ${ }^{56}$ im 5. nachchristlichen Jahrhundert Lukretia, obwohl sie in der römischen Geschichtsschreibung und Rhetorik bis dahin als unbestrittener Inbegriff weiblicher Keuschheit und als Vorbild für verheiratete Frauen galt. Der Hintergrund dieser Umwertung war natürlich die radikale Änderung, die das Christentum in der Bewertung des Selbstmords brachte, den in der Antike besonders die Philosophenschule der Stoa als ehrenhafte Strategie der Selbstbehauptung des Individuums propagiert hatte. Wird Lukretia weiterhin als exemplum virtutis verwendet, ist von einer Umbesetzung des moralphilosophischen Hintergrundsinns auszugehen. Politische Konnotationen, wie ihre Rolle in der Entstehung der römischen Republik, lösen den Aspekt der persönlichen Selbstbehauptung ab. Der Selbstmord der Lukretia ${ }^{57}$ wird deshalb in der Historienmalerei der Frühen Neuzeit entweder politisch gedeutet oder auf den Aspekt der weiblichen Keuschheit reduziert. Vergleichbare Umbesetzungen des Rezeptionshorizontes finden sich in der Darstellung des Freitods der Kleopat-

\footnotetext{
${ }^{55}$ Ich wähle als Beispiel (Katalog 72) die Kleopatra von Francesco Cozza (1605-1682).

${ }^{56}$ De civitate Dei 1,19

${ }^{57}$ Vgl. ausführlich unten S. $123 \mathrm{ff}$.
} 


\section{I /Schönes Sterben`}

ra. ${ }^{58}$ Es ist zu vermuten, dass die Darstellung von Selbstmörderinnen als Tugendheldinnen (exempla virtutis) in der barocken Historienmalerei komplexe moralphilosophische Voraussetzungen ${ }^{59}$ hatte, die die christliche Wertung des Selbstmords als Todsünde in den Hintergrund treten ließen.

Soll die Anwendung des Begriffs exemplum virtutis aussagekräftig und tragfähig sein, muss auch der den Wechsel des Rezeptionshorizonts bestimmende Wertekanon rekonstruiert werden. ${ }^{60}$ Schon die Rhetorik, wie sie Quintilian und Cicero formulierten, erkannte, dass die Wirkung eines exemplum ${ }^{61}$ die teilweise oder gänzliche Vergleichbarkeit des Vorbilds mit einem Konflikt oder einer Situation der Gegenwart voraussetzte. Vom Künstler und vom Betrachter werden beachtliche hermeneutische Anstrengungen verlangt.

Dergleichen ist im Falle der von Couperus geschilderten Haager Geburtstagsgesellschaft, der Kleopatras Tod als ılebendes Bild vorgeführt wurde, nicht mehr zu erwarten. Der Freitod der antiken Heldin dient ihr, ohne große hermeneutische Anstrengungen, nur noch als historistische Folie eines bürgerlichen Romantizismus. Dass das Motiv des ıschönen Sterbens`, des bewusst gewählten Selbstmords, nicht immer so oberflächlich rezipiert wurde wie am Ende des 19. Jahrhunderts und eine lange ikonographische Geschichte voraussetzt, soll im Folgenden Gegenstand der Untersuchung sein. Dabei wird die Historienmalerei ${ }^{62}$ zwar die $^{2}$ meisten und aussagekräftigsten Beispiele beisteuern, gelegentliche Blicke auf Theater $^{63}$ und Oper ${ }^{64}$ zeigen aber, dass der Bildtypus und die Motivgeschichte der Selbstmörderin als Tugendheldin eine für die frühe Neuzeit nicht unwichtige moralphilosophische Dimension hatte.

\footnotetext{
${ }^{58}$ Vgl. ausführlich unten S. $139 \mathrm{ff}$.

${ }^{59}$ Vgl. ausführlich unten S. $177 \mathrm{ff}$.

60 „Wie Reinhard Koselleck in seiner Studie über den Wandel der Geschichtsauffassungen nachweisen kann, löst das sich erst im 18. Jahrhundert etablierende Interesse an der historischen Zeit den alten Topos auf: das Modell shistoria magistra vitaeı setzt die Wiederholbarkeit historischer Handlungen voraus, oder noch deutlicher, vermittelt das Bild eines geschichtlichen Wandels, der sich gesetzmäßig vollzieht. Die Aufklärung realisierte die von Koselleck beschriebene Umwertung in der Erkenntnis der Einmaligkeit einer historischen Situation.« (Schneemann, Peter Johannes: Geschichte als Vorbild, Die Modelle der französischen Historienmalerei 1747-1789, Berlin 1994, S. 41)

${ }^{61}$ Dazu Daxelmüller, Christoph: Exemplum, in: Enzyklopädie des Märchens, begr. von Kurt Ranke, hrsg. von Rolf Wilhelm Brednich, Bd. 4, Berlin 1987, Sp. 627-649.

${ }^{62}$ Vgl. ausführlich unten, S. $45 \mathrm{ff}$.

${ }^{63}$ Vgl. ausführlich unten, S.193ff.

${ }^{64} \mathrm{Vgl}$. ausführlich unten, S. 274ff.
} 


\section{Sterbebildtypen und Todesdarstellung bis zur Frühen Neuzeit}

\section{Die klassizistische Engführung}

Die zum ersten Mal 1436 von Leon Battista Alberti ${ }^{1}$ als eigene Gattung beschriebene frühneuzeitliche Historienmalerei entwickelte ein umfangreiches Repertoire mythologischer, religiöser und historischer Themen, zu dem auch der ıTod des Helden` gehörte.

In diesem Umkreis entstand das Bildmotiv der ISelbstmörderin als Tugendheldin`, das im Folgenden näher untersucht werden soll. Es lässt sich seit dem 15. Jahrhundert als kontinuierliche ikonographische Tradition in wechselnden Besetzungen und Funktionen verfolgen. Sie kommt allerdings erst dann angemessen in den Blick, wenn sie vor dem Hintergrund der Todesdarstellung in der Kunst gesehen wird, auf die ich zunächst kurz eingehe, um die vom europäischen Klassizismus des 18. Jahrhunderts verstellte Sonderstellung der Frühen Neuzeit und des Barock in den Blick zu rücken.

Für Todesdarstellungen wurden in der Antike, im Mittelalter und in der Frühen Neuzeit Motive und Verfahren entwickelt, die sich in großen Zügen kurz beschreiben lassen. Antike Skulpturen und Vasen überliefern einen bedeutenden Themenkomplex sterbender Halbgötter und Menschen, die sich göttlichem Ratschluss widersetzt hatten oder im Kampf unterlagen. Demgegenüber finden sich im Mittelalter völlig andere, christlich geprägte Todesdarstellungen, die ihrerseits in der Frühen Neuzeit umformuliert wurden. Vor allem entstanden seit dem 15. Jahrhundert profane Todesdarstellungen, die weniger auf die künstlerischen Vorlagen der Antike als auf die moralistisch gedeutete historische Überlieferung des Altertums zurückgriffen.

Die klassizistische Ästhetik des 18. Jahrhunderts, die sich sehr intensiv mit künstlerischen Darstellungen des Todes und Sterbens beschäftigte, hat nicht nur das Mittelalter, sondern auch diese innovativen Aspekte der frühneuzeitlichen

\footnotetext{
${ }^{1}$ Alberti, Leon Battista: Drei Bücher über die Malerei, in: Alberti, Leon Battista: Kleinere kunsttheoretische Schriften, hrsg. von Hubert Janitschek, Osnabrück 1970 (ND der Ausgabe Wien 1877, Quellenschriften für Kunstgeschichte und Kunsttechnik des Mittelalters und der Renaissance, Bd. 11). Vgl. weiterführende Literatur zur Problematik in: Gaehtgens, Thomas / Fleckner, Uwe (Hrsg.): Historienmalerei, Berlin 1996, S. 83.
} 


\section{Sterbebildtypen und Todesdarstellung}

Historienmalerei ausgeblendet. Sie berücksichtigte weder die Bildtraditionen des Mittelalters, die sehr konkret und oft hässlich die Endlichkeit menschlichen Seins betonen, noch bezog sie die variantenreiche Historienmalerei des Barock ein, die dem Thema des Sterbens eine neue Bildwürdigkeit gab.

Ernst Bloch hat darauf aufmerksam gemacht, dass Lessing einen Zeitgeschmack formulierte, der Traditionslinien von eineinhalb Jahrtausenden bewusst ignoriert:

Am einflussreichsten wirkte hier Lessings Untersuchung von 1769: ^Wie die Alten den Tod gebildet،; man kann sie zugleich eine der wärmsten antikischen Kampfschriften gegen das Mittelalter nennen. Sie vollzieht den Trost mit einem hintergründigen Austausch von Emblemen, mit der Verabschiedung von Stundenglas und Hippe zugunsten eines schönen Freundesbildes: des Genius mit gesenkter Fackel. Lessing erneuert also damit nicht nur die Gleichung Tod-Schlaf, die poetisch bis auf Homer zurückgeht und die philosophisch in der Leibnizschen >Einfaltung inm vorlag, er trieb die letzten Reflexe der Gotik aus dem Todesbild aus. Er setzte ein verständig-schönes, ein klassizistisches an seine Stelle, ein eminent ästhetisches, worin die gelöschte Fackel so immanent wirkt wie das Fallen des Vorhangs nach beendetem Schauspiel. ${ }^{2}$

Mit dem Rückgriff auf die Antike in der bekannten Abhandlung ${ }^{3}$ Lessings wird der Tod im letzten Drittel des 18. Jahrhunderts »zur mildesten Form des Lebens « ${ }^{4}$ geschönt, wobei die grundsätzlichen Unterschiede zwischen den mittelalterlichen und neuzeitlichen Darstellungsverfahren nicht verschwiegen werden. Vor der Folie der nachantik-christlichen Darstellungstraditionen lässt Lessing den Genius Tod, der mit Flügeln versehen eher einer Amorette ähnelt, als sympathische, beinahe bezaubernde Personifikation des Lebensendes wiedererstehen. Gemmen, Sarkophage und Vasen werden als Zeugen für die antike Traditionslinie aufgeboten und gewinnen die Leser der Abhandlung für sich. Auch Goethe bewunderte in Dichtung und Wahrheit die milde und gütige Vorstellung des Todes ${ }^{5}$ als Bruder des Schlafs:

Am meisten entzückte uns die Schönheit jenes Gedankens, daß die Alten den Tod als den Bruder des Schlafs anerkannt und beide, wie es Menächmen geziemt, zum Verwechseln gleich gebildet. Hier konnten wir nun erst den Triumph des Schönen höchlich feiern und das Häßliche jeder Art, da es doch einmal aus der Welt nicht zu

\footnotetext{
${ }^{2}$ Bloch, Ernst: Das Prinzip Hoffnung, Frankfurt/Main 1959, S. 1345.

${ }^{3}$ Lessing, Gotthold Ephraim: Werke, hrsg. von Herbert G. Göpfert u.a., Bd. 6 (Kunsttheoretische und kunsthistorische Schriften), Darmstadt 1996, S. 405-462.

${ }^{4}$ Bloch, a.a.O., S. 1346.

5 Johann Sebastian Bach hat interessanterweise in seiner 1726 geschriebenen "Kreuzstabs-Kantate « (BWV 56) im abschließenden Choral das antike Bild des Todes als des Schlafes Bruder aufgegriffen: "Komm, o Tod, du Schlafes Bruder, / Komm und führe mich nun fort; / Löse meines Schiffleins Ruder, / Bringe mich an sichern Port! / Es mag, wer da will, dich scheuen, / Du kannst mich vielmehr erfreuen; / Denn durch dich komm ich herein / Zu dem schönsten Jesulein. « Der Verfasser des Kantatentextes zum 19. Sonntag nach Trinitatis ist unbekannt. Zur theologischen Einordnung des Chorals vgl. Petzold, Martin: Bach-Kommentar, Theologischmusikwissenschaftliche Kommentierung der geistlichen Volkalwerke Johann Sebastian Bachs, Bd. 1, Stuttgart 2004, S. $558 f$.
} 


\section{Sterbebildtypen und Todesdarstellung}

vertreiben ist, im Reiche der Kunst nur in den niedrigen Kreis des Lächerlichen vertreiben. $^{6}$

Der Protagonist in Goethes Novelle »Der Sammler und die Seinigen « fasst beim Betrachten von Kupferstichen die sich von den nachantiken, mittelalterlichen und barocken Todesdarstellungen distanzierende Sicht zusammen:

Ich finde keine Spur vom wütenden Schrecken des Todes, vielmehr in den Statuen die höchste Subordination der tragischen Situation, unter die höchsten Ideen von Würde, Hoheit, Schönheit, gemäßigtem Betragen. Ich sehe hier überall den Kunstzweck die Glieder zierlich und anmutig erscheinen zu lassen. Der Charakter erscheint nur noch in den allgemeinsten Linien, welche durch die Werke, gleichsam wie ein geistiger Knochenbau, durchzogen sind. ${ }^{7}$

Antike, Mittelalter und frühe Neuzeit haben sehr verschiedene Todesdarstellungen entwickelt und heterogene Interpretationen des Todes visualisiert. Erst die einseitig klassizistische Rezeption der Antike hat diese Traditionsstränge ausgeblendet.

\section{Thanatos und Hypnos: Sterben in der antiken Kunst}

Die Darstellung des Todes auf antiken Objekten unterschiedlichster Provenienz betont Harmonie und Wohlgestalt des Sterbenden, wie sich an einigen Beispielen zeigen lässt: Auf einer griechischen Vase des 6. vorchristlichen Jahrhunderts ${ }^{8}$, die sich heute im Metropolitan Museum in New York [Abb. 1] befindet, wird der verwundete und sterbende Sarpedon von den Brüdern Thanatos und Hypnos, gleichwertige Personifikationen des Todes und des Schlafs, niedergelegt; von drei kleinen, allerdings blutenden Wunden abgesehen erscheint der muskulöse Körper des Helden unversehrt; das Sterben gleicht eher dem Einschlafen. Die sterbenden Krieger des Aphaiatempels auf Aigina $^{9}$ [Abb. 2], die um $500 \mathrm{v}$. Chr. auf den Giebelseiten in Marmor skulptiert wurden, be-

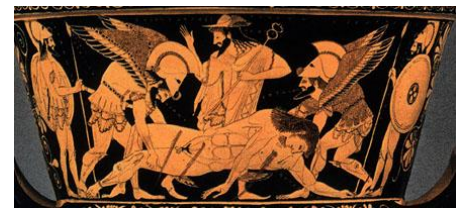

Abb. 1

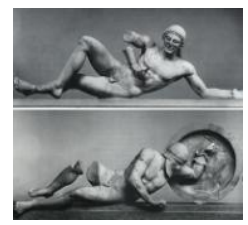

Abb. 2

kräftigen den Eindruck, dass die griechische Kunst Sterbende und Tote in körperlicher Unversehrtheit abbildete.

\footnotetext{
${ }^{6}$ Goethe, Johann Wolfgang: Sämtliche Werke nach Epochen seines Schaffens, Münchner Ausgabe, hrsg. von Richter, Karl, Bd. 16, S. 341-342 (im weiteren Verlauf als MA zitiert).

${ }^{7}$ MA, Bd. 6.2, S. 102.

${ }^{8}$ Die in diesem Kapitel angeführten Beispiele habe ich nicht in den Bildkatalog aufgenommen, da es sich um sehr bekannte Objekte handelt, die meist im Netz abrufbar sind. Die hier angeführte Vase befindet sich heute in New York (Metropolitan Museum) und wurde ca. 550-500 v. Chr. hergestellt.

${ }^{9}$ Heute in München (Glyptothek).
} 


\section{Sterbebildtypen und Todesdarstellung}

Ob man sich nun das berühmte Orpheus-Relief [Abb. 3], auf dem Eurydike vom Psychopompos Hermes an der Hand zu ihrem Ehemann zurückgeführt wird ${ }^{10}$, die große Skulptur des Laokoon mit seinen Söhnen ${ }^{11}$ [Abb. 4] oder die Gruppe der Niobiden $^{12}$ [Abb. 5] vor Augen führt, immer handelt es sich um die Veranschaulichung von zu frühem Tod oder von vorzeitigem, durch Götter veranlasstem Ster-

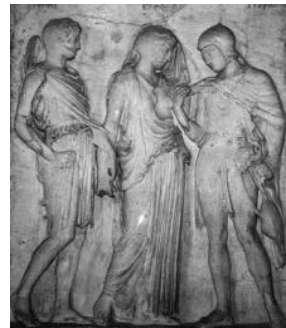

Abb. 3

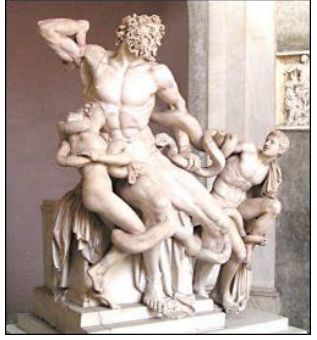

Abb. 4

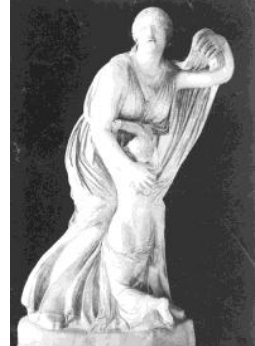

Abb. 5

ben. Die uns erhaltenen griechischen und römischen Kunstwerke stellen einen gewaltsamen Tod, nie das Sterben durch Alter oder Krankheit dar. So schmücken die zahlreich erhaltenen Sarkophage ${ }^{13}$ [Abb. 6 und 7] stets Todesdarstellungen, in denen durch den Ratschluss der unerbittlichen Götter ein Menschenleben zu früh

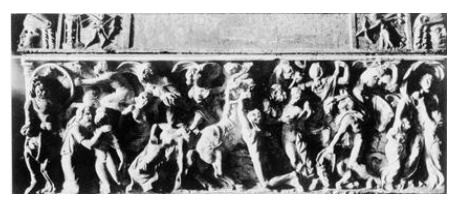

Abb. 6

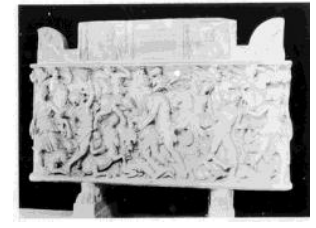

Abb. 7

und vorzeitig beendet und gleichzeitig die durch menschliche Hybris verletzte göttliche Ordnung wiederhergestellt wird. Solche Darstellungsweisen bilden den menschlichen Körper sehr genau ab, deuten aber körperlichen Schmerz, Verletzungen und Verfall allenfalls an. Die Kunst vermittelt das ıSchrecklicheı nur in der dargestellten Nachdrücklichkeit der Affekte, weiß den Menschen in eine große Ordnung gestellt und interpretiert das Sterben als Wiederherstellung der kosmischen Harmonie von Göttern und Menschen.

\footnotetext{
${ }^{10}$ Heute in Neapel (Archäologisches Nationalmuseum).

${ }_{11}^{11}$ Heute in Rom (Vatikanische Museen).

12 Heute in Florenz (Uffizien).

${ }^{13}$ Als Beispiele seien hier nur der Niobiden-Sarkophag (Abb. 6) und Amazonen-Sarkophag (Abb. 7) (beide in den Vatikanischen Museen) genannt.
} 


\section{Sterbebildtypen und Todesdarstellung}

\section{Der personifizierte Tod in Spätantike und Mittelalter}

In der Spätantike bricht die ikonographische Tradition ab, Sterbende wiederzugeben und den Tod als sanftmütigen Jüngling zu personifizieren. Skelettdarstellungen auf Trinkgefäßen ${ }^{14}$ und Mosaiken ${ }^{15}$ [Abb.8] erinnern im täglichen Gebrauch an den Tod. Diese Betonung der Endlichkeit des Menschen konnte ebenso hedonistisch-epikureisch wie stoisch-christlich gedeutet werden.

Im Hochmittelalter herrscht die Ikonographie des Todes als eines den Menschen bedrohenden Feindes vor. Er wird als Töter, als Reiter, Schnitter, Jäger, Totengräber, Spielmann oder Chronos dargestellt. Solche anthropomorphen Gestaltungen werden erstaunlich spät entwickelt, obwohl schon

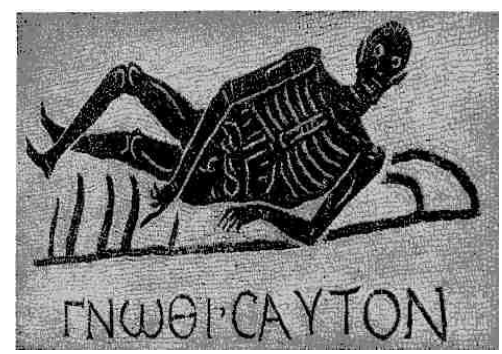

Abb. 8 Paulus den von Christus besiegten Tod personifizierte. ${ }^{16}$ Valentino Pace hat gezeigt, dass es die christliche Ikonographie der Spätantike und des frühen Mittelalters aus guten theologischen Gründen vermied, dem Tod Gestalt zu geben. ${ }^{17}$ Erst um das Jahr 1000 finden sich in der Buchmalerei Personifikationen des Todes. Die wohl berühmteste aus dem Uta-Codex [Abb. 9] zeigt den besiegten Tod. Er trägt in der einen Hand eine Sichel, in der anderen einen zerbrochenen Speer, dessen Spitze inm die Schläfe durchbohrt ${ }^{18}$. Unter dem Kreuz Christi steht der Tod der Personifikation des Lebens gegenüber.

Ein aus dem 13. Jahrhundert stammendes Fresko ${ }^{19} \mathrm{im}$ Dom der Abruzzenstadt Atri zeigt die bekannte Legende ${ }^{20}$ der Begegnung der drei Lebenden mit den

\footnotetext{
${ }^{14}$ Vgl. Rosenfeld, Hellmut: Der mittelalterliche Totentanz, Entstehung - Entwicklung - Bedeutung, Münster / Köln 1954, S. 2. Außerdem Neumann, Wolfgang (Hrsg.): AK Tanz der Toten - Todestanz: der monumentale Totentanz im deutschsprachigen Raum, Dettelbach 1998, S. 16.

${ }^{15}$ So beispielsweise das heute im Thermenmuseum in Rom befindliche Mosaik, das aus dem zweiten oder

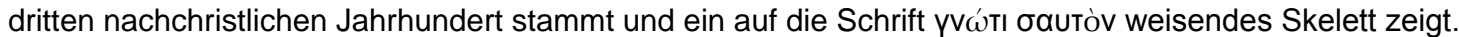

16 »Wenn aber dieses Verwesliche angezogen hat Unverweslichkeit und dieses Sterbliche angezogen hat Unsterblichkeit, dann wird eintreffen das Wort, das geschrieben steht: ıDer Tod ist verschlungen in Sieg. Tod, wo ist dein Sieg? Tod, wo ist dein Stachel?» Der Stachel des Todes aber ist die Sünde, die Kraft der Sünde aber ist das Gesetz.« (1 Cor. 15,54-56)

${ }^{17}$ Pace, Valentino: «)Dalla morte assente alla morte presentes: Zur bildlichen Vergegenwärtigung des Todes im Mittelalter «, in: Borst, A. / von Graevenitz, G. / Patschovsky, A. / Stierle, K. (Hrsg.): Tod im Mittelalter, Konstanz 1993, S. 335-376.

${ }_{18}$ Pace, a.a.O., Abb. 14; heute München, Staatsbibliothek, CIm 13601, $3^{\mathrm{v}}$. Im gleichen Aufsatz von Pace auch eine Abbildung der allegorischen Darstellung der Mors als Todesfurie aus dem Psalter Cotton Tiberius C. VI aus der Mitte des 11. Jahrhunderts.

${ }^{19}$ Abb. bei Pace, a.a.O., Abb.15 a und $15 \mathrm{~b}$

${ }^{20}$ Heyse, E. / Briesemeister, D.: »Drei Lebende und drei Tote«, in: Lexikon des Mittelalters, Bd. 3, Sp. 13901392. Hier in Kürze die Rezeptionsgeschichte der wohl aus dem Orientalischen stammenden Erzählung, die spätestens seit Alkuin belegt ist und sich in allen volkssprachlichen Literaturen und in der lkonographie wiederfindet.
} 


\section{Sterbebildtypen und Todesdarstellung}

drei Toten [Abb. 10]. Die wohl aus dem arabischen Bereich stammende Erzählung schildert das Zusammentreffen vornehmer Jäger mit drei Toten in unterschiedlichen Stadien der Verwesung, die den Lebenden warnend zurufen: Quod sumus, hoc eritis. Die Darstellung der Legende, die auch volkstümliche Ängste vor >Wiedergängern ${ }^{21}$ aufgreift, bot eine für Jahrhunderte richtungweisende Visualisierungsmöglichkeit: Der Tod wird als meist schon zum Skelett zerfallener Toter dargestellt, oft auch als mumifiziertes Hautskelett, dem die Eingeweide aus der Bauchhöhle entnommen wurden. ${ }^{22}$ Im 14.

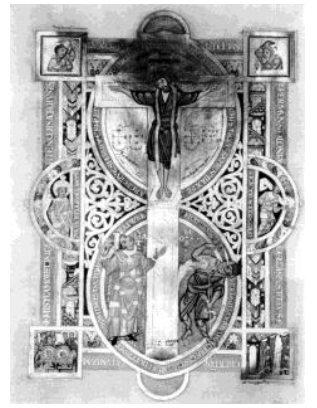

Abb. 9 Jahrhundert wird die mumifizierte Gestalt des Todes dann meist von Würmern und Schlangen zerfressen, die in Ekel erregender Weise aus dem Leib quellen. Im 15. Jahrhundert bürgerte sich in ganz Europa die Darstellung als Skelett oder Knochenmann ein. Der Tod hat das

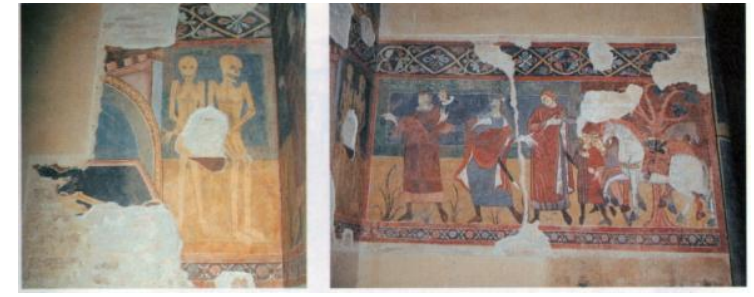

Abb. 10

Aussehen seiner Opfer am Ende des Sterbe- und Verwesungsprozesses angenommen.

\section{Mittelalterliche Kontingenzerfahrung: Totentanz}

Richtete sich in der Antike das Interesse der Künstler auf die exemplarische Darstellung vorzeitig Sterbender, entwickelte das Mittelalter zahlreiche Personifikationen des Todes. Es bedurfte nicht erst der Erfahrungen der Pest, die in einer ersten Welle zwischen 1347 und 1352 Europa heimsuchte, um den Tod übermächtig, über die Lebenden triumphierend, stets auf der Jagd und Hatz nach Opfern darzustellen.

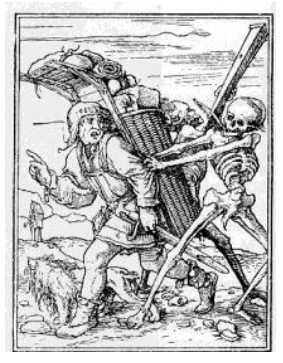

Abb. 11

Im Pisaner Campo Santo wurde er bereits 1350 als Schnitter dargestellt. In Kirchen oder an Friedhofsmauern, in kleinen Elfenbeinskulpturen ebenso wie in der Monumentalplastik tritt er als dominanter Knochenmann auf, der keine Standesrücksichten nimmt [Abb. 11] $]^{23}$.

\footnotetext{
${ }^{21}$ Dinzelbacher, P.: »Tod, Sozial- und Mentalitätsgeschichte «, in: Lexikon des Mittelalters, Bd. 8, Sp. 829-831.

22 Über entsprechende Mumifizierungsbräuche vgl. Rosenfeld, a.a.O., S. 26.

${ }^{23}$ Hier Holbein der Jüngere (1538).
} 


\section{Sterbebildtypen und Todesdarstellung}

Die Kontingenzerfahrung eines unerwartet eintretenden Lebensendes findet häufig im >Totentanzı ihren Ausdruck. In Abfolgen, die meist von Kaiser und Papst, Kardinal und König, Bischof, Herzog, Abt, Bürgermeister, Edelmann bis hin zum Bauern und Kind reichen, wurden Lebensalter, Stände und Berufe verbunden und so die Gleichheit aller Menschen im Hinblick auf ihr Ende hervorgehoben [Abb. 12]. ${ }^{24}$ Eine theologische oder auch nur moralische Reflexion ist allenfalls indirekt damit verbunden, auch wenn in der Forschung auf die gleichzeitige Verbreitung der Bettelund Predigerorden und der Totentänze auf öffentlichen Plätzen aufmerksam gemacht wurde. ${ }^{25}$ In dieser Phase der Beschäftigung mit Todes- und Sterbevorstellungen tritt die

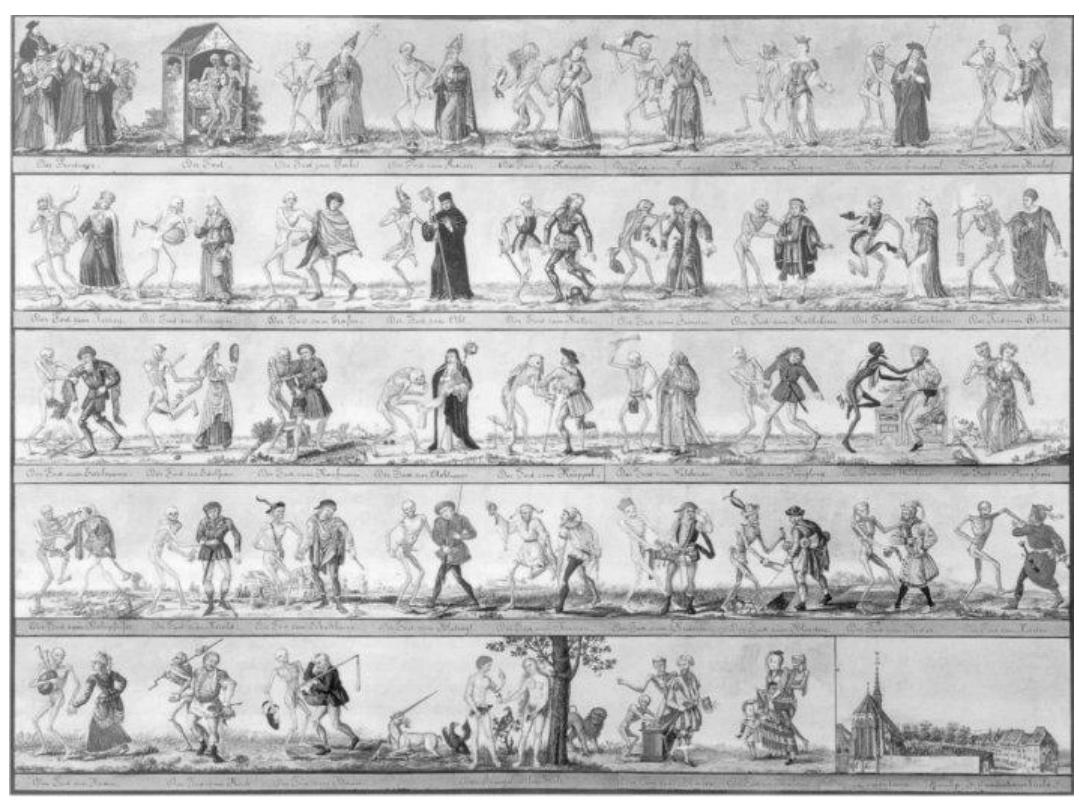

Abb. 12 meist als Skelett den Reigen der Menschen anführende Personifikation des Todes den Menschen gegenüber, die vom unvermuteten plötzlichen Ende bedroht sind, auch wenn sie noch ganz gesund und vital auftreten. Der Gegensatz zwischen den sich ihres Lebens noch erfreuenden Erdenbürgern und der allegorischen Präsenz des Todes wird zur ständigen Mahnung, der in den artes moriendi und im sMarientod exemplarische Formen der Todesvorbereitung entsprechen.

\section{5 artes moriendi}

Zunächst als lateinische Handreichungen für den Klerus entstanden, leiten die artes moriendi des Spätmittelalters zu angemessenem Verhalten in der Sterbestunde an. Sie fanden rasch Eingang in die volkssprachlichen Literaturen und spiegeln in ihren Varianten Bedürfnisse und Frömmigkeitsformen frommer Laien.

Bereits in der zweiten Hälfte des 15. Jahrhunderts wurden den kleinformatigen Drucken der Paränese und Erbauung dienende Holzschnitte hinzugefügt, um

\footnotetext{
${ }^{24}$ Hier der Baseler Totentanz von 1440/45.

${ }^{25}$ So zum Beispiel Schuster, Eva: AK Das Bild vom Tod, Graphiksammlung der Heinrich-Heine-Universität Düsseldorf, Recklinghausen 1992, S. 14.
} 


\section{Sterbebildtypen und Todesdarstellung}

die Vorbereitung auf das Sterben und einen guten Tod auch den nicht des Lesens Kundigen augenfällig zu machen. ${ }^{26}$ Der Sterbende wird von dämonischen Teufeln, deren lateinische Spruchbänder Laster benennen und Hoffnungslosigkeit einflüstern, und von Engeln bedrängt, die den Teufeln widerstehen: an der Schwelle zum Tod wird über das Weiterleben nach dem Tod entschieden. Die Teufel verzweifeln über ihrem Verlust, die Engel nehmen das kleine nackte Menschlein auf, das als Symbol der Seele dem Mund des Verstorbenen entflieht [Abb. 13]. ${ }^{27}$ Die Bildkonzeption stellt vorbereitetes und gutes Sterben vor: Der Alte oder Kranke hat Zeit, sich auf seinen Tod vorzubereiten und ist sich des geistlichen Beistands gewiss, der inm mit Beichte, letzter Ölung und Kommunion als viaticum hilft, den letzten Kampf zu bestehen. Äußerliches Zeichen für diese Konzeption ıguten Sterbensı ist die

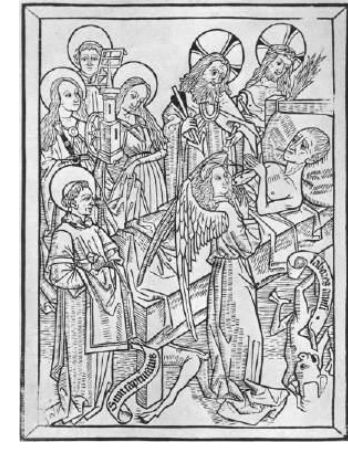

Abb. 13 Kerze in der Hand des Sterbenden. Der Blickwinkel der künstlerischen Bearbeitung hat sich nun ganz auf das christliche Sterben verengt.

\section{Der Marientod als Modell des guten Sterbens}

Am nachhaltigsten hat wohl der Marientod auf die Ikonographie des sguten Sterbens ' gewirkt: die legendäre Ausgestaltung ${ }^{28}$ des Todes der Gottesmutter beginnt mit einem apokryphen Bericht des 5. Jahrhunderts ${ }^{29}$. Zwar blieb die Koimesis in der christologisch orientierten Theologie ohne große Bedeutung, sie gewann aber immer beträchtlicheren Einfluss in der Frömmigkeitspraxis. Der Tod der Gottesmutter, die in der Volksfrömmigkeit als Mittlerin bei ihrem Sohn galt, wurde in Wort und Bild zum exemplarischen Tod ausgestaltet. Für diesen gilt, dass die Todesstunde rechtzeitig erkannt wird und so genügend Zeit zu Buße und meditatio mortis bleibt, wie sie die artes moriendi verlangten. Eng war damit der Wunsch verbunden, in Begleitung nahestehender Menschen zu sterben, die vorlesend und singend dem Sterbenden die Intimität der Glaubensgemeinschaft vermitteln. So stirbt Maria in

\footnotetext{
${ }^{26}$ Abbildungen der Holzschnitte einer Ars moriendi aus dem 15. Jahrhundert in Ariès, Philippe: Bilder zur Geschichte des Todes, München 1984, S. 158-159.

${ }^{27}$ Holzschnitt eines unbekannten deutschen Meisters um 1470.

${ }^{28}$ Dazu besonders Schulz, H.-J. / Restle, M.: »Koimesis «, in: Lexikon des Mittelalters, Bd. 5, Sp. 1249-1250 und der Aufsatz von Schreiner, Klaus: »Der Tod Marias als Inbegriff christlichen Sterbens, Sterbekunst im Spiegel mittelalterlicher Legendenbildung «, in: Borst, A. (Hrsg.): Tod im Mittelalter, a.a.O., S. 261-312.

${ }^{29}$,De transitu beatae Mariae virginis, in: Apocalypses apocryphae, hrsg. von Konstantin von Tischendorf, Hildesheim 1966 (ND der Ausgabe Leipzig 1866), S. 113-123.
} 


\section{Sterbebildtypen und Todesdarstellung}

der Darstellung des Albrechtsmeisters ${ }^{30}$ [Abb. 14] umgeben von allen Aposteln, die nach der Legende, durch Engel vom bevorstehenden Tod Mariens in Kenntnis gesetzt, aus allen Teilen der Welt zusammenkommen. Sie umstehen das Bett, Petrus reicht der Sterbenden eine Kerze und besprengt sie mit Weihwasser. Allein oder in Gruppen singen und lesen die anderen Apostel im Psalter. Mehrere brennende Kerzen deuten an, dass dämonische Kräfte von der Sterbenden ferngehalten werden. Für die Imagination der Gläubigen ist das Ziel solch christlichen Sterbens über der eigentlichen Sterbeszene ins

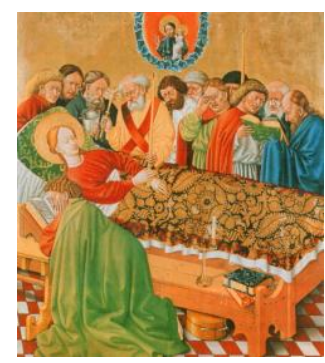

Abb. 14 Bild gesetzt: Christus nimmt den Verklärungsleib Mariens als weißgekleidete kleine Figur im Himmel auf. Die Koimesis, deren Fest am 15. August im römischen und besonders ausgeprägt im byzantinischen Ritus gefeiert wird, wurde zur exemplarischen Inszenierung christlichen Sterbens, das viele Gläubige am Lebensende zum Vorbild wählten, wie wir aus zahlreichen Zeugnissen wissen. ${ }^{31}$

\section{Monumentale Grabmäler}

Monumentale Grabmäler bekamen eine individualisierende Ausgestaltung, als reich ausgestattete Memorialgräber für die Vornehmen in den Kirchen Mode wurden, in denen durch ihren Rang ausgezeichnete Tote als gisants dargestellt wurden [Abb. 15]. ${ }^{32}$

Die Entwicklung dieses Grabmaltyps ist bis in seine

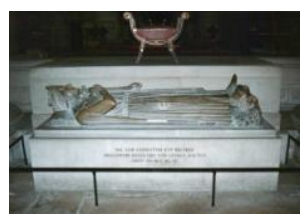

Abb. 15

Sonderformen als Gelehrtengrab oder >Doppeldeckergrabı untersucht worden. ${ }^{33}$ Einige wichtigen Merkmale sind allen Variationen der pompösen Inszenierung gemeinsam: Die Verstorbenen werden in individueller Kleidung vollplastisch als $\mathrm{Ru}$ hende mit allen Zeichen ihres Rangs in einer representacion au vif inszeniert. Dabei zeigt der Faltenwurf der Kleidung, dass die Dargestellten, obwohl meist ein Kopfkissen das Haupt stützt, als Stehende in der Blüte ihrer Jahre, meist mit geöffneten Augen konzipiert sind. Die Haltung der Hände variiert stark nach Moden und Konventionen: die gisants können sie zum Gebet falten, ein Gebetbuch halten oder

\footnotetext{
${ }^{30}$ Aus der Zeit zwischen 1438 und 1440.

${ }^{31}$ Dazu vor allem der Aufsatz von Borst, Arno: „Ein exemplarischer Tod«, in: Tod im Mittelalter, a.a.O., S. 2558. Borst vergleicht den gut dokumentierten Tod Hermanns des Lahmen mit dem Sterben des Abbo von Fleury und des Anselm von Canterbury.

${ }^{32}$ Hier das Grab des Richard Coeur de Lion in der Kathedrale von Rouen.

${ }^{33}$ Es sei hier nur auf die zahlreichen Literaturhinweise der Standardwerke von Panofsky Erwin: Grabplastik, Vom alten Ägypten bis Bernini, Köln 1964, und Ariès, Philippe: Bilder zur Geschichte des Todes, München 1984, verwiesen.
} 


\section{Sterbebildtypen und Todesdarstellung}

Insignien ihres Rangs führen. ${ }^{34}$ Die Verstorbenen werden in einem mittleren Idealalter portraitiert und in ihrer Gestalt genau wiedergegeben. Dabei wird auf die erreichten Würden, Ämter und Funktionen, aber auch auf die in Szene gesetzte Frömmigkeit Wert gelegt.

>Doppeldeckergräber` [Abb. 16] sind gleichsam Stein gewordenes Memento mori. Im unteren Bereich der Sepulkralarchitektur wird der Verstorbene als Skelett oder Mumie vorgestellt. Darüber werden die Dargestellten als ideale gisants modelliert. Da diese Mode einen großen architektonischen Aufwand erforderte, konnten sich solche Sepulkralarrangements nur selten durchsetzen. Eine Weiterentwicklung des

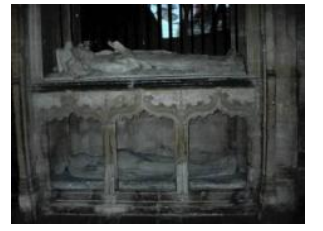

Abb. 16 gisant sind Grabmäler mit einem priant: Der Verstorbene kniet betend auf seiner Tumba. Charakteristisch für solch pompöse Grabplastik ist, unabhängig davon ob sie mit einem gisant, einem priant oder einem im Verwesungsprozess befindlichen transi ausgeführt wird, die idealisierte Gestalt der Dargestellten, die alle Attribute der erlangten Ehren und Würden in die andere Welt mitnehmen.

In der beginnenden Renaissance verselbständigte sich die idealisierende Abbildung des Gestorbenen; weltliche Würden wurden ins Monumentale überhöht und die Grabplastik zum programmatisch durchdachten Ehrenmal für den diesseitigen Ruhm gestaltet. In diesem Sinn entwarf Michelangelo in Rom

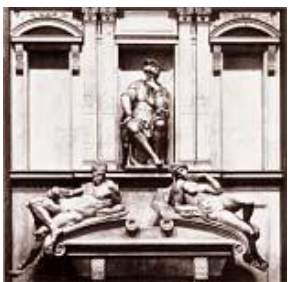

Abb. 17 das Grabmal für Julius II. und in Florenz die Grabkapelle der Medici [Abb. 17]. In der Grabplastik sind die Toten selbst und nicht mehr die Sterbenden Gegenstand, wobei das tremendum des Todes und die Vergänglichkeit des Menschen in bizarren und grotesken Formen, etwa den transis, in unerhörter Drastik dargestellt wurde, obwohl bald erneut eine Idealisierung der Gestorbenen einsetzte. Dies ist umso bemerkenswerter, als für die Darstellung Kreuzestods Jesu, dem für die spätmittelalterliche Frömmigkeit wichtigsten und jeden Tag wieder neu memorierten Sterben, sich geradezu >realistische` Verfahren durchsetzt hatten.

\footnotetext{
${ }^{34}$ Reiches Bildmaterial bei Panofsky, a.a.O., Abb. 197-416.
} 


\section{Sterbebildtypen und Todesdarstellung}

\section{Der Kreuzestod: Vom Triumph zur compassio}

Obwohl der Kreuzestod Jesu als Erfüllung prophetischer Voraussagen und Beweis der Menschwerdung des Erlösers im Zentrum der christlichen Religion steht, wird die Erwartung, diese zentrale Aussage des Christentums müsse auch zu einem wichtigen Thema der christlichen Ikonographie geworden sein, zunächst enttäuscht, denn in den ersten Jahrhunderten wurde der Kreuzestod Christi durchaus nicht veranschaulicht. Erste, noch ganz hieratische Zeugnisse ${ }^{35}$ finden sich im 5. Jahrhundert: Christus ist mit offenen Augen, erhobenen Hauptes, ohne Ausdruck von Schmerzen ans Kreuz genagelt, wie dies etwa auf der Holztür der römischen Kirche Santa Sabina zu sehen ist [Abb. 18]. Solche Darstellungen betonen die Göttlichkeit des Erlösers, auch wenn gelegentlich der Schächer, Maria und Johannes hinzutreten. Wenn man von der durch ikonoklastische Phasen gestörten byzantinischen Entwicklung absieht, wird der Kreuzestod im frühen Mittelalter stets als triumphaler Opfertod ausge-

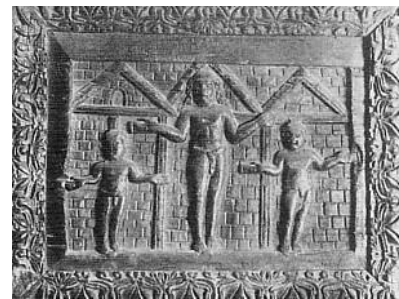

Abb. 18 legt.

Das Gero-Kruzifix ${ }^{36}$, das den Gekreuzigten als bereits verstorben, mit geschlossenen Augen und in sich zusammengesunken präsentiert [Abb. 19], und das Lotharkreuz $^{37}$ aus dem Domschatz in Aachen sind hingegen erste Belege für theologische und lehramtliche Kontroversen, die zunehmend das Menschsein Christi und die compassio der Gläubigen in den Vordergrund rückten. Diese Entwicklung, die eine ganz eigene Christusfrömmigkeit ausbildete und den Gekreuzigten ins Zentrum stellte, ist in den Predigten Bernhards von Clairvaux und in den Texten

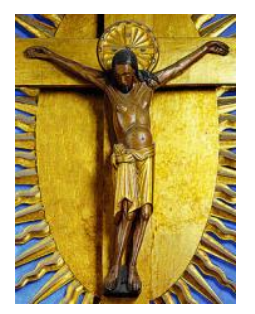

Abb. 19 des Franciscus von Assisi theologisch ausformuliert. Der duldende, leidende oder gestorbene Christus wird so seit 1300 bevorzugter Gegenstand der Mystik; Andachtsbilder und Mystikerkruzifixe verhelfen dem Gläubigen in Meditation und Kontemplation durch die Darstellung naturalistisch gesteigerten Leidens zum emotionalen Dialog und zur betrachtenden Anteilnahme am Leiden Christi. Ein expressives Exempel, das die Funktionalisierung für diese besondere Form religiösen Erle-

\footnotetext{
${ }^{35}$ Abbildung des Elfenbeinkästchens (um 420 n. Chr.), das die Kreuzigung Christi und den Selbstmord des Judas zeigt (British Museum, London), ist zu finden im Aufsatz Paces, a.a.O., S. 337, als Abb. 1.

${ }^{36}$ Um 970 n. Chr.

${ }^{37}$ Ebenfalls 10. Jahrhundert, Abb. im Aufsatz Paces, a.a.O., S. 342.
} 


\section{Sterbebildtypen und Todesdarstellung}

bens verdeutlicht, ist in den ersten Jahren des 14. Jahrhunderts der Kruzifixus aus der Kölner Kirche St. Maria im Kapitol [Abb. 20]. Der Körper hängt mit steil emporgereckten und verdrehten Armen an einem Astkreuz in Gabelform. Der Unterleib ist eingesunken, der Brustkorb mager und gewölbt, die Rippen erkennbar. Die Seitenwunde des durch Geißelhiebe nachhaltig verunstalteten Körpers blutet stark. Der nach rechts gesunkene Kopf lässt das faltige, ausgetrocknete und fast schon mumifizierte Gesicht nur erkennen, wenn der Gläubige unter dem Kreuz aufblickt. Das in den Tod übergehende Leiden ist so erbarmungslos dargestellt, dass allzu voreilig vermutet wurde, der Künstler habe wohl Studien an Gehängten gemacht, um diese Steigerung des Ausdrucks zu erreichen. ${ }^{38}$

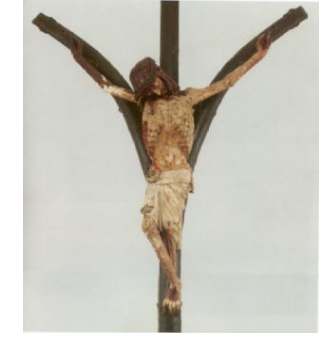

Abb. 20

Da in der spätmittelalterlichen Frömmigkeit neben das Gemeinschaftserlebnis der Liturgie individuelle Meditations- und Andachtsformen der compassio traten, entwickelten sich neben den crucifixi dolorosi neue Andachtsbildtypen. In Skulptur, Malerei und Graphik wurden einzelne Phasen der Passion Christi isoliert zu Andachtsangeboten ausgebildet: Der Bildtypus des Ecce Homo fokussiert die Leiden des gegeißelten, dornengekrönten und verspotteten Herrn, dem Bildtypus `Christus in der Rast` vergleichbar, der typologisch mit Hiob verknüpft die Verlassenheit Jesu auf dem Weg zum Kreuz beklagt und Erschöpfung und körperlichen Verfall drastisch wiedergibt. Das ıVesperbild , heute oft mit dem Bildtypus der Pietà gleichgesetzt, hat keinen biblischen Textbezug, sondern entstand im 14. Jahrhundert aus mystischen Vorstellungen und wurde rasch so volkstümlich, dass es bereits im Spätmittelalter [Abb. $21]^{39}$ zur verbreiteten Kirchenausstattung gehörte. Aspekte der Totenklage und der Gottesmutterschaft überlagern sich in diesem

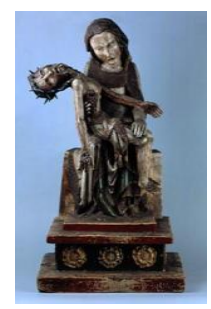

Abb. 21 besonderen Typus und lassen deswegen die Darstellung des toten Körpers meist zurücktreten. Im Andachtsbildtypus des ıSchmerzenmannes` allerdings, der sich wohl bereits im 12. Jahrhundert aus byzantinischen Ikonen entwickelte [Abb. 22], werden die Wunden der Passion und der Kreuzigung deutlich betont, obwohl die geöffneten Augen eine gewissermaßen visionäre Aussage andeuten. ${ }^{40}$

\footnotetext{
${ }^{38}$ Vgl. Feulner, A. / Müller, Th.: Geschichte der deutschen Plastik, München 1953, S. 164.

${ }^{39}$ Pietà Roettgen (Bonn, Rheinisches Landesmuseum).

${ }^{40}$ Schmerzensmann aus der Dreifaltigkeitskirche in Görlitz.
} 


\section{Sterbebildtypen und Todesdarstellung}

Für private Andacht und Meditation bestimmte Kunstwerke zeichnen sich im Spätmittelalter und am Übergang zur Frühen Neuzeit durch großen Realismus aus; körperliche Qualen, seelische Verlassenheit, Sterben und Tod durften in der devotio moderna nachgezeichnet und sogar überzeichnet werden, um die Gedanken und Gefühle zur imitatio Christi zu führen. Intention und Adressatengruppen beeinflussten hier und in den Märtyrerbildern unübersehbar die künsterischen Verfahren.

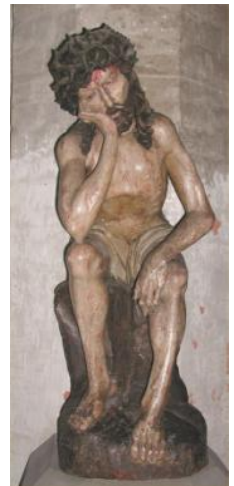

Abb. 22

\section{Nachfolge oder Triumph: Märtyrer}

Pace hat an einigen Beispielen gezeigt, dass die Ikonographie der Märtyrer sich parallel zur Ikonographie des Kreuzestodes entwickelte. ${ }^{41} \mathrm{Da}$ im Verständnis der Alten Kirche der Todestag eines Märtyrers sein Geburtstag (dies natalis) zum ewigen Leben war, wurde im frühen Christentum das Martyrium zunächst gar nicht und später ohne Betonung der Schmerzen und des Leidens dargestellt. Dies gilt für den im 8. Jahrhundert entstandenen Freskenzyklus der heiligen Quiricus und Julitta [Abb. 23] in der römischen Kirche St. Maria Antiqua. Wer »die Bilderfolge betrachtet, ohne auf den Text der Heiligenlegende zurückzugreifen, könnte

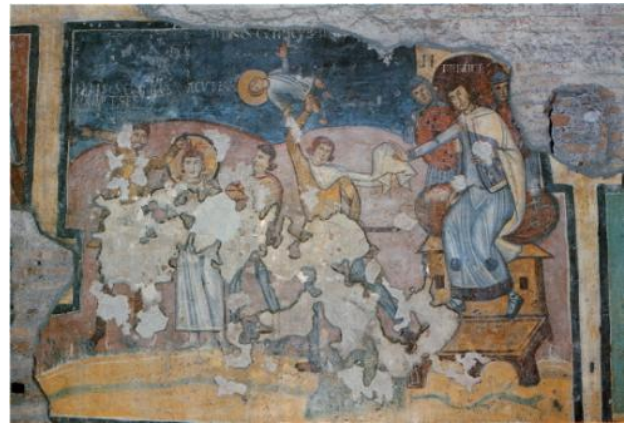

Abb. 23 sogar zweifeln, daß die Märtyrer infolge von Folterungen zu Tode kamen: Ihre Augen bleiben auch dann noch geöffnet, als sie in sartagine missi sunt, $d$. h. in einer Art Pfanne zum Schmoren gebracht werden. « 42

In einer späteren Phase stehen vor allem Blutzeugen der römischen Kaiserzeit im Mittelpunkt der Ikonographie. Obwohl die Verehrung der Begräbnisstätten oft unmittelbar nach dem Märtyrertod einsetzte, schon bald Martyrien als Gedächtniskirchen errichtet wurden und Reliquien stets begehrt waren, entwickelte sich eine Ikonographie der Märtyrer erst lange nach der literarischen Legendenbildung. Zur folgenreichsten Sammlung von Märtyrer-Viten wurde im Spätmittelalter die Legenda aurea ${ }^{43}$ des Jacobus de Voragine (um 1270), die in zahlreiche Volkssprachen übersetzt im 14. Jahrhundert viele gemalte oder freskierte Märtyrer-Zyklen

\footnotetext{
${ }^{41}$ Pace, a.a.O., S. 357-359.

${ }^{42}$ Pace, a.a.O., S. 358.

${ }^{43}$ Barone, G.: "Legenda aurea«, in: Lexikon des Mittelalters, Bd. 5, Sp. 1796-1797.
} 


\section{Sterbebildtypen und Todesdarstellung}

hervorrief. Nun beginnt, der Entwicklung verschiedener Andachtsbild-Typen mit christologischen Themen entsprechend, ein breiter Strom von Illustrationen, der den Märtyrertod naturalistisch und realistisch [Abb. 24 und 25] ${ }^{44}$ wiedergibt.

Im Spätmittelalter verfügten die Künstler über zwei Darstellungsmuster zur Wiedergabe von Sterben und Tod, die je nach Wirkungsabsicht eingesetzt wurden. Wirklichkeitsnahe, naturalistische und ins Expressive gesteigerte Darstellungsweisen wurden gewählt, wenn das Kunstwerk zu Einfühlung und Identifikation in der Nachfol-

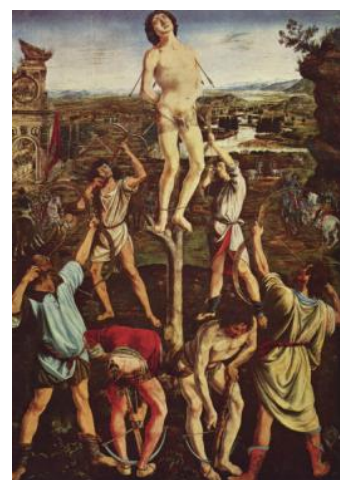

Abb. 24

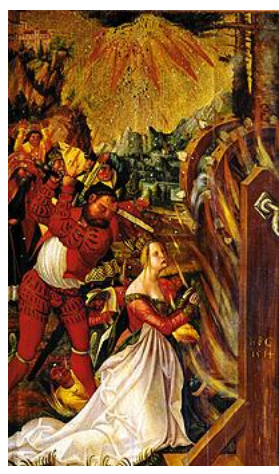

Abb. 25 ge Christi anleiten sollte. Stand nicht die compassio des Betrachters, sondern der Triumph der Kirche im Vordergrund, wird die Realität des Todes nurmehr durch `Beigaben` wie die Dornenkrone oder die Seitenwunde Jesu, den Rost des Laurentius oder das Rad der Katharina angedeutet.

\section{Erweiterungen der Bildthemen im Humanismus und in der Frühen Neuzeit}

Erst der Humanismus erweiterte den Kanon bildwürdiger Themen entscheidend. Dabei fällt auf, dass in aller Regel neue Bildthemen im Sinnbereich des Sterbens zunächst literarisch entwickelt und erst dann von den darstellenden Künsten aufgegriffen wurden.

In der ersten Phase des Humanismus wurden durch die Editionen klassischer Texte mythologische und historische Themen wieder bekannt gemacht. Sie ist durch die philologische Arbeit der Herausgeber gekennzeichnet, die nach Handschriften fahndeten und diese in Erstdrucken einer gebildeten Leserschaft zur Verfügung stellten. ${ }^{45}$ In einer zweiten, häufig unmittelbar nach und mit der Edition beginnenden Phase begann die produktive Rezeption: Den moralischen Allegoresen der >Metamorphosen` Ovids oder den von Boccaccio zusammengestellten Exempelsammlungen berühmter Männer und Frauen wurden Holzschnitte beigegeben. Dabei verlangte die Illustrierung römischer Historiographie und Mythologie von den Künstlern eine neue Auseinandersetzung mit dem Themenbereich des Todes.

\footnotetext{
${ }^{44}$ Hier der Sebastian (1475) von Antonio Pollaiuolo (1432-1498) (heute in London, National Gallery) und eine Katharina des Meisters H. G. von 1514 (heute in der Staatsgalerie Stuttgart).

${ }^{45}$ Vgl. unten S. $177 \mathrm{ff}$.
} 


\section{Sterbebildtypen und Todesdarstellung}

Illustrationen zum Selbstmord Sophonisbes oder Lukretias in Boccaccios Sammlung ${ }^{46}$ zeigen ebenso wie der $>$ Verwandlungstod Daphnes oder Thisbes in illuminierten Handschriften ${ }^{47}$ oder mit Holzschnitten versehenen Ausgaben ${ }^{48}$ die künstlerischen Möglichkeiten, mit denen Künstler der beginnenden Renaissance Sterben und Tod ins Bild setzten. Es fällt auf, dass die künstlerischen Interpretationen bei mythologischen Themen (Metamorphosen) und historischen Exempeln durchgängig Formen verfrühten oder freiwilligen Todes darstellten: Die Sterbenden sind nie von Schmerz und Leid gezeichnet, sondern stets in der Integrität ihres blühenden Lebens abgebildet. Die Renaissancekünstler griffen auf Verfahren zurück, die sich beim ızurückhaltenden` Typus der Märtyrerbilder ${ }^{49}$ bewährt hatten, und bildeten den physischen Schmerz nicht ab. Stärke und Überlegenheit der ıHelden bewähren sich bis zum letzten Moment; Leid und Schmerzen werden in Analogie zu der christlichen Heilsgewissheit der Märtyrer ıstoischı verachtet.

Allmählich trat der Bildbereich des Profanen gleichberechtigt neben den Bereich des Sakralen: die Palette der bildwürdigen Todesdarstellungen erweiterte und diversifizierte sich dadurch entscheidend. Dazu kam, dass sich die Darstellungsweisen kirchlicher, höfischer und städtischer Auftragsarbeiten immer mehr annäherten: Ein heiliger Sebastian unterscheidet sich auf den ersten Blick kaum von einem Narcissus; in beiden Fällen setzten die Künstler in ihren Körperstudien genaue anatomische Beobachtungen um. Erst Details wie Pfeile oder ein das Spiegelbild reflektierender See vereindeutigten die vorgestellte Person für den Betrachter. Für die Künstler stand, unabhängig von den religiösen, mythologischen, historischen oder allegorischen Inhalten ${ }^{50}$, die beabsichtigte Wirkung im Vordergrund.

Besonders augenfällig ist dies in der nachtridentinischen Kunst, deren gegenreformatorische Intention eine neue Blüte der Märtyrerbilder mit sich brachte. Ihre Wirkungsästhetik setzte auf die minutiöse Schilderung des Leidens und Ster-

\footnotetext{
${ }^{46}$ Hoepfl, Simon (Hrsg.): Boccacios Buch der berühmten Frauen, mit 79 Holzschnitten der Ausgabe von Joh. Zainer, Ulm, München 1924.

${ }_{47}$ Zum Beispiel Handschrift aus dem 14. Jahrhundert in Paris, Bibliothèque de l'Arsenal, 5069.

${ }^{48}$ Zum Beispiel Ausgabe Brügge von 1484 mit Holzschnitten von Mansion.

49 Vgl. S. $41 \mathrm{f}$.

${ }^{50}$ So schreibt 1584 Giovanni Paolo Lomazzo in seinem Trattato dell'arte delle pittura, scoltura et architettura: "Avendo il pittore a rappresentare le istorie di tutte le parti del mondo e di tutte le età, chi non vede ch'egli ha da procedere con infinito riguardo, per rappresentarle decentemente, con le circonstanze che gli si convengono rispetto alle maniere e costumi di quel paese e di quel età, in cui successe l'istoria che rappresenta? « (Zitiert nach Gaehtgens, Th. W. / Fleckner, U. [Hrsg.]: Historienmalerei, Berlin 1996, S. 133)
} 


\section{Sterbebildtypen und Todesdarstellung}

bens der Heiligen, um mit ihrem Vorbild den nachtridentinischen Frömmigkeitsstil zu propagieren und gegen den Protestantismus agitatorisch abzusetzen. ${ }^{51}$

Dagegen setzte die Historienmalerei die im Humanismus gefundenen Darstellungsmöglichkeiten mit profanen Inhalten fort: dem Kampfestod des Helden, dem >Verwandlungstod der sstarken Frauk. Stets wird an das in der Antike geprägte Darstellungsmuster ${ }^{52}$ angeknüpft: Schmerzen und Verwundungen werden allenfalls angedeutet, der Sterbende idealisiert und geschönt dargestellt. Gerade das Sterben ıfeiertı den Wert des Individuums und seiner selbstbestimmten Tat; es soll nicht als serlittenı, sondern als ıgewolltı erscheinen. Im Historiengemälde wurde die Freiheit des Subjekts, die philosophische Entwicklung durchaus antizipierend, zur zentralen Aussage.

Insofern entwickelte sich der von Bloch so scharfsichtig bei Winckelmann diagnostizierte Klassizismus bereits in vielen Todesdarstellungen der frühneuzeitlichen Historienmalerei, deren Ikonographie im Rückgriff auf die Themen der als mustergültig erscheinenden Antike formuliert wurde ${ }^{53}$, auch wenn die eingesetzten formalen Mittel durchaus smodern waren. Wurde in der mittelalterlichen Kunst der Tod als bedrohliche Macht dargestellt, rückte in der profanen, aber auch in der kirchlichen Historienmalerei das Sterben als Inszenierung in den Vordergrund: die Ikonographie stellte das ıschöne Sterbenı des Helden, des Märtyrers, des Philosophen oder der sstarken Fraur als ideale und zugleich bewusst gewählte Inszenierung vor. Dass in diesem Zusammenhang das Thema der freiwillig sterbenden Frau als Tugendheldin Beachtung fand, verdient eine genauere Untersuchung, die im Folgenden geleistet werden soll.

\footnotetext{
${ }^{51}$ Vgl. unten S. $204 \mathrm{ff}$.

52 Vgl. oben S. $31 \mathrm{ff}$.

${ }^{53}$ Ich widerspreche hier Garrard, Mary D.: Artemisia Gentileschi, the image of the female hero in Italian Baroque art, Princeton 1989, besonders S. 214. Garrard geht davon aus, dass die Maler der Renaissance und des Barock bei der Darstellung sich selbst durch den Tod opfernder Frauen auf misogyne und sado-erotische Betrachter abzielten, und postuliert zwischen den spätmittelalterlich-humanistischen Darstellungen historischer Selbstmörderinnen (beispielsweise den Boccaccio-lllustrationen) einerseits, der frühneuzeitlichen Malerei andererseits einen Bruch. Bezeichnenderweise bindet Garrad die sich als Illustration von Boccaccios De claris mulieribus selbst den Tod gebende Lukretia an die mittelalterlichen ınine worthiesı (vgl. unten, S. 123ff.) zurück. Zwar konnte Lukretia auch als Emblem für Keuschheit interpretiert werden, doch ist das Neue des Holzstichs, dass sie individuell und historisch verstanden wird. Die Lukretia der Boccaccio-Illustration gehört deshalb in einen Zusammenhang, der mit den humanistischen Illustrationen neu emendierter historischer Texte beginnt und in die Frühe Neuzeit weiterführt.
} 


\section{Bildthemen exemplarischen Sterbens}

\section{Exemplarisches Sterben im Kanon der frühneuzeitlichen Historienmalerei}

Seit der Renaissance setzten sich Historienbild, Porträt, Genre, Landschaft und Stilleben als klar getrennte Bildgattungen durch, die eine Spezialisierung der Künstler auf einen oder zwei Bereiche zur Folge hatte. Dabei nahm die Historienmalerei in der Hierarchie der Bildgattungen stets einen hervorgehobenen Platz ein und wurde von Künstlern und Theoretikern als Krönung künstlerischer Tätigkeit angesehen. Dass sich diese Gattungshierarchie bis ins 19. Jahrhundert gehalten hat, ist vor allem einer beeindruckenden Reihe von Kunsttheoretikern zu verdanken, die mit Leon Battista Alberti beginnend über Lodovico Dolce, Giorgio Vasari, Karel van Mander, André Félibien, Anthony Ashley Cooper Earl of Shaftesbury, Johann Joachim Winckelmann, Denis Diderot, Johann Georg Sulzer bis zu Georg Wilhelm Friedrich Hegel reicht. ${ }^{1}$ Der pictor doctus wurde zum Ideal der Kunsttheoretiker, setzte die Historienmalerei doch umfassendes Wissen voraus.

Zu den Bildgegenständen der Historienmalerei gehörten nicht nur geschichtliche Ereignisse im engeren Sinn, sondern auch mythologische und biblische Themen. Diese breite Palette historischer und fiktionaler Stoffe stellte für lange Zeit den verbindlichen Themenkanon der Historienmalerei dar. Dabei ist es in unserem Zusammenhang besonders wichtig, dass sich Darstellungen rexemplarischen Sterbensı zu einem ikonographischen Sonderbereich der kirchlichen wie der profanen Historienmalerei entwickelten. Dieser umfasste in der Frühen Neuzeit ein weit breiteres Spektrum als in den vorangehenden Jahrhunderten und reichte vom sschönen Sterben des Helden, des Märtyrers und des Philosophen bis zur Selbstmörderin als Tugendheldin. ${ }^{2}$ Mit dem $>$ Tod des Helden ${ }^{3}$ ist der Themenbereich nur unzureichend beschrieben.

\footnotetext{
${ }^{1}$ Alberti, Leon Battista: Della Pictura, 1436; Dolce, Ludovico: Dialogo della pittura, intitolato l'Aretino, 1557; Vasari, Giorgio: Vite de' più eccellenti pittori, scultori e architettori, 1568; van Mander, Karel: Den Grondt der Edel vry Schilder-const, 1604; Félibien, André: Conférences de l' Académie Royale de Peinture et de Sculpture, 1668; Cooper Earl of Shaftesbury, Anthony Ashley: A Notion of the Historical Draught or Tablature of the Judgement of Hercules, 1712; Winckelmann, Johann Joachim: Gedanken über die Nachahmung der Griechischen Werke in der Malerey und Bildhauerkunst, 1755; Diderot, Denis: Essai sur la peinture, 1765; Sulzer, Johann Georg: Allgemeine Theorie der Schönen Künste, 1771-1774; Hegel, Georg Wilhelm Friedrich: Vorlesungen über die Ästhetik, 1820-1829.

${ }^{2}$ Vgl. S. $42 \mathrm{ff}$.
} 


\section{Bildthemen exemplarischen Sterbens}

Zunächst sei deshalb kurz der gesamte Umfang der Bildthemen exemplarischen Sterbens umrissen, um danach das von mir zu untersuchende Bildkorpus näher eingrenzen zu können. Die `Freiwilligkeitı und damit ১Tugendhaftigkeit` ihres Todes verbindet in der Tat so verschiedene Themenbereiche wie das christliche Sterben der Märtyrer, den Verwandlungstod der Metamorphosen, den Heldentod, aber auch den >Tod des Philosophen` und den Selbstmord ıstarker Frauen`.

\section{Der Verwandlungstod der Metamorphose}

Am Rande des so umrissenen ikonographischen Sonderbereichs exemplarischen Sterbens steht der Verwandlungstod der Metamorphosen. Der heilsgeschichtlichen Gerichtetheit steht die Kreisform des Mythos gegenüber, der eine eigenartig ıschwache` Form der Todesdarstellung hervorgebracht hat.

Allerdings handelt es sich beim mythologischen Sterben durchgängig um Metamorphosen: Wird Daphne in einen Lorbeerstrauch oder Narcissus in eine Frühlingsblume verwandelt, geht es um einen als Verwandlung aufgefassten Tod. Ovids Metamorphosensammlung, das wichtigste Reservoir der mythologischen Ikonographie, beschreibt Sterben als eine sich in Stufen vollziehende Verwandlung, die Wesen und Charakter des Sich-Verwandelnden nicht aufhebt, sondern vielmehr erst zum eindeutigen Ausdruck bringt. In der Metamorphose tritt somit das fortdauernde Wesen der verwandelten Person in Erscheinung, unabhängig davon, ob Metamorphosen (wie bei Narcissus) Folgen eines Vergehens oder (wie bei Daphne) Errettung aus höchster Bedrohung sind. Augustinus hat die der Metamorphose zugrunde liegende mythische Denkfigur am prägnantesten umschrieben: figura praeterit, non natura ${ }^{4}$. Metamorphosen unterscheiden die wandelbare Gestalt von der unzerstörbaren Natur, die als unwandelbares Substrat erhalten bleibt. Die scheinbar sterbende Person verwandelt sich in eine andere, ihre Eigenart noch schärfer konturierende Gestalt. Metamorphosen setzen eine Veränderung ins Bild, die mit künstlerischen Mitteln wesentlichen Charakterzügen einer Person zur Dauer verhilft. ${ }^{5}$

\footnotetext{
${ }^{3}$ Vgl. S. $18 f f$.

${ }^{4}$ De civitate Dei 20,14

${ }^{5}$ Hegel definiert in seinen Vorlesungen zur Ästhetik im Kapitel »Die bewusste Symbolik der vergleichenden Kunstform «, zu der neben der Metamorphose die Fabel, die Parabel, der Apolog und das Sprichwort gezählt werden, die Metamorphosen über die vom Rezipienten verlangte Verstandesleistung: »Wir können in dieser Beziehung zwei Hauptstufen unterscheiden. A. In der ersten macht die konkrete Erscheinung, sei sie aus der Natur oder aus menschlichen Begebnissen, Vorfällen und Handlungen hergenommen, einerseits einen Ausgangspunkt, andererseits das für die Darstellung Wichtige und Wesentliche aus. Sie wird zwar nur der allgemeineren Bedeutung wegen, die sie enthält und andeutet, ausgeführt und nur insoweit entfaltet, als es der
} 


\section{Bildthemen exemplarischen Sterbens}

Seit Beginn der Frühen Neuzeit spielt im weiten Bereich mythologischer Darstellungen der Verwandlungstod eine der religiösen Ikonographie durchaus vergleichbare Rolle. Da das uneigentliche Sterben, die Verwandlung einer Person nicht das wirkliche Ende bedeutet, zeigten die Maler bei derartigen Sterbeszenen meist beide Gestalten. Dabei fält auf, dass die sich verwandelnde Person meist in ihrer ursprünglichen Gestalt wiedergegeben und die gerade einsetzende Umformung sich nur an einem Körperteil wie zum Beispiel den schon zu Ästen werdenden Gliedern Daphnes andeutet: Die Metamorphose kann nur als noch andauernder Formwechsel in eine Voll-Endung in Szene gesetzt werden, die von ewiger Dauer sein wird.

Während christlich motiviertes Sterben auf ein transzendentes und mit ästhetischen Mitteln nicht darstellbares Telos ausgerichtet bleibt, ist der Verwandlungstod der Metamorphose ein Prozess, der einen Wesenszug der verwandelten Person zur Prägnanz bringt. Der Übergang von einer Gestalt in die andere hebt den wesentlichen Zug ästhetisch hervor; die Verwandlung bringt das Substrat zu dauerhafter Erscheinung. So markiert der >Verwandlungstod in der Metamorphose nicht das Ende, sondern die Dauer, die Unvergänglichkeit eines herausragenden Wesenzuges. »Die Metamorphosen vergegenwärtigen das fortdauernde Ende ästhetisch ${ }^{6}{ }^{6}$ und verweisen damit auf ihre immanente mythische Denkstruktur, während christlich motiviertes Sterben über sich selbst hinausweist. Insofern zeigt sich in der Darstellung christlichen Sterbens das dahinter stehende lineare undzielgerichtete Denken, das dem mythischen und mithin kreisförmigen Denken der Metamorphose diametral zuwiderläuft.

\section{Das nachtridentinische Märtyrerbild}

Mit der tridentinischen Reform entwickelte sich eine ausdifferenzierte Ikonographie des Märtyrerbilds, deren Bildsprache sich deutlich von profanen Sterbedarstellungen der Historienmalerei abhebt, obwohl die wechselseitige Beeinflussung der iko-

Zweck, diese Bedeutung in einem damit verwandten einzelnen Zustande oder Vorfall zu veranschaulichen, erfordert; das Vergleichen aber der allgemeinen Bedeutung und des einzelnen Falls als subjektive Tätigkeit ist noch nicht ausdrücklich herausgestellt und die ganze Darstellung will nicht ein bloßer Zierat an einem auch ohne diesen Schmuck selbständigen Werke sein, sondern tritt noch mit der Prätension auf, für sich schon ein Ganzes abzugeben. Die Arten, die hieher gehören, sind die Fabel, die Parabel, der Apolog, das Sprichwort und die Verwandlungen. « (Hegel, Georg Wilhelm Friedrich: Ästhetik, hrsg. von F. Bassenge, Frankfurt / Main 1955, S. 379). Jacob Burckhardt hingegen bindet in seiner Griechischen Kulturgeschichte (München ${ }^{2} 1987$ ['Basel 1956-1957], Bd. 2, S. 7-19) das Phänomen Metamorphose religionsgeschichtlich und philosophisch an noch ältere religiöse Vorstellungen, denen Vorstellungen der Seelenwanderung zugrunde liegen, wie sie unter anderen Pythagoras formuliert hat.

${ }^{6}$ Herzog, Reinhart: »Vom Aufhören«, in: Stierle, Karlheinz / Warning, Rainer (Hrsg.): Das Ende, Figuren einer Denkform, München 1996 (Poetik und Hermeneutik 16), S. 283-329, hier S. 315. 


\section{Bildthemen exemplarischen Sterbens}

nographischen Verfahren nicht zu bestreiten ist. Nunmehr traten das Martyrium selbst und die zu erwartende Belohnung der Blutzeugenschaft in den Mittelpunkt. Das Ziel solch heroischer Tugend wurde in die Darstellung integriert; in der Bildsprache der Gemälde haben sich Siegeskranz und Palmenzweig ${ }^{7}$ als Märtyrerattribute durchgesetzt. Waren die Künstler in vielen Märtyrerdarstellungen der Renaissance noch ohne vereindeutigende Beigaben ausgekommen, verband die nachtridentinische lkonographie das Selbstopfer der Märtyrer ${ }^{8}$ mit der Aufnahme in den Himmel und betonte damit die Differenz zum Sterben sprofaner Helden, deren Tod als solcher exemplarisch ist.

Der Märtyrertod steigert die ıLeistung des Glaubenshelden ins Heroische und Unüberbietbare: Insofern wurde die Veranschaulichung eines qualvollen und daher nicht schönen Märtyrertodes durchaus angestrebt; drückten die minutiös nachgezeichneten Torturen doch aus, zu welch heroischen Tugenden die Heilsgewissheit führen kann. Das Martyrium ist insofern kein Akt moralischer Selbstbehauptung, als die Finalisierung des Glaubens die Geringschätzung und Preisgabe der irdischen Existenz geradezu einschließt. ${ }^{9}$ Der Akzent liegt gerade nicht auf der Individualität des Heiligen, sondern auf der kollektiven Heilsvergewisserung.

Nachtridentinische Märtyrerdarstellungen gehen zwar von den eingeübten Bildstrategien profaner Sterbeszenen aus, fügen aber oft Hinweise auf die als solche nicht darstellbare Transzendenz hinzu und geben dem Sterbenden einen überindividuellen Gesichtsausdruck, den man heute oft als sschwärmerisch oder sentrücktı bezeichnet. ${ }^{10}$ Auf diesem Umwege gelingt als Kontrapunkt zur abstoßenden Konkretheit des Sterbens in der Physiognomie des Sterbenden, die die Vision des Jenseits zum Ausdruck bringt, doch noch ein ıschönes Sterben<.

Die heilsgeschichtliche Finalität wird exemplarisch dargestellt, ohne dass das gewählte ıExempek eigenes Gewicht erhielte. Der Märtyrer bleibt als heroischer Sonderfall eingebunden in den beim Betrachter vorausgesetzten Zusammenhang von Bekenntnis und Erlösung.

\footnotetext{
${ }^{7}$ Vgl. Flemming, J.: »Palme«, in: Kirschbaum, Engelbert (Begr.) / Braunfels, Wolfgang (Hrsg.), Lexikon der christlichen Ikonographie, Rom / Freiburg im Brsg. 1968-1976, Bd. 3, Sp. 364-365.

${ }^{8}$ Von Marquard recht ungeschickt als sacrificium praesentiae bezeichnet (Marquard, Odo: "Finalisierung und Mortalität«, in: Stierle, K. / Warning, R (Hrsg.): Das Ende, Figuren einer Denkform, München 1996 (Poetik und Hermeneutik 16), S. 467-475, hier S. 472).

${ }_{9}$ Marquard, a.a.O., S. 472-473.

${ }^{10}$ Vgl. dazu Henning, A. / Weber, G. (Hrsg.): >Der himmelnde Blickı, Zur Geschichte eines Bildmotivs von Raffael bis Rotari, Dresden 1998.
} 


\section{Bildthemen exemplarischen Sterbens}

\section{Sterbende Helden}

Exemplarische Helden aus Mythos und Geschichte bilden den größten Themenvorrat der frühneuzeitlichen Künste. Wir sind heute gewohnt, historisches gegen mythisches Denken abzugrenzen und die spezifische Fiktionalität des Mythos ${ }^{11} \mathrm{zu}$ betonen. In der produktiven Rezeption der Frühen Neuzeit zogen Künstler und Auftraggeber allerdings zwischen Mythos und Geschichte keine oder nur unscharfe Grenzen; für das kulturelle Gedächtnis gilt dies ohnehin: »Der Unterschied zwischen Mythos und Geschichte wird hier hinfällig. Für das kulturelle Gedächtnis zählt nicht die faktische, sondern nur erinnerte Geschichte. Man könnte auch sagen, daß im kulturellen Gedächtnis faktische Geschichte in erinnerte und damit in Mythos transformierte wird. « ${ }^{12}$

Sterbende Helden, die in das kulturelle Gedächtnis Eingang gefunden hatten, lassen sich im griechisch-trojanischen Epenkreis ${ }^{13}$ ebenso finden wie in der legendären Vorgeschichte Roms. Wenn dabei in der frühneuzeitlichen Ikonographie vor allem römische Helden im Vordergrund standen, geht dies gewiss zunächst auf ihre Präsenz ad usum delphini im Lateinunterricht der gebildeten Oberschichten zurück. Allerdings machte sich wohl auch der Umstand geltend, dass die römische Geschichte sehr unterschiedliche politische und gesellschaftliche Modelle anbot, die einen weiten Spielraum für Adaptierungen und Umdeutungen ließen. Der auffällige Sachverhalt, dass der europäische Klassizismus seine politischen Referenzen vorzugsweise im römischen Bereich suchte, bedürfte gleichwohl einer eingehenden Untersuchung, für die es allenfalls Vorarbeiten gibt. ${ }^{14}$ Wenn Salvatore Settis die These vertritt, die griechische Klassik habe sich schon früh selbst zum Kanon stilisiert und das Polis-Modell mit der gestuften Beteiligung aller Gesellschaftsgruppen zum Ideal erhoben, kann dies nur teilweise befriedigen. So lässt sich vielleicht das geringe Interesse der frühneuzeitlichen Künste an Figuren der griechischen Geschichte erklären, nicht aber die bis zum Klassizismus marginale Rolle shomerischerı Gestalten begründen. Die Wiederentde-

\footnotetext{
${ }^{11}$ Vgl. dazu Blumenberg, Hans: Arbeit am Mythos, Frankfurt ${ }^{2} 1981$; Bailey, C. / Hamilton, C. A. (Hrsg.): AK Les Amours des Dieux, La peinture mythologique de Watteau a David, Paris 1991.

${ }^{12}$ Assmann, Jan: Das kulturelle Gedächtnis. Schrift, Erinnerung und politische Identität in frühen Hochkulturen, München ${ }^{2} 1997$, S. 52.

${ }_{13}^{13}$ Beispielsweise der Kampf von Achill und Hektor oder der Tod des Laokoon mit seinen Söhnen.

14 Dazu in jüngster Zeit die konzeptionellen und einleitenden Aufsätze in Zimmer, F. (Hrsg.): AK Die griechische Klassik, Idee oder Wirklichkeit, Berlin 2002, insbesondere der Aufsatz von Salvatore Settis: „Der Klassizismus und das Klassische«, S. 26-53.
} 


\section{Bildthemen exemplarischen Sterbens}

ckung der griechischen Antike im Humanismus weckte in der Historienmalerei vor allem das Interesse für Philosophen, nicht aber für die politischen Figuren.

Jedenfalls haben sich Theater, Musik und Malerei der Frühen Neuzeit ${ }^{15}$ ihre Sujets mit besonderer Vorliebe in der römischen Geschichte gesucht. Zur dramatischen Rezeption ${ }^{16}$ eigneten sich offensichtlich Figuren der frühen Republik, mit denen exemplarisch Kampfbereitschaft und Opfermut illustriert werden konnte. Vergleichbares gilt für die bildenden Künste: Das Sujet des die Tiberbrücke allein gegen die herandrängenden Etrusker verteidigenden Horatius Cocles ${ }^{17}$ wurde nicht zufällig von Strozzi und Lairesse ${ }^{18}$ aufgegriffen, ließ sich doch auf diese Weise außergewöhnliche militärische und politische Unerschrockenheit ${ }^{19}$ vorführen. Der Opfertod des Helden wird vor dem Hintergrund bewundernder und erschütterter Mitkämpfer und über den historischen Vorwurf hinaus als vorbildlicher Einsatz für die Gemeinschaft inszeniert.

\section{Der Tod des Philosophen}

In auffälliger Weise tritt in der Historienmalerei neben die politischen und militärischen Helden eine weitere Reihe historischer exempla, die den >Tod des Philosophen aufgreifen. Gabriele Oberreuter-Kronabel hat in einer Monographie ${ }^{20}$ die Darstellung des Philosophentodes in der Malerei des französischen Klassizismus am Beispiel von Sokrates, Seneca und Cato näher untersucht und darauf hingewiesen, dass Sterben und Tod in der Epoche der Aufklärung eine neue Bewertung erfuhren. Sie konnte zeigen, dass Sterbebilder in Reaktion auf die gegenreformatorische Betonung der Sterbestunde für das Seelenheil des Einzelnen nunmehr zu

\footnotetext{
${ }^{15}$ Zu den Themen der Historienmalerei der Frühen Neuzeit vgl. besonders die einleitenden Aufsätze in Mai, Ekkehard / Repp-Eckert, Anke (Hrsg.): AK Triumph und Tod des Helden, a.a.O., S. 12-164.

${ }^{16}$ Vgl. unten S. $193 \mathrm{ff}$.

${ }^{17}$ Livius, Ab urbe condita 2,10,2-11

18 Strozzis Orazio Coclite sul ponte Sublicio gehört in der Villa Centurione-Carpaneto (in GenovaSampierdarena) neben einem Fresko mit Marcus Curtius und einem weiteren mit Aeneas und Dido zur Ausstattung des großen salone, der sich der Verherrlichung der römischen Frühgeschichte und ihrer Tugendhelden widmet (Abb. in Gavazza, E. / Sciré, G. / Terminello, G. [Hrsg.]: AK Bernardo Strozzi, Genova 1581/82Venezia 1644, Milano 1995, S. 160). Lairesse hat seinen Horatius (Abb. in Roy, Alain: Gérard Lairesse, 16401711, Paris 1992, S. 349) im heute >Lairessezaalk genannten Raum des Haager Binnenhofes, wo sich die Raadkamer van den Hove van Justitie van Holland, Zeeland en West-Vriesland versammelte, noch deutlicher in einen kollektiven Anspruch eingebunden, da die anderen Gemälde den seinen Vater aus Troja tragenden Aeneas, die Allegorie der Justitia, die continentia des Scipio, die Vaterlandsliebe des Pompejus und die virtus der Römer beim Heranrücken des Hannibal zeigen. Traditionsbewusstsein, Gerechtigkeit, Besonnenheit, aber auch Tapferkeit werden so als wichtige Säulen eines funktionierenden Gemeinwesens vorgestellt.

${ }^{19}$ So zum Beispiel auch Manlius Torquatus, der seinen Sohn enthaupten lässt, oder Marcus Curtius, der sich mit seinem Pferd auf dem Forum Romanum in die Erdspalte stürzt, um dem Orakelspruch zu genügen.

${ }^{20}$ Oberreuter-Kronabel, Gabriele: Der Tod des Philosophen, Zum Sinngehalt eines Sterbebildtypus der französischen Malerei in der zweiten Hälfte des 18. Jahrhunderts, München 1986.
} 


\section{Bildthemen exemplarischen Sterbens}

»Tugendbildern « ${ }^{21}$ umgedeutet wurden. Der `Philosophentod rückt die Autonomie des seinen Tod frei wählenden Sterbenden in den Mittelpunkt und entwirft den Prototyp eines aufgeklärten, angstfreien, nur sich und seiner Vernunft verpflichteten Menschen.

Dies mag in Abwehr der von kirchlichen Kreisen wach gehaltenen Angst vor dem eigenen Sterben in der französischen Aufklärung plausibel sein, vernachlässigt aber, dass bereits vor dem 18. Jahrhundert die von Gabriele OberreuterKronabel behandelten Philosophen in der Historienmalerei eine deutlich profilierte Gruppe darstellten, deren spektakulärer Selbstmord ${ }^{22}$ als Gegenmodell zum militärisch-aristokratischen Heldentod entworfen wurde. Der philosophische Freitod wurde geadelt und dem Tod des Helden auf dem Schlachtfeld gleichgesetzt. Die im Bild inszenierten Affekte sind ebenso wie die hervorgehobene Bewunderung der Assistenzfiguren der entsprechenden Staffage eines Heldentodes durchaus ebenbürtig. ${ }^{23}$ Besonders stark akzentuierte affetti der dem Freitod beiwohnenden Freunde oder Verwandten lassen vermuten, dass die besondere Botschaft dieses Bildtypus $^{24}$ auf die Würde und constantia des Sterbenden abhob, der im Gegensatz zu seiner Umwelt besonnen und gelassen seinem Ende entgegensieht. Die Gleichwertigkeit sheroischen` und sphilosophischen` Sterbens lässt als thematischen Hintergrund eine latent neustoische Konzeption moralischer Autonomie ${ }^{25}$ vermuten, die erst in der Frühen Neuzeit denkbar ist: Heroen wie Philosophen wählen in sittlicher Autonomie ihren Tod. Die von Oberreuter-Kronabel beschriebene Funktion des ıPhilosophentodes` im französischen Klassizismus des 18. Jahrhunderts wäre dann eine spätere Weiterentwicklung dieses Bildtyps. Dafür spricht auch, dass es neben dem Motiv des philosophischen Freitods eine ganze Reihe weiblicher Protagonisten in der Historienmalerei der Frühen Neuzeit gibt, die durch das gemeinsame Motiv des freiwilligen Todes verbunden sind.

\footnotetext{
${ }^{21}$ Oberreuter-Kronabel, a.a.O., S. 12.

22 Der Tod des Sokrates wurde meist als Selbstmord eingestuft, da seine Schüler eine Flucht aus dem Gefängnis vorbereitet hatten. Sokrates nahm mit Hinweis auf seine philosophischen Überzeugungen diese Möglichkeit nicht wahr und akzeptierte die Verurteilung zum Schierlingsbecher.

${ }^{23}$ Vergleicht man beispielsweise Le Bruns Tod des Cato (Abb. in AK Triumph und Tod des Helden, a.a.O., S. 178) mit seinem Mucius Scaevola vor Porsenna (Abb. in Mégevand, M.-Ch. / Julhiet, C. [Hrsg.]: Grand Siècle, Peintures françaises du XVII siècle dans les collections publiques françaises, Paris 1993, S. 236), wird deutlich, dass der Maler bei beiden Sujets dem Ausdruck der Affekte und des Entsetzens gleich große Aufmerksamkeit geschenkt hat.

${ }^{24}$ So auch Mérot, Alain: »Der Held in der französischen Malerei des 17. Jahrhunderts«, in: AK Triumph und Tod des Helden, a.a.O., S. 30-38.

${ }^{25}$ Vgl. S. $177 \mathrm{ff}$.
} 


\section{Die Selbstmörderin als Tugendheldin}

In diese frühneuzeitliche `Galerie starker Frauen` ${ }^{26}$ gehören einige Frauengestalten der römischen Geschichte, die in der Historienmalerei der Frühen Neuzeit in wechselnder Besetzung, aber deutlichem Zusammenhang auftreten: Dido, Lukretia, Porzia, Sophonisbe, Kleopatra. ${ }^{27}$ Dazu treten gelegentlich Virginia und Paulina. Gemeinsam ist der eigenartigen ikonographischen Gruppe sstarker Frauen politische Rolle und exemplarischer Tod: mit den militärischen und politischen Heroen teilen die Tugendheldinnen eine herausragende politische Rolle, mit den sterbenden Philosophen das Motiv des Selbstmords.

Während Dido als Gründerin Karthagos in die sagenhafte Vorgeschichte und mémoire collective Roms gehört, sind Lukretia und Virginia ${ }^{28}$ wichtige Figuren der frühen Republik, Sophonisbe und Kleopatra Gegenspielerinnen Roms. Porzia ist als Frau des Cäsarmörders Brutus mit dem Ende der römischen Republik verbunden, während Paulina als Frau des Seneca zum Umkreis der sterbenden Philosophen zählt. Offensichtlich fand die nur auf den ersten Blick sehr heterogene Reihe von Frauengestalten im Hinblick auf das Bildthema des tugendhaften Selbstmords Eingang in die frühneuzeitliche Ikonographie.

Dieser Umstand erklärt auch, warum Virginia ${ }^{29}$ und Paulina ${ }^{30}$ nur gelegentlich als Vorwurf aufgegriffen wurden. In beiden Fällen ımissglückteı der Selbst-

\footnotetext{
${ }^{26}$ Vgl. S. 23ff. und S. $232 \mathrm{ff}$.

${ }^{27}$ Nach langem Zögern habe ich für diese Untersuchung die Schreibweisen Dido, Kleopatra, Lukretia, Porzia und Sophonisbe gewählt und damit die geläufigen Namensformen im Deutschen respektiert. Bei Zitaten aus literarischen Texten und Libretti wird natürlich die jeweils angewandte Schreibweise übernommen.

${ }^{28}$ Fögen, Marie Theres: Römische Rechtsgeschichten, Über Ursprung und Evolution eines sozialen Systems, Göttingen 2002, behandelt Virginia und Lukretia rechtssoziologisch.

${ }^{29} \mathrm{~V}$ irg in i a (Livius, Ab urbe condita III,44-48) wurde bereits im 15. Jahrhundert zu einem beliebten Sujet, vor allem für cassoni (dazu vgl. Pigler, Andor: Barockthemen, Eine Auswahl von Verzeichnissen zur Ikonographie des 17. und 18. Jahrhunderts, Budapest 1956, S. 420-421). In der künstlerischen Umsetzung wurde stets die Differenz zwischen männlichem Handeln (hier des Vaters) und weiblicher Fügsamkeit in die zugedachte Rolle betont, die bis zum Verlust des eigenen Lebens führen kann. So setzt beispielsweise Fügers Tod der Viginia (Abb. in Trnek, Renate: Gemäldegalerie der Akademie der Bildenden Künste in Wien, Illustriertes Bestandsverzeichnis, Wien 1989, S. 83) die Tragödie in zwei Handlungsebenen ins Bild: Im Vordergrund sinkt Virginia gerade zu Boden; aufgeregte Zuschauer reagieren mit starken Affekten auf die schreckliche Tat, während der Vater, den Dolch noch in der Hand, ruhig inmitten des Geschehens steht und auf den eigentlich Schuldigen, den Decemvirn Appius, zeigt, der betroffen auf die Ermordete blickend mit seinem Gefolge die Tempelstufen herunterschreitet. Gemälde mit dem Virginia-Thema betonen stets das überlegte Vorgehen des Vaters, der seine Tochter vor Schande schützen will, und das einwilligende Hinsinken der bedrohten jungen Frau.

${ }^{30} \mathrm{P}$ a ulina, die Ehefrau des Seneca, erscheint in den `Galerien starker Frauen (vgl. unten S. 257) und ansonsten ausschließlich in Gemälden, deren Thema das angeordnete Sterben des Philosophen ist. Zu nennen ist beispielsweise Sandrarts Tod des Seneca (ursprünglich in den Staatlichen Museen, Berlin, seit 1945 verschollen; Abb. in Squarzina, Silvia Danesi [Hrsg.]: AK Caravaggio in Preussen, Die Sammlung Giustiniani und die Berliner Gemäldegalerie, Berlin 2001, S. 118) und Concas Tod des Seneca (Herzog Anton UlrichMuseum, Braunschweig; Abb. in Oberreuter-Kronabel, Nr. 52). Tacitus (Ann. XV, 63-64) überliefert sowohl die letzten Worte des Philosophen an seine Frau als auch ihren Selbstmordversuch, der auf Befehl des Kaiser Nero verhindert wurde. So erhält Paulina eine Rolle unter den Assistenzfiguren, die das stoische Sterben des Philosophen begleiten (z. B. bei Sandrart), oder wird, dem Bericht des Tacitus entsprechend (so bei Conca), in
} 


\section{Bildthemen exemplarischen Sterbens}

mord: Virginia ${ }^{31}$ wurde von ihrem Vater ermordet, um sie vor den Nachstellungen des Decemvir Appius zu schützen. Bei Paulina ließ Nero die Tat verhindern. ${ }^{32}$

Diese bemerkenswerte Gruppe fünf ıstarker Frauenı - Dido, Lukretia, Porzia, Sophonisbe, Kleopatra - fand in der kunsthistorischen Forschung bisher nur unter dem Gesichtspunkt ihrer politischen Rolle Beachtung, bildet in der frühneuzeitlichen Historienmalerei aber ein überraschend stabiles ikonographisches Muster. $^{33}$ Zunächst scheint es die intrikate Vermischung von politischer Rolle und sich im tugendhaften Freitod ${ }^{34}$ ausdrückender moralischer Autonomie gewesen zu sein, die das Interesse an den >römischen Tugendheldinnen` weckte. Der epochale und lange nachwirkende Erfolg des Themas auf der Bühne und in der bildenden Kunst ebenso wie die überraschend positive Wertung des Selbstmords ${ }^{35} \mathrm{im}_{\text {Gegensatz }}$ zu seiner kirchlichen Ächtung lässt aber auch einen moralischen Hintergrundssinn im Kontext des Neustoizismus ${ }^{36}$ vermuten, der die politischen und künstlerischen Eliten des 16. Jahrhunderts konfessionsübergreifend prägte.

Diese Vermutung kann allerdings nur die Entstehung des ikonographischen Musters, nicht die bis ins 19. Jahrhundert und zu Makart ${ }^{37}$ reichende produktive Rezeptionsgeschichte der ıstarken Frauen erklären. Auf der Bühne, in der Historienmalerei, in Oper und Kantate, Monodrama und Attitüde wirkte in wie immer umbesetzter und verselbständigter Weise die frühneuzeitliche Invention weiter. Die Verbindung von ıweiblicher Tugendı, Selbstmord und ıschönem Sterben erwies

einem Nebenraum gezeigt, wo sie ihre geöffneten Adern in eine Fußschale ausbluten lässt. Besonders bei Conca wird durch die korrespondierende Anordnung der Ehepartner (Seneca im linken Vordergrund, von männlichen Bediensteten umgeben, Paulina im rechten Hintergrund von Dienerinnen umsorgt) die liebevolle, symbiotische Beziehung der Lebensgefährten dramatisch ins Bild gesetzt.

${ }^{31}$ Vgl. Gundel, H.: »Virginia«, in: Paulys Realencyclopädie der classischen Altertumswissenschaft, Neue Bearbeitung, unter Mitwirkung zahlreicher Fachgenossen herausgegeben von Georg Wissowa, fortgeführt von Wilhelm Kroll und Karl Mittelhaus, 1890-1978, 2. Reihe, Bd. 16, Sp. 1530-1535.

${ }^{32}$ Schmidt, G.: "Seneca«, in: Der Kleine Pauly, Lexikon der Antike, auf der Grundlage von Pauly's Realencyclopädie der classischen Altertumswissenschaft, unter Mitw. zahlr. Fachgelehrter bearb. u. hrsg. von Konrat Ziegler [u.a.], 5 Bde, Stuttgart 1964-1975, hier, Bd. 5, Sp.109-115. Außerdem Schmidt, P. L.: »Pompeius«, in: ${ }^{1}$ Kleiner Pauly, Bd. 4, Sp. 1031.

${ }^{33}$ Vgl. S. $103 \mathrm{ff}$.

${ }^{34}$ Einen ersten Hinweis auf die Verbindung von dramatischer Handlung und weiblichem Selbstmord als Indiz für einen stoischen Hintergrund gab in jüngster Zeit Marina Mojana in: Mahon, Denis / Pulini, Massimo / Sgarbi, Vittorio (Hrsg.): Guercino, Poesia e sentimento nella pittura del '600, Novara 2003, S. 290 in ihrer Interpretation von Fidanis La morte di Didone: "Grandi protagoniste del melodramma seicentesco, le eroine cantate alla corte fiorentina di Ferdinando de' Medici come Didone, Giuditta, Sofonisba, Cleopatra, Tomiri, Artemisia, sono la esemplificazione femminile dello stoicismo antico. «

${ }^{35}$ Daniela Bohde, die in einem Kapitel ihrer Dissertation (Haut, Fleisch und Farbe, Körperlichkeit und Materialität in den Gemälden Tizians, Emsdetten / Berlin 2002) sexuelle Gewalt als Bildthema am Beispiel der Vergewaltigung Lukretias untersucht, spricht von "erotisierten Suizidbildern« (S. 183). Obwohl Lukretia als »Keuschheits-Märtyrerin « (S. 186) interpretiert wurde, habe die häufig herausfordernde und verführerisch erotische Inszenierung ihres Körpers der Tugendheldin eine Mitschuld an ihrer Vergewaltigung zugewiesen, die ihren Selbstmord als Strafe erscheinen lassen konnte.

${ }^{36}$ Vgl. S. $177 \mathrm{ff}$.

${ }^{37}$ Vgl. S. $13 \mathrm{ff}$. 


\section{Bildthemen exemplarischen Sterbens}

sich als so attraktiv, dass sich die gründliche Untersuchung dieses ikonographischen Musters lohnte, die im Folgenden vorgelegt wird.

Dabei geht es neben einer repräsentativen Zusammenstellung des Bildmaterials darum, dem geistesgeschichtlichen Hintergrund des ikonographischen Musters und seiner produktiven Rezeptionsgeschichte nachzugehen. Die ästhetische Entschärfung und moralische Überhöhung des schockierenden weiblichen Selbstmords verweist - so meine These - auf einen neustoischen Hintergrund, der im Lauf der Jahrhunderte immer mehr verblasst und in den >Attitüden des 19. Jahrhunderts gänzlich depotenziert ist.

\section{Gegenstand der Untersuchung}

Im Folgenden wende ich mich also der ikonographischen Gruppe srömischer< Tugendheldinnen ${ }^{38} \mathrm{zu}$, die sich an der Wende zur Neuzeit aus den Figuren Dido, Lukrezia, Sophonisbe, Kleopatra und Porzia gebildet hat, und untersuche die historischen und literarischen Quellen der Bildkonzeptionen, ihre wechselnde Funktionalisierung und ihr Weiterwirken bis ins 19. Jahrhundert.

Für jede der genannten Frauengestalten lässt sich eine eigene literarische und ikonographische Rezeptionsgeschichte rekonstruieren; sie treten aber auch in Reihen (wie den femmes fortes) und als Pendants ${ }^{39}$ auf. Dabei wurden die Tugendheldinnen durchaus verschieden akzentuiert: sie konnten für soziale Rollen und Tugenden in Anspruch genommen werden, aber auch für ıschönes Sterben stehen und gingen schließlich, fast gänzlich enthistorisiert, in einer attitude ${ }^{40}$ auf. Insgesamt ergibt sich ein erstaunlicher Rezeptionsspielraum, den erst eine Analyse der entsprechenden Bildkorpora ${ }^{41}$ differenzierter darstellen kann. Die Figur der Sophonisbe ist dem heutigen Bildgedächtnis am weitesten entrückt, obwohl sie ganz offensichtlich historisch am Anfang der Konstituierung des ikonographischen Musters der Tugendheldin stand. Deshalb widme ich ihr in einem eigenen Kapitel ${ }^{42}$ besondere Aufmerksamkeit.

Eine auch nur annähernde Vollständigkeit des Bildmaterials war nicht zu erreichen und wurde auch nicht angestrebt, da es mir vor allem auf den wechselnden

\footnotetext{
${ }^{38}$ ২Römisch ist als ızur römischen mémoire collective gehörend zu verstehen, da Dido, Sophonisbe und Kleopatra natürlich keine Römerinnen waren.

${ }^{39}$ Vgl. S. $259 \mathrm{ff}$.

${ }^{40}$ Vgl. S. $294 \mathrm{ff}$.

${ }^{41}$ Sie sind unten in einem Bildkatalog (S. 379ff.) zusammengestellt.

${ }^{42}$ Vgl. S. $57 \mathrm{ff}$.
} 


\section{Bildthemen exemplarischen Sterbens}

ıSitz im Leben ${ }^{43}$ des ikonographischen Musters und auf seine Umbesetzungen im Laufe der Rezeptionsgeschichte ankam. Wichtiger erschien es, die literarische und dabei vor allem die theatralische Tradition mit heranzuziehen sowie punktuell den Vergleich mit den anderen ikonographischen Mustern ıschönen Sterbens` (Märtyrer, Helden und Philosophen) zu suchen. Auch galt meine Aufmerksamkeit dem Übergang des Motivs der Tugendheldin in andere künstlerische Gattungen wie Oper, Kantate ${ }^{44}$ und Attitüde ${ }^{45}$.

Auch die Frage nach Publikum und Auftraggeber der Bilder wird verschiedentlich aufgegriffen ${ }^{46}$ und der ausführliche Versuch gemacht, den neustoischen Hintergrund ${ }^{47}$ sowohl der eigenartigen ikonographischen Konzeption als auch der bemerkenswerten moralischen Umbesetzung des Selbstmords wahrscheinlich zu machen. Beliebig verfügbar wurden die Bildmotive erst mit dem Verschwinden dieses neustoischen Hintergrunds. ${ }^{48}$

Es bleibt bemerkenswert, dass sich trotz gründlicher Recherchen ${ }^{49}$ nur wenig Reproduktionsgraphik für den hier untersuchten Bildbereich nachweisen lässt. ${ }^{50}$ Vielleicht erklärt sich dieser Sachverhalt zumindest teilweise aus der komplexen Verweisstruktur und Intertextualität des zugrunde liegenden ikonographischen Musters. Als Auftraggeber der Historiengemälde ist, jedenfalls für das 16 . und 17. Jahrhundert, ein elitärer Kreis humanistisch Gebildeter anzunehmen, dem die moralischen Deutungen der Bildkonzeption durchsichtig waren, deren gelehrte Themen sich wohl gegen eine Popularisierung sperrten. ${ }^{51}$

Das im Folgenden untersuchte ikonographische Muster entstand in der Epochenschwelle zur Frühen Neuzeit mit der Erweiterung der Bildthemen der Historienma-

\footnotetext{
${ }^{43}$ Dieser Begriff wurde in der Bibelexegese entwickelt und bezeichnet dort die liturgische, frömmigkeitsgeschichtliche und gruppensoziologische Funktion biblischer Erzählstrukturen, Gattungen und Motive.

${ }^{44} \mathrm{Vgl}$. unten, S. $284 \mathrm{ff}$.

${ }^{45} \mathrm{Vgl} .294 \mathrm{ff}$.

${ }^{46}$ So u. a. S. $202 \mathrm{ff}$. und S. $225 \mathrm{ff}$.

47 Besonders unten S. 198ff.

${ }^{48}$ Vgl. unten S. $294 \mathrm{ff}$.

49 An dieser Stelle sei Gerd Unverfehrt (Göttingen) für Hinweise auf verschiedene, wenn auch vergebliche, Recherchewege gedankt.

${ }^{50}$ Allerdings spielten graphische Vorlagen bei der Entstehung des ikonographischen Musters eine gewisse Rolle (vgl. S. 79ff.).

${ }^{51}$ Der direkte Versuch, die Themengruppe ıSelbstmörderin als Tugendheldin in der Reproduktionsgraphik nachzuweisen, war ebenso erfolglos, wie eine Recherche, die vom Korpus der besprochenen Historienbilder ausgehend, einschlägige Graphik suchte. Eine Ausnahme stellen einige sstarke Frauen von Reni dar. Der spezifische Stil Renis und die halb- oder ganzfigurige Nacktheit von (Nummern nach Pepper, Stephen: Guido Reni, L'opera completa, Novara 1988) Porzia (96), Lukretia (97) und Kleopatra (101, 111, 173) ließen die Frauengestalten in mehreren Drucken Verbreitung finden. Auf den typischen Stil Renis, der seine istarken Frauen ganz der historischen Situation enthob und nur über das Attribut der Schlange oder des Dolches einen schwachen Hinweis auf die Gemeinte gab, wird S. 216ff. ausdrücklich eingegangen.
} 


\section{Bildthemen exemplarischen Sterbens}

lerei ${ }^{52}$ im Humanismus; es löste sich um 1800 in der Epochenschwelle zur Moderne in Attitüden, theatralischen Kleinformen und Variationen der femme fatale auf. ${ }^{53}$ Daraus ergibt sich der Aufbau meiner Untersuchung.

Die ikonographische Gruppe der römischen Tugendheldinnen wird so dargestellt, dass zunächst (IV und V) auf die historischen Quellen des Bildmotivs, danach auf die literarische und dramatische Rezeption und schließlich auf die künstlerischen Bearbeitungen eingegangen wird. Bildkorpus und Darstellung folgen den Leitfiguren, obwohl auch andere, systematische Ordnungsprinzipien (wie die repräsentierten virtutes oder die politisch-sozialen Rollen der Tugendheldinnen) denkbar wären. Am Beispiel der als Bildmotiv kaum mehr vertrauten Figur der Sophonisbe werden die Gesichtspunkte und Fragestellungen erarbeitet, die dann auch auf die anderen untersuchten Frauenfiguren Anwendung finden; jede hat in der Frühen Neuzeit ein eigenes Profil entwickelt, wobei die ersten bildkünstlerischen Bearbeitungen stets vorausgehende literarische Rezeptionsformen aufgreifen.

Dem ersten Durchgang durch das Bildkorpus und seine literarischen Voraussetzungen und der Darstellung des Rezeptionsspielraums der ikonographischen Motive folgen zwei systematische Kapitel, die auf den Neustoizismus als Voraussetzung des ikonographischen Musters (VI) und auf das Bildprogramm der posttridentinischen Märtyrer in Konkurrenz zu den stoischen Tugendhelden (VII) eingehen.

Die Bildprogramme starker Frauen in der Frühen Neuzeit und die von Auftraggebern und Sammlern intendierten Pendant-Bildungen (VIII) können Hinweise auf die Funktion und Interpretation der ikongraphischen Gruppe geben. An die Stelle des neustoisch geprägten moralischen Bilddiskurses tritt allmählich das Interesse an der Affektdarstellung, der in einem Kapitel (IX) nachgegangen wird, das mit der Oper einsetzt und mit den Attitüden als neuen Ausdruckskünsten endet. Das Schlusskapitel $(\mathbf{X})$ ordnet die ikonographische Gruppe der >römischen Tugendheldinnen in das rhetorisch-ikonographische Verfahren der exempla virtutis ein und überprüft kritisch die Verwendung dieses Begriffs in der Kunstgeschichte.

\footnotetext{
${ }^{52}$ Vgl. S. $42 f f$.

${ }^{53}$ Vgl. S. $13 \mathrm{ff}$. und S. $288 \mathrm{ff}$.
} 


\section{Liebe, Patriotismus und Selbstbestimmung: Sophonisbe als Tugendheldin}

Ein Gemälde von Nicolas Régnier (1590-1667) in der Kasseler Gemäldegalerie des Schlosses Wilhelmshöhe [Abb. 1] trägt offenkundig und augenfällig >große Gefühler vor, ohne dass sich das Thema selbst dem heutigen Betrachter sofort erschlösse. ${ }^{1}$

Die Protagonistin sitzt dreiviertelfigurig an den Betrachter herangerückt und nimmt mit ausladender Gestik die Bildmitte ein. Sie trägt ein violettes Kleid mit tiefem Dekolleté und einen goldgelben, pelzbesetzten Mantel, der sich vorne links über der mit Edelsteinen verzierten Armlehne ihres Sessels bauscht. Ein Brief entgleitet ihrer rechten Hand. Die geöffnete linke Hand mit eleganten, leicht gespreizten Fingern kehrt die Handfläche nach oben - ob diese Geste als deiktisch, ergeben oder verzweifelt zu verstehen ist, bleibt zunächst offen. Die Handbewegung steht jedenfalls in Beziehung zu der weißen

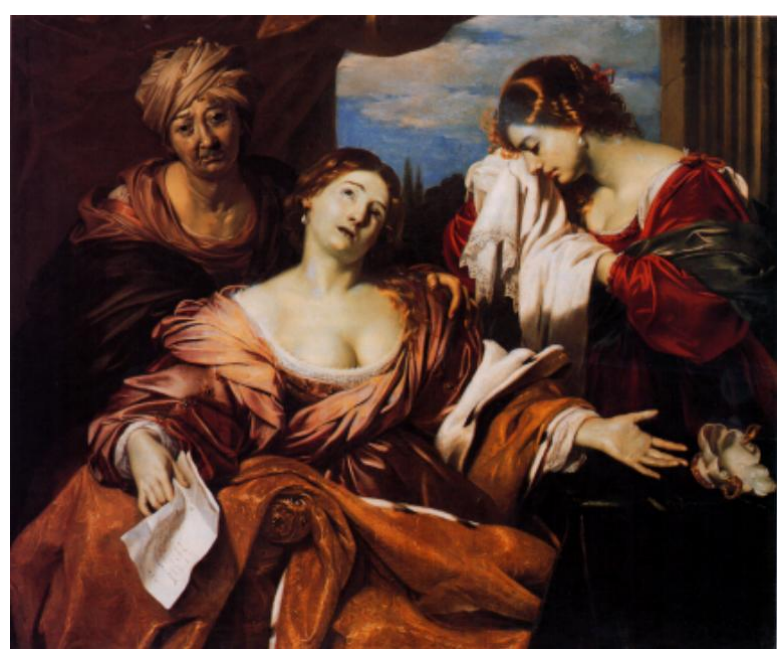

Abb. 1

Muschelschale mit Goldrand, die ganz rechts auf einem mit dunklem Tuch gedeckten Tischchen gerade umstürzt. Der schmerzvolle shimmelnde، Blick ${ }^{2}$, den die Hauptperson mit leicht nach rechts geneigtem Haupt nach oben richtet, lässt das Arrangement der Empfindungen als Verzweiflung interpretieren.

Unterstützt wird diese Deutung durch zwei begleitende Frauenfiguren, die die Protagonistin passepartourieren. Die links hinter der Protagonistin stehende alte Frau ist in braunbeige Gewänder gekleidet und verbirgt ihre Haare unter einem hellen Turban. Sie blickt ruhig aus dem Bild den Betrachter an, während sie ihrelinke Hand in tröstender, schützender oder bedauernder Absicht auf die Schulter

\footnotetext{
${ }^{1}$ Baumgärtel, Bettina / Neysters, Silvia (Hrsg.): AK Die Galerie der Starken Frauen, Düsseldorf 1995, Abb.170.

2 Zum Motiv des shimmelnden Blicksı Henning, Andreas / Weber, Gregor (Hrsg.): AK >Der himmelnde Blickı, Zur Geschichte eines Bildmotivs von Raffael bis Rotari, Dresden 1998.
} 
der Hauptfigur gelegt hat. Die rechts hinter der Protagonistin stehende junge Frau, die in ein prächtiges rotes Kleid und einen grünen Mantel gehüllt ist, vereindeutigt die Syntax der im Bild dargestellten Gefühle: Sie drückt ein großes weißes Tränentuch an ihr im Profil gegebenes Gesicht, ihr gesenktes Haupt bringt Trauer zum Ausdruck. Die Szene spielt in einem Innenraum; doch wird hinter der Protagonistin der Ausblick in eine Mittelmeerlandschaft mit Zypressen und bewölktem Himmel freigegeben.

Der heutige Betrachter dieser Inszenierung von Verzweiflung, Pathos und Affekten ist zum Verständnis des Sujets und der Bilddramaturgie meist auf die Hilfe des Katalogs angewiesen; die dort zu findende Bezeichnung »Tod der Sophonisbe ${ }^{3}$ wird ihm allerdings schwerlich weiterhelfen. Mögen der spektakuläre Selbstmord der vergewaltigten Lukretia oder das besonnene Sterben des zu Unrecht verurteilten Philosophen Sokrates auch gegenwärtig noch zum historischen Allgemeinwissen gehören, gilt dies gewiss nicht mehr für den Tod der nordafrikanischen Königin Sophonisbe, obwohl sie wie Dido und Kleopatra zu den berühmten Gegnerinnen Roms zählte. Ihr von den Historikern des Altertums ${ }^{4}$ mehrfach geschilderter politisch-moralisch motivierter Selbstmord brachte es im Spätmittelalter und in der Frühen Neuzeit zu einer erstaunlich breiten literarischen ${ }^{5}$ und künstlerischen ${ }^{6} \mathrm{Re}$ zeptionsgeschichte: der heute weitgehend unbekannte und fremde Stoff wurde in Renaissance und Barock zum beliebten, oft aufgegriffenen und variierten Vorwurf der Historienmalerei.

Im Folgenden soll am Beispiel der Sophonisbe das ikonographische Muster ${ }^{7}$ der ıSelbstmörderin als Tugenheldinı ausführlicher dargestellt werden, zumal dieses Bildmotiv heutigen Rezipienten am fernsten gerückt ist. ${ }^{8}$ Petrarcas Aufgreifen des Stoffes ließ die afrikanische Königin in der Frühen Neuzeit zu einem der literarischen Modelle der profanen Tugendheldin avancieren und bildete die Voraus-

\footnotetext{
${ }^{3}$ Lehmann, Jürgen M.: Staatliche Kunstsammlungen Kassel, Italienische, französische und spanische Gemälde des 16. bis 18. Jahrhunderts, Fridingen 1980, S. 214-215.

${ }^{4}$ Volkmann, Hans: »Sophoniba«, in: Kleiner Pauly, Bd. 5, Sp.280.

${ }^{5}$ Frenzel, Elisabeth: Stoffe der Weltliteratur, Stuttgart ${ }^{7} 1988$, S. 709-711.

${ }^{6}$ Pigler, Andor: Barockthemen, Eine Auswahl von Verzeichnissen zur Ikonographie des 17. und 18. Jahrhunderts, Budapest 1956, Bd. 2, S. 413-415.

${ }^{7}$ Ich verwende diesen Begriff nicht zur Bezeichnung einer mehr oder weniger reproduzierbaren künstlerischen Vorlage, sondern als eine Zusammenfassung einer Reihe von ikonographischen Versatzstücken, die das Konzept der profanen Tugendheldin in der Frühen Neuzeit bestimmten.

${ }^{8}$ Trotz mehrerer Korrespondenzen ist es mir nicht gelungen, den derzeitigen Stand eines Promotionsprojekts (http://www.onderzoekinformatie.nl; zuletzt aufgerufen: 16.03.2007) von Marieke Berhout an der Universität Leiden (»De zelfmoord van Lucretia, Dido, Cleopatra en Sophonisba in de Nederlandse schilder-, teken- en prentkunst tussen ca.1500 en 1730 «) zu eruieren.
} 
setzung für den ikonographischen Erfolg der Figur in der Historienmalerei. Viele Aspekte der literarischen und künstlerischen Darstellungen und Inszenierungen Sophonisbes lassen sich auch auf die anderen, hier thematischen sömischen Tugendheldinnen übertragen. Dies gilt für die frühen dramatischen Gestaltungen des Stoffes, die eine wichtige Voraussetzung der Historienmalerei waren, aber auch für die ikonographischen und künstlerischen Entwicklungen des Sujets bis hin zu den Attitüden des 19. Jahrhunderts ${ }^{9}$.

Nach einer Zusammenfassung der antiken Quellen gehe ich auf die literarische Rezeption des Stoffs im Spätmittelalter und in der Frühen Neuzeit ein. Die mannigfachen literarischen Bearbeitungen, Inszenierungen, Verwandlungen und Reduktionen sind die Voraussetzung der bildkünstlerischen Gestaltungen des heute geradezu exotischen Sujets. Die Ikonographie des Themas in der Historienmalerei nahm nicht - wie vermutet wurde ${ }^{10}$ - von der frühneuzeitlichen Graphik, sondern von den dramatischen Entwürfen in Italien und Frankreich ihren Ausgang.

\section{Antike Quellen}

Nach den historischen Quellen wurde Sophonisbe, Tochter des Karthagers Hasdrubal, 215 v. Chr. mit dem ostnumidischen Prinzen Mas siniss a ${ }^{11}$ verlobt. Diesem misslang es nach dem Tode seines Vaters, sich die numidische Herrschaft gegen andere Prätendenten zu sichern. Der westnumidische Fürst Syphax erlangte die Herrschaft über ganz Numidien und heiratete 206 Sophonisbe. In der Zwischenzeit war Massinissa ein Bündnis mit Rom eingegangen, das seit 204 unter dem Feldherrn Scipio in Afrika mit Karthago Krieg führte. Mit seiner Hilfe besiegten die Römer Syphax, der 201 als Kriegsgefangener in Rom starb. Nach dem erfolgreichen Feldzug heiratete Massinissa 203 seine frühere Verlobte, obwohl Scipio die Auslieferung der Ehefrau des Syphax als Kriegsbeute verlangte. Um ihre Auslieferung zu verhindern, ließ Massinissa Sophonisbe Gift überbringen, damit sie selbst ihrem Leben ein Ende setzen konnte. Massinissa wurde 201 zum Dank für seine Unterstützung der römischen Expansionspolitik in Nordafrika Herrscher über ganz Numidien.

\footnotetext{
${ }^{9}$ Vgl. S. $294 \mathrm{ff}$.

${ }^{10}$ Vgl. S. 85.

11 Verschiedene Schreibungen des Namens sind gebräuchlich (»Masinissa«, »Massinissa« oder auch numidisch »Massanassa«). Ich verwende im Folgenden durchgehend »Massinissa Artikel »Massinissa« von Hans Volkmann in: Kleiner Pauly, Bd. 3, Sp. 1068-1070.
} 
IV Liebe, Patriotismus und Selbstbestimmung: Sophonisbe als Tugendheldin

Der augusteische Historiograph Titus Livius gibt in seinem monumentalen Werk Libri ab urbe condita ${ }^{12}$ als erster Informationen über Sophonisbe und zeichnet ein Charakterbild der Königin.

Zum Verständnis seiner Darstellung ist es von Gewicht, dass Livius die tragische Episode um Sophonisbe und Massinissa dort in seine Schilderung des Zweiten Punischen Krieges einordnet, wo sich ein positiver Umschwung für die Römer abzeichnet - wird doch zuvor vor allem von Hannibal und seinem für das römische Imperium bedrohlichen Zug über die Alpen berichtet. Obwohl sich Hannibal mit seinem Heer noch in Italien aufhält, ist Publius Cornelius Scipio, der später den Beinamen Africanus erhalten sollte, mit Truppen nach Afrika gesegelt, wo er 204 die ersten militärischen Erfolge erringt. Der Zweite Punische Krieg wird 202 durch die Entscheidungsschlacht bei Zama zugunsten der Römer entschieden und 201 durch einen Friedensschluss beendet, der den karthagischen Einfluss auf Afrika stark eingrenzt. Livius zeichnet Publius Cornelius Scipio als großen Gegenspieler der karthagischen Politiker und lässt inn mit positiven Eigenschaften wie virtus (mannhaftes, sittlich bewusstes Handeln), fides (Verlässlichkeit), iustitia (Gerechtigkeit) und moderatio (Mäßigung) überkommene Wertvorstellungen (mores maiorum) vertreten und den Aufstieg der frühen Republik fördern. Die ımoralischen Absichten seiner Geschichtsschreibung bestimmen die Darstellung: sie zeichnet nicht nur den Erfolg des Scipio nach, sondern schildert auch die politischen Gegner gebührend und beeindruckend, um damit die römischen Verdienste aufzuwerten. In diesen smoralischen und ideologischen Zusammenhang ist auch seine Darstellung der Geschichte Sophonisbes einzuordnen. Die Tapferkeit (magnus animus) und Unerschrockenheit (ferocitas) der Königin soll dem Leser die Gefährlichkeit der Gegner Roms vor Augen führen.

Nach der römischen Einnahme von Utica formieren sich die Karthager neu und beziehen die Truppen des Syphax in ihre militärische Planung ein. In diesem Zusammenhang erwähnt Livius beiläufig Sophonisbe als moralische Stütze des Syphax, den sie zur Festigung des Bündnisses mit Karthago geheiratet hat. ${ }^{13}$ Als kurz darauf Cirta, die Hauptstadt des Syphax ${ }^{14}$, erobert wird, reitet Massinissa sofort in die Stadt, um zum Königspalast zu eilen, wo sich ihm Sophonisbe zu Füßen wirft. In direkter Rede lässt Livius Sophonisbe den Sieger bitten, sie auf keinen Fall den Römern auszuliefern. ${ }^{15}$ Mit der Einführung der direkten Rede dramatisiert Livius

\footnotetext{
12 Wichtige Forschungsbeiträge bei Burck, Erich (Hrsg.): Wege zu Livius, Darmstadt 1977 (Wege der Forschung 132). Ich zitiere Livius nach der Ausgabe von W. Weissenborn / H. J. Müller, Dublin / Zürich ${ }^{7} 1968$

${ }_{13}$ »Inde dilectus in urbe agrisque haberi coeptus, et ad Syphacem legati missi, summa ope et ipsum reparantem bellum, cum uxor non iam ut ante blanditiis, satis potentibus ad animum amantis, sed precibus et misericordia ualuisset, plena lacrimarum obtestans ne patrem suum patriamque proderet, iisdemque flammis Carthaginem quibus castra conflagrassent absumi sineret." (>Man begann, in der Stadt und auf dem Land Truppen auszuheben. Gesandte wurden zu Syphax geschickt, der den Krieg unbedingt wiederaufleben lassen wollte, weil seine Frau mit Bitten und dem Appell an das Mitgefühl Einfluss nahm, nicht mehr nur - wie schon zuvor - mit Schmeicheleien, die schon stark genug für ein liebendes Herz waren. Voller Tränen beschwor sie Syphax, Vater und Vaterland nicht zu verraten und Karthago nicht von den gleichen Flammen zerstören zu lassen, die schon das Lager vernichtet hätten.८) (Ab urbe condita, 30,7,8)

${ }^{14}$ Ab urbe condita, 30,12,5

15 »Intranti uestibulum in ipso limine Sophoniba, uxor Syphacis filia Hasdrubalis Poeni, occurrit; et cum in medio agmine armatorum Masinissam insignem cum armis tum cetero habitu conspexisset, regem esse, id quod erat, rata, genibus aduoluta eius. Omnia quidem ut possisı inquit in nos di dederunt uirtusque et felicitas tua. sed si captiuae apud dominum uitae necisque suae uocem supplicem mittere licet, si genua, si uictricem
} 
seinen Bericht und macht damit bereits wichtige Vorgaben für die spätere Rezeptionsgeschichte. ${ }^{16}$ Verzweiflung, Pathos und Affekte lösen eine überstürzte Handlungsfolge aus: Von Mitleid, aber auch von plötzlich wieder entflammter Liebe erfasst, verspricht Massinissa Sophonisbe Hilfe gegen die Römer und nimmt sie zur Frau. Laelius, der Vertreter Scipios, ist über die überstürzte Ehe ungehalten, überlässt jedoch Scipio die Entscheidung über Sophonisbes Schicksal. Da der inzwischen als Gefangener vor Scipio geführte Syphax seine antirömische Politik mit dem Einfluss Sophonisbes ${ }^{17}$ entschuldigt, verlangt Scipio von Massinissa, sie als Kriegsbeute Rom auszuliefern, und wirft dem Liebeseifer des nubischen Herrschers mangelnde Mäßigung (temperantia) vor. ${ }^{18}$

attingere dextram, precor quaesoque per maiestatem regiam, in qua paulo post ante nos quoque fuimus, per gentis Numidarum nomen, quod tibi cum Syphace commune fuit, per huiusce regiae deos, qui te melioribus ominibus accipiant quam Syphacem hinc miserunt, hanc ueniam supplici des ut ipse quodcumque fert animus de captiua tua statuas, neque me in cuiusquam Romani superbum et crudele arbitrium uenire sinas. si nihil aliud quam Syphacis uxor fuissem, tamen Numidae atque in eadem mecum Africa geniti quam alienigenae et externi fidem experiri mallem; quid Carthaginiensi ab Romano, quid filiae Hasdrubalis timendum sit uides. si nulla re alia potes, morte me ut uindices ab Romanorum arbitrio oro obtestorque. " ( Als er in die Vorhalle kam, trat inm bereits auf der Schwelle Sophoniba entgegen, die Gattin des Syphax und Tochter des Karthagers Hasdrubal. Als sie ihn, durch seine Rüstung sowie durch sein ganzes Auftreten ausgezeichnet, mitten in der Schar der Bewaffneten erblickte, war sie überzeugt, dass er der König sei, was ja auch wirklich zutraf. Sie warf sich vor ihm auf die Knie und sagte: Die Götter, deine Tapferkeit und dein Glück haben uns ganz in deine Gewalt gegeben. Aber wenn eine Gefangene vor dem Herrn über ihr Leben und ihren Tod die flehende Stimme erheben, wenn sie seine Knie, seine siegreiche Rechte umfassen darf, bitte ich flehentlich bei der königlichen Würde, die auch uns vor kurzem noch gebührte, beim numidischen Volk, dem du gemeinsam mit Syphax angehörst, bei den Göttern dieses Hauses, die dich unter besseren Vorzeichen empfangen mögen, als sie Syphax von hier entlassen haben, gewähre der Flehenden diese Gnade; entscheide du allein über deine Gefangene, wozu immer dein Herz dich treibt, und überantworte mich nicht der hochmütigen und grausamen Willkür eines Römers. Wäre ich auch nur die Gemahlin des Syphax, wollte ich doch lieber mein Schicksal in die Hände eines Numiders und eines Mannes gelegt sehen, der wie ich in Afrika geboren ist, als in die eines Fremden und Ausländers. Was eine Karthagerin, was die Tochter Hasdrubals von einem Römer zu befürchten hat, siehst du selbst. Ich bitte und beschwöre dich, mich durch den Tod vor der Willkür der Römer zu retten, wenn kein anderer Ausweg bleibt.ı) (Ab urbe condita, 30,12,11-12)

${ }^{16}$ Direkte Rede beanspruchte in der antiken Historiographie keine Authentizität, musste aber der Wahrscheinlichkeit der Situation und Charaktere angepasst sein. Vgl. Laggner, Brigitte: Untersuchungen zur Topologie in den Reden der ersten und dritten Dekade des livianischen Geschichtswerkes, Diss. phil. Graz 1972.

17 »tum se insanisse, tum hospitia priuata et publica foedera omnia ex animo eiecisse, cum Carthaginiensem matronam domum acceperit. illis nuptialibus facibus regiam conflagrasse suam; illam furiam pestemque omnibus delenimentis animum suum auertisse atque alienasse, nec conquiesse donec ipsa manibus suis nefaria sibi arma aduersus hospitem atque amicum induerit. (〉Er sei wahnsinnig geworden und habe alle Gebote der Gastfreundschaft und alle Vereinbarungen vergessen, als er eine Karthagerin heiratete. Die Hochzeitsfackeln hätten seinen Palast in Asche verwandelt, die verderbenbringende Furie habe seinen Sinn mit allen möglichen Betäubungsmitteln verführt und verblendet und erst Ruhe gegeben, als sie ihm eigenhändig die verbrecherische Rüstung gegen den Gastfreund und persönlichen Freund angelegt habe.ı) (Ab urbe condita, $30,13,11$ )

18 »et regem coniugemque eius, etiamsi non ciuis Carthaginiensis esset, etiamsi non patrem eius imperatorem hostium uideremus, Romam oporteret mitti, ac senatus populique Romani de ea iudicium atque arbitrium esse, quae regem socium nobis alienasse atque in arma egisse praecipitem dicatur. « (〉Daher müsse man den König und seine Gemahlin nach Rom schicken, und dies selbst wenn sie keine Karthagerin wäre und ihr Vater kein feindlicher Feldherr. Dem Senat und dem römischen Volk sei die letzte Entscheidung über eine Frau überlassen, die einen verbündeten König abspenstig gemacht und Hals über Kopf in den Krieg getrieben haben soll.८) (Ab urbe condita, 30,14,10) 
Die römische Unnachgiebigkeit stürzt Massinissa in einen unlösbaren politisch-moralischen Konflikt ${ }^{19}$ : Durch einen Boten teilt der König Sophonisbe mit, er sei nicht mehr Herr seiner eigenen Entscheidungen und könne nur seine Zusage halten, sie nicht in die Macht der Römer gelangen zu lassen. Er lässt ihr einen Becher mit Gift überbringen, damit sie eine ihrer politischen Rolle würdige Entscheidung $^{20}$ treffen kann. Livius dramatisiert auch diese Szene und gibt Sophonisbe noch einmal das Wort, bevor sie furchtlos den Giftbecher trinkt. ${ }^{21}$ Dieser Auftritt der Königin, in dem Wort und Handlung theatralisch miteinander verknüpft sind, erlangte in der Rezeptionsgeschichte der historischen Episode zentrale Bedeutung.

Im Zusammenhang seiner Geschichtsschreibung und seiner Darstellung des Zweiten Punischen Krieges ist die Katastrophe der Sophonisbe ${ }^{22}$ für Livius eine Episode, mit der sich die Gefährlichkeit der nordafrikanischen Gegner Roms veranschaulichen ließ. In der Frühen Neuzeit konnte die beiläufige Anekdote zum Vorwurf für großes politisches Theater werden, weil Livius, der die hellenistische Geschichtsschreibung aufgreifend nicht annalistisch erzählte, aus ihr eine spannende und unterhaltsame Szene gestaltete, die Boccaccio zu Recht faszinierte.

Weitere Details ließen sich in der im zweiten nachchristlichen Jahrhundert

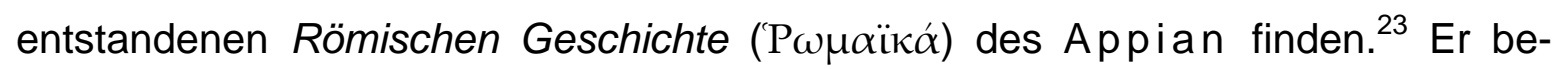
handelt in seinem Karthagischen Buch die römische Eroberungspolitik und kommt in diesem Zusammenhang auch auf Sophonisbe zu sprechen. Seine Erzählregie ist nicht an der Persönlichkeit der karthagischen Königin, sondern am politischen Wechselspiel interessiert, das ihre Verbindungen mit Syphax und Massinissa bestimmt. Im Gegensatz zu Livius setzt er eine Verlobung mit Massinissa voraus, als Sophonisbe auf politischen Druck der Karthager mit Syphax verheiratet wird, dem damals mächtigsten Mann in Afrika. Deshalb stehen das gekränkte Ehrgefühl und

\footnotetext{
${ }^{19}$ Den inneren Konflikt begleiten bei Livius lebhafte Gefühlsäußerungen (suspiritus und gemitus) (Ab urbe condita, 30,15,3).

20 "memor patris imperatoris patriaeque et quorum regum quibus nupta fuisset» (১Sie solle an ihren Vater, den Feldherrn, an ihr Vaterland denken und daran, dass sie mit zwei Königen verheiratet warı.) ( $A b$ urbe condita, $30,15,6)$

21 »Accipio< inquit ınuptiale munus, neque ingratum si nihil maius uir uxori praestare potuit. hoc tamen nuntia, melius me morituram fuisse si non in funere meo nupsissem.ı non locuta est ferocius quam acceptum poculum, nullo trepidationis signo dato, impauide hausit. « (১Sie sagte: Ich nehme die Hochzeitsgabe an; sie ist mir willkommen, wenn der Ehemann seiner Gattin nichts Besseres bieten kann. Sage inm jedoch, der Tod wäre mir leichter gefallen, wenn ich nicht an meinem Todestag geheiratet hätte. Gelassen, wie sie den Giftbecher entgegengenommen hatte, trank sie ihn ohne Zeichen von Unruhe aus.ı) ( $A b$ urbe condita, 30,15,7) ${ }^{22}$ Ab urbe condita, 30,12-15

${ }^{23}$ Appian von Alexandria: Römische Geschichte, Erster Teil: Die römische Reichsbildung, hrsg. und übers. von Veh, Otto / Brodersen, Kai, Stuttgart 1987.
} 
die verletzte Liebe Massinissas am Anfang der dramatischen Episode. ${ }^{24}$ Als Syphax im weiteren Kriegsverlauf in Gefangenschaft gerät, lässt Sophonisbe Massinissa durch Gesandte wissen, sie habe sich nur unter Zwang mit Syphax verbunden. ${ }^{25}$ Der römische Feldherr fordert von Massinissa ihre Auslieferung, weil Sophonisbe von Syphax als glühende karthagische Patriotin geschildert wird. Massinissa eröffnet Sophonisbe die ausweglose Situation und reicht ihr selbst das Gift; anders als bei Livius kommt die Königin nicht mehr selbst zu Wort. ${ }^{26}$

Ein fait divers aus den römisch-karthagischen Auseinandersetzungen wird von Livius und Appian, deren Darstellungen sich in bemerkenswerter Weise ergänzen, zu einer Episode konturiert, die es im Humanismus und in der Renaissance zu einem späten literarischen Erfolg brachte, weil sich im Konflikt Sophonisbes der Antagonismus zwischen Liebe und Politik exemplarisch darstellen ließ. Während Appian die politischen Hintergründe und Motivationen hervorhebt, rückt Livius den inneren Konflikt Sophonisbes in den Vordergrund. In der Frühen Neuzeit konnte so die nebensächliche Episode aus den Punischen Kriegen ein bemerkenswertes revival verzeichnen.

\section{Spätmittelalterliche Rezeption}

Der frühneuzeitliche theatralische und ikonographische Erfolg der Episode aus dem Zweiten Karthagischen Krieg wäre nicht möglich gewesen, hätte nicht ein so prominenter Humanist wie Petrarca (1304-1374) den Stoff aufgegriffen und Sophonisbe in seinem großen lateinischen Epos und in einem volkssprachlichen alle-

\footnotetext{
24 »Über die Numider Afrikas herrschten viele Dynasten, getrennt nach ihren einzelnen Gebieten. Den ersten Rang unter allen nahm Syphax ein, und er genoß bei den anderen hohes Ansehen. Auch gab es einen gewissen Masinissa, den Angehörigen eines mächtigen Stammes, der Massylier, und Sohn ihres Königs. Dieser war in Karthago erzogen und ausgebildet worden, und da er ein stattlicher Mann von vornehmem Charakter war, hatte ihm Hasdrubal, der Sohn des Gisko, der an Rang keinem Karthager nachstand, seine Tochter verlobt, obschon jener ein Numider, er selbst aber ein Karthager war. Nach der Verlobung nahm er als Feldherr den jungen Mann nach Iberien mit. Doch Syphax, der ebenfalls von Liebe zu dem Mädchen erfaßt war, begann das karthagische Land zu plündern und verabredete mit Scipio, der eigens zu einem Treffen mit ihm aus Iberien herübergefahren war, ein gemeinsames Vorgehen, wenn dieser Karthago angreife. Die Karthager hörten davon, und da sie großen Wert darauf legten, Syphax' Hilfe für den Krieg gegen die Römer zu gewinnen, gaben sie ihm das Mädchen, ohne daß Hasdrubal und Masinissa, die beide in lberien weilten, irdendwelche Kenntnis davon hatten. Masinissa war über das Vorgehen äußerst erbittert und schloß nun seinerseits - von Hasdrubal unbemerkt, wie er wähnte - in Iberien ein Abkommen mit Scipio. (KA 36-40)

${ }^{25} \gg$ Es fanden sich bei innen auch Gesandte aus Cirta ein und boten innen den Palast des Syphax an. Wiederum einige kamen von Sophoniba, der Gattin des Syphax, eigens zu Masinissa und machten Angaben über deren erzwungene Heirat. Mit Freuden nahm Masinissa die Sophoniba entgegen und machte sie zu seiner Frau. Dann ließ er sie in Cirta zurück und kehrte selbst zu Scipio zurück, da er die weitere Entwicklung deutlich voraussah.« (KA 111f.)

${ }^{26}$ »Sophoniba zeigte ihrer Amme den Becher, bat sie, nicht zu weinen, wenn sie jetzt einen ehrenvollen Tod sterbe, und trank dann von dem Gift. Sobald die Römer erschienen, wies ihnen Massinissa die Leiche vor und begrub sie königlich.« (KA 119)
} 
gorischen Text zur Protagonistin gemacht, wobei er ausschließlich die Darstellung von Livius aufgriff. ${ }^{27}$

Als Petrarca sein neulateinisches Epos Africa $^{28}$ mit dem Anspruch konzipierte, ein Vergils Aeneis gleichwertiges Werk zu schaffen, wählte er Scipio Africanus zum epischen Helden. Zur ıErneuerung Vergils gehörte auch eine Parallele zur Liebesgeschichte von Dido und Aeneas, die Vergil im vierten Buch seiner Aeneis dramatisch in Szene gesetzt hatte, um den Dauerkonflikt Roms und Karthagos mythisch zu begründen. Im fünften Gesang der Africa erhielten Massinissa und Sophonisbe eine dem vierten Buch der Aeneis analoge Funktion: Das eindrucksvolle Szenario gibt dem Hass der den Römern Unterliegenden Ausdruck.

Der Handlungsablauf folgt weitgehend Livius. Sophonisbe bittet den siegreichen Massinissa in Cirta um Gnade (vv. 1-105). Mit dem Versprechen, sie vor den Römern zu schützen, heiratet er die Königin (vv. 106-151, 242-272), was auf heftige Kritik Scipios stößt (vv. 371-437). In einem langen Monolog (vv. 438-486) beschreibt Massinissa seine Gefühle und sucht nach einem Ausweg durch Flucht (vv. 510-533), bevor er sich dazu durchringt, der Königin Gift zu senden (vv. 689-718). Die Szene endet mit einem langen Abschiedsmonolog Sophonisbes (vv. 727-766).

Die intertextuellen Bezüge zu Vergil sind zahlreich: Wie bei Vergil übernimmt Fama, die Personifikation des Gerüchts, eine wichtige epische Rolle. ${ }^{29}$ Machte sie im vierten Buch der Aeneis die Beziehung von Dido und Aeneas publik, verbreitet sie nun die Nachricht von der Ehe Sophonisbes und Massinissas und leitet zum Einspruch Scipios über. Auch wenn Petrarca das Sterben Sophonisbes beschreibt, tritt er in einen intertextuellen Wettbewerb mit den letzten Versen der Aeneis ${ }^{30}$, in denen der Tod des Turnus berichtet wird:

[...] Inde malignum

Ceu sitiens haurit non mota fronte venenum, tartareasque petit violentus spiritus umbras. ${ }^{31}$

Mit dem Tod des Turnus fand der Kampf um das von den Göttern verheißene Italien ein Ende; Aeneas wurde Stammvater und Gründer eines neuen Weltreiches.

\footnotetext{
${ }^{27}$ Appian blieb Petrarca offensichtlich unbekannt.

${ }^{28}$ Petrarca, Francesco: Africa, hrsg. von Nicola Festa, Firenze 1926 (Edizione Nazionale delle Opere di Francesco Petrarca, 1). Eine für unseren Zusammenhang unbrauchbare Teiledition: Petrarca, Francesco: Rime, Trionfi e Poesie Latine, hrsg. von Neri, F. / Martellotti, G. / Bianchi, E. / Sapegno, N., Milano / Napoli 1951, S. 625-703. - Das Jugendwerk Petrarcas entstand zwischen 1338 und 1341. Der Text ist bequem im Netz zugänglich: http://www.gelahn.asso.fr/docs87.html (zuletzt aufgerufen: 04.05.2008).

${ }^{29}$ Vv. 273-329.

30 Der italische Gegenspieler Turnus wird von Aeneas im Zweikampf getötet: »vitaque cum gemitu / fugit indignata sub umbras « ( ‘aufstöhnend fährt seine Seele / voll Unmut hinab zu den Schatten`) (XII, 952).

${ }^{31}$,Dann trinkt sie wie eine Durstige mit unbewegtem Gesicht das verderbliche Gift, und ihr ungebändigter Geist strebt zu den Schatten des Tartarus.ı (vv. 771-773)
} 
Analog gilt für Petrarca Scipio nach dem Tod der afrikanischen Heldin und Patrio$\operatorname{tin}^{32}$ als ızweiter Stammvater« römischer Macht.

Gleichwohl wird Massinissa der größte Raum im fünften Gesang der Africa zugedacht: In einem langen Monolog ${ }^{33}$ formuliert er seinen Loyalitätskonflikt zwischen Sophonisbe und Scipio. Die Verpflichtung gegenüber der Gattin und die strikte Forderung des Feldherrn, die Königin auszuliefern, treiben inn in eine Aporie, die Petrarca in überraschender Weise löst: Massinissa gehorcht der römischen Forderung, weil er sich damit tröstet, das Leben mit Sophonisbe in der Unterwelt ohne zeitliche Begrenzung fortführen zu können. ${ }^{34}$ Galt die Ehe Sophonisbes und Massinissas bei Livius als letzter Versuch, die bedrohte Königin zu retten, wird sie bei Petrarca zum eigentlichen Grund der strikten Forderung Scipios; Massinissa wird zum tragischen Verursacher des Untergangs der Königin: „Tibique / auctor mortis ego. ${ }^{35}$

Petrarcas Darstellung kontrastiert Politik und Liebe und stellt damit der späteren Rezeption viele Möglichkeiten zu Verfügung, dieses Themenfeld unterschiedlich zu akzentuieren. In einer von Petrarca geschickt interpolierten Anspielung auf Valerius Maximus ${ }^{36}$ kündigt die sterbende Königin dem römischen Sieger ein unehrenhaftes Alter an.

Im seinem volkssprachlichen Triumphus Amoris ${ }^{37}$, der den Triumphzug des Liebesgottes schildert, stilisiert Petrarca Sophonisbe und Massinissa noch stärker zu exemplarisch Liebenden. In der Traumvision des Erzählers treten sie in der Entourage des Gottes Amor auf. Vor innen gehen einige der großen Liebespaare wie Caesar und Kleopatra, Augustus und Livia, Theseus und Ariadne, Venus und Mars, Pluto und Proserpina. ${ }^{38}$ Sophonisbe und Massinissa schreiten, sich an der

\footnotetext{
${ }^{32}$ So wird Sophonisbe von Syphax in den vv. 330-370 charakterisiert. Mit Sophonisbes Eintreffen beginnt sein Verrat gegenüber den Römern (vv. 348-350). Seine Frau hat ihm selbst die Rüstung gegen die Römer angelegt und die Waffen in die Hand gedrückt (vv. 356-362). Seine Gefangennahme durch die Römer ist nur die gerechte Strafe für seine politische Unzuverlässigkeit (vv. 363-366).

${ }_{33}$ Vv. 534-688.

34 »Scipio nostros non scindet amores«. (১Scipio wird unsere Liebe nicht zerbrechen.ı) (v. 545); »lbimus una ambo flentes, et passibus isdem / ibimus, eterno connexi federe; nec nos / ferreus aut nostros Scipio interrumpet amores. « (>Weinend werden wir zusammen gehen und gemeinsam schreiten; in einen ewigen Bund sind wir vereint, weder uns noch unsere Liebe wird der unbarmherzige Scipio scheiden. 1 ) (vv. 549-551)

${ }_{35}^{35}$,Bin ich doch der Urheber deines Todesı (vv. 615f.).

${ }^{36}$ Valerius Maximus, Facta et dicta memorabilia, III, 5,1 (De ingratis)

${ }^{37}$ Petrarca, Francesco: Rime, Trionfi e Poesie Latine, hrsg. von Neri, F./ Martellotti, G./ Bianchi, E./ Sapegno, N., Milano / Napoli 1951, S. 481-508. Der Triumphus Amoris, an dem Petrarca seit den 50er Jahren bis zu seinem Tod (1374) arbeitete, blieb unvollendet. Vgl. den Artikel Petrarca von Rossi, Luciano in: Lexikon des Mittelalters, Bd. 6, Sp. 1945-1949. Die halballegorische Traumvision greift Elemente der Comedia Dantes auf; der Erzähler übernimmt zugleich die erklärende und kommentierende Rolle Vergils.

${ }^{38}$ Triumphus Amoris I,1-160
} 
Hand haltend (a mano a mano) und weinend (dolcemente lagrimando), am Erzähler vorbei. ${ }^{39}$ Massinissa berichtet, seine unglückliche Liebe zu Sophonisbe sei am Loyalitätskonflikt mit Scipio gescheitert. Noch in der Traumvision ist Massinissa voll Bewunderung und Verehrung für Scipio (sommo uom), seine Leistung (virtute) und seinen Gerechtigkeitssinn (gran giustizia). Augenfällig ist Sophonisbe ${ }^{40} \mathrm{im}$ Triumphus Amoris als liebende Frau charakterisiert, die zum Opfer der Politik wird. Wie in der Africa avanciert Scipio zum zweiten römischen Nationalhelden.

Gleichzeitig mit Petrarcas Bearbeitungen des Sophonisbe-Stoffs nahm auch B o ccaccio (1313-1375) die antike Tugendheldin in sein historisch-mythologisches Sammelwerk De claris mulieribus ${ }^{41}$ auf. Das hier entworfene Bild beeinflusste für Jahrhunderte die gelehrte, literarische und ikonographische Rezeption der Sophonisbe. Boccaccio hielt sich eng an die Vorlage des Livius, dramatisierte die Episode aber dadurch, dass er nur Sophonisbe (und dies gleich mehrfach) zu Wort kommen lässt. Diese Vorgaben wurden in den ersten Theaterfassungen der Episode aufgegriffen, zumal Boccaccio den Grundkonflikt zwischen Liebe und Politik zuspitzte.

Über Livius hinausgehend hob Boccaccio den politischen Hintergrund der ersten Ehe Sophonisbes hervor. Hasdrubal versucht, Syphax auf die karthagische Seite zu ziehen und setzt dabei auf die Reize seiner Tochter. ${ }^{42}$ Die politische Instrumentalisierung der Liebe gelingt: Der liebesblinde Syphax kann sogar zum Vertragsbruch gebracht werden. ${ }^{43}$ Auch die sich nach der Gefangennahme des Syphax entwickelnde Beziehung zwischen Sophonisbe und Massinissa wird von Boccaccio

\footnotetext{
${ }^{39}$ II, $1-87$

40 Ihr sind nur wenige Verse (vv. 77-78 und 82-84) direkter Rede zugedacht.

${ }^{41}$ Abgefasst zwischen 1361 und 1375. Ich zitiere nach der Ausgabe Boccaccio, Giovanni: Tutte le opere, hrsg. von Branca, Vittore, Milano ${ }^{2} 1970$.

42 „Que cum esset etate florens et forma satis egregia, a patre, Syphaci, potentissimo Numidie regi, in coniugium virgo copulata est; nec equidem desiderio regie affinitatis tantum; sed optabat vir sagax, instante Romanorum bello, non solum barbarum regem Romanis subtrahere, sed opere filie blandientis in partes Cartaginiensium adversus Romanos convertere; nec a precogitata fallacia deceptus est. Nam cum nuptias Syfax celebrasset, a premonita adolescentula, formositate favente, in tantum sue dilectionis ardorem tractus est, ut nil preter illam sibi carum aut delectabile arbitraretur Syphax. (〉Die junge und recht schöne Frau wurde von ihrem Vater mit Syphax, dem mächtigsten König Numidiens, verheiratet, weil er königliche Verwandtschaft wünschte und weil der scharfsichtige Mann den barbarischen König angesichts eines unmittelbar bevorstehenden Krieges mit den Römern den Feinden entfremden und durch den Einfluss seiner Tochter auf die karthagische Seite ziehen wollte. Er hatte mit seiner wohlbedachten Intrige Erfolg. Denn nach der Hochzeitsfeier wurde Syphax von der in die Intrige eingeweihten jungen Frau unter Einsatz ihrer Schönheit in einen solchen Liebestaumel versetzt, dass ihm nichts außer ihr lieb und erfreulich erschien.८) LXX,2-3 (De Sophonisba regina Numidie)

${ }^{43}$ »et sic, dum ureretur infelix et appareret Cornelium Scipionem ex Sycilia in Affricam [sic!] cum exercitibus traiecturum, Hasdrubalis monitu, Sophonisba blanditiis precibusque adeo Syphacis animum in desiderium suum traxit, ut, non solum Romanos relinqueret, quibus amicitie fidem prestiterat, et Cartaginensibus iungeretur, verum ultro alieni belli principatum assumeret.« (`Als erkennbar wurde, dass Cornelius Scipio mit seinen Heeren von Sizilien nach Afrika übersetzen würde, zog Sophonisbe auf Wunsch Hasdrubals den liebestollen Unglücklichen durch Schmeicheleien und Bitten so sehr in ihren Bann, dass er nicht nur die Römer im Stich ließ, mit denen er einen Freundschaftspakt geschlossen hatte, und sich mit den Karthagern verbündete, sondern sogar die Führung in diesem auswärtigen Krieg übernahm.ı) (LXX, 3)
} 
dramatisiert. Die exemplarische Unerschrockenheit ${ }^{44}$, mit der Sophonisbe den Tod wählt, steht am Ende einer sich überstürzenden Entwicklung, in der sie sich immer der politischen Dimension ihres Handelns bewusst ist, auch wo sie ihre durch das Unglück noch verstärkten Reize (pium quoddam et insolitum decus) erneut einsetzt. In ihrer prekären Lage wendet sie sich an den numidischen König ${ }^{45}$, verlangt selbstbewusst den Schutz Massinissas und beteuert - der Handlung vorgreifend -, den Tod aus der Hand des Massinissa dem durch die Römer vorzuziehen. Von Sympathie und sexueller Begierde motiviert, heiratet Massinissa Sophonisbe auf der Stelle; die knappe Schilderung Boccaccios betont die erotische Ausstrahlung der Königin. ${ }^{46}$ Mit dem unerbittlichen Widerstand Scipios konfrontiert, zieht sich Massinissa weinend in sein Zelt zurück und schickt seinen treuesten Sklaven mit Gift zu Sophonisbe. ${ }^{47}$ Das der Königin in den Mund gelegte ultimum verbum hat Boccaccio fast wörtlich von Livius übernommen und dabei die Zweideutigkeit be-

44 „Nec acrius dicta dedit quam poculum sumpserit et, nullo signo trepidationis ostenso, confestim hauxit omne; nec diu tumescens in mortem, quam petierat, miserabunda collapsa est. - Edepol annoso homini, cui iam vita tedium, nec spes alia preter mortem, nedum puellule regie, tunc, habito ad notitiam rerum respectu, vitam intranti et quid in ea dulcedinis sit percipere incipienti, magnum et admirabile fuisset, et nota dignum, morti certe adeo impavide occurrisse. « ( Sie sagte das so wenig verbittert, wie sie auch den Becher nahm und ohne sichtbares Zeichen der Furcht ganz leerte; sie rang nicht lange um Atem und starb, die Ärmste, wie sie sich es gewünscht hatte. - Selbst für einen betagten Menschen, den schon der Lebensüberdruss ergriffen hat und dem keine andere Hoffnung mehr als der Tod bleibt, wäre dies eine bewundernswert große Handlungsweise gewesen, noch mehr aber unter diesen Umständen, und gar für eine junge Königin, die am Beginn ihres Lebens zu erkennen begann, welche Wonnen es bietet. Bemerkenswert unerschüttert trat sie dem Tod entgegen. 1 ) (LXX,10f.)

45 "Sic, rex incilte, deo visum est et felicitati tue ut in nos, qui paulo post ante reges eramus, que velis possis omnia. Verum si permissum est captive ut coram victore et vite mortisque sue domino supplices voces emictere possit eiusque genua atque dexteram victricem contingere, deiecta precor per maiestatem tuam, in qua et ego paulo ante eram, perque genus regium et comune numidicum nomen, etsi meliori suscipiaris omine, quam hinc abierit Syphax, in me, quam tui iuris noviter adversa fecit fortuna, agas quod in oculis tuis pium bonumque visum sit, dum modo insolenti et fastidioso, potissime Penis, Romanorum arbitrio viva non tradar. Facile enim potes advertere quid romana hostis, cartaginensis et Hasdrubalis filia - sino quod Syphacis coniunx - timere possim; et, si omnis in hoc alius tollitur modus, ut tua manu potius moriar facito, quam hostium in potestatem viva deveniam, precor et obsecro -.« (〉Den Göttern und deinem Glück hat es gefallen, berühmter König, dass du mit uns, die wir gerade auch noch Könige waren, tun kannst, was du willst. Wenn eine Gefangene dem Sieger und Herrn über Leben und Tod Bitten vortragen, seine Knie und seine siegreiche Rechte umfassen darf, bitte ich dich vom Schicksal Begünstigten kniefällig, nachdem Syphax nicht mehr da ist, bei deiner königlichen Würde, die auch ich eben noch besaß, und beim gemeinsamen numidischen Namen, gegen mich zu handeln, wie du willst, da das Geschick mich von dir abhängig gemacht hat, wenn ich, mächtiger König, nur nicht lebend der Willkür der unverschämten und widerwärtigen Römer ausgeliefert werde. Was ich als Feindin der Römer, Karthagerin und Tochter des Hasdrubal und auch als Frau des Syphax befürchten muss, kannst du dir leicht vorstellen; dringend bitte ich dich, mich lieber mit eigener Hand zu töten - wenn es denn keine andere Möglichkeit gibt - als mich lebend in die Gewalt der Feinde geraten zu lassen. 1 ) (LXX,5-7)

46 »Massinissa qui et ipse numida erat et, uti omnes sunt, in libidinem pronus, venustatem oris orantis inspiciens - addiderat quippe infortunium, pium quoddam et insolitum decus suplici - motus et humanitate et libidine tractus, cum nondum adventasset Lelius, uti erat in armis, dextera data, inter feminarum querulos ululatus et tumultum discurrentium undique militum, levavit orantem eamque sibi extemplo iunxit in coniugem, medio in strepitu armorum nuptiis celebratis. " (>Massinissa, selbst Numider und wie alle Numider der Sinnlichkeit sehr zugetan, betrachtete das schöne Antlitz der Bittstellerin; das Unglück hatte der Flehenden eine ungewöhnliche und gleichsam erhabene Schönheit verliehen. Mitleid und Begierde brachten ihn dazu, ihr, bewaffnet wie er war, inmitten des Geschreis der Frauen und des Lärms der von allen Seiten durcheinander laufenden Soldaten, noch vor dem Eintreffen des Laelius die Rechte zu reichen, die Bittende aufzuheben und sie sich als Ehefrau zu verbinden; die Hochzeitsformalitäten wurden inmitten des Waffenlärms vollzogen.८) (LXX, 8)

47 »accersiri ad se iussit quem ex servis fidelissimum habebat, cui commiserat servandum venenum ad incertos fortune casus, eique precepit ut illud, poculo dilutum, Sophonisbe deferret diceretque libenter se illi, quam sponte dederat fidem, servaturum si posset; verum, quoniam a quibus poterat arbitrium subtrahebatur suum, quam ipsa petierat, non absque merore suo, praestabat fidem, si uti velit, scilicet ne in potestatem viva veniat Romanorum; ipsa tamen patris patrieque et duorum regum, quibus paulo ante nupserit, memor, sibi quod videretur consilium summeret. « (`Massinissa ließ den treuesten seiner Sklaven herbeiholen, dem er für mögliche Schicksalsschläge Gift in Verwahrung gegeben hatte, und befahl inm, das Gift Sophonisbe in einem Becher aufgelöst zu überbringen und ihr mitzuteilen, er hätte sein ihr freiwillig gegebene Versprechen gerne gehalten, wäre es in seiner Macht; nun erfülle er, weil sein Wunsch von den Mächtigen missachtet würde, nicht ohne Trauer sein von ihr erbetenes Versprechen, sie nicht lebend in die Hand der Römer geraten zu lassen; eingedenk des Vaters, des Vaterlandes und zweier Könige, die sie geheiratet habe, solle sie die für richtig gehaltene Entscheidung treffen.८) (LXX,9f.) 
wusst beibehalten, die offen lässt, ob die Königin die Heirat mit Massinissa oder das Scheitern der damit verbundenen politischen Absicht bedauert. ${ }^{48}$

\section{Von der Novelle zur Tragödie}

Als der Dominikaner Matteo Bandello (1484/85-1561) seine 41. Novelle (Infelice esito de l'amore del re Masinissa e de la reina Sofonisba sua moglie ${ }^{49}$ Rinuccio Farnese widmete, erinnerte er an die compassione, die die bella istoria di Masinissa e Sofonisba bei den Zuhörern auslöste, als sich der Condottiere mitten im Krieg in der Nähe Viterbos bei einem Essgelage in idyllischer Szenerie Verse aus Petrarcas Trionfi vorlesen ließ und Giorgio Santa Croce bat, diese Liebesgeschichte ausführlicher zu erzählen. Bandellos Novelle ist ein Cento, für den der Verfasser auf Livius und auf Petrarcas Africa zurückgriff und den er durch zahlreiche direkte Reden dramatisch gestaltete. Den Gattungsregeln der Renaissance-Novelle entsprechend hat Bandello die tragische Beziehung Massinissas und Sophonisbes in eine Rahmenerzählung eingebaut, die zeigt, dass das Sophonisbe-Thema bereits weite Verbreitung gefunden hatte und seine dramatischen Qualitäten bekannt waren. Die Handlung des merkwürdigen historischen Ereignisses wird in die zahlreichen Dialoge und Monologe der Novelle verlegt, in denen mit genormter Virtuosität Schönheit, Liebesklage, Todeswillen und Verklärung Sophonisbes evoziert werden. ${ }^{50}$ Trotz der petrarkistischen Sprache deuten knappe Exposition und ostentative Peripetie bereits auf dramatische Inszenierungsmöglichkeiten des Stoffes hin. Das historiographische Exemplum, von Petrarca zur Liebesgeschichte vor bedeutsamer politischer Kulisse umgewertet, spielt denn auch eine bedeutende Rolle in der frühneuzeitlichen Wiederentdeckung der Tragödie.

\footnotetext{
48 »Accipio nuptiale munus et, si nil aliud a viro coniugi dari poterat, gratum habeo; sed refer satius me morituram fuisse si non in funere meo nupsissem «. (২Wenn der Gatte seiner Gemahlin nichts anderes zum Hochzeitsgeschenk machen konnte, nehme ich es dankbar an. Richte aber aus, dass ich zufriedener gestorben wäre, wenn ich nicht an meinem Todestag geheiratet hätte.ı) (LXX,10) - Mit fast gleichen Worten Livius: »Accipio nuptiale munus, neque ingratum si nihil maius uir uxori praestare potuit. hoc tamen nuntia, melius me morituram fuisse si non in funere meo nupsissem«. (>Wenn der Gatte seiner Gemahlin nichts Größeres zum Hochzeitsgeschenk machen konnte, nehme ich es dankbar an. Melde jedoch, dass ich besser gestorben wäre, wenn ich nicht an meinem Todestag geheiratet hätte.ı) (Ab urbe condita, 30,15,7)

${ }^{49}$ Bandello, Matteo: Le Novelle, hrsg. von Brognoligo, Gioachino, Bari 1928, S. 101-114. - Weitere Informationen zu Matteo Bandello bei: Rosa, Alberto Asor (Hrsg.): Letteratura Italiana, Gli Autori, Dizionario BioBibliografico e Indici, Torino 1990, Bd. 1, S. 167-168.

$50 \gg$ O Sofonisba mia cara, o vita de la mia vita e a me assai piú che la luce degli occhi miei amabile e dolce, che sará di noi? Oimè, piú concesso non mi sará veder il tuo vago ed amoroso viso, le bionde chiome, quei begli occhi che mille volte hanno fatto invidia al sole e sentir la soave armonia de le parole, la cui dolcezza può a Giove nel maggior furore, quando irato le folgoranti saette vibra, l'arme tor di mano. ( $>$ meine teure Sophonibe, o du Leben meines Lebens, die du mir weit süßer und liebenswerter bist als das Licht meiner Augen, - was wird aus uns werden? Weh mir! Es wird mir nicht mehr vergönnt sein, dein reizendes liebevolles Antlitz zu sehen, deine blonden Flechten, deine schönen Augen, die tausendmal den Neid der Sonne erweckt haben, nicht vergönnt, die süße Harmonie der Worte zu hören, deren bestrickender Wohlklang Jupitern im höchsten Zorn, wenn er ergrimmt die blitzenden Pfeile schwingt, die Waffe aus der Hand zu winden vermag.ı (Floerke, Hanns [Übers.]: Die Novellen des Bandello, München 1920, Bd. 3, S. 234)
} 
Bereits in der ersten dramatischen Bearbeitung in einer Volkssprache wird das theatralische und sphilosophischer Potential des Stoffes deutlich. Die Sofonisba des Galeotto del Carretto (ca. 1455-1530) ${ }^{51}$ wurde 1502 in Mantua aufgeführt, wenn man der Dedikation ${ }^{52}$ des erst 1546 postum erschienen Drucks an Isabella di Mantova Glauben schenken darf.

Das Stück ${ }^{53}$ behandelt den gesamten Zusammenhang der »notabili gesti « Scipios in Afrika, nicht nur das Schicksal der Sofonisba, die erst gegen Ende der Handlung auftritt. Das noch ganz sunaristotelische` Stück spielt, seine Herkunft aus der Historiographie nicht verbergend, in einem bilderbogenartigen Aufbau an fünf Handlungsorten: Cirta, Carthago, Cadiz, Sizilien und in einem Zelt. Dem Zuschauer werden erhebliche Zeitsprünge zugemutet: zu Beginn des Stückes ist Syphax noch nicht einmal Sofonisbas Ehemann. Nach klassischem Vorbild hat Galeotto Chorlieder eingefügt, um die Handlung zusammenzufassen, die in 229 Strophen (ottaveri$m e$ ) ein breites Bild der Episode im Zweiten Punischen Krieg entwickelt. Sofonisba selbst tritt nur in vier Szenen auf: sie hat bereits in die Heiratspläne Hasdrubals einwilligt und zieht Syphax auf die karthagische Seite. Nach seiner Gefangennahme bittet sie Massinissa um Hilfe, die er nur als Ehemann gewähren kann, weshalb er auf die Verheiratung drängt. In der letzten Szene empfängt Sofonisba das Gift und tötet sich. ${ }^{54}$

Die stoische (und neustoische) Einschätzung des Selbstmords als Möglichkeit des animo gentile zur Bewahrung der inneren Freiheit findet in dem sich selbst monumentalisierenden Epitaph Ausdruck, den Sofonisba für sich entwirft:

Qui giace Sofonisba, ch'ebbe a vile

Questa vita mortal, per gire a morte,

E per spogliarsi l'abito servile

Bevve il veleno, sì che la sua sorte

Sia esempio a qualunque animo gentile,

Che al viver nostro non son l'ore corte,

Ov'ei muor per onore, anzi la vita

L'onorata sen va, resta infinita. ${ }^{55}$

In einer hoffnungslosen Konstellation rettet nur der selbst gewählte Tod die moralische Freiheit (»bella e pietosa libertà«). Diesen Grundgedanken seines Theater-

\footnotetext{
${ }^{51}$ Rosa, Alberto Asor (Hrsg.): Letteratura Italiana, Gli Autori, Turin 1990, Bd. 1, S. 679-680.

52 Del Carretto, Galeotto: Li sei contenti e La Sofonisba, hrsg. von Gregoli-Russo, Mauda, Madrid 1982 , S. 149-151.

${ }^{53}$ In der Widmung wird die Handlung knapp zusammengefasst: „One l'animo m'ha indotto a scrivere i notabili gesti di Scipione in Africa fatti doppo la superata Spagna, e di Siface l'infortunato successo, e di Sofonisba sua prima moglie il miserevole caso: la quale più tosto elesse di bere il veleno di Massinissa suo novo sposo mandato, che perdendo libertade andar cattiva in servitù de' Romani. « (S. 150)

${ }^{54}$ Siehe Andrae, August: Sophonisbe in der französischen Tragödie mit Berücksichtigung der Sophonisbebearbeitungen in den anderen Litteraturen, Jena 1891 (Zeitschrift für französische Sprache und Litteratur, Supplement 6), S. 43.

55 A.a.O., S. 242-243. Vergleichbar: "Torna al tentorio in viso col rossore, / Con la vergogna, e col cordoglio in seno, / E poiché ha volt' in pensier vari 'I cuore, / A Sofonisba manda 'I dir veneno, / Con dir, se ben è di sua morte autore, / Che la sua libertà gli salva almeno. / Ed ella il beve intrepida ed ardita, / E fatta in libertà perde la vita.«(a.a.O., S. 157)
} 
stückes spricht del Carretto selbst in der Widmung an Isabella di Mantua höfisch verklausuliert, aber deutlich genug aus. ${ }^{56}$

Das Stück war allerdings rasch veraltet, weil von Giovan Battista Giraldi Cinzio (1504-1573) und Gian Giorgio Trissino (1478-1550) ${ }^{57}$ die bei Galeotto noch nicht beachteten aristotelischen Regeln in die Literaten- und Theoretikerdebatte des 16. Jahrhunderts eingeführt wurden. Cinzios Discorso ovvero lettera intorno al comporre delle commedie e delle tragedie (1543) und Trissinos Poetica (1529 und 1562) erörterten den regelgerechten Aufbau des Dramas und das moralische Ziel der erneuerten Tragödie. Nicht mehr Götter oder Schicksal sollten wie bei Aischylos oder Sophokles den tragischen Ausgang herbeiführen, sondern Einsicht und Wille der Protagonisten, wie es bereits Seneca in seinen Theaterstücken propagiert hatte, dem sich die humanistischen Theoretiker der Frühen Neuzeit anschlossen. $^{58}$

Es ist bemerkenswert genug, dass gerade der Sophonisbe-Stoff zum Vorwurf des ersten, folgenreichen Versuchs gewählt wurde, das antike Tragödienmodell neu zu beleben. ${ }^{59}$ Gian Giorgio Trissino wählte die historisch-epische Vorlage als Thema der ersten klassizistischen Tragödie der Neuzeit. Er ließ seine Sofonisba 1515 während des Karnevals vor Leo X. aufführen. ${ }^{60} \mathrm{Im}$ Vorraum des Teatro Olimpico von Vicenza, dem sogenannten Antiodeo, das Vincenzo Scamozzi nach palladia-

\footnotetext{
56 „Ricordandole in questa, quanto è da stimare la bella e pietosa libertà, la quale nè per oro, né per gemme, né manco per stati, si può vendere né commutare, e sì stimando voi esser una di quelle, a cui tal privilegio sopra ogni tesoro piace, leggetela dunque quando averete oportunità di leggerla, tenendomi di continuo nel vivo della memoria sua sì come merta il candido della servitù vera. « (a.a.O., S. 151) (〉Das Stück mag Euch daran erinnern, wie hoch die schöne und tugendhafte Freiheit einzuschätzen ist, welche nicht für Gold oder Edelsteine, auch nicht für Länder zu verkaufen oder einzutauschen ist. Auch bin ich der Auffassung, dass Ihr zu den Frauen gehört, denen dieses Privileg wertvoller als alle Schätze ist. Lest also bei Gelegenheit das Stück und behaltet mich in lebhafter Erinnerung, wie es meine aufrichtige Ergebenheit verdient.८)

${ }^{57}$ Informationen zu diesen Autoren bei: Rosa, Alberto Asor (Hrsg.): Letteratura Italiana, Gli Autori, Turin 1990, Bd. 1, S. 917-918; Bd. 2, S. 1749-1750.

${ }^{58}$ Das »fuggire il vizio e seguire la virtù (Mauda Bregoli-Russo in ihrer Ausgabe der Sofonisba Galeottos, a.a.O., S. 34) wird zum Dauerthema des Theaters und der Historienmalerei: »[...] e la tragedia o sia di fin lieto o d'infelice col miserabile, e col terribile purga gli animi da vizj, e gl'induce a buoni costumi (Cinzio nach Bregoli-Russo, a.a.O.).

59 Manzoni hat es im Vorwort seines Conte di Carmagnola beklagt, dass »regelmäßige Tragödie überall mit einer langweiligen Sophonisbe ihren Anfang nehmen müsse (Maurer, Karl: Goethe und die romanische Welt, Paderborn 1997, S. 239f.).

${ }^{60}$ Ariani, Marco (Hrsg.): Il teatro italiano, Bd. 2, La tragedia del Cinquecento, Turin 1977. Die editio princeps erschien im Juli 1524 und wurde im 16. Jahrhundert in mindestens 31 verschiedenen Drucken in Italien verbreitet. Der europäische Erfolg der klassizistischen Tragödie ist ohne dieses Stück nicht vorstellbar. Vgl. Ciampolini, Ermanno: La prima tragedia regolare della letteratura italiana, Firenze 1896. Mauda Gregoli-Russo schreibt im Vorwort ihrer Ausgabe von del Carrettos Li sei contenti e La Sofonisba, a.a.O., S. 30 zur Einführung der Sciolti in Trissinos Sofonisba: »Il dramma delcarrettiano fa nascere naturalmente il confronto con la Sofonisba del Trissino, considerata la prima tragedia regolare in lingua italiana, nel nuovo endecasillabo sciolto riproducente il trimetro giambico catalettico del dramma tragico classico. «
} 
nischen Plänen dem Theaterbau hinzugefügt hat, sind Fresken aus den neunziger Jahren des 16. Jahrhunderts erhalten, die an wichtige Theaterereignisse erinnern. Ein Fresko zeigt die Aufführung der Sofonisba des Trissino. ${ }^{61}$ Dem Theaterpublikum und einer breiteren Öffentlichkeit war die initiatorische Bedeutung des Stückes für die frühneuzeitliche Bühne durchaus bewusst, wie diese Illustration belegt.

Der Vorwurf des Stücks folgt den beiden antiken Hauptquellen, wird aber nicht mehr wie bei del Carretto historisch-chronistisch in eine Bilderfolge umgesetzt, sondern um einen »nucleo erotico-politico «"22 konstruiert. Mit seiner Sofonisba folgt Trissino nicht römischen, sondern griechischen Modellen und nimmt damit in einer Streitfrage unter den Humanisten Stellung, die sich zum Beispiel auch in der ersten kommentierten Aristoteles-Ausgabe (1548) des Francesco Robortello ${ }^{63}$ und der ersten italienischen Übersetzung der aristotelischen Poetik (1549) von Bernardo Segni niederschlug. ${ }^{64}$ Trissino selbst hat in seiner Quinta divisone della Poetica (1562 postum veröffentlicht) Aufbau und Ausführung seiner Sofonisba begründet. ${ }^{65}$ Seine Tragödie wurde mit den drei Einheiten von Handlung, Ort und Zeit und mit der Handlungsdurchführung in fünf Akten (Exposition, Steigerung der Verwicklung, Höhepunkt mit entscheidendem Geschehen, Peripetie und Katastrophe) eine entscheidende Weichenstellung für das klassizistische europäische Theater. Das dramentechnische Repertoire (Teichoskopie, Stichomythie, Rückblende, Retardierung, vaticinatio ex eventu) beherrschte Trissino bereits meisterhaft.

In seiner dramatischen Umsetzung fügt Trissino der historischen Überlieferung zwei Personen hinzu: Auf die Emotionen der Zuschauer zielend wird Sofonisba Mutter eines Sohnes von Syphax. ${ }^{66}$ Dramentechnisch besonders folgenreich ist die Einführung der Erminia als einer Vertrauten Sofonisbas. ${ }^{67}$ Im Zwiegespräch mit ihr wird in einem Rückblick an die aufgelöste Verlobung mit Massinissa erinnert. Die Einführung der Vertrauten erlaubt es der Protagonistin, ıöffentlicheı und sprivate Sphäre zu unterscheiden. In der Sterbeszene übernimmt Erminia die Rolle eines alter ego, das Emotionen, Trennungsängste und Affekte formulieren darf. ${ }^{68}$

Angelpunkte des dramatischen Geschehens ${ }^{69}$ sind die Unterredung zwischen Sophonisbe und Massinissa (vv. 390-605), der Dialog zwischen Scipio und Massinissa

\footnotetext{
${ }^{61}$ Abgebildet bei Beyer, Andreas: Andrea Palladio, Teatro Olimpico, Triumpharchitektur für eine humanistische Gesellschaft, Frankfurt 1987, S. 36.

${ }^{62}$ So Ariani, Marco, a.a.O., im Vorwort o. S.

63 In librum Aristotelis de arte poetica explicationes Florenz, 1548 bei Torrentino erschienen.

${ }^{64}$ Die Übersetzung der Poetik des Aristoteles erschien zusammen mit anderen aristotelischen Texten ebenfalls bei Torrentino. Vgl. Stillers, Rainer: Humanistische Deutung, Studien zu Kommentar und Literaturtheorie in der italienischen Renaissance, Düsseldorf 1988, bes. S. 107-179.

${ }^{65}$ Ariani, Marco (Hrsg.): II teatro italiano, Bd. 2: La tragedia del Cinquecento, Turin 1977, S. XV.

${ }^{66}$ Das Motiv wird in der Historienmalerei im Gegensatz zur Bühnentradition selten aufgegriffen. Vgl. aber zu Giambattista Crosato S. 99.

${ }^{67}$ In ihrer Premessa bezeichnet Ariani fälschlicherweise Erminia als nutrice, was sich durch einen einzigen Blick in den Text widerlegen lässt. Sofonisba vertraut kurz vor ihrem Tod Erminia ihren kleinen Sohn an und bezeichnet sie als Verlobte ihres Bruders (»E stando in casa ancor darai conforto / a la mia vecchia e sconsolata madre, / che già ti elesse moglie a mio fratello, / e ora le sarai figliuola e nuora.« [vv 1818ff.]).

${ }^{68}$ Vv. 1737-2091.

${ }^{69}$ Obwohl die heute gebräuchliche Einteilung in Akte und Szenen noch nicht vorgenommen ist, lassen sich in den 2103 Versen des Stücks fünf Akte unterscheiden, da der Fragen stellende und wertende Chor jeweils am
} 
(vv. 1256-1427) und die Katastrophe, die in zwei Phasen strukturiert ist: suicidio (vv. 1554-1732) und morte (vv. 1733-1989). Eine Dienerin schildert in einer langen narratio (vv. 1569-1672), wie ein Bote Massinissas das Gift überbringt. Äußerst theatralisch berichtet sie die Reaktionen Sophonisbes, referiert nicht nur Gesagtes, sondern setzt zu direkter Rede an, das Vorgefallene einerseits von außen erzählend, andererseits in direkter Rede vorstellend. Noch ist Sophonisbe nicht aufgetreten und der Spannungsbogen bis zum Zerreißen gespannt. Erst nach einer weiteren Retardation erscheint die Protagonistin selbst, bereits vom Tode gezeichnet. Der Fortgang der Handlung wird weiter retardiert: Sophonisbe trinkt das Gift erst, nachdem sie Juno als Göttin der Ehe ein Opfer dargebracht hat. Ganz Herrin ihrer Gefühle, nimmt sie von Sohn und Hofstaat Abschied. Wieder werden private und öffentliche Rolle unterschieden; die Gefühle der Mutter treten vor denen der Regentin zurück.

Nach einem Opfer für Proserpina beginnt die Sterbeszene mit einem langen Gespräch zwischen Sophonisbe und Erminia. Trissino veranschaulicht in Sophonisbes Bühnentod die neustoische Auffassung, ein schöner und ruhmreicher Tod (»una bella e glorïosa morte «) zeichne ein ganzes Leben aus. ${ }^{70}$ Sophonisbe wird in ihrer privaten Rolle als liebende Mutter gezeigt, der die Versorgung des kleinen Sohnes kurz vor ihrem Tod am Herzen liegt. Auch an ihre Rolle als Tochter und Schwester wird nochmals erinnert. ${ }^{71}$ Die von Syphax als Patriotin charakterisierte Königin ${ }^{72}$ versteht ihren Tod als Auflehnung gegen die römische Gewalt. ${ }^{73}$ Der Konflikt zwischen Scipios Staatsräson und Sophonisbes unbedingtem Willen, nicht in die Hände der Todfeinde zu geraten, findet seine Auflösung im Tod der Protagonistin, hinter deren Gelassenheit und Stärke alle anderen Personen verblassen. Am stärksten betont Trissino jedoch die stoische Entschlossenheit seiner Heldin, den Tod nicht als etwas Bedrohliches, sondern als Befreiung zu empfinden.

Erst Trissino entwickelte aus der historischen Überlieferung einen stimmigen Charakter, der sich noch im Scheitern bühnengerecht entwickelt und bewährt. Dabei tritt das Motiv der Liebe Sofonisbas zu Massinissa zugunsten der Selbstbehauptung der Königin völlig zurück. Eine letzte Steigerung bringt nach den Klagen des Chores und der Vertrauten das Eintreffen Massinissas, der zu spät doch noch einen Weg zur Rettung Sofonisbas gefunden hat: Trissino erreicht es durch diese Wendung, dass der freiwillige Tod seiner Tugendheldin nicht mehr politischen Zu-

\footnotetext{
Ende eines Aktes emotional Stellung zum eben vergangenen Geschehen bezieht (1. Akt: 1-228, 2. Akt: 229691, 3. Akt: 692-1161, 4. Akt: 1162-1553, 5. Akt: 1553-2103).

70 "La vita nostra è come un bel tesoro, / che spender non si deve in cosa vile, / illustra tutta la passata vita. / né risparmiar ne l' onorate imprese: / perché una bella e glorïosa morte / illustra tutta la passata vita. « (vv. 334339)

${ }^{71}$ v. 1881

72 "La causa fu la bella Sofonisba« (v. 1190), sagt Syphax, als er von Scipio nach dem Grund gefragt wird, warum er den Vertrag mit den Römern gebrochen habe.

73 „ivi ai parenti miei tu narrerai / il modo, e la cagion de la mia morte, / sí come per fuggir la servitute, / e per non far vergogna al nostro sangue, / ne la mia gioventú presi ‘l veneno. « (vv. 1813-1817)
} 
fällen, sondern der moralischen Selbstbehauptung Sofonisbas geschuldet ist und macht sie damit zur tragischen Figur.

Im Jahre 1559 eröffnet Mellin de Saint-Gelais mit seiner französischen Prosabearbeitung von Trissinos Sofonisba, die vor Caterina de' Medici in Blois aufgeführt wurde, den breiten europäischen Strom der Bearbeitungen und Adaptionen ${ }^{74}$ des Stoffes, die bis zu Vittorio Alfieris (1749-1803) Sofonisba (1784) und Emmanuel Geibels (1815-1884) Sophonisbe $(1868)^{75}$ reicht und mannigfache Gewichtungen und Betonungen, Varianten und Mischungen erprobte. Schon im 16. Jahrhundert erschienen französische Adaptionen Trissinos von Claude Mermet (1584), Antoine de Montchrestien (1596) und Nicolas de Montreux (1601). die die Form der Tragödie nicht mehr in Frage stellten. ${ }^{76}$ Die zweifellos folgenreichste dramatische Fas-

${ }^{74}$ Axelrad, Albert-José: Le thème de Sophonisbe dans les principales tragédies de la littérature occidentale (France, Angleterre, Allemagne), Lille 1956

75 Zugänglich über www.projekt.gutenberg.de (zuletzt aufgerufen: 11.05.2008).

${ }^{76}$ Die französischen Bühnenbearbeitungen des Stoffes beziehen seit Nicolas de Montreux neben den oben besprochenen antiken Quellen auch auf einen PI ut a rch zugeschriebenen Text, der sich in der verbreiteten Übersetzung von Jacques Amyot fand. Sie fasst die Sophonisbe-Episode kurz zusammen und legt den Akzent auf den tiefen Fall des Syphax, der durch Sophonisbe zu unloyalem Verhalten gegenüber den Römern verleitet worden war, sich aber damit trösten konnte, dass auch Massinissa alsbald ihrem Charme unterlag. Ich zitiere den Text nach: Plutarque: Les Vies des Hommes illustres, übersetzt von Jacques Amyot, 9 Bde, Paris, 1783-86, Bd. IX, S. 550-553. (Vgl. Nicolas de Montreux, La Sophonisbe, hrsg. von Donald Stone, Genève 1976, S. 27-29.)

"[XXVIII] Syphax estant arrive en Numidie, et de là en son royaume paternel et hereditaire, leva à la haste une armee ramassee de toutes sortes de gens, et venant à rencontrer Masinissa et $\mathrm{C}$. Lælius, ne redouta point de leur donner la bataille. Toutefois ce fut follement faict a luy, attendu qu'il n'estoit point a beaucoup près si fort que son ennemy, ny en nombre de combatans, ny en egalité de soudards: car les soudards ny les capitaines de son armee ne pouvoyent estre comparez aux soudards et capitaines du camp des Romains. Parquoy il fut facilement vaincu par hommes tant belliqueux, et qui pis est prins en la bataille avec beaucoup d'autres grands personnages: ce que Masinissa eust a grand peine ose souhaitter: puis il les vint presenter a Scipion. Du commencement tous furent joyeux, quand il leur fut dit qu'on amenoit Syphax prisonnier au camp: mais après quand ils le veirent lie et garroté, tous furent esmeus à pitié le voyans en si piteux estat, pour la memoire qu'ils avoyent de sa grandeur et majeste. Car il leur souvenoit combien grande avoit esté un peu auparavant la renommée de ce roy, combien grandes avoyent esté ses richesses, et la puissance d'un si grand royaume: mais le voyans puis apres tumbé de si hault estat en ceste misere, ils en avoyent pitié. Mais le capitaine Romain le receut humainement, et parlant gracieusement a luy, luy demanda, quelle occasion l'avoit fait changer de courage, et l'avoit poulsé a faire la guerre aux Romains. Alors le roy se souvenant de son anciene amitié et de la foy donnée, luy respondit franchement, que ç'avoit esté l'amour qu'il portoit a sa femme Sophonisba, lequel l'avoit incité de se porter si laschement et malheureusement envers les Romains, et que soudain il en auroit reçu tel supplice que les autres y prendroyent exemple, et se garderoyent de rompre la foy promise. Toutefois que ce luy estoit un grand soulas en ses adversitez extremes, de voir son ennemy mortel Masinissa estre esprins de la mesme rage et fureur qu'il avoit. [XXIX] Car apres que Syphax eut este vaincu et prins, Masinissa alla vers Cyrthe, ville capitale du royaume, laquelle il print, et y trouva Sophonisba, de laquelle il devint amoureux: incontinent qu'elle l'eut commencé à flatter avec beaucoup de caresses, il luy promeit aussi de la delivrer d'entre les mains des Romains: et à fin de venir mieulx a but de son entreprinse, il l'avoit prinse en mariage. Ces choses furent bien tost signifiees, à Scipion, dequoy il fut grandement troublé. Car il estoit tout notoire que Syphax avoit esté vaincu soubs la conduitte et par le moyen des Romains, et pourtant tout ce qui avoit appartenu a luy estoit subject a leur jugement: si doncques Masinissa avoit sans le consentement de Scipion entreprins de soustenir la cause de Sophonisba, il sembloit mespriser la puissance du capitaine, et la majesté du peuple Romain. Davantage son orde paillardise aggravoit grandement sa faute, laquelle sembloit beaucoup plus insupportable, d'autant que la continence du capitaine Romain estoit plus grande, laquelle Masinissa avoit devant les yeux pour pouvoir imiter. Car Scipion, oultre les autres declarations et demonstrations de sa vertu, s'estoit tousjours abstenu des femmes prisonnieres en tous les lieux ou il avoit esté victorieux. Estant doncques grandement courroucé contre Masinissa, combien que devant la compagnie il n'en fist semblant, et le receust fort amiablement ainsi qu'il retournoit au camp, toutefois puis après le tirant à part, il le tensa si aspre- 
sung ist die 1634 aufgeführte Sophonisbe von Jean Mairet ${ }^{77}$, die - der Bedeutung Trissinos für Italien vergleichbar - als erste regelmäßige Tragödie der französischen Bühne gilt. ${ }^{78}$ Mairet nahm zwei entscheidende Änderungen vor: zum einen lässt er Syphax in der Schlacht fallen, um zu vermeiden, dass Sophonisbe zwei lebende Gatten hat; zum anderen tötet sich auch Massinisse am Ende des Stückes an der Bahre Sophonisbes, um den Gesetzen der bienséance Genüge zu tun. ${ }^{79}$ Die Sophonisbe von Pierre Corneille (1663) belegt den Erfolg des Stoffes in Frankreich ebenso wie die vollständige Neufassung, die Voltaire 1770 von Mairets Tragödie (»réparée à neuf«) vorgelegt hat. Allerdings verweigert Corneilles Sophonisbe sich »der ihr zugedachten weiblichen Opferrolle « ${ }^{80}$, weist das von Massinisse gesandte Gift zurück und tötet sich mit einem Gift, das sie immer selbst mit sich getragen hat. Die starke Sophonisbe Corneilles ist eine durchwegs politische Persönlichkeit, deren einzige Schwäche die Eifersucht auf Eryxe, ihre von Corneille erfundene Konkurrentin bei Massinisse, bleibt, welche die überstürzte Heirat von Massinisse und das Misstrauen der Römer veranlasst. Voltaires Sophonisbe (1770) gibt sich als Überarbeitung des Stücks von Mairet, ist aber eine völlige Neu-

ment, qu'il cogneut bien que force luy seroit d'obeïr a un capitaine fort moderé, et tout ensemble fort severe. Parquoy il se retira en sa tente tout plourant, et ne sachant quel conseil prendre: mais bien tost apres, voyant qu'il luy estoit impossible de pouvoir tenir la promesse qu'il avoit faitte a Sophonisba, et que pourtant il en estoit en grande angoisse, il luy envoya du poison avec quelque mandement: elle beut le poison incontinent, et ainsi mourut vouluntairement. «

77 Der Text Mairets ist bequem im Netz unter http://www.educnet.education.fr/lettres/lycee/latin/mairet.pdf (zuletzt aufgerufen: 04.05.2008) zugänglich. Kritische Ausgabe von Charles Dédéyan Paris ${ }^{2} 1969$ ('1945); Jean Mairet: Théâtre complet, La Sophonisbe - Le Marc-Antoine ou la Cléopâtre - Le Grand et Dernier Solyman ou la mort de Mustapha, Bd. I, hrsg. von Bénédicte Louvat / Alain Riffaud/ Marc Vuillermoz, Paris, 2004.

${ }^{78}$ Maurer, Karl: Goethe und die romanische Welt, Paderborn 1997, S. 223-241 hat in seinem Kapitel »Die verkannte Tragödie, die Wiedergeburt der Tragödie aus dem Geist der Pastorale« interessante gattungsgeschichtliche Überlegungen vorgetragen, in deren Mittelpunkt die Sophonisbe-Fassungen Trissinos, Mairets und Corneilles stehen. „Vor allem bot die [...] Sophoniba-Episode [...] die geradezu ideale Vorlage für eine Tragödie jenes neuen Typs, den die paratragische Pastorale vorbereitet hatte: ein Spiel um Liebeswerben, Liebesverbot und Liebeserfüllung, auf des Messers Schneide zwischen Leben und Tod, nur eben mit tragischem Ausgang « (S. 241) Maurer verweist darauf, dass die Liebeshandlung erst in den beiden letzten Akten zugunsten der Politik in den Hintergrund tritt. -- Man könnte Maurers Analysen und seiner Umbesetzung des pastoralen Schemas noch hinzufügen, dass die dramatische Konstellation, in der Sophonisbe an einem Tag zwischen zwei Gatten zu wählen hat, zugleich an das komische Motiv der Witwe von Ephesus erinnert. Corneille erst hat aus seiner Sophonisbe eine politisch agierende, starke Frau gemacht, während Voltaire die starke Sophonisbe und den zunächst schwankenden Massinisse zu ebenbürtigen Partnern gestaltet.

${ }^{79}$ Mairet hebt diese Änderungen im Vorwort hervor: "Le sujet de cette tragédie est dans Tite-Live, Polybe, et plus au long dans Appien Alexandrin. II est vrai que j'ai voulu ajouter pour l'embellissement de la pièce, et que j'ai même changé deux incidents de l'histoire assez considérables, qui sont la mort de Syphax, que j'ai fait mourir à la bataille afin que le peuple ne treuvât point étrange que Sophonisbe eût deux maris vivants, et celle de Massinisse, qui vécut jusques à l'extrême vieillesse. Les moins habiles doivent croire que je n'ai pas altéré I'histoire sans sujet, et les plus délicats verront, s'il leur plaît en prendre la peine, la défense de mon procédé dans Aristote. [...] Tant y a que je fais faire à Massinisse ce qu'il devait avoir fait, et que la fin de la tragédie étant la commisération, je ne la pouvais mieux treuver qu'en le faisant mourir... ¿ Die Schlussszene, Massinisse ersticht sich an der Bahre Sophonisbes, wurde m. W. in der Historienmalerei nie aufgegriffen. Dies gilt auch für die beeindruckende Szene, in der Sophonisbe und Massinisse sich nach der von Syphax verlorenen Schlacht begegnen.

${ }^{80}$ Maurer a.a.O., S. 248. 
fassung, die für sich in Anspruch nimmt, die familiarité comique ${ }^{81}$ zu tilgen, die sich durch die Verbindung von Liebe und Politik im Handlungsaufriss Mairets ${ }^{82}$ ergab. Voltaires Sophonisbe ist ein konsequent politischer Charakter, der die Liebe von Massinisse erst akzeptiert, als dieser sich auf die Seite Karthagos schlägt. Sie lässt sich in der dramatischen Schlussszene, als die Römer der punischen Verschwörung zuvorkommen, von Massinissa erstechen, der seinerseits Gift nimmt. An den Stücken Mairets, Corneilles und Voltaires, den in Europa wohl einflussreichsten Fassungen des Stoffes nach Trissino, Iassen sich die Spielräume ablesen, die der Stoff den frühneuzeitlichen Dramatikern bot: der Konflikt zwischen Liebesaffekt und Politik ließ bei den Hauptfiguren, Sophonisbe wie Massinissa, eine Reihe von Varianten zu, die alle Dramatiker sich zunutze machten. ${ }^{83}$ Daniel Caspar von Lohensteins (1635-1683) Sophonisbe (1680) nimmt im deutschen Barockdrama eine zentrale Stellung ein und thematisiert den Tod der Königin im Kontext der politischen Souveränität. ${ }^{84}$

Der Sophonisbe-Stoff wurde auch ein erfolgreiches Thema im Umkreis der frühneuzeitlichen Amadis-Romane. François de Soucy, sieur de Gerzan, veröffentlichte 1627 seine Histoire Afriquaine de Cléomède et de Sophonisbe, die Philipp von Zesen (1619-1689) als Afrikanische Sophonisbe (1647 und 1674) $)^{85}$ übersetzte. Auch eine anonyme niederländischen Version $D^{\prime}$ Afrikaanse Sofonisba ${ }^{86}$ (1661) liegt vor. Jacob Cats hat den Stoff in seinem die Ehe behandelnden populären

\footnotetext{
${ }^{81}$ Aus der Widmung an den Duc de la Vallière.

${ }^{82} \mathrm{Am}$ deutlichsten vielleicht in der Rücknahme des komischen Motivs, den Maitet im Altersunterschied von Syphax und Sophonisbe hervorgehoben hat. Voltaires Sophonisbe ist Syphax durchaus gleichwertig: "Je cherche autant que vous une mort glorieuse « $(I, 2)$.

${ }^{83}$ Auch im Elisabethanischen Theater wurde der Stoff aufgegriffen: John Marston (1576-1634), The Wonder of Women, or The Tragedy of Sophonisba (1606). Er fand Nachfolger in Nathaniel Lee (c. 1653-1692) mit Sophonisba, or Hannibal's Overthrow (1681) und James Thomson (1700-1748) mit The Tragedy of Sophonisba (1734)

${ }^{84}$ Barner, Wilfried: »Disponible Festlichkeit, Zu Lohensteins Sophonisbe«, in: Haug, Walther/ Warning, Rainer (Hrsg.): Das Fest, München 1989 (Poetik und Hermeneutik 14), S. 247-275. - Peter-André Alt ist in einer neueren Untersuchung auf den funktionalen Zusammenhang von politischer Souveränität, Körper und Geschlecht in der deutschen Literatur des 17. Jahrhunderts eingegangen (Der Tod der Königin, Frauenopfer und politische Souveränität im Trauerspiel des 17. Jahrhunderts, Berlin / New York 2004). Im Kapitel »Die Königin im Krieg « (S. 94-127) interpretiert er Lohensteins Inszenierungen des Todes der Sophonisbe und der Kleopatra als "geschichtsmetaphysisch-finalistisch « (S. 119); beide Königinnen seien als "Repräsentantin eines - aus der Geschichtsperspektive des Dramas - überlebten kulturellen Denkkreises « (S. 119) dargestellt und den Regeln einer »historischen Teleologie « (S. 123) unterworfen; deshalb fielen sie dem Finalismus der translatio imperii zum Opfer. Kleopatras Tod werde als »ästhetisches Ereignis «(S. 123), Sophonisbes Sterben als »eine Selbstverklärung des mythischen Denkens « (S. 123) inszeniert.

${ }^{85}$ Philipp von Zesen: Die afrikanische Sofonisbe, hrsg. von Volker Meid), Berlin 1972 (Sämtliche Werke, Bd. 6)

${ }^{86} \mathrm{http}: / /$ www.dbnl.org/tekst/buis006popu01/buis006popu01_1417.htm [zuletzt aufgerufen: 12.05.2008]) D'Afrikaanse Sofonisba ist 1661 bei I.I. Schipper in Amsterdam erschienen.
} 
Lehrgedicht Trouwring met den proef-steen (1657) behandelt. ${ }^{87}$ Die Beliebtheit des Themas belegt auch die Aufnahme einer rhetorisch ausgefeilten `Adresse Sophonisbes an Masinissa, die Madeleine de Scudéry in ihre Sammlung Les Femmes Illustres ou les Harangues Héroïques (1642) aufgenommen hat. $^{88}$

Hofmilieu, spannende Handlung und ergreifendes Ende machten den SophonisbeStoff auch zu einem geeigneten Vorwurf für Opernbearbeitungen. Doch bereitete der in der Oper übliche lieto fine Komponisten und Librettisten erhebliche Schwierigkeiten, musste doch auf überraschende Lösungen wie Milde und Einsicht des Scipio oder eine Begnadigung durch den römischen Senat zurückgegriffen werden, um den Selbstmord der afrikanischen Königin in ein glückliches, den Usancen der Renaissance- und Barockoper entsprechendes Ende abzuändern.

Die zahlreichen Sophonisbe-Opern ${ }^{89}$ sind noch kaum untersucht, so dass die folgende Aufzählung nicht vollständig sein kann: Luigi Riccoboni (1681), Antonio Caldara (1708 Venedig), Niccolò Jommelli (1746), Georg Gebel (1753), Tommaso Traetta (1762), Antonio Boroni (1764), Maria Teresa Agnesi Pinottini (1765) ${ }^{90}$, Christoph Willibald Gluck (1765) ${ }^{91}$, Ferdinando Paer (1806), Luigi Petrali (1844). Dazu kommen Opern, die Syphax zum Titelhelden gemacht haben: Nicola Porpora (1725), Gioacchino Cocci (1749), Ignazio Fiorillo (1752), Domenico Fischietti (1761), Pietro Allessandro Guglielmi (1802), Francesco Antonio Feo (1723). Schließlich sind konzertant aufzuführende Kammerkantaten (cantate da camera) wie "Sophonisbe or Hannibal's Overthrow« (1690) von Henry Purcell oder Christian

\footnotetext{
${ }^{87}$ Jacob $\mathrm{C}$ at s hat in den dritten Teil seines Lehrgedichts Trouwring met den proef-steen (im Folgenden zitiert nach der Erstausgabe bei Jan Jacobsz. Schipper, Amsterdam 1657, S. 172f.) Sophonisbe als Exempel ehelicher Treue aufgenommen (»Kort Verhael van het droevigh Trouw-geval tusschen twee vorstelicke persoonen; te weten den Koning Masanissa, en de Koninginne Sophonisba«). Die in Paarreimen nach Livius erzählte Episode ist mit einem Kupfer illustriert, auf dem Sophonisbe vor dem hereinreitenden Massinissa in die Knie fällt. Die Episode veranschaulicht eheliche Liebe: »Hoe dat de liefde speelt ontrent het wreede stael, / Ontrent den harden krijgh, en midden inde swaerden, / En midden in den woel van duysent felle paerden; / Op dat een yder mensch magh leeren dese wet, dat staegh op sijn gemoet is nut te zijn gelet. « Der Selbstmord Sophonisbes wird mit großer Hochachtung geschildert: »Hy nam een gulden kop, hy gaet de kruyden mengen, / hy laet het droef geschenk aen Sophonisbe brengen:/ Hy voeght' er woorden by, Doet als een Koningin, / Hier is uw leste troost, hier uw verlosser in. / So haest de jonge vrouw de bootschap heeft ontfangen, / Daer rees een bleyke verw ontrent haer rode wangen; / Maer des al niet-te-min sy nam den beker aen, / En toont dat sy het woort ten vollen heeft verstaen, / Is dit de bruylofts-gift de my te deser stonden / Van mijnen Bruydegom uyt liefde wert gesonden? / Is dit het schoonjuweel? Edoch ick been bereyt; / De Vorst die heeft gedaen gelijck' er was geseyt. / Mach ick niet na den eysch en als Prinçesse leven, / Soo will ick aen het graf my willigh overgeven; / Een dinck dat is my leet, dat ick als met de doot / Ontfing een tweede man tot mijnen bed-genoot. / Het woort is nau volënt, sy heeft den wij $n$ gedronken, / En wat'er boven dreef, en wat'er is gesoncken; / Daer bleef geen druppel in: sy leyt haer op het bed, / En wacht de bleecke doot en haer gestrenge wet. / Sy maekt geen los gebaer met eenich selsaem huylen, / Sy geeft haer uyt het volk, en gaet in 'tduyster schuylen: / En als het vinnich spook haer gaf de leste steeck, / So was het gansch verbaest dat sy niet eens en weeck. "Als weiteres Beispiel ehelicher Liebe und Treue folgen im Lehrgedicht Kleopatra und Antonius (S. 174-181).

${ }^{88}$ Leicht zugänglich über: http://www.gelahn.asso.fr/docs81.html (zuletzt aufgerufen: 12.05.2008).

${ }^{89}$ Erste Informationen bei http://www.operone.de (zuletzt aufgerufen: 14.01.2007).

${ }^{90}$ Nach einem Libretto von Giuseppe Maria Tomasi. Agnesi (1720-1795) scheint aber schon 1747 oder 1748 in Wien für Maria Theresia eine Sofonisba nach einem Libretto von Antonio Maria Zanetti aufgeführt zu haben.

${ }^{91}$ Es handelt sich um eine dem Fürsten Georg Christian Lobkowitz gewidmete Oper, die 1744 in Mailand (Regio Ducal Teatro) aufgeführt wurde. Die Rezitative stammen von Fr. Silvani, die Arien von Metastasio. Erhalten sind nur elf Arien und ein Duett.
} 
Gottlob Neefes Vertonung (1778) des Monodramas von August Gottlieb Meißner zu erwähnen.

Erst 1762 wagte es Tommaso Traetta (1727-1779), Sophonisbes Selbstmord auf die Opernbühne zu bringen, obwohl dies noch immer als regelwidrig galt. Traetta ${ }^{92}$ schockierte sein Mannheimer Hofpublikum nicht nur durch die Todesszene auf der Bühne (morte in scena), sondern verweigerte der Protagonistin auch die obligate Abgangsarie. ${ }^{93}$

Sophonisba haucht ihre letzten Worte als Accompagnato-Rezitativ in einer musikalischen Aposiopesis ohne formalen Schluss aus. Mit der Einführung eines Sohns der Sophonisbe steigerte Traetta ganz in der von Trissino begründeten theatralischen Tradition den sentimentalen Aspekt der Handlung. ${ }^{94}$ Das Kind versteht den Abschied der Mutter nicht (III,ix ${ }^{1}$ : "Madre, che faci mai? Lungi da te mi scacci. In che ti offesi? Ecco, se reo pur sono, ecco mi a piedi tuoi, madre perdoni. «) und hält sie in einem verzweifelten Arioso fest (III,ix ${ }^{2}$ : "Se non mi stringi al seno, / Lascia, che un baccio al meno / Molle di pianto il ciglio / sulla tua destra, o madre, imprima il figlio.«). Der Konflikt von Politik und Liebe wird akzentuiert, wenn Sophonisbe, das von Massinissa gesandte Gift in Händen, aus dem Palastfenster römische Soldaten Gefangene auf Schiffe verladen sieht (»Invano m'attendete, o superbi«). Der Antagonismus findet in der Verbindung martialischer Marschmusik der römischen Legionäre und Sophonisbes von Todeserwartung geprägter Arie musikalischen Ausdruck. Zu spät überbringen Massinissa, Syphax, Scipio und Laelius die Begnadigung durch den römischen Senat; die Szene mündet in einem Quintett (III, xi : "Ma piangete «) und der abschließenden Klage des Chors (III, $\mathrm{xi}^{2}$ : "Ah, d'Aletto - il core à in petto / Chi qui resta a ciglio asciutto! / A il furore in seno à tutto / Di Tisifonie, e Megèra / Chi resistere qui può!«).

Noch 1805 trug Ferdinando $\mathrm{Paer}^{95}$ in seiner zur Eröffnung des Teatro del Corso in Bologna komponierten Sofonisba der Forderung nach einem lieto fine Rechnung. In seinem »dramma serio per musica« lässt er eine Dienerin das für Sofonisba bestimmte Gift austauschen und fügt darüber hinaus einen Selbstmordversuch Massinissas hinzu, der ebenso vergeblich bleibt.

Das Libretto in zwei Akten von Domenico Rossetti ist schon deshalb bemerkenswert, weil es den tragischen Konflikt des Stoffes moralisierend und geradezu biedermeierlich auflöst. Es darf deshalb als Dokument dafür gelten, dass sich dem Stoff keine neue Sinnkonfiguration mehr abgewinnen ließ. Im ersten Akt ist Sofonisba bereit, Massinissa zu heiraten, um inn auf die karthagische Seite zu ziehen.

\footnotetext{
92 Die Schreibweisen variieren: Traetta, Traëtta und Trajetta.

${ }^{93}$ Vgl. Riedlbauer, Jörg: Die Opern von Tommaso Trajetta, Hildesheim/Zürich/New York 1994, S. 180-185 und Horschansky, Klaus: »Tommaso Traetta: Sofonisba«, in: Pipers Enzyklopädie des Musiktheaters, Bd. 6, hrsg. von Dahlhaus, Carl, München 1997, 315-318. Die Oper wurde 2006 vom Nationaltheater Mannheim wieder aufgeführt. Das Programmheft reproduziert die deutsche Übersetzung des Textbuches von 1762 und Einzelpassagen des italienischen Originaltextes.

94 Dem Opernbegleitheft ist zu entnehmen, dass die Aufführung im Jahre 1762 den Sohn noch als stumme Figur führte; zur Wiederaufführung ein Jahr später wurde der Sohn mit zwei Arien und einem Rezitativ ausgestattet, um einen neuen Anreiz zum erneuten Besuch des Opernhauses zu bieten (Opernbegleitheft der Mannheimer Aufführung 2006, S. 59).

${ }^{95}$ Vgl. Brzoska, Matthias: »Ferdinando Paer: Sofonisba, Dramma serio per musica«, in: Pipers Enzyklopädie des Musiktheaters, Bd. 4, hrsg. von Dahlhaus, Carl, München 1991, $626 f$.
} 
Der vermeintlich gefallene Siface wird als römischer Gefangener in den Palast gebracht und schwört, an seiner Gattin Rache zu nehmen. Der zweite Akt bringt die Wendung: Im Anblick ihrer beiden Kinder versöhnen sich Sofonisba und Siface. Massinissa wird überwältigt, als er aus Eifersucht Siface töten will, doch rettet das Eingreifen Scipiones sein Leben. Der Selbstmordversuch der Königin, über den Siface und Scipione entsetzt sind, lässt sich auf diese Weise allerdings nicht mehr handlungslogisch begründen, scheitert aber ohnehin am Eingreifen der Dienerin. Scipione gibt Siface und Sofonisba Freiheit, Besitz und Thron zurück. Massinissa wird von Lelio am Selbstmord gehindert und tritt dem Freundesbund bei. Die moralische Selbstbehauptung, die die Figur der Sofonisba in der Frühen Neuzeit interessant machte, hat sich in dieser Fassung völlig verloren und die Tragik liegt eher auf der Seite Massinissas, der deshalb in einigen Aufführungen zur Titelfigur wurde. Zu dieser Umbesetzung passt es, dass Scipione die Züge eines spätaufklärerischen Herrschers annimmt.

Bereits den Zeitgenossen und den Rezensenten ${ }^{96}$ galt das Ende als konstruiert; nur zehn außeritalienische Aufführungen sind belegt.

Gelegentlich wurden auch Monodramen vertont. So hat Christian Gottlob Neefe das Monodrama ${ }^{97}$ Sophonisbe (1776) von August Gottlieb Meißner teilweise in Musik gesetzt. Die Erstaufführung fand 1778 im Mannheimer Nationaltheater statt, wo schon die Oper von Traetta aufgeführt worden war; dieser Hof scheint am Thema Gefallen gefunden zu haben. Im folgenden Jahr fand am Darmstädter Hof eine Aufführung unter der musikalischen Leitung des Erbprinzen Ludwig X. statt, bei der die Erbprinzessin Luise von Hessen-Darmstadt in der Titelrolle auftrat. ${ }^{98}$ Neefe hat allerdings nur die Monologe vertont. Unterschiedliche Bezeichnungen wie »Musikalisches Drama mit historischem Prolog und Chören« (Textbuch), »Drama mit musikalischer Begleitung « (Autograph), »Drama« (Darmstädter Partitur von 1779) und »Monodrama « (Klavierauszug) zeigen an, dass es sich um eine instabile späthöfische Mischgattung mit deutlicher Nähe zur Attitüde handelte. Bekanntlich führte Lady Hamilton auch Sophonisbe als Attitüde auf. ${ }^{99}$

\section{Ikonographische Entwicklung in der Frühen Neuzeit}

Da Boccaccios historisch-mythographische Enzyklopädien ${ }^{100}$ von Gelehrten, Literaten und Künstlern eifrig als Nachschlagewerke genutzt wurden, wirkten die Illustrationsholzschnitte des ersten Drucks von De claris mulieribus prägend auf die Ikonographie antiker Frauengestalten in der Frühen Neuzeit. Boccaccios Kompendium bedeutender Frauen ${ }^{101}$ erschien 1473 in der Ulmer Offizin des Frühdruckers Johannes Zainer ${ }^{102}$, zunächst in einer lateinischen Ausgabe, ein Jahr später auch in der deutschen Übersetzung des Humanisten Heinrich Steinhöwel. Beide Drucke

\footnotetext{
${ }^{96}$ Die vernichtende Kritik von E. T. A. Hoffmann unterstreicht die auch musikalische Epigonalität (vgl. Broska, Matthias, a.a.O., S. 627).

${ }^{97}$ Siehe unten S. 290.

${ }^{98}$ Schwarz, Monika: »Neefe: Sophonisbe (1778)«, in: Pipers Enzyklopädie des Musiktheaters, Bd. 4, hrsg. von Carl Dahlhaus, München 1991, S. $401 f$.

${ }^{99}$ Vgl. unten S. 297.

100 Genealogia deorum, De casibus virorum illustrium, De claris mulieribus.

101 Siehe oben S. 66

102 Koschatzky, Walter: Die Kunst der Graphik, Technik, Geschichte, Meisterwerke, München ${ }^{11} 1993$, S. 71.
} 
waren mit denselben 79 Holzschnitten eines unbekannten Holzschneiders prächtig ausgestattet. ${ }^{103}$ Die Nähe früher Drucke zu kolorierten Handschriften zeigt sich darin, dass die Holzschnitte ursprünglich farbig ausgemalt werden sollten: Neben den Abbildungen bleibt häufig Platz für Schmuckinitialen und Rubrizierungen. ${ }^{104}$

Der die Geschichte der Sophonisbe [Abb. 2] illustrierende Holzschnitt ${ }^{105}$ teilt das Geschehen in zwei Phasen. Auf der rechten Seite sind Massinissa und Laelius in eine heftige Diskussion vertieft. Laelius scheint eben erst eingetroffen zu sein und trägt noch Rüstung und Standarte. Der elegant-höfisch gekleidete Massinissa tritt mit einem Schwert als Zeichen seiner königlichen Würde auf und beantwortet die fordernde Geste des Laelius mit einer abweisenden Handbewegung. Die linke Seite des Holzschnitts zeigt eine von der ersten Szene nicht geschiedene, durch die Beschriftung aber deutlich erkennbare zweite Szene. Ein höfisch gekleideter Bote fasst sich verzweifelt an den Kopf, während er Sophonisbes beobachtet, die den Becher an die Lippen geführt hat und sich nach hinten beugt, um ihn in einem Zug leeren zu können.

Viele der Zainerschen Holzschnitte

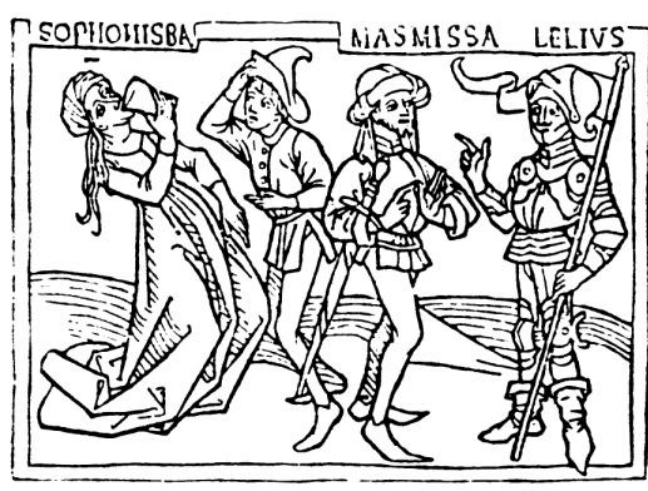

Abb. 2 zu De claris mulieribus illustrieren den Text mit Abbildungen, die mehrere Szenen verbinden. ${ }^{106}$ In der späteren Ikonographie der Sophonisbe wurde die Debatte zwischen Massinissa und Laelius nur noch selten wiedergegeben. ${ }^{107}$ Die Gesprächssituation stellte sich als zu beliebig heraus, um beim Betrachter einen eindeutigen Bezug auf Sophonisbe herzustellen, sobald der unmittelbare Zusammenhang von Wort und Bild entfiel. ${ }^{108}$ So reduzierte sich das ikonographische Muster der Sophonisbe-Darstellung bald auf die Szene, in der sie das Gift trinkt. Darstellungen

\footnotetext{
${ }^{103}$ Unpaginierter Nachdruck: Boccaccios Buch der berühmten Frauen, mit 79 Holzschnitten der Ausgabe von Joh. Zainer, Ulm, 1473, hrsg. von Simon Hoepfl, München 1924.

${ }_{104}$ In einem Exemplar des Zainerschen Drucks findet sich eine kolorierte Kleopatra (vgl. S. 145).

${ }^{105}$ Vgl. Katalog 11.

106 Die Illustrationen zu Boccaccios De claris mulieribus sind bei Bartsch (80, 8073, 334-375) zusammengestellt. So ist auch die Geschichte Lukretias in zwei Szenen (Vergewaltigung durch Tarquinius und Selbstmord in Anwesenheit der männlichen Verwandten) gegliedert (Bartsch 80, 8073, 338). Die Geschichte der Porzia (Bartsch 80, 8073, 363) ist sogar in drei Szenen (Selbstverletzung Porzias, Ermordung Cäsars und Selbstmord) aufgeteilt.

${ }^{107}$ Eine Ausnahme bildet ein Cassone von Bernardino Fungai (vgl. Katalog 137), der neben der (ganz links angeordneten) Todesszene noch ein Gespräch Scipios mit Laelius und Syphax zeigt, dem die Braut versprochen wird. Rechts daneben bedeutet in einer zweiten Szene Scipio dem Massinissa, auf Sophonisbe zu verzichten, da sie die Verlobte des Syphax sei.

${ }_{108}$ Vgl. Willems, Gottfried: Anschaulichkeit, Zu Theorie und Geschichte der Wort-Bild-Beziehungen und des literarischen Darstellungsstils, Tübingen 1989, S. 54.
} 
ohne erläuternden Text verlangten einen eindeutigen »ikonologischen Code «, der die Sophonisbe-Episode auf den entscheidenden und sinntragenden Augenblick reduzierte.

Eine solch verdichtende Reduktion der Geschichte Sophonisbes auf das Trinken des Giftbechers erfolgt bereits in einer grisailleartigen Darstellung, die

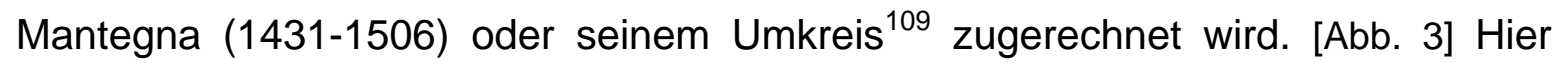
führt eine isoliert stehende Sophonisbe mit der Rechten einen Pokal an die Lippen. Im Gegensatz zu ihrem frontal gegebenen Körper ist das Gesicht ins Profil gewendet, um das Trinken des Gifts zu akzentuieren.

Dass Sophonisbe bereits zu diesem Zeitpunkt in eine Serie exemplarischer Frauen der Antike gehörte, scheint eine weitere, ebenfalls in der Londoner Nationalgalerie befindliche Grisaille aus der gleichen Reihe nahezulegen, die die Vestalin Tuccia präsentiert. Die in Tempera auf Pappelholz ausgeführten Frauengestalten imitieren vergoldete Bronzeskulpturen, die vor gemalten Marmorhintergrund gesetzt sind. Die gemalten Skulpturen waren Teil einer Wandverkleidung und dienten als Klappläden zum Verdunkeln von Fenstern. Da Isabella d' Este in ihrem Studierzimmer bronzi finti von Mantegna besaß, dürften die beiden erhaltenen Grisaillen

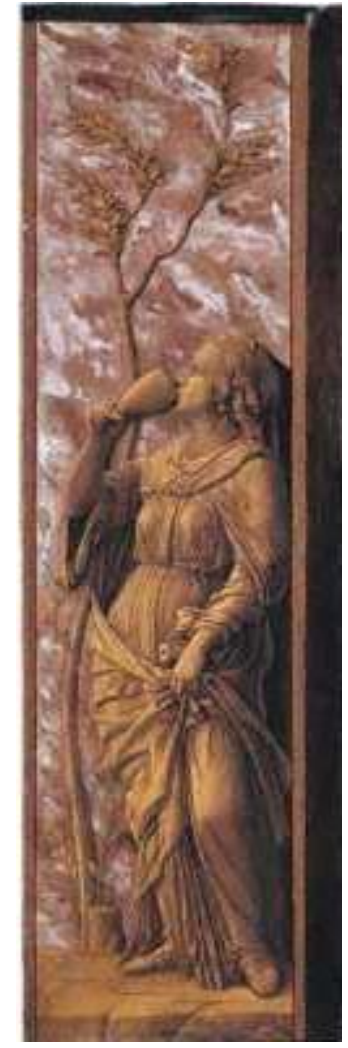

Abb. 3 aus dieser Folge stammen. ${ }^{110}$ Unter mehreren Gesichtspunkten sind beide für die spätere ikonographische Entwicklung der Darstellung Sophonisbes interessant: Sophonisbe wird bereits in eine Serie aufgenommen und das Motiv ist schon so bekannt, dass es auf das Trinken des Giftbechers verkürzt noch erkannt wird.

Dies bestätigen zwei andere aus dem gleichen Zeitraum stammende Serien ${ }^{111}$ der Sieneser Sammlung Chigi-Saracini, in denen Sophonisbe ebenfalls mit dem Giftbecher eingeführt wird: In der Serie des >Maître des héroïnes de Chigi-

\footnotetext{
${ }^{109}$ Vgl. Katalog 227 (Sophonisbe). Im Katalog der National Gallery von 1986 (Braham, Allan [Hrsg.]: Illustrated General Catalogue, London ${ }^{2} 1986$, S. 350, Nr. 1125 B) werden beide in London befindliche Grisaillen (auch Katalog 228: Tuccia) noch dem Umkreis Mantegnas zugerechnet, während sie in der Neubearbeitung des Kataloges (Baker, Christopher / Henry, Tom [Hrsg.]: The National Gallery, Complete Illustrated Catalogue, London 1995, S. 407) Mantegna (um 1495-1506) selbst zugesprochen werden.

${ }^{110}$ Ich komme unten, S. 240, auf das Bild zurück. Vgl. im Übrigen: Christiansen, Keith: »The Studiolo of Isabella d'Este and late themes «, in Martineau, Jane (Hrsg.): AK Andrea Mantegna, London / New York 1992, S. 394-468.

${ }^{111}$ Näheres unten S. 242
} 
Saracini findet sich Sophonisbe ${ }^{112}$ neben Kleopatra und Judith. ${ }^{113}$ Sie steht dem Betrachter frontal gegenüber und weist mit der Rechten auf den Pokal in ihrer Linken. Der von Perugino und Pinturicchio beeinflusste Maler hat wie seine anderen Frauenfiguren auch Sophonisbe ganzfigurig in eine heitere Landschaft gesetzt. [Abb. 4] Zwei Bäume im Hintergrund deuten ihren vorzeitigen Tod symbolisch an, da nur ein Baum frühlingshaft belaubt, der andere aber kahl ist. In einer anderen Serie der gleichen Sammlung lässt Domenico Beccafumi (1486-1551) [Abb. 5] die ins Profil gewendete Sophonisbe ${ }^{114}$ mit der Rechten eine zum Himmel weisende Geste ausführen, während die Linke das Trinkglas hält. Auch hier erscheint Sophonisbe bereits in einer Reihe bekannter Heroinen: neben Kleopatra und

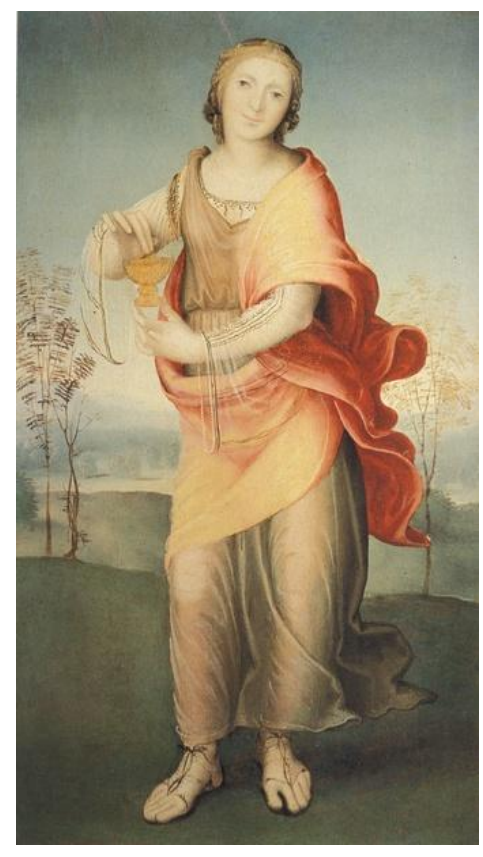

Abb. 4

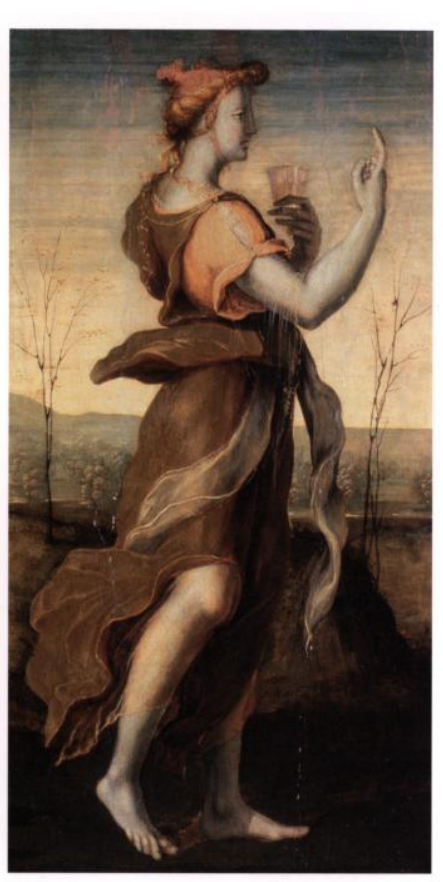

Abb. 5

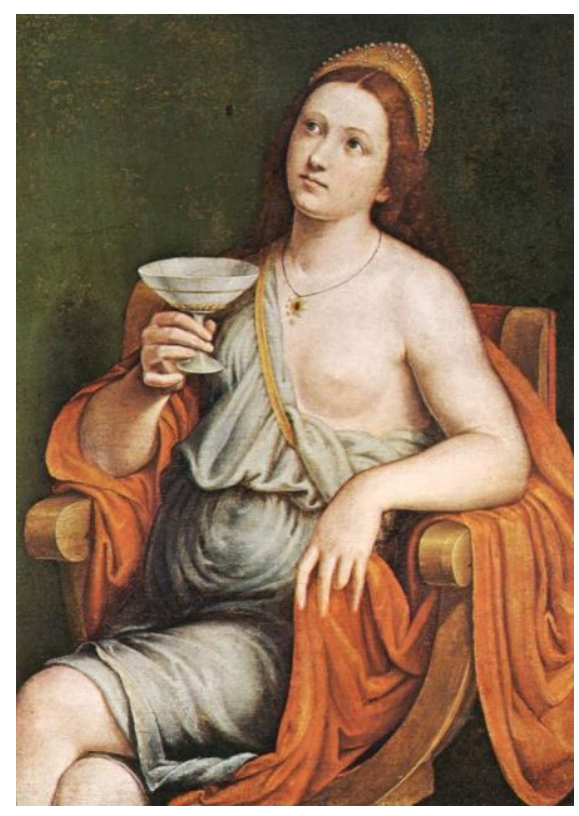

Abb. 6

Judith ${ }^{115}$ kann noch eine Lukretia für die um 1508 entstandene Serie angenommen werden.

Seit Beginn des 16. Jahrhunderts scheint sich neben der IStehfigurı auch die sitzende Darstellung Sophonisbes als ikonographisches Muster durchzusetzen. Die wohl zu keiner Serie gehörende Sophonisbe [Abb. 6] des Giovanni Francesco Caroto $(1488-1562)^{116}$ stellt die Königin bereits sitzend und nicht mehr stehend

\footnotetext{
112 Vgl. Katalog 221.

113 Vgl. Richard-Jamet, Céline: „Cléopâtre: Femme forte ou femme fatale? Une place équivoque dans les galeries de Femmes fortes aux XVI ${ }^{e}$ et XVII ${ }^{e}$ siècles«, in Ritschard, Claude / Morehead, Allison (Hrsg.): AK Cléopâtre dans le miroir de l'art occidental, Genève 2004, S. 37-52.

114 Vgl. Katalog 26.

${ }^{115}$ Vgl. Richard-Jamet (wie Fußnote 113), S. 40.

${ }^{116}$ Katalog 59.
} 
dar; Sophonisbe hält gelassen und nachdenklich ein edles Trinkgefäß in der Rechten. Weiterhin gilt den Künstlern die Darstellung der Giftbecher-Szene als das Motiv, das am effektvollsten die von Alberti geforderte kunstvolle Zusammenfassung der Episode (rerum copia et elegantia) erlaubte. ${ }^{117}$ Die graphischen Darstellungen des 16. Jahrhunderts übernehmen deshalb meist dieses Thema. Dazu gehören der anonyme Holzschneider ${ }^{118}$ des Mainzer Livius-Drucks von 1557, aber auch Georg Pencz ${ }^{119}$ (um 1535), Heinrich Aldegrever ${ }^{120}$ (1553) [Abb. 7] und Jost Am$\operatorname{mann}^{121}$ (1570) [Abb. 8].

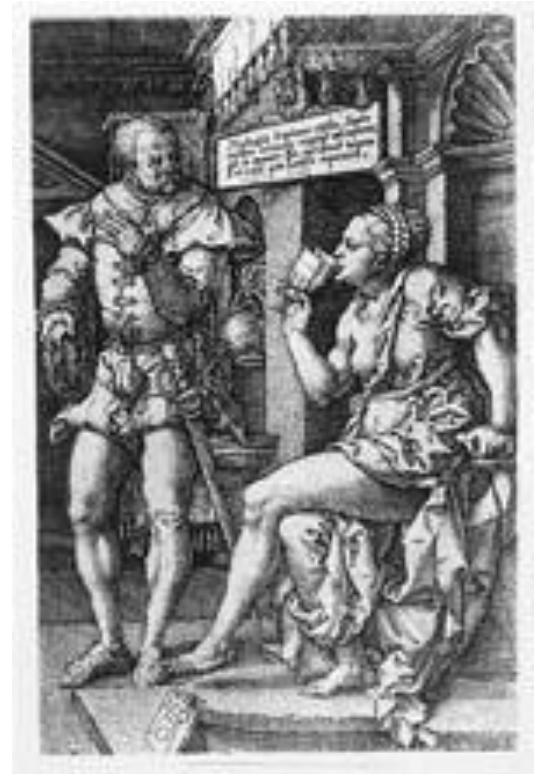

Abb. 7

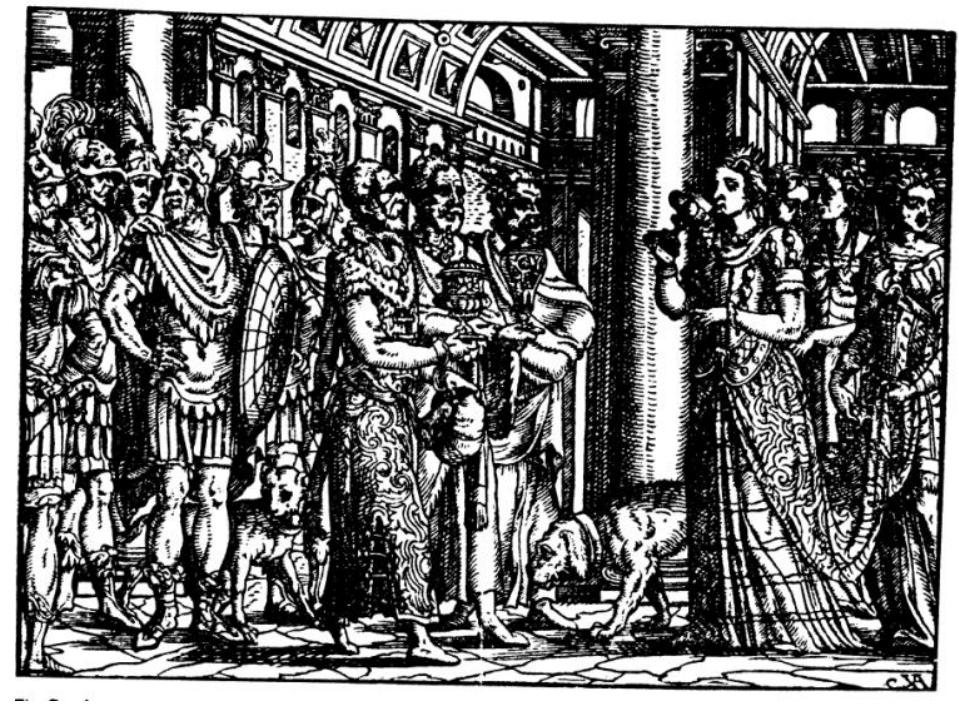

Abb. 8

Lateinische und volkssprachliche Drucke des Livius ${ }^{122}$, vor allem aber die Adaptierungen Petrarcas und Boccaccios hielten die Geschichte der Sophonisbe in mehrfacher Weise präsent; die Künstler konnten ihre Kenntnis beim Betrachter voraussetzen. Das Szenario wurde nun in einen privaten Rahmen mit einer vereinzelten Protagonistin oder in einen öffentlichen Raum mit Hofstaat verlegt. Den hohen Status der Königin betonen Pencz und Aldegrever dadurch, dass Sophonisbe

\footnotetext{
117 „Summum pictoris opus historia, in qua quidem omnis rerum copia et elegantia adesse debet«. (〉Die höchste Aufgabe des Malers ist die Geschichte, in der sich freilich die ganze Stoffülle und feiner Geschmack zeigen muss.ı) (Alberti, L. B.: De pictura, 1435, Basel 1540 [Neudruck Portland 1972], S. 60).

${ }^{118}$ Katalog 413.

119 Katalog 267.

120 Katalog 3.

121 Katalog 6.

122 Vgl. Brunhölzl, Franz / Düchting, Reinhard: »Livius «, in: Lexikon des Mittelalters, Bd. 5, Sp. 2043-2045. Die editio princeps des Livius war 1469 in Rom erschienen. Zur weiteren Rezeption des Livius vgl. Worstbrock, Franz J.: Verzeichnis der deutschen Übersetzungen antiker Autoren, mit einer Bibliographie der Übersetzer, Boppard 1976; außerdem Rieks, Rudolf: "Zur Wirkung des Livius vom 16. bis zum 18. Jahrhundert«, in Lefèvre, Eckard / Olshausen, Eckart (Hrsg.): Livius, Werk und Rezeption, Festschrift für Erich Burck zum 80. Geburtstag, München 1983, S. 367-397.
} 
unter einem Baldachin auf einem Thron sitzt, während der Bote steht. Die Ehrerbietung ausdrückende stehende Haltung des Boten, der mit gezogenem Hut seine Reverenz erweist, demonstriert elegantia. Die sich in einem großen Hofstaat manifestierende Machtfülle der Regentin bildet den starken Gegensatz zur inneren Notsituation der politischen Verliererin.

Während Boccaccio die historiographische Tradition des Livius weiterführte, akzentuierte Petrarca sowohl im italienischen Triumphus Amoris als auch in der lateinischen Africa die Sophonisbe-Episode als Liebesromanze und machte Sophonisbe und Massinissa zu einem seiner exemplarischen Liebespaare. Diese Traditionslinie griffen im 16. Jahrhundert allerdings nur wenige Künstler auf: Zu nennen sind einige Cassoni ${ }^{123}$, auf denen im Triumphzug des Amor zusammen mit mythologischen Liebespaaren wie Pyramus und Thisbe auch historische Paare wie Pompejus und Cornelia, aber auch Sophonisbe und inr zweiter Mann dargestellt sind. In diese Tradition scheint mir auch die Arbeit des Bildhauers und Medailleurs Hans Kels des Älteren (um 1480-um 1559) zu gehören: sein in Holz gearbeitetes Spielbrett »Für den langen Puff « (heute in Wien) ${ }^{124}$ zeigt auf einem Spielstein Sophonisbe, die den eben vom Boten erhaltenen Giftbecher trinkt. Hans Kels d. Ä. hat

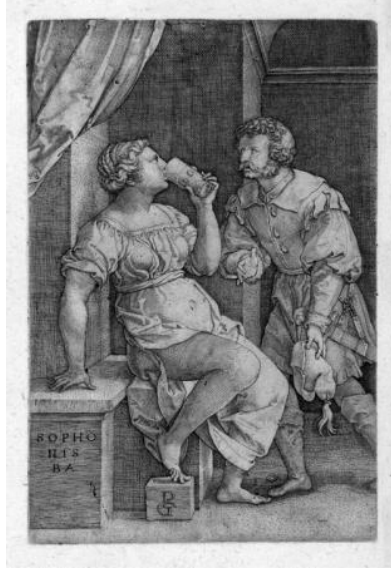

Abb. 9

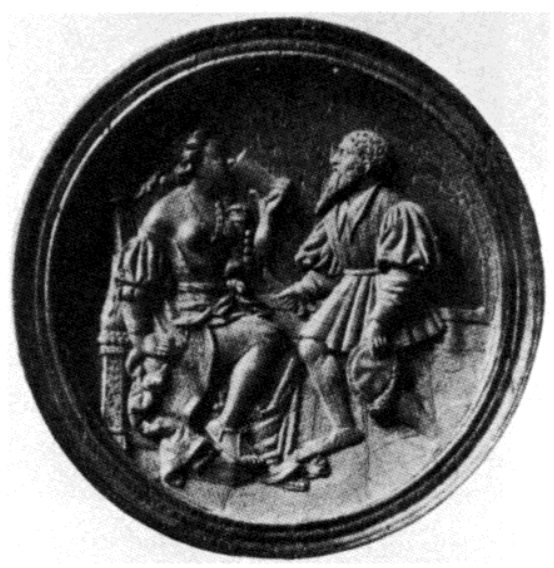

Abb. 10

zwar den um 1535 entstandenen Kupferstich von Pencz ${ }^{125}$ [Abb. 9] als Vorlage genommen, den Boten des Kupferstichs aber in Massinissa umgedeutet und so Sophonisbe zusammen mit dem afrikanischen König unter die imponierenden Lie-

\footnotetext{
${ }^{123}$ Vgl. Pigler, a.a.O., S. 20, und Schubring, Paul: Cassoni, Truhen und Truhenbilder der italienischen Frührenaissance, Leipzig 1923, Katalog Nr. 485 und Tafel 115. Näheres zu den Cassoni unten S. 123, Anm. 35.

${ }^{124}$ Es wurde im Jahre 1537 signiert. Vgl. Leithe-Jasper, Manfred / Distelberger, Rudolf: Kunsthistorisches Museum Wien, Schatzkammer und Sammlung für Plastik und Kunstgewerbe, München 1982, S. 79 (Abbildung) und Planiscig, L. / Kris, E.: Katalog der Sammlungen für Plastik und Kunstgewerbe (Führer durch die Kunsthistorischen Sammlungen in Wien), Wien (Kunsthistorisches Museum) 1935, S. 38, Nr.10.

${ }^{125}$ Vgl. Fußnote 119.
} 
besgeschichten aus Antike und Mittelalter eingereiht, die auf den 32 Spielsteinen [Abb. 10] vorgeführt werden. ${ }^{126}$

Am Ende des 15. Jahrhunderts und zu Beginn des 16. Jahrhunderts gab es also zwei Darstellungsvarianten Sophonisbes: eine stützt sich auf die von Boccaccio aufgegriffene historiographische Überlieferung ${ }^{127}$, die andere deutet, Petrarca folgend, Sophonisbe als große Liebende. Entsprechend wechselt der sikonologische Code ${ }^{128}$ für die Figur Sophonisbe. Die historiographische Variante stellt meist das Trinken des Gifts ${ }^{129}$ dar und gibt diese Szene oft ganzfigurig; sie genügte offenbar, um beim Betrachter die komplexe Geschichte ${ }^{130}$ der Sophonisbe aufzurufen. Wird - wie bei Tobias Stimmer - das Gewicht der Illustrationen auf die Hauptund Staatsaktionen des Zweiten Punischen Krieges gelegt, fokussieren sich die Livius-Illustrationen auf Syphax als unterliegenden König. ${ }^{131}$ Sophonisbe wird dann als vor Massinissa kniefällig Bittende und nicht als politisch Agierende gezeigt. Die sromantischer Akzentuierung des Petrarca aufnehmend kann Sophonisbe aber auch als große Liebende gedeutet werden. Dann tritt sie im engen Anschluss an den Text des Petrarca zusammen mit Massinissa auf. ${ }^{132}$ Diese Variante hat bei Kels zu einem Missverständnis geführt. Er übernahm die sromantische` Deutung Petrarcas und interpretierte seine Vorlage, den die historiographische Variante bietenden Kupferstich von Pencz falsch: der Bote im Kupferstich wird als Massinissa aufgefasst. Entsprechend erscheint auf dem Spielstein anstelle der Königin mit dem Überbringer der Todesbotschaft ein romantisches Liebespaar.

\footnotetext{
${ }^{126}$ Zum Spiel vgl. Thieme, U. / Becker, F.: Allgemeines Lexikon der bildenden Künstler von der Antike bis zur Gegenwart, Leipzig 1929/1930 (ND München / Leipzig 1992), Bd. 19/20, S. 127-129.

127 Anregungen verdanke ich, auch wenn ich der Hauptthese nicht folgen kann, dem Aufsatz von Tümpel, Christian: »Bild und Text: Zur Rezeption antiker Autoren in der europäische Kunst der Neuzeit (Livius, Valerius Maximus) «, in Schlink, Wilhelm / Sperlich, Martin (Hrsg.): Forma et subtilitas, Festschrift für Wolfgang Schöne zum 75. Geburtstag, Berlin / New York 1986, S. 198-218.

128 Der Begriff nach Willems, Gottfried: Anschaulichkeit, Zu Theorie und Geschichte der Wort-BildBeziehungen und des literarischen Darstellungsstils, a.a.O., S. 54.

${ }^{129}$ Hier widerspreche ich Christian Tümpel, der die Auffassung vertritt, »bei vielen Themen« habe »sich schon im Mittelalter die Bildtradition vom wörtlichen Text gelöst«. »In dichterischer Phantasie « seien »Motive hinzugefügt worden, von denen der Text nichts berichtet. «(a.a.O., S. 205) Die Darstellungen folgen stets Livius (vgl. Fußnote 159).

130 »Die erste und wichtigste Aufgabe des Kunstwerks ist [...], eine Geschichte vorzuführen. Diese Geschichte galt es aus zuverlässigen literarischen Quellen auszuwählen, die entweder geistlich oder weltlich sein konnten. [...] dieser neue Begriff von istoria [sollte] ikonographische Überlegungen für länger als dreihundert Jahre beherrschen [...]«. (Bialostocki, Jan: »Skizze einer Geschichte der beabsichtigten und interpretierenden Ikonographie « in Kaemmerling, E. [Hrsg.]: Bildende Kunst als Zeichensystem, Köln 1979, S. 15-63, hier S. 27.)

${ }^{131}$ Druck von 1568, vgl. Katalog 386.

132 Diese sromantischer Deutung, die den Akzent auf das Liebepaar Massinissa und Sophonisbe legt, wird von der Historienmalerei, die meist auf den Konflikt von Liebe und Politik abhebt, nur selten aufgegriffen. Vgl. unten S. $97 \mathrm{ff}$
} 
IV Liebe, Patriotismus und Selbstbestimmung: Sophonisbe als Tugendheldin

\section{Ikonographie der Historienmalerei}

Christian Tümpel vertritt die Auffassung, die Sophonisbe-lkonographie des Barock sei durch Buchillustrationen und Graphik der Frühen Neuzeit geprägt. ${ }^{133}$ Träfe seine These zu, müsste allerdings auch in der Historienmalerei das Trinken des Giftbechers im Mittelpunkt stehen; gerade dies ist aber nicht der Fall. ${ }^{134}$ Wahrscheinlich ist der Einfluss der Bühnenbearbeitungen des Sophonisbe-Stoffes für die Ikonographie entscheidender. Diesen folgend wählten die Historienmaler des 17. und 18. Jahrhunderts ihren Vorwurf und das punctum temporis der Bilddramaturgie: oft die Szene ${ }^{135}$, in der Sophonisbe durch einen Boten die Nachricht Massinissas und den Giftbecher erhält, oder - noch häufiger - eine Audienzszene, in der die afrikanische Königin dem Boten ruhig Gehör schenkt. Dabei kann Sophonisbe als einsame Heroine oder als Regentin mit Hofstaat dargestellt werden. Ausnahmsweise findet sich auch eine Sterbeszene. ${ }^{136}$ Im Gegensatz zur frühen Graphik tritt das Trinken des Giftbechers nicht mehr auf.

Die Historienmalerei hat zwei Grundtypen der Darstellung Sophonisbes entwickelt: einerseits die isolierte ganzfigurige oder halbfigurige Darstellung der afrikanischen Königin, andererseits die szenische Umsetzung einer Episode aus der Geschichte Sophonisbes.

In der um 1642 von Nicolas Prévost (1604-1670) ausgeführten Serie ${ }^{137}$ ıstarker Frauen`, die eine Wand des Schlosses Richelieu paneelenartig dekorierte, erscheint Sophonisbe [Abb. 11] - wie die sechs anderen Tugendheldinnen stehend

\footnotetext{
${ }^{133}$ A.a.O., S. 205.

134 In der Sammlung Chigi-Saraceni findet sich ein möglicher Übergang. Auf den Gemälden des Maître des heroïnes de Chigi-Saraceni und Beccafumis wird der (nicht mehr getrunkene) Giftbecher bereits zum Attribut (vgl. unten, S. 242ff.).

135 Tümpel verwendet für diesen Bildtypus den nicht recht geeigneten Begriff »Erkenntnisszene «.

136 Tümpels These, das "Zueinander von Literatur [gemeint ist Livius] und bildender Kunst « müsse neu beschrieben werden (a.a.O., S. 218), hat inm den Blick für Veränderungen des ikonologischen Codes zwischen dem 16. und 17. Jahrhundert verstellt. Das Hauptinteresse seiner Abhandlung ist es, die Darstellungen der Artemisia und der Sophonisbe durch ihre Attribute und ikonologischen Codes zu unterscheiden. Dabei verlor Tümpel aus dem Blick, dass in der Graphik des 15. und 16. Jahrhunderts Sophonisbe emblematisch mit dem Trinken des Gifts dargestellt wurde, während den Historienmalern des 17. und 18. Jahrhunderts eine weitaus größere Bandbreite an Darstellungsmöglichkeiten zur Verfügung stand. Die literarische Entwicklung des Stoffes auf der Bühne (und später als Opernsujet) hatte eine facettenreiche Figur und eine differenzierte Konfliktpalette herausgebildet. Die Darstellung des historischen Stoffes auf der Bühne hat den ikonologischen Code in viel stärkerem Maße beeinflusst, als dies die Graphik der beginnenden Neuzeit vermochte. Es bleibt allerdings auffallend, dass die interessante Invention der Bühne, Sophonisbe als Mutter von einem oder mehreren kleinen Kindern auftreten zu lassen und so Emotionen und Mitleid der Rezipienten stark zu schüren, nach meiner Kenntnis im Historiengemälde nur zweimal, von Manetti und Crosato, aufgegriffen wurde (vgl. unten, S. 97f.).

${ }^{137} \mathrm{Vgl}$. unten S. 173ff. Zu der Serie gehörten Kleopatra, Judith, Artemisia, Dido, Thomyris, die Frau des Hasdrubal und Sophonisbe. Vgl. Richard-Jamet, Céline: „Cléopâtre: femme forte ou femme fatale, une place équivoque dans les galeries de femmes fortes aux XVI et XVII ${ }^{e}$ siècles «, in: AK Cléopâtre dans le miroir del'art occidental, a.a.O., S. 37-52, hier S. 42. Außerdem Schloder, M. John E.: »Un artiste oublié, Nicolas Prévost, peintre de Richelieu«, in: Bulletin de la Société de l'histoire de l'art français, (1980), Paris 1982, 59-69.
} 
- mit einem Trinkgefäß in der Hand. ${ }^{138}$ Die auf Fernwirkung kalkulierte Serie ganzfiguriger sstarker Frauen setzt den Giftbecher, dem Attribut einer Heiligen vergleichbar, als Identifizierungshilfe ein. Von der Ausnahme der Serien sstarker Frauenı abgesehen, wählen die Künstler bei isolierten Darstellungen Sophonisbes meist die Halbfigur. Die Sophonisbe [Abb. 12] von Nicolas

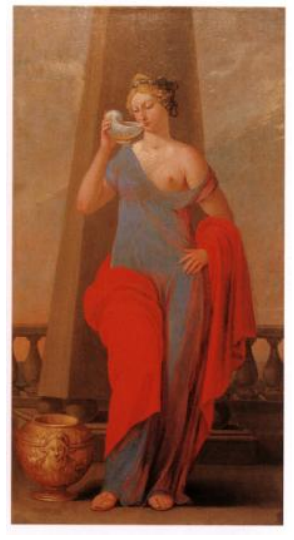

Abb. 11

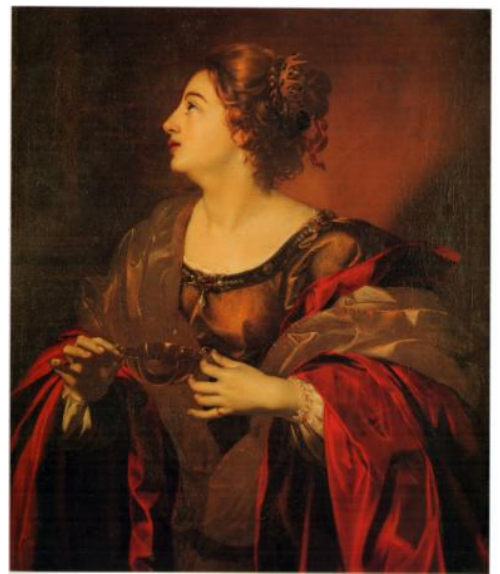

Abb. 12

Régnier (1591-1667) beispielsweise wendet ihr Gesicht nach links ins Profil, wodurch das Krönchen als Hoheitszeichen sichtbar wird, und hält mit beiden Händen eine goldene Trinkschale. ${ }^{139}$

Markant und sinngebend ist der Augenaufschlag, der den von Raffael für religiöse Historienmalerei geprägten shimmelnden` Blick ${ }^{140}$ ins profane Historienbild übernimmt. Ob der nach oben gleitende Blick Verzweiflung, Schicksalsergebenheit oder Todessehnsucht ausdrückt, bleibt dem Betrachter überlassen. Die Hände halten die Trinkschale in elegant-zierlicher Manier, ohne dass eindeutig zu bestimmen wäre, ob Sophonisbe das Gift bereits getrunken hat oder sich erst im nächsten Augenblick dazu anschicken wird. Gerade die Unentschiedenheit der Geste und die Unbestimmtheit des innere Ergriffenheit signalisierenden Blicks verdeutlichen, dass vom Betrachter des Bildes zwar nicht »Betrachtungsfrömmigkeit « ${ }^{141}$ wie bei Heiligenbildern, aber doch ein meditierendes Sich-Einlassen auf den Gemütszustand der Dargestellten erwartet wird.

Guido Reni (1575-1642), als dessen Markenzeichen der shimmelnder Blick von Heiligen bezeichnet werden kann ${ }^{142}$, hat zweien seiner drei Sophonisben ${ }^{143}$ eben diesen `Seelenblickı gegeben. Das heute in Birmingham gezeigte Bild [Abb. 13],

\footnotetext{
${ }^{138}$ Vgl. Katalog 292 und 289 (Kleopatra), 290 (Dido), 291 (Frau des Hasdrubal).

${ }^{139}$ Vgl. Katalog 335.

140 Dazu Henning, Andreas / Weber, Gregor J. M. (Hrsg.): AK `Der himmelnde Blickı, Zur Geschichte eines Bildmotivs von Raffael bis Rotari, Dresden 1998.

${ }^{141}$ Diesen Begriff nach Günther, Heinz: »Carlo Dolci, Studien zur religiösen Malerei im 17. Jahrhundert«, in: Jahrbuch der kunsthistorischen Sammlungen, Wien, 56 (N.F.20) (1960), S. 197-234.

${ }_{142}$ Dazu Ebert-Schifferer, Sybille: "Guido Reni: klassische Norm, christliches Pathos und reine Farbe in: AK Guido Reni und Europa, Ruhm und Nachruhm, Schirn Kunsthalle Frankfurt 1988, S. 16-31.

${ }_{143}$ Sie werden von Pepper, Stephen: Guido Reni, L'opera completa, Novara 1988, Nr. 170, 174 und 200, als Artemisia identifiziert. Ich schließe mich der Argumentation Tümpels (a.a.O., S. 209) an, der die Bilder als Darstellungen der Sophonisbe deutet.
} 
das sich ursprünglich in der Sammlung des Kardinals Mazarin ${ }^{144}$ befand, zeigt eine halbfigurige Sophonisbe mit affektierter Handhaltung eine Schale haltend und den Blick unverhüllt pathetisch nach oben wendend. Die Sophonisbe [Abb. 14] aus einer Privatsammlung in Genua ${ }^{145}$ weist mit ihrer Rechten auf das Glas in ihrer anderen Hand und blickt aus dem Bild heraus, aber nicht auf den Betrachter, sondern

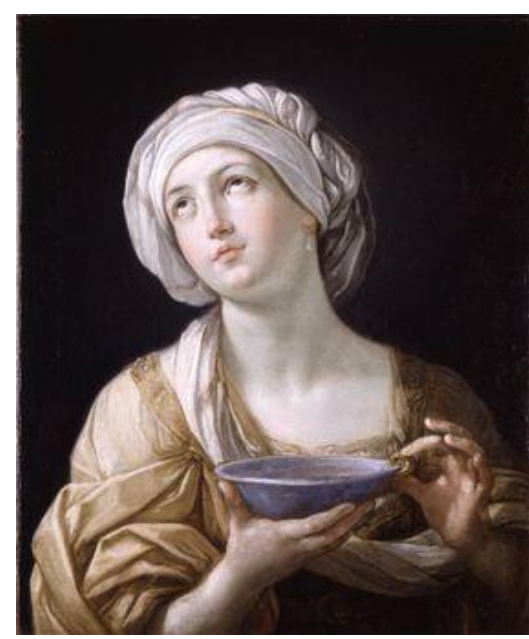

Abb. 13

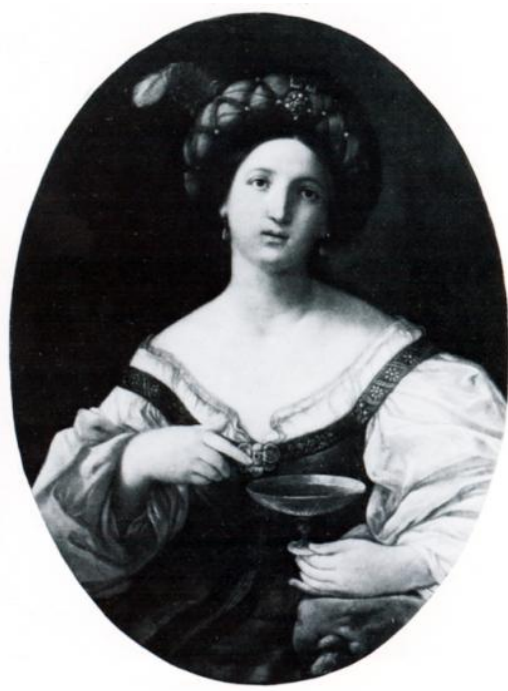

Abb. 14

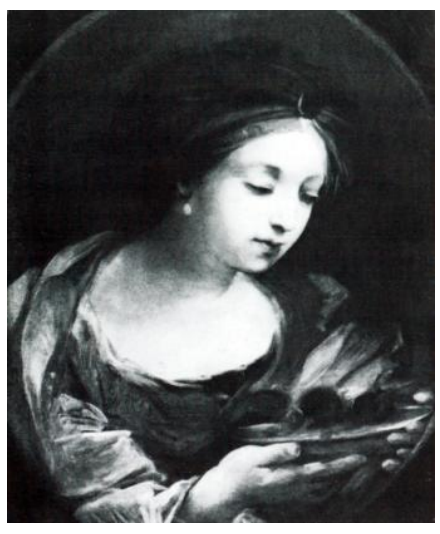

Abb. 15

unbestimmbar über inn hinweg. Nur die aus der Sammlung Gonzaga stammende Sophonisbe ${ }^{146}$ in Minneapolis [Abb. 15] findet eine andere Lösung: Sophonisbe betrachtet konzentriert die Schale in ihren Händen. Die Sophonisbe [Abb. 16] von Luca Ferrari (1605-1654) im Puschkin-Museum ${ }^{147}$ nimmt um 1640 den shimmelnden Reni-Typus auf, während Giovan Gioseffo dal Sole (1654-1719) um 1710 für seine Sophonisbe ${ }^{148}$ als halbfigurige junge Frau, die eine goldene Trinkschale betrachtet [Abb. 17], eine dem Bild aus der GonzagaSammlung vergleichbare Lösung wählte und Ergriffenheit mit Versenkung kombinierte.

Renis Bildformel des himmelnden Blicks geht bekanntlich auf die antiken Vorbilder des

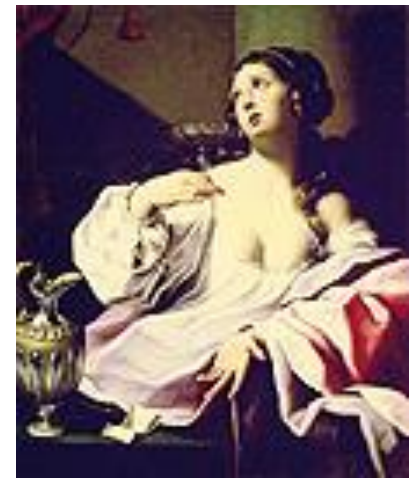

Abb. 16

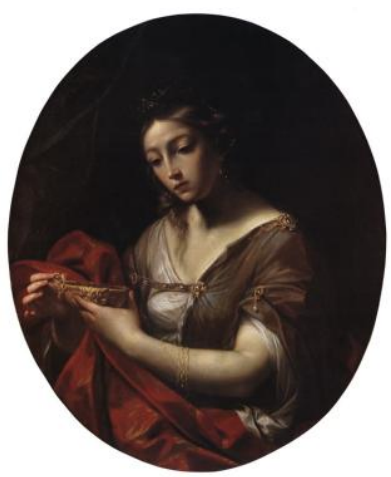

Abb. 17

\footnotetext{
${ }^{144}$ Vgl. Katalog 324.

${ }^{145}$ Vgl. Katalog 322. Das von Pepper in die Jahre zwischen 1638-39 datierte Gemälde (oval 96x71) befindet sich heute in einer Privatsammlung in Genua. Sein Pendant zeigt eine Lukretia.

${ }^{146}$ Vgl. Katalog 332.

147 Katalog 124.

${ }^{148}$ Vgl. Katalog 87. Abgebildet und besprochen in Ebert-Schifferer, Sybille (Hrsg.): AK /l gusto bolognese, Darmstadt 1994, S. 130 und 131.
} 
sterbenden Laokoon und der zu Stein gewordenen Niobe zurück. ${ }^{149}$ Sie wurde zunächst im »Andachtsbild des gegenreformatorischen Katholizismus « ${ }^{150}$ aufgegriffen, dann aber sehr rasch in der allgemeineren Deutung von Cesare Ripa ${ }^{151}$ als »kontemplative Vision « polyvalent verfügbar und zur »Ausdrucksgebärde der Seele ${ }^{152}$ auch profaner Tugendheldinnen. Die der unverhüllt propagandistischen Theatralik der gegenreformatorischen Heiligenbilder entsprechende Bilderfindung übertrug Reni sogleich in die Historienmalerei. Der shimmelnde Blickı konnte mit der Semantik des Heiligenbildes auch profane Motive nobilitieren. Spätestens mit der Darstellung der Entrückung (ravissement) als Expression des passions de l'âme (1668) bei Charles Le Brun [Abb. 18] setzte sich die profane Wendung des Affekts allgemein durch. ${ }^{153}$

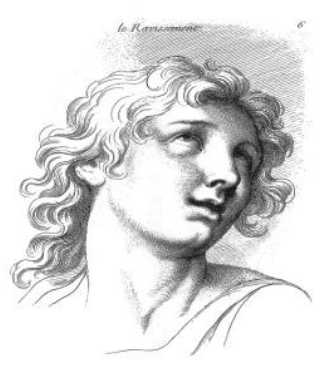

Abb. 18

Auch die Beigabe einer Trinkschale oder eines Bechers als Attribut identifizieren die Darstellungen der Sophonisbe als isolierte Halbfigur nicht so eindeutig, dass in dieser kleinen Bildgruppe nicht Verwechslungen mit Artemisia möglich wären. ${ }^{154}$ Es kam Reni und anderen wohl mehr auf die Ausdrucksgebärde der Tugendheldin an als auf ihre unzweifelhafte Identifikation; verschiedene Deutungen blieben durchaus möglich. So kann es nicht überraschen, dass selbst Kenner das Sujet nicht mehr erkannten. ${ }^{155}$ Der Typus der Halbfigur evozierte wahrscheinlich schon beim zeitgenössischen Betrachter vor allem eine elegische Stimmung, ohne dass der Bildinhalt präzise festgelegt wurde.

\footnotetext{
${ }^{149}$ Ausführlicher unten S. 219.

150 Riegl, Alois: Die Entstehung der Barockkunst in Rom, München 1977 ('1908), S. 182.

${ }_{151}$ Ripa, Cesare: Iconologia, Roma 1603 (ND Hildesheim und New York 1970). Ripa stattet zum Beispiel die Embleme Amore verso Iddio (S. 18), Desiderio verso Iddio (S. 101) und Martirio (S. 304) mit himmelnden Blicken (occhi riuolti al cielo) (S. 304) aus.

${ }^{152}$ Ich übernehme die Wendung von Ebert-Schifferer aus einer Objektbeschreibung, die Renis Magdalena von 1615-16 zum Gegenstand hat (AK Guido Reni und Europa, a.a.O., S. 124).

153 Siehe unten, S. 90.

$154 \mathrm{Da}$ auch in Darstellungen der Arte misia eine Trinkschale als identifizierende Beigabe diente, gibt es Überschneidungen mit Sophonisbe, zumal bereits Maria de' Medici und Anne d'Autriche Artemisia als vorbildliche Witwe und Regentin in ihr Bildprogramm aufgenommen hatten (vgl. S. 23, 25, 239, 241, 244, 246, 247, 254). Artemisia II., Schwester und Ehefrau des karischen Königs Mausolos von Myala, regierte nach seinem Tod (353-351 v. Chr.) Sie ließ ihrem Ehemann ein grandioses Grabmal errichten und trank seine Asche mit Wein vermischt, weil sie selbst das vornehmste Grab ihres geliebten Gatten sein wollte.

${ }_{155}$ "La testa d'una donna che regge una tazza blu e un velo avvolge la testa; la sua cornice è dorata. Guido. « Schon im Inventar von 1653 (bei Pepper, Stephen, a.a.O., S. 295.) wurde das heute in Birmingham befindliche Gemälde nicht mehr als Sophonisbe erkannt. Vgl. im Übrigen Fußnote 143.
} 
Fast noch zu dieser Gruppe gehört ein Bild ${ }^{156}$ von Girolamo Forabosco (1605-1679) in Cesena [Abb. 19], das Sophonisbe und eine Dienerin halbfigurig vor dem Trinken des Gifts zeigt und dem damit eine melancholisch-intime Stimmung gelingt.

Eine weitaus umfangreichere Gruppe in der Historienmalerei versucht szenische Umsetzungen der SophonisbeGeschichte, zu deren Gunsten die isolier-

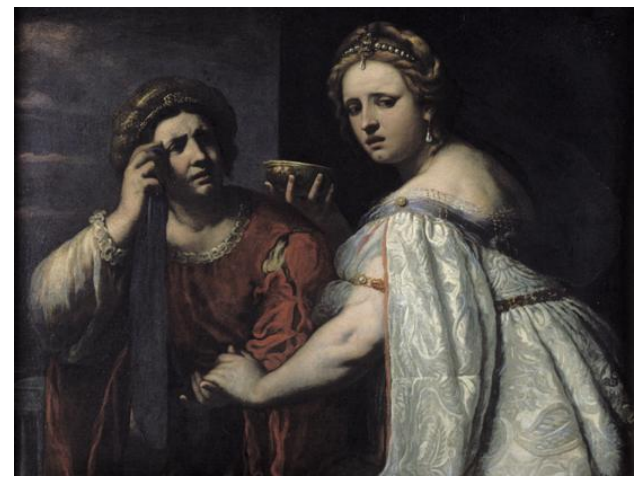

Abb. 19 ten Darstellungen langsam zurücktreten. Diente in den Halbfigurenbildern meist nur der Giftbecher als Identifikationsattribut, ist die Mehrzahl der den Freitod Sophonisbes darstellenden Historiengemälde des 17. und 18. Jahrhunderts, dem Stellenwert der Handlung angemessen, mit Hoheitssymbolen wie Säulen und Baldachin, höfischem Personal, wertvollen Stoffen und einer prächtigen Palastarchitektur ausgestattet.

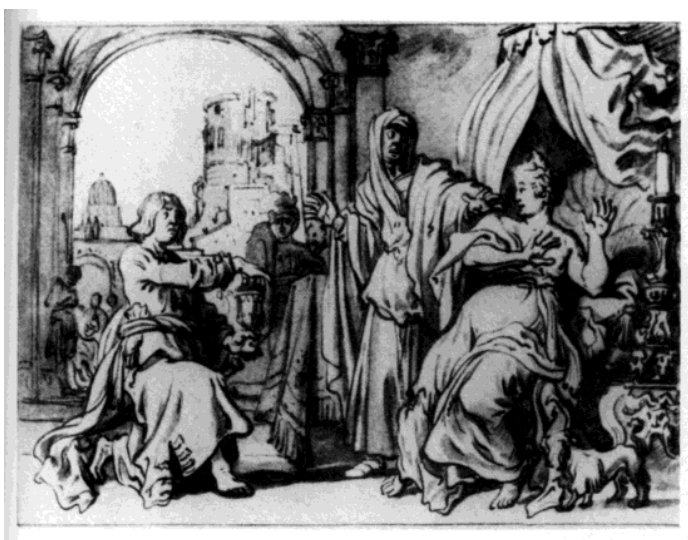

Abb. 20

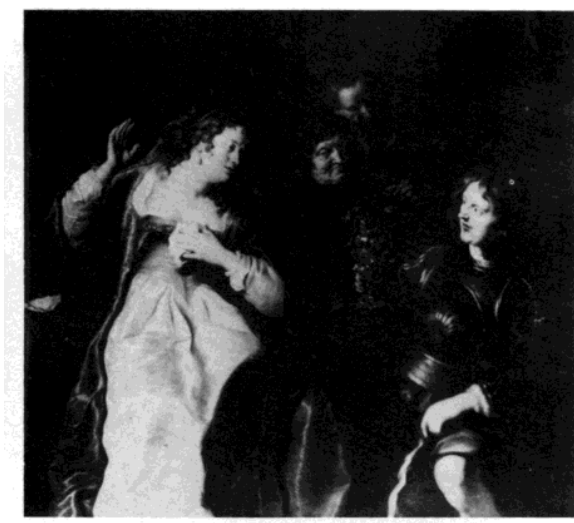

Abb. 21

Nur selten wird Sophonisbe so in Szene gesetzt, dass sie mit Emotion und Erschrecken auf die von einem Boten überbrachte Botschaft Massinissas reagiert. Pieter Lastman (1583-1633) wählte in einem nur in der Nachzeichnung von François Venant (1591-1636) ${ }^{157}$ überlieferten Gemälde [Abb. 20] dieses Motiv. Bei dem in Rembrandts Manier arbeitetenden Amsterdamer Salomon Koninck (1609-1656) verstärkt der starke Helldunkelkontrast noch die Heftigkeit des Gefühlsausdrucks. ${ }^{158}$ Mit einer abwehrenden Geste weicht die Protagonistin [Abb. 21]

\footnotetext{
156 Katalog 129.

157 Vgl. Katalog 204 (um 1630 zu datieren).

158 Vgl. Katalog 194.
} 
vor dem Giftpokal zurück, während sie mit der Linken ein Taschentuch an die Brust drückt. Lastman wie Koninck verlegen die Szene in das Innere eines Palastes. Bei beiden Malern kniet ein jugendlicher Bote vor der sitzenden Königin. Die räumliche, aber auch emotionale Distanz zwischen dem ruhigen Überbringer von Botschaft und Gift und der fassungslosen Sophonisbe wird gestisch durch eine stehende, als Amme oder Dienerin zu deutende alte Frau überbrückt. So entsteht auf beiden Gemälden eine nervöse Spannung zwischen dem in Ruhe und Gleichmut auftretenden Boten und der in äußerste Panik und seelische Bedrängnis gestürzten Sophonisbe.

In den meisten Historiengemälden steht allerdings nicht dieser Gegensatz der Affekte im Mittelpunkt, sondern die neustoisch getönte Gelassenheit und Affektbeherrschung, mit der Sophonisbe ihrem freiwilligen Tod entgegengeht: Würde, Tapferkeit und Selbstbeherrschung zeichnen in diesen Bildern die Protagonistin aus. ${ }^{159}$ Oft zieht der Giftbecher als Zentrum der Bilddramaturgie die Blicke der Nebenfiguren, aber auch des Betrachters auf sich. Allerdings hat er nicht mehr wie in der Graphik des 15. und 16. Jahrhunderts die Funktion eines identifizierenden Attributs, das narrative Zusammenhänge in Erinnerung ruft, sondern dient nunmehr als Anlass und Katalysator gegensätzlicher Affekte, entsetzter Unruhe beim Hofstaat und stoischer Gelassenheit bei Sophonisbe. Der Kontrast konturiert die constantia der Tugendheldin.

Die Darstellung der Affekte (expression des passions) war im 17. Jahrhundert zentrales Thema kunsttheoretischer Auseinandersetzungen. ${ }^{160}$ In den Conférences der Pariser Kunstakademie wurde das Thema seit 1667 - von der Laokoon-Gruppe ausgehend - vor dem Hintergrund der berühmten Abhandlung Les passions de l'âme (1649) von René Descartes lebhaft und kontrovers diskutiert. ${ }^{161}$ Die mit Zeichnungen illustrierte Akademie-Rede Expression des passions de l'âme (1668) von Charles Le Brun fasste die Debatte zusammen und erzielte europaweite Wirkung. ${ }^{162}$ Die europäischen Akademien griffen die Debatte auf und beschäftigten

\footnotetext{
159 Tümpel irrt, wenn er (a.a.O., S. 208) behauptet: „Sophonisbe selbst gibt sich ihren Gefühlen hin, verzweifelt, wie Livius es ausführlich beschreibt. « Bei Livius ist Massinissa nach der Unterredung mit Scipio verzweifelt, nicht aber die Königin, die sich ruhig und ohne Angst den Tod gibt: „Non locuta est ferocius quam acceptum poculum, nullo trepidationis signo dato, impauide hausit. ( $(G e l a s s e n$, wie sie den Giftbecher entgegengenommen hatte, trank sie inn ohne Zeichen von Unruhe aus.ı). (Ab urbe condita, 30, 15, 8)

${ }_{160}$ Vgl. Kirchner, Thomas: L'expression des passions, Ausdruck als Darstellungsproblem in der französischen Kunst und Kunsttheorie des 17. und 18. Jahrhunderts, Mainz 1991 und Montagu, Jennifer: The Expression of the Passions. The Origin and Influence of Charles Le Bruns's `Conférence sur l'expression générale et particulières, New Haven / London 1994.

${ }^{161}$ Der Bildhauer Gérard Van Obstal eröffnete die Vortragsreihe (Jouin, Henry [Hrsg.]: Conférences de I'Académie royale de peinture et de sculpture, Paris 1883, S. 20).

${ }^{162}$ Nach dem Tode Le Bruns wurden die Zeichnungen gestochen und hatten als Illustrationen zu seiner Abhandlung, aber auch als isolierte Schautafeln großen Einfluss: Le Brun, Charles: Méthode pour apprendre à dessiner les passions: proposée dans une conférence sur l'expression générale et particulière, Amsterdam 1702, (ND Hildesheim 1982); Charles Le Brun: L'expression des passions, autres conférences, correspondance, hrsg. von Julien Philipe, Paris 1994. Die Kupferstiche sind in einer Ausgabe von 1727 über den elekt-
} 
sich in Theorie und Praxis mit der Darstellung und der Systematisierung der Affekte. Der Comte de Caylus lobte 1759 sogar einen prix d'expression aus. Die Verbildlichung der Affekte wurde so im 17. und 18. Jahrhundert zu einer wichtigen Aufgabe der Historienbilder.

Auch in der Wiedergabe der Sophonisbe trat nunmehr der psychologische Aspekt in den Vordergrund. Die Repräsentation der Affekte bestimmt die Darstellung der Tugendheldin ebenso wie die der Assistenzfiguren; unverkennbar hat die breite Rezeption des Stoffes auf der Bühne das Spektrum der dargestellten Affekte im Historienbild erweitert. ${ }^{163}$

Einige Gemälde stellen mit durchaus differierenden Lösungen den Augenblick dar, in dem Sophonisbe durch einen Boten Botschaft und Gift erhält. ${ }^{164}$ Nikolaus Knüpfer (1603-1655) $)^{165}$ hat die Szene [Abb. 22] ins Bürgerliche gewendet: in einer Guckkastenbühne wird ein gediegener Wohnraum mit Bett gezeigt. Drei Dienerinnen reagieren mit Angst, Entsetzen und Mitleid auf das Schicksal der Protagonistin. Von einem Pagen

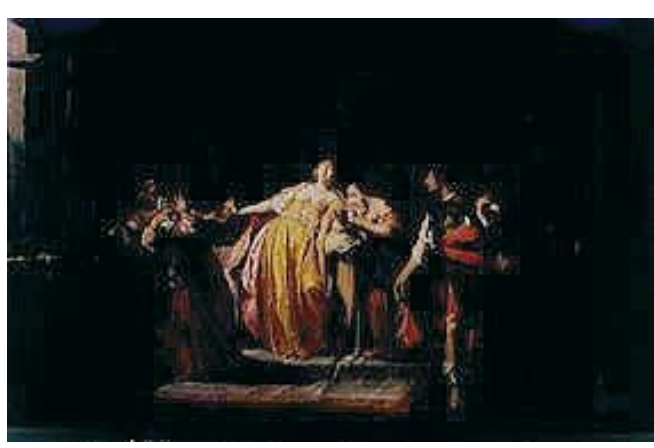

Abb. 22 begleitet verlässt der Überbringer des Giftes soeben die Szenerie, in der wiederum der Giftbecher eine zentrale Stelle erhalten hat. Simon V ou et (1590-1649) ${ }^{166}$ hingegen ordnet im Breitformat [Abb. 23] Sophonisbe und ihre Assistenzfiguren, eine zentrale Rolle im Bildgeschehen zugewiesen, die allerdings durch den intensiven und beinahe liebevollen Blickkontakt zwischen der Königin und dem Boten kontrebalanciert wird. Die Lösung von Rembrandts Gemälde im Prado ${ }^{167}$ besticht

ronischen Dienst der Bibliothèque Nationale de France am einfachsten zu konsultieren (http://visualiseur.bnf.fr/Visualiseur?Destination=Gallica\&O=NUMM-8496; zuletzt aufgerufen: 22.02.2007)

${ }^{163} \mathrm{Vgl}$. oben S. $70 \mathrm{ff}$.

164 Siehe dazu die keineswegs vollständige Liste bei Pigler (a.a.O., S. 413-415), der häufig mit seinen Zuweisungen (Sophonisbe oder Artemisia) falsch entscheidet. Von Pigler nicht erfasst sind Buchillustrationen, wie zum Beispiel die von Sandrart gestochene Titelillustration für das Trauerspiel Sophonisbe in der dritten Sammelausgabe von Daniel Casper von Lohensteins Werken, Breslau, Fellgiebel, 1689 (Abbildung im Auktionskatalog Bassenge, Ende 2000/Anfang 2001, Berlin 2001, Nr.1846).

${ }^{165}$ Vgl. Katalog 193.

166 Vgl. Katalog 427.

167 Vgl. Katalog 307. Die kürzlich von Golahny, Amy (»Rembrandt's Artemisia: Arts Patron«, in: Oud Holland 114 [2000], S. 139-154) vertretene Auffassung, es handle sich bei Rembrandts Gemälde um eine Artemisia, kann nicht überzeugen. Golahny misst dem auf einem Tisch liegenden Folianten eine ebenso große Bedeutung zu wie dem Nautiluspokal und nimmt an, Artemisia werde hier als Vollstreckerin des Testaments ihres Mannes Mausolos und als Patronin der ıschönen Künste inszeniert. In der geläufigen ikonographischen Tradition wird Artemisia allerdings beim Trinken des Bechers mit der Asche ihres Ehemanns, gleichsam als >lebendes Grabmahl für die Asche des Ehemannesı dargestellt. Die Beweisführung für die neue Deutung scheint mir weder durch literarische noch ikonographische Traditionen gesichert zu sein. Ich halte deshalb an der opinio communis (so J. Bruyn u.a.: A Corpus of Rembrandt Paintings, The Hague 1982, Bd. 1, S. 504-510) fest, dass 
durch ihre raffinierte Lichtregie: eine jugendliche Sophonisbe nimmt in Dreiviertelfigur und frontal beinahe den gesamten Bildraum ein [Abb. 24]. Das von links einfallende Licht betont den in Gold montierten Nautiluspokal ebenso wie die Lichtgestalt der Empfängerin, deren Blick ruhig über die von hinten und im verlorenen Profil gegebene Dienerin hinweggeht. Der dunkle Hintergrund, vor dem sich nur undeutlich Draperien und eine ältere Dienerin abheben, verstärkt die isolierte Gelassenheit der in einem Sessel sitzenden Königin. In den Schnittpunkt der Diagonalen ist der Pokal mit dem todbringenden Gift gesetzt. Bei allen Differenzen in Aufbau, Ambiente und Personal wird von beiden Künstlern die Unbeirrbarkeit

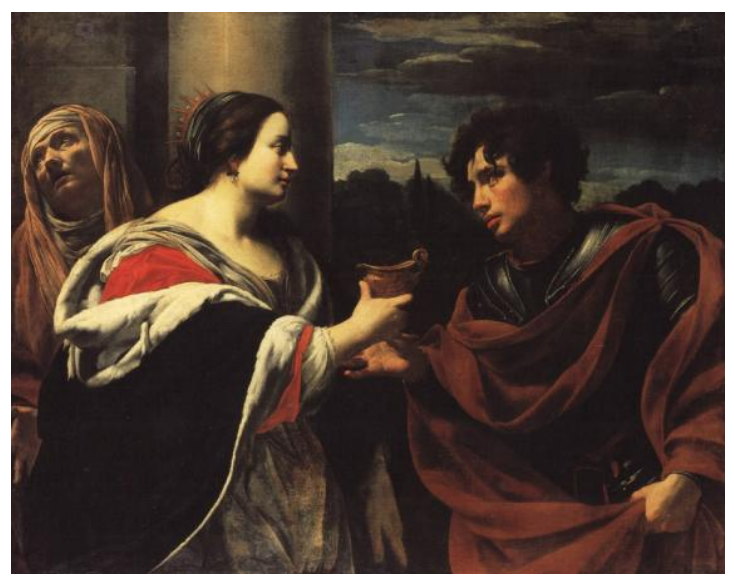

Abb. 23

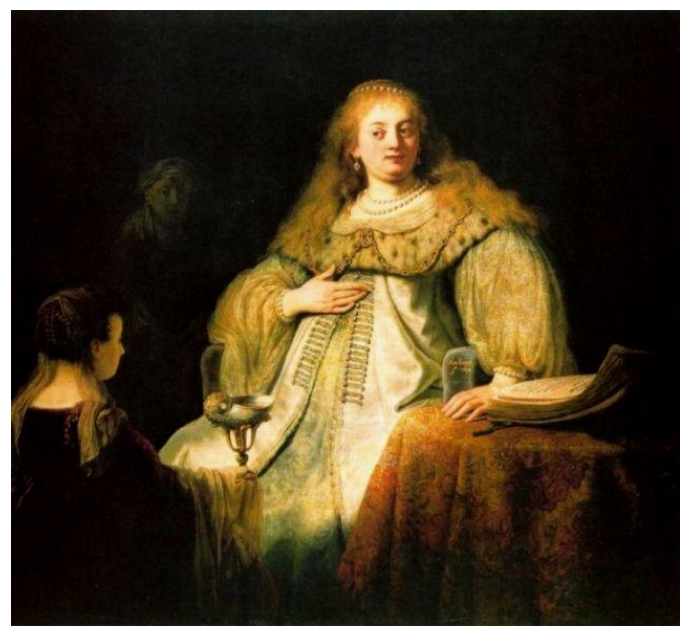

Abb. 24 der Hauptperson vor Augen geführt und die Peripetie des Geschehens neu bestimmt. Als bilddramatischer >Umschlagspunkt» wird die Übergabe des Gifts durch den Boten gewählt, während in der Gruppe der Halbfigurenbilder, die auf den gröBeren narrativen Zusammenhang verzichtet, Sophonisbe bereits allein oder allenfalls mit einer Dienerin gezeigt wird.

Die Historienmalerei ist in ihrer Bilddramaturgie auf den »fruchtbaren Augenblick « ${ }^{168}$ angewiesen, der dem Betrachter die moralische Problematik der histori-

es sich um eine Sophonisbe handelt. Im Katalog der Amsterdamer Ausstellung Rembrandt - Caravaggio (2006) wird zwar die Hauptfigur des Gemäldes richtig gedeutet, gleichwohl in der Objektbeschreibung des Gemäldes irrtümlich behauptet, der Giftbecher werde von Massinissa gereicht:: »Als das Gemälde im 18. Jahrhundert in Spaniens königliche Sammlung gelangte, wurde die junge Frau als Artemisia, Frau und Schwester des Königs Mausolos, bezeichnet. [...] Zu Beginn des 20. Jahrhunderts meinte man, in der Königin Sophonisbe eine weitere Figur aus der klassischen Antike, zu erkennen. Sophonisbe gab lieber ihr Leben für ihren geliebten Ehemannn Massinissa, indem sie Selbstmord beging, als in die Hände des römischen Generals Scipio zu fallen. Sollte diese Interpretation zutreffen, so hat Rembrandt genau den Moment gewählt, bevor Sophonisbe den Giftbecher trinkt, den Massinissa ihr reicht. Was auch immer die Wahrheit sein mag, beide Frauenfiguren [Artemisia oder Sophonisbe] stehen Modell für die weiblichen Tugenden der ehelichen Treue und Selbstaufopferung. Rembrandt stellt den Moment dar, in dem die Frau über ihr eigenes Schicksal entscheidet.« (Taco Dibbits in: Bull, Duncan [Hrsg.] AK Rembrandt-Caravaggio, Stuttgart 2006, S. 136).

168 Diesen Begriff verwendet Lessing in seinem "Laokoon oder über die Grenzen der Malerei und Poesie « (1766), um die Phase einer Handlung oder Handlungsabfolge zu bezeichnen, die der Künstler in der Absicht auswählt, dem Betrachter die imaginative Konstitution der Gesamthandlung zu ermöglichen. Der »Augenblick « muss im Bild das Ganze umfassen, aber auch so "fruchtbar « sein, dass er auf die vorausgehenden und nach- 
schen Handlung vor Augen führt. Anders als in der klassizistischen Theaterdramaturgie, die in vergleichbarer Weise das punctum temporis (oder den prégnant moment) suchte, aber immerhin eine geraffte $\mathrm{Handlungsfolge} \mathrm{dargestellen} \mathrm{konn-}$ te, bleibt das »monoszenische Einzelbild « ${ }^{169}$ auf einen Handlungsausschnitt angewiesen, der Vergangenheit und Zukunft noch enger zusammenbindet. Die Szene der Übergabe des Gifts an Sophonisbe verknüpft für den Betrachter emphatisch Vorgeschichte und bevorstehenden Selbstmord. ${ }^{170}$ Vouet und Rembrandt stellen den Augenblick des Übergangs dar, als die Königin bereits ihren Entschluss gefasst hat und die tragische Endgültigkeit der Situation feststeht, auf die Sophonisbe gelassen reagiert; die Erschütterung der Dienerin signalisiert die Übermittlung der Botschaft und nimmt das bevorstehende Ende der Königin vorweg. Wie in einer Tragödie sollen die in Szene gesetzten Affekte der Nebenfiguren oder des Hofstaa-

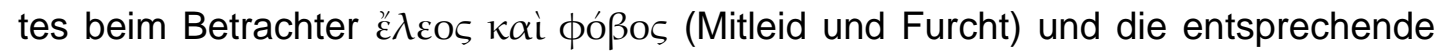
kathartische Wirkung (expiatio affectuum) auslösen. Im Identifikationsangebot der gelassen auf Schicksalsschläge reagierenden Hauptfigur und ihrer impassibilité findet hingegen die neustoisch verstandene Vernunft und Affektsteuerung exemplarischen Ausdruck. ${ }^{171}$

Der Rembrandt-Schüler Gerbrand van den Eeckhout (1621-1674) ${ }^{172}$ stellt bei einem völlig anders angelegten Bildaufbau [Abb. 25] Sophonisbe ruhig und gelassen dar und legt den Akzent auf den Gegensatz von Staatsräson und persönlichem Glück. Im linken Bildraum nimmt die Königin unter einer Throndraperie, mit Krone und Hermelinmantel bekleidet, den Giftkelch entgegen; der ihn begleitende

folgenden Handlungsphasen verweist: „Kann der Künstler von der immer veränderlichen Natur nie mehr als einen einzigen Augenblick, und der Maler insbesondere diesen einzigen Augenblick auch nur aus einem einzigen Gesichtspunkte, brauchen; sind aber ihre Werke gemacht, nicht bloß erblickt, sondern betrachtet zu werden, lange und wiederholter maßen betrachtet zu werden: so ist es gewiß, daß jener einzige Augenblick und einzige Gesichtspunkt dieses einzigen Augenblickes, nicht fruchtbar genug gewählet werden kann. Dasjenige aber nur allein ist fruchtbar, was der Einbildungskraft freies Spiel läßt. Je mehr wir sehen, desto mehr müssen wir hinzu denken können. Je mehr wir darzu denken, desto mehr müssen wir zu sehen glauben. « (Lessing, Gotthold Ephraim: Werke, hrsg. von Herbert G. Göpfert u.a., Bd. 6 (Kunsttheoretische und kunsthistorische Schriften), Darmstadt 1996, S. 25f.). Zu vergleichbaren Überlegungen bei Diderot: Bernier, Marc André: »La lettre sur les sourdes et muets (1751) de Denis Diderot: une rhétorique du punctum temporis«, in: Lumen, Bd. 18,2000 , S. 1-10.

${ }^{169}$ »Beide [Historienbild und Tragödie] müssen die Krise zentral stellen, alles Vorangehende nur andeuten, möglichst nahe an die Krise herankommen. Mit Recht kann aber die Frage gestellt werden, ob in diesen Fällen noch immer eine vom Betrachter perzipierbare narratio dargestellt wird. Während die anderen drei Arten der visuellen narratio eine temporale Folge von Handlungen zeigen, die der Betrachter ziemlich leicht zu einer Geschichte zusammenfügen kann, kann er im Falle eines monoszenischen Einzelbildes nur eine Handlung wahrnehmen, jedoch keine Geschichte. Diese entsteht erst, wenn er die Handlung als Teil eines größeren narrativen Zusammenhanges erkannt hat, zum Beispiel nachdem er den Titel des Bildes gelesen hat. Seit dem 18. Jahrhundert wird des öfteren auf diese Schwierigkeit der Historienmalerei hingewiesen: der Künstler wählt entweder immer wieder dieselben allgemein bekannten historischen Ereignisse, mit dem Risiko der Banalität und der Langeweile, oder aber er wählt weniger bekannte Geschichten, mit dem Risiko, daß die Betrachter diese nicht erkennen und demzufolge auch ihre menschlich-moralische Bedeutung nicht verstehen können. « (Varga, Aron Kibédi: »Visuelle Argumentation und visuelle Narrativität«, in Harms, Wolfgang [Hrsg.]: Text und Bild, Bild und Text [DFG-Symposion 1988], Stuttgart 1990, S. 356-367, hier S. 363-364)

${ }^{170}$ Eine vergleichbare Funktion hat die durch einen Brief visualisierte Übermittlung der Nachricht, wie sie zum Beispiel bei Koninck auftritt. Vgl. zum Motiv Schulze, Sabine (Hrsg.): AK Leselust, Niederländische Malerei von Rembrandt bis Vermeer, Frankfurt 1993.

${ }^{171}$ Vgl. Brassat, Wolfgang: „Tragik, versteckte Kompositionskunst und Katharsis im Werk von Peter Paul Rubens «, in Heinen, Ulrich / Thielemann, Andreas (Hrsg.): Rubens Passioni, Kultur der Leidenschaften im Barock, Göttingen 2001, S. 41-69.

${ }^{172}$ Vgl. Katalog 417. 
Brief liegt auf einem Tisch. Obwohl sie in ihrer Rechten ein Tränentuch hält,

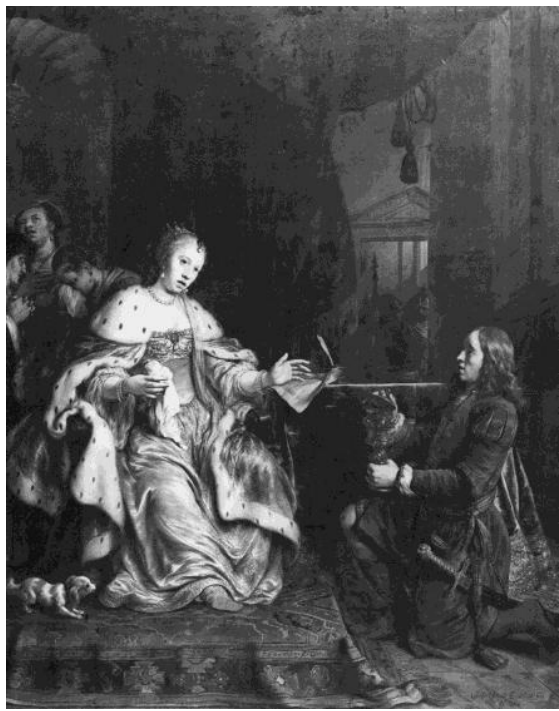

Abb. 25

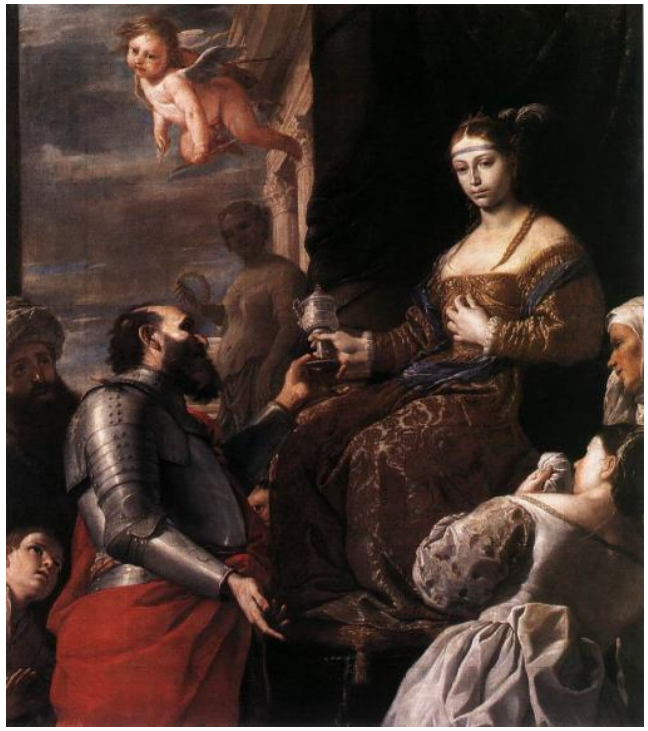

Abb. 26

blickt sie selbst gelassen, während drei Zofen Trauer und Schmerz gestisch beeindruckend freien Lauf lassen. Der beim Überreichen des Nuppenkelches vor Sophonisbe kniende Bote hält noch die höfischen Regeln ein, doch verdeutlichen die hinter ihm in einem Durchblick ins Freie sichtbaren Soldaten die drohende Gefahr der römischen Gefangenschaft.

Auch Mattia Preti (1613-1699) hat

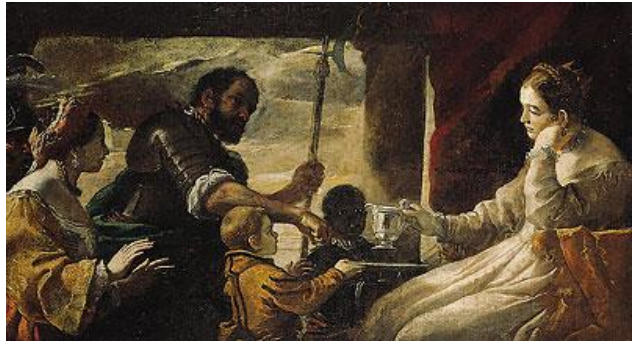

Abb. 27 diese Szene mit vergleichbaren Akzenten mehrfach bearbeitet. Die Version in Lyon $^{173}$ [Abb. 26] unterstreicht - wie das Bild Eeckhouts - die gegensätzlichen Reaktionen der Protagonistin und ihres Hofstaates, Ruhe und klaglose Ergebung der Königin, Bestürzung bei den Frauen des Hofstaates. Der `Cavaliere Calabrese veränderte in den verschiedenen Varianten nur den Habitus des die Botschaft überbringenden Boten: Die Variante in Lyon lässt einen älteren, mit Harnisch gerüstet Boten den Becher mit einer entschuldigenden Handbewegung der erhöht sitzenden Königin hinaufreichen, während in der Melbourner Fassung ${ }^{174}$ [Abb. 27] ein Kurier mit Hellebarde ${ }^{175}$ den Giftbecher mit einer autoritären Handbewegung

\footnotetext{
${ }^{173}$ Vgl. Katalog 283.

${ }^{174}$ Vgl. Katalog 286

175 Walther Lang betont im Zusammenhang der Darstellungen des Martyriums der Agathe, die aufgepflanzte Lanze eines Soldaten sei ein »demonstratives Symbol seiner Männlichkeit« (Grausame Bilder, Sadismus in der neapolitanischen Malerei, Berlin 2001, S. 194). Áuch wenn die sexuelle Bedeutung solcher Symbole erst durch Freud erkannt wurde, kann eine unterschwellig-sexuelle Konnotation bei der Darstellung von Lanzen, Schwertern etc. auch schon im Barock vorausgesetzt werden.
} 
aushändigt. Der Melancholie-Gestus Sophonisbes deutet die Einwilligung in ihr Schicksal an.

Der Antagonismus zwischen Staatsräson und individuellem Glück wird in den Sophonisbe-Darstellungen der späten Barockmalerei durch den Kontrast zwischen Mann und Frau, zwischen bewaffnetem Boten und schicksalsergebener Königin ins Bild gesetzt. So erscheint in der Ölskizze ${ }^{176}$ von Francesco Solime na (1657-1747) der Bildraum [Abb. 28] zweigeteilt: Von links eilt ein Kurier in voller Rüstung herbei und überreicht der erhöht thronenden Königin ein zierliches Gefäß. Diese beherrscht mit allen Herrschaftsinsignien die rechte Bildhälfte. In sich ge-

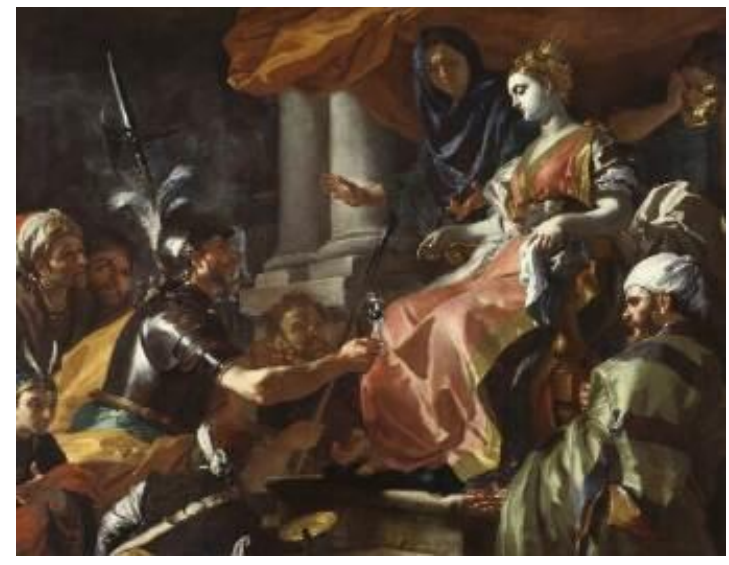

Abb. 28

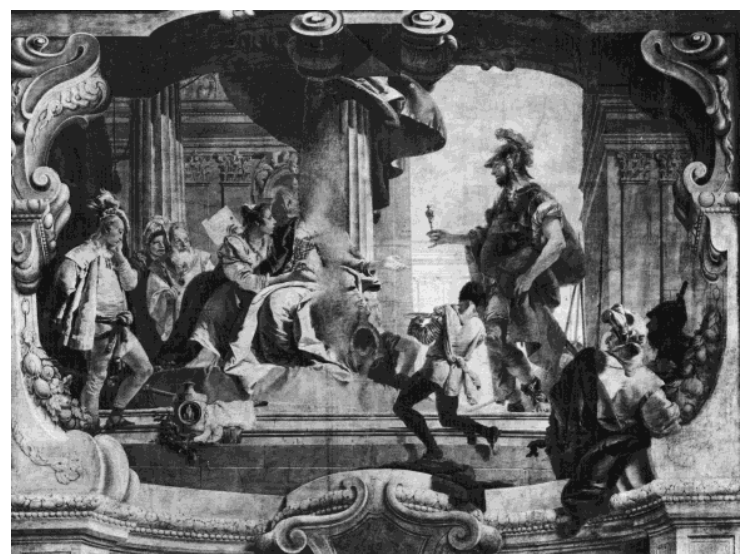

Abb. 29

kehrt und beinahe versteinert blickt sie auf den todbringenden Trank. In ihrem fahlen, bleichen Inkarnat deutet sich der bevorstehende Tod bereits an.

Der zahlreich versammelte Hofstaat reagiert mit starken Emotionen. Im Rahmen eines Scipio-Zyklus ${ }^{177}$, den Giambattista Tiepolo 1731 im heutigen Palazzo Dugnani ${ }^{178}$ in Mailand ausführte, ist Sophonisbe ein großes Fresko ${ }^{179}$ gewidmet. [Abb. 29] In luxuriöser Palastarchitektur thront die Königin in der linken Bildhälfte, den Brief Massinissas noch in der Hand haltend und von einer Zofe liebevoll umfangen. Rechts erscheint, durch die da sotto in su-Perspektive hervorgehoben, ein mit Harnisch und Helm gerüsteter Bote, der eben einen zierlichen Krug von einem Tablett genommen hat, das ihm ein kleiner Mohrenpage reicht. Sophonisbe streckt ihre geöffnete Hand, Einverständnis und Einwilligung signalisierend, dem Gefäß entgegen. Erschrecken, Angst und Trauer sind auch in diesem elegan-

\footnotetext{
${ }^{176}$ Vgl. Katalog 380.

${ }^{177}$ Ich gehe darauf unten, S. 225ff. ein.

178 Der Palazzo wurde vom Conte Casati erbaut und trug auch dessen Namen.

179 Katalog 390 (im Zweiten Weltkrieg beschädigt). Eine Abbildung in: Levey, Michael: Giambattista Tiepoli: his life and art, New Haven / London 1986, S. 63. Abbildung des ganzen Zyklus in Pallucchini, Anna / Piovene, Guido (Hrsg.): L'opera completa di Giambattista Tiepolo, Mailand 1981, Abb. 62 A bis H.
} 
ten Rokoko-Fresko dem männlichen Hofstaat zugeordnet. Etwa gleichzeitig entstand ein Ölgemälde Gianantonio Pellegrinis (1675-1741), das sich seit 1789 in Genua in der Sammlung Durazzo Pallaviccini (sala della Maddalena) befindet. ${ }^{180}$ Sitzend nimmt die ganzfigurige Sophonisbe in gelbbeiger Kleidung die rechte Hälfte des quadratischen Bildes ein. [Abb. 30] In ihrer aufgestützten Linken hält sie den eben geöffneten Brief Massinissas. Mit ihrer Rechten greift sie nach einem kleinen Gefäß, das ihr eine der beiden Dienerinnen auf einem Silbertablett reicht. Die beiden Dienerinnen konzentrieren sich auf das Verhalten der Königin; die Hände einer Dienerin verleihen dem um sich greifenden Entsetzen beredten Ausdruck. Ganz links blicken zwei gerüstete Soldaten auf das Geschehen. Obwohl Herrscherattribute wie ein blauer Baldachin und eine Säule nicht fehlen, ist die ganze Aufmerksamkeit des Betrachters auf die Protagonistin gerichtet. Die Bilddramaturgie stellt

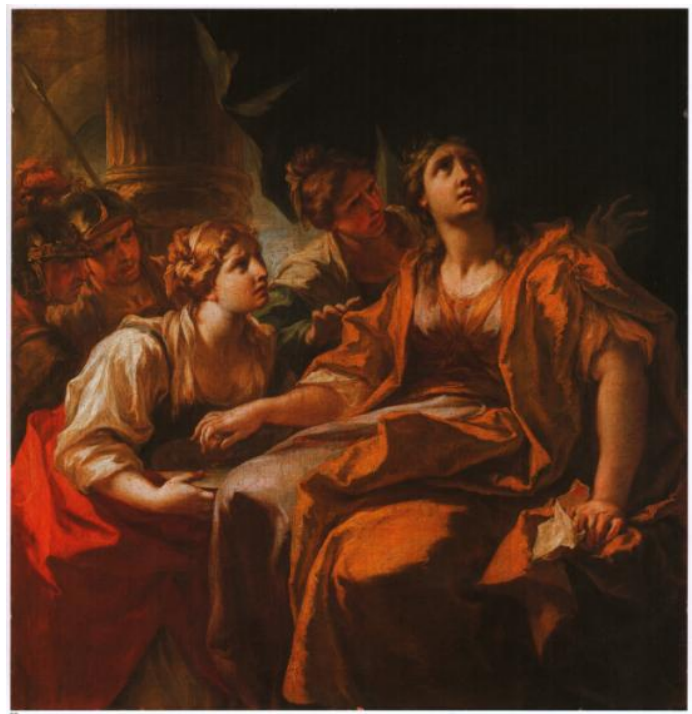

Abb. 30

nicht mehr das unmittelbar bevorstehende Trinken des Gifts in den Mittelpunkt, sondern weckt durch den himmelnden Blick der Tugendheldin das Interesse des Betrachters für die sphilosophische` Aussage des Motivs. Sophonisbe scheint dem Giftbecher keine Beachtung zu schenken, greift gleichsam en passant nach inm; ihr ıSeelenblickı gibt einen größeren Interpretationsspielraum frei.

Ein kürzlich im Handel aufgetauchtes großes Historienbild [Abb. 31] von Sebastiano Ricci (1659-1734) $)^{181}$ versammelt geläufige Motive (den das Gift überreichenden Diener, den gelesenen Brief, einen Mohren und zwei Bedienstete) und gibt innen einen intimen $\mathrm{Zu}$ schnitt vor einer Parklandschaft mit der

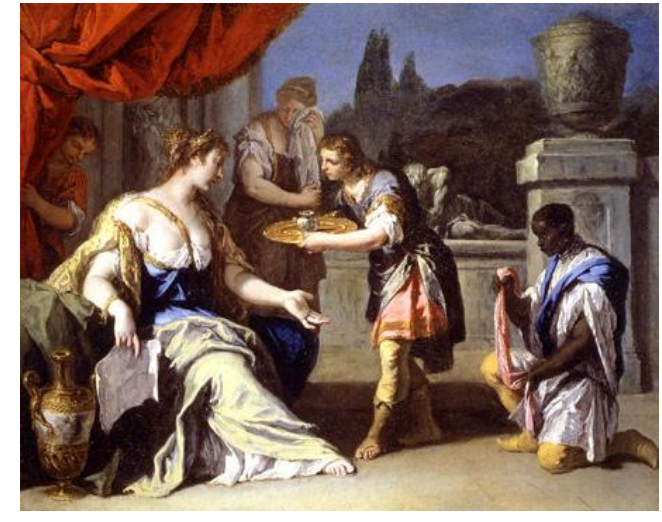

Abb. 31

\footnotetext{
180 Katalog 266.

${ }^{181}$ Katalog 345 (Sotheby London Januar 2005).
} 
IV Liebe, Patriotismus und Selbstbestimmung: Sophonisbe als Tugendheldin

Skulptur des ısterbenden Galliersı.

Das Sterben Sophonisbes wird trotz seiner Dramatik nur ausnahmsweise dargestellt. Zu nennen ist ein Gemälde von Giovanni Battista Pittoni (16871767) im Puschkin-Museum, das den Tod Sophonisbes nach Einnahme des Gifts

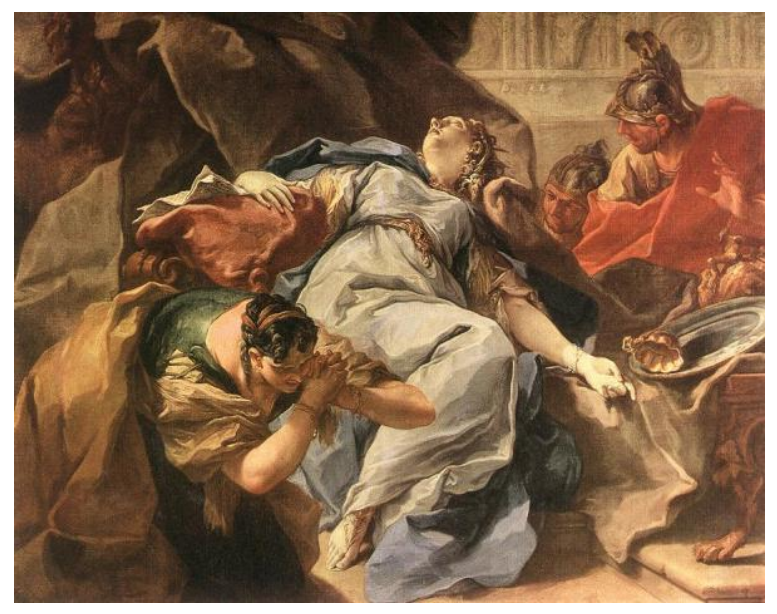

Abb. 32

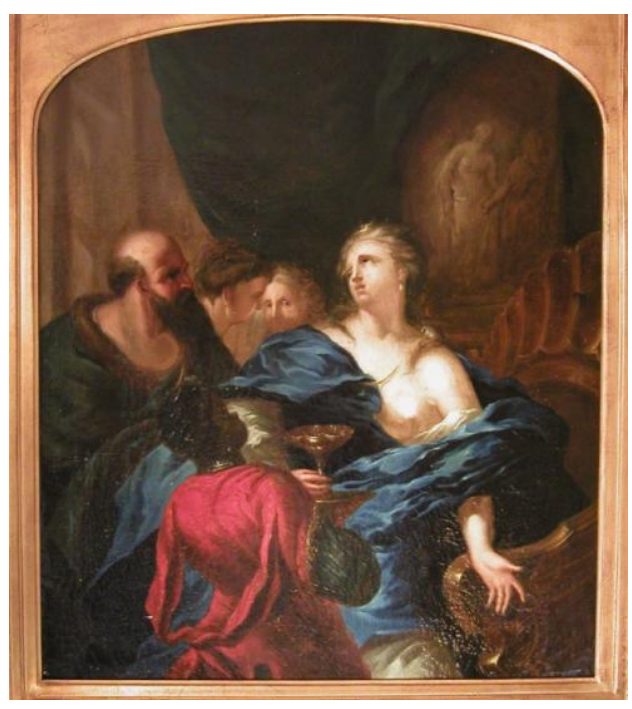

Abb. 33

in eine bewegte Szene umsetzt. [Abb. 32] Pittoni hat auch in einem anderen Gemälde [Abb. 33], das kürzlich im Handel war, ein weiteres, relativ ungewöhnliches Motiv aufgegriffen: das Gemälde zeigt Sophonisbe dreiviertelfigurig mit Becher, mit einem Mohren und zwei Dienerinnen. Ihr Gatte Massinissa hat ihr wohl soeben selbst den Giftbecher gebracht - bezeichnenderweise fehlt deshalb der Brief, der sich in den geläufigeren Varianten fast immer findet. Im Hintergrund erscheint, den Verlust der Gattin mythisch überhöhend, ein Relief mit Orpheus und Eurydike.

Massinissa tritt auch sonst gelegentlich in der Ikonographie der Sterbeszene Sophonisbes auf. Bekanntlich bringt bei Appian der König selbst das Gift seiner Frau. Ganz selten wird diese Überlieferung der Version bei Livius vorgezogen, was in der Forschung bisher noch keine Beachtung gefunden hat. Rutilio Manetti (1571-1639) etwa hat um 1623/25 für die Villa Poggio Imperiale ${ }^{182}$ in Florenz Sophonisbe und Massinissa mit dieser Szene ins Bild gebracht [Abb. 34]. ${ }^{183}$ Umgeben von einem zahlreichen Hofstaat werden Sophonisbe und Massinissa gleichgewichtig dargestellt, wobei es sich bei dem klagenden Knaben rechts um den Sohn Sophonisbes aus der Ehe mit Syphax handeln könnte.

\footnotetext{
182 Vgl. zu diesem Zusammenhang unten S. 247ff.

183 Katalog 226.
} 


\section{Die Darstellung der ganzen Familie findet sich seit Trissino in den Bühnen} und Opernbearbeitungen des Stoffs. ${ }^{184}$ Massinissa und Sophonisbe könnten auch auf einem nur fragmentarisch erhaltenen Gemälde von Antonio Balestra (1666-1740) in Pommersfelden dargestellt gewesen sein. ${ }^{185}$ Das 1724 für den Grafen von Schönborn entstandene und in der gleichen Sammlung

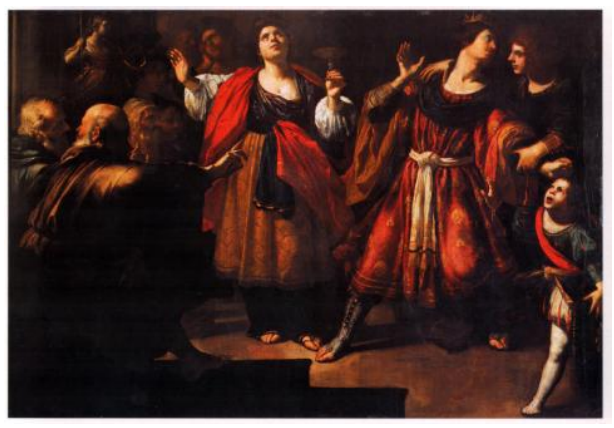

Abb. 34 befindliche Bild [Abb. 35] von Antonio Pellegrini (1675-1741) zeigt allerdings entgegen der geläufigen Deutung nicht Sophonisbe und Massinissa, wie der Brief zeigt, den die Königin in ihrer Rechten hält. ${ }^{186}$ Hingegen könnte ein 2006 im Handel aufgetauchtes Bild die Version mit Massinissa bieten. Es wurde der Augsbur-

${ }^{184}$ S. oben S. $70 f f$.

185 Das Gemälde hing als Allegorie ehelicher Treue bis in den Tod (Minges, Klaus: Das Sammlungswesen in der Frühen Neuzeit, Kriterien der Ordnung und Spezialisierung, Münster 1998, S. 151) im Marmorsaal des Schlosses Weissenstein. Ein alter Bestandskatalog, der Aussehen und Zustand des Marmorsaales beschreibt, notiert: »Uber Ihro Mayestät der Kaiserin Contrefait. 8. Die Sophonisba, wie sie aus Treu gegen ihren Gemahl den König / Gifft trincket / mit vielen Figuren / in grosleben. Von Balestra. (Hofmann, Walter Jürgen: Schloss Pommersfelden, Geschichte seiner Entstehung, Nürnberg 1968, S. 137). Aus einer Beschreibung von 1953 (Kreisel, Heinrich: Das Schloss zu Pommersfelden, München 1953, S. 32) lässt sich kein klarer ikonographischer Zusammenhang rekonstruieren (»In der oberen Wandzone sitzen entsprechend den hochovalen Fenstern ebenso große Gemälde, und zwar in der Reihenfolge von links nach rechts, ausgehend von der Ostwand: Antonio Balestra (1666/1740), Sophonisbe, Venus und Vulkan sowie Moses befreit die Tochter des Jethro von den Hirten [...].«) In der ursprünglichen Konzeption scheint aus gegebenem Anlass die eheliche Treue das Motiv für die Sophonisbe-Darstellung gewesen zu sein: »Inhaltlich auf die weiblichen und männlichen Herrschertugenden bezogen war die Ausstattung ihrer künstlerischen Umgebung [der Porträts des Kaisers und der Kaiserin, die von 1719-1721 im Marmorsaal hingen RSG]. Über den Kaiserbildern ragten großformatige Gemälde bis in die Deckenzone. Über dem Kaiser: Wie Merkur die goldene Zeit ins Land bringt (Thulden), über der Kaiserin: Sophonisbe, die aus Treue zu ihrem Gemahl Gift nimmt (Balestra), ein Hinweis auf die eheliche Treue der Kaiserin (Lothar Franz stiftete die Ehe zwischen dem Kaiserpaar). (Bott, Katharina: ") La mia galleria Pommersfeldianaく, Die Geschichte der Gemäldesammlung des Lothar Franz von Schönborn «, in Bott, Gerhard [Hrsg.]: AK Die Grafen von Schönborn. Kirchenfürsten, Sammler, Mäzene, Nürnberg 1989, S. 112-128, hier S. 116) Nach anderen Veränderungen wurde 1938 das »Monumentalgemälde « »Sophonisbe trinkt aus Liebe zu ihrem Gemahl Gift« beschnitten und »als Ausschnitt in ein Oval eingepasst (ebd. S. 125). Die Kuratorin der `Kunstsammlungen Graf von Schönborn`, Dorothee Feldmann, teilte am 16.12.2004 brieflich mit, dass sich das Gemälde Balestras (Inv.Nr. 22b) noch immer im Bestand der Sammlung befindet und als Oval im Marmorsaal von Schloss Weissenstein in Pommersfelden hängt. Es gebe allerdings keine Abbildung des Gemäldes. Ob auf der ursprünglichen, nicht beschnittenen Fassung des Gemäldes auch Massinissa gezeigt wurde, wie es dem Thema der ehelichen Treue entsprechen würde, lässt sich wohl leider nicht mehr rekonstruieren.

${ }^{186}$ Der Streit über das Thema des Bildes ist ein schöner Beleg für die relative Vergessenheit, in die die Sophonisbe-Geschichte gefallen war. Zwar hatten bereits Rodolfo Pallucchini und George Knox die nordafrikanische Königin erkannt, doch versuchte noch August Rave im AK Die Grafen von Schönborn, Kirchenfürsten, Sammler, Mäzene, Nürnberg 1998, Nr. 313 das Bild mit großem Aufwand als >Timokleia und der thrakische Feldherr zu deuten. Offensichtlich ist er dabei von Tiepolos Bild in der Samuel H. Kress Collection (Washington) ausgegangen, das in der Tat eine Variation der Komposition Pelligrinis sein könnte und von manchen Kunsthistorikern als >Timokleiar gedeutet wird. Der bei Tiepolo fehlende Becher ebenso wie der Brief lassen das Bild Pellegrinis aber eindeutig als Darstellung Sophonisbes erkennen. So auch Bettagno, Alessandro (Hrsg.): AK Antonio Pellegrini, Il maestro veneto del Rococò alle corti d' Europa, Venezia 1998, Nr.37. Allerdings wird dort der Bote fälschlich als Massinissa identifiziert, weil der Brief Massinissas, den Sophonisbe eben gelesen hat, keine Beachtung findet. 
ger Schule ${ }^{187}$ zugewiesen [Abb. 36], dürfte freilich in den Umkreis von Lairesse gehören.

Am überzeugendsten ist die Sterbeszene Sophonisbes im Kreise ihrer Familie in einem großen Historienbild [Abb. 37] der Ca' Rezzonico ${ }^{188}$ aus dem Umkreis Giambattista Tiepolos gelungen: Giambattista Crosato (ca. 1697-ca. 1758) zeigt Sophonisbe unmittelbar vor dem Trinken des Giftbechers. Die Komposition hebt durch die Darstellung Massinissas, des weinenden Sohnes der Königin und der Schwester Sophonisbes zu ihrer Linken ganz auf die Akzentuierung der Gattenliebe ab. Auch sie greift damit Motive aus der Theater- und Operntradition auf. Der raffinierte Aufbau mit dem Giftbecher im Zentrum, der farblichen Akzentuierung der weinenden Dienerin in rotem Gewand, der Säule oben links als Herrschaftszeichen und der orientali-

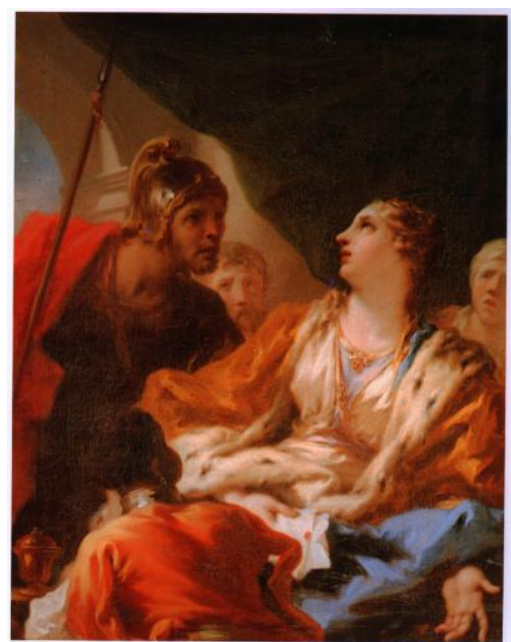

Abb. 35

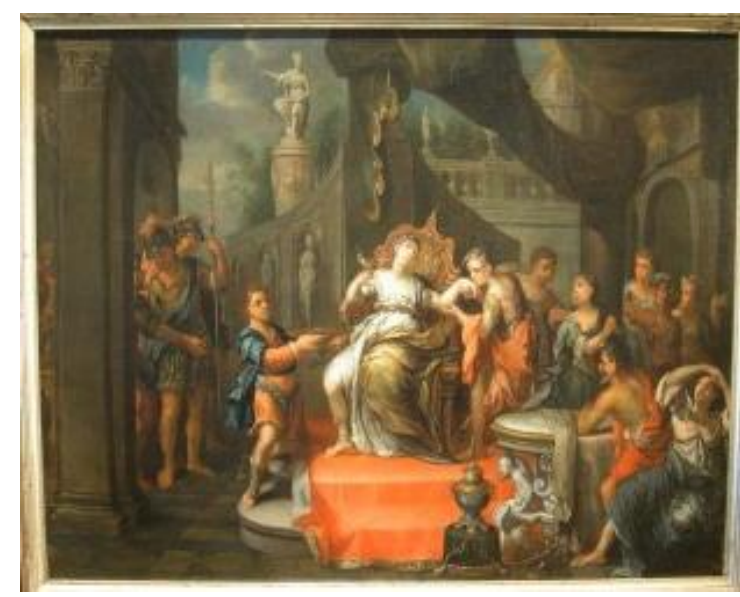

Abb. 36 schen Kopfbedeckung des Massinissa vereindeutigt mit dem Hund als Emblem ehelicher Treue den Sinn der Komposition.

Mit der Französischen Revolution verschwindet Sophonisbe allmählich aus dem Themenrepertoire des Historiengemäldes. Allerdings treten Sophonisbe [Abb.38] und Lukretia noch einmal in der recht verbreiteten Stichesammlung ${ }^{189}$ zur Geschichte der römischen Republik von Silvestre David Mirys (1742/1750-1810)

\footnotetext{
${ }_{187}^{187}$ Katalog 346; Johann Rieger (1660-1730) oder Johann Spillenberger (1628-1679).

${ }^{188}$ Katalog 78.

189 Katalog 246. Folgende Ausgaben sind mir bekannt geworden: Mirys, Silvestre David: Figures de I'Histoire Romaine, accompagnées d'un Précis historique au bas de chaque estampe, [0. O.] [ca. 1800]; Mirys, Silvestre David de: Histoire de la République romaine, représentée par figures, accompagnée d'un Précis historique, Paris [Leblanc] 1800; [Mirys, Silvestre David]: Histoire de la république romaine depuis sa fondation jusqu'au reǵne d'Auguste en 181 gravures en taille-douce, d'apres les dessins de Mirys, Silvestre David, Paris [Stone] 1810.
} 
auf. Beide Motive wurden in Teller-Serien der Porzellanmanufaktur von Creil ${ }^{190}$ aufgegriffen [Abb. 39]. Immerhin wurden noch 1806 und 1844 mit wenig Erfolg Sophonisbe-Opern ${ }^{191}$ komponiert. Ein letztes Mal taucht das Motiv, bezeichnenderweise ganz auf sein psychologisches Interesse reduziert, in den Attitüden [Abb. 40] der Lady Hamilton auf. Der neustoische Hintergrund der Tugendheldin ist nunmehr endgültig zugunsten der Affektdarstellung verschwunden. Das Monodrama des ausgehenden 18. Jahrhunderts dürfte diese letzte, nur noch auf weibliche Affekte abhebende Wendung des Stoffes hervorgebracht haben.

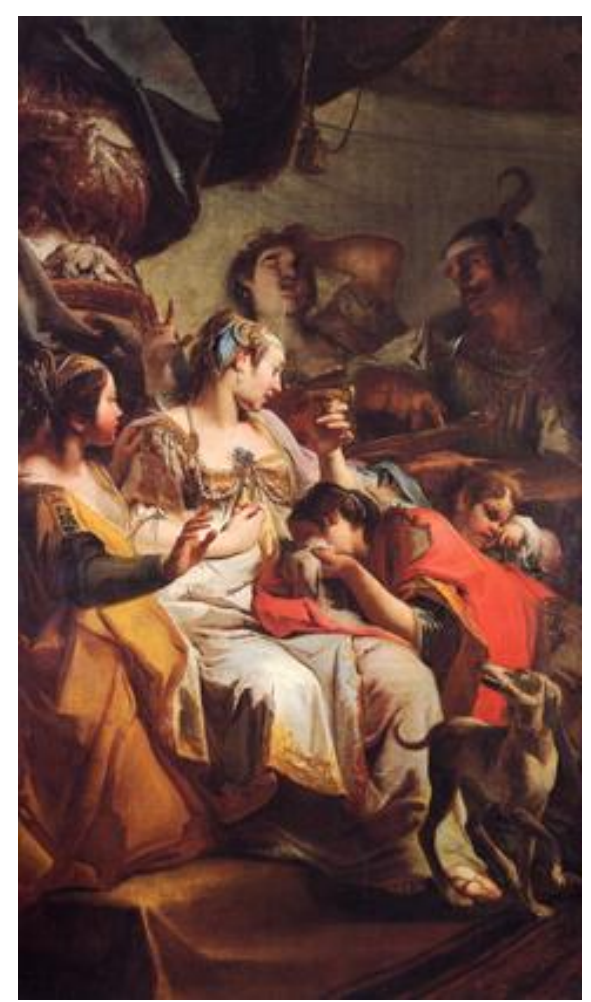

Abb. 37

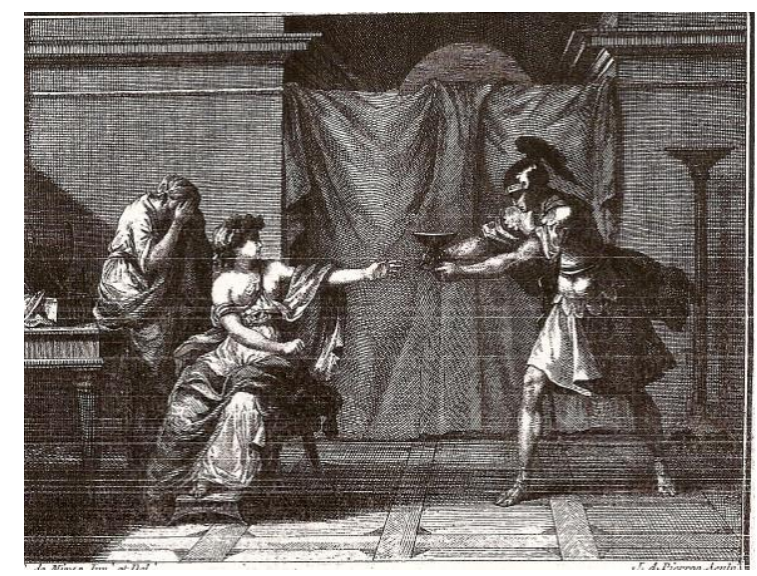

Abb. 38

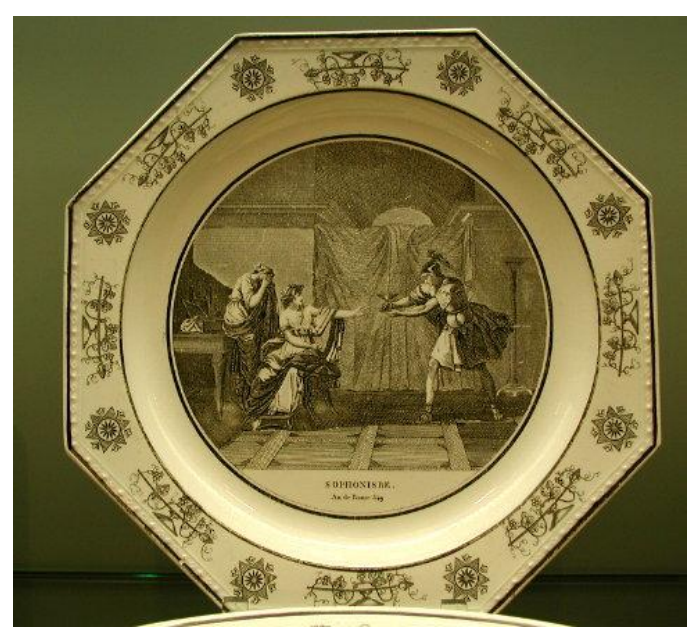

Abb. 39

Sophonisbe war über die literarische Rezeption bei Petrarca und Boccaccio in das Motivrepertoire der Historienmalerei und in die Reihe profaner Tugendheldinnen der Frühen Neuzeit geraten. Naturgemäß veränderten sich Funktion, Bilddramaturgie und Deutung in der Entwicklung von der Graphik des 16. Jahrhunderts bis zum nunmehr psychologischen Interesse des ausgehenden 18. Jahrhunderts. Die frühneuzeitlichen Buchillustrationen brachten eine erste Konzentration auf den Gift-

\footnotetext{
190 Exemplare im Bayerischen Nationalmuseum (nachgewiesen in der Eichstätter Datenbank zur AntikeRezeption/Kunst: http://www1.ku-eichstaett.de/SLF/Klassphil/grau/eichst.htm [zuletzt aufgerufen 04.01.2007]). ${ }^{191}$ Siehe oben, S. $76 \mathrm{ff}$.
} 
becher, aber auch bereits die Alternative, Sophonisbe als `Politikerin` oder als große Liebende darzustellen. Immer neu machte sich seit Trissino der Einfluss der Bühne bemerkbar, ganz unabhängig davon, ob Sophonisbe isoliert oder szenisch ins Bild gebracht wurde. Im Halbfigurenbild konnte die gefühlvolle oder sentimentale Interpretation des Augenblickes dargestellt werden, in dem die Tugendheldin ihren unmittelbar bevorstehenden Tod meditiert. In großen szenischen Darstellungen steht die Reaktion Sophonisbes und ihres Hofstaats auf die fatale Nachricht

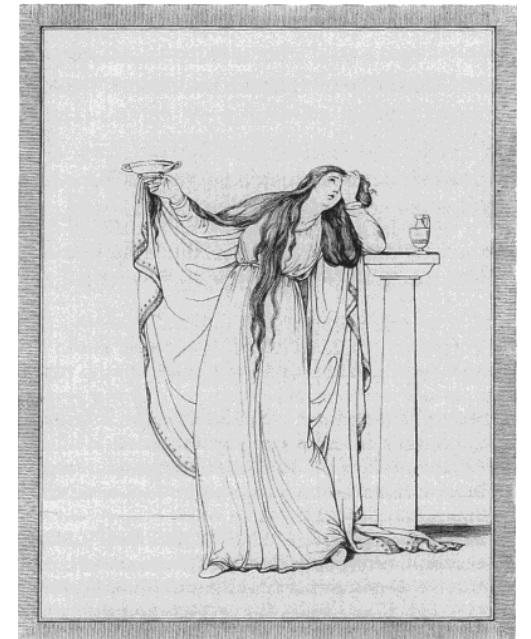

Abb. 40 Massinissas im Mittelpunkt des Interesses, doch stellen die Künstler Sophonisbe meist als exemplum stoischer $\dot{\alpha} \tau \alpha \varrho \alpha \xi i \alpha$ und Seelengröße dar und folgen damit dem Muster der Tugendheldin. Weit weniger als Dido oder Kleopatra scheint Sophonisbe als Herrscherexempel eingesetzt worden zu sein. Meist bestimmte die einmal gefundene Pathosformel der neustoischen Deutung, die die Königin und Liebende unbeirrt in den Tod gehen lässt, die Bilddramaturgie, ganz unabhängig davon, welcher Aspekt hervorgehoben wird. Der Gegensatz von Staatsräson und persönlichem Glück, der die Bühnengeschichte des Stoffs bestimmte, konnte auch im Bild verschieden akzentuiert werden: im Vordergrund stehen die philosophische Aussage, die Affektbeherrschung der Tugendheldin, die Sentimentalisierung der Szene, am Ende der Entwicklung schließlich das psychologische Interesse.

Das als Einleitung ${ }^{192}$ des Kapitels gewählte Kasseler Gemälde Régniers, das die sterbende Sophonisbe mit himmelndem Blick und bereits geleerter Trinkschale, umgeben von verzweifelten Frauen ihres Hofstaates zeigt, ist in der so skizzierten ikonographischen Entwicklung des Sujets deshalb ungewöhnlich, weil es mehrere Deutungen und Akzentuierungen zulässt. Es vereint - insofern ein Unikat in der ikonographischen Entwicklung des Themas - mehrere Phasen der Episode: Sophonisbe hat die Nachricht Massinissas erhalten und reagiert heftig darauf. Die Schale, die aus ihrer linken Hand geglitten ist und im nächsten Moment zerbrechen wird, zeigt, dass die Königin das Gift bereits zu sich genommen hat. Ihr himmelnder Blick lässt also bei Régnier mehrere Deutungen zu: eine realistische, 
IV Liebe, Patriotismus und Selbstbestimmung: Sophonisbe als Tugendheldin

in der die einsetzende Agonie ebenso wie die Verzweiflung der Liebenden gemeint wäre, aber auch ein Nachwirken der neustoisch-philosophischen Deutung, die viele andere Maler dem Blick der Heldin unterlegten, scheint möglich. Régnier hat sich nicht eindeutig für eine dieser Interpretationen entschieden und hat Möglichkeiten kombiniert, die ihm die ikonographische Tradition bot: das auf Emotionen angelegte Halbfigurenbild ebenso wie die aufwendige Theatralik großer Historiengemälde oder die Inszenierung einer Tugendheldin. 


\section{Römische Tugendheldinnen in der Ikonographie der Frühen Neuzeit: Dido, Lukretia, Kleopatra und Porzia}

Der neustoische Hintergrund ebenso wie die Beeinflussung der Bildkonzeption durch die frühneuzeitliche Bühne, aber auch das Interesse an der Affektdarstellung und damit verbunden die allmähliche Sentimentalisierung der Darstellung trifft auch für die anderen römischen Tugendheldinnen des hier behandelten Bildkorpus zu. Sie werden im Folgenden nach gleichen Darstellungsregeln vorgestellt. Auf die historischen und literarischen Quellen der Antike folgt die mittelalterliche und frühneuzeitliche Rezeptionsgeschichte, der sich eine ikonographische Zusammenfassung der Bildgeschichte des Motivs anschließt.

\section{Dido: Herrscherin und Liebende}

\section{Dido: antike Quellen}

In antiken Quellen häufig mit ihrem phönikischen Namen Elissa genannt, wird Dido beim Dichter Naevius (3. Jahrhundert vor Chr.) als sagenhafte Gründerin und Königin Karthagos erwähnt ${ }^{1}$ und erst im 2. Jahrhundert nach Chr. von Justinus ${ }^{2}$ historisch eingeordnet, lange nachdem Vergil in seinem Epos der afrikanischen Regentin eine mythische Schlüsselrolle in der Vorgeschichte Roms gegeben hatte. Ein ganzes, in der Form eines Dramas aufgebautes Buch seiner Aeneis ${ }^{3}$ ist ihrer Liebesgeschichte mit Aeneas, dem sagenhaften Gründer Roms, gewidmet. Das negative oder doch ambivalente Bild, das Vergil von der afrikanischen Gegnerin Roms zeichnete, entsprach den neuen Legitimationszwängen der frühen Kaiserzeit, wie aus Ovids Aufgreifen des Themas ${ }^{4}$ hervorgeht, der Dido ebenfalls als exemplarisch Liebende zeichnet.

Am folgenreichsten war ohne Zweifel das zwiespältige Bild Didos in Vergils Epos, das sie zunächst als durchaus vorbildliche Herrscherin schildert, die nach der Ermordung ihres Ehemannes mit wenigen Getreuen Libyen verließ, in Nord-

\footnotetext{
${ }^{1}$ Naevius: Belli Punici carmen, Fragment 21.

2 Justinus: Epitoma Historiarum Philippicarum Pompei Trogi, XVIII, IV,1 - VI,8.

${ }^{3}$ Vergil: Aeneis I, 335-368 und IV (ganz).

${ }^{4}$ Ovid: Heroides VII; Fasti, III,523-712; Metam. XIV,75 -81.
} 
afrika Zuflucht fand und ein neues Reich gründete. Im Fortgang der epischen Handlung wird das die Rezeptionsgeschichte beherrschende ambivalente Bild der Herrscherin angelegt: In der Begegnung mit Aeneas ${ }^{5}$ rückt Vergil die persönlichen Gefühle der Königin in den Vordergrund und beschreibt eine schmerzlich enttäuschte Liebende. Die Gefühle der schmählich Verlassenen gegen den nach Italien segelnden Aeneas schlagen in tiefen Hass um, der keinen anderen Ausweg als den Selbstmord zulässt. Dido verflucht den Flüchtenden mit einer vaticinatio ex eventu, die die Punischen Kriege ankündigt:

Nullus amor populis nec foedera sunto.

Exoriare aliquis nostris ex ossibus ultor, qui face Dardanios ferroque sequare colonos, nunc olim, quocumque dabunt se tempore vires. Litora litoribus contraria, fluctibus undas Imprecor, arma armis: pugnent ipsique nepotesque. ${ }^{6}$

Die Feindseligkeit der tief verletzten und um ihre Hoffnungen betrogenen Königin wird im römischen Nationalepos zur mythischen Ursache der Auseinandersetzung von Römern und Karthagern im Mittelmeerraum. Die fiktive Liebesgeschichte von Dido und Aeneas legitimiert die Expansionspolitik Roms als Fortführung eines vorhistorischen Geschehens.

\section{Dido: Literarische Rezeption}

In der literarischen Rezeptionsgeschichte des Stoffs wurden beide Aspekte des antiken Materials aufgegriffen: Eine Textgruppe hebt die politische Rolle der Königin hervor, die nach dem Tod ihres Ehemanns Sychaeus Herrscherqualitäten entwickelte und in Afrika einen neuen Stadtstaat gründete. Diese Rezeptionsvariante verbindet mit der politischen Rolle Didos meist das Bild einer über den Tod hinaus treu ergebenen Ehefrau. Ihr prominentester Vertreter wurde Boccaccio. ${ }^{7}$

Die andere literarische Tradition legte das Gewicht auf den inneren Konflikt der Liebenden und der Politikerin: Dido wurde hier zur einer Regentin, die unter dem Eindruck des durch Aeneas auslösten Affektsturms ihre politische Rolle als Regentenwitwe und univira aufgab und von ihren Emotionen mitgerissen am Ende

\footnotetext{
${ }^{5}$ Es ist strittig, ob die Verbindung von Dido und Aeneas auf Naevius, dessen Werk nur fragmentarisch erhalten ist, oder auf Vergil zurückgeht. Vgl. Eisenhut, W.: »Dido «, in: ${ }^{1}$ Kleiner Pauly, Bd. 2, Sp.9-10.

6 »Nie soll Liebe die Völker vereinen und nimmer ein Bündnis! / wachse doch, wer du auch seist, aus unsern Gebeinen, du Rächer, / der du mit Feuer und Schwert heimsuchst dardanische Siedler / jetzt oder einst, wann immer zur Zeit die Kräfte bereit sind. / Strand sei Gegner dem Strand, und Woge der Woge, so bitt' ich, / Waffen den Waffen, und Kampf entzweie sie selbst und die Enkel!« (IV, 624-629; Vergil: Aeneis [hrsg. und übers. von Götte, Johannes], Kempten ${ }^{3} 1971$ )

${ }^{7}$ Bereits Tertullian vertritt die Auffassung, Dido habe den Scheiterhaufen (»ignes «) nicht gescheut, um ihrem verstorbenen Ehemann treu zu bleiben (»ne post virum dilectissimum nubere cogeretur « [mart. 4,5).
} 
zutiefst verletzt den Freitod wählte. Diese Version findet sich vor allem in volkssprachlichen episch-romanesken Texten des Mittelalters.

Da Vergils Text im durch die römischen Klassiker geprägten lateinischen Schulunterricht der Spätantike und des Mittelalters immer präsent war, finden sich schon früh literarische Adaptierungen. Vor allem im Übergang vom volkssprachlichen Epos in den volkssprachlichen Roman erhielt die Figur Didos eine neue Konturierung. `Antikisierende، Romane lösten im Frankreich der zweiten Hälfte des 12. Jahrhunderts die karolingischen Epenstoffe ab und spielten in der Frühgeschichte des höfischen Romans eine große Rolle. So konnte der anonyme altfranzösische Roman d'Enéas ${ }^{8} \mathrm{zu}$ einem durchschlagenden europäischen Erfolg werden. Die Darstellung Vergils wurde ganz in Kontext, Motivik und Problemstellungen der ritterlichen Welt des Mittelalters transponiert. Für die Konzeption des amour courtois wurde die Geschichte der Dido so zu einem wichtigen Exempel. ${ }^{9}$ Besonders die Pflichtvergessenheit des Ritters Enéas wird angeprangert, der wegen seiner unkontrollierten Affekte wichtige höfische Normen nicht beachtet. Aber auch Dido, die durch ihre Schönheit und ihr voreiliges Entgegenkommen den Affektsturm des Enéas ausgelöst hat, wird schuldig gesprochen und erhält die folgenreiche Konnotation einer femme fatale. Diese Neufassung des Stoffs setzte sich in den volkssprachlichen Literaturen durch: Im mittelhochdeutschen Bereich etwa folgte die Eneït Heinrichs von Veldeke ${ }^{10}$ in Handlungsablauf und Wertung weitgehend dem altfranzösischen Vorbild und damit indirekt auch der Vergilschen Vorlage.

Ganz im Gegensatz zu dieser episch-romanesken Tradition, die ein vor allem negatives Bild Didos zeichnete, rechtfertigte Boccaccio in seinem literarisch und ikonographisch lange nachwirkenden De claris mulieribus ${ }^{11}$ Didos Tod und griff deshalb erstmals auf die andere, von Justinus repräsentierte Traditionslinie zurück. Er hob ihren christliche Normen erfüllenden Verzicht auf eine zweite Eheschließung hervor und interpretierte den Selbstmord als unvermeidliche Folge eines unlösbaren Wertekonflikts. Um Didos Keuschheit und Treue zum ersten

\footnotetext{
${ }^{8}$ Le Roman d'Enéas, hrsg. u. übers. von Monica Schöler-Beinhauer, München 1972 (Klassische Texte des romanischen Mittelalters in zweisprachigen Ausgaben 9).

${ }^{9}$ Vgl. Frappier, Jean / Grimm, Reinhold R. (Hrsg.): Le roman jusqu'à la fin du XIII siècle, Partie historique, Heidelberg 1978 (Grundriss der romanischen Literaturen des Mittelalters, IV,1) und Grimm, Reinhold R. (Hrsg.): Le roman jusqu'à la fin du XIII ${ }^{e}$ siècle, Partie documentaire, Heidelberg 1984 (Grundriss der romanischen Literaturen des Mittelalters, IV,2); Schnell, Rüdiger: `Causa amorisı, Liebeskonzeption und Liebesdarstellung in der mittelalterlichen Literatur, Bern 1985.

${ }^{10}$ Heinrich von Veldeke: Eneasroman, hrsg. u. übers. von D. Kartschoke, Stuttgart 1986.

${ }^{11}$ Boccaccio, Giovanni: Tutte le Opere, hrsg. von Vittore Branca, Milano ${ }^{2} 1970$, Bd. X: De mulieribus claris, XLII, De Didone, S. 168-183.
} 
Ehemann zu konturieren, muss Boccaccio in De claris mulieribus die Begegnung mit Aeneas unterschlagen und aus Dido eine zweite Penelope machen, deren Ablehnung ihrer afrikanischen Freier sich moralphilosophisch und didaktisch instrumentalisieren ließ. Vor dem Hintergrund der moraltheologischen Vorstellung dreier aufeinander folgender gesellschaftlicher Rollen der Frau als Jungfrau, Ehefrau und Witwe $^{12}$ stilisiert Boccaccio, die Vergilsche Traditionslinie verschweigend, Dido zum Idealbild einer christlichen Ehefrau, die sich einer zweiten Ehe widersetzt. Auf diesem Umweg gelingt es Boccaccio, überraschend genug, den Selbstmord Didos in bonam partem zu interpretieren, weil die Königin den Pflichten der Witwe den Vorzug vor einer neuen Liebe gibt.

Aber auch bei Boccaccio gerät Dido aufgrund einer anderen, durchaus mittelalterlichen Kausalitätskette ${ }^{13}$ in einen Konflikt zwischen konkurrierenden Pflichten als Ehefrau und als Herrscherin. Zwar legt sie als Staatsgründerin und Regentin ımännliche، Eigenschaften an den Tag, wenn sie auf der Flucht aus Libyen eine Begleitmannschaft requiriert und auf Zypern junge Mädchen entführen lässt, um in Afrika ein neues Volk zu gründen. Gleichwohl lehnt sie die Bitten ihrer Untertanen, sich wieder zu verheiraten, ab und gibt der Treue zum verstorbenen Ehemann den Vorrang. Aus dem Vergilschen Konflikt zwischen Herrscherin und Liebender wird ein Konflikt zwischen Regentin und christlicher Ehefrau.

Christine de Pizan, die wohl bedeutendste volkssprachliche Schriftstellerin des französischen Mittelalters, entwickelte die von Boccaccio entworfene Rechtfertigung des Selbstmords der Dido im Livre de la Cité des Dames (1404/1405) auf ihre Weise weiter. Auch sie begreift Dido als selbständige Frau (virago), die ein keusches, unabhängiges und autonomes Leben führt. Um Didos Herrscherfähigkeiten zu demonstrieren, greift Christine auf die schon von Justinus überlieferte Anekdote ${ }^{14}$ zurück, nach der Dido viel Land erwarb, indem sie eine Rinderhaut in dünne Streifen schnitt und zu einem langen Gurt zusammenband, um damit das ihr zustehende Land abzugrenzen.

Et tant se gouverna nottablement et par grant prudence qu'en toutes terres en aloient les nouvelles et ne parloit on se d'elle non telement que pour la grant vertu qui fu veue en elle, tant pour la hardiece et belle entreprise que fait avoit comme pour son tres prudent gouvernement. Lui transmuerent son nom et l'appellerent Di-

\footnotetext{
12 Boccaccio, Giovanni: De claris mulieribus, Die großen Frauen, hrsg. u. übers. von I. Erfen / P. Schmitt, Stuttgart 1995, S. $241 \mathrm{f}$.

${ }^{13}$ Vgl. Kolsky, Stephen D.: The Genealogy of Women, Studies in Boccaccio's De mulieribus claris, New York / Bern / Frankfurt/Main 2003, S. 30 und S. 60.

${ }^{14}$ M. Iunianus lustinus: Epitoma Historiarum Philippicarum XVIII, 5,9.
} 


\section{Dido: Herrscherin und Liebende}

do, qui vault a dire comme virago en latin, qui est a dire celle qui a vertu et force d'omme. ${ }^{15}$

Christine wertet den Selbstmord Didos dadurch moralisch noch weiter auf, dass die Beständigkeit der Liebe zum ersten Gatten ihre weibliche Tugend bestätigt. ${ }^{16}$

Spätestens zu Beginn des 16. Jahrhunderts setzte sich das von der epischromanesken Tradition geprägte Bild Didos durch, das vor allem auf Vergils dramatischer Ausgestaltung der Liebesgeschichte beruht. Mit dem Drama Dido in Cartagine (1524) des Pazzi de' Medici (1483-1530) wurde der Stoff auf die Bühne gebracht, wo er bis weit ins 18. Jahrhundert ${ }^{17}$ ein beliebter, verschieden besetzbarer Vorwurf blieb. Die Bühnenbearbeitungen waren für die Ikonographie der Historienmalerei besonders folgenreich, weil sie dem Konflikt zwischen politischer Rationalität und weiblicher Affektivität einen neuen Themenbereich eröffneten. In einer Epoche, in der divergierende Modelle gesellschaftlichen Handelns diskutiert und erprobt wurden, konnten im Gewand antiker Geschichte paradigmatisch aktuelle Probleme erörtert werden. Da der Dido-Stoff bereits in der Antike als Konflikt zwischen sPolitik und Liebe` verstanden worden war, eröffnete er den Dramatikern und damit der Historienmalerei einen großen Aktualisierungsspielraum. ${ }^{18}$

\footnotetext{
${ }^{15}$ Christine de Pizan: La Cité des dames, I, 46: "Sie regierte so vortrefflich und unsichtig, daß die Kunde davon in alle Länder drang; man sprach von nichts anderem als von ihr. Das ging so weit, daß man wegen ihrer großen Tugend, der Kühnheit und der Vollkommenheit ihres Werks und ihrer äußerst klugen Regierungsweise ihren Namen umänderte in Dido: das bedeutet soviel wie virago auf lateinisch, will sagen: eine Frau, die die Tugend und die Kraft eines Mannes besitzt. «

Ich zitiere nach Skemp, Mary (Hrsg.): ıLe Livre de la Cité des Damesı de Christine de Pizan: an electronic transcription, Electronic Text Research Center, University of Minnesota, Minneapolis, MN, 1999 (http://erc.lib.umn.edu/dynaweb/french/pizalaci/@Generic_BookView;lang=fr). Die Übersetzung nach Christine de Pizan: Das Buch von der Stadt der Frauen, hrsg. u. übers. von Margarete Zimmermann, Berlin ${ }^{2} 1987$, S. 46. $\mathrm{Zu}$ Christines Umdeutung antiker Heroinen vgl. Feichtinger, Barbara: »Antikerezeption mit Ambitionen. Christine de Pizans Livre de la Cité des Dames und Boccaccios De claris mulieribus«, in: Schmidt, Paul Gerhard (Hrsg.): Die Frau in der Renaissance, Wiesbaden 1994, S. 203-222.

16 „S'en ala, sans congié prendre, de nuit, en recelee, traytreusement, sans le sceu d'elle. Et ainsi paya son oste, laquelle departie fu si grant douleur a la lasse Dido qui trop amoit que elle voult renoncier a joye et vie." (»Ohne von ihr Abschied zu nehmen, schlich er sich des Nachts heimlich und ohne ihr Wissen davon: auf diese Weise belohnte er seine Gastgeberin. Diese Trennung schmerzte die arme Dido, deren Liebe grenzenlos war, so sehr, daß sie beschloß, von nun an auf jegliche Freude und überhaupt das Leben zu verzichten. «) (Cité des Dames, II,55)

17 Vgl. S. $278 f f$.

${ }^{18}$ Vgl. Frenzel, Elisabeth: Stoffe der Weltliteratur, Stuttgart ${ }^{7} 1988$, S. 150-153; Leube, Eberhard: Fortuna in Karthago, Die Aeneas-Dido-Mythe Vergils in den romanischen Literaturen vom 14. bis zum 16. Jahrhundert, Heidelberg 1969; Kailuweit, Thomas: Dido - Didon - Didone, Eine kommentierte Bibliographie, Frankfurt / Berlin / Bern 2005.- Im 16. Jahrhundert wurde der Dido-Stoff in allen europäischen Literaturen für das Th e a t e r bearbeitet; zu nennen sind u. a. G. B. Giraldi Cinthio (1541), Ludovico Dolce (1547), Étienne Jodelle: Didon se sacrifiant (1560 [Erstdrucke 1574,1583 und 1597, kritische Edition von Christine de Buzon / JeanClaude Ternaux 2002], Guillaume de La Grange (1582) und Christopher Marlowe (1594), Alexandre Hardy: Didon se sacrifiant (1603), Georges Scudéry: Didon (1638), François Le Métel de Boisrobert: Didon la Chaste, ou les amours d'Hyarbas (1642), Jacob Montfleury: Les Amours de Didon et d'Enée, ou l'Ambigu comique (1673). - Walthaus, Rina: La nieve que arde o abrasa. Dido en Lucretia in het Spaanse drama van de 16de en 17de eeuw, Leiden 1988 (abzurufen unter: http://home.wxs.nl/ pagklein/rina/tesis.html; zuletzt aufgerufen: 08.08.2006) untersucht eine ganze Reihe von Dido- und Lukretia-Dramen im spanischen Theater des 16. und 17. Jahrhunderts: Juan Cirne (Tragedia de los amores de Eneas y de la Reyna Dido), Guillén de Castro (Dido y Eneas), Guillén de Castro (Dido y Eneas. No ay mal que por bien no venga), Francisco de Villegas (El más
} 
Auch die Historienmalerei, die insgesamt den Vorwürfen der Bühne folgte, entwickelte bis ins 19. Jahrhundert immer neue Interpretationsvarianten: Die Ikonographie Didos reicht von der ızarten Seeleı bis zum Emblem des archaischen und archetypischen Hasses einer verschmähten Liebenden, die der Anblick des davonsegelnden Liebhaber zur Furie macht.

\section{Dido: Ikonographie der Historienmalerei}

Die Behandlung des Dido-Stoffes in der Historienmalerei folgte den großen Tendenzen der historiographisch-literarischen Bearbeitungen. So ist es nicht überraschend, dass die Ikonographie der Selbstmord begehenden Königin zwei nacheinander entwickelte, dann aber konkurrierend weitergeführte Akzentuierungen kennt.

Die ältere Bildtradition stellte die Regentin in den Vordergrund; eine Ausgabe des Roman d'Enéas (14. Jahrhundert) zeigt in den Text begleitenden Miniaturen [Abb. 1 und Abb. 2] die wichtigen Stationen der Reise des Aeneas und gibt

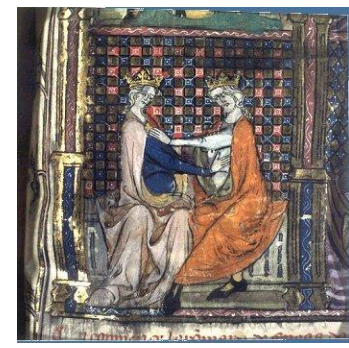

Abb. 1

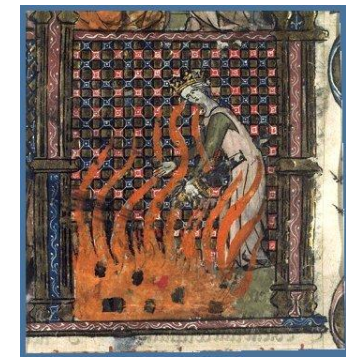

Abb. 2

der Dido-Episode nur einen unter geordneten Stellenwert. ${ }^{19}$ Erst unter dem Einfluss der frühneuzeitlichen Historiendramen konnte sich eine andere Bildtradition entwickeln, die pointiert den Konflikt Didos zwischen Politik und Liebe aufgriff.

Die Holzschnittillustrationen der frühen Wiegendrucke zeigen, Justinus folgend, Dido als Städtegründerin, Herrscherin und treue Witwe (univira). Der Holzschnitt des unbekannten Meisters [Abb. 3], der 1473 zunächst die lateinische,

piadoso troyano), Cristóbal de Morales (Los amores de Dido y Eneas), Lorenzo de las Llamosas (Destinos vencen finezas), Cristóbal de Virués (Elisa Dido), Gabriel Lobo Lasso de la Vega (Tragedia de la honra de Dido restaurada), Alvaro Cubillo de Aragón (La honestidad defendida de Elisa Dido, Reyna, y fundadora de Cartago), Juan Pastor (Farsa de Lucrecia), Francisco de Rojas Zorrilla (Lucrecia y Tarquino) und Agustín Moreto y Cabaña (Baile de Lucrecia y Tarquino). Walthaus zeigt, dass (im Übrigen vergleichbar mit der französischen Entwicklung) der zunächst auf den inneren moralischen Kern der Identität zielende, aristokratische Begriff der Ehre (honor / honra / honestidad) mit der Wende vom 16. zum 17. Jahrhundert eine spolitischer (gesellschaftliche) Dimension erhält. - Zu den Operbearbeitungen ausführlich unten, S. $274 \mathrm{ff}$, bes. S. 275; Anm. 22. Im 17. Jahrhundert hatte der Stoff seinen größten Einfluss in der Oper (u. a. Purcell 1688, Steffani 1695). Der andauerndste Erfolg gelang 1724 Metastasio mit seinem Libretto, das die Vorlage zahlreicher Vertonungen wurde. - Im 18. Jahrhundert ist Dido wieder verstärkt im Drama und neuen theatralischen Formen wie dem Monodrama zu finden; Charlotte von Steins Drama von 1794 (Charlotte von Stein: Dramen, hrsg. von Susanne Kord, Hildesheim / Zürich / New York 1988) entspricht ganz dem etwas epigonalen Zeitstil wie auch August Siegfried von Goués »Duodrama« (Wetzlar 1771), das neben Dido ihre Schwester Anna zur Protagonistin macht (zum Monodrama vgl. unten S. 292).

${ }^{19}$ Katalog 350. 
ein Jahr später die deutsche Ausgabe Boccaccios ${ }^{20}$ in der Offizin des Ulmer Frühdruckers Johannes Zainer illustrierte, zeigt die Königin, wie sie die Gründung Karthagos beaufsichtigt und Anweisungen erteilt. Andere staatspolitische Aktionen, etwa die bereits erwähnte

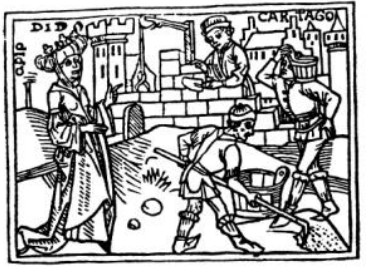

Abb. 3 List mit der zerschnittenen Ochsenhaut ${ }^{21}$ oder der Empfang von Aeneas und seinen Gefährten ${ }^{22}$, werden vergleichsweise selten aufgegriffen. Ein Blick in Piglers Kompendium ${ }^{23}$ zeigt, dass solche den politischen Scharfsinn betonenden Szenen besonders zu Beginn des 16. Jahrhunderts häufig als Teil von Aeneas- oder DidoZyklen konzipiert wurden.

Aeneas-Serien ${ }^{24}$ waren als Ausstattung von Rathäusern oder Palazzi beliebt. Dido-Folgen wurden hingegen für Hochzeitstruhen (cassonı) ${ }^{25}$ verwendet und zeigen die Königin als vorbildliche höfische Gastgeberin [Abb. 4], aber auch, ihre Treue bis in den Tod betonend, den Selbstmord [Abb. 5], wie beispielsweise

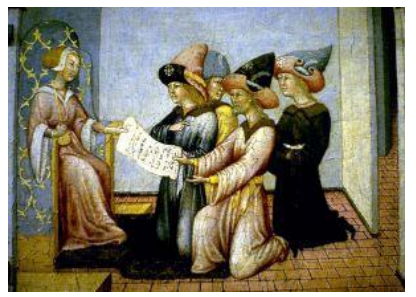

Abb. 4

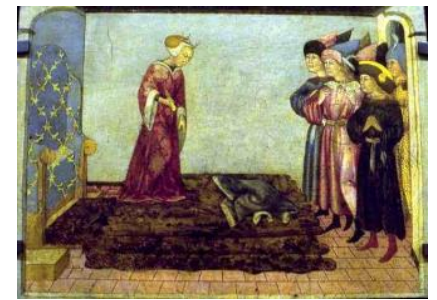

Abb. 5

um die Mitte des 15. Jahrhunderts der >Meister von Lecceto ${ }^{26}$ Auch Liberale da Verona (ca. 1445-1530) hat auf der Londoner Tafel ${ }^{27}$, die wohl ebenfalls Teil eines cassone war, den Selbstmord Didos eindrucksvoll [Abb. 6] in einer imposanten

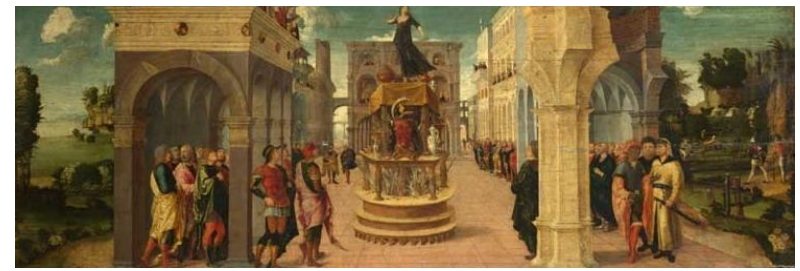

Abb. 6

\footnotetext{
${ }^{20}$ Vgl. Katalog 414; Gathercole, Patricia M.: Tension in Boccaccio: Boccaccio and the fine arts, Mississippi 1975 , S. $61 \mathrm{f}$

${ }^{21}$ Vgl. oben S. 106 und Pigler, Andor: Barockthemen, Eine Auswahl von Verzeichnissen zur Ikonographie des 17. und 18. Jahrhunderts, Bd. II (Profane Darstellungen), Budapest / Berlin 1956, S. 298.

${ }^{22}$ Vgl. Katalog 79. In einer der Aeneis-Illustrationen zeigt Giovanni Antonio da Brescia Dido beim Empfang des Aeneas.

${ }^{23}$ Vgl.Pigler, a.a.O. (immer Bd. II), S. 267-268, 270, 298-300.

${ }^{24}$ Vgl. Pigler, a.a.O., S. 267-280.

${ }^{25}$ So die im Niedersächsischen Landesmuseum Hannover befindlichen Cassoni-Tafeln von Apollonio di Giovanni, die die Ankunft des Aeneas bei Dido, ihre gemeinsame Jagd und ein Festbankett zeigen (vgl. Katalog 18 und 19). Näheres zu den Cassoni unten S. 123, Anm. 35. Allgemeinere Überlegungen zur Cassoni-Malerei in jüngster Zeit bei Baskins, Cristelle: Cassone painting, humanism, and gender in early modern Italy, Cambridge 1998.

${ }^{26}$ Katalog 219.

27 Katalog 84; vgl. Baker, Christopher / Henry Tom (Hrsg.): The National Gallery, Complete Illustrated Catalogue, London 1995, S. 378.
} 
Stadtarchitektur in Szene gesetzt. Ausschließlich auf die Funktion als Herrscherin hebt Mantegna (ca. 1430-1506) ab, der Dido in einer Grisaille [Abb. 7] ganzfigurig und statuarisch zeigt. ${ }^{28}$

Die über Boccaccio auf Justinus zurückführende Akzentuierung, die Didos Status als Politikerin und treue Ehefrau betont hatte, nahm unter dem Einfluss der frühneuzeitlichen Bühnenbearbeitungen des Stoffs eine neue Wendung. Während die offiziellen Rollen zurücktreten, bestimmten nun auch in den Künsten Emotion und Leidenschaft, Verzweiflung und Hass, ganz in der Tradition der Aeneis die Bildkonzeption. Viele graphische Einzelblätter zeugen von der Faszination dieses Selbstmords. Sowohl Marcantonio Raimondi (1475-1534) [Abb. 8] ${ }^{29}$ als auch Albrecht Altdorfer (um 1480-1538) ${ }^{30}$ [Abb. 9] haben in vergleichbarer Weise

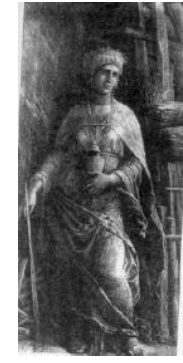

Abb. 7 Didos Tod isoliert und ganzfigurig inszeniert.

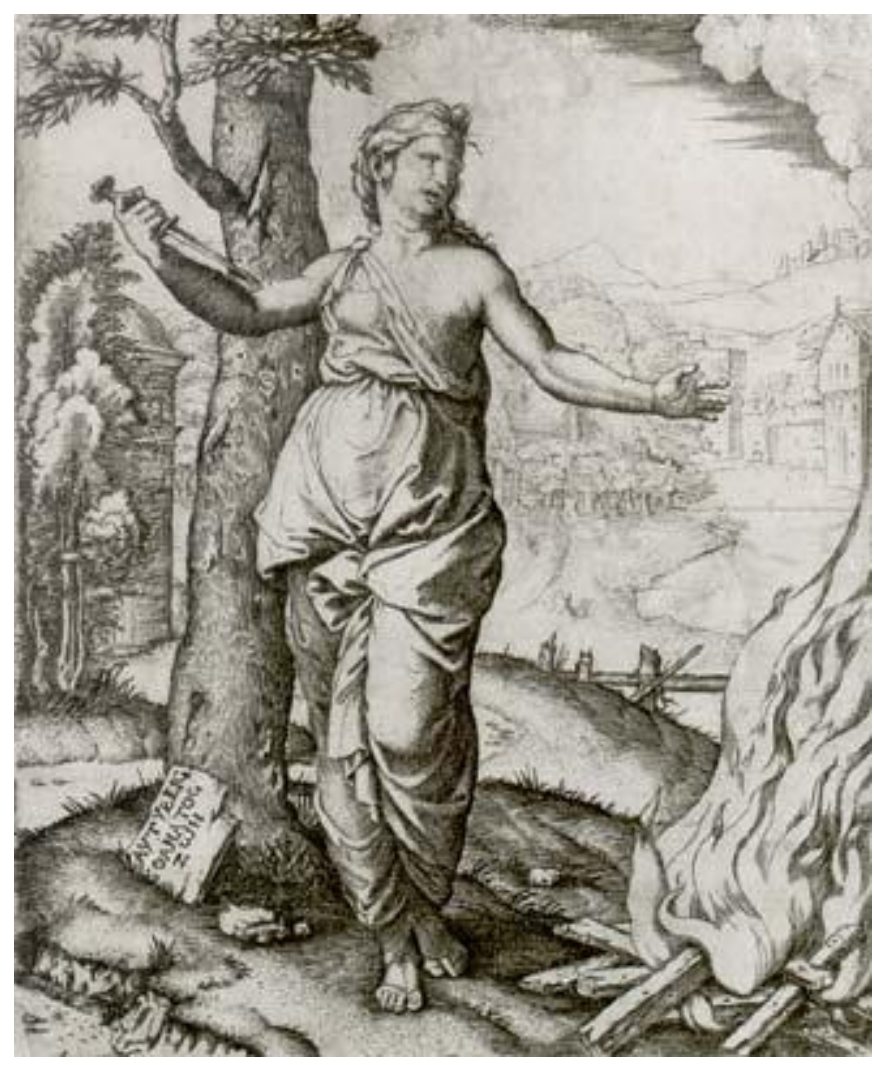

Abb. 8

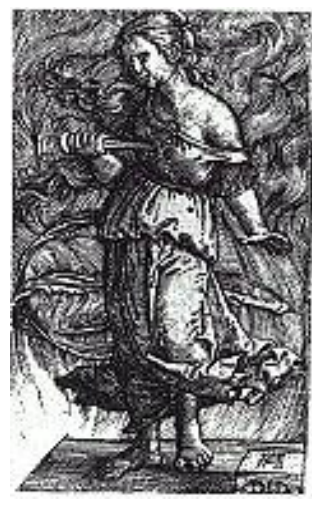

Abb. 9

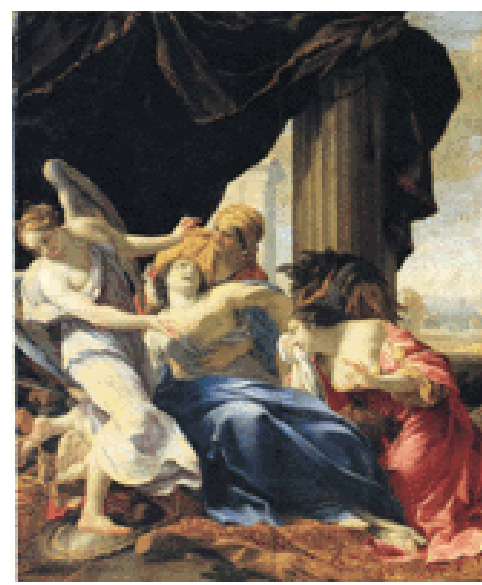

Abb. 10

\footnotetext{
${ }^{28}$ Katalog 229.

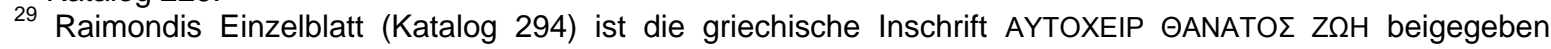
(Selbstmord ist Leben); das Blatt geht wohl auf eine Zeichnung Raffaels zurück; vgl. Höper, Corinna (Hrsg.): AK Raffael und die Folgen, Stuttgart 2001, S. 204 mit teils unklaren, teils falschen Angaben zur Inschrift. ${ }^{30}$ Katalog 5.
} 
Die Liebesgrotte, in der Aeneas und Dido zueinander finden, wird erst in der Romantik ${ }^{31}$ ein reizvolles Bildmotiv; der frühneuzeitliche Geschmack wertete eine derartige Darstellung wohl als indezent und unziemlich. Vielmehr lieferte das Ende der Liebesgeschichte die bevorzugten Vorwürfe.

Simon Vouet (1590-1649) greift bei seiner Dido ${ }^{32}$ [Abb. 10] ebenso wie Guercino (1591-1666) [Abb. 11] auf an großes Theater erinnernde Gesten zurück. ${ }^{33}$ Vouet hält sich dabei sehr eng an die literarische Vorlage der Aeneis und lässt neben Schwester und Dienerin auch die Götterbotin Iris zur Sterbenden eilen. Das sich heute in der Galleria Spada befindende Gemälde Guercinos zeigt eine Dido, die sich das Schwert des Aeneas bereits durch den Körper gestoßen hat. Sie liegt verblutend auf dem Scheiterhaufen, auf dem die Erinne

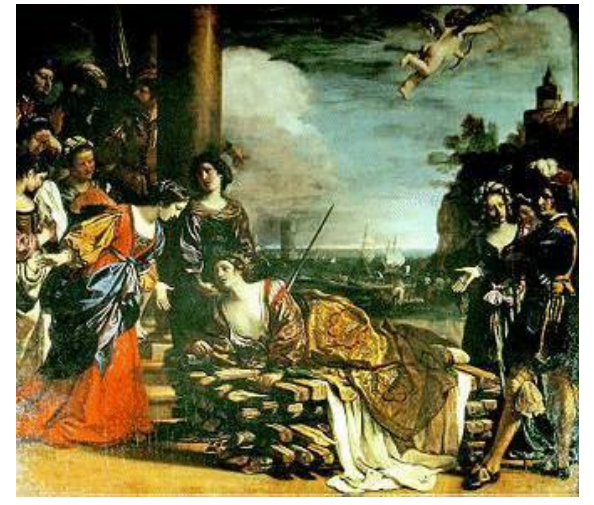

Abb. 11 rungsstücke an Aeneas verbrannt werden sollen. Der die Szene mit intensiven Af-

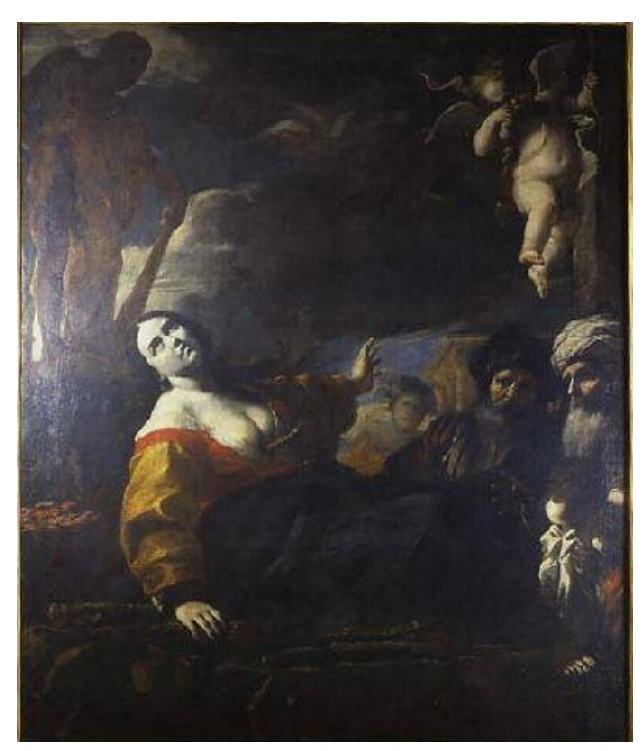

Abb. 12

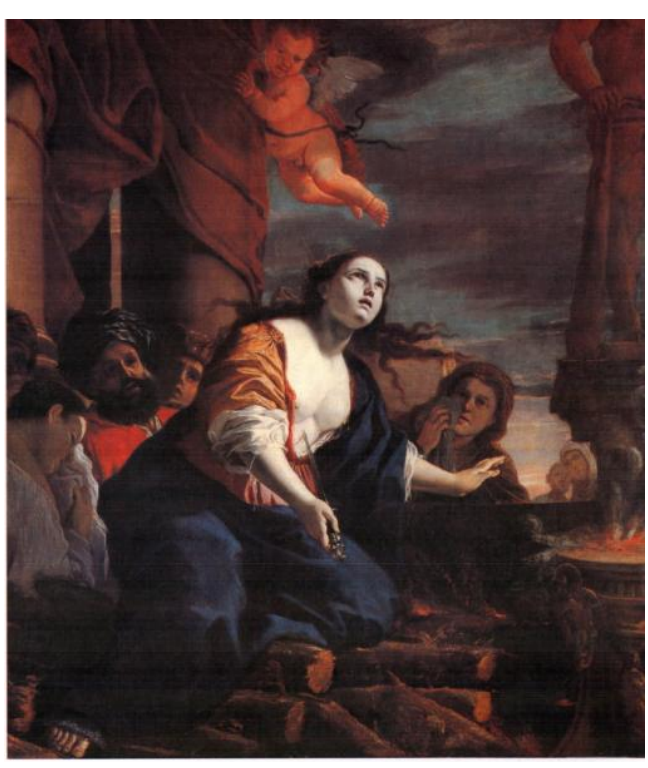

Abb. 13

fekten kommentierende Hofstaat könnte direkt aus einer theatralischen Inszenierung stammen.

\footnotetext{
${ }^{31}$ So beispielsweise Jacob Philipp Hackerts Aeneas und Dido von 1804 (im Landesmuseum Hannover, vgl. Katalog 174). Im Vordergrund flüchten Dido und Aeneas, in leichter Jagdkleidung und nur von Hunden begleitet, in die Höhle. Im Mittel- und Hintergrund sind Landschaft, bewegte See und ein sich eben entladendes Gewitter zu sehen.

${ }^{32}$ Katalog 426.

${ }^{33}$ Heute in der Galleria Spada, vgl. Katalog 170.
} 


\section{Römische Tugendheldinnen in der Ikonographie der Frühen Neuzeit}

Mattia Preti (1613-1699) hat sich mindestens zweimal mit dem Thema beschäftigt. Zu der Version, die sich heute in Chambéry [Abb. 12] befindet, gehört als Pendant eine Judith, die das abgeschlagene Haupt des Holofernes vorweist. ${ }^{34}$ In der Zusammenstellung einer alttestamentlichen und einer profanen Tugendheldin werden Entschlossenheit und Mut der beiden Frauengestalten betont. ${ }^{35}$ Den Aufbau des Braunschweiger Bildes [Abb. 13] konzipierte Preti ganz ähnlich: Dido ist, obwohl ganzfigurig gegeben, dadurch ganz an den Betrachter herangerückt,

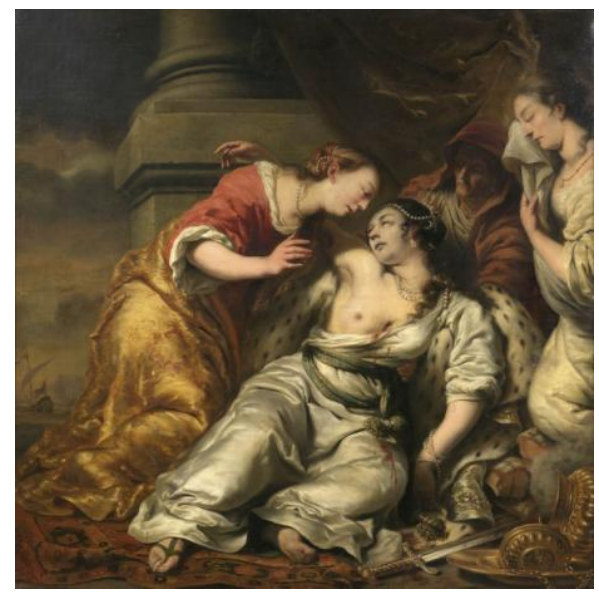

Abb. 14 dass sie auf dem Scheiterhaufen kniet. Das fahle Inkarnat der entblößten Brust lenkt den Betrachter auf ihre das Kurzschwert führende Hand und ihren himmelnden Blick. Orientalisch gekleidete Männer beobachten den Selbstmord, während die Frauen bereits ihrem Schmerz Ausdruck verleihen. Trotz der Gedrängtheit der Szene hat der Maler nicht auf die Hoheitssymbole des Baldachins und der Säulen verzichtet. Herakles-Statuen weisen in beiden Ausführungen darauf hin, dass der Selbstmord der afrikanischen Königin als constantia gedeutet wird.

Ferdinand Bol (1616-1680) umgibt die sterbende Königin in einem erst seit

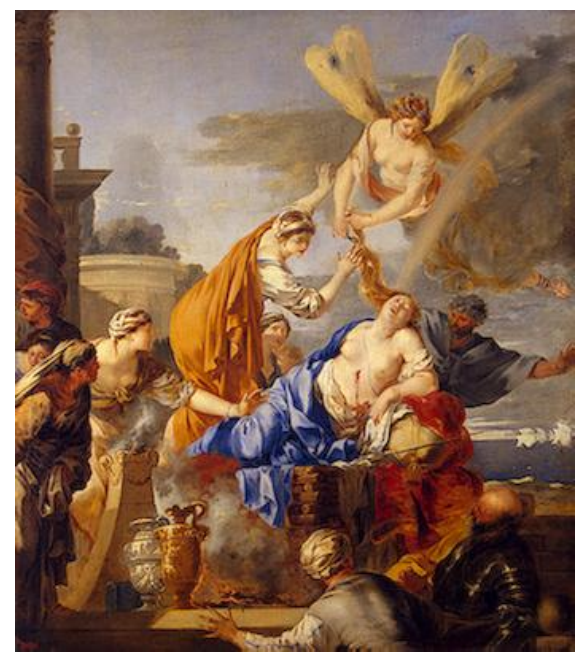

Abb. 15

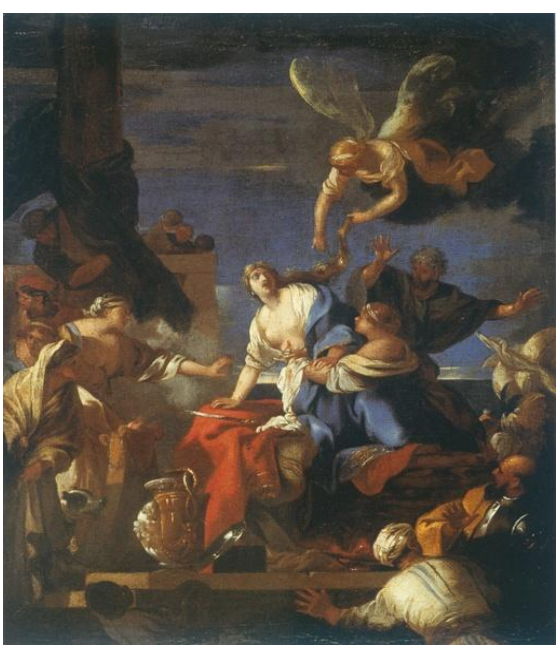

Abb. 16

kurzem bekannt gewordenen Historiengemälde [Abb. 14] mit ihren Zofen und ihrer Amme. ${ }^{36}$ Das ganz auf die Affektdarstellung der bis zur Selbstaufgabe treuen Dido

\footnotetext{
${ }^{34}$ Vgl. Katalog 285 (Braunschweig) und Katalog 284 (Chambéry).

${ }^{35}$ Vgl. unten S. $251 \mathrm{ff}$.

${ }^{36}$ Katalog 39. »Dieses bislang in der Literatur nicht erwähnte Gemälde ist laut Werner Sumowski ein ıHauptwerk im Spätwerk Bols, von musealem Rangr. [...] Laut Sumowski dürfte Didos Tod kurz nach 1660 entstan-
} 
und ihrer trauernden Umgebung konzentrierte Gemälde besticht durch das sorgfältig ausgeführte Stilleben und die dekorative Pracht der Gewänder.

Große, an das Schlusstableau auf der Bühne erinnernde Szenen haben im 17. Jahrhundert eindeutig den Vorrang. Die Bildlösungen, die Sébastien Bourdon $(1616-1671)^{37}$ [Abb. 15 und 16], Orazio Fidani (ca. 1610 - nach 1656) [Abb. 17], Gregorio Lazzarini (1655-1730) ${ }^{38}$ [Abb. 18] oder Johann Heiss $(1640-1704)^{39}$ [Abb. 19] gefunden haben, umgeben die stets ganzfigurig gegebene Sterbende mit ihrem Hofstaat. Bourdon lässt in allen bekannten Fassungen ${ }^{40}$ wie Vouet die Götterbotin Iris auftreten und entwirft eine bewegte `Opferszene` am Meer. Fidani ${ }^{41}$ hat die Szene mit einem weinroten Samtvorhang hinterfangen und zeigt bildparallel fünf Bediente, die sich um die tödliche Wunde ihrer Königin kümmern. Die caravaggeske Lichtregie hebt die in der linken Bildhälfte sitzende und nach hinten sinkende Königin hervor. Ge-

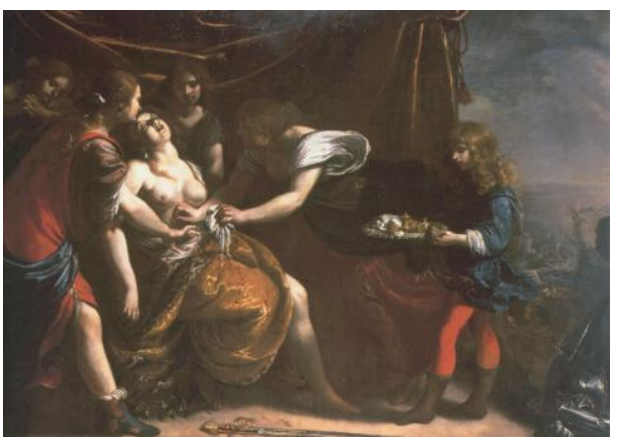

Abb. 17 schlossene Augen, halbgeöffnete Lippen und die Marmorblässe des nackten Oberkörpers akzentuieren die Agonie der Protagonistin. Im Vordergrund liegt das blutige Schwert auf der Erde; ganz rechts wird der Blick auf einen Hafen hinunter freigegeben, aus dem das

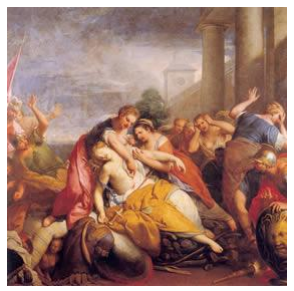

Abb. 18

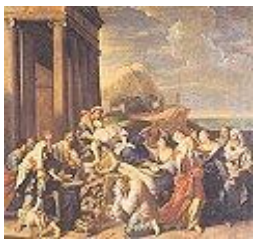

Abb. 19 Schiff des Aeneas hinaussegelt.

\footnotetext{
den sein: >Der Künstler verbindet damals in großformatigen Historienbildern für öffentliche Gebäude und für Patrizier-Palais rembrandteske und flämische, von Rubens abzuleitende Stilelemente. Die Gemälde (mit antiken oder biblischen Sujets) propagieren religiöse, politische und allgemein menschliche Ideale. [...] In der monumentalen Komposition, in der eleganten Malweise und im virtuosen Kolorit passt das Bild zur Allegorie auf den Unterricht von 1663 im Rijksmuseum in Amsterdam [...].« (Aus dem Katalog des Auktionshauses Nagel)

${ }^{37}$ Katalog 48 (Bézier, Ölskizze), 49 (St. Petersburg) und 50 (Bilbao). Vgl. den kritischen Gesamtkatalog von Thuillier, Jacques: Sébastien Bourdon, 1616-1671, Paris 2000, S. 101f., 223ff., 383.

${ }^{38}$ Katalog 206.

${ }^{39}$ Katalog 177.

40 Juan J. Luna (»Bourdon et l'Espagne«, in: Thuillier, Jacques, a.a.O., S. 102) hält die Fassung von Bilbao offensichtlich für eine vielleicht eigenhändige Replik des Bildes von St. Petersburg. Eine weitere Fassung (1982 im römischen Kunsthandel) wäre nach Thuillier deutlich später als das Bild in St. Petersburg anzusetzen und könnte die Kopie eines verlorenen Originals sein.

${ }^{41}$ Katalog 127.
} 
Ottmar Elliger der Ältere (1633-1679) ${ }^{42}$ und Ottmar Elliger der Jüngere (1666-1732) scheinen geradezu auf das Dido-Thema spezialisiert gewesen zu sein und haben dramatisch bewegte Szenen des Todes der Dido entworfen. ${ }^{43}$ Das Augsburger Bild [Abb. 20] ${ }^{44}$ des jüngeren Elliger ist zentralperspektivisch ganz auf die Hauptfigur ausgerichtet; im Zentrum der Bilddiagonalen lagert Dido, der sich die Assistenzfiguren in heftigen Bewegungen von links und rechts nähern. Auch in der Braunschweiger Fassung [Abb. 21] $]^{45}$ hat Elliger mit einer Pyramidalkonstruktion

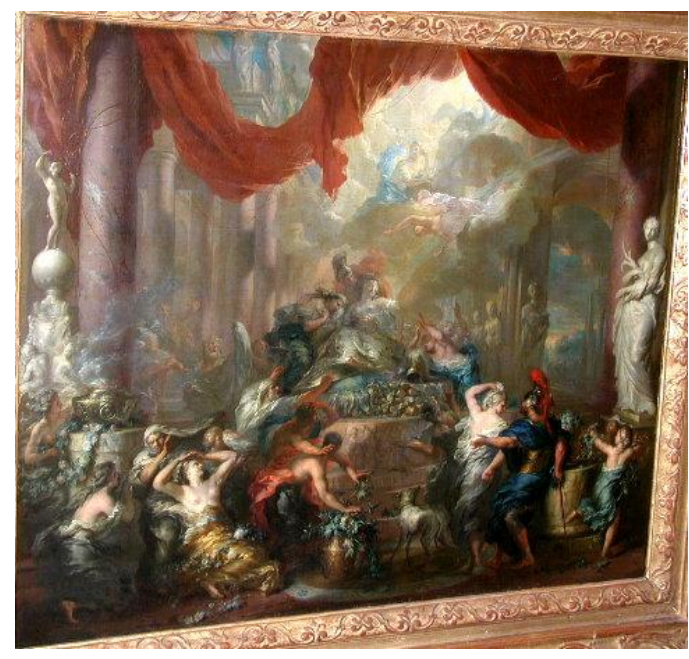

Abb. 20

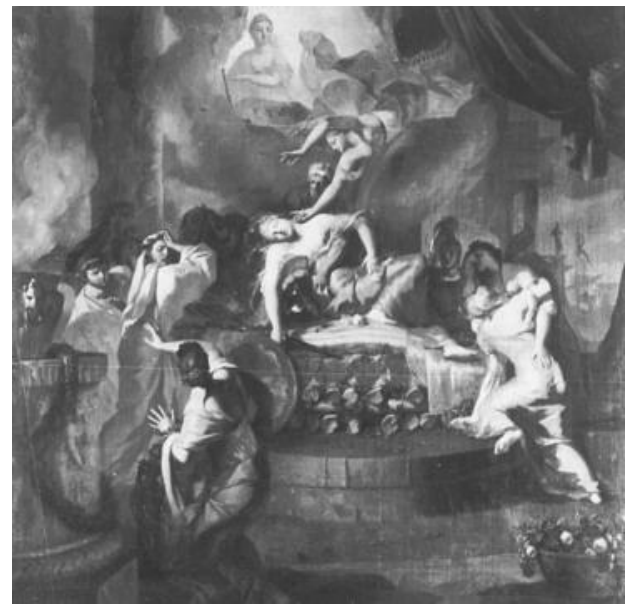

Abb. 21

und pathosreichen Figuren das heroische Ende der afrikanischen Königin klassizistisch inszeniert; er folgt dabei einer Eau-forte-Ausführung ${ }^{46}$ seines Lehrers Gerard de Lairesse (1640-1711). Noch Joshua Reynolds (1723-1792) löst [Abb. 22] 1781 die Aufgabe traditionell und mythisierend, wenn auch er die Götterbotin Iris eine Locke der Königin abschneiden lässt, um ihrem Sterben ein Ende zu bereiten. ${ }^{47}$

Die Variante, mit der 1756 Matthäus Günther

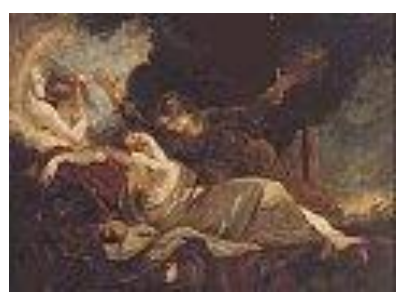

Abb. 22

\footnotetext{
${ }^{42}$ Eine für mich nicht lokalisierbare dramatisch-bewegte Szene des älteren Elliger (Katalog 115) findet sich bei: http://www.ac-nancy-metz.fr/enseign/lettres/LanguesAnciennes/Textes/Virgile/Didon.htm. Dort sind auch mehrere Fassungen des Themas von Elliger d. J. abgebildet (zuletzt aufgerufen: 07.01.07).

${ }^{43}$ Eine Auflistung in Jacoby, Joachim: Kat. Herzog Anton Ulrich-Museum Braunschweig, Die deutschen Gemälde des 17. und 18. Jahrhunderts, Braunschweig 1989, S. 110.

${ }^{44}$ Katalog 116. In diesen Zusammenhang könnte ein weiteres Gemälde im Puschkin-Museum (http://www.acnancy-metz.fr/enseign/lettres/LanguesAnciennes/Textes/Virgile/Didon.htm) gehören.

${ }^{45}$ Katalog 117.

${ }^{46}$ Es handelt sich um die Illustration zu einem Dido-Drama von Andries Pels (1668). Eine Entwurfszeichnung befindet sich in Braunschweig. Abbildungen in Roy, Alain: Gérard de Lairesse, 1640-1711, Paris 1992, S. 426f. (Nr. G 24 und D 10).

${ }^{47}$ Katalog 336.
} 
(1705-1788) [Abb. 23] die Szene aus starker Untersicht bietet, gehört zum zweiten Typ der Bildlösungen, in denen Dido allein auftritt. ${ }^{48}$ Auch Dosso Dossi (um 14801542) ${ }^{49}$ [Abb. 24], Elisabetta Sirani (1620-1671) [Abb. 25] und Andrea Sacchi(15991661) [Abb. 26] betonen die Einsamkeit der Verlassenen. ${ }^{50}$ Meist wird der melancholische Blick der Königin durch einen Ausblick auf einen Hafen oder das offene Meer subtil erläutert, auf dem die abfahrende Flotte des Aeneas zu sehen ist. Dido hat also soeben den Verrat bemerkt und sich, umgeben von Erinnerungsstücken wie Rüstung und Schwert des Ungetreuen, zum Tod entschlossen. In ihrem Blick mag der Betrachter Abschied, Verzweiflung und Schmerz erkennen. Komplexer ist die Bildkonzeption von Peter Paul Rubens (1577-1640) ${ }^{51}$, der das Thema [Abb. 27]

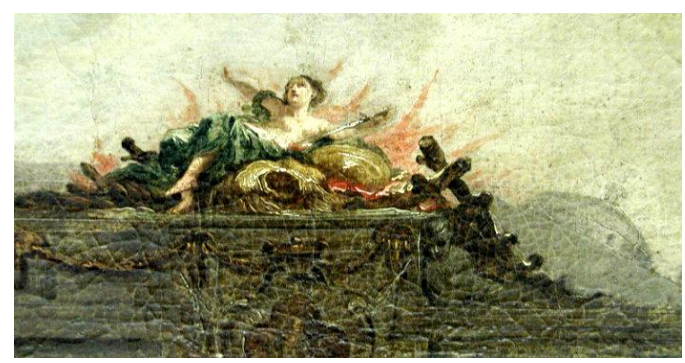

Abb. 23

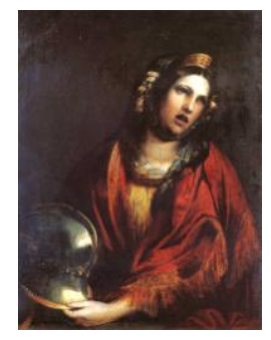

Abb. 24

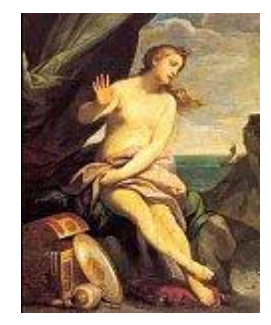

Abb. 25

nur einmal aufgegriffen zu haben scheint: Die sitzende Dido, deren unbekleideter Körper als große Diagonale das Bild füllt, ist ganzfigurig an den Betrachter herangerückt. Jeder Hofstaat fehlt, allerdings verweisen der rote Samtmantel und eine Krone auf die Herrscherrolle Didos. Sie führt das Kurzschwert des Aeneas, ein Relikt aus den Tagen der Liebe, zum Stoß an ihre Brust, die Augen sind untröstlich gegen den Himmel gerichtet. Obwohl Rubens vordergründig nur Didos Verzweiflung betont, verzichtet er doch nicht ganz auf gelehrte An-

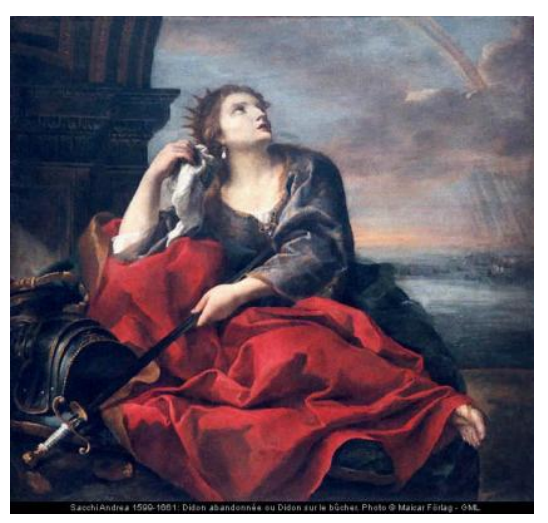

Abb. 26 spielungen, die den ins Bild gesetzten Liebeskonflikt in eine allgemeinere Wertediskussion einbetten: Auf Prunkbett im rechten Hintergrund erinnert die goldene Büste des Sychaeus an die zugesagte Witwentreue der Justinus-Tradition. Damit deutet der pictor doctus eine weitere moralistische Sinndimension des

\footnotetext{
${ }^{48}$ Katalog 173.

49 Katalog 105.

${ }^{50}$ Katalog 361 (Sacchi), Katalog 373 (Sirani).

51 Vgl. Katalog 355.
} 
Selbstmords der verlassenen Frau an: Dido hat für Aeneas ihr Gelübde, dem ersten Mann ewig treu zu bleiben, gebrochen und wird nun ihrerseits verraten.

Johann Heinrich Tischbein der Ältere (1722-1789) wählte für seine heute in Gotha befindliche Dido [Abb. 28] ein halbfiguriges Format. Dido hält in exaltierter Wut das Kurzschwert in der Rechten und blickt offensichtlich nur noch dem Davonsegelnden

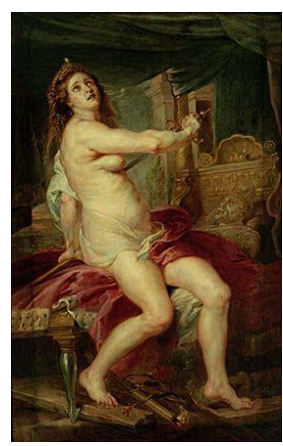

Abb. 27 nach, bevor sie sich ersticht. ${ }^{52}$ Heinrich Füßli (1741-1825) hat seine Dido auf dem Scheiterhaufen ${ }^{53}$ [Abb. 29] in Chiaroscuro gehalten, um die Aufmerksamkeit ganz auf Gebärde und Ausdruck der Sterbenden zu lenken, zu deren Füßen eine verzweifelte Dienerin erkennbar ist. Über Dido schwebt Iris, die aus dem langwallenden Haar eine Locke abschneidet. Angelika Kauffmann (1741-1807) wählte

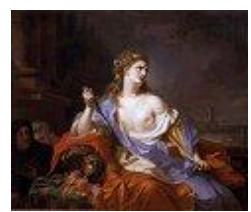

Abb. 28

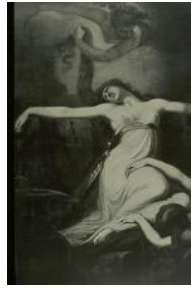

Abb. 29

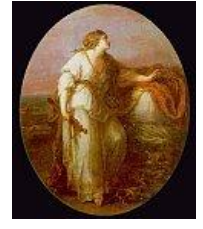

Abb. 30 Dido eine ruhige, elegische Haltung, die erst durch den aufs Meer gerichteten Abschiedsblick etwas Schmerzhaftes erhält [Abb. 30]. ${ }^{54}$

Das Bildkorpus zum Tod Didos lässt deutlich erkennen, dass der über Christine de Pizan und Boccaccio auf Justinus zurückgehende shistorisierende، Bildtypus ebenso wie die sromaneske` Auffassung, die über die Bühnenfassungen und den höfischen Roman Vergil aufgreift, lange nachwirkten und die ikonographische Rezeption des Themas auf Dauer geprägt haben. Eine andere, in ihrer Auswirkung weniger folgenreiche und in unserem Zusammenhang nicht thematische Bildtradition betonte im Übrigen die politische Rolle der afrikanischen Königin, deren Repräsentation, umsichtiges Agieren und Gastfreundschaft ins Bild gesetzt werden. Noch Claude Lorrains (1600-1682) Aeneas und Dido in Karthago ${ }^{55}$ [Abb. 31] und William

\footnotetext{
${ }^{52}$ Katalog 399.

${ }^{53}$ Katalog 138.

${ }^{54}$ Katalog 191. Baumgärtel weist im AK Angelika Kauffmann, a.a.O., S. 412 darauf hin, dass das Motiv der Trauernden als Penelope, Kalypso und Dido von Angelika Kauffmann mehrfach im Ovalformat variiert wurde. Dort auch Abbildungen von Reproduktionsstichen.

${ }^{55}$ Katalog 214.
} 


\section{Dido: Herrscherin und Liebende}

Turners (1775-1851) Dido building Carthage $^{56}$ [Abb. 32] belegen mit inren Gemälden die Beliebtheit dieser Auffassung des Themas, das den Erfolg bei einem gebildeten Publikum bis ins

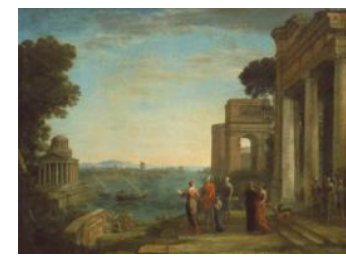

Abb. 31

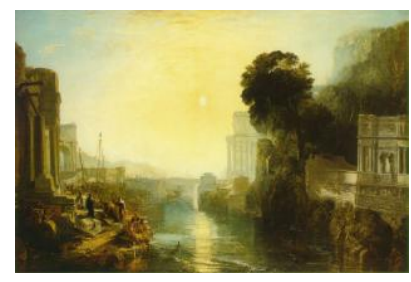

Abb. 32 19. Jahrhundert garantierte.

Noch publikumswirksamer blieb allerdings die Darstellung des Selbstmordes, die ihre literarischen Wurzeln in Vergils dramatischer Inszenierung hat. Die Liebesgeschichte selbst tritt meist in den Hintergrund, während mehr und mehr das Drama der verlassenen Frau aufgegriffen wurde, deren Freitod im Bildgeschehen durch die Abfahrt des Aeneas motiviert wird. Wenn Dido vor dem Scheiterhaufen steht, auf dem Erinnerungsstücke ihrer Liebe verbrennen, oder sich in das Schwert des Treulosen stürzt, tritt der Konflikt zwischen Politik und Liebe zugunsten der Verzweiflung über die betrogene Liebe zurück. In der Ikonographie wurde damit die komplexe Figur der literarischen Tradition deutlich vereinfacht und in ihrer intimprivaten Umgebung vorgestellt: die Regentin wird als verzweifelt Liebende allmählich zu einem überhistorischen Frauentypus. Die ikonographische Rezeption banalisierte die in der Aeneis mythisierte Ursache des unversöhnlichen Kampfes zwischen Römern und Puniern, so wie der dem Davonsegelnden nachgerufene Fluch der Königin ins Allgemein-Menschliche gewendet wurde. Wenn Dido zum Emblem rasender Eifersucht wird, ohne dass der Konflikt zwischen Liebe und Politik noch eine wichtige Rolle spielt, unterscheidet dies die ikonographische Deutung Didos deutlich von Lukretia, einem anderen weiblichen Tugendmuster freiwilligen Sterbens.

\footnotetext{
${ }^{56}$ Katalog 405.
} 
Lukretia: Keuschheit, eheliche Treue, politischer Umsturz

\section{Lukretia: Antike Quellen}

Livius verbindet die gewalttätige Episode der Lukretia geschickt mit dem Sturz der Königsherrschaft. ${ }^{1}$ Die Einleitung seiner Komposition greift vertraute literarische Motive auf: während der Belagerung der Stadt Ardea streiten die Söhne des Königs mit ihrem Vetter Collatinus, wessen Frau die tugendhafteste sei. Bei einem überraschenden nächtlichen Besuch in Rom spinnt Lukretia, die Frau des Collatinus, um Mitternacht noch mit ihren Mägden, während sich die Prinzessinnen nur amüsieren. Wenig später wird Lukretia von Sextus Tarquinius, einem der Königssöhne, unter Mordandrohung zum Beischlaf gezwungen. Nicht nur das Leben der tugendhaften Lukretia ist in Gefahr, sondern auch ihre Ehre, weil Tarquinius plant, einen Ehebruch vorzutäuschen, und beabsichtigt, einen ermordeten Sklaven neben ihre Leiche zu legen, sollte die junge Frau inm nicht willfährig sein. Lukretia berichtet Vater, Ehemann und Freunden von ihrer Vergewaltigung, bevor sie Hand an sich legt. Über ihrer Leiche schwören die Verwandten Rache; das skandalöse Verhalten des Königssohns führt zum Aufstand, zum politischen Umsturz und zum Ende der Monarchie. Lukretias Tugend und die Unmoral des Königssohns werden zu Emblemen der ımoralischen` Republik und des slasterhaften` Königtums.

Bereits in der Antike wurde der Stoff häufig aufgegriffen, zumal der ausführliche Bericht des Livius erlaubte, verschiedene Akzente zu setzen und auf das Verhalten der Lukretia selbst oder auf seine politische Folgen abzuheben. Dionysios von Halikarnassos ${ }^{2}$ betont den psychischen Schock der Heldin: Florus ${ }^{3}$ legt

\footnotetext{
${ }^{1}$ Ab urbe condita I,57,6-59,6

2 Dionysios von Halikarnassos: Antiquitates Romanae IV, 64,1-67,4 und 70,1ff. Dionysios scheint von Livius unabhängig zu sein.

${ }^{3}$ Lucius Annaeus Florus: Opera, hrsg. von Paul Jal, Paris 1967, I,1 (I,7): »Tam diu superbiam regis populus Romanus perpessus est, donec aberat libido; hanc ex liberis eius inportunitatem tolerare non potuit. Quorum cum alter ornatissimae feminae Lucretiae stuprum intulisset, matrona dedecus ferro expiavit; imperium regibus abrogatum. « (〉Das römische Volk ertrug die Anmaßung des Königs so lange, bis sexuelle Zügellosigkeit dazu kam; eine solche Rücksichtslosigkeit der königlichen Söhne konnte das Volk nicht ertragen. Als einer von innen die schöne Lucretia vergewaltigt hatte, sühnte die verheiratete Frau die Schande mit dem Dolch; den Königen wurde die Herrschaft entzogen.८) und I, 3 (I,9): »Igitur Bruto Collatinoque ducibus et auctoribus, quibus ultionem sui moriens matrona mandaverat, populus Romanus ad vindicandam libertatis ac pudicitiae decus quodam quasi instinctu deorum concitatus regem repente destituit, bona diripit, agrum Marti suo consecrat, imperium in eosdem libertatis suae vindices transfert, mutato tamen et iure et nomine. " (>Deshalb gab das römische Volk, wie durch eine Eingebung der Götter veranlasst, unter seinen maßgeblichen Führern Brutus und Collatinus, denen die sterbende Frau ihre Rache aufgetragen hatte, den König schnell preis, um Freiheit und Ehre wiederherzustellen, es nimmt dem König den Besitz weg, weiht den Besitz dem Gott Mars, überträgt die Regierungsgewalt auf seine Befreier und ändert die politische Verfassung.८)
} 
das Gewicht auf die politische Dimension des Ereignisses, Ovid ${ }^{4}$ akzentuiert die erotische Komponente, Valerius Maximus ${ }^{5}$ stellt, der Intention seiner ExemplaSammlung entsprechend, die moralische Bewertung der heroischen Tat in den Mittelpunkt. Lukretias Freitod, ihre weibliche Scham (pudicitia) ${ }^{6}$ und ihr männlicher Mut (virilis animus) wurde von den Kirchenvätern kontrovers bewertet. Die Kritik überwiegt jedoch: Nach Tertullian handelte Lukretia aus eigensüchtigen Motiven ${ }^{7}$, trotz der positiven Einschätzung des Hieronymus wird sie für Augustinus geradezu zum Typus einer ruhmsüchtigen Römerin (»Romana mulier, laudis avida nimium«), die ein Übel durch ein noch größeres zu tilgen sucht. ${ }^{8}$

\section{Lukretia: Literarische Rezeption}

In der literarischen Rezeption des Lukretia-Stoffes ${ }^{9}$ lassen sich, sehr stark vereinfacht, zwei Traditionslinien unterscheiden, die sich gelegentlich auch miteinander verbinden. Auf der einen Seite stehen mehr oder weniger aktualisierende politische Interpretationen, auf der anderen Seite wird der Selbstmord Lukretias zunächst moralistisch, dann psychologisch gedeutet, wobei die historischen Umstände ganz zurücktreten können.

Die lateinische Historiographie des Mittelalters tradierte den Stoff weitgehend unverändert, eine neue Variante erhielt die Lukretia-Geschichte erst in volkssprachlichen Bearbeitungen des Hohen Mittelalters. ${ }^{10}$ Die um die Mitte des 12. Jahrhunderts wahrscheinlich in Regensburg von Klerikern verfasste und weit verbreitete, bis ins 15. Jahrhundert hinein bearbeitete und fortgesetzte Kaiserchro-

\footnotetext{
${ }^{4}$ Ovid: Fasti II,685 und 721-852.

${ }^{5}$ Valerius Maximus: Factorum et dictorum memorabilium libri VI,1,1

${ }^{6}$ Unter dem Stichwort pudicitia wertet Hieronymus (Adversus Jovianum I,46) Lukretia als positives Beispiel: »Ad Romanas feminas transeam; et primam ponam Lucretiam, quae violatae pudicitiae nolens supervivere, maculam corporis cruore delevit. « (১Ich komme zu den römischen Frauen und erwähne an erster Stelle Lukretia, die aus Scham ihre Vergewaltigung nicht überleben wollte und die körperliche Schmach mit ihrem Blut tilgte.८) Vergleichbares zu Porzia unten S. 167.

7 Tertullian zählt Lukretia unter die Frauen, die »famae et gloriae causa (des Ruhmes und der Ehre wegen) Selbstmord begingen (Ad martyres 4,3): »De feminis ad manum est Lucretia, quae vim stupri passa cultrum sibi adegit in conspectu propinquorum, ut gloriam castitati suae pareret. « $(4,4)$

${ }^{8}$ „Si adulterata, cur laudata; si pudica, cur occisa?« (>Warum verdient sie Lob, wenn sie eine Ehebrecherin war, warum hat sie sich getötet, wenn sie keusch blieb?^) (De civitate Dei I,19)

9 Zur Rezeption der antiken Tradition: Galinsky, Hans: Der Lucretia-Stoff in der Weltiteratur, Breslau 1932; Heinz, Günther »Gedanken zu Bildern der `Donne Famose` in der Galerie des Erzherzogs Leopold Wilhelm» in: Jahrbuch der kunsthistorischen Sammlungen, Wien, 77 (1981), S. 105-118; Donaldson, lan: The rapes of Lucretia. A Myth and its Transformation, Oxford 1982; Follak, Jan: Lucretia zwischen positiver und negativer Anthropologie, Coluccio Salutatis > Declamatio Lucretie und die Menschenbilder im exemplum der Lucretia von der Antike bis in die Neuzeit, Diss. Konstanz 2002. - Galinsky hat in seiner positivistischen Materialsammlung, die heutigen Ansprüchen nicht mehr entspricht, die unterschiedlichen Bearbeitungen des Stoffes zusammengetragen. Anregende Gedanken zum Thema, wenn auch nur auf die Galerie des Erzherzogs Leopold Wilhelm beschränkt, formuliert Heinz. Die Untersuchung Follaks ist im Sonderforschungsbereich 511 ,Literatur und Anthropologies (http://www.ub.uni-konstanz.de/kops/volltexte/2002/914/pdf/follak01-text.pdf [letzter Zugriff: 11.11.2006]) entstanden und im Netz zugänglich.

${ }^{10}$ Vgl. Galinsky, a.a.O., S. 20-22.
} 
nik baute die Episode zu einer streng durchkomponierten Novelle aus. Die Handlung ist in die Kaiserzeit zwischen Nero und Galba verlegt und wie in den santikisierenden Romanen ${ }^{11}$ höfisch stilisiert. Collatinus wird folgerichtig zu einem aus Trier stammenden Gefolgsmann des Kaisers. Blieben in dieser höfischen Variante politische und moralische Deutung noch ineinander verschränkt, diente die Episode in den Gesta Romanorum des 13. Jahrhunderts geradezu als positiv gedeutetes Exempel christlicher Lebensführung: alle Einzelheiten berücksichtigend werden Vergewaltigung, Geständnis und Selbstmord Lukretias allegorisch gedeutet. Das Verhalten der Lukretia gilt als positives Exempel christlicher Lebensführung: die Vergewaltigung durch Tarquinius wird als Exempel für Versuchung und Sünde, das Geständnis den Verwandten gegenüber als Beichtgespräch und aktive Reue, der Selbstmord als Buße interpretiert. Dabei berufen sich die Gesta Romanorum sogar auf Augustinus, obwohl gerade dieser Lukretias Selbstmord der durch das Christentum endgültig überwundenen archaischen Anthropologie Roms zurechnete. ${ }^{12}$

Eine politisch akzentuierte positive Rezeption fand Lukretia im italienischen Humanismus; Dante und Petrarca stilisierten die Tugendheldin zu einer römischen Freiheitskämpferin, die auch für die aktuelle Situation des Reichs und seine mémoire collective von Bedeutung war. Die moralistische Deutung erlaubte die Rechtfertigung ihres Selbstmords: So wird Lukretia in der Divina Commedia ${ }^{13}$ nicht unter die Selbstmörder des siebten Höllenkreises eingereiht, sondern zusammen mit den unschuldigen Opfern des bethlehemitischen Kindermords, den alttestamentlichen Patriarchen und heidnischen Philosophen im ersten Höllenkreis situiert. Dante billigt ihr damit das höchste Maß von ıRehabilitation` zu, das inm möglich war. ${ }^{14}$

In Petrarcas lateinischem Epos Africa ${ }^{15}$, aber auch in seinen volkssprachlichen Texten ${ }^{16}$ nimmt Lukretia breiten Raum ein. Während sie in den Trionfi und in den Rime als vorbildliche und über den Tod hinaus treue Ehefrau ${ }^{17}$ zum moralisti-

\footnotetext{
${ }^{11}$ Vgl. S. 105.

12 Vgl. Galinsky, a.a.O., S. 22-31. - »Der anonyme Bearbeiter der Gesta Romanorum funktioniert das exemplum der Lucretia wieder zu einem Beispiel für die Normen einer christlichen Lebensweise um. Als Ergebnis kommt eine spositive Anthropologie، zustande, die nicht mehr pagan, sondern jetzt christlich begründet ist. Diese spositive die Augustin gegeben hatte. Denn jetzt gibt es wieder feste, äußerlich erkennbare Regeln und Normen, an denen sich ablesen läßt, ob sich ein Mensch als richtiger Christ verhält oder nicht. « (Follak a.a.O., S. 58.)

${ }^{13}$ Ich zitiere die Divina Commedia nach der Ausgabe von Giuseppe Vandelli (Milano 1969).

${ }^{14}$ Inferno, IV, 128

${ }^{15}$ Ich zitiere nach der Ausgabe von Festa, Nicola, Firenze 1926.

${ }^{16}$ Ich zitiere nach der Ausgabe von Neri, F.: Rime, Trionfi e Poesie Latine, Milano/Napoli 1951.

17 Triumphus Pudicitie (v. 132) und Rime CCLX, 9; CCLXII, 9; CCCLX, 100.
} 
schen exemplum wird, steht in der Africa ihre politische Rolle als Freiheitsheldin ${ }^{18}$ im Vordergrund. Petrarca sieht sie in einem Traditionszusammenhang, der für das Imperium und die Identität Italiens von bleibender Bedeutung ist, und eröffnet damit Lukretia eine glanzvolle Karriere in der politischen Neuzeit. In der Historienmalerei wurde diese politische Bedeutung des Motivs der sterbenden Tugendheldin allerdings erst aufgegriffen, als in der Französischen Revolution die römische Geschichte eingängige Vorbilder für den republikanischen Patriotismus liefern sollte. In der Frühen Neuzeit überwiegt in der bildenden Kunst der moralistische Überlieferungsstrang: meist wird Lukretia isoliert und halbfigurig dargestellt, als körperlich schwache, aber willensstarke Tugendheldin und Kämpferin gegen männliche Willkür und Aggression betont.

In De claris mulieribus ${ }^{19}$ gilt Lukretia als eines der prominenten Vorbilder keuschen und schamhaften Verhaltens (pudicitia). Boccaccio macht sie geradezu zur dux pudicitiae ${ }^{20}$ und schwächt damit politische Akzentuierungen ab, ohne sie ganz zu unterdrücken ${ }^{21}$. Anders als die christliche Allegorese der Gesta Romanorum stellt die moralistische Deutung Boccaccios Lukretias Schönheit (formositas) und haushälterische Tugend (parsimonia) heraus und rechtfertigt den Selbstmord mit der Keuschheit der jungen Frau.

Dass sich >politisches` und >moralistisches` Rezeptionsmuster verbinden ließen, zeigt die Declamatio Lucretie ${ }^{22}$ des Florentiner Humanisten und Kanzlers Coluccio Salutati (1331-1406). Er benutzt durchaus Boccaccios Handbuch, deutet die moralistischen Begriffe aber politisch. Abwechselnd kommen in der rhetori-

\footnotetext{
${ }^{18}$ Im unvollendet gebliebenen Epos Africa erzählt der Römer Lelius als Gast des Königs von Numidien neben anderen Ereignissen der römischen Geschichte auch die Lukretia-Episode (III, 684-773). Dabei wird die Handlung äußerst verknappt, der Schilderung der verzweifelten Seelenlage der Frau aber breiter Raum gewährt (vv. 692-698 und 715-722). Lukretia wird von Petrarca als politisch Handelnde gezeichnet, die die zusammengerufenen männlichen Verwandten zum Racheeid auffordert (vv. 720-722) (»Porgite dextras / Et prestate fidem, scelus hoc ne turpis ad umbras / Auferat impunis tumuloque insultet adulter. " [>Reicht euch die Rechte und schwört, dass der Verbrecher nicht unbestraft leben und der Eheschänder nicht mein Grab verhöhnen darf.८]) Brutus spricht den Schwur, der zur Aufhebung der Königsherrschaft (vv. 769-773) führt (»Hoc duce pelluntur reges, exulque senexque / Tarquinius moritur, nati omnes diraque coniunx / Supplicium scelerum non una morte tulerunt: / Corruit in cineres regis domus alta Superbi. / Regnorum hic finis. « [>Unter Brutus werden die Könige vertrieben, Tarquinius stirbt betagt im Exil, alle Söhne und die schreckliche Gattin erlitten einzeln die Todesstrafe für ihre Verbrechen: So endete das edle Geschlecht des Königs Superbus. Dies war das Ende der Könige.८]).

${ }^{19}$ Giovanni Boccaccio: Tutte le opere, hrsg. von Vittore Branca, Bd. 10, Milano ${ }^{2} 1970$, Kap. 48

${ }^{20}$ Boccaccio greift die von Valerius Maximus geprägte Formel »dux Romanae pudicitiae« wieder auf, erweitert sie um »sanctissimum vestute parsimonie decus « und betont neben der heroischen Tat Umsicht und Fleiß Lukretias als Haus- und Ehefrau.

${ }^{21}$ Am Ende des Kapitels über Lukretia heißt es: „Cum ex eadem non solum reintegratum sit decus, quod feditate facionoris iuvenis labefactarat ineptus, sed consecuta sit romana libertas. " (>Durch diese Tat wurde nicht nur ihre Ehre wiederhergestellt, die der törichte junge Mann durch seine Schandtat verletzt hatte, auch Roms Freiheit war ihre Folge.८)

${ }^{22}$ Vgl. dazu Follak, Jan, a.a.O., der im Anhang zum ersten Mal Text und Übersetzung verfügbar macht.
} 
schen Übung Vater und Ehemann, danach Lukretia zu Wort, die Debatte kreist um Normen der Individualität und der Gesellschaft (gloria, pudicitia und libertas). ${ }^{23}$ Der interessante Text zeigt, dass sich die Figur der Lukretia im Rhetorikunterricht der frühen Neuzeit dafür eignete, christlich geprägte moralistische Begriffe für die politische Kultur der Frühen Neuzeit umzubesetzen. Vor diesem Hintergrund wird die zugleich moralistische und politische Deutung Lukretias in der Ikonographie der frühen Historienmalerei verständlich.

Im Humanismus erfährt ein anderer Rezeptionsstrang eine eigenartige Akzentuierung: So wird die bei Livius erwähnte `Frauenwette ${ }^{24}$ aufgegriffen und Lukretia sverbürgerlichtı. Hatte bereits Boccaccio die häuslichen Tugenden der Römerin erwähnt, konfrontiert Francesco Barbaro (1390-1454) in seinem ıHausbuch De re uxoria $(1415)^{25}$ die bescheidene und schlichte Bewirtung bei Lukretia mit der höfischen Verschwendung Kleopatras ${ }^{26}$. So kann es nicht verwundern, wenn Hans Sachs (1494-1576), dessen Tragedia von der Lucretia (1527) ${ }^{27}$ in einem Bürgerhaus spielt, Lukretia als Prototyp der umsichtigen Hausfrau vorstellt und psychologisches Interesse für den inneren Konflikt der Römerin mit moralistischer Ehelehre und politischen Aspekten verbindet.

Die literarischen Bearbeitungen des 15. und 16. Jahrhunderts zeigen immer wieder Interesse für die Motive des Tarquinius und für die Konfliktsituation Lukretias, wofür die neunte Novelle Bandellos (1554) angeführt werden mag. Shakespeare führt in seinem Kurzepos The Rape of Lucrece $(1594)^{28}$ diesen Rezeptionsstrang fort und analysiert den psychologischen Antagonismus zwischen Tarquinius und Lukretia ${ }^{29}$.

Im Gegensatz zu den anderen römischen Tugendheldinnen wurde der Lukretia-Stoff überraschend spät von der neustoischen Tragödie der frühen Neuzeit

\footnotetext{
${ }^{23}$ Follak, a.a.O., S. $105 \mathrm{ff}$.

${ }^{24}$ Vgl. S. 118.

${ }^{25}$ Francesco Barbaro: De re uxoria, Argentorati 1612; Buch II der Schrift behandelt die Haushaltsführung der Ehefrau (victus uxoris) und kontrastiert Lukretia und Kleopatra: »Et Lucretiae potius frugales mensas, quam Tarquiniarum et Cleopatrae sumptuosas delitias probent ac imitentur. (〉Hausfrauen sollen die bescheidenen Gerichte der Lukretia den kostspieligen Leckerbissen der Tarquinierinnen und der Kleopatra vorziehen und übernehmen.८)

${ }^{26}$ Vgl. Lentzen, M.: »Auffassungen über Ehe und Familie in Francesco Barbaros De re uxoria (1415) und Albrecht von Eybs Ehebüchlein (1472), Textstruktur und Textfunktion«, in: Guthmüller, Bodo (Hrsg.): Deutschland und Italien in ihren wechselseitigen Beziehungen während der Renaissance, Wiesbaden 2000, S. 44-60.

${ }^{27}$ Hans Sachs: Tragedia von der Lucretia, in: Hartmann, Horst (Hrsg.): Heinrich Bullinger / Hans Sachs, Lucretia-Dramen, Leipzig 1973, S. 99-112.

${ }^{28}$ Shakespeare, William: The Rape of Lucrece, in: The Complete Works of Shakespeare, hrsg. von Peter Alexander, London / Glasgow 1990, S. 1284-1307. Vgl. dazu Breitenberg, Mark: Anxious masculinity in early modern England, Cambridge 1996, insbesondere das dritte Kapitel: `Publishing chastity: Shakespeare's »The Rape of Lucrece«, S. 97-127.

${ }^{29}$ Shakespeare nennt Lukretia eine »earthly saint« (v. 85).
} 


\section{Lukretia: Keuschheit, eheliche Treue, politischer Umsturz}

aufgegriffen. ${ }^{30}$ Erst mit The Rape of Lucrece (1603) von Thomas Heywood (ca. 1570-1641) ${ }^{31}$ und Lucrezia (1656) von Giovanni Delfino wird Lukretia wie Dido oder Sophonisbe zu einer neustoischen Tugendheldin, deren von Schicksalsschlägen unbeeindruckte costanza ihr eine glänzende Karriere im barocken Drama und der barocken Oper eröffnete. ${ }^{32}$

Das Bild der Tugendheldin hat sich in zwei Rezeptionssträngen entwickelt und zeigt eine moralistische oder eine politische Konnotation. Wird Lukretias pudicitia in den Vordergrund gerückt, löst ihre »passionierte Tugend « ${ }^{33}$ den Selbstmord aus. Werden Rachegedanke und Auflehnung gegen die überholte Monarchie als Auslöser für den Selbstmord betont, wird Lukretias Tat als öffentliches und revolutionäres Handeln pointiert. Ihr Selbstmord, der den Verwandten den öffentlichen Racheschwur abringt, ist dann nur Anstoß eines radikalen politischen Umsturzes. Beiden Interpretationstraditionen finden sich auch in der Historienmalerei wieder.

\section{Lukretia: Ikonographie der Historienmalerei}

In der Ikonographie der Lukretia lassen sich zunächst einfigurige von szenischen Darstellungen unterscheiden. Letztere haben entweder die Vergewaltigung zum Vorwurf oder zeigen die sterbende Tugendheldin im Kreis ihrer Familie. Heben die einfigurigen Darstellungen meist auf die Keuschheit der Tugendheldin ab, stellen die szenischen oft auf den Gegensatz der Geschlechter ab oder thematisieren (vor allem in Großkompositionen) den Opfertod der Tugendheldin als Gründungsakt der römischen Republik.

Wie bei Sophonisbe, Dido und Porzia entwickelte sich eine Ikonographie der Lukretia zuerst auf cassoni, Hochzeitstruhen ${ }^{34}$ der oberitalienischen Renaissance des 15. Jahrhunderts, die vielfältige Funktionen mit durchaus öffentlichem Reprä-

\footnotetext{
${ }^{30}$ Weder Hans Sachs noch Shakespeare gehören in diesen Zusammenhang.

${ }^{31}$ Heywood, Thomas: The Dramatic Works, Bd. 5, London 1874, S. 161-257.

32 Folgende D ram e n seien erwähnt: Nicolas Filleuil: Lucrèce (1566), Pierre Du Ryer: Lucrèce (1638), Samuel Junius: Lukretia (1599), Hendrik Tollens: Lukretia of de verlossing van Rome (1805), Francois Ponsard: Lucrèce (1843). Auf der Opernbühne beispielsweise: Giovanni Battista Tomasi: Sesto Tarquinio (1678), Reinhard Keiser: Die kleinmütige Selbst-Mörderin Lucretia oder die Staats-Thorheit des Brutus (1705), K. K. Schweitzelsperger: Lucretia, die keusche Römerin (1715), Antonio Pollarol: Furia Lucrezia (1726). Die Reihe endet im 19. Jahrhundert mit Heinrich Marschners Lukretia (1827) und im 20. Jahrhundert mit Benjamin Brittens The rape of Lucretia (1946). - Im Gegensatz zu den anderen Tugendheldinnen fand Lukretia auch Eingang in den höfischen Rom a n des Barock. Die römische Frühgeschichte im Spannungsfeld von Monarchie und Militärelite bot die Möglichkeit, vergleichbare Konflikte der frühneuzeitlichen französischen Eliten des entstehenden Absolutismus zu spiegeln. So ist es kein Zufall, wenn Mlle de Scudéry den Lukretia-Stoff in ihrer Clélie (1654-1660) aufgreift und, bemerkenswert genug, um eine Affäre Lukretias mit Brutus erweitert, in der sich die Ehe- und Liebesauffassungen der französischen höfischen Gesellschaft des 17. Jahrhunderts wiederfinden.

${ }^{33}$ Ich übernehme den Begriff von Pia Holenstein-Weidmann (»Passionierte Tugend: Lukrezia«, in: Deutsche Vierteljahrsschrift für Literaturwissenschaft und Geistesgeschichte 68 (1994), S. 1-21).

${ }^{34}$ Vgl. von Bode, Wilhelm: Die italienischen Hausmöbel der Renaissance, Leipzig ${ }^{2} 1920$; Schubring, Paul: Cassoni, Truhen und Truhenbilder der italienischen Frührenaissance, Leipzig 1923.
} 
sentationsanspruch übernahmen. ${ }^{35}$ Dabei können zwei zeitlich aufeinander folgende Typen der halböffentlich aufgestellten Truhen unterschieden werden. ${ }^{36}$ Der frühere bevorzugt eine umfängliche Bildfolge, in der die Geschichte Lukretias wie in einem Leporello von der `Frauenwette` und dem nächtlichen Besuch der Ehemänner bis zu Lukretias Vergewaltigung und der Vertreibung der römischen Könige dramatisch entwickelt wird. ${ }^{37}$ Wenn die häuslichen Tugenden Lukretias in den ersten Szenen dieses Typus betont werden, greift dies die HausbuchLiteratur $^{38}$ der Frührenaissance auf und erinnert die Hausfrau an ihre Aufgaben. Später setzte sich ein reduziertes Programm durch, das meist auf drei Szenen (Vergewaltigung der Lukretia, Geständnis und Selbstmord, Racheschwur der Verwandten) beschränkt war. Dabei fällt auf, dass allmählich die häuslichen Tugenden der Römerin zugunsten einer politischen Interpretation zurücktreten, während beide Aspekte zunächst gleichrangig behandelt worden waren. Dass Lukretia als Emblem weiblicher Tugenden (wie Sparsamkeit, Gastfreundschaft und eheliche Treue) und als Verteidigerin weiblicher pudicitia zu einem cassone-Thema wurde, überrascht weniger als die Akzentuierung republikanischen Selbstbewusstseins und Anspruchs im späteren ikonographischen Typus.

Biagio di Antonio Tucci (1446-1516) reduzierte auf zwei Tafeln in Venedig [Abb. 1] die narrative Abfolge, wobei sich die erste Tafel mit der Belagerung von Ardea, der Frauenwette und dem Ritt des Tarquinius auf die männlichen Akteure zeigt, die zweite die bekannteren Szenen (Vergewaltigung, Selbstmord, Beisetzung und Racheschwur der Männer) darstellt.

\footnotetext{
${ }^{35}$ Hochzeitstruhen (cassoni) sind Ausstattungsgegenstände der Renaissance, von denen heute meist nur die vorgeblendeten gemalten Schauseiten erhalten sind. Schränke wurden erst im 16. Jahrhundert üblich; vorher dienten Truhen zur Aufbewahrung von Wäsche, Kleidern und anderen wertvollen Dingen wie Schmuck. Die Hochzeitstruhen wurden anfangs vom Brautvater, später vom Bräutigam in Auftrag gegeben und zum ersten Mal der Öffentlichkeit gezeigt, wenn die Braut mit der Truhe (in der sich ihre Aussteuer befand) in einem rituellen Umzug vom Haus ihrer Eltern ins Haus ihres zukünftigen Ehemannes gebracht wurde. Anschließend wurde die Truhe in der camera, dem offiziellen Schlafzimmer, aufgestellt, welches Repräsentationszwecke hatte und als Empfangsraum für Bekannte und Freunde diente. Die dekorative Wirkung der Truhe stand also ohne Zweifel im Vordergrund, dokumentierte sie doch Rang und Wohlstand der Braut. Bettina Uppenkamp (http://www2.hu-berlin.de/ffz/dld/bettinauppenkamp.pdf; letzter Aufruf am 25.10.2006) sieht in der vorwiegend repräsentativen Bedeutung des cassone auch den Grund dafür, dass die bereits übliche Zentralperspektive auf den meisten Hochzeitstruhen noch keine Anwendung fand; es kam wohl auf den reichen Gesamteindruck an, den das "Kompositmedium « durch Schnitzereien, Vergoldungen und Stuckdekor zustande brachte und der den Rang der Familie materiell verkörperte. Graham Hughes (Renaissance Cassoni, Masterpieces of Early Italian Art: Painted Marriage Chests 1400-1550, London 1997) hat nach der verdienstvollen, aber inzwischen überholten Arbeit von Paul Schubring aus dem Jahre 1923 in jüngerer Zeit cassoni wieder untersucht und in Übersicht zusammengestellt.

${ }^{36}$ Vgl. Follak, a.a.O., S. 65ff.

37 Schubring, a.a.O., schreibt einzelne Truhenbilder zum Beispiel Guidoccio Cozzarelli (Tafel CXI, Nr. 468), Niccolò Gilfino (Tafel CLII, Nr. 695), Sandro Botticelli (Tafel LXXII, Nr. 304) und Filippino Lippi (Tafel LXXVII, Nr. 321) zu, kann aber in vielen Fällen nur eine regionale Zuordnung vornehmen (so zum Beispiel: Tafel III, Nr. 21 als »florentinisch«, Tafel CXXXVIII, Nr. 644 als »veronesisch« oder Tafel CLIV, Nr. 727 als »mailändisch«). ${ }^{38}$ Vgl. S. 122
} 


\section{Lukretia: Keuschheit, eheliche Treue, politischer Umsturz}

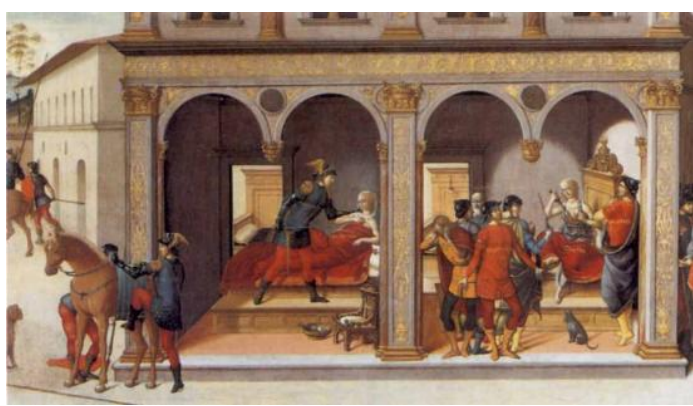

Abb. 1

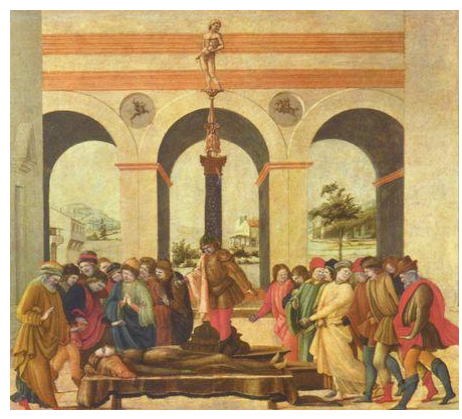

Abb. 2 (Ausschnitt)

Im Übrigen ist auch ein die Ikonographie lange Zeit bestimmender Holzschnitt des unbekannten Künstlers, der Boccaccios De claris mulieribus 1473 illustrierte, narrativ angelegt und zeigt in der linken Hälfte den auf die im Bett Liegende eindringenden Tarquinius, während in der rechten Hälfte Brutus und Collatinus die sterbende Lukretia [Abb. 3] umfangen.

Auf einem von Filippino Lippi (1457-1504) bemalten cassone [Abb. 2] im

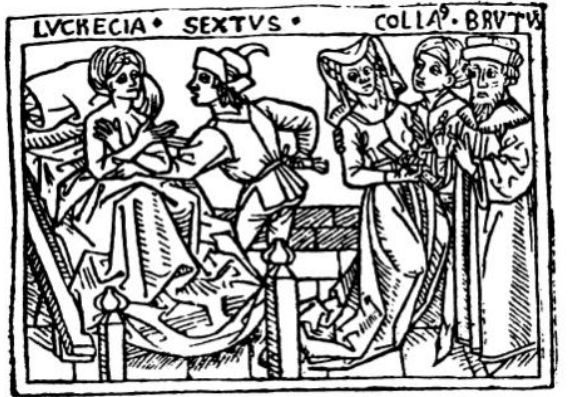

Abb. 3

Palazzo Pitti ${ }^{39}$ findet sich das reduzierte Programm der Lukretia-Geschichte besonders eindrucksvoll. Der politische Anspruch konzentriert sich auf den Racheschwur der Verwandten Lukretias, bei dem - wie in späteren Fassungen des Themas - die starke männliche Präsenz auffällt. ${ }^{40}$ Obwohl für einen anderen Zweck bestimmt, stellt sich die Geschichte der Lukretia (1528) ${ }^{41}$ von Jörg Breu d. Ä. (1475/80-1537) in ganz ähnlicher Weise dar [Abb. 4]. Sie gehörte zu einer Serie von Historienbildern, die Herzog Wilhelm IV. von Bayern und seine Gemahlin Jacobaea von Baden für die Münchner Residenz in Auftrag gegeben hatten und deren genauer Bestimmungsort heute nicht mehr rekonstruiert werden kann. Hochformatige Tafeln (u. a. von Jörg Breu d. Ä., Melchior Feselen und Albrecht Altdorfer) stellten männliche Helden dar, während in breitformatigen Tafeln die Taten berühmter Frauen wie der Kaiserin Helena, Cloelias, Susannas und Virginias nacherzählt wurden. Die Episode der Lukretia umfasst zwei Szenen: links berichtet

\footnotetext{
${ }^{39}$ Vgl. Katalog 212.

40 Vgl. Garrard, Mary D.: Artemisia Gentileschi, the image of the female hero in Italian Baroque art, Princeton 1988, S. 221-222.

${ }^{41}$ Katalog 52.
} 
Lukretia ihren Verwandten die Vergewaltigung, rechts geloben die Männer über ihrem Leichnam Rache. ${ }^{42}$

Durch die Graphik vermittelt setzte sich im ersten Drittel des 16. Jahrhunderts die isolierte Einzelfigur der sich erdolchenden Lukretia durch, die bekanntlich sogleich von Cranach d. Ä. (1472-1553) übernommen wurde und auch in den Galerien starker Frauen ${ }^{43}$

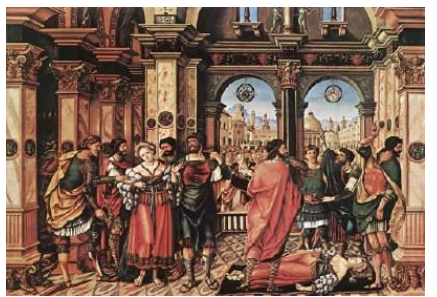

Abb. 4

auftritt. Zugleich trat das Bildmotiv der angesichts der Leiche Lukretias Rache schwörenden Verwandten zurück.

Der »Bildtyp der isolierten Lucretia ${ }^{44}$ wurde durch einen Kupferstich ${ }^{45}$ von Marcantonio Raimondi (um 1510/11) nach einer Zeichnung von Raffael [Abb. 5] entscheidend beeinflusst. ${ }^{46} \mathrm{Er}$ ist von einer heute verlorenen antiken Skulptur $^{47}$ inspiriert, die um 1500 in Rom gefunden wurde. Raimondis Lukretia präsentiert sich frontal und ist durch einen durch das sich bauschende Gewand noch betonten kraftvollen Kontrapost, nach beiden Seiten in emphatischer Bewegung ausgestreckte Arme und einen zur Seite geneigten Kopf charakterisiert. Obwohl Lukretia den Dolch mit der einen Hand bereits zum Stich ansetzt, zeigt ihre Haltung eher

\footnotetext{
${ }^{42}$ Martin Schawe (Kat. Alte Pinakothek, Altdeutsche und altniederländische Malerei, München 2006, S. 142) hat darauf hingewiesen, dass die Bildtradition zwei Möglichkeiten kennt: »die ausgeschmückte szenische Variante [...] und die eher sinnbildhafte, formal reduzierte «. Für erstere verweist er auf Jörg Breu d. Ä. und ordnet das nachher besprochene Bild Dürers in der Alten Pinakothek (vgl. unten S. 128) gleichsam dazwischen ein: "Dürers Bemühen, die statuarische, das Lehrhafte und Exemplarische betonende Version wieder an die Szene rückzubinden, wird deutlich, indem er im Hintergrund ein Schlafzimmerinterieur gestaltet - so wirklichkeitsnah, dass er auch den Nachttopf nicht vergisst. «Wie ich in der Folge zeige, hat sich die e m ble m a t is che Version vor allem unter dem Einfluss Renis weitgehend durchgesetzt.

${ }^{43}$ Siehe S. $241 \mathrm{ff}$.

${ }^{44}$ Follak, a.a.O., S. 64, Anm.

${ }^{45}$ Vasari unterrichtet $1568 \mathrm{im}$ Abschnitt Marcantonio Bolognese e d'altri intagliatori di stampe detailliert über die Entstehung dieses Kupferstichs: "Ma tornando a Marcantonio, arivato in Roma, intagliò in rame una bellissima carta di Raffaello da Urbino, nella quale era una Lucrezia romana che si uccideva, con tanta diligenza e bella maniera, che essendo subito portata da alcuni amici suoi a Raffaello, egli si dispose a mettere fuori in istampa alcuni disegni di cose sue, et appresso un disegno, che già avea fatto, del giudizio di Paris, nel quale Raffaello per capriccio aveva disegnato il carro del sole, le ninfe de' boschi, quelle delle fonti e quelle de' fiumi, con vasi, timoni et altre belle fantasie attorno. E così risoluto furono di maniera intagliate da Marcantonio, che ne stupì tutta Roma. « (>In Rom angelangt stach Marcantonio eine sehr schöne Zeichnung Raffaels von Urbino von der sich selbst tötenden Römerin Lucrezia mit so vielem Fleiß und trefflicher Manier in Kupfer, dass Raffael, als einige seiner Freunde ihm das Blatt brachten, sich entschied, mehrere Zeichnungen stechen zu lassen.ı) Hier zitiert nach der elektronischen Ausgabe: http://www.liberliber.it/biblioteca/v/vasari/index.htm (letzter Zugriff: 25.10.2006).

${ }^{46}$ Vgl. Katalog 295. Bei Höper, Corinna: Raffael und die Folgen, das Kunstwerk in Zeitaltern seiner graphischen Reproduzierbarkeit, Stuttgart 2001, S. 200 (A 82.1) ist eine seitenverkehrte Kopie nach Raimondi von Enea Vico (1523-1567) abgebildet. Bei Raimondi wie bei Vico lautet die griechische Inschrift: AMEINON

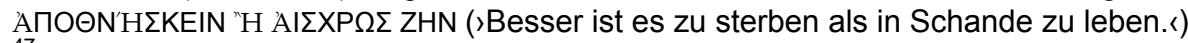

${ }^{47}$ Auf diese Statue bezog sich wahrscheinlich das Gedicht In Lucretiam statuam, das Giovanni de' Medici, der spätere Papst Leo X., verfasst hat. Eine kritische Edition des Textes liegt nicht vor; so muss man auf die Wiedergabe bei Roscoe, William: The life and pontificate of Leo the Tenth, London ${ }^{5} 1876$, S. 430 zurückgreifen. Stechow, Wolfgang: »Lucretiae Statua «, in: Goetz, Oswald (Hrsg.): Essays in honor of Georg Szwarzenski, Chicago 1951, S. 114-124 hat als erster auf den Zusammenhang hingewiesen, der den Fund einer VenusStatue in Rom um 1500 wahrscheinlich macht. Offensichtlich wurde diese antike Plastik sogleich für verschiedene andere Themen rezipiert, so auch für die Lukretia-Episode.
} 
eine tänzerische Versunkenheit, zumal ikonographische Merkmale der Venus pudica Eingang in die Darstellung fanden. Dabei mag das antike Thema auch den erotischen Reiz der Nacktheit legitimiert haben. Raimondis Kupferstich und in der Folge Blätter anderer Künstler ${ }^{48}$ fanden jedenfalls eine solche Verbreitung, dass die ganzfigurige Darstellung einer jungen nackten Frau zum Emblem für Keuschheit wurde, ohne dass immer ein eindeutiger Bezug auf Lukretia beibehalten wurde: Viele Lukretia-Variationen konnten mit Venusdarstellungen verwechselt werden; allenfalls ein Dolch als typisches Attribut verwies den Betrachter auf die richtige Deutung.

Dies gilt auch für die über dreißig

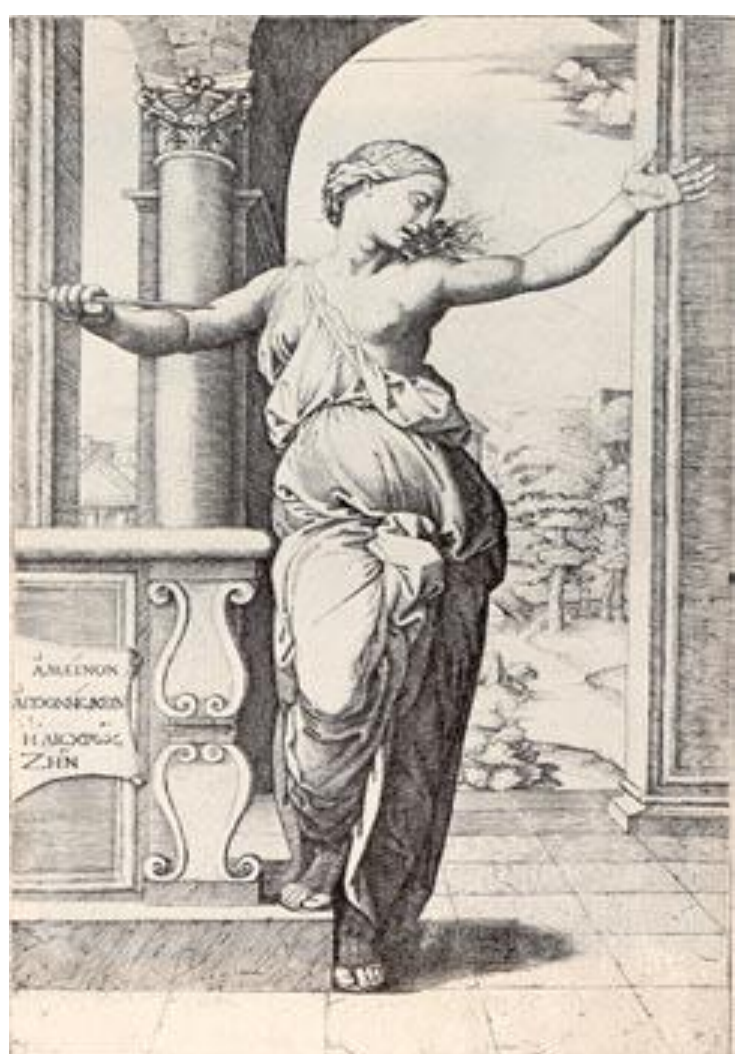

Abb. 5 Arbeiten $^{49}$, in denen Lucas Cranach (1472-1553) den Bildtyp der einzelfigurigen und als moralisches Emblem zu deutenden Lukretia variiert hat. Die Version der Alten Pinakothek ${ }^{50}$ [Abb. 6], um 1524 entstanden, betont ebenso wie die Berliner Version ${ }^{51}$ [Abb. 7] von 1533 die überzeitliche Funktion als »moralisches Tugendexempel « und lässt Lukretia »emotionslos und in neutralem Raum agieren «. ${ }^{52}$ Die vereinzelte Figur der Lukretia vor dunklem Hintergrund, der Kontrapost mit manieristisch überlängten Beinen, die modische Frisur und die frontale Präsentation des nackten, allenfalls mit einem Schleier mehr betonten als verhüllten Körpers sind unverwechselbare Besonderheiten Cranachs geworden. Allein der Dolch lässt

\footnotetext{
${ }^{48}$ So beispielsweise Daniel Hopfer (Bartsch 17, 50), Hans Sebald Beham (Bartsch 15, 78 und 79), Georg Pencz (Bartsch 16, 79).

${ }^{49}$ So die Varianten in Berlin (Stiftung Preußischer Kulturbesitz), in der Akademie der Künste in Wien und im Städel in Frankfurt am Main. Vgl. Garrard, a.a.O., S. 224-225. Grundlegend immer noch Friedländer, Max J. / Rosenberg, Jakob / Schwartz, G.: Die Gemälde von Lucas Cranach, Stuttgart 1989 (Nachweis der LukretiaVersionen S. 203-204).

${ }^{50}$ Katalog 75.

${ }^{51}$ Cranachs Lukretia von 1533 in Berlin (Bestandskatalog der Gemäldegalerie Berlin-Dahlem 1975, S. 121; Inv.-Nr. 1832). Follak, a.a.O., S. 64, will zeigen, dass die Lukretia-Darstellungen Cranachs ein zweideutiges Spiel mit pudicitia und voluptas wagen: "Gerade dadurch, daß Lucretia einen auffallend attraktiven Körper hat, kann sie deutlich machen, daß ihr nur an der pudicitia liegt. Denn obwohl sie damit einen Betrachter zur voluptas reizen und verführen könnte, verletzt sie ihren Körper freiwillig mit dem Messer und zerstört ihn schließlich. « Katalog 74.

${ }^{52}$ Schawe, Martin: Kat. Alte Pinakothek, Altdeutsche und altniederländische Malerei, München 2006, S. 120.
} 
als typisches Attribut Lukretia von Venus unterscheiden und führt den Betrachter zur moralischen Deutung als Emblem der Keuschheit. Die Münchner und Berliner Varianten unterscheiden sich nur durch die dramatischere Haltung der Hand mit dem Dolch in der früheren Fassung. ${ }^{53}$

In der Folgezeit wurde das ganzfigurige isolierte Modell vielfältig variiert: so beispiels-

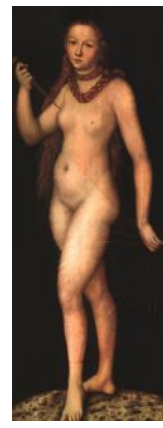

Abb. 6

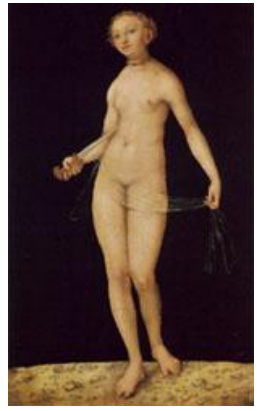

Abb. 7 weise von Albrecht Dürer (1471-1528) in seiner Lukretia der Alten Pinakothek [Abb.8 $]^{54}$ und von Guido Reni (1575-1642) in seinem Potsdamer Bild [Abb. 10]. Aber auch den Gemälden von Massimo Stanzione (1585-1656) [Abb. 11], von Simon

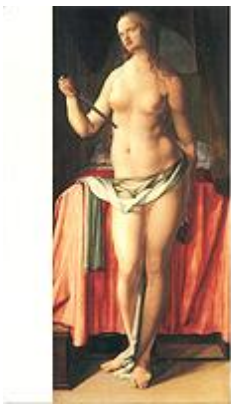

Abb. 8

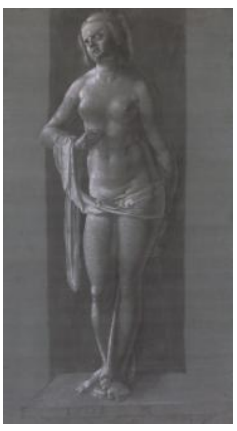

Abb. 9

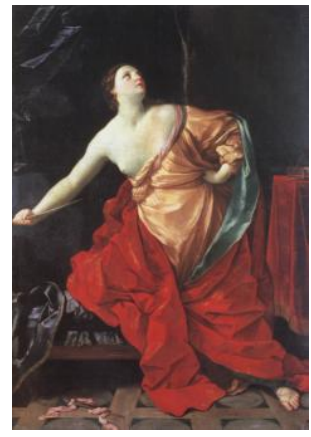

Abb. 10

Vouet (1590-1649) [Abb. 12] und Artemisia Gentileschi (1593-1653) [Abb. 13] liegt dieser Grundtypus zugrunde. Dabei wird der starre frontale Kontrapost im Laufe des 16. Jahrhunderts durch dynamische Bewegung und affektreiche Gesten ab-

\footnotetext{
${ }^{53}$ Zu den um 1530 entstandenen Gemälden mit weiblichen Aktfiguren und dem identischen Figurenbestand verschiedener Bildthemen (Silbernes Zeitalter, Grazien, Paris-Urteil, Lukretia, Venus und Amor, Adam und Eva) Erichsen, Johannes in: AK Lucas Cranach, hrsg. von Grimm, Claus u. a., Regensburg 1994, S. 350.

${ }^{54}$ Katalog 110. Das 1518 bezeichnete Gemälde (Schawe, Martin: Kat. Alte Pinakothek, Altdeutsche und altniederländische Malerei, München 2006, S. 142) greift eine zehn Jahre früher datierbare Zeichnung [Abb. 9] der Albertina auf (AK Albertina: Albrecht Dürer, hrsg. von Schröder, Klaus Albrecht / Sternath, Marie Luise, Wien 2003, Nr. 121, S. 373ff.). Wie die Zeichnung der Albertina bestätigt gehört die Lukretia Dürers zunächst in den Zusammenhang seiner Proportionsstudien. Auf einen weiteren möglichen Zusammenhang der als $\mathrm{Ni}$ schenfigur dargestellten Lukretia der Albertina (Katalog 111) hat Anna Scherbaum im genannten Katalog hingewiesen: ein Beitrag zur Paragone-Problematik könnte intendiert sein. Eine zweite, gleichzeitige Zeichnung der Albertina (Nr. 122) zeigt den erhobenen Arm mit dem Dolch und steht bereits in einem eindeutigen Zusammenhang mit dem Gemälde der Alten Pinakothek, das also vielleicht doch schon 1508 intendiert war. Das Bild der Alten Pinakothek hat im Übrigen eine in mehrerer Hinsicht interessante ১Rezeptionsgeschichte.८ Es befand sich spätestens seit 1598 in der herzoglichen Kunstkammer. Das »knappe Schamtuch der Nackten« wurde »malerisch verbreitert. (Schawe a.a.O.). »Im frühen 17. Jahrhundert war das Bild unter einer Verschlusstür verborgen, auf der zunächst eine Darstellung des Cato Uticensis von Peter Candid angebracht war, später die Lukretia des Lucas Cranach [heute auch in der Alten Pinakothek], deren Blöße durch die Übermalung eines Gewandes verdeckt wurde.« (Gisela Goldberg, in Kat. Alte Pinakothek, München 1983, S. 174). Zu diesen Zusammenhängen vgl. unten S. 262
} 
Lukretia: Keuschheit, eheliche Treue, politischer Umsturz

gelöst. Beibehalten werden der einer Niobide ähnelnde Kopf und Blick, der entblößte Oberkörper und die den Dolch

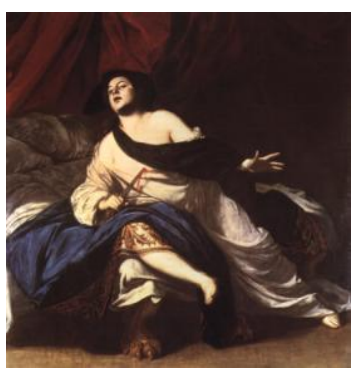

Abb. 11

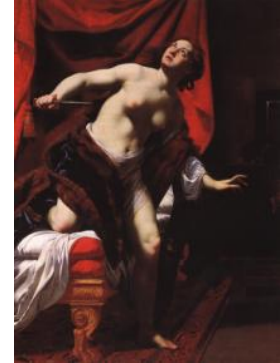

Abb. 12

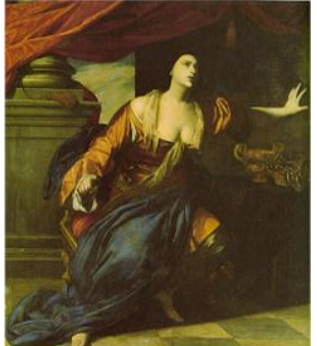

Abb. 13

führende Rechte.

Zu Beginn des 16. Jahrhunderts wurde daneben auch ein halb- bis dreiviertelfiguriger isolierter Typus entwickelt: Joos van Cleve (1485-1540) [Abb. 14] und Lucas Cranach (1472-1553) [Abb. 15] scheinen mit ihren Mustern prägend geworden zu sein. ${ }^{55}$ Bei beiden frühen Tafeln fält auf, dass Lukretia in zeitgenössischer Kleidung als reiche Patrizierin dargestellt wird Die Reverenz

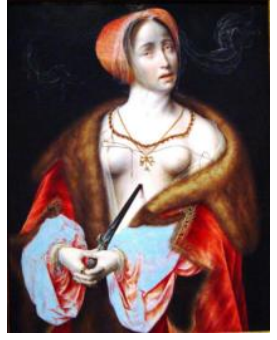

Abb. 14

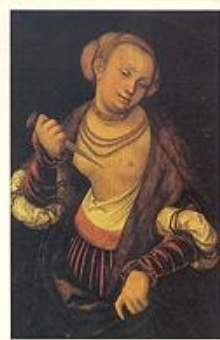

Abb. 15 an die aktuelle Mode kann ein Hinweis auf einen Abnehmerkreis sein, der sich von dem unterschied, der den ganzfigurigen Typus bevorzugte.

Ein fast gleichzeitig mit Cranachs Lukretia-Darstellungen entstandenes Gemälde von Lorenzo Lotto (ca.1480-1556) ${ }^{56}$ verdeutlicht die exemplarische Bedeutung, die die römische Tugendheldin inzwischen gewonnen hatte [Abb. 16]: Eine junge Frau in modischer norditalienischer Kleidung hält in ihrer Linken einen Kupferstich der sich tötenden Lukretia und weist mit ihrer Rechten auf ein kleines, auf einem Tisch liegendes Blatt mit dem von Livius der sterbenden Lukretia in den Mund gelegten ultimum verbum. ${ }^{57}$ Auch wenn ihre

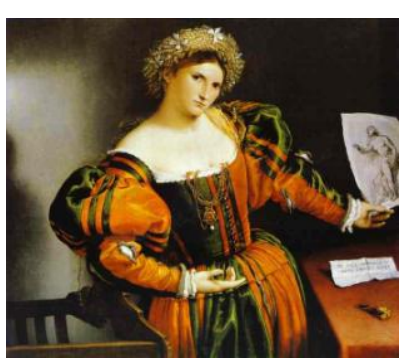

Abb. 16 Identität nicht abschließend geklärt ist, könnte es sich bei der abgebildeten Frau um Lucrezia Valier handeln, die 1533 in die Familie Pesaro einheiratete und aus deren Besitz das Gemälde stammt. ${ }^{58}$ Allerdings wird in der Forschung auch die

\footnotetext{
${ }^{55}$ Katalog 74.

${ }^{56}$ Lorenzo Lotto: A lady with a drawing of Lucretia (National Gallery London) aus der Zeit zwischen 1530 und 1533 (Katalog 217).

57 »Nec ulla impudica Lucretiae exemplo vivet« (`Keine schamlose Frau wird sich auf das Beispiel der Lukretia berufen können.८)

58 So Jaffé, Michael: »Pesaro Family Portraits: Pordenone, Lotto and Titian « in: The Burlington Magazine 113 (1971), S. 696-702. Diese gängige Auffassung wird auch im Bestandskatalog der National Gallery in London übernommen.
} 
Auffassung vertreten, es handle sich um das Porträt einer Kurtisane. Kunsthistorisch wichtiger ist die mise en abyme, die Funktion des Bildes im Bild: Lukretia ist als Personifikation der Keuschheit zum beliebig einsetzbaren Emblem geworden; wie bei Heiligendarstellungen genügt ein Attribut als Verweis auf größere narrative Zusammenhänge. Der Bezug auf Lukretia im Porträt einer vornehmen Dame würde die Tugend der Dargestellten hervorheben, während der Verweis im Portrait einer Prostituierten ${ }^{59}$ im Sinne einer »Kontrastikonographie ${ }^{60}$ als Bekenntnis zum unkeuschen Lebenswandel zu werten wäre. In jedem Fall ist die selbstbewusste Berufung der Porträtierten auf Lukretia bemerkenswert.

\section{Eine vergleichbar emblematische Bedeutung} hat wohl die Skulptur einer Lukretia, die Jacopo Tintoretto (1519-1594) dem um 1555 entstandenen Porträt eines jungen Mannes [Abb. 17] ${ }^{61}$ eingefügt hat. Die Hand des Unbekannten ruht »in lässiger Geste « auf dem Haupt Lukretias. Die Bedeutung der eigenartigen Zusammenstellung muss rätselhaft bleiben, solange der junge Mann nicht identifiziert ist. Die LukretiaStatue könnte »als symbolischer Hinweis auf Treue

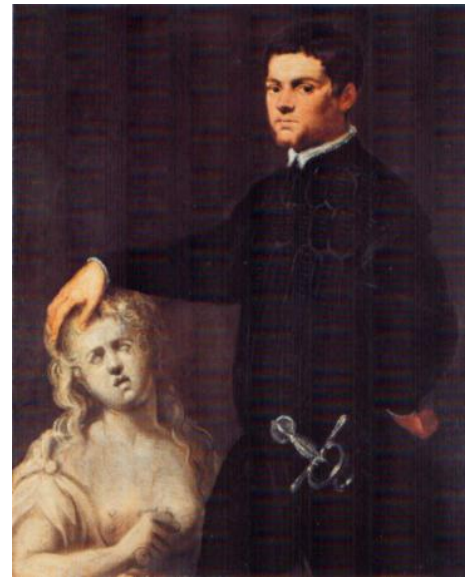

Abb. 17 bis in den Tod « ${ }^{62}$ gemeint sein. In jedem Fall ist die Komposition Tintorettos ein weiterer Beleg für die emblematische und moralische Bedeutung der Darstellungen Lukretias im 16. Jahrhundert.

Guido Reni (1575-1642) hat den einfigurigen Typus in einer raffinierten Synthese weitergeführt, die Anleihen bei der Venus pudica und bei antiken Darstellungen der Niobe mit starker »Gefühlshaltigkeit « ${ }^{63}$ verbindet. Der himmelnd nach oben geführte Blick Lukretias, der das antike Muster der Niobe zitiert, und der teil-

\footnotetext{
${ }^{59}$ So Ost, Hans: "Tizians sogenannte ıVenus von Urbino und andere Buhlerinnen « in: Müller Hofstede, J. / Spies, W. (Hrsg.): Festschrift für Eduard Trier zum 60. Geburtstag, Berlin 1981, S. 129-149 und sich ihm anschließend Follak, a.a.O., S. 70ff. Beide vertreten die Auffassung, bei Lottos Porträt handle es sich um eine Prostituierte; der Lukretia zeigende Stich wäre dann im Sinne einer »Kontrastikonographie (Ost, a.a.O., S. 136) so zu interpretieren, dass die Porträtierte sich zu ihrem Lebenswandel bekennt und das Opfer Lukretias für unsinnig hält.

${ }^{60}$ Goffen, Rona: «Lottos's Lucretia« in: Renaissance Quarterly 52 (1999), S. 742-781 deutet die demonstrative Gestik der Porträtierten als eine in der Porträtkunst der Renaissance nur einem Mann zukommende Inszenierung von Stärke. Mit dekonstruktivistischen Methoden will die von der Gender-Forschung beeinflusste Kunsthistorikerin in allerdings wenig überzeugender Weise zeigen, gagliardia bleibe nicht an Geschlechterrollen gebunden: "gender definitions become malleable, sexual differences fungible, and the admixture of masculine and feminine is seen as a desideratum, devoutly to be wished for, and indeed to be emulated.« (S: 776).

61 Jetzt in München. Katalog 396.

${ }^{62}$ Cornelia Syre, in: Kat. Alte Pinakothek, Ausgewählte Werke, München 2005, S. 378.

${ }^{63}$ Schmidt-Linsenhoff, Viktoria: Guido Reni im Kunsturteil des siebzehnten Jahrhunderts - Studien zur literarischen Rezeptionsgeschichte und Katalog der Reproduktionsgrafik, Diss. Kiel 1974, S. 44f.
} 
weise entblößte Oberkörper ebenso wie die den Dolch führende Rechte finden sich beim halbfigurigen Typ [Abb. 18] der Lukretia in Rom ${ }^{64}$, aber auch bei der Lukretia in Campione ${ }^{65}$ [Abb. 19]. Ein dunkler Hintergrund hebt die marmorne Blässe des

Oberkörpers hervor und betont Opferhaltung und Verzweiflung der Dargestellten. Gerade bei Reni wird deutlich, wie sehr das Affektische im einfigurigen Lukretia-Typus im Vordergrund steht, zumal das Attribut des Dolches den nunmehr einzigen Hinweis gibt, an welche der Tugendheldinnen gedacht ist.

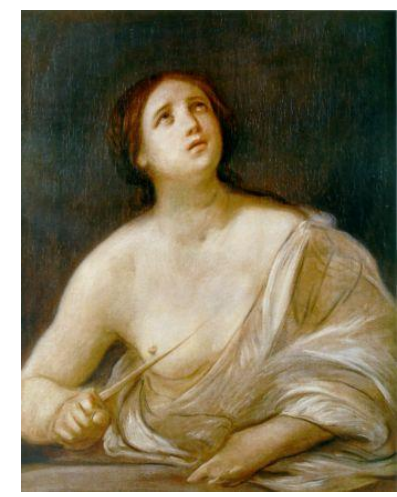

Abb. 18

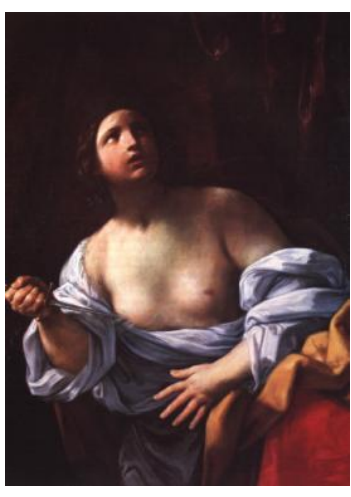

Abb. 19

Guido Cagnacci (1601-1681) übernahm [Abb. 20 und 21] die von Reni stark mit Affekten aufgeladene Inszenierung der Lukretia. ${ }^{66}$ In einer jüngst in den Handel

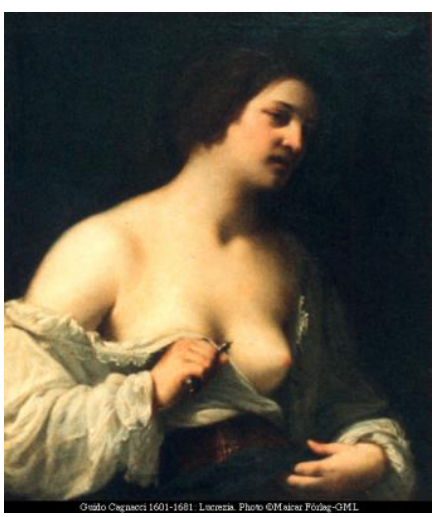

Abb. 20

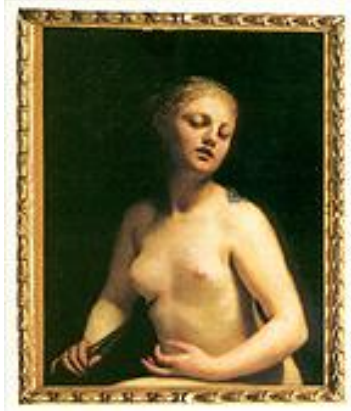

Abb. 21

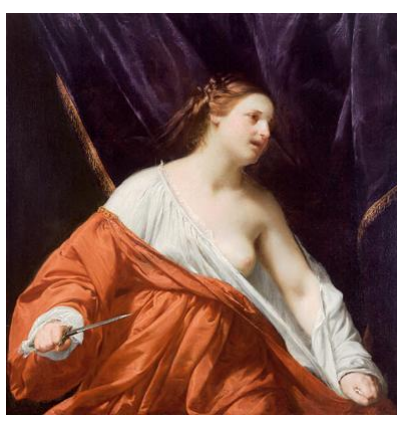

Abb. 22

gekommenen Variante [Abb. 22] nahm Cagnacci allerdings die Nacktheit zurück und steigerte die Dramatik durch die abgestufte Darstellung verschiedener Stoffe, die als roter und blauer Samt des Hintergrunds und weißes Leinen des geöffneten Hemdes und roter Gewandstoff den marmorblassen Körper Lukretias rahmen. ${ }^{67}$

\footnotetext{
${ }^{64}$ Katalog 325.

65 Katalog 314.

${ }^{66}$ Katalog 56 und 54

67 Katalog 57. „Das Gemälde entspricht der Beschreibung eines Werks, das sich im 18. Jahrhundert in der Galerie des Kardinals Tommaso Ruffo in Ferrara befand. [...] Zu dem vorliegenden Gemälde gibt es eine signierte und snapoli 1762، datierte und beiderseits erweiterte Zeichnung von Angelica Kauffmann, welche die Künstlerin zweifellos nach dem Original angefertigt hatte. Das Gemälde wurde erstmals in einem Gutachten vom 24. Juni 1924 von Wilhelm Suida als eigenhändiges Werk von Cagnacci anerkannt. Und zwar aufgrund von dessen der Kleopatra im Kunsthistorischen Museum in Wien entsprechenden smorbidess und geistreicher Luftigkeitı (Katalog der Gemäldegalerie 1991, S. 153, Nr. 232). [...] Die Beziehung zu Guido Reni sowie zur Lukretia von Tizian, die Cagnacci zweifellos kannte, wurde übrigens schon in der Beschreibung der Lukretia betont, als diese sich noch in der Galerie des Kardinals Ruffo befand: 'Lucrezia Romana di palmi 4 e 5 con stilo in mano in atto di volersi ferire strappando la propria camicia, dipinta con grande espressione del miglior gusto di Guido Cagnacci quando seguendo ancora i dettami, e gli esempli di Guido Reni, spiccava celebre allievo di tale celebratissima mano.ı« (Aus dem Katalog des Dorotheum). Das Gemälde wurde im April 2007
} für 1,15 Millionen Euro versteigert. 
Wie vergleichsweise zurückhaltend hingegen in der niederländischen Tradition das gleiche Thema bearbeitet wurde, zeigen zwei Gemälde Rembrandts (1606-1669), der sowohl seine Lukretia aus Minneapolis [Abb. 23] als auch die aus Washington [Abb. 24] in großer Selbstversunkenheit vorstellt. ${ }^{68}$

In der italienischen Tradition scheint hingegen nur der stark ver-

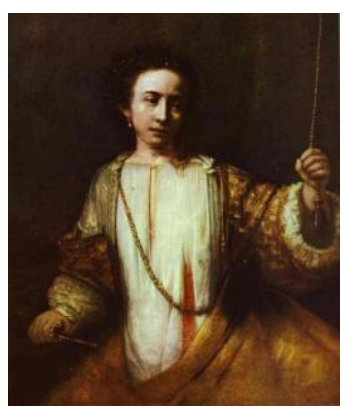

Abb. 23

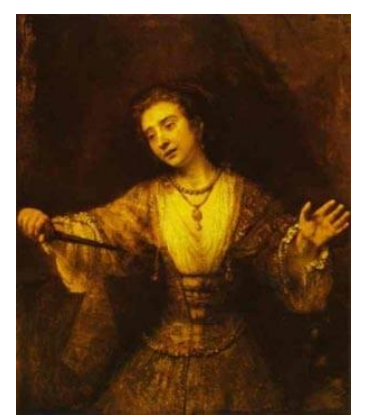

Abb. 24 zweifelte und emphatisch entblößte Lukretia-Typus Käufer gefunden zu haben; als

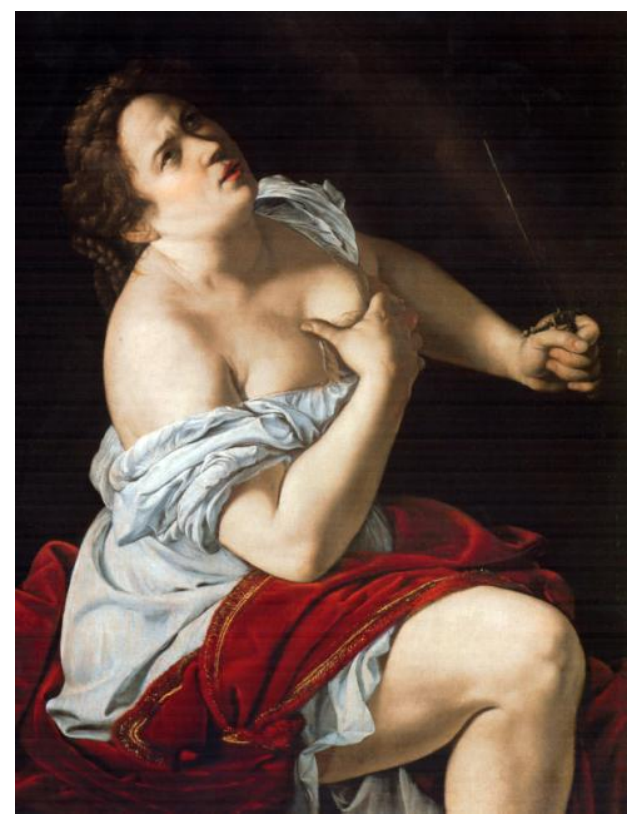

Abb. 25

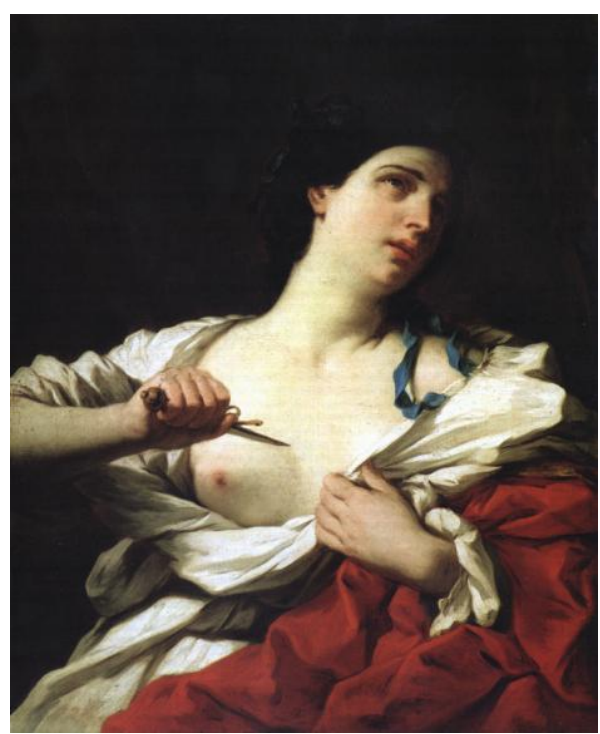

Abb. 26

Beispiele mögen Bearbeitungen des Themas von Artemisia Gentileschi (15931653) [Abb. 25] und Gaetano Gandolfi (1734-1802) [Abb. 26] dienen. ${ }^{69}$ Pietro Ricchi (1606-1675) hat eine ungewöhnlich blutige Variante des Themas [Abb. 27] gewagt: er lässt seine Sterbende im Stürzen den gesamten Bildraum des beinahe quadratischen Gemäldes einnehmen; Lukretia scheint sich die Verletzung soeben erst beigebracht zu haben, hält sie doch noch in ihrer Rechten den Dolch und scheint den Fall mit ihrer geöffneten Linken aufzufangen zu wollen. Der brechende Blick, der

\footnotetext{
${ }^{68}$ Katalog 306 und 305

${ }^{69}$ Katalog 143 und 141.
} 
Lukretia: Keuschheit, eheliche Treue, politischer Umsturz

marmorne Oberkörper und das aus der Stichwunde strömende Blut setzen das Selbstopfer der Römerin in Szene. ${ }^{70}$

Noch das romantische Rollenporträt Angelika Kauffmanns (1741-1807), welches die Fürstin Maria Santacroce als Lukretia [Abb. 28] zeigt, weist die in Italien bevorzugte Verzweiflung im Mienenspiel auf. ${ }^{71}$

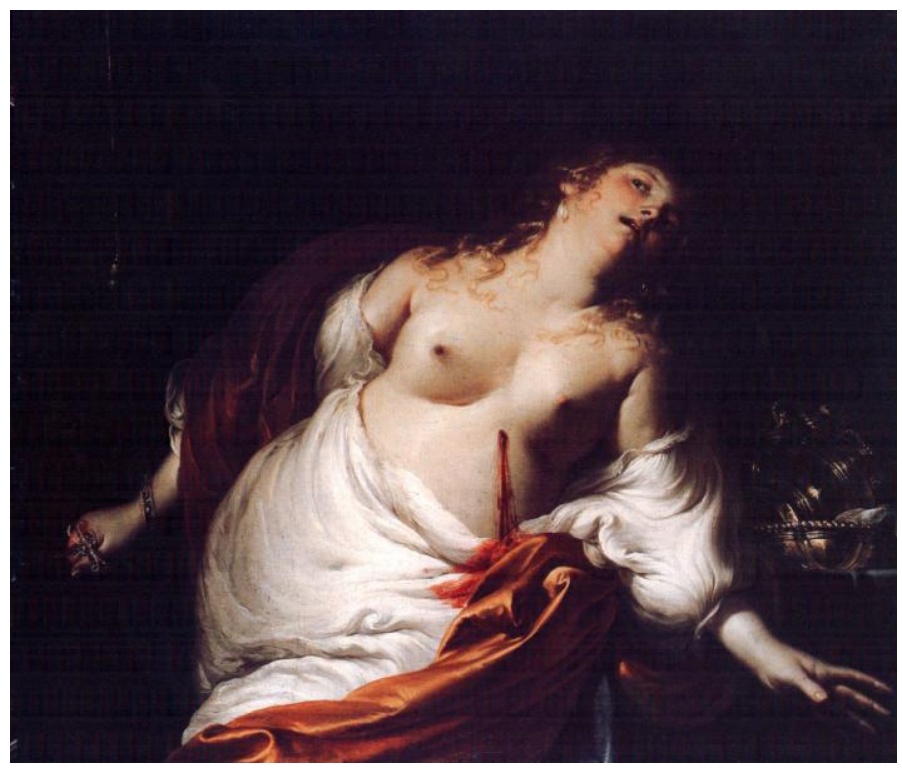

Abb. 27

Wenn die Vergewaltigungsszene ins Bild gesetzt wurde, standen hingegen die Darstellung von Aggression und Gewalt, aber auch die Gegensätze von männlicher und weiblicher Körperlichkeit im Vordergrund. Dieses Motiv ist in der Graphik des 16. Jahrhunderts von Heinrich Aldegrever (1502-ca. 1555) [Abb. 29] und Cornelis Cort (1522-1578) [Abb. 30] in Einzelblättern entwickelt worden. In beiden Stichen bekräftigen die Körper im Hochformat die Diagonale und deuten so mit künstlerischen Mitteln die Schwäche der unterliegenden Lukretia an.

Hans von Aachen ${ }^{72}$ (1552-1615) betonte [Abb. 31] in seinem Wiener Gemälde eben-

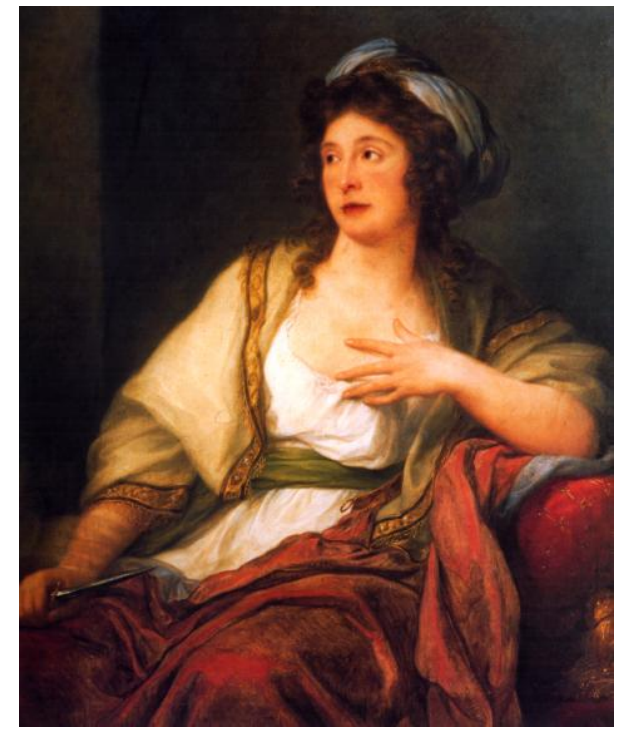

Abb. 28

so wie Thoman Weber $^{73}$ (um 1535 nachgewiesen) [Abb. 32] und Tizian (1487-1576) [Abb. 33], der das Thema ${ }^{74}$ mehrfach bearbeitete, die abwehrenden Gesten Lukretias. Peter Paul Rubens (1577-1640) hat in seiner Szene [Abb. 34] zwischen Lukretia und Tarquinius den Blickkontakt intensiviert, der durch die gekreuzten Arme und

\footnotetext{
${ }^{70}$ Katalog 341.

${ }^{71}$ Vgl. unten, S. 299 und Katalog 188.

72 Katalog 1.

${ }^{73}$ Katalog 434.

74 Katalog 400 und (hier) 402.
} 
Beine eine besonders pikante Note erhält. ${ }^{75}$ Luca Giordano (1632-1705) [Abb. 35] stellte Lukretia ${ }^{76}$ in der Pose der nackten Venus zur Schau.

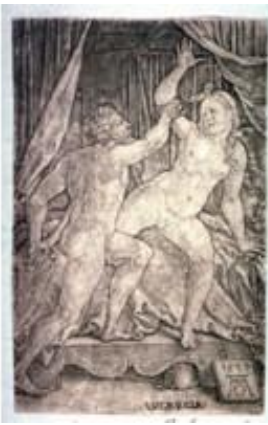

Abb. 29

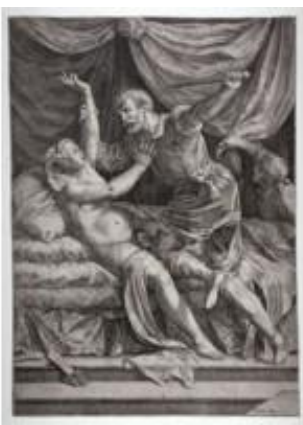

Abb. 30

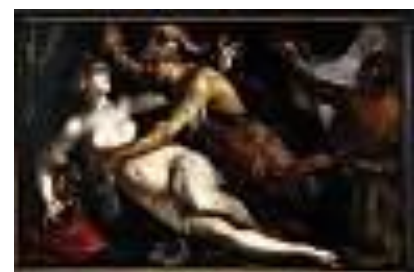

Abb. 31

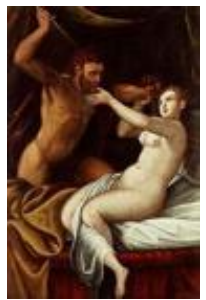

Abb. 32

Auch spätere Bearbeitungen des Themas wie die von Sebastiano $\operatorname{Ricci}^{77}$ (1659-1734) [Abb. 36] und Giuseppe Maria Crespi (1665-1747) [Abb. 37] be-

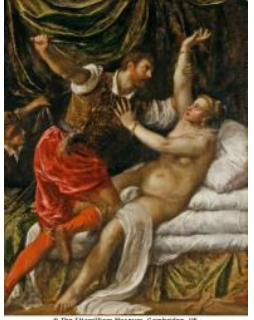

Abb. 33

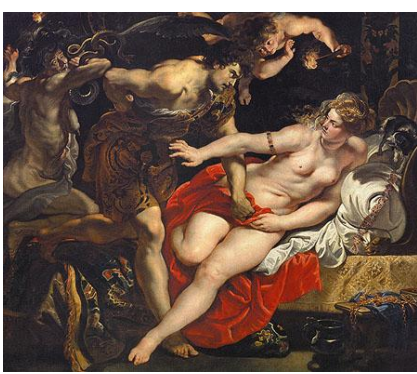

Abb. 34

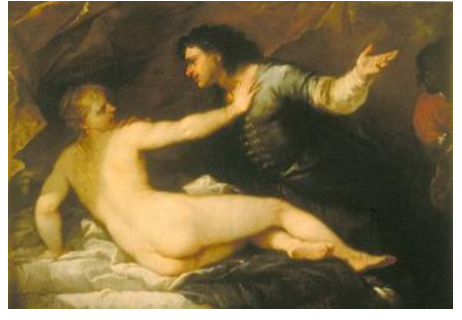

Abb. 35

tonten über dynamische Bewegungen und geschlechtsspezifische Inkarnate die Aggressivität des Vergewaltigers und die Wehrlosigkeit des weiblichen Opfers. Pietro Ricchi (1606-1675) wählte wie für den Selbstmord der Tugendheldin auch für die Vergewaltigungsszene ${ }^{78}$ die Diagonale [Abb. 38] als bestimmendes Bildelement: Lukretias Marmorkörper hebt die sprechend auf den Sklaven deutende Hand des Tarquinius wie einen Schattenriss hervor. Geöffneter Mund und geschlossene Augen der

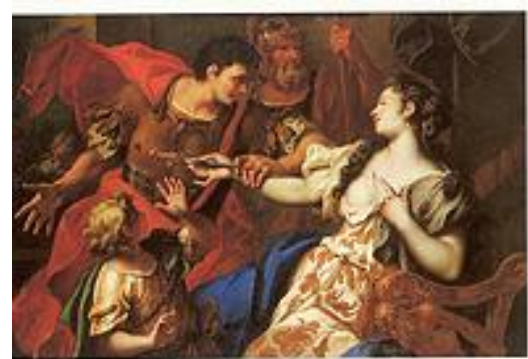

Abb. 36

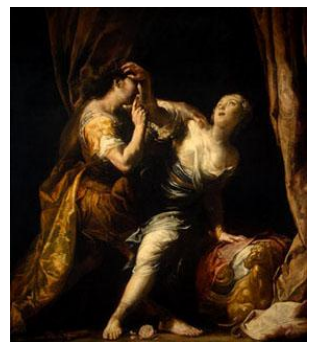

Abb. 37

Römerin deuten Wehrlosigkeit und Ohnmacht der Tugendheldin an. Werden die Rache schwörenden Verwandten ins Bild gesetzt, hebt die Komposition meist auf den bevorstehenden politischen Umsturz ab.

\footnotetext{
${ }^{75}$ Das Potsdamer Gemälde ist als ১Beutekunst‘ 2003 wieder aufgetaucht (Katalog 358).

76 Katalog 158.

${ }^{77}$ Katalog 344.

${ }^{78}$ Katalog 340.
} 


\section{Lukretia: Keuschheit, eheliche Treue, politischer Umsturz}

Bei den frühen Versionen des 16. und 17. Jahrhunderts ist dies allerdings noch nicht der Fall. Sie akzentuieren immer noch den intimen Charakter der Szene und erweitern sie dramatisierend um die Familienmitglieder, ohne den Racheschwur in den Mittelpunkt zu stel-

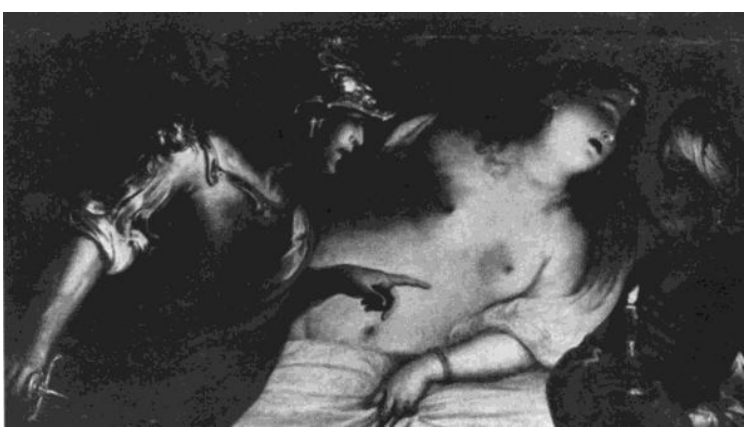

Abb. 38 len.

$\operatorname{Tizian}^{79}$ (1477-1576) hat in seinem Wiener Bild (um 1515) die Szene auf Lukretia und ihren Ehemann Collatinus verkürzt und durch diese Ausschnitthaftigkeit in ganz ungewöhnlicher Weise verdichtet [Abb. 39]: Lukretia blickt, halbfigurig und frontal gegeben, unbestimmt nach links oben und hält den Dolch bereits entschlossen in ihrer Rechten. Collatinus ist erst auf den zweiten Blick zu erkennen: Sein Gesicht erscheint hinter Lukretias rechter Schulter; auch umfasst er ihren linken Arm und scheint seine Frau vom Selbstmord abhalten zu wollen. Ungleich dramatischer ist die Szene bei Giovanni Sodoma ${ }^{80}(1477-1549)$ [Abb. 40]:

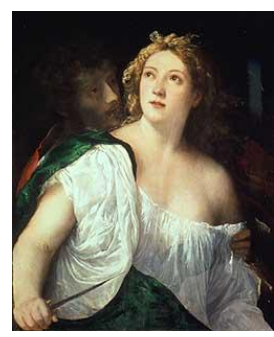

Abb. 39

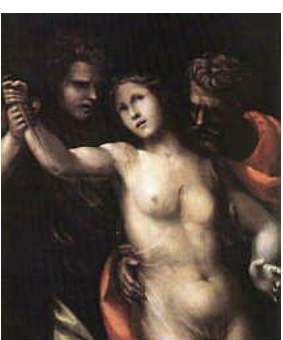

Abb. 40

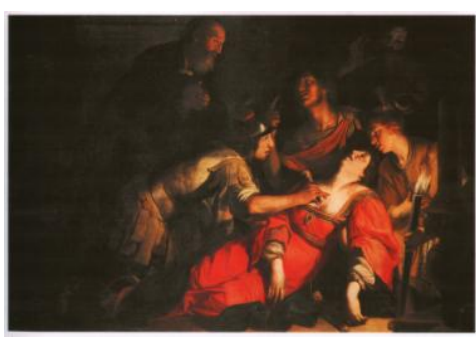

Abb. 41

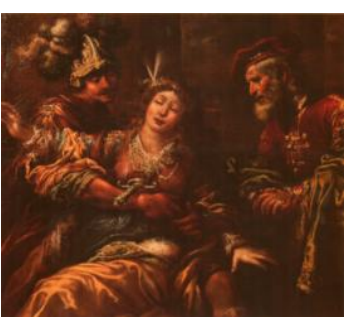

Abb. 42

Collatinus versucht zu spät, Lukretia am Stich zu hindern, während ihr Vater Lukretius sie, ihren Fall voraussehend, bereits stützt. Die völlige Nacktheit Lukretias betont ihre Schutzlosigkeit und Stigmatisierung durch die Vergewaltigung.

Das durch optisches Heranrücken die Intimität der Familie evozierende Brust- oder Kniestück ${ }^{81}$ blieb lange das vorherrschende Format für das Thema. Allenfalls die Lukretia [Abb. 41] des Francesco Rustici ${ }^{82}$ (1592-1626), als Pendant einer Sophonisbe ${ }^{83}$ für die Ausstattung der Florentiner Villa Poggio Imperiale der Maria Magdalena von Österreich konzipiert, nimmt bereits andeutend den Rache-

\footnotetext{
${ }^{79}$ Katalog 400.

${ }^{80}$ Katalog 375.

${ }^{81}$ Vgl. Katalog 308, 311, 312, 314, 317, 321, 325, 326, 327, 328, 329 (Brustbilder oder halbfigurige Gemälde von Reni). Auch Gandolfi (141), Guercino (168), Carneo (58) und Cifrondi (66) haben für ihre LukretiaGemälde das halbfigurige Format gewählt.

${ }^{82}$ Katalog 360.

${ }^{83}$ Vgl. unten, S. $247 f$.
} 
schwur auf. Die caravaggeske Lichtregie lenkt den Blick des Betrachters auf die Sterbende, um die sich die drei Männer und eine Dienerin bemühen. Collatinus deutet eine beschwörende Geste gegenüber dem Schwiegervater an. Claude Vignon $^{84}$ (1593-1670) reduziert im Dreiviertelformat [Abb. 42] das Personal auf Lukretia, ihren Mann und ihren Vater. Collatinus hält seine Frau umfangen, während der Vater verzweifelt mit den Händen ringt. Ganz in der Nachfolge Poussins entwickelt Charles-Alphonse Dufresnoy $^{85}$ (1611-1668) [Abb. 43] die Szene: Vor der in einer klassizistischen

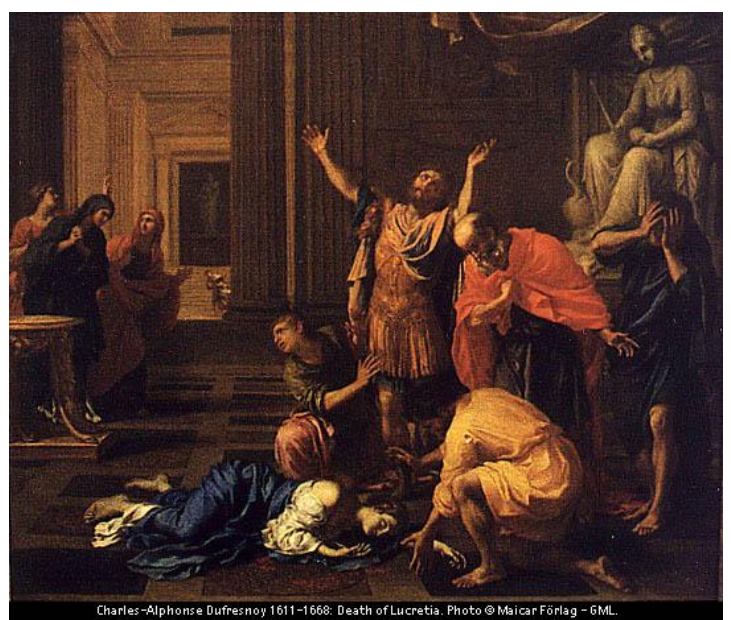

Abb. 43

Vorhalle aufgestellten Juno-Statue reagieren Vater, Ehemann und Brutus mit starken Affekten auf die bereits tot am Boden liegende Lukretia. Das Pathos der Männer wird in den Affekten dreier Frauen im Mittelgrund gespiegelt. Der Durchblick in ein Treppenhaus lässt einen weiteren herbeieilenden Römer erkennen. Den männlichen Rächern werden allerdings selten so starke Emotionen wie bei Dufresnoy zugedacht.

Immer häufiger wird im 17. und 18. Jahrhundert das Thema des Racheschwurs aufgegriffen. Wie bei den einfigurigen Bildern steht dabei meist der Dolch im Mittelpunkt des Bildaufbaus, doch gewinnt er einen auf die Zukunft verweisen-

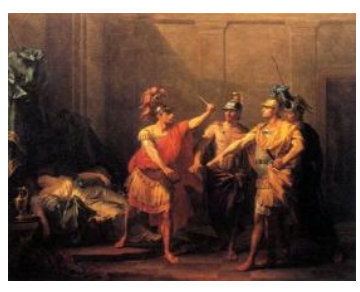

Abb. 44

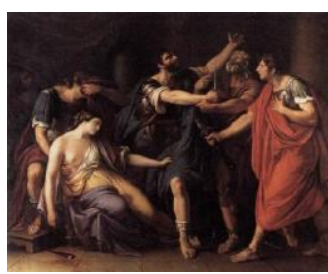

Abb. 45

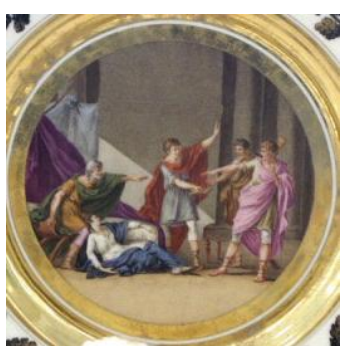

Abb. 46

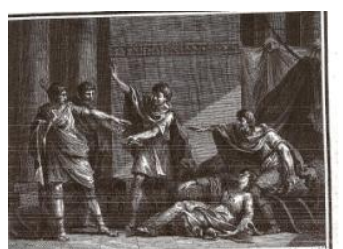

Abb. 47

den Sinn, da die männlichen Verwandten über inm geloben, der Königsherrschaft ein Ende zu bereiten. ${ }^{86}$ Jacques Antoine Beaufort (1721-1784) wurde mit seinem Gemälde [Abb. 44] in die Akademie (1771) aufgenommen. Der blutige Dolch hat

\footnotetext{
${ }^{84}$ Katalog 421.

${ }^{85}$ Katalog 108.

${ }^{86}$ Bereits Pigler unterscheidet zwei ikonographische Gruppen: „Der Selbstmord der Lucretia, I: als Einzelfigur « (a.a.O., S. 386-389) und »Der Selbstmord der Lucretia, II: sie ersticht sich in Gegenwart ihres Gemahls L. Tarquinius Collatinus, ihres Vaters Spurius Lucretius und des L. Junius Brutus« (S. 389-390).
} 


\section{Lukretia: Keuschheit, eheliche Treue, politischer Umsturz}

sich vom Attribut Lukretias zum Emblem des Umsturzes gewandelt. Mit den gleichen bildnerischen Mitteln arbeitete um 1763 Gavin Hamilton (1748-1825) [Abb. 45], aber auch der unbekannte Porzellanmaler [Abb. 46], der die graphische Vorlage [Abb. 47] von Silvestre David Mirys (1742/1750-1810) (um 1810) in Farbe ${ }^{87}$ umgesetzt hat. Die Beispiele inszenieren augenfällig, dass die LukretiaThematik im Laufe des 18. Jahrhunderts an politischer Brisanz gewonnen hat. Lukretia liegt bereits tot am Boden, während in der anderen Bildhälfte die männlichen Verwandten stehend Vergeltung

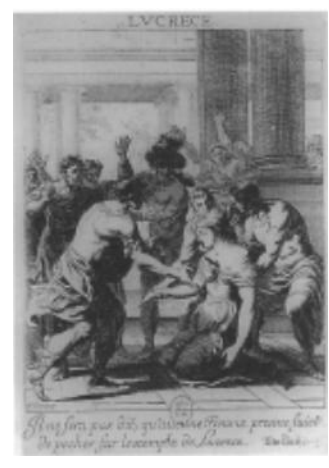

Abb. 48

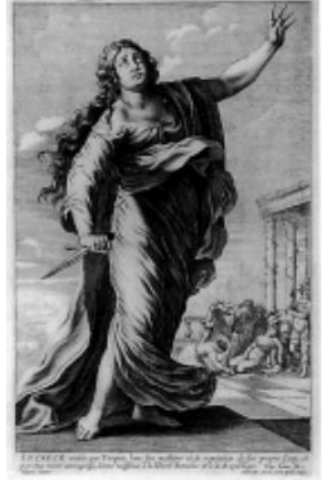

Abb. 49

schwören. Das Inszenierungsmuster der französischen Aufklärung kontrastiert `Frauenopferı und zu erringende Souveränität. Lukretias Selbstmord ist nicht mehr nur Emblem weiblicher Keuschheit; archaische Gründungsmythen aufgreifend gilt das weibliche Opfer darüber hinaus als entscheidende Voraussetzung eines politischen Umsturzes und wird so auch ins Bild gesetzt. ${ }^{88}$

Lukretias untergeordnete Rolle als Ehefrau eines römischen Aristokraten verhinderte wohl ihre Aufnahme in die dekorativen Galerien des Frühbarock, die offensichtlich für Regentinnen reserviert waren. ${ }^{89}$ Dagegen findet sie sich in den graphischen Serien von du Bosc (1645) [Abb. 48] und Le Moyne (1647) [Abb. 49]. ${ }^{90}$ Bei ersterem liegt der Akzent noch ganz auf der Tugendheldin nach Livius ${ }^{91}$, bei letzterem kommt bereits, ebenso unter Berufung auf Livius, die politische Deutung ins Spiel, die dann in der französischen Aufklärung eine besondere Rolle spielen sollte. ${ }^{92}$

Die Figur der Lukretia bietet in ihren ikonographischen Inszenierungen mehr Varianten als die Darstellungen der Dido, Sophonisbe oder Kleopatra. Galt der

\footnotetext{
${ }^{87}$ Katalog 246.

${ }^{88}$ Vgl. dazu Loraux, Nicole: Tragische Weisen, eine Frau zu töten, Frankfurt u. a. 1993; Fögen, Marie Theres: Römische Rechtsgeschichten, Über Ursprung und Evolution eines sozialen Systems, Göttingen 2002; Mathes, Melissa M.: The Rape of Lucretia and the Foundation of Republics, Pennsylvania State UP 2000.

${ }^{89}$ Vgl. unten im Zusammenhang der Serien, S. 232.

${ }^{90}$ Katalog 64 (Du Bosc) und 42 (Le Moyne).

${ }^{91}$ Die subscriptio lautet: "ll ne sera pas dit, qu'aucune Femme prenne sujet de pécher sur l'exemple de Lucrèce.«

92 Die subscriptio lautet: »Lucrèce, violée par Tarquin, lave son malheur et sa réputation de son propre sang; et par une mort courageuse, donne naissance a la liberté Romaine et à la République.«
} 
Selbstmord Lukretias den Kirchenvätern noch als verwerfliche Tat einer ruhmsüchtigen Römerin, wurde Lukretia in der Frühen Neuzeit zur sprofanen Heiligen der Keuschheit und ehelichen Treue, ihr Dolch zum Attribut einer Märtyrerin. Daneben tritt die ganz auf die Affektkonturierung abhebende, meist halbfigurige Darstellung der Tugendheldin, die bis in die Romantik fortgeführt wurde. Schließlich findet sich in szenischen Historienbildern mit den Rache schwörenden Verwandten eine politische Deutung des durch den Selbstmord der Tugendheldin ausgelösten politischen Umsturzes, die obwohl sie bereits bei Livius angelegt war, in der Historienmalerei wohl erst im 18. Jahrhundert zur Geltung kam. 


\section{Kleopatra: Tugendheldin oder femme fatale}

\section{Kleopatra: Antike Quellen}

Kleopatras Schönheit war bereits in der Antike sprichwörtlich, wenn sie auch wohl nicht der Wirklichkeit entsprach. Ihr Leben und Sterben ${ }^{1}$ fand sogleich das Interesse der augusteischen Historiographen und Dichter, da sie für das römische Publikum einen fremden und exotischen Orient verkörperte. Dass die Herrscherin des Ptolemaierreiches mit ihrem Brudergemahl Ptolemaios XIII. und nach dessen Tod mit ihrem Bruder Ptolemaios XIV. in Geschwisterehe lebte, wurde in Rom als Inzest gewertet, obwohl es pharaonischer Sitte entsprach. Auch dass Kleopatra ihren Machtbereich, überdies noch als Frau, ständig erweitern konnte, ließ sie aus römischer Sicht zu einem fatale monstrum ${ }^{2}$ werden. Den römischen Machthabern gegenüber verhielt sie sich taktisch geschickt, wurde Cäsars Geliebte, verließ Rom, wo sie sich 46-44 v. Chr. aufgehalten hatte, nach seiner Ermordung und kehrte mit dem gemeinsamen Sohn Kaisarion nach Ägypten zurück. Später wurde sie als Geliebte des Antonius, mit dem sie drei Kinder hatte, zur Herrscherin des römischen Ostreichs erhoben, so dass der nach der Ermordung Cäsars entbrannte Bürgerkrieg nominell zwischen Octavian und Kleopatra ausgetragen wurde. Trotz des Einsatzes einer großen Flotte und ungeheurer Geldmittel ging die Schlacht von Actium (31 v. Chr.) verloren. Kleopatra veranlasste Antonius, nach dem verlorenen Bürgerkrieg Selbstmord zu begehen und wählte für sich selbst den Tod durch Schlangenbiss, um nicht von Octavian im römischen Triumphzug mitgeführt zu werden.

\section{Kleopatra: Literarische Rezeption}

Aus einsichtigen Gründen entwarf die antike Historiographie von Anbeginn ein negatives Bild und charakterisierte Kleopatra als intrigant und ausschweifend. ${ }^{3}$ Die

\footnotetext{
${ }^{1}$ Stähelin s. v. in: RE, Bd. 11, Stuttgart 1922, Sp. 750-781. - Hier vor allem Horaz (c. I,37,26ff); Plutarch (Antonius 84-86), Properz (c. III,1 und IV,6), C. Velleius Paterculus (Historia Romana II, 42ff.). Zur historischen Wertung weiterer antiker Quellen vgl. Volkmann, Hans: Kleopatra, Politik und Propaganda, München 1953, S. 217-224 und Clauss, Manfred: Kleopatra, München 1995, S. 104ff.

${ }^{2}$ So Horaz (c.1,37,21), ohne ihr in der letzten Strophe die Anerkennung zu versagen: Deliberata morte ferocior: / Saevis Liburnis scilicet invidens / Privata deduci superbo / Non humilis mulier triumpho. (c. 37). (>Mit dem frei gewählten Tod zeigte sie Mut genug und verwehrte es den grausamen römischen Kriegsschiffen, als ihres Rangs entkleidete, aber durchaus nicht demütige Frau in einem anmaßenden Triumphzug vorgeführt zu werden.८)

${ }^{3}$ Nach Plutarch hat Kleopatra auch zu den weiblichen Mitteln des Weinens und Hungerns gegriffen, um Antonius an sich zu binden und seine Ehefrau Octavia aus dem Feld zu schlagen (Antonius 53). Er schildert anschaulich, wie Kleopatra sich bei der Begegnung mit Antonius in Tarsos als Aphrodite inszeniert haben soll (Antonius 26). Diese Episode wurde ein beliebtes Motiv der Historienmalerei.
} 
diffamierenden Darstellungen der römischen Dichtern Vergil ${ }^{4}$ und Lukan $^{5}$ deuten Kleopatra als treibende Kraft im Bürgerkrieg, die Antonius gewissermaßen behext und zu ihrem Instrument macht. Kleopatra wird so in der Dichtung zur Inkarnation des fremden, mysteriösen und deshalb bedrohlichen Ostens, der beinahe über die westliche Welt und ihre Kultur triumphiert hätte. ${ }^{6}$ Dieses Zerrbild wird im Mittelalter übernommen: Dante charakterisiert Kleopatra als lussorïosa ${ }^{7}$ und versetzt sie zusammen mit Semiramis, Dido und Helena ins Inferno. Ihr Bild wird von Prunk, Verschwendung und Luxus geprägt. Boccaccio wendet in De claris mulieribus ${ }^{8}$ seine ganze Imaginationskraft auf, um eine von Verschwendungssucht und sexueller Maßlosigkeit getriebene Frau zu zeichnen. Er charakterisiert die ägyptische Königin als »zügellos bösartige Frau von hohem Selbstbewusstsein « (e[ff]renata malitiis mulier, de se plurimum fidens) ${ }^{9}$, welche die Männer sexuell hörig machte und als Marionetten ihrer politischen Absichten und Intrigen benützte. Breit schmückt Boccaccio eine von Plinius d. Ä. ${ }^{10}$ überlieferte Anekdote aus. Kleopatra gewann eine Wette mit Antonius, als sie bei einem Bankett hunderttausend Sesterzen auf einmal verzehrte, indem sie eine Perle in Essig auflöste und trank. In der späteren Bildtradition wird dieses Perlenmotiv oft aufgegriffen. Moralisierend zeichnet Boccaccio das Bild einer machtbewussten und schönen, intriganten und raffinierten

\footnotetext{
${ }^{4}$ Aeneis VIII, 675-713

${ }^{5}$ Besonders Pharsalia X, 53-69.

${ }^{6}$ So Vergil, Aen. VIII, 696-700: "Regina in mediis patrio vocat agmina sistro / necdum etiam geminos a tergo respicit anguis. / Omnigenumque deum monstra et latrator Anubis / contra Neptunum et Venerem contraque Minervam / tela tenent. Saevit medio in certamine Mavors. « (>Inmitten der Schlacht ruft die Königin ihre Scharen mit dem väterlichen Sistrum, sieht noch nicht die beiden Schlangen im Rücken. Monstren von Göttern jeglicher Art und der Räuber Anubis führen die Waffen gegen Neptun, Venus und Minerva. Mitten im Kampf rast Mars.ı) - Lukan, Pharsalia X, 66-67: »Leucadioque fuit dubius sub gurgite casus, / an mundum ne nostra quidem matrona teneret. « ( Es war auf dem leukadischem Meer der Ausgang unsicher, ob eine Frau und gar eine fremde die Welt regieren sollte. $\iota)$

7 Inf. V, 63 (»poi è Cleopatràs lussuriosa«); außerdem Par. VI, 75-78 (»Piangene ancor la trista Cleopatra, / che, fuggendoli innanzi, dal colubro / la morte prese subitana e atra $)$.

${ }^{8}$ LXXXVIII: De Cleopatra regina Egyptiorum

${ }^{9}$ LXXXVIII, 7

${ }^{10}$ Naturalis historia, IX, 119-121: »[...] Haec, cum exquisitis cotidie Antonius saginaretur epulis, superbo simul ac procaci fastu, ut regina meretrix lautitiam eius omnem apparatumque obtrectans, quaerente eo, quid adstrui magnificentiae posset, respondit una se cena centiens HS absumpturam.[...] Ex praecepto ministri unum tantum vas ante eam posuere aceti, cuius asperitas visque in tabem margatitas resolvit. Gerebat auribus cum maxime singulare illud et vere unicum naturae opus. Itaque expectante Antonio, quidnam esset actura, detractum alterum mersit ac liquefactum obsorbuit. Iniecit alteri manum L. Plancus, iudex sponsionis eius, eum quoque parante simili modo absumere, victumque Antonium pronuntiavit omine rato. « (>Als sich Antonius täglich mit erlesenen Mahlzeiten mästete, antwortete [Kleopatra] auf seine Frage, ob man noch größeren Luxus bieten könne, mit anmaßender und zugleich frecher Verachtung, als ob die hurende Königin seine Bewirtung und den ganzen Aufwand herabsetzen wollte, sie werde bei einem einzigen Gastmahl hunderttausend Sesterzen verzehren. [...] Auf ihren Befehl besorgten die Bediensteten ein Gefäß mit Essig, in dessen Schärfe sich Perlen auflösen ließen. Kleopatra trug als Ohrschmuck dieses einzigartige und unvergleichliche Produkt der Natur [bereits von Plinius erwähnte Perlen unvergleichlicher Größe]. Als Antonius wartete, was sie denn nun tun würde, nahm sie eine Perle aus dem Ohrgehänge, tauchte sie in den Essig und trank sie aufgelöst. Als sie auch die zweite Perle auf gleiche Weise vernichten wollte, verkündete L. Plancus, der Schiedsrichter der Wette, dass Antonius unter den vereinbarten Bedingungen die Wette verloren habe.८)
} 
femme fatale und eröffnet damit eine Sichtweise, die bis in die Darstellung Kleopatras als dekadenter Herrscherin in der Historienmalerei des Fin de siècle nachwirkt. ${ }^{11}$ Versagten römische Schriftsteller wie Horaz ihrem mutigen Selbstmord nicht die Achtung ${ }^{12}$, erzählt Boccaccio neben dem Selbstmord eine zweite, weniger schmeichelhafte Todesversion, nach der Antonius die Regentin gezwungen hätte, das Gift zu trinken,das sie inm bestimmt hatte. Beschimpfte bereits Properz Kleopatra als shurende Königin ${ }^{13}$, verdichtete nun der Humanist inr Bild zu dem einer »männermordenden Sirene «. ${ }^{14}$

Historiengemälde griffen verschiedene und gegensätzliche Aspekte auf. Vor allem im 19. Jahrhundert wurde Kleopatra als laszive und dekadente Herrscherin ${ }^{15}$ dargestellt, ein Motiv, für das sich zahlreiche antike und mittelalterliche Quellen anführen ließen. Ganz im Gegensatz dazu stand in der Frühen Neuzeit die Tugendheldin im Vordergrund, die ihren Tod selbst wählt. ${ }^{16}$ Daneben erscheint Kleopatra als Königin und als große Liebende. Beide Motive gehen offensichtlich auf das frühneuzeitliche Historiendrama zurück, ohne dessen Vermittlung wie bei Sophonisbe und Dido die Ikonographie des Historiengemäldes nicht zu erklären wäre. In der Tat war die Figur der Kleopatra - hierin Dido vergleichbar - ein ausgesprochener Bühnenerfolg. Bis 1900 sind weit über hundert Bearbeitungen ${ }^{17}$ zu verzeichnen, zunächst Historiendramen, dann aber auch viele Opern und Ballette bis

${ }_{12}^{11}$ Zu Makarts Kleopatra vgl. S. 13ff.

12 Horaz (c. 37, 21) betont ihren männlichen Mut, der sie auch in dieser verzweifelten Situation nicht fliehen lässt: "Quae generosius/ perire quaerens nec muliebriter / Expavit ensem nec latentis / Classe cita reparavit oras. " (〉Diese will auf edlere Weise sterben und schreckt nicht nach Frauenart vor dem Schwert zurück noch verbirgt sie sich mit einer schnellen Flotte in einer entlegenen Bucht.८)

13 »meretrix regina « (Elegien III, 11, 39)

${ }^{14}$ So Clauss, a.a.O., S. 107f., der im Übrigen zeigt, dass bereits die römischen Schriftsteller (Horaz, Vergil, Cassius Dio, Aurelius Victor) den Bürgerkrieg immer mehr personalisiert, Kleopatra zur wichtigsten Gegenspielerin des Oktavian gemacht und Antonius zum Opfer stilisiert hatten: »Indem die Autoren Kleopatra als männermordende Sirene zeichneten, entwarfen sie ein Traumbild männlicher Obsessionen. Da für den Krieg gegen die ägyptische Königin auch ein Grund notwendig war, wuchsen mit dem Abstand von den Ereignissen in der römischen Geschichtsschreibung die Ambitionen Kleopatras immer gewaltiger. Der Krieg gegen sie geriet schließlich zum Kampf um Freiheit und Ehre, aber auch zum Kampf für Moral und Unzucht. Was zunächst als Konflikt zweier politischer Parteiungen begonnen hatte, endete in der Dichtung und Historiographie als Rettung vor dem barbarischen Osten und vor der monarchischen Staatsform hellenistischer Prägung. «

${ }^{15}$ Vgl. Lindinger, Michaela: „Der verzauberte Blick - Imaginationen des >Orientalischen in Europa«, in: MayrOehring, Erika / Doppler, Elke (Hrsg.): AK Orientalische Reise, Malerei und Exotik im späten 19. Jahrhundert, Wien 2003, S. 10-17.

${ }^{16}$ Immerhin konnte sich diese Interpretation auf Tertullian berufen, der den Selbstmord Kleopatras dadurch motiviert, dass sie nicht in die Hände der Feinde fallen wollte ("serpentes tauro vel urso horridiores, quas Cleopatra immisit sibi, ne in manus inimici perveniret « [mart. 4,6]).

17 Dazu Brambach, Joachim: Kleopatra und ihre Zeit, Legende und Wirklichkeit, München 1991, S. 7: »Zwischen 1540 und 1905 sind allein 127 Bühnenstücke, nämlich 77 Dramen, 45 Opern und 5 Ballette über den Kleopatra-Stoff erschienen, unter innen Shakespeares `Antonius und Kleopatra sowie G. B. Shaws `Caesar und Kleopatraı. " Außerdem Hughes-Hallett, Lucy: Cleopatra, Histories, Dreams and Distortions, London 1990. 
hin zur heute noch vielfach aufgeführten scène lyrique von Hector Berlioz ${ }^{18}$ oder den Opern von Victor Massé ${ }^{19}$ und Jules-Émile-Frédéric Massenet. ${ }^{20}$

Es ist kein Zufall, dass die lange Reihe dramatischer Bearbeitungen mit zwei klassizistischen Historiendramen ${ }^{21}$ beginnt, die politischen Konflikt und Liebestragödie miteinander verknüpfen und deren Handlung nach der militärischen Niederlage bei Actium einsetzt. Die Cleopatra (1552) von Cesare de' Cesari ${ }^{22}$ und die Cléopâtre captive (1552) von Étienne Jodelle ${ }^{23}$ kontrastieren den Todesentschluss Kleopatras mit dem Triumph ihres politischen Gegners Octavian. Auch Giambattista Cinzio (Cleopatra [1555]), Giulio Landi (La Vita di Cleopatra [1551]), Celso Pistorelli (Marc'Antonio e Cleopatra [1576]) und Nicolas de Montreux (Cléopâtre $[1594])^{24}$ thematisieren in ihren Theaterstücken den Konflikt der beiden Gegenspieler. Robert Garnier setzte in seinem Marc-Antoine (1578) die Akzente anders und betont die Skrupel und mütterlichen Gewissensbisse der Königin, die sich zum Selbstmord entschließt und damit ihre Kinder schutzlos den Römern ausliefert.

Vertreter einer kritischen Haltung, die moralisierend das Verhalten der Königin auf die Bühne bringen und an die antiken Vorgaben anknüpfen, sind so verschiedene Autoren wie Hans Sachs (Die Königin Cleopatra mit Antonio dem Römer [1560]) und Daniel Casper von Lohenstein (Cleopatra [1661]).

Eine andere dramatische Traditionslinie setzt mit Shakespeares Tragödie Antony and Cleopatra (1607) ein, die, vielen Dido-Dramen vergleichbar ${ }^{25}$, Kleopatra als große Liebende in Szene setzt und den politischen Konflikt in den Hintergrund treten lässt. Shakespeare beeinflusste damit für Jahrhunderte massgeblich das Bild Kleopatras auf der Bühne. Die von Plutarch ${ }^{26}$ übernommene negative Ein-

\footnotetext{
${ }^{18}$ La mort de Cléopâtre, Scène lyrique pour soprano et orchestre (1829); der Text des Libretto findet sich am einfachsten unter: http://www.hberlioz.com/BerliozLibretti/Rome.htm.

${ }^{19}$ Une nuit de Cléopâtre (1885)

${ }^{20}$ Cléopâtre (1914)

${ }^{21}$ Ein Blick in die Bibliotèque des théâtres von Maupoint (1733), einem immer noch nützlichen Repertorium der französischen Bühne des 16. und 17. Jahrhunderts, zeigt den Erfolg der sstarken Frauen in Frankreich. Am bequemsten ist Maupoint zugänglich unter http://www.cesar.org.uk/cesar2/books/maupoint/index.php (letzter Zugriff 10.12.2006).

${ }^{22}$ De'Cesari, Cesare: Cleopatra, Tragedia di M. Cesare de'Cesari, Venezia (Giovanni Griffio) 1552 (Mikrofilm 952,2 der Biblioteca Casanatense, Rom)

${ }^{23}$ Étienne Jodelle, Cléopâtre captive (1553), erste Drucke 1574 und 1583, kritische Edition von Charles MartyLavaux 1868, bequem zugänglich unter http://hypo.ge.ch/athena/jodelle/jod_cleo.html (zuletzt aufgerufen am 13.06.2008).

${ }^{24}$ Erstdruck 1601; ktitische Edition von Donald Stone jr, Genève1976.

${ }^{25}$ Shakespeare markiert den intertextuellen Zusammenhang deutlich, weist doch Antonius darauf hin, dass Kleopatra und Antonius dem Liebespaar Dido und Äneas Konkurrenz machen. (»Stay for me. / Where souls do couch on flowers, we'll hand in hand, / And with our sprightly port make the ghosts gaze. / Dido and her Aeneas shall want troops, / And all the haunt be ours. " [IV,14,50])

${ }^{26}$ Vgl. Pelling, Christopher: »Anything truth can do, we can do better: the Cleopatra legend «, in: Walker, Susan

/ Higgs, Peter (Hrsg.): AK Cleopatra of Egypt, From History to Myth, London 2001, S. 292-301; Bonnefoy,
} 
schätzung von Kleopatras politischer Rolle wird im Stück nur von untergeordnetem Personal ${ }^{27}$ wiedergegeben; Kleopatra und Antonius aber zu einem der großen Liebespaare der Geschichte gestaltet. Angesichts der Leiche des Antonius verzichtet die Königin auf diplomatisch-politische Zurückhaltung und lässt ihren Emotionen freien Lauf. ${ }^{28}$ In der englischen Tradition griffen vor allem Thomas May (The Tragedy of Cleopatra, Queen of Egypt [1626]) und John Dryden All for Love [1678]) das Bild Kleopatras als großer opferbereiter Liebender auf.

Noch Vittorio Alfieri begann seine Karriere als tragischer Dichter mit einer Tragödie Antonio e Cleopatra (1775) und knüpfte damit an die politisch-moralische Aufnahme des Stoffs auf der Bühne der französischen Klassik an, deren Autoren aus dem politischen Gegensatz der Akteure einen Konflikt moralischer Normen entwickelt hatten. Jean Mairet ${ }^{29}$ (Le Marc-Antoine ou la Cléopâtre 1630) stellte mit Octavie, der ersten Frau des Marc-Antoine und Schwester Caesars, Cléopâtre eine tugendhafte Gegenspielerin gegenüber. Ähnlich verfuhr Pierre Corneille ( $L a$ Mort de Pompée 1643), bei dem Cornélie, die Frau des Pompée diese Rolle übernahm.

Auch in den zahlreichen Opernfassungen ${ }^{30}$ wurde der politische Konflikt mehr und mehr zugunsten der prominenten Liebesgeschichte zurückgedrängt. Drama und Oper des 18. Jahrhunderts fügen dem Bild Kleopatras als großer Liebender, aber auch als orientalischer femme fatale nichts grundsätzlich Neues mehr hinzu. Als typisch kann das Bild Kleopatras in Händels Oper Giulio Cesare in Egit$t^{31}$ gelten, deren Handlung in der Zeit nach der Schlacht bei Pharsalos (48 v. Chr.) spielt. Im Vordergrund der Handlung steht die bühnentechnisch effektvoll ge-

\footnotetext{
Yves: "La noblesse de Cléopâtre «, in: AK Cléopâtre dans le miroir de l'art occidental, (Ritschard, Claude / Morehead, Allison [Hrsg.]), Genéve 2004, 147-164.

${ }^{27}$ So z. B. III,5; III,7 oder IV,10.

${ }^{28}$ IV , 13, 67-69: [...] the odds is gone, / And there is nothing left remarkable / Beneath the visiting moon. « (〉Das Ausserordentliche ist dahin; Und es ist nichts Bemerkenswertes unter dem Mond mehr übrig.८)

${ }_{29}$ Jean Mairet: Théâtre complet, La Sophonisbe - Le Marc-Antoine ou la Cléopâtre - Le Grand et Dernier Solyman ou la mort de Mustapha, Bd. I, hrsg. von Bénédicte Louvat / Alain Riffaud/ Marc Vuillermoz, Paris, 2004. Die Ausgabe von 1637 ist im Netz konsultierbar: http://gallica.bnf.fr/ark:/12148/bpt6k576548 (zuletzt aufgerufen: 14.06.2008).

${ }^{30}$ Vgl. Stieger, Franz: Opernlexikon, Titelkatalog, Tutzing 1975, Band 1, S. 252 und Band 2, S. 677-678. Zu finden sind u. a. Opern von Antonio Canazzi (1653), Christoph Anschütz (1686), Johann Mattheson (1704), Karl Heinrich Graun (1742), Pasquale Anfossi (1779) und Domenico Cimarosa (1789). Besonders im 19. Jahrhundert erfreute sich das Thema in ganz Europa großer Beliebtheit, so u. a. Joseph Weigl (1807), Ferdinando Paer (1809), Lahoz y Otal (1852), Richard Genée (1875), Lauro Rossi (1876), Vittorio Sacchi (1877), Ferdinando Bonamici (1879), Wilhelm Freudenberg (1882), Felipe Pedrell (1885), Giuseppe Bensa (1889), Hervé (eigentlich Florimond Ronger) (1889), Melasio Morales (1891), August Enna (1894), Alphonse Duvernoy (1894); vgl. auch den einführenden Artikel von Perroux, Alain: „Cléopâtre à l'opera, splendeur et misère d'une reine d'Égypte«, in: AK Cléopâtre dans le miroir de l'art occidental, Ritschard, Claude / Morehead, Allison (Hrsg.), Genéve 2004, 171-178.

${ }^{31}$ Die Oper, deren Libretto von Nicola Haym stammt, wurde 1724 in London uraufgeführt.
} 
staltete Liebesbeziehung zwischen Cleopatra und Giulio Cesare, der eben Pompeo geschlagen hat. Die politische Handlung tritt aber durchaus in den Hintergrund, obwohl Cleopatra die Unterstützung Cesares gegen ihren Bruder Tolomeo sucht, der sich die Krone Ägyptens angeeignet hat. Als Cesare in einer Seeschlacht mit dem ägyptischen Heer umgekommen zu sein scheint, will sich Cleopatra durch Selbstmord der Unterwerfung unter ihren Bruder entziehen, wird aber nach der Rettung des römischen Geliebten und nach der Ermordung des Tolomeo (als Rache für die Hinrichtung des Pompeo) zur Königin Ägyptens gekrönt. Im Kontrast zur sittenstrengen Cornelia, der Witwe des Pompeo, wird in Händels Oper Cleopatra als erfolgreiche und bestrickende femme fatale gestaltet.

In der Spätphase der Rezeption tritt die Darstellung der lasziven und dekadenten Herrscherin in den Vordergrund, für die wohl Makart die abschließende Fassung gefunden hat. ${ }^{32}$ In diesen Zusammenhang gehört der epochale Erfolg von Théophile Gautiers Novelle Une nuit de Cléopâtre (1845), die von zwei Opernlibretti aufgegriffen wurde. ${ }^{33}$ Offensichtlich entsprach die Liebesnacht, die die Königin einem Sklaven um den Preis seines Lebens schenkt, dem trivialisierten Bild der Ptolemäerin, das in den zahlreichen Verfilmungen des 20. Jahrhunderts, teilweise bis ins Kitschige kommerzialisiert, weitergeführt wurde. ${ }^{34}$

Stand in der Frühen Neuzeit eindeutig Kleopatras Konflikt zwischen Liebe und Politik oder die Liebestragödie im Vordergrund, setzte sich im 17. Jahrhundert allmählich ein doppeldeutiges und gespaltenes Bild durch, wobei Kleopatra entweder zur Tugendheldin oder zur femme fatale vereindeutigt wurde. So taucht sie um 1642 in Nicolas Prévosts (1604-1670) Serie der sstarken Frauen neben Dido und Sophonisbe auf; andererseits reiht sie zur gleichen Zeit Stefano della Bella (16101664) neben der Königin von Saba und Poppaea unter die »Reines galantes«

\footnotetext{
${ }^{32}$ Vgl. oben, S. 13.

${ }^{33}$ Wilhelm Freudenberg verwendete 1882 ein Libretto von Ernst Pasqué, Victor Massé 1885 in seiner Oper Une Nuit de Cléopâtre ein Libretto von Jules Barbier (1885). Das Gautiers Novelle aufnehmende Ballett Cléopâtre, das der russische Impresario und Choreograph Sergei Diaghilew (1872-1929) den Komponisten Michail Michailowitsch Fokin (1880-1942) zusammenstellen ließ und 1909 in Paris aufführte, gilt als das erste der exotisch-erotischen Ballette, mit denen Diaghilews Truppe Ballets Russes Westeuropa in Ekstase versetzte (zu weiteren Einstudierungen und Wiederaufführungen dieses Balletts vgl. Harris, Dale: „Cléopâtre, Ballett en un acte « unter: »Michail Michailiowitsch Fokin «, in : Pipers Enzyklopädie des Musiktheaters, hrsg. von Carl Dahlhaus, München / Zürich 1987, Bd. 2, S. 231f.)

${ }^{34}$ Vgl. Hamer, Mary: »The myth of Cleopatra since the Renaissance «, in: Walker, Susan / Higgs, Peter (Hrsg.): AK Cleopatra of Egypt, London 2001, S. 302-311, besonders S. 309-310.
} 
ein. ${ }^{35}$ Dieses ikonographische Echo spiegelt die Bandbreite, die Kleopatra als Bühnenfigur in der Frühen Neuzeit gewonnen hatte: sie kann als Politikerin erscheinen, die für die Verwirklichung ihrer Ziele bis zum eigenen Tod kämpft, aber auch als `Circe`, die viele römische Staatsmänner in den Tod reißt. Zweifellos ist sie unter den römischen Tugendheldinnen die Figur mit der größten Palette.

\section{Kleopatra: Ikonographie}

Mit ihren sukzessiven römischen Liebhabern bot die Figur der Kleopatra im Vergleich mit den anderen hier behandelten Tugendheldinnen den Künstlern die breiteste und ambivalenteste Themenpalette. Allerdings wurden in der Graphik und der Historienmalerei schon früh einige Episoden bevorzugt: die Verführung Cäsars, die Begegnung mit Antonius in Tarsos, das Bankett mit der Perlenwette, der Bittgang zu Octavian und vor allem der Selbstmord der Königin.

Dabei wurden höfisches Bankett und Selbstmordszene schon früh moralistisch miteinander verbunden. Neben vereinzelten frühen Miniaturen ${ }^{36}$ wie der Miniatur von 1480 [Abb.1] zeigen bereits die ersten als Holzschnitte oder Kupferstiche verbreiteten Bildentwürfe eine eindeutige Konzentration auf Perlenwette und Selbstmord.

Beide Szenen sind in der Zainerschen Ausgabe von Boccaccios De claris mulieribus, die seit 1473 maßgeblich die Ikonographie prägte, in einem Holzschnitt zusammengefasst. ${ }^{37}$ [Abb. 2] Das linke Bildfeld des Holzschnitts zeigt, wie Kleopatra eine Trinkschale mit der aufgelösten Perle an die Lippen setzt und die Wette gewinnt, während der mit am Tisch sitzende Antonius erstaunt und kritisch zusieht. Das rechte Bildfeld zeigt mit dem bereits erstochen am Boden liegenden Antonius

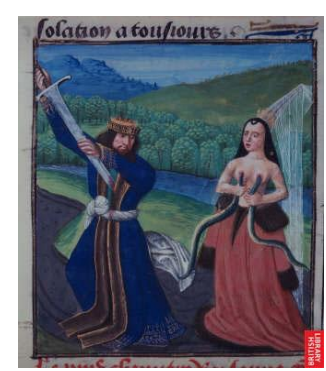

Abb. 1

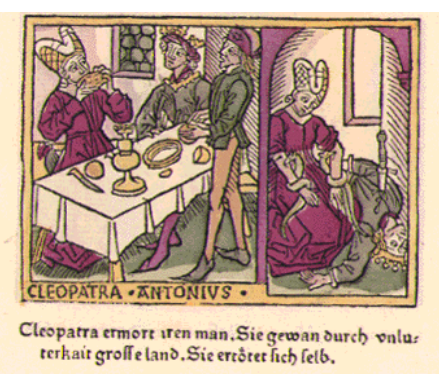

Abb. 2

und den beiden an Kleopatras Armen emporkriechenden Vipern die Bestrafung solch anmaßenden Übermuts. Die Verbindung beider Szenen im Holzschnitt thematisiert Aufstieg und Fall der Herrscherin, setzt ihre moralisierende Deutung vor-

\footnotetext{
${ }^{35}$ Vgl. Richard-Jamet, Céline: „Cléopâtre: femme forte ou femme fatale, une place équivoque dans les galeries de femmes fortes aux XVle et XVIle siècles «, in: Ritschard, Claude / Morehead, Allison (Hrsg.): AK Cléopâtre dans le miroir del'art occidental, a.a.O., S. 37-52.

${ }^{36}$ Vgl. Katalog 407 (um 1405) und (hier) 408 (um 1480).

${ }^{37}$ Vgl. Katalog 409.
} 
aus und betont die `Fallhöhe`, um einen Begriff der aufklärerischen Dramentheorie aufzugreifen. Nicht zufällig wurde die Verbindung von Bankett und Selbstmord, wie sie die frühneuzeitliche Graphik hergestellt hatte, in Pendants und Zyklen ${ }^{38}$ der Historienmalerei aufgegriffen.

Die Graphik des 16. Jahrhunderts hat für den Tod der Kleopatra zwei deutlich voneinander zu trennende Darstellungsmuster entwickelt, die beide in der Ikonographie der Historienmalerei aufgegriffen wurden und sich mit verschiedenen Pathosformeln verbinden. Ein Muster zeigt die stehende oder sitzende Kleopatra und hebt pathetisch auf die Verzweiflung der Königin ab; die Schlangen als Verursacher ihres Todes übernehmen dabei eine saktiveı Rolle. Die andere Pathosformel zeigt die ausgestreckte und liegende Königin im Sterben meist mit geschlossenen Augen, wobei die Schlangen eine eher dekorative Funktion erhalten. An dieses Darstellungsmuster ließ sich die neustoische Interpretation Kleopatras als Tugendheldin am besten anschließen.

Die Pathosformel der Verzweiflung wird zum Beispiel von Hans Sebald Behams (1500-1550) Kleopatra ${ }^{39}$ [Abb. 3] aufgegriffen. Die Königin sitzt im Gefängnis; ein vergittertes Fenster und Ketten betonen ihre elende Situation. Mit manieristisch verdrehter Körperhaltung und himmelndem Blick drückt sie ihr Unglück aus. Die Schlange am linken Unterarm offenbart, dass die Königin sich bereits zum Selbst-

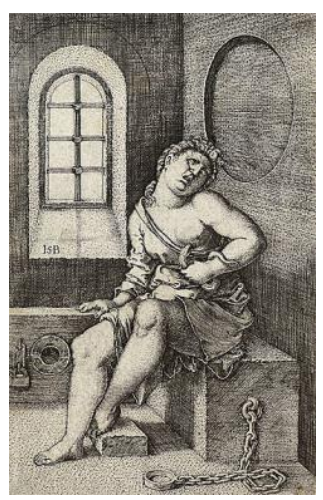

Abb. 3

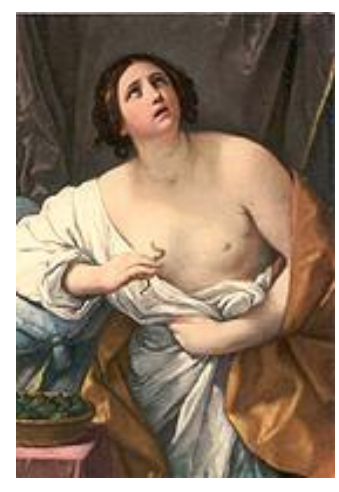

Abb. 4

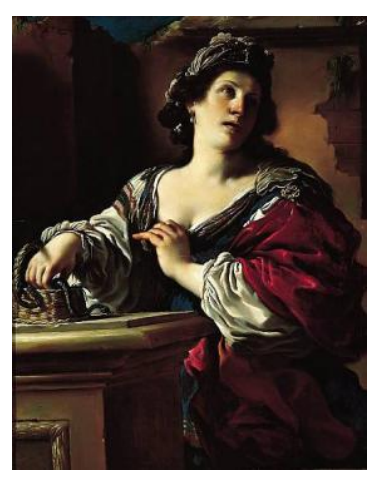

Abb. 5 mord entschlossen hat. Mit ähnlichen künstlerischen Mitteln heben auch Bartel Beham, Jan Muller und Valesio ${ }^{40}$ auf den Affekt der Verzweiflung ab. In dieser Bildtradition wird Kleopatra nicht als souveräne Herrscherin und bezaubernde Frau,

\footnotetext{
${ }^{38}$ Darauf gehe ich weiter unten (S. 162) ausführlich ein. Jacob Jordaens (Katalog 184 und 185), CharlesJoseph Natoire (Katalog 254 und 255) und Gerard de Lairesse (Katalog 201 und 202) beispielsweise haben Pendants gemalt, die sowohl Glück als auch Unglück der ägyptischen Königin veranschaulichen. Viele dieser Pendants oder Zyklen fanden zudem als Vorlagen für Tapisserien Verwendung. Von den hier behandelten Tugendheldinnen nahm besonders Kleopatra einen herausragenden Platz in Gobelin- und Wandteppichserien ein.

${ }^{39}$ Vgl. Katalog 29.

${ }^{40}$ Vgl. Katalog z. B. Bartel Beham (Katalog 28), Monogrammist I. F. (Katalog 248), Hans Sebald Beham (Katalog 31 und 29), Jan Muller (Katalog 250 und 251) und Valesio (Katalog 416).
} 
sondern als Gefangene gezeigt, deren hartes Schicksal zu Herzen gehen soll. Eine Traditionslinie der Historienmalerei hat dieses Muster aufgegriffen und eine eigene Pathosformel für den verzweifelten Entschluss zum Selbstmord entwickelt, die meist mit einem Näherrücken der nun halbfigurig dargestellten Heldin verbunden war. Diese Tradition haben besonders Reni (1575-1642) [Abb. 4] und Guercino (1591-1666) [Abb. 5] mit zahlreichen Beispielen geprägt. ${ }^{41}$

Die andere, ebenfalls von der Graphik vorgebildete Tradition zeigt Kleopatra liegend und greift ohne Zweifel auf ein antikes Vorbild zurück. ${ }^{42}$ Eine zu Beginn des 16. Jahrhunderts in Rom gefundene Ariadne-Statue [Abb. 6] galt als Darstellung Kleopatras, weil ein Armreif am linken Oberarm als Schlange gedeutetet wurde. Papst Julius II. erwarb die Skulptur von der Familie Maffei und verwandte sie in einer repräsentativen Brunnenanlage des Cortile del Belvedere. ${ }^{43}$ [Abb. 7] Die Aufstellung der vermeintlichen Kleopatra in einem öffentlich zugänglichen Raum

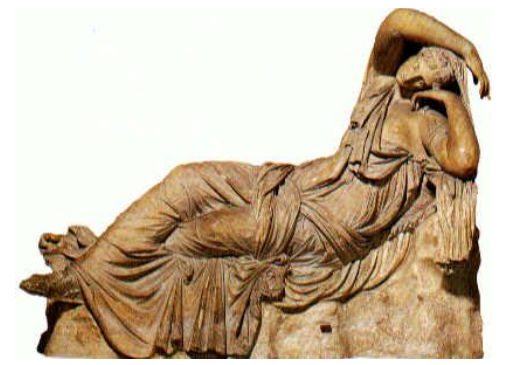

Abb. 6 des Vatikan begeisterte viele Künstler: Baldassare Castiglione (1478-1529) widmete ihr ein neulateinisches Gedicht. Raphael studierte und skizzierte sie, um die Statue als Modell der Muse im Parnass der Stanza della Segnatura ${ }^{44}$ zu verwenden. Das Motiv des >Lagerns mit übergeschlagenem Bein ${ }^{45}$ wurde so zur zweiten Pathosformel der sterbenden Kleopatra.

Die Graphiker des 16. Jahrhunderts experimentierten in zahlreichen Varianten mit diesem Grundmuster. ${ }^{46}$ Alle Versionen greifen auf die in der Antike geprägte Gleichsetzung des Todes mit dem Schlaf zurück. Im Gegensatz zum ersten Grundmuster (der verzweifelten Königin in stehender oder sitzender Haltung) inszeniert die zweite Pathosformel der Graphik die Königin völlig affektfrei

\footnotetext{
${ }^{41}$ Vgl. Katalog 323 (Reni) und Katalog 165 (Guercino).

42 Vgl. Guillaume, Jean: »Cleopatra nova Pandora« in: Gazette des Beaux-Arts 114 (80), 1972, S. 185-194.

${ }^{43}$ Katalog 8. Vgl. Brummer, Hans Henrik: The Statue Court in the Vatican Belvedere, Stockholm 1970 (grundlegend). Zum Statuenhof im Vatikan fand in jüngerer Zeit ein Kongress statt: Winner, M. / Andreae, B. / Pietrangeli, C. (Hrsg.): Il Cortile delle Statue, Der Statuenhof des Belvedere im Vatikan (Akten des internationalen Kongresses zu Ehren von Richard Krautheimer [Rom 1992]), Mainz 1998. Die 1538/39 angefertigte Zeichnung im Skizzenbuch des Francisco da Hollanda (Madrid, Escorial, Cod. 28-I-20, fol. $8^{\mathrm{v}}$ ) zeigt die Brunnenanlage, in deren Zentrum die antike Statue einmontiert war.

${ }^{44}$ Zuletzt Höper, Corinna (Hrsg.): AK Raffael und die Folgen, Stuttgart 2001, S. 199; dort auch die ältere Literatur zum Themenbereich.

${ }^{45}$ So Corinna Höper, a.a.O., S. 199.

${ }^{46}$ So Marcantonio Raimondi (Katalog 299), der Meister von 1515 (Katalog 241), Augustin Hirschvogel (Katalog 179), der Meister HTA (Katalog 239).
} 
und konnotiert ihr Sterben neustoisch.

\author{
Exkurs: Die vermeintliche Kleopatrastatue im Cor- \\ tile del Belvedere
}

Eine heute meist als Ariadne gedeutete antike Statue, die unmittelbar nach ihrem Fund ${ }^{47}$ als Kleopatra interpretiert wurde, kam 1512 unter dem Pontifikat von Julius II. (1503-1513) aus der Sammlung der Maffei in den vatikanischen Cortile del Belvedere und wurde dort als Kleopatra zur zentralen Figur eines Brunnens.

Sowohl ihr hoher Preis als auch ihre Aufstellung sind bezeugt: Giovanni Francesco Pico della Mirandola ${ }^{48}$, der sich in Erbschaftsangelegenheiten in Rom aufhielt, berichtet nämlich im August $1512^{49}:$ : [...] et quodam in angulo spectrum - demorsae ab aspide Cleopatrae, cuius quasi de

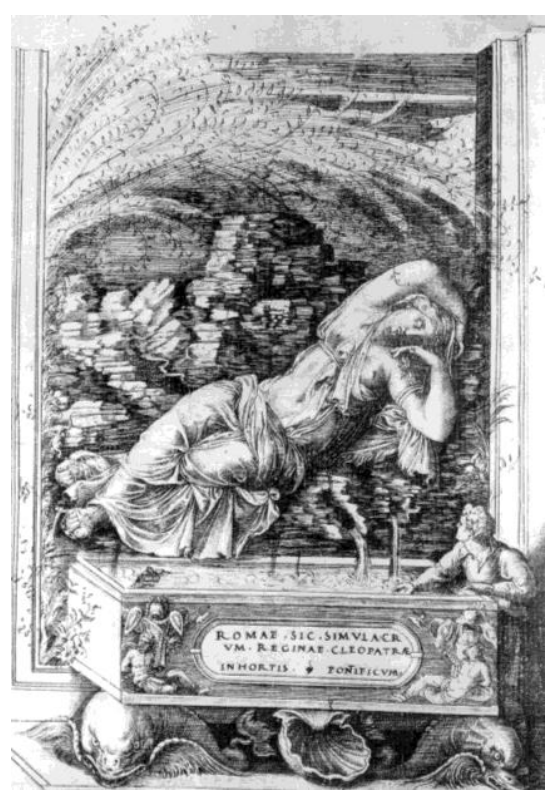

Abb. 7

mammis destillat fons uetustorum instar aqueductuum excipiturque antiquo, in quo[d] relata sunt Traiani Principis facinora quaepiam, marmoreo sepulchro. « ${ }^{50}$ Weitere Belege finden sich 1513 und $1527 .{ }^{51}$ Durch eine Skizze des Amico Aspertini (ca. 1474-1552) wissen wir, dass die rechte Hand der Statue fehlte [Abb. 8] und

${ }^{47}$ Das genaue Ausgrabungsdatum ist unbekannt; es handelt sich um eine aus der Zeit des Hadrian oder des Antoninus Pius stammende römische Kopie eines griechischen Originals. - Erst Winckelmann brach endgültig mit der Deutung als Kleopatra. Er interpretierte die vermeintlichen Todesschlangen als Schlangenarmbänder, die er als gebräuchliche Schmuckform der Antike nachweisen konnte. Der erhobene rechte Arm und die entspannte Mimik der Dargestellten ließen inn zu dem Schluss kommen, es handle sich um eine schlafende Nymphe oder Venus. Er griff damit auf eine frühe Deutung des Giovanni Battista de Cavalieri (Antiquarum Statuarum Urbis Romae, liber I-III, ed. Madrucci, Rom vor 1584) zurück. Der die Kleopatra-Statue abbildende Stich in Cavalieris Werk (pl. 6) ist mit folgender Unterschrift versehen: "Nymphae cuiusdam dormientis simulacrum e marmore mira arte factum in viridario / Vaticano Romae; quidam propter adiectum serpentem Cleopatrae imaginem putant«. (Abb. bei Brummer, a.a.O., S. 255). Vgl. Kunze, Max: »Winckelmanns Beschreibungen im Lichte des Florentiner Nachlaßheftes «, in: // Cortile delle Statue, Der Statuenhof des Belvedere im Vatikan, a.a.O., S. 431-441, besonders S. 435.

${ }^{48}$ Zum Neffen des berühmten Philosophen, der zur Unterscheidung als Gianfrancesco Pico della Mirandola II bezeichnet wird, vgl. Schmitt, Charles B.: Gianfrancesco Pico della Mirandola (1469-1533) and his critique of Aristotle, The Hague 1967, S. 24-26.

49 , Und in einer Ecke [sieht man] das Bild der von einer Schlange gebissenen Kleopatra, aus deren Brüsten gleichsam eine Quelle nach Art der alten Wasserleitungen fließt und in einem marmornen Sarkophag aufgefangen wird, auf dem die Taten des Kaisers Trajan dargestellt sind.ı - Gianfrancesco schreibt im August 1512 an Lilius Gregorius Giraldi (seinem De Venere et Cupidine expellendis carmen [Rom 1513] vorangestellt).

${ }^{50}$ Auch Ernst H. Gombrich (Das symbolische Bild, Zur Kunst der Renaissance II, Stuttgart 1986, S. 129) zitiert den Brief: »Lilius, kennst du Venus und Amor, die Götter des nichtigen Altertums? Julius II., Pontifex Maximus, holte sie sich aus römischen Ruinen, wo sie vor kurzem entdeckt wurden, und stellte sie in seinem dunkel gepflasterten, herrlich duftenden Zitronenhain auf, in dessen Mitte die Kolossalstatue des Blauen Tiber steht. Aber überall stehen antike Statuen, jede auf ihrem eigenen kleinen Altar. Auf der einen Seite ist der troische Laokoon dargestellt, wie Vergil inn schilderte; auf der anderen sieht man die Gestalt Apollos mit seinem Köcher, wie Homer inn beschreibt. Und in einer Ecke sieht man auch eine Figur der Kleopatra, nachdem sie von der Natter gebissen worden war, aus deren Brüsten, sozusagen, das Wasser gleichsam wie aus alten Aquädukten fließt und in einen Marmorsarkophag fällt, auf dem die Taten des Kaisers Trajan erzählt werden. « Gombrich geht auf die Entwicklung des Belvederegartens ein, der von Bramante für Julius II. eingerichtet wurde, und behandelt den Einfluss der Hypnerotomachia auf die Gartengestaltung, die eine antike Atmosphäre herstellen wollte.

${ }^{51}$ Brummer (a.a.O., Appendix I, S. 265) zitiert eine handschriftliche Notiz zu den Antiquaria Urbis bzw. Antiquitates Urbis des Fulvius aus dem Jahre 1513 (»Stat Cleopatra super cubito subnixa grauato: / Serpentis spira / quo concidit ipsa reuincto. « [>Kleopatra stützt sich auf den von der Schlange bedrängten Arm, durch deren Umwindung sie stirbt.८] und eine weitere aus dem Jahre 1527 (»Cleopatra fonti apposita exangui simillima» ıKleopatra, zu einem Brunnen gehörig, einer Toten sehr ähnlichı). 
ergänzt wurde. ${ }^{52}$ Noch 1536 erwähnt Johannes Fischard unter dem Pontifikat Pauls III. die Aufstellung der Kleopatra-Statue über einem Brunnen: »[...] in altero inferiori angulo eiusdem lateris est Cleopatrae cubantis ad rupem effigies, sub qua similiter in suppositum alveum fonticulus scatet, alveolus ille delphinis cum latis pinnis veluti, auribus, sustinetur. « ${ }^{53}$ Diese Hinweise werden von der Skizze Francisco da Hollandas [Abb. 7] bestätigt, die 1538/39 entstanden sein muss. Allerdings gibt Hollanda (1517-1585) nicht das Relief des als Brunnenwanne verwendeten Sarkophags wieder, sondern hat sich in seinem Skizzenbuch an dieser Stelle seiner Zeichnung in einer Kartusche notiert, dass die Kleopatra-Statue in den Gärten des Vatikan auf diese Weise aufgestellt war. ${ }^{54} \mathrm{Da}$ Hollanda jedoch die Eckfiguren und Tropaia des Sarkophags wiedergegeben hat, können zuverlässige Rückschlüsse auf den verwendeten Sarkophag gezogen werden. ${ }^{55}$

Unter Julius III. (1550-1555) wurde die Statue aus dem Cortile entfernt und in einem Stanza della Cleopatra genannten Saal über einem Kamin pla-

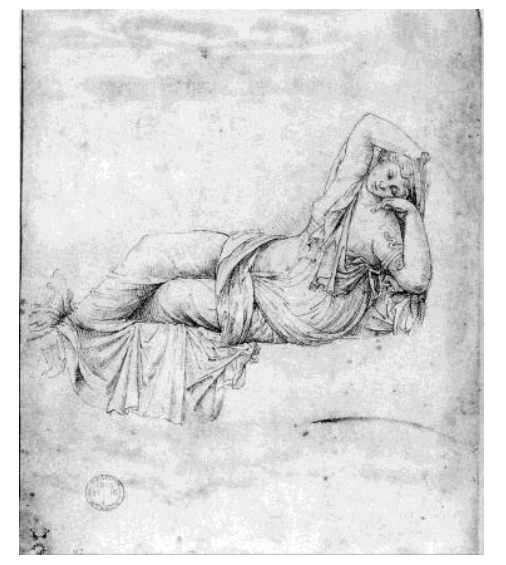

Abb. 8

ziert, der mit zwei stützenden Termini und einer geflügelten Maske dekoriert war. Unter der Statue war ein Kamin als Grotte ausgestaltet, die von einer großen Muschel begrenzt wurde. Die neue Anordnung nahm in der Dekoration sehr deutlich die sich inzwischen durchsetzende Deutung der Figur als Nymphe auf. ${ }^{56}$ Unter Paul V. (1605-1621) wurde die Interpretation als Nymphe noch deutlicher hervorgehoben, da aus der Kaminkonstruktion wieder ein Brunnen wurde. Heute sieht der Besucher des Vatikan die Statue unter einem von zwei Säulen getragenen Bogen auf einem Sarkophag stehend aufgestellt. ${ }^{57}$

\footnotetext{
${ }^{52}$ Katalog 21. Weiteres zu Amico Aspertini und seinem taccuino bei Brummer, a.a.O., S. 161ff.

53 ,In der anderen Ecke der gleichen Seite findet sich unten die Darstellung der an einem Felsen gelehnt liegenden Kleopatra, unter der ebenso [wie in der anderen Ecke] eine Quelle in eine darunter befindliche Wanne sprudelt, die Wanne wird von Delphinen mit großen, Ohren ähnelnden Flossen gestützt.ı (vgl. Brummer, a.a.O., S. 267 aus: Italia: observationes antiquitatum et aliarum rerum magis memorabilium quae Romae videntur. Collectae per Joannem Fichardum J.C. in eadem mense VII ${ }^{\text {bri }}$ et VIII ${ }^{\text {bri }}$ Anno MDXXXVI)

${ }^{54}$ Die Notiz lautet: "ROMAE. SIC. SIMVLACRVM. REGINAE. CLEOPATRAE IN HORTIS. PONTIFICVM«. Von Kartuschen gerahmte Notizen verwandte da Hollanda des öfteren in seinen Skizzenbüchern, die zu Hause als Erinnerungsstützen für weitere Arbeiten dienen sollten (s. Deswarte-Rosa, Sylvie: "Francisco de Holanda et le Cortile di Belvedere «, in: Winner, M. / Andreae, B. / Pietrangeli, C. [Hrsg.]: Il Cortile delle Statue, Der Statuenhof des Belvedere im Vatikan, a.a.O., S. 389-410). Bei Deswarte-Rosa sind der Apoll von Belvedere, Kleopatra, Venus, Laokoon, Merkur und Masken aus dem Cortile mit den markanten `Erinnerungsinschriften des Skizzenbuches abgebildet.

${ }^{55} \mathrm{Vgl}$. Abb. 138 und 139 in der grundlegenden Untersuchung von Brummer. Es handelt sich um den heute `Feldherrensarkophagı genannten Sarkophag aus der Zeit 180-190 n.Chr. (Katalog 182)

${ }^{56}$ Ulisse Aldrovandi bestätigt in seinem Beitrag Delle statue antiche, che per tutta Roma [...] si veggono, der in Mauros Le antichità delle Città di Roma (Venedig 1556) erschien, das Arrangement: "A man manca di Antinoo si vede la statua di Cleopatra, che giace col braccio destro sul capo, e pare tramortisca e venga meno. Gli è poi una pila antica, nella quale và l'acqua, che scorre dal fonticello, che sotto questa statua versa. Fu Cleopatra Regina dell'Egitto, si dimesticò volentieri con molti Principi Romani, e specialmente con lulio Cesare, e con M. Antonio: finalmente essendo ella vinta in battaglia insieme col suo amante M. Antonio da Cesare Augusto, per non venire viva mano del nemico, si fe da uno aspe sordo mordere il petto sotto la mammella, e morì: \& in questo atto fu questa sua effigie scolpita.« (২Zur Linken des Antinous sieht man die Statue der Kleopatra, die mit dem rechten Arm über dem Haupt liegend ohnmächtig und geschwächt zu sein scheint. Dort gibt es auch ein antikes Wasserbecken, in das das Wasser eines Brunnen fließt, der unterhalb der Statue Wasser spendet. Kleopatra war die Königin Ägyptens, die mit vielen führenden Römern sehr vertraut umging, besonders mit Julius Cäsar und Marcus Antonius: sie wurde schließlich zusammen mit ihrem Liebhaber Marcus Antonius in einer Schlacht von Cäsar Augustus besiegt. Um nicht lebend in die Hand des Feindes zu fallen, ließ sie sich von einer tauben Schlange unterhalb der Brustwarze beißen und starb. Diesen Moment stellt ihre Skulptur dar.ı) (Ich zitiere den italienischen Text nach Brummer, a.a.O., S. 268.) (In der Antike galten Schlangen als taub; heute weiß man, dass Schlangen kein Gehör wie andere Wirbeltiere haben, sondern mit ihrem Innenohr niederfrequenten Schall wahrnehmen können.)

${ }^{57} \mathrm{Vgl}$. Abb. 134 in Brummer, a.a.O., S. 155.
} 
Der Statue galt unmittelbar nach ihrer Aufstellung die ungeteilte Bewunderung der Besucher des Vatikan; Künstler skizzierten sie, Besucher hielten ihren Eindruck in ihren Aufzeichnungen fest, humanistische Dichter widmeten dem Kunstwerk Verse. Vor allem das in diesem Zusammenhang entstandene Gedicht Baldassare Castigliones führen Kunsthistoriker häufig als Beleg für die Deutung der Skulptur an, allerdings ohne die weiteren Informationen des Textes auszuwerten. ${ }^{58}$

Die erste Ekphrasis ist Evangelista Maddaleni Fausto di Capodiferro zu verdanken. Der Verfasser von sechs kleineren Gedichten auf die Kleopatra-Statue scheint bis 1508, dem Tod des Kardinals Giovanni Colonna, zu den Familiaren der Colonna, später zum Haus des Kardinals Giovanni de' Medici gehört zu haben, der 1513 als Leo X. zum Papst gewählt wurde.

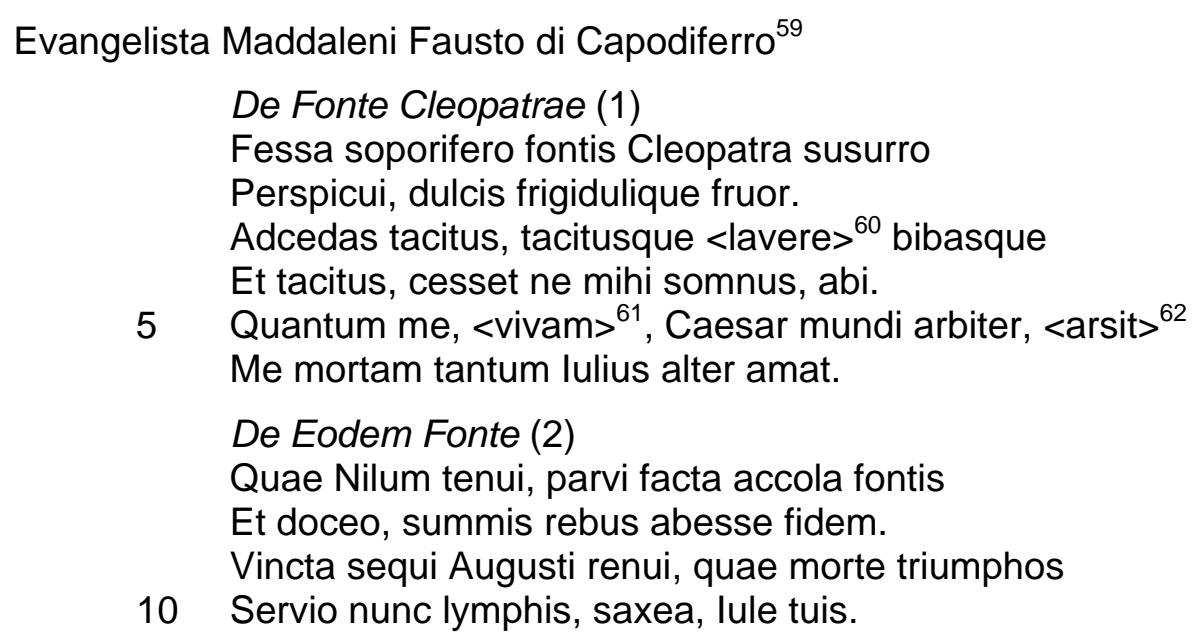

Aliud $(3)^{63}$

Accedas et abi tacitusque lavere bibasque Infaelix somno dum Cleopatra fruor. Iulius invicta nulli pietate secundus Quam duxit statuit me bene propter aquam

15 Nam veluti fluit ista fluunt mortalia regna Maiorique cadunt impete magna satis.

Aliter (4)

Fons parvus licet est: simulatum credite Nilum Veraque sum lymphis, quae, Cleopatra, fruor. Niliacas Caesar domuit, has lulius undas

20 Duxit: solum annis iste Secundus erat.

$5 \quad$ Aliud (5)

Ne me tange, precor, dulci ne me excute somno. Vivo ego, ni caleo, frigida lympha facit.

\footnotetext{
${ }^{58}$ So beispielsweise von Höper, a.a.O., S. 199: "Die Statue, die damals als Cleopatra gedeutet wurde (Baldassare Castiglione besang sie in einem Sonett [sic!] seiner Carmina Veneta als Cleopatra), wurde von Julius II. aus dem Besitz der Familie Maffei zu einem hohen Preis erworben. Es handelt sich bei Castigliones Gedicht natürlich nicht um ein Sonett.

${ }^{59}$ Evangelista Maddaleni Fausto di Capodiferro hat in seinem Zibaldone (Vat. Lat. 3351) mehrere Gedichte zu Statuen des Cortile del Belvedere notiert; neben den im Folgenden angeführten zu Kleopatra auch zur ApolloStatue und zur Nil-Statue. Die Kleopatra-Gedichte Capodiferros werden von Brummer (a.a.O., S. 221f.) mit erheblichen Fehlern zitiert, so dass ich mich an die alte Abschrift Janitscheks halte (Janitschek, Hubert: »Ein Hofpoet Leo's X. über Künstler und Kunstwerke«, in: Repertorium für Kunstwissenschaft, 3 (1879), S. 52-60).

${ }^{60}$ Bei Janitschek irrtümlich lavero, Brummer richtig lavere [= laveris].

${ }^{61}$ Bei Janitschek irrtümlich vivens, bei Brummer richtig vivam.

${ }^{62}$ Bei Janitschek irrtümlich arsi, bei Brummer richtig arsit.

${ }^{63}$ Nach Brummer, a.a.O., S. 221; die Verse 11-16 der Handschrift hat Janitschek ausgelassen.
} 


\title{
Kleopatra: Tugendheldin oder femme fatale
}

\author{
Niliacas Caesar me vinxit magnus ad undas \\ $<$ Praefecitque $>^{64}$ suis lulius alter aquis.
}

Aliter (6)

25 Somno an somnifero langues Cleopatra veneno; Immiscet curis somnia murmur aquae.

O utinam haec essent fatalis flumina Lethes, Non mecum aspicerem regna perire mea. Utilius hodie est cito et occubuisse beata, Post tria quam misera saecula morte premi. ${ }^{65}$

Evangelista Maddaleni Fausto di Capodiferro spielt in den ersten fünf kleinen Gedichten wiederholt auf Papst Julius II. (1503-1513) ${ }^{66}$ an und betont die besondere Vorliebe des Papstes für diese Statue (vv. 6, 24). Unzweifelhaft lässt sich aus den Gedichten auch die Aufstellung der Statue als Brunnenfigur ableiten. Der Dichter hat den Zufall, dass der Kardinal, der Aufstellung der Statue und Installation des Brunnens veranlasst hatte, als Papstnamen Julius wählte, zu verschiedenen Wortund Gedankenspielen genutzt, die zahlreiche Beziehungen zwischen Julius Cäsar und Julius II. herstellen. Alle in den Gedichten entwickelten Motive spielen auf die vom historischen Cäsar als Person geliebte und vom zeitgenössischen Papst Julius als Kunstgegenstand geschätzte Figur Kleopatra an.

Reicher an Informationen sind die Verse Baldassare Castigliones ${ }^{67}$, die zwischen 1513 bis 1516 entstanden sind:

\footnotetext{
${ }^{64}$ Nach Brummer, bei Janitschek irrtümlich Praefeatque.

65 Über den Brunnen der Kleopatra (1)

Müde genieße ich, Kleopatra, das einschläfernde Murmeln der klaren, lieblichen und kühlen Quelle. Mögest du schweigend herbeikommen, schweigend dich waschen und trinken, dann geh schweigend weg, damit mir nicht der Schlaf entweicht. Wie mich Caesar, der Herr der Welt, liebte, als ich noch lebte, so liebt mich als Statue der zweite Julius.
}

Über denselben Brunnen (2)

Einst herrschte ich über den Nil, nun bin ich bin zur Betreuerin einer kleinen Quelle geworden und zeige, dass auf die höchsten Dinge kein Verlass ist. Ich habe durch meinen Tod verweigert, als Besiegte dem Triumphzug des Augustus zu folgen, und diene nun, Julius, als Stein deinen Wassern.

Ein weiteres Gedicht (3)

Komm und geh, wasche dich schweigend und trinke, während ich, unglückliche Kleopatra, den Schlaf genieße. Julius II., der keinem an unübertreffbarer Treue (pietas) nachsteht, stellte mich geschickt zu der Quelle, die er einrichtete. Denn wie Wasser fließen, fließen die menschlichen Reiche dahin und große genug fallen unter dem Angriff noch größerer.

Ein anderes Gedicht (4)

Sicher, die Quelle ist klein; glaubt, es stelle den Nil dar, bin ich doch wirklich Kleopatra, die dieses Wasser genießt. Caesar hat die Wasser des Nil bezwungen, Julius diese hier gefasst, nur den Jahren nach war er der Zweite.

Ein weiteres Gedicht (5)

Berühre mich bitte nicht, wecke mich nicht aus süßem Schlaf. Ich lebe: wenn ich nicht warm bin, liegt das am kalten Wasser. Der große Caesar hat mich an den Wassern des Nil besiegt, der zweite Julius mich seinem Brunnen zur Aufsicht gegeben.

Ein anderes Gedicht (6)

Vom Schlaf oder schlafbringenden Gift bist du, Kleopatra, erschöpft; das Murmeln des Wassers mischt Träume in die sorgenvollen Gedanken. Wäre dieses Wasser die schicksalhafte Lethe, müsste ich nicht ansehen, wie meine Reiche mit mir untergehen. Besser ist es heute, schnell und glücklich gestorben zu sein, als nach vielen Jahrhunderten einen elenden Tod zu sterben.

${ }^{66}$ Zuletzt Verspohl, Franz-Joachim: Michelangelo Buonarroti und Papst Julius II., Moses - Heerführer, Gesetzgeber, Musenlenker, Göttingen 2004.

${ }^{67}$ Das neulateinische Gedicht muss nach dem Pontifikat Julius' II. entstanden sein, da dieser Papst zwar erwähnt wird (v. 25: »miratus lulus «), die Verse selbst aber einen anderen Adressaten haben. Leo X. wird mit dem Vokativ »Magne Leo « (v. 36) angesprochen. Giuliano della Rovere wurde am 01.11.1503 gewählt und nahm am Tage seiner Inthronisation (26.11.1503) den Namen Julius II. an. Er starb am 21.03.1513. Castiglione wurde 1513 Botschafter des Francesco Maria I. della Rovere am päpstlichen Hof, ging aber bereits 1516 nach Mantua zurück. Giovanni de' Medici wurde am 09.03.1513 gewählt, nahm am 19.03.1513, dem Tag der 
Marmore quisquis in hoc saevis admorsa colubris Brachia, et aeterna torpentia lumina nocte Aspicis, invitam ne crede occumbere letho. Victores vetuere diu me abrumpere vitam,

5 Regina ut veherer celebri captiva triumpho, Scilicet et nuribus parerem serva Latinis Illa ego progenies tot ducta ab origine regum, Quam Pharij coluit gens fortunata Canopi, Deliciis fovitque suis Aegyptia tellus,

10 Atque oriens omnis Divum dignatus honore est.

Sed virtus pulchreque necis generosa cupido

Vicit vitae ignominiam, insidiasque tiranni, Libertas nam parta nece est, nec vincula sensi, Umbraque tartareas descendi libera ad undas,

15 Quod licuisse mihi indignatus perfidus hostis, Saevitiae insanis stimulis exarsit et ira, Namque triumphali invectus Capitolia curru, Insignes inter titulos, gentesque subactas Extinctae infelix simulachrum duxit, et amens

20 Spectaclo explevit crudelia lumina inani; Neu longaeva vetustas facti famam aboleret, Aut seris mea sors ignota nepotibus esset, Effigiem excudi spiranti e marmore iussit, Testari et casus fatum miserabile nostri.

25 Quam deinde, ingenium artificis miratus lulus Egregium, celebri visendam sede locavit Signa inter veterum Heroum, saxoque perennes Supposuit lacrimas aegrae solatia mentis; Optatae non ut deflerem gaudia mortis,

30 (Nam mihi nec lacrimas lethali vipera morsu Excussit, nec mors ullum intulit ipsa timorem). Sed charo ut cineri, et dilecti coniugis umbrae Aeternas lacrimas, aeterni pignus amoris Moesta darem, inferiasque inopes; et tristia dona.

35 Has etiam tamen infensi rapuere Quirites. At tu, Magne LEO, Divum genus, aurea sub quo Saecula, et antiquae redierunt laudis honoris, Si te praesidium miseris mortalibus ipse Omnipotens Pater aetherio demisit Olimpo;

40 Et tua si immensae virtuti est aequa potestas, Munificaque manu dispensas dona Deorum, Annue supplicibus votis, nec vana precari Me sine, parva peto, lacrimas Pater optime redde, Redde oro fletum, fletus mihi muneris instar,

45 Improba quando aliud nil iam Fortuna reliquit. At Niobe ausa Deos scelerata incessere lingua, Induerit licet in durum praecordia marmor, Flet tamen, assiduusque liquor de marmore manat. Vita mihi dispar, vixi sine crimine, si non

50 Crimen amare vocas, fletus solamen amantum est. Adde, quòd afflictis nostrae iucunda voluptas 
Sunt lacrimae, dulcesque invitant murmure somnos,

Et cum exusta siti Icarius canis arva perurit.

Huc potum veniunt volucres, circumque supraque

55 Frondibus insultant, tenero tum gramine laeta

Terra viret, rutilantque suis poma aurea ramis;

Hic ubi odoratum surgens densa nemus umbra

Hesperidum dites truncos non invidet hortis. ${ }^{68}$

In 58 Hexametern gibt Castiglione der Marmorstatue das Wort und lässt sie den Betrachter an die Lebensgeschichte der Kleopatra erinnern. Dabei inszeniert der Dichter die Statue als effigies (Abbild), wie sie die Römer in ihren Triumphzügen oft

${ }^{68}$ Baldassare Castiglione: Cleopatra

Wer du auch bist, der du diese Marmorstatue mit den von wilden Schlangen gebissenen Armen und den in von ewiger Nacht erstarrten Augen erblickst, glaube nicht, dass ich mich gegen meinen Willen dem Todesschlaf hingebe. Lange haben mich die Sieger daran gehindert, mein Leben zu beenden, um mich in feierlichem Triumph als königliche Beute mitzuführen. Vielleicht sollte ich römischen Frauen als Sklavin dienen, obwohl das glückliche Volk Ägyptens mich als Spross so vieler Könige verehrte, obwohl die ägyptische Erde mich mit ihren Wonnen hegte und obwohl der ganze Orient mich göttlicher Ehren für würdig hielt. Die im Leben widerfahrene Schande und die Verfolgung durch den Tyrannen wurden durch meine Tugenden und meinen hochherzigen Wunsch bezwungen, einen schönen [und würdigen] Tod zu sterben, bringt doch der Tod die Freiheit mit sich: Fesseln nahm ich nicht wahr, als ich als Schatten frei zu den Fluten des Tartarus hinab stieg, was mir selbst der unwürdige und treulose Feind gestatten musste.

Der Feind entbrannte in schamloser Grausamkeit und Zorn, führte er doch zusammen mit den Siegeszeichen und den unterworfenen Völkerschaften eine Darstellung der unglücklichen Toten mit, als er im Triumphwagen auf das Kapitol fuhr und den grausamen Zuschauern ein unwürdiges Schauspiel zeigte. Er ließ ein Abbild aus atmendem Marmor schaffen, um unser bemitleidenswertes Geschick und unseren Untergang zu bezeugen, damit nicht die Kunde des Geschehens in späteren Zeiten unterginge oder mein Schicksal späteren Geschlechtern unbekannt bliebe.

Dieses Abbild ließ Julius, der das Talent des Künstlers bewunderte, an einem viel besuchten Ort unter den Statuen antiker Helden zur Betrachtung aufstellen. Er ließ unter den Marmorblock [einen Brunnen errichten], ewige Tränen zum Trost des ergriffenen Herzens; nicht damit ich den freudig ersehnten Tod beweinte - denn die Schlange hat mir durch ihren todbringenden Biss keine Tränen entlockt und selbst der Tod hat mir keinen Schrecken eingejagt -, sondern damit ich traurig der teuren Asche und dem Schatten des geliebten Ehemanns als Totenopfer ewige Tränen, als Pfand ewiger Liebe geringe und traurige Gaben darbrächte. Diese [Tränen des Brunnens] haben feindliche Römer entfernt.

Aber du, großer Leo, aus göttlichem Geschlecht, unter dessen Regierung die goldenen Zeiten und die Verehrung der Antike zurückgekehrt sind, erhöre die demütigen Bitten und lass mich nicht vergeblich flehen, wenn dich der allmächtige Vater zur Herrschaft über die elenden Sterblichen aus dem himmlischen Olymp herabgeschickt hat und wenn deine Macht deiner unbegrenzten Tugend entspricht, der du mit freigebiger Hand die Gaben der Götter austeilst. Ich erbitte nur wenig: gib, bester Vater, die Tränen [= den Brunnen] zurück, gib, so bitte ich, das Weinen zurück, das Weinen ist für mich ein Geschenk, hat mir doch das launische Schicksal nichts anderes gelassen. Obwohl Niobe es wagte, mit frevelhafter Rede die Götter herauszufordern, durfte sie trotzdem ihr Gefühl in den harten Marmor einschließen, weint sie doch gleichwohl und fließt doch beständig Wasser aus dem Marmor. Mein Leben war anders, ich lebte ohne Verbrechen, wenn man nicht Liebe ein Verbrechen nennt, Tränen sind der Trost der Liebenden. Füge [den Brunnen] hinzu, weil unsere Tränen den Kummervollen ein angenehmer Trost sind und durch ihr Murmeln zu süßem Schlaf einladen, wenn die Hundstage die verbrannten Felder mit Durst verbrennen. Hierher kommen Vögel zum Trinken und hüpfen um und über die Zweige, mit zartem Halm grünt die fröhliche Erde und goldene Früchte röten sich auf ihren Zweigen, hier, wo ein wohlriechender Hain mit dichtem Schatten den reich tragenden Bäume in den Gärten der Hesperiden nicht nachsteht.

Meine Übersetzung berücksichtigt die Doppeldeutigkeit von lacrimae als Tränen der Kleopatra und gleichzeitig als Anspielung auf den von Papst Julius II. errichteten Brunnen. Die Anspielung auf Niobe kann sich nicht auf die heute in Florenz aufgestellten Niobiden beziehen, da diese Statuengruppe erst 1583 in Rom ausgegraben wurde. Vielmehr scheint Castiglione auf die Metamorphose der Niobe anzuspielen (z. B. Ovid, Metam. VI, 148ff.); im Mythos wird sie nach dem Tod ihrer vierzehn Kinder auf ihre Bitte von Zeus in einen Fels verwandelt, der häufig Tränen vergießt (Ovid, Metam. VI, 612). - Ich zitiere den Text nach: Castiglione, Baldassare: Opere volgari e latine / novellamente raccolte, ordinate, ricorrette, ed illustrate, come nella seguente lettera può vedersi, da Gio. Antonio, e Gaetano Volpi - Padova Comino, 1733. Diese Ausgabe steht im Netz zur Verfügung: http://www.ub.uni-bielefeld.de/diglib/castiglione/opere/index.htm (zuletzt aufgerufen: 10.12.2006). Eine im Besitz der UB München befindliche Ausgabe (Carmina quinque illustrium poetarum; Quorum nomina in seguenti pagina continentur. Additis nonnullis M. Antonij Flaminij libellis nunquam antea impressis. Venetiis Presb. Hieronymus Lilius, \& socij excudebant. M.D.LVIII, S. 31f.) enthält zahlreiche Fehler. 
mitführten, wenn sie einen besiegten Feind nicht in persona vorführen konnten. Mit dieser fiktiven Identität steigt die Bedeutung der Statue für den Leser, der sich nun vorstellen mag, die originale effigies aus Augustus' Zeiten vor sich zu haben. Die von Julius II. (v. 25ff.) veranlasste Aufstellung als Brunnenfigur wird so interpretiert, dass Kleopatra in dieser Inszenierung noch immer Tränen über den Tod des Antonius vergießt. Kurz darauf muss der als Brunnentrog dienende Sarkophag entfernt worden sein (v. 35). Leo X. hat bekanntlich den Brunnen restituiert; die Bitte der Statue (v. 36ff.) ist wohl als vaticinatio ex eventu zu deuten. Der Schluss des Gedichts beschreibt eine Idylle mit plätscherndem Brunnen, Bäumen und Vögeln, die wohl der Ausgestaltung des Statuenhofs als kleinem Innenhofgarten (viridarium) entsprach. ${ }^{69}$

Castigliones Verse belegen, dass die von Julius II. veranlasste erste Aufstellung verändert wurde und die Kleopatra-Statue wohl vorübergehend im Statuenhof ohne Brunnen zu sehen war. ${ }^{70}$ Die alte Inszenierung und Deutung als »weinende Kleopatra « muss aber von Leo X. alsbald (also doch 1513) wieder hergestellt worden sein. Vielleicht wurde - aus welchen Gründen auch immer - der Sarkophag ausgewechselt.

Unter mehreren Gesichtspunkten ist das Gedicht Castigliones für das sich in der Frühen Neuzeit herausbildende literarische und künstlerische Kleopatra-Bild von Interesse: Kleopatra erscheint als große Liebende (v. 32ff.), ihre Tränen gelten nicht dem eigenen Tod, sondern dem ihres Ehemannes Antonius (v. 32). Das rhetorische und dichterische Spiel mit den Tränen (lacrimae) und dem Brunnen der Inszenierung im Statuenhof bezieht die Tränen nicht auf den Selbstmord Kleopatras, sondern auf ihre Gattenliebe. Zur neustoisch beeinflussten Auffassung der ıSelbstmörderin als Tugendheldinı gehört auch, dass Castiglione wohl als erster den Selbstmord selbst neustoisch als generosa cupido und ihren Tod (pulchra nex) als Voraussetzung der neu gewonnenen Freiheit (libertas parta nece) deutet.

Wenn die Historienmalerei in der Folge die Ikonographie der als Kleopatra gedeuteten Statue aufgriff, die die Tugendheldin gelassen und beinahe entspannt in den Freitod hinübergleiten lässt, übernahm sie wohl den zum ersten Mal in der Ekphrasis Castigliones greifbaren neustoischen Deutungsansatz. ${ }^{71}$

Die von der antiken Ariadne-Kleopatra-Statue sich ableitende Pathosformel, die der auf die Verzweiflung abhebenden völlig entgegengesetzt ist, wurde von der Historienmalerei unermüdlich aufgegriffen und variiert. So hat die Graphik des 16. Jahrhunderts zwei unterschiedliche Mustervorstellungen des Sterbens Kleopatras hervorgebracht. Dies unterscheidet Kleopatra deutlich von den anderen hier behandelten Tugendheldinnen; denn nur Kleopatras Sterben wurde in so entgegengesetzten Interpretationen behandelt. Einzelne Künstler wie Guercino haben den

\footnotetext{
${ }^{69}$ Vgl. Gombrich, a.a.O., S. 128ff. Auch Giovanni Francesco Pico della Mirandola spricht in seinem Brief an Lilius Gregorius Giraldi (August 1512) von einem »nemore citriorum illo odoratissimo constrato silice « und von »ucus« (vgl. Abdruck des Briefes vom August 1512 bei Brummer, a.a.O., S. 273)

${ }^{70}$ Der Cortile wird in Castigliones Gedicht als signa veterum heroum (v. 27) bezeichnet.

${ }^{71}$ Vgl. S. $177 \mathrm{ff}$.
} 
Tod Kleopatras sogar in beiden zur Verfügung stehenden Modi ausgeführt. ${ }^{72}$ Noch im 16. Jahrhundert entstand eine ikonographische Lösung aus dem Um-

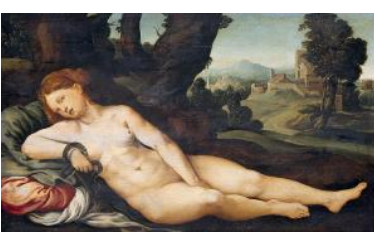

Abb. 9

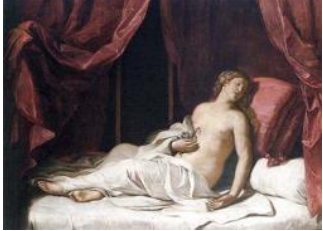

Abb. 10 kreis von Jan van Scorel (1495-1562) [Abb. 9], die Kleopatra im Freien lagern lässt. ${ }^{73}$ Am rechten Handgelenk ist die zum Attribut gewordene Schlange erkennbar. Guercino ${ }^{74}$ (1591-1666) hingegen [Abb. 10] hat seine Lösung in einen Schlafraum verlegt und lässt Schlaf und Tod ineinander übergehen. Die Königin ruht auf einem prächtigen Bett, dessen roter Baldachin mit üppigen Draperien die Szene rahmt. Der bloße Oberkörper wird von mehreren voluminösen Kissen so gestützt, dass Kleopatra zu sitzen scheint. Das gelöste Gesicht ist mit geschlossenen Augen nach links zum Betrachter gewandt und vermittelt zusammen mit dem entspannten linken Arm den Eindruck, als ob die Königin schliefe. Erst die Schlange, die sich an der rechten Brust windet, macht deutlich, dass das einer Marmorskulptur ähnelnde Inkarnat die Hautfarbe einer Toten ist. Das Hüften und Beine umhüllende Leintuch wird nunmehr in den Augen des Betrachters zum Leichen-

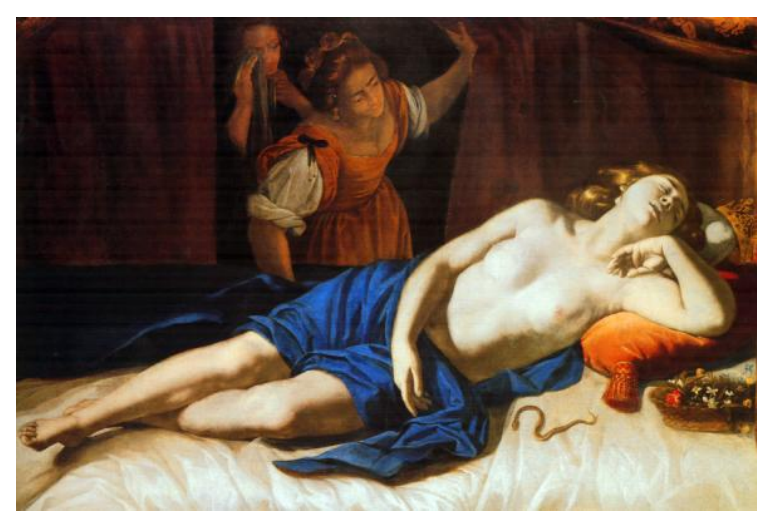

Abb. 11

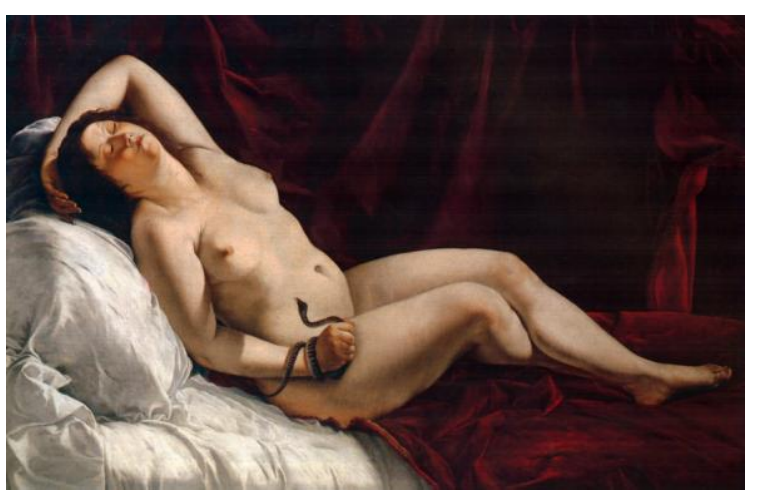

Abb. 12

tuch. Erst auf den zweiten Blick ist die Ruhende als Tote erkennbar, da der Künstler sich bewusst der täuschenden Nähe von Schlaf und Tod bediente.

\footnotetext{
${ }^{72}$ Beispiele für die verzweifelte Kleopatra bieten in der Historienmalerei beispielsweise Francesco Cozza (Katalog 72), Luca Giordano (Katalog 157), Jacopo Cestaro (Katalog 61). Beispiele der stoisch ge Iassenen Kle opatra, deren Tod einem Schlafzustand ähnelt, sind ungleich zahlreicher, so die Varianten von Guercino (Katalog 163), Anthony van Dyck (Katalog 112), Pierre Mignard (Katalog 245), Artemisia Gentileschi (Katalog 144), Joseph Esperlin (Katalog 123). Die Möglichkeit, in einem mehrfigurigen Historienbild die Affekte den Assistenzfiguren zu überlassen, nützten u. a. Guido Cagnacci (Katalog 53), Jacques Blanchard (Katalog 36), Ottmar Elliger d. J. (Katalog 118).

${ }^{73}$ Katalog 369.

${ }^{74}$ Vgl. Katalog 163 (von 1648).
} 
Artemisia Gentileschi ${ }^{75}(1593-1651)$ nahm die bewährte Lesart des Todes als Schlaf auf. In ihrer heute sich in einer römischen Privatsammlung befindlichen Ausführung [Abb. 11] wird der scheinbare Schlaf durch die Trauer der eintretenden Zofen enthüllt. Die entspannte, aber doch etwas unnatürliche Haltung der toten Königin wird als erste Phase des rigor mortis gedeutet. ${ }^{76}$ Artemesia Gentileschis Mailänder Version [Abb. 12] ${ }^{77}$ greift noch deutlicher auf die Armhaltung der antiken Ariadne-Statue zurück $^{78}$ und erinnert, wenn auch seitenverkehrt, deutlich an

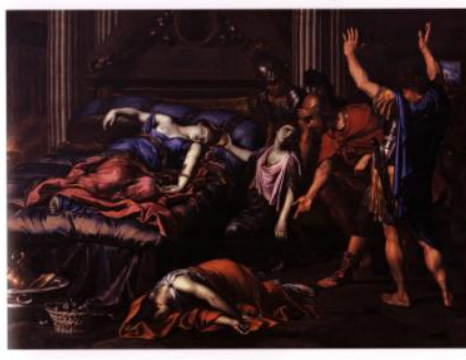

Abb. 13 die Lösung Guercinos.

In der Folgezeit griffen Künstler wie Pierre Mignard (1612-1695) [Abb. 13] und Gerard de Lairesse (1641-1711) [Abb. 14] auf die bewährte Pathosformel zurück, wobei allerdings das mit immer ausdrucksstärkeren Affekten reagierende Publikum bei Mignard und Lairesse ${ }^{79}$ der Täuschung keinen Raum ließ, wie es noch bei den einfigurigen Lösungen von Scorel oder Guercino der Fall war.

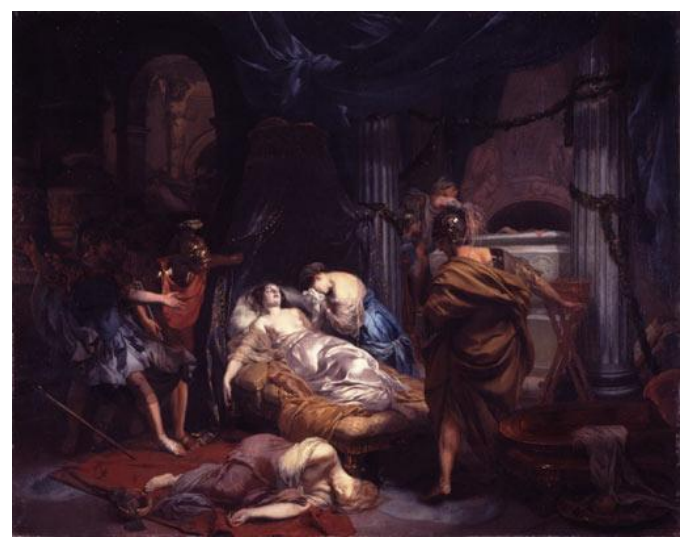

Abb. 14

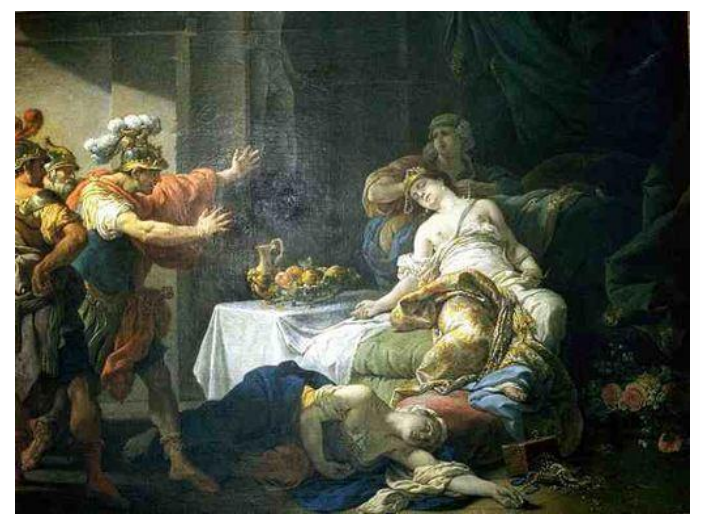

Abb. 15

Noch neuklassizistische Künstler wie Louis Langrenée (1725-1805) [Abb. 15] kamen Ende des 18. Jahrhunderts auf diese Formel zurück. ${ }^{80}$ Auch im Orientalismus des 19. Jahrhundert bot die scheinbar entspannt in den Tod hinübergleitende Kleo-

\footnotetext{
${ }^{75}$ Katalog 147 (Abb. 11) und Katalog 144 (Abb. 12).

${ }^{76}$ Vgl. Riccardo Lattuada in: Christiansen, Keith / Mann, Judith (Hrsg.): AK Orazio e Artemisia Gentileschi, Mailand 2001, S. 402-404.

77 In neuerer Literatur wird die Zuordnung dieses Gemäldes wieder diskutiert; so sind sich sogar die Autoren im gleichen Ausstellungskatalog nicht einig darüber, ob diese Version von Orazio oder von Artemisia stammt. Im AK Orazio e Artemisia Gentileschi, a.a.O., plädiert Keith Christiansen (S. 97-100) für eine Zuschreibung an Orazio; hingegen hält mit ebenfalls gewichtigen Gründen Patrizia Cavazzini (S. 302-305) Artemisia für wahrscheinlich.

${ }^{78}$ Vgl. oben S. $147 \mathrm{ff}$.

${ }^{79}$ Katalog 245 (Mignard) und 202 (Lairesse).

${ }^{80}$ Katalog 195.
} 
patra noch ein anziehend-laszives Motiv, das beispielsweise Jean Andre Rixens ${ }^{81}$ (1846-1924) [Abb. 16] und Reginald Arthur $^{82}$ (1875-1922) [Abb. 17] aufgriffen.

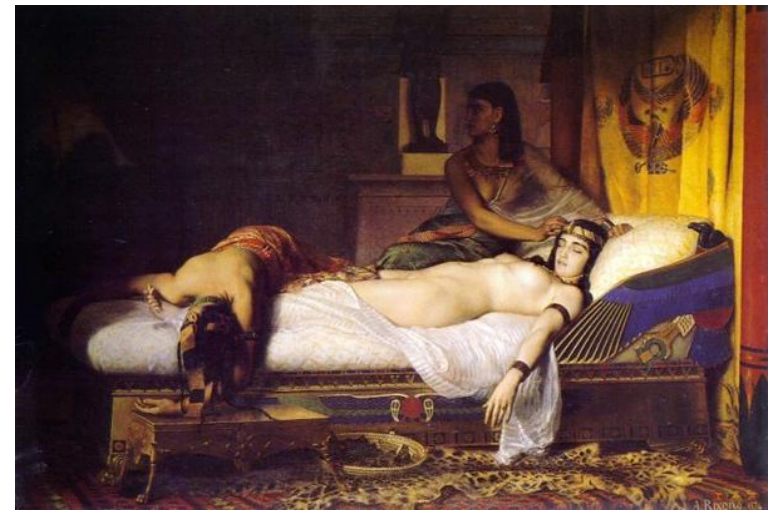

Abb. 16

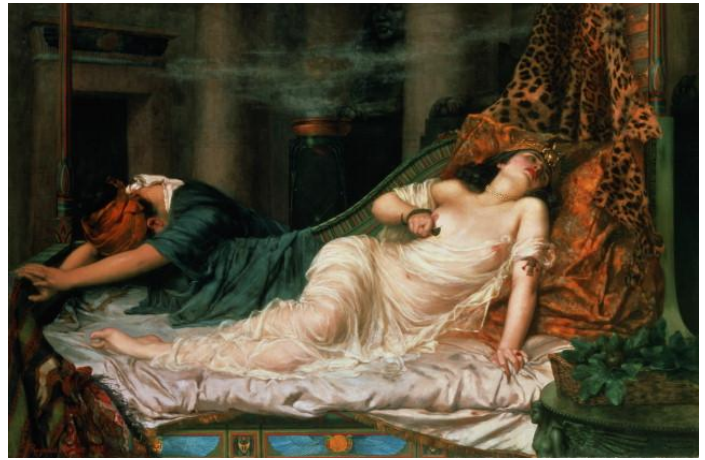

Abb. 17

Übernahmen die Historienmaler das andere graphische Muster - die verzweifelte Kleopatra -, verbanden sie meist das Näherrücken der Heldin an den Betrachter mit einer halbfigurigen Darstellung; für dieses Muster entschieden sich Künstler noch weit bis ins 19. Jahrhundert hinein, bot doch diese Inszenierung die Möglichkeit, die Affekte an den Betrachter heranzurücken. Bei Domenico Puligo (14921527) [Abb. 18] dominiert der schmerzvoll himmelnde Blick ${ }^{83}$, während Reni (15751642), der geradezu auf das Thema spezialisiert gewesen zu sein scheint, Kleopatra stets [Abb. 19, 20, 21, 22] leicht gedreht ins Bild setzte. ${ }^{84}$ Unterschiedliche, stets sehr prächtige Kleidung umrahmt den der Schlange gebotenen Busen dekorativ, mit dem himmelnden Blick konzentriert sich die Tugendheldin auf ihr Sterben.

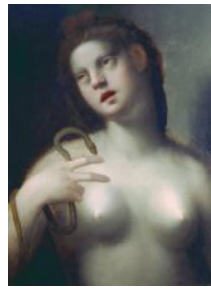

Abb. 18

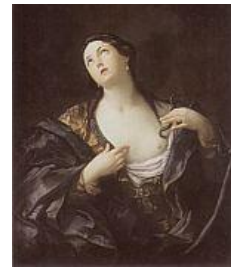

Abb. 19

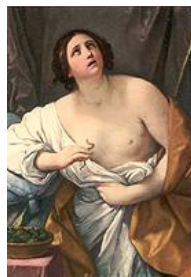

Abb. 20

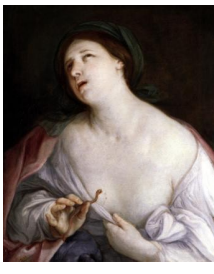

Abb.21

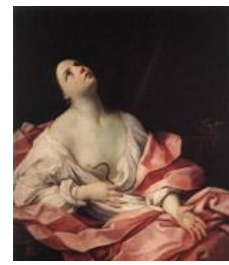

Abb. 22

Renis halbfigurige Potsdamer Kleopatra ${ }^{85}$ [Abb. 19] steht vor monochromraumlosem Hintergrund dem Betrachter frontal gegenüber. Blau und Gold der Kleidung rahmen und betonen Dekollete und Gesicht. Das Niobidengesicht richtet sich himmelnd nach oben; die rechte Hand hält eine kleine Schlange, die bereits in die

\footnotetext{
${ }^{81}$ Katalog 348.

${ }^{82}$ Katalog 20.

${ }^{83}$ Katalog 293.

${ }^{84}$ Abb. 18: Katalog 310; Abb. 19: Katalog 323; Abb. 20: Katalog 313; Abb. 21: Katalog 334.

85 Katalog 310.
} 
entblößte rechte Brust gebissen hat, wie ein Blutstropfen erkennen lässt. Die Linke liegt verweisend oder fragend auf der Brust, so dass die Bedeutung des sehnsuchtsvoll-fragenden Blicks zwischen Verzweiflung und Ergebung oszilliert. Dieser Typus der verzweifelt-ergeben sterbenden Kleopatra macht verständlich, warum Renis Gemälde von Sammlern wegen ihrer »speziellen Umsetzung in eingängige und affektiv ansprechende Bildprägungen ${ }^{86}$ so beliebt waren.

Antiveduto Gramatica (1569-1626) ${ }^{87}$ lässt seine Kleopatra [Abb. 22a] dem Betrachter frontal gegenübertreten. Mit schmerzlich zusammengezogenen Brauen blickt die Tugendheldin aus dem Bild; die Verschattung der einen Gesichtshälfte betont die verzweifelte Lage, lässt aber andererseits den mamorweißen Oberkörper um so heller hervortreten.

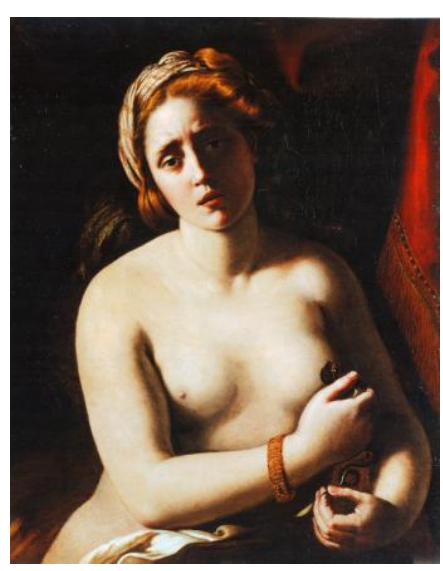

Abb. 22a

Marcantonio Bassetti (1586-1630) hat seiner dreiviertelfigurig gegebenen Kleopatra [Abb. 22b] ${ }^{88}$ den bewährten Niobidenblick gegeben. Der plastisch gestaltete Oberkörpers vollzieht soeben eine scharfe Gegenbewegung zur Hüfte und deutet so vor einem beinahe monochromen Hintergrund eine Fluchtbewegung an. Eine andere, weniger idealisierte Wendung nimmt das Thema in einer wohl zu Unrecht Artemisia Gentileschi (1593-1653) zugeschriebene Kleopatra [Abb. 23]. Die Behandlung des Themas besticht durch den an die Caravaggisten erinnernden Realismus,

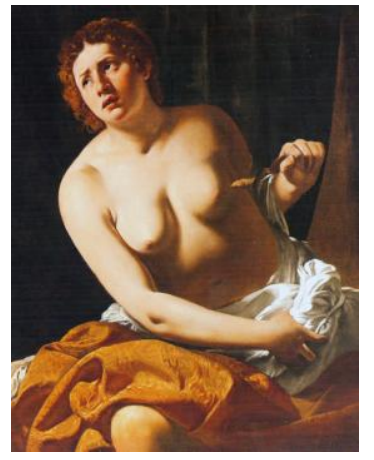

Abb. 22b der den voluminösen Köper betont. ${ }^{89}$ Eine ebenso ungewöhnliche Wendung gab Sebastiano Mazzoni (1611-1678) seiner Kleopatra90: er wählte die Perspektive eines Beteiligten, der auf die frontal aufgebahrte Königin blickt [Abb. 24]. Die Perspektive verkürzt den Körper der Sterbenden und betont so Oberkörper und Ge-

\footnotetext{
${ }^{86}$ Schmidt-Linsenhoff, Viktoria: Guido Reni im Kunsturteil des siebzehnten Jahrhunderts - Studien zur literarischen Rezeptionsgeschichte und Katalog der Reproduktionsgrafik, Diss. Kiel 1974, S. 12.

${ }^{87}$ Katalog 161a.

${ }^{88}$ Katalog 24a.

89 „Ogni altro quadro dello stesso tempo, a fianco di questo, mostra una grazia, un'intenzione di far quasi dimenticare il gesto estremo, nella misura delle forme, nel deliquio di un'attrice che recita la parte. La Cleopatra di Artemisia è una donna che muore e non ha tempo di pensare all'eleganza del suo corpo, a mostrarsi in ordine. II dolore è fisico, non è l'idea del dolore. « Mit dieser Charakterisierung hat Vittorio Sgarbi eine Zuschreibung des Gemäldes an Artemisia Gentileschi begründet (Spezzaferro, Luigi / Calzavara, Benedetta (Hrsg.): AK Caravaggio e l'Europa da Caravaggio a Mattia Preti, Mailand 2005, S. 216).

${ }^{90}$ Katalog 236.
} 
sicht der Sterbenden. Der Betrachter reiht sich, weil er im vorne geöffneten Kreis der Dienerinnen seinen virtuellen Platz findet, in die ausdrucksvolle Trauer des Hofes ein. Claude Vignon (1593-1670) hat in seiner Variante ${ }^{91}$ die Verzweiflung der Sterbenden [Abb. 25] so aggressiv ins Bild gesetzt, dass Kleopatra mit der

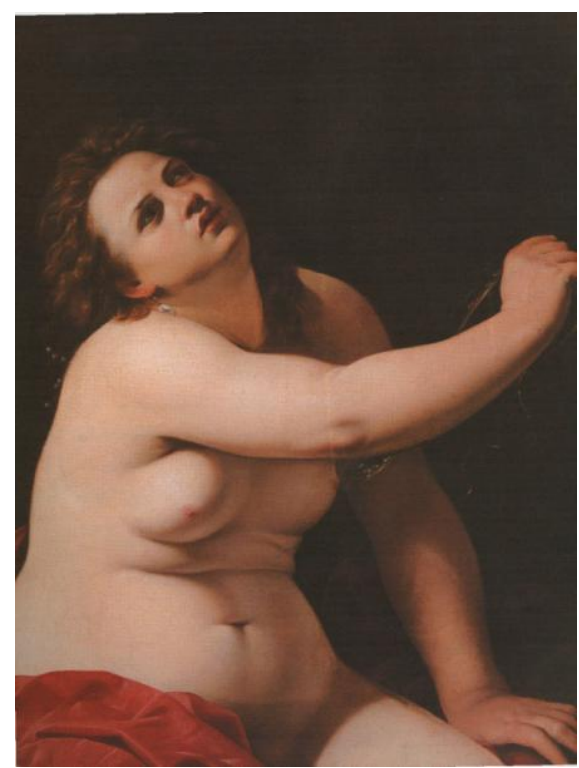

Abb. 23

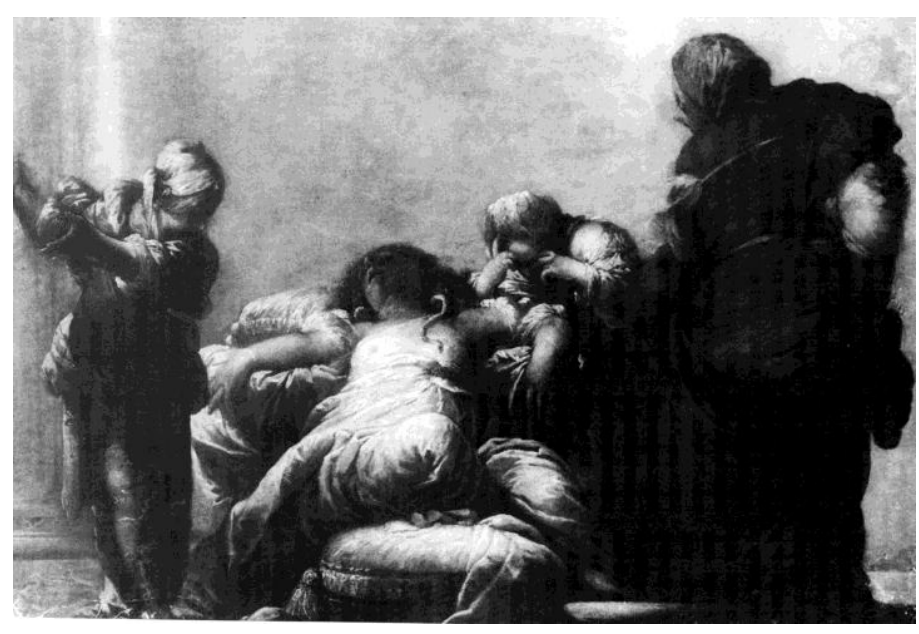

Abb. 24

Schlange zu kämpfen scheint.

Johann Liss ${ }^{92}$ (1595-1631) [Abb. 26] und Guido Cagnacci (1601-1681) [Abb.

27] inszenieren ihre Heldinnen auch im Sterben als Königin, die von Hofstaat umgeben ist. ${ }^{93}$ Interessanterweise hat Cagnacci [Abb. 28] sich mehrfach am Motiv versucht, so dass die unterschiedlichen Fassungen - einer von zahlreichen Dienerinnen umgebenen und einer vereinzelten Kleopatra - in ihren Wirkungen gegenübergestellt werden können. ${ }^{94}$ Auch Francesco Cozza (1605-1682)

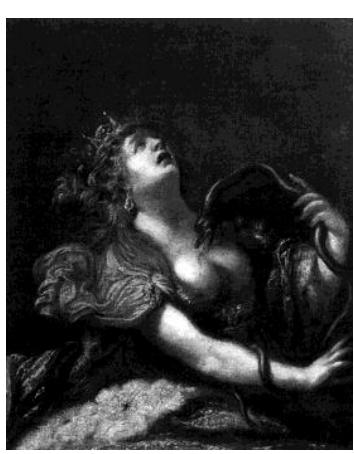

Abb. 25

[Abb. 29] hat seine Kleopatra als einsam Sterbende dargestellt, ${ }^{95}$ doch wird sie durch verschiedene Elemente zur Märtyrerin stilisiert: Ihre linke Hand hält die Schlange wie ein Heiligenattribut; ihre Krone gleicht dem Nimbus einer Märtyrerin.

So wertet Cozza durch wenige Bildelemente den Selbstmord zur Tat einer Blutzeugin auf. Luca Giordano ${ }^{96}$ (1632-1705) [Abb. 30] und Antoine Rivalz ${ }^{97}$ [Abb.

\footnotetext{
${ }^{91}$ Katalog 423.

92 Katalog 213.

${ }^{93}$ Katalog 53.

${ }^{94}$ Katalog 55.

${ }^{95}$ Katalog 72.

${ }^{96}$ Katalog 157.

${ }^{97}$ Katalog 347.
} 
31] (1667-1735) lassen bei ihren Bearbeitungen des Themas den Betrachter ganz nah an das Geschehen heranrücken und betonen durch starke Lichtregie den Gegensatz zwischen körperlicher Schönheit und psychischer Verlassenheit. Noch

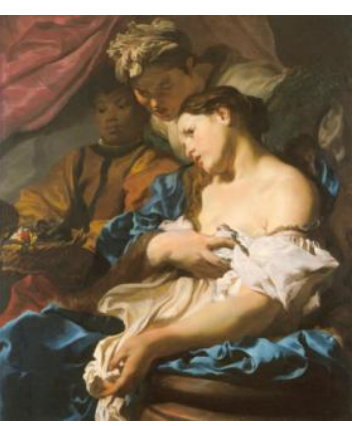

Abb. 26

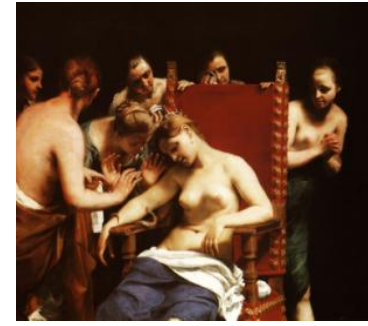

Abb. 27

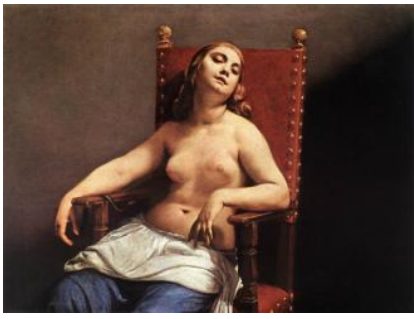

Abb. 28

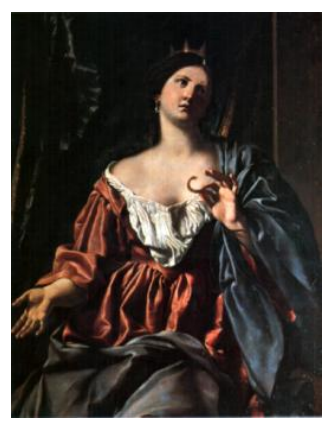

Abb. 29

Auguste Delacroix ${ }^{98}$ (1809-1868) [Abb. 32] und Arnold Böcklin ${ }^{99}$ (1827-1901) [Abb.

33] greifen zu den über Jahrhunder-

te bewährten Mustern der Darstel-

lung und kombinieren die verführe-

rische Schönheit mit Hinweisen auf den bevorstehenden Tod.

Es gab somit für den frühneuzeitlichen Historienmaler zwei erprobte Muster, das Sterben Kleo-

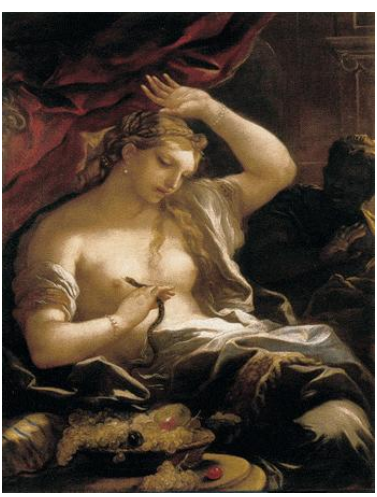

Abb. 30

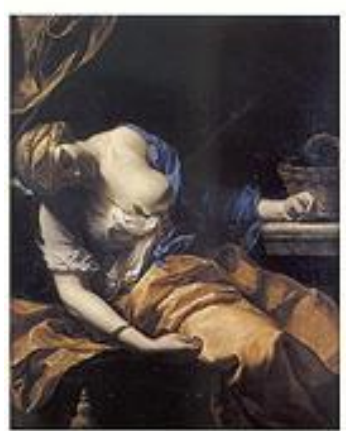

Abb. 31

patras als verzweifelte Tat oder als stoisch gelassenenen Akt ins Bild zu setzen; daneben konnte das Thema als ıgroßes Historienbild entfaltet werden, eine in den nördlichen Ländern favorisierte Lösung, während in der italienischen Malerei ${ }^{100}$ eine deutliche

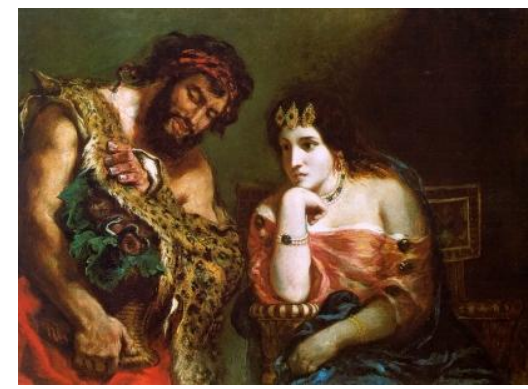

Abb. 32

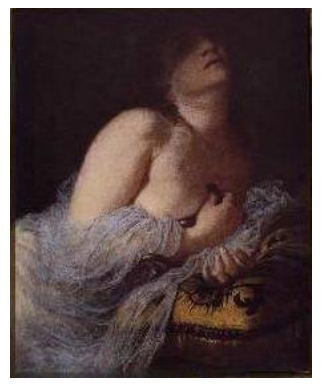

Abb. 33

Tendenz zur einfigurigen Darstellung ${ }^{101}$ festzustellen ist. Daneben stellten Kleopatra-Zyklen oder Zyklen mit Cäsar und Kleopatra für Paläste und Schlösser beliebte

\footnotetext{
${ }^{98}$ Katalog 98.

${ }^{99}$ Katalog 38.

${ }_{100}$ Einen ersten Überblick gibt Pigler, a.a.O., S. 382-386.

${ }^{101}$ Bei zwei Gemälden Guarinos, die einerseits die Märtyrerin Agathe und andererseits Kleopatra in identischer Körperhaltung zeigen, weist Lang (Grausame Bilder, Sadismus in der neapolitanischen Malerei, Berlin 2001, S. 219) darauf hin, dass Guarino hochmütige Körperhaltung mit erotischer Animation, Majestät mit Dirnenhaftigkeit verknüpfe. "Die Tradition kolportiert freilich ein projiziertes Phantasma. Kleopatra muß ihren Namen hergeben für die latent masochistische Vorstellung der zugleich erhabenen und verworfenen Frau. Die bildliche Darstellung ihres Selbstmords gerät jedoch vielfach zu einer Inszenierung, in der die masochistische Fas-
} 
Dekorationsserien dar, in denen Kleopatras Selbstmord keinen Platz hatte. ${ }^{102}$ In diesen Zyklen stehen der Prunk eines ägyptischen Hofes und das Zusammentreffen von römischer und orientalischer Kultur im Vordergrund. So erweiterte Giambattista Tiepolo im venezianischen Palazzo Labia ${ }^{103}$ den Salon durch eine raffinierte, teilweise illusionierte Türen- und Fensterarchitektur ${ }^{104}$ in einer Weise, dass Gäste den Eindruck hatten, als Teil des Gefolges am ıZusammentreffen von Antonius und Kleopatraı [Abb. 34] und am >Bankettı [Abb. 35] teilzunehmen. Wenn das Sterben Kleopatras als mehrfiguriges Historiengemälde entwor-

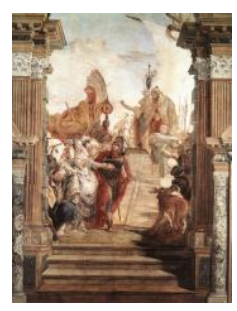

Abb. 34

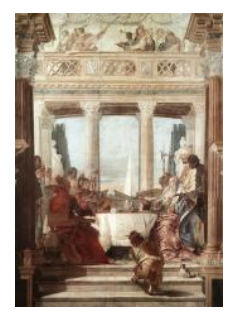

Abb. 35

fen wurde, bildete der Gegensatz zwischen der stoisch gelassenen Königin und

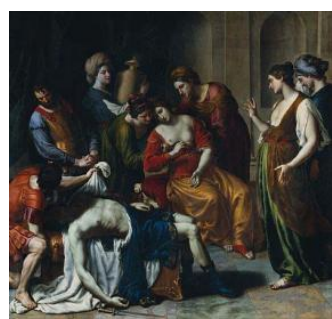

Abb. 36

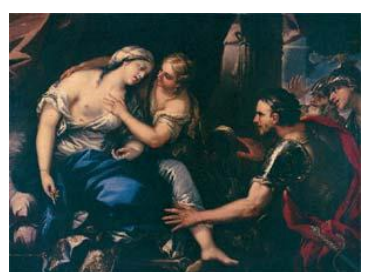

Abb. 37

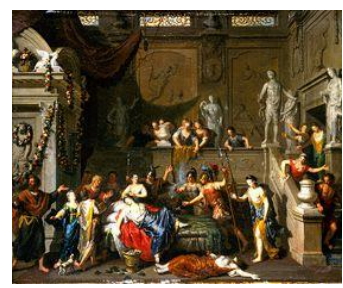

Abb. 38

ihrem verzweifelt reagierenden Hofstaat das Zentrum. Sogar so unterschiedliche Bildlösungen wie die von Guido Cagnacci [Abb. 37] und Alessandro Turchii ${ }^{105}$ (1578-1649) [Abb. 36] lassen sich auf diese Grundspannung reduzieren. ${ }^{106}$ Einer-

zination für das besagte Frauenbild in Sadismus umschlägt, in Form der Tötung durch den angeblich selbst gewählten Schlangenbiß in die Brust.«

${ }^{102}$ So zum Beispiel der Palazzo I m periali in Genua mit einer Freskenfolge von Cambiaso und Castello, die bei Pigler (II, S. 379) erwähnt wird; Tiepolo hat den Palazzo Labia in Venedig mit dem bereits erwähnten Kleopatra-Zyklus ausgemalt (vgl. Katalog 395). Bildteppiche, die meist auch als Zyklen gearbeitet wurden, müssten unter diesem Aspekt gesondert untersucht werden. Allerdings ist die Literatur über Bildteppiche einigermaßen unübersichtlich und unsystematisch. In einem jüngeren Werk wie Heinz, Dora: Europäische Tapisseriekunst des 17. und 18. Jahrhunderts, Die Geschichte ihrer Produktionsstätten und ihrer künstlerischen Zielsetzungen, Wien / Köln / Weimar 1995 werden immerhin viele Zyklen mit Cäsar bzw. Antonius und Kleopatra erwähnt (vgl. S. 18, 32, 36, 38, 59, 80, 104, 112, 116, 161, 206, 252, 304, 307).

103 Vgl. Katalog 395; Giambattista Tiepolos zentrale Fresken im Palazzo Labia (Treffen von Antonius und Kleopatra und Bankett) sind beide 650 × 300 groß.

${ }^{104}$ Die illusionistische Architekturmalerei entwarf Tiepolo, der sie zusammen mit dem Quadraturmaler Gerolamo Mengozzi ausführte (dazu Romanelli, Giandomenico: Venedig, Kunst und Architektur, Bd. 2, Köln 1997, v.a. S. 628).

${ }^{105}$ Katalog 404. Vgl. Scaglietti Kelescian, Daniela (Hrsg.): AK Alessandro Turchi detto l'Orbetto, 1578 - 1649 , Milano 1999; der Katalog (http://www.comune.verona.it/Castelvecchio/cvsito/docs/catalogo.pdf [letzter Aufruf: 28.10.2007]) ist auch im Netz verfügbar.

${ }_{106}$ Vgl. Katalog 53 (Cagnacci) und 404 (Turchi). Turchis Gemälde hing in der Galerie des Hôtel des Louis Phélypeaux de la Vrillière (1599-1681), die mit weiteren neun exempla aus der Antike ausgestattet war, u. a. mit Abschied des Cato von seinem Sohn (Guercino), Augustus schließt die Pforten des Janustempels (Maratta) und Hersilia trennt Römer und Sabiner (Guercino). Pietro da Cortona (1596-1669) hat für diese Galerie ein Gemälde mit einem weiteren Thema aus Kleopatras Leben geliefert: César remet Cléopâtre sur le trône d'Égypte. (vgl. Richard-Jamet: "Cléopâtre: Femme forte ou femme fatale? Une Place équivoque dans les galeries de femmes fortes aux XVle et XVIle siècles «, in: AK Cléopâtre dans le miroir de l'art occidental, a.a.O., S. 37-52, besonders S. 44). 
seits bemühen sich die Dienerinnen noch um die bereits ohnmächtige Regentin, andererseits verweisen Händeringen und Tränentücher bereits auf die Vergeblichkeit dieses Handelns. Ganz ähnlich verfuhren Luca Giordano ${ }^{107}$ (1632-1705) [Abb. 37] und Gerard Hoet ${ }^{108}$ [Abb. 38] (1648-1733) mit ihren Bildlösungen, die stets in prächtigen Räumen angeordnet sind.

Jacob Jordaens (1593-1678) stellt zwischen dem >Bankett der Kleopatra [Abb. 39] und seinem Pendant, dem >Tod der Kleopatra ${ }^{109}$ [Abb. 40], ein komplexes Beziehungsgeflecht ${ }^{110}$ her, das die moralistische Deutung des Selbstmords unterstreicht. Unter einem prächtigen Baldachin ist Kleopatra beinahe ganzfigurig in der Mitte plaziert. Von rechts reicht ein älterer Bediensteter einen Früchtekorb. Zusam-

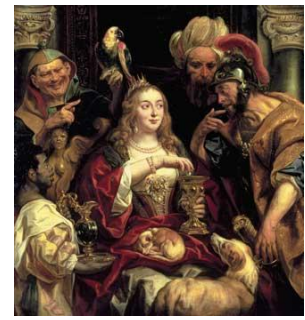

Abb. 39

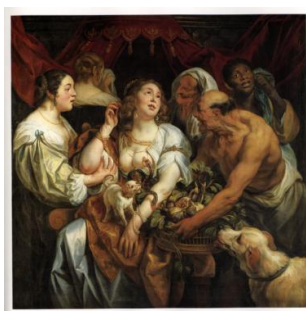

Abb 40

men mit zwei weiteren Dienern bildet er eine Gegengruppe zu den Dienerinnen, die zur Linken auf Kleopatras Selbstmord mit Entsetzen reagieren. Während sich die erste Dienerin bereits mit einem Taschentuch wegwendet, blickt die zweite ihrer Herrin aufmerksam ins Gesicht. Die luxuriös gekleidete, mit Geschmeide und Krone geschmückte Sterbende hat ihren Busen der Schlange bereits zum Biss geboten. Ihr Blick ist himmelnd nach oben gerichtet. Das irdische Glück, das im Bankettbild prachtvoll in Szene gesetzt und durch den Fingerzeig des Hofnarren bereits als Hybris gedeutet ist, wird im Pendant, ohne den moralischen Verweis, als

\footnotetext{
${ }^{107}$ Katalog 159

108 Katalog 181.

109 Vgl. Katalog 184. Das heute in der Gemäldegalerie in Kassel ausgestellte Gemälde hat die Maße $171 \times$ 172; allerdings wurden Anstückungen vorgenommen, so dass man auf das ursprüngliche Format von $156 \mathrm{x}$ 156 schließen kann. Vgl. Schnackenburg, Bernhard: Gemäldegalerie Alte Meister, Gesamtkatalog, Mainz 1996, Band 1, S. 162 (Inventarnummer 917) und Abbildung in Band 2, Tafel 52.

${ }^{110}$ Abbildung in d'Hulst, R.-A. / de Poorter, N. / Vandenven, M. (Hrsg.): AK Jacob Jordaens (1593 - 1678), Anvers 1993, S. 268-269. Das Gemälde befindet sich heute in der Eremitage in St. Petersburg (Inventarnummer 8536). Es hat die Maße 156,4 x 149,3. Im Testament des Jacomo-Antonio Carenna aus dem Jahre 1669 werden die Bilder als »due pitture similmente fatte a misura «eschrieben. (Vgl. AK Jacob Jordaens, a.a.O., S. 268) Jedes der beiden Gegenstücke hing ursprünglich über einer Tür der »saletta maggiore « im Carennas Antwerpener Haus. Nicht nur die Signaturen (beide sind signiert mit »J. Jor. 1653«), sondern vor allem mehrere Bildelemente, die in beiden Gemälden auftauchen und miteinander korrespondieren, weisen darauf hin, dass die Gemälde als Gegenstücke konzipiert waren. Während auf dem Bankettbild ein kleiner Hund eingerollt auf Kleopatras Schoß schläft, steht der gleiche Hund aufgeregt bellend in ihrem Schoß, als ihr der Korb mit Früchten und den darunter verborgenen Schlangen gereicht wird. In beiden Bildern taucht im rechten Vordergrund ein großer, das Geschehen aufmerksam verfolgender Jagdhund auf. Die Korrespondenzen werden im Personal fortgesetzt. Der Mohrenpage, der im Bankett den Essigkrug herbeiträgt, erscheint im Tod der Kleopatra im Hintergrund stark emotionalisiert wieder. In der Bankettszene deutet ein Narr, der einen Papagei auf der Hand trägt, mit verweisender Geste auf den Vogel und damit auf die moralische Bedeutung der Handlung. Der gleiche Narr starrt im korrespondierenden Gemälde der Sterbenden fasziniert ins Gesicht. Es wird also über wiederkehrendes Personal und Tiere ein Geflecht zwischen den beiden Gemälden hergestellt, das dem
} Betrachter die Zusammengehörigkeit und moralische Korrespondenz der beiden Gegenstücke signalisiert. 
vergängliches geschildert. Der verzweifelte Blick der Sterbenden und die Affekte des Hofstaats lassen keine andere Interpretation zu.

In den frühen Serien der 'Starken Frauen noch ganz selbstverständlich als eine der exemplarischen Figuren vor, so bei Domenico Beccafumi (1486-1551) [Abb. 41] und beim »Maître des héroïnes de ChigiSaracini « ${ }^{111}$ [Abb. 42]. Sie ist stets ganzfigurig und frontal als junge Frau gegeben, die an ihrem Attribut, der Schlange, zu erkennen ist. Auch die Serie des Nicolas Prévost (1604-1670), die 1642 [Abb. 43] entstand, bietet eine vergleichbare Inszenierung: unter einem purpurroten Baldachin hält die auf einem prächtigen Bett

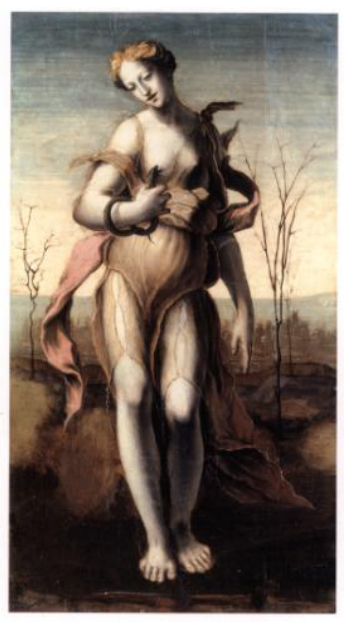

Abb. 41

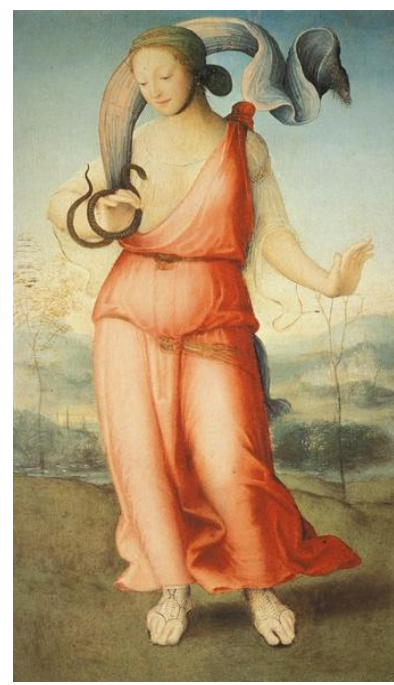

Abb. 42

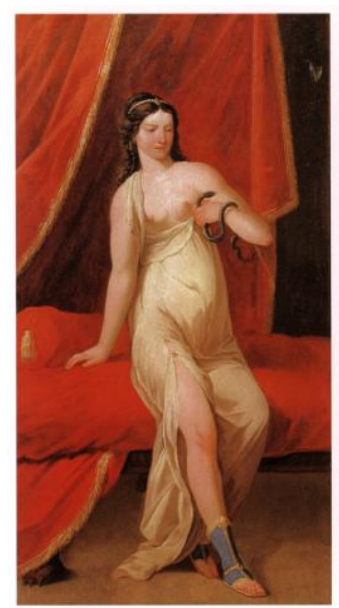

Abb. 43

sitzende Königin die Schlange am Busen.

Es ist bemerkenswert, dass Kleopatra nicht in die Graphikserien von François Chauveau (1613-1676) und Abraham Bosse (1602-1676) aufgenommen wurde, die die Schriften von Du Bosc (1645) und von Le Moyne (1647) illustrierten. Inzwischen hatte sich das Bild der Königin offensichtlich von der vorbildlichen und selbstbewussten Regentin zur lasziven femme fatale verändert.

In der Sterbeszene kann Kleopatra auf den ersten Blick leicht mit anderen Königinnen wie Dido und Sophonisbe verwechselt werden. Deshalb sind die Schlangen zu ihrem spezifischen, sie von den anderen Heldinnen unterscheidenden Attribut geworden. Ganz augenfällig ist aber auch, dass frühneuzeitliche Historienmaler bei der Darstellung Kleopatras ihre körperlichen Reize ungenierter als bei den anderen

\footnotetext{
${ }^{111}$ Eine Judith, eine Kleopatra (Katalog 220) und eine Sophonisbe (Katalog 221) wurden früher den »Maestri di Pandolfo Petrucci«, werden jetzt von Richard-Jamet dem »Maître des heroïnes de Chigi-Saracini « zugeordnet. Vgl. unten, S. $241 f$.
} 
Tugendheldinnen illustrierten - ein spätes und unverhohlenes Echo auf den schlechten Ruf, den sie bei den Historiographen als mit allen Mitteln Politik machende femme fatale genoss.

Als sich am Ende des 18. Jahrhunderts das Genre beinahe schleichend in die Historienmalerei integrierte, versuchten Maler, der ägyptischen Königin typisch ıweiblicher Seiten abzugewinnen. Besonders Anton Raphael Mengs (17281779) ${ }^{112}$ und Angelika Kauffmann (1741-1807) ${ }^{113}$ betonten geschlechtsspezifische Tugenden wie Demut und Selbstaufopferung und hoben als herausragende Leistungen Kleopatras Kniefall vor Octavian und ihre Trauer um Antonius hervor. Kauffmann [Abb. 44] stellt durch caravaggeske Beleuchtung die den Sarkophag des Geliebten mit Blumen schmückende Kleopatra als intime Szene dar. Ganz im Sinne Sulzers ${ }^{114}$ wird die Historienmalerin zur Malerin »des menschlichen Gemüthes, seiner Empfindungen und seiner Leidenschaften «. Kleopatra dekoriert den Sarkophag mit einer Blumengirlande und drückt in ihrer gefassten Trauer völlig in sich gekehrt die vom Zeitgeschmack geforderte »stille Größe« aus. Be-

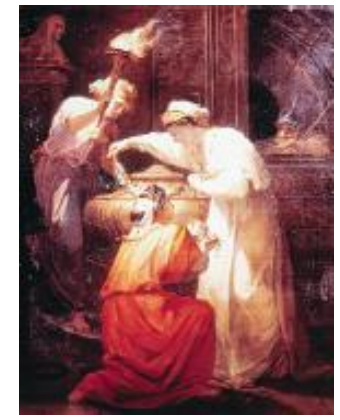

Abb. 44

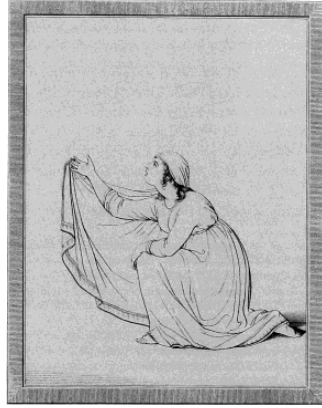

Abb. 45 zeichnenderweise greift Lady Hamilton ${ }^{115}$ in einer ihrer berühmten Attitüden diese betont demütige Kleopatra auf: sie inszenierte stets den unterwürfigen Kniefall vor Octavian [Abb. 45]. Am Ende des 18. Jahrhunderts wird politisches Handeln einer Königin, einer neuen Ästhetik entsprechend, in geschlechtsadäquates Verhalten wie Trauer, Selbstaufopferung und Verzicht umgedeutet. ${ }^{116}$

\footnotetext{
${ }^{112}$ Vgl. Katalog 242.

${ }^{113}$ Vgl. Katalog 189 (Kleopatra schmückt den Sarg des Antonius) und 190 (hier wird Kleopatra im Kniefall vor dem späteren Augustus gezeigt).

114 Johann Georg Sulzer: Allgemeine Theorie der schönen Künste, in einzeln, nach alphabetischer Ordnung der Kunstwörter auf einander folgenden Artickeln abgehandelt, 4 Bde, Frankfurt/Main und Leipzig, ${ }^{3} 1798$, hier Bd. 2, S. 671.

${ }^{115}$ Vgl. Katalog 303; ausführlich dazu Ittershagen, Ulrike: Lady Hamiltons Attitüden, Mainz 1999, S. 101-104; außerdem Baumgärtel, Bettina (hier als Autorin) im Katalogteil des AK Angelika Kauffmann, Düsseldorf 1998, S. 262.

${ }_{116}$ Reynolds (Katalog 337) porträtierte Kitty Fisher als Kleopatra, die eben die Perle in die mit Essig gefüllte Trinkschale fallen lässt. Dabei zitiert er im Ausschnitt die Geste aus Trevisanis Bankett der Kleopatra (heute in der römischen Galleria Spada). Kitty Fisher hatte sich in London einen Ruf als Lebedame und Kourtisane erworben und konnte mit solch gewagtem Rollenporträt ihr Ansehen nicht weiter verschlechtern. Die Marmorbüste von Richard Cockle Lucas, die die berühmte Salonnière Lady Stepney als Kleopatra mit einer Schlange am Arm zeigt (Abb. bei Walker / Higgs, a.a.O., S. 350), spielt wohl auf eine Rolle in einem Theater- oder Lesestück an.
} 
Getragen von den Moden der Ägyptomanie und des Orientalismus wurde Kleopatra im weiteren 19. Jahrhundert ausschließlich als dekadente Herrscherin inszeniert, die ein entsetzliches, aber letztlich gerechtes Ende fand. In Variationen der femme fatale lassen Rixens (1846-1924) ${ }^{117}$, Arthur (1875-1922) ${ }^{118}$, Böcklin $(1827-1901)^{119}$ und Makart (1840-1884) ${ }^{120}$ die Regentin ihren frühen Tod finden. Dabei sind auch noch in diesen späten Bildfindungen die aus der Graphik entwickelten frühneuzeitlichen Grundmuster zu erkennen: in Böcklins Kleopatra scheint noch die Verzweifelte des Hans Sebald Beham durch, die Reni und Guercino in halbfigurige Darstellungen übertrugen und affektisch aufluden. Rixens, Arthur und Makart lassen ihre über die Verzweiflung ihres Hofstaats erhabene Heldin eindrucksvoll souverän erscheinen. Noch einmal wirkt das von der vermeintlichen Kleopatra-Statue des Cortile del Belvedere inspirierte stoische Grundmuster nach.

\footnotetext{
117 Vgl. Katalog 348.

${ }^{118}$ Vgl. Katalog 20.

${ }^{119}$ Vgl. Katalog 38; Franz von Stuck zitierte Böcklins Sterbende Kleopatra in seinem Gemälde Sünde (1891) mit wenigen Veränderungen und verdeutlicht damit die zeitgenössische Sicht der ägyptischen Königin.

${ }^{120} \mathrm{Vgl}$. oben, S. 13 (Katalog 223).
} 


\section{Porzia: Republikanerin, Ehefrau und Stoikerin}

\section{Porzia: Antike Quellen}

In die Reihe römischer Tugendheldinnen, die in der Ikonographie der Frühen Neuzeit eine Rolle spielen, gehört am Rande auch Porzia ${ }^{1}$, Tochter des Cato Uticensis und Gattin des Cäsarmörders M. Brutus ${ }^{2}$. Sie war bereits in den Epigrammen des Martial sprichwörtlich ${ }^{3}$ und wurde von Aelian neben Cloelia und Cornelia unter die berühmten tugendhaften römischen Frauen gerechnet. ${ }^{4}$ Von ihr berichten Plutarch in der Biographie des Brutus ${ }^{5}$ und Valerius Maximus ${ }^{6}$ in den Memorabilien. Sie gehörte als Tochter des Cato $^{7}$ zum republikanischen Lager und wurde durch ihren heroischen Selbstmord zur Verkörperung republikanischer und stoischer Gesinnung. Schon vor dem Anschlag auf Cäsar verletzte sie sich mit einem Messer, um ihren Mut für den Fall auf die Probe zu stellen, dass die Verschwörung misslingen

\footnotetext{
${ }^{1}$ Miltner, Franz s. v. in: RE, Bd. 43, Stuttgart 1953, Sp. 216-218.

2 Sie war in erster Ehe mit M. Bibulus verheiratet, der 48 v. Chr. starb. Brutus hatte sich von seiner ersten Frau Claudia scheiden lassen und heiratete Porzia im Juni 45. Als Tochter des Cato, der 46 v. Chr. Selbstmord begangen hatte, war sie zum Zeitpunkt ihrer Ehe mit Brutus eine Repräsentantin der römischen Republik.

3 „ Coniugis audisset fatum cum Porcia Bruti / Et subtracta sibi quaereret arma dolor, / >Nondum scitisı ait >mortem non posse negari? / Credideram, fatis hoc docuisse patrem.ı / Dixit et ardentis avido bibit ore favillas. / I nunc et ferrum, turba molesta, nega.« $(\mathrm{I}, 42)$ (>Als Porzia das Schicksal des Gatten Brutus vernommen hatte und in ihrem Schmerz nach den versteckten Waffen suchte, sagte sie: »Wisst ihr nicht, dass man den Tod nicht verhindern kann? Ich glaubte, dass dies das Geschick meines Vaters gezeigt hat. « Sprach's und nahm begierig die glühende Asche zu sich. Geh jetzt, lästige Menge, und verweigere den Dolch.ı)

${ }_{5}^{4}$ Claudius Aelianus: Поıкі́^п 'Iбторía, XIV, 45 (übersetzt von DeVoto, James), Chicago 1995, S. $339 f$.

${ }^{5}$ Plutarch: Brutus 53,5

6. „Tuos quoque castissimos ignes, Porcia M. Catonis filia, cuncta saecula debita admiratione prosequentur. Quae, cum apud Philippos victum et interemptum virum tuum Brutum cognosses, quia ferrum non dabatur, ardentes ore carbones haurire non dubitasti, muliebri spiritu virilem patris exitum imitata. Sed nescio an hoc fortius, quod ille usitato, tu novo genere mortis absumpta es " (Valerius Maximus: Factorum et dictorum memorabilium libri IV,6,5) - Cuius filia minime muliebris animi. Quae, cum Bruti viri sui consilium, quod de interficiendo ceperat Caesare, ea nocte, quam dies taeterrimi facti secutus est, cognosset, egresso cubiculum Bruto cultellum tonsorium quasi unguium resecandorum causa poposcit eoque velut forte elapso se vulneravit. Clamore deinde ancillarum in cubiculum revocatus Brutus obiurgare eam coepit, quod tonsoris praeripuisset officium. Cui secreto Porcia `Non est hoc inquit stemerarium factum meum, sed in tali statu nostro amoris mei erga te certissimum indicium: experiri enim volui, si tibi propositum parum ex sententia cessisset, quam aequo animo me ferro essem interemptura.ı $(I I I, 2,15)$ (>Auch deine keusche Leidenschaft, Porcia, Tochter des $M$. Cato, werden alle Jahrhunderte mit gebührender Bewunderung ehren. Als du erfahren hattest, daß dein Mann Brutus bei Philippi besiegt und getötet worden war, hast du, weil man dir keine Waffe gab, nicht gezögert, glühende Kohlen zu verschlucken; mit weiblichem Mut hast du den mannhaften Tod deines Vaters nachgeahmt. Ich vermute aber, daß deine Tat tapferer war, weil jener auf die übliche, du aber auf eine neue Weise starbst.ı [Übersetzung von Ursula Blank-Sangmeister: Valerius Maximus, Facta et dicta memorabilia, Denkwürdige Taten und Worte Stuttgart 1991, S. 119] - ıSeine Tochter Porcia war völlig frei von weiblichen Schwächen. Als sie in der Nacht vor der entsetzlichen Tat erfahren hatte, daß ihr Mann Brutus plante, Cäsar zu töten, erbat sie sich, nachdem Brutus das Schlafzimmer verlassen hatte, ein Barbiermesser, angeblich, um sich die Nägel zu schneiden; sie ließ es wie zufällig aus den Händen gleiten und verletzte sich damit. Da wurde Brutus durch das Geschrei der Mägde ins Schlafzimmer zurückgerufen und begann, sie auszuschimpfen, weil sie dem Barbier seine Arbeit abgenommen habe. Unter vier Augen sagte Porcia zu ihm: „Es war dies kein Versehen von mir, sondern angesichts unserer Lage ein unumstößlicher Beweis meiner Liebe zu dir: Ich wollte nämlich herausfinden, wie angstfrei ich mich, wenn dein Vorhaben nicht den erwünschten Erfolg hätte, erdolchen könnte.“ [S. 79]) Außerdem erwähnt Appian das Ende Porzias in seiner

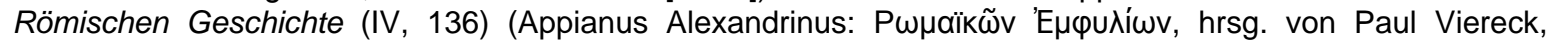
Leipzig 1986, S. 515 [= 136]).

${ }^{7}$ Zu Cato Uticensis vgl. Fehrle, Rudolf (Hrsg.): Cato Uticensis, Darmstadt 1983.
} 
sollte. Brutus beging nach der Niederlage der Republikaner bei Philippi 43 v. Chr. Selbstmord. Da Porzias Entschlossenheit, dem Beispiel ihres Mannes zu folgen, bekannt war $^{8}$ und deshalb alle Waffen aus ihrer Reichweite entfernt wurden, musste sie sich auf ungewöhnliche Art, durch Schlucken glühender Kohlen, den Tod geben.

\section{Porzia: Literarische Rezeption}

Nachdem bereits Hieronymus Porzia enthusiastisch als vorbildliche Ehefrau (»felix et pudica matrona « $)^{9}$ gerühmt hatte, nahmen sie Boccaccio ${ }^{10}$ und Christine de $\mathrm{Pi}$ zan $^{11}$ in ihre Zusammenstellungen berühmter Frauen auf und werteten ihr Verhalten als Inbegriff von Gattentreue, Verschwiegenheit und Tapferkeit. Boccaccio hebt in gleicher Weise ihre politische Haltung (patria fortitudo et perseverantia) und ihre Gattenliebe (amor inexhausti vigoris) hervor und preist Brutus glücklich, dem eine solche Frau (integre et caste) zur Seite stand. In ihrer Polemik gegen frauenfeindli-

${ }^{8}$ Plutarch (Brutus 32,2) berichtet, dass Porzia nach Flucht ihres Mannes von den politischen Gegnern nicht behelligt wurde.

${ }_{9}$ Adversus Jovianum 1, 46 (PL 23,2); das Urteil des Hieronymus verwundert angesichts seiner positiven Haltung zu Lukretias Selbstmord nicht (vgl. oben, S. 119).

${ }^{10}$ Boccaccio, Giovanni: Tutte le Opere, hrsg. von Vittore Branca, Milano ${ }^{2} 1970$, Bd. X, De mulieribus claris, LXXXII: De Portia Catonis Uticensis filia, S. 326-331.

11 »Dit Cristine a Dame Droiture contre ceulx qui dient que femmes ne scevent riens celer, et la responce que lui fait est de Porcia, fille de Catho. xxv $/ /$ /Dame, je congnois certainement maintenant, et autrefoiz l'ay apperceu, que grant est l'amour et la foy que maintes femmes on eu et ont a leurs maris. Pour ce je me donne merveille d'un lengage que cuert assez communement entre les hommes et mesmement maistre Jehan de Meun trop fort l'afferme en son Rommant de la Rose, et autres aucteurs aussi le font, que homme ne die a sa femme chose que il vueille celer et que femmes ne se scevent taire.ı Responce : >Amie chiere, tu dois savoir que toutes femmes ne sont mie sages et semblablement ne sont les hommes, par quoy se un homme a aucun scavoir, il doit bien voirement aviser quel sens sa femme a et quel bonté, ains qu'il lui die gaires chose qu'il vueille celer, car peril y peut avoir. Mais quant un homme sent qu'il a une femme bonne, sage et discrete, il n'est ou monde chose plus fiable ne qui tant le peust reconforter. / Et que femmes fussent si pou secretes comme yceulx veulent dire, et ancore a propos de femmes amantes leurs maris, n'ot mie celle oppinion jadis a Romme le noble homme Brutus, mari de Porcia. Celle noble dame portia fu fille de Cathon le Mendre qui neveu estoit au grant Catho. Son dit mari, qui la senti tres sage, secrete et chaste, lui dist l'entencion que il avoit, lui et Cassien, qui estoit un autre noble homme de Romme, de occire Julius Cesar au conseil, laquelle chose la sage dame, avisant le grant mal qui en vendroit, de tout sa puissance lui desconseilla et desloua. Et du soucy de ceste chose fu a si grant meschef que toute nuit dormir ne pot. Le matin venu, quant Brutus yssoit de sa chambre pour aler parfournir son emprise, la dame, qui moult voulentiers l'en destournast, prist le rasoir du barbier, si comme pour trancher les ongles et le laissa cheoir. Puis fist maniere de le reprendre et tout de gré le se ficha en la main, par quoy ses femmes, qui navree la virent, si fort s'escrierent que Brutus retourna. Et quant bleciee la vit il la blasma et dist que ce n'estoit mie son office de ouvrer de resouer, mais au barbier. Et elle lui respondi qu'elle ne l'avoit pas fait si follement comme il pensoit, car ce avoit elle fait tout de gré pour essayer comment elle se occiroit se l'emprise qu'il avoit faicte venoit mal pour lui. Mais cellui ne s'en laissa oncques et ala et occist tantost apres, entre lui et Cassien, Julius Cesar. Mais ilz en furent exillez et en fu puis occis Brutus, nonobstant qu'il s'en fust fuy hors de Romme. Mais quant Porcia sa bonne femme sceut sa mort, tant fu grande sa douleur qu'elle renonça a joye et vie. Et pour ce que on lui tolli couteaulx et toute chose dont occire se peust, car on veoit bien ce que faire vouloit, elle ala au feu et prist charbons ardans et les avala et ainsi se ardi et estaigni. Et par celle voye, qui fu la plus estrange dont oncques autre mourust, fina la noble Porcia.» " Christine de Pizan: Le Livre de la Cité des Dames, hier zitiert nach der elektronischen Edition von Skemp, Mary, Electronic Text Research Center, University of Minnesota, Minneapolis, MN, 1999 (http://erc.lib.umn.edu/dynaweb/french/pizalaci/@Generic_BookTextView) (zuletzt aufgerufen: 15.12.2006); deutsche Übersetzung bei Margarete Zimmermann (Christine de Pizan: Stadt der Frauen, Berlin ${ }^{2} 1987, \mathrm{~S}$. 166f.). 
che Positionen des Roman de la Rose führt Christine de Pizan ${ }^{12}$ Porzia als positives Beispiel für weibliche Klugheit und Verschwiegenheit an, weil sie den Anschlag missbilligte und gleichwohl schwieg.

Es lag schon deshalb nahe, dass auch dieser Stoff vom Historiendrama der Frühen Neuzeit aufgegriffen wurde, weil der Untergang der römischen Republik in Renaissance und Barock ein viel behandeltes Thema war. So spielt Porzia nicht nur in zahlreichen Caesar-Tragödien von Shakespeare ${ }^{13}$ (1599/1623) über Georges Scudéry (1635) bis Voltaire (1735) eine verschieden akzentuierte Rolle; auch ihr selbst wurden (zumindest in Frankreich) eine Reihe von Tragödien gewidmet, von Robert Garnier (Porcie, tragédie françoise, représentant la cruelle et sanglante saison des guerres civiles de Rome [1568]) ${ }^{14}$ über Guerin du Bouscal (La mort de Brute et de Porcie ou la vengance de la mort de César [1637]) ${ }^{15}$ bis Claude Boyer (La Porcie Romaine [1646]) $^{16}$, die stets von Plutarchs Biographie des Brutus inspiriert sind. Der Stoff konnte sich im unmittelbaren Umfeld von Corneille ${ }^{17}$ behaupten, da der Konflikt zwischen Liebe und Politik, der in vielen frühneuzeitlichen Tragödien von zentraler Bedeutung ist, in Porzia schon deshalb einen geeigneten Vorwurf fand, weil sich Gattenliebe und politisches Engagement in ihrer Person verbindet: „Si je l'aime beaucoup, c'est un peu moins que Rome«. ${ }^{18}$ Zwar entfällt wegen der perfekten Harmonie zwischen Brutus und Porzia die Liebesintrige, die in einem klassischen Drama meist ihren Platz hat; dafür erhalten Reflexionen über die Staatsräson einen umso breiteren Platz. Boyer lässt Brutus als möglichen Retter Roms erscheinen, der als einziger zu verhindern versuchte, dass der römische Staat zum Spielball von Erbauseinandersetzungen wurde. ${ }^{19}$ Die Figur der Porzia ließ sich ebenso wie Kleopatra oder Dido dem Programm der französischen Früh-

\footnotetext{
${ }^{12}$ A.a.O., S. 168f. (XXVIII)

${ }^{13}$ In Shakespeares Julius Cäsar wird die Chronologie der Handlung insofern verändert, als Brutus selbst Cassius berichtet, dass seine Frau aus Gram über seine durch den Bürgerkrieg bedingte Abwesenheit und aus Melancholie, die sie über die wachsende Macht des Antonius und des Octavian überfiel, Selbstmord begangen habe. (IV, 3, v151ff: Impatient of my absence,/ And grief that young Ocatvius with Mark Antony / Have made themselves so strong; for with her death / That tidings came. With this she fell distract, / And, her attendants absent, swallow'd fire.) (Shakespeare, William: Julius Caesar (Dorsch, T. S. Hrsg.) London ${ }^{6} 1955$, S. 105)

14 Das Stück wurde erst 1573 im Hôtel de Bourgogne aufgeführt. Garnier, Robert: Porcie, hrsg. von R. Lebègue, Paris [Les Belles Lettres] 1973; Robert Garnier, Porcie, hrsg. von Jean-Claude Trenaux, Paris 1999.

15 Der einzige Druck (Toussaint Quinet, Paris 1637) ist inzwischen über die Bibliothèque Nationale (http://gallica.bnf.fr/scripts/ConsultationTout.exe?E=0\&O=N071608) (zuletzt aufgerufen: 15.12.2006) leicht elektronisch zugänglich. Vgl.www.publifarum.farum.it/n/02/pdf/Doiron.pdf (zuletzt aufgerufen: 15.12.2006).

${ }^{16}$ Marie Roux hat 1997 unter der Leitung von Georges Forestier an der Université de Paris IV Sorbonne eine kritische Ausgabe vorgelegt, die auf der Netzseite des Centre de Recherche sur l'Histoire du Théâtre (CRHT) abzurufen ist (http://www.crht.org/?Biblioth\%E8que+dramatique/La+Porcie+Romaine) (zuletzt aufgerufen: 15.12.2006).

17 Vgl. unten S. $196 \mathrm{ff}$.

${ }^{18}$ Boyer II, 2, v. 418

${ }^{19}$ Boyer I, 3, v. 92: »Taschons par nostre exemple à guérir les Romains «
} 


\section{Porzia: Republikanerin, Ehefrau und Stoikerin}

klassik dienstbar machen. ${ }^{20}$ Auch in der Folge blieb Porzia zumindest über die verbreiteten Cäsar-Dramen so bekannt, dass Madame de Charrière sie noch 1785 sprichwörtlich als vorbildliche Ehefrau anführen kann. ${ }^{21}$ Das Thema der ehelichen Treue griff auch Johann Gottfried Herder noch einmal auf, als er 1774 seinem von Johann Christoph Friedrich Bach, dem Bückeburger Bach, vertonten Libretto Brutus eine Porzia-Szene einfügte, die eine interessante Referenz auf die Historienmalerei enthält: Herders zunächst heldenhaft von Brutus Abschied nehmende Porzia wird zu Tränen gerührt, als sie ein Bild mit Hektors Abschied von Andromache erblickt. $^{22}$

\section{Porzia: Ikonographie}

In den Holzschnitten [Abb. 1] der ersten illustrierten Ausgabe von Boccaccios De claris mulieribus ${ }^{23}$ aus dem Jahre 1473 wurde die Geschichte Porzias von einem unbekannten Künstler auf drei nebeneinander gesetzte Szenen verdichtet: Ganz links hat sich Porzia eben mit dem Dolch am Fuß verletzt, der Dolch selbst steckt noch dramatisch in ihrem Fuß. Brutus beugt sich besorgt zu ihr, während sie mit sprechend erhobener Hand andeutet, die Verletzung mit Absicht herbeigeführt zu

\footnotetext{
${ }^{20}$ »En mettant en scène cet affrontement dont l'issue est capitale pour le destin de Rome, Boyer a voulu en faire une tragédie politique. Le sujet de la pièce est conforme à la définition de la tragédie politique que donne Corneille dans le Discours du poème dramatique: la dignité de la tragédie demande «quelque grand intérêt d'Etat, ou quelque passion plus noble et plus mâle que l'amour, telles que sont l'ambition ou la vengeance». La pièce de Boyer illustre les deux termes de l'alternative énoncée par Corneille. D'une part, elle met en jeu «l'intérêt d'Etat» puisque Brutus se bat pour instaurer la République et pour mettre fin aux proscriptions et aux souffrances que les Triumvirs font endurer au peuple. Brutus et Porcie font même passer cet sintérêt d'Etatı avant leur propre vie. Cette notion de patriotisme, omniprésente dans la pièce, étoffe la dimension politique de cette tragédie. D'autre part, La Porcie Romaine est aussi l'illustration du second terme de l'alternative énoncée plus haut, c'est-à-dire «quelque passion plus noble et plus mâle que l'amour, telles que sont l'ambition et la vengeance». (Roux, Marie, Introduction, vgl. Fußnote 16)

21 „Mais ne serions-nous pas fâchées d'apprendre que [...] Porcie, fille de Caton, ait eu des amants? « (zitiert nach der elektronischen Ausgabe von Michel Pacaud http://un2sg4.unige.ch/athena/charriere/char_lau.rtf) (zuletzt aufgerufen: 15.12.2006).

22 Die Szene ist durch eine Passage bei Plutarch (Brutus 23) inspiriert, die ihrerseits als früher Beleg für durch Gemälde ausgelöste Affekte gelten kann. Der Text bei: Herder, Johann Gottfried: Sämmtliche Werke, hrsg. von Suphan, Bernhard, Berlin 1884, Bd. 27, S. 52-68 (die Fassung von 1772 ohne die Porzia-Szene S. 11-27). Porzia sagt bei Herder (S. 64): "Ach, alles, alles war er mir, / mir Vater, Bruder, Freund! / Und bald, ach, wird die Stunde seyn / und Brutus ist nicht mehr! / was ist dann mir geblieben / in aller Welt! / O mit Dir! mit Dir sterben!« Herder schreibt am 12.12.1772 an seine Verlobte: »P.S. In meinen Brutus, den ich etwas umgearbeitet, ist noch die Porcia, sein edles Weib, gekommen: denn Ein Zug von ihr hat mich im Plutarch bis zum Erstaunen gerührt. Da sie beide von einander Abschied nehmen, bezwingt sie sich, und geht Thränenlos weg: es fällt ihr aber das Gemälde in die Augen sder Abschied Hektors von der Andromache aus Homerı, der sehr rührend ist, und die sich nie wieder sehen. Da bricht sie in Thränen und in die Worte Homers aus - ich werde Ihnen nächst die Stelle abschreiben [...]. Auch habe ich gehört, Klopstock habe eigentlich statt Sokrates den Brutus in seinen Messias bringen wollen, aber sich vorm Selbstmorde gefürchtet: Porcia ist daher geblieben, und ist dieselbe Porcia des Brutus. « (Herders Briefwechsel mit Caroline Flachsland, hrsg. von Schauer, Hans, Weimar 1928, Bd. 2, S. 300f.)

${ }^{23}$ Katalog 412.
} 
haben, um ihren Mut auf die Probe zu stellen. ${ }^{24}$ In der Mitte wird die Ermordung Cäsars auf die drei Hauptbeteiligten konzentriert in Szene gesetzt: Cassius und Brutus stechen auf den als König gekleideten Cäsar ein. Im rechten Teil des Holzschnittes kniet Porzia allein am Feuer und tötet sich mit einem Kohlenstück. Ganz im Sinne Boccaccios wird zugleich ihre politische Rolle als Vertraute und Mitwis-

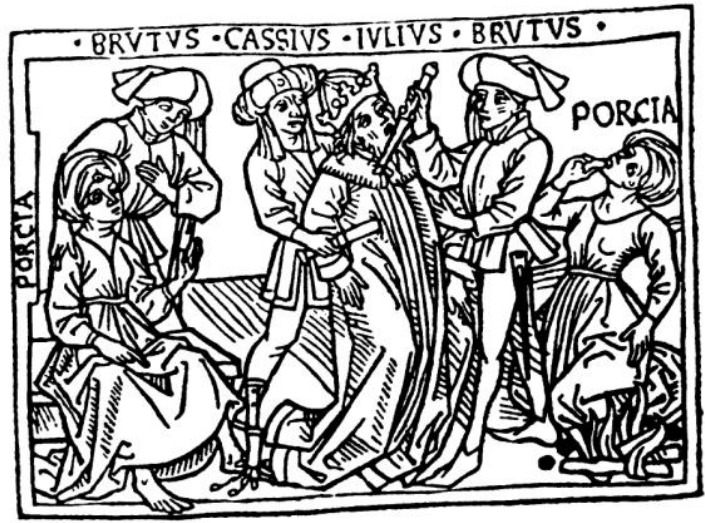

Abb. 1

serin an der geplanten Ermordung Cäsars und die Gattenliebe in dieser ersten künstlerischen Bearbeitung des Themas herausgestellt.

Von einer sich selbst verletzenden Porzia auf einem cassone ${ }^{25}$ von Michele da Verona (um 1470-1536) abgesehen, scheint die politische Rolle Porzias auf cassoni-Darstellungen ${ }^{26}$ nicht aufgegriffen worden zu sein; die Darstellungen konzentrierten sich auf die Selbstmordszene. Eine mit Pinsel und Feder ausgeführte Zeichnung von Barend van Orley $^{27}$ (ca. 14881541), die den Selbstmord Porzias inmitten ihrer häuslichen Umgebung wiedergibt [Abb. 2], mag eine Vorstellung von verlorenen Darstellungen auf cassoni vermitteln. Sehr bald entfällt die Darstellung

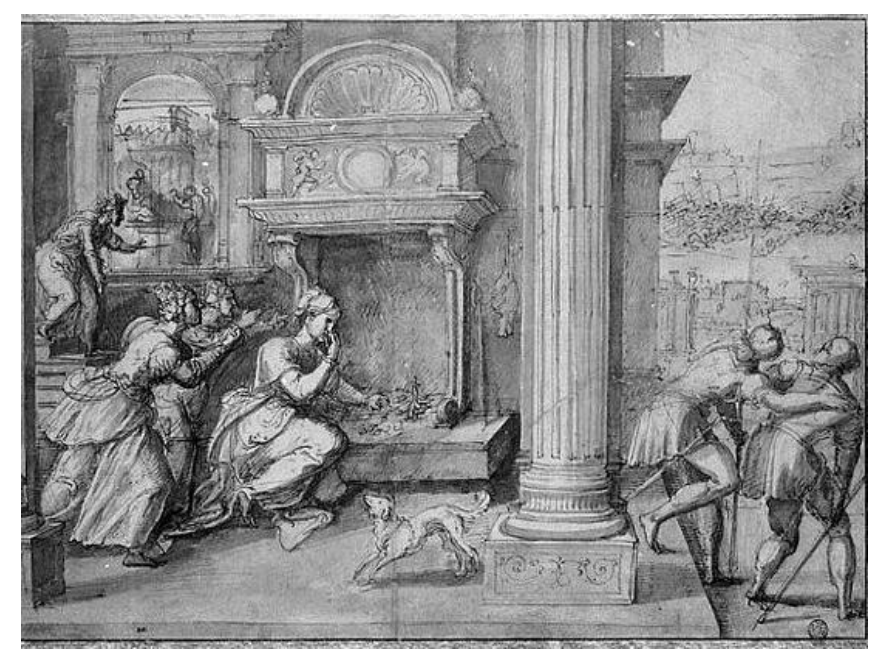

Abb. 2

der probeweisen Selbstverletzung Porzias, die ihr Mitwissen an der Verschwörung andeutet: Porzia wird zuförderst zum Emblem treuer Gattenliebe. ${ }^{28}$

\footnotetext{
${ }^{24}$ Boccaccio hat (De claris mulieribus, LXXXII: De Portia Catonis Uticensis filia, 8, a.a.O., S. 328) diese Szene dramatisiert (»Minime temerarie factum quod putas est; tentatura autem quo animo me ipsam gladio perimere et mortem perpeti possem, si minus tibi pro votis cepta succederent, feci. « (>lch habe das keineswegs unbedacht getan, wie du glaubst; ich hab es getan, weil ich erproben wollte, ob ich mich selbst mit dem Schwert töten und den Tod ertragen könnte, falls dein Vorhaben nicht den erhofften Erfolg haben sollte.८))

${ }^{25}$ Katalog 85. Porzia sticht sich in den Fuß und fasst Brutus am Arm.

${ }^{26}$ Siehe Schubring, a.a.O., 306, 365, 376, 682.

27 Katalog 262.

${ }^{28}$ Die von Pigler (II, S. 396) notierte Aufnahme in eine Ausgabe der Emblemata des Alciat (1602) konnte ich nicht verifizieren.
} 
Dies gilt zum Beispiel für eine hervorragende Dreiviertel-Skulptur ${ }^{29}$ des Gian Maria da Padova, gen. il Mosca (1493/95 - nach 1574) aus der Sammlung Franchetti in Venedig [Abb. 3]. Allerdings vereint die subtile und geistreiche subscriptio noch einmal die Gattenliebe und den Stolz der Tochter des republikanischen Hauptgegners Cäsars. ${ }^{30}$

Im Vergleich mit den anderen in dieser Untersuchung behandelten Tugendheldinnen, Dido, Lukretia, Sophonisbe und Kleopatra, wurde Porzia selten zum Bildthema gewählt. ${ }^{31} \mathrm{Da}-$ bei mag eine Rolle gespielt haben, dass die Figur der untröstlichen Witwe den latenten Grundkonflikt zwischen Liebe und Politik überdeckte und damit das Sujet an Dramatik verlor. Immerhin spielte Porzia eine gewisse Rolle in den >Galerien starker Frauen ${ }^{32}$

Während Lukretias Tod einen politischen

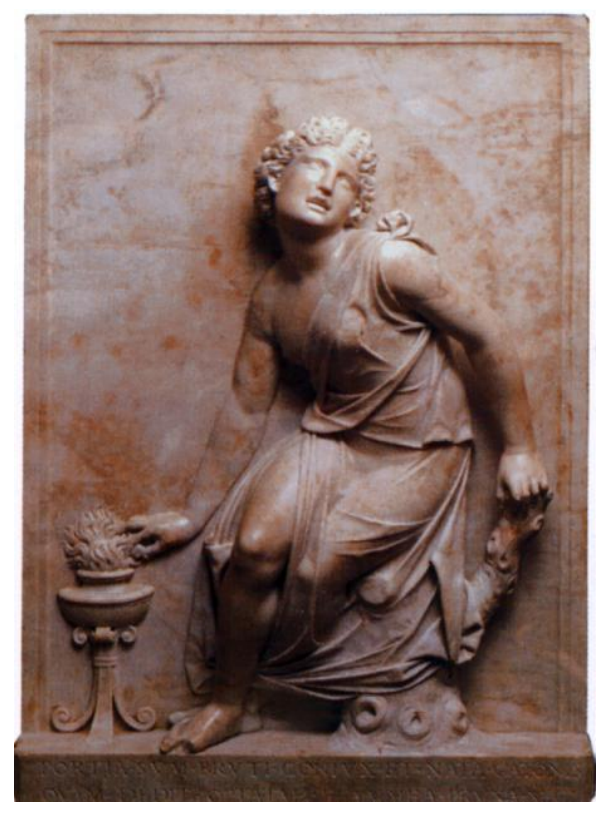

Abb. 3 Umsturz auslöste und bei den Regentinnen Dido, Sophonisbe und Kleopatra Herrscherrolle und Liebesleidenschaft in einen unlösbaren Konflikt führten, stimmen bedingungslose Gattentreue und politische Haltung bei Porzia so nahtlos überein, dass sich kein wirklicher dramatischer Konflikt und damit auch kein entsprechendes ikonographisches Motiv entwickeln lie ${ }^{33}$. Die mangelnde dramatische FFallhöhe ‘ kann erklären, dass Porzia weder im Historiendrama noch im Historienbild der Frühen Neuzeit eine große Karriere machte. Im Umkehrschluss, dass der dramatische Erfolg der anderen Tugendheldinnen die Voraussetzung ihrer ikonographischen Laufbahn war.

Im Historiengemälde wurde Porzias vorbildliche Gattenliebe hervorgehoben und die Tugendheldin zur stoischen Märtyrerin stilisiert, deren Darstellung sich

\footnotetext{
${ }^{29}$ Katalog 83.

30 PORTIA SVM BRVTI CONIVX ET NATA CATONIS // QVAM DEDIT OPTATAE FLAMMEA PRVNA NECI. (>Porzia bin ich, Frau des Brutus und Tochter des Cato, // der die glühende Kohle den gewünschten Tod gab.८) ${ }_{31}$ Auch Pigler, a.a.O., S. 396, hat nur eine geringe Zahl von Bearbeitungen gefunden.

${ }^{32}$ Vgl. unten, S. 253.

${ }^{33}$ Boyer versuchte dem abzuhelfen, wenn er Porzia sich im Lager der Cäsarmörder aufhalten und an der letzten Schlacht indirekt teilnehmen lässt. So kommt es zu einer konfliktuösen Begegnung $(\mathrm{V}, 2)$ Porzias mit Octavian, der seine politische Gegnerin zu erniedrigen sucht. Boyer funktionalisiert den letzten Auftritt Porzias dazu, ihre Willensstärke und politische Haltung zu verdeutlichen. Der Selbstmord selbst wird, den Erfordernissen des frühklassischen Theaters entsprechend, als Bericht gegeben. Die politische Rolle in den Historiendramen nehmen stets Brutus (und Caesar) ein. Porzias Tod wird stets mit der Gattenliebe, nicht mit ihrer Zugehörigkeit zum republikanischen Lager motiviert.
} 
nicht von Heiligenbildern unterschied. Ihr spektakulärer Selbstmord wird zum Beispiel von Guido Reni (1575-1642) ${ }^{34}$ [Abb. 4] und von Pierre Mignard (1612-1695) ${ }^{35}$ durch Halbfigurigkeit an den Betrachter herangerückt und so gleichsam intim inszeniert. Reni hat seine Porzia vor dunklen Hintergrund gestellt, so dass die helle Hautfarbe des Gesichts, des Dekolletés und der Hände besonders stark hervortreten. Porzia wendet ihren Blick himmelnd nach oben, während die Linke den Deckel der Kohlenschale anhebt und die Rechte nach den Kohlen greift. Der Blick widerspricht der Gestik und deutet an, wie nebensächlich der schmerzhafte Griff nach den glühenden Kohlen für die zum Selbstmord Entschlossene ist. Pierre Mignard stellt Porzia [Abb. 5] noch deutlicher in der Pose einer christlichen Märtyrerin vor und arbeitet mit einer Farbpalette, die marianische Farben bevorzugt. Der Künstler betont die Ergebung ins Schicksal, die

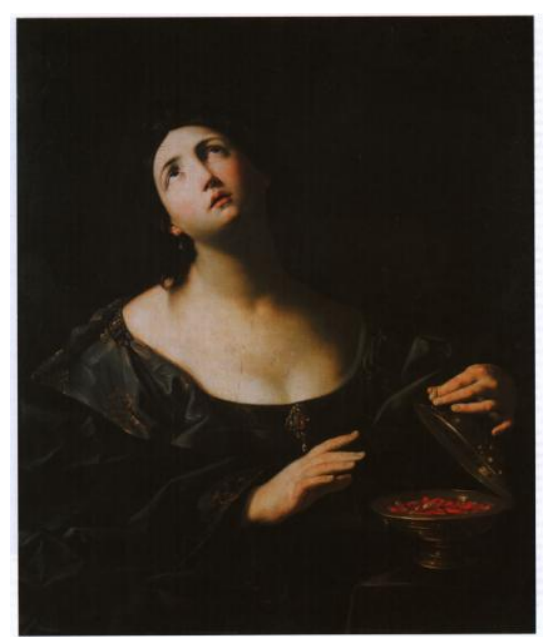

Abb. 4

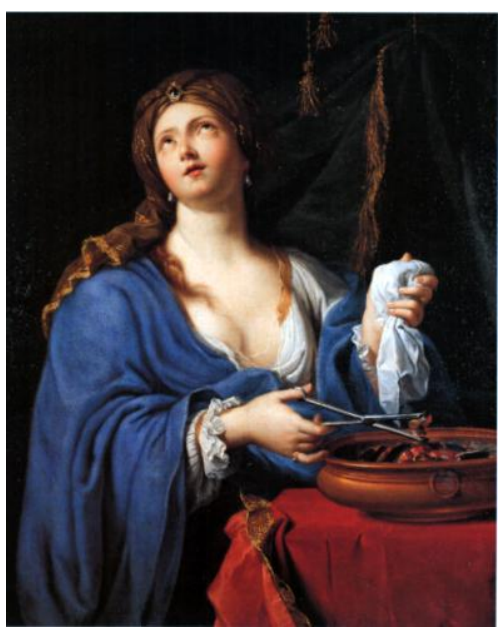

Abb. 5

Heldin blickt himmelnd nach oben, während sie mit einer Zange eine glühende Kohle aus dem Becken greift. In ihrer Linken hält sie ein Taschentuch. Über einem weiBen Untergewand mit großem Dekolleté trägt sie einen blauen Mantel, der mit dem roten Tischtuch des rechten Vordergrunds kontrastiert. Vom Haar ist nur eine einzelne Strähne zu sehen, da sie eine turbanartige Kopfbedeckung in Brauntönen trägt.

Jacques Bellange (1602-1616 als tätig nachgewiesen) ${ }^{36}$ hat in einer manieriert ausgeführten Radierung [Abb. 6] eine ganzfigurige Porzia sitzend im Profil nach rechts gegeben; wiese nicht das Kohlenbecken auf Porzias bevorstehenden Selbstmord hin, könnte man eine Darstellung der Melan-

\footnotetext{
${ }^{34}$ Katalog 331.

${ }^{35}$ Katalog 224.

${ }^{36}$ Vgl. Katalog 32.
} 
cholie vermuten. Porzia stützt das Haupt mit ihrer Linken, die gleichzeitig ein Taschentuch hält.

Erst auf den zweiten Blick erkennt man, dass die Rechte bereits zu den Kohlen ausgestreckt ist. Der übergroßen Trauer als bestimmendem Bildeindruck ordnete der Künstler alles unter, auch wenn so der Griff nach der glühenden Kohle irreal wird, weil er von der Protagonistin ungesteuert und ins Leere ausgeführt wird.

Nicolas Prévost (1604-1670) führte seine Porzia [Abb. 7] als Dekoration ${ }^{37}$ eines Raums im Schloss Richelieu aus. ${ }^{38}$ Mit drei Begleiterinnen steht Porzia ganzfigurig nach links in einem Tempelbezirk. Ihre Inszenierung als stoische Märtyrerin ist offensichtlich: Mit der Rechten nimmt die Tugendheldin eine glühende Kohle vom Altar. Die beiden hinter ihr stehenden Begleiterinnen haben dies noch nicht bemerkt, während die am Altar stehende Frau bereits klagend die Hand hebt. Im Zusammenhang des

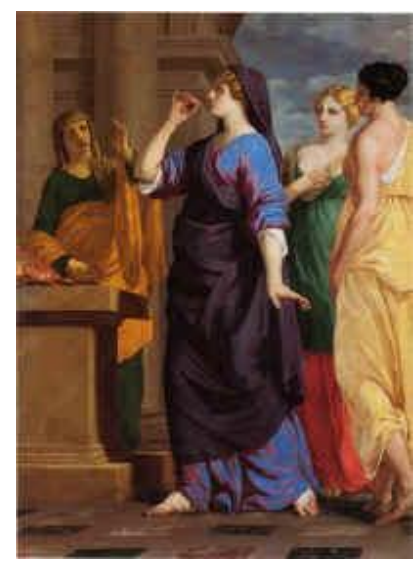

Abb. 7

Bildprogramms für Anne d'Autriche im Schloss Richelieu steht nicht die Republikanerin, sondern die treue Witwe im Vordergrund.

Auch François Chauveau [Abb. 8], der La femme herö̈que des Franziskaners Jacques du Bosc (1645) illustrierte ${ }^{39}$, hebt in seiner subscriptio ${ }^{40}$ mit Nachdruck den Aspekt der Gattenliebe hervor, obwohl er mit seiner Publikation vor allem die Gleichwertigkeit der Frauen beweisen wollte, wozu er Vergleichspaare aus Männern und Frauen zusammenstellte. In der naturgemäß plakativen Deutung der suscriptio stirbt Porzia für ihren Gatten, während dieser sich dem Vaterland und der Freiheit ${ }^{41}$ opfert; die geschlechsspezifischen Rollen blei-

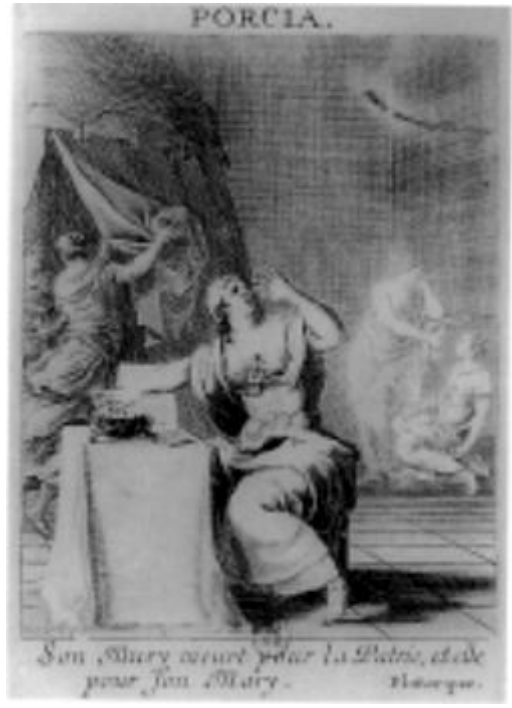

Abb. 8 ben so doch noch erhalten. In den Kupferstich-Illustrationen zu Pierre Le Moynes La Galerie des Femmes Fortes (1647), die Claude Vignon als Zeichnungen ent-

\footnotetext{
${ }^{37}$ Katalog 288.

38 Über ursprüngliche Hängung, Geschichte und Restauration des Gemäldes vgl. Goldfarb, Hilliard Todd (Hrsg.): AK Richelieu (1585-1642), Kunst, Macht und Politik, Ghent 2002, S. 315.

${ }^{39} \mathrm{Vgl}$. Katalog 63.,

40 "Son mary meurt pour la patrie, et elle pour son mary.«

41 „Il prefere la mort a la servitude. «
} 
warf und die Abraham Bosse und Gilles Rousselet ${ }^{42}$ ausführten, wird Porzia [Abb. 9] als große Figur im Vordergrund statuarisch und monumentalisiert gegeben, um exemplarische Größe und Stärke zu betonen. Den Prinzipien dieser Reihe entsprechend, tritt die Präsentation in den Vordergrund, während der Selbstmord als kleine zarte Zeichnung im Hintergrund erscheint. Porzia erhält in der subscriptio allerdings eine bedeutend bessere Bewertung und wird ihrem Vater Cato und ihrem Mann Brutus gleichgestellt. ${ }^{43}$ Der Kupferstich hatte Erfolg und wurde auf einem emaillierten Becher des 17. Jahrhunderts [Abb. 10]

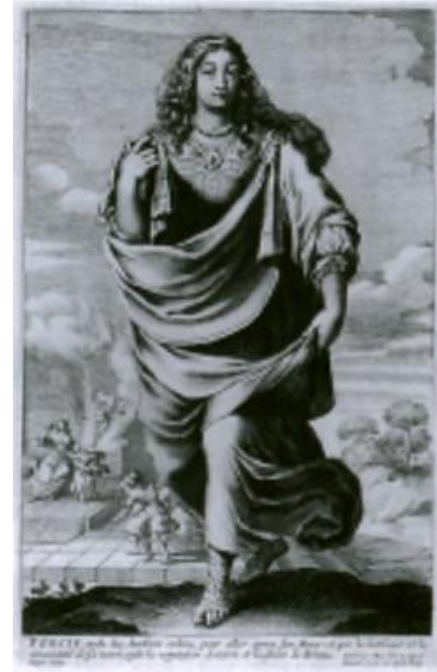

Abb. 9

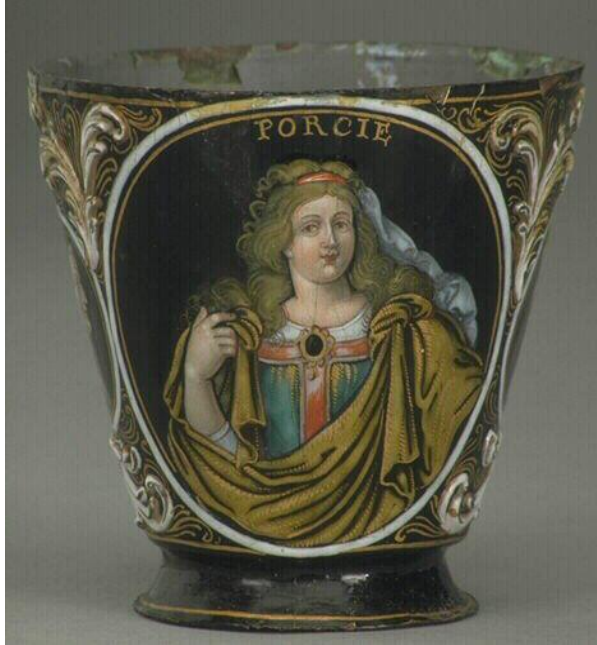

Abb. 10

übernommen, der Porzia allerdings nur noch als Abbreviatur zeigt.

Charles Errards ${ }^{44}$ (vor 1607-1689) [Abb. 11] und Luca Giordanos ${ }^{45}$ (16341705) [Abb. 12] Beschäftigungen mit dem Thema fallen sehr ähnlich aus, auch wenn sich Errards dreiviertelfigurige Porzia unter einem Baldachin und vor einem Ausblick auf antike Architektur gegen die beinahe bäuerlich gekleidete Porzia Giordanos äußerst elegant ausnimmt. Giordano hat sei-

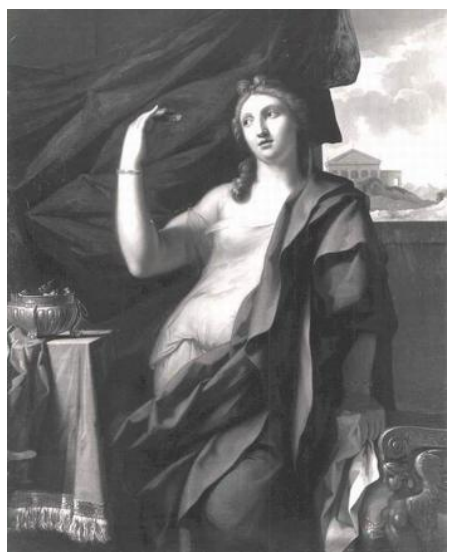

Abb. 11

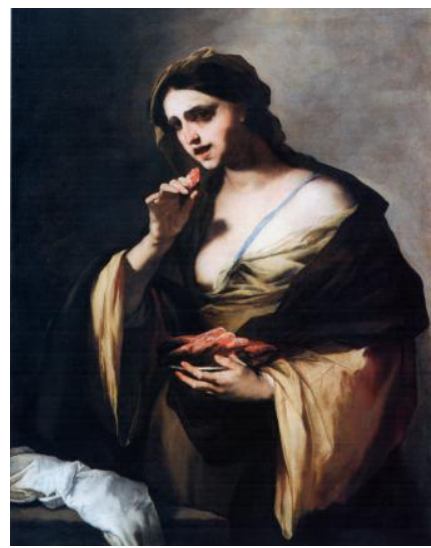

Abb. 12 ne Farbpalette im Braun-Gelb-Bereich gehalten, so dass das Rot der glühenden Kohlen ins Auge springt. Während Porzia bei Errard das Kohlenstück in ihrer

\footnotetext{
${ }^{42}$ Vgl. Katalog 65.

${ }^{43}$ Die subscriptio lautet. "Porcie auale des charbons ardens, pour aller après son Mary: et par la hardiesse et la nouueauté de sa mort, egale la reputation de Caton et la gloire de Brutus. «

${ }^{44}$ Katalog 122. Dazu Kerspern, Sylvain: " À propos de l'Énée transportant Anchise du Musée des Beaux-Arts de Dijon : jalons pour l'œuvre de Charles Errard«, in: http://www.latribunedelart.com/Etudes_2005/Errard.htm ${ }^{45}$ Katalog 155.
} 
Rechten fixiert, nimmt Giordanos Tugendheldin Blickkontakt mit dem Betrachter auf. Errards Porzia ist als Vertreterin der römischen Nobilität dargestellt, während Giordano mit seinen Bildmitteln Einfachheit und republikanische Gesinnung andeutet, für die vor allem Cato Uticensis, Vater Porzias, stand.

In ihrem Gemälde Porzia, sich selbst verletzend (1664) [Abb. 13] ${ }^{46}$ greift Elisabetta Sirani (1638-1665) noch einmal die selten dargestellte probeweise Verletzung Porzias auf und lässt die dreiviertelfigurig gegebene Tugendheldin den gesamten Vordergrund ausfüllen: Sie hat sich

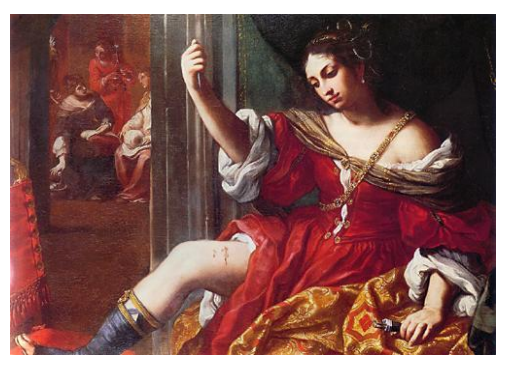

Abb. 13

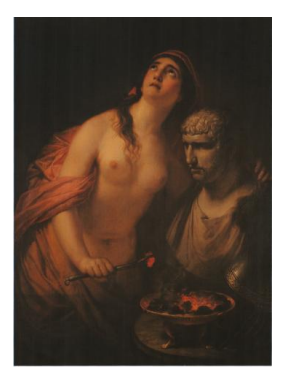

Abb. 14

soeben mit einem Barbiermesser am rechten Oberschenkel verletzt. Ein Durchblick hinten links zeigt drei Frauen bei häuslichen Arbeiten und zeigt die gefühlsmäßige Isolierung und Angst der Heldin. Auch in dieser Szene steht die schöne Inszenierung im Vordergrund, wie dies auch für die Selbstmorddarstellungen gilt.

Franz Caucig (1755-1828), ein Schüler Heinrich Frieder Fügers und in seiner künstlerischen Praxis Winckelmann und dem Klassizismus verpflichtet, wählte für sein Gemälde in Graz [Abb. 14] zwei antikisierende Referenzen ${ }^{47}$ : Porzia umarmt als trauernde Witwe mit ihrer Linken eine BrutusBüste, die in Grisailletechnik eine antike Bronzebüste als Marmorbüste umdeutet. In deutlicher Übernahme der NiobidenDarstellung wendet Porzia Gesicht und Blick himmelwärts, während sie in ihrer

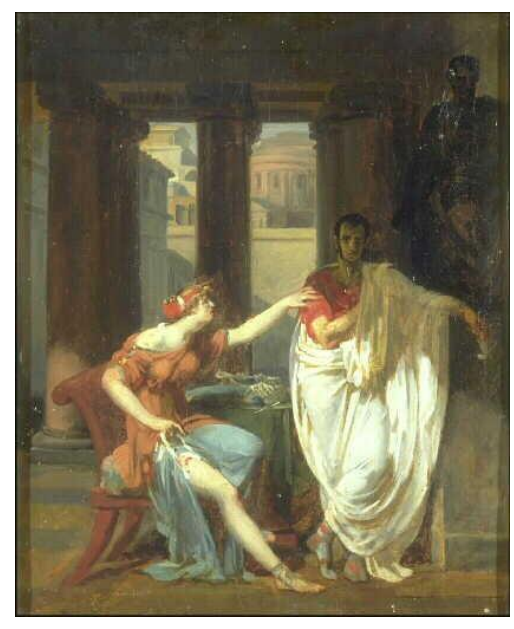

Abb. 15

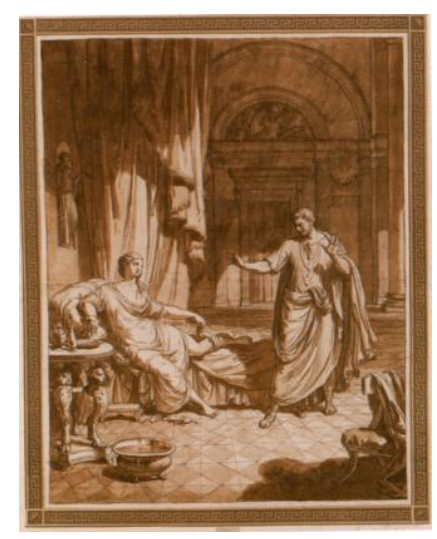

Abb. 16

Rechten bereits eine Zange mit glühender Kohle hält. Trauer und Selbstmord der jungen Witwe werden gleichgewichtig ins Bild gesetzt. ${ }^{48}$ Auch Felix Auvray (18001833) greift das Thema der Selbstverletzung ${ }^{49}$ auf und erarbeitete eine Lösung

\footnotetext{
${ }^{46}$ Vgl. Katalog 372.

47 Katalog 131.

${ }_{48}^{4}$ Vgl. Hagen, Bettina (Hrsg.): AK Antike in Wien, Die Akademie und der Klassizismus um 1800, Mainz 2002.

${ }^{49}$ Katalog 23.
} 
[Abb. 15], die der von Franz Caucig [Abb. 16] sehr ähnlich ist. ${ }^{50}$ Beide Künstler situieren die Szene in einem reich dekorierten Innenraum: Porzia sitzt und erläutert mit starker Gestik ihrem Ehemann den Grund ihrer Selbstverletzung. Auvray wie Caucig stellen Brutus stehend dar, die Körperhaltung drückt bei Auvray Nachdenklichkeit, bei Caucig Unverständnis aus. Am Ende der Motivgeschichte tritt so im Biedermeier der heroische Selbstmord zurück: Porzia interessiert als Ehefrau des Brutus und Mitwisserin am geplanten Cäsarmord, wobei Anmut und Demut ebenso wie weibliches Zagen und weibliche Ängstlichkeit betont werden. 


\section{Der Neustoizismus: Leitphilosophie der Frühen Neuzeit}

\section{Heroische Tugend und Neustoizismus}

Der neustoische Hintergrund des Bildmotivs der Selbstmörderin als Tugendheldin ist unübersehbar. Zwar veränderte die bemerkenswerte Erweiterung des Kanons bildwürdiger Themen aus Mythos, Geschichte und Religion ${ }^{1}$ in der Frühen Neuzeit auch die Ikonographie tugendhaften Sterbens, gleichwohl wäre die Darstellung des Selbstmords als moralische Handlung ohne die neustoische Leitphilosophie, die oft nur eine vielseitig einsetzbare Leitrhetorik geblieben sein mag, unter den Voraussetzungen des entstehenden konfessionellen Zeitalters gänzlich unverständlich. Dies gilt aber auch für das signifikante Nebeneinander von religiösen und profanen Todesdarstellungen, von Märtyrern und Tugendhelden, das für die frühneuzeitliche Bühne und bildende Kunst charakteristisch ist. Die zumindest theatralische und ikonographische Vergleichbarkeit des freiwilligen Todes der Märtyrer und des moralisch motivierten Selbstmords der Tugendhelden zeigt, dass selbst für das Verständnis der kirchlichen Kunst der Hinweis auf ihre Funktionalisierung in der durch das Konzil von Trient ausgelösten katholischen Reform allein nicht ausreicht.

Zwar ist der Einfluss der tridentinischen Dekrete ${ }^{2}$ und der sich daraus ableitenden neuen Frömmigkeitsformen auf die kirchliche Malerei unbestreitbar, werden doch die in der Zeit der katholischen Reform auffällig zunehmenden Heiligen- und Märtyrerbilder manchmal geradezu skrupellos der posttridentinischen propaganda fidei nutzbar gemacht. Ein dieser »Kultur des Martyriums « ${ }^{3}$ durchaus vergleichba-

\footnotetext{
${ }^{1}$ Vgl. oben S. $45 \mathrm{ff}$.

2 Vgl. unten S. $204 \mathrm{ff}$.

${ }^{3}$ Im Rahmen des inzwischen abgeschlossenen Freiburger Sonderforschungsbereichs »Identitäten und Alteritäten, Die Funktion von Alterität für die Konstitution und Konstruktion von Identität« (SFB 541) beschäftigte sich eine Gruppe (Projekt B 7) mit der Fragestellung "Sterben und Unsterblichkeit, Zur Kultur des Martyriums in der frühen Neuzeit« (http://www.phil.uni-freiburg.de/SFB541/B7 [zuletzt aufgerufen: 14.01.2007]). Die Arbeitsgruppe untersuchte unter kulturanthropologischen Gesichtspunkten frühneuzeitliche Märtyrer-Kulte und berührt deshalb eine meiner Fragestellung verwandte Thematik. Die Freiburger Studien rekonstruieren die kollektiven Selbstentwürfe, die sich in solchen »kollektiven « oder »kollektivierten Toten « manifestiert. So wurden Einblicke in die Genese und Entwicklung konfessioneller Kulturen gewonnen und Funktionen und Profile dieser Kulturen freigelegt. In (erst teilweise veröffentlichten) Einzeluntersuchungen wurden Martyriumskonzeptionen und Heiligkeitsmodelle dargestellt, Medien und Formen der Darstellung, Verbreitung und Rezeption heroischer Todesinszenierungen bestimmt, Märtyrerkulte und ihre Katechese analysiert, aber auch individuelle und kollektive Erfahrungen, Wahrnehmungen und Deutungsmuster religiös bestimmter Gewalt entziffert. Da das Projekt historisch und kulturanthropologisch ausgerichtet war, berührte es kunsthistorische Fragestellungen nur am Rande. Verwiesen sei vor allem auf die im Rahmen dieses Projekts entstandenen Untersuchungen von Burschel, Peter: "Männliche Tode - weibliche Tode. Zur Anthropologie des Martyriums in der frühen Neu-
} 
rer moralistischer Anspruch findet sich aber auch in den Sterbeszenen der profanen, nicht im Dienst der Kirche stehenden Historienmalerei, und so liegt es nahe, gemeinsame hermeneutische Voraussetzungen für die profane und kirchliche lkonographie von Sterben und Tod zu vermuten.

Damit kommt zwingend die europäische Wirkung des Neustoizismus in den Blick, ohne welchen die profanen Sterbeszenen der Historienmalerei kaum verständlich sind. Der gleiche neustoische Hintergrund ist auch für posttridentinische Märtyrerbilder unverkennbar. ${ }^{4}$ Umso mehr gilt dies für mythologische und historische Vorwürfe in der bildenden Kunst und auf der Bühne. Gerade die Themengruppen der ssterbenden Philosophen und der ssterbenden Tugendheldinnen beide einen denkwürdigen, meist freiwilligen Tod darstellen, setzen bei Auftraggeber und Betrachter einen neustoischen Hintergrund voraus, der den unter christlichen Rahmenbedingungen kaum erträglichen Skandal des freiwilligen Selbstmords zu neutralisieren vermochte. Das in der Antike entwickelte sProtokolk des Philosophentods ${ }^{5}$ wurde in den kirchlichen und in den profanen Darstellungen der Frühen Neuzeit aufgegriffen und fand eine Anwendung auch in der Ikonographie des Selbstmords ıstarker Frauen<.

Mit dem Neustoizismus verband sich im 16. Jahrhundert ein wichtiger Paradigmenwechsel in der humanistischen Rezeption antiker Philosophie, sein Einfluss ist allerdings im Einzelnen nur schwer zu fassen. Bekanntlich hat Calvin (15091564) als erster 1536 von >Neustoikern (novi Stoici) ${ }^{6}$ gesprochen und versucht, mit dieser Bezeichnung eine neue philosophisch-moralistische Strömung ein-

zeit«, in: Saeculum, Jahrbuch für Universalgeschichte 50 (1999), S. 75-97 und »Paradiese der Gewalt. Martyrium, Imagination und die Metamorphosen des nachtridentinischen Heiligenhimmels « in: Jahrbuch des Historischen Kollegs 2001, München 2002, S. 139-181 sowie Sterben und Unsterblichkeit, Zur Kultur des Martyriums in der frühen Neuzeit, München 2004.

${ }^{4}$ Wie ich im Kapitel »Posttridentinische Märtyrer und stoische Tugendhelden« (S. 204ff.) zeige, gleichen sich die ästhetischen Mittel der zur Andacht geschaffenen Märtyrerbilder und die Todesdarstellungen profaner Tugendhelden und -heldinnen. Oft sind Märtyrer von Tugendhelden nur durch ins Bild gesetzte Palmzweige und Kronen zu unterscheiden.

${ }^{5}$ In der Antike wurde der exitus illustrium virorum zu einem >Protokoll vorbildlichen Sterbens entwickelt, das stets am Tod des Sokrates orientiert blieb und den Akzent auf die freie Entscheidung für den Selbstmord legte. Geradezu topisch wurde der ultima vox als Vermächtnis an die Nachwelt große Aufmerksamkeit geschenkt: Vor allem die kaiserzeitliche römische Historiographie setzte sie zur Charakterisierung der politischen Gegner des Herrschers ein, die sich freiwillig oder gezwungen töteten. Ihr sinszeniertes Sterben brachte ihre politische und moralische Haltung enkomiastisch auf den Begriff. Diese literarische Inszenierung wurde unter veränderten Vorzeichen von den spätantiken Märtyrerakten übernommen, obwohl sich auf den ersten Blick der sinszenierte Selbstmord، schwerlich in einen christlichen Kontext übertragen ließ. (Dazu Ronconi, A.: "exitus illustrium virorum « in: RAC VI, Stuttgart 1966, Sp. 1258-1268.)

${ }^{6}$ „Nunc quoque sunt inter Christianos novi Stoici, quibus non modo gemere ac flere, sed tristari quoque et sollicitum esse vitiosum est. [...] At nihil nobis cum ferrea ista philosophia. « (>Nun gibt es unter den Christen auch neue Stoiker, denen nicht nur seufzen und weinen, sondern auch traurig und bewegt sein als Laster gilt. [...] Aber wir haben mit dieser gefühllosen Philosophie nichts zu tun.८) (Inst. Rel. Christ. III,8,9 [Corpus Reformatorum XXX, 2, Braunschweig 1864, S. 520]). Calvin verfasste 1532 einen Kommentar zu Senecas De clementia und war mit der (neu)stoischen Philosophie vertraut. 
zuordnen, deren Anthropologie er als einer der theologischen Vordenker der Reformation ablehnen musste. Vielleicht hatte Calvin scharfsichtig erkannt, dass sich in dieser philosophischen Unterströmung eine die entstehende Konfessionalisierung unterlaufende moralische Normbildung manifestierte. Die Forschung hat sich mit dieser politisch-kulturellen Bedeutung des Neustoizismus in der Frühen Neuzeit bisher nur in Teilaspekten auseinandergesetzt. So fand die wohl einflussreichste Persönlichkeit des sich herausbildenden Neustoizismus, Justus Lipsius (15471606), in der Forschung bisher meist nur wegen seiner Rolle in der Entwicklung des neuzeitlichen Staatsrechts Beachtung. ${ }^{7}$ In diesem Zusammenhang wurde allerdings dem überkonfessionellen neustoischen Wertekanon kaum Aufmerksamkeit geschenkt, den Lipsius und andere am Modell der kaiserzeitlichen Historiographie entwickelt haben, obwohl dieser Kanon für das Drama $^{8}$ der frühen Neuzeit (und damit für die Historienmalerei) geradezu konstitutiv wurde.

\section{Exkurs (1): Die moralphilosophische Wende im frühneuzeitlichen Humanis- mus}

Natürlich waren die zentralen Thesen der Stoa immer bekannt und präsent geblieben, zumal sie seit inrer kritischen Rezeption durch die Theologie der Alten Kirche in den Traditionszusammenhang der Spätantike und des Mittelalters ${ }^{9}$ gehörten. Gleichwohl entwickelte sich im 16. Jahrhundert auf verschlungenen Wegen eine Neuentdeckung der Stoa, die geradezu zur konfessionsübergreifenden Leitphilosophie wurde und zu einer moralphilosophischen Wendung des frühneuzeitlichen Humanismus führte. Aus heutiger Sicht entwarf die neustoische Wendung zur praktischen Philosophie, die ohne Rückbindung an ein großes philosophisches System auskam, erste Ansätze einer modernen Ethik und bewirkte eine Umorientierung, deren Folgen in der bildenden Kunst und im Theater der frühen Neuzeit unübersehbar sind.

Zu den wichtigen Voraussetzungen der frühneuzeitlichen Renaissance der Stoa gehörte die Revision der Cicero-Rezeption, die sich im Frühhumanismus vor allem für Ciceros Rhetorik und seine Vermittlung platonischer und aristotelischer Philosophie $^{10}$ interessiert hatte. Erst die Entdeckung der Briefsammlungen rückte

\footnotetext{
${ }^{7}$ Oestreich, Gerhard: Antiker Geist und moderner Staat bei Justus Lipsius (1547-1606), Der Neostoizismus als politische Bewegung, Göttingen 1989; Abel, Günter: Stoizismus und Frühe Neuzeit, Zur Entstehungsgeschichte modernen Denkens im Felde von Ethik und Politik, Berlin / New York 1978; Evans, Robert C.: Lipsius and the Politics of Renaissance Stoicism, Longwood 1992.

${ }^{8}$ Zum Beispiel Schings, Hans-Jürgen: Die patristische und stoische Tradition bei Andreas Gryphius: Untersuchungen zu den Dissertationes funebres und Trauerspielen, Köln 1966; Barner, Wilfried: Produktive Rezeption: Lessing und die Tragödien Senecas, München 1973; Barner, Wilfried: Barockrhetorik: Untersuchungen zu ihren geschichtlichen Grundlagen, Tübingen 1970; Plume, Cornelia: Heroinen in der Geschlechterordnung, Wirklichkeitsprojektionen bei Daniel Casper von Lohenstein und die 'Querelle des Femmes', Stuttgart/Weimar 1996. Zur französischen Klassik und Corneille: Paul Bénichou, Morales du grand siècle, Paris 1948 u.ö.; Jacques Maurens, La tragédie sans tragique, Le néo-stoïcisme dans l'œuvre de Pierre Corneille, Paris 1966.

${ }^{9}$ Trotz des zum Diktum avancierten Graeca non leguntur wurden Grundkenntnisse griechischer Philosophie vor allem über die philosophischen Schriften Ciceros ins Mittelalter tradiert, in denen der Eklektiker Begriffe der antiken Philosophenschulen ins Lateinische vermittelt hatte. Vgl. vor allem Courcelles, Pierre: Les lettres grecques en occident, De Macrobe à Cassiodore, Paris ${ }^{2} 1948$.

${ }^{10}$ Für den europäischen Humanismus war Cicero zunächst vor allem als Muster römischer Beredsamkeit wichtig. Schon Augustinus hatte inm in De doctrina christiana neben Vergil eine Rolle im Kanon christlicher Bildung
} 


\section{Der Neustoizismus: Leitphilosophie der Frühen Neuzeit}

das eklektische Verfahren Ciceros und sein Interesse an praktischer Philosophie ins Bewusstsein. Als in der veränderten politischen Landschaft der oberitalienischen Stadtstaaten im 13. Jahrhundert auch der Politiker Cicero ${ }^{11}$ ins Blickfeld geriet, deuten sich bereits wichtige Veränderungen im Rezeptionshorizont an: die Politiker der römischen Republik wurden jetzt als Modelle für das politische Handeln der eigenen Zeit entdeckt und die antiken Texte auf anthropologische Muster hin gelesen. Formal waren zwar Sprache und Rhetorik durch den Einfluss der römischen Kurie schon längst ciceronianisch geprägt, doch werden nun darüber hinaus ontologische Fragestellungen, wie sie noch die Scholastik beherrschten, durch anthropologische abgelöst und Bildung und Erziehung zum Programm des Humanismus. $^{12}$

Gleichzeitig suchten urbane Gesellschaftsschichten, die im Gegensatz zum Schwertadel nicht auf Ahnenreihen zurückblicken konnten, in der römischen $\mathrm{Re}$ publik Vorbilder, die die neuen Führungseliten legitimieren konnten: Sie fanden in den exempla der republikanischen Phase Roms ihre Maßstäbe moralischen Handelns. Dieses Interesse für Modelle aus der römischen Republik wurde erst spät auf die nachrepublikanische Epoche erweitert. Die politischen Krisen des ausgehenden Mittelalters - Schisma, Hundertjähriger Krieg, Niedergang des Kaisertums, Territorialstreitigkeiten, Türkengefahr, Hungersnöte und Pest - veranlassten die Humanisten, auch andere Epochen der römischen Geschichte zum Vergleich mit den eigenen Zeitläuften heranzuziehen und die zuversichtliche Welt- und Menschensicht zu relativieren. Die stoisch geprägten kaiserzeitlichen Autoren rückten nun ins Zentrum des Interesses.

Zunächst wurden Senecas Epistulae morales ad Lucilium und seine Traktate De clementia und De tranquilitate animi unter anderen Vorzeichen ${ }^{13}$ gelesen. Im Zeitalter der Konfessionsstreitigkeiten ließ sich in den moralphilosophischen Schriften Senecas ein Ausweg finden, der einen neuen Subjektivismus jenseits der Konfessionsstreitigkeiten ${ }^{14}$ zuließ. Diese Tendenz verband sich mit dem steigenden Interesse, das Senecas Dramen als Vorbilder für das sich langsam entwickelnde frühneuzeitliche Theater gefunden hatten. Lovato Lovati und Albertino Mussato, einflussreiche Vertreter des Paduaner Frühhumanismus, hatten schon um 1300 die wiedergefundenen Tragödien Senecas ${ }^{15}$ bekannt gemacht und eine Renaissance seiner Theaterkunst eingeleitet. ${ }^{16}$ Mit seinem Tractatus super tragediis componen-

zugestanden. Deswegen wurden im Gegensatz zu den Briefen und philosophischen Abhandlungen alle rhetorischen Schriften Ciceros im Mittelalter breit überliefert und im universitären Grundstudium der artes liberales verwendet.

${ }^{11}$ Noch Petrarca (Fam. 24,3.4) war 1345 tief enttäuscht, als das Bild Ciceros nach der Entdeckung der Briefe an Atticus um seine philosophische Neigung zur vita contemplativa erweitert werden musste. Schon zwei Generationen später konnte Salutati (1392) nach der Entdeckung der zweiten Briefsammlung (Epistulae ad familiares) in seinem Cicero-Bild neben dem Staatsmann, Politiker und Philosophen auch den Privatmann mit seinen Stärken und Schwächen zulassen.

${ }^{12}$ Eine sodalitas aller Humanisten und eine sancta societas eruditorum (Erasmus) sollte entstehen, für die die literarischen Textformen des Briefs und des Dialogs Kennzeichen intellektueller Kommunikation wurden. Die europäische sodalitas bedient sich weiterhin der eingeführten Sprech- und Schreibformen des Briefs, des Dialogs und des Traktats. Diese scheinbare Kontinuität verstellt dem heutigen Leser oft den Blick darauf, dass die Inhalte allmählich wechselten. Vgl. dazu Muller Jeffrey M.: »Rubens's Collection in History«, in: AK A House of Art, Rubens as Collector (Belkin Lohse, Kristin / Healy, Fiona Hrsg.) Antwerpen 2004, S. 10-85, bes. S. 40.

${ }^{13}$ Dazu auch Etter, Else-Lilly: Tacitus in der Geistesgeschichte des 16. und 17. Jahrhunderts, Basel/Stuttgart 1966, hier S. 13. - Senecas moralphilosophische Schriften waren während des ganzen Mittelalters unter christlichen Vorzeichen gelesen worden; der um 375 fingierte Briefwechsel Senecas mit seinem Zeitgenossen Paulus zeigt, dass Seneca schon in der Spätantike als Christ oder doch zumindest als dem Christentum nahestehend eingeordnet wurde. Mit dem Urteil Seneca saepe noster drückte Tertullian (De anima 20,1) die moralische Nähe zum Christentum aus, Hieronymus (De viris illustribus 12) nahm inn sogar als einzigen heidnischen Autor in seinen christlichen Schriftstellerkatalog auf.

${ }^{14}$ Grundlegend immer noch Burdach, Konrad: Reformation, Renaissance, Humanismus, Berlin 1918.

${ }^{15}$ Aus dem Codex Etruscus der Abtei Pomposa.

${ }^{16}$ Dazu noch immer gültig der Aufsatz von Regenbogen, Otto: "Schmerz und Tod in den Tragödien Senecas «, in: Vorträge der Bibliothek Warburg 7 (1927/28), S. 167ff. (ND Darmstadt 1963). 


\section{Der Neustoizismus: Leitphilosophie der Frühen Neuzeit}

dis beeinflusste Mussato die frühhumanistische Konzeption der literarischen Gattungen und noch bis ins späte 18. Jahrhundert die europäische Dramenproduktion. Dabei ist es von Bedeutung, dass Mussatos Tragödie Ecerinis in der Nachfolge von Senecas Octavia einen zeitgenössischen politischen Konflikt aufgriff. ${ }^{17}$ Die stoische Anthropologie der Tragödien Senecas und ihre Darstellung der Affekte wurden für lange Zeit modellbildend.

Das moralphilosophische Interesse an Seneca wurde 1470 durch den beeindruckenden Lebens- und Sterbebericht in den Annalen (XV,60-64) ergänzt und aufgewertet. Es ist nicht erstaunlich, dass sich alsbald das Interesse auf Tacitus richtete, bei dem sich zahlreiche kaiserzeitliche Paradigmen stoischer Lebensführung finden ließen. Zu Beginn des 16. Jahrhunderts waren alle überlieferten Schriften des Tacitus gedruckt ${ }^{18}$ und standen einem größeren Publikum zur Verfügung. ${ }^{19}$ Neben der philologischen Editionsarbeit und Kommentierung setzte sofort eine produktive imitatio ein, die sich zum Beispiel bei deutschen Humanisten wie Conrad Celtis (1459-1508) und Beatus Rhenanus (1485-1547) auf die Germania konzentrierte. In Frankreich ${ }^{20}$ lassen sich intensive Beschäftigung und Auseinandersetzung mit Tacitus bei Michel de Montaigne (1533-1592), Marc Antoine Muret (1526-1585), Etienne de la Boétie (1530-1563), Claude Fauchet (1530-1601) und Jean Bodin (1529-1596) nachweisen. In Italien trifft man vor allem bei Niccolò Machiavelli (1469-1527) in seinen Schriften II principe (1513) und Discorsi sulla prima deca di Tito Livio (1531) auf Spuren einer gründlichen Auseinandersetzung mit Tacitus. In ganz Europa entwickelte sich so mit der philologischen und historischen Beschäftigung mit Tacitus eine kritische Adaption, die zur Entstehung des Neustoizismus beitrug.

\section{Exkurs (2): Justus Lipsius als Leitfigur des Neustoizismus}

Nach dem Gesagten überrascht es nicht, dass der niederländische Humanist Justus Lipsius ${ }^{21}$, der zur Leitfigur des Neustoizismus werden sollte, sich zu Beginn seiner Laufbahn philologisch mit Tacitus und Seneca beschäftigte. Er besorgte 1574 eine Ausgabe des Tacitus, ließ inr 1581 einen Kommentar folgen und edierte 1605 die Werke Senecas. So kann er als Prototyp eines zunächst textkritisch arbeitenden Philologen und Redakteurs gelten, der erst in einer zweiten Phase der Auseinandersetzung und Aneignung zum Philosophen wurde; er selbst sah seine Ent-

\footnotetext{
17 Den literarischen Ruhm, den die Tragödie dem Autor einbrachte, führte bekanntlich zur ersten Dichterkrönung der Neuzeit, als Mussato Weihnachten 1315 zum poeta laureatus ausgerufen wurde.

${ }_{10}^{18}$ Editio princeps der Schriften des Tacitus 1470 von Vindelino de Spira (Venedig).

19 Tacitus, dessen Lektüre in deutschen Klöstern des 9. Jahrhunderts nachgewiesen werden kann, hat eine ungemein schwierige Überlieferungs- und Wiederentdeckungsgeschichte, deren einzelne Phasen oft einem Kriminalfall ähneln. Es begann damit, dass der heute Mediceus II genannte Codex (Florenz Laurent. 68 II), der um die Mitte des 11. Jahrhunderts in Montecassino geschrieben wurde, von Boccaccio und seinem Freundeskreis zwischen 1357 und 1363 entdeckt, gestohlen und nach Florenz gebracht wurde. Der Diebstahl war durch die Erwartung motiviert, Tacitus gebe in seinen Annales und Historiae wichtige Informationen und Kommentare zum römischen Prinzipat. Schon 1403 zitiert Bruni Tacitus, um seinen `Bürger-Humanismusı zu untermauern. Der Codex Hersfeldensis, der neben der Germania die Vita Agricolae und den Dialogus enthält, wurde wohl im 9. Jahrhundert im Kloster Fulda geschrieben. Über einen Hersfelder Benediktinermönch lernte inn der Humanist und päpstliche Sekretär Poggio Bracciolini während des Konstanzer Konzils kennen und brachte ihn, wohl durch Bestechung, nach Rom. Hier wurde die Handschrift abgeschrieben und weiterverkauft, um erst 1902 wiedergefunden zu werden. Als 1470 die erste Ausgabe des Tacitus erschien, enthielt sie die Germania und den Dialogus, die Historiae und einen Teil der Annalen (XI-XVI). 1476 wurde die Ausgabe um die Biographie des Agricola ergänzt. Der Codex Mediceus I, in einem Skriptorium des 9. Jahrhunderts geschrieben und die Bücher I bis VI der Annalen enthaltend, wurde von Giovanni de' Medici, seit 1513 als Leo X. Papst, erworben, vom Kloster Corvey nach Rom gebracht und von Beroaldus 1515 veröffentlicht.

${ }^{20}$ Für den Bereich der Romania: Stackelberg, Jürgen von: Tacitus in der Romania, Studien zur literarischen Rezeption des Tacitus in Italien und Frankreich, Tübingen 1960.

${ }^{21}$ Über den Forschungsstand zu Lipsius vgl. Oestreich, Gerhard, a.a.O., S. 43-47 und Abel, Günter: Stoizismus und Frühe Neuzeit, Berlin / New York 1978, S. 67-72. - Ich zitiere im Folgenden Lipsius nach dem 2001 erschienenen Nachdruck der Gesamtausgabe: Lipsius, Justus: Opera omnia, 4 Bde in 8 Teilen, Wesel 1675 (ND Hildesheim / Zürich / New York 2001). Der Nachdruck behält die fehlerhafte Paginierung des Originals bei.
} 


\section{Der Neustoizismus: Leitphilosophie der Frühen Neuzeit}

wicklung nicht anders: "Ego ad sapientiam primus vel solus mei aevi Musas converti, ego e philologia philosophiam feci.«22

Justus Lipsius, als Joost Lips 1547 in Overijse zwischen Brüssel und Löwen geboren $^{23}$, begann nach dem juristischen Examen seine wissenschaftliche Karriere mit der Veröffentlichung der textkritischen Schrift Variarum lectionum libri III, die seinen Ruhm als Philologe begründete. Im Gefolge des Kardinals Granvelle kam er 1568 nach Rom, wo sich inm bedeutende Bibliotheken öffneten und wo er den Umgang mit Marc-Antoine de Muret (1526-1585) und anderen führenden Humanisten seiner Zeit pflegte. Die Unterdrückung des niederländischen Aufstands durch Alba veranlasste inn 1572, eine Professur an der protestantischen Universität Jena anzunehmen. Dort beschäftigte er sich intensiv mit römischen Historikern und bereitete den Druck der neuen Tacitus-Ausgabe vor, die 1574 bei Plantin in Antwerpen erschien und erstmals die Historien und die Annalen mit vielen wichtigen Konjekturen in der Reihenfolge ihres Entstehens wiedergab. In unserem Zusammenhang ist es nicht unwichtig, dass das an Kaiser Maximilian II. gerichtete Vorwort mit den letzten Worten des zum Selbstmord genötigten Senators Thrasea Paetus ${ }^{24}$, der wegen seiner konservativen und freimütig vorgetragenen Gesinnung den Hass Neros auf sich gezogen hatte, einen aktuellen Bezug herstellte:

Tristia ex iis [den Annalen] pleraque, fateor, et legentibus maesta, sed singulis nostrum a Thrasea iam moriente dictum putemus ispecta, iuvenis, et omen quidem dii prohibeant, ceterum in ea tempora natus es quibus firmare animum expediat constantibus exemplis! ${ }^{25}$

Fraglos interessiert sich Lipsius für Geschichtsschreibung als historia magistra vitae ${ }^{26}$ : Die Antike bekommt unmittelbare Relevanz für das politische Handeln in der Gegenwart, wenn der neustoische Philosoph den tapferen Tod des Thrasea am Ende der Annalen paränetisch als Vorbild notwendiger constantia interpretiert.

Im Jahre 1581 lässt Lipsius historische und politische Erläuterungen zu den Annalen folgen. Seine philologische und historische Beschäftigung mit Tacitus mündet 1584 in einen eigenen philosophischen Dialog, der formal ganz dem humanistischen Diskurs verpflichtet ist. De constantia nimmt in Kürze und Prägnanz des Satzbaus stilistisch das Vorbild des Tacitus auf. Auch inhaltlich orientiert sich die im Dialog diskutierte Handlungsnorm an historischen Protagonisten des Tacitus wie Seneca, Helvidius und Thrasea, deren innere Autonomie und Todesverachtung sie über Herrscherwillkür und Schicksalsschläge erhob.

Es ist für die Entstehung des ıneuen Stoizismusı signifikant, dass Lipsius mit einem Traktat zur Ethik begann, 1604 mit seiner Manuductio ad stoicam philosophiam $^{27}$ eine logische Systematik folgen ließ und erst 1604 die naturphilosophischen Voraussetzungen des Stoizismus in der Physiologia Stoicorum formulierte. Schon bei den griechischen Begründern der Stoa und ihren kaiserzeitlichen Schülern Musonius, Seneca, Epiktet oder Marc Aurel stand die Moralphilosophie im Mittelpunkt, auf die Logik und Physik funktional ausgerichtet blieben. Fragen der Lebensführung stellten den wichtigsten Inhalt stoischen Philosophierens dar.

\footnotetext{
22 Lipsius schreibt an Johannes Woverius: ıAls erster oder sogar einziger meiner Generation habe ich die Musen zur Weisheit bekehrt, von der Philologie kam ich zur Philosophie.ı (Opera omnia, a.a.O., Bd. 2,1, S. 412-413)

${ }^{23}$ Ich stütze mich im Folgenden vor allem auf Oestreich, a.a.O., S. 49 ff.

${ }^{24}$ Ann. XVI,35,1

${ }^{25}$ >Die meisten Ereignisse in den Annalen sind, wie ich zugebe, schrecklich und betrüben die Leser. Allerdings sollten sich manche von uns durch die Worte des sterbenden Thrasea getroffen fühlen, der Folgendes sagte: "Schau hierher, junger Mann! Die Götter mögen verhüten, dass mein Tod ein Vorzeichen für dich ist. Doch bist du in eine Zeit hineingeboren, in der man sein Herz durch Beispiele standhaften Verhaltens stark machen muss."' (Lipsius, Justus: C. Cornelii Taciti Historiarum et Annalium libri qui exstant, Antwerpen1574, Einleitung, o.S.)

${ }^{26}$ Cicero, de oratore II,9,36

${ }^{27}$ Lipsius, Justus: Manuductio ad stoicam philosophiam libri tres, Opera omnia, a.a.O., Bd. 4,2, S. 613-832.
} 
Der Untertitel des Dialogs De constantia hatte ausdrücklich die moralistische Ausrichtung hervorgehoben, die dem Leser Hilfe in publicis malis bieten sollte. ${ }^{28}$ Fünf Jahre später richtete sich Lipsius in seiner politischen Hauptschrift Politicorum sive civilis doctrinae libri sex, qui ad principatum maxime spectant ausdrücklich an die politische Führungseliten, Kaiser, Könige und Fürsten ${ }^{29}$. Sein Vorwort weist darauf hin, dass sich die erste Schrift an Bürger (cives), die neue an Fürsten wendet: ${ }^{30}$

Quod nunc tibi damus, Politica esse vides. In quibus hoc nobis consilium, ut quemadmodum in Constantia cives formavimus ad patiendum et parendum, ita hic eos, qui imperant, ad regendum. ${ }^{31}$

Beide Werke wurden ein europäischer Erfolg, wie zahlreiche Drucke bezeugen: Man hat 48 Auflagen der Constantia und 53 der Politica gezählt. ${ }^{32}$ Hinzu kommen Übersetzungen beider Werke in niederländischer, französischer, englischer, deutscher, spanischer, italienischer und polnischer Sprache. Der Zeitraum der intensivsten Rezeption beider Schriften reicht von 1590 bis 1640, doch gehörten sie noch bis zum Beginn des 18. Jahrhunderts zum festen Kanon politischer und moralistischer Literatur. Als Lipsius 1605 am Ende seiner wissenschaftlichen und philosophischen Karriere seine Seneca-Edition abschloss, hatte er sein ins Philosophische gewandeltes philologisches Ziel erreicht.

Als 1637 in Antwerpen eine Gesamtausgabe des führenden Neustoikers erschien, inszenierte Cornelis Galle die Summe des editorischen und philosophischen Werks von Justus Lipsius in einem Titelkupferstich ${ }^{33}$ : Seneca und Tacitus flankieren als Hermen den Triumphbogen, unter dem der Titel erscheint. [Abb. 1] Über dem Schluss-Stein des Bogens erscheint in einem Lorbeerkranz das Brustbild des Lipsius mit seinem Lebensmotto moribus antiquis. Vor der Herme des Seneca sitzt, gerüstet mit Helm und Schwert, die Allegorie der Virtus, assistiert von der hinter ihr stehenden Minerva. Auf der Seite des Tacitus sitzt eine Allegorie der doppelgesichtigen Prudentia, die in der rechten Hand eine Schlange hält, während sie die linke auf das Glücksrad stützt. Hinter ihr steht Merkur. Über allem thronen die Personifikationen der Philosophie und der Politik. Die als alte Frau dargestellte Philosophie ist mit Löwenfell und Herakles-Keule ausgestattet und hält die einflussreichsten Werke des Lipsius unter dem Arm: Stoica und Constantia. Die Personifikation der Staatskunst (Politica) ist als jüngere Frau mit Speer, Ruder und Erdkugel dargestellt. So erfasst der Titelkupferstich den ganzen Spannungsbogen der produktiven Rezeption der antiken Stoa durch

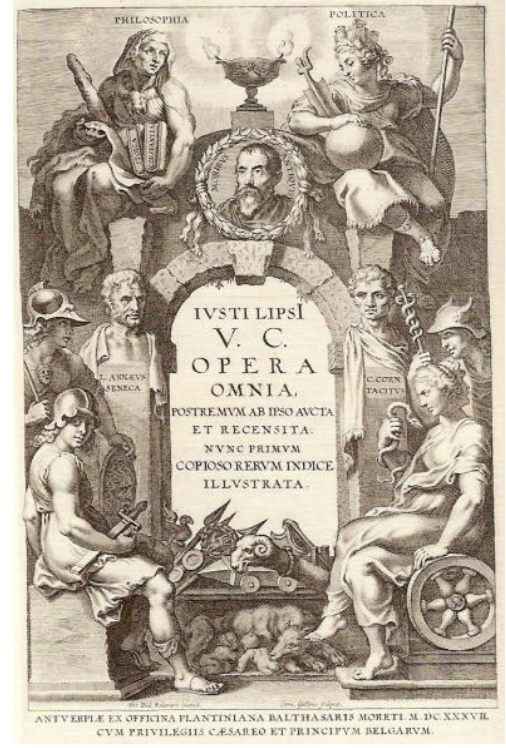

Abb. 1

Justus Lipsius: sie hat einerseits (unter frühneuzeitlichen Bedingungen) den Einzelnen und seine Seelenruhe im Auge und bedenkt andererseits das Zusammenleben im entstehenden modernen Staat so, dass dem Individuum Spielräume gewährt werden.

\footnotetext{
${ }^{28}$ Libri duo qui alloquium praecipue continent in publicis malis

${ }^{29}$ Monita et exempla politica, Opera omnia, a.a.O., Bd. 4,1, S. 2.

${ }^{30}$ Lipsius: Politica, Opera omnia, a.a.O., Bd. 4,1, S. $125 f$.

31 ,Wir legen jetzt, wie man sieht, eine Abhandlung über Regierungskunst (Politica) vor. Wenn es uns in der Schrift über Standhaftigkeit (Constantia) darum ging, Bürger zu Geduld und Gehorsam anzuleiten, geht es uns hier darum, Fürsten in der Regierungskunst zu unterweisen.ı

${ }^{32}$ Oestreich, a.a.O., S. 213-218.

${ }^{33}$ Vgl. Morford, Mark: Stoics and Neostoics, Rubens and the Circle of Lipsius, Princeton 1991, Abbildung 17.
} 


\section{Der Neustoizismus: Leitphilosophie der Frühen Neuzeit}

\section{Die meditatio mortis im neustoischen Denken}

[Überkonfessionelle Ethik des Neustoizismus] Der Erfolg des Neustoizismus bei den frühneuzeitlichen Eliten liegt darin begründet, dass er eine überkonfessionelle, innerweltliche Ethik formulierte, die im frühneuzeitlichen konfessionellen ıBürgerkriegく von allen Seiten akzeptiert werden konnte. Es ist für den Jesuitenzögling Lipsius bezeichnend, dass er kontroverstheologischen Streitfragen keine Beachtung schenkte und häufig die Konfession wechselnd über das Luthertum und den Kalvinismus zum Katholizismus zurückkehrte. Dass er theologischen und konfessionelIen Argumenten keine Bedeutungen beimaß, wurde inm deshalb vor allem von den Jesuiten vorgehalten. ${ }^{34}$ Gerade ihre konfessionelle Unbestimmtheit und Indifferenz machte die neustoische Ethik aber als Leitphilosophie der europäischen Eliten aller Konfessionen attraktiv. Ihr unterschwelliger Pantheismus und ihre abstrakten anthropologischen Normen sapientia, constantia und ratio ${ }^{35}$ unterliefen gleichsam die >offiziellen` Bekenntnisse. ${ }^{36}$ So ist es nicht überraschend, dass sich bei Lipsius ganz in der Tradition der antiken Stoa gelegentlich latent pantheistische Wendungen finden: »Nec praeest solum divinitas haec rebus omnibus, sed interest, imo inest. $\ll 37$

Das Hauptwerk des Lipsius, der Dialog De constantia, verdankt seine epochale Wirkung als Kompendium für Philosophen, Dramenautoren und Künstler nicht zuletzt dem Umstand, dass es stoische Philosopheme frühneuzeitlicher Welterfahrung adaptierte und seinen Lesern aktuelle Anknüpfungspunkte und Identifikationsangebote bot. Die Editionen und Kommentare des Lipsius aktualisierten die Grundthesen der stoischen Philosophie in der durch Konfessionsstreitigkeiten geprägten Zeit und entwickelten eine privaten und öffentlichen Bereich zum ersten

\footnotetext{
${ }^{34}$ ilm Vorwort der zweiten Auflage seiner Constantia ging Lipsius auf diesen Vorwurf ein: »Negant satis pie hoc argumentum a me tractum« (`Sie sagen, dieses Problem sei von mir nicht fromm genug behandelt worden $)$. Als christlicher Philosoph (»Philosophum ego agam, sed Christianum«) trage er seinen Glauben nicht auf der Zunge, sondern im Herzen (»Sum enim ex iis, quibus pietas in corde magis quam in ore «). (De constantia, Opera omnia, a.a.O., Bd. 4,2, S. 511-612, hier S. 513) (Verweise auf De constantia werden im Folgenden nur noch mit Buch- und Kapitelangabe gemacht).

35 »Rationi origo a caelo, imo a deo est: et magnifice eam Seneca celebravit, >Partem in homine divini spiritus mersam.« (〉Die ratio hat ihren Ursprung im Himmel, ja in Gott selbst, wie Seneca dies sehr schön sagt, wenn er sie einen Teil des göttlichen Geistes nennt, der in den Menschen eingegangen ist. $)$ (De constantia, I,5)

${ }^{36} \mathrm{Im}$ Übrigen darf nicht übersehen werden, dass Lipsius nicht nur auf die Stoa, sondern synkretistisch auch auf aristotelische und platonische Philosopheme zurückgriff, die Lipsius seiner anthropologischen Zielsetzung dienstbar machte. (Dazu: Beuth, Karl: Weisheit und Geistesstärke, Eine philosophiegeschichtliche Untersuchung zur ,Constantia des Justus Lipsius, Frankfurt/Main / New York 1990.) So übernahm er die platonische Trennung von anima und corpus und interpretierte den Tod als Loslösung der Seele von ihrer leiblichen Hülle. Dazu etwa das Anknüpfen an Phaidon (64 b-c) in De constantia II,19 ("Simplex mors. Et ne nomen ipsum te terreat, animae a corpore abscessus. « [〉Der Tod ist etwas Einfaches. Sein Name soll dir keine Angst machen, er bezeichnet die Trennung der Seele vom Körperı]).

37 ,Das Göttliche lenkt nicht nur alles, sondern ist an allem beteiligt, wohnt sogar allem inne.ı (De constantia $\mathrm{I}, 13)$
} 
Mal grundsätzlich unterscheidende Ethik. Eine ihrer Wirkungen war, dass im 16. und 17. Jahrhundert die stoischen Begriffe prudentia und sapientia, verstanden als Staatsräson und als vernünftige Lebensführung, eng mit Seneca und Tacitus verbunden blieben. ${ }^{38}$ Allerdings wurden die antiken Normen allmählich so sumbesetztı, dass sie das Bedürfnis der frühneuzeitlichen Eliten nach einer handlungsorientierenden Ethik erfüllten. ${ }^{39}$ In allen europäischen Ländern belegen zahlreiche Traktate das Interesse für die zentralen Themen der neustoischen Philosophie. In Frankreich ist vor allem Guillaume du Vair (1556-1621) ${ }^{40}$ zu nennen, dessen Werkausgaben in der ersten Hälfte des 17. Jahrhunderts elf Auflagen erlebten. ${ }^{41}$ In Deutschland sind besonders Kaspar Schoppe (1576-1649) ${ }^{42}$, in Spanien Francisco de Quevedo (1580-1645) ${ }^{43}$ und in England Thomas Gataker (1574-1654) ${ }^{44}$ hervorzuheben.

[Affektkontrolle] Der Neustoizismus bot dem Einzelnen im durch religiöse und politische Auseinandersetzungen geprägten frühneuzeitlichen Europa eine intellektuelle Möglichkeit, den Konflikten der Konfessionsstreitigkeiten zu entgehen, auch wenn er nicht wie Lipsius mehrfach emigrieren musste:

Itaque non patria fugienda, Lipsi, sed adfectus sunt, et firmandus ita formandusque hic animus, ut quies nobis in turbis sit et pax inter media arma. ${ }^{45}$

Die von den Neustoikern propagierte Affektkontrolle gilt nicht zu Unrecht als Voraussetzung der entstehenden höfischen Gesellschaft der Frühen Neuzeit. ${ }^{46}$ Den Zwängen der von den Religionsstreitigkeiten geprägten frühmodernen Gesellschaf-

\footnotetext{
38 »Licebit in hoc $\sigma \varepsilon \mu v u ́ v \varepsilon \sigma \theta$ aı, quod duos optimos auctores protraxerim et lucem dederim Tacito et Senecae, illi ad prudentiam, huic ad sapientiam duci? « (sich darf mich rühmen, zwei vorzügliche Schriftsteller wieder entdeckt und ans Licht gebracht zu haben, nämlich Tacitus und Seneca, ersteren als Führer zur politischen Klugheit, letzteren als Führer zur Weisheit.ı) Aus einem Brief an die Brüder Guilielmus und Antonius Richardotus; Opera omnia, a.a.O., Bd. 2,2, S. 902)

${ }^{39}$ Richard Tuck hat die philosophisch-politischen Entwicklungslinien von Lipsius und Montaigne über Hugo Grotius, Thomas Hobbes zu Kant nachgezeichnet (Tuck, Richard: Philosophy and Government 1572-1651, Cambridge 1993).

${ }^{40}$ Philosophie morale des Stoiques (1599) und Traité de la constance et consolations ès calamitéz publiques (1595).

${ }^{4}$ Seine Wendung zum Stoizismus (La Philosophie morale des stoïques [1599]) ist durch die Erfahrungen der Religionskriege veranlasst. Noch seine Philosophie saincte (1588) ist stoisch beeinflusst, obwohl er sie bereits als Bischof schrieb. Vgl. Oestreich, a.a.O., S. 94-94.

${ }^{42}$ Elementa philosophiae stoicae moralis (1606).

${ }^{43}$ La cuna y la sepultura para el conocimiento proprio y desengano des las cosas ajenas (1634) und Nombre, origen, intento, recomendación y descendencia de la doctrina estoica (1635).

${ }_{44}$ De disciplina stoica (1652).

45 ,Deshalb darf man nicht die Emigration als Ausweg wählen [...], sondern muss die Affekte unter Kontrolle halten. Und diese Einstellung sollte so stark ausgebildet werden, dass für uns mitten im Kriegsgetümmel Ruhe und mitten unter den Waffen Frieden herrscht. ( De constantia I,1)

${ }^{46}$ Norbert Elias hat in seiner soziogenetischen Untersuchung Über den Prozeß der Zivilisation (2 Bde, Frankfurt/Main ${ }^{1} 1976$, besonders Bd. 2, S. 312-341) die zunehmende Steuerung der Affekte und die daraus resultierende Transformation von Gesellschafts- und Persönlichkeitsstrukturen untersucht.
} 


\section{Der Neustoizismus: Leitphilosophie der Frühen Neuzeit}

ten stellen die Neustoiker ein in sich gefestigtes Individuum gegenüber, dessen constantia von Lipsius bezeichnenderweise meist mit Metaphern umschrieben wird, die Senecas Diktum »vivere militare est « ${ }^{47}$ aufgreifen und die vernünftige Lebensführung mit Krieg und Militärdienst vergleichen ${ }^{48}$. Wie bei den Stoikern der Antike gelten Affekte wie Angst, Wut und Mitleid als verdächtig und bedürfen der Steuerung ${ }^{49}$ : Es gilt, die Affekte durch strenge Rationalität zu domestizieren und zu kontrollieren und damit innere Ruhe und Beständigkeit des Lebensentwurfs durch rationale Orientierung des Handelns zu gewinnen. »Voluntas et intellectus unum et idem sunt ${ }^{50}$ wird es Spinoza später auf den Begriff bringen.

Philosophie wird dergestalt zur praktischen Handlungsanweisung und Lebenshilfe $^{51}$; die durch Affektkontrolle gewonnene innere Freiheit ist nie endgültiger Besitz, sondern muss stets neu errungen werden, da politische Rahmenbedingungen (fatum und necessitas) beständig die Handlungsfreiheit des sich seiner bewusst werdenden Individuums bedrohen. Auf die epochale Erfahrung ständig neuer Kontingenz reagiert der Neustoiker nicht mit Apathie und Resignation, sondern mit aktivem und selbstbestimmtem Handeln. ${ }^{52}$ „Necessitate autem nihil fortius est « ${ }^{53}$ : Gerade weil er sich den Zwängen der politischer Rahmenbedingungen nicht widersetzt, handelt er selbstbestimmt:

Necessitatis non aliud effugium est, quam velle quod ipsa cogat. Eximie eximius ille Sapientum: sInvictus esse poteris, si in nullum certamen te dimittes, quod in te non est vincere. $i^{54}$

\footnotetext{
47 „Atqui vivere, Lucili, militare est. « (২Leben heißt freilich, Kriegsdienst leisten, mein Lucilius.ı) (Epistulae morales 96,5$)$; "Nobis quoque militandum est, et quidem genere militiae quo numquam quies, numquam otium datur: debellandae sunt in primis voluptates. " (>Auch wir müssen Kriegsdienst leisten, und zwar so dass niemals Ruhe, niemals Muße eintritt: vor allem die Affekte müssen bekämpft werden.ı) (Epistulae morales 51, 6)

48 "Miles in castris, audito viae signo, vasa colligit; audito pugnae, deponit; animo, oculis, auribus, paratus ad omne imperium et intentus. Idem nobis sit, et in hac militia sequamur alacres et pleno gradu quocumque vocantem Imperatorem. « (>Der Soldat im Lager sammelt beim Marschsignal das Gepäck zusammen, setzt beim Kampfsignal das Gepäck ab; aufmerksam und mit allen Sinnen achtet er auf jeden Befehl. So sollten auch wir uns verhalten und in diesem Kampf engagiert und im Sturmschritt dem Befehlshaber folgen, wohin immer er ruft.ı) (De constantia I,15)

49 "Sicut bonae plantae in feraci agro, si negligantur, sylvescunt et horrescunt: cultura adhibita, utiles et fructiferae fiunt: sic affectus. "(>Wie gute Pflanzen auf einem fruchtbaren Acker verwildern und unfruchtbar werden, wenn sie vernachlässigt werden, aber nützlich und fruchttragend sind, wenn sie Pflege erhalten, verhält es sich auch mit den Affekten.८) (Manuductio ad stoicam philosophiam, Opera omnia, a.a.O.,Bd. 4,2, S.613-821, hier: III,7, S. 698f.)

${ }^{50}$,Wille und Vernunft sind ein und dasselbe.ı (Ethica II prop. 49, leicht verfügbar über [zuletzt aufgerufen: 13.02.2007]: http://www.thelatinlibrary.com/spinoza.ethica2.html)

51 "Nihil palpat ille medicus, nihil blanditur: sed penetrat, pungit, radit, et acri quodam sermonum sale sordes absterget animorum« (〉Der [Philosoph als] Arzt schmeichelt nicht, liebkost nicht: sondern dringt ein, sticht, schneidet aus und entfernt mit dem scharfen Salz der Ermahnung die Schlacken des Herzens.ı) (De constantia I,10)

52 "Arma adversum haec indue, et arripe hoc fatale telum. (〉Bewaffne dich dagegen und nimm diese todbringende Waffe. $)$ (De constantia I,21)

${ }_{53}$,Nichts ist stärker als die Notwendigkeitı. (De constantia I,21)

54 ,Der Notwendigkeit entgeht man nur, wenn man will, wozu sie ohnehin nötigt. Ein bekannter Denker [Seneca] hat es treffend ausgedrückt: ,Du kannst nur unbesiegt bleiben, wenn du dich nicht auf Kämpfe einlässt, die nicht zu gewinnen sind.'` (De constantia I,21)
} 
Standhaftigkeit (constantia) ${ }^{55}$ wird so zur wichtigsten Leistung (১Tugend $)$ ), die das entstehende Individuum charakterisiert: sie steht für geradlinige Lebensführung, Ruhe und Festigkeit in der Verfolgung des Lebensentwurfs, Besonnenheit in der Affektabwehr, beharrliches Verfolgen von Zielen, konsequentes Verhalten und Charakterfestigkeit. Die Leittugend der constantia unterstützt das Individuum im nicht endenden Kampf gegen die vier Hauptaffekte cupiditas, gaudium, metus und dolor (Begierde, Freude, Furcht, Schmerz) und hilft dem Bürger Kriege und Katastrophen (bellum, pestis, fames, tyrannis und caedes) zu ertragen. Eine bemerkenswerte Leistung des Neustoizismus, die seinen Erfolg in der Frühen Neuzeit erklären mag, war die Umbesetzung spätantiker Begriffe (etwa der `Tugenden` und 'Laster(): verteidigten sie ursprünglich die moralische Autonomie des Philosophen gegenüber dem kaiserzeitlichen Ausschließlichkeitsanspruch des Staates, werden sie im beginnenden Konfessionszeitalter zu einer ersten Möglichkeit, gegenüber den entstehenden, moralische Ausschließlichkeit beanspruchenden modernen Staaten die Rechte des Individuums zu formulieren. Gleichzeitig definieren sie das Selbstbewusstsein der sich allmählich formierenden Funktionseliten der entstehenden modernen Staaten. In beiden Besetzungen werden die ıTugendkataloge، in Literatur und bildender Kunst übernommen.

[Lipsius und der Selbstmord] Für die Fragestellung dieser Untersuchung ist vor allem von Gewicht, dass die vom Neustoizismus propagierte Stärkung der Identität des Individuums zu einer differenzierten Beurteilung des moralisch begründeten Selbstmords führte, die sich auch in der frühneuzeitlichen Ikonographie des Philosophentods und der profanen Tugendheldinnen wiederfindet. Dieser Aspekt des Neustoizismus dürfte geradezu eine Voraussetzung des ikonographischen Motivs der Tugendheldin sein.

Lipsius selbst scheint sich in der in seinen Leidener Jahren erarbeiteten Schrift Thrasea sive de mortis contemptu ausführlich zum Selbstmord geäußert zu haben, wagte es allerdings nicht, die Abhandlung zu veröffentlichen. ${ }^{56}$ Gleichwohl

\footnotetext{
$55 »[. .$.$] constantiam hic appello, rectum et immotum animi robur, non elati externis aut fortuitis, non depressi «$ (>lch begreife Standhaftigkeit als einsichtige und unerschütterliche innere Kraft, die sich von Äußerlichem oder Zufälligem weder übermütig machen noch niederdrücken lässt.ı) (De constantia I,4)

${ }^{56}$ Lipsius weist in einer Randnotiz zu De constantia $(I I, 19)$ selbst auf die geplante Schrift hin: »Plura nos huius rei in Thrasea nostro sive De contemptu mortis « (>Mehr zu diesem Thema in meiner Schrift Thrasea oder Über die Verachtung des Todes $\iota)$. Der Index der Gesamtausgabe von 1675 vermerkt, dass der Dialog von Lipsius zwar geschrieben, aber nicht veröffentlicht wurde (»Thrasea, Dialogus de contemptu mortis, a Lipsio scriptus, sed ab ipso suppressus«). Dazu Etter, a.a.O.,S. 137.
} 


\section{Der Neustoizismus: Leitphilosophie der Frühen Neuzeit}

lassen sich seine Thesen rekonstruieren, da er sie an anderer, unauffälligerer Stelle hinreichend klar angedeutet hat. Angesichts der zwischen den Konfessionen unstrittigen Ablehnung des Selbstmords war es durchaus nicht ungefährlich, das Thema zur Sprache zu bringen. Andererseits begründete in der antiken Stoa die moralische Autonomie des Individuums und der damit verbundene Ausweg des Selbstmords die Widerstandsmöglichkeit gegenüber der Tyrannenwillkür und nahm deshalb einen wichtigen Platz in der stoischen Ethik ein.

Nicht immer lässt sich der subversive Charakter neustoischer Umbesetzungen traditionaler christlicher Wertungen auf den ersten Blick erkennen. Wenn Lipsius einen fiktiven Gesprächspartner ${ }^{57}$ tröstet, der die Nachricht vom Tod eines gemeinsamen Freundes überbringt, erscheint Sterben geradezu wünschenswert und gilt, ganz den Auffassungen der vorchristlichen Stoa entsprechend, als Zufluchtsort vor den Übeln der Welt:

Profecto illa [i.e.: mors] medicina morborum, refugium et asylum malorum est: et in mundi his fluctibus portus, quem sapiens numquam fugiat, imo (Deo vocante) totis velis in eum feratur. ${ }^{58}$

Der paränetische Kontext und ein flüchtiger rhetorischer Gottesbezug verdecken, dass die Wünschbarkeit des Todes die Billigung des Freitodes wohl einschließt. Gerade weil es sich um eine beiläufige Äußerung handelt, dürfte sie die neustoische Grundposition wiedergeben. An anderer Stelle ${ }^{59}$ finden sich vergleichbare Wendungen: Wie alle Umstände und Gefahren, die die moralische Identität (constantia) des Menschen bedrohen, zählt der Tod zu den indifferentia, denen mit Gleichmut zu begegnen ist und die den Kernbereich der Identität nicht berühren. ${ }^{60}$ Erst die ständige Meditation des Todes ${ }^{61}$ lässt die notwendige Distanz der Lebens-

\footnotetext{
${ }^{57}$ De magnitudine Romana, in: Opera Omnia, a.a.O., Bd. 3,2, S. 655-864, hier: 810.

58 ,In Wirklichkeit ist der Tod ein Heilmittel aller Krankheiten, Zuflucht und Asyl vor Übeln und ein vor den Fluten dieser Welt [schützender] Hafen, den der Weise niemals scheuen soll, in den er vielmehr, wenn Gott ihn ruft, mit vollen Segeln einfahren sollte.r

59 "Duo sunt, quae arcem hanc in nobis constantiae oppugnant, falsa bona, falsa mala. Utraque sic appello, quae non in nobis sed circa nos, quaeque in interiorem hunc hominem, id est animum, proprie non iuvant aut laedunt. [...] In priori classe numerant opes, honoris, potentiam, sanitatem, longaevitatem, in posteriore inopiam, infamiam, impotentiam, morbos, mortes: et ut verbo uno complectar, quidquid aliud fortuitum aut externum. « (De constantia I,7) (২Zwei Dinge belagern gewissermaßen das Bollwerk unserer constantia, vermeintliche Güter und vermeintliche Übel. Beide bezeichne ich so, da sie nicht in uns sind, sondern uns umgeben und da sie den inneren Menschen - den Geist - nicht wirklich unterstützen oder schädigen [...]. Zu der Gruppe der vermeintlichen Güter zählen Reichtum, Ansehen, Macht, Gesundheit, langes Leben, zur Gruppe der vermeintlichen Übel Not, mangelndes Ansehen, eine einflusslose gesellschaftliche Stellung, Krankheiten und Tod. Um es mit einem Wort zusammenzufassen: dies alles sind zufällige und außerhalb des Menschen liegende Dinge.ı)

60 „Causae communes, quia vitae haec inter indifferentia est, itemque ipsa mors. " (>Allgemeine Gründe, warum dieses Leben zu den unwichtigen Dingen gehört, selbst der Tod.८) Manuductio ad stoicam philosophiam III,22 in: Opera omnia, a.a.O., Bd. 4,2, S. 808-813.

61 "Incertum est, quo te loco mors exspectet: itaque tu illam omni loco exspecta. Philosophia autem, ut tetigi, eo ducet et hanc meditationem, et ab ea robur animo tuo indet. « ( Es ist ungewiss, wo dich der Tod erwartet:
} 
führung gewinnen: »mori, quod faciendum semel, cogitandum saepe. « ${ }^{62}$ Der Tod ist nicht mehr Anlass zu Umkehr und Buße, die stets zur Verfügung stehende Möglichkeit des Todes ist vielmehr die Garantie individueller Freiheit. Unvermerkt besetzt Lipsius so das christliche memento mori um, obwohl die Konsequenzen für die stoische Lebensführung durchaus christlich akzentuiert werden. Gerade dadurch verdeckt er seine implizite Billigung des Freitods.

[profane meditatio mortis] Mehrere Abschnitte der Manuductio ad stoicam philosophiam $^{63}$ entwickeln unter Rückgriff auf antike Exempel geradezu eine profane meditatio mortis ${ }^{64}$, die christliche und neustoische Gedankengänge so eng verknüpft, dass die Umbesetzungen zunächst gar nicht auffallen. Dem Zustand vor der Geburt vergleichbar, ist der Tod nichts Schreckliches, obwohl er den Menschen unaufhörlich beschäftigt. ${ }^{65}$ Gilt das Sterben des Sokrates ${ }^{66}$ immer wieder als vorbildlich, beruft sich Lipsius zur philosophischen Begründung vor allem auf Seneca:

Vivere tota vita discendum est, et quod magis fortasse miraberis, tota vita discendum est mori. Idem alibi: Egregia res est mortem condiscere. Meditare mortem: qui hoc dicit, meditari libertatem iubet. ${ }^{67}$

Auf den ersten Blick stellt Lipsius ganz im Sinn der christlichen Tradition die meditatio mortis in den Mittelpunkt, wobei er allerdings die Leitbilder dieser Lebensführung in der vorchristlichen Antike sucht und damit das christliche memento mori unterläuft. Diese vorsichtige Sprachregelung erlaubt eine implizite Umbesetzung des Verhältnisses zum Tod und die Erweiterung des Freiraums individueller Selbstbestimmung bis hin zum Selbstmord, wie sie bereits der Titel der Abhand-

erwarte inn deshalb überall. Die Philosophie aber wird dich, wie erwähnt, zu ihm führen und dir mit diesen Überlegungen Stärke verleihen.ı) Physiologiae stoicorum II,1 in: Opera omnia, a.a.O., Bd. 4,2, S. 895f.

62 Physiologiae stoicorum II,1, in: Opera omnia, a.a.O., Bd. 4,2, S. 895f.

${ }^{63}$ Manuductio ad stoicam philosophiam III,22 und 23 in: Opera omnia, a.a.O., Bd. 4,2, S. 808-818.

64 "Sed et est alia definitio, si non Stoicorum, digna ipsis: philosophiam esse meditationem mortis. " (Manuductio ad stoicam philosophiam II,2 in: Opera omnia, a.a.O., Bd. 4,2, S. 685f.) (>Aber es gibt noch eine andere Definition, die zwar nicht von den Stoikern stammt, aber ihrer würdig ist: Philosophie ist das Bedenken des Todes. 1 )

65 »At ego mortem diu expertus sum. Quando? Antequam nascerer: Mors est non esse; id quale sit, iam scio «. (Physiologiae stoicorum III,11 in: Opera omnia, a.a.O., Bd. 4,2, S. 989-992) (>Aber ich habe den Tod schon lange kennen gelernt. Wann? Vor meiner Geburt: der Tod bedeutet ein Nicht-Sein, das ich bereits kenne.८)

66 »Praeit et huc Socrates apud Platonem: Quicumque philosophiae studium recte et vere sunt amplexi, etsi nesciunt hoc alii, aliud nihil cogitant et student, quam abire et mori. « (Manuductio ad stoicam philosophiam II,2 in: Opera omnia, a.a.O., Bd. 4,2, S.685f.) (>Auch dies hat bereits der platonische Sokrates [im Phaidon] vorweggenommen: Wer das Studium der Philosophie richtig und ernsthaft ergriffen hat, beschäftigt sich ausschließlich mit dem Abschied und Sterben, auch wenn dies anderen unverständlich ist.ı)

67 , Leben muss man lebenslang lernen, und was noch erstaunlicher ist: Man muss das ganze Leben lang lernen zu sterben. An anderer Stelle sagt Seneca: Es ist wichtig, den Tod zu lernen. Wer über den Tod nachdenken lässt, fordert dazu auf, über die Freiheit nachzudenken.ı - Weiteres in Manuductio ad stoicam philosophiam II,2, wo Lipsius aus De brevitate vitae (107) und den 26. Brief der Epistuale morales zitiert. 


\section{Der Neustoizismus: Leitphilosophie der Frühen Neuzeit}

lung ankündigt: »Sapientem sumere aliquando mortem posse, decere, debere: ex Stoico quidam decreto. « 68

Werden Autonomie und freier Willen als oberstes Ziel der stoischen Lebensführung bedroht, kann der Freitod moralisch gerechtfertigt sein:

Sapiens vivit quantum debet, non quantum potest. Videbit ubi victurus sit, cum quibus, quomodo, quid acturus. Si multa occurrunt molesta et tranquillitatem turbantia, emittit se; nec hoc tantum in necessitate ultima facit, sed cum primum illi coepit suspecta esse fortuna. Nihil existimat sua referre, faciat finem an a c cipiat. ${ }^{69}$

Äußere Umstände (necessitas), Krankheit, Alter, Armut oder politischer Druck können die Autonomie des Einzelnen bedrohen und einschränken. Wird dabei die eigene Identität bedroht, darf auch der Selbstmord in Erwägung gezogen werden. Zu dieser Entscheidung gibt es allerdings keine klare Grenzziehung, da der Ermessensspielraum subjektiv ist und eine die persönliche Freiheit bedrohende Situation ganz unterschiedlich bewertet werden kann. Die frühneuzeitliche Wertung der persönlichen Freiheit und Verantwortung des Individuums ${ }^{70}$ wird erneut deutlich und steht im Zentrum der neustoischen Philosophie, die zwischen einem natürlichen und einem selbstgewählten Tod nicht grundsätzlich unterscheidet: das Leben ist einem Gastmahl vergleichbar, das man auch verlassen darf, wenn sich dadurch die Willensfreiheit retten lässt. ${ }^{71}$

68 ,Nach Auffassung eines gewissen Stoikers [Senecas] kann, darf und muss ein Philosoph unter bestimmten Umständen den Tod wählen.ı (Manuductio ad stoicam philosophiam III,22 in: Opera omnia, a.a.O., Bd. 4,2, S. 808-813) Die Todesarten sind dabei vielfältig: »Unam nascendi viam natura dedit, mille moriendi. « (Manuductio in stoicam philosophiam III,22 in: Opera omnia, a.a.O., Bd. 4,2, S. 808-813) (>Einen einzigen Weg, geboren zu werden, hat die Natur vorgesehen, tausend, um zu sterben.ı)

69 ,Der Philosoph lebt, solange er muss, nicht solange er kann. Er achtet darauf, wo, mit wem, auf welche Weise er lebt und was er tut. Begegnet inm viel Beschwerliches, das seine innere Ruhe stört, ergreift er für sich selbst die Freiheit, nicht erst in äußerster Bedrängnis, sondern sobald ihn das Glück verlässt. Es is $t$ für ihn ohne Bedeutung, ob er sein Ende herbeiführt oder es annimmt. ( (Manuductio ad stoicam philosophiam III,22 in: Opera omnia, a.a.O., Bd.4,2, S. 808-813) Lipsius zitiert an dieser Stelle Passagen aus Senecas 70. Brief an Lucilius.

70 „Malum est in necessitate vivere; sed in necessitate vivere, necessitas nulla est«. (〉Es ist ein Übel, in Bedrängnis zu leben; aber es ist nicht notwendig, in Bedrängnis zu leben.८) Lipsius zitiert hier den 12. Brief des Seneca. »Et nonne haec (libertas dico) finis aut fructus sapientiae est?« (〉Und liegt nicht darin (in der Freiheit) das Ziel und der Ertrag des Philosophierens?) (Manuductio ad stoicam philosophiam III,22 in: Opera omnia, a.a.O., Bd.4,2, S. 808-813)

71 „Sicut a convivio satur possum surgere et abire, ludum, cum libet, relinquere, tale hic esse. Epictetus: Cui enim licet, cum lubet, a convivio discedere, neque ultra ludere: etiamne is manens affligitur et nauseat? Non potius, ut ludo, interest quamdiu oblectatur? Modus tantum et occasio has res temperant: neque interest multum, mors ad nos veniet, an ad illam nos. " (Manuductio ad stoicam philosophiam III,22 in: Opera omnia, a.a.O., Bd.4,2, S. 808-813) (>Wie ich gesättigt von einem Gastmahl aufstehen und weggehen darf oder ein Spiel verlassen, wenn ich es mag, so verhält es sich auch hier. Wem sollte es (nach Epiktet) nicht erlaubt sein, nach Belieben ein Gastmahl zu verlassen und sich nicht weiter am Spiel zu beteiligen, wenn er sonst unglücklich und krank würde? Ist es nicht besser, nur so lange mitzuspielen, wie es gefällt? Nur die zufälligen Umstände regeln diese Dinge, und es ist kein großer Unterschied, ob der Tod zu uns kommt oder wir zu ihm.८) Auch wenn andere Todesarten nicht ausgeschlossen werden, bleiben der durch Sokrates nobilitierte Giftbecher und das von Seneca legitimierte Öffnen der Venen bevorzugte Formen des philosophischen Freitods: Quaeris igitur, quod sit ad libertatem iter? Quaelibet in corpore tuo vena. (>Du fragst also, welchen Weg es zur Freiheit gibt? Jede beliebige Vene in deinem Körper.ı [Manuductio ad stoicam philosophiam III,22 in: Opera omnia, a.a.O., Bd.4,2, S. 808-813]) 
Wenn Lipsius seine Überlegungen mit einer scheinbaren Distanzierung von der stoischen Position zum Selbstmord abschließt und die christliche Position der Unverfügbarkeit des Lebens zitiert, geht es inm wohl mehr darum, den provokativen Gedankengang für das konfessionelle Umfeld abzuschwächen und zu relativieren:

Mortem arbitrii nostri non esse: nec Stoicis me, hac parte, suffragium dare. ${ }^{72}$ Die Einschränkung, demonstrativ ans Ende des Kapitels und für den kritischen Blick des Zensors signifikant hervorgehoben, kann allenfalls als oberflächliche und formale Konzession an kirchliche Positionen gewertet werden. Allzu ausführlich wird die stoische Haltung zum Selbstmord in Form aneinander gereihter Paradoxa und unter Zitierung vieler Beispiele aus der Antike dargelegt und dem Leser der Freitod als exemplarische, ein selbstbestimmtes Leben krönende Entscheidung vor Augen geführt, als dass die Behauptung Glauben finden könnte, die Theologen selbst verträten unterschiedliche Auffassungen:

Quid autem nostri hic theologi? Firmiter nescio et audio in scholis dissentire. ${ }^{73}$ Der theologischen Korrektheit wird Genüge getan, gleichzeitig die stoische Lehrmeinung in aller Ausführlichkeit dargestellt. Dieses Verfahren ermöglichte es Lipsius, den Freitod in seinem Handbuch stoischen Philosophierens zu enttabuisieren, mit unübersehbaren Folgen für die Ästhetik des frühneuzeitlichen Dramas und für die Ikonographie des Historienbildes.

[Christliche und profane Tugendhelden] Unter dem Gesichtspunkt der moralischen Selbstbehauptung (constantia) wurde an der Schwelle zur Neuzeit der frei gewählte oder akzeptierte Tod der Tugendhelden mit dem Bekenntnistod der Märtyrer vergleichbar. So gelten Lipsius antik-profane und christlich-moderne Exempla stugendhaften Verhaltensı als völlig gleichwertig; er zitiert zur Illustration der constantia die üblichen antiken Modelle, greift in der >christlichen Moderne` aber ganz selbstverständlich auf christliche Herrscher und auf Märtyrerlegenden zurück. Dem neustoischen Philosophen gilt Affektkontrolle und mutiges Sterben, seien sie stoisch oder christlich motiviert, in gleicher oder doch vergleichbarer Weise als vor-

\footnotetext{
72: >Der Tod steht nicht in unserem Ermessen: in diesem Teilbereich kann ich den Stoikern meine Zustimmung nicht geben.ı (Manuductio ad stoicam philosophiam III,23 in: Opera omnia, a.a.O., Bd.4,2, S.814-818)

73 ,Was aber sagen hierzu unsere Theologen? Zuverlässiges kenne ich nicht und höre, dass sie unterschiedliche Auffassungen vertreten.ı (Manuductio ad stoicam philosophiam III,23 in: Opera omnia, a.a.O., Bd.4,2, S.814-818)
} 
bildlich: »Ad Christiana et nostra exempla tutius transeo, quae in sanctis viris et martyribus sunt infinita. ${ }^{74}$

So geht Lipsius in seinen Monita et exempla politica ausführlich auf Herrschertugenden und Herrscherlaster (»virtutes et vitia principum «) ein und versammelt Beispiele mustergültiger constantia, die auf der frühneuzeitlichen Bühne und in der Historienmalerei oft aufgegriffen wurden. ${ }^{75}$ Ausführlich rühmt er Cato, der stets die republikanische Sache gegen Cäsar verteidigt und am Ende sogar den Tod gewählt hat, um nicht der Tyrannei zu erliegen. Bemerkenswert ist, dass auch das heroische Verhalten seiner Tochter Porzia in diesem Zusammenhang genannt wird. ${ }^{76}$ Lipsius referiert die bekannte Anekdote, sie habe sich die Verschwörung ihres Mannes gegen Cäsar vermutend mit dem Messer verletzt, um ihre Selbstbeherrschung zu erproben. Lipsius dramatisiert die Szene in einem Monolog, in dem Porzia Brutus ihre Ebenbürtigkeit demonstriert. ${ }^{77}$ Die stoische Tugendheldin ist bereit, Schmerzen zu ertragen und zu sterben. Nachdem sie glühende Kohlen geschluckt hat, reiht sie sich mit ihrer ultima vox in die Tradition heroischen Sterbens ein: "Quid mortem aliquis impediat, aut neget? Non potest: et pater vos docuit." (১Wie sollte man meinen Tod aufhalten oder verhindern? Dies ist nicht möglich, wie euch mein Vater bereits gezeigt hat.ı) Wenn Lipsius die Exempelreihe in die nachantike Zeit weiterführt, nennt er ganz selbstverständlich Märtyrer ${ }^{78}$ als Beispiele bemerkenswerter constantia. Für den neustoischen Philosophen ist stoisches und christliches Sterben in gleicher Weise vorbildlich. Seine bewegende Schilderung des Todes, die sich erkennbar auf die literarische Tradition der exitus illustrium virorum bezieht, gipfelt in der verklärenden ultima vox, die das Sterben eine Christen oder

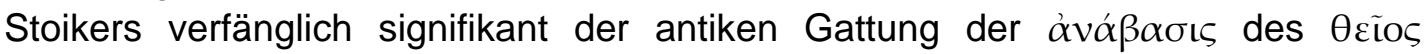
$\alpha \ddot{v} \theta \varrho \omega \pi \circ$, der Schilderung des vorbildlichen Sterbens, annähert. Im Sterben erhält der Stoiker ebenso wie der Christ eine Vorbildfunktion für die Zurückbleibenden; diese Vorbildfunktion stützt sich auf die Taten und die Haltung des nun zu Ende gehenden Lebens. Die Summe des Lebens wird in der ultima vox meist pathetisch, zumindest aber pointiert zugespitzt und gebündelt.

Für den Neustoizismus ebenso wie für die Frömmigkeitspraxis der entstehenden nachreformatorischen Konfessionen ist das entschiedene Interesse an der Inszenierung des Lebensendes charakteristisch. Die Schwelle zum Tod erlaubt einen kritischen Rückblick, der sich durchaus auf eine den Neustoikern ${ }^{79}$ unaufhörlich zitierte Passage Senecas beziehen kann, deren ethische Normen sich ebenso christlich deuten ließen:

Quid profecerim morti crediturus sum. Non timide itaque componor ad illum diem quo remotis strophis ac fucis de me iudicaturus sum, utrum loquar fortia an sen-

\footnotetext{
74 ,Mühelos komme ich zu Beispielen aus unserer christlichen Epoche, weil sich zahllose unter Heiligen und Märtyrern finden.r (Monita et exempla politica in: Opera omnia, a.a.O., Bd. 4,1, S. 123-321, hier: S. 177)

${ }^{75}$ Monita et exempla politica in: Opera omnia, a.a.O., Bd. 4,1, S. 123-321, hier bes. S. 174-176.

76 „Porciam subnecto, patri filiam, nupserat ea M. Bruto, marito heroina hac digno.« (১Die Tochter Porzia schließe ich dem Vater an; sie hatte M. Brutus geheiratet, einen Gatten, der dieser Heldin würdig war.८)

77 "Sum, confide, possum ferre, possum contemnere: et mori o Brute cum marito, et pro marito possum. Proinde si quid tu honesti agitas, quod utrumque nostrum sit dignum, ne sile." (〉So bin ich, verlass dich darauf, ich kann [Schmerzen] ertragen und verachten. Und ich kann, Brutus, mit dem Gatten zusammen und für ihn sterben. Deshalb verschweige nicht dein Vorhaben, wenn es unser beider würdig ist.८)

${ }^{78}$ Als Beispiele einer in den Tod führenden constantia nennt Lipsius (Manuductio ad stoicam philosophiam III,23 in: Opera omnia, a.a.O., Bd. 4,2, S. 817) u.a. die Heiligen Sophronia und Pelagia.

${ }^{79}$ So zum Beispiel Lipsius in der Manuductio ad stoicam philosophiam III,12 (in: Opera omnia, a.a.O., Bd. 4,2, S. 783ff.)
} 
tiam, numquam simulatio fuerit et mimus quidquid contra fortunam iactavi verborum contumaciam [...]. Disputationes et litterata colloquia et ex praeceptis sapientum verba collecta et eruditus sermo non ostendunt verum robur animi; est enim oratio etiam timidissimis audax. Quid egeris tunc apparebit cum animam ages. ${ }^{80}$

Für neustoische `Tugendhelden` wie für nachtridentinische Märtyrer gilt deshalb der Tod als Stunde der Bewährung, in der sich die Authentizität der Lebensführung bewähren muss. Erneut bestätigt sich die Hypothese, dass die profane und die kirchliche Ikonographie ıvorbildlichen Sterbensı auf gemeinsame neustoische Voraussetzungen zurückgeht. In vergleichbarer Weise gilt dies für frühneuzeitliche Märtyrer- und Historiendramen. Christliches Martyrium und neustoischer Freitod sind beide auferlegt, aber zugleich frei gewählt.

\section{3 gloire und vertu auf der Bühne}

[exitus illustrium virorum] Die praktische Ethik des Neustoizismus entwickelte über alle konfessionellen Differenzen hinweg gültige Modelle exemplarischen Sterbens, die es durchaus mit den nachtridentinischen Sterberitualen ${ }^{81}$ aufnehmen konnten, die

80 ,Dem Tod bin ich Rechenschaft darüber schuldig, welche [moralischen] Fortschritte ich gemacht habe. Furchtlos bereite ich mich daher auf jenen Tag vor, an dem ich ohne Kunstgriffe und Ausflüchte beurteilen kann, ob ich nur mutige Reden führe oder auch so fühle, ob alle aufsässigen Worte, die ich gegen das Geschick geschleudert habe, nur Heuchelei und Farce gewesen sind. [...] Disputationen, gelehrte Gespräche, aus philosophischen Schulmeinungen zusammengestellte Sentenzen und eine gebildete Ausdrucksweise beweisen noch keine Seelenstärke; denn kühne Reden führen sogar die Furchtsamsten. Was man geleistet hat, zeigt sich dann, wenn man sterben muss.ı (ep. mor. 26,5-6)

${ }^{81}$ In diesen Zusammenhang ist besonders die von der nachtridentinischen Kirche propagierte Rolle Josephs als Patron des guten Sterbens erwähnenswert. In der mittelalterlichen Frömmigkeit (und Ikonographie) lag die Bedeutung des Heiligen Joseph in seiner Rolle als »Nährvater Christi (nutritor domini) und Ehemann Mariens, der mit der Flucht nach Ägypten die Familie gerettet hatte. Bereits frühe Inszenierungen des 4. und 5. Jahrhunderts, die Joseph sorgenvoll mit Trauergebärde auf das Kind in der Krippe blicken lassen, zeigen ihn in Meditationen über das Kind und seinen späteren Opfertod. Bisweilen wird im hohen und späten Mittelalter seine Stellung an der Schwelle zwischen Altem und Neuem Bund betont: der Tau-Stab oder der (verrutschte) Judenhut können darauf hinweisen. Im Wesentlichen konzentrieren sich Kult und Ikonographie des Mittelalters auf seine Rolle als Familienvater während der Geburt, der Kindheit und Erziehung Jesu. (Dazu: Heublein, Brigitte: Der »verkannte « Joseph, Zur mittelalterlichen Ikonographie des Heiligen im deutschen und niederländischen Kulturraum, Weimar 1998 und Kaster, Gabriela: »Joseph von Nazareth «, in: $L C l$, Bd. 7, Sp. 210-221.) Im späten Mittelalter wurde seine Rolle als pater familias noch durch seinen Beruf des Zimmermanns ergänzt, woraus ihm verschiedene Schutzfunktionen für Handwerker, insbesondere Zimmerleute erwuchsen. So konnte er um 1500 als moralisch integrer Familienvater und als arbeitsamer Handwerker zu einer Leitfigur beginnenden bürgerlichen Selbstbewusstseins avancieren. (Heublein, a.a.O., S. 217ff.) - Seine weitere wichtige Funktion erhielt Joseph im Laufe des 17. Jahrhunderts. Als 1621 Gregor XV. den 19. März als Josephstag in den Festkalender der katholischen Kirche aufnahm, kam er wohl einer immer breiter werdenden volkstümlichen Verehrung nach. (Dazu, wenn auch auf den Bereich der Habsburger eingeschränkt, MikudaHüttel, Barbara: Vom >Hausmann zum Hausheiligen des Wiener Hofes, Zur Ikonographie des hl. Joseph im 17. und 18. Jahrhundert, Marburg 1997, bes. S. 77-94.) Als »refugium agonizantium« rückt nun in Traktaten, Graphik und Malerei Josephs Lebensende immer mehr in den Vordergrund. Begleiten Maria und der erwachsene Jesus das Sterben Josephs, so steht noch immer die (Heilige) Familie im Vordergrund. Das Sterben wird meist als familiäre Abschiedsszene ins Bild gesetzt, in der als Requisiten eines arbeitsamen Lebens Werkzeuge und bearbeitetes Holz nicht fehlen. Ein fleißiges Leben und eine Lebensgemeinschaft mit Maria und Jesus garantieren einen guten Tod und lassen sogar auf traditionelle Sterbeseelsorge, wie sie im ıMarientod nötig war, verzichten: "Joseph hat mit Jesu und Maria allezeit gelebt / mit Jesu und Maria ist er gestorben« (Palma Iosephina, Das ist. Leben und Lob des hochheyligen Patriarchen IOSEPHS, Christi Nährvatter / MARIAE Bräutigambs, Augsburg 1657, S. 393 [zitiert nach Mikuda-Hüttel, a.a.O., S. 93]) Der Augenblick des Sterbens hat nicht mehr das schwere Gewicht wie im Mittelalter, sondern soll sanft und gelassen geschehen wie der Josephstod: "Es ist der Tod des Gerechten, der seinen physischen Tod nicht erst bedenkt, wenn er nahe ist, 


\section{Der Neustoizismus: Leitphilosophie der Frühen Neuzeit}

eine eigene Anleitung und Praxis der Reflexion, der Reue und der Bitte um Sündenvergebung entwickelt hatten. Der für den Neustoizismus bezeichnende »akonfessionelle Theismus « ${ }^{82}$ verdeckte oft die Differenzen zur christlichen Vorstellung. Auf der Bühne wie in der Historienmalerei wurden in der Frühen Neuzeit Todesinszenierungen (meditationes mortis) in unzähligen Varianten vorgeführt, wobei sich christliche und neustoische Elemente oft nicht unterscheiden lassen, weil sowohl Märtyrerdramen und Historiendramen als auch die Historienmalerei auf Charakterstärke (constantia) und Tapferkeit (virtus) der Protagonisten abheben. ${ }^{83}$ Nicht zufällig stellt Lohenstein seinem Kleopatra-Drama ein Tacitus-Zitat voran, das den tugendhaften Tod dem schändlichen gegenüberstellt ${ }^{84}$; erst in der Katastrophe (necessitas) kann der Protagonist wahre Größe zeigen. Die Furchtlosigkeit vor dem Tod teilen Historien- und Märtyrerdrama: »Wer rühmlich stirbt der hat genung gelebt ${ }^{85}$, erklärt Antonius in der Cleopatra Lohensteins.

Für Inszenierungen vorbildlichen Sterbens konnte das profane und das religiöse Drama der Frühen Neuzeit auf die durch den Neustoizismus vermittelte literarische Tradition der antiken Populärphilosophie zurückgreifen. Die literarische Inszenierung des exitus illustrium virorum hatte in der Antike ein >Protokolk exemplarischen Sterbens entwickelt, das stets am Tod des Sokrates orientiert blieb und den Akzent auf die freie Entscheidung für den Selbstmord legte. Geradezu tropisch wurde der ultima vox ${ }^{86}$ als Vermächtnis an die Nachwelt große Aufmerksamkeit geschenkt: Vor allem die kaiserzeitliche römische Historiographie setzte sie zur Charakterisie-

sondern ihn sein ganzes Leben lang bedacht hat. (Ariès, Philippe: Geschichte des Todes, München / Wien 1980, S. 398) Das Sterben geschieht in der Gewissheit einer »Verdienstfrömmigkeit « (Mikuda-Hüttel, a.a.O., S. 94) Unaufgeregt und heilsgewiss stirbt der Patron des guten Sterbens in Historiengemälde von Rutilio Manetti (1571-1639) oder Franz Anton Maulbertsch (1724-1796), aber auch im Oratorium La morte di San Giuseppe (um 1730) von Giovanni Battista Pergolesi (1710-1736), begleitet von Maria, dem Amor Divino und San Michele: „Se Giuseppe così more, / Di morir non ha timore / Chi servir sempre lo sa. / Ei lo guida, ei lo difende / Dalle furie più tremende / E gli impetra al fin pietà. « (So singen im abschließenden Tutti-Satz Maria, Amor Divino und San Michele.)

${ }^{82}$ Hankamer, Paul: Deutsche Gegenreformation und deutsches Barock, Stuttgart ${ }^{2} 1947$, S. 313

${ }^{83}$ So widersetzt sich - um ein wenig beachtetes Beispiel zu wählen - im Märtyrerdrama Maeghden von Joost van den Vondel (1587-1679) Ursula dem sie bestürmenden Hunnen Attila zunächst lange Zeit argumentativ, am Ende auch physisch, als Attila ihr die Kreuzesfahne entreißen will: "Ghy boedermoorder, most dien Maeghdenmoord beginnen / Met zoo een schendigh stuck, als tschenden van het Kruis. / Zoo komen u met recht Gods plagen t'effens t'huis. " (IV,1258) (>Du Brudermörder musst diesen Jungfrauenmord mit etwas so Schändlichem beginnen wie der Entweihung des Kreuzes. So treffen dich zu Recht alle Strafen Gottes zugleich.ı) Nach diesem Protest tötet Attila die junge Frau mit einem Pfeil und gibt das Signal zur Ermordung ihrer Begleiterinnen (van den Vondel, Joost: De werken, hrsg. von J. F. M. Sterck u.a., Amsterdam 1929, Bd. 3, S. 708-780.). -- Vgl. zum Thema: Szarota, Elida Maria: Künstler, Grübler und Rebellen, Studien zum europäischen Märtyrerdrama des 17. Jahrhunderts, Bern 1967.

84 "Moriendum victis, moriendum deditis: id solum referre, novissimum spiritum per ludibrium et contumelias effundant, an per virtutem. « (Hist. III,66) ('Sterben müssen die Besiegten, sterben auch die, die sich ergeben haben; allein darauf kommt es an, ob man den letzten Atemzug unter Hohn und Schande oder in Tapferkeit tut.ı)

${ }^{85}$ Lohenstein, Daniel Casper von: Cleopatra, Stuttgart 1998, III,435

${ }^{86}$ Es ist anzunehmen, dass bereits die kaiserzeitlichen Sammlungen >letzter Worte eine antimonarchistische Tendenz verfolgten und die Selbständigkeit des Bürgers gegenüber Kaisern und Tyrannen betonten. Genannt seien nur der erzwungene Tod des Senators Thrasea Paetus, der mehrfach offen Nero kritisiert hatte (Annales XVI,21-34), oder der Tod des Philosophen und ehemaligen Prinzenerziehers Seneca, der wegen seines als Missbilligung interpretierten Rückzugs aus der Politik den Hass Neros auf sich gezogen hatte (Annales XV,6064). 
rung der politischen Gegner des Herrschers ein, die sich freiwillig oder gezwungen töteten. Solch sinszeniertes Sterbenı brachte ihre politische und moralische Haltung enkomiastisch auf den Begriff. In den antiken Kompilationen wurden exempla nach einem festgelegten Muster stilisiert: Der Sterbende rechtfertigt seinen Freitod mit philosophischen >Vorgängern den Trost zu, dankt den Göttern und deutet sein Handeln als Schritt in die Freiheit. Tacitus etwa hat herausragende Vertreter der kaiserzeitlichen, antimonarchistischen Nobilität mit ausgefeilten Darstellungen solch stugendhaften Sterbens ausgezeichnet. Seine Schilderungen erzwungener oder freiwilliger Selbstmorde deuten das `Protokolk der Todesstunde als endgültige Bewährung eines philosophischen oder politischen Lebenslaufs.

Der vorbildliche Tod gibt, wie es später der Kirchenvater Ambrosius prägnant formulieren wird, ein testimonium vitae ${ }^{87}$. Unter veränderten Vorzeichen wurde das antike Formular von den spätantiken Märtyrerakten übernommen, obwohl sich auf den ersten Blick der sinszenierte Selbstmord schwerlich in einen christlichen Kontext übertragen ließ. ${ }^{88}$

[Märtyrer- und Barockdrama] Die neustoischen Modelle exemplarischen Sterbens beeinflussten über alle Konfessionsgrenzen hinaus das Drama der Frühen Neuzeit. Besonders im Jesuitendrama und in der Barocktragödie, die vorwiegend auf mythologische und historische Stoffe der Antike zurückgriff, konnte die neustoische Konzeption in sdramatischen sterbenden Protagonisten in der letzten Szene zum Ideal heroischen und damit gleichzeitig philosophischen oder christlichen Sterbens zu überhöhen.

Barocke Tragödien verdichten das Lebensgefühl der Zeitgenossen und erproben an antiken Modellen die angemessenen Verhaltensweisen in extremen Situationen. Vorbildliches Verhalten im ıVerhängnisı wird der Maßstab für die Beurteilung einer Figur. Erst in der Katastrophe kann der Mensch seine wahre Größe zeigen und seine `Rolle` voll ausspielen. Das barocke Lebensgefühl, das dem Menschen den Eindruck vermittelte, Akteur im theatrum mundi ${ }^{89}$ zu sein und Beifall zu erhalten, ist eine wichtige Voraussetzung, will man die psychologischen Strategien des Neustoizismus verstehen. Da vor dem Tod kein Entkommen ist, kommt es darauf an, ihn mit virtus zu bestehen; für jeden, der in diesem großen Spiel mitspielt, ist der Beifall der Umwelt und der Nachwelt das Wichtigste. der den europäischen Neustoizismus prägte, war das Leben und Handeln im Diesseitigen; das, was alle sehen und beurteilen konnten - Taten und Geisteshaltung - waren Ge-

\footnotetext{
87 »Mors igitur vitae est testimonium. «(〉Der Tod legt Zeugnis für das Leben abく.) (Ambrosius, De bono mortis VIII,35)

${ }^{88}$ Dazu Ronconi, A.: »exitus illustrium virorum« in: RAC VI, Stuttgart 1966, Sp. 1258-1268.

${ }^{89}$ Alewyn, Richard: Das große Welttheater, Die Epoche der höfischen Feste, Berlin 1985.
} 
genstand allgemeiner Bewertung. Hier, in der Freiheit, sich adäquat zu verhalten und so den Willen mit der Vorsehung in Einklang zu bringen, manifestierte sich ein Rest der lutherischen Wertkategorie von der >Freiheit eines Christenmenschen . Die profane barocke Tragödie, in der überwiegend antike Helden auftraten, bot exempla neustoischer Ethik; das gleichzeitig und durchaus als Konkurrenz entwickelte Jesuitentheater ließ als Helden sterbende Märtyrer auftreten, die in der Nachfolge der passio Christi stehen. Gemeinsam ist beiden theatralischen Erscheinungsformen, dass sie thematisch und formal auf die antiken Sammlungen exemplarischer Todesfälle (exitus illustrium virorum [et feminarum]) zurückgehen.

Diese Konzeption des neustoischen Tugendhelden erscheint im in zahlreichen Varianten und Konfigurationen und hat auch die dramatische Behandlung der istarke Frauen beeinflußt. ${ }^{90}$ Besonders die französische Dramaturgie hob dabei auf die bei weiblichen Helden besonders sinnfällige am Konflikt von Politik und Liebe konturierbare Opposition von Normen der Gesellschaft (gloire) und Normen der Individualität (vertu) ab, in der sich ein Grundkonflikt der Frühen Neuzeit abbildet.

[gloire und vertu] In barocken Dramen eines Gryphius, eines Lohenstein oder eines Corneille treten in beispielhafter Weise Protagonisten auf, die der Kontingenz und Gewalttätigkeit des Lebens entgegentreten und dabei versuchen, ihre Mitte immer neu zu gewinnen, um ein selbstbestimmtes Subjekt zu bleiben. ${ }^{91}$ Es geht der neustoischen Ethik immer wieder darum, dass sich das Subjekt seiner vergewissert, um gegen fatum und necessitas gewappnet zu sein, und sich von Gegebenheiten nicht in Unruhe und Angst bringen lässt, die außerhalb seiner selbst und von ihm nicht zu verantworten sind. Helden barocker Tragödien stellen mustergültig die Handlungsnormen (virtutes) dar, zu denen Lipsius seine Leser erziehen will. Als Beispiel sei das Kleopatra-Drama von Daniel Casper von Lohenstein ${ }^{92}$ genannt. Bei Lohenstein ermuntert sich Cleopatra im Beisein ihrer Zofen, die sich abzeichnende Verschleppung nach Rom nicht zu ertragen, sondern den Selbstmord zu wählen:

Nein! Dis zu schaun bin ich zu edel vom Geblütt'

\footnotetext{
${ }^{90}$ Vgl. oben S. 68f., 107f., 122f., 142f., 168f.,

91 "Bonus animus et sibi conscius summum bonum est» (〉Eine moralische und selbstbewußte Haltung ist das höchste Ziel.ı) Justus Lipsius: Epistolarum selectarum centuria prima ad Belgas II,85, Antverpiae, ex officina Plantiniana, apud loannem moretum MDCII (Brief an loannes Hemelarius), Wesel 1675 (ND Hildesheim / Zürich / New York 2001).

${ }_{92}$ Daniel Casper von Lohenstein: Cleopatra, Trauerspiel [Text der Erstfassung von 1661], Stuttgart 1998
} 
An Tugend viel zu groß / zu Hertzhafft im Gemütt.

Entschleuß dich / hoher Geist / wi du dir vorgenommen/

Durch den behertzten Tod den Fässeln vorzukommen;

Vollbring' es hoher Geist! Ein rühmlich Todt ist mehr /

Als tausend Jahre wehrt. Gebt / Libste / nicht so sehr

Di Kleinmuth an den Tag. Laßt Thrän' und Seufzer schwinden. ${ }^{93}$

Positive stoische Schlüsselbegriffe wie »Tugend« (virtus), »Hertzhafft im Gemütt'« (constantia), »hoher Geist« (magnanimitas) fallen in den Blick, aber auch negativ besetzte wie »Kleinmuth « (metus) und »Thrän' und Seufzer «(dolor). Im Schlussakt greift Cleopatra nach dem Selbstmord des Antonius auf das mittelalterliche Bild des Glücksrads zurück:

Wer auf das leichte Rad des blinden Glückes trau't /

Auf seiner Tugend Grund nicht schlechte Thürme baut /

Di Fürsten dieser Welt der Erde Götter nennet /

Wer viel weiß ausser sich / sich in sich selbst nicht kennet /

Wer sich auf's Zepters Glas / des Thrones Grund-Eiß stützt;

Der komm' und lern' allhier / wider so schwanckend sitzt /

Der auf dem Gipffel steht. ${ }^{94}$

Das Schicksal ist abhängig von von fatum und necessitas und außerhalb der Reichweite des Menschen. So finden sich In Lohensteins 1666 aufgeführtem Trauerspiel Sophonisbe ${ }^{95}$ neustoische Handlungsanweisungen und Normen zu griffigen Sentenzen verkürzt: Amilcar fordert die zu Beginn des Stücks noch mit ihrer Contenance ringende Sophonisbe auf, sich nach stoischen Normen zu verhalten:

Sie halte Maas im Schmertze.

Die Götter schencken uns keinmal nicht Wermuth ein:

$\mathrm{Daß}$ nicht Grosmüttigkeit darein kann Zucker streu'n! $!^{96}$

In der anschließenden Szene wird von einem anderen Vertrauten, Vermina, das Ziel der constantia formuliert:

Großmüttigkeit schafft Ruhm / Furcht ist der Hasen Schutz. ${ }^{97}$

Scipio, der römische Gegenspieler der Heldin, stuft das Ziel stoischen Handelns (virtus) hoch ein:

Der ist der Götter Kind recht / den die Tugend ziert. ${ }^{98}$

\footnotetext{
93 III, 124-129.

${ }^{94} \mathrm{~V}, 1-7$.

${ }^{95}$ Lohenstein, Daniel Casper von: Sophonisbe, Trauerspiel, Stuttgart 1996

96 I, 251-254.

97 I, 318.

98 IV, 308.
} 
Als am Ende der Tragödie die necessitas zunimmt und die Handelnden in Angst und Furcht stürzt, wird der letzte Rettungsanker für den Stoiker deutlich, den zu ergreifen nicht in jeder Lebenslage nötig, den sich jedoch vor Augen zu halten, innere Freiheit zurückgibt. In diesem Sinne sagt Sophonisbe:

Der Tod ist ein Geschenck' in solchen Freyheits-Nöthen. ${ }^{99}$

Wenig später in der gleichen Szene hat sich die Heldin schon so gefasst, dass sie ihren Hofstaat ermuntern kann:

[...] Nichts / als der Tod nur kann

Der Freyheits-Ancker sein / des Elends Hafen werden.

Spar't / liebsten Freinde spart die ängstigen Gebehrden.

Ein steiler Felß und Geist weicht Sturm und Glücke nicht.

Die Eiche trotzt den Wind / der weiche Pappeln bricht. ${ }^{100}$

Sie reicht auch ihren Söhnen den Gifttrank:

Recht so! wer hertzhaft stirbt / lacht Feinde / Glück und Zeit;

Verwechselt Ruh und Ruhm mit Angst und Eitelkeit. ${ }^{101}$

\section{Neustoisches Meditationsbild und nachtridentinisches Andachtsbild}

[exemplum und Andachtsbild] Die Ikonographie der Selbstmörderin als Tugendheldin setzt bekanntlich das frühneuzeitliche Historiendrama voraus, in dem Sophonisbe und Lukretia, Dido und Kleopatra, aber auch Porzia häufig auftreten. ${ }^{102}$ Die bildende Kunst übernahm das Thema und stellte meist den ıletzten Augenblickı dar, der - wie die ultima vox auf der Bühne - dem Betrachter das Vorbild eines exemplarischen Sterbens vermittelte. Während die Andachtsbilder der kirchlichen Kunst ${ }^{103}$ in der öffentlichen und privaten Frömmigkeitspraxis den frommen Betrachter auf seine persönliche Lebensführung und kommende Bewährung in der Todesstunde aufmerksam machten, sind Funktion und Wirkungsstrategie profaner Sterbebilder in der Frühen Neuzeit, von ihrer unmittelbar politischen Rolle einmal abgesehen, schwerer zu bestimmen, obwohl die ikonographischen Parallelen in der Darstellung von Märtyrern und Tugendhelden auf der Hand liegen. ${ }^{104}$ Gerade einfigurige

\footnotetext{
${ }^{99} \mathrm{~V}, 358$

${ }^{100} \mathrm{~V}, 400-404$.

$101 \mathrm{~V}, 479-480$

102 Das Bildmotiv der starken Frauen geht in allen Fällen auf die frühneuzeitliche Bühne zurück. Dazu oben S. $68 f f$. (Sophonisbe), S. 107ff. (Dido), S. 122ff. (Lukretia), S. 142ff. (Kleopatra), S. 168ff. (Porzia).

${ }^{103}$ Vgl. unten S. $207 \mathrm{ff}$.

104 Vgl. unten S. 204. - Freilich gewährt der philosophische Tod des Stoikers nur das Weiterleben im Nachruhm, während die Seele zur überindividuellen göttlichen Substanz (pneuma) zurückkehrt. Ambrosius musste deshalb das antike Sterbeformular des exitus illustrium virorum umdeuten und das testimonium vitae als testimonium fidei interpretieren. "Mors igitur solutio est animae et corporis. « (>Der Tod ist also die Trennung von Seele und Körper.८) (De bono mortis III, 8); »Opus est ut constanter transeas. Transitus autem a corruptione ad incorruptionem, a mortalitate ad immortalitatem, a perturbatione ad tranquillitatem. Non igitur nomen te
} 
profane Tugendheldinnen scheinen ein Äquivalent zu kirchlichen Andachtsbildern zu sein. ${ }^{105}$

Repräsentiert das exemplarische Sterben einer Katharina oder eines Sebastian die Vorbildlichkeit christlicher Lebensführung, lässt sich ein vergleichbarer Rezeptionshorizont für profane Tugendhelden wie Cato oder Sophonisbe zwar postulieren, allerdings aus den zeitgenössischen Quellen kaum belegen. Ein solcher Analogieschluss liegt gleichwohl nahe und wird durch die Gleichsetzung antiker und christlicher Tugendhelden in den neustoischen Texten gestützt. Für den frühneuzeitlichen Kenner waren Darstellungen des vorbildlichen Sterbens eines Cato oder einer Porzia immer schon durch literarische und theatralische Behandlungen des Themas >moralisch vorbildliche testimonium des Märtyrers, repräsentieren Darstellungen profaner Tugendhelden exempla philosophischer Lebensführung. Wie Katharina oder Sebastian im öffentlichen oder privaten Andachtsbild verkörpern Sokrates oder Kleopatra ikonographisch weitgehend verselbständigte neustoische Handlungsanweisungen, die durch den Erfolg der Historiendramen in der Frühen Neuzeit mit dem Verständnis ihres Appellcharakters rechnen konnten.

[neustoische Meditationsbilder] In der Tat lässt sich wahrscheinlich machen, dass das ikonographische Motiv des profanen Tugendhelden in neustoisch beeinflussten Milieus in Analogie zum Andachtsbild im öffentlichen und privaten Raum entwickelt wurde und der Frömmigkeitspraxis entsprechende populärphilosophische Funktionen übernahm. Exemplarisch sterbende Tugendhelden erinnerten wie Märtyrer an die Werte stoischer Lebensführung und spielten eine den Andachtsbildern vergleichbare pädagogische Rolle.

[conversatio] Es hat in diesem Zusammenhang noch nicht hinreichend Beachtung gefunden, dass sich im populärphilosophischen Werk des Lipsius Begriffsbildungen finden, die eine weitgehend säkulare Frömmigkeitspraxis umschreiben. Nachtridentinischen Frömmigkeitsübungen vergleichbar stellte Lipsius in seinen didaktischen Schriften ${ }^{106}$ philosophische Techniken vor, die täglich eingeübt und perfektioniert

mortis offendat, sed boni transitus beneficia delectent. « (〉Man muss also beständig hinübergehen. Das Hinübergehen aber geschieht von der Verderbtheit zur Unvergänglichkeit, von der Sterblichkeit zur Unsterblichkeit, von der Unruhe zur Ruhe. Deshalb möge dich nicht der Begriff `Tod irritieren, sondern es mögen dich die Wohltaten des guten Hinübergangs erfreuen.८) (IV, 15); "Solutio autem ista quid aliud autem agit, nisi ut corpus resolvatur et quiescat: anima autem convertatur in requiem suam, et sit libera, quae si pia est, cum Christo futura sit? « (>Was bewirkt aber diese Trennung anderes, als dass der Körper aufgelöst ruht, die Seele aber zu ihrer Ruhe kommt und frei ist, da sie mit Christus sein wird, wenn sie fromm ist?^) (III, 8) Dem Märtyrer gilt das Leben nur als transitus in eine andere Welt, in der die Seele des Individuums erhalten bleibt.

${ }^{105}$ Es ist einigermaßen auffällig, dass diese Darstellungsform nur für weibliche Tugendhelden gewählt wurde.

${ }^{106}$ Dazu zählt vor allem die Manuductio ad stoicam philosophiam, die in Dialogform einem Schüler die Hauptstücke neustoischen Denkens vermittelt. 
werden sollten. Die praktische Philosophie entwickelte ein geradezu pädagogisches Programm zur Einübung ihrer Normen (virtus), das der Selbstkontrolle (disciplina) und der ständigen Ausbildung (exercitatio) in gleicher Weise Rechnung trug. ${ }^{107} \mathrm{Die}$ Begriffe, die Lipsius für solche adiumenta vel instrumenta philosophischer Lebensführung wählte, lassen die Nähe seiner Überlegungen zu Formen religiöser Lebensführung noch deutlich erkennen: exempla, conversatio, examen. ${ }^{108}$

Vergleichbar der kirchlichen Frömmigkeitspraxis wurde die philosophische Lebensführung zu einer Technik, die sich nicht auf theoretische Kenntnisse (doctrina) verließ, sondern wie die nachtridentinische Kunsttheorie auf die emotionale Aneignung vorbildlicher Handlungen (exempla) setzte: "aliena facta [...] movent et iuvant «. ${ }^{109}$ Antike und moderne Vorbilder galten dabei als gleichwertig. ${ }^{110}$ Höher im pädagogischen Wert noch als das exemplum ist die conversatio einzuschätzen:

Sed conversatio iuvabit maxime: de qua Seneca [...] Nulla res magis animis honesta induit, dubiosque et in pravum inclinantes revocat ad rectum, quam bonorum virorum conversatio. ${ }^{11}$

Der von Lipsius verwendete Begriff conversatio umfasst den persönlichen Umgang im Gespräch ebenso wie die Lektüre eines vorbildlichen Autors und die ständige Auseinandersetzung mit seinem Beispiel:

Occursus mehercule ipse sapientium iuvat: et est aliquid, quod ex magno viro vel tacente proficias? Quid? Imo iuvabit illeipse vel cogitatus. Nam et Senecae hoc admonitum admitte: [...] Aliquis vir bonus eligendus est, ac sem-

107 »Quid iuvat ista omnis dissertio, et indagatio, si ea tantum? Non enim qui sermone sapit, is mihi sapit (ait vir sanctus) nec qui linguam disertam et volubilem habet, mentem autem inconstantem et indoctam: sed magis, qui pauca de virtute disserit, multa autem factis ostendit, et fidem verbis suis ipsa vita conciliat. Sed et cum Seneca monemus (Epist. XCIIII). Pars virtutis disciplina constat, pars exercitatione. Et discas oportet; et quod didicisti agendo confirmes." (/Was nützt alles Diskutieren und Debattieren, wenn es dabei bleibt? Wie ein verehrungswürdiger Mann sagt, ist nämlich nicht der Philosoph, der mit Worten klug umzugehen weiß, und auch nicht der, der sich gewandt und geläufig ausdrücken kann, aber selbst unbeständig und ungebildet ist, sondern vielmehr der, der nur wenig Worte über die Tugend verliert, aber vieles durch sein Handeln erkennen lässt und durch die Lebensführung seinen Worten Glauben verschafft. Mit Seneca muss darauf hingewiesen werden, dass [philosophische] Tugend Unterweisung ebenso wie Einübung verlangt. Du musst lernen und das Gelernte im Handeln bestätigen.ı) (Manuductio ad stoicam philosophiam III,24 in: Opera omnia, a.a.O., Bd.4,2, S. 819)

108 „Quod si aliena facta sic movent et iuvant, quid tua? Tria autem ad exercitium utiliter instituendum conducent, exempla, conversatio, examen. (>Wenn [tugendhaftes] Handeln anderer zum mitreißenden Vorbild werden kann, wie steht es dann um dich? Drei Verfahren gibt es, [eine philosophische Lebensweise] erfolgreich einzuüben: Vorbilder, Umgang mit den Vorbildern und kritische Selbstprüfung.ı (Manuductio ad stoicam philosophiam III,24 in: Opera omnia, a.a.O., Bd.4,2, S. 818-821) - Der Begriff der conversatio ist bewusst doppeldeutig, den philosophischen Gedankenaustausch ebenso umfassend wie den Umgang mit Exempeln. Lipsius lehnt sich wohl an ein Verfahren des Lateinunterrichts in der Frühen Neuzeit an, der in den Schritten praeceptum - exemplum - imitatio vorging; zunächst (praeceptum) wurde die grammatische Regel erlernt und eingeprägt; dann (exemplum) wurden Musterbeispiele aus antiken Autoren übersetzt; schließlich (imitatio) musste der Schüler das Gelernte in engem Anschluss an das sprachliche Vorbild umsetzen und einen eigenen Text schreiben (Fink, Hanns-Peter: Exercitia Latina, Vom Unterricht lippischer Junggrafen zur Zeit der Spätrenaissance, Marburg 1991, S. 25ff., außerdem Paulsen, Friedrich: Geschichte des gelehrten Unterrichts, 2 Bde, Leipzig ${ }^{3}$ 1919-1921, hier Bd.1, S. 345).

109 S. Fußnote 108.

110 »xempla, et a veteribus licet sumere, quos iure miramur: atque etiam e notis aut novis non deerunt, quos in tali aut tali re imitere. Opus est iis, ad quos mores nostri seipsi exigant: nisi ad regulam, prava non corriges." (Manuductio ad stoicam philosophiam III,24 in: Opera omnia, a.a.O., Bd. 4,2, S. 819) (`Beispiele finden sich bei den zu Recht bewunderten Alten, unter den bekannten oder neuen finden sich Vorbilder in der einen oder anderen Hinsicht. Vorbilder sind nötig, an denen sich unsre Lebensführung schulen kann; Fehler lassen sich nur an Leitbildern korrigieren.८)

111 \Am meisten indes wird der Umgang nützen, über den Seneca im 94. Brief schreibt: Nichts bringt den Menschen das moralisch Wertvolle näher und ruft Menschen, die im Zweifel sind und zum Schlechten neigen, zum Richtigen zurück als der Umgang mit Vorbildern.ı (Manuductio ad stoicam philosophiam III,24 in: Opera omnia, a.a.O., Bd. 4,2, S. 819) 


\section{Der Neustoizismus: Leitphilosophie der Frühen Neuzeit}

per ante oculos habendus, ut sic tanquam illo spectante vivamus, et omnia tanquam illo vidente faciamus. ${ }^{112}$

Vorbildliche Handlungen ebenso wie der direkte oder indirekte Umgang mit moralischen Autoritäten beeinflussen die Lebensführung und führen zur philosophischen Selbsterforschung (examen), die Lipsius in Anlehnung an die Beichtpraxis in zwei Vorgehensweisen differenziert: kritische Befragung durch andere - der pädagogischen Wirkung wegen möglichst im Beisein von Dritten - oder persönliche Gewissenserforschung. ${ }^{113}$

Quod hodie malum tuum sanasti? Cui vitio obstitisti? Qua parve melior es? ${ }^{114}$

In der täglich einzuübenden philosophischen Lebensform mit ihren Strategien des exemplum, der conversatio und des examen konnten die stoischen exempla der Historienmalerei antike Vorbilder visualisieren, als Gesprächsstoff unter Freunden dienen und die Richtschnur eigenen Handelns bilden. ${ }^{115}$

Da die emotionale Aneignung vorbildlichen Handelns für die eigene Lebensführung zur von den Neustoikern propagierten Lebensform gehörte, könnte die Ikonographie der Tugendhelden in der neustoischen Ausrichtung der frühneuzeitlichen Eliten durchaus eine ihrer Begründungen finden. Die neustoischen Techniken der Selbstvergewisserung, die sich analog zur nachtridentinischen Beichtpraxis an exempla orientierten, führten zu den ersten Formen profaner Andachtsbilder. Beispiele vorbildlichen Sterbens waren für den Neustoizismus und die nachtridentinische Frömmigkeitspraxis in vergleichbarer Weise wichtig. Deshalb erfreute sich das Einfigurenbild im Themenbereich des sprofanen Sterbensı besonderer Beliebtheit. Gerade das sreduzierteı, also sich auf den Ausschnitt beschränkende und durch Nahsicht mehr auf die Emotionen des Betrachters zielende Sterbebild erfüllte seine Verweisfunktion besonders gut. Es lenkte nicht durch große historische

\footnotetext{
112 ,Der Umgang mit Philosophen ist in der Tat nützlich: und du profitierst von einem großen Mann, selbst wenn er schweigt. Er ist selbst eine Hilfe oder doch die Vorstellung, die wir von ihm haben. Folge also der Ermahnung Senecas: ,Man muss ein moralisches Vorbild wählen und immer vor Augen haben, um sozusagen unter seinen Blicken zu leben und nur unter seiner Aufsicht zu handeln.'، (Manuductio ad stoicam philosophiam III,24 in: Opera omnia, a.a.O., Bd. 4,2, S. 819)

113 „Dupliciter adhiberi potest, ab aliis, ut a sese.« (〉Die kritische Selbsterforschung kann von anderen oder vom Philosophen selbst durchgeführt werden.८) (Manuductio ad stoicam philosophiam III,24 in: Opera omnia, a.a.O., Bd. 4,2 , S. 820 )

114 ,Welche deiner Schwächen hast du heute überwunden? Welchem Laster hast du widerstanden? Welche kleinen moralischen Fortschritte hast du gemacht?^ - Am Beispiel Senecas lässt sich die tägliche Gewissenserforschung als elementare Grundlage moralischer Fortschritte demonstrieren: »Utor, inquit, hac potestate, et cottidie apud me causam dico. Cum sublatum est lumen, et conticuit uxor moris mei iam conscia, totum diem mecum scrutor, facta et dicta mea remetior. Nihil mihi ipse abscondo, nihil transeo. " (Seneca sagt: Ich nutze diese Möglichkeit und gehe täglich mit mir zu Rate. Wenn das Licht gelöscht ist und meine Frau, die meine Gewohnheit schon kennt, schweigt, gehe ich den ganzen Tag mit mir durch und beurteile meine Taten und Worte nochmals. Nichts verberge ich vor mir, nichts übergehe ich.ı [Manuductio ad stoicam philosophiam III,24 in: Opera omnia, a.a.O., Bd. 4,2, S. 820])

${ }^{115}$ Die von Lipsius vorgeschlagenen Strategien moralischer Selbstprüfung leiten sich aus dem zentralen Begriff der stoischen Anthropologie und Ethik, der Oikeiosis, ab. Sie stellt Fremdes (á $\lambda$ ó́трıоv) und Eigenes (oíkعĩov) gegenüber und versteht die moralische Selbstfindung des Menschen (secundum naturam vivere) als Vermeidung der Fremdbestimmung (vitia) und Verstärkung der Autonomie (virtutes). Seneca hat sich ausführlich mit diesem Grundproblem stoischer Ethik beschäftigt (ep. mor. 121).
} 
Inszenierungen ab, sondern rief als Ikone stoischen Philosophierens emblematisch ein vorbildliches Ende auf.

[Klerikale Sammler] Lassen sich gerade die Einfigurenbilder sterbender Tugendheldinnen als profane neustoische Andachtsbilder interpretieren, mussten sie gleichwohl nicht in Opposition zur nachtridentinischen Frömmigkeitspraxis stehen, obwohl das Skandalon des dargestellten Selbstmords dies vermuten lassen könnte. So befanden sich Guido Renis sterbende Tugendheldinnen auch im Besitz von Kardinälen: Eine Kleopatra wurde dem Kardinal Leopoldo di Toscana geschenkt ${ }^{116}$, der Kardinal Francesco Barberini besaß eine Lukretia ${ }^{117}$, eine andere Lukretia der Kardinal Sacchetti ${ }^{118}$; in der Sammlung des Kardinals Carlo de' Medici befand sich eine Porzia ${ }^{119}$, Mazarin erwarb eine Sophonisbe ${ }^{120}$. Wie selbstverständlich gehörten solche Ikonen neustoischer Philosophie in die Bildersammlungen frühneuzeitlicher Intellektueller, auch wenn sie geistliche Würdenträger waren.

Ein gut dokumentiertes Beispiel neustoisch orientierter Sammlungstätigkeit ist die römische Familie der Giustiniani. Der Marchese Vincenzo Giustiniani (1564$1637)^{121}$ war von der Philosophie des Justus Lipsius so beeindruckt, dass er 1606 den, allerdings kurz zuvor verstorbenen, Gelehrten auf einer Reise in Löwen besuchen wollte. ${ }^{122}$ Im römischen Stadtpalast der Familie, dem heutigen Senat, den Vincenzo zusammen mit seinem ebenfalls als Mäzen hervorgetretenen Bruder, dem Kardinal Benedetto Giustiniani (1554-1621), bewohnte, wurde geradezu ein neustoisches Gesamtprogramm verwirklicht. Dort befand sich neben der umfangreichen Bibliothek des Sammlers und Mäzens ${ }^{123}$, die alle grundlegenden Schriften neustoischer Philosophie umfasste, eine umfangreiche Bildersammlung, die ihrerseits eindeutig neustoisch geprägt war. Vincenzo ließ einen der Galerieräume, die stanza dei filosofi, mit Supraporten schmücken, die das Sterben von Sokrates, Seneca und Cicero ${ }^{124}$ darstellen. Die mehr als 600 Gemälde und 1200 antike Statuen

\footnotetext{
${ }_{116}^{116}$ Pepper, Stephen: Guido Reni, L'opera completa, Novarra 1988, S. 294 (Nr. 173).

117 Pepper, a.a.O., S. 258 (Nr. 92),

118 Pepper, a.a.O., S. 303 (Nr. 202).

119 Pepper, a.a.O., S. 260 (Nr. 96),

120 Pepper, a.a.O., S. 295 (Nr. 174); diese Sophonisbe ist manchmal als Artemisia bezeichnet. Vgl. oben S. 86.

121 Kurzinformationen über das Giustiniani-Projekt der Arbeitsgruppe von Silvia Danesi Squarzina unter: http://w3.uniroma1.it/cattedra_danesi_squarzina/Statica.asp (letzter Aufruf am 07.11.2006).

${ }_{122}$ B. Bizoni im Diario di viaggio di Vincenzo Giustiniani, hrsg. von B. Agosti, Porretta Terme 1995, S. 71:»I signor Vincenzo ebbe intenzione di visitare il Lipsio, ma trovò che era morto poco avanti."

${ }_{123}$ Baldriga, Irene: »Vincenzo Giustinianis Persönlichkeit im Spiegel seiner Bibliothek « in Squarzina Danesi, Silvia (Hrsg.): AK Caravaggio in Preussen, Die Sammlung Giustiniani und die Berliner Gemäldegalerie, Milano 2001, S. 73- 80.

${ }^{124}$ Abbildung der Gemälde im AK Caravaggio in Preussen, Die Sammlung Giustiniani und die Berliner Gemäldegalerie in Preussen, a.a.O., S. 118: Tod des Seneca von Joachim von Sandrart (1945 verschollen); S. 119:
} 
umfassenden Sammlungen der Giustiniani, die in jüngster Zeit wegen ihrer Protektion Caravaggios besondere Beachtung der Forschung fanden, lassen ein intellektuelles Klima rekonstruieren, in dem Bibliothek und Bildersammlung aufeinander bezogen und durch die gleiche philosophische Aufgeschlossenheit charakterisiert waren. ${ }^{125}$ Die kunstliebenden Brüder verstanden offensichtlich ihre Sammlungen stoischer und neustoischer Texte und ihre darauf bezogenen Historiengemälde als ein zusammenhängendes Ganzes, das mit Besuchern und Freunden betrachtet und im gemeinsamen Gespräch erörtert werden konnte. Im Stadtpalast der Giustiniani konnte ein neustoisches contubernium ${ }^{126}$ Lektüre und Bildbetrachtung ebenso wie nachtridentinische Frömmigkeit und neustoische Ethik verbinden.

Tod des Sokrates von Giusto Fiammengo (1945 verschollen) und S. 344. Tod des Cicero von François Perrier (heute im Schloss in Bad Homburg). Ob der Bethlehemitische Kindermord von Poussin diese Philosophenreihe ergänzte, wurde von der Forschung diskutiert und scheint, schon wegen der völlig anderen Maße, eher unwahrscheinlich. (vgl. Baldriga in der Besprechung des Bildes von Perrier, a.a.O., S. 344-346).

${ }_{125}$ Die wissenschaftliche Beschäftigung mit der großen Kunstsammlung der Brüder Vincenzo und Benedetto Giustiniani und die beginnende Aufarbeitung des reichen Quellenmaterials hat vor kurzem zu einer Ausstellung in Berlin und Rom (Squarzina Danesi, Silvia) [Hrsg.]: AK Caravaggio in Preussen, Die Sammlung Giustiniani und die Berliner Gemäldegalerie in Preussen, Milano 2001) geführt, die neue Erkenntnisse zur neustoischen ıHintergrundsphilosophier des ausgehenden 16. und beginnenden 17. Jahrhunderts gebracht hat. Zuletzt: Danesi Squarzina, Silvia: La collezione Giustiniani, 3 Bde, Turin 2003.

${ }_{126}$ Zum contubernium als wichtigem, dem römischen Militärleben nachempfundene Freundschaft vgl. Muller, Jeffrey M.: »Rubens's Collection in History«, in: AK A House of Art, Rubens as Collector (Belkin Lohse, Kristin / Healy, Fiona Hrsg.) Antwerpen 2004, S. 10-85, bes. S. 40. 


\section{Posttridentinische Märtyrer und stoische Tugendhelden}

\section{Kirchliche Andachts- und profane Meditationsbilder}

Überschneidungen religiöser und profaner Ikonographie ${ }^{1}$ sind in der Frühen Neuzeit unverkennbar, auch war die "Trennlinie [...] in Sammlerkreisen bereits aufgeweicht ${ }^{2}$ : Halbfigurige Darstellungen etwa einer Magdalena oder einer Kleopatra, wie sie spätestens Reni in Mode gebracht hat, sind jedenfalls auf den ersten, flüchtigen Blick kaum zu unterscheiden und verfolgen vergleichbare Wirkungsstrategien in der Affektdarstellung. ${ }^{3}$ Schon Jacob Burckhardt hat auf diesen Sachverhalt hingewiesen: „Ob heilige oder profane Personen dargestellt werden, ändert im Ganzen nicht viel. Die Lucretien, Cleopatren, auch die Judith wo sie ekstatisch aufwärts schaut [...], der siegreiche David in ähnlichem Moment [...], ja selbst der sich erstechende Cato [...] zeigen nur andere Nuancen desselben Ausdruckes. « ${ }^{4}$ Profane und sakrale Themen sind nicht nur durch die Affektdarstellung und die gemeinsamen anthropologischen Voraussetzungen verbunden. Da beide Bildtypen auf compassio und consolatio abheben, liegt es nahe, kirchliche `Andachtsbilder und profane $>$ Meditationsbilder ${ }^{5}$ nebeneinander zu stellen. ${ }^{6}$ Damit ist dem Umstand Rechnung getragen, dass dem Sterbebild eines Cato oder einer Porzia in der Frühen Neuzeit eine dem Andachtsbild vergleichbare Funktion zukam. Im Übergang zur Barockmalerei hat das sschöne Sterben chen Tugendhelden ganz offensichtlich Konjunktur. Schon deshalb lassen sich

\footnotetext{
${ }^{1}$ Vgl. oben S. $47 \mathrm{ff}$.

2 Lang, Walther K.: Grausame Bilder, Sadismus in der neapolitanischen Malerei, Berlin 2001, S. 215.

${ }^{3}$ Vgl. unten S. $216 \mathrm{ff}$.

${ }^{4}$ Burckhardt, Jacob: Der Cicerone, München / Basel 2001, S. 251

${ }^{5}$ Beiden Bildtypen ist gemeinsam, dass sie über die Affektdarstellung zu einer meditativen Identifikation des Betrachters mit dem Gegenstand des Bildes führen wollen. Die frühneuzeitlichen Kunst griff Meditationstechniken auf, die seit der Erbauungsliteratur der Mystik, den Ars-moriendi-Traktaten des späten Mittelalters, über die Exercitia spiritualia (1548) des Ignatius von Loyola bis hin zur Barockästhetik eingeübt waren (Trillhaas, Wolfgang: "Meditation « in ${ }^{3} R G G$, Bd. 4, Sp. 824-826). Lange vor der Romantik wurde im Barock eine Affektästhetik entwickelt, die Kunst als Anleitung zu meditativer Identifikation versteht. Schon Christian Weise formuliert den Sachverhalt deutlich: »Ich gedencke an die Affe cte $n$ : denn wo der gantze Mensch und ein rechter Ernst nicht darbey ist / da wird das Werck allemahl unkräfftig seyn / und was nicht von Hertzen kömt / das geht auch nicht wieder zu Hertzen. Dannenhero wer was lustiges oder trauriges / was grimmiges oder verliebtes aufsetzen will / der muß sich so lange in der meditation vertieffen / biß er den affect bey sich fühlt und gleichsam alles ungezwungen hinlauffen läst. « (Curiöse Gedanken von deutschen Versen, verlegt bei Johann Friedrich Gleditsch, Leipzig ${ }^{2} 1693$, II. Theil, Cap. I, XXIV)

${ }^{6}$ Zur profane wie religiöse Themen übergreifenden Rhetorik des 17. Jahrhunderts: Fumaroli, Marc: L'école du silence, le sentiment des images au XVII siècle, Paris 1994.
} 


\title{
VII Posttridentinische Märtyrer und stoische Tugendhelden
}

\author{
Ikonographie und persuasive Funktion kirchlicher und profaner >Andachtsbilder \\ durchaus miteinander vergleichen.
}

Als erster hat bekanntlich Goethe im Faust-Fragment von 1790 den Begriff des Andachtsbildes verwendet. Voll Reue versenkt sich Gretchen vor einer Madonna ins Gebet: »In einer Mauerhöhle ein Andachtsbild der Mater dolorosa, Blumenkrüge davor. Gretchen steckt frische Blumen in die Krüge. ${ }^{7}$ In der kunstwissenschaftlichen Begriffsgeschichte des $>$ Andachtsbilds $\iota^{8}$ konkurrieren ikonographische und funktionale Ansätze. Das Andachtsbild wurde von Georg Dehio und Wilhelm Pinder nach 1920 zunächst iko nographisch definiert und nur auf Skulpturen bezogen. Erwin Panofsky erweiterte den Begriff über die Plastik hinaus auf die Malerei und unterschied mit seinem formgeschichtlichen Ansat $z^{9}$ verschiedene Bildtypen des Andachtsbilds. Dorothee Klein greift diesen Ansatz in ihrem zusammenfassenden Artikel ${ }^{10}$ auf und spricht mit Panofsky vom "Zeigegestus « der Bildsprache, der das Andachtsbild vom »szenischen Historienbild « und vom »kultischen Repräsentationsbild « unterscheide. Einen funktionalen Ansatz vertritt implizit bereits Rudolf Berliner $^{11}$, wenn er jedem Kunstwerk die Möglichkeit zugesteht, devotionale Gefühlsbeziehungen auszulösen, und im Rückbezug auf mittelalterliche Erbauungsliteratur den Begriff `Erbauungsbilder v vorschlägt. Auch Hans Aurenhammer sen. vertritt eine funktionale Definition und bezeichnet als Andachtsbilder Werke, die eine liturgisch nicht gebundene Frömmigkeit freisetzen. ${ }^{12}$ Während Sixten Ringbom ${ }^{13}$ noch einmal auf den ikonographischen Ansatz Panofskys zurückgreift, verbindet erst Horst Appuhn den ikonographischen und den funktionalen Ansatz: So wie auch szenische Historienbilder der Andacht dienen können, ohne dass sie einem der Bildtypen Panofskys zuzurechnen wären, können auch Andachtsbilder im engeren Sinne andere Funktionen als die vorgesehene kontemplative Versenkung über-

\footnotetext{
${ }^{7}$ FA 7/1, hrsg. von Albrecht Schöne), S. 156. Bereits im Faust-Fragment lautet die Szenenanweisung genauso, vgl. MA 3,1, S. 585.

${ }^{8}$ Schade, Karl: Andachtsbild, Die Geschichte eines kunsthistorischen Begriffs, Weimar 1996. Meine Untersuchung, die auf die Vergleichbarkeit profaner und kirchlicher >Andachtsbilder abhebt, kann sich der funktionalen Definition Schades anschließen: „Andachtsbilder sind religiöse Bilder für den Gebrauch des einzelnen Gläubigen, deren Form von der Aufgabe bestimmt ist, diesem eine affektive Annäherung an das Dargestellte nahezulegen. Andachtsbilder sollen das Innerste anrühren und gleichzeitig als Gegenüber empfunden werden können. Dieser Aufgabe konnten zu unterschiedlichen Zeiten unterschiedliche Motive dienen. Daher kann man sAndachtsbild nicht endgültig definieren, sondern immer nur in seinen konkreten historischen Formen und Funktionen untersuchen «(a.a.O., S. 96). Dieser Sachverhalt gilt mutatis mutandis auch für das neustoisch inspirierte Historiengemälde (vgl. oben S. 198ff.).

9 Panofsky, Erwin: »Imago pietatis. Ein Beitrag zur Typengeschichte des Schmerzensmannes und der Maria Mediatrix«, in: Festschrift für Max Friedländer zum 60. Geburtstag, Leipzig 1927, S. 261-308. Unter formgeschichtlichen Gesichtspunkten situiert Panofsky das Andachtsbild zwischen epischem Historien- und hieratischem Repräsentationsbild; es entsteht aus der »Verzuständlichung « des Historienbildes oder der »Verbeweglichung « des Repräsentationsbildes. Die Mystik des frühen 14. Jahrhunderts, insbesondere ihre Ausprägung in Frauenklöstern, entwickelte verschiedene Typen des Andachtsbildes (Pietà, Schmerzensmann, Marienklage, Christus-Johannes-Gruppe etc.). Seit dem 15. Jahrhundert und verstärkt in der Gegenreformation wurden kleine Andachtsbilder graphisch (als Teil oder Einlage eines Gebetbuches, zur Erinnerung an eine Wallfahrt, einen Ablass etc.) reproduziert. Neue Motive (Herz-Jesu-Verehrung, Pia Anima, Memento mori) treten auf.

${ }^{10}$ Klein, Dorothee: »Andachtsbild«, in: Reallexikon zur deutschen Kunstgeschichte, Stuttgart 1937, Sp. 681687.

${ }^{11}$ Berliner, Rudolf: »Arma Christi«, in: Münchener Jahrbuch der bildenden Künste, 3 (1955), S. 53-152, und »Bemerkungen zu einigen Darstellungen des Erlösers als Schmerzensmann«, in: Das Münster 9 (1956), S. 97-117.

${ }^{12}$ Aurenhammer, Hans: Die Mariengnadenbilder Wiens und Niederösterreichs in der Barockzeit, Diss. Wien 1956

${ }^{13}$ Ringbom, Sixten: Icon to narrative: The Rise of Dramatic close-up in fifteenth-century devotional Painting, Ábo 1965 und: „Devotional images and imaginative devotions«, in: Gazette des Beaux-Arts (1969), S. 159170.
} 


\section{Posttridentinische Märtyrer und stoische Tugendhelden}

nehmen. ${ }^{14}$ Weil sich die Untersuchung von Frank O. Büttner ${ }^{15}$ auf das Mittelalter beschränkt, interessiert sie sich nicht für durch das Andachtsbild ausgelöste psychologische Mechanismen der imitatio, sondern für Bildinhalte, deren Gestaltung oder Umgestaltung den Betrachter zu Frömmigkeitsübungen anleiten und sich an der ins Bild gesetzten pietas orientieren. Hans Belting verbindet ikonographische, formanalytische und funktionsgeschichtliche Methoden mit der Begrifflichkeit der Semiotik und Semantik. ${ }^{16} \mathrm{Er}$ fasst Andacht als "Stil affektiver Religiosität « auf, »der vor Bildern einen analogen Stil der Betrachtung ins Leben rief« (S. 77). Ein Andachtsbild will »mit visuellen Mitteln deklamieren und an die Gefühle des Betrachters appellieren «; es erzeugt im Betrachter eine Stimmung, ermöglicht es aber zugleich dem Betrachter seine eigene Stimmungslage im Bild wiederzufinden (S. 98). Dieses funktionale Verständnis des Andachtsbilds lässt verschiedenste Typen, Motive und Ausgestaltungen zu und trägt auch dem Umstand Rechnung, dass Bilder ihren Status als Andachtsbilder wieder verlieren können, wenn sich neue Andachtsformen und -motive entwickeln, so wie unter anderen Vorzeichen konzipierte Bilder den Status von Andachtsbildern erhalten. ${ }^{17}$

Die ikonographische Nähe kirchlicher und neustoischer Andachts- oder Meditationsbilder entging bereits den zeitgenössischen Theoretikern nicht. So überrascht es nicht, wenn sich die in Kunsttraktaten der Epoche beschriebenen Wirkungsstrategien auf Historien- wie auf Andachtsbilder beziehen lassen. Der spanische Maler und Kunsttheoretiker Francisco Pacheco (1564-1644) etwa, der sich intensiv mit der Kunsttheorie der Antike und des Cinquecento auseinandergesetzt hat, entwickelte in seinem 1649 in Sevilla veröffentlichten Traktat Arte de la pintura ${ }^{18}$ eine ikonographische Rhetorik, deren moralische Absichten sich über den Bereich der religiösen Malerei hinaus auch auf die Historienmalerei anwenden lassen:

No se puede cabalmente declarar el fruto que de las imágines se recibe: amaestrando el entendimiento, moviendo la voluntad, refrescando la memoria de las cosas divinas; produciendo juntamente en nuestros ánimos los mayores y más eficaces efectos que se pueden sentir de alguna cosa en el mundo; representándose a nuestros ojos y, a la par, imprimiendo en nuestro corazón actos heróicos y magnánimos, ora de paciencia, ora de justicia, ora de castidad, mansedumbre, misericordia y desprecio del mundo. De tal manera que, en un instante, causa en nosotros deseo de la virtud, aborrecimiento del vicio, que son los caminos principales que conducen a la bienaventuranza. ${ }^{19}$

\footnotetext{
14 Appuhn, Horst: »Das private Andachtsbild: Ein Vorschlag zur kunstgeschichtlichen und volkskundlichen Terminologie «, in: Museum und Kulturgeschichte: Festschrift Wilhelm Hansen, Münster 1978, S. 289-292, und Einführung in die Ikonographie der mittelalterlichen Kunst in Deutschland, Darmstadt 1969.

${ }^{15}$ Büttner, Frank O.: s/mitatio pietatisı, Motive der christlichen Ikonographie als Modelle der Verähnlichung, Berlin 1983.

${ }_{17}^{16}$ Belting, Hans: Das Bild und sein Publikum im Mittelalter, Berlin 1981.

${ }^{17}$ Neuere Arbeiten beschäftigen sich mit Detailfragen: z. B. Kecks, Ronald: Madonna und Kind: das häusliche Andachtsbild im Florenz des 15. Jahrhunderts, Frankfurt 1988; Bertling, Claudia: Die Darstellung der Kreuzabnahme und der Beweinung Christi in der ersten Hälfte des 16. Jahrhunderts, Hildesheim 1992; Slenczka, Ruth: Lehrhafte Bildtafeln in spätmittelalterlichen Kirchen, Köln 1998; Beer, Manuela: Das kleine Andachtsbild: Graphik vom 16. bis zum 20. Jahrhundert, Hildesheim 2004.

${ }^{18} \mathrm{Vgl}$. Hellwig, Karin: Die Anfänge der Kunstgeschichtsschreibung in Spanien im 17. Jahrhundert, Diss. phil. FU Berlin 1995, v.a. S. $180 \mathrm{ff}$.

${ }^{19}$, Es ist müßig, all den Gewinn, den uns die Bilder bringen, aufzuzählen: Sie schärfen unseren Verstand, sie stärken unseren Willen, sie frischen unser Gedächtnis für die göttlichen Dinge auf; sie bewirken, alles in allem, in unseren Seelen die edelsten und stärksten Gefühle, die man für die Dinge dieser Welt haben kann, indem sie uns die heldenhaften und großmütigen Taten, sei es der Geduld, sei es der Keuschheit, der Sanftmut, der
} 


\section{Posttridentinische Märtyrer und stoische Tugendhelden}

Nicht nur der Bildappell zu heroischem und selbstlosem Handeln (actos heróicos y magnánimos) lässt sich mühelos auch auf die Historienmalerei übertragen; auch die angestrebte Wirkung der Bilder, die Pacheco in der traditionellen Opposition von Tugenden und Lastern formuliert, setzt gemeinsame anthropologische Grundwerte voraus.

Märtyrerbilder ${ }^{20}$ riefen den betenden Betrachter zu identifikatorischer Einfühlung (compassio) auf, unabhängig davon, ob sie in großen Formaten für Altäre oder in kleinen Formaten für die private Andacht bestimmt waren. Darstellungen sterbender Heiliger leiteten als Andachtsbilder zur Betrachtung und Meditation der Heiligenvita (sanctorum [...] vitam moresque) an. Um dem Betrachter die affektive Vergegenwärtigung des dargestellten Geschehens zu ermöglichen, lassen Andachtsbilder der meditierenden Betrachtung weiten Spielraum. Die Darstellung sterbender Tugendhelden profaner Meditationsbilder (ebenfalls in großen und kleinen Formaten) bietet ein den Andachtsbildern entsprechendes Identifikationspotential und überträgt die christliche compassio in eine dazu nicht im Widerspruch stehende stoische consolatio.

Der Vorschlag, die ^Heroisierung posttridentinischer Märtyrern und neustoischer Tugendhelden zu vergleichen ${ }^{21}$, soll natürlich nicht übersehen lassen, dass die kirchliche Kunst entscheidend von der theologischen Debatte auf und nach dem Konzil von Trient geprägt ist. Das bekannte tridentinische Dekret De invocatione,

Barmherzigkeit, der Verachtung der Welt vor Augen führen und sie gleichzeitig in unsere Herzen einprägen, so dass sie in uns, in einem einzigen Augenblick, den Wunsch nach Tugend und den Wunsch nach Verabscheuung des Lasters entstehen lassen, den beiden wichtigen Wegen, um die ewige Seligkeit zu erlangen.ı (Übersetzung von Jutta Seeger in: Gaehtgens, Thomas W. / Fleckner, Uwe [Hrsg.]: Historienmalerei, Berlin 1996, S. 149 u. 153)

${ }^{20}$ Vgl. Smith, Lacey Baldwin: Fools, Martyrs, Traitors, Chicago 1999; Gregory, Brad Stephen: Salvation at Stake, Cambridge (Mass.) 1999; Ameling, Walter (Hrsg.): Märtyrer und Märtyrerakten, Stuttgart 2002; Burschel, Peter: Sterben und Unsterblichkeit, Zur Kultur des Martyriums in der Frühen Neuzeit, München 2004. Im Gottesdienst, in der stillen Fürbitte in der Kirche oder auch beim privaten Gebet sind Märtyrer Vorbilder für die Gemeinde und den Einzelnen. - Die Einbindung der Andachtsbilder in die Frömmigkeitspraxis wird in der katholischen Reform durchgängig gefördert. Märtyrerbilder rufen beim Betrachter die Erinnerung an den vorbildlichen und heroischen Bekennertod des Heiligen auf. Der Analogieschluss, dass das Sterbebild eines Cato oder einer Porzia beim Betrachter die Vorbildlichkeit des freiwilligen, sphilosophischen` Todes evozierte und zu philosophischer Meditation und Reflexion anregte, drängt sich auf.

${ }^{21}$ Er kann sich immerhin auf Tertullian berufen, der in Ad martyres durchaus den Vergleich mit sheidnischen Märtyrern zieht und den christlichen Märtyrern nur darin einen Vorzug gibt, dass sie nicht durch »terrena gloria « und »laus humana " motiviert sind, sondern den christlichen Märtyrertod im Hinblick auf die «gloria caelestis « auf sich nehmen. (»Igitur si tantum terrenae gloriae licet de corporis et animae vigore, ut gladium, ignem, crucem, bestias, tormenta contemnat sub praemio laudis humanae, possum dicere, modicae sunt istae passiones ad consecutionem gloriae caelestis et divinae mercedis. Si tanti vitreum, quanti verum margaritum? Quis ergo non libentissime tantum pro vero habet erogare, quantum alii pro falso? « [mart. 4,9)]. Tertullian erwähnt ausdrücklich Dido, Lukretia und Kleopatra als profane Märtyrerinnen zitiert. Vgl. oben S. 104, 119 und 141. 


\section{Posttridentinische Märtyrer und stoische Tugendhelden}

veneratione et reliquiis sanctorum et sacris imaginibus (1564) setzte sich - mit Folgen für die gesamte Barockmalerei - implizit mit der protestantischen Polemik gegen die Bilderverehrung auseinander und fasst wohl am prägnantesten die katholische Position zur Funktion religiöser Bilder zusammen:

Illud vero diligenter doceant episcopi, per historias mysteriorum nostrae redemptionis, picturis vel aliis similitudinibus expressas, erudiri et confirmari populum in articulis fidei commemorandis et assidue recolendis; tum vero ex omnibus sacris imaginibus magnum fructum percipi, non solum quia admonetur populus beneficiorum et munerum, quae a Christo sibi collata sunt, sed etiam quia Dei per sanctos miracula et salutaria exempla oculis fidelium subiiciuntur, ut pro iis Deo gratias agant, ad sanctorumque imitationem vitam moresque suos componant, excitentur ad adorandum ac diligendum Deum, et ad pietatem colendam. ${ }^{22}$

Der Darstellung des Heilsgeschehens oder der Heiligen liegt eine ikonographische Rhetorik der Vergegenwärtigung und des Appells zugrunde. ${ }^{23}$ Die theologischen Bildtheoretiker der Gegenreformation entwickelten eine Ikonologie der fiktionalen Vergegenwärtigung, die den Gläubigen das Heilsgeschehen nahe bringt und zur Nachfolge und zur Nachahmung (imitatio) der Heiligen aufruft. Aller Nachdruck des tridentinischen Dekrets liegt auf diesem Verweischarakter der religiösen Bilder, auf der moralischen Funktion religiöser Erbauung. Aus der Polemik gegen die missbräuchliche Bilderverehrung, die übrigens eine substantialistische Ästhetik voraussetzt, ergibt sich eine auch über die theologische Veranlassung hinaus folgenreiche Ästhetik des Verweises und eine moralische Funktionsbestimmung der Kunst, zugleich aber auch eine theologische Rechtfertigung künstlerischer Fiktionalität. Nur das moralische Ziel rechtfertigt die fiktionale Vergegenwärtigung durch die Kunst:

Non credatur inesse aliqua in iis divinitas vel virtus, propter quam sint colendae, vel quod ab eis sit aliquid petendum, vel quod fiducia in imaginibus sit figenda, veluti olim fiebat a gentibus, quae idolis spem suam collocabant: sed quoniam honos, qui eis exhibetur, refertur ad prot ot y pa, quae illae representant. ${ }^{24}$

\footnotetext{
${ }^{22}$ Decretum de invocatione, veneratione et reliquiis Sanctorum et sacris imaginibus, in: Denzinger, Heinrich [Hrsg.]: Enchiridion Symbolorum definitionum et declarationum de rebus fidei et morum, Freiburg ${ }^{24} 1967, \mathrm{~S}$. 419-420: (>Die Bischöfe sollen darauf achten, - dass das Volk durch die Erzählungen der Geheimnisse unserer Erlösung, wie sie in Bildern oder anderen Kunstwerken dargestellt werden, erbaut und in den Glaubensartikeln bestärkt wird, die einzuprägen und regelmäßig vor Augen zu führen sind; - dass so aus allen religiösen Bildern tatsächlich großer Nutzen zu ziehen ist, nicht nur weil das Volk an die Wohltaten und Gaben Christi erinnert wird, sondern auch weil die Heiligen den Gläubigen die Wunder Gottes und nützliche Beispiele vor Augen führen. Sie werden so veranlasst, Gott Dank zu sagen, ihren Lebenswandel auf die Nachfolge (imitationem) der Heiligen auszurichten, und aufgerufen, Gott liebend zu verehren und den Glauben zu bewahren.८) [Hervorhebungen hier und in den weiteren Zitaten von mir.]

${ }^{23}$ Fumaroli, Marc: L'âge de l'éloquence: rhétorique et sres literariar de la Renaissance au seuil de l'époque classique, Paris ${ }^{3} 2002$

${ }^{24}$ Ebd., S. 420. (>Man soll nicht glauben, den Bildern komme etwas Göttliches oder eine Eigenschaft zu, weswegen sie verehrt werden müssten, oder man könne von den Bildern etwas erflehen oder sein Vertrauen auf sie richten, wie das einst von den Heiden geschah, die ihre Hoffnungen auf Götzenbilder richteten: die den Bildern gewährte Ehrerbietung bezieht sich auf das Dargestellte (prototypa), das sie nur repräsentieren.८)
} 


\section{Posttridentinische Märtyrer und stoische Tugendhelden}

Das substantialistische Missverständnis der einfachen Gläubigen und des populären Wunderglaubens beschäftigte die theologische Reflexion natürlich weiterhin, zumal sich aus der tridentinischen Ikonologie die paradoxe Folge ergab, dass gerade rhetorisch besonders gelungene Darstellungen den bloßen Repräsentationscharakter gefährdeten oder doch für die Gläubigen in den Hintergrund treten lieBen. Deshalb verhandelten Lokalsynoden, wie die venezianische von 1594, weiter die Bilderfrage und versuchten, gegen den von den Protestanten geschmähten Missbrauch religiöser Bilder anzugehen:

Cum imagines Christi, Deiparae Virginis, et aliorum sanctorum in templis praesertim habendas et retinendas esse a catholicis patribus sit definitum, non quod in eis aliquid divinitatis, vel virtutis insit, sed ut omnis veneratio ac cultus ad pro to ty pa earundem referatur. Proinde parochi diligenter attendant, ne quis simplicitate ductus labatur, sed doceant mente repetenda esse quae picta, vel sculpta oculus prospicit, cum hinc profecto ad veram Dei adorationem et dilectionem quis pervenire possit. ${ }^{25}$

Bilder religiösen Inhalts sollten auf keinen Fall als solche verehrt werden, auf ihrem Verweischarakter war zu bestehen. Die kirchliche Unterweisung hob darauf ab, dass die auf den Bildern nur dargestellten prototypa als Exempel für vorbildliches christliches Leben zu >lesen waren und auf keinen Fall die Bilder als solche verehrt werden durften. Diese Ästhetik des Verweises ${ }^{26}$ hat in der nachtridentinischen Kunst der katholischen Reform oberste Priorität.

In der katholischen Reformbewegung wurde lebhaft darüber diskutiert, wie sich kontroverstheologische katholische Glaubensinhalte überzeugend ıins Bild setzenı ließen. Johannes Molanus (De Picturis et Imaginibus Sacris, 1570), Gabriele Paleotti (De sacris et profanis imaginibus, 1582) und vor allem Federico Borromeo mit seinem 1624 erschienenen einflussreichen Traktat De Pictura Sacra förderten die Entwicklung gegenreformatorischer Bildkonzepte, die auf identifikato-

\footnotetext{
${ }^{25}$ Das Dekret der venezianischen Synode von 1594 nach Seidel, Martin: Venezianische Malerei zur Zeit der Gegenreformation, Kirchliche Programmschriften und künstlerische Bildkonzepte bei Tizian, Tintoretto, Veronese und Palma il Giovane, Münster 1996, S. 311. (১Wenn die Konzilsväter bestimmt haben, dass die Bilder Christi, der jungfräulichen Gottesmutter und anderer Heiligen besonders in den Kirchen ihren Platz finden sollen und zu bewahren sind, dann nicht, weil den Bildern etwas Göttliches oder eine besondere Eigenschaft zukäme, sondern damit sich alle Verehrung und Anbetung auf das Dargestellte richtet. Deshalb sollen die Pfarrer sorgfältig darauf achten, dass niemand aus Einfalt irrt; vielmehr sollen sie lehren, dass Bilder und Skulpturen, die das Auge erblickt, erst vom Verstand aufgegriffen werden müssen, wenn sie in der Tat zur wahren Gottesverehrung und Gottesliebe führen sollen.८)

${ }^{26}$ Es wurde zurecht darauf hingewiesen (Imorde, Joseph: Affekt-Übertragung, Berlin 2004, S. 172ff.), dass Ignatius von Loyola, Filippo Neri und Clemens VIII. eine Betrachtungskultur propagierten, die sich nicht auf das Bild, sondern auf das Bezeichnete konzentrierte und im »Akt der Beschauung « zum verborgenen Prototypus durchzudrang. Ihre stark affektisch geprägte Frömmigkeitspraxis ist zwar stark der »Empfindungskultur des späten 16. Jahrhunderts « verpflichtet, demonstriert aber gerade deshalb »die Trennung des Zeichens vom Bezeichneten « und das Überwinden der Kunst »in einem inneren Kontemplationsakt«.
} 


\section{Posttridentinische Märtyrer und stoische Tugendhelden}

rische Erbauung frommer Betrachter abzielten. ${ }^{27}$ Die ikonographische Rhetorik der kirchlichen Kunst bemächtigt sich mit allen zur Verfügung stehenden Mitteln der Emotionen und Affekte des Betrachters, um ihr moralisches Ziel zu erreichen, das Gabriele Paleotti, ein bedeutender Akteur des Konzils, in seinem Discorso intorno alle imagini sacre e profane (1582) treffend mit »persuadere le persone alla pietà « ${ }^{28}$ umschreibt. Von inm stammt auch eine interessante Unterscheidung der Rezipientengruppen kirchlicher $\mathrm{Kunst}^{29}$, die sich vielleicht ebenso auf die Auftraggeber, Sammler und Rezipienten der Historienmalerei übertragen lässt. Unter pastoralen Gesichtspunkten blieb es problematisch, einerseits beim Gläubigen durch die Vermittlung der picturae und similitudines die Identifikation mit den dargestellten prototypa anzustreben, andererseits den Unterschied zwischen Abbild und Urbild stets bewusst zu halten. Paradoxerweise lässt die ikonographische Rhetorik der posttridentinischen Kunst, gerade wenn sie gelingt, diesen Unterschied in den Hintergrund treten.

In dieser Hinsicht an das frühneuzeitliche Historiendrama ${ }^{30}$ anknüpfend und dessen Verfahren übernehmend, dramatisierten viele Barockkünstler ihre Altarund Andachtsbilder und wählten in ihren ikonographischen Konzepten den theatralischen Moment der Peripetie, die Umkehr und Bekehrung eines Heiligen als Höhepunkt eines dramatischen Geschehens, in das der Betrachter einbezogen wird. Die Bekehrung des Paulus avancierte wohl deshalb zu einem beliebten Paradigma. ${ }^{31}$ Andererseits werden narrative Verfahren gewählt, die es etwa in der ebenso beliebten Darstellung Maria Magdalenas als büßender Sünderin ermöglichten, zu-

\footnotetext{
${ }^{27}$ Vgl. Freedberg, David: „Kunst und Gegenreformation in den südlichen Niederlanden 1560-1660«, in: AK Von Bruegel bis Rubens, Das goldene Jahrhundert der flämischen Malerei, Köln / Antwerpen / Wien 1992, S. 55-70.

${ }^{28}$ Vgl. Paleotti, Gabriele: Discorso intorno alle imagini sacre e profane, in: Barocchi, Paola (Hrsg.): Trattati d'arte del cinquecento tra manierismo e controriforma, 3 Bde, Bari 1960, hier Bd. 2, S. 148. Dazu Steinemann, Holger: Eine Bildtheorie zwischen Repräsentation und Wirkung. Kardinal Gabriele Paleottis >Discorso intorno alle imagini sacre e profaner (1582), Hildesheim 2006.

29 $E$ da queste quattro cose giudicheressimo noi che si venessero ad abbracciare quattro gradi o professioni di persone, che sono i pittori, i letterati, gl'idioti e gli spirituali, come appresso si dichiarerà. « (ebd., S. 497)

${ }^{30}$ Vgl. S. $193 f f$.

${ }^{31}$ Man denke nur an Caravaggios 1601 ausgeführte Conversione di San Paolo, die sich noch in der römischen Kirche Santa Maria del Popolo in situ befindet. Grundsätzliches zu den von der Gegenreformation bevorzugten Heiligen bei Mâle, Émile: L'art religieux après le concile de Trente, Paris 1932, S. 65ff. Joseph Imorde (AffektÜbertragung, Berlin 2004, S. 83-138, insbesondere S. 113f.) geht in seinem Kapitel »Göttlicher Süßstoff« ausführlich auf Maria Magdalena und Petrus ein. In der Gegenreformation wurde die Bußgesinnung des gläubigen Betrachters durch die wichtigen Bildthemen der büßenden Maria Magdalena und des seine Verleugnung bereuenden Petrus unterstützt. Tränen waren das ersehnte Ziel solcher Bildbetrachtungen; besonders unter dem Pontifikat Clemens VIII. wurden Weinen und Rührseligkeit als Zeichen gelungener Affektion und Umkehr gewertet. Den Endpunkt dieser empfindsamen religiösen Kunst sieht Imorde in Carlo Dolce, dessen gefühlsselige Produktion (»dolce e leccato «) Andachtsbilder für den Devotionalienmarkt lieferte.
} 


\section{Posttridentinische Märtyrer und stoische Tugendhelden}

rückgelassenen Reichtum und aufgegebenen Luxus einerseits, Askese, Leibfeindlichkeit und Weltflucht andererseits zu kontrastieren.

Während für die kirchliche Malerei und ihre Funktionen das tridentinische Dekret und die sich daraus ergebende theologische Debatte herangezogen werden können, stehen vergleichbare Hintergrundstexte für die Tugendhelden der profanen Malerei nicht zur Verfügung, sieht man vom allgemeinen neustoischen Referenzrahmen ${ }^{32} \mathrm{ab}$. Eine entsprechende kunsttheoretische Diskussion fand allerdings in der facettenreichen poetologischen Debatte zum frühneuzeitlichen Historiendrama statt. Sie kann in diesem Zusammenhang mit Gewinn herangezogen werden.

Die Wirkungsstrategien und moralischen Absichten profaner Historiengemälde unterscheiden sich keineswegs grundsätzlich von Altar- und Andachtsbildern, wenn sie an die Stelle der Heiligen Tugendhelden und Tugendheldinnen verschiedenster Provenienz treten lassen. Allerdings lässt sich aus heutiger Sicht ihr sweltlicher` Wirkungsraum oft nur ungenau bestimmen und damit ihre ursprüngliche Wirkungsabsicht nur noch ungefähr rekonstruieren. Gleichwohl bestehen zwischen religiöser Erbauung und moralischem Diskurs die mannigfachsten Übergänge: Meditationsbilder wandeln vanitas-Motive und Varianten des memento mori in religiösen und profanen Kontexten ab. Eine ıneustoische Ikoner wie Der sterbende Seneca von Rubens ${ }^{33}$ übernimmt ganz demonstrativ Funktionen des Heiligenbildes. Der Einfluss der Theaterästhetik auf kirchlichen wie profanen Historiengemälden ist unübersehbar. Auch die letzteren rekonstruieren exemplarische Lebensläufe von ihrem Ende her und setzen wie beim Zuschauer im Theater auf die Identifikationsaffekte des Betrachters. Neben ihrer dekorativen, panegyrischen oder historischen Funktion streben Historiengemälde eine kathartische Wirkung auf den Betrachter an, die mit der eines Andachtsbilds auf den meditierenden Gläubigen durchaus übereinstimmt. Wie ein Andachtsbild verfolgt das Historienbild überdies intellektuelle und emotionale Strategien.

Im Folgenden untersuche ich an Beispielen von Rubens (1577-1640), Reni (15751642) und Tiepolo (1696-1770) und damit über den gesamten hier in Frage stehenden Zeitraum hinweg die Wirkungsstrategien thematisch vergleichbarer kirchlicher und profaner Gemälde, um zu zeigen, dass posttridentinische Märtyrerbilder

\footnotetext{
${ }^{32}$ Vgl. S. $177 \mathrm{ff}$.

${ }^{33}$ Vgl. S. $213 \mathrm{ff}$.
} 


\section{Posttridentinische Märtyrer und stoische Tugendhelden}

und frühneuzeitliche Darstellungen sterbender ıneustoischerı Tugendhelden bei allen Konvergenzen und Differenzen analoge Wirkungsstrategien einsetzen. Dabei sind die künstlerischen Mittel ebenso von Interesse wie die Frage, ob sich hinter der religiösen Begrifflichkeit der Andacht und Erbauung (compassio und consola-

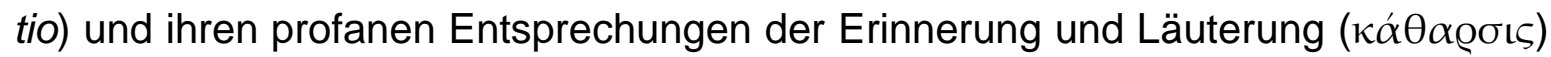
eine gemeinsame frühneuzeitliche Konzeption des Heroischen abzeichnet.

\section{Rubens: Christliche compassio und stoische consolatio}

Die Kunstproduktion der katholischen südlichen Niederlande, bis 1714 spanische, danach österreichische Provinz, war für die gesamteuropäische Entwicklung des Barock von großer Bedeutung. Die von der Kirche wie vom erzherzoglichen Hof als wichtigsten Auftraggeber bevorzugten große Formate wirkten aufgrund der engen Beziehungen Flanderns mit den anderen europäischen Höfen prägend und beeinflussten den Typus des barocken Altarbildes, aber auch des profanen Repräsentationsbildes entscheidend. ${ }^{34}$ Demgegenüber traten - im Unterschied zur nordniederländischen Schule - bürgerliche Kunstabnehmer in den Hintergrund. ${ }^{35}$

Das Martyrium des heiligen Laurentius ${ }^{36}$ von Peter Paul Rubens (heute in der Alten Pinakothek) [Abb. 1] entstand 1615 für die Brüsseler Kirche Notre-Dame-de-laChapelle ${ }^{37}$ und kann als typisches Beispiel eines barocken Altarbilds der südlichen Niederlanden gelten. Den Vordergrund des Bildes nimmt der jugendlich weiche, nur mit einem Lendentuch bedeckte Körper des bartlosen Diakons ein, den zwei Schergen mit muskulösen Armen auf den glühenden Rost zwingen. Die Hände hinter dem Rücken mit einer Kette gefesselt, wird der Körper bereits in eine Diagonale nach links gezwungen, während die Füße noch auf dem Boden stehen. Die

\footnotetext{
${ }^{34}$ Vgl. North, Michael: Kunst und Kommerz im Goldenen Zeitalter, Zur Sozialgeschichte der niederländischen Malerei des 17. Jahrhunderts, Köln / Weimar / Wien 1992.

${ }^{35}$ In der Republik der vereinigten Niederlande, die sich 1579 nach der Utrechter Union der nördlichen Provinzen Holland, Seeland, Utrecht, Geldern, Overijssel, Friesland und Groningen gegen Spanien und die Habsburger herausbildete, entwickelte sich schon bald die sogenannte holländische (oder nordniederländische) Schule. Wirtschaftliche, soziologische und religiöse Unterschiede ließen die künstlerischen Entwicklungen in den nördlichen Niederlanden eine eher bürgerliche Entwicklung nehmen. Genre, Landschaft, Seestück, aber auch kleinformatige Historiengemälde fanden in der wohlhabenden und bürgerlichen Gesellschaft guten Absatz. Vgl. zu diesem Themenkomplex den knappen, aber sehr instruktiven Aufsatz von Baudouin, Frans: »Religion und Malerei nach der Teilung der Niederlande«, in August Buck (Hrsg.): Renaissance - Reformation. Gegensätze und Gemeinsamkeiten, Wiesbaden 1984, S. 7-22.

${ }^{36}$ Vgl. Katalog 357, Bestandskatalog der Alten Pinakothek München, München 1983, S. 450-451 und Corpus Rubenianum, Saints II, hrsg. von Hans Vlieghe,) Brüssel 1973, S. 107-108. Die Maße des Leinwandbildes sind $244 \times 174$.

${ }^{37}$ Es gelangte in die Gemäldesammlung des Kurfürsten Johann Wilhelm von der Pfalz, der durch seinen Kunstagenten Jan Frans Douven vor allem flämische Gemälde ankaufen ließ. Die Sammlung war 1711 auf 341 Werke angewachsen und erforderte ein eigenes Galeriegebäude. Glanzvolles Kernstück der Düsseldorfer Bildergalerie waren 46 Werke von Peter Paul Rubens.
} 


\section{Posttridentinische Märtyrer und stoische Tugendhelden}

aufgerissenen Augen des Laurentius blicken nach oben, wo ein Putto mit Siegerkranz und Palmzweig das Ziel des Martyriums verheißt. Vorne links schürt ein Mann mit nacktem Oberkörper das Feuer unter dem Rost, das den Märtyrer bereits mit heftigem Rauch umhüllt. Rechts versucht ein in rotes Tuch gehüllter Priester unter einer Zeusstatue den jungen Mann zur römischen Staatsreligion zurückzurufen. An beiden Bildrändern drängen sich an ihren Helmen erkennbare römische Soldaten und sogar ein Pferd: die turbulente Folterszene vergegenwärtigt dem Betrachter die Bedrängnis des Blutzeugen. Rubens hat sich in seinem Altarbild wohl an Gemälden Tizians orientiert; so kann er in Venedig das 1548 entstandene Martyrium des heiligen Laurentius in der Jesuitenkirche ${ }^{38}$ gesehen haben.

Nur wenig kleiner ist ein Historiengemälde der Alten Pinakothek, dessen Thematik völlig ohne Vorbild war und als Invention des flämischen Meisters zu gelten

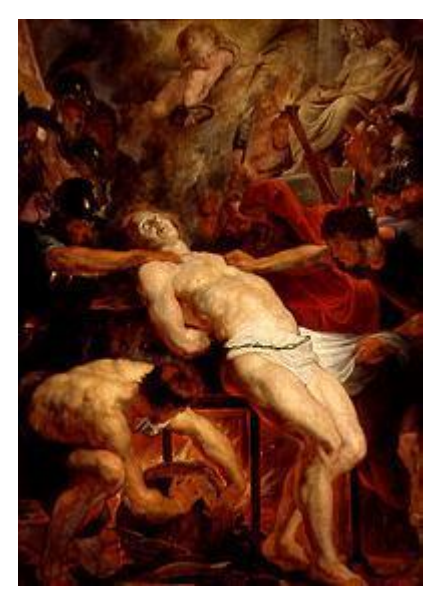

Abb. 1 hat. ${ }^{39}$ Der sterbende Seneca ${ }^{40}$ [Abb. 2] stammt wie das Martyrium des Laurentius aus der Düsseldorfer Galerie des Kurfürsten Johann Wilhelm von der Pfalz. Das Tafelbild paraphrasiert die Darstellung, die Tacitus vom erzwungenen Selbstmord des Philosophen Seneca gegeben hat, dem von seinem früheren Eleven Nero vorgeworfen wurde, an der Pisonischen Verschwörung beteiligt gewesen zu sein. ${ }^{41}$ Allerdings ist die Komposition des Bildes ganz von der moralischen Vorbildfunktion des stoischen Weisen bestimmt, der auch die historische Detailgenauigkeit dient. Nur mit einem Lendentuch bekleidet steht Seneca dem Betrachter in einem Wasserbecken frontal gegenüber. Der hagere Körper ist einer hellenistischen Marmorstatue nachgebildet, die Rubens während seines Romaufenthaltes im Besitz des Kardinals Scipione Borghese gesehen und gezeichnet hat ${ }^{42}$. Rubens folgte damit

\footnotetext{
${ }^{38} \mathrm{Zu}$ Tizians Martirio di San Lorenzo aus der venezianischen Jesuitenkirche vgl. Sandro Sponzas Katalogartikel in Biadene, Susanna (Hrsg.): AK Tiziano, Venezia 1990, S. 308-313 (mit Abb.).

${ }^{39}$ Dazu ausführlich Günter Hess: »Der Tod des Seneca, Ikonographie - Biographie - Tragödientheorie « in: Jahrbuch der deutschen Schillergesellschaft 25 (1981), S. 196-228, bes. S. 196-199.

${ }^{40} \mathrm{Vgl}$. Katalog 354 und Bestandskatalog der Alten Pinakothek München, München 1983, S. 461-462 (Eichenholz, 185 x 154,7). Am linken und rechten Bildrand wurden Anstückungen vorgenommen, ebenso am unteren Bildrand. Das Gemälde wird auf die Zeit um 1611 datiert. - Eine heute im Prado (Inv. Nr. 3048) befindliche Version ist wohl die erste Fassung des Themas. Ulrich Heinen erörtert in seinem Beitrag zum Madrider Seneca ausführlich die Problematik der Wiederholungen. Vgl. Büttner, Nils / Heinen, Ulrich (Hrsg.): AK Peter Paul Rubens, Barocke Leidenschaften, Braunschweig 2004, S. 234-243.

${ }^{41}$ Ann. XV, 60-65.

42 Die Statue befindet sich heute, gedeutet als Afrikanischer Fischer, im Louvre. Dazu: Van der Meulen, Marjon: Rubens' Copies after the Antique, 3 Bde, London 1994-1995 (Corpus Rubenianum 23), hier: Bd. 3, Abb. 19.
} 


\section{Posttridentinische Märtyrer und stoische Tugendhelden}

der Deutung der Zeitgenossen, die diese Statue als Seneca auffassten. Er ersetzte allerdings den Kopf der skulpturalen Vorlage in seinem Gemälde durch eine weit verbreitete römische Porträtbüste, von der Rubens selbst eine Replik erworben hatte, die den Eingang seines Hauses schmückte. ${ }^{43}$ Der weißhaarige und weißbärtige Seneca blickt, der Bildrealität bereits enthoben, konzentriert nach oben; wie eine Aureole umgibt dünnes weißes Haar den asketischen Kopf. Wie segnend ${ }^{44}$ unterstreicht die rhetorische Geste des rechten Arms die ultima verba, die ein links vom Philosophen kaurnder Schreiber notiert. Rechts steht ein Arzt, der den Blutfluss aus der geöffneten Armvene überprüft. ${ }^{45}$ Im linken Hintergrund betrachten ein römischer Centurio und ein Soldat als Stellvertreter des abwesenden Despoten

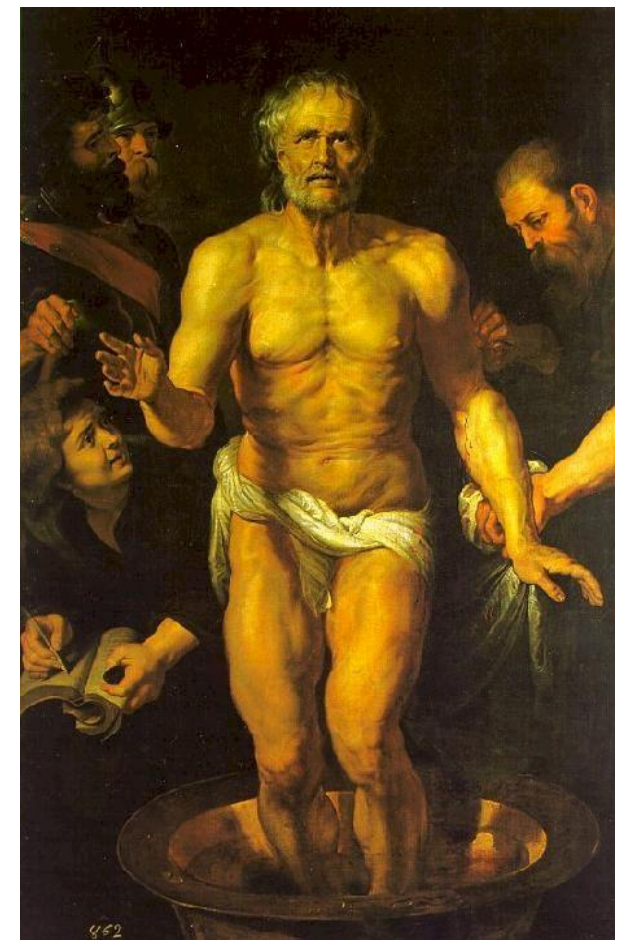

Abb. 2 gleichgültig das Geschehen. Der räumlich nicht strukturierte Hintergrund ist in dunklem Braun gehalten. Die vier Assistenzfiguren sind farblich zurückhaltend gestaltet, nur das hervorstechende Rot des Offiziersmantels lenkt den Blick kurz ab.

So stellt die Lichtregie den nackten Körper Senecas in den Mittelpunkt, während Gestik und konzentrierter Blick des Sterbenden ein profanes Äquivalent zum shimmelnden Blickı entwickeln. In der Bildformel ${ }^{46}$, die Rubens dem segnenden Christus nachbildet, hat die herausragende Bedeutung des Philosophen beredten

\footnotetext{
43 Justus Lipsius hat in seiner Abhandlung über Bibliotheken, De bibliothecis syntagma (1602), das neunte Kapitel (Ornatus bibliothecarum, ebore et vitro. Armaria et foruli, et plutei et cunei) der Ausstattung einer Bibliothek mit Skulpturen, Büsten und Porträts berühmter Männer gewidmet (Lipsius, Justus: De bibliothecis syntagma, Antwerpen 1602 [ND Hildesheim / Zürich / New York 2001], Bd. 3,2, S. 1122-1140). Zur Ausstattung von Villen und Palästen mit Büsten antiker Vorbilder (neben Evers, Hans Gerhard: Peter Paul Rubens, München 1942, S. 93) ausführlich Ulrich Heinen in: AK Peter Paul Rubens, Barocke Leidenschaften, a.a.O., S. 236ff. - Lucas Vorstermann hat den Seneca-Kopf nach einer Zeichnung von Rubens gestochen und in eine Serie von zwölf Blättern aufgenommen, die bedeutende Männer wie Demokrit, Sokrates, Scipio, Cicero und Nero umfasste. Über die Bedeutung des Seneca-Stiches in neustoischen Kreisen ausführlich Ulrich Heinen, a.a.O., S. 237-242. - Zu Rubens als Sammler und seinem Haus als ıKunstkammer Muller, Jeffrey M.: »Rubens's Collection in History«, in: Lohse Belkin, Kristin / Healy, Fiona (Hrsg.): AK A House of Art, Rubens as Collector Antwerpen 2004, S. 10-85.

${ }^{44}$ Der rechte Arm der antiken Skulptur eines afrikanischen Fischers hielt wohl ursprünglich eine Angel, während zur Linken wohl ein Eimer gehört haben dürfte. Rubens hat die Armbewegungen, anders aufgefasst, übernommen.

${ }^{45}$ Heinen, Ulrich: »Haut und Knochen - Fleisch und Blut. Rubens' Affektmalerei«, in: Heinen, Ulrich / Thielemann, Andreas (Hrsg.): Rubens Passioni, Kultur der Leidenschaften im Barock, Göttingen 2001, S. 70-109 (bes. S. 90-97) hat ausführlich die medizinischen Kenntnisse von Peter Paul Rubens untersucht.

46 Dazu vor allem von Simson, Otto: Peter Paul Rubens (1577-1640), Humanist, Maler und Diplomat, Mainz 1996, S. 151- 156. Außerdem Hess, Günter: »Der Tod des Seneca«, a.a.O.
} 


\section{Posttridentinische Märtyrer und stoische Tugendhelden}

Ausdruck gefunden ${ }^{47}$, der als Vorbild gelebter stoischer Lehre für den neustoischen Freundeskreis um Peter Paul Rubens eine wichtige Rolle spielte, zu dem neben seinem Bruder Philipp vor allem der Philosoph Justus Lipsius gehörten. Die vielfach kopierte und in Kupferstichen verbreitete Invention kann geradezu als ıneustoische Ikoneı der frühbarocken Historienmalerei und als der Prototyp eines profanen Andachtsbildes gelten.

Im Martyrium des heiligen Laurentius wie im Sterbenden Seneca - beide aus der Düsseldorfer Galerie stammend - betont die Lichtregie den nackten Körper. Das Inkarnat des Heiligen ist ebenso hell wie das des Philosophen, während in beiden Gemälden die braune Hautfarbe der übrigen Personen Tätigkeit und Männlichkeit ausdrückt. Die helle Haut lässt den Betrachter schutzlose Körperlichkeit, eine fast weibliche Verletzbarkeit assoziieren. Andererseits verweist sie auch auf die Leichenblässe und den demnächst eintretenden Tod. Seneca stirbt stehend und zeigt damit bis zum letzten Atemzug constantia: noch in seinem Sterben verwirklicht er gleichsam swörtlich die zentrale stoische Tugend des fortiter stare ${ }^{48}$, die konkret und metaphorisch zugleich ins Bild gesetzt wird. Auch Laurentius bleibt ıstandhaft bei seinem Glauben. Er steht bei Rubens noch auf beiden Füßen, obwohl sein Körper schon auf den Rost gebunden wird. Die sweltlicheı Macht wird in beiden Bildern mit der Farbe Rot evoziert: Ein rot gekleideter Priester versucht, Laurentius zum Widerruf zu überreden; die Botschaft des Tyrannen wird dem Philosophen von einem Offizier in rotem Umhang übermittelt.

Laurentius hat das Ziel seines Leidens visionär und unmittelbar vor Augen, während der vorbildliche Tod des stoischen Philosophen sein Weiterleben im Gedächtnis der Anhänger und philosophischen Freunde in Szene setzt. Doch intendieren beide Bilder eine vergleichbare Wirkung: bei Laurentius die christliche com-

\footnotetext{
${ }^{47}$ McGrath, Elizabeth: Rubens, Subjects from History (Corpus Rubenianum Ludwig Burchard, 13), 2 Bde, London 1997. Eine kritische Würdigung dieser Bände findet sich in der Rezension von Christine Göttler: »Elizabeth McGrath, Rubens, Subjects from History«, in: Kunstchronik 9/10 (2000), S. 482-489.

${ }_{48}$ Bei Seneca finden sich mehrere Belege für die zentrale stoische Tugend der Standhaftigkeit: De vita beata $\mathrm{XV}, 5$ (»illa [sc. virtus] fortiter stabit et quicquid evenerit feret non patiens tantum sed etiam volens «); Ep. 71, 25 (»illud mirare, ibi extolli aliquem, ubi omnes deprimuntur, ibi s t a re , ubi omnes iacent«); Ep. 71, 26 (»s t a t rectus [vir sapiens] sub quolibet pondere«). Auch in der patristischen Literatur wird häufig ein Bezug zu dieser stoischen Tugend hergestellt, etwa von Cyprian, De mort. 14 (»Contra tot impetus vastitatis et mortis inconcussi animi virtutibus congredi, quanta pectoris magnitudo est! Quanta sublimitas inter ruinas generis humani stare e rectum.«) oder von Johannes Chrystostomus, In ep. ad Hebr. III, hom. V, 4 (»Hoc autem fortium et philosophorum, firmiter stare.«[PG 63, 52])
} 


\section{Posttridentinische Märtyrer und stoische Tugendhelden}

passio des Frommen, im profanen Gegenstück die stoische consolatio ${ }^{49}$ des meditierenden Betrachters. Das Philosophenbild weckt im Bildaufbau und mit der segnenden Geste christologische Assoziationen und nähert zugleich den profanen Selbstmord dem Martyrium an. Im Heiligenbild wird das verheißene Jenseits in den Emblemen der Palme und des Siegeskranzes angedeutet; für den modernen Betrachter scheint die Botschaft des stoischen Sterbens verschlüsselter zu sein. Für die Zeitgenossen jedoch dürfte der neustoische Hintergrund unmittelbar erfassbar gewesen sein. ${ }^{50}$ Obwohl sich Rubens im Sterbenden Seneca eng an den Bericht des Tacitus anschließt und auch sein Martyrium des heiligen Laurentius eine vorgefundene Bildtradition aufgreift, gehen >christliches` und >philosophisches` Sterben in ihrer vergleichbaren Vorbildlichkeit fast ineinander über.

\section{Reni: Sehnsuchtshalbfigurenı als Meditationsbilder}

Guido Reni hat die büßende Magdalena ${ }^{51}$ ebenso wie den Selbstmord der Kleopatra mehrfach dargestellt und dabei halbfigurige und ganzfigurige Varianten erarbeitet. $^{52}$ In seinen halbfigurigen Darstellungen treten die narrativen Elemente des Historienbildes zurück; in dieser Variante wird deshalb die ikonographische und semantische Nähe von christlicher Märtyrerin und neustoischer Tugendheldin besonders deutlich. Da gerade die Reduktionsformel der Halbfigurenbilder Renis, unabhängig von ihrem kirchlichen oder profanen Thema, bis zu den Attitüden des 19. Jahrhunderts ${ }^{53}$ weiterwirkte, liegt der Gedanken nahe, dass sich die Langzeitwirkung der gemeinsamen Pathosformel (exemplum virtutis) des kirchlichen wie des profanen Motivs verdankt.

Die Büßende Magdalena in der Walters Art Gallery (Baltimore) [Abb. 3] stammt aus dem letzten Schaffensjahrzehnt des Künstlers, wie die charakteristische Wahl der durchsichtigen Farben unverkennbar anzeigt. ${ }^{54}$ Der erste Besitzer war Kardinal

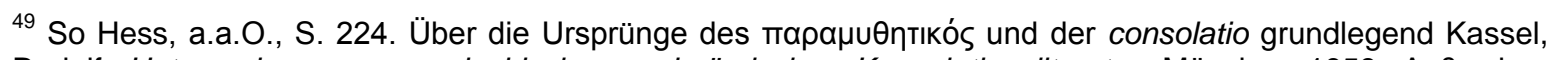
Rudolf: Untersuchungen zur griechischen und römischen Konsolationsliteratur, München 1958. Außerdem Kern, Manfred: »Konsolationsliteratur«, in: Der Neue Pauly, Stuttgart / Weimar 2000, Bd. 14, Sp. 1079-1082.

${ }^{50}$ Zum neustoischen Hintergrund vgl. S. $177 \mathrm{ff}$.

${ }^{51}$ Magdalena ist natürlich im strengen Sinn keine Märtyrerin, gleichwohl hat ihr Adreini das Epitheton martire del pianto verliehen (vgl. unten S. 218).

${ }^{52}$ Vgl. Pepper, Stephen: Guido Reni, L'opera completa, Novara 1988. Pepper kennt vier ganzfigurige Ausführungen mit Putti (Nr. I/130, I/197, I/142 und I/41) und zwei Brustbilder (Nr. I/143 und I/205). Halbfigurig erscheint Magdalena auf den Gemälden I/59, I/44, I/40, I/49 und I/115. Vier Gemälde (I/135, I/109, I/43 und I/28) sind dreiviertelfigurig ausgeführt. Nur eine Kleopatra (Nr. l/101) ist ganzfigurig, eine weitere dreiviertelfigurig (Nr. I/173), während die übrigen (Nr. I/95, I/111, I/181 und I/204) halbfigurig sind.

${ }^{53}$ Vgl. S. $294 \mathrm{ff}$.

${ }^{54}$ Vgl. Pepper, a.a.O., S. 339; Katalog 333: die Maße des von 1635 stammenden Gemäldes sind 90,5 × 74.
} 


\section{Posttridentinische Märtyrer und stoische Tugendhelden}

Antonio Barberini ${ }^{55}$, aus dessen Sammlung das Gemälde 1692 in die Kollektion der Chigi gelangte; seit diesem Zeitpunkt kann der weitere Weg des Bilds genau verfolgt werden. ${ }^{56}$

Oberkörper und Haupt der frontal und halbfigurig gegebenen Heiligen bilden eine Pyramide, die durch die Drehung des Kopfes der Büßerin nach links oben aufgelöst wird. Der sich im beigetonigen Hintergrund als Aufhellung abzeichnende Lichteinfall verstärkt die Diagonalbewegung von unten rechts nach oben links. Magdalena ist als junge Frau mit offenem hellbraunen Haar und sehr hellem Inkarnat dargestellt; das weite faltige Gewand in einem perligen Grauton

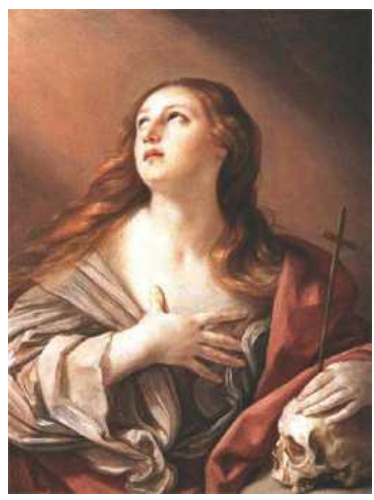

Abb. 3 unterstreicht die Diaphanität ihrer Erscheinung. Festigkeit erhält die Kontur durch einen roten Mantel, der den auf einem Totenschädel ruhenden linken Arm umhültt. In der Linken hält die Heilige ein schlichtes braunes Holzkreuz. Die rechte Hand führt sie im >Anbetungsgestus ${ }^{57}$ an die entblößte Brust und unterstreicht die Demutsgebärde durch den shimmelnden Blickı, der - entsprechend der mittelalterlichen Legende - nach Buße und Kontemplation die dritte Bewusstseinstufe der Erleuchtung andeutet. ${ }^{58}$ Die Pupillen sind nach oben links zum himmlischen Licht gerichtet, von den Augen sind nur noch die weißen Augäpfel zu sehen: Seit dem Erscheinen von Cesare Ripas »Iconologia«im Jahre 1593 waren »gli occhi rivolti al cielo « als »Teilhabe an göttlicher Gnade « ${ }^{59}$ kodiert. Der Mund hat sich leicht geöffnet und deutet das demütige Empfangen der sakramentalen gratia divina an.

\footnotetext{
${ }^{55}$ Dazu Cola, Alberto / Salvagni, Anna / Scolaro, Francesca / Scolaro, Michaela / Caroselli, Susan (Hrsg.): AK Guido Reni, 1575 - 1642, Bologna 1988, S. 154.

${ }^{56}$ Vgl. Pepper, a.a.O., S. 339.

57 Dazu schon 1938 Weise, Georg / Otto, Gertrud: Die religiösen Ausdrucksgebärden des Barock und ihre Vorbereitung durch die italienische Kunst der Renaissance, Stuttgart 1938 (Schriften und Vorträge der Württembergischen Gesellschaft der Wissenschaften, Geisteswissenschaftliche Abteilung, Heft 5). Die Autoren unterscheiden Gesten der Ergebenheit, der Inbrunst und der Beteuerung. Der Gestus der Beteuerung wird immer stärker zum Ausdruck des Schwärmerischen und der Ekstase (S. 48-63). Zuletzt dazu Ubl, Ralph: »Zu einer Interpretation von Guido Renis Andachtsbildern« in: Wiener Jahrbuch für Kunstgeschichte, 44, 1991, S. 159-173.

${ }^{58}$ Die Legenda aurea des Jacobus a Voragine erwähnt (XCVI) die Ekstase der Heiligen (»[...] qualibet autem die septem horis canonicis ab angelis in aethera elevabatur et coelestium agminum gloriosos concentus etiam corporalibus auribus audiebat, unde diebus singulis his suavissimis dapibus satiata et inde per eosdem angelos ad locum proprium revocata corporalibus alimentis nullatenus indigebat. «) und legt ihr einen weiteren Bericht in den Mund: ")Egos, inquit, ssum illa, quae per triginta annorum spatium omnibus hominibus ignota permansi et sicut tibi heri cernere permissum est, singulis diebus angelicis manibus in aethera sublevata coelestium agminum dulcissimam jubilationem septenis vicibus per singulos dies corporeis auribus audire permerui.ı (Hrsg. Graesse, Th., Dresden 1890 [ND Osnabrück 1965], S. 413-414)

${ }^{59}$ Henning, Andreas: »Die Physiognomie der Vision, Inspiration und Anbetung «; in: Andreas Henning / Gregor J. M. Weber (Hrsg.): AK >Der himmelnde Blickı, Zur Geschichte eines Bildmotivs von Raffael bis Rotari, Dresden 1998., hier S. 22.
} 


\section{Posttridentinische Märtyrer und stoische Tugendhelden}

Der Vergleich mit Renis ganzfigurigen Darstellungen ${ }^{60}$ Magdalenas verdeutlicht den hohen Abstraktionsgrad dieser um 1635 entstandenen halbfigurigen Variante. Im ganzfigurigen Typus [Abb. 4], den Reni ebenfalls mehrfach variierte ${ }^{61}$, wird die Schönheit der reumütigen Sünderin akzentuiert. Er zeigt Magdalena als Büßerin in einer Höhle und in verschiedenen Sitzpositionen, wobei Totenschädel und Kreuz ebenso wenig fehlen wie einige Bücher; Wurzelgemüse veranschaulicht das asketische Leben. Schwebende Putti verweisen in den ganzfigurigen Magdalenenbildern auf die mystische Vision der Büßerin.

Der unübersehbare Erfolg der Heiligen in der posttridentinischen Ikonographie hängt nicht zuletzt mit der Propagierung des von den Reformatoren abgelehnten Bußsakraments in der gegenreformatorischen Erneuerungsbewegung zusammen. ${ }^{62}$ Außerdem gehört ihre lkonographie in den Umkreis der vor allem von Domenico Fetti variierten, vanitas-Motive und Varianten des memento mori in religiösen und profanen Kontexten abwandelnden Meditationsbilder.

Es ist bezeichnend für diesen Typus von Meditationsbildern, dass sich bei der bekannten Melanconia Domenico Fettis in den venezianischen Gallerie dell'Accademia [Abb. 5] nicht entscheiden lässt, ob es sich noch um ein Heiligenbild oder bereits um eine rabstrakte، Melancholie handelt. Vergleichbares gilt für FettisMaddalena in Treviglio [Abb. 6]. Seine Maddalena penitente in der römischen Galleria Doria Pamphilj ${ }^{63}$ und eine andere Version in einer florentinischen Privatsammlung ${ }^{64}$ sind nur durch den Nimbus der Heiligen vereindeutigt. - Mit Robert Bellarmins kontroverstheologischem Hauptwerk (Disputationes de controversiis Christianae fidei adversus huius temporis haereticos, 1586-93) war die fromme Büßerin zu einer zentralen Gestalt katholischer Frömmigkeit avanciert. ${ }^{65}$ Domenico Fetti war im Übrigen mit dem Autor und Schauspieler Giovan Battista Andreini (1579-1654) befreundet, der 1617 eine srappresentazione sacraı La Maddalena in fünf Akten veröffentlichte, deren Prolog (ıSo le penne de' ventic) von Claudio Monteverdi vertont wurde. Andreini versammelte in seinem Werk alle gebräuchlichen Epitheta der Büßerin. ${ }^{66}$

Schon Giovanni Pietro Bellori ${ }^{67}$ hat erkannt, dass Renis Varianten der Büßenden Magdalena antike Bildformeln aufgreifen. Zu nennen ist vor allem die Niobiden-

\footnotetext{
${ }^{60} \mathrm{Zu}$ Renis großformatigen religiösen Gemälden im Rahmen der nachreformatorischen Bildertheologie vgl. Wimböck, Gabriele: Guido Reni (1575-1642), Funktion und Wirkung des religiösen Bildes, Regensburg 2002.

${ }^{61}$ Als Beispiel greife ich die in der römischen Galleria Nazionale d'Arte Antica des Palazzo Corsini gezeigte Magdalena heraus (Pepper, a.a.O., S. 275, Nr. 130).

${ }^{62}$ Vgl. Mâle, Émile: L'art religieux après le concile de Trente, Paris 1932, S. 67-72 und S. 190-191.

${ }^{63}$ Safarik, Eduard A. (Hrsg.): AK Domenico Fetti, 1588/89-1623, Mailand 1996, Nr. 22 mit Abb. Zur Melancholie neuerdings Cortenova, Giorgio (Hrsg.): AK Il settimo splendore, La modernità della malinconia, Venedig 2007.

${ }^{64}$ Safarik, a.a.O., Nr. 21 mit Abb.

65 Vgl. Mâle, a.a.O., S. 67-69; allgemein zur römischen ıHeiligenoperı: Schrammek, Bernhard: »»Benedette martiri... - Martyrium und Tod in römischen Heiligenopern des frühen 17. Jahrhunderts «, in: Fleischhauer, Günter / Ruf, Wolfgang / Siegmund, Bert / Zschoch, Frieder (Hrsg.): Tod und Musik im 17. und 18. Jahrhundert, Michaelstein 2001, S. 83-93.

66 Z. B.: >Penitente famosa, la Martire del Pianto, la Peccatrice Santa, l'Apostola beata, la Serafica devota, Scapigliata nel Crine, Lagrimosa ne' lumi, Genuflessa tremante, Disornata, ed humile, Pallida e sospiranter (vgl. Safarik, a.a.O., S. 124).

67 » lo seppi da chi fu seco famigliare in Roma, che Guido studiò molto statue di Niobe e delle figliole, le quali è in dubbio se siano di mano di Scopas o di Prasitele ma di qualunque di loro eccellentissime. In queste statue oltre l'altre parti esemplari, si comprendono bellissime alzate e mosse di testa che furono a lui di molto profitto alla maniera grande, ed all'alzate d'occhi delle sue Madalene, Lucrezie e Madonne, nelle quali osservazioni
} 


\section{Posttridentinische Märtyrer und stoische Tugendhelden}

Gruppe, die 1583 ausgegraben wurde und der Reni besondere Aufmerksamkeit geschenkt hat: Renis shimmelnder Blickı greift die Kopfhaltung der Niobe auf. ${ }^{68}$

Die schamhafte Handbewegung der halbfigurigen Magda-

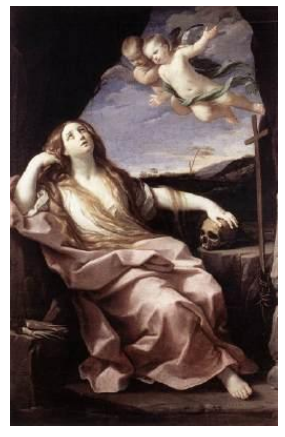

Abb. 4

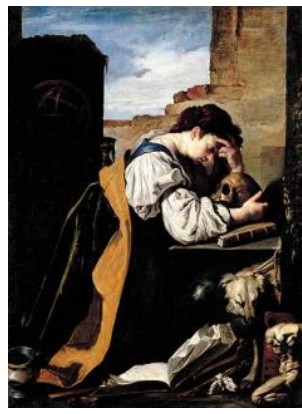

Abb. 5

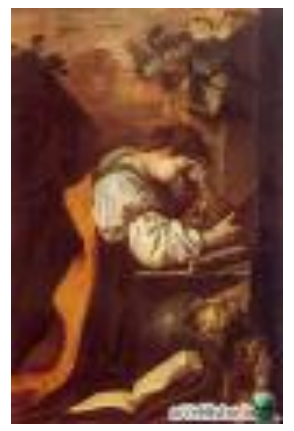

Abb.6

lena Renis lässt das Modell der Venus pudica erkennen; die Umdeutung der ihre Nacktheit ${ }^{69}$ verbergenden Geste in eine Bewegung dürfte durch Tizian vermittelt sein. ${ }^{70}$ Reni legt die Hand tiefer auf die entblößte Brust und verbindet auf diese Weise Schamhaftigkeit mit Ergebung in den göttlichen Willen. Das gegenreformatorische Heiligenbild integriert dem kulturellen Gedächtnis vertraute und geläufige Muster der Antike als Pathosformeln. In diesem Typus des Halbfigurenbilds entsteht so die "gegenreformatorische Bildformel für religiöse Hingabe schlechthin ${ }^{71}$.

Nun ist es für meine Fragestellung bemerkenswert, dass beide Verfahren Halbfigurigkeit und antikisierende Pathosformeln - nicht nur in Andachtsbildern, sondern auch in profanen Meditationsbildern Anwendung finden. Renis halbfigurige Kleopatra ${ }^{72}$ [Abb. 7], heute in der Sammlung Sir Denis Mahon (London), ließe sich durch eine einfache Retouche in eine Magdalena verwandeln, ersetzte man die Schlange in der Rechten der Königin durch ein kleines Holzkreuz. Inszenierung und Ausdruck gleichen sich in beiden Bildern; die Identität der Protagonistinnen ergibt sich ausschließlich aus ihren Attributen.

Auch diese halbfigurige Kleopatra stammt aus der letzten Arbeitsphase Renis. ${ }^{73}$ Vor einem dunkelbraunen Hintergrund ist die Königin an den Betrachter herangerückt. Wie bei der halbfigurigen Magdalena sind Kopf und Oberkörper in der bewährten Pyramidalkonstruktion arrangiert. Kleopatra wendet ihr Gesicht mit

essendo egli eccellente, riponeva difficoltà in girar bene una testa. (Bellori, G. P.: Le vite de' Pittori, Scultori e Architetti moderni, hrsg. von E. Borea, Turin 1976, S. 529)

${ }^{68} \mathrm{Vgl}$. oben S. 32. Schon 1594 erschienen die ersten Stiche der Niobiden-Gruppe. AK Guido Reni und Europa, Ruhm und Nachruhm, a.a.O., Abb. 28.

69 Zur Nacktheit der Darstellungen Magdalenas und Sebastians im 16. Jahrhundert vgl. Seidel, Martin: Venezianische Malerei zur Zeit der Gegenreformation, Kirchliche Programmschriften und künstlerische Bildkonzepte bei Tizian, Tintoretto, Veronese und Palma il Giovane, Münster 1996, S. 74-104.

${ }_{70}$ Näheres führt Sybille Ebert-Schifferer anläßlich einer frühen Magdalena Renis in den Sammlungen des Fürsten von Liechtenstein aus (AK Guido Reni und Europa, Ruhm und Nachruhm, a.a.O., S. 122-124).

${ }^{71}$ Ebert-Schifferer, a.a.O., S. 124.

72 Abbildung in: AK Guido Reni, 1575 - 1642, Bologna, a.a.O., S. 170-171. Die Maße des in Öl auf Leinwand ausgeführten Gemäldes sind 77 x 65. Vgl. Katalog 313.

${ }^{73}$ Pepper, a.a.O., S. 298 setzt die Entstehungszeit zwischen 1639 und 1640 an. 


\section{Posttridentinische Märtyrer und stoische Tugendhelden}

leicht geöffnetem Mund nach oben links, wohin sich auch ihr shimmelnder Blickı richtet. Die braunen Haare der Königin werden von einem turbanartig gewundenen grünen Tuch zusammengehalten; ein weißes gefälteltes Hemd unter einem roten Mantel steht über den Brüsten weit offen. Das totenbleiche Inkarnat der entblößten Brust, das sich kaum von der Farbe des Hemdes unterscheidet, bestimmt das Zentrum des Blickfelds. Mit graziöser Geste hält Kleopatra in ihrer Rechten eine kleine braune Schlange, die ihr Werk bereits getan hat, wie zwei winzige rote Blutstropfen auf der Brust andeuten.

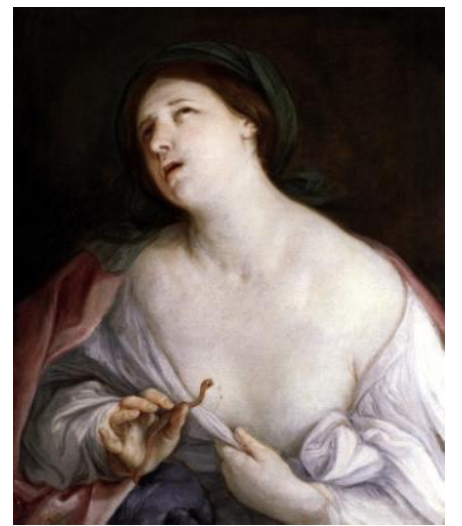

Abb. 7

In Renis ganzfigurigen Darstellungen der Magdalena stehen narrative Elemente im Vordergrund, in die sich der Betrachter der Altargemälde oder Andachtsbilder vertiefen kann. Typisierte Details demonstrieren die asketische und meditative Existenzform der Heiligen. Die halbfigurige Präsentation der Heiligen verfolgt hingegen durch die Verengung des Bildausschnitts eine andere Wirkungsstrategie. Die Heilige ist räumlich und emotional an den Betrachter herangerückt. Die Attribute Totenschädel und Kreuz sind an den Rand gedrängt, die Bildaussage konzentriert sich auf die Vision der Heiligen. Die zurückgenommene Farbigkeit unterstützt die Konzentration; der Betrachter wird zu einfühlender Andacht geführt. Der den Bildhintergrund bestimmende amor vacui ${ }^{74}$ lässt keine Abschweifung der Devotion des Betrachters zu.

Das gefühlsbetonte Devotionsbild, geradezu eine Invention Renis, wurde von Otto Kurz als »raffiniert-sentimental ${ }^{75}$ charakterisiert: Es zielt auf unmittelbare Wirkung und fordert den Betrachtenden auf, sich emotional auf die abkürzende Pathosformel des Bildes einzulassen, das auf Einzelheiten der Legende verzichtet. Die verkürzte Bildformel verknüpft sinnliche Attraktivität mit einer großen Bandbreite von Rezeptionsmöglichkeiten. Das posttridentinische Andachtsbild führt in die emotionale Nähe der Heiligen und erreicht so seine rhetorische Funktion: persuadere le persone alla pietà ${ }^{76}$.

\footnotetext{
${ }^{74}$ Nach Hibbard, H.: "Guido Reni' s Painting of the Immaculate Conception«, in: Bulletin of the Metropolitan Museum, 28 (1969/70), S. 19-32, hier S. 29.

${ }^{75}$ Kurz, Otto: "Guido Reni, in: Jahrbuch der kunsthistorischen Sammlungen, Wien, N. F., 1937, S. 189-220, hier S. 211.

${ }^{76}$ Vgl. Paleotti, Gabriele: Discorso intorno alle imagini sacre e profane, Bologna 1582, in: Barocchi, Paola (Hrsg.): Trattati d'arte del cinquecento tra manierismo e controriforma, 3 Bde, Bari 1960, Band 2, S. 148.
} 


\section{Posttridentinische Märtyrer und stoische Tugendhelden}

Die »estenuata malinconia « ${ }^{77}$ der halbfigurigen Kleopatra Renis konvergiert augenfällig mit der büßenden Exaltation seiner der Welt entrückten Magdalena. Beide Motive demonstrieren in ihrer Verkürzung zugleich Verzweiflung und moralische Selbstbehauptung. Auch hier gilt, dass die Heilige und die Tugendheldin nicht zu unterscheiden wären, dienten nicht ihre Attribute zur Identifikation. Jakob Burckhardt hat für diesen Bildtypus Renis den Begriff "Sehnsuchtshalbfiguren ${ }^{78}$ geprägt: die Konzentration auf einen aus einem größeren Erzählzusammenhang herausgeschnittenen, dramatisch gestalteten Nahausschnitt hebt ganz auf die Gemütsbewegung und den pathetischen Ausdruck ab. Christliche und neustoische Andachtsbilder erinnern noch durch ein Attribut an den narrativen Zusammenhang ${ }^{79}$, reduzieren ihn aber auf einen als >Projektionsflächeく dienenden Affekt, in den sich der Betrachter seinfühlen soll. Aus einem »szenischen Historienbild « ${ }^{80}$ wird ein im Ausdruck überhistorisches »kultisches Repräsentationsbild«. Es »deklamiert ${ }^{81}$ mit visuellen Mitteln und appelliert in erheblichem Maße an die Gefühle des Betrachters: In diesem Sinne hat Reni auch seine halbfigurige Kleopatra zu einem Andachtsbild gemacht, das die Gefühlsqualität des selbstgewählten Todes betont und aus einem klassischen Thema der Historienmalerei ein profanes Andachtsbild hervorgehen lässt.

\footnotetext{
${ }_{78}^{77}$ So Cristina Casali Pedrielli in: AK Guido Reni 1575 - 1642, Bologna, a.a.O., S. 170.

78 Ich übernehme den Ausdruck von Jakob Burckhardt, der im Cicerone schreibt: "Wir wenden uns nun zu denjenigen Bildern, in welchen der Seelenausdruck vor dem erzählenden Element den Vorrang hat, um dann zur Behandlung des Überirdischen überzugehen. [...] Zu einer endlosen Masse vermehren sich nunmehr jene einzelnen Halbfiguren, welche von den frühern Schulen in verschiedener Absicht, z. B. in Venedig als schöne Daseinsbilder waren gemalt worden. Jetzt liegt ihr Hauptwerth darin, dass man jenen gesteigerten Ausdruck ohne weitere Motivirung darin anbringen kann. Die Sehnsuchtshalbfigur bildet fortan eine stehende Gattung. (Burckhardt, Jacob: Der Cicerone [hrsg. von Roeck, Bernd / Tauber, Christine / Warnke, Martin], München 2001, [Kritische Gesamtausgabe Bd. 3] S. 250)

${ }^{79}$ Hierin liegt der entscheidende Unterschied dieses Bildtyps zu den tronies, Einfigurenbrustbildern, die von Rembrandts Orientalen bis zu isolierten Charakter- und Affektstudien reichen. Vgl. den Forschungsbericht von Hirschfelder, Dagmar / Raupp, Hans-Joachim: "Tronies in de Italiaanse, Vlaamse en Nederlandse schilderkunst van de 16de en 17de eeuw « in: Kunstchronik, 2001, S. 197-202.

${ }^{80}$ Panofsky, Erwin: »ı/mago Pietatisı. Ein Beitrag zur Typengeschichte des `Schmerzenmannes und der >Maria Mediatrixı«, in: FS Max Friedländer zum 60. Geburtstag, Leipzig 1927, S. 261- 308, hier S. 264.

81 „Die Andachtsbilder verbinden also das Angebot einer Vision, mit Personen zu sprechen, mit dem anderen Angebot, das Leben Christi oder der Heiligen plastisch nachzuerleben. Das subjektive Moment, über das man noch wenig nachgedacht hat, liegt nicht allein im erzählerischen Habitus begründet, sondern setzt die Offenheit des Ausdrucks oder der Situation voraus. Gerade damit kommt das Bild der Imagination des Betrachters entgegen, indem es ihr wenig Widerstand in den Weg setzt und keine Fesseln anlegt. Die Stimmung ist wichtiger als das Thema, und über dieses darf der Betrachter verfügen. Diese Offenheit ist insofern ein subjektives Moment, als auch die Metamorphosen des seelischen Zustands, wie ihn die mystische Praxis verlangt, ein solches Moment sind. Die Gemeinschaft verlangt gewöhnlich feste Verabredungen. In der Einheit des Individuums können sie entfallen. « (Belting, Hans: Bild und Kult, Eine Geschichte des Bildes vor dem Zeitalter der Kunst, München 1990, S. 464)
} 


\section{Posttridentinische Märtyrer und stoische Tugendhelden}

\section{Tiepolo: Bene mori est libenter mori}

Auch in Giovanni Battista Tiepolos Werk lassen sich eine Märtyrerin und eine Tugendheldin in bezeichnender Weise in Beziehung setzen; noch im 18. Jahrhundert ist der neustoische Hintergrund der kirchlichen wie der profanen Bildkonzeptionen nicht ganz verblasst. Die moralistische Deutung des selbstgewählten heroischen Todes überschreitet die Grenzen der Bildgattungen.

Bereits das Format des heute in Berlin befindlichen Martyriums der $\mathrm{HI}$. Agathe $^{82}$ von Giovanni Battista Tiepolo lässt seine ursprüngliche Bestimmung als Altarbild [Abb. 8] erkennen. Durch eine gegensinnige Radierung [Abb. 9] seines Sohnes Giandomenico ist bekannt, dass das Bild oben um ein Viertel beschnitten wurde und ursprünglich halbrund abschloss. ${ }^{83}$ Das irdische Geschehen wurde in der originalen Fassung durch die Vision des flammenden Herzens Christi überhöht, das von der Dornenkrone und zwei Engelsköpfen umgeben war. Tiepolo führte das Martyrium der $\mathrm{HI}$. Agathe um 1750 für den Hochaltar

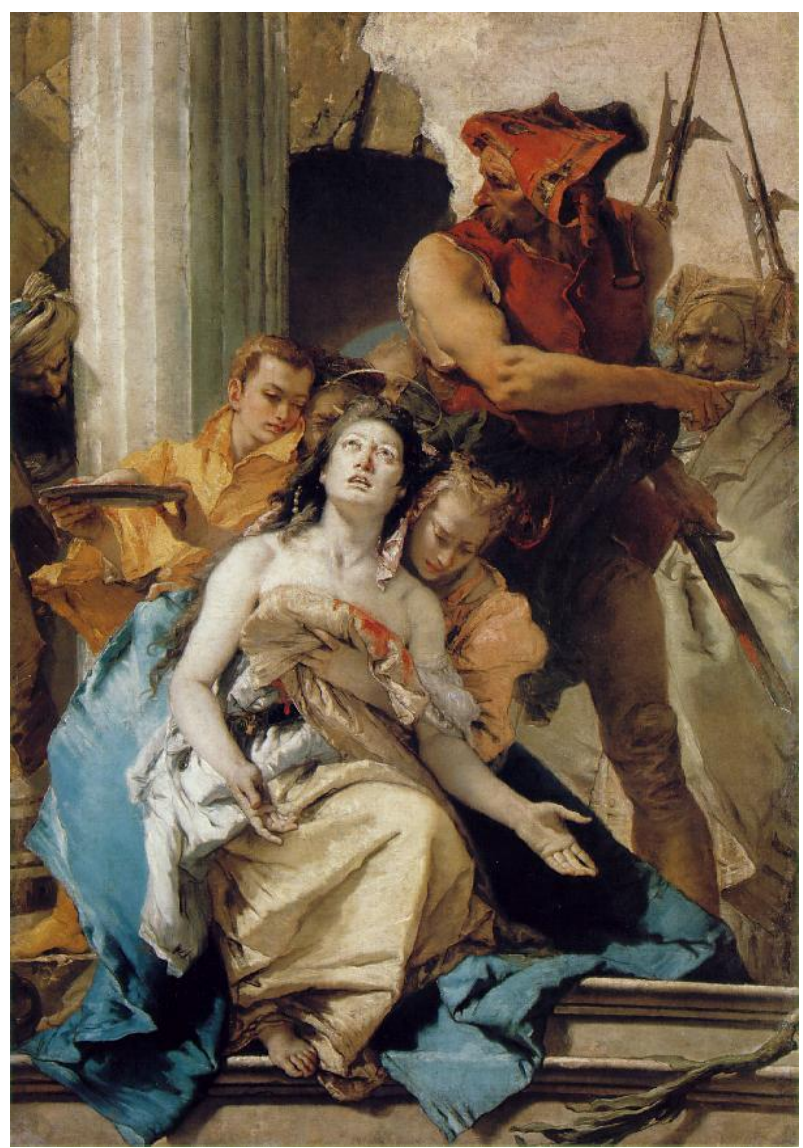

Abb. 8 des Benediktinerinnenklosters Santa Agata in Lendinara (bei Rovigo) aus. ${ }^{84}$ Die Heilige, die ihr Martyrium während der Christenverfolgungen unter Kaiser Decius in Catania erlitt, kniet in Tiepolos Komposition auf den Stufen eines durch eine kannelierte Säule angedeuteten Gebäudes. Von hinten rechts die Heilige umfassend, verdeckt eine junge Dienerin mit einem Tuch die verstümmelte Brust; ein in strahlendes Gelb gehüllter Knabe trägt die abgeschnittenen Brüste auf einem silbernen

\footnotetext{
${ }^{82}$ Vgl. Katalog 391 und S. 425 (Nr.459 B) im Katalog der ausgestellten Gemälde des 13.-18. Jahrhunderts, Gemäldegalerie Berlin 1975 (184 x 131).

${ }^{83}$ Wiedergabe der in Acquaforte ausgeführten Radierung in: Christiansen, Keith (Hrsg.): AK Giambattista Tiepolo 1696-1996, Milano 1996, S. 234.

${ }^{84}$ Nach der Aufhebung des Klosters kam das Altarbild 1810 in den Handel und gelangte schließlich 1878 in die Berliner Gemäldegalerie. Vgl. Christiansen, Keith (Hrsg.): AK Giambattista Tiepolo, a.a.O., S. 238.
} 


\section{Posttridentinische Märtyrer und stoische Tugendhelden}

Tablett nach links weg. In aggressives Rot gekleidet, erscheint ein muskulöser Henker hinter der zentralen Gruppe, sein blutiges Schwert noch in der Linken haltend und mit energischem Gestus des anderen Arms nach rechts weisend. An den Bildrändern blicken Männer mit orientalischen Kopfbedeckungen auf das Geschehen. In jungfräuliches Weiß und Beige geklei-

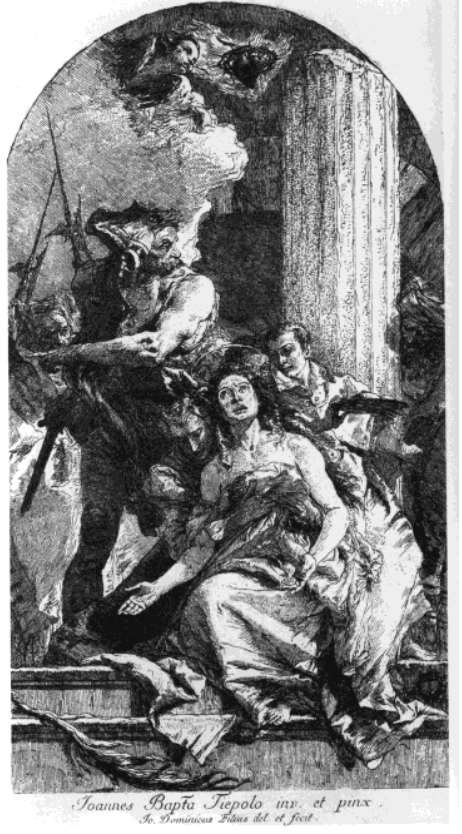

Abb. 9

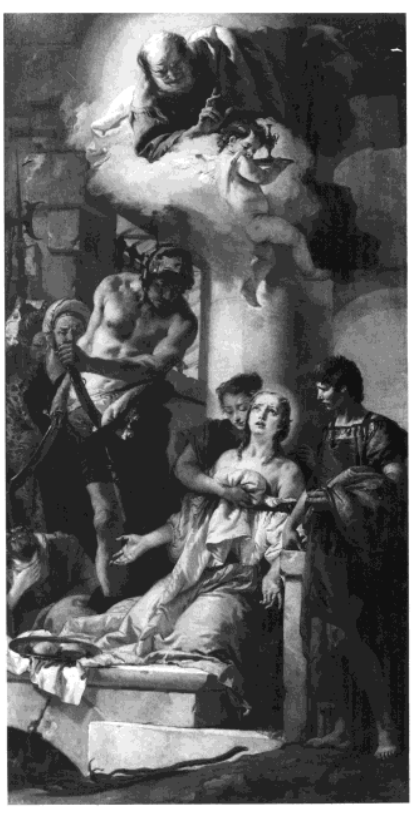

Abb. 10

det, kniet Agathe frontal zum Betrachter und scheint nur noch körperlich präsent zu sein; sie erhebt ihr bleiches Gesicht mit vergeistigten Augen und leicht geöffnetem Mund zum Himmel. Die »religiöse Ausdrucksgebärde « ${ }^{85}$, ausgebreitete Armen und offene Handflächen, inszeniert Ergebung und visionäre Schau der Heiligen.

Im jetzt fragmentarischen Zustand des Altarblatts fehlt der Gegenstand der Vision. Aber auch das auf diesem Bild ursprünglich dargestellte Herz Jesu war bereits eine entschiedene Reduktion einer älteren Bildkonzeption Tiepolos. Sein 1736 entstandenes und sich noch in situ befindliches Altarbild [Abb. 10] in der Paduaner Basilika zeigt eine beinahe noch kindliche Agathe $^{86}$, die auf einer Wolke Petrus und einen Engel mit Salbgefäß erblickt. Diese Fassung der Vision spielt auf eine von den Künstlern des Barock gerne illustrierte Episode der Heiligenlegende ${ }^{87}$ an, in der nach der Amputation der Brüste Petrus im Gefängnis erscheint und die Wunden Agathes heilt; erst eine weitere Folterung mit glühenden Kohlen führt zum Märtyrertod.

In der ersten Bearbeitung des Themas von 1736 greift Tiepolo verschiedene Episoden der Heiligenlegende auf und setzt damit einen narrativen Schwerpunkt. So erscheint am rechten Bildrand der Stadtpräfekt Quintian, der die Heilige nach der Ablehnung seiner Anträge dem Martyrium auslieferte. Die Folter ist gerade

\footnotetext{
${ }^{85}$ Vgl. Weise, Georg / Otto, Gertrud: »Die religiösen Ausdrucksgebärden des Barock« a.a.O. [vgl. Anm. 57], S. $5 \mathrm{ff}$.

${ }^{86}$ Vgl. Abbildung in: Christiansen, Keith (Hrsg.): AK Giambattista Tiepolo, S. 239. Nach Pallucchini, Anna / Le Foll, Joséphine: Tout l'oeuvre peint de Tiepolo, Paris 1990 [italienisch ${ }^{1} 1968$ ], S. 102 sind die Maße 350 x 170. ${ }^{87}$ Vgl. Squarr, Christel: »Agatha von Catania«, in: LCI, Bd. 5, S. 44-48.
} 


\section{Posttridentinische Märtyrer und stoische Tugendhelden}

vollzogen worden, noch agiert der Scherge heftig mit zwei Krummschwertern; im Vordergrund liegen unten links auf einem Teller die abgeschnittenen Brüste, eine Dienerin drückt ein Tuch auf die Wunde. Aber auch das bevorstehende Wunder wird bereits in die Darstellung einbezogen: Petrus erscheint über der Folterszene in einer Wolke und sichert mit segnender Hand baldige Heilung zu.

Gegenüber dieser älteren Fassung des Themas dramatisiert und reduziert die Berliner Version das Martyrium. Im Berliner Bild ist Agathe nicht als Mädchen, sondern als reife Frau gegeben. ${ }^{88}$ Sie erblickt ein brennendes, von einer Dornenkrone umgebenes Herz, Symbol der Liebe Christi und seines stellvertretenden Leidens. Im 17. Jahrhundert propagierten besonders die Jesuiten die auf die hochmittelalterliche Mystik zurückgehende Herz-Jesu-Verehrung. ${ }^{89}$ Durch die Vision stellt der Maler einen Bezug zwischen Märtyrerin und leidendem Christus her.

In der zweiten Fassung sind die gegenreformatorischen Intentionen unübersehbar. Während Tiepolos erste Beschäftigung mit der Märtyrerin noch narrativ ausgerichtet war und viele konventionelle Elemente der Legende integrierte, reduzierte er zwanzig Jahre später die narrativen Strukturen auf ein Minimum und pointierte die Aussage des Andachtsbildes. Der grausame Wendepunkt dieser Heiligenvita, das Abschneiden der Brüste ${ }^{90}$, steht nunmehr im Mittelpunkt, der Akzent wird aber auf die Vision der Märtyrerin gelegt. Das Herz Jesu ruft die Erinnerung an Christi Leiden auf, der visionäre Blick Agathes verbindet ihr Martyrium mit der Passion Christi, eröffnet dem Betrachter eine »bildgestützte, bildgelenkte und bildkontrollierte Meditation « ${ }^{91}$ seiner eigenen Rolle und appelliert an den Gläubigen, sich in eine analoge Gemeinschaft mit Christus zu begeben.

Als Tiepolo 1762 nach Spanien aufbrach, beschrieb er Funktion und Intention seiner Historienmalerei mit den Begriffen »sublime«, »eroico« und »perfezione«. Für die aristokratische Klientel sind Bildthemen und Bildprogramme mit historischen und mythologischen Themen der Antike bestimmt, die sich von den Fachleuten

\footnotetext{
${ }^{88}$ Der Künstler fertigte, wie Vorstudien zum Gesicht Agathes im Berliner Kupferstichkabinett zeigen, zunächst eine Skizze nach dem Modell an, die er dann idealisierte und im Ausdruck expressiver gestaltete (Abbildungen in: AK Giambattista Tiepolo, a.a.O., S. 238).

${ }^{89}$ Papst Clemens XIII. approbierte 1765 Messe und Offizium vom Herzen Jesu.

${ }^{90}$ Lang, Walther K.: Grausame Bilder, a.a.O., hat der psychoanalytisch bedenkenswerten Grausamkeit von Männern gegen eine Frau, die sich im Martyrium der Agathe niederschlägt, ein ganzes Kapitel gewidmet. (Kapitel 5: `Die verstümmelten Brüste: Mann gegen Frau<). Dort auch noch weitere Bildbeispiele für die bildkünstlerische Behandlung des Themas (S. 171-228).

${ }^{91}$ Burschel, Peter: Sterben und Unsterblichkeit, Zur Kultur des Martyriums in der Frühen Neuzeit, München 2004, S. 288
} 


\section{Posttridentinische Märtyrer und stoische Tugendhelden}

(professori) als exemplarisch auch für die Gegenwart interpretieren ließen. ${ }^{92} \mathrm{Im}$ Zusammenhang einer seiner Großaufträge für die norditalienische Aristokratie ${ }^{93}$ gestaltete Giovanni Battista Tiepolo auch den exemplarischen Tod einer profanen Tugendheldin. Im Mittelpunkt der 1731 für den conte Casati ${ }^{94}$ begonnenen Freskierung und Dekoration der großen sala im Mailänder Palazzo Dugnani ${ }^{95}$ steht Scipio Africanus $^{96}$, dessen magnanimitas das Fresko des zentralen Deckenplafonds verherrlicht.

Zwei große Historienfresken veranschaulichen an den Wänden die virtus des römischen Feldherrn: Die Selbstbeherrschung des Scipio und Scipio und die Freilassung des Sklaven. Diese bekannten und häufig ins Bild gesetzten Episoden aus dem Zweiten Punischen Krieg zeigen Scipio, wie er die ihm als Sieger zustehende junge Frau ihrem Verlobten zurückgibt und einen Sklaven frei lässt, Szenen, die die continentia und die clementia des römischen Feldherrn illustrieren.

Ganz pictor doctus nahm Tiepolo im dritten Fresko [Abb. 11] auch den Selbstmord der Sophonisbe ${ }^{97}$ in das Programm auf, obwohl das Thema für den heutigen Betrachter auf den ersten Blick nicht in das Gesamtprogramm des Zyklus passt, zumal Scipio nicht selbst auftritt. Erst der Rekurs auf Livius oder das früh-

\footnotetext{
92 „Quindi è che la mente del Pittore deve sempre tendere al Sublime, all'Eroico, alla Perfezione. « Zitiert nach Haskell, Francis: Maler und Auftraggeber, a.a.O., S. 360. Es folgt: "Aggiunse che li Pittori devono procurare di riuscire nelle opere grandi, cioè in quelle che possono piacere alli Signori Nobili, e ricchi, perchè questi fanno la fortuna de' Profe s s ori, e non già l'altra gente, la quale non può comprare Quadri di molto valore." ${ }_{93}$ Neben kirchlichen Auftraggebern arbeitete Tiepolo auch für private, meist aristokratische Abnehmer. Vor allem das venezianische Patriziat versuchte seine meist noch kurze Familientradition durch ostentative Kunstförderung wettzumachen und ließ seine den neu erworbenen Reichtum demonstrativ zur Schau stellenden Landvillen und Stadtpaläste üppig ausmalen (vgl. Haskell, Francis: Maler und Auftraggeber, Kunst und Gesellschaft im italienischen Barock, Köln 1996 [englisch $\left.{ }^{1} 1980\right]$, S. 361). Die Dekorationsprogramme greifen meist auf die griechisch-römische Mythologie und Geschichte zurück. Mit einem Scipio-Zyklus in der Villa Cordellina (Montecchio Maggiore), einem Kleopatra-Zyklus im Palazzo Labia (Venedig) und einem allegorischen Zyklus im Palazzo Rezzonico (Venedig) (Pallucchini, Anna / Le Foll, Joséphine, a.a.O., S. 108, 113, 127) erfüllte Tiepoloden Wunsch seiner Auftraggeber, ihre Familiengeschichte mit der Antike zu verbinden (vgl. Haskell, a.a.O., S. 350ff.).

${ }_{94}$ Gemin, Massimo / Pedrocco, Filippo: Giambattista Tiepolo, Leben und Werk, München 1995, S. 224. Giuseppe Casati, der seinen Adelstitel erst seit kurzem führte, hatte den Palast ein Jahr zuvor gekauft und Tiepolo den Auftrag zur Ausschmückung erteilt.

${ }_{95}$ Abbildungen in Pallucchini / Le Foll, a.a.O., S. 95.

${ }^{96}$ Wie nochmals 1743 , als er die Villa Cordellina ausmalte.

${ }^{97}$ Katalog 390. Ausführlicher zu diesem Fresko oben, S. 95ff.- Abbildungen in: Pallucchini / Le Foll, a.a.O., S. 95 (»Die continentia des Scipio « 520 x 650; "Scipio und der Sklave 520 x 450 und "Sophonisbe nimmt aus der Hand des Massinissa den Giftbecher « 520 x 650). Die in der Literatur eingeführte Bezeichnung des dritten Freskos ist unzutreffend, da trotz der teilweisen Zerstörung des Freskos im Zweiten Weltkrieg deutlich zu erkennen ist, dass Sophonisbe in ihrer rechten Hand einen Brief hält. Es handelt sich um die Botschaft Massinissas, die ein Bote zusammen mit dem Gift überbringt. Die in der rechten Hälfte des Freskos erscheinende Figur in römischer Kleidung ist also nicht Massinissa, sondern sein Bote. Die falsche Bezeichnung findet sich auch bei Gemin, Massimo / Pedrocco, Filippo: Giambattista Tiepolo, Leben und Werk, München 1995, S. 224.
} 


\section{Posttridentinische Märtyrer und stoische Tugendhelden}

neuzeitliche Theater $^{98}$ macht das Bild lesbar: Es illustriert die Staatsräson des Feldherrn, der auf dem Anspruch Roms bestand, Sophonisbe ohne Rücksicht auf ihre überstürzte Heirat mit Massinissa auszuliefern.

Altarbild und Wanddekoration, Martyrium der Heiligen Agathe und Selbstmord der Sopho-

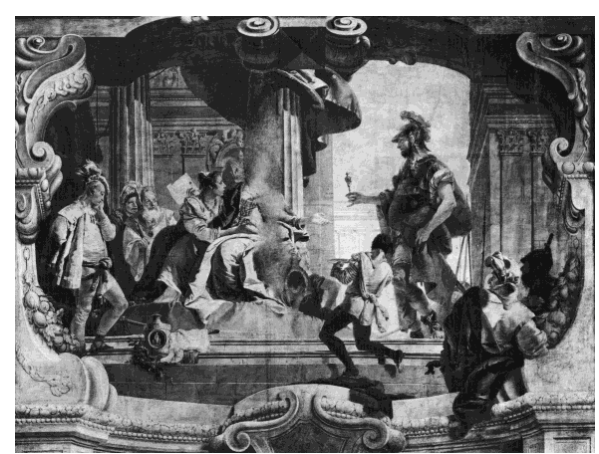

Abb. 11 nisbe instrumentalisieren eine vergleichbare Blicklenkung da sotto in su, die den Betrachter des Altarbilds wie des profanen Freskos auf die Vorbildlichkeit und Erhabenheit der dargestellten Szenen aufmerksam macht. Ebenso unterstreichen die antiken Architekturzitate in beiden Gemälden die Dignität der Dargestellten. Sophonisbe ist als Königin selbstverständlich luxuriös gekleidet, Agathe zeichnet sich als bekennende Christin durch eine einfache, farblich zurückhaltende Kleidung aus.

Die staatliche Gewalt wird im Martyrium der Heiligen Agathe in der Person des Henkers sinnfällig dargestellt. Die Umwelt reagiert auf die tödliche Bedrohung der Heiligen nicht, Knabe und Dienerin assistieren gleichgültig, beinahe apathisch. Der Hofstaat Sophonisbes reagiert hingegen aufgebracht; der Page links ist schon ganz in vorwegnehmender Trauer versunken. Im Hintergrund blicken zwei ältere Männer entsetzt auf die Überreichung des Gifts. Ihnen korrespondieren zwei männliche Rückenfiguren im rechten Vordergrund, deren gespannte Aufmerksamkeit auf Sophonisbe gerichtet ist. Eine starke emotionale Betroffenheit zeigt die Zofe der Königin.

In beiden Werken hat Giovanni Battista Tiepolo der Haltung der Protagonistin stärkste Aussagekraft gegeben: Agathes visionärer Blick in den Himmel wird von der Demutsgeste ihrer Hände begleitet; Sophonisbe streckt die geöffnete Linke dem Giftbecher entgegen. Der Maler hat die Hand der afrikanischen Königin auf den Schnittpunkt der Diagonalen gesetzt und damit stark betont. Die Heilige bekundet Ergebung ins Martyrium und Sterben, die Königin die von der stoischen Philosophie verlangte, das fatum bejahende Willensstärke. Die ausgestreckte Hand der Regentin, die das Unausweichliche bereitwillig akzeptiert, steht für den

\footnotetext{
${ }^{98}$ Siehe dazu oben S. $60 \mathrm{ff}$. und S. $68 \mathrm{ff}$.
} 


\section{Posttridentinische Märtyrer und stoische Tugendhelden}

stoischen Willensakt, den Seneca mit der Formel Bene mori est libenter mori ${ }^{99} \mathrm{zu}$ sammengefasst hat.

Beide Tugendheldinnen repräsentieren eine heroische Haltung angesichts des Todes, die unabhängig von ihrer heilsgeschichtlichen oder philosophischen Begründung mit durchaus vergleichbaren, bereits sautomatisierten` Bildmitteln umgesetzt wird. Im Bildmotiv der kirchlichen und der profanen Tugendheldin nähern sich heilsgeschichtliche und anthropologische Aussagen in bemerkenswerter Weise an. Der meditierende Betrachter des Altarbilds bewundert die Bereitwilligkeit der Heiligen zum Martyrium, die Unbeugsamkeit der stoischen Tugendheldin ruft schon bei den bildimmanenten Zuschauern bewunderndes Mitgefühl (das stoische $\sigma v \mu \pi \alpha \dot{\theta} \theta \varepsilon \mathrm{v})$ hervor. Auch solche neustoisch inspirierten Historienbilder mögen im Gesprächs- und Freundeskreis Anlass zu Gesprächen über constantia angesichts des Todes geboten haben. ${ }^{100}$

\section{Posttridentinische Andachtsbilder und neustoische Ikonen}

Émile Mâle hat auf die besondere Vorliebe des nachtridentinischen europäischen Barock hingewiesen, Märtyrer im Leiden, in der Vision und in der Ekstase darzustellen. ${ }^{101}$ Für das neue Selbstverständnis der römischen Kirche, ihre Abwehr der protestantischen Kritik am Kult der Heiligen und ihre Außendarstellung waren der Märtyrerkult und seine bildliche Umsetzung von zentraler Bedeutung. Dabei wurden altkirchliche Schlüsselbegriffe der Martyrologie, wie sie schon Ignatius von Antiochien ${ }^{102}$ formuliert hatte, wieder aufgegriffen: mit affektiver Identifikation ( $\pi \alpha \dot{\theta} \theta$ o )

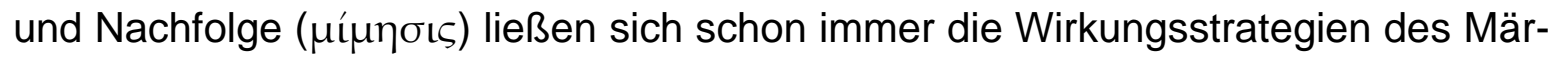
tyrerkults umschreiben. Allerdings erhielten sie in der katholischen Reform des 16. und 17. Jahrhunderts eine neue Zuspitzung. Es ging nun nicht mehr um die Selbstvergewisserung der Gemeinde in einer heidnischen Umwelt, sondern um die Entwicklung einer konfessionellen Kultur, die Begründung eines neuen Frömmigkeitsstils und seine Außenwirkung auf die Häretiker. ${ }^{103}$

\footnotetext{
${ }^{99}$ Ep. mor. 61,2 (২Gut sterben heißt bereitwillig sterben.ı).

${ }^{100}$ Vgl. oben S. 177.

${ }^{101}$ Vgl. Mâle, Émile: L'art religieux après le concile de Trente, Paris 1932, v. a. Kap. III und IV.

102 Campenhausen, Hans Freiherr von: Die Idee des Martyriums in der alten Kirche, Göttingen ${ }^{2} 1964$, S. 74.

${ }^{103}$ Vgl. Burschel, Peter: Sterben und Unsterblichkeit, Zur Kultur des Martyriums in der Frühen Neuzeit, München 2004. Burschel behandelt das Martyrium als kulturanthropologisches Phänomen der Frühen Neuzeit, das in besonderer Weise die Ziele einer Gemeinschaft oder Gesellschaft erkennen lässt. Dabei richtet er sein Augenmerk in gleicher Weise auf Märtyrer der protestantischen und der katholischen »Bewegungen «. Abhebend auf anthropologische Konstanten, interessiert er sich mehr für die Entwicklungen in der Volksfrömmigkeit und deren Manifestationen (zum Beispiel in ıBekenntnisliedern`), deshalb wird der Neustoizismus als Leitphiloso-
} 


\section{Posttridentinische Märtyrer und stoische Tugendhelden}

Allerdings rekurrierten die ikonographischen Muster der kirchlichen Malerei und ihre Darstellung der Vorbildlichkeit (constantia) der Märtyrer auf anthropologische Versatzstücke des Neustoizismus und damit auf verallgemeinerbare >Tugenden`, die auch von der profanen Historienmalerei übernommen und variiert werden konnten. Der gleiche Sachverhalt lässt sich auch in der umgekehrten Richtung beschreiben und bestätigt, dass die Ikonographie der Märtyrer und der Tugendhelden eine gemeinsame Anthropologie voraussetzt.

Die frühneuzeitliche und vor allem barocke Vorliebe für Märtyrerdarstellungen hat frömmigkeitsgeschichtliche, mentalitätsgeschichtliche, psychoanalytische oder soziologische Deutungen erfahren. Der antiprotestantische Akzent liegt auf der Hand, doch schloss dies kontrafaktische protestantische Märtyrerdarstellungen durchaus nicht aus: so wurde das Märtyrerdrama zur konfessionsübergreifenden Mode. ${ }^{104}$ Der mentalitätsgeschichtliche Ansatz, die nachtridentinischen Märtyrerbilder und ihre Ikonographie aus der pessimistischen und todesbegeisterten Grundstimmung der Zeit und ihrer Kontingenzerfahrung abzuleiten, ist schon deshalb wenig überzeugend, weil sie das Ergebnis mit der Begründung gleichsetzt. ${ }^{105}$ Einen anderen, zweifellos interessanten Aspekt greift eine neuere, psychoanalytisch orientierte Studie zum Sadismus in der neapolitanischen Malerei auf, deren Ergebnisse sich aber wohl nicht verallgemeinern lassen, obwohl sie sich auf Märtyrerinnen wie auf Tugendheldinnen beziehen lassen. ${ }^{106}$

\footnotetext{
phie der frühneuzeitlichen Eliten in dieser Untersuchung nur am Rande gestreift. "Martyrium - das ist der Ort, der es erlaubt, der es vielleicht sogar besser als jeder andere Ort erlaubt, jene Grenzziehungen, Grenzüberschreitungen und nicht zuletzt auch Grenzöffnungen zu beobachten, die den Prozeß der Ents te hung und Entwicklung konfessioneller Kulturen ausmachten. [...] Hier ließen sie [Lutheraner, Reformierte, Katholiken etc. RSG] schließlich alle erkennen, dass es nicht die Erfahrung gemeinsamen Tötens ist, die Kultur hervorbringt, sondern die Erfahrung gemeinsamen Sterbens. (Burschel, a.a.O., S. 288)

${ }^{104} \mathrm{Vgl}$. dazu Valentin, Jean-Marie: Les jésuites et le théâtre (1554-1680): contribution à l'histoire culturelle du monde catholique dans le Saint-Empire romain germanique, Paris 2001; außerdem den Sammelband Chiamò, Maria (Hrsg.): I Gesuiti e i Primordi del Teatro barocco in Europa, Roma 1995. - Die Einzelstudie von Raffy, Jean-Louis: Le ıPapinianusı d'Andreas Gryphius (1616-1664), drame de martyr et sécularisation du théâtre en Allemagne au XVII siècle, Bern / Frankfurt / New York 1992 zeigt, dass das protestantische Barockdrama nicht als Säkularisation oder Entkonfessionalisierung des Märtyrerdramas, sondern als seine sentkatholisierte، Fassung gelten muss. Das protestantische (vor allem schlesische) Barockdrama emanizipierte sich allmählich von der Hagiographie und den Jesuiten, blieb aber der religiösen Thematik weiterhin eng verbunden.

105 Delumeau, Jean: Le catholicisme entre Luther et Voltaire, Paris 1971, S. 88.

106 Lang, Walther K.: Grausame Bilder, Sadismus in der neapolitanischen Malerei, Berlin 2001 hat in einer interessanten, psychoanalytisch inspirierten Studie die auffällige `Grausamkeitı der neapolitanischen Barockmalerei untersucht und darauf hingewiesen, dass die profane und die religiöse Kunst der Epoche vergleichbare psychologische Mechanismen voraussetzt. Sadomasochistische Phantasiebefriedigungen umgehen die Abwehrmechanismen des Ich und bleiben gleichwohl kontrollierbar. Obwohl die Konvergenzen kirchlicher und profaner Malerei meiner eigenen Argumentation entgegenkommen, scheint mir Lang allenfalls einen Teilaspekt der Problematik zu behandeln. Es fällt übrigens auf, dass im Gegensatz zu den Darstellungen von Märtyrerinnen der Tugendtod sstarker Frauen Befriedigung « des Betrachters zielte.
} 


\section{Posttridentinische Märtyrer und stoische Tugendhelden}

Einleuchtender ist der Verweis auf den sich in vielen Bereichen der Frühen Neuzeit manifestierenden Konflikt zwischen dem sich langsam konturierenden Individuum und dem entstehenden absoluten Staat, der dem einzelnen Bürger Unterordnung abverlangte. ${ }^{107}$ Auf dieser Abstraktionsebene lässt sich die Ikonographie der posttridentinischen Märtyrer mit der lkonographie der profanen stoischen Tugendhelden eng verknüpfen, auch wenn das ıschöne Sterben` der Märtyrer und der Tugendhelden entschieden verschiedene Akzentuierungen der moralischen Selbstbehauptung des Individuums ins Bild setzte. Der allzu missbräuchlich verwendete und vorschnell verallgemeinerte Begriff des exemplum virtutis ${ }^{108}$ lässt sich hier im Sinne der moralischen Selbstbehauptung deuten. Bekunden Heilige Ergebung ins Martyrium und Sterben, beweisen Tugendhelden Willensstärke und akzeptieren das fatum, wie es die stoische Philosophie verlangte.

Ob freilich die Protagonisten barocker Märtyrerdramen, die Tugendhelden der Historiengemälde, die Märtyrer der kirchlichen Kunst und die fast automatisierte rhetorische Referenz auf die Antike im politischen Diskurs der Frühen Neuzeit in gleicher Weise, abgesehen von ihrer abstrakten Funktion als exempla virtutis, hinreichend gedeutet sind, ist eine andere Frage. Dichter, Künstler und Redner setzten nämlich auf den überraschenden Transfer, die teilweise Umbesetzung vertrauter Inhalte des kulturellen Gedächtnisses, entwickelten neue Applikationen scheinbar unveränderlicher Verhaltensnormen und deuteten kollektive Normen und Werte um. >Christliches` und sphilosophisches` Sterben konnte so unter heroischen Vorzeichen ikonographisch kompatibel werden. Vergleichbares gilt für die lkonographie der vor allem von Domenico Fetti variierten Meditationsbilder, die vanitasMotive und Varianten des memento mori in religiösen und profanen Kontexten abwandeln. ${ }^{109}$

Christliche und neustoische Andachts- und Meditationsbilder stellen heroische Tugend dar, greifen dabei auf gemeinsame anthropologische Voraussetzungen zurück und verwenden vergleichbare Bildformeln des Heroischen und des

\footnotetext{
107 So die These von Held, Jutta: Caravaggio, Politik und Martyrium der Körper, Berlin 1996: »Das Martyrium, die Kulmination eines heiligmäßigen Lebens, muss zu allererst als eine Chiffre erkannt werden, die den kirchen- und staatspolitischen Strategien zur Anrufung der Individuen mit dem Ziel ihrer Unterwerfung diente und erst sekundär Effekte der Verunsicherung, des `Pessimismusı und vor allem der Leidensbereitschaft erzeugte und erzeugen sollte. « (S. 215) Held verkennt allerdings, dass sich die Dialektik von entstehendem Individuum und entstehendem Staat in der Frühen Neuzeit gegenseitig bedingt. Nicht nur in der Ikonographie, sondern auch im Grundkonflikt des klassizistischen Dramas, aber auch in der Staatstheorie lässt sich diese Fragestellung nachvollziehen. Deshalb übersieht Jutta Held den Aspekt der Selbstbehauptung, der posttridentinische Märtyrer mit Corneilleschen Helden verbindet.

${ }^{108}$ Vgl. unten S.302.

109 Vgl. S. 218.
} 


\section{Posttridentinische Märtyrer und stoische Tugendhelden}

Sublimen. Der shimmelnde Blickı der Heiligen findet sein profanes Äquivalent, der Standhaftigkeit des Glaubens entspricht die stoische Tugend des fortiter stare, der christlichen compassio des Frommen im profanen Gegenstück die stoische consolatio, der Gemeinde - jedenfalls gelegentlich ${ }^{110}$ - der neustoische Freundeskreis. Rubens gelingt es mit seinem Seneca ebenso wie Reni mit seiner Kleopatra ein klassische Themen der Historienmalerei in profane Andachts- und Meditationsbilder umzusetzen. Diente das kirchliche Andachtsbild der Bildung einer konfessionellen Frömmigkeitskultur, unterstützte sein profanes Äquivalent die moralische und politische Identität der Individuen in der sich langsam herausbildenden Welt moderner Staaten.

Die Keuschheit der Lukretia, die enttäuschte Liebe der Dido oder die Selbstbehauptung Kleopatras und Sophonisbes sind in der Frühen Neuzeit deshalb attraktive Bildmotive, weil sie die Affektdarstellung mit einem moralischen und zugleich politischen Hintergrundssinn verbinden konnten. Das Motiv des ıschönen Sterbensı gestattete eine ästhetische, auf den Affekt abhebende Betrachtung ebenso wie eine philosophische, auf den Hintergrundssinn bedachte. »Erleben mit gesammeltem Bewusstsein und konzentrierter innerer Anteilnahme $~{ }^{111}$ bestimmte die Rezeptionsweise der kirchlichen wie der profanen Meditationsbilder, auch wenn ihre Wertsysteme durchaus verschieden waren. Die Tugendhelden der profanen Historienmalerei können so als neustoische >Meditationsbilder begriffen werden, deren Rezeption sich kaum von der der Märtyrerbilder unterscheidet; sie setzen den Konflikt zwischen den Normen des Individuums und den Normen des entstehenden Staates zum ersten Mal ins Bild und artikulieren exemplarisch die Selbstbehauptung des Individuums.

ıHeroische Tugend reich übergreifenden Motiv der Künste. Inszenierte Gefühle und stilisiertes Pathos verbinden profane und kirchliche ıAndachtsbilderı, zum Beispiel Renis Magdalena und Renis Kleopatra, die beide nicht an den Intellekt, sondern an die Emotionen der Betrachter appellieren. Die Bildmittel des pittore dell'anima lenken die Aufmerksamkeit auf die Affekte und Gefühle der Tugendheldinnen ${ }^{112}$, die sich sogar in einer auf historisch-narratives Beiwerk verzichtenden Reduktionsformel darstellen

\footnotetext{
${ }^{110}$ Vgl. S. 215 und 227.

111 So definiert L. Richter den Begriff Andacht in: ${ }^{3} R G G$, Bd. 1. Sp. 360-362.

112 Mazza, Angelo in: AK Guido Reni, 1575 - 1642, Bologna (Pinacoteca Nazionale), a.a.O., S. 90 hebt die »attenzione sulla resa degli affetti, sulla manifestazione espressiva dei sentimenti hervor.
} 


\section{Posttridentinische Märtyrer und stoische Tugendhelden}

lassen. Auch wenn sich die imitatio pietatis ${ }^{113}$, zu der die Darstellung der Heiligen aufruft, nicht einfach auf die Darstellung profaner Tugendheldinnen wie Kleopatra übertragen lässt, verweisen gleichwohl die gemeinsamen Bildmittel auf ein - jedenfalls aus postmoderner Sicht - gemeinsames moralisches Substrat, das sich im frühneuzeitlichen Tugendbegriff als frühe Form moralischer Selbstbehauptung artikuliert. Nur so ist zu erklären, warum der Selbstmord der Tugendheldinnen moralisch gleichsam neutralisiert wurde.

Die Nähe der ikonographischen Mittel sollte allerdings nicht darüber hinwegtäuschen, dass die profane Variante der heroischen Tugend bereits im 17. Jahrhundert im Ansatz vorwegnahm, was später den stugendhaften Selbstmord zur radikalsten Form moralischer Selbstbehauptung werden ließ. Aus dem von Rubens zur neustoischen Ikone gestalteten philosophischen Märtyrer, dessen Vorbildlichkeit im tugendhaften Ertragen staatlicher Willkür liegt, wurde der profane Tugendheld, dessen moralische Selbstbehauptung im Selbstmord gipfelt. ${ }^{114}$ Allmählich verblasste die ursprüngliche Nähe zur posttridentinischen Märtyrerdarstellung. Aus dem exemplum virtutis, das gemeinsame, profane oder kirchliche Normen voraussetzte, wurde die Darstellung der Selbstbehauptung des Individuums, die den Tod als »unverzichtbaren Seismograph für kulturhistorische Erschütterungen und Veränderungen ${ }^{115}$ nutzte.

In der weiteren Entwicklung konnte einerseits die Darstellung des Affekts als solche in den Mittelpunkt des Interesses treten, bis hin zum Extremfall der Attitüdenkunst. ${ }^{116}$ Wie in der Barockoper tritt auch in der bildenden Kunst mehr und mehr die neustoische Auffassung der vertu zugunsten der Darstellung extremer Affekte zurück. ${ }^{117}$ In der Romantik schließlich ist das Konzept der Tugendheldin endgültig verblasst.

\footnotetext{
${ }^{113}$ Vgl. dazu passim Belting, Hans: Das Bild und sein Publikum im Mittelalter, Berlin 1981; Büttner, Frank: ıImitatio pietatisı, Motive der christlichen Ikonographie als Modelle der Verähnlichung, Berlin 1983.

${ }^{114}$ Es genügt der Hinweis auf Richardsons Clarissa (1748) oder Lessings Emilia Galotti (1772), um zu verdeutlichen, dass im Zeitalter der Aufklärung die Möglichkeit des Selbstmords zu einer Bestimmung der Individualität geworden ist, während die in dieser Untersuchung im Mittelpunkt stehenden Tugendheldinnen den Selbstmord noch als Teil ihrer sozialen Rolle begriffen. Gleichwohl präfigurieren sie die spätere moralphilosophische Entwicklung.

${ }^{115}$ Schlaeger, Jürgen: „Poetik des Todes, Zur Ästhetisierung des Endes in der englischen Romantik«, in: Stierle, Karlheinz / Warning, Rainer (Hrsg.): Das Ende, Figuren einer Denkform, München 1996 (Poetik und Hermeneutik 16), S. 515-527, hier S. 515.

${ }^{116}$ Siehe unten S. $294 \mathrm{ff}$.

117 Siehe unten S. $272 \mathrm{ff}$.
} 


\section{Tema con variazioni - Bildprogramme}

\section{Bilder im Bild}

Selbstexplikativ ist das ikonographische Motiv der Tugendheldin in den wenigen Beispielen, in denen es als Bild im Bild auftritt, womit seine schon früh emblematische Funktion deutlich wird. Die beiden bereits angeführten Porträts ${ }^{1}$ von Lorenzo Lotto (ca.1480-1556) und Jacopo Tintoretto (1519-1594) zeigen, dass diese Be-

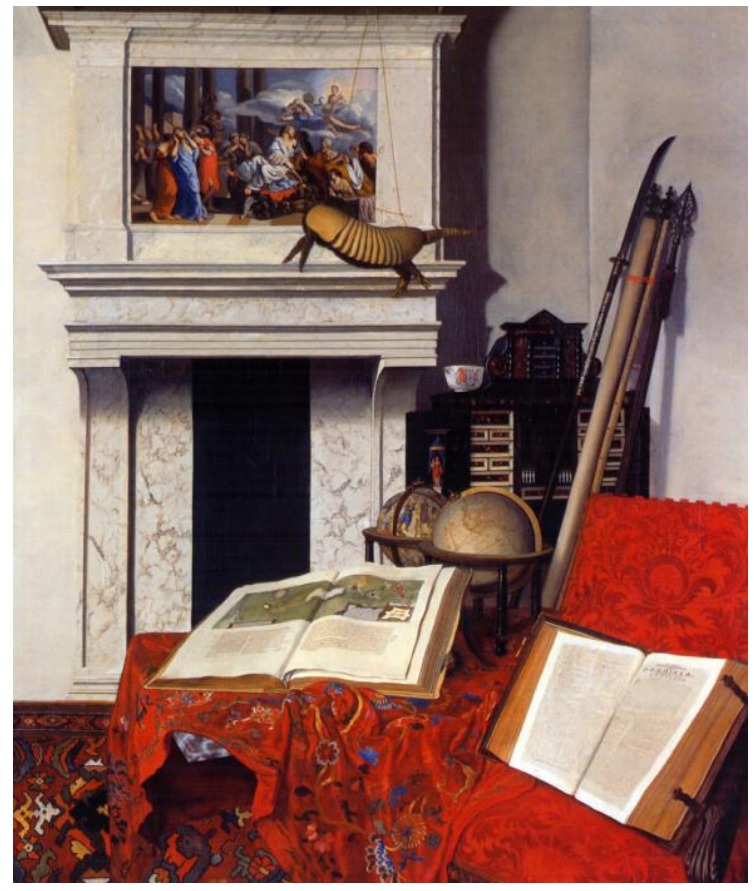

Abb. 1

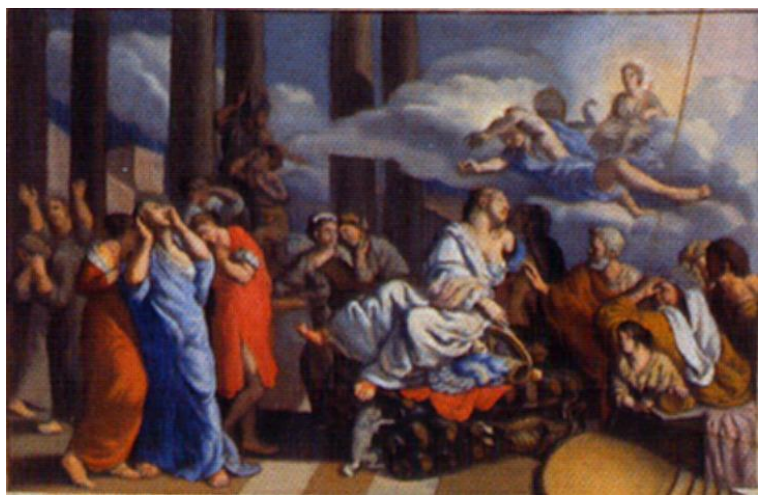

deutungsebene schon in der Mitte des 16. Jahrhunderts verbreitet war. Nicht zufällig handelt es sich um Lukretia-Referenzen in Porträts, die sich des Motivs bedienen, um eheliche Tugenden ins Bild zu setzen: Im Frauenporträt Lottos ist Lukretia zum Emblem weiblicher Keuschheit geworden; im Männerporträt Tintorettos dürfte sie als Hinweis auf Treue bis in den Tod aufzufassen sein.

Eine emblematische Funktion hat auch der Tod der Dido [Abb. 1a], als Bild im Bild bei Jan van der Heyden (1637-1712), dessen Zimmerecke mit Raritäten [Abb. 1] ${ }^{2}$ von 1712 die karthagische Tugendheldin als Exempel der vanitas zitiert, die manifest das Thema des Gemäldes ist, wie aus dem aufgeschlagenen Eccle-

\footnotetext{
${ }^{1}$ Vgl. S. $129 f$.

${ }^{2}$ Budapest, Szépmüvészeti Múzeum, Inv. 201. Katalog 178.
} 
siastes hervorgeht. Van der Heyden benützte einen Stich von Giovanni Cesare Testa (1630-1655) nach einem Gemälde von Pietro Testa (1611-1650). ${ }^{3}$

\section{Bildprogramme}

Profane Tugendheldinnen treten bereits in der Frühen Neuzeit nicht nur als vereinzelte Bildmotive, sondern auch in größeren ikonographischen Zusammenhängen auf, die sich gelegentlich noch nachweisen lassen. Sie umfassen komplexe Bildprogramme der Wandmalerei, thematisch komponierte aristokratische Bildersammlungen (`Galerien $)$, Pendants, die bereits als solche in Auftrag gegeben oder nachträglich durch gezielte Erwerbungen zusammengestellt wurden, aber auch graphische Serien, deren moralisch-politische Intentionen unübersehbar sind. In solchen Konstellationen kann die ursprüngliche Funktion und Interpretation des Bildmotivs leichter rekonstruiert werden, als dies bei den zahlreich überlieferten isolierten Beispielen möglich ist, vom Ausnahmefall des Bildes im Bild einmal abgesehen. Bildprogramme, die profane Tugendheldinnen integrieren, sind deshalb für diese Untersuchung von besonderer Relevanz.

Im Gegensatz zu Märtyrerbildern, deren Funktion in der nachtridentinischen theologischen Kunstdebatte ${ }^{4}$ ausführlich erörtert wurde, ist über Funktion und Interpretation des Bildmotivs der sprofanen Tugendheldinnen<, vom neustoischen Hintergrund ${ }^{5}$ einmal abgesehen, wenig bekannt. In einzelnen Fällen lässt sich allerdings nachweisen, dass Bilder mit diesem Motiv als Pendants konzipiert oder zur Pendant-Bildung erworben wurden. ${ }^{6}$ Auch treten femmes fortes mehrfach in umsichtig zusammengestellten thematischen Galerien auf. ${ }^{7}$ Solche Formen der Serienbildung des ikonographischen Themas in höfischen Galerien könnten auf ursprüngliche Funktionen hinweisen, zumal sich vergleichbare Serien in bürgerlichen Sammlungen nicht nachweisen lassen. Wenn in der Frühen Neuzeit Gemälde aus dem Motivbereich der ıSelbstmörderin als Tugendheldin in fürstlichen Sammlungen als Pendants gehängt oder zu >Galerien` zusammengefügt wurden, kann abgesehen von formalen Erwägungen ein Programm vermutet werden, das nur im Fall der Galerie des femmes fortes explizit gemacht wurde. ${ }^{8}$

\footnotetext{
${ }^{3}$ Vgl. Mai, Ekkehard / Paarlberg, Sander / Weber Gregor J. M. (Hrsg.): AK Vom Adel der Malerei, Holland um 1700, Köln 2006, S. 144, Nr. 21 (Ildikó Ember).

${ }^{4}$ Vgl. S. $207 \mathrm{ff}$.

${ }^{5}$ Vgl. S. $177 \mathrm{ff}$.

${ }^{6}$ Landgraf Wilhelm VIII. von Hessen-Kassel ließ Kunstagenten nach Gemälden mit einschlägigen Motiven suchen und erwarb zu einer Sophonisbe von Vouet ein Gemälde Renieris mit gleichem Thema hinzu. Dazu weiter unten S. 268f. Für viele Paläste und Schlösser wurden Tugendheldinnen und Tugendhelden in unterschiedlichen Zusammenstellungen als Pendants erworben; vgl. dazu unten S. 259 mit einer Liste eindeutig identifizierbarer Pendants.

${ }^{7}$ Vgl. unten S. $245 \mathrm{ff}$.

8 Bedeutung und Funktion von Serien oder Pendants in der Frühen Neuzeit wurden bisher nicht gründlich untersucht. Ein erster Ansatz: Moiso-Diekamp, Cornelia: Das Pendant in der holländischen Malerei des 17. Jahrhunderts, Frankfurt / Bern / New York 1987. In der zweiten Hälfte des 19. Jahrhunderts und im 20. Jahrhundert erhielten Serien und Zyklen unter dem Einfluss der Photographie seit Monets 15 Varianten des Getreideschobers (1891) und 20 Varianten der Kathedrale von Rouen (1895) eine ganz neue Bedeutung. Serie, Reihung und Repetition, ebenso wie serielle Wiederholung, Addition und Spiegelung wurden zu radikalen Techniken moderner Kunst. Dazu die einleitenden Aufsätze in: Schneede, Uwe / Heinrich, Christoph (Hrsg.): AK Monets Vermächtnis, Serie, Ordnung und Obsession, Hamburg 2001, S. 7-58.
} 
Heutige Hängungen geben allerdings keine Hinweise auf ursprüngliche Pendants, da museale Anordnungen von Gemälden dem Zeitgeschmack unterliegen. Aus diesem Grunde können Pendant-Hängungen am zuverlässigsten in seit ihrer Einrichtung wenig veränderten Barockgalerien beurteilt werden, über deren Bestand hinreichende Informationen vorliegen, auch wenn viele als Pendants erworbene Gemälde inzwischen ohne ihr Gegenstück gezeigt werden. ${ }^{9}$ Auch in einer ursprünglich aristokratischen oder fürstlichen Barockgalerie hat heute das Prinzip der Variation und der Wunsch, viele Meister und Objekte vorzustellen, Vorrang vor der zunächst intendierten ikonographischen Ausgewogenheit. Nur Bestandskataloge geben noch Auskunft über die Anschaffungspolitik und dokumentieren, dass als Gegenstücke vor allem Landschaften, Genrebilder und Verlobten- oder Ehepaarbilder beliebt waren. Mythologische, biblische und historische Themen wurden seltener als Pendants erworben; das Gleiche gilt für Stilleben. ${ }^{10}$

Am bekanntesten sind heute die graphischen Reihen des französischen 17. Jahrhunderts, die in den letzten Jahren mit dem feministischen Interesse für die femmes fortes besondere Beachtung gefunden haben: Die Illustrationen zu La femme heroïque ou les heroïnes comparées avec les heros en toute sorte de vertus von Jacques Du Bosc (1645) und zu La gallerie des femmes fortes von Pierre Le Moyne (1647) fanden weite Verbreitung und haben zweifellos entscheidend zur Verbreitung des Themas der Tugendheldin beigetragen. Diese Graphikserien stehen aber keineswegs am Beginn der Bildprogramme. Bereits um 1500 sind in Italien genau komponierte Gemäldeserien mit dem Bildmotiv der sstarken Frauen nachweisbar, in Frankreich unterstützte die im 16. Jahrhundert aufkommende architektonische Mode der aristokratischen `Galerien` die Reihenbildung. Außerdem brachten politische Gründe in der ersten Hälfte des 17. Jahrhunderts das Thema erneut in Mode.

Die ikonographische Reihung weiblicher Tugendheldinnen wurde in der Frühen Neuzeit einerseits von der mittelalterlichen Konzeption der neuf preuses, andererseits von literarischen Katalogen berühmter Frauen beeinflusst.

Jacques de Longuyon preist in den Voeux du Paon (1312/1313) panegyrisch die Kriegstaten von Hektor, Alexander, Cäsar, Josua, David, Judas Makkabäus, Artus, Karl dem Großen und Gottfried von Bouillon. Daraus entstanden die neuf preux, deren Katalog früh feststand. Die preux wurden als Exempel ritterlicher und höfischer Lebensführung in altfranzösischen, mittelenglischen, mittelhochdeutschen, mittelniederländischen, gelegentlich auch in italienischen und spanischen Texten übernommen. ${ }^{11}$ Die kanonisierte Reihe, deren Dreiergruppen die geläufige heilsgeschichtliche Konzeption (ante legem, sub lege und sub gratia) aufgriff, wurde wohl zuerst im Livre de Leësce des Jehan Le Fèvre (zwischen 1373 und 1387) durch neun weibliche preuses ergänzt. Die ebenfalls in Triaden eingeteilten preuses waren weniger festge-

\footnotetext{
${ }^{9}$ Ich wähle das Herzog Anton Ulrich-Museum in Braunschweig und das dazugehörige Verzeichnis der Gemälde vor 1800, hrsg. von Jacob, Sabine / Klessmann, Rüdiger, Braunschweig 1976.

${ }^{10} \mathrm{Vgl}$. Fußnote 165.

${ }^{11}$ Dazu Ott, Norbert: »Neun Gute Helden«, in: Lexikon des Mittelalters, Bd. 6, Sp. 1103-1106.
} 
legt. ${ }^{12}$ Zunächst umfasste der im französischen Spätmittelalter ausgebildete Katalog weiblicher preuses ${ }^{13}$ nur kriegerische Königinnen und Amazonen der Antike (Deipyle, Sinope, Hippolyte, Menalippe, Semiramis, Lampeto, Tomyris, Teuta und Penthesilea). Erst im 15. Jahrhundert und wohl vor allem im deutschsprachigen Bereich ${ }^{14}$ setzte sich auch für die preuses eine triadische Gliederung nach heilsgeschichtlichen Epochen durch: eine antike Dreiergruppe (Lukretia, Veturia, Virginia) stand dann neben einer alttestamentlichen (Esther, Judith, Jaël) und einer christlichen (Helena, Brigitta, Elisabeth).

Die neun preux wurden seit dem letzten Drittel des 14. Jahrhunderts in den Bildkünsten aufgegriffen; über siebzig Zeugnisse in Skulptur, Freskomalerei, Glasmalerei, Textilkunst und Druckgraphik sind nachgewiesen. In Bildprogrammen werden die Helden meist durch auf ihre Taten verweisende inscriptiones vereindeutigt, gemalte Bänder oder Scheinarchitektur stellen rahmend zusätzlich einen Zusammenhang her und bringen die Fresken in die Nähe antiker Skulpturengalerien. Die Bildprogramme spiegeln auch subtile Wandlungen des Wertekanons wider. ${ }^{15}$ Die später hinzutretenden preuses greifen gelegentlich die üblichen weiblichen Personifikationen der drei theologischen und der vier Kardinaltugenden auf. Hans Burgkmair d. Ä. scheint als einer der ersten diese Aufteilung nach »Glaubenstriaden ${ }^{16}$ bei den männlichen und weiblichen Helden ins Bild gesetzt zu haben.

Die literarischen Kataloge berühmter Männer, die Petrarca wieder aufgegriffen hatte, wurden seit Boccaccio durch Kataloge berühmter Frauen ergänzt. Entsprechend finden sich zunächst Bildprogramme, in denen weibliche Tugendheldinnen zusammen mit illustren Männern auftreten; erst allmählich entstanden auch Bildfolgen, die nur weibliche Exempel zusammenstellen. Céline Richard-Jamet hat dafür die Begriffe ıgemischteı und sautonome` Serie eingeführt. ${ }^{17}$

Die `Galerie starker Frauen`, auf den ersten Blick eine `feministische` Akzentuierung von Mythos und Geschichte, hat, lange bevor sie in die barocken Bildkünste Eingang fand, Vorläufer in den literarischen Katalogen der Antike: Cornelius Nepos, Plinius der Jüngere und Valerius Maximus stellten in ihren Sammelwerken herausragende Männer und Frauen unter verschiedenen Aspekten zusammen. ${ }^{18}$ Petrarca griff in der

${ }^{12}$ Vgl. Sedlacek, Ingrid: Die Neuf Preuses, Heldinnen des Spätmittelalters, Marburg 1997.

${ }^{13}$ Dazu Fajen, Robert: Die Lanze und die Feder, Untersuchungen zum sLivre du Chevalier errantı von Thomas III., Markgraf von Saluzzo, Wiesbaden 2003.

${ }^{14}$ Sedlacek, a.a.O., S. 128.

${ }^{15}$ Vgl. Schroeder, Horst: Der Topos der >Nine Worthiesı in Literatur und bildender Kunst, Göttingen 1971. - So Hans Burgkmair d. Ä. in seiner Serie der neun Helden und neun Heldinnen (Abbildungen in: Baumgärtel, B. / Neysters, S. [Hrsg.]: AK Die Galerie der Starken Frauen, Düsseldorf 1995, S. 160-161). Hans Burgkmairs Holzschnitt wurde auch als Vorlage für andere künstlerische Techniken und Neuinterpretationen verwendet; so ließen sich Pfalzgraf Ottheinrich, sein Bruder Philipp und sein Schwager Herzog Wilhelm IV. von Bayern auf einem kleinen, aus Solnhofer Stein gefertigten Steinrelief als Artus, Karl der Großen und Gottfried von Bouillon porträtieren, um ihre Rollen für die Reformation zu verdeutlichen. Vgl. Bäumler, S. / Brockhoff, E. / Henker, M. (Hrsg.): Von Kaisers Gnaden, 500 Jahre Pfalz-Neuburg, Regensburg 2005, S. $349 f$.

${ }^{16} \mathrm{Vgl}$. AK Die Galerie der Starken Frauen, S. $160 f$.

${ }^{17}$ Richard-Jamet, Céline Catherine Jeanne: Les galeries de sfemmes fortesı dans les arts en Europe au XVIe et au XVIle siécles: une étude iconographique comparative; thèse Université Michel de Montaigne-Bordeaux III, 2003, passim. Die Unterscheidung von »séries mixtes « und »séries autonomes « ist nicht ganz glücklich, weil es natürlich auch ıautonomeı Bildfolgen mit ıstarken Männern gibt.

${ }^{18}$ So gliederte Valerius Maximus in der frühen Kaiserzeit seine Sammlung Facta et dicta memorabilia thematisch nach Tugenden und Lastern. Als Kapitelüberschriften dienen gute oder schlechte Eigenschaften wie moderatio (Maßhalten), clementia (Milde), fortitudo (Tapferkeit) oder crudelitas (Grausamkeit), avaritia (Habgier) und perfidia (Treulosigkeit). In den einzelnen Kapiteln werden Römern Personen aus der nichtrömischen Geschichte gegenübergestellt. Der patriotisch-konservativen Haltung des Valerius Maximus entsprechend überwiegen die römischen Beispiele (636 römischen Beispielen stehen 320 exempla externa gegenüber). 
nicht vor 1367 als Sammelband konzipierten, von Lombardo della Seta fortgesetzten Sammlung De viris illustribus ebenso wie Boccaccio in De casibus virorum illustrium (1356-1360) auf diese Kompendien zurück. Boccaccios zwischen 1361 und 1375 verfasste Exempelsammlung De claris mulieribus erweiterte den Kanon auf illustre Frauen. Diese literarischen Vorlagen dienten vereinzelt schon zeitgenössisch als Vorwurf für Freskenzyklen in Villen und Palästen. ${ }^{19}$.Das in den Kompendien ausgebreitete Material bot die Möglichkeit, Bildprogramme unter dem Aspekt der Analogie oder unter dem Gesichtspunkt der Opposition zu konzipieren.

Die frühneuzeitlichen Bildprogramme und Bildfolgen sstarker Frauen wiederholen die Entwicklung beider literarischer Vorbilder aus Antike und Mittelalter: zunächst traten Frauen nur als unselbständige Begleitfiguren in gemischten Reihen auf, erst später entstanden autonome Reihen, in die allmählich auch das Motiv der Tugendheldin als Selbstmörderin Aufnahme fand. Eine wichtige Rolle spielte dabei das ikonographische Programm höfischer Galerien, die sich diesem Thema im Gegensatz zu bürgerlichen Sammlungen früh öffneten.

Als neue Architekturmode entstanden in italienischen und französischen Schlössern und Palästen des 16. Jahrhunderts Galerien als Schau- und Festräume ${ }^{20}$ mit neuartigen Fensterlösungen, zunächst mit freistehenden Statuen und Büsten, dann auch mit Gemälden ausgestattet, wobei die Durchfensterung auf einer Langseite wieder zurückgenommen werden musste. Solche Bildergalerien konnten ein Programm mit wandverbundenen Fresken oder mit gerahmten, aber in der Reihenfolge klar festgelegten Gemälden vorsehen. Andere Ausstattungsvarianten waren in der Konzeption flexibler; Gemälde wurden nach dem Geschmack des Besitzers und unter dekorativen Aspekten gehängt, so dass neue Akzentuierungen vorgenommen werden konnten; allmählich entwickelten sich aus den Galerien Schausammlungen. Die Hängungen in fürstlichen Galerien sind aufschlussreich, weil reflektierte Bildprogramme und Hängungen im Bereich der "Schwatz- und Spaziersäle « ${ }^{21}$ kulturelles Selbstverständnis, Herrscherwürde und Machtansprüche der Auftraggeber zum Ausdruck brachten.

\section{Bildfolgen und Galerien}

In der Forschung wird meist davon ausgegangen, dass als erster Giotto (ca.12671337) in einer Freskenserie des neapolitanischen Castel Nuovo das Thema der uomini famosi aufgegriffen habe. ${ }^{22}$

Der hypothetische, bereits im 16. Jahrhundert zerstörte Freskenzyklus, den Lorenzo Ghiberti (1378-1455) wohl noch gesehen hat, Vasari aber nur noch vom Hörensagen gekannt haben kann, könnte im Auftrag Roberts von Anjou zwischen 1328

\footnotetext{
Allerdings strukturiert er seine Sammlung auch noch nach weiteren Gesichtspunkten: Er stellt die Vergangenheit der Gegenwart gegenüber, Frauen werden mit Männern verglichen, bekannte Männer werden unbekannten gegenübergestellt, ähnliche Verhaltensweisen werden wertend gestuft.

19 Vgl. Hansmann, Martina: Andrea del Castagnos Zyklus der 'Uomini famosi' und 'Donne famose', Geschichtsverständnis und Tugendideal im florentinischen Frühhumanismus, Münster / Hamburg 1993.

${ }^{20}$ Vgl. Prinz, Wolfram: Die Entstehung der Galerie in Frankreich und Italien, Berlin 1970.

${ }^{21}$ Vgl. "Galerie«, in: Lexikon der Kunst, Bd. 2, München 1996, S. 627. Der Begriff der »Schwatz-und Spaziersäle« wurde 1699 von Leonhard Sturm in seiner Vollständigen Anweisung zu der Civil Bau-Kunst (Braunschweig 1699) geprägt.

${ }^{22}$ Christiane Joost-Gaugier: „Giotto's Hero Cycle in Naples. A Prototype of Donne Illustri and a Possible Literary Connection«, in: Zeitschrift für Kunstgeschichte, 43 (1980), S. 311-318.
} 
und 1333 entstanden sein. Ein Aufenthalt Giottos in Neapel ist für diese Jahre belegt, allerdings sind die Quellen im Detail widersprüchlich oder doch ungenau. In der Giotto-Biographie Vasaris findet sich keine nähere Angabe zum Sujet, auch bei Ghiberti ist nur die Rede von den huomini famosi, die Giotto in der sala del re Uberto gemalt habe. ${ }^{23}$

So wird die Thematik des Freskenzyklus meist aus neun ekphrastischen Sonetten des 14. Jahrhunderts rekonstruiert. Die anonymen Gedichte ${ }^{24}$ scheinen unter reichlicher Verwendung dantesken Sprachmaterials die Gegenstände des Freskenzyklus zu beschreiben. Allerdings sind die neun sonetti ritornellati in keiner Handschrift zusammen überliefert. Es ist also nicht einmal gesichert, dass Giotto im Castelnuovo wirklich neun Helden (Alexander, Solomon, Hektor, Äneas, Achilles, Paris, Herkules, Samson und Cäsar) dargestellt hat. Die Sonette sind jedenfalls zu umfänglich, um als subscriptiones gedient zu haben. Gleichwohl hält Christiane JoostGaugier $^{25}$ den so rekonstruierten Zyklus für eine "visual inauguration of what was to become a major ideological preoccupation of Renaissance literati, humanists, princely patrons and artists «.

Auch die Bezüge zu Petrarca sind nicht so eindeutig, wie sie gelegentlich dargestellt werden. Joost-Gaugier weist darauf hin, dass Petrarcas De viris illustribus $\mathrm{n}$ ach Giottos Freskierung der neapolitanischen sala grande entstanden sein müsse, kann allerdings belegen, dass Robert von Anjou und Petrarca sich bereits vor 1330 kannten. Mit einiger Wahrscheinlichkeit mag deshalb davon ausgegangen werden, dass Petrarca konzeptuell an Giottos Darstellung der uomini famosi beteiligt war. Bei einem späteren Freskenzyklus, der nach 1367 in Padua für Francesco da Carrara (il Vecchio) ausgeführt wurde und der ebenfalls verloren ist, darf der Einfluss Petrarcas hingegen als sicher vorausgesetzt werden. ${ }^{26}$ Umso gewichtiger ist es, dass dort weibliche Begleitpersonen der uomini famosi offenbar fehlten.

Geradezu als sich verselbständigender kunsthistorischer Mythos hat sich die Auffassung durchgesetzt, die neun uomini famosi seien in Giottos neapolitanischem Zyklus von ihren ıEhefrauenı begleitet worden. ${ }^{27}$ Noch Richard-Jamet vertritt diese Auffassung in etwas abgeschwächter Form: »Certains auteurs ont établi que ces

\footnotetext{
23 „Molto egregiamente dipinse la sala del re Uberto de' huomini famosi, in Napoli, dipinse nel castello dell' uovo. (Ghiberti, Lorenzo: I commentarii, hrsg. von Bartoli, Lorenzo, Firenze 1998, S. 84).

${ }^{24}$ Blasiis, Giuseppe de: »Immagini di uomini famosi in una sala di Castelnuovo«, in: Napoli nobilissima, 9 [1900], S. 65-67.

25 Joost-Gaugier, a.a.O., S. 317

${ }^{26}$ Hierzu: Mommsen, Theodor E.: »Petrarch and the Decoration of the Sala Virorum Illustrium in Padua «, in: The Art Bulletin 34 (1952), S. 95-116. Mommsen stützt sich vor allem auf den Briefwechsel Petrarcas mit Francesco da Carrara zwischen 1361 und 1374. Wie aus dem Proömium (»lllustres quosdam viros, quos excellenti gloria floruisse doctissimorum hominum ingenia memorie tradiderunt, in diversis voluminibus tanquam sparsos ac disseminatos rog at u tuo, plaustrifer insignis, qui modestissimo nutu inclite urbis Patavine sceptra unice geris, locum in unum colligere et quasi quodammodo stirpare arbitratus sum. «) hervorgeht, veranlasste wohl Francesco da Carrara Petrarca zunächst einzeln konzipierte Biographien in De viris illustribus zusammenzustellen. Da das Proömium nicht vor 1367 entstanden sein kann, die Fresken der sala aber nach Mommsen (S. 98, Fußnote 33) bereits 1370 über Padua hinaus bekannt waren, kann Petrarcas Einfluss auf dieses Programm als sicher gelten. Am Ende des 15. Jahrhunderts oder zu Beginn des 16. Jahrhunderts hat wohl ein Brand die Halle und ihre Ausmalung zerstört, wie Untersuchungen anlässlich einer Restaurierung 1928 ergaben. 1539 wurde die Halle wieder hergestellt und erneut mit viri illustres der Antike freskiert. Diese Dekoration des 16. Jahrhunderts ist der eigentliche Gegenstand der Untersuchung Mommsens. Das spätere Programm stellt die viri illustres ohne weibliche Begleitpersonen dar, so dass dies wohl auch für das ursprüngliche gelten mag.

27 Joost-Gaugier hat ihre Beschreibung »in the company of their women « (a.a.O., S. 317) wohl von Mommsen übernommen, der zunächst davon spricht, wahrscheinlich seien auch die Ehefrauen der Helden dargestellt worden: "Their wives were probably also represented. «Wenig später wird dies kühn als Tatsache vorausgesetzt: »In regard to the pictures of the strange `Nine Worthies` and their wives in the Castelnuovo at Naples [...]« (a.a.O., S. 113 und 116).
} 
hommes représentés avec leurs femmes officielles ou leurs maîtresses: Penthésilée et Polyxène auraient accompagnés Achille, Dalila aurait accompagné Samson et la femme de Salomon, Salomon. « ${ }^{28}$ Solche und ähnliche Behauptungen beruhen auf einer ungenauen Lektüre der neun ekphrastischen Gedichte, auf die sich die Forschung beruft. Sie nennen nämlich nur dreimal weibliche Bezugspersonen, wobei es sich aber nicht nur um Ehefrauen handelt. Hektor wird von Penthesilea begleitet (magnanima reina); die schöne Königin der Amazonen stand bekanntlich den Trojanern nach dem Tode Hektors bei und wurde im Zweikampf von Achill getötet, der sich in die Sterbende verliebte. Achill wird seine Gattin Polyxena beigesellt, zu Salomon gehört »questa maledetta creatura«, womit ganz offensichtlich die Königin von Saba gemeint ist, ohne dass man daraus auf Misogynie schließen müsste. ${ }^{29}$ Joost-Gaugier betont zu Recht, dass bei Giotto die Frauen noch nicht als donne illustri und damit als selbständiges Thema, sondern nur als serläuternde، Begleitung aufgefasst waren ${ }^{30}$.

Wenn Richard-Jamet ihre Reihe sgemischter` Serien männlicher und weiblicher Helden mit italienischen Freskenzyklen des 15. Jahrhunderts beginnen lässt, hat sie damit nur teilweise Recht, da die weiblichen Figuren zunächst nur als Ergänzung, Begleitung und Illustration männlicher Helden in diese Zyklen aufgenommen wurden. Erst in der Frührenaissance ${ }^{31}$ findet sich unter dem Einfluss von

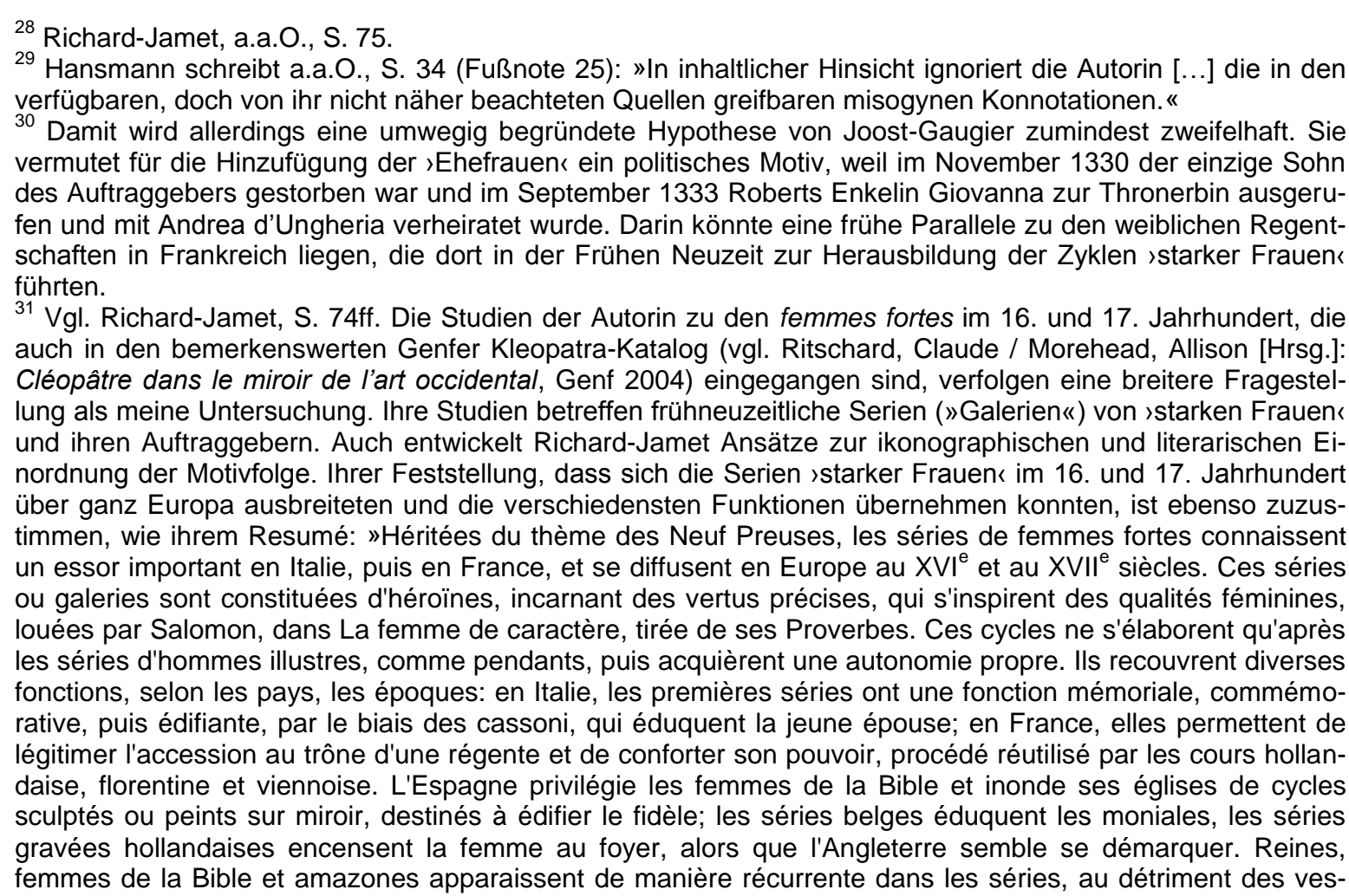


Boccaccios De claris mulieribus auch in den Bildkünsten eine selbständige Konzeption profaner weiblicher Tugendheldinnen. Es ist im Übrigen bemerkenswert, dass das Motiv der Selbstmörderin als Tugendheldin zum ersten Mal in den folgenreichen Holzschnitten ${ }^{32}$ auftritt, die 1473 in Zainers Werkstatt zu Boccaccios De claris mulieribus entstanden und mit denen der Bildtypus der mulier fortis ${ }^{33}$ Konturen gewinnt. In den selbständigen Bildzyklen des 15. Jahrhunderts scheint die Tugendheldin als Selbstmörderin noch keine Rolle gespielt zu haben. ${ }^{34}$

Um die Jahrhundertwende datiert Richard-Jamet einen inzwischen zerstreuten Zyklus, der mit der Familie Piccolomini in Siena in Zusammenhang gebracht wird. ${ }^{35}$ Es handelt sich vielleicht um die erste Bildfolge, die männliche und weibliche Protagonisten gleichberechtigt nebeneinander stellt. Die Auftraggeber ließen, soweit sich dies rekonstruieren lässt, durch mehrere Künstler eine Folge von vier Männer und vier Frauen zusammenstellen: Scipio ${ }^{36}$, Judith ${ }^{37}$, Sulpicia ${ }^{38}$, Claudia Quinta [Abb. 2] ${ }^{39}$, Artemisia, Alexander [Abb. 3], Tiberius Gracchus und Eunostos von Tanagra ${ }^{40}$. Dieser ıgemischte Zyklusı könnte eine Schlüsselrolle in der Entwicklung in Siena gespielt haben und ist deshalb für meine Argumentation im Folgenden von Gewicht.

Am Beginn rautonomer Bildprogramme weiblicher Tugendheldinnen ste-

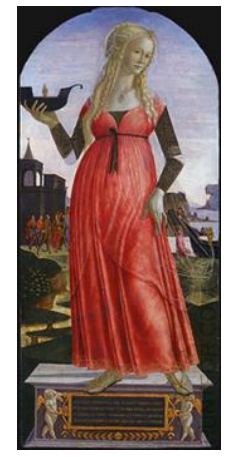

Abb. 2

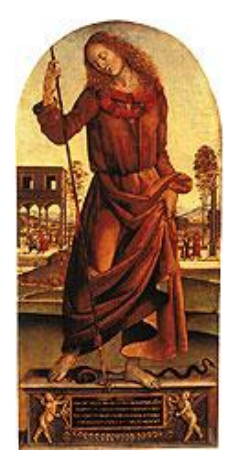

Abb. 3

\footnotetext{
tales, des saintes. On jette l'opprobre sur les héroïnes les plus irréprochables, on justifie les actes des plus barbares ; certaines ne sont pas exemptes d'un certain érotisme, d'une sensualité avérée, faussant ainsi l'image de l'héroïne et déformant ses exploits.«

${ }^{32}$ Vgl. oben S. 78.

${ }^{33}$ Der Begriff der sstarken Frau geht auf Prv 31, 10 (Mulie re m forte $m$ quis inveniet procul et de ultimis finibus eius confidit in ea cor viri sui et spoliis non indigebit.) zurück.

${ }^{34}$ Hinzuweisen ist besonders auf den Zyklus der uomini famosi und donne famose, den Andrea del Castagno um 1450 in der suburbanen Villa Carducci (die in der Literatur auch nach dem Vorort von Florenz, in dem sie sich befindet, als Villa Le gna i a bezeichnet wird) freskiert hat. Es handelt sich vielleicht um den frühesten erhaltenen >gemischten Zyklus` (heute in den Uffizien) mit Männern und Frauen, der auch eine Sibylle, eine Amazone und eine Esther enthält. Vgl. Hansmann, a.a.O., S. 96 und Abb. 1, 5, 6 und 7.

${ }^{35}$ Vgl. an versteckter Stelle Richard-Jamet, a.a.O., S. 528. Die Gemälde sind in Öl auf Holz ausgeführt und enden alle oben im Halbrund. Das Piedestal der Dargestellten enthält eine erläuternde lateinische Inschrift. Jede Figur hält ihr Attribut und steht, durch den Sockel erhöht, vor einer Landschaft, in der häufig eine Stadt zu sehen ist. Alle Gemälde, außer der Sulpicia, tragen das gleiche halbmondähnliche Zeichen, das auf die Familie Piccolomini verweisen könnte (dazu Richard-Jamet, S. 83).

${ }^{36}$ Von Francesco di Giorgio; heute in Florenz (Bargello).

${ }^{37}$ Von Matteo di Giovanni heute in Bloomington (Indiana University Art Museum).

${ }^{38}$ Von Giacomo Pacchiarotto; heute in Baltimore (Walters Art Gallery).

${ }^{39}$ Von Neroccio de'Landi und Le Maître de Griselda; heute in Washington (National Gallery of Art).

${ }^{40}$ Alle vom Maître de Griselda. Artemisia heute in Mailand (Museo Poldi Pezzoli); Alexander heute in Birmingham (Barber Institute of Fine Arts); Tiberius Gracchus heute in Budapest (Szepmueveszeti Muzeum); Eunostos von Tanagra heute in Washington (National Gallery of Art).
} 
hen wahrscheinlich zwei Bildfolgen in Mantua und in Siena. Zwei heute in London (National Gallery) befindliche Holztafeln mit der Vestalin Tuccia ${ }^{41}$ [Abb. 4] und mit Sophonisbe ${ }^{42}$ werden Mantegna (ca. 1430-1506) zugeschrieben und sind wahrscheinlich zwischen 1495 und 1506 entstanden. Die Grisaillen ${ }^{43}$ stammen wohl aus dem studiolo der Isabella d'Este (1474-1539) und dürften dort als Klappläden gedient haben. Sie könnten die Reste eines größeren Programms sein, wofür auch spricht, dass die Darstellung der Sophonisbe [Abb. 5] bereits emblematisch reduziert ist. ${ }^{44}$ Diese Sophonisbe dürfte - nach den Holzschnitten zu Boccaccio - die älteste bekannte Aufnahme des Bildmotivs der Selbstmörderin als Tugendheldin in einen größeren Zusammenhang sein.

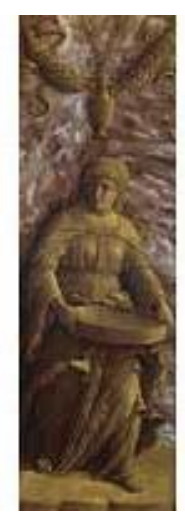

Abb. 4

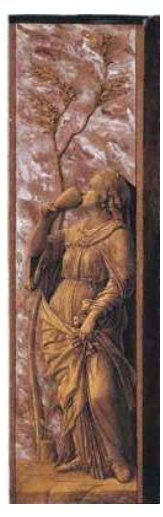

Abb. 5

Die engen Beziehungen Isabellas zu Siena ${ }^{45}$ und seinem Herrscher Pandolfo Petrucci $(1452-1512)^{46}$ stellen die Verbindung zu einem zweiten Ensemble her, das sich teilweise immer noch im Sieneser Palazzo Chigi-Sarace $\mathrm{i}^{47}$ befindet und zweifellos die umfänglichste und erstaunlichste Sammlung weiblicher Tugendheldinnen der ganzen Epoche darstellt. Das gesamte Bildprogramm des Palazzo war diesem Thema gewidmet, wie man aus sieben Serien schließen muss, die vollständig oder teilweise erhalten sind. Vielleicht hat der bereits erwähnte, zwischen 1495 und 1500 entstandene ıgemischte Zyklusı, der mit der Familie Piccolomini in Zusammenhang gebracht wird, eine Anregung für das Bildprogramm gegeben. ${ }^{48}$ Anlass dieser ikonographischen Fixierung waren wohl eine Reihe von Hochzeiten: 1507 heiratete Pandolfos Tochter, Sulpicia Petrucci, in die Familie Chigi, 1509 verband sich der älteste Sohn, Borghese Petrucci, mit der Familie Piccolomini. $^{49}$

\footnotetext{
${ }^{41}$ Katalog 228.

42 Katalog 227.

${ }^{43}$ Sie wurden erstaunlicherweise von Richard-Jamet nicht berücksichtigt.

${ }^{44}$ Vgl. oben, S. 80.

${ }^{45}$ Ein Besuch Isabellas in Siena ist für 1514 nachgewiesen, wo ihr zu Ehren ein Fest gegeben wurde. Vgl. Agosti Giovanni / Farinella, Vicenzo: »Interni senesi all'antica«, in: Agosti, Giovanni / Bagnoli, Alessandro (Hrsg.): AK Domenico Beccafumi e il suo tempo, Milano 1990, S. 578-599.

${ }^{46}$ Für Niccolò Macchiavelli ist Pandolfo Petrucci im 22. Kapitel des Principe das Vorbild eines zielstrebigen und machtbewussten Herrschers.

${ }^{47}$ Verwirrenderweise wird er in der Literatur gelegentlich auch als Palazzo Petrucci bezeichnet.

${ }^{48}$ Vgl. oben, S. 239.

${ }^{49}$ Auch Richard-Jamet vermutet eine Heirat als Anlass (a.a.O., S. 118).
} 
Zur Ausstattung des Palazzo Chigi-Saraceni in Siena gehörten zweifelsfrei sieben Bildfolgen ıstarker Frauen :

(1) Eine Judith, eine Sophonisbe (Katalog 221) und eine Kleopatra (Katalog 220) ${ }^{50}$, die früher den »Maestri di Pandolfo Petrucci « ${ }^{51}$ zugesprochen wurden, werden von Richard-Jamet dem »Maître des héroïnes de Chigi-Saracini« zugeordnet.

(2) Von Domenico Beccafumi stammen vier Tugendheldinnen (Kleopatra [Katalog 25], eine Sophonisbe (Katalog 26) ${ }^{52}$, eine Lukretia (Katalog 27) $)^{53}$ und eine Ju$\operatorname{dith}^{54}$.

(3) Eine Sophonisbe (oder Artemisia) ${ }^{55}$ weist Richard-Jamet dem »Maître des héroïnes de Chigi-Saracini« oder aber Girolamo Genga zu. Die Zuordnung zu einer Serie ist unklar.

(4) Von Girolamo di Benvenuto ${ }^{56}$ sind eine Kleopatra (Katalog 102), eine Porzia (Katalog 101) und eine Tuccia. $^{57}$

(5) Domenico Beccafumi führte 1519 den sogenannten »Zyklus Petrucci« aus, der Penelope $^{58}$, Tanaqui $^{{ }^{9}}{ }$ Marcia $^{60}$ und Cornelia ${ }^{61}$ umfasste.

(6) Folgt man Richard-Jamet ${ }^{62}$, gehören eine von Bartolomeo Neroni ausgeführte Claudia Quinta und eine Tuccia in den Umkreis dieser Reihe.

(7) Drei Wandpaneelen (»spalliere«) des 15. Jahrhunderts mit Hippo, Lukretia und Camilla stammen von Guidoccio Cozzarelli. ${ }^{63}$

Unabhängig davon, dass die Zuschreibungen im Einzelnen noch strittig bleiben, ist das Gesamtprogramm sstarker Frauen in der Ausstattung des Sieneser Palazzo Chigi-Saraceni bemerkenswert und geradezu einmalig. Es kann davon ausgegangen werden, dass die verschiedenen Reihen ursprünglich thematische Schwerpunkte hatten; die ıZyklus Petrucci genannte Serie (5) beispielsweise scheint mit Penelope, Tanaquil, Marcia und Cornelia besonders die Rolle und Treue verheirateter Frauen in den Vordergrund zu rücken. ${ }^{64}$ In vier der wohl sieben Reihen treten

\footnotetext{
${ }^{50}$ Alle drei in Öl auf Holz gemalten Tafeln heute in Siena in der Sammlung del Monte dei Paschi di Siena (Inv. 844: Judith; Inv. 845: Sophonisbe; Inv. 848: Kleopatra).

${ }^{51}$ Vgl. Santoro, Fiorella Sricchia zur Katalognummer 51 (»Maestri di Pandolfo Petrucci«: Giuditta, Sofonisba und Cleopatra), in: Agosti, Giovanni / Bagnoli, Alessandro (Hrsg.): AK Domenico Beccafumi e il suo tempo, Milano 1990, S. 266-269.

${ }_{52}$ Sophonisbe und Kleopatra befinden sich heute in Bayonne (Musée Bonnat).

${ }^{53}$ Die Lukretia befindet sich heute in Oberlin, Ohio (Oberlin College).

54 Die Judith befindet sich heute in London (Wallace Collection).

${ }_{56}^{5}$ Öl auf Holz, heute in einer Privatsammlung; Abb. bei Richard-Jamet Abb. 78.

${ }^{56}$ Beide Öl auf Leinwand; die Porzia heute in Chambéry (Musée d'Art et d'Histoire); die Kleopatra heute in Florenz (Slg. Grassi).

${ }^{57}$ Befindet sich heute in der Burg von Šternberk (Tschechien).

${ }_{58}$ Heute in Venedig (Seminario Patriarcale); Abb. 85 bei Richard-Jamet. Alle vier Bilder Öl auf Leinwand.

${ }^{59}$ Heute in London (National Gallery); Abb. 86 bei Richard-Jamet.

${ }^{60}$ Heute in London (National Gallery); Abb. 87 bei Richard-Jamet.

${ }^{61}$ Heute in Rom (Galleria Doria Pamphili); Abb. 88 bei Richard-Jamet.

62 Richard-Jamet, S. 539.

${ }^{63}$ Heute in Siena (Vicobello, Marchesa Chigi-Zondadari Monelli), Abb. 90 bei Richard-Jamet.

${ }^{64}$ Deshalb kann ich Richard-Jamets Vermutung nicht zustimmen, auch Claudia Quinta und Tuccia könnten zu dieser Serie gehört haben, da Vestalinnen für Keuschheit, nicht für eheliche Treue stehen.
} 
Selbstmörderinnen als Tugendheldinnen auf, wobei Lukretia, Sophonisbe und Kleopatra mehrfach vertreten sind.

Zur wahrscheinlich nicht vollständig erhaltenen Reihe des »Maître des héroïnes de Chigi-Saracini « ${ }^{65}$ (1) gehörte neben einer Kleopatra und einer Sophonisbe eine Judith. Kleopatra [Abb. 6] und Sophonisbe [Abb. 7] treten dem Betrachter in gleicher Manier frontal entgegen; eine tief liegende Landschaft, die zart und verschwimmend hinter den Figuren als durch-

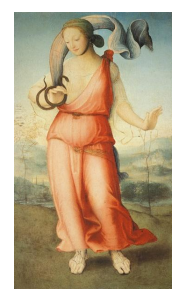

Abb. 6

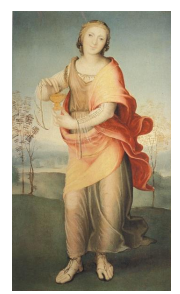

Abb. 7 gehende Linie zu sehen ist, betont die Zusammengehörigkeit der Serie. Kleopatra und Sophonisbe werden ebenso wie Judith als junge Frauen typisiert. All'antica gekleidet, sind sie für den Betrachter nur durch Schlange und Giftbecher zu identifizieren. Beide Tugendheldinnen, schöne blühende Frauen mit flatternden Gewändern, scheinen eher zu tanzen als in den Tod zu gehen; nur ihre Attribute rufen die vertrauten Geschichten ihres Tugendtodes auf. Der Darstellung fehlt noch jeglicher Ausdruck von Schmerz oder Verzweiflung, wie er wenig später häufig zum Charakteristikum der Selbstmord begehenden Tugendheldinnen wurde.

In ähnlicher Weise verfuhr Domenico Beccafumi (1486-1551) in seiner Bildfolge (2), von der wir Kleopatra [Abb. 8], Sophonisbe ${ }^{66}$ [Abb. 9], Judith und, mit groBer Wahrscheinlichkeit, eine Lukretia $^{67}$ kennen. Auch seine Tugendheldinnen erscheinen wie die des »Maître des héroïnes de Chigi-Saracini« in einer lieblichen Landschaft. Beccafumi hat allerdings unterschiedliche Varianten der ganzfigurigen Darstellung gewählt: die Heldinnen treten frontal (Lukretia, Kleopatra) oder im Profil (Sophonisbe, Judith) auf und sind wiederum über ihre Attribute zu identifizieren. Auch in dieser Serie steht die Reihenbildung sstarker

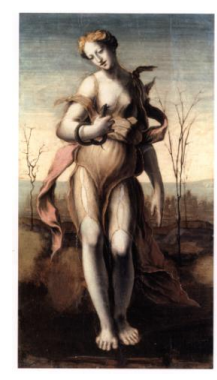

Abb. 8

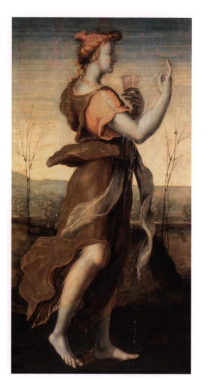

Abb. 9 Frauen`, Heiligenserien vergleichbar, und nicht die Einzelfiguren im Vordergrund.

\footnotetext{
${ }^{65}$ Vgl. Katalog 220 (Kleopatra) und 221 (Sophonisbe).

${ }^{66}$ Vgl. Katalog 25 (Kleopatra) und 26 (Sophonisbe).

67 Eine wohl fragmentarische Lukretia, die in die Serie gehört haben könnte, befindet sich heute in Oberlin (Ohio) (Oberlin College). Vgl. Richard-Jamet, Céline: „Cléopâtre: femme forte ou femme fatale? Une place équivoque dans les galeries de femmes fortes aux $\mathrm{XVI}^{\mathrm{e}}$ et $\mathrm{XVII}{ }^{\mathrm{e}}$ siècles «, in: AK Cléopâtre dans le miroir de l'art occidental, a.a.O., S. 37-52.
} 
Die Girolamo Genga (1476-1551) zugeschriebene Sophonisbe ${ }^{68}$ (3) zeigt ebenso wie die von Girolamo di Benvenuto (1470-1524) stammenden Porzia und Kleopatra (4) durchgängig die Charakteristika früher Serien ıstarker Frauen`: monumentalisiert ganzfigurig dargestellte Tugendheldinnen stehen vor einer lieblichen Landschaft und sind nur über ihre Attribute (Giftschale, Schlange oder Kohlen) zu identifizieren. Die Guidoccio Cozzarelli (1450-1516) zugeschriebene Bildfolge der Hippo, Lukretia und Camilla (7) inszeniert die Heldinnen in gleicher Weise. Besonders bemerkenswert ist hier allerdings, dass die vollständig erhaltenen aufwendigen Holzrahmungen der ursprünglichen Wandverkleidung mit den Bezeichnungen der Dargestellten und erläuternden subscriptiones die Funktion des Bildzyklus eindeutig belegen. ${ }^{69}$ Alle drei Figuren heben auf die Keuschheit der gewählten Exempel ab. ${ }^{70}$

Überhaupt müssen sich mythologische und historische Tugendexempla in Siena besonderer Beliebtheit erfreut haben; sie finden sich nicht nur im Palazzo Chigi-Saraceni, sondern auch in der Dekoration des Palazzo Venturi, der zwischen 1519 und 1523 von dem schon für die Petrucci tätigen Domenico Beccafumi freskiert wurde. Der Palazzo Venturi zeigt im durch Stichkappen gegliederten Deckengewölbe [Abb. 10] der camera eine in vier Zyklen gestaffelte Dekoration mit Tugendhelden und Tugendheldinnen ${ }^{71}$.

Die Fresken bilden ein komplexes und gestuftes Gesamtprogramm, in dessen Mittelpunkt historische Szenen stehen, die von mythologischen Szenen gerahmt und durch emblematische Frauenfiguren ergänzt werden. Die beiden zentralen Deckenbilder zeigen als fingierte Bildteppiche die Enthaltsamkeit des Scipio und Zeuxis und die Mädchen von Kroton. Sechs an die zentralen Fresken angelagerte Oktogone bilden historische Beispiele für vorbildliches männliches Verhalten szenisch ab. Zehn als oculi gegebene Szenen verweisen auf mythologische

\footnotetext{
${ }^{68}$ Die Deutung als Sophonisbe scheint mir wahrscheinlicher. Bei einer Artemisia wäre das Mausoleum im Hintergrund zu erwarten. Auch Richard-Jamet neigt ohne Begründung der Einordnung als Sophonisbe zu.

${ }^{69}$ Misciatelli, Piero: „Une cassone nuziale di Matteo Giovanni«, in: Rassegna d'Arte Senese, 1910, S. 36-38, hier nach Richard-Jamet, a.a.O., S. 127.

${ }^{70}$ Die subscriptiones (vielleicht nach dem Vorbild der Sieneser Piccolomini-Serie) und lauten:

"LUCREZIA ROMANA CASTISSIMA « / "POI CHE DALL ADVLTERO FVI POLVTA / COSI ME DOLSE CHE ME STESA OCISE / NE VITA VOLSE A CASTITA PERDVTA“ "HIPPO VIRGO GRECA / "LAMOR CONTRA ME TVTA VIRTV PERSE / CHE PER NON ESER DA NAVTE POLLVTA / PIV TOSTO NEL MAR VIVA ME SVBMERSE. «

"CAMLLA VIRGO VOLSCORUM REGINA“ / »IN BATAGLIA EXCESSI EL FOEMINIL MODO / MA PVR VINCENDO VENVS E CVPIDO / E VIRGINE STANDO ACQVISTAI PIV LODO«

${ }^{71}$ Vgl. Kliemann, Julian: »Siena, Palazzo Venturi (später Agostini, Bindi Sergardi, Casuccini)«, in: Kliemann, Julian / Rohlmann, Michael (Hrsg.): Wandmalerei in Italien, Die Zeit der Hochrenaissance und des Manierismus 1510-1600, München 2004, S. 258-269. Bei Kliemann auch weiterführende Literatur zum Palazzo Venturi.
} 
Exempla (den seinen Vater rettenden Äneas, Deukalion und Pyrrha usw.). Alle oculi werden von zwei in der gemalten Zwickelarchitektur sitzenden Tugendheldinnen gerahmt, die meist ${ }^{72}$ an ihrem Attribut zu identifizieren sind: Eva, Pero, Lukretia, Tuccia, Penelope, Sophonisbe, Dido, Esther, Judith, Porzia, Artemisia, Julia, Claudia Quinta, Sulpicia, Camilla und Hypsikratea. ${ }^{73}$ Die Verbindung männlicher und weiblicher Tugenden als Gesamtthema des Bildprogramms, in das sich die durch die weiblichen Figuren verkörperten Tugenden der Keuschheit, Treue und Schamhaftigkeit einfügen, verweist auf seinen vermutbaren Anlass, die Vermählung von Alessandro Venturi und Bartolomea Luti (1519). Zwar nehmen die zwanzig Tugendheldinnen einen relativ bescheidenen Platz im gesamten Bildprogramm ein; doch bleibt es bemerkenswert, dass inre Typisierung bereits zu Beginn des 16. Jahrhunderts so weit gedie-

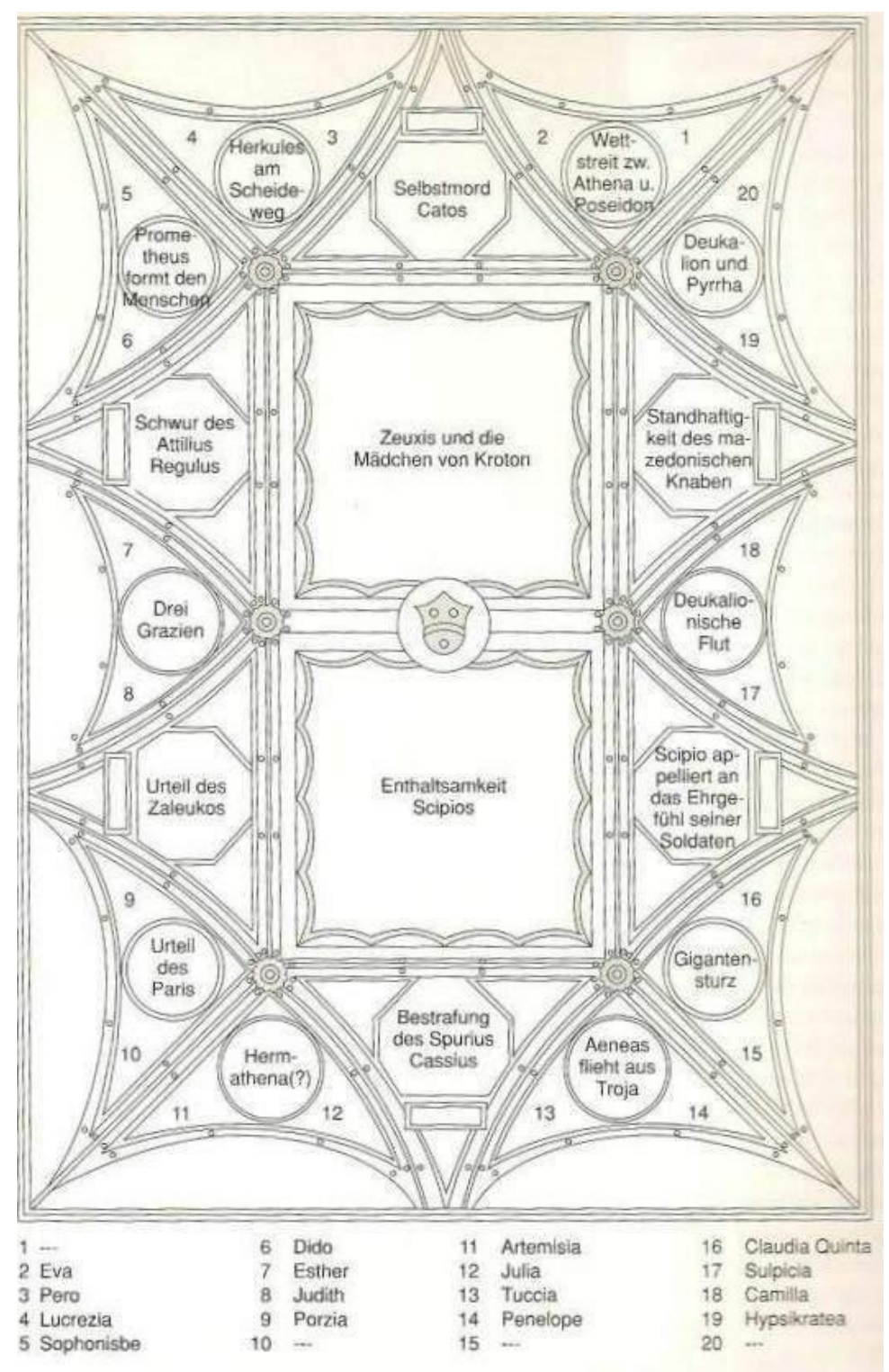

Abb. $10^{74}$ hen war, dass sie allein durch Attribute identifizierbar waren. ${ }^{75}$

Das Thema der sstarken Frauen wird im 16. Jahrhundert immer wieder in Bildprogrammen aufgegriffen. ${ }^{76}$ Allerdings ergibt sich eine allmähliche Verlagerung in

\footnotetext{
${ }^{72}$ Zwei Frauenfiguren lassen sich nicht zu identifizieren.

${ }^{73}$ Die in das Bildprogramm aufgenommenen Frauenfiguren finden sich meist bei Valerius Maximus oder in Boccaccios De mulieribus claris (vgl. Kliemann, a.a.O., S. 261).

${ }_{75}^{74}$ Das hier wiedergegebene Aufbauschema des Freskenzyklus bei Kliemann, S. 264.

75 Die Inschriften des Deckengemäldes erläutern nur die historischen Szenen. Das gänzlich humanistisch ausgerichtete Konzept des Bildprogramms nimmt übrigens nur bei den Tugendheldinnen auch biblische Figuren (Eva, Esther und Judith) auf.
} 
den öffentlichen und politisch-repräsentativen Bereich. Während die Zyklen in den beiden palazzi Sienas auf eheliche Tugenden abheben, stehen in Rom und München ıöffentliche` Tugenden im Vordergrund: So malte Cristofano Gherardi (1508-

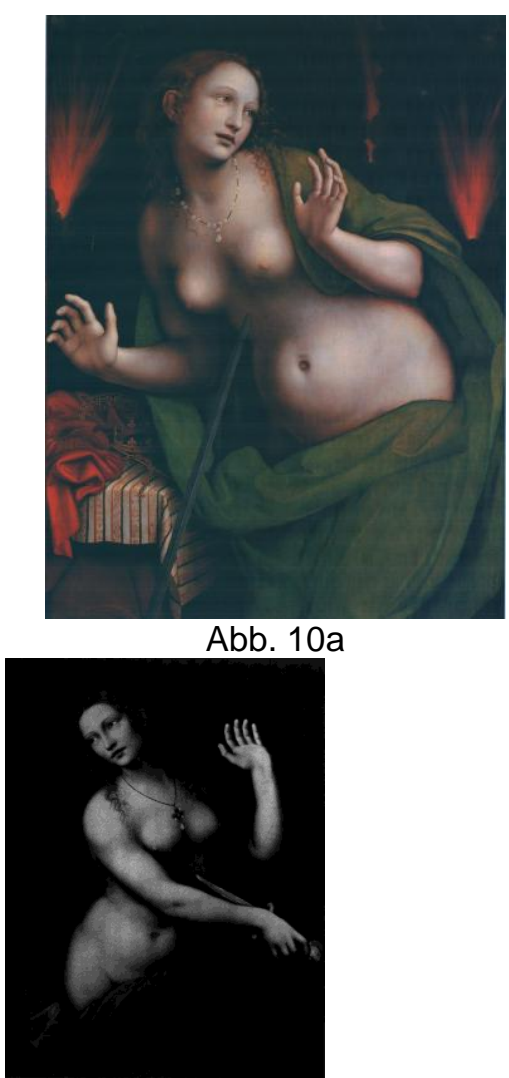

Abb. 10c

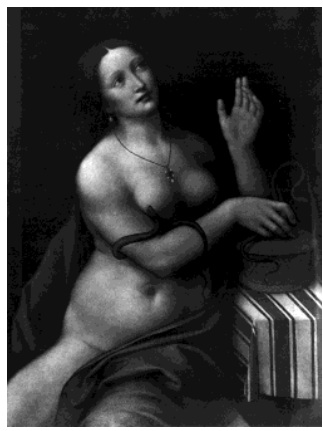

Abb. 10d
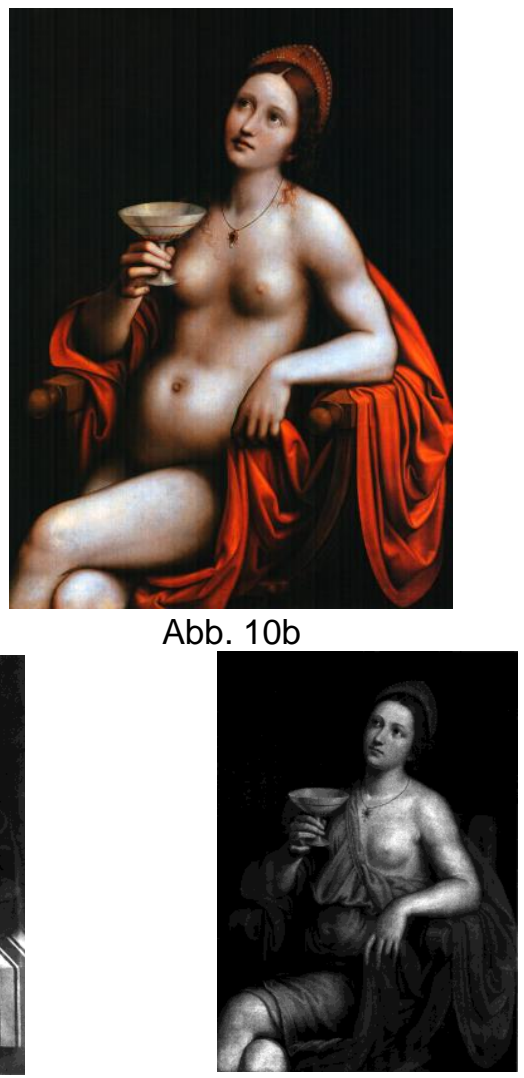

Abb. 10e

1556) zwischen 1538 und 1554 für die sala delle aquile im römischen Ko nse rva torenpalast eine Bildfolge mit Römerinnen, die neben Lukretia Cloelia, Hersilia,

\footnotetext{
${ }^{76}$ [Nach dem vorläufigen Abschluss der Arbeit wurde ich auf eine weitere Serie von Giovanni Pietro Rizzoli, gen. Giampietrino (um 1485-1553) aufmerksam. Es handelt sich um eine Dido [Abb. 10a] (Katalog 150a) und eine Sopohonisbe [Abb. 10b] (Katalog 150b), die sich heute in der Sammlung Borromeo befinden, sowie um eine Lukretia [Abb. 10c] (Katalog 150c) und eine Kleopatra [Abb. 10d] (Katalog 150d), die als Teile der Sammlung Kress heute in Madison (Wisconsin) und Lewisburg (Pennsylvania) sind. Cristina Geddo hat in ihrem Beitrag zu den beiden Bildern in der Sammlung Borromeo (Natale, Mauro / Di Lorenzo, Andrea (Hrsg): AK Die Sammlung Borromeo, Malerei und Skulptur in der Nachfolge Leonardo da Vincis, Milano 2007, S. 170-179) den Zusammenhang dieser vier Bilder wahrscheinlich gemacht, wofür übereinstimmende Maße, identische Materialien und analoger Bildaufbau sprechen.

Allerdings scheint es bei der Aufteilung der Sammlung Borromeo (vor 1676) zu einer unglücklichen Trennung gekommen zu sein: kompositorisch waren einander wohl Dido und Lukretia als Beispiele für Selbstmord aus Liebe, Kleopatra und Sophonisbe als Beispiele für Selbstmord zur Rettung der Ehre einander zugeordnet. Für die ursprüngliche Zuordnung von jeweils zwei Pendants sprechen unübersehbar stilistische Akzentuierungen: affektgeladene Emphase charakterisiert die stehenden Dido und Lukretia, während Kleopatra und Sophonisbe, sitzend dargestellt, in stoischer Gelassenheit Selbstmord begehen. Der europäischen Leserichtung entsprechend müssten also Lukretia (links vom Betrachter) und Dido (rechts) einander zugeordnet gewesen sein; die zweite Gruppe wurde von Kleopatra (links) und Sophonisbe (rechts) gebildet. Die von Giovan Francesco Caroto (Katalog 59) hergestellte versione moralizzata [Abb. 10e], die Giampietrinos Sophonisbe kopiert, aber in Kleidung verhült, kann leider zur genaueren Datierung der Reihe nichts beitragen. Es handelt sich jedenfalls um eine bemerkenswert frühe Serie der Selbstmörderinnen als Tugendheldinnen, die wohl um 1520 zu datieren ist. Über ihre ursprüngliche Lokalisierung lässt sich immerhin sagen, dass zumindest die beiden Bilder der Sammlung Borromeo zur Sammlung des Conte Bartolomeo Arese (1610-1674) gehörten. Die Serie dürfte also einen Mailander Palazzo geschmückt haben.]
} 
die Sabinerinnen, Claudia Quinta und Tuccia umfasste. ${ }^{77}$ Die Medaillons sind in einen dekorativen Fries eingefügt, der unter der kassettierten und ebenfalls ausgemalten Decke verläuft, und stechen in der pompejanischen Ausmalung mit Grotesken, Festons und Abbildungen antiker Monumente deutlich hervor. Die Leistungen römischer istarker Frauen` wurden bewusst unter republikanischen Gesichtspunkten ausgewählt, der Bedeutung der Räumlichkeiten entsprechend, in der die Insignien der Konservatoren aufbewahrt wurden.

Ein bemerkenswert komplexes Programm entstand im 16. und im beginnenden 17. Jahrhundert in der Münchener Residenz: Bereits 1528 gab Herzog Wilhelm IV. eine 'gemischte، Bilderserie ${ }^{78}$ von jeweils acht Männern und Frauen in Auftrag, die sich heute in München (Alte Pinakothek) und Stockholm (Nationalmuseum) befindet und zu der auch eine Lukretia gehörte. Dieses Programm wurde von Andrea Michieli, gen. II Vicentino (1540/42-1617) zwischen 1611 und 1613 mit einer sgemischten، Serie für den Kaisersaal fortgesetzt, teilweise auf die bereits vorhandene Ausstattung Bezug nehmend. Sieben Tugendheldinnen, (Lukretia, Kaiserin Helena, Cloelia, Virginia, Esther, Artemisia, die Königin von Saba und Judith) sind Scipio, Cäsar, Titus Manlius Torquatus, Horatius Cocles, Marcus Curtius, Scaevola, Hannibal und Alexander an die Seite gestellt. Dabei werden die Taten der Protagonisten in der unteren Bildhälfte der monumentalen Repräsentationsbilder illustriert. Herzog Maximilian I. gab 1604 für den Festsaal der Residenz bei Hans van der Biest mehrere Tapisserie-Serien in Auftrag, zu denen auch zwölf Teppiche mit männlichen und weiblichen Helden aus Antike und Bibel gehörten. Auf den riesigen Teppichen erläutern Distichen die Taten der Dargestellten, zu denen wiederum eine Lukretia gehörte. ${ }^{79}$ Aus den beiden Bilderserien und den Tapisserien lässt sich ein Gesamtprogramm rekonstruieren, das antike und biblische Figuren, Frauen wie Männer, beziehungsreich miteinander kombinierte. ${ }^{80}$

In der zweiten Hälfte des 16. und im beginnenden 17. Jahrhundert war es vor allem die Familie der Medici, die dem politisch-repräsentativen Aspekt des Themas der Tugendheldin zu europäischer Verbreitung verhalf. Als Cosimo I. das Appar-

\footnotetext{
77 Der nach den Plänen Michelangelos erst 1568 vollendete Konservatorenpalast war Sitz der Stadtregierung. Die Fresken befinden sich noch in situ. Vgl. dazu Richard-Jamet; S. 538 und Abb. 91 bis 93.

${ }^{78} \mathrm{Vgl}$. Richard-Jamet, S. 96ff. und Abb. 58. Die männlichen Helden sind: Moses, Lykurg, Herkules, Samson, Horatius Cocles, Judas Maccabäus, Marcus Valerius Corvinus, David. Die weiblichen exempla sind: Penthesilea, Jaël, Veturia, Judith, Esther, Lukretia, Susanna und Thomyris.

${ }^{79}$ Vgl. Abb. 59 bis 64 bei Richard-Jamet, der die Distichen allerdings nicht bekannt sind.

${ }^{80}$ Richard-Jamet versucht S. 94ff., die ursprünglichen oder doch zeitweiligen Hängungen zu rekonstruieren.
} 
tement seiner Ehefrau Eleonora von Toledo (1522-1562) im florentinischen Palazzo Vecchio zwischen 1561 und 1562 von Giorgio Vasari und Johannes Stradanus freskieren lie $\beta^{81}$, wurden für die Plafonds die Themen der Penelope, Hersilia, Esther und Gualdrada ${ }^{82}$ gewählt. Das Programm verbindet historisch ausgewogen griechische, römische, biblische und florentinische Exempla. Zwar taucht hier das Thema der Selbstmörderin als Tugendheldin noch nicht auf, doch ist es nicht ohne Belang, dass das Appartement Eleonoras, die bereits 1562 an Malaria starb, 1565 von Johanna von Österreich nach der Heirat mit Francesco I. übernommen wurde, weil ihre Tochter Maria de' Medici (1575-1642) als französische Königin das vertraute ikonographische Programm der ıstarken Frauen für ihre eigene politische Propaganda nutzen sollte. ${ }^{83}$

Als Maria Magdalena von Österreich 1622 nach dem Tod ihres Ehemannes Cosimo II. die florentinische Villa Pogg io Imperiale ${ }^{84}$ als Witwensitz umgestalten ließ, entwickelte sie für die sala und für die camera delle udienze eine interessantes ikonographisches Programm, das ganz weiblich ausgerichtet war. ${ }^{85}$ Der von der Mutter und ihrem noch minderjährigen Sohn, Ferdinando II., gemeinsam genutzte Saal ist mit seiner gesamten Freskierung erhalten und zeigt

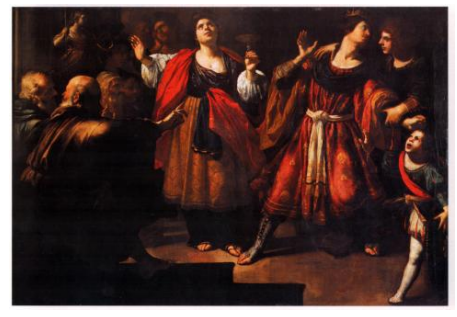

Abb. 11

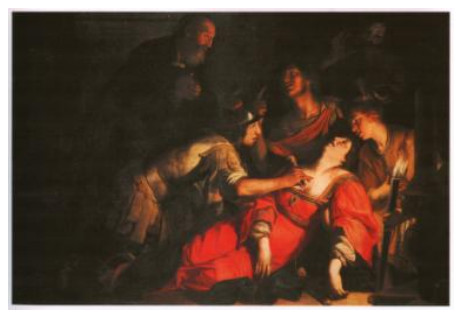

Abb. 12

weibliche Heilige und Regentinnen. ${ }^{86}$ Außerdem waren vier großformatige Gemälde weiblicher Tugendheldinnen an den Wänden angebracht: Semiramis ${ }^{87}$, Artemisia $^{88}$, Sophonisbe [Abb. 11] ${ }^{89}$ und Lukretia [Abb. 12] ${ }^{90}$. Das von der sala betretbare

\footnotetext{
81 Die Korrespondenz zwischen Cosimo und Vasari informiert darüber. Vgl. Frey, Herman-Walther (Hrsg.): Giorgio Vasari, Der literarische Nachlass, Bde 1-3, München 1923-1940.

82 Gualdrada ist eine auch im 16. Canto des Inferno erwähnte Gestalt der florentinischen Geschichte. Als Kaiser Otto IV. bei einem Fest, das inm zu Ehren gegeben wurde, die junge Frau küssen wollte, soll sie dies mit Hinweis auf einen künftigen Gatten äußerst tugendhaft abgelehnt haben. Der Kaiser verheiratete sie darauf mit einem seiner Barone, Guido, und schenkte dem Paar große Ländereien. Aus dieser Verbindung leitete sich die Familie der Guidi ab.

${ }^{83}$ Vgl. S. 249.

${ }^{84}$ Die Villa trug ursprünglich den Namen der Familie Baroncelli und wurde nach den Umbauten durch ein Edikt der Auftraggeberin in Villa Poggio Imperiale umbenannt. Vgl. Zangheri Luigi: Ville della provincia di Firenze. La città, Mailand 1989.

${ }^{85}$ Hoppe, Ilaria: »Räume von und für Frauen? Die Gemächer der Maria Magdalena von Österreich in der Villa Poggio Imperiale bei Florenz «, in: Bonnet, Anne-Marie / Schellewald, Barbara (Hrsg.): Frauen in der Frühen Neuzeit, Lebensentwürfe in Kunst und Literatur, Köln / Weimar / Wien 2004, S. 213-234. Die Verf. bereitet eine Dissertation zum Thema vor.

${ }^{86}$ Die Fresken werden von fingierten Bilderrahmen eingefasst und durch italienische Bildunterschriften erläutert.

${ }^{87}$ Von Matteo Rosselli.

${ }^{88}$ Von Francesco Curradi, heute Florenz (Villa Petraia).
} 
und camera delle udienze genannte Vorzimmer, das zum Schlafgemach Marias führte, war mit alttestamentlichen Fresken (Sephora, Esther, Jaël und Judith), das Schlafzimmer der Erzherzogin selbst, gewissermaßen als Steigerung, ausschließlich mit Märtyrerinnen geschmückt. Bis zur Volljährigkeit Ferdinandos im Jahre 1628 fanden viele Empfänge und repräsentative Veranstaltungen in sala und camera delle udienze der Villa Poggio Imperiale und nicht im nahe gelegenen Palazzo Pitti statt. Dabei führte die sweibliche` Dekoration der sala und der sich anschließenden Räume ${ }^{91}$ dem Hof und seinen Gästen Stellung und Selbstbewusstsein der Regentin vor Augen. ${ }^{92}$ Zum ersten Mal ergab sich eine Konstellation, die sich in Frankreich mehrfach wiederholen sollte: Eine Regentin nutzte das ikonographische Programm sstarker Frauen zur Illustration ihrer dynastischen und politischen Ansprüche. ${ }^{93}$

Es ist sicher kein Zufall, dass die französischen Regentinnen aus der Familie Medici, Caterina und Maria, sich an das Modell der Villa Poggio Imperiale erinnerten und ihre Herrschaftsansprüche gleichfalls ikonographisch durch Darstellungen ıstarker Frauen` zu legitimieren suchten. Die weiblichen Mitglieder der Familie Medici nahmen seit dem 16. Jahrhundert als Folge einer gezielten Heiratspolitik an vielen europäischen Höfen Schlüsselstellungen ein; sie sind für einen politisch wie kunsthistorisch bemerkenswerten Kulturtransfer aus Italien verantwortlich und entwickelten lange nachwirkende Legitimationsstrategien für Herrschaftsansprüche im entstehenden absoluten Staat. ${ }^{94}$ Der Zufall wollte es, dass in drei aufeinander fol-

\footnotetext{
${ }^{89}$ Von Rutilio Manetti (Katalog 226), heute Florenz (Uffizien).

${ }^{90}$ Von Francesco Rustici (Katalog 360), heute Florenz (Uffizien).

91 Die Räume Ferdinandos waren im Gegensatz zu denen seiner Mutter mit ımännlichenı, die dynastischen Bezüge illustrierenden Fresken ausgestattet.

${ }_{92}$ Maria Maddalena d'Austria hatte zusammen mit ihrer Schwiegermutter, Christina von Lothringen, die Vormundschaft inne.

93 „Vergegenwärtigt man sich den Besuch des französischen Gesandten, so empfing der junge Großherzog inmitten der weiblichen Exempla, wahrscheinlich genau vor Mathilde, Galla Placidia und Semiramis. Das Zeremoniell ließ inm formal den Vortritt, womit seine Position als Herrscher Bestätigung fand. Durch die Fresken und Bilder war jedoch ein >Bildraumı entstanden, der auf die positiven Auswirkungen weiblicher Herrschaft verwies und die politische Situation der Regentschaft legitimierte. In diesem Moment überlagerten sich geschlechtsspezifische Raumzuweisung mit einem durch das Zeremoniell abgesteckten Handlungsraum. Die Regentinnen warteten, als dem Großherzog untergeordnete Frauen, in der Camera. Geht man von geradlinigen Handlungsabläufen aus, so könnten diese durchaus unter Jaël und Judith gesessen haben, die Kraft ihres Glaubens den Mut hatten, die Feinde ihres Volkes zu töten. Dies taten sie jedoch für das Allgemeinwohl und zur Stabilisierung der herrschenden Ordnung und nicht um selbst Macht zu erlangen. Architektur, Ausstattung und Zeremoniell konnten in ein Wechselverhältnis treten, das die normativen Grenzen des Geschlechterdiskurses zugleich überschritt und bestätigte. Durch die Ausnutzung des relativen Freiraums einer Villa hatte Maria Magdalena v. Österreich sich jedoch einen Handlungsraum geschaffen, der gänzlich ihrer Repräsentation diente.« (Hoppe, a.a.O., S. 233f.)

${ }^{94}$ Ein Kongress (»Le donne Medici nel sistema Europeo delle corti«) hat sich im Oktober 2005 in Florenz mit diesem Thema ausführlich beschäftigt und verspricht wichtige Erkenntnisse: »La scommessa storiografica è stata quella di fare del caso toscano un punto di osservazione più generale per valutare l'incidenza delle donne
} 
genden Generationen Frauen die Regentschaft Frankreichs übernehmen mussten, obwohl dies eigentlich dem salischen Recht widersprach und deshalb auf Widerstände stieß. Bereits Caterina de' Medici (1519-1589) versuchte deshalb während der Regentschaft für den erst zehnjährigen Sohn Karl IX. (1550-1574), ihre durchaus umstrittenen politischen Ansprüche in einem groß angelegten Bildprogramm zu propagieren. Als ızweite Artemisiaı inszenierte sie ihre Rolle als Witwe und Regentin nach dem Vorbild der karischen Königswitwe. ${ }^{95}$ Antoine Caron (um 15151593) schuf eine Serie von Zeichnungen, die wohl als Vorlagen für eine Serie von Tapisserien gedacht waren.

Die Intention der nie ausgeführten Tapisserien ${ }^{96}$ wurde von Caterinas Schwiegertochter, Maria von Medici, nach der Ermordung Heinrichs IV. (1610) aufgegriffen und als großformatige Bilderserie verwirklicht, zu der beispielsweise die Artemisia ${ }^{97}$ Vouets [Abb. 13] gehört. Für ihren Witwensitz im Palais du Lu xembourg ${ }^{98}$ beauftragte Maria de' Medici Rubens mit zwei Bildzyklen, die die Politik Heinrichs IV. und ihre eigenen dynastischen Ansprüche illustrieren sollten. Bekanntlich wurde der Zyklus mit Heinrich IV. nicht realisiert, während Maria in dem ihr gewidmeten Zyklus ${ }^{99}$ ihre Regentschaft von Minerva, Providentia und Prudentia als göttliche Vorsehung und politische Notwendigkeit deuten ließ. ${ }^{100}$

nel modo di organizzare l'identità, le strategie, e gli stessi indirizzi politici e culturali delle dinastie. « (Prospekt des Kongresses nach: http://www.archiviodistato.firenze.it/memoriadonne/materiali_donne/donnemedici.htm (zuletzt aufgerufen: 06.04.2007).

${ }^{95}$ Vgl. Gaehtgens, Barbara: "Macht-Wechsel oder die Übergabe der Regentschaft«, in: AK Die Galerie der Starken Frauen, a.a.O., S. 64-78.

${ }_{96}$ Vgl. Gaehtgens, a.a.O., S. 69; dort auch die Nachweise der erhaltenen Zeichnungen.

${ }^{97}$ Simon Vouet: Artemisia beim Bau des Mausoleums mit den Maßen 161 x 139 (Öl auf Leinwand); heute in Stockholm (Nationalmuseum, Inv. NM 5179). Katalog 432.

98 Über die Architektur, die in besonderer Weise Ansprüche einer Regentin zu repräsentieren versuchte, zuletzt Tönnesmann, Andreas: »Pariser Witwensitze«, in: Bonnet, Anne-Marie / Schellewald, Barbara (Hrsg.): Frauen in der Frühen Neuzeit, Köln / Weimar / Wien 2004, S. 189-211.

${ }^{99}$ Aus der umfangreichen Literatur seien nur genannt: Thuillier, Jacques: "La `Galerie de Médicis` de Rubens et sa genèse «, in: Revue de l'Art 4 (1969), S. 52-62; Saward, Susan: The Golden Age of Marie de' Medici, Ann Arbor (Michigan) 1982; Millen, Ronald Forsyth / Wolf, Robert Erich: Heroic Deeds and Mystic Figures, A new Reading of Rubens' Life of Maria de'Medici, Princeton 1989; Graziani, Françoise / Solinas, Francesco (Hrsg.): Le ssiècler de Marie de Médicis, Actes du Séminaire de la Chaire Rhétorique et Société en Europe $\left(\mathrm{XVI}^{\mathrm{e}}-\mathrm{XVII}{ }^{\mathrm{e}}\right.$ siècles) du Collège de France sous la direction de Marc Fumaroli (Franco-Italia; Sonderheft 21/22), Turin 2003; Bassani Pacht, Paola / Crépin-Leblond, Thierry / Sainte Fare Garnot, Nicolas / Solinas, Francesco (Hrsg.): AK Marie de Médicis, un gouvernement par les arts, Paris 2004.

100 Für den Palais du Luxembourg ließ die Regentin von Nicolas Claude Fabri de Peiresc (1580-1637) ein geschlossenes Ausstattungskonzept entwerfen, das eine Statuen-Galerie von Guillaume Berthelot (1576/15801648) mit acht illustren Müttern und Frauen von Königen umfasste. Aus dem Briefwechsel zwischen Rubens und Peiresc geht hervor, dass die Verweisfunktion auf Maria de' Medici eine sorgfältige Auswahl der weiblichen Exempel nötig machte. Rubens hatte u.a. Kleopatra vorgeschlagen, was Peiresc wegen ihrer allzu groBen Lasterhaftigkeit ablehnte (vgl. Richard-Jamet, a.a.O:, S. 268f.). Zur piktoralen Gesamtausstattung des Luxembourg gehörten weibliche Tugendenallegorien, Göttinnen und Sibyllen. Vgl. Boudouin-Matuszek, MarieNoëlle: Marie de Médicis et le Palais du Luxembourg, Paris 1991; Baumgärtel, Bettina: »Die Tugendheldin als Symbol kirchlicher und staatlicher Macht«, in: AK Die Galerie der Starken Frauen, S. 140-204, bes. S. 151. 
Zur Zeit der Regentschaft von Anne d'Autriche (1643 bis 1661) wird in Frankreich

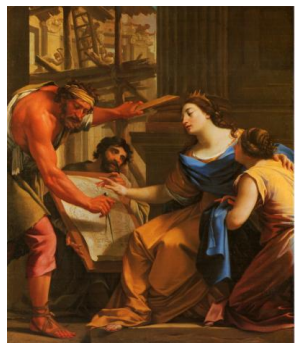

Abb. 13

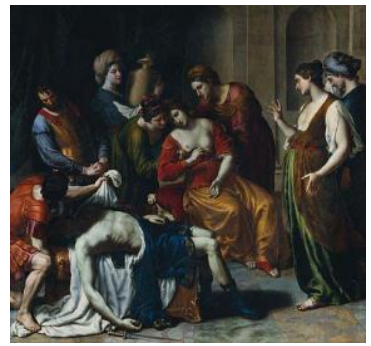

Abb. 14

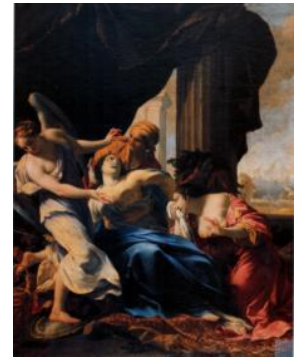

Abb. 15

die Ikonographie ıstarker Frauenı erneut unter politischen Gesichtspunkten aufgegriffen und geradezu strategisch eingesetzt. Anders als in den bisher angeführten Beispielen (von Mantegna einmal abgesehen) findet sich nun aber auch das Thema der Tugendheldin als Selbstmörderin. Als Louis de La Vrillière zwischen 1631 und 1660 für die Bildergalerie seines von Mansart erbauten Pariser Hôtels (heute der Sitz der Banque de France) bei berühmten Künstlern eine ıgemischte Serie r römischer Tugendhelden ${ }^{101}$ in Auftrag gab, wurde neben dem sterbenden Cato auch eine Kleopatra [Abb. 14] von Turchi (1578-1649) ${ }^{102}$ in das Programm einbezogen. Es ist auch kein Zufall, dass Pierre Le Moyne 1647 seine Galerie des femmes fortes Anne d'Autriche widmete. ${ }^{103}$ Als sie 1643 für ihren noch unmündigen Sohn, Ludwig XIV., die Regentschaft übernahm, führte sie die ikonographische Kampagne ihrer Schwiegermutter fort und nahm bewusst auf die öffentliche Kontroverse über die Regentschaft von Frauen Bezug. Eine ganze Reihe von Serien sstarker Frauen w wurde von ihr in Auftrag gegeben. ${ }^{104}$ So beauftragte sie 1645 Simon Vouet mit einer Bildfolge berühmter Frauen für ihre Räume im Palais Royal (damals noch Palais Cardinal); sie lässt sich allerdings nicht genau rekonstruieren, da das Appartement der Königin 1752 zerstört wurde. Offensichtlich war sie als Pendant zu einer Galerie des Hommes Illustres im gleichen Palast gedacht, die auf Simon Vouet und Philippe de Champaigne zurückging. ${ }^{105}$ Zwei wohl die-

\footnotetext{
${ }^{101}$ Es handelt sich um zehn großformatige Ölbilder: Camillus und der Schulmeister von Falerii (Poussin), Coriolan bittet seine Mutter, Hersilia trennt die kämpfenden Römer und Sabiner, Tod des Cato (alle von Guercino), Romulus und Remus werden von Faustulus gefunden, Marc Anton weist seine Frau zurück, um Kleopatra zu heiraten, Die Sibylle von Tibur kündigt das Kommen unseres Herrn an (alle von Cortona), Raub der Helena (Reni), Augustus schließt die Tore des Janustempels (Maratta) und Tod der Kleopatra (Turchi). Vgl. RichardJamet, S. 170ff. und S. 526. Zum Hôtel de la Vrillière vgl. Dubois, Isabelle / Gady, Alexandre / Ziegler, Hendrik: La Place des Victoires, Paris 2003 (Editions de la Maison des Sciences de l'Homme).

102 Das Bild wird oben, S. 161, besprochen. Katalog 404.

${ }^{103}$ Siehe unten S. 257.

104 Vgl. Baumgärtel, a.a.O., S. 140-157.

105 Vgl. Richard-Jamet, a.a.O., S. 270. Zu Richelieus Galerie des Hommes Illustres: Sylvain Laveissière: »Der Rat und der Mut, Die Galerie des Hommes Illustres im Palais Cardinal - ein Selbstporträt Richelieus «, in Goldfarb, Hilliard Todd (Hrsg.): AK Richelieu (1585 - 1642), Kunst, Macht und Politik, Ghent 2002, S. 64-71. Unter
} 
sem Zusammenhang zuzuordnende Gemälde Vouets lassen vermuten, dass die Serie aus Allegorien bestanden haben könnte. ${ }^{106} \mathrm{Zu}$ einer weiteren Serie Vouets für Anne d'Autriche mögen eine Artemisia ${ }^{107}$ in Stockholm und eine Dido ${ }^{108}$ [Abb. 15] in Dôle gehören, zumal ein architektonisches Detail die Bilder verbindet. Beide Bilder dürften mit dem Projekt eines Pavillons und Triumphbogens zu Ehren Ludwigs XIII. zusammenhängen ${ }^{109}$, in deren Konzeption die inzwischen herausgebildete Tradition aufgegriffen wurde, weibliche Regentschaften durch historische Verweise auf exemplarische Herrscherinnen zu legitimieren.

Schon die beachtliche Anzahl der Aufträge der Regentin belegt den bewussten Einsatz der Ikonographie sstarker Frauen ${ }^{110}$ Auch die Ausstattung des Appartements der Regentin im Schloss Richelieu gehört in den gleichen ikonographischen Zusammenhang. Nicolas Prévost (1604-1670) wurde mit zehn Ölbildern

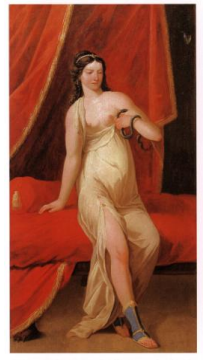

Abb. 16

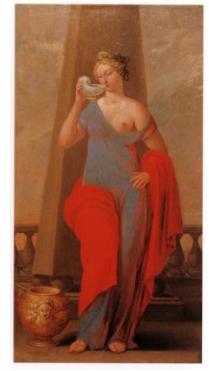

Abb. 17

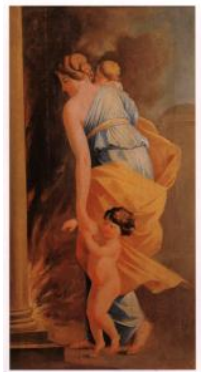

Abb. 18

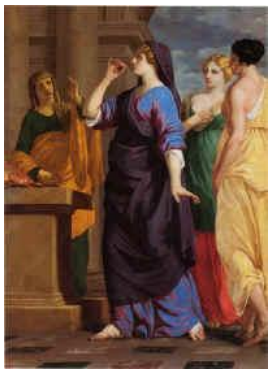

Abb. 19

weiblicher Tugendheldinnen für das nach der Revolution großenteils abgetragene Schloss beauftragt. Seine Darstellungen von Kleopatra [Abb. 16], Dido, Sophonisbe [Abb. 17] ${ }^{111}$, Judith, Artemisia, der Frau des Hasdrubal [Abb. 18] und Thomyris zeigten Exempla politisch handelnder Frauen. ${ }^{112}$ Die erhaltenen Bilder zielen deutlich auf dekorative Fernwirkung und verbinden ungewöhnlich starke Farbgebung mit

den 24 ausgeführten Bildnissen finden sich auch drei Frauen: Jeanne d'Arc, Maria de' Medici und Anne d'Autriche.

${ }^{106}$ Die beiden Allegorien Vouets (Thuillier, Jacques [Hrsg.]: AK Vouet, Paris 1990, Nr.62 und 62 bis) gehörten wohl zur Ausstattung der Räume der Regentin im ehemaligen Palais Cardinal und sind vielleicht ein Indiz für die Wahl allegorischer Motive. Der von Richard-Jamet, a.a.O., S. 270 zitierte Vertrag mit dem Künstler belegt jedenfalls für die Allegorie der Prudentia in Montpellier diesen Zusammenhang.

107 Thuillier, Jacques (Hrsg.): AK Vouet, Paris 1990, Nr. 58 nimmt einen Zusammenhang mit Anne d' Autriche und vielleicht mit dem Pavillon und Triumphbogen für Ludwig XIII. an.

108 Katalog 426.

109 »Ces deux héroïnes, qui incarnent la fidélité conjugale, conviennent parfaitement au statut de veuve de la régente. (Richard-Jamet, a.a.O., S. 271)

${ }^{110}$ In diesen Zusammenhang gehört es auch, dass Anne d'Autriche 1656 von Philippe de Champaigne ihre Räume im Kloster Val-de-Grâce mit einer Serie von »heiliger Königinnen und Regentinnen « ausmalen ließ. Vgl. dazu Baumgärtel, Bettina: »Die Tugendheldin als Symbol kirchlicher und staatlicher Macht, Über die Galerie der Starken Frauen in Ausstattungsprogrammen und Buchillustrationen «, in: AK Die Galerie der Starken Frauen, a.a.O., S. 140-223 und besonders Maclean, lan: Woman Trimphant, Feminism in French Literature 1610-1652, Oxford 1977, S. 209-232.

111 Vgl. Katalog 289 (Kleopatra), 290 (Dido), 291 (Frau des Hasdrubal) und 292 (Sophonisbe).

112 Aus einer anonymen Beschreibung des 18. Jahrhunderts ist bekannt, dass noch eine Judith, eine Esther und eine Artemisia in diese Reihe gehörten (vgl. Richard-Jamet, S. 272). 
relativ schematischer Gestaltung der ganzfigurigen Heldinnen. Schon deshalb waren auch in dieser Serie die Tugendheldinnen nur durch ihre Attribute zu unterscheiden.

Die Zusammenhänge sind allerdings vorläufig im Einzelnen noch nicht geklärt. Im Schloss Richelieu gab es neben der Serie ıstarker Frauenı, die Nicolas Prévost im Auftrag Richelieus für die Räumlichkeiten der Regentin anfertigte, wohl einen größeren ikonographischen Zusammenhang, zu dem auch eine aus dem `Zimmer der Porziaı stammende Porzia ${ }^{113}$ [Abb. 19] gehörte. Aus dem `Zimmer der Lukretiar stammt eine erhaltene Polyxena, ${ }^{114}$ ebenfalls von Nicolas Prévost; in diesem Raum befand sich vielleicht auch eine nicht erhaltene Lukretia. ${ }^{115}$ Es ist also mehr als wahrscheinlich und bemerkenswert, dass die ursprüngliche Gesamtkonzeption der Ausstattung des Schlosses Richelieu politisch und künstlerisch ganz auf das Thema der sstarken Frauen ausgerichtet war. ${ }^{116}$

Eine wichtige Rolle spielten die sstarken Frauen auch in der Ausstattung des Hôtel de l'Arsenal. Allerdings sind die Zusammenhänge und Abhängigkeiten der ikonographischen Programme im Palais Cardinal, im Schloss Richelieu und im Arsenal im Einzelnen sehr komplex und verwickelt, zumal unklar bleibt, ob die auf Zeichnungen von Vignon zurückgehenden Graphikserien Le Moyne als Vorlage dienten oder vielmehr umgekehrt die bereits realisierten Programme der ıfemmes fortesı unter der Regentschaft der Anne d'Autriche durch diese Graphikserie verbreitet und popularisiert wurden. Eine ursprünglich für das cabinet der Duchesse de La Meilleraye bestimmte Reihe von vierzehn ıstarken Frauen ist erhalten. Allerdings lässt sich das Programm des cabinet nicht mehr mit Sicherheit rekonstruieren, da die Räumlichkeiten mehrfach verändert wurden und die Ausstattung nur teilweise erhalten blieb. Mit einiger Gewissheit lassen sich im Arsenal drei verschiedene Arbeitsphasen ${ }^{117}$ unterscheiden; erst in der letzten um 1646/1647 nahm ein in die Wandpaneele eingelassener, umlaufender Attika-Fries unterhalb der De-

\footnotetext{
${ }^{113}$ Vgl. oben, S. 173.

114 Porzia und Polyxena befinden sich heute in Orléans.

${ }^{115}$ Eine in Vorbereitung befindliche Ausstellung der Museen von Tours und Orléans wird sich mit der künstlerischen Ausstattung des Schlosses befassen und könnte weitere Informationen bringen. Erste Informationen finden sich im Katalog einer Ausstellung in Meaux (Sylvain Kerspern [Hrsg.]: AK Bossuet, Miroir du Grand Siècle, Paris 2004). In zwei weiteren Beiträgen in der Tribune de l'Art ist Sylvain Kerspern noch einmal auf Prévosts Tätigkeit für das Schloss Richelieu und auf die problematischen Zuschreibungen eingegangen: "Retour sur l'exposition Bossuet, et sur quelques unes de ses attributions « und »Retour sur l'exposition Bossuet, suite: du nouveau pour Prévost et Licherie« (http://www.latribunedelart.com/Etudes_2004/Suite_Bossuet.htm und http://www.latribunedelart.com/Etudes_2004/Suite_Bossuet_2_123.htm) (zuletzt aufgerufen: 06.04.2007).

${ }^{116}$ Vgl. Ballon, Hillary: »Richelieus Architektur in: AK Richelieu [1585-1642], Kunst, Macht und Politik, a.a.O., S. 246-259.

${ }_{117}$ Vgl. Richard-Jamet, S. 194.
} 
cke die Serie der ıfemmes fortesı auf, die wahrscheinlich von Charles Poerson (1609-1667) stammt. ${ }^{118}$ Allerdings könnte er auch Mitarbeiter benutzt haben; der schlechte Erhaltungszustand und die wiederholten Übermalungen lassen ein eindeutiges Urteil nicht zu. Irrtümer in den französischen subscriptiones zeigen an, dass die Reihe nicht vollständig erhalten ist. Der Zusammenhang mit Anne d'Autriche ist durch ein Deckengemälde gesichert, das eine Allegorie der französischen Monarchie mit den Zügen der Regentin darstellt. Die erhaltenen Holztafeln des Frieses zeigen - den Illustrationen bei Le Moyne entsprechend - ıfortes juivesı (Jaël, Judith, Deborah, Esther), ıfortes barbaresı (Semiramis, Antiope, Penthesilea, Berenike), ıfortes romainesı (Porzia, Lukretia, Paulina) und ıfortes chrétiennes de l'époque contemporaine` (Maria Stuart, die französische Judith, Jeanne d'Arc). Alle für das Programm ausgewählten Römerinnen sind durch ihren Selbstmord zu Tugendheldinnen geworden. Im Unterschied zur Graphikserie nach Vignon wählte Poerson dreiviertelfigurige Darstellungen.

In den gleichen Jahren wurde die Ikonographie sstarker Frauen sichtspunkten auch in Rom und Florenz eingesetzt. Giacinto Gimignani (1606-1681) freskierte um 1648 einen privaten Raum des römischen Palazzo Pamphili ${ }^{119}$ für Olympia Pamphili mit alttestamentlichen donne illustri (Judith, Thermutis, Esther und Abigaïl), die in verschiedener Weise für die Familienehre eintraten und weibliche Tugenden exemplifizieren. Männliche Herrschertugenden standen hingegen im Vordergrund, als Ferdinando II. de' Medici (1610-1670) 1641/1642 den Saal der Venus im Palazzo Pitti von Pietro Cortona (1596-1669) freskieren ließ. In den Lünetten werden als Beispiele hochherzigen Liebesverzichts auch Sophonisbe und Kleopatra in einer eigenartigen Deutung dargestellt. ${ }^{120}$ Ein spätes Beispiel ist ein durch Bellori beschriebener sautonomer` Zyklus von ursprünglich sechs sstarken Frauen`, den 1694 Carlo Maratta (1625-1713) für den römischen Bankier Francesco Montioni gemalt hat. ${ }^{121}$ Von einer Ausnahme abgesehen ist er nur noch durch Kupferstiche bekannt. ${ }^{122}$ Für unseren Zusammenhang ist die Aufnahme des Selbstmords der Lukretia bemerkenswert. Spuren einer weiteren sautonomen، Serie sstarker Frauen von Jean-Baptiste Nattier (1678-1726), darunter eine Lukretia, eine Artemisia, eine Kleopatra und eine Porzia, bezeugen die andauernde Beliebtheit des Motivs. Wie andere Werke des Malers könnten auch diese Gemälde bereits als Rollenbilder konzipiert gewesen sein. ${ }^{123}$

\footnotetext{
${ }^{118}$ Vgl. Richard-Jamet, a.a.O., S. 197ff. und Abb. 148-155.

119 Vgl. Richard-Jamet, a.a.O., S. 162ff. und Abb. 110-112.

120 Das Deckengemälde zeigt Athene, die die Jugend den Armen der Venus entreißt, ein Motiv, das in den Lünetten an acht Beispielen (Cyrus und Panthea, Alexander und die Frau des Darius, Antiochus und Stratonice, Antiochus III. und die Priesterin der Diana, Enthaltsamkeit des Scipio Africanus, Massinissa und der Tod Sophonisbes, Fausta und Crispus, Kleopatra und Augustus) demonstriert wird. Die »Heroicae Virtutis Imagines « des Palazzo Pitti wurden in einer Graphikserie verbreitet (AK Die Galerie der Starken Frauen, Nr.59). Richard-Jamet (S. 142f.) vermutet zu Recht, die Fresken von Pietro Cortona im Palazzo Pitti könnten Anne d' Autriche und ihr Konzept der ıstarken Frauen beeinflusst haben, zumal Mazarin vergeblich den Künstler nach Paris zu ziehen versuchte. In diesen Zusammenhang gehört auch, dass Pietro da Cortona das Deckblatt der Galerie des femmes fortes des Pierre Le Moyne entwarf.

${ }^{121}$ Bellori nennt Kleopatra (heute im Palazzo Venezia), Lukretia, Proba Falconia und Tuccia. Vgl. Bellori, Giovanni Pietro: Le Vite de' Pittori, Scultori e architetti moderni, hrsg. von Evelina Borea, Turin 1976, S. 651.

${ }^{122}$ Vgl. AK Die Galerie der Starken Frauen, Nr.141.1 und 141.2. und Richard-Jamet, a.a.O., S. 134f.

${ }^{123}$ Richard-Jamet, a. a.O., S. 415 und Abb. 318. Die Bilder tauchten 1977 und 1994 auf Auktionen auf.
} 
Zum Verständnis der höfischen Bedeutung des Motivs der sstarken Frauen ist auch ein Blick auf die Gebrauchskunst hilfreich. Spielkarten griffen bereits früh das Motiv der preux und der preuses auf; besonders ein von Jean Desmarets de Saint-Sorlin konzipiertes und von Stefano della Bella (1644) gestochenes, aus 52 Karten bestehendes Kartenspiel ist interessant, das ein vollständiges Repertorium berühmter Herrscherinnen darstellt (Jeu de Cartes des Reines renommées de la Géographie et de l'Histoire). Es war für den jungen Ludwig XIV. bestimmt und stellte auch Dido und Kleopatra dar. ${ }^{124}$

Das Thema der ıfemmes illustres findet sich schon seit dem Spätmittelalter in Tapisserie-Programmen. ${ }^{125}$ Die Beliebtheit der ıstarken Frauen unter der Regentschaft der Anne d'Autriche belegt auch eine Teppichserie (heute in Châteaudun) mit berühmten Frauen des Altertums, die wohl vom schon genannten Charles Poerson entworfen wurde. Sie könnte in den Fünfziger Jahren des 17. Jahrhunderts entstanden sein und integriert Dido, Lukretia, Porzia und Kleopatra. ${ }^{126}$ Hervorzuheben ist des Weiteren eine Teppichserie nach Kartons von Jacob Jordaens mit dem gleichen Thema; sie findet sich auch in Nachlassinventaren Mazarins und hat Kleopatra ebenso wie Dido aufgenommen. ${ }^{127}$

\section{4 ıLa gallerie des femmes fortesı}

Seit Caterina de' Medici hielten in Frankreich die Kontroversen über weibliche Regentschaften an und verbanden sich rasch mit der die Frühe Neuzeit begleitenden querelle des femmes, in der über die moralische und gesellschaftliche Stellung der Frau gestritten wurde. $^{128}$ Schon das auslösende Pamphlet Alphabet de l'imperfection et malice des femmes (1617) stand offensichtlich mit beiden Aspekten der politischen und zugleich anthropologisch-moralischen >Frauendebatte Zusammenhang. Die wohl von dem Franziskaner Alexis Trousset stammende Schrift ${ }^{129}$ nahm bereits im Frontispiz eindeutig Stellung: „Virum de mille unum reperi: mulierem ex omnibus non inveni « $(\mathrm{Ecl} 7,29)^{130}$ und löste mit ihrer misogynen Tendenz eine Kaskade von Streitschriften aus. Die zugleich publizistisch und ikonographisch ausgetragene Debatte über die Herrscherrolle von Frauen erreichte nach dem Beginn der Regentschaft von Anne d'Autriche (1643) einen neuen Höhepunkt, ohne den der Erfolg der Femme heroïque von Du Bosc (1645) und der

\footnotetext{
${ }^{124}$ Vgl. Richard-Jamet, a.a.O., S. 175 und 278ff., Abb. 210-213 und AK Die Galerie der Starken Frauen, a.a.O., S. 160-161 und Staatliche Kunsthalle Karlsruhe AK Stefano della Bella, Karlsruhe 2005, S. 78. Della Bella hat im Auftrag Mazarins insgesamt vier Kartenspiele für den Dauphin entworfen.

${ }^{125}$ Vgl. Richard-Jamet, a.a.O., S. $175 \mathrm{ff}$.

${ }^{126}$ Vgl. Richard-Jamet, a.a.O., S. 182ff. und S. $531 \mathrm{ff}$.

127 Vgl. Richard-Jamet, a.a.O., S. 185f. und S. 529.

128 Die gesamteuropäischen Zusammenhänge erörtert Ferrari Schiefer, Valeria: La Belle Question, Die Frage nach der Gleichheit der Geschlechter bei François Poullain de la Barre (1647-1723) auf dem Hintergrund der (früh-)neuzeitlichen Querelle des Femmes, Luzern 1998 (Theologie in Geschichte und Gesellschaft 8). Vgl. Maclean, a.a.O., S. 25ff.

${ }^{129}$ Alle weiteren Auflagen erschienen aber unter dem Verfassernamen Jacques Olivier; es handelt sich um die Amplifikation einer Schrift des Florentiner Bischofs Antoninus (Antonio Pierozzi de' Forciglioni 1389-1459).

${ }_{130}$, Unter tausend Männern habe ich einen gefunden, aber unter allen Weibern fand ich nicht eine einzige.، Unter dem Eingangszitat spielt die Abbildung einer vornehmen, zeitgenössisch gekleideten Dame, die deutlich Porträtzüge von Maria de' Medici zeigt, erkennbar auf die Gemeinte an (nach Baumgärtel, a.a.O., S. 148).
} 
Gallerie des femmes fortes von Le Moyne (1647) nicht zu erklären wäre. Gleichzeitig erschienen übrigens weitere Galerien ${ }^{131}$ : François de Grenaille publizierte 1643 La Galerie des dames illustres, Jean Puget de la Serre (1600-1665) widmete 1645 und 1648 Anne d'Autriche seinen Temple de la gloire contenant les éloges historiques de treize Annes royales et princesses de France und eine entsprechende Zusammenstellung von Frauen des Hauses Habsburg. ${ }^{132}$ Die folgenreichen Graphikserien bei Du Bosc und Le Moyne sind vor dem Hintergrund der Debatte der 1640er Jahre zu sehen, in der sich unmittelbare politische Interessen der Regentin mit einer eigenartig paratheoretischen Diskussion der gesellschaftlichen Rolle der Frauen vermischten, die zwischen 1630 und 1650 in apologetischen, fiktiven und moralistischen Texten geführt wurde. ${ }^{133}$ In diesen Graphikserien fand das Motiv der Tugendheldin als Selbstmörderin endgültig Aufnahme in die Ikonographie ıstarker Frauen`, wie dies auch in anderen Bildprogrammen unter Anne d'Autriche der Fall ist. ${ }^{134}$

Francois Chauveau illustrierte La femme heroïque ou les heroïnes comparées avec les heros en toute sorte de vertus des Franziskaners Jacques Du Bosc (1645). Bereits das Titelblatt mit dem Plutarch-Zitat: »La Vertu de l'Homme et de la Femme, n'est qu'vne mesme Vertu « ${ }^{135}$ propagiert die Gleichberechtigung der Frauen: es stellt eine Lorbeerkränze an Männer und Frauen verteilende Siegesgöttin dar. [Abb. 20] Im Text und in sechzehn Kupferstichen werden als prominente historische Beispiele acht illustren Helden ebenso viele sstarke، Frauen gegen-

\footnotetext{
${ }^{131} \mathrm{Vgl.} \mathrm{Garrard,} \mathrm{Mary} \mathrm{D.:} \mathrm{Artemisia} \mathrm{Gentileschi,} \mathrm{the} \mathrm{image} \mathrm{of} \mathrm{the} \mathrm{female} \mathrm{Hero} \mathrm{in} \mathrm{Italian} \mathrm{Baroque} \mathrm{Art,} \mathrm{Princeton}$ 1989, S. 524-525.

${ }^{132}$ L'isthoire [!] et les portraits des imperatrices, des reynes et des illustres princesses de l'auguste maison d'Austriche [!], qui ont porté le nom d'Anne.

${ }_{133}$ Unter anderen sind zu nennen: Jacques Du Bosc: Honneste femme (1632), derselbe: Nouveau recueil de lettres des dames de ce temps (1635), derselbe: La femme heroïque, ou les heroïnes comparées avec les heros en toute sorte de vertu (1645), Louis Machon: Discours ou sermon apologetique, en faveur des femmes (1641), Francois de Grenaille: La galerie des dames illustres (1643), derselbe: L'honneste fille (1639-40), derselbe: L'honneste marriage (1640), derselbe: L'honneste veuve (1640), Francois Dinet: Le theatre françois, des seigneurs et dames illustres (1642), Georges de Scudéry: Les femmes illustres, ou les harangues heroïques, avec les veritables portraits de ces heroïnes, tirez des medailles antiques (1642), Suzanne de Nervèze: Apologie en faveur des femmes (1642), dieselbe: Genereux mouvements d'une dame heroïque et pieuse (1644), Francois Du Soucy Gerzan: Le triomphe des Dames (1646), derselbe: La vraie philosophie des dames (1653), Gabriel Gilbert: Panegyrique des dames (1650). Eine Übersicht über die Schriften, die sich in dieser Zeit mit der >Frauenfrage triumphant, Feminism in French Literature 1610-1652, Oxford 1977, S. 271-295. - Weitere Informationen sowie »dictionnaires et listes de femmes célèbres « nach Jahrhunderten geordnet stellt der Link (http://www.siefar.org/RessourcesListeDico.html; zuletzt aufgerufen: 01.02.2007) der Société Internationale pour l'Étude des Femmes de l'Ancien Régime zur Verfügung.

${ }_{134}$ Siehe oben, S. 250.
}

135 Baumgärtel, a.a.O., S. 174f. 


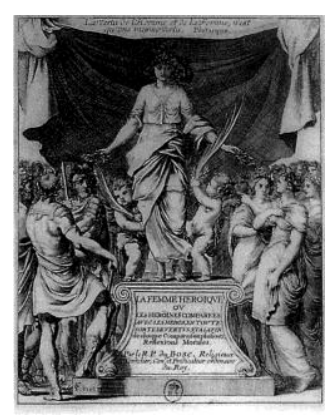

Abb. 20

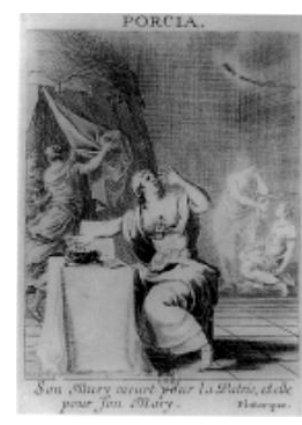

Abb. 21

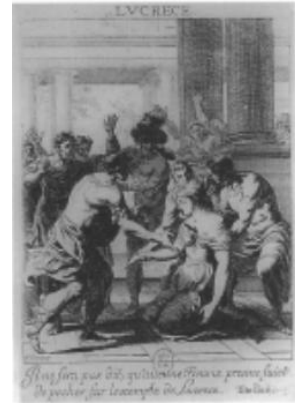

Abb. 22

übergestellt: Josua und Debora, Cyrus und Tomyris, Abraham und Salomone, Brutus und Porzia ${ }^{136}$ [Abb. 21], David und Judith, Tarquinius und Tanaquil, Joseph und Susannna, Cato und Lukretia ${ }^{137}$ [Abb. 22]. Die bühnenartige Szenerie, in der die Illustrationen männliche wie weibliche Tugendhelden zeigen, betont die affektgeladene Gestik der Protagonisten und Assistenzfiguren. Lukretias Selbstmord wird als moralischer Appell inszeniert, der dem Selbstmord Catos an Dignität nicht nachsteht: » $n$ ne sera pas dit, qu'aucune Femme prenne suiet de pecher sur l'exemple de Lucrece«. Porzias Tod ist als Akt ehelicher Solidarität dem Opfertod des Brutus durchaus gleichwertig: »Son Mary meurt pour la Patrie, et elle pour Son Mary. « ${ }^{138}$.

Als 1647 der Jesuit Pierre Le Moyne La gallerie des femmes fortes gegen die antifeministische Streitschrift des Franziskaners Alexis Troussets veröffentlichte, wurde sie mit Kupferstichen von Abraham Bosse und Gilles Rousselet nach Zeichnungen von Claude Vignon illustriert. Die Stecher griffen auf die bereits seit dem 16. Jahrhundert übliche Typisierung und Monumentalisierung illustrer Frauen zurück.

Schon die ersten frühneuzeitlichen graphischen Zyklen illustrer Frauen führten die bereits beim Maître des héroïnes de Chigi-Saracini ${ }^{139}$ begonnene Typisierung weiter. So präsentieren bei Hans Burgkmair d. Ä. Lukretia den Dolch, Jaël den Hammer und Helena das Kreuz ${ }^{140}$. Die Identifizierung der Tugendheldin erfolgt immer stärker durch Attribute, während die `Tugendlegenden` allenfalls noch als Miniatur im Hintergrund dargestellt werden. Allmählich erfahren die Tugendheldinnen in graphischen Serien eine Monumentalisierung zu Skulpturen und werden mehr und mehr zu Personifikationen der von ihnen exemplarisch verwirklichten Tugenden. ${ }^{141}$

Zwanzig Kupferstiche gruppieren die Tugendheldinnen nach dem schon mittelalterlichen Schema in fortes Juives, fortes Barbares, fortes Romaines und fortes Chres-

\footnotetext{
${ }^{136}$ Vgl. Katalog 63.

${ }^{137}$ Vgl. Katalog 64.

138 Valerius Maximus: Facta et dicta memorabilia IV,6,5 und III,2,15.

139 S. oben, S. 242.

140 S. oben, Fußnote 15.

141 So bei einem unbekannten Stecher, der nach Maarten van Heemskerck Frauen des AT als Inbegriff von Standhaftigkeit, Gerechtigkeit und Klugheit darstellt (Abbildungen in: AK Die Galerie der Starken Frauen, a.a.O., S. 146-147).
} 
tiennes. ${ }^{142}$ Die Widmung an Anne d'Autriche ${ }^{143}$ [Abb. 23] bezieht die Regentin selbst, gemeinsam mit anderen skatholischen Tugendheldinnen`, Jeanne d'Arc und Maria Stuart, in die etablierte Reihe der femmes fortes ein; im Frontispiz wird eine Statue mit ihren Gesichtszügen verehrt. Zwei Selbstmörderinnen, Lukretia [Abb. 24] und Porzia [Abb. 25] ${ }^{144}$, werden als Tugendheldinnen aufgenommen, wozu mit Einschränkungen noch Paulina [Abb. 26] ${ }^{145}$ gerechnet werden kann. Die sstarken Frauen<, deren exemplarische Handlungen im Hintergrund dargestellt sind und die neben ihren Attributen auch durch eine subscriptio identifiziert werden, sind stark

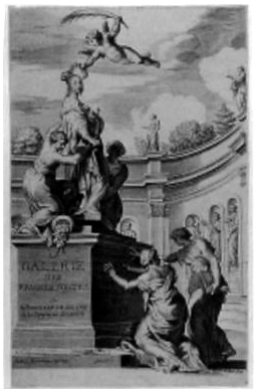

Abb. 23

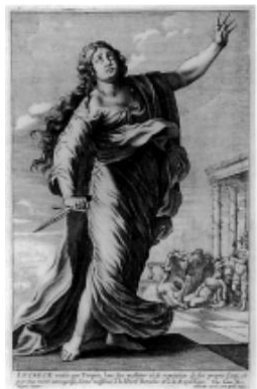

Abb. 24

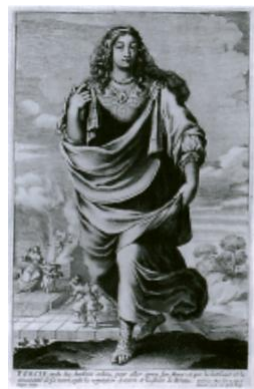

Abb. 25

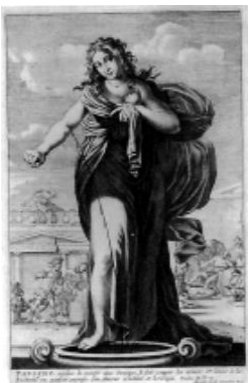

Abb. 26

monumentalisiert. Der sich wiederholende shimmelnde Blickı und die sprechende Gestik der Hände und des Körpers unterstreichen den Seriencharakter. ${ }^{146}$ Die >Galerie des Pierre Le Moyne hat im Übrigen großen Einfluss auf die Bildkünste und das Kunsthandwerk des 17. Jahrhunderts ausgeübt; die Kupfer von Rousselet und Bosse nach Vignon dienten als Vorlage oder doch Anregung für das ikonographische Programm mehrerer Schlösser. Bereits der Sammler und Kenner Pierre-Jean Mariette (1694-1774) wies auf diese Zusammenhänge hin: »Cette série avait grand succès alors, et on la trouverait peinte dans plus d'un château.« Er erwähnt insbesondere das oratoire der Mme de Meilleraye im Arsenal. ${ }^{147}$

Der neustoische Hintergrund ${ }^{148}$ der Gallerie des femmes fortes von Le Moyne ist offensichtlich:

\footnotetext{
${ }^{142}$ Es handelt sich, neben den hier relevanten Tugendheldinnen (Lukretia und Porzia) um Arria, Artemisia, Camma, Cloelia, Debora, Isabella von Kastilien, Jaël, Jeanne d'Arc, Judith, die sfranzösische Judithı, Maria Stuart, Mariamne, Monime (Frau des Mithridates), Panthea, Paulina, Salomone, Zenobia und eine zyprische Heldin im Kampf gegen die Türken.

${ }^{143} \mathrm{Vgl}$. Katalog 41.

${ }^{144}$ Vgl. Katalog 42 (Lukretia) und 43 (Porzia).

${ }^{145}$ Vgl. Katalog 44.

${ }^{146}$ Vgl. Maclean, a.a.O., S. 221 und Maber, Richard G.: The Poetry of Pierre Le Moyne (1602-1671), Bern / Frankfurt/Main 1982, besonders. S. 42, 141 und 160. Bis 1672 wurden 17 Auflagen der Gallerie des Femmes Fortes verzeichnet; sie wurde außerdem ins Deutsche, Italienische, Spanische und Englische übersetzt.

${ }^{147}$ Mariette, Pierre-Jean: Abecedario et autres notes inédites de cet amateur sur les arts et les artistes, hrsg. von Ph. Chennevières, / A. de Montaiglon, Paris 1853-1862, Bd. 5, S. 57 (zu Rousselet). S. oben S. 252.

148 "It is clear from a later passage in his Gallerie that Le Moyne conceives of $>$ force as an amalgam of stoic apathy and fortitudo. (Maclean, a.a.O., S. 82) Zum Begriff der fortitudo schreibt Maclean an gleicher Stelle in
} 
La Philosophie Morale nous a esté donnée pour gouuerner nos Passions; pour distinguer nos deuoirs et nos offices; pour nous apprendre les exercices de la Vertu; pour nous conduire comme par la main à la Beatitude. ${ }^{149}$

Der komplexere Wertediskurs frühneuzeitlicher Eliten manifestiert sich in einem Tugendkatalog, in dem nicht mehr nur kriegerisch-männliche Qualitäten gefordert waren:

Cette Force armée et robuste n'est que la subalterne d'vne Force generale, qui assiste toutes les Vertus; qui est de toutes les grandes actions; qui soustient toutes les bonnes oeuures, qui est la directrice de tous les Heros de paix, et tous les Heros de guerre. C'est à cette force que Sainct Ambroise et Sainct Gregoire, attribuent aprez Platon, les victoires de l'esprit sur la chair, celles de la Vertu sur la Fortune, celles de l'honneste sur l'agreable et sur l'vtile. C'est de cette Force que parle le Sage [Prv 31,10] dans cette peinture, où la Femme Forte est tirée auec de si belles couleurs, et couronnée d'vn si magnifique eloge. ${ }^{150}$

Da der Beweggrund aller grandes actions sich auch an weiblichen Exempeln darstellen lässt, konnte in einer Galerie ıstarkerı Frauen ein vollständiger Tugendkatalog geboten werden, wobei das exemplarisch tugendhafte Handeln Lukretias oder Porzias den Skandal des Selbstmords in den Hintergrund treten ließ. Für die frühneuzeitlichen Eliten konnten solche Galerien die Funktion eines mittelalterlichen Fürstenspiegels ${ }^{151}$ übernehmen, der nicht nur den Regenten, sondern auch die ihn umgebende Aristokratie in paränetischer und oft utopisch-didaktischer Form mit den gruppenspezifischen Normen vertraut machte. Die `Galerien starker Frauen exemplifizierten Tugenden, die in der entstehenden höfisch-absolutistischen Gesellschaft als Schlüsselqualitäten galten. ${ }^{152}$ Dabei trat der aktuelle Ausgangspunkt, die Diskussion über die politische Ebenbürtigkeit von Frauen, rasch gegenüber der allgemeinen, neustoisch gefärbten Wertediskussion in den Hintergrund. Literarisch

der Fußnote: „The four functions of sforce preparation for death.

149 Le Moyne, Pierre: La gallerie des femmes fortes, Paris 1647, S. 254 (Maclean S. 67) (>Die Moralphilosophie wurde uns gegeben, um unsere Affekte zu beherrschen, unsere Pflichten und unsere Aufgaben zu erkennen, um uns den Gebrauch der Tugend zu lehren und um uns gleichsam an der Hand zur Glückseligkeit zu führen.८)

${ }^{150}$ Le Moyne a.a.O., S. aa4r (nach Maclean S. 82) (`Körperliche und kriegerische Fähigkeiten sind einer weiterreichenden (heroischen) Seelenstärke untergeordnet, die alle Tugenden unterstützt, an allen großen Taten beteiligt ist, alle guten Werke unterstützt, alle Heroen des Friedens und des Krieges lenkt. Dieser Seelenstärke schreiben der Heilige Ambrosius und der Heilige Gregor, hierin Platon folgend, die Siege des Geistes über das Fleisch, der Tugend über das Schicksal, des Ehrenhaften über das Angenehme und Nützliche zu. Von dieser Seelenstärke spricht Salomon (Prv 31,10) in der Beschreibung, die der Starken Frau so schöne Farben verleiht und sie mit so großartigem Lob krönt.८)

${ }^{151}$ Vgl. Anton, Hans: »Fürstenspiegel« , in: Lexikon des Mittelalters, Bd. 4, Sp. 1040-1058.

152 Auf die sich in der Frühen Neuzeit in völlig neuer Weise ausbildenden funktionalen Zusammenhänge zwischen Ikonographie, Propaganda und Legitimation hat jüngst Gérard Sabatier hingewiesen (»lkonographische Programme und Legitimation der königlichen Autorität in Frankreich im 17. Jahrhundert«, in: Asch, Ronald / Feist, Dagmar [Hrsg.]: Staatsbildung als kultureller Prozess: Strukturwandel und Legitimation von Herrschaft in der Frühen Neuzeit, Köln 2005, S. 255-265). Sabatier greift dabei auf ein Forschungsprogramm des französischen CNRS zurück, das sich seit 1985 mit der Entstehung des modernen Staates befasst. Die Sektion 7 untersucht Veränderungen und Funktionen der politischen Ikonographie. Dazu u.a. Ellenius, Allan (Hrsg.): Iconography, Propaganda and Legitimation, Oxford 1998 und Sabatier, Gérard: "Les rois de représentation, Image et pouvoir (XVI ${ }^{\mathrm{e}}-\mathrm{XVII}{ }^{\mathrm{e}}$ siècles) «, in: Revue de synthèse 112 (1991), S. 387-422. 
und bildkünstlerisch immer neu diskutierte und präsentierte Exempel standen im Mittelpunkt der politisch-gesellschaftlichen Erziehung frühneuzeitlicher Eliten und griffen häufig Leitsätze neustoischer Philosophie auf. ${ }^{153}$ Stets wiederholte exempla virtutum dienten der illustrierenden Anschaulichkeit und der Memorierung: non nova, non ardua. ${ }^{154}$ Gerade das Exemplarische ließ sich offenkundig auch oder besonders an Frauenfiguren zeigen. Das Bildmotiv der Tugendheldin als Selbstmörderin konnte in diesem Zusammenhang Karriere machen, weil nicht der Selbstmord, sondern die mit inm demonstrierte Tugend thematisch war.

Rückt man Le Moyne in diese weitere Perspektive, zeigt sich, dass Produkte wie die Gallerie des femmes fortes einen neu formulierten, von den männlichkriegerischen Idealen abgerückten profanen Tugendbegriff etablierten, der Willensstärke an die Stelle der physischen rückte und deshalb besonders im Bild der ıstarken` Frau dargestellt werden konnte, deren körperliche Unterlegenheit ihre Tugend umso bewundernswerter machte.

Ce n'est pas la hauteur de la taille, ny la force du corps qui fait les Heros: c'est la grandeur et l'élevation de l'ame; c'est la vigueur et la fermeté de l'Esprit: et il peut y auoir des Ames fort èleuees et de premiere grandeur en de petits Corps; il peut y auoir vn Esprit extremement ferme et d'vne extréme vigueur, dans vne chair fort infirme. ${ }^{155}$

\section{Pendants}

Als kleinste Form der Serienbildung sind auch Pendants, abgesehen von ihrer dekorativen Wirkung, eine verbreitete Form deutender Zusammenstellung ikonographisch verwandter Motive. Da Erbfolgen und Besitzveränderungen meist die ursprünglichen Zusammenhänge verwischt haben, beginnt die Kunstgeschichte erst jetzt, der Pendant-Bildung die gebührende Aufmerksamkeit zu schenken. ${ }^{156}$ Auch

\footnotetext{
153 Lipsius erörtert mehrfach den pädagogischen Nutzen von exempla für die moralische Bildung: „Sicut herbas qui sevit, opportune eas irrigat atque alit, ut adolescant: sic tu sentiarum istos velut frutices fove et attolle, vel sole vel pluvia, ut sic dicam, exemplorum. Utrumvis [sententiae et decreta] enim praestant, illustrant, dum in rem velut praesentem ducunt et facta ostendunt, quae facienda suadentur; fovent etiam, dum animum erigunt, et re docent non nova, non ardua proponi. « (Monita et exempla politica, I,1, in: Opera omnia, IV,1, Wesel 1675 (ND 2001 Hildesheim/Zürich/New York) S. 127 bis 128) (>Wer junge Saat ausgebracht hat, wässert und hegt sie auch, damit sie wächst: nimm dich in gleicher Weise philosophischer Lehrmeinungen wie junger Triebe an und lass sie durch Beispiele wie durch Sonnenschein und Regen wachsen, um mich im Bild auszudrücken. Beispiele nämlich demonstrieren und erläutern Thesen und Lehrsätze, vergegenwärtigen sie und zeigen nachahmenswerte Taten. Sie erbauen und leiten durch Vorbilder dazu an, Neuerungen und Schwierigkeiten zu vermeiden.८)

${ }^{154}$ Vgl. oben S. 290.

155 Le Moyne in La Gallerie, Zitat nach Maclean, a.a.O., S. 86.

156 So sind zum Beispiel für das Schloss Stuttgart-Ludwigsburg (Petermann, Erwin: Katalog der Staatsgalerie Stuttgart, Stuttgart 1962) folgende Pendants nachzuweisen: Heilige (5), Paare (4), Landschaften (7), biblische Themen (3), Stadtansichten (2), Genre (5), Stilleben (3), historisches Thema (1); in Den Haag (The Royal Cabinet of Paintings, Illustrated General Catalogue, [ohne Hrsg.] The Hague 1977) sind folgende Pendants nachweisbar: Paare (16), Landschaften (6), Jahreszeiten (1), biblische Themen (2), Stadtansichten (1), Stilleben (4), Genre (4), Historie (1). - Bisher hat sich nur Moiso-Diekamp, Cornelia: Das Pendant in der holländi-
} 
die Quellen und die Kunstliteratur gehen nur selten auf vom Künstler, vom Auftraggeber oder vom Sammler konzipierte Pendants ein.

Sieht man von zwei Bildbeschreibungen Carel van Manders in seinem SchilderBoeck (1604) ab, die sich mit Gegenstücken von Cornelis Ketel und von Hans Holbein $\mathrm{d}$. J. befassen, finden Pendant-Hängungen leider in schriftlichen Zeugnissen des 17. Jahrhunderts keine Erwähnung. ${ }^{157} \mathrm{Um}$ so bemerkenswerter ist es, dass Gerard de Lairesse in seinem Groot Schilderboek (1707) auf Konzeption und Hängung von Pendants nur im Zusammenhang mit der Landschaftsmalerei zu sprechen kommt, obwohl die Historienmalerei im Mittelpunkt seiner Erörterungen steht. ${ }^{158}$ Seine Überlegungen bleiben allerdings formal: So erörtert der klassizistische Theoretiker die Lichtverhältnisse in Landschaftsbildern und ihr wünschenswertes Verhältnis zur Architektur und zu den realen Lichtverhältnissen im für sie bestimmten Raum (de waare zon). ${ }^{159}$ Erst in diesem Zusammenhang kommt Lairesse - immer in Bezug auf die Landschaftsmalerei - auf Pendants (wedergaas) zu sprechen. Dabei legt er weniger Wert auf Übereinstimmung von Thema (begrip) und Bildaufbau (schikking) als auf Variationen bei gleicher Rahmung und Perspektive. ${ }^{160}$ Gerade formale und in-

schen Malerei des 17. Jahrhunderts, Frankfurt / Bern / New York 1987, für einen eingegrenzten Bereich mit dem Thema näher beschäftigt. - Minges, Klaus: Das Sammlungswesen in der Frühen Neuzeit, Kriterien der Ordnung und Spezialisierung, Münster 1998, trägt zur ursprünglichen Hängung in einzelnen Sammlungen und Galerien leider nichts Erhellendes bei. Er unterscheidet »hierarchische « und »dekorative « Prinzipien beim Aufbau von Gemäldesammlungen. Das »hierarchische « Prinzip bei der Hängung der Gemälde folgte »akademischen « Kriterien und unterschied nach Schulen und Gattungen, trug also eher dem Connaisseur Rechnung; das »dekorative « Prinzip hob auf die in der »Bildertapete « gipfelnde, monumentale Gesamtwirkung einer Sammlung ab. Der Sensualismus des 17. und besonders des 18. Jahrhunderts förderte die Tendenz zum ästhetischen Gesamteindruck, der allerdings im Detail sehr wohl auf fortlaufende Kontraste (und damit auch den dauernden Vergleich) abhob. Minges geht auf Pendants nicht ein.

157 Vgl. Mander, Carel van: Das Leben der niederländischen und deutschen Maler (von 1400 bis ca. 1615), hrsg. von Hanns Floerke, München / Leipzig 1906 (ND Worms 1991), S. 304-322 und S. 105-117. Als Gegenstücke bei Cornelis Ketel werden Demokrit und Heraklit genannt, von denen es wohl mehrere Versionen gab. (Zur Problematik der Textüberlieferung und seiner unterschiedlichen Deutung Moiso-Diekamp, a.a.O., S. 356f.) Bei Hans Holbein werden Gegenstücke mit dem Triumph der Armut und des Reichtums beschrieben.

${ }^{158}$ Als Lairesse 1690 seine Karriere als Maler und Stecher wegen Erblindung beenden musste, fasste er in öffentlichen Vorträgen, die später von seinem Sohn Abraham in den Kompendien Grondlegginge der Teekenkunst (1701) und Het groot Schilderboek (1707) veröffentlicht wurden, seine klassizistische Ästhetik zusammen.

159 »Een goed Konstenaar moet zich voorzichtig gedraagen in het schikken en verkiezen van zyn werk, zorgvuldiglyk acht geevende op de eigenschap der plaats, op dat zyne konst de bouwkunde niet ontbinde, maar veel eêr versterke; maakende de Landschappen, die men natuurlyk will verbeelden, hoe zy verder van het waare licht, dat in de kamer valt, zyn, zo veel helderder als die naby het zelve zyn: want anders doende, zou het maar een schildery vertoonen. « (Lairesse, Gerard de: Groot schilderboek, Haarlem ${ }^{2} 1740$ [ND Davaco Publishers, Dornspyck 1969], S. 363) (»Ein guter Künstler muß sich bey Einrichtung und Erwählung seines Werckes vorsichtig aufführen / daß er sorgfältig auf die Beschaffenheit des Ortes Achtung gebe, damit seine Kunst die Architectur nicht schwäche, sondern viel eher befestige, und die Landschafften, wenn man sie natürlich vorstellen will, je weiter sie von dem in dem Zimmer einfallenden wahren Licht entfernet, um so viel heller mache, als die demselben nahe seynd. Verfährt man anderst, so wird es nur eine Mahlerey vorstellen. «) (Des Herrn Gerhard de Lairesse, Welt=belobten Kunst=Mahlers / Grossen Mahler=Buchs, Aus dem Holländischen in das Hoch=Teutsche übersetzt. Nürnberg, Im Verlage Joh. Christoph Weigel, Kunst Händlers, seel. Wittib, gedruckt bey Lorenz Bieling, 1729, Ersten Theils II Continuation, S. 122ff.)

160 "Myn gevoelen is, dat dit voorige meest uit eigenzinnigheid van den Konstenaar voortkomt; en dat er niets meer in een Wedergaa word vereischt, als een evengeleyk oogpunt en gelykvormigheid der beelden, wanneer ze op een gelyke hoogte hangen moeten: maar die het overige daar by will gevoegd hebben, zoekt het vyfde rad aan een wagen. Want waarom zoude ik myn vermaak niet mogen hebben, na myne lust in het beschouwen van een naare wildernis te hebben geboet, zulks ook te doen in het zien van een aangenaame vlakte, of in het verschil van een Landschap met bosch in tegenstelling van een zoete rivierkant en een vermaakelyke doorzicht? «( (a.a.O., S. 363f.) (»Meine Meinung ist / daß erstgemeldetes meistens von dem Eigensinne der Künstler herkömmet, und daß bey einem Compagnon weiter nichts erfodert wird, als ein eben solcher Aug=Punct und eine Gleichförmigkeit der Bilder, so ferne sie in einer gleichen Höhe hängen müssen; wer aber das üperige will hinzugethan haben, der suchet das fünffte Rad an einem Wagen. Denn warum würde ich meine Ergötzung nicht haben mögen / nachdem ich meine Lust in Beschauung einer furchtsamen Wildniß gebüsset, wenn ich solches auch in Besehung einer angenehmen Ebene, oder an dem Unterscheid einer 
haltliche Differenzen bilden den Reiz der Pendantbildung (»hoe verschillender, hoe beter en aangenaamer «).

Die überraschende Beschränkung der Pendants auf Landschaftsbilder und der implizite Ausschluss der Historienmalerei bei Lairesse wird in einem gewissen Umfang von den empirischen Untersuchungen von Moiso-Diekamp zu den Pendants ${ }^{161}$ der holländischen Malerei des 17. Jahrhunderts bestätigt. Immerhin lässt der Sonderfall der Seitenstücke die Möglichkeit zu, Pendants auf beiden Seiten eines größeren und thematisch unabhängigen Mittelstücks als ıBegleiter`zu hängen. Im niederländischbürgerlichen Bereich wurden Pendants offensichtlich als thematische Gegensätze (Arm-Reich, Morgen-Abend, Tugend-Laster, Land-See) oder als thematische Ergänzungen (Verkündigung und Anbetung, Christus und Maria, verschiedene Musikanten) aufgefasst, aber auch zur Eskortierung eines Historiengemäldes eingesetzt, das, zwischen zwei kleinere Pendants gehängt, durch seine größeren Maße die Aufmerksamkeit des Betrachters auf sich zog. Unabhängig davon, ob Pendants im bürgerlichen Haushalt als Zweiergruppe oder als ıBegleiterı eines thematisch heterogenen Mittelstücks eingesetzt wurden, lag ihr ästhetischer Reiz in der Gleichzeitigkeit von `Differenzı und `Korrespondenzı.

Felix Thürlemann hat neuerdings auf die semiotische Funktion von PendantHängungen hingewiesen und sie als »metatextliches Konstrukt« bezeichnet, das als übergreifender semantischer Zusammenhang (»hypersign«) den Blick des Betrachters lenke. ${ }^{162}$ Nicht immer sind die semantischen Beziehungen freilich so evident wie bei der bekannten Gegenüberstellung von Demokrit und Heraklit als weinendem und lachendem Philosophen. ${ }^{163}$ Die Zusammenstellung einer Lukretia und einer Judith lässt gegenüber dem Vergleich zweier philosophischer Grundeinstellungen zweifellos größere Deutungsspielräume zu. ${ }^{164}$

Auch in fürstlich-repräsentativen Galerien wurden wie in niederländischen Bürgerhäusern Genre, Landschaften, Jahreszeiten und Paare als Themen für Pendants bevorzugt. ${ }^{165}$ Allerdings unterscheiden sich fürstliche Galerien durch eine weitere Gruppe, die sich in bürgerlichen Sammlungen nicht finden: auch Historienbilder wur-

\footnotetext{
Landschafft mit Wäldern, und gegen über angebrachten hübschen Ufers eines Flusses, und eines annehmlichen Prospects suche? «)

${ }^{161}$ Die Begriffe paire, Gegenstücke, Nebenbilder, Seitenstücke, tegenhangers, wedergaas, companion pictures, counterparts, quadri di riscontro, quadri compagni, paio, compañeros, parejas werden mit gleicher Bedeutung verwendet und spiegeln die gegenseitige Bezogenheit in Format und Thema. (Moiso-Diekamp, a.a.O., S. 16-22)

162 Thürlemann, Felix: »Vom Sinn der Ordnung, Die Bildersammlung des Frankfurter Konditormeisters Johann Valentin Prehn (1749-1821)«, in: Assmann A./ Gomille, M./ Rippl, G. (Hrsg.): Sammler - Bibliophile - Exzentriker, Tübingen 1998, S. 315-324; hier S. 319: "Zum anderen ist jede Zusammenstellung bedeutungstragender Objekte zu einem syntaktisch geordneten neuen Gebilde mehr als die Addition der Teile. Die Zusammenstellung etwa zweier Bilder aktualisiert in einem Spiel von Analogien und Differenzen semantische Kategorien, die die Lektüre der betroffenen Werke in ganz bestimmte Richtungen lenkt.«

${ }^{163}$ Vgl. Weisbach, Werner: "Der sog. Geograph von Velasquez und die Darstellungen des Demokrit und des Heraklit«, in: Jahrbuch der preußischen Kunstsammlungen 49 (1928), S. $141 \mathrm{ff}$.

${ }^{164}$ So schreibt Gerlinde Volland skeptisch zu zwei Blättern von Nicolas-Gabriel Dupuis (1695-1771), die eine Lukretia und eine Judith Renis wiedergeben: „Die Verbindung zwischen Lukretia und Judith besteht u.a. darin, dass beide eine Bluttat begehen, um höherer, transzendentaler Werte willen. Ob der Gegensatz in der Darstellung der leidenschaftlichen heidnischen Heldin und der in sich ruhenden christlichen auch inhaltliche Wertungen impliziert, muß dahin gestellt bleiben. « (in: AK Die Galerie der Starken Frauen, a.a.O., S. 310)

${ }_{165} \mathrm{Im}$ Herzog Anton Ulrich-Museum sind 95 Pendants in verschiedenen Bildgattungen nachzuweisen: biblische Themen (11), Heilige (2), Mythos und antike Geschichte (13), Genre (22), Landschaften (20), Stilleben (6), Porträts (Mann/Frau) (19), Porträts (Mann/Mann) (2).
} 
den als Pendants gehängt. ${ }^{166}$ Schon die Bildformate weisen darauf hin, dass die Gemälde für repräsentative Räumen bestimmt waren; oft lässt sich die ursprüngliche Hängung in der Galerie noch ermitteln. In diesem Zusammenhang finden sich auch Beispiele aus dem Themenbereich des ıschönen Sterbensı.

Während in bürgerlichen Sammlungen das Motiv der ıSelbstmörderin als Tugend-

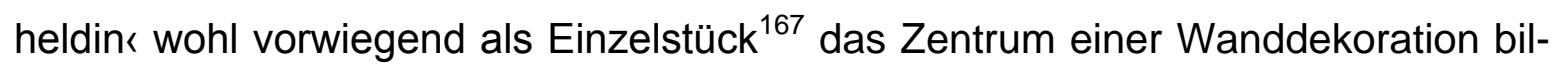
den mochte, konnte es in aristokratischen und höfischen Galerien zusammen mit einem Pendant eine Sinneinheit bilden oder ein Historiengemälde mit anderer Thematik seskortieren<. Wohl nur im höfischen Zusammenhang sind sterbende Tugendheldinnen in drei deutlich gegeneinander abgrenzbaren Arrangements nachzuweisen: als Einzelstücke, als Gruppen im Sinne von zwei sich thematisch aufeinander beziehenden Pendants oder als Gegenstücke, die links und rechts von einem größeren, thematisch unterschiedlichen Historiengemälde gehängt wurden. Gemälde aus dem Motivkreis des Tugendtodes wurden von einem bürgerlichen Publikum offensichtlich anders als von einem aristokratischen Publikum betrachtet und bewertet.

Pendantbildungen mit Selbstmörderinnen als Tugendheldinnen sind im Übrigen selten nachweisbar. ${ }^{168}$ Wie aus der folgenden Zusammenstellung hervorgeht, scheinen sich immerhin auf den ersten Blick drei Grundtypen unterscheiden zu lassen: Pendants mit zwei verschiedenen Tugendheldinnen, Zusammenstellungen verschiedener Bildmotive derselben Tugendheldin und Verdoppelungen des gleichen Bildmotivs. Daneben tritt die vergleichende Pendantbildung von männlichen und weiblichen Tugendhelden auf. ${ }^{169}$

$\begin{array}{llll}\begin{array}{l}\text { Albrecht Dürer } \\ (1471-1528)\end{array} & \text { Tod der } \text { Lukretia }^{1 / 0} & \begin{array}{l}\text { beide } 168 \times 74,8 \\ \text { (ganzfigurig) }\end{array} & \begin{array}{l}\text { München: Alte Pinako- } \\ \text { thek }\end{array} \\ \text { Peter Candid } & \text { Tod des Cato Uticensis }^{171} & & \text { verloren }\end{array}$

${ }^{166}$ Vgl. unten, S. 262.

167 So das Gemälde Vouets (Sophonisbe erhält den Giftbecher), das ursprünglich in die Sammlung des Amsterdamer Bürgermeisters Willem Six gehörte und 1734 versteigert wurde. Auch das thematisch entsprechende Gemälde Renieris stammt aus einer bürgerlichen Sammlung (vgl. unten, Anm. 205).

${ }^{168}$ Vorarbeiten fehlen, da Sammlungskataloge auf Pendant-Hängungen in der Regel nicht eingehen. Die oben erwähnte Untersuchung von Cornelia Moiso-Diekamp (vgl. Fußnote 8) ist für profane Tugendheldinnen nicht einschlägig, weil es sich um ein Bildmotiv handelt, das vorwiegend in aristokratischen Kreisen beliebt war.

169 Natürlich finden sich auch Zusammenstellungen zweier männlicher Tugendhelden. So setzt Sebastiano Conca mit dem Tod des Seneca und dem Tod des Cato (Braunschweig: Herzog Anton Ulrich-Museum, beide 61,5 x 75,5) zwei Ikonen stoischer Philosophie ins Bild und vergleicht die modi moriendi.

${ }^{170}$ Katalog 110. Es handelt sich hier nur sehr indirekt um eine Pendant-Bildung: Der eigenartige Zusammenhang beider Bilder entstand, weil die anstößige Nacktheit der Dürerschen Lukretia vom Kurfürsten dadurch kaschiert wurde, dass zunächst eine Cato-Darstellung Candids, dann das (aus demselben Grund retouchierte) Bild Cranachs mit dem gleichen Sujet ıvorgehängt` wurde. »Im frühen 17. Jahrhundert diente Cranachs Lucretia, deren Körper mit einem roten Kleid züchtig übermalt war, als Verschlusstür für Dürers Gemälde. Ein weitere moralische Komponente war ins Spiel gekommen: Nacktheit hatte im prüden Klima des Münchner Hofs ihre humanistische Unschuld verloren. «(Schawe, Martin: Alte Pinakothek, München 2006, S. 120) Siehe oben S. 128. 


\begin{tabular}{|c|c|c|c|}
\hline $\begin{array}{l}\text { Paolo Veronese } \\
(1528-1588)^{173}\end{array}$ & $\begin{array}{l}\text { Tod der Lukretia } \\
\text { Judith mit dem Haupt des Holo- } \\
\text { fernes }\end{array}$ & $\begin{array}{l}109 \times 90,5 \text { (oben be- } \\
\text { schnitten) } \\
111 \times 100,5 \\
\text { (dreiviertelfigurig) }\end{array}$ & Wien: KHM \\
\hline $\begin{array}{l}\text { Pietro Ricchi } \\
(1605-1675)^{174}\end{array}$ & $\begin{array}{l}\text { Tod der Lukretia } \\
\text { Joseph und Potiphars Weib }\end{array}$ & $\begin{array}{l}127 \times 98 \\
\text { (dreiviertelfigurig) }\end{array}$ & $\begin{array}{l}\text { Braunschweig: Herzog } \\
\text { Anton Ulrich-Museum }\end{array}$ \\
\hline $\begin{array}{l}\text { Guido Reni } \\
(1575-1642)^{175}\end{array}$ & $\begin{array}{l}\text { Tod der Lukretia } \\
\text { Tod der Sophonisbe (Artemi- } \\
\text { sia?) }\end{array}$ & $\begin{array}{l}\text { oval } 96 \times 71 \\
\text { (beide halbfigurig) }\end{array}$ & Genua: Privatsammlung \\
\hline Guido Reni & $\begin{array}{l}\text { Judith } \\
\text { Tod der Lukretia }\end{array}$ & $\begin{array}{l}202 \times 143 \\
215 \times 151 \\
\text { (beide ganzfigurig) }\end{array}$ & $\begin{array}{l}\text { Genf: Slg. Sedlmayer } \\
\text { Potsdam: Neues Pa- } \\
\text { lais }^{176}\end{array}$ \\
\hline Guido Reni & $\begin{array}{l}\text { Tod der Lukretia } \\
\text { Tod der Kleopatra }\end{array}$ & $\begin{array}{l}91 \times 73 \\
\text { (beide halbfigurig) }\end{array}$ & $\begin{array}{l}\text { Rom: Kapitolinische } \\
\text { Museen }\end{array}$ \\
\hline Guido Reni & $\begin{array}{l}\text { Tod der Lukretia } \\
\text { Tod der Kleopatra }\end{array}$ & $\begin{array}{l}125,5 \times 93,5 \\
122 \times 96 \\
\text { (beide dreiviertelfigurig) }\end{array}$ & $\begin{array}{l}\text { Campione d'Italia: Slg. } \\
\text { Lodi } \\
\text { Florenz: Palazzo Pitti }{ }^{177}\end{array}$ \\
\hline $\begin{array}{l}\text { Massimo Stanzio- } \\
\text { ne }(1585-1656) \\
\text { Francesco Guarino } \\
(1611-1654)^{178}\end{array}$ & $\begin{array}{l}\text { Tod der Lukretia } \\
\text { Tod der Kleopatra }\end{array}$ & $\begin{array}{l}122 \times 100 \\
\text { (beide dreiviertelfigurig) }\end{array}$ & $\begin{array}{l}\text { Genua: Palazzo Durazzo } \\
\text { Palaviccini }\end{array}$ \\
\hline $\begin{array}{l}\text { Simon Vouet } \\
(1590-1649)^{179}\end{array}$ & $\begin{array}{l}\text { Tod der Lukretia } \\
\text { Tod der Sophonisbe }\end{array}$ & $\begin{array}{l}120 \times 171 \\
121 \times 170 \text { (angestückt) } \\
\text { (beide dreiviertelfigurig) }\end{array}$ & $\begin{array}{l}\text { Potsdam: Gemäldegale- } \\
\text { rie }\end{array}$ \\
\hline $\begin{array}{l}\text { Artemisia Gentile- } \\
\text { schi } \\
(1593-1653)^{180}\end{array}$ & $\begin{array}{l}\text { David und Bathseba } \\
\text { Lukretia }\end{array}$ & Ohne Maße & Potsdam: Neues Palais \\
\hline $\begin{array}{l}\text { Mattia Preti } \\
(1613-1699)^{181}\end{array}$ & $\begin{array}{l}\text { Tod der Dido } \\
\text { Judith mit dem Haupt des Holo- } \\
\text { fernes }\end{array}$ & $\begin{array}{l}247 \times 209 \\
239 \times 209 \\
\text { (beide ganzfigurig) }\end{array}$ & $\begin{array}{l}\text { Chambery: Musée des } \\
\text { Beaux-Arts }\end{array}$ \\
\hline $\begin{array}{l}\text { Ludovico Mazzanti } \\
(1686-1775)\end{array}$ & $\begin{array}{l}\text { Tod der Lukretia } \\
\text { Joseph und die Frau des Poti- } \\
\text { phar }\end{array}$ & $\begin{array}{l}\text { keine Maßangaben } \\
\text { (beide ganzfigurig) }\end{array}$ & $\begin{array}{l}\text { New York: Kunstmarkt } \\
\text { Rom: Privatsammlung }\end{array}$ \\
\hline $\begin{array}{l}\text { Johann Carl Loth } \\
(1632-1698)^{183}\end{array}$ & $\begin{array}{l}\text { Tod der Lukretia } \\
\text { Tod der Kleopatra }\end{array}$ & $\begin{array}{l}136,5 \times 116,5 \\
135 \times 111,5\end{array}$ & $\begin{array}{l}\text { Meersburg: Neues } \\
\text { Schloss }\end{array}$ \\
\hline
\end{tabular}

${ }_{171}^{171}$ Nicht erhalten. Vgl. Katalog 110.

172 Zu Dürers Selbstmord der Lucretia Gisela Goldberg, in: Steingräber, Erich (Hrsg.): Kat. Alte Pinakothek München, München 1983, S. 174.

${ }_{173}$ Katalog 420.

${ }^{174}$ Früher Lionardo Corona zugeschrieben. Katalog 338 (Lukretia) und 339 (Joseph).

175 Vgl. Pepper, a.a.O., S.293.

${ }^{176}$ Renis Judith wurde offensichtlich mehrfach kopiert; ausführliche Nachweise bei Pepper, a.a.O., S. 258, der auch auf die Möglichkeit eingeht, dass die Judith und die Lukretia als Pendants kombiniert worden sein könnten.

${ }_{177}$ Vgl. Pepper, a.a.O., S. 340 und 294.

178 Katalog 384 (Lukretia) und 162 (Kleopatra).

179 Katalog 429 (Lukretia) und 430 (Sophonisbe).

180 Katalog 145 (Lukretia) und 146 (David).

181 Katalog 284.

182 Vgl. Spinosa, Nicola: Pittura napoletana del Settecento dal Rococò al Classicismo, Napoli 1987, S. 145.

183 Katalog 215 (Lukretia) und 216 (Kleopatra). 


\begin{tabular}{|c|c|c|c|}
\hline $\begin{array}{l}\text { Francesco Pittoni } \\
\text { (aktiv 1687-1712). }\end{array}$ & $\begin{array}{l}\text { Tod des Seneca } \\
\text { Tod der Kleopatra }\end{array}$ & keine Maßangaben & unbekannt \\
\hline $\begin{array}{l}\text { Franz Caucig } \\
(1755-1828)\end{array}$ & $\begin{array}{l}\text { Porzia, glühende Kohlen ver- } \\
\text { schluckend }{ }^{185} \\
\text { Orpheus am Grab der Eurydike }\end{array}$ & $\begin{array}{l}113 \times 84 \text { (dreiviertelfigu- } \\
\text { rig) }\end{array}$ & Graz: Joanneum ${ }^{186}$ \\
\hline
\end{tabular}

Es überrascht nicht, dass unter den nachweisbaren Pendants Lukretia die am häufigsten gewählte Tugendheldin zu sein scheint, da ihr Selbstmord in der Frühen Neuzeit ohnehin das beliebteste ikonographische Thema unter den römischen Tugendheldinnen war. ${ }^{187}$ Bemerkenswerter ist, dass Lukretia in den als Pendants konzipierten (oder doch gehängten) Darstellungen immer als Einzelfigur gegeben wird. Damit tritt die Keuschheit der jungen Frau thematisch in den Vordergrund; ihr Selbstmord wird ausschließlich als moralische Rehabilitation gedeutet. Deshalb stellen die Pendants mit Lukretia nie spolitischer Szenen, etwa mit den Rache schwörenden Verwandten, dar; ebenso wenig wird die Lukretia-Episode als Beginn eines politischen Umsturzes interpretiert. Die Künstler konzentrieren sich auf den moralistischen Aspekt und verzichten auf eine mögliche politische Deutung der Heldin.

Männliche und weiblicher Tugendhelden treten bei Dürer und Candid (Lukretia und Cato) sowie bei Pittoni (Kleopatra und Seneca) auf; nicht zufällig stellen Ludovico Mazzanti und Pietro Ricchi männliche und weibliche Keuschheit gegenüber, wenn sie Lukretia mit Joseph und der Frau des Potiphar kombinieren. Auch Artemisia Gentileschi hat in ihren heute in Potsdam gezeigten Pendants ${ }^{188}$ die naive Bathseba [Abb. 27] mit der vergewaltigten Lukretia [Abb. 28] kombiniert und jeweils sehr höfisch in Szene gesetzt. Daraus lässt sich wohl auch die beliebte Zusammenstellung von Lukretia und Kleopatra ableiten; erneut dürfte die moralische Rehabilitation der Tugendheldinnen durch den selbst gewählten Tod verglichen werden.

Die Kombinationen einer Lukretia mit einer Sophonisbe bei Reni, einer Lukretia mit einer Judith bei Veronese [Abb. 29 und 30] oder einer Dido mit einer Judith bei Preti gehen mit großer Wahrscheinlichkeit auf die Kataloge der femmes fortes

\footnotetext{
${ }^{184}$ In Slowenien scheint sich im Rahmen einer Serie von wohl 23 Bildern des Francesco Pittoni (ca. 1654 bis nach 1724) auch ein Pendant mit dem Tod des Seneca (1714 signiert) und dem Tod der Kleopatra erhalten zu haben. Vgl Šerbelj, Ferdinand (Hrsg.): AK La Pittura barocca nel Goriziano, Ljubljana 2002, S. $24 f$. und 196. Abbildungen waren leider nicht zu ermitteln.

${ }^{185}$ Siehe unten, S. 266.

${ }_{186}$ Katalog 131. Mehrfache Anfragen wurden leider nicht beantwortet.

187 Siehe oben, S. 123.

${ }^{188}$ Falls die Zuschreibungen berechtigt sein sollten.
} 
zurück. In seriellen Zusammenstellungen der femmes fortes, die zunächst vorwiegend für die Ausschmückung größerer Räume als Fresken oder wandfeste Gemälde (oder popularisierend in der Graphik) verwendet wurden, finden sich meist

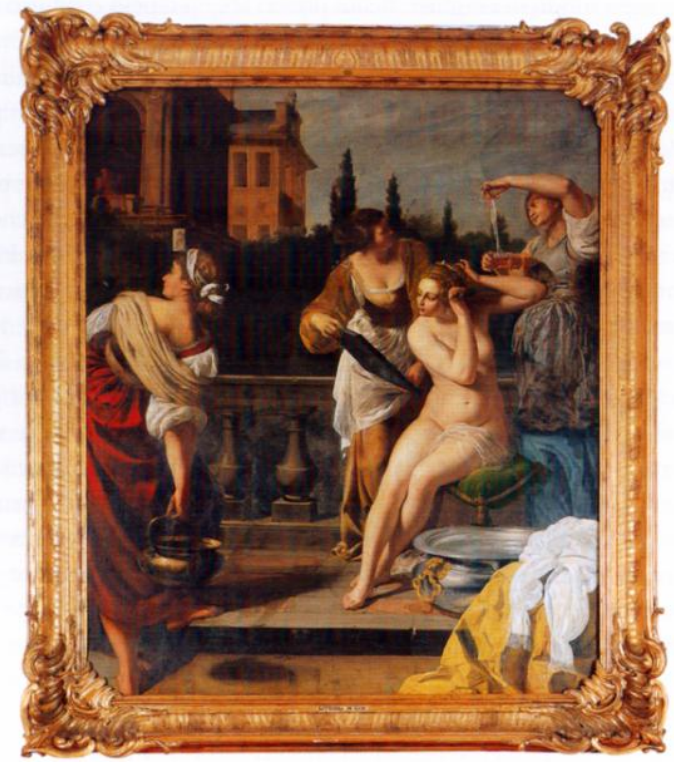

Abb. 27

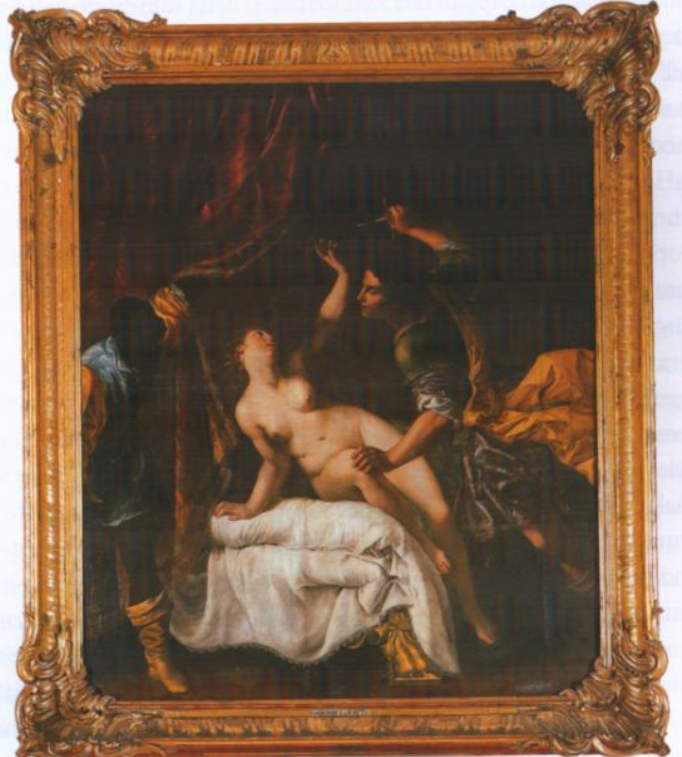

Abb. 28

drei starke Frauen des Alten Testaments mit drei exemplarischen Frauen der Antike und mit drei weiteren aus der Neuzeit kombiniert. ${ }^{189}$ Allerdings waren auch andere Zusammenstellungen möglich, so dass Verbindungen von Dido mit Judith

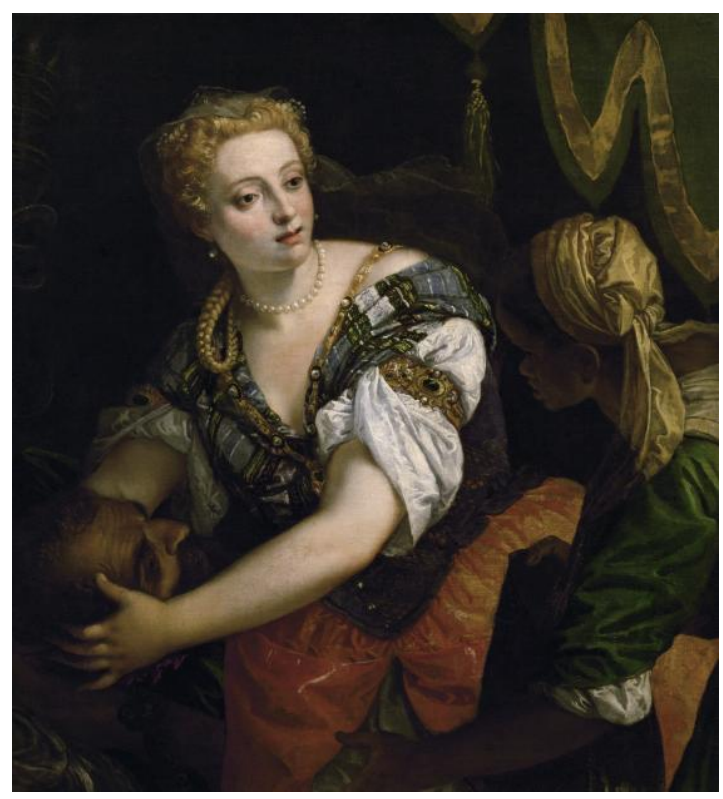

Abb. 29

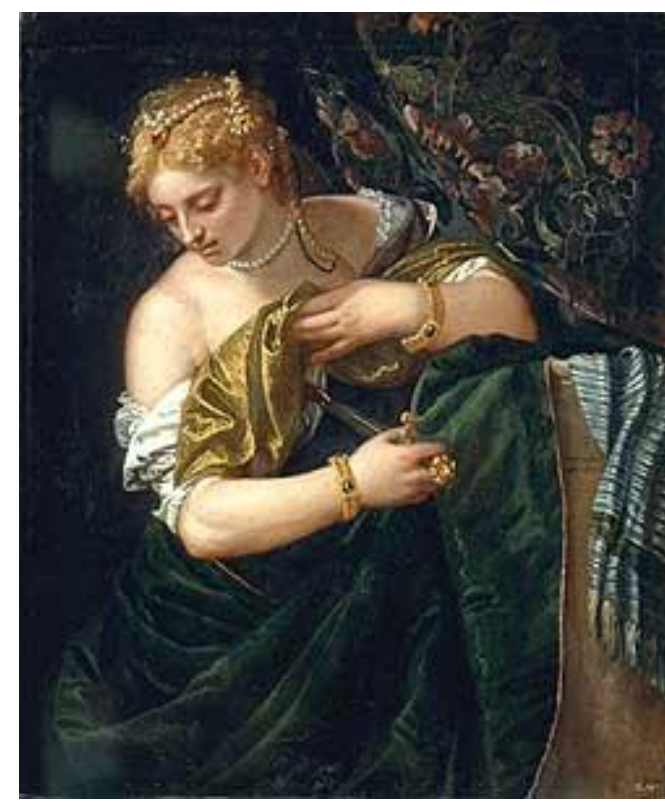

Abb. 30

oder von Lukretia mit Judith wohl als extrem reduzierte Verknüpfungen von Tugendheldinnen aus verschiedenen Sinnbezirken gelten können. Ähnlich ist die Zu-

\footnotetext{
${ }^{189}$ Zu Herkunft, Verwendung und Kombinationsmöglichkeiten vgl. Baumgärtel, Bettina: »Die Tugendheldin als Symbol kirchlicher und staatlicher Macht«, in: AK Die Galerie der Starken Frauen, a.a.O., S. 140-204.
} 
sammenstellung von Francesco Guarinos (1611-1654) Kleopatra [Abb. 31] und Massimo Stanziones (1585-1656) Lukretia [Abb. 32] zu interpretieren, die heute noch der ursprünglichen Konzeption entsprechend im Genueser Palazzo Durazzo Palaviccini so zu sehen sind.

Noch in der Romantik konnte die moralisierende und entpolitisierte Deutung der Tugendheldinnen aufgegriffen werden, wie die von Franz Caucig als Pendants konzipierten Bilder Porzias Tod [Abb. 33] und Orpheus am Grab der Eurydike ${ }^{190}$

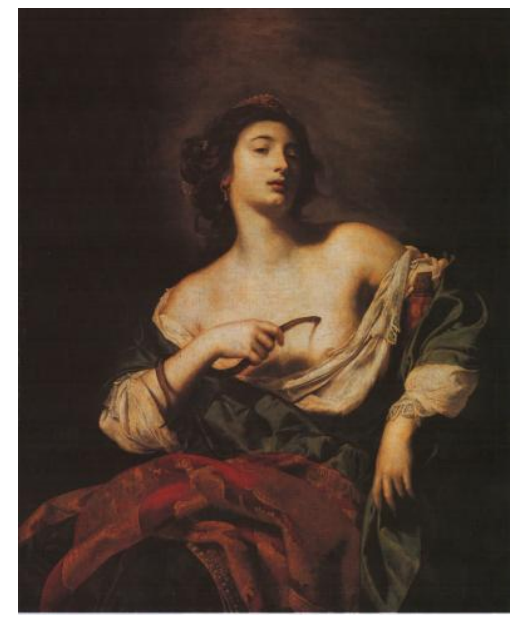

Abb. 31

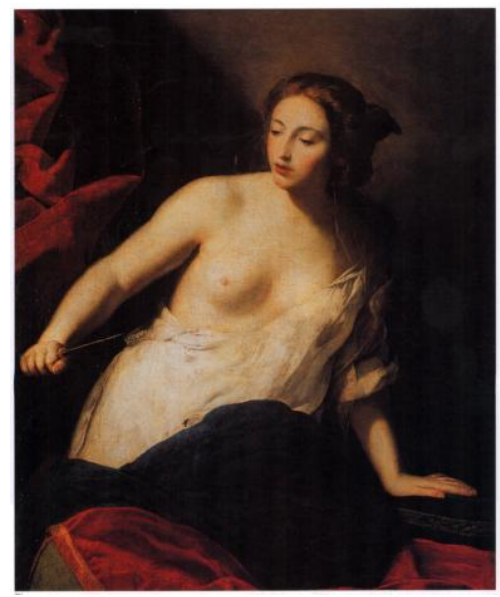

Abb. 32

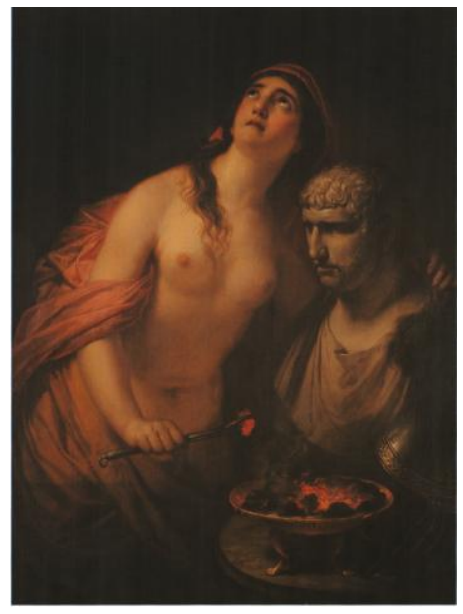

Abb. 33

zeigen. Porzias Selbstmord wird nicht als letzte republikanische Auflehnung gegen Cäsar, sondern als romantisches Selbstopfer einer Liebenden und als herausragender Beweis der Gattenliebe gedeutet. Entsprechend ist Orpheus in dieser Zusammenstellung als vorbildlicher Ehemann zu bewerten.

Die meisten Pendants sind nicht als große Historiengemälde konzipiert, sondern rücken sterbende Tugendheldinnen als Halbfiguren- oder Dreiviertelfiguren in den Mittelpunkt. Auch wenn die etwas größeren Bildmaße wohl für höfischaristokratische Auftraggeber sprechen, werden die Sujets nicht als große Historien mit Hofstaat und prächtigem Ambiente, sondern als gefühlsbetonte und intime Inszenierung ausgeführt. Die Pendants lenken den Betrachter auf die Affekte der Tugendheldinnen und können als indirekter moralischer Diskurs gedeutet werden. Nicht die politische Rolle der Tugendheldinnen, sondern ihre geradezu emblematisch auf einen Affekt verkürzte Darstellung erinnert an vergleichbare Wirkungsstrategien des Barocktheaters, das ebenso über Affektmodellierungen moralische Wirkungen zu erzielen sucht.

${ }^{190}$ Die Museumsdirektion in Graz konnte leider keine Abbildung beschaffen. 
Anders verhält es sich bei als ınarrativ ${ }^{191}$ zu bezeichnenden Bildpaaren der Historienmalerei, auch wenn das Thema der sterbenden Tugendheldin selten in Pendants behandelt wird.

$\begin{array}{llll}\begin{array}{l}\text { Ottmar Elliger der } \\ \text { Jüngere } \\ (1666-1735)^{192}\end{array} & \begin{array}{l}\text { Gastmahl der Kleopatra } \\ \text { Tod der Kleopatra }\end{array} & 55,4 \times 69 & \text { Hamburg: Kunsthalle } \\ \begin{array}{l}\text { Gerard de Lairesse } \\ (1640-1711)^{193}\end{array} & \begin{array}{l}\text { Gastmahl der Kleopatra } \\ \text { Tod der Kleopatra }\end{array} & \begin{array}{l}74 \times 95,5 \\ 74,9 \times 95,6\end{array} & \begin{array}{l}\text { Amsterdam: Rijksmuseum } \\ \text { Toronto: Art Gallery }\end{array} \\ \begin{array}{l}\text { Jacob Jordaens } \\ (1593-1678)^{194}\end{array} & \begin{array}{l}\text { Kleopatra löst die kostbare Perle } \\ \text { auf } \\ \text { Der Tod der Kleopatra }\end{array} & 156,4 \times 149,3 & \text { St. Petersburg: Eremitage } \\ & \begin{array}{l}\text { 171 x } \\ \text { Simon Vouet }\end{array} & & \text { Kassel: } \\ \text { (1590-1649) } & \text { Tod der Sophonisbe } & 128 \times 156 & \text { Staatliche Gemäldegalerie } \\ \begin{array}{l}\text { Nicolas Régnier } \\ (1591-1667)^{195}\end{array} & \text { Tod der Sophonisbe } & 128,3 \times 153 & \begin{array}{l}\text { Kassel: Staatliche Gemäl- } \\ \text { degalerie }\end{array}\end{array}$

Wahrscheinlich für bürgerliche Abnehmer haben sowohl Gerard de Lairesse und als auch Ottmar Elliger der Jüngere die Bankettszene der Kleopatra und des Antonius mit der Todesszene der Tugendheldin zusammengestellt. Es ist bekannt, dass Lairesse die Pendants für einen Amsterdamer Kaufmann gemalt hat. ${ }^{196}$

In einem prächtigen Palast ruht Kleopatra rechts im Bild und greift eben zum Perlenohrring, um den am anderen Ende des Tisches sitzenden Antonius im Wettstreit um das teuerste Gastmahl zu überbieten. [Abb. 32] Der mit Baldachinen, Säu- len und zahlreichem Gefolge reich ausgestattete Bankettszene wird die Entdeckung der toten Königin durch den von rechts herbeistürzenden Octavian gegenübergestellt. [Abb. 33] Die Königin ruht, scheinbar schlafend, auf einer Kline; im rechten Hintergrund erinnert ein Kindersarkophag an ihren von Soldaten des Octavian getöteten Sohn Kaesarion.

\footnotetext{
191 Moiso-Diekamp nennt derartige Pendants santithetischı (vgl. Moiso-Diekamp, a.a.O., passim), weil verschiedene Handlungen des gleichen Protagonisten kontrastiv vor Augen geführt werden.

${ }^{192}$ Katalog 118 (Gastmahl) und 120 (Tod).

${ }^{193}$ Vgl. Roy, Alain: Gérard de Lairesse, 1640-1711, Paris 1992, S. 270 und 272. Katalog 201 (Gastmahl) und 202 (Tod).

${ }_{194}$ Katalog 185 (Bankett) und 184 (Tod). Dazu Roger-Adolf d'Hulst: Jacob Jordaens, Stuttgart 1982, S. 241

und 245.
195 Katalog 427 (Vouet) und 302 (Régnier).

${ }^{196}$ Gerard de Lairesses Bankett der Kleopatra (Katalog 273, heute Amsterdam, Rijksmuseum) und Tod der Kleopatra (Katalog 274, heute Toronto, Art Gallery) haben identische Maße $(74$ x 95,5); die Gemälde hingen ursprünglich im an der Keizergracht liegenden Hause des Amsterdamer Kaufmanns David Hompton. Weitere Informationen über die Provenienz bei Alain Roy, a.a.O., S. 270-273, der allerdings auf die Problematik der Pendants nur am Rande eingeht.
} 
Ottmar Elliger d. J. ${ }^{197}$ hat für seine Version der Wette ganz offensichtlich eine Radierung des Gemäldes von Lairesse als Vorlage benutzt ${ }^{198}$, während für die Todesszene keine Vorlage nachgewiesen ist. Obwohl Elliger (wie Lairesse) Octavian

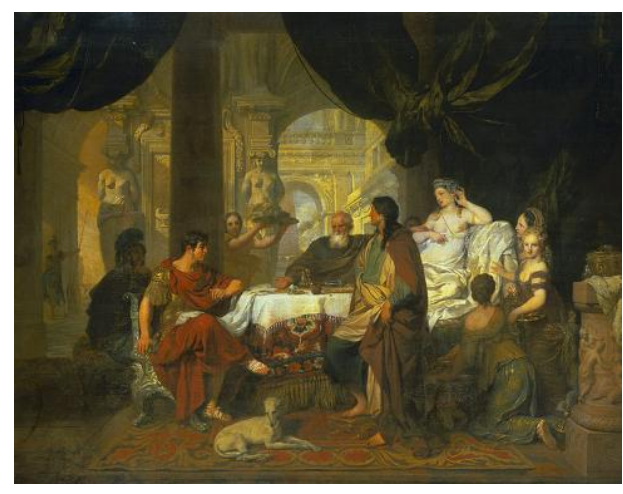

Abb. 32

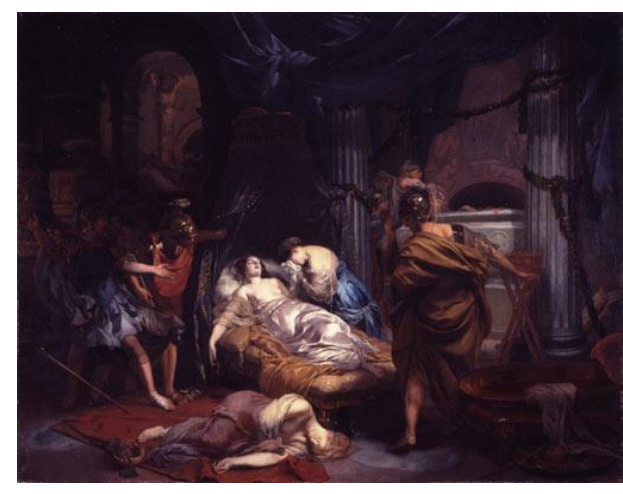

Abb. 33

auftreten lässt, ist bei inm die Dramatik dadurch abgeschwächt, dass Rührung und Trauer durch die Dienerinnen Kleopatras ausgedrückt werden. ${ }^{199}$ Jacob Jordaens verknüpft durch signifikante Anspielungen die Wettszene [Abb. 34] und den Tod

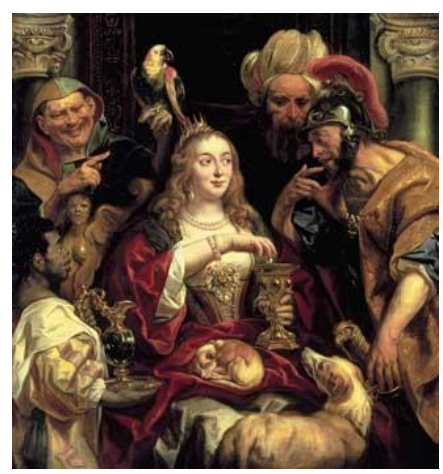

Abb. 34

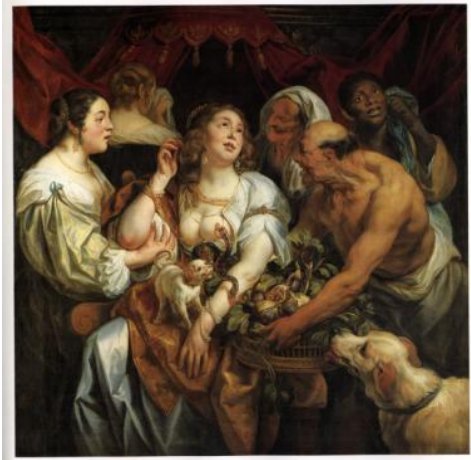

Abb. 35

Kleopatras miteinander. Beide Gemälde wiederholen Bildelemente wie den Schoßhund der Königin, den Mohrenpagen und den Jagdhund. ${ }^{200}$ Solch wiederkehrende Details lassen den Betrachter vermuten, dass nur wenig Zeit zwischen den beiden dargestellten Szenen vergangen ist. Dramatische Exposition und tragi-

\footnotetext{
${ }^{197}$ Ottmar Elliger d. J.: Tod der Kleopatra und Gastmahl der Kleopatra (Katalog 118 und 120) in der Kunsthalle Hamburg in: Katalog der Alten Meister der Hamburger Kunsthalle, Hamburg ${ }^{5} 1966$, S. 58f. Die Gemälde gehörten ursprünglich in die bürgerliche Sammlung Eimbcke, wie der Katalog von 1761 belegt. Der Katalog der Hamburger Kunsthalle deutet den römischen Feldherrn fälschlicherweise als Antonius, nicht als Octavian. Alle literarischen Quellen lassen Antonius vor Kleopatra sterben.

${ }_{198}$ Vgl. Roy, a.a.O., S. 271f. Aufgrund der Seitenverkehrung sitzt bei Elliger Kleopatra in der Bankettszene ganz links, während sich die Todesszene in der Leserichtung rechts anschließt.

99 Charles-Joseph Natoires große Ölgemälde, die Kleopatras Bankett (Katalog 254) und Ankunft in Tarsos (Katalog 255) zeigen, übergehe ich, da sie ursprünglich in eine Marc-Antonius-Serie gehörten, die als Gobelins ausgeführt wurde. Vgl. AK Cléopâtre dans le miroir de l'art occidental, a.a.O., S. 208-211.

200 Kleopatra löst die kostbare Perle auf (Katalog 185; heute in St. Petersburg, Eremitage) und Der Tod der Kleopatra (Katalog 184, heute in Kassel, Staatliche Gemäldegalerie). Die Maße $(171 \times 172)$ zeigen, dass das Pendant für einen fürstlich-aristokratischen Abnehmerkreis konzipiert war. Vgl. Roger-Adolf d'Hulst: Jacob Jordaens, Stuttgart 1982, S. 241 und 245. Über den Verweischarakter der Bildelemente vgl. S. 162.
} 
sche Katastrophe werden in korrespondierenden Bildern komprimiert, [Abb. 35] und veranschaulichen auf diese Weise die tragische $>$ Fallhöhe ${ }^{201}$.

Über das Zustandekommen eines weiteren ınarrativen` Pendants sind wir genauer unterrichtet: Landgraf Wilhelm VIII. von Hessen-Kassel ließ 1734 in Amsterdam Vouets Sophonisbe empfängt durch einen Boten den Giftbecher ${ }^{202}$ [Abb. 36] erwerben. Das heute Vouet zugeschriebene Gemälde ${ }^{203}$ gehörte ursprünglich in die Sammlung des Amsterdamer Bürgermeisters Willem Six und wurde am 12. Mai 1734 als ein Werk Renis versteigert. ${ }^{204}$ Ebenfalls in Amsterdam konnte Wilhelm VIII. einige Zeit später durch Vermittlung von Anthonie Rutgers Régniers Tod der Sophonisbe [Abb. 37] als Pendant erwerben. Am 22. März 1738 berichtet Rutgers, er habe im Hause einer vornehmen Witwe das gesuchte Gegenstück gefunden. ${ }^{205}$ Es liegt hier das selten dokumentierte Beispiel vor, dass auf besonderen

\footnotetext{
201 Der von Charles Batteux geprägte Begriff der `Fallhöhe، hängt in der Dramaturgie mit der Ständeklausel zusammen, die bedeutende Konflikte im klassischen Theater (im Gegensatz zum bürgerlichen Trauerspiel) nur Personen höheren Standes erleben lässt. Eine höhere, meist fürstliche oder königliche Stellung des Protagonisten ist die unabdingbare Voraussetzung des dramatischen Konflikts.

${ }^{202}$ Simon Vouets Tod der Sophonisbe (Katalog 427) und Nicolas Régniers Tod der Sophonisbe (Katalog 302) befinden sich immer noch im Schloss Wilhelmshöhe Kassel. Vgl. Lehmann, Jürgen M.: Italienische, französische und spanische Gemälde des 16. bis 18. Jahrhunderts der Staatlichen Kunstsammlungen Kassel, Fridingen 1980, S. 288f. (Vouet) und S. 214f. (Renieri).

203 Herzog, Erich: Die Gemäldesammlung der Staatlichen Kunstsammlungen Kassel, Geschichte der Galerie, Hanau 1969, S. 18

${ }^{204}$ Der "Catalogus van Schildereyen van Mr. Willem Six, Burgermeester der Stadt Amsteldam, Verkogt den 12 Mey 1734 in Amsterdam « wurde von Gerard Hoet veröffentlicht. Als Nr. 23 findet sich das hier besprochene Gemälde: »De Historie van Sophonisba, door Guarcin del Cento, kragtig en heerlyk in de manier van Guido geschildert. « Vgl. Hoet, Gerard: Catalogus of Naamlyst van Schildereyen met derzelver Pryzen, 2 Bände, 's Gravenhage 1752, hier Bd. 1, S. 410-422.

205 »...] Presentement je trouve de mon devoir d'informer Votre Altesse d'une affaire assée casuelle, c'est: qu'etant avant hier, avec Monsieur le Drossart VAN HOVEN, dans la maison d'une Dame Veuve de distinction, pour voir des Battailles de FRANX, dont ce Monsieur aura écrit hier à Votre Altesse, je decouvris dans la meme salle, au dessus de la Porte, un Tableau du GUIDE, qui me parut très magnifique, et qui seroit un parfait Compagnon pour le Massanissa \& Sophonisbe de Votre Altesse. Icy, c'est Sophonisba assise, et commencente à agoniser, àprès avoir bu la Coupe mortelle: elle tient la Lettre de Massinissa dans la main, et deux de ses Dames d'honneuer sont auprès d'elle. je n'en fis rien paroitre d'abord; mais etants sortis, je dis la Chose á Monsieur VAN HOVEN; et nous sommes convenus de la traiter avec toute la secretesse possible; en esperance de pouvoir effectuer une Aquisition agréable à Votre Altesse: et à ce moment Monsieur VAN HOVEN vient m'aporter la juste mesure du Tableau, cy jointe; qu'il a su procurer en secret, et de meme l'information que Madame n'auroit point de repugnance à s'en defaire, comme d'un sujet trop triste et melancolique pour elle.« (22. März 1738) (von Drach, Allard: »Briefe des Kunstsammlers Antonie Rutgers an den Landgrafen Wilhelm VIII. von Hessen«, in: Oud Holland VIII (1890), S. 196-197) - Am 29. April 1738 ergänzt Antonie Rutgers: » [...] A l'éguard du Sophonisbe, du GUIDE, je l'ai deja chés moi, suivant le conseil que Monsieur VAN HOVEN m'a donné, et sera envoiée en meme tems: aussi je ne doute point ou Votre Altesse aura reçu depuis une Lettre à cet éguard. Cependant Monseigneur, j'ai l'honneur de Vous assurer que ce Tableau est de la derniere magnifisance, et de très grande Valeur: mais c'est la une chose que je croi bien faire de tenir secrette; et cela pour des raisons que Votre Altesse comprendra très bien, après avoir reçu la Lettre de Monsieur VAN HOVEN: meme je serois d'avis de ne rien faire paroitre de cela à Mr. VAN HOVEN meme; le lui dirai seulement, en termes generales, que c'est un bon Tableau, que je ne doute ou sera agréable à Votre Altesse, comme en ayant le Compagnon - car Monseigneur, la Dame de qui il vient, est du parentage de Monsieur VAN HOVEN: comme elle l'est aussi de moi, étant ma Cousine du coté de son Mary deffunt; mais non obstant cela, Votre Altesse peut ètre très sure que je traitrai la chose comme sudit, \& avec toute la circumspection possible.«
} 


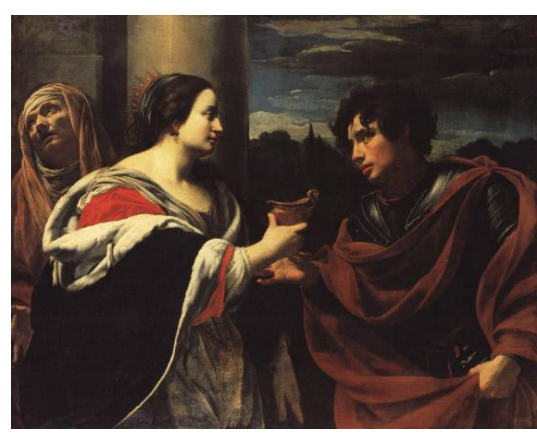

Abb. 36

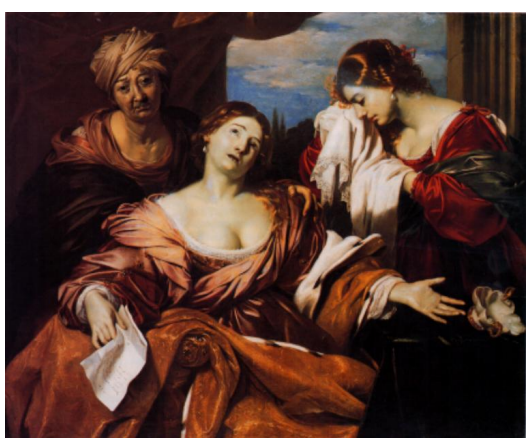

Abb. 37

Wunsch des Besitzers ein Pendant mit gleichem Sujet gesucht wurde. Beide Gemälde, die heute in Kassel leider nicht mehr als Gegenstücke gehängt sind, stellen als ınarrativer Pendants insofern eine bemerkenswerte Ausnahme dar, als die identische Szene mit verschiedener Akzentuierung dargestellt wird.

Bei Vouet empfängt Sophonisbe mit stoischer Gelassenheit den Giftbecher. Nur der erregte Blick der Dienerin im linken Hintergrund kontrastiert mit der Affektbeherrschung der Protagonistin. Régnier hat hingegen Emotionen und Affekte zum zentralen Thema seines Gemäldes gemacht: Die ältere Dienerin im linken Hintergrund schaut traurig, aber gefasst und nimmt Blickkontakt mit dem Betrachter auf. Die jüngere, rechts stehende Zofe weint; ihren verzweifelten Zustand unterstreicht ein übergroßes >Tränentuchı. Ein noch größeres emotives Spektrum zeigt Sophonisbe: die Giftschale entgleitet aus verzweifelter Schwäche der Linken, in der Rechten hält sie den die Ausweglosigkeit der Situation übermittelnden Brief Massinissas, der himmelnde Blick der Tugendheldin geht beinahe schon entrückt nach oben.

Dem Betrachter wird die gleiche Szene in durchaus verschiedenen Deutun-

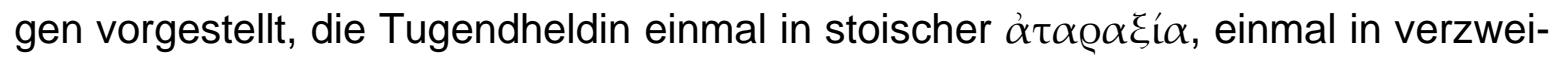

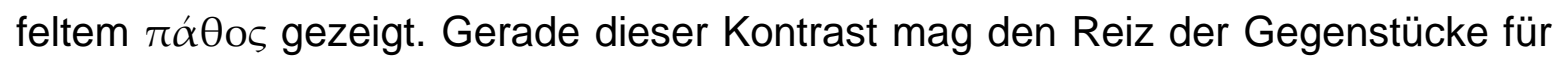
den Sammler gebildet haben. Wenn die Gemälde nebeneinander - wofür die durch Anstückungen angeglichenen Maße sprechen - oder zumindest in einem Raum gezeigt wurden, boten sie dem Betrachter zwei außergewöhnlich zugespitzte Inszenierungen des ıschönen Sterbensı einer profanen Tugendheldin. Er findet eine Version, in der der stoische Hintergrund des exemplum virtutis noch im Vordergrund steht, und eine andere, die den Akzent nicht mehr auf die Mäßigung, sondern auf den Ausdruck der Affekte legt. 
Die Tugendheldin als Selbstmörderin war ein Motiv, das sich zunächst an die aristokratischen Eliten des entstehenden frühneuzeitlichen Absolutismus richtete. Für die ikonographischen Wirkungsstrategien war es dabei durchaus von Belang, ob die Tugendheldinnen als Teil einer 'Galerie starker Frauen oder als Pendants konzipiert wurden. In den Galerien überwog der neustoisch gefärbte moralische Diskurs, während in den Pendants mehr und mehr die Affekte in den Vordergrund traten.

Insofern rücken die Bildprogramme von Galerien und Serien in erstaunliche Nähe zum frühneuzeitlichen Theater, dessen Leitthemen gloire und vertu ebenso auf den Ausgleich individueller und öffentlicher Interessen und damit auf Affektkontrolle ausgerichtet waren. Beide zunächst aristokratischen >Inszenierungsformen`, Theater und Bildprogramme, verbanden Unterhaltung mit höfischer Erziehung, solange der neustoische Hintergrund bewusst blieb. ${ }^{206}$ Mit seinem Verblassen zugunsten der Affektdarstellung bis hin zur bloßen ^Attitüdeく, einem Vorgang, der sich am deutlichsten in der Bühnengeschichte nachvollziehen lässt, tritt das Motiv der Selbstmörderin als Tugendheldin in seine abschließende Phase ein.

\footnotetext{
${ }^{206}$ Es ist kein Zufall, wenn Justus Lipsius in seinen Monita et exempla politica (1605) einen Katalog zusammenstellt (religio, conscientia, probitas, constantia, prudentia, tranquilitas, concordia, iustitia, clementia, fides, modestia, cultus, castitas, patientia, magnitudo animı), der gleichsam ein frühneuzeitliches Repertoire politischer Tugenden ist, zu dessen Illustration die Bildkünste und das Theater entscheidend beigetragen haben (Opera omnia, Bd. IV,1, Wesel 1675 [ND Hildesheim/Zürich/New York 2001]).
} 


\section{Von der vertu zum Affekt \\ Oper und Kantate, Monodrama und Attitüde}

\section{Affektmodellierung und moralischer Diskurs}

Stand in der frühneuzeitlichen Ikonographie der profanen Tugendheldinnen der sich an die Eliten des entstehenden Absolutismus richtende politisch-moralische Sinn im Vordergrund, konzentriert sich in der weiteren Entwicklung das Interesse auf die Affektmodellierung, während der moralische Diskurs allmählich in den Hintergrund tritt. Renis Bildformel des himmelnden Seelenblicks stellte bei seinen halbfigurigen Sophonisben ${ }^{1}$ ebenso wie bei seinem einfigurigen Typus der Lukretia $^{2}$ oder seinen Kleopatra-Darstellungen ${ }^{3}$ eingängige und affektiv ansprechende Bildprägungen zur Verfügung, die auch dann noch nachwirkten, als die ISehnsuchtshalbfiguren bereits ihren religiösen und neustoischen Hintergrund verloren hatten. ${ }^{4}$ Noch 1791 griff Angelika Kauffmann in ihrem Porträt der Fürstin Maria Santacroce auf den Typus einer zum Selbstmord entschlossenen Lukretia zurück, um ein dramatisch gefärbtes Rollenporträt zu inszenieren. Auch Dido und Kleopatra boten im 19. Jahrhundert weiterhin Vorlagen für Affektdarstellung und elegische Stimmung, wie andere Gemälde von Kauffmann (Dido), Böcklin (Kleopatra) oder Arthur (Kleopatra) verdeutlichen können. Selbst der in der Ikonographie eher selten ins Bild gesetzten Porzia nehmen sich romantische Maler wie Auvray und Caucig noch einmal an und betonen besonders aufopferungsvolle Gattenliebe. ${ }^{5}$

Diese ikonographische Entwicklung von der vertu zum Affekt findet sich nicht nur in der bildenden Kunst, sondern lässt sich auch in Oper und Kantate, Monodrama und Attitüde der späteren Neuzeit nachvollziehen. Die ikonographische Affektmodellierung, zunächst zur rhetorischen Hervorhebung des moralischen (oder religiösen) Diskurses entwickelt, weckt in der Attitüde nurmehr psychologisches Interesse. Damit verbunden tritt nicht nur ein Funktionswechsel der antikisierenden Referenz ein; der historische Hintergrund selbst verblasst wie in den von

\footnotetext{
${ }^{1}$ Vgl. S. $86 f$.

${ }^{2}$ Vgl. S. 131.

${ }^{3}$ Vgl. S. $157 f$

${ }^{4}$ Vgl. S. $216 f$.

${ }^{5}$ Vgl. oben S. 175.
} 


\section{Von der vertu zum Affekt}

Couperus $^{6}$ beschriebenen, illuminierten lebenden Bildern: Kleopatra repräsentiert jetzt den im Orientalismus des 19. Jahrhunderts gängigen Bildtypus einer femme fatale. Vergleichbares gilt für die Oper, die zunächst ebenfalls den Konflikt von Normen und Affekten aus der frühneuzeitlichen Tragödie übernommen hatte. Auch in ihrer Inszenierung der sstarken Frauenı verschwindet langsam der neustoische Hintergrund zugunsten der Affektkonturierung. Besonders evident ist dies in den Kammerkantaten.

Das Monodrama führt zu einer weiteren Affektüberzeichnung, manchmal geradezu zu einer Affektkonfusion. In der Attitüdenkunst dienen historische Reminiszenzen zur sukzessiven Darstellung von Gefühlskontrasten; manche dieser Inszenierungen von Sophonisbe, Kleopatra und Dido stehen schon an der Schwelle zum Varieté.

\section{Die Anfänge der Oper}

Die im letzten Jahrzehnt des 16. Jahrhunderts in Italien ausgebildete Oper ${ }^{7}$ blieb dem Sprechdrama und seinen Themen eng verbunden, auch wenn sich die Handlungsstruktur im Musiktheater tiefgreifend veränderte. Die neustoischen Tugendhelden und ihre Konflikte, die im Theaterrepertoire des 16. Jahrhunderts eine herausragende Rolle spielten, wurden in der neuen musikdramatischen Gattung allerdings nicht sogleich übernommen; die erste Librettisten und Komponisten griffen fast ausschließlich mythologische Themen auf. Als Vorwürfe erfreuten sich Orpheus und Eurydike sowie die Befreiung der Ariadne besonderer Beliebtheit. ${ }^{8}$ Rezitative übernahmen die Aufgabe, die Dramenhandlung voranzutreiben, während Arien den Protagonisten Gelegenheit boten, ihre inneren Konflikte ausführlich zum musikalischen Ausdruck zu bringen. Bereits der späte Claudio Monteverdi ${ }^{9}$ erweiterte aber das Repertoire und brachte 1642 mit seiner Incoronazione di Poppea einen historischen Stoff auf die Opernbühne. Damit erhob er das Musiktheater zu einer dem Drama ebenbürtigen Gattung, die nicht nur der gehobenen Unterhaltung diente, sondern sich auch am moralischen Diskurs beteiligte, den die neustoisch geprägte Bühne entwickelt hatte. Gleichwohl blieb für jede Opernhandlung der lieto fine $^{10}$ noch lange Zeit verbindlich und stellte die Librettisten vor die schwierige Aufgabe, historischen Vorwürfen ein glückliches Ende aufzwingen zu müssen. Auch waren italienische Opernhäuser - das erste wurde 1637 in Venedig eröffnet - von

\footnotetext{
${ }^{6}$ Vgl. oben, S. $12 \mathrm{ff}$.

${ }^{7}$ Abert, Anna Amalie: Oper, in: ${ }^{1}$ MGG 10, München 1989, $1 \mathrm{ff}$.

${ }^{8} \mathrm{Zu}$ den Themen der frühen Opern vgl. Koch, Klaus-Dietrich: Die Aeneis als Opernsujet, Dramaturgische Wandlungen vom Frühbarock bis zu Berlioz, Konstanz 1990, S. 86-89.

${ }^{9}$ Gier, Albert: Das Libretto, Theorie und Geschichte einer musikoliterarischen Gattung, Darmstadt 1998, besonders S. 41-55.

${ }^{10}$ Der Begriff wurde wahrscheinlich vom Librettisten Giacinto Cicognini in der ersten Hälfte des 17. Jahrhunderts geprägt (vgl. Seeger, Horst: Opernlexikon, Berlin ${ }^{4} 1988$, S. 384). Der Konvention des lieto fine folgend ließ noch 1805 Ferdinando Paer seine Sofonisba durch einen zweifelhaften Kunstgriff glücklich enden: Sophonisbe trinkt statt des Giftes eine ungefährliche Substanz und wird von Scipio begnadigt, den ihr Mut beeindruckt. Das zeitgenössische Publikum empfand diesen Ausgang der Handlung allerdings bereits als künstlich (vgl. Brzoska, Matthias: »Paer: Sofonisba«, in: Pipers Enzyklopädie des Musiktheaters, München 1991, Bd. 4, S. 626-627).
} 


\section{Von der vertu zum Affekt}

Anfang an als sich selbst tragende Einrichtungen organisiert und mussten in hohem Maß dem Publikumsgeschmack folgen. ${ }^{11}$

Die italienische Oper $^{12}$ erweiterte früh ihre Themenpalette und verzichtete allmählich auch auf das happy end. Sollte die Norm der Wahrscheinlichkeit beachtet werden, ließ sich den historischen Stoffen nicht immer eine glückliche Wendung geben, zumal einem Teil des Publikums der srichtige، Ausgang vertraut war. Auch wenn die neuere Opernforschung vor allem die unterschiedlichen Wirkungsstrategien von Theater und Oper ${ }^{13}$ hervorhebt, gilt doch für das Musiktheater der Frühen Neuzeit ebenso wie für das Sprechtheater, dass der »Konflikt zwischen Liebe und Politik (oder Ehre) « ${ }^{14}$ der handlungsmotivierende Antagonismus bleibt: nicht die äußere Handlung, sondern der innere Konflikt fesselte Zuschauer und Zuhörer. Pietro Metastasio bezeichnete den »contrasto di questi due universali principii delle operazioni umane, passione e raziocinio « als Fundament jeder Oper. ${ }^{15}$ In den theoretischen Diskursen wurden die dramaturgischen Verfahren bereits im 17. Jahrhundert unabhängig davon erörtert, ob vom Musik- oder vom Sprechtheater die Rede ist.

\section{Tugendheldinnen in der Oper}

Neben den üblichen griechischen und römischen Heroen eroberten auch Dido, Sophonisbe, Kleopatra und Lukretia rasch die opera seria und wurden zum Vorwurf vieler Libretti. ${ }^{16}$ Obwohl einschlägige Untersuchungen fehlen und ein gesicherter Überblick deshalb derzeit noch nicht zu erreichen ist, zeigen dies die bereits verfügbaren Aufführungsstatistiken. ${ }^{17}$ Didos Liebesgeschichte war 1641 das Thema der ersten, vom Publikum offensichtlich begeistert gefeierten venezianischen Oper; über hundert Opern griffen den Stoff in der Folge auf. ${ }^{18}$ Den zweiten Rang in der Beliebtheitsskala erreichte Kleopatra mit mehr als vierzig Opernbearbeitungen. Aber auch Sophonisbe übte auf Librettisten und Komponisten noch großen Reiz aus und erscheint in mindestens zwanzig musikalischen Versionen. Demgegenüber konnte das Thema der bedrohten Keuschheit das auf >Liebe und Politikı programmierte Opernpublikum zunächst nicht faszinieren und reichte für

\footnotetext{
${ }^{11}$ Im Gegensatz zu den italienischen Opernbühnen entwickelte sich die französische tragédie lyrique vorwiegend unter dem Einfluss des Hofes. Das höfisch-aristokratische Publikum in Versailles bevorzugte lange Zeit mythologische Themen und die Pastorale. Ebenso trugen die in Frankreich fast obligatorischen Balletteinlagen dem Hofgeschmack Rechnung.

12 Hierzu Gerhard, Anselm: "Rollenhierarchie und dramaturgische Hierarchien in der italienischen Oper des 18. Jahrhunderts «, in: Hortschansky, Klaus (Hrsg.): Opernheld und Opernheldin im 18. Jahrhundert, Aspekte der Librettoforschung, Ein Tagungsbericht, Hamburg 1991, S. 35-55.

${ }_{13}$ Dahlhaus, Carl: "Dramaturgie der italienischen Oper «, in: Geschichte der italienschen Oper, Bd. 6, Regensburg 1992, S. 75-178 (Italienische Ausgabe hrsg. von Lorenzo Bianconi / Giorgio Pestelli, Torino 1988).

${ }_{15}^{14}$ Dahlhaus, a.a.O., S. 87.

${ }^{15}$ Brief vom 10. Juni 1747 an Giuseppe Bettinelli (Metastasio, Pietro: Tutte le Opere, hrsg. von Bruno Brunelli, Milano 1951, Bd. 3, S. 307).

${ }^{16}$ Ein früher Beleg einer mehrstimmige Vertonung der Didonis novissima verba findet sich bereits in den 1538 mit einem Vorwort Martin Luthers gedruckten Sinfoniae iucundae atque adeo breves. Vgl. Herder, Johann Gottfried: Briefe zu Beförderung der Humanität, hrsg. von Irmscher, Hans Dietrich, Frankfurt am Main 1991 (Bibliothek deutscher Klassiker), S. 184 und Anm.

${ }_{17}$ Vgl. Stieger, Franz: Opernlexikon, Titelkatalog, 3 Bde, Tutzing 1975.

${ }^{18}$ Später gibt es auch Ballett-Bearbeitungen des Stoffes. Stieger, a.a.O., S. 324 und 326 hat für das 18. Jahrhundert in Mannheim, Turin und Petersburg, für das 19. Jahrhundert in Mailand Ballettinszenierungen nachgewiesen.
} 


\section{Von der vertu zum Affekt}

eine ergreifende und über mehrere Stunden tragende Bühnenhandlung wohl nicht aus. So lassen sich bisher weder Virginia noch Lukretia oder Camma auf den frühen Spielplänen nachweisen.

Nach der venezianischen Dido von 1641 setzte 1653 die Reihe der Kleopatra-Bearbeitungen ein. Lukretia und Sophonisbe traten erst zu Beginn des 18. Jahrhunderts in den Gesichtskreis der Librettisten. ${ }^{19}$ Andere ıstarke Frauen der römischen Geschichte wie Virginia ${ }^{20}$ und Camma $^{21}$ kamen erst als eigenartige ıSpätprodukte des ausgehenden 18. Jahrhunderts auf die Opernbühne, als das Publikum bereits einen gewissen Überdruss an den bekannten Stoffen zeigte und neue, entlegenere Themen begierig aufnahm, zumal wenn sie das sich entwickelnde Bedürfnis nach empfindsamen Inhalten befriedigten. Es fällt auf, dass der KleopatraStoff zwar seit der Mitte des 17. Jahrhunderts gelegentlich bearbeitet wurde, es aber erst im 19. Jahrhundert zu größerer Beliebtheit brachte, weil er das dem Zeitgeschmack entsprechende orientalische Kolorit bot. Aber auch Dido wurde im 18. Jahrhundert noch einmal zum Opern-Bestseller. ${ }^{22}$ Eine ähnlich steile Karriere machte etwa gleichzeitig der Sophonisbe-Stoff ${ }^{23}$.

Einige Rückschlüsse lässt auch der noch unvollständige erste Überblick zu: Dido, Kleopatra und Sophonisbe waren Themen mit vergleichbarem Erfolg auf der Sprech- wie auf der Musikbühne, die mit ihrer Arientechnik eine noch pointiertere Zuspitzung der Handlung verlangte. Der von der Tragödie ohnehin geforderte hohe Stand der Protagonistin erhöhte ihre Attraktivität für das Opernpublikum, das luxuriöse Ausstattung und umfängliche Statisterie bevorzugte. Anders als das Thema der bedrohten Keuschheit bei Figuren wie Lukretia, Virginia und Camma brachte

\footnotetext{
${ }^{19}$ Lukretia 1706 in Naumburg, Sophonisbe 1708 in Venedig.

${ }^{20}$ Virginia wird 1785 in Florenz das erste Mal auf die Bühne gebracht. Der Virginia-Stoff wird in mindestens siebzehn Opernfassungen aufgegriffen.

${ }^{21}$ Camma tötet den Tetrachen Synorix und sich selbst, als dieser sie nach der Ermordung ihres Ehemanns bedrängt. Insgesamt sind nur drei Bühnenbearbeitungen des Stoffs (ein Ballett, eine Oper und ein Drama) zu Beginn des 19. Jahrhunderts nachgewiesen.

${ }^{22}$ Von folgenden Komponisten (in zeitlicher Reihenfolge) sind Dido -Opern belegt: Francesco Cavalli (1641), Henry Purcell (1689), Henry Desmarest (1693), Christoph Graupner (1707), Domenico Sarro (1724), Tommaso Albinoni (1725), Thomas Augustine Arne (1734), Egidio Romualdo Duni (1739), Baldassare Galoppi (1740), Johann Adolf Hasse (1742), Antonio Aurisicchio (1745), Andrea Adolfati (1747), Niccolò Jommelli (1747), Ferdinando Bretoni (1748), Pietro Chiarini (1748), Andrea Bernasconi (1751), Ignazio Fiorillo (1751), Vincenzo Legrenzio Ciampi (1754), Giovanni Andrea Fioroni (1755), Tommaso Traetta (1757), Pietro A. Auletta (1759), Antonio Ferradini (1760), Antonio Boroni (1768), Ignazio Celoniati (1769), Giacomo Insanguine ([gen.Monopoli] 1770), Giuseppe Colla (1773), Pasquale Anfossi (1774), Joseph Haydn (1776), Gennaro Astarita (1780), Nicola Piccinni (1783), Gaetano Andreozzi (1784), Giuseppe Gazzaniga (1787), Leopold Koželuh (1795), Franz Danzi (1811), Bernhard Klein (1823), Davorin Jenko (1892). Zur ersten Bearbeitung des Dido-Stoffes durch Francesco Cavalli (1602-1676), der den Text von Giovanni Francesco Busenello zugrunde legte, vgl. Koch, Klaus-Dietrich: Die Aeneis als Opernsujet, Dramaturgische Wandlungen vom Frühbarock bis zu Berlioz, Kons$\operatorname{tanz} 1990$, S. 27-33.

${ }^{23}$ Vgl. oben S. $76 f$.
} 


\section{Von der vertu zum Affekt}

die Kombination von `Privatem nisbe den Antagonismus hervor, der ein ganzes Drama oder eine Oper hindurch trug. Entsprechende Beachtung fanden diese Tugendheldinnen gleichzeitig auch in der Historienmalerei, in der allerdings, anders als auf der Bühne, auch Lukretia häufig dargestellt wurde. Die Darstellung der sich selbst behauptenden Tugend war wohl, verbunden mit den Reizen einer entblößten jungen Frau, im Bild attraktiver als auf der Bühne.

\section{Didone abbandonata}

Offensichtlich bot unter den in dieser Untersuchung thematischen ıSelbstmörderinnen als Tugendheldinnen` Dido eine Verknüpfung von Liebe und Politik, die Librettisten und Komponisten ebenso wie bildende Künstler und ihre Auftraggeber lange interessierte. Deshalb ist es auch unter kunsthistorischen Fragestellungen von Interesse, die Entwicklung Didos als Opernfigur an zwei Beispielen darzustellen. Ich wähle dafür die erste überlieferte Oper dieses Themas von Francesco Cavalli (1602-1676) und die spätere Fassungen von Domenico Natale Sarro (1679-1744) und Leonardo Vinci (um 1690-1730), die ein Libretto Metastasios vertonten. Zwischen den Aufführungsdaten 1641 und 1724/1726 verschob sich das Interesse des Publikums vom historischen Stoff, den Busenello für Cavalli umständlich aufbereitete, zur Affektdarstellung, in der Metastasio brillierte; nicht zufällig gilt sein Libretto als das erfolgreichste in der Operngeschichte überhaupt. ${ }^{24}$ Auch in der Oper verschob sich das Interesse vom moralischen Diskurs zur Affektmodellierung.

La Didone ${ }^{25}$ von Francesco Cavalli wurde zum ersten Mal im Karneval 1641 im Teatro di S. Cassiano aufgeführt. Für die erste Opernbearbeitung des Stoffes lieferte Giovanni Francesco Busenello ${ }^{26}$ die Textvorlage.

Ein Prolog Fortunas (oder der Götterbotin Iride ${ }^{27}$ ) führt den Fall Trojas auf das Eingreifen der gekränkten Giunone zurück. Der erste Akt spielt in Troja. Als Pirro versucht, Cassandra aus dem Tempel zu schleppen; tötet er im Zweikampf Corebo und wird selbst verletzt. Auf Befehl der Venere flieht Enea mit Vater und Sohn aus der brennenden Stadt, seine Gattin Creusa wird tödlich verletzt. Ecuba und

\footnotetext{
${ }^{24}$ Zu Metastasio vgl. Kimbell, David: Italian Opera, Cambridge 1991, S. 192-205.

${ }^{25}$ Das Libretto verfasste Giovanni Francesco Busenello; vgl. Osthoff, Wolfgang: „Francesco Cavalli«, in: Pipers Enzyklopädie des Musiktheaters, Bd. 1, München / Zürich 1986, S. 514f.

${ }^{26}$ Zu Giovanni Francesco Busenello (1598-1659), einem der Wegbereiter der venezianischen Oper, vgl. Janke, Pia: Dramaturgie der Leidenschaften, Libretti aus vier Jahrhunderten, Wien 2000, S. 13-22. Der venezianische Humanist verfasste als Mitglied verschiedener Akademien neben drei Libretti für Francesco Cavalli und einem für Monteverdi ( $L$ 'incoronazione di Poppea) Oden, Sonette, Romanzen, aber auch lateinische laudationes und Gedichte im venezianischen Dialekt.

${ }_{27}$ Die Textüberlieferung ist nicht eindeutig.
} 


\section{Von der vertu zum Affekt}

Cassandra beweinen den Untergang Trojas; der Grieche Sinon verspottet die Trojaner. Der Schatten der Creusa verspricht Ascanio die Herrschaft über Italien. Venere bittet Fortuna, Enea in das verheißene Land zu führen. Der zweite Akt spielt bereits in Karthago, wo Giunone und der Sturmgott Eolo das Schiff des Enea stranden lassen. Didone, noch immer ihrem Mann Sicheo nachtrauernd, verweigert die Heirat mit larba und berichtet ihrer Schwester Anna einen Unheil verkündenden Traum. In der Gestalt des Ascanio trifft Amore mit seinem Pfeil Didone; sie empfindet sogleich tiefe Liebe zu Enea, dem Venere in Gestalt einer Nymphe Hilfe verspricht. Drei Hofdamen kommentieren die Verliebtheit der Königin; der eifersüchtige Mitbewerber larba fällt in Wahnsinn. Im d ritte $n$ Akt rät Anna der Schwester, eine Jagd als Anlass zu nehmen, ihren Gefühlen für Enea nachzugeben. Die Hofdamen treiben mit dem wahnsinnigen larba ihren Spott; ein Jägerchor beschreibt die Jagd, das hereinbrechende Gewitter und die Liebesszene in einer Höhle. Mercurio befiehlt den Aufbruch nach Italien; vergebens versucht die vor Schmerz in Ohnmacht fallende Didone Enea zurückzuhalten. Der Schatten des verstorbenen Ehemannes wirft ihr ihre Untreue vor. Die Hofdamen kommentieren den Aufbruch der Trojaner und die Verzweiflung der Königin, während Mercurio den Mitbewerber gesunden lässt. Das Ende ist freilich überraschend: larba verhindert Didones Selbstmord und heiratet die von Enea Verlassene.

Cavalli und sein Librettist Busenello übernehmen die Vorlage Vergils in bemerkenswerter Stoff-Fülle. Das Libretto stellt, hierin an die mythologischen Themen der ersten Opern des beginnenden Seicento erinnernd, ausführlich das Eingreifen der Götter dar, als deren bloßer Spielball alle handelnden Personen erscheinen. Erst im letzten Akt tritt die Affäre zwischen Enea und Didone in den Mittelpunkt. Allerdings werden Didone und Enea nicht als Liebespaar gezeigt; die Liebesszene selbst wird nur indirekt vom Chor geschildert. Im Mittelpunkt stehen so nicht die Affekte der Liebenden, sondern das Eingreifen der Götter in die menschlichen Belange und die Verheißung Italiens (»imperio d' Italia, anzi del mondo«). Dramatisch verkündet Mercurio den Ratschluss des Göttervaters, auf den Enea gelassen und gehorsam reagiert; gegen die Verzweiflung Didones setzt er seine welthistorische Rolle. Die Opernhandlung verbindet Heroisches mit Komischem: Zwei LamentoSzenen (für Cassandra und Ecuba) und zwei Ombra-Szenen (für Creusa und Sicheo) kontrastieren mit komischen, an das elisabethanische Theater erinnernden und auf die opera buffa ${ }^{28}$ vorausweisenden Szenen. So unterbrechen sowohl der in Troja zurückgebliebene Grieche Sinon als auch die mehrfach auftretenden Hofdamen in Possenszenen den Spannungsbogen. ${ }^{29}$ Hervorzuheben ist, dass Busenello das dramatische Ende der Vergilischen Dido-Episode nicht zu übernehmen

\footnotetext{
${ }^{28}$ Diese heitere Opernvariante gibt es erst im 18. Jahrhundert; vgl. Schmierer, Elisabeth: Kleine Geschichte der Oper, Stuttgart 2001, S. 27.

${ }_{29}$ Zur musikalischen Zeichnung der Protagonisten und zu ihrem Tonumfang vgl. Schulze, Hendrik: Odysseus in Venedig, Sujetwahl und Rollenkonzeption in der venezianischen Oper des 17. Jahrhunderts, Frankfurt/Main 2004, S. 221-236.
} 


\section{Von der vertu zum Affekt}

wagte, sondern einen lieto fine konstruierte, der den Selbstmord Didos durch eine Heirat ersetzte. ${ }^{30}$

Erst Pietro Metastasio (1698-1782) scheint, wohl unter dem Einfluss des klassizistischen französischen Theaters, auch auf der Opernbühne das tragische Ende zugelassen zu haben. Das Dido-Libretto war sein erfolgreichstes Bühnenwerk; von Domenico Sarro ${ }^{31} 1724$ vertont, wurde das Libretto sogleich von Leonardo Vinci (1726), danach von weit über sechzig Komponisten aufgegriffen, die bis ins 19. Jahrhundert im Text Metastasios eine Erfolg versprechende Vorlage fanden. ${ }^{32}$ In seiner Didone abbandonata wagte es Metastasio nicht nur als erster, in der ultima scena der Oper das tragische Ende der Dido beizubehalten, sondern ließ die Königin sogar - ein weiterer Tabubruch - auf der Bühne sterben.

Auch in den späteren Libretti ${ }^{33}$ Metastasios, Catone in Utica (1727) und Attilio Regolo (1750), sterben die Titelhelden am Ende. Dass ein tragischer Schlussakt für die Seh- und Hörgewohnheiten der zeitgenössischen Zuschauer ungewohnt und anstößig war, zeigen mehrere Umarbeitungen der letzten Szenen dieser drei Libretti: Für eine Aufführung der Didone abbandonata in Madrid fügte Metastasio 1751 dem Libretto von 1724 eine licenza an, die mit dem Auftreten Neptuns ${ }^{34}$ den Selbstmord Didos entschärft und in einen mythologischen Zusammenhang einordnet. Der letzte Eindruck des Opernbesuchers ist nun nicht mehr der Flammentod

\footnotetext{
30 Die Oper wurde 1998 mit Thomas Hengelbrock als Dirigenten, dem Balthasar-Neumann-Ensemble und Yvonne Kenny in der Titelrolle wieder aufgeführt (Deutsche Harmonia Mundi 0547277354 2). Allerdings hat der lieto fine Thomas Hengelbrock so sehr gestört, dass er inn dem Publikum seiner Neuinszenierung der Barockoper nicht zumuten wollte: »Für eine Auslassung allerdings müssen wir des geneigten Hörers Nachsicht erbitten: Selten hat uns ein >lieto finer in einer Barockoper gestört, weil wir stets in ihr die Welt im Spiel aufgehoben sahen. Wenn aber in dieser bestürzenden Tragödie, deren Wirren Aeneas die Menschlichkeit, Jarbas den Verstand und Didone fast das Leben gekostet haben, schlussendlich - und wirklich wie aus heiterem (?!) Himmel - eine Hochzeit zwischen Jarbas und Didone anberaumt wird, wollen wir zu selbiger diesmal nicht aufspielen. « (Booklet, S. 18) Galt Busenello und Cavalli das tragische Ende Didos als anstößig, provoziert nunmehr der lieto fine den modernen Regisseur.

${ }^{31}$ Domenico Natale Sarro (1679-1744) wird in der Literatur auch häufig als »Sarri« geführt. Seine Dido-Oper wurde am 5. Februar 1724 im Teatro San Bartolomeo in Neapel uraufgeführt.

${ }^{32}$ Domenico Sarro (1724), Domenico Scarlatti (1724), Tomaso Albinoni (1725), Leonardo Vinci (1726), Geminiano Giacomelli (1728), Gaetano Maria Schiassi (1735), Georg Friedrich Händel (1736), Giuseppe Ferdinando Brivio (1739), Giovan Battista Lampugnani (1739), Andrea Bernasconi (1739), Egidio Romualdo Duni (1740), Baldassare Galuppi (1741), Rinaldo da Capua (1741), Nicola Porpora (1741), Johann Adolf Hasse (1742), Antonio Caputi (1745), Nicola Jomelli (1747), Andrea Aldofati (1747), Paolo Scalabrini (1747), Ferdinando Bertoni (1748), Domenico Terradellas (1750), Gennaro Manna (1751), Ignazio Fiorillo (1751), Davide Perez (1751), Antonio Mazzoni (1752), Giuseppe Bonno (1752), Giuseppe Scolari (1752), Vincenzo Legrenzio Ciampi (1754), Giovanni Andrea Fioroni (1755), Pietro Chiarini (1756), Andrea Bernasconi (1756), Tomaso Traetta (1757), Francesco Araia (1758), Antonio Ferradini (1760), Giuseppe Sarti (1762), Johann Gottfried Schwanberg (1765), Francesco Zanetti (1766), Gianfrancesco De Maio (1769), Antonio Sacchini (1769), Ignazio Coloniat (1769), Nicola Piccinni (1770), Giacomo Insanguine (1770), Michele Mortellari (1771), Giuseppe Colla (1773), Domenico Mombelli (1775), Pasquale Anfossi (1775), Giuseppe Schuster (1776), Bernardino Ottani (1780), Francesco Piticchio (1780), Alessio Prati (1783), Gaetano Andreozzi (1784), Giuseppe Antonio Capuzzi (1786), Pietro Alessandro Guglielmi (1786), Giuseppe Gazzaniga (1787), Luigi Cherubini (1787), Vincenzo Federici (1794), Giovanni Paisiello (1794), Leopold Koželuh (1795), Settimio Marino (1799), Valentino Fioravanti (1810), Ferdinando Paer (1811), Karl Reissiger (1823), Bernhard Klein (1823), Saverio Mercadante (1823).

${ }^{33}$ Vgl. Gerhard, Anselm: »Rollenhierarchie und dramaturgische Hierarchien in der italienischen Oper « in Opernheld und Opernheldin im 18. Jahrhundert, hrsg. von Klaus Hortschansky, Hamburg / Eisenach 1991, S. 35-55 (hier S. 40).

${ }^{34}$ Vgl. Koch, Klaus-Dietrich: Die Aeneis als Opernsujet, Dramaturgische Wandlungen vom Frühbarock bis zu Berlioz, Konstanz 1990, S. 42-43.
} 


\section{Von der vertu zum Affekt}

Didos; vielmehr löscht das Meer die brennenden Ruinen Karthagos, während der Meeresgott die entfesselten Elemente beruhigt. Fand in der ersten Fassung des Catone in Utica der Selbstmord des Protagonisten ${ }^{35}$ noch auf der Bühne statt, verlegt bereits die Überarbeitung die Szene hinter die Bühne und lässt sie von Emilia, der Witwe des Pompejus, berichten. ${ }^{36}$ Cato schleppt sich sterbend auf die Bühne, während die Schlussarie in resignativer Melancholie ausgerechnet von seinem Todfeind Cäsar gesungen wird. Im Spätwerk Attilio Regolo verzichtet Attilio in der ultima scena zum Wohl der Republik auf seine Freiheit und erwartet in karthagischer Gefangenschaft den Tod. Die Bühnenhandlung beendet aber der von Metastasio selbst als "parte necessarissima della catastrofe ${ }^{37}$ bezeichnete Chor. Ein neues Modell des Opernschlusses bildet sich heraus, das den Chor die affetti der handelnden Personen kommentieren und als allgemein gültiges exemplum in größere Zusammenhänge einordnen lässt. Die Handlungslogik tritt demgegenüber zurück.

Die von Metastasio entwickelte opera seria ${ }^{38}$ beseitigt den lieto fine, reduziert die handelnden Personen radikal und konzentriert die Handlung auf einen zentralen Konflikt. Die Didone abbandonata ${ }^{39}$ kommt, im Gegensatz zur Stoff- und Personenfülle bei Busenello und Cavalli, mit sechs statt vierundzwanzig handelnden Personen aus und entwickelt ein neues Intrigenschema. Neben Didone und Enea treten Osmida als Vertrauter der Didone und Araspe als Vertrauter des larba auf; beide wechseln im Verlauf der Handlung die Seite. Die Schwester Didones, die bei Vergil keine selbständige Rolle spielt, erhält unter dem Namen Selene (statt Anna) eine völlig neue Rolle als zweite Liebhaberin. Das Intrigenschema bietet beiden Protagonisten affektive Alternativen: Didone wird von Enea und larba, Enea von Didone und Selene geliebt.

Enea kann sich im ersten Akt nicht dazu entschließen, Didone von seinem bevorstehenden Aufbruch zu unterrichten. In der Gestalt seines eigenen Gesandten wirbt larba um die inn abweisende Didone. Osmida, der Vertraute Didones, macht sich selbst Hoffnungen auf den Thron und unterstützt deshalb larbas Rachepläne gegen Enea, obwohl Araspe, der Vertraute larbas, Einwände erhebt. Nach einem Streit im Palasthof will larba Enea im Tempel des Neptun ermorden; der Anschlag wird von Araspe verhindert. Erst jetzt kündigt Enea Didone seinen bevorstehenden

\footnotetext{
${ }^{35}$ Siehe Metastasio, Pietro: Tutte le Opere, Bd. 1, a.a.O., S. 1404: »in atto di uccidersi «.

${ }^{36}$ Durch die Literatur (so z. B. bei Gerhard, Anselm in: »Rollenhierarchie und dramaturgische Hierarchien in der italienischen Oper«, a.a.O., S. 41) schleppt sich die irrtümliche Behauptung, die Tochter Marzia berichte den Selbstmord. Ein Blick in den Text Metastasios (III, 11) hätte eines anderen belehren können: "Emilia (ad Arbace): Principe, aita! / Arbace: Che fu? / Emilia: Muore Catone. / Fulvio: E chi l'uccide? / Emilia: Si feri di sua mano. (Metastasio: Tutte le Opere, Bd. 1, a.a.O., S. 185)

37 Brief an Johann Adolf Hasse vom 20. Oktober 1749 (Metastasio, Pietro: Tutte le Opere, hrsg. von Bruno Brunelli, Milano 1951, Bd. 3, S. 435).

${ }^{38} \mathrm{Im}$ Gegensatz zu der im 17. Jahrhundert allmählich zum bunten Spektakel verwilderten italienischen Oper orientiert sich Metastasios opera seria an den Regeln der klassizistischen französischen Tragödie, reduziert das Personal auf (meist) sechs Sänger, begrenzt die Handlung auf drei Akte (mit höchstens 15 Szenen) und gliedert klar in Rezitative und Arien (vgl. Schmierer, a.a.O., S. 37ff.). Die Arientexte sind bei Metastasio meist Stanzen, die sich in zwei Teile von je vier Versen mit abgeschlossener syntaktischer Struktur gliedern, deren erster in der musikalischen Fassung wiederholt werden kann. Die Rezitativtexte sind metrisch variabler; oft von beträchtlicher Länge, wechseln sie Versarten und Rhythmen. Bei den meisten Komponisten werden sie seit 1650 als recitativi secchi nur vom Cembalo und eventuell einem anderen Generalbassinstrument (Cello, Fagott oder Bassgambe) begleitet. (Vgl. dazu Koch, Klaus-Dietrich: Die Aeneis als Opernsujet, Dramaturgische Wandlungen vom Frühbarock bis zu Berlioz, Konstanz 1990, S. 94-96.)

${ }^{39}$ Metastasio, Pietro: Tutte le Opere, hrsg. von Bruno Brunelli, Milano 1953, Bd. 1, S. 1-66
} 


\section{Von der vertu zum Affekt}

Aufbruch an. Trotz seiner Skrupel gibt er den Bitten Didones nicht nach. - Im zweiten Akt wirbt Araspe vergeblich um Didones Schwester Selene, die ihrerseits Enea liebt. Didone verurteilt larba zum Tode, lässt sich aber von Enea umstimmen. Der unglückliche Bewerber erfährt von seinem Konkurrenten, dass er inm sein Leben verdankt. An seiner Stelle fordert Araspe Enea zum Duell; Selene verhindert den Kampf, gesteht dabei aber Enea unabsichtlich ihre Liebe. Um die Eifersucht des Enea zu provozieren, kündigt Didone nun an, larba doch heiraten zu wollen. Als Enea bestürzt davoneilt, nimmt sie ihr Heiratsversprechen allerdings sofort zurück und kränkt damit erneut larba. - Im dritten Akt wird der sich gerade einschiffende Enea von larba und seinen Leuten überfallen. Enea entscheidet den Kampf für sich und schenkt larba zum zweiten Mal das Leben. Um sich an Didone zu rächen, will larba nun Osmida umbringen, was Enea vereitelt. Auch Enea und Selene treffen noch einmal zusammen; ein offenes Liebesgeständnis beschleunigt nur den Aufbruch des Helden. Inzwischen hat larba Karthago in Brand stecken lassen. Osmida, Selene und Araspe können die Königin nicht zur Flucht bewegen, obwohl larba ihr erneut die Ehe anbietet. Didone muss erkennen, dass Osmida sie hintergeht und dass auch ihre Schwester Enea liebt. Während sich die Königin in die Flammen stürzt, fliehen alle aus dem brennenden Karthago.

Bereits in ihrer ersten Arie $(1,5)$ formuliert die Protagonistin mit »son regina e sono amante « ihr Dilemma, auch wenn sie noch glaubt, die Rolle der Herrscherin und die Rolle der Liebenden miteinander vereinbaren zu können. Entsprechend formuliert Enea den ihn umtreibenden Konflikt: » Fra il dovere e l'affetto / ancor dubbioso in petto / ondeggia il core.« (II,7) Dass das fatum Enea nötigen wird, Didone zu verlassen, steht schon in der ersten Szene fest. In der Anlage des Librettos ist eine Symmetrie zu erkennen: Die prima donna Didone ist zunächst selbstsicher und am Ende verzweifelt, der primo uomo Enea hingegen tritt zu Beginn der Oper unsicher und zögerlich, bei der Abfahrt entschlossen und selbstbewusst auf. ${ }^{40}$ Diese chiastische Struktur, die Didone anfangs optimistisch und im Hochgefühl ihrer Liebe, Enea zweifelnd und in Angst vor der bevorstehenden Entscheidung zeigt, reicht bis in die Wortwahl des Libretto. So kommt die emotionale Zerrissenheit des Enea beim seinem ersten Auftreten in Halbsätzen, Anakoluthen und Aposiopesen zum Ausdruck:

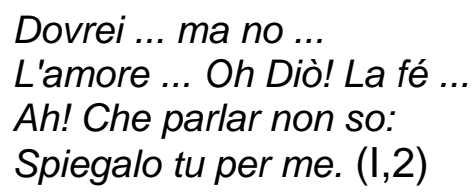

In vergleichbar verstümmelter Syntax stammelt Didone am Ende der Opernhandlung ihre Verzweiflung, bevor sie sich in den Tod stürzt.

\footnotetext{
${ }^{40}$ Gerhard, Anselm: "Rollenhierarchie und dramaturgische Hierarchien in der italienischen Oper «, a.a.O., S. $50 \mathrm{ff}$.
} 


\section{Von der vertu zum Affekt}

Diese Umkehrung der Affekte wurde auch von den Komponisten aufgegriffen. ${ }^{41}$ So hat Leonardo Vinci in seiner Vertonung Enea nur einen verkleinerten Tonartenbereich zwischen B-Dur und G-Dur zugewiesen, der seiner Rolle in der Oper gerecht wird, aber auch die reduzierten Affekte des Trojaners musikalisch umsetzt. Didone hingegen erhält bei Vinci einen erweiterten Tonartenbereich von Es-Dur bis zu c-moll, dessen musikalische Fülle ihre führende Stellung in der Rollenhierarchie unterstreicht und die Bandbreite der von ihr ausgedrückten Affekte widerspiegelt.

Obwohl das Libretto Metastasios von der Dramaturgie des klassizistischen französischen Theaters geprägt ist, darf es nicht als Dramentext ${ }^{42}$ missverstanden werden, der mit Musik zu >unterlegen८ ist: „Die Oper ist kein defizienter Modus des Schauspiels «. ${ }^{43}$ Während die aufeinander folgenden Szenen des Dramas, aber auch des Libretto handlungslogisch miteinander verknüpft sind, wird in der musikalischen Umsetzung jede einzelne Szene zur »reine[n] Gegenwart «" ${ }^{44}$, die sich ausschließlich auf die bewusst zuspitzten Affekte der auftretenden Person konzentriert. Diese vom Libretto durchaus vorgegebene und intendierte Isolierung der Arien hält den Affekt in der Bühnengegenwart fest und hebt vorübergehend die Handlungslogik des Dramas auf. Im Gegensatz zum klassizistischen Theater (und damit auch zur Handlungslogik des Libretto) ist die Wirkungsstrategie der opera seria nicht auf Affektkontrolle, sondern vielmehr auf möglichst ausdrucksvolle und komplexe Präsentation von Affekten ausgerichtet. ${ }^{45}$

Es geht in der Oper nicht wie im klassizistischen Theater um Charaktere und ihre Entwicklungsmöglichkeiten in einem unauflösbaren Konflikt ${ }^{46}$, sondern um

\footnotetext{
${ }^{41}$ Zu musikalischen Verfahren sei besonders hingewiesen auf Strohm, Reinhard: Die italienische Oper im 18. Jahrhundert, Wilhelmshaven 1979, S. 171-187.

${ }^{42}$ Zwar ist von den Libretti Metastasios bekannt, dass sie auch als Lesedramen gedruckt und verbreitet waren (vgl. Dahlhaus, Carl: » Dramaturgie der italienischen Oper «, in: Geschichte der italienischen Oper, Theorien und Techniken, Bilder und Mythen, Bd. 6, Regensburg 1992, S. 75-178, hier: S. 99), doch sind ihre Wirkungsstrategien ganz auf die musikalische Umsetzung ausgerichtet.

${ }^{43}$ Dahlhaus, Carl: »Dramaturgie der italienischen Oper«, in: Geschichte der italienischen Oper, Theorien und Techniken, Bilder und Mythen, a.a.O., S. 104.

${ }^{44}$ Dahlhaus, Carl: »Dramaturgie der italienischen Oper«, a.a.O., S. 78.

45 Deshalb ist Albert Gier zu widersprechen, wenn er behauptet, der "Zweck der Arie « bei Metastasio sei »nicht Affektdarstellung, sondern Affektkontrolle «. In der, vom Libretto durchaus vorbereiteten, musikalischen Umsetzung geht es, der zeitgenössischen Historienmalerei entsprechend, gerade nicht um Affektkontrolle, sondern vielmehr um die breite Darstellung von Affekten (Gier, Albert: Das Libretto, Theorie und Geschichte einer musikoliterarischen Gattung, Darmstadt 1998, hier S. 70). Gier überträgt die Wirkungsstrategie des klassizistischen französischen Theaters (Affektkontrolle) auf die ganz auf Affektdarstellung abhebende italienische Oper des beginnenden 18. Jahrhunderts.

${ }^{46} \mathrm{Da}$ Gier nach den Normen des französischen klassischen Theater urteilt, unterliegt er hier einem Irrtum und kommt zu einer falschen Bewertung der Oper.
} 


\section{Von der vertu zum Affekt}

»stazioni sentimentali « ${ }^{47}$, die Darstellung von extremen Affekten. Hierin berührt sich die Ästhetik der opera seria durchaus mit der Affektkonturierung in der gleichzeitigen Historienmalerei, wie sie Le Brun in seinem Traktat Expression des passions de l'âme formuliert hat. ${ }^{48}$ Zur Operntechnik, möglichst abwechslungsreiche und kontrastive Affektinszenierungen zu zeigen, gehört die sich immer stärker durchsetzende Abgangsarie, bei der die Sänger nach der ausdrucksvollen Schilderung ihrer Affekte abtreten und so beim Zuschauer den Eindruck eines absoluten Affekts hinterlassen.

Die musikalische Affektkonturierung findet so in der ultima scena ihren Höhepunkt, in der Metastasio das Sterben Didos eindrucksvoll inszeniert, ein Schlussbild, auf das hin die ganze Opernhandlung angelegt ist. Die abschließende Szene der Didone abbandonata präsentiert nicht nur ein eindrucksvolles Finale, zu dem übrigens Zuschauer ${ }^{49}$ unentgeltlich eingelassen wurden, um sie zu künftigen Opernbesuchen zu animieren, sondern erinnert nicht zufällig auch an die Affektdarstellung der Historienmalerei des 18. Jahrhunderts, die vor allem in den einfigurigen Varianten ebenfalls isolierte Affekte darstellte, mit Folgen bis zur Attitüdenkunst des beginnenden 19. Jahrhunderts. ${ }^{50}$

Metastasio schildert in der Tiefenstruktur seines Libretto den psychologischen Prozess einer gänzlichen Vereinsamung, in der alle Verletzungen gleichwertig werden. Der Aufbau des Libretto beruht auf dem immer wieder verzögerten Aufbruch des Enea und der sich stets steigernden Vereinsamung der Didone bis zum Schlussbild, das die Königin in völliger Isolation zeigt: sola, tradita, abbandonata (III,17). Sie verliert alle Vertrauten: Enea mi lascia, trovo Selene infida, larba $m^{\prime}$ insulta, e mi tradisce Osmida (III,20). Ohne Dialogpartner ist die Schlussarie nurmehr ein stammelndes Selbstgespräch, das Verzweiflung (furore) als letzten und absoluten Affekt zum Ausdruck bringt:

Ah che dissi, infelice! A qual eccesso mi trasse il mio furore?

Oh dio, cresce l'orrore! Ovunque io miro, mi vien la morte e lo spavento in faccia: trema la reggia e di cader minaccia.

Selene, Osmida! Ah! tutti,

\footnotetext{
${ }^{47}$ Ferroni, Giulio in: Storia della letteratura italiana, 4 Bde, Milano ${ }^{2} 1992$, Bd. 2, S. 380.

${ }^{48} \mathrm{Vgl}$. oben S. 90.

49 Die ultima scena fasste die Handlungs-und Affektstruktur der Oper zusammen und warb damit beim potentiellen Publikum: Gottdang, Andrea: Venedigs antike Helden, Die Darstellung der antiken Geschichte in der venezianischen Malerei von 1680 bis 1760, München 1999, S. 160.

${ }^{50}$ Vgl. oben S. 219.
} 


\section{Von der vertu zum Affekt}

tutti cedeste alla mia sorte infida:

non v'è chi mi soccorra, o chi m'uccida.

Das ungewöhnlicherweise die Oper abschließende Rezitativ zeigt durch Suchen nach Worten und durch Abbrechen begonnener Satzstrukturen die verstummende Heldin, deren Sprachverlust ihr Sterben vorwegnimmt:

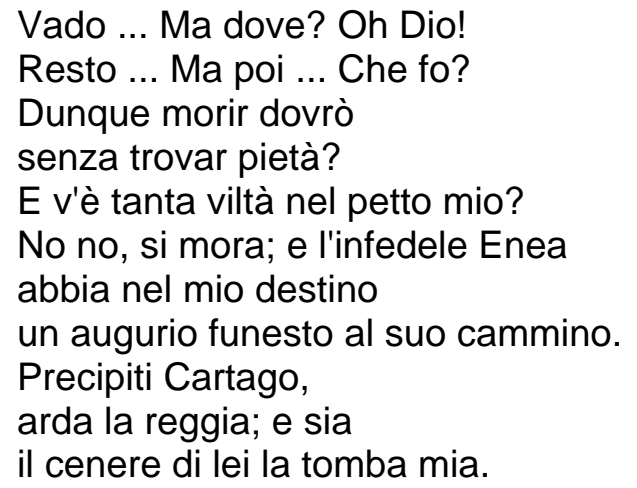

Vinci hat die letzte Arie zurückhaltend instrumentiert und einen deutlichen Kontrast zum abschließenden Rezitativ gesetzt, in dem Didone, sich selbst bereits entfremdet, in der dritten Person spricht. Didone verstummt, während die letzten Worte im forte der Instrumente untergehen. Der Sturz der Königin in die brennenden Ruinen Karthagos verbildlicht in der Oper nurmehr die Selbstaufgabe der Vereinsamten. ${ }^{51}$ Wie in einem großen Historiengemälde zeigt das Schlussbild die Königin verlassen und verzweifelt in großer Geste den Selbstmord suchend.

Von Busenello zu Metastasio hat sich die Struktur der Didone-Libretti vom breiten historischen Gemälde zum psychologischen Drama verschoben, eine Entwicklung, die sich durchaus mit der Entwicklung des Motivs in der Historienmalerei vergleichen lässt. Auch in der bildenden Kunst wird zugunsten der Darstellung des Affekts allmählich, jedenfalls teilweise, auf die historische Staffage verzichtet. In der Oper wie in der Historienmalerei schwindet langsam der neustoische Hintergrund, der das Thema in der Frühen Neuzeit geprägt hatte. ${ }^{52}$ Didos Selbstmord gilt

\footnotetext{
51 So auch Schreiber, Ulrich: Opernführer für Fortgeschrittene, Eine Geschichte des Musiktheaters, Kassel 1988, S. 275.

${ }^{52}$ Die Dido abbandonata scheint im Übrigen eine interessante Wirkungsgeschichte gehabt zu haben. Am Endes des 18. Jahrhunderts war sie so populär geworden, dass sie zur Marktunterhaltung im venezianischen Karneval dienen konnte, wie der weimarische Sänger David Heinrich Grave 1789 berichtet, der mit Unterstützung der Herzoginmutter zu Studienzwecken nach Venedig gereist war und sich später der Bildungsreise Anna Amalias anschloss: "Je mehr sich die Fasten näherten, desto glänzender und lustiger wurde die Stadt, viele tausend Menschen in Maschera erfüllten den Markusplatz, das Meeresufer und die Hauptstraßen. Nächstdem, dass sieben Theater offen und täglich zum Erdrücken voll waren, sah man noch eine menge Casotti oder kleine Theater auf dem Markusplatz, darin Seiltänzer, extemporierte Komödien. In Wachs bossierte anatomische Körper, das tragische Ende der Dido abbandonata mit allen ihren Kammerweibern, Schattenspiele, künstliche Pferde, Affen und mechanische Kunstwerke.« (Die Erinnerungen der Karoline Jagemann, hrsg. von Eduard von Bamberg, Dresden 1926, S. 176)
} 


\section{Von der vertu zum Affekt}

nicht mehr als moralische Entscheidung in einem Normenkonflikt, sondern wird in der Didone abbandonata als »Ausweg aus der Ausweglosigkeit « ${ }^{53}$ gedeutet.

Erst im Gefolge der Französischen Revolution entstand erneut eine Reihe von Opern, die schon im Titel (»la morte di ...«) das tragische Ende ankündigen und Protagonisten auf die Bühne bringen, die im Konflikt von Freiheit und Tyrannei scheitern oder zum Selbstmord gezwungen sind. ${ }^{54}$ Stand in den frühen Opern der Konflikt zwischen Politik und Liebe, dovere und affetto, im Mittelpunkt, der erst allmählich gegenüber der Affektkonturierung zurücktrat, findet sich nun eine neue `Politisierung ‘ des Selbstmords auf der Bühne wie im Historiengemälde. Dabei scheint von den sstarken Frauen in der Oper Kleopatra, im Historiengemälde Lukretia einen späten Erfolg zu verzeichnen.

\section{Exkurs: Die Kammerkantate}

Die Weiterentwicklung vom neustoischen Konzept der Tugendheldin zum Interesse an der Affektdarstellung findet sich nicht nur in der bildenden Kunst und der Oper. Das Motiv der ıSelbstmörderin als Tugendheldinı wurde auch von einer weiteren musikalischen Invention des Barock, der Kammerkantate, häufig aufgegriffen. ${ }^{55} \mathrm{Be}-$

\footnotetext{
${ }^{53}$ Hortschansky, Klaus: »Der tragische Held in der italienischen Oper am Ende des 18.Jahrhunderts «, in: ders. (Hrsg.): Opernheld und Opernheldin im 18. Jahrhundert, Hamburg / Eisenach 1991, S. 233-252, hier S. 240.

${ }^{54} \mathrm{Im}$ Umkreis der Französischen Revolution wurden die italienischen Opernbühnen mit vierzig Vertonungen und Inszenierungen von La morte di Cesare (erstmals 1789), La morte di Semiramide (erstmals 1790), La morte di Cleopatra (erstmals 1791) und La morte di Mitridate (erstmals 1797) überschwemmt (Hortschansky a.a.O.).

${ }^{55}$ Bisher hat nur Eugen Schmitz (Geschichte der Kantate und des geistlichen Konzerts, Leipzig 1914) die Gattung ausführlich untersucht; eine neuere Untersuchung, die vor allem inzwischen neu erschlossene Quellen berücksichtigt, steht noch aus. Die wissenschaftliche Literatur beschränkt sich bisher auf einzelne Komponisten. Wie die Bezeichnungen »Cantata « oder »Singstück « erkennen lassen, handelt es sich bei der barocken Kammerkantate um Sologesang mit instrumenteller Begleitung (Engel, Hans / Hucke, Helmut: Kantate, in: ${ }^{1}$ MGG, Bd. 7, München 1989, Sp. 554-575). Im Übergang von der Polyphonie zur Monodie löste sie das Madrigal ab (Jakoby, Richard: Die Kantate, Das Musikwerk, Eine Beispielsammlung zur Musikgeschichte, Köln 1968). Es ist bemerkenswert, dass sich die Kammerkantate, zunächst in Florenz und Rom, etwas später auch in Venedig, Bologna und Neapel gleichzeitig mit der Oper entwickelte. Während Opernlibretti professionell erstellt wurden, griff man für die Kammerkantaten zunächst meist auf Texte von Petrarca, Tasso oder Marini zurück. Schon bald fühlten sich allerdings auch Dilettanten berufen, lyrische Vorlagen für Kantaten zu schreiben. Während Opern in kurzer Zeit öffentliche Spektakel wurden, blieben Kammerkantaten (cantate da camera) eine exklusive Unterhaltung aristokratischer oder akademischer Kreise. (Zu Begriff und ıSitz im Lebenı der Kammermusik vgl. Krones, Hartmut: »Zu Begriff und Theorie der »Kammermusik « im 18. Jahrhundert«, in: Vokale Kammermusik im 18. Jahrhundert, Blankenburg 1997 (Michaelsteiner Konferenzberichte 51), S. 10-24 und Schmitz, a.a.O., S. 4 und 15.) Der Sologesang wurde meist vom basso continuo und von bis zu zwei obligaten Instrumenten begleitet. Für kleinere Räume und wenige Zuhörern wurden als Begleitung etwas leisere Instrumente wie Laute, Harfe, Cembalo, Gitarre oder Theorbe vorgezogen. Johann Adolph Scheibe fasste (in: Critischer Musikus, Leipzig 1745, S. 379) den Charakter von Kammermusik so zusammen. "Der Endzweck des Kammerstyls ist aber vornehmlich, die Zuhörer zu ergetzen und aufzumuntern. Er wird also zur Pracht, zur Lust und zum Lachen gebraucht. Eigentlich aber nennet man das Kammermusik, was man in den Zimmern, auf Sälen und bey der tafel musiciret. Man brauchet sie auch zu öffentlichen Abendmusiken, zu dramatischen Stücken, bey Assembleen, bey Jagden, und bey allerhand außer der Kirche und Schaubühne verfallenden Begebenheiten, und also bey allen übrigen Ergetzlichkeiten. «Eine Barockoper dauerte drei bis vier Stunden, während auch in komplexem Wechsel von Arien und Rezitativen aufgebaute Kammerkantaten nur einen kleinen Teil eines Gesellschaftsabends beanspruchten. Dies verbindet die Kammerkantate mit dem später Mode werdenden slebenden Bild (vgl. unten S. 294). Die vielfältigen und meist einmaligen Verwendungsmöglichkeiten (Huldigung für einen Gast, Vortrag von Texten eines Dilettanten, Bravourstücke für professionelle Sängerinnen, Zusammenwirken aristokratischer Dilettanten und professioneller Musiker) sind ein Grund dafür, dass viele Kammerkantaten verloren gingen und die nur handschriftlich erhaltenen meist noch nicht untersucht sind.
} 


\section{Von der vertu zum Affekt}

reits bei einer extensiven Recherche im Werk des bekanntesten Kantatenkomponisten, Alessandro Scarlatti (1660-1725), dem über achthundert KantatenArrangements ${ }^{56}$ zugeschrieben werden, finden sich Soprankantaten mit Titeln wie La Sofonisba, Didone abbandonata, Lucretia oder Cleopatra. ${ }^{57}$ Auch bei Benedetto Marcello (1686-1739) erscheinen neustoische Themen häufig: unter den über fünfzig überlieferten Kantaten gibt es einen Catone, eine Lucrezia und eine Didone abbandonata. $^{58}$

Die in ganz Europa reüssierenden Kammerkantaten (cantata da camera, scena da camera $^{59}$ galten als geistvolle Kreation (musica riservata) ${ }^{60}$ für vornehme und gebildete Rezipienten. ${ }^{61}$ Sie wurden wohl als ıkleine Operı verstanden; so hatten die Kantaten besonders nach dem 1703 im päpstlichen Rom verhängten Opernverbot großen Erfolg. Meist wurden sie von bekannten Opernkomponisten arrangiert; in Italien umfasste die Komponistenliste von Stradella über Scarlatti und Pergolesi alles, was Rang und Namen in der Musikwelt hatte. Vergleichbares gilt für Frankreich, England, Spanien und Deutschland. Die Kantatenthemen reichten vom Lamento unglücklicher Liebender über mythologische und idyllische Szenen bis zu Affektdarstellungen. Letztere, aber auch die thematische Nähe zur Oper und der gebildete Adressatenkreis können erklären, warum das Motiv des ıschönen Sterbens` ein wichtiges Thema für Kammerkantaten wurde. Als signifikantes Beispiel mag in unserem Zusammenhang Händels Lukrezia (HWV 145), seine wohl erfolgreichste, noch heute häufig aufgeführte Kammerkantate, näher betrachtet werden. ${ }^{62}$

\section{Händels Lukrezia}

Die in Händels italienischen Jahren entstandene Lukrezia-Kantate greift gleichsam die ultima scena einer Oper auf und komprimiert die Affektdarstellung in einer der theatralischen Attitüde ${ }^{63}$ durchaus vergleichbaren Weise. ${ }^{64}$

Die Kantate stellt die Klage der sterbenden Lukrezia dar und gliedert sich in zwei große Abschnitte: Im ersten mit zwei Rezitativen und zwei Arien ruft Lukrezia die Götter dazu auf, die Untat des Tarquinius zu bestrafen. Eine rückwärts gewandte

Die im 17 und 18. Jahrhundert publizierten Kammerkantaten lassen keine verlässlichen Schlüsse über den

Themenbereich der neuen Gattung zu.

${ }^{56}$ Hanley, Edwin: »Alessandro Scarlatti«, in: ${ }^{1}$ MGG, Bd. 11, München 1989, S. $1482-1506$ und Jakoby, Richard: a.a.O., S. 11.

${ }^{57}$ Hanley, a.a.O., S. 1490, 1491 und 1494.

58 Dazu Schmitz, a.a.O., S. 151 und 153.

59 Diese Bezeichnungen wurden neben cantata a voce sola gebraucht (Brandenburg, Gottfried Daniel: Zur Geschichte der weltlichen Solokantate in Neapel im frühen Settecento, Die Solokantaten von Domenico Sarro

(1679-1744), Frankfurt/Bern/New York/Paris 1991, S. 27f.).

${ }^{60}$ Engel, Hans: Kantate, in: ${ }^{1}$ MGG, Bd. 7, München 1989, S. 554.

${ }^{61}$ Ein im Aufbau befindlicher nützlicher kommerzieller Link: http://www.baroquecantata.com (zuletzt aufgerufen: 12.04.2007)

$62 \mathrm{Händel} \mathrm{hat} \mathrm{die} \mathrm{häufig} \mathrm{nach} \mathrm{den} \mathrm{Anfangsworten} O$ numi eterni zitierte Kantate wohl nach 1706 in Florenz für Lucrezia d'André, die Primadonna des toskanischen Hofes, geschrieben (Händel-Handbuch [hrsg. von Eisen, Walter / Eisen, Margret], Bd. 2, Leipzig 1984, S. 566.). Als Textautor gilt Benedetto Pamphili (so z. B. im Programmheft eines Konzerts des Giardino Armonico mit Eva Mei am 31.10.1999 in Hannover). Der Kardinal war einer der bekannten italienischen Förderer Händels und hat auch das Textbuch zum Oratorium /I Trionfo del Tempo e della Verità verfasst. Dass Benedetto Marcello seiner Lukrezia-Kantate die gleichen Verse zugrunde legte, entspricht einer verbreiteten Praxis (vgl. Engel, Hans: Kantate, ${ }^{1}$ MGG, Bd. 7, S. 561). Zu den beiden, oft nicht zu trennenden Brüdern Alessandro Marcello (1684-1750) und Benedetto Marcello (16861739) Giegling, Franz: "Marcello«, in: ${ }^{1} M G G$, Bd. 8, S. 1616-1619. Ein Vergleich mit Kantaten Scarlattis bei Mayo, John S. M.: "Zum Vergleich des Wort-Ton-Verhältnisses in den Kantaten von Georg Friedrich Händel und Alessandro Scarlatti «, in: G. F. Händel und seine italienischen Zeitgenossen, hrsg. von Walther-Siegmund Schultze, Halle 1979, S. 31-44).

${ }^{63}$ Vgl. unten S. 294.

${ }^{64}$ Die Kantate besteht aus vier Rezitativen, drei Arien und einem abschließenden, in einem Furioso endenden Arioso. (Vgl. Schmitz, Eugen: Geschichte der Kantate und des geistlichen Konzerts, Hildesheim / Wiesbaden 1966 [ND der Ausgabe Leipzig 1914], S. 253.) Ungewöhnlicherweise übernimmt in der dritten Arie das begleitende Cembalo oder der Basso continuo die Hauptmelodie selbständig. An die gesanglichen Leistungen der Sopranistin stellt das Stück ohnehin höchste Ansprüche. 


\section{Von der vertu zum Affekt}

Erinnerung an das Geschehene bestimmt die Grundstimmung. Mit dem dritten Rezitativ verändert sich allerdings die Sprechhaltung der Tugendheldin: Lukrezia sucht nunmehr moralischen Trost in sich selbst und findet inn im Selbstmord, der ihre moralische Integrität vor dem Ehemann und Vater, vor Rom und der Welt wiederherstellt. Das im Gegensatz zu den Arien nicht da capo gesungene Arioso inszeniert die Wirkung des Dolchstoßes und die einsetzende Agonie. ${ }^{65}$

O Numi eterni! O stelle!

Che fulminate empii tiranni, impugnate a miei voti orridi strali, voi con fochi tonanti incennerite il reo Tarquinio e Roma; dalla superba chioma, omai trabocchi il vacillante alloro; s'apra il suolo in voragini, si celi, con memorando essempio, nelle viscere

sue l'indegno e l'empio.

\section{Aria}

Già superbo del mio affanno, traditor dell'onor mio, parte l'empio, lo sleal. Tu punisci il fiero inganno Del fellon, del mostro rio, Giusto ciel, parca fatal.

\section{Recitativo}

Ma voi forse nel Cielo, per castigo maggior del mio delitto, state oziosi, o provocati Numi; se son sorde le stelle, se non mi odon le sfere, a voi tremende Deità del abisso mi volgo, a voi, a voi s'aspetta del tradito onor mio far la vendetta.

\section{Aria}

II suol che preme,

l'aura che spira

l'empio Romano, s'apra, s'infetti.

Se il passo move, se il guardo gira, incontri larve, ruine aspetti.

\section{Recitativo}

Ah! Che ancor nell'abisso dormon le furie, i sdegni e le vendette.

Giove dunque per me non ha saette, è pietoso l'inferno?

Ah! Ch'io già sono in odio al Cielo, ah!

Dite: e se la pena non piomba

sul mio capo a' miei rimorsi

è rimorso il poter di castigarmi.

Questi la disperata anima mia puniscan,

sì, ma il ferro

che già intrepida stringo,

Aria

alla salma infedel porga la pena.

Recitativo

A voi, padre, consorte, a Roma,

al mondo presento il mio morir;

mi si perdoni il delitto essecrando

ond' io macchiai involontaria il nostro onor,

un' altra più detestabil colpa

di non m'aver uccisa

pria del misfatto

mi si perdoni.

\section{Arioso}

Già nel seno cominicia

a compir questo ferro i duri uffizii; sento ch'il cor si scuote più dal dolor di questa caduta invendicata, che dal furor della vicina morte. Ma se qui non m'è dato castigar il tiranno, opprimer l'empio con più barbaro essempio, per ch'ei sen cada estinto stringerò a danni suoi mortal saetta, e furibonda e cruda nell'inferno farò la mia vendetta.

Die Kammerkantate spielt mit dem Doppelsinn des zweimal an signifikanter Stelle gesungenen Schlüsselworts vendetta: Lukrezia hofft zunächst noch auf das Eingreifen der Götter oder der Familie und die Bestrafung des Vergewaltigers, sorgt dann aber selbst durch den Entschluss zum Selbstmord für die Wiederherstellung ihrer moralischen Identität. Für den gebildeten Zuhörer folgt aus diesem barbaro essempio, das die Tugendheldin inszeniert, der Umsturz (»castigar il tiranno «) und die Errichtung der römischen Republik (»opprimer l'empio«). Pamphili und Händel gelingt es, in komprimierter Form Affektdarstellung und politisches exemplum zu verbinden.

Da Kammerkantaten keine Regieanweisung kennen, blieb es der Sängerin überlassen, den Entschluss zum Selbstmord in Szene zu setzen und den Dolch zu er-

\footnotetext{
${ }^{65}$ Die Kammerkantate ist in der kritischen Halleschen Händelausgabe (HHA) noch nicht erschienen. Ich zitiere den Text im Folgenden nach dem Booklet zu Händels Agrippina, Armida, Lucrezia, gesungen von Eva Mei, begleitet von // Giardino Armonico unter der Leitung von Giovanni Antonini (Teldec 3984-24571-2).
} 


\section{Von der vertu zum Affekt}

greifen: »si, ma il ferro / che già intrepida stringo. « Die dritte, nur den Halbsatz »alla salma infedel porga la pena « umfassende Arie antizipiert das Ende mit der doppelten Bedeutung von »salma« als ıKörper und als ıLeichnam». Das letzte Rezitativ und das Arioso trägt eine gleichsam bereits Tote vor. Das Libretto des Kardinals hebt auf identitätsstiftende Affektdarstellung ab, verbindet sie aber mit der politischen Deutung des Opfergangs der Lukrezia (»presento il mio morir «). Die Tugendheldin inszeniert ihren Tod als Sühne für ein von ihr gar nicht provoziertes Vergehen, dessen unfreiwilliges Opfer sie wurde. Erinnert man sich daran, dass Lukrezias spolitischer Selbstmord in der zeitgenössischen Moraltheologie kontrovers diskutiert wurde und in der Legitimationsdebatte weltlicher Herrschaft eine gewisse Rolle spielte, ist es weniger verwunderlich, dass das Libretto des Kirchenfürsten ausgerechnet das Thema des Selbstmords einer profanen Tugendheldin aufgriff. ${ }^{66}$

So integriert die Kantate in die Affektdarstellung Anspielungen auf einen philosophischen und politischen Kontext, der noch einmal an den neustoischen Hintergrund des frühneuzeitlichen Themas der profanen Tugendheldin in der Literatur und bildenden Kunst erinnert. Die Affektkonturierung der Kammerkantate verbindet in intrikater Weise die Darstellung der Tugendheldin als exemplum ıschönen Sterbens` mit einem politischen Diskurs. Gleichwohl gehört die Lukrezia der Kammerkantate $^{67}$ ebenso wie die antikisierenden Pathosformeln der Halbfigurenbilder Renis zu einer Entwicklung, an deren Ende die Tugendheldinnen zu enthistorisierten exempla werden. Die Attitüden und >lebenden Bilderı des 19. Jahrhunderts sind nicht mehr allzu fern.

\section{Femme fatale}

Noch in den späten Kantaten des 19.Jahrhunderts haben die profanen Tugendheldinnen offenbar eine gewisse Attraktion ausgeübt. Hector Berlioz reichte 1829 für den Prix de Rome des Pariser Konservatoriums eine Kantate Cléopâtre ein, die allerdings abgelehnt wurde. Das Bravourstück führt mit seiner Inszenierung Kleopatras als femme fatale (»Je n'ai pu captiver son farouche regard «) ein Stück weiter in die Dekadenz des 19. Jahrhunderts und erinnert mit dem Interesse für den orientalischen Dekor und den sexuellen Konnotationen (»comparable à Vénus «) an das im Eingang dieser Untersuchung evozierte Gemälde Makarts. ${ }^{68}$ Gleichwohl behalten Berlioz und Vieillard immer noch die historische Reminiszenz und die Funktion des Selbstmords der Tugendheldin zur Wiederherstellung ihrer moralischen Integrität bei: »Cléopâtre en ... quittant ... la vie, / Redevient digne de ... César!« Noch bleiben moralischer Diskurs und Affektdarstellung verbunden. ${ }^{69}$

\footnotetext{
${ }^{66}$ Dazu Emich, Birgit: »Bologneser libertà, Ferrareser decadenza: Politische Kultur und päpstliche Herrschaft im Kirchenstaat der Frühen Neuzeit«, in: Asch, Ronald / Feist, Dagmar (Hrsg.): Staatsbildung als kultureller Prozess, Strukturwandel und Legitimation von Herrschaft in der Frühen Neuzeit, Köln / Weimar / Wien 2005, S. 117-134.

67 Domenico Zipoli (1688-1726), ein Jesuit, hat in seiner Kammerkantate Dell'offese a vendicarmi das gleiche Thema behandelt (Text in: Händels Italianità, Programme, Texte und Werkeinführungen, [Göttinger HändelGesellschaft] Göttingen 1997, S. 122-123). Eine weitere Kleopatra-Kantate (Cleopatra moribonda) hat Giovanni Paolo Colonna (1637-1695) komponiert. Dido-Kantaten stammen beispielsweise von Sigismondo d' India (1582-1629), Giovanni Paolo Colonna (1637-1695), André Campra (1660-1774), Michel Pignolet de Montéclair (1667-1737) und François Collin Delamont (1690-1760).

68 Vgl. oben S. $13 \mathrm{ff}$.

69 Der Text der Kantate wurde von der Jury für den Prix de Rome ausgewählt und stammt von Pierre-Ange Vieillard (Klavierauszug zu der Vertonung von Berlioz: Gilbert, David (Hrsg.): Hector Berlioz, Cléopâtre, o. J., Bärenreiter 5787).
} 


\section{Von der vertu zum Affekt}

La mort de Cléopâtre, scène lyrique

C'en est donc fait! ma honte est assurée.

Veuve d'Antoine et veuve de César,

Au pouvoir d'Octave livrée,

Je n'ai pu captiver son farouche regard.

J'étais vaincue, et suis déshonorée.

En vain, pour ranimer l'éclat de mes attraits,

J'ai profané le deuil d'un funeste veuvage;

En vain, en vain, de l'art épuisant les secrets,

J'ai caché sous des fleurs les fers de l'esclavage;

Rien n'a pu du vainqueur désarmer les décrets.

A ses pieds j'ai traîné mes grandeurs opprimées.

Mes pleurs même ont coulé sur ses mains répandus

Et la fille des Ptolémées

A subi l'affront des refus!

Ah! qu'ils sont loin ces jours, tourment de ma mémoire,

Où sur le sein des mers, comparable à Vénus,

D'Antoine et de César réfléchissant la gloire,

J'apparus triomphante aux rives du Cydnus!

\section{Méditation}

How if when I am laid into the tomb ...

(Shakespeare)]

Grands Pharaons, nobles Lagides,

Verrez-vous entrer sans courroux,

Pour dormir dans vos pyramides,

Une reine indigne de vous?

Non! ... non, de vos demeures funèbres

Je profanerais la splendeur!

Rois, encor au sein des ténèbres,

Vous me fuiriez avec horreur.

Du destin qui m'accable est-ce à moi de me plaindre?

Ai-je pour l'accuser le droit de la vertu?

Par moi nos dieux ont fui d'Alexandrie,

Et d'Isis le culte est détruit.

Grands Pharaons, nobles Lagides,

Vous me fuiriez avec horreur!

Du destin qui m'accable est-ce à moi de me plaindre?
Actium m'a livrée au vainqueur qui me brave;

Mon sceptre, mes trésors ont passé dans ses mains;

Ma beauté me restait, et les mépris d'Octave

Pour me vaincre ont fait plus que le fer des Romains. Ah! qu'ils sont loin ces jours, etc.

Mes pleurs même ont coulé sur ses mains répandus, J'ai subi l'affront des refus.

Moi! ... qui du sein des mers, comparable à Vénus, M'élançai triomphante aux rives du Cydnus!

Au comble des revers, qu'aurais-je encore à craindre? Reine coupable, que dis-tu?

Du destin qui m'accable est-ce à moi de me plaindre? Ai-je pour l'accuser les droits de la vertu?

J'ai d'un époux déshonoré la vie.

C'est par moi qu'aux Romains l'Égypte est asservie,

Et que d'Isis l'ancien culte est détruit.

Quel asile chercher? Sans parents! sans patrie!

II n'en est plus pour moi que l'éternelle nuit!

Ai-je pour l'accuser le droit de la vertu?

Grands Pharaons, nobles Lagides,

Verrez-vous entrer sans courroux,

Pour dormir dans vos pyramides,

Une reine indigne de vous?

Non, j'ai d'un époux déshonoré la vie.

Sa cendre est sous mes yeux, son ombre me poursuit.

C'est par moi qu'aux Romains l'Égypte est asservie.

Par moi nos dieux ont fui les murs d'Alexandrie,

Et d'Isis le culte est détruit.

Osiris proscrit ma couronne.

A Typhon je livre mes jours!

Contre l'horreur qui m'environne

Un vil reptile est mon recours.

Dieux du Nil ... vous m'avez ... trahie!

Octave ... m'attend ... a son char.

Cléopâtre en ... quittant ... la vie,

Redevient digne de ... César!

\section{Die Tugendheldin im Monodrama}

\section{In signifikanter Weise wurde das Thema der profanen Tugendheldinnen auch in} der neuen theatralischen Form des Monodramas ${ }^{70}$ aufgegriffen. Dies mag auch deshalb nahegelegen haben, weil Monodramen eine Domäne weiblicher Schauspielkunst waren. Sophonisbe, Kleopatra und Dido avancierten so zu Protagonisten von Monodramen. ${ }^{71}$

\footnotetext{
${ }^{70}$ Vgl. Vöhler, Martin: "Monodrama«, in: Reallexikon der deutschen Literaturwissenschaft, hrsg. von Harald Fricker, Bd.2, Berlin / New York 2000, S. 627-629. Außerdem Schimpf, Wolfgang: Das Melodrama des 18. Jahrhunderts, Göttingen 1988 und Küster, Ulrike: Das Melodrama, Zum ästhetikgeschichtlichen Zusammenhang von Dichtung und Musik im 18. Jahrhundert, Frankfurt / Berlin / Bern 1993.

${ }^{71}$ Am Anfang steht vielleicht August Gottlieb Meißners Sophonisbe von 1776. Nachgewiesen sind weiterhin ein Duodrama Antonius und Cleopatra von Bernhard Christoph d'Arien, das 1779 zum ersten Mal in Berlin zur Aufführung kam. (Zu weiteren Aufführungen vgl. Schimpf, a.a.O., S. 203). Das Duodrama Cleopatra von Johann Leopold Neumann wurde zuerst 1780 im Mannheimer Hoftheater aufgeführt (zu weiteren Aufführungen vgl. Schimpf, a.a.O., S. 210). Aufführungsorte und -daten des Melodramas Dido von Georg Reinbeck konnten nicht ermittelt werden (vgl. Schimpf, a.a.O., S. 211).
} 


\section{Von der vertu zum Affekt}

Der die Gattung begründende Pygmalion ${ }^{72}$ Jean Jacques Rousseaus wurde 1770 in Lyon und 1772 in Paris aufgeführt. Die musikalisch begleitete "scène lyrique « galt in Frankreich und darüber hinaus in allen europäischen Ländern als Sensation. ${ }^{73}$ Dass Rousseau mit dem Pygmalion-Mythos künstlerisches Selbstverständnis und Kreativität zum Thema machte, sicherte den Erfolg der neuen Gattung beim Publikum, aber auch bei den Künstlern. ${ }^{74}$ Die Gattung des Monodramas verlangt, dass der als vorausgegangen gedachte und als bekannt vorausgesetzte Gang der Handlung schon weit fortgeschritten ist. Die Sprechhandlung setzt erst dort ein, wo sich die dramatis persona in einer sbedeutenden Situation, einer Krise, befindet, die durch den Zwang zur Entscheidung kennzeichnet ist. Extreme Gefühlsschwankungen und bedingungslose Affekte führen den Zuschauern das Dilemma der Hauptfigur vor. Sie sollen an den Emotionen der Protagonistin teilhaben und sich in suggestiver Einfühlung auf den Entscheidungsprozess einlassen. Die Stoffe wurden vorwiegend aus hinlänglich bekannten Mythen und aus der antiken Geschichte gewählt: Elektra, Polyxena, Ariadne auf Naxos, Medea, Sappho, Dido, Niobe, Kleopatra, Hero, Iphigenie, Sophonisbe ${ }^{75}$. Nicht zufällig beschränkte sich das Repertoire weitgehend auf Frauenfiguren. Die in der Epoche der Empfindsamkeit und des Sturm und Drang entstandene neue Gattung verfestigte die Geschlechterdifferenzen $^{76}$ und überlud die weiblichen Protagonisten mit Gefühlen und Affekten. Tugendheldinnen waren deshalb als Vorwurf besonders geeignet. Die modische Gattung reüssierte am Ende des 18. Jahrhunderts rasch. Da beim Publikum die Vorgeschichte als bekannt vorausgesetzt werden konnte, konzentrierten sich die Monologe auf die inneren Konflikte. Die kritische Entscheidungssituation gestattete es, die ganze Bandbreite der Affekte von hoffnungsloser Verzweiflung bis zu grenzenloser Freude in eine einzige Szenenfolge zu drängen, die der Schauspielerin Gelegenheit bot, in der Reflexion des Konflikts kurz hintereinander gegensätzlichste Affekte dar-

\footnotetext{
${ }^{72}$ Rousseau, Jean-Jacques: Oeuvres complètes, hrsg. von Bernard Gagnebin / Marcel Raymond, Paris 1964 (Bibliothèque de la Pléiade), Bd. 2, Text des »Pygmalion« S. 1224-1231; Text zur Zwischenmusik S. 19291930.

${ }^{73} \mathrm{Vgl}$. das entsprechende Kapitel in der Monographie von Demmer, Sybille: Untersuchungen zu Form und Geschichte des Monodramas, Köln 1982, S. 21-29.

${ }^{74} \mathrm{Im}$ Monodrama tritt nur ein sprechender Akteur auf, dem allerdings stumme Personen wie Boten oder Bedienstete assistieren können. Monologe als zentrales Gestaltungsmittel bringen innere Konflikte mit ihren psychischen Auswirkungen auf die Bühne. Pathosreiche Gestik und Mimik boten einer Schauspielerin - männliche Rollen waren im Monodrama eher die Ausnahme - die Möglichkeit, zu brillieren, ohne Aufmerksamkeit und Applaus mit Mitspielern teilen zu müssen. Hierin ist das Monodrama der Kammerkantate vergleichbar. Diese Nähe zeigt sich auch darin, dass für zahlreiche Monodramen musikalische Begleitungen oder Interludien komponiert wurden. so dass sich die Frage aufdrängt, ob die Affinitäten zur im Jahrhundert vorher entwickelten Kammerkantate nicht größer waren als in der Forschung bisher angenommen (so auch Schmitz, Eugen: Geschichte der Kantate, a.a.O., S. 286 und 302). Bereits Rousseau war die Verbindung von Monolog und Musik, die in seinem Monodrama als Zwischenspiele Stimmung und Affekte der nachfolgenden Szenen vorbereitete, so wichtig, dass er im Commentaire des intermédes musicaux de Pygmalion die harmonische Wechselbeeinflussung der beiden Künste und den daraus entstehenden Gesamteindruck grundsätzlich bedachte. Eine literaturwissenschaftliche und musikologische Fragestellungen aufgreifende Untersuchung des Monodramas, welche die Interferenzen zwischen Kantate und Monodrama klärt, steht noch aus.

${ }^{75}$ Eine auf den deutschsprachigen Bereich beschränkte Liste findet sich im Anhang zu Demmers Monographie, a.a.O., S. 265-270; sie zeigt, dass für Monodramen fast ausschließlich weibliche Protagonisten gewählt wurden. Schimpf beschränkt sich (a.a.O., S. 254-267) in seiner Aufführungschronologie ebenfalls auf den deutschsprachigen Raum. Für diesen eingegrenzten Aufführungsraum wird deutlich, dass zwischen 1775 und 1800 Monodramen als attraktive Neuerscheinungen galten und Zuschauerscharen anlockten.

${ }^{76}$ Die These von Butler, Judith: Das Unbehagen der Geschlechter, Frankfurt/Main ${ }^{1} 1990$ (Gender Trouble: Feminism and the Subversion of Identity, Routledge 1990), aufgreifend, könnte man sagen, dass die weiblichen Protagonisten der Monodramen in ihrer >Performance`, der künstlerischen Realisierung und Inszenierung von Geschlecht und von Erwartungen an die Geschlechteridentität, ein höchstes Maß an ıPerformativitätı zeigen. Sie wiederholen in ihrem Spiel am eigenen Körper soziokulturelle Zuschreibungen und machen damit kulturell bedingte Geschlechtsrollen sichtbar. Mit dieser John L. Austin entlehnten Terminologie verdeutlicht die Genderforschung einen wichtigen Aspekt der empfindsamen Umdeutung und Neuinterpretation der überliefer-
} ten Stoffe. 


\section{Von der vertu zum Affekt}

zustellen: diese und nicht die »Begebenheit « ${ }^{77}$ stehen im Mittelpunkt. Allenfalls in elegischer Rückerinnerung taucht vergangenes Geschehen auf und wird von der Hauptperson überdacht. Narrative Elemente treten zurück; das Konfliktpotential wird durch die monologische Situation häufig vom Dramatischen ins Lyrische verschoben und in ein `Seelengemälde` umgesetzt. ${ }^{78}$

\section{August Gottlieb Meißner (1753-1807) trug in seinem Monodrama Sophonisbe ${ }^{79}$, das als »ein musikalisches Drama, mit historischem Prolog und Chören« bereits} 1776 gedruckt wurde, den wesentlich später von Goethe formulierten Ansprüchen ${ }^{80}$ an ein Monodrama vollständig Rechnung.

In acht unmittelbar aufeinander folgenden Situationen wechseln die Affekte der Protagonistin ständig. Zunächst bereitet Sophonisbe feierlich bewegt ihre zweite Vermählung vor. Palastdekoration und Festkleidung der Königin unterstreichen den shohen Stik. Im Rückblick erinnert sich die Königin an ihren im Kampf gegen die Römer gefallenen ersten Mann Syphax. Sie wird den Jugendgeliebten Massinissa heiraten, um inn für die karthagische Sache zurückzugewinnen. In die freudige Stimmung bricht Atarspe mit der Nachricht ein, die Stadt sei von den Römern eingenommen. Sophonisbes Stimmung wandelt sich in Verzweiflung und Hilflosigkeit. Wenig später führt Atarspe den Boten Massinissas herein. Die Königin liest, nach-

\footnotetext{
77 Heinrich Christoph Koch (Musikalisches Lexikon, Frankfurt/Main 1802, S. 945-947) gibt in seinem Artikel "Melodrama« eine Definition, die ganz dem Monodrama entspricht. Es folgt ein Zitat von D. Schmieder (aus dem Theaterjournal, Bd.1, 1799): »Das Melodrama muß als ein lyrisches Kunstwerk, ein Gefühl im Objecte darstellen. Der Dichter hat hier die Obliegenheit, dies Gefühl gleichsam nur anzudeuten, weil die möglichst vollkommenste Darstellung durch die Dichtkunst (wenn es nemlich nicht der Fall ist, daß durch die Töne selbst dies Gefühl einer weit höhern Verstärkung fähig ist,) schon ein an sich bestehendes Kunstwerk ausmachen würde, und die Mitwirkung der Musik nicht ausdrücklich erforderte, da diese in diesem Falle doch weiter nichts thun könne, als das geschilderte Gefühl zu begleiten, aber nicht zu erheben. Das Melodrama schildert nicht Begebenheiten, sondern die Begebenheit ist nur das Mittel, welches dem Dichter dazu behülflich ist, die Affekten [!] selbst darzustellen. Nicht Ariadnens trauriges Schicksal, sondern die Verzweiflung einer Liebenden ist der Hauptgegenstand in diesem Melodrama. Die Begebenheit selbst und ihre Darstellung ist also hier nur gleichsam eine Begleitung, um den Hauptpunkt desto stärker hervor zu heben. Die Obliegenheit des Komponisten ist also hier, die Affekten der handelnden Personen selbst, durch das Mittel, was er in Händen hat, hervorzubringen.«

${ }^{78}$ Der im Monodrama erwarteten Affektüberzeichnung dienen alle Inszenierungsaspekte. Goethe hat sie 1815 anlässlich der Wiederaufführung seiner »Proserpina « zusammengefasst: »1) Dekoration, 2) Rezitation und Deklamation, 3) körperliche Bewegung, 4) Mitwirkung der Kleidung, 5) Musik, und zwar a) indem sie die Rede begleitet, b) indem sie zu malerischen Bewegungen auffordert, c) indem sie den Chor melodisch eintreten lässt. Alles dieses wird 6) durch ein Tableau geschlossen, und vollendet. « (MA 11/2, S. 191-198, hier S. 192)

${ }^{79}$ Meißner, August Gottlieb: Sophonisbe, ein musikalisch [!] Drama mit historischem Prolog und Chören, Leipzig 1776. Dazu Schwarz, Monika: „Christian Gottlob Neefe: Sophonisbe, Drama mit musikalischer Begleitung «, in: Pipers Enzyklopädie des Musiktheaters, Bd. 4, hrsg. von Carl Dahlhaus, München 1991, S. 401f.

${ }^{80}$ Goethe, 1779 selbst mit seiner Proserpina (MA, Bd. 2.1, S. 161-164) Verfasser eines Monodramas, das 1815 mit neu komponierter Musik wieder aufgeführt wurde, fasst im gleichzeitig entstandenen Lustspiel Der Triumph der Empfindsamkeit in scharfsichtiger, wenn auch überzeichnender Weise Merkmale des Monodramas zusammen und formuliert damit zugleich seine Kritik. Die Charakterisierung der neuen Theatergattung legt er Andrason, dem »humoristischen König « der Posse, in den Mund. Der Possenkönig erzählt, seine Frau verhalte sich »wunderbar «, ziehe sich in die Natur zurück und spiele manchmal mit Vergnügen Monodramen. Auf Fragen seines Mitspielers Sora erklärt Andrason die Gattungsbezeichnung korrekt aus dem Griechischen und antwortet ironisch auf den Einwurf, dass das Spiel für sich und mit sich allein doch wohl langweilig sei: »Für den Zuschauer wohl. Denn eigentlich ist die Person nicht allein, sie spielt aber doch allein; denn es können noch mehr Personen dabei sein, Liebhaber, Kammerjungfern, Najaden, Oreaden, Hamadryaden, Ehemänner, Hofmeister; aber eigentlich spielt sie für sich, es bleibt ein Monodrama. Es ist eben eine von den neusten Erfindungen; es lässt sich nichts darüber sagen. Solche Dinge finden großen Beifall. Sora: Und das spielt sie ganz allein für sich? Andrason: O ja! Oder, wenn etwa Dolch oder Gift zu bringen ist - denn es geht meistens etwas bunt her - wenn eine schreckliche Stimme aus dem Felsen oder durchs Schlüsselloch zu rufen hat, solche wichtige Rollen nimmt der Prinz über sich, wenn er da ist, oder in seiner Abwesenheit ihr Kammerdiener, ein sehr alberner Bursche; aber das ist eins. (MA, Bd. 2.1, S. 171)
} 


\section{Von der vertu zum Affekt}

dem sich Dienerin und Bote entfernt haben, Massinissas Brief und ist sofort entschlossen, das Gift zu trinken; doch will sie zuvor noch den Göttern ein Opfer bringen. Sophonisbe betritt den Tempel; ein Chor von Priestern leitet die Opferhandlungen ein. In der letzten Szene trinkt Sophonisbe, allein auf der Bühne, das Gift, verflucht die Römer und dankt ihrem `Retter८ Massinissa, weil er das Gift als »Becher der Freyheit « gesandt hat. Das Abschlusstableau zeigt die Sterbende am Altar hingesunken.

Der zunächst als Grund der erneuten Heirat Sophonisbes beschworene karthagische Patriotismus tritt rasch in den Hintergrund. Die Hälfte der Szenen sind großen Deklamationen der Königin gewidmet, die ständig radikale Gefühlsumschwünge erlebt: in kürzester Zeit müssen Hochzeitsfreude, Verzweiflung, Reflexionen über den Selbstmord und der Selbstmord selbst glaubhaft in Szene gesetzt werden. Die wie in allen Monodramen extrem rhetorische Sprache der Protagonistin häuft Parataxen, Anadiplosen, Anakoluthe, Aposiopesen und Interjektionen, um das gewünschte Pathos zu erreichen. Es bedurfte gewiss nachhaltigen schauspielerischen Talents, um die Szenenfolge nicht ins Triviale absinken und in expressiver Gestik und Mimik ertrinken zu lassen. ${ }^{81}$ Christian Gottlob Neefe lässt die musikalische Begleitung mit häufigen und differenzierten Wechsel der Tempo- und Affektvorschriften die rasch wechselnden Stimmungen unterstützen. ${ }^{82}$ Auch das von Georg Benda, dem erfolgreichsten Vertoner von Monodramen, etablierte rhythmische Sprechen zur Musik ( $\pi \alpha \varrho \alpha \kappa \alpha \tau \alpha \lambda \circ \gamma \eta \dot{)}$ findet sich bereits bei Meißner, bis hin zu einer >Sprecharie in da-capo-Form. ${ }^{83}$

Leopold Neumann hat sein recht dürftiges Duodrama Cleopatra ${ }^{84}$ in zehn Auftritte gegliedert, wobei Monologszenen mit dialogischen alternieren.

Kleopatra befindet sich bereits im Gefängnis, das sie als locus terribilis schildert. ${ }^{85}$ Octavian sucht die ägyptische Königin auf und malt ihr den bevorstehenden römi-

\footnotetext{
${ }^{81}$ Die schwülstige Rhetorik (vgl. Schimpf, a.a.O., S. 165-171) und die Monotonie der stets tödlich endenden Monodramen lösten offensichtlich beim Publikum große Begeisterung aus, provozierten aber auch kritische Einwände. So urteilte zum Beispiel Johann Carl Wetzel scharf über ein Ariadne-Monodrama: „Ariadne kam mir [...] wie ein Epigramm vor, worinne ihr Sturz in das Meer von Pflaumenfedern [sic!] die Pointe ist: je tiefer ich in den Monolog hineingerieth, je mehr fühlte ich die Unbehaglichkeit, die mich sehr stark übernehmen würde, wenn mir jemand ein Epigramm von zwo Oktavseiten vorläse, und ein dritter so viele Erläuterungen und Ausbildungen den einzelnen Ideen dazwischen schwatzte, daß ich die Spitze erst in einer halben Stunde erführe ... Immer dachte ich - aber, beym Himmel! So schweig doch, Orchester! Daß sie endlich einmal sterben kann!« (Wetzel, Johann Carl: Zelmor und Ermide, Ein musikalisches Schauspiel, in: Wetzel, Johann Carl: Lustspiele, Bd. 2, Leipzig 1779, S. 2f.)

${ }^{82}$ Küster (a.a.O., S. 243-245) zählt in den etwas weniger als 900 Takten 78 Tempiwechsel.

83 Zu Benda vgl. Schimpf, a.a.O., S. 268. Genaueres zu den Takten 506-551 bei Küster, a.a.O., S. $246 f$.

${ }^{84}$ Neumann, Leopold: Cleopatra, ein Duodrama, Mannheim 1780 (Beiträge zur Pfälzischen Schaubühne); die Musik komponierte Franz Danzi. Das Stück wurde 1780 mehrfach am Mannheimer Hoftheater gegeben; weitere Aufführungen für Hamburg und Regensburg sind nachgewiesen (vgl. Schimpf, a.a.O., S. 210). - Die genauen Lebensdaten Neumanns konnte ich nicht ermitteln.

${ }^{85}$ Neumann, a.a.O., S. 4: »Sey mir willkommen grauenvolle Einsamkeit! - Vorhof des Todes! - Schreckenvolle Höhle der nagenden Reue, wo sonst Verbrecher, von mir verurtheilt, dem Tode entgegen schauderten [...] Du bist schrecklich, Ort meiner Sicherheit [...].«
} 


\section{Von der vertu zum Affekt}

schen Triumphzug aus, in dem sie als Beute mitgeführt werden soll. Durch Vertraute wird ihr ein Früchtekorb mit einer darin verborgenen Schlange gebracht. Ängste vor dem bevorstehenden Tod beschleichen sie:

[...] in dieser Schale das Ziel meiner Größe, meines Glücks, meiner Hofnung [!], in dir mein Tod? Furchtsame! Warum schaudert dir? Warum bebst du? Antonius nicht mehr? Hinter dir ewige Ketten! Und du zitterst? - - [... $]^{86}$

Als das Gift sie bereits in Agonie versetzt hat, wird der tödlich verwundete Antonius ${ }^{87}$ hereingetragen und stirbt zu ihren Füßen:

Du lebst noch! Wohl mir, dass ich dich noch einmal umarmen kann. - O komm! - Du hörst nicht! Fliehst meine Pein! - (Indem sie sich aufrichtet, sieht sie, dass er schon stirbt.) Ah er stirbt zu meinen Füßen! - Warum ruftest du mich zurück! - Verzeuch noch einen Augenblick, so geh ich mit dir, schon schwingt mein Geist die Flügel. - (Indem sie wieder zurück sinkt und Antonius ganz verscheidet. $)^{88}$

Während ihrer letzten Atemzüge tritt Octavian ins Gefängnis, um Kleopatra auf sein Schiff zu bringen. Im Sterben erbittet Kleopatra ein gemeinsames Grab mit Antonius. Ein Doppelchor kommentiert das triumphierende Schlusswort des Octavian ${ }^{89}$ und wertet überraschenderweise Kleopatras Tod in einem Kehrreim moralisch:

Das ist das Ziel der größten Macht, Wenn Tugend nicht am Throne wacht! $!^{90}$

Entschlusskraft und Liebe, vor allem aber moralische Verwerflichkeit charakterisieren Kleopatra als femme fatale. Der vom Chor vorgetragene smoralischer Kommentar ist nur verständlich, wenn beim Publikum die Kenntnis der gesamten Episode vorausgesetzt wird. ${ }^{91}$

August Siegfried von Goué (1742-1789) lässt in seinem Duodrama Dido ${ }^{92}$ die afrikanische Königin mit ihrer Schwester Anna auftreten.

Anna bewundert Didos Großmut. ${ }^{93}$ Als die Königin sich, effektvoll genug, auf der Bühne ersticht, zerfließt die herbeigeeilte Schwester in Mitgefühl und spricht die abschließenden Worte des Schlusstableaus, ihre tote Schwester, einer Pietà vergleichbar, im Arm haltend:

Sie ist todt!

Bewundern und beklagen muß man sie.

Ihr Herz verdiente wohl ein beß'res Loos,

\footnotetext{
${ }^{86}$ Neumann, a.a.O., S. 15.

${ }^{87}$ Schimpf weist (a.a.O., S. 79) darauf hin, dass die letzten Worte des sterbenden Antonius von der Musik und von der Deklamation als pathetischer Höhepunkt inszeniert werden: »Bei dieser unter der Musik gesprochenen Rede, müsste die Musik nicht zu kurz seyn, damit der Schauspieler, der gebrochen reden muß, frei declamiren könne. "Dieser Effekt, der bereits von Benda versucht worden war, hat beim zeitgenössischen Publikum große Wirkung gehabt (vgl. Schimpf, a.a.O., S. 80).

${ }^{88}$ Neumann, a.a.O., S. 17.

89 »Triumph! Mein Sieg ist nun vollkommen!« (S. 18)

${ }^{90}$ Neumann, a.a.O., S. $19 f$.

${ }^{91}$ Nach Schimpf (a.a.O., S. 40-46) wurden Monodramen an Höfen, in Städten, in adligen Gesellschaften und akademischen Liebhabertheatern gezeigt, häufig aber auch in Universitätsstädten, wo eine Spielerlaubnis für Theatertruppen schwer zu erhalten war und Monodramen als ıKonzerte k kaschiert zur Aufführung kamen.

${ }^{92}$ Goué, August Siegfried von: Dido, ein Duodrama, Wetzlar 1771.

${ }^{93}$ Goué, a.a.O., S. 18. »Ja, Dido, ich / Sprach inn: allein umsonst. Er hörte mich / nicht aus. Er sagte, Jupiters Befehl / Sey widerholt an ihn, dass er die Stadt / Verlasse, schon ergangen. Doch du weißt / Es alles. Ich bewundre dich, dass du / So grosmuthsvoll dein Schicksal trägst. Denn ich / Getrau'te mir im Anfang dir es nicht / zu sagen.«
} 


\section{Von der vertu zum Affekt}

Als Untreu, Gram, und blut'gen Tod. ${ }^{94}$

Im Gegensatz zu Meißners Sophonisbe arbeitet das Duodrama nicht mit der »inneren Fallhöhe ${ }^{95}$ der Protagonistin. Dido ist bereits im ersten Auftritt zu Verzicht und Selbstmord entschlossen und zeigt noch so viel Besonnenheit, ihrer Schwester und ihrer Umgebung den bevorstehenden Selbstmord zu verheimlichen. Das recht inhaltsleere Duodrama hat wohl eine bissige Satire Heinrich von Gemmingens provoziert, die auf ihre Weise die nurmehr melodramatischen Absichten dieser späten Auftritte der Tugendheldin hervorhebt. ${ }^{96}$

Monodramen reduzieren den tragischen Konflikt subjektiver und objektiver Normen im Antagonismus von Politik und Liebe, der das Interesse der Frühen Neuzeit an den Tugendheldinnen geweckt hatte, noch weitergehender auf den Ausdruck subjektiver Affekte, als dies bereits in den stazioni sentimentali ${ }^{97}$ der Oper und den Halbfigurenbildern der Historienmalerei der Fall war. Die Häufung wechselnder extremer Affekte in einer einzigen Szenenfolge wirkt heute einigermaßen angestrengt, auch wenn sie auf moderne Psychodramen vorausweisen mag. Der zugrunde liegende Konflikt findet kein eigenes Interesse mehr; dieses wendet sich vielmehr ganz dem gestischen und mimischen Potential der Schauspielerinnen zu, das den phrasenhaften und konventionalisierten Text erst zum Sprechen bringen konnte. Gerade darin dürfte der Reiz der modischen Monodramen, Melodramen und Duodramen am Ende des 18. Jahrhunderts bestanden haben. Gleichwohl sollte das Monodrama nicht als lyrischer Torso eines Trauerspiels $^{98}$ abgewertet werden. An die Stelle eines klaren Wertedilemmas und weniger, aber starker Affekte, wie sie das frühneuzeitliche Theater verbindlich waren, ist im Monodrama eine Affektkonfusion getreten, die zusammen mit den (oft nicht

\footnotetext{
${ }^{94}$ Goué, a.a.O., S. 30.

${ }^{95}$ Schimpf, a.a.O., S. 110.

${ }^{96}$ Die Satire Dido erschien anonym in der Litteratur- und Theaterzeitung, 32 (1780), S. 497-510. Im ersten Teil werden die Verhandlungen zwischen dem Dichter und einem Grafen auf die Bühne gebracht, der »eine Komödie, wo man weint «, in Auftrag gibt. Da das Stück nicht viel kosten soll, schlägt der Dichter ein »Monodram « vor. Seine Frau wird die Hauptrolle übernehmen, der Schulmeister kann den musikalischen Part übernehmen ("Ja wohl. Wie ich mit dem gnädigen Herrn in der Stadt war, wo ich immer den Kammerdiener vorstelle, da hab ich's wohl gesehen. Alle zwey oder drey Worte wird dazu gegeigt. « [S. 503]) Ein Chor aus vier Sängern genügt. Zu Didos erstem Auftritt heißt die Anmerkung für den Musiker: »Anmerkung für den Tonkünstler. Die Musik muß in dem Ton geschrieben seyn, wie es der Dichter im Prolog verlangte; und bey jedem Gedankenstrich muß die Musik einfallen. « (S. 505) Dido hat drei affektgeladene Auftritte und legt besonderen Wert auf Stottern und Stammeln. ("Wirst begreifen, lieber Leser, daß die Rolle der Dido zum Schreyen eingerichtet ist. Ein Hauptverdienst im Melodram. «) Der Chor versucht am Ende, Dido vor dem Selbstmord zu bewahren. Allerdings ersticht sie »in Wuth « ihre Helfer und dann sich selbst, um mit einem Sprung ins Feuer zu enden. »Ein großes Ballet beginnt, in welchem die vier todtgestochenen aufstehn, und gar niedlich mittanzen. « (S. 510) Die satirischen Überzeichnungen charakterisieren die melodramatischen Verfahren.

${ }^{97}$ Vgl. S. 282.

${ }^{98}$ So bei Schimpf, a.a.O., S. 64-67.
} 


\section{Von der vertu zum Affekt}

überlieferten) musikalischen Begleitungen oder Untermalungen ${ }^{99}$ die Schauspielerin selbst in den Mittelpunkt des Interesses eines ebenso aristokratischen wie bürgerlichen Publikums treten ließ. Damit wurde am Ende des 18. Jahrhunderts ein ständeübergreifendes Publikum erreicht, im Unterschied zur Kantate, die eher für den privaten Gebrauch intimer und elitärer Zirkel bestimmt war. Dies gilt auch für die etwa gleichzeitig in Mode kommenden Attitüden, die durch noch weitergehende Reduktionen auf die Gestik als aristokratische Variante des Monodramas aufgefasst werden können.

\section{Attitüden: Das Motiv des ıschönen Sterbens` in den neuen Ausdruckskünsten}

Verwundert und konsterniert berichtet Marianne Krauss, die Kammerfrau der Malerin Angelika Kauffmann, von einer Frühstückseinladung der Gräfin Solms in Neapel, bei der Lady Hamilton [Abb. 1] einige ihrer bekannten Attitüden aufführte. Neben ihrer Herrin hatten sich auch der Maler Friedrich Rehberg (1758-1835) und der Antiquar Johann Friedrich Reifenstein (1719-1793) eingefunden.

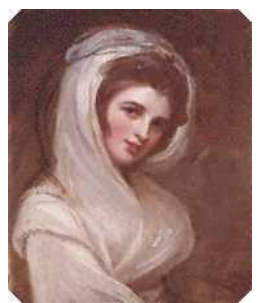

Abb. 1

[...] ich schämte mich meiner starken Nerven, wie ich so Alles, Damens und Herren, weinen sah. wenns ichs so vorgesehen hätte, ich würde mir Sals mitgenommen haben. da sizte also die holzige Kraus neben einer Angelika, die so laut schlukte, das sich steine hätten bewegen können. Der arme Reheberg sah aus wie ein Knabe der düchtige schläge vom H. Schulmeister bekömt, H. Reifenstein weinde doch noch ziehrlich, man konnte die langsam herabrollenden andikischen Tränen zehlen. Miss Schinkens stand das weinen nicht sehr übel, es war der todten blassen gesichtsfarben sehr angemessen. Gräfin Solms weinde sich fast die Nase wider in jhre alte formen. der hofmeister von den prinzen Schwarzenberg weinde auch bitterlich. ${ }^{100}$

Die neue Kunstform der Attitüden, die zur Verblüffung der Kammerzofe in der Frühstücksgesellschaft von Erschütterung und Tränen begleitete sentimentale Affektausbrüche auslöste, wurde am Ende des 18. Jahrhunderts zur modischen Unterhaltung der europäischen Oberschichten. Wie Kammerkantate und Monodrama verlangte die neue theatralische Form, einer Performance vergleichbar, Konzentration und Beschränkung auf einen emotionsgeladenen tragischen Moment, wozu sich Entscheidungs- und Abschiedssituationen anboten. Die frühneuzeitliche In-

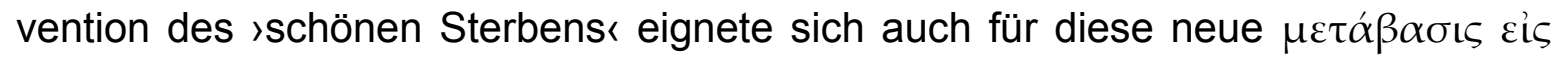

\footnotetext{
${ }^{99}$ Zur musikalischen Begleitung von Monodramen vgl. Jiránek, Jaroslav: "Zur Geschichte des Melodramas «, in: http://publib.upol.cz/ obd/fulltext/Musicologica\%206/musicol6-8.pdf (letzter Aufruf: 16.08.2006)

100 Krauss, Marianne: Sammlung von Allerlei für mich gemerkt auf meiner Reise nach Italien zu Anfang des Jahres 1791, hrsg. von Fritz Muthmann, in: Neue Heidelberger Jahrbücher, 1931, S. 95-177, hier S. 138.
} 


\section{Von der vertu zum Affekt}

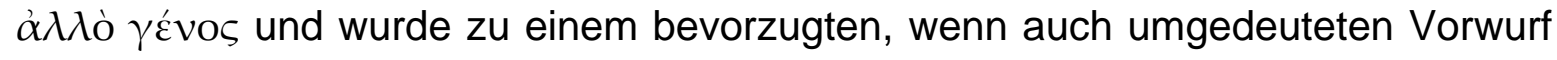
der Attitüden.

Die wortlose Kunstform der Attitüden gehört ebenso wie die Monodramen in die Epoche der Empfindsamkeit. Im Gegensatz zu Monodramen waren Attitüden allerdings für ein kleines, ausgesuchtes und intimes Publikum bestimmt. Goethes berichtet in seiner Italienischen Reise früh über solche Attitüdeninszenierungen:

Wenn man in Rom gern studieren mag, so will man hier [Neapel] nur leben; man vergißt sich und die Welt und für mich ist es eine wunderliche Empfindung nur mit genießenden Menschen umzugehen. Der Ritter Hamilton, der noch immer als englischer Gesandter hier lebt, hat nun, nach so langer Kunstliebhaberei, nach so langem Naturstudium, den Gipfel aller Natur- und Kunstfreude in einem schönen Mädchen gefunden. Er hat sie bei sich, eine Engländerin von etwa zwanzig Jahren. Sie ist sehr schön und wohl gebaut. Er hat ihr ein griechisch Gewand machen lassen, das sie trefflich kleidet, dazu löst sie ihre Haare auf, nimmt ein paar Shawls und macht eine Abwechslung von Stellungen, Gebärden, Mienen etc., daß man zuletzt wirklich meint man träume. Man schaut, was so viele tausend Künstler gerne geleistet hätten, hier ganz fertig, in Bewegung und überraschender Abwechslung. Stehend, knieend, sitzend, liegend, ernst, traurig, neckisch, ausschweifend, bußfertig, lockend, drohend, ängstlich etc. eins folgt aufs andere und aus dem andern. Sie weiß zu jedem Ausdruck die Falten des Schleiers zu wählen, zu wechseln, und macht sich hundert Arten von Kopfputz mit denselben Tüchern. Der alte Ritter hält das Licht dazu und hat mit ganzer Seele sich diesem Gegenstand ergeben. Er findet in ihr alle Antiken, alle schöne Profile der Sicilianischen Münzen, ja den Belvederschen Apoll selbst. Soviel ist gewiß, der Spaß ist einzig! Wir haben inn schon zwei Abende genossen. ${ }^{101}$

Als Emma Hart zwei Monate später erneut »ihre musikalischen und melischen Talente « präsentierte, entdeckte Goethe den klassizistischen Hintergrund der Invention und zugleich den Bildcharakter der Attitüden, die »antike Gemälde « und »selbst neuere Meisterwerke« saufführten` und deshalb im Grunde eines Rahmens bedurften. ${ }^{102}$

\section{Exkurs: Illuminationen, >lebende Bilderı und Attitüden}

Die Attitüden waren keine Invention der Lady Hamilton. Die seit 1782 für die Erziehung der königlichen Kinder verantwortliche aristokratische Schriftstellerin Stéphanie-Félicité de Genlis (1746-1830) hat wohl als erste slebende Bilder und Attitüden einstudiert, wobei sie sich gelegentlich der Hilfe des Malers Jacques-Louis David (1748-1825) versicherte. Das neue Inszenierungsmuster unterhielt den Hofadel in

\footnotetext{
${ }^{101}$ Italienische Reise, 16. März 1787; MA, Bd. 15, S. 257-258.

102 „Auffallend war mir ein aufrechtstehender, an der Vorderseite offener, inwendig schwarzangestrichener Kasten, von dem prächtigsten goldenen Rahmen eingefaßt. Der Raum groß genug um eine stehende menschliche Figur aufzunehmen, und dem gemäß erfuhren wir auch die Absicht. Der Kunst- und Mädchenfreund, nicht zufrieden das schöne Gebild als bewegliche Statue zu sehen, wollte sich auch an ihr als an einem bunten, unnachahmbaren Gemälde ergötzen und so hatte sie manchmal innerhalb dieses goldenen Rahmens, auf schwarzem Grund vielfarbig gekleidet, die antiken Gemälde von Pompeji und selbst neuere Meisterwerke nachgeahmt. Diese Epoche schien vorüber zu sein, auch war der Apparat schwer zu transportieren und ins rechte Licht zu setzen; uns konnte also ein solches Schauspiel nicht zu Teil werden. « (Italienische Reise, 27. Mai 1787; ebd., S. 403)
} 


\section{Von der vertu zum Affekt}

den Sommermonaten auf dem Lande und bot jungen Damen die Gelegenheit, spielerisch anmutiges Verhalten und graziöse Posen zu erlernen. ${ }^{103}$

Gerade in Frankreich unterschieden sich Attitüden nicht immer scharf von der Inszenierung >lebender Bilderı, für die sich verschiedene Vorläuferformen nachweisen lassen. ${ }^{104}$ Doch finden sich Unterscheidungsmerkmale schon in den Frühformen: Tableaux vivants sind an eine Bühne gebunden, auf der meist mehrere Personen ein wirklich vorhandenes oder auch nur gedachtes Gemälde nachstellen. Die meist mythologischen oder historischen Themen verdanken sich der Historienmalerei; später finden sich auch Motive aus dem Genre. Die Mitspielenden, die eigentlich Mitstellende genannt werden müssten, arrangierten sich hinter einem Vorhang. Wurde dieser geöffnet, war absolute Bewegungslosigkeit oberstes Gebot, da dem Publikum für ein oder zwei Minuten die Illusion eines Gemäldes geboten werden sollte. ${ }^{105}$

Attitüden teilen mit dem >lebenden Bild die Bewegungslosigkeit. Ohne Bühne und Vorhang wurden sie vor den Augen aller aus der Bewegung heraus entwickelt, wenn eine Künstlerin die Hauptperson eines realen oder fiktiven Gemäldes oder eine antike Statue nachstellte. Sorgfalt wurde auf Beleuchtung und einen meist dunklen Hintergrund gelegt. Die eingenommene Pose hielt als zum Zitat verdichtete Abbreviation den dramatischen Moment einer Entscheidungssituation fest: Handlung und Katharsis gehen in einem sprachlosen, Transitorisches festhaltenden Moment ineinander über. ${ }^{106}$

Diese eigenartige Form der Antikenrezeption setzte einen Bildungsfundus voraus, über den nur die europäische Oberschicht des ausgehenden 18. Jahrhunderts verfügte, die im Grand Tour ${ }^{107}$ die Originale, aber auch museale Inszenierungen kennengelernt hatte, die dem sich auf Bildungsreise befindenden Publikum durch Illuminationen und andere Inszenierungsformen einen neuen Zugang zu den antiken Werken verschaffen wollten. ${ }^{108}$ Das imaginierende Betrachten antiker Skulpturen setzte auf die Einbildungskraft des Betrachters und ließ die antiken Statuen sbelebtı, satmend in die Rolle des Pygmalion hinein. Illuminatione n, von denen auch Goethe in der Italienischen Reise berichtet, ıverlebendigtenı Skulpturen. Der nächtliche Besuch eines Antikensaals bei Fackelbeleuchtung konnte durch Licht- und Schattenspiel reale Körperlichkeit vortäuschen. ${ }^{109}$

\footnotetext{
${ }^{103}$ Vgl. dazu vor allem Birgit Jooss, a.a.O., S. 93-97.

104 Zwei neuere Untersuchungen arbeiten auch die ältere Forschungsliteratur auf: Ittershagen, Ulrike: Lady Hamiltons Attitüden, Mainz 1999 und Jooss, Birgit: Lebende Bilder, Körperliche Nachahmung von Kunstwerken in der Goethezeit, Berlin 1999; vgl. außerdem Egger, Irmgard: »Eikones: zur Inszenierung der Bilder in Goethes Romanen« in: Goethe-Jahrbuch 2001, Weimar 2002, S. 260-273.

${ }^{105}$ Vgl. Jooss, a.a.O., S. 94 und den sehr materialreichen Aufsatz von Langen, August: »Attitüde und Tableau in der Goethezeit«, in: Jahrbuch der Deutschen Schillergesellschaft 12 (1968), S. 194-258.

${ }_{106}^{\text {} M m e . ~ D e ~ G e n l i s ~ a i m a i t ~ a ̀ ~ o f f r i r ~ l e ~ s p e c t a c l e ~ d e ~ P a m e ́ l a ~ d a n s ~ u n e ~ a t t i t u d e ~ t h e ́ a ̂ t r a l e ~ a ̀ ~ t o u t ~ m o m e n t, ~ d a n s ~ u n ~}$ salon, une promenade ou en visite. Elle disait ainsi: ১Paméla, faites Héloïse!` Paméla enlevait alors son peigne. Ses longs cheveux tombaient en lourdes boucles sur ses reins. Elle se précipitait un genou en terre, le dos courbé, un bras levé, les yeux portés au ciel, figée dans une extase passionnée. On comprend que tous ceux qui assistèrent à ce tableau vivant improvisé en reçurent une impression profonde! Zitiert nach Jooss, a.a.O., S. 95.

${ }^{107}$ Vgl. Wilton, Andrew / Bignamini, llaria (Hrsg.): AK Grand Tour, The Lure of Italy in the Eighteenth Century, London 1996; Allen, Brian: „Die Grand Tour der Briten, Künstler und Reisende in Rom in der Mitte des 18. Jahrhunderts «, in Baumgärtel, Bettina (Hrsg.): AK Angelika Kauffmann, Ostfildern-Ruit 1998, S. 47-51.

${ }^{108}$ Vgl. Diers, Michael: »(Nach-)Lebende Bilder. Praxisformen klassizistischer Kunsttheorie«, in: Burdorf, Dieter / Schweickard, Wolfgang (Hrsg.): Die schöne Verwirrung der Phantasie, Tübingen 1998, S. 175-205.

${ }^{109}$ Ein interessantes Beispiel dokumentiert Karl August Böttigers 1808 veröffentlichter Aufsatz »Die Dresdner Antikengalerie bei Fackelbeleuchtung gesehen « (Angaben bei Langen, a.a.O., S. 208). Auch Louise Seidler berichtet aus der Zeit ihres Romaufenthalts (1818-1823) von einer für die romantische Freundes- und Künstlergruppe veranstalteten Illumination und ihrem nachhaltigen Eindruck: »Unbeschreiblich war der Eindruck, als einst Herr von Quandt nächtlicher Weile die unübersehbare Galerie der plastischen Bildwerke [im Vatikan] durch Fackeln beleuchten ließ. Die Statuen schienen Leben zu athmen, so frappant wirkte die düsterrothe
} 


\section{Von der vertu zum Affekt}

Die Verfahren der slebenden Bilder de $n$ gesteigert; sie ermöglichten eine noch intensivere Vergegenwärtigung der Antike, weil sie stets als Serien einstudiert wurden. Eine isolierte Attitüde genügte nicht; immer wurde eine Reihe unterschiedlicher Posen hintereinander eingenommen, so dass Horace Walpole, als er 1791 maliziös die nicht standesgemäße Verehelichung des britischen Diplomaten mit Emma Hart kommentierte, dieses Reihungsprinzip hervorhob: "Sir William Hamilton has actually married his gallery of statues. « ${ }^{110}$ Aufzeichnungen verschiedener Teilnehmer an derartigen Veranstaltungen belegen, dass Attitüden meist auf Gefühlskontraste abzielten: Die Verzweiflung der Niobe ging in den Rausch einer Bacchantin über, die sich in eine ruhende Sphinx verwandelte, um wenige Minuten später in eine sterbende Kleopatra umgeformt zu werden.

In das Stammbuch der Attitüdenkünstlerin Hendel-Schütz (1772-1849) hat der Dichter Zacharias Werner ein langes Huldigungspoem ${ }^{111}$ eingetragen, das detailliert über die Verfahren der Künstlerin unterrichtet. Sie stellte zunächst Isis, eine Sphinx und Galathea dar, um danach Maria bei der Verkündigung, unter dem Kreuz, als Pietà und bei der Himmelfahrt zu inszenieren. Den Abschluss dieser Serie bildeten die antiken Frauenfiguren Pythia, Kleopatra, Virginia, Arria und Kassandra. Gegensätzliche Seelenzustände in kurzer Zeit überzeugend vorzustellen und damit beim Publikum Tränen hervorzurufen, galt als höchstes Ziel der künstlerischen Performance. Krise oder Kairos einer mythologischen oder historischen Figur zu veranschaulichen, blieb zentrale Aufgabe der hybriden Kunstform. ${ }^{112}$

Friedrich Rehbergs (1758-1835) Zeichnungen geben einen, wenn auch unvollständigen, Eindruck davon, über welches Attitüdenrepertoire Lady Hamilton verfügte; sie wurden schon 1794 von Tommaso Piroli (um 1752-1824) als Umrisse in Flaxmans Art gestochen: eine Sybille, Maria Magdalena [Abb. 2], eine verliebte einsame Träumerin, Sophonisbe, Amymone, eine Muse des Tanzes, Iphigenie, eine Nymphe, eine Priesterin, Kleopatra [Abb. 3], die Heilige Rosa und Niobe [Abb. 4]. ${ }^{113}$ In ganz Europa sorgte die graphische Dokumentation der Attitüden der Lady Hamil-

Gluth, der hin- und herschwankende Schatten. All das Große, das Erhabene trat doppelt siegreich und majestätisch in die Erscheinung, und manches früher Uebersehene entzückte jetzt; so die Gruppe eines Ehepaares, das sich die Hände reicht. Etwas Innigeres kann man kaum sehen; Rauch hat denn auch später diese Idee zum Grabmale des Niebuhrschen Ehepaares benutzt. (Kaufmann, Sylke [Hrsg.]: Goethes Malerin, Die Erinnerungen der Louise Seidler, Berlin 2003, S. 244)

110 Das Zitat stammt aus einem am 11.9.1791 verfassten Brief Walpoles an Marry Berry. (vgl. Ittershagen, a.a.O., S. 41). Lady Hamilton weckte in der europäischen Gesellschaft auch später noch eine gewisse Sensationslust. Karoline Jagemann berichtet von einer Einladung bei der Familie von Arnstein während ihrer Wiener Ausbildungszeit als Sängerin: »In ihrer hübschen Behausung sah man täglich Fremde aus allen Ländern, auch Lord Nelson mit der durch ihre Attitüden bekannten Lady Hamilton wurde erwartet. Nach vielen Stunden der Ungewissheit, ob die Herrschaften der Einladung Folge leisten würden, erschienen sie endlich; Nelson, ein kleiner, magerer Mann mit einem Auge und einem Arm, dem man den Helden nicht ansah, Lady Hamilton eine hohe, stattliche Gestalt mit dem Kopfe einer Pallas, hinter ihm drein, seinen Hut unter dem Arme tragend. Sie blieben den ganzen Abend und ließen ihre Wirte in der größten Satisfaktion über die innen gewordene Ehre zurück. « In: Die Erinnerungen der Karoline Jagemann, hrsg. von Eduard von Bamberg, Dresden 1926, S. 151152.

${ }^{111}$ Schütz, Karl-Friedrich Julius: Blumenlese aus dem Stammbuche der deutschen mimischen Künstlerin Frau Henriette Hendel-Schütz, gebornen Schüler, Leipzig / Altenburg 1815, S. 27-35.

${ }^{112}$ Renis Halbfigurenbilder, die sich auf einen Affekt konzentrierten und durchaus als Serien verstanden werden können, erproben bereits Verfahren der Reduktion, wie sie später in den Attitüden üblich wurden.

${ }^{113}$ Die Serie erschien 1794 in Rom unter dem Titel: Friedrich Rehberg \& Tommaso Piroli: Drawings Faithfully copied from Nature at Naples and with permission dedicated to the Right Honourable Sir William Hamilton. Katalog 303 und 304. 


\section{Von der vertu zum Affekt}

ton für die Verbreitung der neuen Inszenierungskunst; sie wurde als Vorlage von Attitüden-Künstlerinnen, aber auch Malern benützt. Deshalb folgten viele Neuauf-

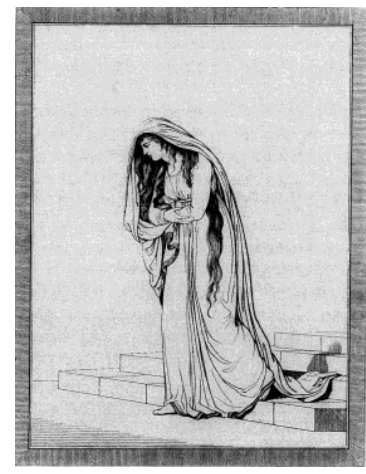

Abb. 2

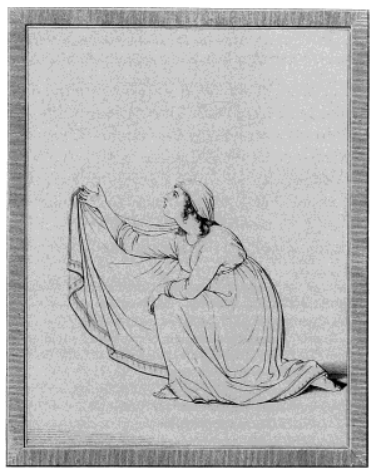

Abb. 3

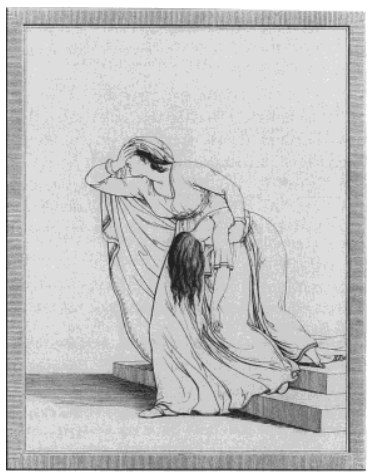

Abb. 4

Lagen und Neuzusammenstellungen, die auch durch Stiche pompejanischer Wandmalerei ${ }^{114}$ ergänzt wurden, um dem antikisierenden Zeitgeschmack entsprechend die Attitüden in einen Zusammenhang mit Tanzdarstellungen des Altertums zu bringen.

Das Motiv der sterbenden Sophonisbe findet sich als Blatt IV im Stichwerk von Piroli. [Abb. 5] Die Königin, in der Frühen Neuzeit vornehmlich durch Stärke und Standhaftigkeit charakterisiert und entsprechend ins Bild gesetzt, wurde von Lady Hamilton äußerst emotionalisiert inszeniert. Das aufgelöste Haar, das aufwärts gewandte Gesicht, der geöffnete Mund steigern den Gesamteindruck ins Schmerzvolle. ${ }^{115}$ Die Künstlerin ahmt die Gestik einer Verzweifelten nach, wobei die Anleihen bei Reni überdeutlich sind. In breiter ausladender Bewegung beider Arme wird zwischen der Trinkschale in Sophonisbes rechter Hand und dem kleinen Giftgefäß auf einer Säule ein Bogen gespannt. Mit dem angewinkelten linken Arm stützt sich die Protagonistin auf die Säule und nimmt so eine konventionell als Trauer und Kontemplation verstandene Haltung ein. ${ }^{116}$ Den stärksten Ausdruck erzielt die Künstlerin durch das `Haareraufen`, mit dem seit der Antike Frauen ihre Trauer

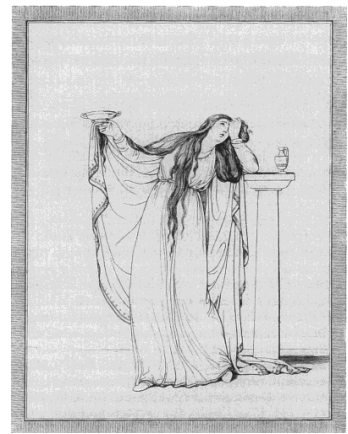

Abb. 5

\footnotetext{
${ }^{114}$ Ausführlich dazu Köhn, Silke (Hrsg.): AK Lady Hamilton und Tischbein, Der Künstler und sein Modell, OIdenburg 1999, S. 15-16. Außerdem Ittershagen, a.a.O., S. 72-110.

${ }_{115}$ Alois Hirt charakterisiert die Inszenierung folgendermaßen: „Vierte Figur. Sie hat die Stellung einer Sofonisbe, stehend, in der Rechten die Giftschale ausgestreckt haltend, ihr Körper seitwärts gelehnt, und das Haupt - die Augen gen Himmel - auf die linke Hand gegen die Säule stützend. Alles drückt das Ringen mit dem Entschluß des Todes aus. « (VI. Kunstanzeige [zu Lady Hamiltons Attitüden], in: Der neue Teutsche Merkur, 2 (1794), S. 415)

${ }^{116}$ Vgl. Ittershagen, a.a.O., S. 91.
} 


\section{Von der vertu zum Affekt}

öffentlich machten. Das nur mäßig gefältelte griechische Gewand lässt auch in dieser angespannten und verzweifelten Haltung noch einen ausgewogenen Kontrapost erkennen.

Die Sophonisbe-Attitüde der Lady Hamilton verdeutlicht, dass sich die Bilddramaturgie der `Selbstmörderin als Tugendheldin` seit der Frühen Neuzeit völlig verändert hat. Stand im neustoischen Bildprogramm Sophonisbes Tod als Beispiel für die Selbstbehauptung einer ıstarken Frauı, tritt nunmehr die Affektdarstellung völlig in den Vordergrund. In einer Attitüdenperformance mythologischer oder historischer Figuren wurden offensichtlich extreme Affekte dargestellt und inszeniert. Die romantischen Betrachter der Sophonisbe-Attitüde interessierten sich nicht mehr für neustoische constantia und den Konflikt von Liebe und Politik, sondern für den verzweifelten Seelenzustand einer zum Selbstmord entschlossenen Frau. ${ }^{117}$ Die immer noch vorausgesetzte historische Reminiszenz dient nur noch als Ausgangspunkt einer Performance, für die der weibliche Körper zur `Einschreibeflächeı für Wandlungen der Seele wird. ${ }^{118}$ Die Modifikationen des Körperausdrucks, auf die die Attitüdenkunst setzt, bringen die psychischen Folgen eines absoluten Affekts zum Ausdruck, versteht man sie als »natürliche Folgen der inneren Beschaffenheit der Seele « ${ }^{119}$, wie es Johann Jakob Engel in seinen Ideen zu einer Mimik formulierte. Das allmähliche Verblassen des neustoischen Tugendbegriffs, der den Affekt nur als Gegenpol benötigte, zeigt sich darin, dass die romantische Attitüde nur noch auf die Affektdarstellung abhebt. ${ }^{120}$

\footnotetext{
${ }^{117}$ Bezeichnenderweise wählte Lady Hamilton für ihre Inszenierung der Kleopatra aus den zahlreichen denkbaren Episoden den Kniefall vor Octavian. Der Epochengeschmack forderte eine ägyptische Königin, die sich demütigt, und nicht eine selbstbewusste Frau, die ihren Selbstmord wählt, um einer (politischen) Erniedrigung zu entgehen.

${ }_{118}$ Es gab übrigens bezeichnenderweise nur einen einzigen männlichen Attitüdenkünstler, Gustav Anton Freiherrn von Seckendorff (1775-1823), der unter dem Künstlernamen Patrik Peale auftrat und dem nicht zufällig homosexuelle Neigungen nachgesagt wurden. Er wird in einem Brief der Friederike Brun an Caroline von Humboldt vom 13. April 1811 erwähnt: »[...] Wir haben hier [in Kopenhagen] den berühmten Pantomimen Deklamateur - Bildsäulen - u. Gemählde-Darsteller Patrick Peale (Sein wahrer Nahmen ist Seckendorff und Er war einst Cammerpräsident in Hildburghausen, welchen Posten Er aufgab weil der Fürst immer mehr Geld für Seine Maitreßen brauchte als der Präsident schaffen konnte. Nun lebt Er nebst der Frau u 3 Kindern von Seinem Talent - ach jämmerlich gering! Er ist voll Geist $u$. Seine Pantomimie u Deklamation ist vortrefflich. Allein Er will zu viel lästern - u hat hier Ärgerniß gegeben durch mahlerische Darstellung der Leiden Christi im Oelberg - u der Himmelfarth. Dies sind auch für mich ärgerliche Spielereien. Aber Wilhem Tell - Lord Lester Macbeth - sollten Sie ihn deklamiren hören - u Erlkönig! U alte Gemählde darstellen! Hier sind wir für all' das noch nicht gebohren; u wenn Er die Progreßion der Kunst von der Mumie, zum ersten aiguptischen Bildhauerwerk - bis zum Apoll v. Belvedere darstellt sollten Sie die Urtheile des Auditoriums hören! Allein vor allem sollte er nach Rom gehen! [...]« (zitiert nach Foerst-Crato, Ilse: Frauen zur Goethezeit, Ein Briefwechsel, Caroline von Humboldt - Friederike Brun, Düsseldorf [Eigenverlag] 1975, S. 31).

${ }^{119}$ Engel, Johann Jakob: Ideen zu einer Mimik, Berlin 1785, 2 Bde, hier Bd. 1, S. 8.

120 Ein weiteres Indiz für diese Entwicklung findet sich in einer anderen Kunstgattung. Auch Roll e n port $r$ äts von Damen der Gesellschaft scheinen in der Romantik zum ersten Mal das Thema der profanen Tugendheldinnen aufzugreifen. So ließen sich die Fürstin Maria Santacroce von Angelika Kauffmann als Lukretia (Katalog 220) und Kitty Fisher von Joshua Reynolds als Kleopatra (Katalog 221) malen, obwohl die Identifika-
} 


\section{Von der vertu zum Affekt}

Attitüden-Soireen und >lebende Bilderı konnten geradezu als »künstlerische Abendandachten « ${ }^{121}$ gestaltet werden, wie sie Joseph von Eichendorff in seinem 1815 veröffentlichten Roman Ahnung und Gegenwart schildert. Dass die Versenkung in eine solche Performance sehr weit gehen und pseudoreligiöse Züge annehmen konnte, demonstriert auch E.T.A. Hoffmanns Erzählung Nachricht von den neuesten Schicksalen des Hundes Berganza ${ }^{122}$. In einer kleinstädtischen Gesellschaft wird die ıHeilige Cäcilieı nach dem heute in Dresden befindlichen Gemälde Carlo Dolces nachgestellt. Die Begeisterung vieler Zuschauer ist so groß, dass sie bei dem Ausruf »Sancta Caecilia, ora pro nobis « wie vor einem Altarbild in die Knie sinken. ${ }^{123}$

\section{Das Ende eines Motivs}

‘Lebende Bilder und Attitüden lösen sich um 1800 weitgehend vom historischen Vorwurf des jeweils nachgestellten Historiengemäldes oder der zu Geste reduzierten Figur, den das Publikum allenfalls im Allgemeinen kennen musste. Das historische Repertoire wird nur noch aufgerufen, um dem aristokratischen oder bürgerlichen Salonpublikum psychologische Extremsituationen als anthropologische Konstanten anzubieten. Die Identifikation der Betrachter und die starke, gefühlsmäßige Reaktion des versammelten intimen Zirkels sprivatisiertı gleichsam das immer noch vorausgesetzte Historiengemälde. In diesem Sinn knüpft die Attitüde an das von Reni entwickelte einfigurige Historienbild an und radikalisiert die Individualisierung

tion mit Selbstmörderinnen gewisse Schwierigkeiten bereitete. Die ästhetische Instrumentalisierung antiker Mythologie und Geschichte nobilitierte die porträtierten jungen Frauen (vgl. hierzu und zum Folgenden Tasch, Stephanie Goda: Studien zum weiblichen Rollenporträt in England von Anthonis van Dyck bis Joshua Reynolds, Weimar 1999) und erklärt die schon lange beliebten Rollenporträts als Schäferin, Diana oder Hebe. Im 18. Jahrhundert kamen Porträts als Priesterinnen der Vesta, der Minerva, des Hymen, der Diana oder der Hygeia hinzu, die um 1800 von weiblichen Freundschaftsbildnissen abgelöst wurden. Als um die Jahrhundertwende der Empfindsamkeitskult den Melancholiegestus im Rollenporträt bevorzugen ließ, der weibliche Versonnenheit und Empfindsamkeit zum Ausdruck bringen sollte, konnten Rollenporträts auch für diesen Zweck eigentlich problematische Figuren wie Lukretia und Kleopatra aufgreifen. Es ist kein Zufall, dass George Romney Lady Hamilton selbst 1786 als Empfindsamkeit porträtierte (Abb. bei Tasch, a.a.O., S. 388). Die Entwicklung des Rollenporträts zeigt, dass die Bildreferenz sich nicht mehr auf eine mythologische oder historische Rolle, sondern nur noch auf den von dieser transportierten Gemütszustand (sensibility) bezog. Gerade Angelika Kauffmann popularisierte das neue, sentimentalische Weiblichkeitsideal. Deshalb ist die von Bettina Baumgärtel vertretene, allerdings von keinen bildimmanenten Hinweisen gestützte Auffassung unnötig, das Rollenbildnis der Maria Santacroce von 1791 deute die Rolle der Lukretia so um, dass eine Vision sie im letzten Moment vom Selbstmord abhalte (AK Angelika Kauffmann, a.a.O., S. 302). Die Referenz auf die sstarken Frauen ist nur noch punktuell und belegt, dass die neustoische Deutung endgültig in Vergessenheit geraten war.

${ }^{121}$ Eichendorff, Joseph von: Werke, hrsg. von Wolfdietrich Rasch, München 1972, S. 660.

122 Hoffmann, Ernst Theodor Amadeus: Fantasie- und Nachtstücke, hrsg. von Walter Müller-Seidel, Darmstadt 1978, S. $79-140$

${ }^{123}$ E.T.A. Hoffmann, a.a.O., S. 118. 


\section{Von der vertu zum Affekt}

des Affekts. ${ }^{124}$ War Sophonisbe als erste ıstarke Frau in den künstlerischen Kanon der profanen Tugendheldinnen der Frühen Neuzeit geraten, repräsentiert sie in der Attitüde der Romantik geradezu im Gegenteil die Mitleid erweckende weibliche Schwäche.

Die fortschreitende Banalisierung des Motivs ${ }^{125}$ zeigt sich auch in anderen Zusammenhängen, die bereits an das moderne Variété gemahnen. In einer Aufführung des Kärntnertortheaters wurde 1819 der Tod der Sophonisbe als slebendes Bild nach einem nicht mehr ermittelbaren Gemälde von Bartolomeo Pinelli (1781-1835) gegeben. ${ }^{126}$ Das bunte Programm umfasste neben Ouvertüren Beethovens Gesangstücke Rossinis, Gedichtrezitationen und ein Opernduett, um schließlich mit einem slebendes Bild nach Poussins Pariser Eliezer und Rebecca zu schließen. Die Programmfolge zeigt, dass hier die romantischen Performancekünste der slebenden Bilderı und der Attitüden den Zusammenhang mit aristokratischer und bürgerlicher Geselligkeit bereits verloren hatten. ${ }^{127}$ Die beiden slebenden Bilder wurden wahrscheinlich nur wegen ihrer erotischen Konnotationen in das Programm aufgenommen. Der mangelnden Information des Publikums konnte abgeholfen werden: Von Karl-Friedrich Julius Schütz, dem Ehemann der Attitüdenkünstlerin Hendel-Schütz, ist bekannt, dass er dem Publikum in den Aufführungspausen Gedichte zum Thema vortrug oder den dargestellten Mythos erläuterte.

Das Motiv der sstarken Frauen sank so im Laufe des 19. Jahrhunderts in die Banalität und diente nur noch als dekadenter Zeitvertreib einer spätbürgerlichen Gesellschaft, wie es Louis Couperus in seinem Haager Roman Eline Vere anschaulich schildert.

\footnotetext{
124 Überlegungen zum einfigurigen Historienbild bei Werner Busch in: Baumgärtel, Bettina (Hrsg.): AK Angelika Kauffmann, Düsseldorf 1998: »Das Einfigurenbild und der Sensibilitätskult des 18. Jahrhunderts « (S. 40-46).

${ }_{125}$ Zur europäischen Verbreitung der Performancekünste hatte die zum Wiener Kongress versammelte Gesellschaft beigetragen, für die während der ballfreien Advents- und Fastenzeit >lebende Bilderı gestellt wurden (vgl. Jooss, a.a.O., S. 128ff. und S. 259ff.).

${ }_{26}$ Ich folge den zeitgenössischen Presseberichten bei Jooss, a.a.O., S. 382.

127 Ein öffentliches Programm verlangte, anders als die privaten ^Aufführungen , in denen die Pausen zu Gesprächen der Kenner über die ikonographischen und mythologischen Referenzen des Gebotenen genutzt wurden, schematisierte Überleitungen und (bald gedruckte) Programme, die Gedichte oder Deutungen des erwarteten Tableaus umfassten. Der ökonomische Erfolg setzte trivialisierte Abwechslung und schnellen oberflächlichen Reiz durch die Verbindung von Wort, Musik und Pantomime voraus. Wenn Böttiger über einen Dresdner Auftritt der Hendel-Schütz im Jahre 1814 berichtet, zu den Marieninszenierungen sei hinter der Bühne das Harmonichord, ein neues Instrument, zur Intensivierung des Eindrucks gespielt worden (Langen, a.a.O., S. 219), zeigt dies, dass auch Verfahren des Monodramas in das entstehende Varieté Aufnahme fanden.
} 


\title{
$X$ Exempla virtutis
}

\author{
Respondit omnis populus, qui erat in porta, et majores \\ natu: Nos testes sumus: faciat Dominus hanc mulierem, \\ quæ ingreditur domum tuam, sicut Rachel et Liam, quæ \\ ædificaverunt domum Israël: ut sit ex emplum virtu- \\ tis in Ephratha, et habeat celebre nomen in Bethlehem. \\ Rt $4: 11^{1}$ \\ Et iste quidem hoc modo vita decessit, non solum ju- \\ venibus, sed et universæ genti memoriam mortis suæ \\ ad exemplum virtutis et fortitudinis derelin- \\ quens. \\ 2Mcc 6:31 \\ Incitamur enim exemplo et quodam quasi stimulo ad \\ virtutem impellimur, cum aliorum benefacta legimus vel \\ audimus. \\ Coluccio Salutati, ep.II,18
}

Das frühneuzeitliche Bildmotiv der Selbstmörderin als Tugendheldin war ein erstaunlicher Erfolg; seine Rezeptionsgeschichte reicht bis ins 19. Jahrhundert. Als neustoisch beeinflusstes exemplum virtutis wurde es durchaus in Konkurrenz mit den nach- und gegenreformatorischen Bildwelten konzipiert. Allmählich verschob sich das Interesse am Bildmotiv von der Tugend zum Affekt; am Ende stand eine schon fast enthistorisierte Inszenierung. Diese allgemeine Entwicklungslinie teilt das Bildmotiv mit der entsprechenden Thematik auf der Theater- und Opernbühne, deren Umbesetzungen die Historienmalerei oft nur nachvollzieht. Allerdings sagt dies alles nur wenig über die von Künstlern oder Auftraggebern intendierte Sinnkonfiguration eines Einzelbilds aus. Die in kunstgeschichtlichen Abhandlungen und in der Präsentation von Ausstellungen üblich gewordene Deutung als exempla virtutis erfasst allenfalls die rhetorische Strategie, nicht aber den konkreten Bezug des Bildmotivs.

So richtig die These sein mag, dass das sich aus antiken und alttestamentlichen Quellen ableitende Bildmotiv der mulier fortis, zumal in der Variante der Selbstmörderin, dann seine provokative Faszination verliert, wenn der letzte Bezug

\footnotetext{
${ }^{1}$ Gemeint sind Ruth und, im folgenden Zitat, Eleazarus.
} 
zur frühneuzeitlich-stoischen Tugendlehre zugunsten der bloßen Affektkonfiguration verloren geht, so oberflächlich und vorläufig bleibt die Charakterisierung als Tugendexempel im Einzelfall. Es scheint deshalb sinnvoll, den Gedankengang dieser Untersuchung mit einigen Überlegungen zum Begriff des Tugendexempels in der neuzeitlichen Historienmalerei zu beschließen und dabei auch über die Beschränkung auf Tugendheldinnen hinauszugehen.

Nicht nur in der kunstgeschichtlichen Erörterung des Historiengemäldes hat das Konzept des exemplum virtutis, das auf alttestamentliche wie auf stoische Begriffe zurückgeht, eine bemerkenswerte Konjunktur. Literatur- und Kunstwissenschaftler rekurrieren gern auf diese wenig präzise Beschreibung, um Funktion und Bedeutung literarischer, künstlerischer oder rhetorischer Referenzen auf historische oder pseudohistorische Vorbilder darzustellen. Das Tugendexempel ist geradezu zum Inbegriff einer verbreiteten kunstgeschichtlichen Trivialhermeneutik geworden, mit der sich viele Bildvorwürfe mit leichter Hand einordnen lassen.

So kann es nicht überraschen, wenn auch im Katalog einer einschlägigen Ausstellung vom exemplum virtutis bei ganz verschiedenen Bildtypen topisch Gebrauch gemacht wird. Zu einem Gemälde von Sebastiano Conca mit dem verbreiteten Barockthema der Großmut des Scipio bemerkt Attilia Scarlini: "Sein

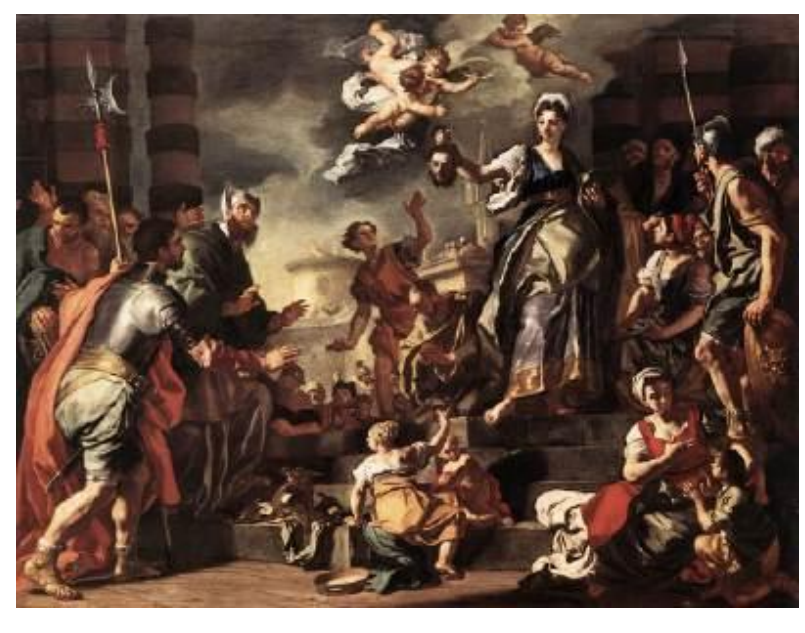

Abb. 1

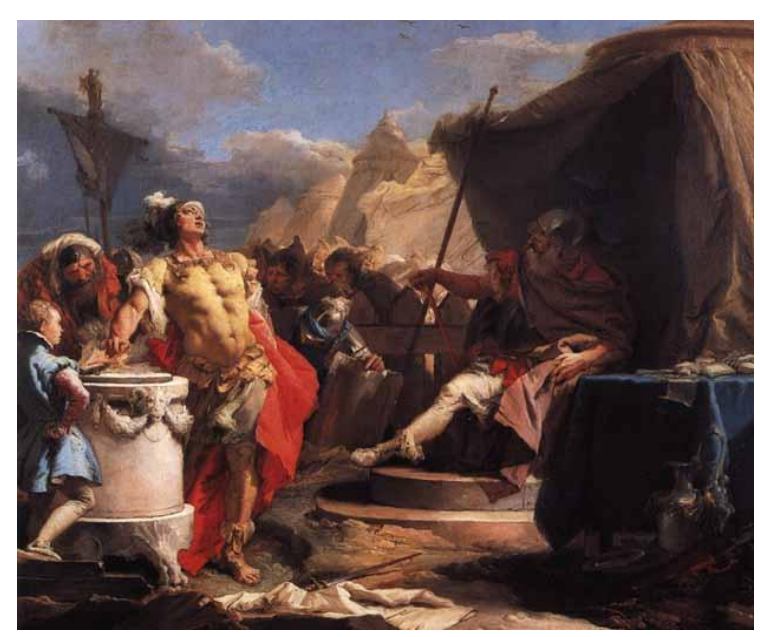

Abb. 2

[Scipios] Handeln liefert ein Beispiel für ehrenhaftes Benehmen und römische Tugendhaftigkeit. « Wenig später notiert Wolfgang Prohaska zu Solimenas Judith zeigt das Haupt des Holofernes [Abb. 1]: »Unter den alttestamentarischen Heroinen ist Judith diejenige, die als Exemplum Virtutis der Keuschheit und Vaterlandsliebe in der bildenden Kunst seit dem 15. Jahrhundert besonders häufig dargestellt wor-

\footnotetext{
${ }^{2}$ Mai, Ekkehard / Repp-Eckert, Anke (Hrsg.): AK Triumph und Tod des Helden, Europäische Historienmalerei von Rubens bis Manet, Köln 1987, hier S. 294.
} 


\section{Exempla virtutis}

den ist. ${ }^{3}$ Kurz darauf wird das gleiche Interpretationsmuster erneut eingesetzt, um Giambattista Tiepolos Mucius Scaevola vor Porsenna [Abb. 2] in einem etwas anderen Sinn als exemplum zu verstehen: Attilia Scarlini sieht in inm einen Stellvertreter für das ganze römische Volk, das sich gegen die Etrusker zur Wehr setzte: »Hiermit wird als Exemplum Virtutis ein ideales und mutiges Volk gefeiert, das sich auch in schweren Zeiten seiner eigenen Würde bewußt blieb. « ${ }^{4}$ Werden freilich die Protagonistin eines barocken Märtyrerdramas, die Zentralfigur eines Historiengemäldes oder der rhetorische Bezug auf ein Vorbild der Antike im politischen Diskurs der Frühen Neuzeit unterschiedslos als exempla virtutis bezeichnet, kann dies für Leser, Betrachter und Hörer nur als Mitteilung eines rhetorischen Verfahrens, nicht aber als differenzierender Interpretationsansatz dafür gelten, was die Verwendung der geläufigen Bildmotive im Einzelfall oder doch in einer Bildgruppe veranlasste. Das Explikationspotential dieser Begrifflichkeit bedarf also zumindest weiterer Präzisierung.

Im persuasiven Kontext der Rhe to rik erscheint das exemplum ${ }^{5}$ seit Aristoteles als seinfache Form ${ }^{6}$, die in politischer Rede, Historiographie, Philosophie und Dichtung eingesetzt wurde, um größere Anschaulichkeit zu erreichen. Kompilationen wie die besonders erfolgreichen Facta et dicta memorabilia des Valerius Maximus stellten Beispiele anthropologischer Standardverhaltensformen (wie iustitia, moderatio, crudelitas oder luxuria) zusammen und wurden als Tugend- und Lasterkataloge gelesen. In rhetorischen, literarischen und wohl auch bildkünstlerischen Zusammenhängen ${ }^{7}$ konnte auf diese bereits in der Antike weitgehend in die mémoire collective ${ }^{8}$ eingegangenen shistorischen Versatzstücke sten Weise, positiv oder negativ, Bezug genommen werden. Die geläufigen Verfahren der antiken Rhetorik wurden in lateinischen Texten von den Kirchenvätern bis zu den Humanisten, aber auch in volkssprachlichen Predigten, Novellen und Fürstenspiegeln übernommen. Zahlreiche mittelalterliche Exempelsammlungen, auch in den verschiedenen Volkssprachen, belegen die Verbreitung und Beliebt-

\footnotetext{
${ }^{3}$ AK Triumph und Tod des Helden, a.a.O., S. 305.

${ }^{4}$ AK Triumph und Tod des Helden, a.a.O., S. 308.

${ }^{5}$ Vgl. Georges, Karl Ernst: Ausführliches Lateinisch-deutsches Handwörterbuch, Hannover 1976 (ND der Ausgabe Gotha $\left.{ }^{14} 1913\right)$, s. v. exemplum. Exemplum wird abgeleitet von eximere, was sherausnehmen, auswählen bedeutet. So hat das vom Partizip Perfekt Passiv abgeleitete Nomen die Bedeutung: >ein aus der Menge glei-

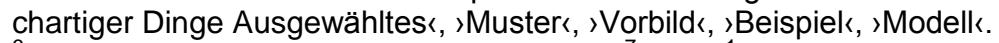

6 Jolles, André: Einfache Formen, Tübingen ${ }^{7} 1999$ ('1930).

${ }^{7}$ Darauf verweisen immerhin einige Bildbeschreibungen bei Plinius und römische Wandgemälde.

${ }^{8}$ Halbwachs, Maurice: La mémoire collective, Paris 1950 u.ö.
} 


\section{Exempla virtutis}

heit der Textsorte. ${ }^{9}$ Historische und mythologische Figuren fanden, ebenso wie Gestalten des Alten Testamentes oder Heilige natürlich auch in den Bildkünsten als exempla Verwendung.

Das exemplum übernahm dabei durchaus verschiedene Funktionen, wobei vor allem der implizite oder explizite Vergleich und die Veranschaulichung oder Konkretion abstrakter Sachverhalte in Frage kommen. Werden exempla in neue Zusammenhänge seinmontiertı, stehen sie in einem Analogie-, Vorbild- oder Kontrast-Verhältnis zur Figur, mit der sie verglichen werden. ${ }^{10}$ In den Bildkünsten handelt es sich dabei allerdings meist um einen impliziten Vergleich, den erst der Betrachter dechiffrieren kann, wenn keine weiteren Hinweise (etwa durch subscriptiones in Kupferstichen) gegeben werden. Andererseits kann ein exemplum moralische Sätze, politische Thesen oder Standesnormen veranschaulichen und mit einer historischen oder pseudohistorischen Figur konkretisieren. ${ }^{11}$ Die halballegorische Veranschaulichung abstrakter Tugenden (Tapferkeit, Patriotismus, Keuschheit, Gerechtigkeit, Gattenliebe) gehört in diesen Zusammenhang.

Das Spektrum der Wirkungsstrategien, die mit dieser Form abgekürzter Vergleiche verfolgt werden, ist ebenso umfassend wie die variierenden Funktionen des exemplum, das belehrend, beweisend, illustrierend, überzeugend, argumentierend, moralisierend oder unterhaltend sein kann. ${ }^{12}$ Schon der Florentiner Humanist Coluccio Salutati (1331-1406) hat aber darauf hingewiesen, dass die Überzeugungskraft des Exempels auf der affektischen Identifikation (oder auch Abstoßung) beruht, die es beim Leser, Zuschauer oder Betrachter auslöst. ${ }^{13}$ Der Hauptvertreter der neustoischen Philosophie, Justus Lipsius (1547-1606), hat mit der Spiegelmetapher die Wirkungsstrategie des Exempels in einer über die literarischen Formen hinaus auch für die Bildkünste gültigen Weise beschrieben: Exempla zwingen den Leser und Betrachter zu affektiver Identifikation und moralischer Anwendung. ${ }^{14}$

\footnotetext{
${ }^{9}$ Vgl. Chesnutt, Michael: s.v. »Exempelsammlungen« in: Enzyklopädie des Märchens, begr. von Ranke, Kurt, hrsg. von Brednich, Rolf Wilhelm, Bd. 4, Berlin / New York 1987.

${ }_{11}^{10}$ Klein, J.: »exemplum «, in: Historisches Wörterbuch der Rhetorik, Tübingen 1996, Bd. 3, S. 60-70.

${ }^{11}$ Dazu Stierle, Karlheinz in: "Geschichte als Exemplum - Exemplum als Geschichte« in: Koselleck, Reinhart / Stempel, Wolf-Dieter (Hrsg.): Geschichte - Ereignis und Erzählung, München 1973 (Poetik und Hermeneutik 5), S. 347-375, besonders S. 356.

12 Daxelmüller, Christoph in: Haug, Walter / Wachinger, Burghart (Hrsg.): Exempel und Exempelsammlungen , Tübingen 1991, S. 80.

${ }^{13}$ Das Zitat (ep.II,18) oben S.302 nach Landfester, Rüdiger: Historia Magistra Vitae, Untersuchungen zur humanistischen Geschichtstheorie des 14. bis 16. Jahrhunderts, Genf 1972, S. 58. ('Wir lassen uns durch ein Beispiel motivieren und zur Tugend antreiben und verleiten, wenn wir die guten Taten anderer lesen oder hören.ı).

14 „Vidistine etiam, qui ad speculum se comunt, faciem et cultum recte disponere? Prorsus hic idem: aliena vita et facta speculum sunt, et imago, in qua te videas et ad eam decore componas. Quod magis fit, vbi varia
} 


\section{Exempla virtutis}

Der Rekurs auf exempla virtutis in Rhetorik, Literatur und Kunst setzt nicht nur Ciceros Diktum vom moralischen Nutzen der Historie (» historia magistra vitae«) voraus, das bis zum Historismus Gültigkeit behielt. ${ }^{15} \mathrm{Er}$ geht auch von der relativen Konstanz anthropologischer Entscheidungssituationen und Handlungsmöglichkeiten aus und leitet aus vergangenen Ereignissen Normen und Regeln für künftige ab. Vergangenes Verhalten in einer Konfliktsituation wird im exemplum zur griffigen Moral oder Handlungsanweisung verdichtet und steht damit dem kulturellen Gedächtnis für nicht voraussehbare Kontexte und Applikationen zur Verfügung. Historische oder pseudohistorische Figuren und Handlungsmuster werden herausgehoben und zu Modellen gestaltet, deren Prägnanz im kollektiven Gedächtnis eines Kulturraumes eine wichtige Rolle übernimmt. Herausgehobene Personen und Verhaltensweisen in Konfliktsituationen ${ }^{16}$ werden für die kollektive Erinnerung semiotisch besetzt, stehen als exempla rhetorisch, literarisch und künstlerisch der interpretierenden Repetition zur Verfügung und tragen zur Identität und zum kulturellen Gedächtnis einer Gesellschaft, einer Gruppe oder eines Standes bei, die sich immer in der Auseinandersetzung mit der historischen oder mythischen Vergangenheit konstituieren. ${ }^{17}$ Exempel sind deshalb immer kulturraum- und gruppenspezifisch: Die exempla virtutis der Frühen Neuzeit reflektieren eine zeitlich und räumlich begrenzte kulturelle Semiotik und sind auch als solche untersuchenswert. Gleichwohl dispensiert dies nicht von der Frage nach der konkreten Funktion eines Textes oder eines Kunstwerks. Was im kulturellen Gedächtnis einer Epoche als exemplarisch gilt und damit kollektive Normen, Werte und Deutungen speichert, unterliegt ständigem Applikations- und Veränderungsdruck; jede literarische oder künstlerische Konkretisierung verändert, jedenfalls potentiell, das Muster.

\footnotetext{
et multiplex lectio Exempla varia et multa suppeditat: vt eligere sit, et ad rem talem aut talem appositum aliquid semper applicare. «(〉Hast du gesehen, wie Leute sich vor dem Spiegel Antlitz und Aussehen zurechtmachen? Noch mehr kann ein anderer Lebenslauf und können Handlungsweisen anderer als Spiegel dienen und als Bild, in dem du dich selbst erblickst und nach dem du dich richten kannst. Was noch besser gelingt, wenn viele und vielseitige Lektüren zahlreiche Exempel bereitstellen, so dass dir für jeden Sachverhalt eine Anwendungsmöglichkeit zur Wahl steht.ı) Aus: Monita et Exempla Politica (1605) in: Lipsius, Justus: Opera omnia, Bd. IV,1, S. 128 (ND Hildesheim/Zürich/New York 2001; zugrundegelegt ist die Ausgabe Wesel 1675).

${ }^{15}$ Cicero, De oratore II, 9,36. Vgl. Koselleck, Reinhart: Vergangene Zukunft, Zur Semantik geschichtlicher Zeiten, Frankfurt am Main 1979.

${ }^{16}$ In den Bildkünsten lassen sich in der Regel nur facta, nicht dicta verwenden, um in der Terminologie des Valerius Maximus zu bleiben.

${ }^{17}$ Assmann, Jan: Das kulturelle Gedächtnis. Schrift, Erinnerung und politische Identität in frühen Hochkulturen, München ${ }^{2}$ 1997, besonders S. 77-89.
} 


\section{$X$ Exempla virtutis}

Ebenso ambivalent und komplex wie der Begriff des Exempels ist der Tugendbegriff (und komplementär der Lasterbegriff). Durch exempla normativ vermittelte Handlungsmuster und Standardverhaltensformen sind gesellschaftsund gruppen- oder standesspezifische Leitbilder, die scheinbar unverändert Kontinuität der gültigen Werte unterstellen. Dabei ist der Begriff der `Tugend` in der Frühen Neuzeit noch nicht auf individuell-moralisches Verhalten reduziert, sondern gilt als komprimierte soziale Norm, die einen Anspruch transportiert, der in der Praxis nicht immer eingelöst werden kann - moralphilosophisch gesprochen ein »sittliches Seinsollen ${ }^{18}{ }^{18}$, Tugenden spiegeln in vormodernen Gesellschaften die Leitsemantiken kulturell führender Gruppen.

Obwohl sich seit der Frühen Neuzeit Veränderungen immer mehr beschleunigten, entstand paradoxerweise zunächst ein größerer Bedarf an exempla virtutis, vielleicht eine der Voraussetzungen für den Erfolg der Bildgattung des Historiengemäldes. Dies schließt jedoch nicht aus, dass ständige U mbe se tzung e ${ }^{19}$ der gruppen- und gesellschaftsspezifischen Semantiken der für Historiker interessanteste Aspekt sind. Entsprechend ist die ständige Neudeutung des zur Verfügung stehenden ikonographischen Materials entscheidende kunsthistorische Gesichtspunkt, der erst eine differenzierte Betrachtung des einzelnen exemplum erlaubt. Traditionelle `Tugenden wie Tapferkeit (fortitudo) verlieren allmählich ihre gruppen- und geschlechterspezifische Bindung - eine der Voraussetzungen der neuzeitlichen Umbesetzung des alttestamentlichen Begriffs mulier fortis -, andere werden individualisiert. Im allmählich entstehenden Konflikt zwischen öffentlichen und privaten Normen werden im Historiengemälde traditionelle exempla virtutis neu interpretiert; dies gilt für den gesamten Bereich der Affektdarstellung. ${ }^{20}$ Exemplarische Tugenden sind nicht mehr statisch, sondern werden in wechselnden Kontexten verändert und uminterpretiert. Dabei geht die gesellschaftliche Semantik manchmal dem Wandel der Trägergruppe voraus, vollzieht jedoch meist einen bereits vollzogenen Wandel nach. Vergleichbares gilt für die literarische oder künstlerische Neuinterpretation der Exempel. Tugendkonzepte haben stets zwei

\footnotetext{
${ }^{18}$ Fellsches, Josef: »Tugend/Laster in Europäische Enzyklopädie zu Philosophie und Wissenschaften, hrsg. von Hans Jörg Sandkühler, Hamburg 1990, Bd. 4, S. 620.

${ }^{19}$ Ich benütze hier die Terminologie des Philosophen Hans Blumenberg (z. B.: Die Legitimität der Neuzeit, Frankfurt am Main $\left.{ }^{3} 1997\right)$.

${ }^{20}$ Fumaroli, Marc: L'âge de l'éloquence: rhétorique et sres literariar de la Renaissance au seuil de l'époque classique, Paris ${ }^{3} 2002$.
} 


\section{$X$ Exempla virtutis}

Bezugspunkte: die »Konzeptbildung « ${ }^{21}$ der Literaten und Künstlern kann in Konflikt mit den Intentionen der Auftraggeber treten.

Nur wenn sie in den historischen Kontext eingeordnet wird, geht die Bezeichnung eines Bildvorwurfs als exemplum virtutis über die bloße Benennung eines rhetorischen Verfahrens hinaus. Die Vorbildlichkeit einer Figur oder einer Szene bestimmt sich in der Übereinstimmung oder Abweichung vom Normen- und Wertesystem der mémoire collective: Die magnanimitas etwa, die als exemplarische Tugend dem verbreiteten Bildmotiv des `Großmuts des Scipio zugrunde liegt, erfuhr in der Neuzeit eine ausdifferenzierte Deutung, die sich sowohl am politischen Kalkül des Fürsten wie an seiner moralischen Identität orientieren konnte. Im frühneuzeitlichen absolutistischen Staat konnte das exemplum virtutis wie bereits in der Antike moralische wie politische Funktionen übernehmen.

So kann vorbildliches Handeln seit der Frühen Neuzeit zunehmend konkurrierend privaten oder öffentlichen Charakter haben. Die Bühne der Neuzeit, etwa in ihrer französischen Ausprägung bei Corneille, liefert hinreichend Beispiele für Konflikte des Tugendhelden in der Spannung und im Widerspruch zwischen öffentlichen Standesnormen und neuen, fast schon privaten Normen der Individualität. Bildmotive aus dem Bereich der Tugendheldin als Selbstmörderin spiegeln die gleiche Entwicklung im Historiengemälde, wenn zum Beispiel Kleopatra als Fürstin oder als Liebende (oder im Konflikt zwischen beiden Rollen) dargestellt wird.

Besonders bedenklich ist der hermeneutisch unreflektierte Einsatz des Begriffs exemplum virtutis in historischen Übergangszeiten. Seine Verwendung in der Kunstgeschichte des Historienbildes verlangt in jedem Einzelfall synchrone und diachrone Perspektivierungen des Motivs, soll nicht unter einem gefälligen Topos das jeweils Spezifische des künstlerischen Vorwurfs verschüttet und verdeckt werden. Synchron ist das exemplum in die Wertvorstellungen einer Gruppe oder einer Gesellschaft einzuordnen; diachron die Entwicklung und Veränderung eines Tugendkonzepts, einer Handlungsnorm nachzuzeichnen. Es ist bemerkenswert, dass das exemplum virtutis in den Bildkünsten vor allem in der Übergangszeit eingesetzt wurde, in der sich allmählich aus den noch ständisch geprägten Gesellschaften neuzeitliche Staatskonzeptionen und die ersten Normen der Individualität entwickelten.

\footnotetext{
${ }^{21}$ Ich übernehme den Begriff von Lachmann, Renate (Hrsg.): Memoria, München 1993 (Poetik und Hermeneutik 15), S. XXV.
} 


\section{Exempla virtutis}

Umbesetzungen von Bildmotiven mit politisch-propagandistischer Intention sind gerade im ausgehenden 18. Jahrhundert nicht selten. Das von Jacques-Louis David (1748-1825) für Ludwig XVI. erstellte überdimensionierte Historiengemälde Die Liktoren übergeben Brutus die Körper seiner Söhne ${ }^{22}$ [Abb. 3] wurde wenig später von der nachrevolutionären Öffentlichkeit geradezu zum revolutionären exemplum virtutis umgedeutet. Vergleichbares widerfuhr einem anderen, ebenso prominenten Historienbild des gleichen Künstlers an der nächsten Zeitenwende. Das Bildmotiv, das er im 1814 entstandenen Gemälde Leonidas auf den

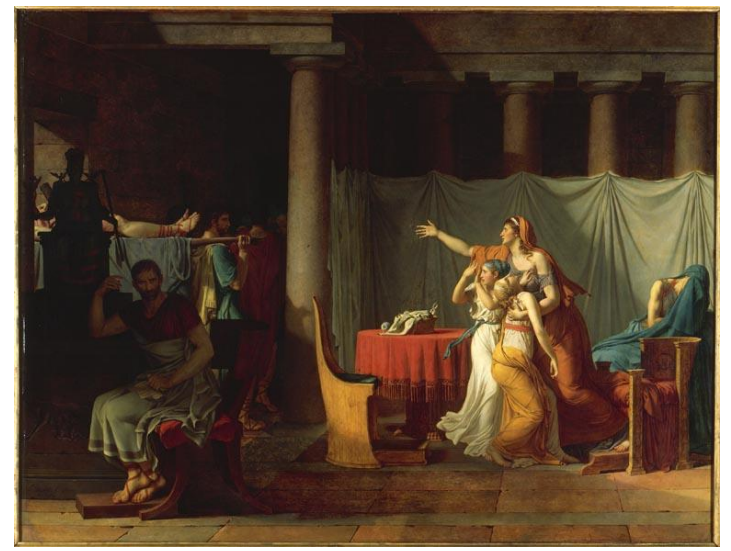

Abb. 3

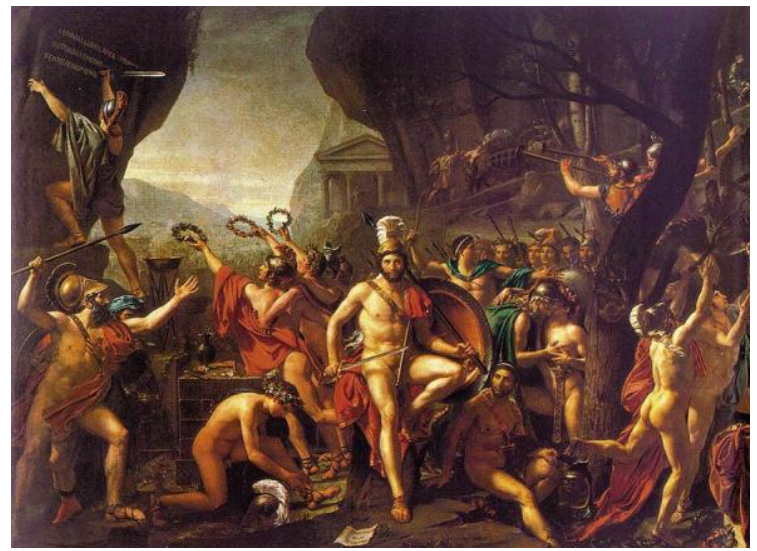

Abb. 4

Thermopylen [Abb. 4] aufgriff, hatte im revolutionären Klassizismus bereits Konjunktur, wurde aber unmittelbar nach der Entstehung des Ölgemäldes umgedeutet. $^{23}$ In der allgemeinen Unruhe vor der Entscheidungsschlacht und der sich in viele Einzelhandlungen auflösenden Kampfesvorbereitung meditiert der spartanische König Leonidas die Unausweichlichkeit des Todes im Kampf gegen den übermächtigen persischen Großkönig. Mit dem Repertoire des Klassizismus wird der Moment unmittelbar vor dem Aufbruch zum Kampf inszeniert. Sparta galt den Anhängern der Revolution längst als exemplum für revolutionäre Bürgertugenden. In seiner berühmten Rede vom 7. Mai 1794 hatte Robespierre Leonidas und seine Mitkämpfer als heroisches Vorbild genannt: "Léonidas aux Thermopyles, soupant avec ses compagnons d'armes, au moment d'exécuter le dessin le plus héroïque que la vertu humaine ait jamais conçu, les invite pour lendemain à un autre banquet dans une vie nouvelle. ${ }^{24}$ David greift mit seinem Kolossalgemälde ${ }^{25}$ ein Bildmotiv auf, das für die Zeitgenossen eindeutig zu dechiffrieren war und in der

\footnotetext{
${ }^{22}$ Schnapper, A. / Sérullaz, A. (Hrsg.): AK Jacques-Louis David, 1748-1825, Paris 1989, S. 194ff. Das Gemälde $(323 \times 422)$ befindet sich heute im Louvre.

${ }_{23}$ Abbildung und Rezeptionsgeschichte im AK Jacques-Louis David, a.a.O., S. 486-512.

${ }^{24}$ Zitiert nach AK Jacques-Louis David, a.a.O., S. 487.

${ }^{25}$ Das Ölgemälde (395 x 531) befindet sich heute im Louvre in Paris.
} 


\section{$X$ Exempla virtutis}

Revolutionsepoche in für den Salon bestimmten Gemälden, in lyrischen Szenen und Opern eingesetzt wurde. Gleichwohl wurde dem zunächst vor der Folie republikanischer Werte entstandene Gemälde ein aktueller Sinn unterlegt, als $1814 \mathrm{Na}$ poleon von Elba zurückkehrte und gegen die alliierten europäischen Truppen kämpfte. Eine kleine Schrift der bonapartistisch eingestellten Comtesse LenoirLaroche $^{26}$ findet in der Betrachtung des Gemäldes »sentiments religieux, sentiments de la patrie, sentiments de la famille et de l'amitié « und deutet das spartanische exemplum virtutis für die aktuelle politische Situation um, die bekanntermaBen mit dem Desaster von Waterloo und der Verbannung Napoleons endete: »les guerriers devant ce tableau viendront apprendre à mourir pour la patrie et la loi!« Die unmittelbaren Umdeutungen geläufiger Bildmotive 1789 und 1814 zeigen, dass die Einordnung als Tugendexempel nur der erste Schritt zur Interpretation sein kann.

Konnten die beiden Historienbilder Davids synchrone Umdeutungen von ins Bild gesetzten Tugendexempeln demonstrieren, lassen sich diachrone Umbesetzungen allenthalben nachweisen, da sie geradezu die Voraussetzung für das Historienbild sind. Wenn etwa in der Aufklärungsepoche Giambattista Pittoni (1687-1767) die Selbstbeherrschung des Scipio $^{27}$ in einem Historiengemälde als Tugendbeispiel [Abb. 5] inszeniert, stehen deutlich moralisierende und paränetische Funktionen im Vordergrund: das großzügige Verhalten des Feldherrn der römischen Republik dient dem

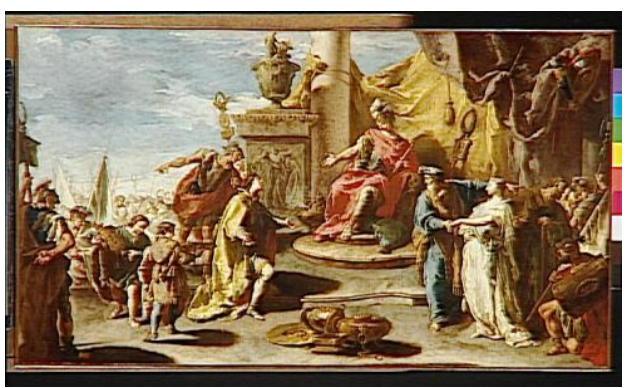

Abb. 5

Künstler oder seinem Auftraggeber nunmehr als idealtypisches Modell eines absoluten Fürsten.

Die Episode aus den Punischen Kriegen stellt bekanntlich den großzügigen Verzicht des siegreichen Feldherrn auf eine attraktive junge Frau dar, die inm als Kriegsbeute selbstverständlich zugestanden hätte. Im neuzeitlichen Historiengemälde dient die Rückgabe an den Bräutigam als Folie verallgemeinerbarer Handlungsnormen, die für Auftraggeber, Künstler und Betrachter durchaus einen aktuellen Sinn hatten. Eine mehrfache Umbesetzung der historischen Reminiszenz liegt

\footnotetext{
${ }^{26}$ Vgl. AK Jacques-Louis David, a.a.O., S. 488.

${ }^{27}$ Heute im Louvre, Inv. 565: ıLa Continence de Scipion،; Brejon de Lavergnée, Arnauld / Thiébaut, Dominique (Hrsg.): Catalogue sommaire illustré des peintures du musée du Louvre, II: Italie, Espagne, Allemagne, Grande-Bretagne et divers, Paris 1981, S. 219.
} 
vor: Bei Livius wurde die großzügige Geste noch unverhohlen als politische Erpressung dargestellt, mit der der keltiberische Verlobte der jungen Frau politisch auf die Seite Roms gezwungen wurde. Schon Valerius Maximus hatte die Szene in die Rubrik De abstinentia et continentia $(4,3)$ seiner Sammlung eingeordnet und sie nicht mehr politisch, sondern moralisch pointiert: Für inn handelt es sich um eine freiwillige Geste des Eroberers, mit der angesichts seiner Jugend nicht zu rechnen war. Das politische Kalkül wird zum erstaunlichen, aber durchaus individuellen exemplum virtutis. ${ }^{28}$ Dem Betrachter des Historienbildes Pittonis hingegen galt Scipio als exemplum für die Handlungsnorm der continentia, die dem absolutistischen Fürsten als Verzicht auf egoistische Interessen abzuverlangen war; er wusste die Szene im synchronen höfischen Kontext anzuwenden und einzuordnen.

Der überraschende Transfer, die teilweise Umbesetzung der Inhalte des exemplum, gelang, weil es für den zeitgenössischen Betrachter des Historiengemäldes ganz selbstverständlich war, erinnerte Geschichte als relevant für das eigene kulturelle Gedächtnis vorauszusetzen. Künstler und Betrachter repetierten im Barock nicht einfach einen selbstexplikativen topischen Bildvorwurf, sondern interpretierten inn neu, besetzten inn um und entwickelten eine neue Applikation scheinbar unveränderlicher Verhaltensnormen. Der neue soziopolitische Bezugsrahmen erlaubte zwar das Aufgreifen des Musters, besetzte es aber mit den Erwartungen und Zielen des frühneuzeitlichen Absolutismus.

\footnotetext{
${ }^{28}$ Valerius Maximus spitzt die Episode aus dem Zweiten Punischen Krieg (218-201) in seinen Facta et dicta memorabilia $(4,3,1)$ auf die continentia und die munificentia des Scipio zu: "Quartum et uicesimum annum agens Scipio, cum in Hispania [...] multos [...] obsides, quos in ea urbe Poeni clausos habuerant, in suam potestatem redegisset, eximiae inter eos formae uirginem aetatis adultae, et iuuenis et caelebs et uictor, postquam comperit inlustri loco inter Celtiberos natam, nobilissimoque gentis eius Indibili desponsam, arcessitis parentibus et sponso inuiolatam tradidit. Aurum quoque, quod pro redemptione puellae adlatum erat, summae dotis adiecit. Qua continentia ac munificentia Indibilis obligatus Celtiberorum animos Romanis adplicando meritis eius debitam gratiam rettulit.« (`Als der 24-jährige Scipio in Spanien [...] viele Geiseln, die die Punier in Cartagena gefangen gehalten hielten, in seine Gewalt gebracht hatte, war unter ihnen auch eine junge Frau von herausragender Schönheit. Nachdem der junge und unverheiratete Sieger Scipio erfahren hatte, dass sie zu den Keltiberern von bedeutender Abstammung gehörte und mit Indibilis, einem adligen jungen Mann dieses Volkes, verlobt war, gab er sie den herbeigerufenen Eltern und dem Verlobten unberührt zurück. Auch das ihm für die Rückerstattung der jungen Frau gebrachte Gold fügte er der Mitgift hinzu. Durch diese Zurückhaltung und Großzügigkeit verpflichtet, verbündete Indibilis die Keltiberer mit den Römern und stattete so den geschuldeten Dank für die Wohltat ab.८) Demgegenüber hatte Livius ( $A b$ urbe condita 26,8,50) noch unverhohlen auf die politische und strategische Bedeutung seiner continentia hingewiesen und mit der Geste nach der Eroberung von Carthago Nova (im Jahre 209) eine politische Erpressung des hochgestellten keltiberischen Verlobten verbunden: "Hanc mercedem unam pro eo munere paciscor: amicus populo Romano sis et, si me virum bonum credis esse quales patrem patruumque meum iam ante hae gentes norant, scias multos nostri similes in civitate Romana esse, nec ullum in terris hodie populum dici posse quem minus tibi hostem tuisque esse velis aut amicum malis. « (`Nur eine einzige Gegenleistung will ich mit diesem Geschenk verbinden: Du sollst ein Bündnis mit dem römischen Volk schließen! Wenn du mich wie meinen Vater und meinen Onkel für einen verlässlichen Mann hältst, sollst du wissen, dass es im römischen Staat viele gibt, die uns gleichen. Auch sollte es heute kein Volk geben, das du weniger zum Feind für dich und die Deinen, sondern vielmehr zum Freund haben möchtest.ı)
} 


\section{Exempla virtutis}

So können exempla virtutis in der Frühen Neuzeit, unabhängig davon, ob sie rhetorisch, literarisch oder künstlerisch eingesetzt wurden, als Erinnerungsfigur aufgefasst werden, deren akkumulierter »kultureller Sinn ${ }^{29}$ stets reaktiviert, an neue Gegebenheiten angepasst und semiotisiert werden kann. Solche Erinnerungsfiguren können allerdings nicht in jeder Phase eingesetzt werden, sondern bleiben zuweilen sin Reserve`, um später neu belebt zu werden, wenn sich neue Aktualisierungsmöglichkeiten ergeben. ${ }^{30}$ In den exempla virtutis manifestiert sich ein literarisches und künstlerisches Verfahren, dessen Herkunft aus der Rhetorik unverkennbar ist und das seinen Wert als abgekürzte Erinnerung an vergangene und gegenwärtige Normkonzepte lange Zeit beibehielt. ${ }^{31}$

Auch als in der historischen Reflexion der Aufklärung Geschichte als 'Fortschrittsgeschichter verstanden wurde und den handelnden Subjekten eine neue Rolle zugewiesen wurde, verloren die exempla virtutis überraschenderweise nicht sofort ihren rhetorischen, literarischen und künstlerischen Wert. Helden der römischen Republik wie Brutus und Cato fanden im Historienbild des ausgehenden 18. Jahrhunderts häufig Berücksichtigung und wurden in der Umbruchphase der französischen Revolution geradezu Leitmotive künstlerischer und rhetorischer Propaganda. Für den noch nie erlebten und gar nicht zu übersehenden gesellschaftlichen Wandel konnte das unerschöpfliche Reservoir der antiken exempla virtutis noch einmal aktiviert und umbesetzt werden, weil diese Erinnerungsfiguren eingeübt und der mémoire collective vertraut waren. Freilich bewährte sich auch hier die immanente Dialektik der Erinnerungsfigur: Das Neue wurde mit Vertrautem interpretiert oder vielmehr den vertrauten exempla neuer Sinn unterlegt, im alten Gewand vertrauter Leitfiguren neue Normen entwickelt. Insofern macht Robert Rosenblum $^{32}$ zu Recht darauf aufmerksam, dass das exemplum virtutis ein wichtiger Aspekt für das Verständnis vor allem des französischen Klassizismus ist. Allerdings übersieht er im Einzelnen die Umbesetzung überlieferter Tugenden, die Umbewertung der Handlungsmuster, kurzum die Aktualisierung alter Normen und Ideale.

\footnotetext{
${ }^{29}$ Ich verwende die Terminologie von Renate Lachmann aus dem Vorwort zu: Haverkamp, Anselm / Lachmann, Renate (Hrsg.): Memoria, München 1993 (Poetik und Hermeneutik 15), v. a. S. XVII-XXV.

${ }^{30}$ Vgl. Renate Lachmann, a.a.O., S. XVIII.

${ }^{31}$ Schon E. R. Curtius (Europäische Literatur und lateinisches Mittelalter, Bern / München ${ }^{8} 1973$, S. 112) beschrieb das Funktionieren eines Topos ganz ähnlich und verwies unter Bezugnahme auf C. G. Jung auf die Tiefenstruktur solch repetitiver Verfahren, mit deren Hilfe das kulturelle Gedächtnis immer neu umgestaltet werden kann.

${ }^{32}$ Rosenblum, Robert: Transformations in Late Eighteenth Century, Princeton ${ }^{3} 1974$.
} 


\section{$X$ Exempla virtutis}

Die umstandslose Einordnung eines Historienbildes oder einer Dramenhandlung als exemplum virtutis vernachlässigt es, in synchronen und diachronen Analyseschritten den konkreten Bezug und damit den `Sinn` der Bildwahl oder des Dramenvorwurfs zu erörtern. Dadurch werden scheinbar statische Interpretationsmöglichkeiten vorausgesetzt, obwohl die Bilder erst dann zu ssprechen beginnen, wenn nach ihrer ursprünglichen Funktion gefragt wird, wie sich auch an Beispielen aus dem hier behandelten Bildkorpus zeigen lässt.

Dies gilt auch für das Bildmotiv der ıstarken Frauen`, von dem es immerhin bereits bei Giovanni Battista Armenini (1530-1609) eine erzieherische Applikation gibt, wenn er es vor allem für die Wohnräume junger Frauen für besonders geeignet hält: »Ma nelle camere poi dove si riposano le matrone e le donne maritate, vi si fingono poi esempi di storie di donne illustri cosi greche come latine, ed il medesimo si dee fare in quelle dove abitano le fanciulle, col fingervi le piu famose per castità, per grandezza di animo e per fede.« ${ }^{33}$

Die Darstellung des Selbstmords der Lukretia nach ihrer Vergewaltigung mag heutigen, vordergründigen Betrachtern als Modell einer überholten Sittlichkeit erscheinen. ${ }^{34} \mathrm{Im}$ ancien régime konnte das Thema aber auch als aktuelle Kritik am Machtmissbrauch verstanden werden, zumal der Sturz des letzten römischen Königs durch den Racheschwur der Verwandten Lukretias ausgelöst wurde. Eine solche Kritik mag etwa im Historiengemälde [Abb. 6] von CharlesAlphonse Dufresnoy (1611-1668) beabsichtigt sein. $^{35}$ Wenn niederländische Maler des 17.

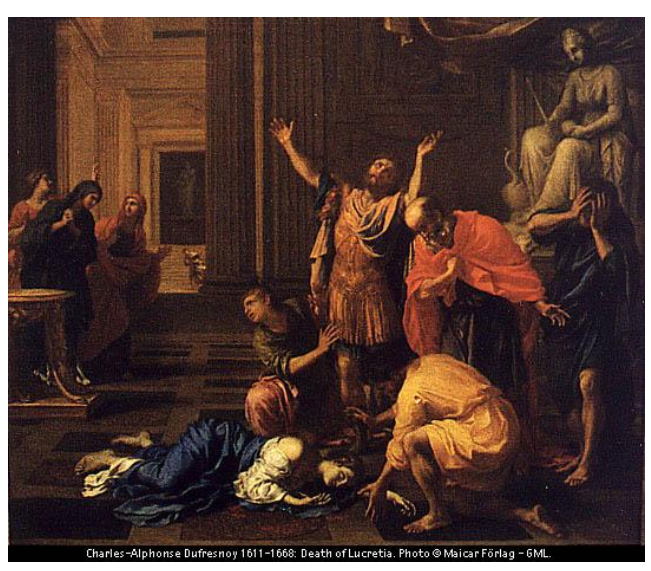

Abb. 6 Jahrhunderts das beliebte Thema aufgreifen, liegt der Verdacht eines versteckten Hinweises auf die Bedrohung der Niederlande durch das habsburgische Spanien nahe. Ganz in diesem Sinn interpretiert der niederländische Poet Jan Vos ${ }^{36}$ in einem Gedicht über Lukretia ihr Selbstopfer: »Gy doet de vryheidt met dez' rooden

\footnotetext{
${ }^{33}$ Armenini, Giovanni Battista: De' veri precetti della pittura, Ravenna 1587 (ND Hildesheim/New York 1971), S. $187 f$.

${ }^{34}$ Vgl. oben, S. $123 f f$.

${ }^{35}$ Katalog 108.

${ }^{36}$ Vos, Jan: Alle gedichten van den Poèet Jan Vos, Amsterdam 1662, S. 550: Lukretia deursteekt zich, door G. F. geschildert (১Lukretia bringt sich um, gemalt von Govert Flinckı)
} 


\section{$X$ Exempla virtutis}

int beschrijven. « ${ }^{37}$ Anlass des Gedichts war eine auch im Titel genannte Lukretia von Govert Flinck ${ }^{38}$, die sich damals in der Sammlung von Joan Huydecoper befand. ${ }^{39}$ Eine vergleichbare Intention könnte, wie Gary Schwartz gezeigt hat, auch bei der Lukretia [Abb. 6] Rembrandts in Washington vorliegen. ${ }^{40}$ In anderen Darstellungen desselben exemplum virtutis konnte das Motiv der sstarken Frau oder die Darstellung des Affekts im Vordergrund stehen. Dies gilt beispielsweise für das Bildmotiv der Sophonisbe. Andrea Mantegna [Abb. 7] griff das von Boccaccio ${ }^{41}$ reaktualisierte Sujet für das Programm ıstarker Frauenı im studiolo der Isabella d' Este auf. Ähnliche Intentionen dürfte der Maître des héroines de Chigi-Saraceni (Ende 15./Anfang 16.Jh.) [Abb. 8] verfolgt haben. Demgegenüber stellt Simon Vouet (1590-1649) in seiner Kasseler Sophonisbe [Abb. 9] im Gegensatz der Königin zu ihrer Dienerin das neu-

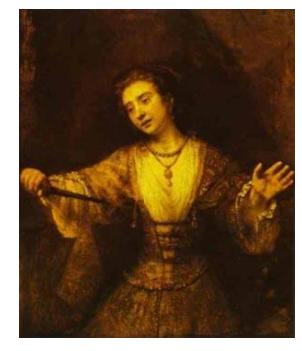

Abb. 6

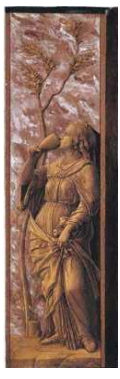

Abb. 7 stoische Thema der Affektbeherrschung dar. Kann die Bearbeitung des Themas

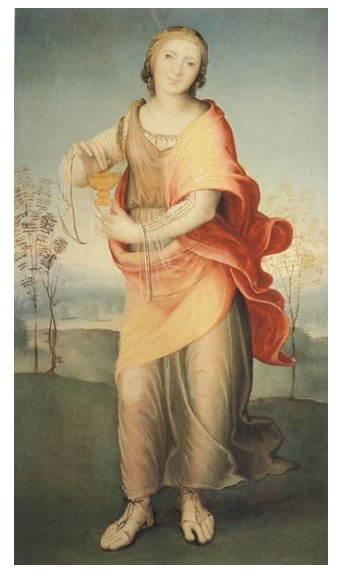

Abb. 8

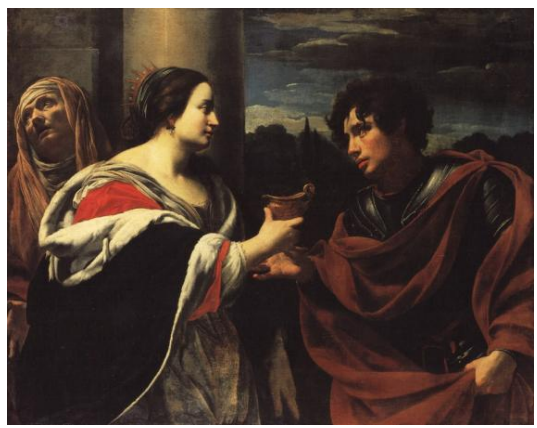

Abb. 9

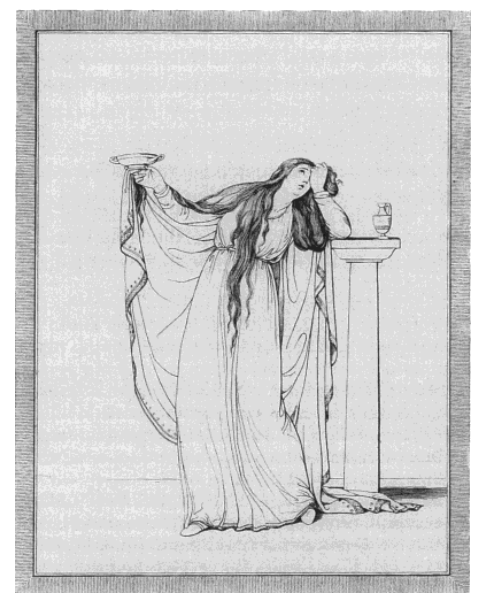

Abb. 10

durch Vouet noch insofern als exemplum virtutis gedeutet werden, als Affektbeherrschung zu den Regentenqualitäten des neuzeitlichen Fürsten zählt, hat die Darstellung des Affekts im 19. Jahrhundert jeden philosophischen oder moralischen Hintergrund aufgegeben, wie sich an der späten Attitüde [Abb. 10] der Lady Hamilton zeigen lässt, die Friedrich Rehberg (1758-1835) gestochen hat.

\footnotetext{
${ }^{37}$ >Mit dieser roten Tinte wird die Freiheit beschrieben.ı (V. 11)

${ }^{38}$ Bredius, Abraham: Künstler-Inventare: Urkunden zur Geschichte der holländischen Kunst des XVI ${ }^{\text {ten }}$ und XVIt ${ }^{\text {ten }}$ Jahrhunderts, Den Haag 1915-1922, Bd. 5, S. 1965.

${ }^{39}$ Die politische Konnotation des Gedichtes ist deutlich, endet es doch (V. 14): „Wie dat het volk bevrijt verkrijgt de grootste zeege.« (>Wer das Volk befreit, erhält den größten Segen.८)

40 Schwartz, Gary: Sämtliche Gemälde Rembrandts in Farbe, Darmstadt 1987, S. 330. Katalog 305.

${ }^{41}$ Katalog 227. De claris mulieribus, 70 (De Sophonisba regina Numidie); vgl. oben, S. 80.
} 


\section{$X$ Exempla virtutis}

Damit hat die Bezeichnung exemplum virtutis endgültig ihren Sinn verloren. Eine durchaus vergleichbare Entwicklung konnte auch bei der Darstellung der Kleopatra aufgezeigt werden. ${ }^{42}$ Wenn Nicolas Prévost (1604-1670) die ägyptische Königin [Abb. 11] für die Gemächer der Regentin im Schloss Richelieu als Teil eines zehn ıstarke Frauen umfassenden Programms weiblicher Exempla darstellte, verfolgte Richelieu das politische Ziel, weibliche Regentschaften zu verteidigen. ${ }^{43}$ Demgegenüber stellen Guido Reni (1575-1642) und Guido Cagnacci (16011663) in verschiedener Akzentuierung Affekte dar. Reni greift in seinem Potsdamer Bild [Abb. 12] auf das antike Modell der Niobe zurück und sucht mit dem shimmelnden Blick ${ }^{44}$ eine der Darstellung heiliger Märtyrerinnen angenäherte Interpretation. Demgegenüber findet Cagnacci in seiner Wiener Fassung [Abb. 13] eine andere Lösung: In seinem mehrfigurigen Historiengemälde bildet der Gegensatz zwischen der stoisch gelassenen Königin und ihrem verzweifelt reagieren-

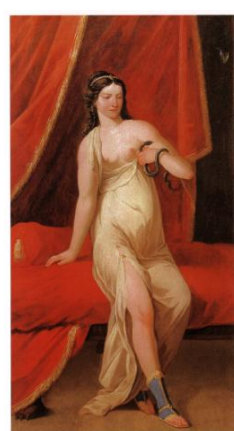

Abb. 11

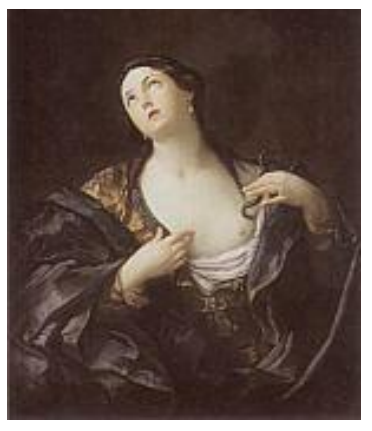

Abb. 12

den weiblichen Hofstaat die Grundspannung. Noch bemühen sich die Dienerinnen um die bereits ohnmächtige Regentin, Händeringen und Tränentücher verweisen zugleich auf die Vergeblichkeit dieses Handelns. Beide Versionen der Selbstmörderin als Tugendheldin $^{45}$ demonstrieren Affektbeherrsch-

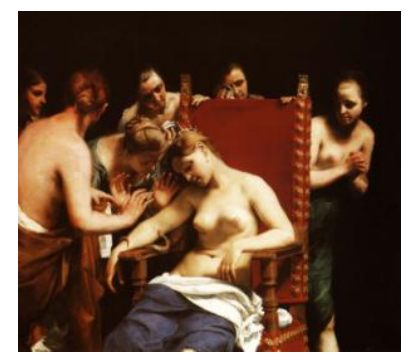

Abb. 13

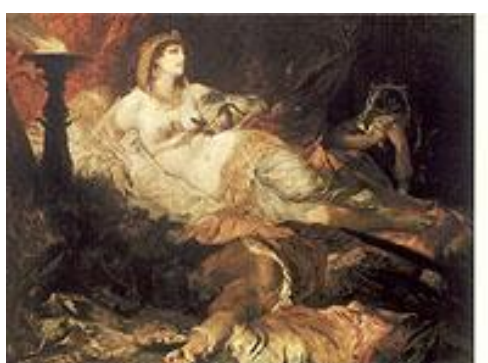

Abb. 14 schung ohne politischen Bezug. Hans Makart (1840-1884) gibt in seinem großen Gemälde in Kassel [Abb. 14] die Tradition des exemplum virtutis gänzlich zugunsten der Interpretation Kleopatras als femme fatale auf ${ }^{46}$, wofür sich bei Jean André Rixens (1846-1924) ${ }^{47}$ und Arnold Böcklin $(1827-1901)^{48}$ andere Beispiele fan-

\footnotetext{
42 S. oben, S. $145 \mathrm{ff}$.

${ }^{43}$ Katalog 289.

${ }^{44}$ Katalog 310. Zum Motiv des shimmelnden Blicksı s. Henning, Andreas / Weber, Gregor (Hrsg.): AK >Der himmelnde Blickı, Zur Geschichte eines Bildmotivs von Raffael bis Rotari, Dresden 1998.

${ }^{45}$ Katalog 53.

${ }^{46}$ Katalog 223.

${ }^{47}$ Katalog 348.

${ }^{48}$ Katalog 38.
} 


\section{$X$ Exempla virtutis}

den. ${ }^{49}$ Folgte das exemplum virtutis zunächst propagandistischen Absichten oder formulierte es politische Kritik, konnte es auch zur Affektmodulierung dienen und auf die moralische Wirkung beim Betrachter abheben. In den späten Versionen des 19. Jahrhunderts liegt das Hauptgewicht auf der absolut gesetzten Darstellung des Affekts.

Exempla virtutis sind ein aus der Rhetorik stammendes Verweisverfahren, das in der Frühen Neuzeit unter zunächst neustoischen Vorzeichen auch in den Bildkünsten eine bedeutende Rolle gespielt hat. Allerdings erläutert der Verweis auf das Verfahren noch nicht den vom Künstler, seinem Auftraggeber oder den Betrachtern beabsichtigten Sinn; das nur scheinbar transhistorische Tugendexempel muss immer in seiner konkreten künstlerischen Umsetzung und seiner historischen Funktion erfasst werden. Aus dem in dieser Untersuchung behandelten Bildkorpus lässt sich eine allgemeine Entwicklung ableiten, die auch zugleich das Ende wenn nicht des Historiengemäldes, so doch des Tugendexempels im Laufe des 19. Jahrhunderts erklären mag. Standen zu Beginn der neuzeitlichen Entwicklung Historienbilder als impliziter Vergleich im Vordergrund, die politische Normen und Ansprüche legitimieren und kritisieren konnten, traten schon früh andere Aktualisierungen der Tugendexempel auf, die neustoisch beeinflusst, Normen der Subjektivität und der Affektbeherrschung ins Bild setzten. Erst die Reduktion auf anthropologische Grundaffekte, wie sie sich in den `Attitüden` der Spätaufklärung finden, vereinfachte den Tugendbegriff radikal zum Affekt, wie er sich in den ästhetischen Inszenierungen der späten Historiengemälde des 19. Jahrhunderts Ausdruck verschafft. Von der Tugend über den Affekt zur Attitüde verbrauchte sich das rhetorische Verfahren des exemplum virtutis ebenso wie das des Bildmotivs der Tugendheldin. ${ }^{50}$

\footnotetext{
${ }_{50}^{49}$ Vgl. oben, S. 165.
} 


\section{Ausstellungskataloge}

[Augsburg / Cleveland]

AK Johann Liss, Augsburg 1975

[Amsterdam]

Bull, Duncan (Hrsg.): Rembrandt - Caravaggio, Stuttgart 2006

[Antwerpen]

Belkin Lohse, Kristin / Healy, Fiona (Hrsg.): A House of Art, Rubens as Collector, Antwerpen 2004

[Antwerpen]

d'Hulst, R.-A. / de Poorter, N. / Vandenven, M. (Hrsg.): Jacob Jordaens (1593 - 1678), Anvers 1993

[Antwerpen]

Koninkliik Museum voor Schone Kunsten Antwerpen: P.P.Rubens, Gemälde Ölskizzen - Zeichnungen, Antwerpen 1977

[Ariccia]

Papi, Gianni: La sscholar del Caravaggio, Dipinti dalla collezione Koelliker, Milano 2006

[Augsburg / Cleveland]

Johann Liss, Augsburg 1975

[Basel]

Lindemann, Bernd Wolfgang (Hrsg.): Arnold Böcklin - eine Retrospektive, Basel 2001

[Basel]

Ten-Doesschate Chu, Petra (Hrsg.): Im Lichte Hollands, Holländische Malerei des 17. Jahrhunderts aus den Sammlungen des Fürsten von Liechtenstein und aus Schweizer Besitz, Zürich 1987

[Berlin / Roma]

Danesi Squarzina, Silvia (Hrsg.): Caravaggio in Preussen, Die Sammlung

Giustiniani und die Berliner Gemäldegalerie in Preußen, Milano 2001 [Berlin]

Contini, Roberto: Pracht und Pathos, Meisterwerke der Barockmalerei aus dem Palazzo Bianco in Genua, Milano 2003 


\section{Ausstellungskataloge}

[Berlin]

Sievernich, G. / Budde, H. (Hrsg.): Europa und der Orient, 800 - 1900, Berlin 1989

[Berlin]

Zimmer, F. (Hrsg.): Die griechische Klassik, Idee oder Wirklichkeit, Berlin 2002

[Blois]

Bassani Pacht, Paola / Crépin-Leblond, Thierry / Sainte Fare Garnot, Nicolas / Solinas, Francesco (Hrsg.): Marie de Médicis, un gouvernement par les arts, Paris 2003

[Bologna / Los Angeles / Fort Worth]

Cola, Alberto / Salvagni, Anna / Scolaro, Francesca / Scolaro, Michaela / Caroselli, Susan (Hrsg.): Guido Reni, 1575 - 1642, Bologna 1988

[Bologna]

Mahon, Denis (Hrsg.): Giovanni Francesco Barbieri, I/ Guercino 1591-1666,

Bologna 1991

[Bologna]

Mahon, Denis (Hrsg.): Guercino, Bologna ${ }^{2} 1991$ (Nachdruck des Katalogs von 1968)

[Boston / Toledo]

Sutton, Peter C.: The Age of Rubens, Boston 1993

[Braunschweig]

Büttner, Nils / Heinen, Ulrich (Hrsg.): Peter Paul Rubens, Barocke Leidenschaften, Braunschweig 2004

[Braunschweig]

Herzog Anton Ulrich-Museum: Europäische Malerei des Barock aus dem Nationalmuseum Warschau, Braunschweig 1989

[Bruxelles]

Le siècle de Rubens, Bruxelles 1965

[Darmstadt]

Ebert-Schifferer, Sybille (Hrsg.): Il gusto bolognese, Barockmalerei aus der Emilia-Romagna, Bologna 1994 


\section{Ausstellungskataloge}

[Delft]

Brink Goldsmith, Jane ten (Hrsg.): Leonaert Bramer, 1595-1674: Ingenious Painter and Draughtsman in Rome and Delft, Zwolle 1994 [Dresden]

Henning, A. / Weber, G. (Hrsg.): ‘Der himmelnde Blickı, Zur Geschichte eines Bildmotivs von Raffael bis Rotari, Dresden 1998

[Düsseldorf / München/ Chur]

Baumgärtel, Bettina (Hrsg.): Angelika Kauffmann, Ostfildern-Ruit 1998 [Düsseldorf]

Baumgärtel, Bettina / Neysters, Silvia (Hrsg.): Die Galerie der Starken Frauen, Düsseldorf 1995

[Düsseldorf]

Schuster, Eva: Das Bild vom Tod, Graphiksammlung der Heinrich-HeineUniversität Düsseldorf, Recklinghausen 1992

[Ferrara / New York]

Humfrey, Peter / Lucco, Mauro (Hrsg.): Dosso Dossi, Court Painter in Renaissance Ferrara, New York 1998

[Frankfurt am Main]

Ebert-Schifferer, Sybille / Emiliani, Andrea / Schleier, Erich (Hrsg.) Guido Reni und Europa, Ruhm und Nachruhm, Frankfurt 1988

[Frankfurt am Main]

Schulze, Sabine (Hrsg.): Leselust, Niederländische Malerei von Rembrandt bis Vermeer, Frankfurt 1993

[Genève]

Ritschard, Claude / Morehead, Allison (Hrsg.): Cléopâtre dans le miroir de l'art occidental, Genève 2004

[Genova]

Gavazza, Ezio / Sciré, Giovanna Nepi / Terminiello, Giovanna Rotondi (Hrsg.): Bernardo Strozzi, Genova 1581/82-Venezia 1644, Milano 1995

[Hamburg]]

Schneede, Uwe / Heinrich, Christoph (Hrsg.): Monets Vermächtnis, Serie, Ordnung und Obsession, Ostfildern-Ruit 2001

[Karlsruhe]

Stefano della Bella, Karlsruhe 2005 


\section{Literaturverzeichnis}

[Kassel]

Neumann, Wolfgang (Hrsg.): Tanz der Toten - Todestanz: der monumentale Totentanz im deutschsprachigen Raum, Dettelbach 1998

[Köln / Antwerpen / Wien]

Mai, Ekkehard (Hrsg.): Von Bruegel bis Rubens, Das goldene Jahrhundert der flämischen Malerei, Köln / Antwerpen / Wien 1992, S. 55-70

[Köln / Dordrecht / Kassel]

Mai, Ekkehard / Paarlberg, Sander / Weber, Gregor J. M. (Hrsg.): Vom Adel der Malerei, Holland um 1700, Köln 2006

[Köln / Montréal]

Goldfarb, Hilliard Todd (Hrsg.): Richelieu (1585-1642), Kunst, Macht und Politik, Ghent 2002

[Köln]

Mai, Ekkehard (Hrsg.): Glanzlichter des Barock, Meisterwerke aus dem Musée des Beaux-Arts in Caen, Köln 1993

[Köln]

Mai, Ekkehard / Repp-Eckert, Anke (Hrsg.): Triumph und Tod des Helden,

Europäische Historienmalerei von Rubens bis Manet, Köln 1987 [Köln]

Mai, Ekkehard / Stukenbrock, Christiane (Hrsg.): Niederländische Malerei des 17. Jahrhunderts aus Budapest, Köln 1987

[Kronach]

Grimm, Claus (Hrsg.): Lucas Cranach, Ein Maler-Unternehmer aus Franken, Regensburg 1994

[Ljubljana]

Serbelj, Ferdinand (Hrsg.): La Pittura barocca nel Goriziano, Ljubljana 2002 [London / New York]

Martineau, Jane (Hrsg.): Andrea Mantegna, London 1992]

[London / Roma]

Wilton, Andrew / Bignamini, Ilaria (Hrsg.): Grand Tour, The Lure of Italy in the Eighteenth Century, London 1996

[London / Washington]

Martineau, Jane / Robinson, Andrew (Hrsg.): The Glory of Venice, Art in the Eighteenth century, London 1994 


\section{Ausstellungskataloge}

[London]

Walker, Susan / Higgs, Peter (Hrsg.): Cleopatra of Egypt, London 2001 [Lugano / Roma]

Kahn-Rossi, Manuela (Hrsg.): Pier Francesco Mola 1612-1666, Milano 1989 [Mantova]

Safarik, Eduard A. (Hrsg.): Domenico Fetti, 1588/89-1623, Milano 1996 [Marseille]

Viatte, Francoise (Hrsg.): Escales du Baroque, Paris 1988

[Meaux]

Kerspern, Sylvain: Bossuet, Miroir du Grand Siècle, Paris 2004 [Milano]

Bossaglia, Rossana / Terraroli, Valerio: Settecento lombardo, Milano 1991 [Milano]

Spezzaferro, Luigi / Calzavara, Benedetta (Hrsg.): Caravaggio e l'Europa, Da Caravaggio a Mattia Preti, Milano 2005

[Milano]

Mahon, Denis / Pulini, Massimo / Sgarbi, Vittorio (Hrsg.): Guercino, Poesia e sentimento nella pittura del '600, Novara 2003

[Montpellier / Strasbourg]

Thuillier, Jacques: [zugleich: AK] Sébastien Bourdon 1616-1671, Catalogue critique et chronologique de l'œuvre complet, Paris 2000

[Montréal / Rennes / Montpellier]

Mégevand, M.-Ch. / Julhiet, C. (Hrsg.): Grand Siècle, Peintures françaises du XVII siècle dans les collections publiques françaises, Paris 1993 [Montréal]

Grand Siècle, Peintures françaises du XVII siècle dans les collections publiques françaises, Paris 1993

[München]

Steingräber, Erich: Venedig, Malerei des 18. Jahrhunderts, München 1987 [Nancy]

La peinture vénitienne 1600-1800, 65 peintures des collections des musées de la Ville de Padoue, Nancy 1991

[Napoli / Wien / Los Angeles]

Cassani, Silvia / Sapio, Mario (Hrsg.): Luca Giordano 1634-1705, Napoli 2001 


\section{Literaturverzeichnis}

[Neuburg an der Donau]

Bäumler, S. / Brockhoff, E. / Henker, M. (Hrsg.): Von Kaisers Gnaden, 500 Jahre Pfalz-Neuburg, Regensburg 2005

[Nürnberg]

Bott, Gerhard (Hrsg.): Die Grafen von Schönborn. Kirchenfürsten, Sammler, Mäzene, Nürnberg 1989

[Oldenburg]

Köhn, Silke (Hrsg.): Lady Hamilton und Tischbein, Der Künstler und sein Modell, Oldenburg 1999

[Paris / London]

Penny, Nicholas (Hrsg.): Reynolds, Paris 1985

[Paris / Philadelphia / Fort Worth]

Bailey, C. / Hamilton, C. A. (Hrsg.): Les Amours des Dieux, La peinture mythologique de Watteau a David, Paris 1991

[Paris / Versailles]

Schnapper, A. / Sérullaz, A. (Hrsg.): Jacques-Louis David, 1748-1825, Paris 1989

[Paris]

Thuillier, Jacques (Hrsg.): Vouet, Paris 1990

[Passariano]

Rizzi, Aldo: Sebastiano Ricci, Milano 1989

[Roma]

Bonfait, O. (Hrsg.): Roma 1630, Il trionfo del pennello, Milano 1994 [Roma]

Lo Bianco, Anna (Hrsg.): Pietro da Cortona 1597-1669, Milano 1997 [Roma / New York / Saint Louis]

Christiansen, Keith / Mann, Judith: Orazio e Artemisia Gentileschi, Milano 2001

[Siena]

Barocchi, Paola [u.a.]: Domenico Beccafumi e il suo tempo, Milano 1990 [Stuttgart]

Höper, Corinna (Hrsg.): Raffael und die Folgen, Stuttgart 2001 [Tours]

Fohr, Robert (Hrsg.): Tableaux français et italiens du XVII siècle, Paris 1982 


\section{Ausstellungskataloge}

[Vaduz]

Wieczorek, Uwe: Fünf Jahrhunderte italienische Kunst aus den Sammlungen des Fürsten von Liechtenstein, Bern 1994

[Venezia / New York]

Christiansen, Keith (Hrsg.): Giambattista Tiepolo 1696-1996, Milano 1996

[Venezia / Washington]

Biadene, Susanna (Hrsg.): Tiziano, Venezia 1990

[Venezia]

Bettagno, Alessandro (Hrsg.): Antonio Pellegrini, Il maestro veneto del Rococò alle corti d' Europa, Venezia 1998

[Venezia]

Romanelli, Giandomenico / Strinati, Claudio (Hrsg.): Paolo Veronese, Miti, ritratti, allegorie, Venezia 2005

[Verona]

Cortenova, Giorgio (Hrsg.): II settimo splendore, La modernità della malinconia, Venezia 2007

[Verona]

Scaglietti Kelescian, Daniela (Hrsg.): Alessandro Turchi detto l'Orbetto, 1578

- 1649, Milano 1999

[Wien]

Kunstverein Wien: Franz Anton Maulbertsch, Wien 1974

[Wien]

Mayr-Oehring, Erika / Doppler, Elke (Hrsg.): Orientalische Reise, Malerei und Exotik im späten 19. Jahrhundert, Wien 2003

[Wien]

Schröder, Klaus Albrecht / Sternath, Maria Luise (Hrsg.): Albrecht Dürer, Ostfildern-Ruit 2003

[Wien]

Trnek, Renate: Traum vom Süden, Die Niederländer malen Italien, Ostfildern 2007

[Wien / Mailand]

Natale, Mauro / Di Lorenzo, Andrea (Hrsg.): Die Sammlung Borromeo, Malerei und Skulptur in der Nachfolge Leonardo da Vincis, Milano 2007 


\section{Literaturverzeichnis}

[Wien / Napoli]

Kunstforum der Bank Austria / Castel Sant'Elmo: Settecento Napoletano, Sulle ali dell'aquila imperiale 1707-1734, Napoli 1994

[Wien / Stendal]

Hagen, Bettina (Hrsg.): Antike in Wien, Die Akademie und der Klassizismus um 1800, Mainz 2002

[Wien / Venedig]

Ferino-Pagden, Sylvia (Hrsg.): Der späte Tizian und die Sinnlichkeit der Malerei, Wien 2007 


\section{Bestandskataloge}

\section{Bestandskataloge}

[Berlin]

Katalog der ausgestellten Gemälde des 13.-18. Jahrhunderts, Gemäldegalerie Berlin 1975

[Biberach]

Hoffmann, Herbert (Hrsg.): Katalog der Gemälde und Skulpturen bis 1900, Band III ${ }^{\mathrm{a}}$, Biberach an der Riß 1975

[Bordeaux]

Habert, Jean (Hrsg.): Bordeaux, Musée des Beaux-Arts, Peinture italienne $X V^{e}-X I X^{e}$ siècles, Paris 1987

[Braunschweig]

Herzog Anton Ulrich-Museum: AK Erwerbungen aus zwei Jahrzehnten, Kunstwerke vor 1900, Braunschweig 1989

[Braunschweig]

Jacob, Susanne / König-Lein, Susanne: [Herzog Anton Ulrich-Museum Braunschweig] Die italienischen Gemälde des 16. bis 18. Jahrhunderts, München 2004

[Braunschweig]

Jacoby, Joachim / Michels, Anette (Hrsg.): [Herzog Anton Ulrich-Museum

Braunschweig] Die deutschen Gemälde des 17. und 18. Jahrhunderts sowie die englischen und skandinavischen Werke, Braunschweig 1989

[Braunschweig]

Klessmann, Rüdiger: [Herzog Anton Ulrich-Museum Braunschweig] Die holländischen Gemälde, Braunschweig 1983

[Bruxelles]

[Musées royaux des Beaux-Arts de Belgique, Département d'Art Ancien:]

Catalogue inventaire de la peinture ancienne, Bruxelles 1984

[Den Haag]

[Mauritshuis:] The Royal Cabinet of Paintings, Illustrated General Catalogue, The Hague 1977

[Dijon]

Brejon de Lavergnée, Arnauld: Dijon, Musée Magnin, Catalogue des tableaux et dessins italiens ( $X V^{e}-X I X^{e}$ siècles), Paris 1980 


\section{Literaturverzeichnis}

[Firenze]

Chiarini, Marco: Palazzo Pitti, Firenze 1988

[Firenze]

Gregori, Mina: Uffizien und Palazzo Pitti, Die Gemäldesammlungen von Florenz, München 1994

[Hamburg]

Hamburger Kunsthalle: Katalog der Alten Meister, Hamburg ${ }^{5} 1966$

[Hannover]

Grohn, Hans Werner: [Landesmuseum Hannover] Die italienischen Gemälde, Hannover 1995

[Karlsruhe]

Lauts, Jan (Hrsg.): Katalog Alte Meister bis 1800, 2 Bde, Karlsruhe 1966 [Kassel]

Heinz, Marianne (Hrsg.): Bestandskatalog der Gemälde des 19. Jahrhunderts, Kassel 1991

[Kassel]

Herzog, Erich: Die Gemäldesammlung der Staatlichen Kunstsammlungen Kassel, Geschichte der Galerie, Hanau 1969

[Kassel]

Lehmann, Jürgen M.: Italienische, französische und spanische Gemälde des 16. bis 18. Jahrhunderts der Staatlichen Kunstsammlungen Kassel, Fridingen 1980

[Kassel]

Schnackenburg, Bernhard: Flämische Meister in der Kasseler Gemäldegalerie, Kassel 1985

[Kassel]

Schnackenburg, Bernhard: Gesamtkatalog Gemäldegalerie Alte Meister Kassel, Mainz 1996

[Köln]

Heße, Christian / Schlagenhaufer, Martina (Hrsg.): Wallraf-Richartz-Museum Köln, Vollständiges Verzeichnis der Gemäldesammlung, Köln/Mailand 1986 [Leipzig]

Sander, Dietulf (Hrsg.): Museum der bildenden Künste Leipzig, Katalog der Gemälde, Leipzig 1995 


\section{Bestandskataloge}

[London]

Baker, Christopher / Henry, Tom (Hrsg.): The National Gallery, Complete IIlustrated Catalogue, London 1995

[London]

Braham, Allan (Hrsg.): The National Gallery, Illustrated General Catalogue, London ${ }^{2} 1986$

[Madrid]

Pita Andrade, José Manuel / del Mar Borobia Guerrero, María (Hrsg.): Old Masters Thyssen-Bornemisza Museum, Barcelona 1992

[München]

Alte Pinakothek, Ausgewählte Werke, München 2005

[München]

Schawe, Martin: Alte Pinakothek, Altdeutsche und altniederländische Malerei,

München 2006

[München]

Steingräber, Erich (Hrsg.): Kat. Alte Pinakothek München, München 1983 [Paris]

Brejon de Lavergnée, Arnauld / Foucart, Jacques / Reynaud, Nicole [Hrsg.]:

Catalogue sommaire illustré des peintures du musée du Louvre, Bd. 1, Écoles flamande et hollandaise, Paris 1979

[Paris]

Brejon de Lavergnée, Arnauld / Thiébaut, Dominique [Hrsg.]: Catalogue sommaire illustré des peintures du musée du Louvre, Bd. 2 Italie, Espagne, Allemagne, Grande-Bretagne et divers, Paris 1981

[Paris]

Brejon de Lavergnée, Arnauld: Dijon, Musée Magnin, Catalogue des tableaux et dessins italiens ( $X V^{e}-X I X^{e}$ siècles), Paris 1980

[Paris]

Compin, Isabelle / Roquebert, Anne (Hrsg.): Catalogue sommaire illustré des peintures du musée du Louvre et du musée d:Orsay, École française, 3 Bde, Paris 1986

[Paris]

Laclotte, Michel / Mognetti, Élisabeth (Hrsg.): Avignon, Musée du Petit Palais, Peinture italienne, Paris 1987 


\section{Literaturverzeichnis}

[Praha]

Kotalik, Jiri: Die Nationalgalerie in Prag, Hanau 1988

[Roma]

Alloisi, Sivigliano: Guida alla Galleria Corsini, Roma 2002

[Roma]

Safarik, Eduard: Catalogo sommario della Galleria Colonna in Roma, Roma 1981

[Roma]

Vicini, Maria Lucrezia: Guida alla Galleria Spada, Rom 1998

[Stuttgart]

Petermann, Erwin: Katalog der Staatsgalerie Stuttgart, Stuttgart 1962 [Stuttgart]

Rettich, Edeltraud / Klapproth, Rüdiger / Ewald, Gerhard (Hrsg.): Alte Meister, Staatsgalerie Stuttgart, Stuttgart 1992

[Venezia]

Augusti, Adriana / Saccardo, Francesca: Ca d'Oro, La Galleria Giorgio Fianchetti, Milano 2002

[Wien]

Balis, Arnout (Hrsg.): Flämische Malerei im Kunsthistorischen Museum Wien, Zürich 1989

[Wien]

Ferino-Pagden, Sylvia / Prohaska, Wolfgang / Schütz, Karl (Hrsg.): Die Gemäldegalerie des Kunsthistorischen Museums in Wien, Verzeichnis der Gemälde, Wien 1991

[Wien]

Leithe-Jasper, Manfred / Distelberger, Rudolf: Kunsthistorisches Museum Wien, Schatzkammer und Sammlung für Plastik und Kunstgewerbe, München 1982

[Wien]

Planiscig, L. / Kris, E.: Katalog der Sammlungen für Plastik und Kunstgewerbe, Wien 1935, (Führer durch die Kunsthistorischen Sammlungen in Wien) 


\section{Bestandskataloge}

[Wien]

Trnek, Renate: Gemäldegalerie der Akademie der Bildenden Künste in Wien, Illustriertes Bestandsverzeichnis, Wien 1989

[Wien]

Kräftner, Johann / Seipel, Wilfried / Trnek, Renate (Hrsg.): Rubens in Wien, Wien 2004

[Würzburg]

Hoffmann, Volker / Koppe, Konrad: Martin von Wagner Museum der Universität Würzburg, Gemäldekatalog, Würzburg 1986 


\section{Literaturverzeichnis}

\section{Quellentexte}

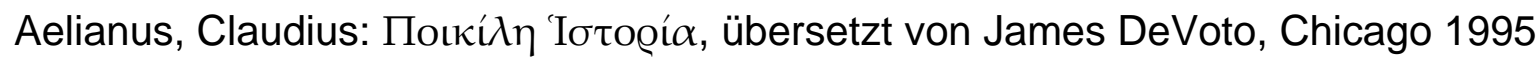
Alberti, Leon Battista: De pictura, Basel 1540 (ND Portland 1972)

Alberti, Leon Battista: Drei Bücher über die Malerei, in: Alberti, Leon Battista: Kleinere kunsttheoretische Schriften, Wien 1877, Quellenschriften für Kunstgeschichte und Kunsttechnik des Mittelalters und der Renaissance, Bd. 11) [ND, hrsg. von Hubert Janitschek, Osnabrück 1970]

Ambrosius: De bono mortis, hrsg. von Felicità Portalupi , Turin 1961

[Anonym]: D' Afrikaanse Sofonisba, Amsterdam 1661

Apocalypses apocryphae, hrsg. von Konstantin von Tischendorf, Hildesheim 1966 (ND der Ausgabe Leipzig 1866)

Appian von Alexandria: Römische Geschichte, Erster Teil: Die römische Reichsbildung, hrsg. und übers. von Otto Veh / Kai Brodersen, Stuttgart 1987

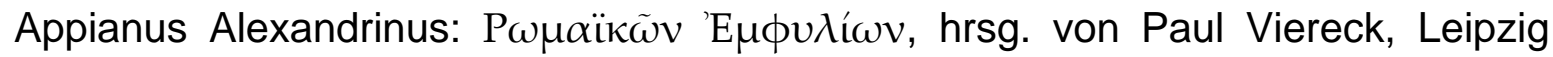
1986

Ariani, Marco (Hrsg.): Il teatro italiano, Bd. 2, La tragedia del Cinquecento, Turin 1977

Armenini, Giovanni Battista: De' veri precetti della pittura, Ravenna 1587 (ND Hildesheim / New York 1971)

Augustinus, De civitate dei. hrsg. von Bernhard Dombart, Stuttgart 1993

Bandello, Matteo: Le Novelle, hrsg. von Gioachino Brognoligo, Bari 1928

[Bandello] Floerke, Hanns (Übers.): Die Novellen des Bandello, München 1920

Barbaro, Francesco: De re uxoria, Argentorati 1612

Barocchi, Paola (Hrsg.): Trattati d'arte del cinquecento tra manierismo e controriforma, 3 Bde, Bari 1960

Bellori, Giovanni Pietro: Le vite de' Pittori, Scultori e Architetti moderni, hrsg. von Evelina Borea, Turin 1976

Berlioz, Hector: La mort de Cléopâtre, Scène lyrique pour soprano et orchestre (Libretto von Pierre-Ange Vieillard) 1829 (zuletzt aufgerufen: 15.12.2006: http://www.hberlioz.com/BerliozLibretti/Rome.htm)

Boccaccio, Giovanni: De claris mulieribus, Die großen Frauen, hrsg. u. übers. von I. Erfen / P. Schmitt, Stuttgart 1995

Boccaccio, Giovanni: Tutte le opere, hrsg. von Vittore Branca, Milano ${ }^{2} 1970$ 


\section{Quellentexte}

[Boccaccio, Giovanni:] Hoepfl, Simon (Hrsg.): Boccacios Buch der berühmten Frauen, mit 79 Holzschnitten der Ausgabe von Joh. Zainer, Ulm 1473 (Nachdruck München 1924)

Bouscal, Guerin du: La mort de Brute et de Porcie ou la vengance de la mort de César 1637 (http://gallica.bnf.fr/ (zuletzt aufgerufen: 15.12.2006] und http://www.publifarum.farum.it/ [zuletzt aufgerufen: 15.12.2006])

Boyer, Claude: La Porcie Romaine, hrsg. von Marie Roux, Paris (http://www.crht.org/?Biblioth\%E8que+dramatique/La+Porcie+Romaine [zuletzt aufgerufen: 15.12.2006])

Calvin, Johannes: Institutio religionis christianae, Braunschweig 1864 (Corpus Reformatorum $X X X, 2)$

[Castiglione, Baldassare]: Carmina quinque illustrium poetarum; Quorum nomina in seguenti pagina continentur. Additis nonnullis M. Antonij Flaminij libellis nunquam antea impressis. Venetiis Presb. Hieronymus Lilius, \& socij excudebant. M.D.LVIII

Castiglione, Baldassare: Opere volgari e latine, novellamente raccolte, ordinate, ricorrette ed illustrate, come nella seguente lettera può vedersi, da Gio. Antonio, e Gaetano Volpi, - Padova: Comino, 1733

(http://www.ub.uni-bielefeld.de/diglib/castiglione/opere/index.htm [zuletzt aufgerufen: 10.12.2006])

Cats, Jacob: Alle de wercken, Amsterdam [Jan Jacobsz. Schipper] 1658

Christine de Pizan: Das Buch von der Stadt der Frauen, hrsg. u. übers. von Margarete Zimmermann, Berlin ${ }^{2} 1987$

Christine de Pizan: >Le Livre de la Cité des Damesı de Christine de Pizan: an electronic transcription, hrsg. von Mary Skemp, Electronic Text Research Center, University of Minnesota, Minneapolis, MN, 1999 http://erc.lib.umn.edu/dynaweb/french/pizalaci/@Generic_BookView;lang=fr (zuletzt aufgerufen: 03.04.2007)

Cicero: De oratore, hrsg. von A. S. Wilkins, Oxford 1969

Couperus, Louis: Eline Vere, Amsterdam / Antwerpen ${ }^{7} 1991$

Del Carretto, Galeotto: Li sei contenti e La Sofonisba, hrsg. von Mauda GregoliRusso, Madrid 1982

Denzinger, Heinrich (Hrsg.): Enchiridion, Symbolorum definitionum et declarationum de rebus fidei et morum, Freiburg ${ }^{24} 1967$ 


\section{Literaturverzeichnis}

Dionysios von Halikarnassos: Antiquitates Romanae, hrsg. von Karl Jacoby, Leipzig 1885

Eichendorff, Joseph von: Werke, hrsg. von Wolfdietrich Rasch, München 1972

[FA] Goethe, Johann Wolfgang: Sämtliche Werke. Briefe, Tagebücher und Gespräche, 40 Bde, Frankfurt am Main 1985ff.

Gemmingen, Heinrich von: Dido, in: Litteratur-und Theaterzeitung, 32 (1780), S. 497-510

Ghiberti, Lorenzo: I commentarii, hrsg. von Lorenzo Bartoli, Florenz 1998

[Giustiniani] Agosti, B. (Hrsg.): Diario di viaggio di Vincenzo Giustiniani, Porretta Terme 1995

Goethe, Johann Wolfgang: Sämtliche Werke nach Epochen seines Schaffens, Münchner Ausgabe, hrsg. von Karl Richter u.a., München 1985ff. [zitiert als MA]

Goethe, Johann Wolfgang: Sämtliche Werke. Briefe, Tagebücher und Gespräche, 40 Bde, Frankfurt am Main 1985ff. [zitiert als FA]

Goué, August Siegfried von: Dido, ein Duodrama, Wetzlar 1771

Graesse, Th. (Hrsg.): Legenda aurea, Dresden 1890 (ND Osnabrück 1965)

Hegel, Georg Wilhelm Friedrich: Ästhetik, hrsg. von F. Bassenge, Frankfurt / Main 1955

Heinrich von Veldeke: Eneasroman, hrsg. u. übers. von D. Kartschoke, Stuttgart 1986

Herder, Johann Gottfried: Briefe zu Beförderung der Humanität, hrsg. von Hans Dietrich Irmscher, Frankfurt am Main 1991 (Bibliothek deutscher Klassiker)

[Herder] Schauer, Hans (Hrsg.): Herders Briefwechsel mit Caroline Flachsland, Weimar 1928Heywood, Thomas: The Dramatic Works, Bd. 5, London 1874 Hieronymus: Adversus Jovianum, in: PL 23

Hirt, Alois: VI. Kunstanzeige [zu Lady Hamiltons Attitüden], in: Der neue Teutsche Merkur, 2 (1794), S. 415

Hoet, Gerard: Catalogus of Naamlyst van Schildereyen met derzelver Pryzen, 2 Bde, 's Gravenhage 1752

Hoffmann, Ernst Theodor Amadeus: Fantasie- und Nachtstücke, hrsg. von Walter Müller-Seidel, Darmstadt 1978 


\section{Quellentexte}

[Humboldt] Foerst-Crato, Ilse: Frauen zur Goethezeit, Ein Briefwechsel, Caroline von Humboldt - Friederike Brun, Düsseldorf [Eigenverlag] 1975

Jagemann, Karoline: Erinnerungen der Karoline Jagemann, hrsg. von Eduard von Bamberg, Dresden 1926

Johannes Chrysostomus: In epistolam ad Hebraeos, in: PG 63 (52)

Justinus, M. Junianus: Epitoma Historiarum Philippicarum Pompei Trogi, hrsg. von Otto Seel, Leipzig 1935

Krauss, Marianne: Sammlung von Allerlei für mich gemerkt auf meiner Reise nach Italien zu Anfang des Jahres 1791, hrsg. von Fritz Muthmann, in: Neue Heidelberger Jahrbücher, 1931, S. 95-177

Lairesse, Gerard de: Groot schilderboek, Haarlem ${ }^{2} 1740$ (ND Davaco Publishers, Dornspyck 1969)

[Lairesse, Gerard de] Des Herrn Gerhard de, Welt=belobten Kunst=Mahlers / Grossen Mahler=Buchs, Aus dem Holländischen in das Hoch=Teutsche übersetzt. Nürnberg, Im Verlage Joh. Christoph Weigel, Kunst Händlers, seel. Wittib, gedruckt bey Lorenz Bieling, 1729

Le Brun, Charles: L'expression des passions, autres conférences, correspondance, hrsg. von Julien Philipe, Paris 1994

Le Brun, Charles: Méthode pour apprendre à dessiner les passions: proposée dans une conférence sur l'expression générale et particulière, Amsterdam 1702 (ND Hildesheim 1982)

Le Moyne, Pierre, La gallerie des femmes fortes, Paris 1647

Lessing, Gotthold Ephraim: Werke, Bd. VI, (Kunsttheoretische und kunsthistorische Schriften), Darmstadt 1996

Lipsius, Justus: C. Cornelii Taciti Historiarum et Annalium libri qui exstant, Antwerpen1574

Lipsius, Justus: Opera omnia, 4 Bde. in 8 Teilen, Wesel 1675 (ND Hildesheim / Zürich / New York 2001)

Livius: Ab urbe condita, hrsg. von W. Weissenborn / H. J. Müller, Dublin / Zürich ${ }^{7} 1968$

Lohenstein, Daniel Casper von: Cleopatra, Stuttgart 1998

Lohenstein, Daniel Casper von: Sophonisbe, Trauerspiel, Stuttgart 1996

Lucius Annaeus Florus: Opera, hrsg. von Paul Jal, Paris 1967 


\section{Literaturverzeichnis}

[MA] Goethe, Johann Wolfgang: Sämtliche Werke nach Epochen seines Schaffens, Münchner Ausgabe, hrsg. von Karl Richter u.a., München 1985ff.

Mander, Carel van: Das Leben der niederländischen und deutschen Maler (von 1400 bis ca. 1615, hrsg. von Hanns Floerke, München / Leipzig 1906 (ND Worms 1991)

Mariette, Pierre-Jean: Abecedario et autres notes inédites de cet amateur sur les arts et les artistes, hrsg. von Ph. Chennevières / A. de Montaiglon, Paris 18531862

Marino, Giovanni Battista: La Galeria, hrsg. von Marzio Pieri, 2 Bde, Padova 1979 Maupoint, [Vorname nicht ermittelbar]: Bibliothèque des théâtres, Paris 1733, http://www.cesar.org.uk/cesar2/books/maupoint/index.php (zuletzt aufgerufen: 10.12.2006)

Meißner, August Gottlieb: Sophonisbe, ein musikalisch [!] Drama mit historischem Prolog und Chören, Leipzig 1776

Metastasio, Pietro: Tutte le Opere, hrsg. von Bruno Brunelli, 3 Bde, Milano 1953

Mirys, Silvestre David de: Histoire de la République romaine, représentée par figures, accompagnée d'un Précis historique, Paris [Leblanc] 1800

Mirys, Silvestre David: Figures de l'Histoire Romaine, accompagnées d'un Précis historique au bas de chaque estampe, [0. O.] [ca. 1800]

Mirys, Silvestre David: Histoire de la république romaine depuis sa fondation jusqu'au regne d'Auguste en 181 gravures en taille-douce, d'apres les dessins de Mirys, Silvestre David, Paris [Stone] 1810

Montreux, Nicolas de, La Sophonisbe, hrsg. von Donald Stone, Genève 1976

Naevius: Belli Punici carmen, hrsg. von Wladislav Strzelecki, Leipzig 1964

Neumann, Leopold: Cleopatra, ein Duodrama, Mannheim 1780 (Beiträge zur Pfälzischen Schaubühne)

Ovid: Fasti, hrsg. von Ernst Alton, Leipzig 1985

Ovid: Heroides, hrsg. von Henri Bornecque, Paris 1991

Ovid: Metamorphoses, hrsg. von R.J. Tarrant, Oxford 2004

Paleotti, Gabriele: Discorso intorno alle imagini sacre e profane, Bologna 1582, in Barocchi, Paola (Hrsg.): Trattati d'arte del cinquecento tra manierismo e controriforma, 3 Bde., Bari 1960, Bd. 2, S. $148 \mathrm{ff}$.

Petrarca, Francesco: Africa, hrsg. von Nicola Festa, Firenze 1926 (Edizione Nazionale delle Opere di Francesco Petrarca, 1) 


\section{Quellentexte}

Petrarca, Francesco: Rime, Trionfi e Poesie Latine, hrsg. von F. Neri / G. Martellotti / E. Bianchi / N. Sapegno, Milano / Napoli 1951

Platon: Phaidon, hrsg. und übersetzt von Barbara Zehnpfennig, Hamburg 1991

Poe, Edgar Allan: The Philosophy of Composition, in: Essays and Reviews, hrsg. von Gary Richard Thompson, New York 1984

Ripa, Cesare: Iconologia, Rom 1603 (ND Hildesheim / New York 1970)

Rollin, Charles: Histoire Ancienne, Amsterdam 1734-1739

Roman d'Eneas, hrsg. u. übers. von Monica Schöler-Beinhauer, München 1972 (Klassische Texte des romanischen Mittelalters in zweisprachigen Ausgaben 9)

Rousseau, Jean-Jacques: CEuvres complètes, hrsg. von Bernard Gagnebin / Marcel Raymond, Paris 1964

Sachs, Hans: Tragedia von der Lucretia, in: Hartmann, Horst (Hrsg.): Heinrich Bullinger / Hans Sachs, Lucretia-Dramen, Leipzig 1973, S. 99-112

Scheibe,Johann Adolph: Critischer Musikus, Leipzig 1745

Schütz, Karl-Friedrich Julius: Blumenlese aus dem Stammbuche der deutschen mimischen Künstlerin Frau Henriette Hendel-Schütz, gebornen Schüler, Leipzig / Altenburg 1815

[Seidel, Louise:] Kaufmann, Sylke (Hrsg.): Goethes Malerin, Die Erinnerungen der Louise Seidler, Berlin 2003

Shakespeare, William: Julius Caesar, hrsg. von T. S. Dorsch, London ${ }^{6} 1955$

Shakespeare, William: The Rape of Lucrece, in: The Complete Works of Shakespeare, hrsg. von Peter Alexander, London / Glasgow 1990

Spinoza: Ethica, in: http://www.thelatinlibrary.com/spinoza.ethica2.html (zuletzt aufgerufen: 13.02.2007)

Stein, Charlotte von: Dramen, hrsg. von Susanne Kord, Hildesheim / Zürich / New York 1988

Sturm, Leonhard: Vollständige Anweisung zu der Civil Bau-Kunst, Braunschweig 1699

Sulzer, Johann Georg: Allgemeine Theorie der schönen Künste, in einzeln, nach alphabetischer Ordnung der Kunstwörter auf einander folgenden Artickeln abgehandelt, 4 Bde, Frankfurt / Main und Leipzig, ${ }^{3} 1798$

Tertullian: Ad martyres, PL 1, Paris 1844 


\section{Literaturverzeichnis}

Valerius Maximus: Facta et dicta memorabilia, hrsg. und übers. von Ursula BlankSangmeister, Stuttgart 1991

Vasari, Giorgio: Le vite de' più eccellenti architetti, pittori et scultori italiani, da Cimabue insino a' tempi nostri, Rom 1550

http://www.liberliber.it/biblioteca/v/vasari/index.htm (zuletzt aufgerufen: 25.10.2006)

Vasari, Giorgio: Der literarische Nachlass, hrsg. von Herman-Walther Frey, 3 Bde, München 1923-1940

Vergil: Aeneis, hrsg. und übers. von Johannes Götte, Kempten ${ }^{3} 1971$

Vondel, Joost van: De werken, hrsg. von J. F. M. Sterck u.a., 10 Bde, Amsterdam 1927-1937

Vos, Jan: Alle gedichten van den Poèet Jan Vos, Amsterdam 1662

Weise, Christian: Curiöse Gedanken von deutschen Versen, Leipzig ${ }^{2} 1693$

Wetzel, Johann Carl: Zelmor und Ermide, Ein musikalisches Schauspiel, in: Wetzel, Johann Carl: Lustspiele, Bd. 2, Leipzig 1779

Zesen, Philipp von: Die afrikanische Sofonisbe, hrsg. von Volker Meid, Berlin 1972 (Sämtliche Werke, 6) 


\section{Forschungsliteratur}

Abel, Günter: Stoizismus und Frühe Neuzeit, Zur Entstehungsgeschichte modernen Denkens im Felde von Ethik und Politik, Berlin / New York 1978

Abert, Anna Amalie: Oper, in: ${ }^{1} M G G$ 10, München 1989, $1 \mathrm{ff}$.

Agosti, B. (Hrsg.): Diario di viaggio di Vincenzo Giustiniani, Porretta Terme 1995

Agosti, Giovanni / Bagnoli, Alessandro (Hrsg.): AK Domenico Beccafumi e il suo tempo, Milano 1990

Agosti, Giovanni / Farinella, Vicenzo: »Interni senesi all'antica«, in: [Siena 1990] AK Domenico Beccafumi e il suo tempo, Milano 1990, S. 578-599

Alewyn, Richard: Das große Welttheater, Die Epoche der höfischen Feste, Berlin 1985

Allen, Brian: „Die Grand Tour der Briten, Künstler und Reisende in Rom in der Mitte des 18. Jahrhunderts«, in: Baumgärtel, Bettina (Hrsg.): AK Angelika Kauffmann, Ostfildern-Ruit 1998, S. 47-51

Alloisi, Sivigliano: Guida alla Galleria Corsini, Rom 2002

Alt, Peter-André: Der Tod der Königin, Frauenopfer und politische Souveränität im Trauerspiel des 17. Jahrhunderts, Berlin / New York 2004

Ameling, Walter (Hrsg.): Märtyrer und Märtyrerakten, Stuttgart 2002

Andrae, August: Sophonisbe in der französischen Tragödie mit Berücksichtigung der Sophonisbebearbeitungen in den anderen Litteraturen, Jena 1891 (Zeitschrift für französische Sprache und Litteratur, Supplement 6)

[Anonym:] »Galerie «, in: Lexikon der Kunst, Bd. 2, München 1996, S. 627

Anton, Hans: Fürstenspiegel, in: Lexikon des Mittelalters, Bd. 4, Sp. 1040-1058

Appuhn, Horst: „Das private Andachtsbild: Ein Vorschlag zur kunstgeschichtlichen und volkskundlichen Terminologie«, in: Bringemeier, Martha (Hrsg.): Museum und Kulturgeschichte, Festschrift Wilhelm Hansen, Münster 1978, S. 289-292

Appuhn, Horst: Einführung in die Ikonographie der mittelalterlichen Kunst in Deutschland, Darmstadt 1969

Ariani, Marco (Hrsg.): Il teatro italiano, Bd. 2, La tragedia del Cinquecento, Torino 1977

Ariès, Philippe: Bilder zur Geschichte des Todes, München 1984

Asch, Ronald / Feist, Dagmar (Hrsg.): Staatsbildung als kultureller Prozess: Strukturwandel und Legitimation von Herrschaft in der Frühen Neuzeit, Köln 2005 


\section{Literaturverzeichnis}

Asor Rosa, Alberto (Hrsg.): Letteratura italiana, Milano 1982-1991

Assmann, Jan: Das kulturelle Gedächtnis, Schrift, Erinnerung und politische Identität in frühen Hochkulturen, München ${ }^{2} 1997$

[Augsburg / Cleveland] Kat. Johann Liss, Augsburg 1975

Augusti, Adriana / Saccardo, Francesca: Ca d'Oro, La Galleria Giorgio Fianchetti, Milano 2002

Aurenhammer, Hans: Die Mariengnadenbilder Wiens und Niederösterreichs in der Barockzeit, Diss. Wien 1956

Axelrad, Albert-José: Le thème de Sophonisbe dans les principales tragédies de la littérature occidentale (France, Angleterre, Allemagne), Lille 1956

Bailey, C. / Hamilton, C. A. (Hrsg.): AK Les Amours des Dieux, La peinture mythologique de Watteau a David, Paris 1991

Baker, Christopher / Henry, Tom (Hrsg.): The National Gallery, Complete Illustrated Catalogue, London 1995

Baldriga, Irene: „Vincenzo Giustinianis Persönlichkeit im Spiegel seiner Bibliothek « in: Danesi Squarzina, Silvia (Hrsg.): AK Caravaggio, Die Sammlung Giustiniani und die Berliner Gemäldegalerie in Preußen, Milano 2001, S. 73- 80

Balis, Arnout (Hrsg.): Flämische Malerei im Kunsthistorischen Museum Wien, Zürich 1989

Banzato, Davide / Pellegrini, Franca (Hrsg.): AK La peinture vénitienne 1600-1800, 65 peintures des collections des musées de la Ville de Padoue, Nancy 1991

Barner, Wilfried: Barockrhetorik: Untersuchungen zu ihren geschichtlichen Grundlagen, Tübingen 1970

Barner, Wilfried: Produktive Rezeption: Lessing und die Tragödien Senecas, München 1973

Barner, Wilfred: »Disponible Festlichkeit, Zu Lohensteins Sophonisbe«, in: Haug, Walther/ Warning, Rainer (Hrsg.): Das Fest, München 1989 (Poetik und Hermeneutik 14), S. 247-275

Barocchi, Paola (Hrsg.): Trattati d'arte del cinquecento tra manierismo e controriforma, 3 Bde, Bari 1960

Barone, G.: »Legenda aurea «, in: Lexikon des Mittelalters, Bd. 5, Sp. 1796-1797

Bartsch, Adam: Le Peintre Graveur, 21 Bde, Leipzig 1854-1876

Baskins, Cristelle: Cassone painting, humanism and gender in early modern Italy, Cambridge 1998 


\section{Forschungsliteratur}

Bassani Pacht, Paola / Crépin-Leblond, Thierry / Sainte Fare Garnot, Nicolas / Solinas, Francesco (Hrsg.): AK Marie de Médicis, un gouvernement par les arts, Paris 2004

Bastet, Frédéric: Louis Couperus, Amsterdam 1989

Baudouin, Frans: »Religion und Malerei nach der Teilung der Niederlande«, in: August Buck (Hrsg.): Renaissance - Reformation, Gegensätze und Gemeinsamkeiten, Wiesbaden 1984, S. 7-22

Baumgärtel, Bettina (Hrsg.): AK Angelika Kauffmann, Ostfildern-Ruit 1998

Baumgärtel, Bettina / Neysters, Silvia (Hrsg.): AK Die Galerie der Starken Frauen, Düsseldorf 1995

Baumgärtel, Bettina: „Die Tugendheldin als Symbol kirchlicher und staatlicher Macht, Über die Galerie der Starken Frauen in Ausstattungsprogrammen und als Buchillustrationen«, in: dies. (Hrsg.): AK Die Galerie der Starken Frauen, a.a.O. , S. $140-204$

Baumgärtel, Bettina: »Die Attitüde und die Malerei «, in: Zeitschrift des deutschen Vereins für Kunstwissenschaft 46 (1992), S. 21-42

Bäumler, S. / Brockhoff, E. / Henker, M. (Hrsg.): AK Von Kaisers Gnaden, 500 Jahre Pfalz-Neuburg, Regensburg 2005

Beer, Manuela: Das kleine Andachtsbild: Graphik vom 16. bis zum 20. Jahrhundert, Hildesheim 2004

Belkin Lohse, Kristin / Healy, Fiona (Hrsg.): AK A House of Art, Rubens as Collector, Antwerpen 2004

Belting, Hans: Bild und Kult, Eine Geschichte des Bildes vor dem Zeitalter der Kunst, München 1990

Belting, Hans: Das Bild und sein Publikum im Mittelalter, Berlin 1981

Paul Bénichou, Morales du grand siècle, Paris 1948 u.ö.

Berhout, Marieke: De zelfmoord van Lucretia, Dido, Cleopatra en Sophonisba in de Nederlandse schilder-, teken- en prentkunst tussen ca.1500 en 1730 (http://www.onderzoekinformatie.nl [zuletzt aufgerufen: 16.03.2007] noch nicht abgeschlossene Diss. Leiden)

Berliner, Rudolf: »Arma Christi«, in: Münchener Jahrbuch der bildenden Künste 3 (1955), S. 53-152

Berliner, Rudolf: "Bemerkungen zu einigen Darstellungen des Erlösers als Schmerzensmann«, in: Das Münster 9 (1956), S. 97-117 


\section{Literaturverzeichnis}

Bernier, Marc André: »La lettre sur les sourdes et muets (1751) de Denis Diderot: une rhétorique du punctum temporis«, in: Lumen 18 (2000), S. 1-10

Bertling, Claudia: Die Darstellung der Kreuzabnahme und der Beweinung Christi in der ersten Hälfte des 16. Jahrhunderts, Hildesheim 1992

Bettagno, Alessandro (Hrsg.): AK Antonio Pellegrini, Il maestro veneto del Rococò alle corti d' Europa, Venezia 1998

Beuth, Karl: Weisheit und Geistesstärke, Eine philosophiegeschichtliche Untersuchung zur >Constantiar des Justus Lipsius, Frankfurt/Main / New York 1990

Beyer, Andreas: Andrea Palladio, Teatro Olimpico, Triumpharchitektur für eine humanistische Gesellschaft, Frankfurt 1987

Bialostocki, Jan: "Skizze einer Geschichte der beabsichtigten und interpretierenden Ikonographie«, in: Kaemmerling, E. (Hrsg.): Bildende Kunst als Zeichensystem, Köln 1979, S. 15-63

Blasiis, Giuseppe de: "Immagini di uomini famosi in una sala di Castelnuovo « in: Napoli nobilissima 9 (1900), S. 65-67

Bloch, Ernst: Das Prinzip Hoffnung, Frankfurt/Main 1959

Blumenberg, Hans: Arbeit am Mythos, Frankfurt ${ }^{2} 1981$

Blumenberg, Hans: Die Legitimität der Neuzeit, Frankfurt am Main ${ }^{3} 1997$

Bode, Wilhelm: Die italienischen Hausmöbel der Renaissance, Leipzig ${ }^{2} 1920$

Bohde, Daniela: Haut, Fleisch und Farbe, Körperlichkeit und Materialität in den Gemälden Tizians, Emsdetten / Berlin 2002

Bonfait, O. (Hrsg.): AK Roma 1630, Il trionfo del pennello, Milano 1994

Bonnefoy, Yves: "La noblesse de Cléopâtre «, in: Ritschard, Claude / Morehead, Allison (Hrsg.): AK Cléopâtre dans le miroir de l'art occidental, Genève 2004, 147-164

Bonnet, Anne-Marie / Schellewald, Barbara (Hrsg.): Frauen in der Frühen Neuzeit, Lebensentwürfe in Kunst und Literatur, Köln / Weimar / Wien 2004

Borst, Arno: »Ein exemplarischer Tod«, in: Tod im Mittelalter, in: Borst, A. / von Graevenitz, G. / Patschovsky, A. / Stierle, K. (Hrsg.): Tod im Mittelalter, Kons$\operatorname{tanz} 1993$, S. 25-58

Bossaglia, Rossana / Terraroli, Valerio: AK Settecento lombardo, Milano 1991

Bott, Gerhard (Hrsg.): AK Die Grafen von Schönborn. Kirchenfürsten, Sammler, Mäzene, Nürnberg 1989 


\section{Forschungsliteratur}

Bott, Katharina: "/La mia galleria Pommersfeldianaく, Die Geschichte der Gemäldesammlung des Lothar Franz von Schönborn «, in: Bott, Gerhard (Hrsg.): AK Die Grafen von Schönborn. Kirchenfürsten, Sammler, Mäzene, Nürnberg 1989, S. $112-128$

Boudouin-Matuszek, Marie-Noëlle: Marie de Médicis et le Palais du Luxembourg, Paris 1991

Braham, Allan [Hrsg.]: The National Gallery, Illustrated General Catalogue, London ${ }^{2} 1986$

Brambach, Joachim: Kleopatra und ihre Zeit, Legende und Wirklichkeit, München 1991

Brandenburg, Gottfried Daniel: Zur Geschichte der weltlichen Solokantate in Neapel im frühen Settecento, Die Solokantaten von Domenico Sarro (1679-1744), Frankfurt/Bern/New York/Paris 1991

Brassat, Wolfgang: "Tragik, versteckte Kompositionskunst und Katharsis im Werk von Peter Paul Rubens«, in: Heinen, Ulrich / Thielemann, Andreas (Hrsg.): Rubens Passioni, Kultur der Leidenschaften im Barock, Göttingen 2001, S. 4169

Bredius, Abraham: Künstler-Inventare, Urkunden zur Geschichte der holländischen Kunst des XVI ten und XVII $I^{\text {ten }}$ Jahrhunderts, Den Haag 1915-1922

Breitenberg, Mark: Anxious masculinity in early modern England, Cambridge 1996 Brejon de Lavergnée, Arnauld / Foucart, Jacques / Reynaud, Nicole [Hrsg.]: Catalogue sommaire illustré des peintures du musée du Louvre, Bd. 1, Écoles flamande et hollandaise, Paris 1979

Brejon de Lavergnée, Arnauld / Thiébaut, Dominique [Hrsg.]: Catalogue sommaire illustré des peintures du musée du Louvre, Bd. 2, Italie, Espagne, Allemagne, Grande-Bretagne et divers, Paris 1981

Brejon de Lavergnée, Arnauld: Dijon, Musée Magnin, Catalogue des tableaux et dessins italiens (XV'-XIX siècles), Paris 1980

Brink Goldsmith, Jane ten / Plomp, Michiel (Hrsg.): AK Leonaert Bramer, 15951674: Ingenious Painter and Draughtsman in Rome and Delft, Zwolle 1994

Bronfen, Elisabeth: Nur über ihre Leiche, Tod, Weiblichkeit und Ästhetik, München 1996

Brummer, Hans Henrik: The Statue Court in the Vatican Belvedere, Stockholm 1970 


\section{Literaturverzeichnis}

Brunhölzl, Franz: »Livius«, in: Lexikon des Mittelalters, Bd. 5, Sp. 2043-2044

Bruyn, J. (Hrsg.): A Corpus of Rembrandt Paintings, Bd. 1, Den Haag 1982

Bruyn, J. u.a. (Hrsg.): A Corpus of Rembrandt, Paintings Bd. 2, Dordrecht 1986

Brzoska, Matthias: »Ferdinando Paer: Sofonisba, Dramma serio per musica «, in:

Pipers Enzyklopädie des Musiktheaters, hrsg. von Carl Dahlhaus, Bd. 4, München 1991, S. $626 f$.

Bull, Duncan (Hrsg.): AK Rembrandt - Caravaggio, Stuttgart 2006

Burck, Erich (Hrsg.): Wege zu Livius, Darmstadt 1977 (Wege der Forschung 132)

Burckhardt, Jacob: Der Cicerone, hrsg. von Bernd Roeck / Christine Tauber / Martin Warnke), München 2001 (Kritische Gesamtausgabe Bd. 3)

Burckhardt, Jacob: Griechische Kulturgeschichte München ${ }^{2} 1987$ (ND der Ausgabe von Schwabe und Co., Basel 1956-1957)

Burdach, Konrad: Reformation, Renaissance, Humanismus, Berlin 1918

Burschel, Peter: "Männliche Tode - weibliche Tode. Zur Anthropologie des Martyriums in der frühen Neuzeit«, in: Saeculum, Jahrbuch für Universalgeschichte 50 (1999), S. 75-97

Burschel, Peter: "Paradiese der Gewalt. Martyrium, Imagination und die Metamorphosen des nachtridentinischen Heiligenhimmels «, in: Jahrbuch des Historischen Kollegs 2001, München 2002, S. 139-181

Burschel, Peter: Sterben und Unsterblichkeit, Zur Kultur des Martyriums in der frühen Neuzeit, München 2004

Busch, Werner: "Das Einfigurenbild und der Sensibilitätskult des 18. Jahrhunderts «, in: Baumgärtel, Bettina (Hrsg.): AK Angelika Kauffmann, Düsseldorf 1998, S. 40-46

Butler, Judith: Das Unbehagen der Geschlechter, Frankfurt/Main ${ }^{1} 1990$ (Gender Trouble: Feminism and the Subversion of Identity, Routledge 1990)

Büttner, Frank: ıImitatio pietatisı, Motive der christlichen Ikonographie als Modelle der Verähnlichung, Berlin 1983

Büttner, Nils / Heinen, Ulrich (Hrsg.): AK Peter Paul Rubens, Barocke Leidenschaften, Braunschweig 2004

Campenhausen, Hans Freiherr von: Die Idee des Martyriums in der alten Kirche, Göttingen ${ }^{2} 1964$

Cassani, Silvia (Hrsg.) AK Settecento Napoletano, Sulle ali dell'aquila imperiale 1707-1734, Milano 1994 


\section{Forschungsliteratur}

Cassani, Silvia / Sapio, Mario (Hrsg.): AK Luca Giordano 1634-1705, Napoli 2001

Cattaneo Adorno, Carlotta (u.a.): Il Palazzo Durazzo Pallavicini, Milano 1995

Charrière, Isabella Agneta Elisabeth de: Lettres écrites de Lausanne (1785), hrsg. von Michel Pacaud

Chesnutt, Michael »Exempelsammlungen« in: Enzyklopädie des Märchens, begr. von Kurt Ranke, hrsg. von Rolf Wilhelm Brednich, Bd. 4, Berlin / New York 1987

Chiamò, Maria (Hrsg.): I Gesuiti e i Primordi del Teatro barocco in Europa, Roma 1995

Chiarini, Marco: Palazzo Pitti, Firenze 1988

Christiansen, Keith (Hrsg.): AK Giambattista Tiepolo 1696-1996, Milano 1996

Christiansen, Keith: »The Studiolo of Isabella d'Este and late themes «, in: Martineau, Jane (Hrsg.): AK Andrea Mantegna, London / New York 1992, S. 394468

Christiansen, Keith / Mann, Judith: AK Orazio e Artemisia Gentileschi, Milano 2001

Chu, Petra ten-Doesschate (Hrsg.): AK Im Lichte Hollands, Holländische Malerei des 17. Jahrhunderts aus den Sammlungen des Fürsten von Liechtenstein und aus Schweizer Besitz, Zürich 1987

Clauss, Manfred: Kleopatra, München 1995

Cola, Alberto / Salvagni, Anna / Scolaro, Francesca / Scolaro, Michaela / Caroselli, Susan (Hrsg.): AK Guido Reni, 1575-1642, Bologna 1988

Compin, Isabelle / Roquebert, Anne (Hrsg.): Catalogue sommaire illustré des peintures du musée du Louvre et du musée d:Orsay, École française, 3 Bde., Paris 1986

Contini, Roberto (Hrsg.): AK Pracht und Pathos, Meisterwerke der Barockmalerei aus dem Palazzo Bianco in Genua, Berlin 2003

Corace, Erminia: Mattia Preti, Roma 1989

Cortenova, Giorgio (Hrsg.): AK II settimo splendore, La modernità della malinconia, Venezia 2007

Courcelles, Pierre: Les lettres grecques en occident de Macrobe à Cassiodore, Paris ${ }^{2} 1948$

Curtius, E. R.: Europäische Literatur und lateinisches Mittelalter, Bern / München ${ }^{8} 1973$ 


\section{Literaturverzeichnis}

d'Hulst, R.-A. / de Poorter, N. / Vandenven, M. (Hrsg.): AK Jacob Jordaens (15931678), Brussels 1993

Dahlhaus, Carl: »Dramaturgie der italienischen Oper «, in: Geschichte der italienischen Oper, Theorien und Techniken, Bilder und Mythen, Bd. 6, Regensburg 1992, S. 75-178 [italienische Originalausgabe hrsg. von Lorenzo Bianconi / Giorgio Pestelli, Torino 1988]

Danesi Squarzina, Silvia (Hrsg.): AK Caravaggio in Preußen, Die Sammlung Giustiniani und die Berliner Gemäldegalerie, Milano 2001

Danesi Squarzina, Silvia: La collezione Giustiniani, 3 Bde, Torino 2003

Daxelmüller, Christoph: »Exemplum«, in: Enzyklopädie des Märchens, begr. von Ranke, Kurt, hrsg. von Brednich, Rolf Wilhelm, Bd. 4, Berlin 1987, Sp. 627-649

Delumeau, Jean: Le catholicisme entre Luther et Voltaire, Paris 1971

Demmer, Sybille: Untersuchungen zu Form und Geschichte des Monodramas, Köln 1982

Denzinger, Heinrich (Hrsg.): Enchiridion, Symbolorum definitionum et declarationum de rebus fidei et morum, Freiburg ${ }^{24} 1967$

Der Kleine Pauly : Lexikon der Antike, auf der Grundlage von Pauly's Realencyclopädie der classischen Altertumswissenschaft unter Mitw. zahlr. Fachgelehrter bearb. u. hrsg. von Konrat Ziegler [u.a.], 5 Bde, Stuttgart 1964-1975.

Deswarte-Rosa, Sylvie: „Francisco de Holanda et le Cortile di Belvedere«, in: Winner, M. / Andreae, B. / Pietrangeli, C. (Hrsg.): I/ Cortile delle Statue, Der Statuenhof des Belvedere im Vatikan, (Akten des internationalen Kongresses zu Ehren von Richard Krautheimer [Rom 1992]), Mainz 1998, S. 389-410

d'Hulst, Roger-Adolf: Jacob Jordaens, Stuttgart 1982

Diderot, Denis: Encyclopédie ou Dictionnaire raisonné des sciences, des arts et des métiers, par une société de gens de lettres, Paris 1751-1780

Diers, Michael: »(Nach-)Lebende Bilder. Praxisformen klassizistischer Kunsttheorie«, in: Burdorf, Dieter / Schweickard, Wolfgang (Hrsg.): Die schöne Verwirrung der Phantasie, Tübingen 1998, S. 175-205

Dinzelbacher, Peter: »Tod, Sozial- und Mentalitätsgeschichte«, in: Lexikon des Mittelalters, Bd. 8, Sp. 829-831

Donaldson, lan: The rapes of Lucretia, A Myth and its Transformation, Oxford 1982 Drach, Allard von: »Briefe des Kunstsammlers Antonie Rutgers an den Landgrafen Wilhelm VIII. von Hessen«, in: Oud Holland 8 (1890), S. 196-197 


\section{Forschungsliteratur}

Dubois, Isabelle/Gady, Alexandre/Ziegler, Hendrik: La Place des Victoires, Paris 2003

Düchting, Reinhard: »Livius «, in: Lexikon des Mittelalters, Bd. 5, Sp. 2044-2045

Ebert-Schifferer, Sybille (Hrsg.): AK II gusto bolognese, Barockmalerei aus der Emilia-Romagna, Bologna 1994

Ebert-Schifferer, Sybille / Emiliani, Andrea / Schleier, Erich (Hrsg.) AK Guido Reni und Europa, Ruhm und Nachruhm, Frankfurt 1988

Ebert-Schifferer, Sybille: »Guido Reni: klassische Norm, christliches Pathos und reine Farbe «, in : AK Guido Reni und Europa, Ruhm und Nachruhm, Frankfurt 1988, S. 16-31

Ebert-Schifferer, Sybille: "Sandrart a Roma 1629-1635: un cosmopolita tedesco nel Paese delle Meraviglie« in: Bonfait, O. (Hrsg.): AK Roma 1630, II trionfo del pennello, Milano 1994, S. 97-114

Egger, Irmgard: »Eikones: zur Inszenierung der Bilder in Goethes Romanen « in: Goethe-Jahrbuch 2001, Weimar 2002, S. 260-273

Eisen, Walter / Eisen, Margret: Händel-Handbuch, Leipzig 1984

Eisenhut, W.: »Dido«, in: ${ }^{1}$ Kleiner Pauly, Bd. 2, Sp.9-10

Elias, Norbert: Über den Prozeß der Zivilisation, 2 Bde, Frankfurt/Main ${ }^{1} 1976$

Ellenius, Allan (Hrsg.): Iconography, Propaganda and Legitimation, Oxford 1998

Emich, Birgit: »Bologneser libertà, Ferrareser decadenza: Politische Kultur und päpstliche Herrschaft im Kirchenstaat der Frühen Neuzeit«, in: Asch, Ronald / Freist, Dagmar (Hrsg.): Staatsbildung als kultureller Prozess, Strukturwandel und Legitimation von Herrschaft in der Frühen Neuzeit, Köln / Weimar / Wien 2005, S. 117-134

Engel, Hans / Hucke, Helmut: Kantate, in: ${ }^{1} M G G$, Bd. 7, München 1989, Sp. 554575

Engel, Johann Jakob: Ideen zu einer Mimik, 2 Bde, Berlin 1785

Enzyklopädie des Märchens, begr. von Ranke, Kurt, hrsg. von Brednich, Rolf Wilhelm, 11 Bde, Berlin 1977-2007

Etter, Else-Lilly: Tacitus in der Geistesgeschichte des 16. und 17. Jahrhunderts, Basel / Stuttgart 1966

Evans, Robert C.: Lipsius and the Politics of Renaissance Stoicism, Longwood 1992

Evers, Hans Gerhard: Peter Paul Rubens, München 1942 


\section{Literaturverzeichnis}

Fajen, Robert: Die Lanze und die Feder, Untersuchungen zum > Livre du Chevalier errant von Thomas III., Markgraf von Saluzzo, Wiesbaden 2003

Fehrle, Rudolf (Hrsg.): Cato Uticensis, Darmstadt 1983 (Impulse der Forschung 43)

Feichtinger, Barbara: »Antikerezeption mit Ambitionen, Christine de Pizans Livre de la Cité des Dames und Boccaccios De claris mulieribus", in: Schmidt, Paul Gerhard (Hrsg.): Die Frau in der Renaissance, Wiesbaden 1994

Fellsches, Josef: "Tugend/Laster « in Europäische Enzyklopädie zu Philosophie und Wissenschaften, hrsg. von Hans Jörg Sandkühler, Hamburg 1990, Bd. 4, S. 620

Ferino-Pagden, Sylvia / Prohaska, Wolfgang / Schütz, Karl (Hrsg.): Die Gemäldegalerie des Kunsthistorischen Museums in Wien, Verzeichnis der Gemälde, Wien 1991

Ferino-Pagden, Sylvia (Hrsg.): AK Der späte Tizian und die Sinnlichkeit der Malerei, Wien 2007

Ferrari Schiefer, Valeria: La Belle Question, Die Frage nach der Gleichheit der Geschlechter bei François Poullain de la Barre (1647-1723) auf dem Hintergrund der (früh-)neuzeitlichen Querelle des Femmes, Luzern 1998 (Theologie in Geschichte und Gesellschaft 8)

Feulner, A. / Müller, Th.: Geschichte der deutschen Plastik, München 1953

Fink, Hanns-Peter: Exercitia Latina. Vom Unterricht lippischer Junggrafen zur Zeit der Spätrenaissance, Marburg 1991

Flemming, Johanna: »Palme«, in: LCl, Bd. 3, Sp. 364-365

Foerst-Crato, Ilse: Frauen zur Goethezeit, Ein Briefwechsel, Caroline von Humboldt - Friederike Brun, Düsseldorf [Eigenverlag] 1975

Fögen, Marie Theres: Römische Rechtsgeschichten, Über Ursprung und Evolution eines sozialen Systems, Göttingen 2002

Fohr, Robert / Gilet, Annie (Hrsg.): AK Tableaux français et italiens du XVIle siècle des Musée des beaux-arts de Tours, Musée de Richelieu, Château d'Azay-leFerron, Paris 1982

Follak, Jan: Lucretia zwischen positiver und negativer Anthropologie, Coluccio Salutatis >Declamatio Lucretie und die Menschenbilder im exemplum der Lucretia von der Antike bis in die Neuzeit, Diss. Konstanz 2002 http://www.ub.uni-konstanz.de/kops/volltexte/2002/914/pdf/follak01-text.pdf (zuletzt aufgerufen: 11.11.2006) 


\section{Forschungsliteratur}

Frappier, Jean / Grimm, Reinhold R. (Hrsg.): Le roman jusqu'à la fin du XIII siècle, Partie historique, Heidelberg 1978 (Grundriss der romanischen Literaturen des Mittelalters, IV,1)

Freedberg, David: "Kunst und Gegenreformation in den südlichen Niederlanden 1560-1660 «, in Mai, Ekkehard (Hrsg.): AK Von Bruegel bis Rubens, Das goldene Jahrhundert der flämischen Malerei, Köln / Antwerpen / Wien 1992, S. 55-70

Frenzel, Elisabeth: Stoffe der Weltliteratur, Stuttgart ${ }^{7} 1988$

Frey, Herman-Walther (Hrsg.): Giorgio Vasari, Der literarische Nachlass 3 Bde, München 1923-1940

Friedländer, Max Julius / Rosenberg, Jakob: Lucas Cranach, [1932] Stuttgart 1989 Frodl, Gerbert: Hans Makart, Monographie und Werkverzeichnis, Salzburg 1974

Fuhrmann, Manfred: »Das Exemplum in der antiken Rhetorik «, in: Koselleck, R. / Stempel, W. (Hrsg.): Geschichte - Ereignis und Erzählung, München 1973 (Poetik und Hermeneutik 5), S. 449-452

Fumaroli, Marc: L'école du silence, le sentiment des images au XVII siècle, Paris 1994

Fumaroli, Marc: L'âge de l'éloquence: rhétorique et ıres literariar de la Renaissance au seuil de l'époque classique, Paris ${ }^{3} 2002$

Gaehtgens, Barbara: „Macht-Wechsel oder die Übergabe der Regentschaft«, in: Baumgärtel, Bettina / Neysters, Silvia (Hrsg.): AK Die Galerie der Starken Frauen, a.a.O., S. 64-78

Gaehtgens, Thomas / Fleckner, Uwe (Hrsg.): Historienmalerei, Berlin 1996

Galinsky, Hans: Der Lucretia-Stoff in der Weltiteratur, Breslau 1932

Garrard, Mary D.: Artemisia Gentileschi, the image of the female hero in Italian Baroque art, Princeton 1989

Gathercole, Patricia M.: Tension in Boccaccio, Boccaccio and the fine arts, Mississippi 1975

Gavazza, E. / Sciré, G. / Terminello, G. (Hrsg.): AK Bernardo Strozzi, Genova 1581/82-Venezia 1644, Milano 1995

Gemin, Massimo / Pedrocco, Filippo: Giambattista Tiepolo, Leben und Werk, München 1995

Gemmingen, Heinrich von: Dido, in: Litteratur- und Theaterzeitung, 32 (1780), S. 497-510 


\section{Literaturverzeichnis}

Georges, Karl Ernst: Ausführliches Lateinisch-deutsches Handwörterbuch, Hannover 1976 (ND der Ausgabe Gotha ${ }^{14} 1913$ )

Gerhard, Anselm: »Rollenhierarchie und dramaturgische Hierarchien in der italienischen Oper des 18. Jahrhunderts «, in: Hortschansky, Klaus (Hrsg.): Opernheld und Opernheldin im 18. Jahrhundert, Aspekte der Librettoforschung, Ein Tagungsbericht, Hamburg 1991, S. 35-55

Giegling, Franz: »Marcello«, in: ${ }^{1} M G G$, Bd. 8, S. 1616-1619

Gier, Albert: Das Libretto, Theorie und Geschichte einer musikoliterarischen Gattung, Darmstadt 1998

Göbel, Heinrich: Wandteppiche in den Niederlanden, Leipzig 1946

Goffen, Rona: „Lottos's Lucretia«, in: Renaissance Quarterly 52 (1999), S. $742-$ 781

Golahny, Amy: »Rembrandt's Artemisia: Arts Patron«, in: Oud Holland 114 (2000), S. $139-154$

Goldfarb, Hilliard Todd (Hrsg.): AK Richelieu (1585-1642), Kunst, Macht und Politik, Ghent 2002

Gombrich, Ernst H.: Das symbolische Bild, Zur Kunst der Renaissance, Bd. 2, Stuttgart 1986

Gottdang, Andrea: Venedigs antike Helden, Die Darstellung der antiken Geschichte in der venezianischen Malerei von 1680 bis 1760, München 1999

[Göttinger Händel-Gesellschaft:] Händels Italianità, Programme, Texte und Werkeinführungen, Göttingen 1997, S. 122-123

Göttler, Christine: »Elizabeth McGrath, Rubens, Subjects from History«, in: Kunstchronik 9/10 (2000), S. 482-489

Graesse, Th. (Hrsg.): Legenda aurea, Dresden 1890 (ND Osnabrück 1965)

Graziani, Françoise / Solinas, Francesco (Hrsg.): Le ssiècler de Marie de Médicis, Actes du Séminaire de la Chaire Rhétorique et Société en Europe $\left(\mathrm{XVI}{ }^{\mathrm{e}}-\mathrm{XVII}{ }^{\mathrm{e}}\right.$ siècles) du Collège de France sous la direction de Marc Fumaroli (FrancoItalia; Sonderheft 21/22), Torino 2003

Gregori, Mina: Uffizien und Palazzo Pitti, Die Gemäldesammlungen von Florenz, München 1994

Gregory, Brad Stephen: Salvation at Stake, Cambridge (Mass.) 1999

Grimm, Claus (Hrsg.): AK Lucas Cranach, Augsburg 1994 


\section{Forschungsliteratur}

Grimm, Reinhold R. (Hrsg.): Le roman jusqu'à la fin du XIII siècle, Partie documentaire, Heidelberg 1984 (Grundriss der romanischen Literaturen des Mittelalters, IV,2)

Grohn, Hans Werner: [Landesmuseum Hannover] Die italienischen Gemälde, Hannover 1995

Grunchec, Philippe (Hrsg.): Les concours des Prix de Rome, 1797-1863, 2 Bde, Paris 1986

Guillaume, Jean: »Cleopatra nova Pandora«, in: Gazette des Beaux-Arts 114 (80), 1972, S. $185-194$

Gundel, Hans Georg: »Virginia«, in: RE, Neue Bearbeitung, 2. Reihe, Bd. 9, 1967, Sp. 1530-1535

Günter Hess: »Der Tod des Seneca, Ikonographie - Biographie - Tragödientheorie« in: Jahrbuch der deutschen Schillergesellschaft 25 (1981), S. 196-228

Günther, Erika: Die Faszination des Fremden, Der malerische Orientalismus in Deutschland, Münster 1990

Günther, Heinz: »Carlo Dolci, Studien zur religiösen Malerei im 17. Jahrhundert«, in: Jahrbuch der kunsthistorischen Sammlungen, Wien, 56 (N.F.20) (1960), S. 197-234

Guthmüller, Bodo (Hrsg.): Deutschland und Italien in ihren wechselseitigen Beziehungen während der Renaissance, Wiesbaden 2000

Habert, Jean (Hrsg.): Bordeaux, Musée des Beaux-Arts, Peinture italienne XV'XIX siècles, Paris 1987

Hagen, Bettina / Betthausen, Peter / Kunze, Max (Hrsg.): AK Antike in Wien, Die Akademie und der Klassizismus um 1800, Mainz 2002

Halbwachs, Maurice: La mémoire collective, Paris 1950 u.ö.

[Hamburg, Kunsthalle:] Katalog der Alten Meister der Hamburger Kunsthalle, Hamburg ${ }^{5} 1966$

Hamer, Mary: »The myth of Cleopatra since the Renaissance «, in: Walker, Susan / Higgs, Peter (Hrsg.): AK Cleopatra of Egypt, London 2001, S. 302-311

Hankamer, Paul: Deutsche Gegenreformation und deutsches Barock, Stuttgart ${ }^{2} 1947$

Hanley, Edwin: »Alessandro Scarlatti«, in: ${ }^{1} M G G$, Bd. 11, München 1989, S. 14821506 


\section{Literaturverzeichnis}

Hansmann, Martina: Andrea del Castagnos Zyklus der ,Uomini famosik und >Donne famoser, Geschichtsverständnis und Tugendideal im florentinischen Frühhumanismus, Münster / Hamburg 1993

Harms, Wolfgang (Hrsg.): Text und Bild, Bild und Text, Stuttgart 1990 (DFGSymposion 1988)

Harris, Dale: »Michail Michailiowitsch Fokin«, in : Pipers Enzyklopädie des Musiktheaters, hrsg. von Carl Dahlhaus, München / Zürich 1987, Bd 2, S. $231 \mathrm{f}$.

Haskell, Francis: Maler und Auftraggeber, Kunst und Gesellschaft im italienischen Barock, Köln 1996 (englisch ${ }^{1} 1980$ )

Haug, Walter / Wachinger, Burghart (Hrsg.): Exempel und Exempelsammlungen, Tübingen 1991

Hauskeller, Michael: Geschichte der Ethik, München 1997

Heinen, Ulrich / Thielemann, Andreas (Hrsg.): Rubens Passioni, Kultur der Leidenschaften im Barock, Göttingen 2001

Heinen, Ulrich: »Haut und Knochen - Fleisch und Blut. Rubens' Affektmalerei«, in: Heinen, Ulrich / Thielemann, Andreas (Hrsg.): Rubens Passioni, Kultur der Leidenschaften im Barock, Göttingen 2001, S. 70-109

Heinz, Dora: Europäische Tapisseriekunst des 17. und 18. Jahrhunderts, Die Geschichte ihrer Produktionsstätten und ihrer künstlerischen Zielsetzungen, Wien / Köln / Weimar 1995

Heinz, Günther: "Gedanken zu Bildern der >Donne Famose` in der Galerie des Erzherzogs Leopold Wilhelm«, in: Jahrbuch der kunsthistorischen Sammlungen, Wien, 77 (1981), S. 105-118

Heinz, Marianne (Hrsg.): Bestandskatalog der Gemälde des 19. Jahrhunderts, Kassel 1991

Held, Jutta: Caravaggio, Politik und Martyrium der Körper, Berlin 1996

Hellwig, Karin: Die Anfänge der Kunstgeschichtsschreibung in Spanien im 17. Jahrhundert, Diss. phil. FU Berlin 1995

Henning, Andreas / Weber, Gregor J. M. (Hrsg.): ১Der himmelnde Blickı, Zur Geschichte eines Bildmotivs von Raffael bis Rotari, Dresden 1998

Herzog, Erich: Die Gemäldesammlung der Staatlichen Kunstsammlungen Kassel, Geschichte der Galerie, Hanau 1969 


\section{Forschungsliteratur}

Herzog, Reinhart: »Vom Aufhören«, in: Stierle, Karlheinz / Warning, Rainer (Hrsg.): Das Ende, Figuren einer Denkform, München 1996 (Poetik und Hermeneutik 16), S. 283-329

[Herzog Anton Ulrich-Museum:] AK Erwerbungen aus zwei Jahrzehnten, Kunstwerke vor 1900, Braunschweig 1989

[Herzog Anton Ulrich-Museum:] AK Europäische Malerei des Barock aus dem Nationalmuseum Warschau, Braunschweig 1989

Heße, Christian / Schlagenhaufer, Martina (Hrsg.): Wallraf-Richartz-Museum Köln, Vollständiges Verzeichnis der Gemäldesammlung, Köln/Mailand 1986

Heyse, E. / Briesemeister, D.: »Drei Lebende und drei Tote «, in: Lexikon des Mittelalters, Bd. 3, Sp. 1390-1392

Hibbard, Howard: »Guido Reni's Painting of the Immaculate Conception«, in: Bulletin of the Metropolitan Museum, 28 (1969/70), S. 19-32

Hirschfelder, Dagmar / Raupp, Hans-Joachim: "Tronies in de Italiaanse, Vlaamse en Nederlandse schilderkunst van de 16de en 17de eeuw«, in: Kunstchronik, 2001, S. 197-202

Hirt, Alois: VI. Kunstanzeige [zu Lady Hamiltons Attitüden], in: Der neue Teutsche Merkur, 2 (1794), S. 415

Hoepfl, Simon (Hrsg.): Boccacios Buch der berühmten Frauen, mit 79 Holzschnitten der Ausgabe von Joh. Zainer, Ulm 1473 (ND München 1924)

Hoet, Gerard: Catalogus of Naamlyst van Schildereyen met derzelver Pryzen, 2 Bde, 's Gravenhage 1752

Hoffmann, Herbert (Hrsg.): Katalog der Gemälde und Skulpturen bis 1900, Band 3a, Biberach an der Riß 1975

Hoffmann, Volker / Koppe, Konrad: Martin von Wagner Museum der Universität Würzburg, Gemäldekatalog, Würzburg 1986

Hofmann, Walter Jürgen: Schloss Pommersfelden, Geschichte seiner Entstehung, Nürnberg 1968

Hofmann, Werner: »Hans Makart - Malerei als Inszenierung«, in: Art 7 (1981), S. 40-49

Holenstein-Weidmann, Pia: »Passionierte Tugend: Lukrezia«, in: Deutsche Vierteljahrsschrift für Literaturwissenschaft und Geistesgeschichte 68 (1994), S. 1-21 Höper, Corinna (Hrsg.): AK Raffael und die Folgen, Stuttgart 2001 


\section{Literaturverzeichnis}

Hoppe, Ilaria: »Räume von und für Frauen? Die Gemächer der Maria Magdalena von Österreich in der Villa Poggio Imperiale bei Florenz «, in: Bonnet, AnneMarie / Schellewald, Barbara (Hrsg.): Frauen in der Frühen Neuzeit, Lebensentwürfe in Kunst und Literatur, Köln / Weimar / Wien 2004, S. 213-234

Horschansky, Klaus: »Tommaso Traetta: Sofonisba «, in: Pipers Enzyklopädie des Musiktheaters, Bd. 6, hrsg. von Carl Dahlhaus, München 1997, 315-318 Hortschansky, Klaus: „Der tragische Held in der italienischen Oper am Ende des 18.Jahrhunderts «, in: ders. (Hrsg.): Opernheld und Opernheldin im 18. Jahrhundert, Hamburg / Eisenach 1991, S. 233-252

Hughes Graham: Renaissance Cassoni, Masterpieces of Early Italian Art, Painted Marriage Chests 1400-1550, London 1997

Hughes-Hallett, Lucy: Cleopatra, Histories, Dreams and Distortions, London 1990 Humfrey, Peter / Lucco, Mauro (Hrsg.): AK Dosso Dossi, Court Painter in Renaissance Ferrara, New York 1998

Imorde, Joseph: Affekt-Übertragung, Berlin 2004

Ittershagen, Ulrike: Lady Hamiltons Attitüden, Mainz 1999

Jacob, Susanne / König-Lein, Susanne (Hrsg.): [Herzog Anton Ulrich-Museum Braunschweig] Die italienischen Gemälde des 16. bis 18. Jahrhunderts, München 2004

Jacoby, Joachim / Michels, Anette (Hrsg.): [Herzog Anton Ulrich-Museum Braunschweig] Die deutschen Gemälde des 17. und 18. Jahrhunderts sowie die englischen und skandinavischen Werke, Braunschweig 1989

Jaffé, Michael: »Pesaro Family Portraits: Pordenone, Lotto and Titian «, in: The Burlington Magazine 113 (1971), S. 696-702

Jakoby, Richard: Die Kantate, Das Musikwerk, Eine Beispielsammlung zur Musikgeschichte, Köln 1968

Janitschek, Hubert: »Ein Hofpoet Leo's X. über Künstler und Kunstwerke«, in: Repertorium für Kunstwissenschaft, 3 (1879), S. 52-60

Janke, Pia: Dramaturgie der Leidenschaften, Libretti aus vier Jahrhunderten, Wien 2000

Jiránek, Jaroslav: »Zur Geschichte des Melodramas «

http://publib.upol.cz/ obd/fulltext/Musicologica\%206/musicol6-8.pdf (letzter Aufruf: 16.08.2006)

Jolles, André: Einfache Formen, Tübingen ${ }^{7} 1999$ ( $\left.{ }^{1} 1930\right)$ 


\section{Forschungsliteratur}

Jooss, Birgit: Lebende Bilder, Körperliche Nachahmung von Kunstwerken in der Goethezeit, Berlin 1999

Joost-Gaugier, Christiane: "Giotto's Hero Cycle in Naples, A Prototype of Donne Illustri and a Possible Literary Connection «, in: Zeitschrift für Kunstgeschichte, 43 (1980), S. 311-318

Kaemmerling, E. (Hrsg.): Bildende Kunst als Zeichensystem, Köln 1979

Kahn-Rossi, Manuela (Hrsg.): AK Pier Francesco Mola 1612-1666, Milano 1989

Kailuweit, Thomas: Dido - Didon - Didone, Eine kommentierte Bibliographie, Frankfurt / Berlin / Bern 2005

Kassel, Rudolf: Untersuchungen zur griechischen und römischen Konsolationsliteratur, München 1958

Kaufmann, Sylke (Hrsg.): Goethes Malerin, Die Erinnerungen der Louise Seidler, Berlin 2003

Kecks, Ronald: Madonna und Kind, Das häusliche Andachtsbild im Florenz des 15. Jahrhunderts, Frankfurt 1988

Kelescian, Daniela Scaglietti (Hrsg.): AK Alessandro Turchi detto l'Orbetto, 1578 1649, Milano 1999

Kern, Manfred: „Konsolationsliteratur «, in: Der Neue Pauly, Stuttgart / Weimar 2000, Bd. 14, Sp. 1079-1082

Kerspern, Sylvain: " À propos de l'Énée transportant Anchise du Musée des Beaux-Arts de Dijon: jalons pour l'œuvre de Charles Errard», in: Tribune de l'Art 2005

http://www.latribunedelart.com/Etudes_2005/Errard.htm (zuletzt aufgerufen: 15.12.2006)

Kerspern, Sylvain: »Retour sur l'exposition Bossuet, et sur quelques unes de ses attributions «, in: Tribune de l'Art 2004

http://www.latribunedelart.com/Etudes_2004/Suite_Bossuet_2_123.htm

Kerspern, Sylvain: »Retour sur l'exposition Bossuet, suite: du nouveau pour Prévost et Licherie «, in: Tribune de l'Art 2004

http://un2sg4.unige.ch/athena/charriere/char_lau.rtf (zuletzt aufgerufen: 15.12.2006)

http://www.latribunedelart.com/Etudes_2004/Suite_Bossuet.htm

Kerspern, Sylvain: AK Bossuet, Miroir du Grand Siècle, Paris 2004

Kindler, Simone: Ophelia, Der Wandel von Frauenbild und Bildmotiv, Berlin 2004 


\section{Literaturverzeichnis}

Kirchner, Thomas: L'expression des passions, Ausdruck als Darstellungsproblem in der französischen Kunst und Kunsttheorie des 17. und 18. Jahrhunderts, Mainz 1991

Kirschbaum, Engelbert (Begr.) / Braunfels, Wolfgang (Hrsg.), Lexikon der christlichen Ikonographie, Rom / Freiburg im Brsg. 1968-1976

Klein, Dorothee: »Andachtsbild«, in: Reallexikon zur deutschen Kunstgeschichte, Stuttgart 1937, Sp. 681-687

Klein, J.: »exemplum: in: Historisches Wörterbuch der Rhetorik, Tübingen 1996, Bd. 3, S. 60-70

Klemm, Christian: Joachim von Sandrart, Kunstwerke und Lebenslauf, Berlin 1986

Klessmann, Rüdiger: [Herzog Anton Ulrich-Museum Braunschweig] Die holländischen Gemälde, Braunschweig 1983

Kliemann, Julian / Rohlmann, Michael (Hrsg.): Wandmalerei in Italien, Die Zeit der Hochrenaissance und des Manierismus 1510-1600, München 2004

Kliemann, Julian: „Siena, Palazzo Venturi (später Agostini, Bindi Sergardi, Casuccini)«, in: Kliemann, Julian / Rohlmann, Michael (Hrsg.): Wandmalerei in Italien, Die Zeit der Hochrenaissance und des Manierismus 1510-1600, München 2004, S. 258-269

Koch, Heinrich Christoph: Musikalisches Lexikon, Frankfurt/Main 1802

Koch, Klaus-Dietrich: Die Aeneis als Opernsujet, Dramaturgische Wandlungen vom Frühbarock bis zu Berlioz, Konstanz 1990

Kohl, Karl-Heinz: "Cherchez la femme d'orient«, in: Sievernich, G. / Budde, H. (Hrsg.): AK Europa und der Orient, 800 - 1900, Berlin 1989, S. 356- 367

Köhn, Silke (Hrsg.): AK Lady Hamilton und Tischbein, Der Künstler und sein Modell, Oldenburg 1999

Kolsky, Stephen D.: The Genealogy of Women, Studies in Boccaccio's De mulieribus claris, New York / Bern / Frankfurt / Main 2003

[Koninkliik Museum voor Schone Kunsten Antwerpen:] AK P.P.Rubens, Gemälde Ölskizzen - Zeichnungen, Antwerpen 1977

Koschatzky, Walter: Die Kunst der Graphik, Technik, Geschichte, Meisterwerke, München ${ }^{11} 1993$

Koselleck, Reinhart / Stempel, Wolf-Dieter (Hrsg.): Geschichte -Ereignis und Erzählung, München 1973 (Poetik und Hermeneutik 5) 


\section{Forschungsliteratur}

Koselleck, Reinhart: Vergangene Zukunft, Zur Semantik geschichtlicher Zeiten, Frankfurt am Main 1979

Kotalivik, Jiri: Die Nationalgalerie in Prag, Hanau 1988

Kräftner, Johann / Seipel, Wilfried / Trnek, Renate (Hrsg.): Rubens in Wien, Wien 2004

Kreisel, Heinrich: Das Schloss zu Pommersfelden, München 1953

Krones, Hartmut: "Zu Begriff und Theorie der Kammermusik« im 18. Jahrhundert«, in: Vokale Kammermusik im 18. Jahrhundert, Blankenburg 1997 (Michaelsteiner Konferenzberichte 51), S. 10-24

[Kunstverein Wien:] AK Franz Anton Maulbertsch, München / Wien 1974

Kunze, Max: „Winckelmanns Beschreibungen im Lichte des Florentiner Nachlaßheftes «, in: Winner, M. / Andreae, B. / Pietrangeli, C. (Hrsg.): /l Cortile delle Statue, Der Statuenhof des Belvedere im Vatikan (Akten des internationalen Kongresses zu Ehren von Richard Krautheimer [Rom 1992]), Mainz 1998, S. 431-441

Kurz, Otto: »Guido Reni«, in: Jahrbuch der kunsthistorischen Sammlungen, Wien, N. F., 1937, S. 189-220

Küster, Ulrike: Das Melodrama, Zum ästhetikgeschichtlichen Zusammenhang von Dichtung und Musik im 18. Jahrhundert, Frankfurt / Berlin / Bern 1993

Lachmann, Renate (Hrsg.): Memoria, München 1993 (Poetik und Hermeneutik 15) Laclotte, Michel / Mognetti, Élisabeth (Hrsg.): Avignon, Musée du Petit Palais, Peinture italienne, Paris 1987

Laggner, Brigitte: Untersuchungen zur Topologie in den Reden der ersten und dritten Dekade des livianischen Geschichtswerkes, Diss. phil. Graz 1972

Landfester, Rüdiger: Historia Magistra Vitae, Untersuchungen zur humanistischen Geschichtstheorie des 14. bis 16. Jahrhunderts, Genf 1972

Lang, Walther K.: Grausame Bilder, Sadismus in der neapolitanischen Malerei, Berlin 2001

Langen, August: »Attitüde und Tableau in der Goethezeit«, in: Jahrbuch der Deutschen Schillergesellschaft 12 (1968), S. 194-258

Lauts, Jan (Hrsg.): Katalog Alte Meister bis 1800, 2 Bde, Karlsruhe 1966

Laveissière, Sylvain: "Der Rat und der Mut, Die Galerie des Hommes Illustres im Palais Cardinal - ein Selbstporträt Richelieus«, in: Goldfarb, Hilliard Todd 


\section{Literaturverzeichnis}

(Hrsg.): AK Richelieu (1585 - 1642), Kunst, Macht und Politik, Gent 2002, S. 64-71

[LCI] Lexikon der christlichen Ikonographie. begr. von Engelbert Kirschbaum, hrsg. von Wolfgang Braunfels, 8 Bde, Freiburg im Breisgau u.a. 1968-1976

Lehmann, Jürgen M.: Italienische, französische und spanische Gemälde des 16. bis 18. Jahrhunderts der Staatlichen Kunstsammlungen Kassel, Fridingen 1980

Leithe-Jasper, Manfred / Distelberger, Rudolf: Kunsthistorisches Museum Wien, Schatzkammer und Sammlung für Plastik und Kunstgewerbe, München 1982

Lemaire, Gerard-George: Orientalismus, das Bild des Morgenlandes in der Malerei, Paris / Köln 2000

Lentzen, M.: "Auffassungen über Ehe und Familie in Francesco Barbaros De re uxoria (1415) und Albrecht von Eybs Ehebüchlein (1472), Textstruktur und Textfunktion «, in: Guthmüller, Bodo (Hrsg.): Deutschland und Italien in ihren wechselseitigen Beziehungen während der Renaissance, Wiesbaden 2000, S. 44-60

Leube, Eberhard: Fortuna in Karthago, Die Aeneas-Dido-Mythe Vergils in den romanischen Literaturen vom 14. bis zum 16. Jahrhundert, Heidelberg 1969

Levey, Michael: Giambattista Tiepolo, his life and art, New Haven / London 1986

Lexikon der Kunst, begr. von Gerhard Strauss, hrsg. von Harald Olbrich, 7 Bde., München 1996

Lexikon des Mittelalters, München / Zürich 1980-1998

Lindemann, Bernd Wolfgang (Hrsg.): AK Arnold Böcklin - eine Retrospektive, Basel 2001

Lindinger, Michaela: »Der verzauberte Blick - Imaginationen des `Orientalischen in Europa«, in: Mayr-Oehring, Erika / Doppler, Elke (Hrsg.): AK Orientalische Reise, Malerei und Exotik im späten 19. Jahrhundert, Wien 2003, S. 10-17

Lo Bianco, Anna (Hrsg.): AK Pietro da Cortona 1597-1669, Milano 1997

Loraux, Nicole: Tragische Weisen, eine Frau zu töten, Frankfurt / Main 1993

Maber, Richard G.: The Poetry of Pierre Le Moyne (1602-1671), Bern / Frankfurt/Main 1982

Maclean, Ian: Woman Trimphant, Feminism in French Literature 1610-1652, Oxford 1977 


\section{Forschungsliteratur}

Mahon, Denis (Hrsg.): AK Giovanni Francesco Barbieri, II Guercino 1591-1666, Bologna 1991

Mahon, Denis (Hrsg.): AK Guercino, Bologna ${ }^{2} 1991$ (ND des Katalogs von 1968)

Mahon, Denis / Pulini, Massimo / Sgarbi, Vittorio (Hrsg.): Guercino, Poesia e sentimento nella pittura del '600, Novara 2003

Mai, Ekkehard (Hrsg.): AK Glanzlichter des Barock, Meisterwerke aus dem Musée des Beaux-Arts in Caen, Köln 1993

Mai, Ekkehard (Hrsg.): AK Von Bruegel bis Rubens, Das goldene Jahrhundert der flämischen Malerei, Köln 1992

Mai, Ekkehard / Paarlberg, Sander / Weber, Gregor J. M. (Hrsg.): AK Vom Adel der Malerei, Holland um 1700, Köln 2006

Mai, Ekkehard / Repp-Eckert, Anke (Hrsg.): AK Triumph und Tod des Helden, Europäische Historienmalerei von Rubens bis Manet, Köln 1987

Mai, Ekkehard / Repp-Eckert, Anke (Hrsg.): Historienmalerei in Europa, Paradigmen in Form, Funktion und Ideologie, Mainz 1990

Mai, Ekkehard / Stukenbrock, Christiane (Hrsg.): AK Niederländische Malerei des 17. Jahrhunderts aus Budapest, Köln 1987

Mâle, Émile: L'art religieux après le concile de Trente, Paris 1932

Marquard, Odo: »Finalisierung und Mortalität«, in: Stierle, Karlheinz / Warning, Rainer (Hrsg.): Das Ende, Figuren einer Denkform, München 1996 (Poetik und Hermeneutik 16), S. 467-475

Martineau, Jane (Hrsg.): AK Andrea Mantegna, London / New York 1992

Martineau, Jane / Robinson, Andrew (Hrsg.): AK The Glory of Venice, Art in the Eighteenth century, London / New Haven 1994

Mathes, Melissa M.: The Rape of Lucretia and the Foundation of Republics, Pennsylvania State 2000

Matsche, Franz: Die Kunst im Dienst der Staatsidee Kaiser Karls VI., 2 Bde, Berlin 1981

Maurens, Jacques, La tragédie sans tragique, Le néo-stoïcisme dans l'œuvre de Pierre Corneille, Paris 1966

Maurer, Karl: Goethe und die romanische Welt, Paderborn 1997

[Mauritshuis:] The Royal Cabinet of Paintings, Illustrated General Catalogue, The Hague 1977 


\section{Literaturverzeichnis}

Mayo, John S. M.: "Zum Vergleich des Wort-Ton-Verhältnisses in den Kantaten von Georg Friedrich Händel und Alessandro Scarlatti«, in: G. F. Händel und seine italienischen Zeitgenossen, hrsg. von Walther-Siegmund Schultze, Halle 1979, S. 31-44

Mayr-Oehring, Erika / Doppler, Elke (Hrsg.): AK Orientalische Reise, Malerei und Exotik im späten 19. Jahrhundert, Wien 2003

McGrath, Elizabeth: Rubens, Subjects from History, 2 Bde, London 1997 (Corpus Rubenianum13)

Mégevand, Marie-Christine / Julhiet, C. (Hrsg.): Grand Siècle, Peintures françaises du XVIle siècle dans les collections publiques françaises, Paris 1993

Mérot, Alain (Hrsg.): La peinture française au XVII siècle, Paris 1994

Mérot, Alain: »Der Held in der französischen Malerei des 17. Jahrhunderts«, in: Mai, Ekkehard / Repp-Eckert, Anke (Hrsg.): AK Triumph und Tod des Helden, Europäische Historienmalerei von Rubens bis Manet, Köln 1987

Mérot, Alain: Eustache Le Sueur (1616-1655), Paris 1987

Merz, Martin Jörg: Pietro da Cortona, der Aufstieg zum führenden Maler im barocken Rom, Tübingen 1991

Meulen, Marjon van der: Rubens' Copies after the Antique, 3 Bde, London 19941995 (Corpus Rubenianum 23)

['MGG] Die Musik in Geschichte und Gegenwart, hrsg. von Friedrich Blume, 17 Bde, München 1998

Millen, Ronald Forsyth / Wolf, Robert Erich: Heroic Deeds and Mystic Figures, A new Reading of Rubens' Life of Maria de'Medici, Princeton 1989

Miltner, Franz: »Porzia«, in: RE, Bd. 43, Stuttgart 1953, Sp. 216-218

Minges, Klaus: Das Sammlungswesen in der Frühen Neuzeit, Kriterien der Ordnung und Spezialisierung, Münster 1998

Misciatelli, Piero: „Une cassone nuziale di Matteo Giovanni «, in: Rassegna d'Arte Senese, 1910, S. 36-38

Moiso-Diekamp, Cornelia: Das Pendant in der holländischen Malerei des 17. Jahrhunderts, Frankfurt / Bern / New York 1987

Mommsen, Theodor E.: »Petrarch and the Decoration of the Sala Virorum Illustrium in Padua«, in: The Art Bulletin 34 (1952), S. 95-116 


\section{Forschungsliteratur}

Montagu, Jennifer: The Expression of the Passions, The Origin and Influence of Charles Le Bruns's `Conférence sur l'expression générale et particulière`, New Haven / London 1994

Moos, Peter von: Geschichte als Topik, Das rhetorische Exemplum von der Antike zur Neuzeit und die historiae im >Policraticusı Johanns von Salisbury, Hildesheim / Zürich / New York 1988

Morford, Mark: Stoics and Neostoics, Rubens and the Circle of Lipsius, Princeton 1991

Muller, Jeffrey M.: "Rubens's Collection in History«, in Belkin Lohse, Kristin / Healy, Fiona (Hrsg.): AK A House of Art, Rubens as Collector, Antwerpen 2004, S. $10-85$

[Musées royaux des Beaux-Arts de Belgique, Département d'Art Ancien:] Catalogue inventaire de la peinture ancienne, Bruxelles 1984

[Musées royaux des Beaux-Arts de Belgique:] AK Le siècle de Rubens, Bruxelles 1965

Natale, Mauro / Di Lorenzo, Andrea (Hrsg.): AK Die Sammlung Borromeo, Malerei und Skulptur in der Nachfolge Leonardo da Vincis, Milano 2007

Neumann, Wolfgang (Hrsg.): AK Tanz der Toten - Todestanz: der monumentale Totentanz im deutschsprachigen Raum, Dettelbach 1998

North, Michael: Kunst und Kommerz im Goldenen Zeitalter, Zur Sozialgeschichte der niederländischen Malerei des 17. Jahrhunderts, Köln / Weimar / Wien 1992

Oberreuter-Kronabel, Gabriele: »Der Philosoph und sein Tod, Beobachtungen zu einem Thema für die Malerei des 18. Jahrhunderts in Frankreich«, in: Mai, Ekkehard / Repp-Eckert, Anke (Hrsg.): AK Historienmalerei in Europa, Paradigmen in Form, Funktion und Ideologie, Mainz 1990, S. 95-105

Oberreuter-Kronabel, Gabriele: Der Tod des Philosophen, Zum Sinngehalt eines Sterbebildtypus der französischen Malerei in der zweiten Hälfte des 18. Jahrhunderts, München 1986

Oestreich, Gerhard: Antiker Geist und moderner Staat bei Justus Lipsius (15471606), Der Neostoizismus als politische Bewegung, Göttingen 1989

Ost, Hans: „Tizians sogenannte /Venus von Urbino und andere Buhlerinnen« in: Müller Hofstede, J. / Spies, W. (Hrsg.): Festschrift für Eduard Trier zum 60. Geburtstag, Berlin 1981, S. 129-149 


\section{Literaturverzeichnis}

Osthoff, Wolfgang: »Francesco Cavalli«, in: Pipers Enzyklopädie des Musiktheaters, Bd. 1, München / Zürich 1986, S. 514 f.

Ott, Norbert.: »Neun Gute Helden«, in: Lexikon des Mittelalters, Bd. 6, Sp. 11031106

Ottaviani Botteri, Marina (Hrsg.): AK Pietro Ricchi, Milano 1996

Pace, Valentino: ১Dalla morte assente alla morte presentes: Zur bildlichen Vergegenwärtigung des Todes im Mittelalter «, in: Borst, A. / von Graevenitz, G. I Patschovsky, A. / Stierle, K. (Hrsg.): Tod im Mittelalter, Konstanz 1993

Pallucchini, Anna / Le Foll. Joséphine: Tout l'œuvre peint de Tiepolo, Paris 1990

Pallucchini, Anna / Piovene, Guido (Hrsg.): L'opera completa di Giambattista Tiepolo, Milano 1981

Panofsky, Erwin: »Imago pietatis. Ein Beitrag zur Typengeschichte des Schmerzensmannes und der Maria Mediatrix«, in: Festschrift für Max Friedländer zum 60. Geburtstag, Leipzig 1927, S. 261-308

Panofsky, Erwin: Grabplastik, Vom alten Ägypten bis Bernini, Köln 1964

Papi, Gianni (Hrsg.): AK La sscholar del Caravaggio, dipinti dalla collezione Koelliker, Milano 2006

Paulsen, Friedrich: Geschichte des gelehrten Unterrichts, 2 Bde, Leipzig ${ }^{3} 1919$ 1921

[Pauly-Wissowa] Paulys Realencyclopädie der classischen Altertumswissenschaft, Neue Bearbeitung, unter Mitwirkung zahlreicher Fachgenossen herausgegeben von Georg Wissowa, fortgeführt von Wilhelm Kroll und Karl Mittelhaus, 1890-1978

Pelling, Christopher: „Anything truth can do, we can do better: the Cleopatra legend«, in: Walker, Susan / Higgs, Peter (Hrsg.): AK Cleopatra of Egypt, From History to Myth, London 2001, S. 292-301

Penny, Nicholas (Hrsg.): AK Reynolds, Paris / London 1985

Pepper, Stephen: Guido Reni, L'opera completa, Novara 1988

Perroux, Alain: „Cléopâtre à l'opéra, splendeur et misère d'une reine d'Égypte«, in: Ritschard, Claude / Morehead, Allison (Hrsg.): AK Cléopâtre dans le miroir de l'art occidental, Genéve 2004, S. 171-178

Petermann, Erwin: Katalog der Staatsgalerie Stuttgart, Stuttgart 1962 


\section{Forschungsliteratur}

Petzold, Martin: Bach-Kommentar, Theologisch-musikwissenschaftliche Kommentierung der geistlichen Volkalwerke Johann Sebastian Bachs, Bd. 1, Stuttgart 2004

Pigler, Andor: Barockthemen, Eine Auswahl von Verzeichnissen zur Ikonographie des 17. und 18. Jahrhunderts, 2 Bde, Budapest 1956

Pipers Enzyklopädie des Musiktheaters, hrsg. von Carl Dahlhaus, 6 Bde, München 1998-1997

Pita Andrade, José Manuel / del Mar Borobia Guerrero, María (Hrsg.): Old Masters Thyssen-Bornemisza Museum, Barcelona 1992

Planiscig, L. / Kris, E.: Katalog der Sammlungen für Plastik und Kunstgewerbe, Wien 1935 (Führer durch die Kunsthistorischen Sammlungen in Wien),

Plume, Cornelia: Heroinen in der Geschlechterordnung, Wirklichkeitsprojektionen bei Daniel Casper von Lohenstein und die >Querelle des Femmesı, Stuttgart / Weimar 1996

Prinz, Wolfram: Die Entstehung der Galerie in Frankreich und Italien, Berlin 1970 Puyvelde, Leo van: Rubens, Paris / Bruxelles 1952

[RAC] Reallexikon für Antike und Christentum, Sachwörterbuch zur Auseinandersetzung des Christentums mit der antiken Welt, hrsg. von Theodor Klauser [u.a.], Stuttgart $1941 \mathrm{ff}$.

Raffy, Jean-Louis: Le sPapinianusı d'Andreas Gryphius (1616-1664), Drame de martyr et sécularisation du théâtre en Allemagne au XVII siècle, Bern / Frankfurt / New York 1992

Reallexikon der deutschen Literaturwissenschaft, 3 Bde, hrsg. von Klaus Weimar Berlin / New York 2007ff.

[RE] Paulys Realencyclopädie der classischen Altertumswissenschaft, Neue Bearbeitung, unter Mitwirkung zahlreicher Fachgenossen herausgegeben von Georg Wissowa, fortgeführt von Wilhelm Kroll und Karl Mittelhaus, 18901978Reallexikon für Antike und Christentum, hrsg. von Ernst Dassmann u.a., Stuttgart $1941 \mathrm{ff}$.

Regenbogen, Otto: "Schmerz und Tod in den Tragödien Senecas«, in: Vorträge der Bibliothek Warburg 7 (1927/28), S. 167ff. (ND Darmstadt 1963)

Rehberg, Friedrich / Piroli, Tommaso: Drawings Faithfully copied from Nature at Naples and with permission dedicated to the Right Honourable Sir William Hamilton, Rom 1794 


\section{Literaturverzeichnis}

Rettich, Edeltraud / Klapproth, Rüdiger / Ewald, Gerhard (Hrsg.): Alte Meister, Staatsgalerie Stuttgart, Stuttgart 1992

$\left[{ }^{3} \mathrm{RGG}\right]$ Religion in Geschichte und Gegenwart, hrsg. von Kurt Galling, 7 Bde., ${ }^{3}$ Tübingen 1957-1965

Richard-Jamet, Céline Catherine Jeanne: Les galeries de ıfemmes fortesı dans les arts en Europe au XVle et au XVIle siècles, une étude iconographique comparative; thèse Université Michel de Montaigne-Bordeaux III, 2003

Richard-Jamet, Céline: „Cléopâtre: Femme forte ou femme fatale? Une place équivoque dans les galeries de Femmes fortes aux $\mathrm{XVI}^{\mathrm{e}}$ et $\mathrm{XVII}$ siècles «, in: Ritschard, Claude / Morehead, Allison (Hrsg.): AK Cléopâtre dans le miroir de l'art occidental, Genève 2004, S. 37-52

Richter, L.: »Andacht«, in: ${ }^{3} R G G$, Bd. 1, Sp. 360-362

Riedlbauer, Jörg: Die Opern von Tommaso Trajetta, Hildesheim / Zürich / New York 1994

Riegl, Alois: Die Entstehung der Barockkunst in Rom, Wien 1908 (ND München 1977)

Rieks, Rudolf: "Zur Wirkung des Livius vom 16. bis zum 18. Jahrhundert«, in: Lefèvre, Eckard / Olshausen, Eckart (Hrsg.): Livius, Werk und Rezeption, Festschrift für Erich Burck zum 80. Geburtstag, München 1983, S. 367-397

Ringbom, Sixten: »Devotional images and imaginative devotions «, in: Gazette des Beaux-Arts 73 (1969), S. 159-170

Ringbom, Sixten: Icon to narrative, The Rise of Dramatic close-up in fifteenthcentury devotional Painting, Ábo 1965

Ritschard, Claude / Morehead, Allison (Hrsg.): AK Cléopâtre dans le miroir de l'art occidental, Genève 2004

Rizzi, Aldo (Hrsg.): AK Sebastiano Ricci, Udine 1989

Rogelio Buendia, J.: Begegnung mit dem Prado, Madrid 1989

Romanelli, Giandomenico / Strinati, Claudio (Hrsg.): AK Paolo Veronese, Miti, ritratti, allegorie, Venezia 2005

Romanelli, Giandomenico: Venedig, Kunst und Architektur, Köln 1997

Ronconi, A.: "exitus illustrium virorum « in: Reallexikon für Antike und Christentum, hrsg. von Ernst Dassmann u.a., Stuttgart 1941ff., Bd. 6, Stuttgart 1966, Sp. 1258-1268 


\section{Forschungsliteratur}

Rosa, Alberto Asor (Hrsg.): Letteratura Italiana, Gli Autori, Dizionario BioBibliografico e Indici, Torino 1990

Roscoe, William: The life and pontificate of Leo the Tenth, London ${ }^{5} 1876$

Rosenblum, Robert: Transformations in Late Eighteenth Century, Princeton ${ }^{3} 1974$

Rosenfeld, Hellmut: Der mittelalterliche Totentanz, Entstehung - Entwicklung Bedeutung, Münster / Köln 1954

Rossi, Luciano: »Petrarca« in: Lexikon des Mittelalters, Bd. 6, Sp. 1945-1949

Roy, Alain: Gérard de Lairesse, 1640-1711, Paris 1992

Sabatier, Gérad: »lkonographische Programme und Legitimation der königlichen Autorität in Frankreich im 17. Jahrhundert«, in: Asch, Ronald / Feist, Dagmar (Hrsg.): Staatsbildung als kultureller Prozess: Strukturwandel und Legitimation von Herrschaft in der Frühen Neuzeit, Köln 2005, S. 255-265

Sabatier, Gérard: "Les rois de représentation, Image et pouvoir $\left(\mathrm{XVI}^{\mathrm{e}}-\mathrm{XVII}{ }^{\mathrm{e}}\right.$ siècles) «, in: Revue de synthèse 112,3/4 (1991), S. 387-422

Safarik, Eduard A. (Hrsg.): AK Domenico Fetti, 1588/89-1623, Milano 1996

Safarik, Eduard: Catalogo sommario della Galleria Colonna in Roma, Roma 1981

Sander, Dietulf (Hrsg.): Museum der bildenden Künste Leipzig, Katalog der Gemälde, Leipzig 1995

Saward, Susan: The Golden Age of Marie de' Medici, Ann Arbor (Michigan) 1982

Schade, Karl: Andachtsbild, Die Geschichte eines kunsthistorischen Begriffs, Weimar 1996

Schauer, Hans (Hrsg.): Herders Briefwechsel mit Caroline Flachsland, Weimar 1928

Schawe, Martin: Alte Pinakothek, Altdeutsche und altniederländische Malerei, München 2006

Schimpf, Wolfgang: Das Melodrama des 18. Jahrhunderts, Göttingen 1988

Schings, Hans-Jürgen: Die patristische und stoische Tradition bei Andreas Gryphius, Untersuchungen zu den Dissertationes funebres und Trauerspielen, Köln 1966

Schlaeger, Jürgen: »Poetik des Todes, Zur Ästhetisierung des Endes in der englischen Romantik«, in: Stierle, Karlheinz / Warning, Rainer (Hrsg.): Das Ende, Figuren einer Denkform, München 1996 (Poetik und Hermeneutik 16), S. 515527 


\section{Literaturverzeichnis}

Schlink, Wilhelm / Sperlich, Martin (Hrsg.): Forma et subtilitas, Festschrift für Wolfgang Schöne zum 75. Geburtstag, Berlin / New York 1986

Schloder, M. John E.: »Un artiste oublié, Nicolas Prévost, peintre de Richelieu «, in: Bulletin de la Société de l'histoire de l'art français, (1980), Paris 1982, S. 59-69

Schlumbohm, Christa: „Der Typus der Amazone und das Frauenideal im 17. Jahrhundert, Zur Selbstdarstellung der Grande Mademoiselle«, in: Romanistisches Jahrbuch 29 (1978), S. 77-99

Schmidt, G.: »Seneca«, in: ${ }^{1}$ Kleiner Pauly, Bd. 5, Sp.109-115

Schmidt, P. L.: »Pompeius «, in: ${ }^{1}$ Kleiner Pauly, Bd. 4, Sp. 1031

Schmidt-Linsenhoff, Viktoria: Guido Reni im Kunsturteil des siebzehnten Jahrhundert, Studien zur literarischen Rezeptionsgeschichte und Katalog der Reproduktionsgrafik, Diss. Kiel 1974

Schmierer, Elisabeth: Kleine Geschichte der Oper, Stuttgart 2001

Schmitt, Charles B.: Gianfrancesco Pico della Mirandola (1469-1533) and his critique of Aristotle, Den Haag 1967

Schmitz, Eugen: Geschichte der Kantate und des geistlichen Konzerts, Hildesheim / Wiesbaden 1966 (ND der Ausgabe Leipzig 1914)

Schnackenburg, Bernhard: Flämische Meister in der Kasseler Gemäldegalerie, Kassel 1985

Schnackenburg, Bernhard: Gesamtkatalog Gemäldegalerie Alte Meister Kassel, Mainz 1996

Schnapper, A. / Sérullaz, A. (Hrsg.): AK Jacques-Louis David, 1748-1825, Paris 1989

Schneede, Uwe M. / Heinrich, Christoph (Hrsg.): AK Monets Vermächtnis, Serie, Ordnung und Obsession, Ostfildern-Ruit 2001

Schneemann, Peter Johannes: Geschichte als Vorbild, Die Modelle der französischen Historienmalerei 1747-1789, Berlin 1994

Schnell, Rüdiger: `Causa amoris`, Liebeskonzeption und Liebesdarstellung in der mittelalterlichen Literatur, Bern 1985

Schrammek, Bernhard: ")Benedette martiri...८ - Martyrium und Tod in römischen Heiligenopern des frühen 17. Jahrhunderts«, in: Fleischhauer, Günter / Ruf, Wolfgang / Siegmund, Bert / Zschoch, Frieder (Hrsg.): Tod und Musik im 17. und 18. Jahrhundert, Michaelstein 2001, S. 83-93 


\section{Forschungsliteratur}

Schreiber, Ulrich: Opernführer für Fortgeschrittene, Eine Geschichte des Musiktheaters, Kassel 1988

Schreiner, Klaus: "Der Tod Marias als Inbegriff christlichen Sterbens, Sterbekunst im Spiegel mittelalterlicher Legendenbildung «, in: Borst, A. / von Graevenitz, G. / Patschovsky, A. / Stierle, K. (Hrsg.): Tod im Mittelalter, Konstanz 1993, S. 261-312

Schröder, Klaus Albrecht / Sternath, Maria Luise (Hrsg.): AK Albrecht Dürer, Wien 2003

Schroeder, Horst: Der Topos der >Nine Worthiesı in Literatur und bildender Kunst, Göttingen 1971

Schubring, Paul: Cassoni, Truhen und Truhenbilder der italienischen Frührenaissance, 2 Bde, Leipzig 1923

Schulz, H.-J. / Restle, M.: »Koimesis«, in: Lexikon des Mittelalters, Bd. 5, Sp. 12491250

Schulze, Hendrik: Odysseus in Venedig, Sujetwahl und Rollenkonzeption in der venezianischen Oper des 17. Jahrhunderts, Frankfurt/Main 2004

Schulze, Sabine (Hrsg.): AK Leselust, Niederländische Malerei von Rembrandt bis Vermeer, Frankfurt 1993

Schumacher, Fritz: Das bauliche Gestalten, Basel 1991

Schuster, Eva: AK Das Bild vom Tod, Graphiksammlung der Heinrich-HeineUniversität Düsseldorf, Recklinghausen 1992

Schwartz, Gary: Sämtliche Gemälde Rembrandts in Farbe, Darmstadt 1987

Schwarz, Monika: »Christian Gottlob Neefe: Sophonisbe (1778)«, in: Pipers Enzyklopädie des Musiktheaters, Bd. 4, hrsg. von Carl Dahlhaus, München 1991, S. $401 f$.

Sedlacek, Ingrid: Die Neuf Preuses, Heldinnen des Spätmittelalters, Marburg 1997 Seeger, Horst: Opernlexikon, Berlin ${ }^{4} 1988$

Seidel, Martin: Venezianische Malerei zur Zeit der Gegenreformation, Kirchliche Programmschriften und künstlerische Bildkonzepte bei Tizian, Tintoretto, Veronese und Palma il Giovane, Münster 1996

Šerbelj, Ferdinand (Hrsg.): AK La Pittura barocca nel Goriziano, Ljubljana 2002

Settecento Napoletano, Sulle ali dell'aquila imperiale 1707-1734, AK Kunstforum der Bank Austria / Castel Sant'Elmo, Napoli 1994 


\section{Literaturverzeichnis}

Settis, Salvatore: »Der Klassizismus und das Klassische in: Zimmer, F. (Hrsg.): AK Die griechische Klassik, Idee oder Wirklichkeit, Berlin 2002, S. 26-53

Sievernich, G. / Budde, H. (Hrsg.): AK Europa und der Orient, 800 - 1900, Berlin 1989

Simson, Otto von: Peter Paul Rubens (1577-1640), Humanist, Maler und Diplomat, Mainz 1996

Skemp, Mary (Hrsg.): > Le Livre de la Cité des Damesı de Christine de Pizan: an electronic transcription, Electronic Text Research Center, University of Minnesota, Minneapolis, MN, 1999

http://erc.lib.umn.edu/dynaweb/french/pizalaci/@Generic_BookView;lang=fr (zuletzt aufgerufen: 03.04.2007)

Slenczka, Ruth: Lehrhafte Bildtafeln in spätmittelalterlichen Kirchen, Köln 1998

Smith, Lacey Baldwin: Fools, Martyrs, Traitors, Chicago 1999

Spezzaferro, Luigi / Calzavara, Benedetta (Hrsg.): AK Caravaggio e l'Europa, Da Caravaggio a Mattia Preti, Milano 2005

Spinosa, Nicola (Hrsg.): Pittura napoletana del Settecento dal Barocco al Rococò, Napoli 1986

Spinosa, Nicola (Hrsg.): Pittura napoletana del Settecento dal Rococò al Classicismo, Napoli 1987

Spinosa, Nicola: La pittura napoletana del ‘600, Milano 1984

Squarr, Christel: »Agatha von Catania«, in: LCl, Rom / Freiburg 1990, Band 5, S. 44-48

[Staatliche Kunsthalle Karlsruhe]: AK Stefano della Bella, Karlsruhe 2005

Stackelberg, Jürgen von: Tacitus in der Romania, Studien zur literarischen Rezeption des Tacitus in Italien und Frankreich, Tübingen 1960

Stähelin [Vorname nicht ermittelbar]: »Kleopatra« in: RE, Bd. 11, Stuttgart 1922, Sp. $750-781$

Stechow, Wolfgang: »Lucretiae Statua«, in: Goetz, Oswald (Hrsg.): Essays in honor of Georg Szwarzenski, Chicago 1951, S. 114-124

Steinemann, Holger: Eine Bildtheorie zwischen Repräsentation und Wirkung, Kardinal Gabriele Paleottis »Discorso intorno alle imagini sacre e profane« (1582), Hildesheim 2006

Steingräber, Erich (Hrsg.): Kat. Alte Pinakothek München, München 1983

Steingräber, Erich: AK Venedig, Malerei des 18. Jahrhunderts, München 1987 


\section{Forschungsliteratur}

Stieger, Franz: Opernlexikon, Titelkatalog, 3 Bde, Tutzing 1975

Stierle, Karlheinz / Warning, Rainer (Hrsg.): Das Ende, Figuren einer Denkform, München 1996 (Poetik und Hermeneutik 16)

Stillers, Rainer: Humanistische Deutung, Studien zu Kommentar und Literaturtheorie in der italienischen Renaissance, Düsseldorf 1988

Strauss, Walter L. (Hrsg.): The Illustrated Bartsch, New York, 1978ff.

Strohm, Reinhard: Die italienische Oper im 18. Jahrhundert, Wilhelmshaven 1979

Sturm, Leonhard: Vollständige Anweisung zu der Civil Bau-Kunst, Braunschweig 1699

Sulzer, Johann Georg: Allgemeine Theorie der schönen Künste, in einzeln, nach alphabetischer Ordnung der Kunstwörter auf einander folgenden Artickeln abgehandelt, 4 Bde, Frankfurt / Main und Leipzig, ${ }^{3} 1798$

Sutton, Peter C.: AK The Age of Rubens, Boston 1993

Syndram, Karl Ulrich: »Der erfundene Orient in der europäischen Literatur vom 18. bis zum Beginn des 20. Jahrhunderts «, in: Sievernich, G. / Budde, H. (Hrsg.): AK Europa und der Orient, 800 - 1900, Berlin 1989, S. 324-341

Szarota, Elida Maria: Künstler, Grübler und Rebellen, Studien zum europäischen Märtyrerdrama des 17. Jahrhunderts, Bern 1967

Thieme, U. / Becker, F.: Allgemeines Lexikon der bildenden Künstler von der Antike bis zur Gegenwart, Leipzig 1929/1930 (ND München / Leipzig 1992)

Thuillier, Jacques (Hrsg.): [zugleich: AK] Sébastien Bourdon 1616-1671, Catalogue critique et chronologique de l'œuvre complet, Paris 2000

Thuillier, Jacques (Hrsg.): AK Vouet, Paris 1990

Thuillier, Jacques: "La `Galerie de Médicis` de Rubens et sa genèse«, in: Revue de l'Art 4 (1969), S. 52-62

Thürlemann, Felix: »Vom Sinn der Ordnung. Die Bildersammlung des Frankfurter Konditormeisters Johann Valentin Prehn (1749-1821)«, in: Assmann, A./ Gomille, M./ Rippl, G. (Hrsg.): Sammler - Bibliophile - Exzentriker, Tübingen 1998, S. 315-324

Tischendorf, Konstantin von (Hrsg.): Apocalypses apocryphae, Hildesheim 1966 (ND der Ausgabe Leipzig 1866)

Tönnesmann, Andreas: „Pariser Witwensitze«, in: Bonnet, Anne-Marie / Schellewald, Barbara (Hrsg.): Frauen in der Frühen Neuzeit, Köln / Weimar / Wien 2004, S. 189-211 


\section{Literaturverzeichnis}

Trillhaas, Wolfgang: »Meditation«, in: ${ }^{3} R G G$, Bd. 4, Sp. 824-826

Trnek, Renate: Gemäldegalerie der Akademie der Bildenden Künste in Wien, Illustriertes Bestandsverzeichnis, Wien 1989

Trnek, Renate: AK Traum vom Süden, Die Niederländer malen Italien, Ostfildern 2007

Tuck, Richard: Philosophy and Government 1572-1651, Cambridge 1993

Tümpel, Christian: »Bild und Text: Zur Rezeption antiker Autoren in der europäische Kunst der Neuzeit (Livius, Valerius Maximus)«, in: Schlink, Wilhelm / Sperlich, Martin (Hrsg.): Forma et subtilitas, Festschrift für Wolfgang Schöne zum 75. Geburtstag, Berlin / New York 1986, S. 198-218

Ubl, Ralph: "Zu einer Interpretation von Guido Renis Andachtsbildern « in: Wiener Jahrbuch für Kunstgeschichte 44 (1991), S. 159-173

Uppenkamp, Bettina: Bericht über Habilitationsprojekt »Die italienischen Hochzeitstruhen des Quattrocento «

http://www2.hu-berlin.de/ffz/dld/bettinauppenkamp.pdf (zuletzt aufgerufen: 25.10.2006)

Valcanover, Francesco [u.a.] (Hrsg.): AK Tiziano, Venezia 1990

Valentin, Jean-Marie: Les jésuites et le théâtre (1554-1680), contribution à l'histoire culturelle du monde catholique dans le Saint-Empire romain germanique, Paris 2001

Varga, Aron Kibédi: »Visuelle Argumentation und visuelle Narrativität«, in: Harms, Wolfgang (Hrsg.): Text und Bild, Bild und Text, Stuttgart 1990 (DFGSymposion 1988), S. 356-367

Verspohl, Franz-Joachim: Michelangelo Buonarroti und Papst Julius II., Moses Heerführer, Gesetzgeber, Musenlenker, Göttingen 2004

Viatte, Francoise (Hrsg.): AK Escales du Baroque, Paris 1988

Vicini, Maria Lucrezia: Guida alla Galleria Spada, Rom 1998

Vieillard, Pierre-Ange (Klavierauszug zu der Vertonung von Berlioz: Gilbert, David (Hrsg.): Hector Berlioz, Cléopâtre, o. J. (Bärenreiter 5787)

Vlieghe, Hans (Hrsg.): Corpus Rubenianum, Saints II, Brüssel 1973

Vöhler, Martin: »Monodrama«, in: Reallexikon der deutschen Literaturwissenschaft, hrsg. von Harald Fricker, Bd.2, Berlin / New York 2000, S. 627-629

Volkmann, Hans: »Massinissa « in: Kleiner Pauly, Bd. 3, Sp. 1068-1070

Volkmann, Hans: »Sophoniba«, in: Kleiner Pauly, Bd. 5, Sp. 280 


\section{Forschungsliteratur}

Volkmann, Hans: Kleopatra, Politik und Propaganda, München 1953

Walker, Susan / Higgs, Peter (Hrsg.): AK Cleopatra of Egypt, from history to myth, London 2001

Walthaus, Rina: La nieve que arde o abrasa, Dido en Lucretia in het Spaanse drama van de 16de en 17de eeuw, Leiden 1988,

Walthaus, Rina: La nieve que arde o abrasa, Dido en Lucretia in het Spaanse drama van de 16de en 17de eeuw, Leiden 1988

in: http://home.wxs.nl/ pagklein/rina/tesis.html (zuletzt aufgerufen: 08.08.2006)

Weisbach, Werner: »Der sog. Geograph von Velasquez und die Darstellungen des Demokrit und des Heraklit«, in: Jahrbuch der preußischen Kunstsammlungen 49 (1928), S. $141 \mathrm{ff}$.

Weise, Georg / Otto, Gertrud: Die religiösen Ausdrucksgebärden des Barock und ihre Vorbereitung durch die italienische Kunst der Renaissance, Stuttgart 1938 (Schriften und Vorträge der Württembergischen Gesellschaft der Wissenschaften, Geisteswissenschaftliche Abteilung, Heft 5)

Wieczorek, Uwe (Hrsg.): AK Fünf Jahrhunderte italienische Kunst aus den Sammlungen des Fürsten von Liechtenstein, Bern 1994

Willems, Gottfried: Anschaulichkeit, Zu Theorie und Geschichte der Wort-BildBeziehungen und des literarischen Darstellungsstils, Tübingen 1989

Wilton, Andrew / Bignamini, Ilaria (Hrsg.): AK Grand Tour, The Lure of Italy in the Eighteenth Century, London 1996

Wimböck, Gabriele: Guido Reni (1575-1642), Funktion und Wirkung des religiösen Bildes, Regensburg 2002

Winner, M. / Andreae, B. / Pietrangeli, C. (Hrsg.): /l Cortile delle Statue, Der Statuenhof des Belvedere im Vatikan (Akten des internationalen Kongresses zu Ehren von Richard Krautheimer [Rom 1992]), Mainz 1998

Wolfzettel, Friedrich: 'Ce désir de vagabondage cosmopoliter, Wege und Entwicklung des französischen Reiseberichts im 19. Jahrhundert, Tübingen 1986

Worstbrock, Franz J.: Verzeichnis der deutschen Übersetzungen antiker Autoren, mit einer Bibliographie der Übersetzer, Boppard 1976

Zangheri Luigi: Ville della provincia di Firenze. La città, Mailand 1989

Zimmer, F. (Hrsg.): AK Die griechische Klassik, Idee oder Wirklichkeit, Berlin 2002 


\section{Bildkatalog ${ }^{1}$}

\begin{tabular}{|c|c|c|c|c|c|c|}
\hline 1 & $\begin{array}{l}\text { Aachen, Hans von } \\
(1552-1615)\end{array}$ & $\begin{array}{l}\text { Tarquinius und } \\
\text { Lukretia }\end{array}$ & 1600 & $\begin{array}{l}\text { Wien } \\
\text { KHM }\end{array}$ & - & $\begin{array}{l}\text { http://www.scholarsresource/images } \\
\text { /thumnails/191/m//mgf0504.jpg (zu- } \\
\text { letzt aufgerufen: } 15.01 .2007)\end{array}$ \\
\hline 2 & $\begin{array}{l}\text { Abel, Josef } \\
(1764-1818)\end{array}$ & Cato von Utica & 1817 & $\begin{array}{l}\text { Wien } \\
\text { Akademie }\end{array}$ & $\begin{array}{l}274 \times 201 \\
\text { Lwd. }\end{array}$ & $\begin{array}{l}\text { Trnek 1989, S. 16, } \\
\text { Hagen, S. } 98\end{array}$ \\
\hline 3 & $\begin{array}{l}\text { Aldegrever, Heinrich } \\
(1502-1555 / 61)\end{array}$ & Sophonisbe & 1553 & - & $\begin{array}{l}115 \times 74 \\
\text { Kupferstich }\end{array}$ & Tümpel, Tafel XLII, 95 \\
\hline 4 & Alizard, J.B & $\begin{array}{l}\text { Tod des Sokra- } \\
\text { tes }\end{array}$ & 1762 & $\begin{array}{l}\text { Paris } \\
\text { Ecole des Beaux Arts }\end{array}$ & Lwd. & $\begin{array}{l}\text { Oberreuter-Kronabel, 1986, } \\
\text { Abb.11 }\end{array}$ \\
\hline 5 & $\begin{array}{l}\text { Altdorfer, Albrecht } \\
\text { (um } 1480-1538 \text { ) }\end{array}$ & Dido & - & - & $\begin{array}{l}65 \times 38 \\
\text { Kupferstich }\end{array}$ & Bartsch $14,42(56)$ \\
\hline 6 & $\begin{array}{l}\text { Ammann, Jost } \\
(1539-1591)\end{array}$ & Sophonisbe & 1572 & - & $\begin{array}{l}108 \times 150 \\
\text { Holzschnitt }^{2}\end{array}$ & Bartsch 20,1(3.86[367]) \\
\hline
\end{tabular}

\footnotetext{
${ }^{1}$ Die Literaturverweise des Bildkatalogs beziehen sich auf das Verzeichnis der Forschungsliteratur, S. $346 \mathrm{ff}$.

${ }^{2}$ Livius-Illustration.
} 


\section{Bildkatalog}

\begin{tabular}{|c|c|c|c|c|c|c|}
\hline 7 & $\begin{array}{l}\text { Ammann, Jost } \\
(1539-1591)\end{array}$ & $\begin{array}{l}\text { Sophonisbe } \\
\text { kniet vor Massi- } \\
\text { nissa }\end{array}$ & 1572 & - & $\begin{array}{l}110 \times 150 \\
\text { Holzschnitt }^{1}\end{array}$ & Bartsch 20,1(3.85[367]) \\
\hline 8 & [entfällt] & - & - & - & - & - \\
\hline 9 & Anonym & Lukretia & - & $\begin{array}{l}\text { Florenz } \\
\text { Castello Vincigliata }\end{array}$ & $1,35 \times 0,56$ & Schubring, Tafel III, Nr. 21 \\
\hline 10 & Anonym & Lukretia & - & $\begin{array}{l}\text { Paris } \\
\text { Musée Jacquemart-André }\end{array}$ & $1,05 \times 0,32$ & $\begin{array}{l}\text { Schubring, Tafel CXXXVIII, } \\
\text { Nr. } 644\end{array}$ \\
\hline 11 & Anonym & $\begin{array}{l}\text { Tod der Sopho- } \\
\text { nisbe }\end{array}$ & 1473 & - & Holzschnitt $^{2}$ & Bartsch 80,1473/355 \\
\hline 12 & $\begin{array}{l}\text { Anonym } \\
\text { römische Kopie eines } \\
\text { griechischem Originals }\end{array}$ & $\begin{array}{l}\text { Schlafende } \\
\text { Ariadne }\end{array}$ & $\begin{array}{l}\text { 2. Jh. vor } \\
\text { Chr. }\end{array}$ & $\begin{array}{l}\text { Rom } \\
\text { Vatikan }\end{array}$ & $\begin{array}{l}161,5 \times 195 \\
\text { Marmor }\end{array}$ & $\begin{array}{l}\text { Ritschard, S. 82; } \\
\text { Walker / Higgs, S. } 304\end{array}$ \\
\hline 13 & Anonym & Lukretia $^{3}$ & 1571 & - & - & Richard-Jamet 2003, S. 533 \\
\hline 14 & Anonym & Porzia & 1517 & $\begin{array}{l}\text { Paris } \\
\text { B.N. }\end{array}$ & Skizze $^{4}$ & Richard-Jamet 2003, S. 533 \\
\hline
\end{tabular}




\section{Bildkatalog}

\begin{tabular}{|c|c|c|c|c|c|c|}
\hline 15 & Anonym, florentinisch & Lukretia & um 1505 & $\begin{array}{l}\text { Paris } \\
\text { Slg. Artaud de Montor }\end{array}$ & $0,40 \times 0,70$ & Schubring, Tafel LVIII, Nr. 262 \\
\hline 16 & Anonym, mailändisch & Lukretia & - & $\begin{array}{l}\text { Mailand } \\
\text { Castello Sforzesco }\end{array}$ & $1,91 \times 0,56$ & $\begin{array}{l}\text { Schubring, Tafel CLIV, Nr. } \\
727\end{array}$ \\
\hline 17 & Anonym, umbrisch & Tod der Lukretia & um 1480 & $\begin{array}{l}\text { Wien } \\
\text { Slg. Albert Figdor }\end{array}$ & $0,41 \times 0,37,5$ & $\begin{array}{l}\text { Schubring, Tafel CXXI, Nr. } \\
539\end{array}$ \\
\hline 18 & Apollonio di Giovanni & $\begin{array}{l}\text { Ankunft des } \\
\text { Äneas bei Dido }\end{array}$ & um 1450 & $\begin{array}{l}\text { Hannover } \\
\text { Nieders. Landesmuseum }\end{array}$ & $\begin{array}{l}42,5 \times 164 \\
\text { Holz }\end{array}$ & Grohn, S. 18 \\
\hline 19 & Apollonio di Giovanni & $\begin{array}{l}\text { Gastmahl und } \\
\text { Jagd der Dido }\end{array}$ & um 1450 & $\begin{array}{l}\text { Hannover } \\
\text { Nieders. Landesmuseum }\end{array}$ & $\begin{array}{l}42,5 \times 164 \\
\text { Holz }\end{array}$ & Grohn, S. 19 \\
\hline 20 & $\begin{array}{l}\text { Arthur, Reginald } \\
(1875-1922)\end{array}$ & Tod Kleopatras & 1892 & $\begin{array}{l}\text { London } \\
\text { Roy Miles Gallery }\end{array}$ & - & $\begin{array}{l}\text { www.abaxjp.com/cleopatra/cleopatr } \\
\text { a.html } \\
\text { (zuletzt aufgerufen: 04.01.2007) }\end{array}$ \\
\hline 21 & Aspertini, Amico & Kleopatra & $\begin{array}{l}1496 / \\
1503\end{array}$ & $\begin{array}{l}\text { London } \\
\text { British Museum }\end{array}$ & $\begin{array}{l}\text { Skizze } \\
\text { Feder, schw. } \\
\text { Tinte }\end{array}$ & Winner, S. 6 \\
\hline
\end{tabular}

\footnotetext{
${ }^{4}$ Illustration zu Pierre Gringoire (1475-1539).
} 


\section{Bildkatalog}

\begin{tabular}{|c|c|c|c|c|c|c|}
\hline 22 & $\begin{array}{l}\text { Assereto, Gioacchino } \\
(1600-1649)\end{array}$ & $\begin{array}{l}\text { Selbstmord Ca- } \\
\text { tos }\end{array}$ & - & $\begin{array}{l}\text { Genua } \\
\text { Palazzo Bianco }\end{array}$ & $\begin{array}{l}203 \times 279 \\
\text { Lwd. }\end{array}$ & Contini, S. 103 \\
\hline 23 & $\begin{array}{l}\text { Auvray, Felix } \\
(1800-1833)\end{array}$ & $\begin{array}{l}\text { Porzia, sich } \\
\text { selbst verlet- } \\
\text { zend }\end{array}$ & $\begin{array}{l}\text { Anf. } 19 . \\
\text { Jh. }\end{array}$ & $\begin{array}{l}\text { Valenciennes } \\
\text { Musée des Beaux-Arts }\end{array}$ & $\begin{array}{l}46 \times 38,3 \\
\text { Lwd. }\end{array}$ & $\begin{array}{l}\text { http://www.culture.gouv.fr/document } \\
\text { ation/joconde/fr/pres.htm } \\
\text { (zuletzt aufgerufen:04.01.2007) }\end{array}$ \\
\hline 23a & Bachiacca & siehe 406 & & & & \\
\hline 24 & $\begin{array}{l}\text { Barry, James } \\
(1741-1806)\end{array}$ & $\begin{array}{l}\text { Tod des Gene- } \\
\text { ral Wolfe }\end{array}$ & $1775 / 76$ & $\begin{array}{l}\text { New Brunswick } \\
\text { New Brunswick Museum }\end{array}$ & $\begin{array}{l}148,6 \times 236,2 \\
\text { Lwd. }\end{array}$ & Mai 1987, Nr. 96 \\
\hline $24 a$ & $\begin{array}{l}\text { Bassetti, Marcantonio } \\
(1586-1630)\end{array}$ & Kleopatra & - & Slg. Koelliker, Mailand & $\begin{array}{l}111 \times 87,5 \\
\text { Lwd. }\end{array}$ & Papi, S. 183 \\
\hline 25 & $\begin{array}{l}\text { Beccafumi, Domenico } \\
(1486-1551)\end{array}$ & Kleopatra & $\begin{array}{l}1508- \\
1510\end{array}$ & $\begin{array}{l}\text { Bayonne } \\
\text { Musée Bonnat }\end{array}$ & $\begin{array}{l}75,5 \times 47 \\
\text { Holz }\end{array}$ & Ritschard, S. 39 \\
\hline 26 & $\begin{array}{l}\text { Beccafumi, Domenico } \\
(1486-1551)\end{array}$ & Sophonisbe & $\begin{array}{l}1508- \\
1510\end{array}$ & $\begin{array}{l}\text { Bayonne } \\
\text { Musée Bonnat }\end{array}$ & $\begin{array}{l}75,5 \times 47 \\
\text { Holz }\end{array}$ & Ritschard, S. 39 \\
\hline 27 & $\begin{array}{l}\text { Beccafumi, Domenico } \\
(1486-1551)\end{array}$ & Lukretia & $\begin{array}{l}1513 / \\
1518\end{array}$ & $\begin{array}{l}\text { Oberlin (Ohio) } \\
\text { Oberlin College }\end{array}$ & Lwd. & Richard-Jamet 2003, S. 539 \\
\hline 28 & $\begin{array}{l}\text { Beham, Bartel } \\
(1502-1540)\end{array}$ & Kleopatra & - & - & $\begin{array}{l}58 \times 40 \\
\text { Kupferstich }\end{array}$ & Bartsch 15,12 \\
\hline
\end{tabular}




\section{Bildkatalog}

\begin{tabular}{|c|c|c|c|c|c|c|}
\hline 29 & $\begin{array}{l}\text { Beham, Hans Sebald } \\
(1500-1550)\end{array}$ & Kleopatra & - & - & $\begin{array}{l}112 \times 72 \\
\text { Kupferstich }\end{array}$ & Bartsch 15,77 \\
\hline 30 & $\begin{array}{l}\text { Beham, Hans Sebald } \\
(1500-1550)\end{array}$ & Dido & 1520 & - & $\begin{array}{l}117 \times 90 \\
\text { Kupferstich }\end{array}$ & Bartsch $15,80 \|(148)$ \\
\hline 31 & $\begin{array}{l}\text { Beham, Hans Sebald } \\
(1500-1550)\end{array}$ & Kleopatra & - & - & $\begin{array}{l}83 \times 47 \\
\text { Kupferstich }\end{array}$ & Bartsch 15,76 \\
\hline 32 & $\begin{array}{l}\text { Bellange, Jacques } \\
(1602-1616 \text { in Nancy } \\
\text { tätig) }\end{array}$ & Porzia & um 1613 & $\begin{array}{l}\text { Düsseldorf } \\
\text { Kunstmuseum }\end{array}$ & $\begin{array}{l}24,2 \times 18,1 \\
\text { Radierung }\end{array}$ & Baumgärtel 1995, S. 315 \\
\hline 33 & $\begin{array}{l}\text { Berchem, Nicolaes } \\
(1620-1683)\end{array}$ & Tod der Dido & 1678 & $\begin{array}{l}\text { Wien / Vaduz } \\
\text { Sammlungen des Fürsten } \\
\text { von und zu Liechtenstein }\end{array}$ & $\begin{array}{l}169 \times 124 \\
\text { Lwd. }\end{array}$ & $\begin{array}{l}\text { Chu, S. } 80 \\
\text { Trnek } 2007, \text { S. } 152-155\end{array}$ \\
\hline 34 & $\begin{array}{l}\text { Biagio di Antonio Tucci } \\
(1446-1516)\end{array}$ & Lukretia 1 & - & $\begin{array}{l}\text { Venedig } \\
\text { Ca d'Oro }\end{array}$ & $\begin{array}{l}\text { Front einer } \\
\text { Hochzeits- } \\
\text { truhe }\end{array}$ & Augusti, S. 104 \\
\hline 35 & $\begin{array}{l}\text { Biagio di Antonio Tucci } \\
(1446-1516)\end{array}$ & Lukretia 2 & - & $\begin{array}{l}\text { Venedig } \\
\text { Ca d'Oro }\end{array}$ & $\begin{array}{l}\text { Front einer } \\
\text { Hochzeits- } \\
\text { truhe }\end{array}$ & Augusti, S. 104 \\
\hline
\end{tabular}




\section{Bildkatalog}

\begin{tabular}{|c|c|c|c|c|c|c|}
\hline 36 & $\begin{array}{l}\text { Blanchard, Jacques } \\
(1600-1638)\end{array}$ & $\begin{array}{l}\text { Tod der Kleo- } \\
\text { patra }\end{array}$ & um 1630 & $\begin{array}{l}\text { Reims } \\
\text { Musée des Beaux-Arts }\end{array}$ & $\begin{array}{l}110 \times 146 \\
\text { Lwd. }\end{array}$ & $\begin{array}{l}\text { Baumgärtel 1995, Kat.135 } \\
\text { Mégevand, Kat.30 }\end{array}$ \\
\hline 37 & $\begin{array}{l}\text { Blanchet, Thomas } \\
(1614-1689)\end{array}$ & Tod der Dido & $\begin{array}{l}1655 / \\
1660\end{array}$ & $\begin{array}{l}\text { Dijon } \\
\text { Musée des Beaux-Arts }\end{array}$ & $\begin{array}{l}152 \times 185 \\
\text { Lwd. }\end{array}$ & Baumgärtel 1995, Kat. 92 \\
\hline 38 & $\begin{array}{l}\text { Böcklin, Arnold } \\
(1827-1901)\end{array}$ & $\begin{array}{l}\text { Sterbende } \\
\text { Kleopatra }\end{array}$ & 1872 & $\begin{array}{l}\text { Basel } \\
\text { Kunstmuseum }\end{array}$ & $\begin{array}{l}\text { 76x61,5 } \\
\text { Lwd. }\end{array}$ & Lindemann, S. 227 \\
\hline 39 & $\begin{array}{l}\text { Bol, Ferdinand } \\
(1616-1680)\end{array}$ & Tod der Dido & $\begin{array}{l}\text { nach } \\
1660\end{array}$ & $\begin{array}{l}\text { Stuttgart } \\
\text { Auktion Nagel } \\
(21 .-22.03 .2007)\end{array}$ & $\begin{array}{l}169 \times 167 \\
\text { Lwd. }\end{array}$ & $\begin{array}{l}\text { http://www.nagel- } \\
\text { liveaucti- } \\
\text { ons.de/scripts/auctions_object.php } \\
\text { (zuletzt aufgerufen: 18.03.2007) }\end{array}$ \\
\hline 40 & Bologneser Schule & Lukretia & um 1650 & $\begin{array}{l}\text { Würzburg } \\
\text { Martin von Wagner Mu- } \\
\text { seum }\end{array}$ & $\begin{array}{l}110 \times 88 \\
\text { Lwd. }\end{array}$ & Hoffmann / Koppe, Nr.32 \\
\hline 41 & $\begin{array}{l}\text { Bosse / Rousselet / Vig- } \\
\text { non }\end{array}$ & $\begin{array}{l}\text { Statue der Anna } \\
\text { von Österreich, } \\
\text { umgeben von } \\
\text { allegorischen } \\
\text { Figuren }\end{array}$ & 1647 & $\begin{array}{l}\text { Paris } \\
\text { B.N. }\end{array}$ & $\begin{array}{l}\text { ca. } 34 \times 21,5 \\
\text { Kupferstich }\end{array}$ & Baumgärtel 1995, S. 170 \\
\hline
\end{tabular}




\section{Bildkatalog}

\begin{tabular}{|c|c|c|c|c|c|c|}
\hline 42 & $\begin{array}{l}\text { Bosse / Rousselet / Vig- } \\
\text { non }\end{array}$ & Lukretia & 1647 & $\begin{array}{l}\text { Paris } \\
\text { B.N. }\end{array}$ & $\begin{array}{l}\text { ca. } 43 \times 21,5 \\
\text { Kupferstich }\end{array}$ & Baumgärtel 1995, S. 172 \\
\hline 43 & $\begin{array}{l}\text { Bosse / Rousselet / Vig- } \\
\text { non }\end{array}$ & Porzia & 1647 & $\begin{array}{l}\text { Paris } \\
\text { B.N. }\end{array}$ & $\begin{array}{l}\text { ca. } 43 \times 21,5 \\
\text { Kupferstich }\end{array}$ & Baumgärtel 1995, S. 172 \\
\hline 44 & $\begin{array}{l}\text { Bosse / Rousselet / Vig- } \\
\text { non }\end{array}$ & Paulina & 1647 & $\begin{array}{l}\text { Paris } \\
\text { B.N. }\end{array}$ & $\begin{array}{l}\text { ca. } 43 \times 21,5 \\
\text { Kupferstich }\end{array}$ & Baumgärtel 1995, S. 172 \\
\hline 45 & $\begin{array}{l}\text { Botticelli, Sandro } \\
(1444-1510)\end{array}$ & Tod der Lukretia & um 1460 & $\begin{array}{l}\text { Boston } \\
\text { Mrs. Gardener Museum }\end{array}$ & $\begin{array}{l}70 \times 331 / 3 \\
\text { inch. }\end{array}$ & $\begin{array}{l}\text { Schubring, Tafel LXXII, Nr. } \\
304\end{array}$ \\
\hline 46 & $\begin{array}{l}\text { Bouchet, Louis André } \\
\text { Gabriel } \\
(1759-1842)\end{array}$ & Tod des Cato & 1797 & $\begin{array}{l}\text { Paris } \\
\text { École des Beaux-Arts }\end{array}$ & - & $\begin{array}{l}\text { Oberreuter-Kronabel 1986, } \\
\text { Abb.62 }\end{array}$ \\
\hline 47 & $\begin{array}{l}\text { Bouillon, Pierre } \\
(1776-1831)\end{array}$ & Tod des Cato & 1797 & $\begin{array}{l}\text { Paris } \\
\text { École des Beaux-Arts }\end{array}$ & - & $\begin{array}{l}\text { Oberreuter-Kronabel 1986, } \\
\text { Abb.61 }\end{array}$ \\
\hline 48 & $\begin{array}{l}\text { Bourdon, Sébastien } \\
(1616-1671)\end{array}$ & Tod der Dido & - & $\begin{array}{l}\text { Béziers } \\
\text { Musée des Beaux-Arts }\end{array}$ & $\begin{array}{l}49 \times 43 \\
\text { Lwd. }^{5}\end{array}$ & Thuillier 2000, S. 223 \\
\hline 49 & $\begin{array}{l}\text { Bourdon, Sébastien } \\
(1616-1671)\end{array}$ & Tod der Dido & - & $\begin{array}{l}\text { Sankt Petersburg } \\
\text { Eremitage }\end{array}$ & $\begin{array}{l}158,5 \times 136,5 \\
\text { Lwd. }\end{array}$ & Thuillier 2000, S. 224 \\
\hline
\end{tabular}

\footnotetext{
${ }^{5}$ Ölskizze der Fassung von St. Petersburg.
} 


\section{Bildkatalog}

\begin{tabular}{|c|c|c|c|c|c|c|}
\hline 50 & $\begin{array}{l}\text { Bourdon, Sébastien } \\
(1616-1671)\end{array}$ & Tod der Dido & - & $\begin{array}{l}\text { Bilbao } \\
\text { Museo de Bellas Artes }\end{array}$ & - & Thuillier 2000, S. $101 \mathrm{f}$. \\
\hline 51 & $\begin{array}{l}\text { Bramer, Leonaert } \\
(1596-1674)\end{array}$ & $\begin{array}{l}\text { Opferung der } \\
\text { Iphigenie }\end{array}$ & - & $\begin{array}{l}\text { Amsterdam } \\
\text { (Christie's) }\end{array}$ & $\begin{array}{l}28 \times 38 \\
\text { Kupfer }\end{array}$ & Brink Goldsmith, Abb.2 \\
\hline 52 & $\begin{array}{l}\text { Breu, Jörg D. Ä. } \\
(1475-1537)\end{array}$ & Lukretia & 1528 & $\begin{array}{l}\text { München } \\
\text { Alte Pinakothek }\end{array}$ & $\begin{array}{l}103,5 \times 148,5 \\
\text { Nadelholz }\end{array}$ & Schawe, S.88 \\
\hline 53 & $\begin{array}{l}\text { Cagnacci, Guido } \\
(1601-1663)\end{array}$ & $\begin{array}{l}\text { Selbstmord der } \\
\text { Kleopatra }\end{array}$ & vor 1662 & $\begin{array}{l}\text { Wien } \\
\text { KHM }\end{array}$ & $\begin{array}{l}153 \times 168,5 \\
\text { Lwd. }\end{array}$ & Baumgärtel 1995, Kat. 134 \\
\hline 54 & $\begin{array}{l}\text { Cagnacci, Guido } \\
(1601-1663)\end{array}$ & $\begin{array}{l}\text { Selbstmord der } \\
\text { Lukretia }\end{array}$ & $1655-60$ & $\begin{array}{l}\text { Kassel } \\
\text { Staatliche Museen }\end{array}$ & $\begin{array}{l}89,7 \times 77,5 \\
\text { Lwd. }\end{array}$ & Lehmann, S. 61 \\
\hline 55 & $\begin{array}{l}\text { Cagnacci, Guido } \\
(1601-1663)\end{array}$ & Kleopatra & 1659 & $\begin{array}{l}\text { Mailand } \\
\text { Brera }\end{array}$ & $\begin{array}{l}158 \times 120 \\
\text { Lwd. }\end{array}$ & Ritschard, S. 123 \\
\hline 56 & $\begin{array}{l}\text { Cagnacci, Guido } \\
(1601-1663)\end{array}$ & Lukretia & - & $\begin{array}{l}\text { Bologna } \\
\text { Pinacoteca Nazionale }\end{array}$ & Lwd. & - \\
\hline 57 & $\begin{array}{l}\text { Cagnacci, Guido } \\
\text { (1601-1663) }\end{array}$ & Lukretia & - & $\begin{array}{l}\text { Wien } \\
\text { Dorotheum } \\
\text { (Auktion 24.04.2007) }\end{array}$ & $\begin{array}{l}\text { Lwd. } \\
114,5 \times 112\end{array}$ & $\begin{array}{l}\text { http://www.dorotheum.com/deu/aukti } \\
\text { onstermine.html } \\
\text { (zuletzt aufgerufen: 03.04.2007) }\end{array}$ \\
\hline
\end{tabular}




\section{Bildkatalog}

\begin{tabular}{|c|c|c|c|c|c|c|}
\hline 58 & $\begin{array}{l}\text { Carneo, Antonio } \\
(1637-1692)\end{array}$ & $\begin{array}{l}\text { Sterbende Luk- } \\
\text { retia }\end{array}$ & - & $\begin{array}{l}\text { Warschau } \\
\text { Muzeum Narodowe w } \\
\text { Warzawie }\end{array}$ & $\begin{array}{l}99 \times 82,5 \\
\text { Lwd. }\end{array}$ & $\begin{array}{l}\text { Herzog Anton Ulrich-Museum } \\
\text { 1989, Kat.28 }\end{array}$ \\
\hline 59 & $\begin{array}{l}\text { Caroto, Giovanni Fran- } \\
\text { cesco } \\
(1488-1562)\end{array}$ & Sophonisbe $^{6}$ & - & $\begin{array}{l}\text { Verona } \\
\text { Museo di Castelvecchio }\end{array}$ & Holz & $\begin{array}{l}\text { http://images.google/imgres?imgurl= } \\
\text { http://www.weblettres.net/languesan } \\
\text { c/tite-live/sophonisbe_caroto.jpg } \\
\text { (zuletzt aufgerufen: 04.01.2007) }\end{array}$ \\
\hline 60 & $\begin{array}{l}\text { Cestaro, Jacopo } \\
(1718-1778)\end{array}$ & Lukretia & - & $\begin{array}{l}\text { Neapel } \\
\text { Slg. Solima }\end{array}$ & $\begin{array}{l}96 \times 73,5 \\
\text { Lwd. }\end{array}$ & Spinosa 1987, Tav. 4 \\
\hline 61 & $\begin{array}{l}\text { Cestaro, Jacopo } \\
(1718-1778)\end{array}$ & Kleopatra & um 1750 & $\begin{array}{l}\text { Rom } \\
\text { Slg. Sestieri }\end{array}$ & Lwd. & Spinosa 1987, Abb. 27 \\
\hline 62 & $\begin{array}{l}\text { Cestaro, Jacopo } \\
(1718-1778)\end{array}$ & Kleopatra & - & $\begin{array}{l}\text { Neapel } \\
\text { Museo di Capodimonte }\end{array}$ & $\begin{array}{l}101 \times 75 \\
\text { Lwd. }\end{array}$ & Spinosa 1987, Abb. 28 \\
\hline 63 & $\begin{array}{l}\text { Chauveau, François } \\
(1613-1676)\end{array}$ & Porzia & 1645 & $\begin{array}{l}\text { Paris } \\
\text { B.N. }\end{array}$ & Kupferstich ${ }^{7}$ & Baumgärtel 1995, S. 177 \\
\hline 64 & $\begin{array}{l}\text { Chauveau, François } \\
(1613-1676)\end{array}$ & Lukretia & 1645 & $\begin{array}{l}\text { Paris } \\
\text { B.N. }\end{array}$ & Kupferstich ${ }^{8}$ & Baumgärtel 1995, S. 178 \\
\hline
\end{tabular}

\footnotetext{
${ }^{6}$ Nach Giampietrino (Katalog 150b).

${ }^{7}$ Illustration zu Jacques du Bosc: La Femme Héroïque.

${ }^{8}$ Illustration zu Jacques du Bosc: La Femme Héroïque.
} 


\section{Bildkatalog}

\begin{tabular}{|c|c|c|c|c|c|c|}
\hline 65 & $\begin{array}{l}\text { Chauveau, François } \\
(1613-1676)\end{array}$ & Porzia & 1645 & $\begin{array}{l}\text { Paris } \\
\text { B.N. }\end{array}$ & Kupferstich & Baumgärtel 1995, S. 177 \\
\hline 66 & $\begin{array}{l}\text { Cifrondi, Antonio } \\
(1656-1730)\end{array}$ & Lukretia & $\begin{array}{l}1698- \\
1700\end{array}$ & Privatsammlung & $\begin{array}{l}86 \times 69 \\
\text { Lwd. }\end{array}$ & Bossaglia / Terraroli, S. 66) \\
\hline 67 & $\begin{array}{l}\text { Cignaroli, Gianbettino } \\
(1706-1770)\end{array}$ & $\begin{array}{l}\text { Tod des Sokra- } \\
\text { tes }\end{array}$ & - & $\begin{array}{l}\text { Budapest } \\
\text { Szépmüvészeti Múzeum }\end{array}$ & - & Oberreuter-Kronabel 1986, 16 \\
\hline 68 & $\begin{array}{l}\text { Conca, Sebastiano } \\
(1680-1764)\end{array}$ & Tod des Seneca & - & $\begin{array}{l}\text { Braunschweig } \\
\text { Herzog Anton Ulrich- } \\
\text { Museum }\end{array}$ & Lwd. & Oberreuter-Kronabel 1986, 52 \\
\hline 69 & $\begin{array}{l}\text { Conca, Sebastiano } \\
(1680-1764)\end{array}$ & Tod des Cato & - & $\begin{array}{l}\text { Braunschweig } \\
\text { Herzog Anton Ulrich- } \\
\text { Museum }\end{array}$ & Lwd. & $\begin{array}{l}\text { Oberreuter-Kronabel 1986, } \\
\text { Abb.57 }\end{array}$ \\
\hline 70 & $\begin{array}{l}\text { Corneille, Jean-Baptiste } \\
(1649-1695)\end{array}$ & Tod des Cato & 1686 & $\begin{array}{l}\text { Dijon } \\
\text { Musée des Beaux-Arts }\end{array}$ & $\begin{array}{l}131 \times 163 \\
\text { Lwd. }\end{array}$ & Mégevand, Kat. 120 \\
\hline 71 & $\begin{array}{l}\text { Cortona, Pietro da } \\
(1596-1669)\end{array}$ & $\begin{array}{l}\text { Opferung der } \\
\text { Polyxena }\end{array}$ & - & $\begin{array}{l}\text { Rom } \\
\text { Pinacoteca Capitolina }\end{array}$ & $\begin{array}{l}277 \times 423 \\
\text { Lwd. }\end{array}$ & Lo Bianco, Abb.139 \\
\hline
\end{tabular}




\section{Bildkatalog}

\begin{tabular}{|c|c|c|c|c|c|c|}
\hline 72 & $\begin{array}{l}\text { Cozza, Francesco } \\
(1605-1682)\end{array}$ & Kleopatra & 1675 & $\begin{array}{l}\text { Nizza } \\
\text { Musée des Beaux-Arts } \\
\text { Jules Chéret }\end{array}$ & $\begin{array}{l}126 \times 98 \\
\text { Lwd. }\end{array}$ & Baumgärtel 1995, Kat.133 \\
\hline 73 & $\begin{array}{l}\text { Cozzarelli, Guido } \\
\text { (um } 1470 \text { erwähnt) }\end{array}$ & Lukretia & um 1400 & $\begin{array}{l}\text { Siena } \\
\text { Slg. Marchese Chigi- } \\
\text { Zondadori }\end{array}$ & - & Schubring, Tafel CXI, Nr. 468 \\
\hline 74 & $\begin{array}{l}\text { Cranach d. Ä., Lucas } \\
(1472-1553)\end{array}$ & Lukretia & 1533 & $\begin{array}{l}\text { Berlin } \\
\text { Staatliche Museen }\end{array}$ & $\begin{array}{l}37,3 \times 23,9 \\
\text { Holz }\end{array}$ & $\begin{array}{l}\text { Friedländer / Rosenberg, S. } \\
118 \text { und Abb.Nr.239 }\end{array}$ \\
\hline 75 & $\begin{array}{l}\text { Cranach d. Ä., Lucas } \\
(1472-1553)\end{array}$ & Lukretia & 1524 & $\begin{array}{l}\text { München } \\
\text { Alte Pinakothek }\end{array}$ & $\begin{array}{l}194 \times 75 \\
\text { Lindenholz }\end{array}$ & Schawe, S. 121 \\
\hline 76 & $\begin{array}{l}\text { Crespi, Giuseppe Maria } \\
(1665-1747)\end{array}$ & $\begin{array}{l}\text { Lukretia und } \\
\text { Tarquinius }\end{array}$ & um 1695 & $\begin{array}{l}\text { Washington } \\
\text { National Gallery }\end{array}$ & $\begin{array}{l}195 \times 171,5 \\
\text { Lwd. }\end{array}$ & $\begin{array}{l}\text { http://images.google.de/imgres?img } \\
\text { url=http://www.charlise.com/lucretias } \\
\text { /crespiwa..jpg } \\
\text { (zuletzt aufgerufen:05.01.2007) }\end{array}$ \\
\hline 77 & $\begin{array}{l}\text { Crosato, Giovanni Batti- } \\
\text { sta } \\
(1686-1758)\end{array}$ & $\begin{array}{l}\text { Opferung der } \\
\text { Polyxena }\end{array}$ & $\begin{array}{l}1740- \\
1750\end{array}$ & $\begin{array}{l}\text { Dijon } \\
\text { Musée Magnin }\end{array}$ & $\begin{array}{l}67 \times 84,5 \\
\text { Lwd. }\end{array}$ & $\begin{array}{l}\text { Brejon de Lavergnée 1980, S. } \\
64\end{array}$ \\
\hline
\end{tabular}




\section{Bildkatalog}

\begin{tabular}{|c|c|c|c|c|c|c|}
\hline 78 & $\begin{array}{l}\text { Crosato, Giovanni Bat- } \\
\text { tista } \\
(1686-1758)\end{array}$ & Sophonisbe & um 1750 & $\begin{array}{l}\text { Venedig } \\
\text { Ca Rezzonico }\end{array}$ & $\begin{array}{l}218 \times 128 \\
\text { Lwd. }\end{array}$ & $\begin{array}{l}\text { http://www.artericerca.com/ven_set } \\
\text { crosato/4.htm } \\
\text { (zuletzt aufgerufen: } 17.01 .2007 \text { ) }\end{array}$ \\
\hline 79 & $\begin{array}{l}\text { Da Brescia, Giovanni } \\
\text { Antonio } \\
\text { (um 1460-1531) }\end{array}$ & $\begin{array}{l}\text { Aeneis- } \\
\text { Ilustrationen }\end{array}$ & 1515 & - & $\begin{array}{l}243 \times 178 \\
\text { Kupferstich }\end{array}$ & Bartsch $25,2511(025)$ \\
\hline 80 & $\begin{array}{l}\text { Da Cortona, Pietro } \\
(1596-1669)\end{array}$ & Sophonisbe & $\begin{array}{l}1641- \\
1642\end{array}$ & $\begin{array}{l}\text { Florenz } \\
\text { Palazzo Pitti }\end{array}$ & Fresko & Richard-Jamet 2003, S. 527 \\
\hline 81 & $\begin{array}{l}\text { Da Cortona, Pietro } \\
(1596-1669)\end{array}$ & Kleopatra & $\begin{array}{l}1641- \\
1642\end{array}$ & $\begin{array}{l}\text { Florenz } \\
\text { Palazzo Pitti }\end{array}$ & Fresko & Richard-Jamet 2003, S. 527 \\
\hline 82 & $\begin{array}{l}\text { Da Modena, Nicoletto } \\
(1480-1538)\end{array}$ & Kleopatra & - & - & $\begin{array}{l}60 \times 90 \\
\text { Kupferstich }\end{array}$ & Bartsch $25,2508(075)$ \\
\hline 83 & $\begin{array}{l}\text { Da Padova, Gian Maria, } \\
\text { detto il Mosca } \\
(1493 / 95-\text { nach } 1574)\end{array}$ & Porzia & - & $\begin{array}{l}\text { Venedig } \\
\text { Ca d'Oro }\end{array}$ & $\begin{array}{l}\text { Weißgrauer } \\
\text { Marmor }\end{array}$ & Augusti, S. 42 \\
\hline 84 & $\begin{array}{l}\text { Da Verona, Liberale } \\
\text { (um 1445-1527/9) }\end{array}$ & $\begin{array}{l}\text { Selbstmord Di- } \\
\text { dos }\end{array}$ & $\begin{array}{l}\text { frühes } 16 . \\
\text { Jh. }\end{array}$ & $\begin{array}{l}\text { London } \\
\text { National Gallery }\end{array}$ & $\begin{array}{l}42,5 \times 123,2 \\
\text { Holz }\end{array}$ & Baker, S. 378 \\
\hline
\end{tabular}




\section{Bildkatalog}

\begin{tabular}{|c|c|c|c|c|c|c|}
\hline 85 & $\begin{array}{l}\text { Da Verona, Michele } \\
\text { (um 1470-1536 oder } \\
1544 \text { ) }\end{array}$ & Porzia & - & $\begin{array}{l}\text { Krakau } \\
\text { Czartoryski Museum }\end{array}$ & $\begin{array}{l}\text { Hochzeits- } \\
\text { truhe } \\
1,48 \times 1,18\end{array}$ & $\begin{array}{l}\text { Schubring, Tafel CXLVI, Nr. } \\
681\end{array}$ \\
\hline 86 & $\begin{array}{l}\text { Dal Sole, Giovan Giosef- } \\
\text { fo } \\
(1654-1719)\end{array}$ & $\begin{array}{l}\text { Pyrrhos und } \\
\text { Polyxena }\end{array}$ & um 1690 & $\begin{array}{l}\text { Marano di Castenaso } \\
\text { Slg. Molinari Pradelli }\end{array}$ & $\begin{array}{l}158 \times 137 \\
\text { Lwd. }\end{array}$ & Ebert-Schifferer 1994, Kat. 40 \\
\hline 87 & $\begin{array}{l}\text { Dal Sole, Giovan Giosef- } \\
\text { fo } \\
(1654-1719)\end{array}$ & $\begin{array}{l}\text { Artemisia } \\
\text { (Sophonisbe?) }\end{array}$ & $\begin{array}{l}\text { um } 1700- \\
1715\end{array}$ & $\begin{array}{l}\text { Cesena } \\
\text { Cassa di Risparmio }\end{array}$ & $\begin{array}{l}103 \times 85 \\
\text { Lwd. }\end{array}$ & Ebert-Schifferer 1994, Kat. 42 \\
\hline 88 & $\begin{array}{l}\text { dal Sole, Giovan Giosef- } \\
\text { fo } \\
(1654-1719)\end{array}$ & Lukretia & - & $\begin{array}{l}\text { Rom } \\
\text { Galleria Corsini }\end{array}$ & $\begin{array}{l}103 \times 80 \\
\text { Lwd. }\end{array}$ & Alloisi, S. 115 \\
\hline 89 & $\begin{array}{l}\text { David, Jacques-Louis } \\
(1748-1825)\end{array}$ & Tod des Marat & 1793 & $\begin{array}{l}\text { Brüssel } \\
\text { Musées des Beaux-Arts }\end{array}$ & $\begin{array}{l}165 \times 128 \\
\text { Lwd. }\end{array}$ & Mai 1987, Nr. 21a \\
\hline 90 & $\begin{array}{l}\text { David, Jacques-Louis } \\
(1748-1825)\end{array}$ & $\begin{array}{l}\text { Tod des Sokra- } \\
\text { tes }\end{array}$ & 1787 & $\begin{array}{l}\text { New York } \\
\text { Metropolitan Museum }\end{array}$ & - & Oberreuter-Kronabel 1986, 27 \\
\hline 91 & $\begin{array}{l}\text { David, Jacques-Louis } \\
(1748-1825)\end{array}$ & Tod des Seneca & 1773 & $\begin{array}{l}\text { Paris } \\
\text { Musée du Petit Palais }\end{array}$ & - & $\begin{array}{l}\text { Oberreuter-Kronabel 1986, } \\
\text { Abb.47 }\end{array}$ \\
\hline
\end{tabular}




\section{Bildkatalog}

\begin{tabular}{|c|c|c|c|c|c|c|}
\hline 92 & $\begin{array}{l}\text { de Peters, Johann Anton } \\
(1725-1795)\end{array}$ & Tod des Seneca & - & $\begin{array}{l}\text { Köln } \\
\text { Wallraf-Richartz-Museum }\end{array}$ & $\begin{array}{l}97,5 \times 86,5 \\
\text { Lwd. }\end{array}$ & Mai 1987, Nr. 87 \\
\hline 93 & $\begin{array}{l}\text { Del Cairo, Francesco } \\
(1607-1665)\end{array}$ & Lukretia & $\begin{array}{l}\text { um 1635- } \\
1640\end{array}$ & $\begin{array}{l}\text { Wien / Vaduz } \\
\text { Sammlungen des Fürsten } \\
\text { von und zu Liechtenstein }\end{array}$ & $\begin{array}{l}\text { 63,7x50,5 } \\
\text { Lwd. }\end{array}$ & Wieczorek, S. 75 \\
\hline 94 & $\begin{array}{l}\text { del Conte, Jacobino } \\
\text { (zugeschrieben) } \\
(1510-1598)\end{array}$ & Kleopatra & - & $\begin{array}{l}\text { Rom } \\
\text { Villa Borghese }\end{array}$ & $\begin{array}{l}81 \times 56 \\
\text { Lwd. }\end{array}$ & - \\
\hline 95 & $\begin{array}{l}\text { del Conte, Jacobino } \\
\text { (zugeschrieben) } \\
(1510-1598)\end{array}$ & Lukretia & - & $\begin{array}{l}\text { Rom } \\
\text { Villa Borghese }\end{array}$ & $\begin{array}{l}55 \times 43 \\
\text { Lwd. }\end{array}$ & - \\
\hline 96 & $\begin{array}{l}\text { Del Nassaro. Matteo } \\
\text { (gestorben 1548) }\end{array}$ & Porzia & 1518 & $\begin{array}{l}\text { Paris } \\
\text { B. N. }\end{array}$ & Zeichnung & Richard-Jamet 2003, S. 533 \\
\hline 97 & $\begin{array}{l}\text { Del Nassaro. Matteo } \\
\text { (gestorben 1548) }\end{array}$ & Lukretia & 1518 & $\begin{array}{l}\text { Paris } \\
\text { B. N. }\end{array}$ & Zeichnung & Richard-Jamet 2003, S. 533 \\
\hline 98 & $\begin{array}{l}\text { Delacroix, Eugène } \\
(1798-1863)\end{array}$ & Kleopatra & - & $\begin{array}{l}\text { Chapel Hill } \\
\text { University of North Caro- } \\
\text { lina }\end{array}$ & Lwd. & Walker / Higgs, S. 307 \\
\hline
\end{tabular}




\section{Bildkatalog}

\begin{tabular}{|c|c|c|c|c|c|c|}
\hline 99 & $\begin{array}{l}\text { della Bella, Stefano } \\
(1610-1664)\end{array}$ & $\begin{array}{l}\text { Dido aus dem } \\
\text { Kartenspiel für } \\
\text { Anne d'Autriche }\end{array}$ & 1644 & & Graphik & $\begin{array}{l}\text { http://musis.bsz.de/pan/kunsthalle- } \\
\text { karlsru- } \\
\text { he/kupferstichkabinett/DellaBella/virt } \\
\text { uelle_ausstellung.htm } \\
\text { (zuletzt aufgerufen.05.01.2007) }\end{array}$ \\
\hline 100 & $\begin{array}{l}\text { della Bella, Stefano } \\
(1610-1664)\end{array}$ & $\begin{array}{l}\text { Kleopatra aus } \\
\text { dem Kartenspiel } \\
\text { für Anne d'Aut- } \\
\text { riche }\end{array}$ & 1644 & & Graphik & $\begin{array}{l}\text { http://musis.bsz.de/pan/kunsthalle- } \\
\text { karlsru- } \\
\text { he/kupferstichkabinett/DellaBella/virt } \\
\text { uelle_ausstellung.htm } \\
\text { (zuletzt aufgerufen.05.01.2007) }\end{array}$ \\
\hline 101 & $\begin{array}{l}\text { Di Benvenuto, Girolamo } \\
(1470-1524)\end{array}$ & Porzia & um 1500 & $\begin{array}{l}\text { Chambéry } \\
\text { Musées d'Art et d'Histoire }\end{array}$ & - & Richard-Jamet 2003, S. 538 \\
\hline 102 & $\begin{array}{l}\text { Di Benvenuto, Girolamo } \\
\text { 1470-1524) }\end{array}$ & Kleopatra & um 1500 & $\begin{array}{l}\text { Florenz } \\
\text { Slg. Grassi }\end{array}$ & - & Richard-Jamet 2003, S. 538 \\
\hline 103 & $\begin{array}{l}\text { Di Luca Ferrari, Cerchia } \\
(1605-1654)\end{array}$ & Lukretia & - & $\begin{array}{l}\text { Genua } \\
\text { Palazzo Durazzo Pallavi- } \\
\text { cini }\end{array}$ & $\begin{array}{l}\text { 108x133 } \\
\text { (angestückt } \\
\text { auf 133x153) } \\
\text { Lwd. }\end{array}$ & Cattaneo Adorno, S. 309 \\
\hline 104 & $\begin{array}{l}\text { Di Sandro, Amico } \\
\text { (Botticelli-Werkstatt) }\end{array}$ & Tod der Lukretia & um 1460 & $\begin{array}{l}\text { Florenz } \\
\text { Palazzo Pitti }\end{array}$ & $1,25 \times 0,41$ & Schubring, Tafel VIII, Nr. 321 \\
\hline
\end{tabular}


Bildkatalog

\begin{tabular}{|c|c|c|c|c|c|c|}
\hline 105 & $\begin{array}{l}\text { Dossi, Dosso } \\
(1486-1542)\end{array}$ & Dido & um 1518 & $\begin{array}{l}\text { Rom } \\
\text { Galleria Doria Pamphilj }\end{array}$ & $\begin{array}{l}95,5 \times 75 \\
\text { Lwd. }\end{array}$ & Humfrey, S. 137 \\
\hline 106 & $\begin{array}{l}\text { Dubois, Ambroise } \\
(1543-1614)\end{array}$ & $\begin{array}{l}\text { Kleopatra oder } \\
\text { Lukretia }\end{array}$ & 1600 & - & $?$ & Richard-Jamet 2003, S. 532 \\
\hline 107 & $\begin{array}{l}\text { Dufresnoy, Charles- } \\
\text { Alphonse } \\
(1611-1668)\end{array}$ & $\begin{array}{l}\text { Tod des Sokra- } \\
\text { tes }\end{array}$ & - & $\begin{array}{l}\text { Florenz } \\
\text { Uffizien }\end{array}$ & Lwd. & $\begin{array}{l}\text { Oberreuter-Kronabel 1986, } \\
\text { Abb.45 }\end{array}$ \\
\hline 108 & $\begin{array}{l}\text { Dufresnoy, Charles- } \\
\text { Alphonse } \\
(1611-1668)\end{array}$ & $\begin{array}{l}\text { Selbstmord der } \\
\text { Lucretia }\end{array}$ & 1645 & $\begin{array}{l}\text { Kassel } \\
\text { Staatliche Museen }\end{array}$ & $\begin{array}{l}116,3 \times 137,5 \\
\text { Lwd. }\end{array}$ & $\begin{array}{l}\text { http://www.univ- } \\
\text { montp3.fr/ pictuta/GenerateurNotice } \\
\text {.ph.?numnotice=A4457 } \\
\text { (zuletzt aufgerufen: } 15.01 .2007 \text { ) }\end{array}$ \\
\hline 109 & $\begin{array}{l}\text { Dughet, Gaspard } \\
\text { (1615-1675) (mit Carlo } \\
\text { Maratta ? [1625-1713]) }\end{array}$ & $\begin{array}{l}\text { Landschaft mit } \\
\text { Dido und Ae- } \\
\text { neas }\end{array}$ & um 1664 & $\begin{array}{l}\text { London } \\
\text { National Gallery }\end{array}$ & $\begin{array}{l}152,4 \times 224,2 \\
\text { Lwd. }\end{array}$ & Baker, S. 201 \\
\hline 110 & $\begin{array}{l}\text { Dürer,Albrecht } \\
(1471-1528)\end{array}$ & $\begin{array}{l}\text { Selbstmord der } \\
\text { Lukretia }\end{array}$ & 1518 & $\begin{array}{l}\text { München } \\
\text { Alte Pinakothek }\end{array}$ & $\begin{array}{l}\text { 168x74,8 } \\
\text { Lindenholz }\end{array}$ & Steingräber 1983, S. 705 \\
\hline 111 & $\begin{array}{l}\text { Dürer, Albrecht } \\
(1471-1528)\end{array}$ & Lukretia & 1508 & $\begin{array}{l}\text { Wien } \\
\text { Albertina }\end{array}$ & $42,3 \times 22,6^{9}$ & Schröder, S. 375 \\
\hline
\end{tabular}

\footnotetext{
${ }^{9}$ Pinsel in schwarz und grau, grau laviert, mit Deckweiß gehöht auf Papier.
} 


\section{Bildkatalog}

\begin{tabular}{|c|c|c|c|c|c|c|}
\hline 112 & $\begin{array}{l}\text { Dyck, van Antoine(1599- } \\
\text { 1641) }\end{array}$ & $\begin{array}{l}\text { Tod der Kleo- } \\
\text { patra }\end{array}$ & - & $\begin{array}{l}\text { Sibiu (Rumänien) } \\
\text { Museul Național Bruken- } \\
\text { thal }\end{array}$ & $\begin{array}{l}\text { 120x198 } \\
\text { Lwd. }\end{array}$ & Musées royaux, S. 61 \\
\hline 113 & $\begin{array}{l}\text { Earlom, Richard } \\
(1728-1822)\end{array}$ & $\begin{array}{l}\text { Augustus und } \\
\text { Kleopatra }\end{array}$ & 1784 & $\begin{array}{l}\text { London } \\
\text { British Museum }\end{array}$ & $63 \times 45,8$ & Walker / Higgs, S. 346 \\
\hline 114 & $\begin{array}{l}\text { Eeckhout, Gerbrandt } \\
\text { van den } \\
(1621-1674)\end{array}$ & $\begin{array}{l}\text { Sophonisbe } \\
\text { empfängt den } \\
\text { Giftbecher }\end{array}$ & 1664 & $\begin{array}{l}\text { Braunschweig } \\
\text { Herzog Anton Ulrich- } \\
\text { Museum }\end{array}$ & $\begin{array}{l}248 \times 197 \\
\text { Lwd. }\end{array}$ & Klessmann, S. 60, Abb.260 \\
\hline 115 & $\begin{array}{l}\text { Elliger d. Ä., Ottmar } \\
(1633-1679)\end{array}$ & Tod der Dido & - & - & - & $\begin{array}{l}\text { http://www.ac-nancy- } \\
\text { metz.fr/enseign/lettres/LanguesAnci } \\
\text { ennes/Textes/Virgile/Didon.htm } \\
\text { (zuletzt aufgerufen: } 20.01 .2007 \text { ) }\end{array}$ \\
\hline 116 & $\begin{array}{l}\text { Elliger d. J., Ottmar } \\
(1666-1735)\end{array}$ & Tod der Dido & - & $\begin{array}{l}\text { Augsburg } \\
\text { Städtische Kunstsamm- } \\
\text { lungen }\end{array}$ & $\begin{array}{l}59 \times 72 \\
\text { Lwd. }\end{array}$ & Mai 1987, Nr. 80 \\
\hline 117 & $\begin{array}{l}\text { Elliger d. J., Ottmar } \\
(1666-1735)\end{array}$ & $\begin{array}{l}\text { Dido auf dem } \\
\text { Scheiterhaufen }\end{array}$ & $\begin{array}{l}\text { nach } \\
1686\end{array}$ & $\begin{array}{l}\text { Braunschweig } \\
\text { Herzog Anton Ulrich- } \\
\text { Museum }\end{array}$ & $\begin{array}{l}163 \times 166 \\
\text { Lwd. }\end{array}$ & Jacoby / Michels, Kat.1038 \\
\hline
\end{tabular}




\section{Bildkatalog}

\begin{tabular}{|c|c|c|c|c|c|c|}
\hline 118 & $\begin{array}{l}\text { Elliger d. J., Ottmar } \\
(1666-1735)\end{array}$ & $\begin{array}{l}\text { Tod der Kleo- } \\
\text { patra }\end{array}$ & - & $\begin{array}{l}\text { Hamburg } \\
\text { Kunsthalle }\end{array}$ & $\begin{array}{l}55,4 \times 69 \\
\text { Lwd. }\end{array}$ & Hamburg Kunsthalle, Nr. 359 \\
\hline 119 & $\begin{array}{l}\text { Elliger d. J., Ottmar } \\
(1666-1735)\end{array}$ & $\begin{array}{l}\text { Tod der Sopho- } \\
\text { nisbe }\end{array}$ & - & $\begin{array}{l}\text { Hamburg } \\
\text { Kunsthalle }\end{array}$ & $\begin{array}{l}67,5 \times 52,7 \\
\text { Lwd. }\end{array}$ & Hamburg Kunsthalle, Nr. 684 \\
\hline 120 & $\begin{array}{l}\text { Elliger d. J., Ottmar } \\
(1666-1735)\end{array}$ & $\begin{array}{l}\text { Gastmahl der } \\
\text { Kleopatra }\end{array}$ & - & $\begin{array}{l}\text { Wien } \\
\text { Dorotheum } 2005\end{array}$ & $\begin{array}{l}55 \times 67 \\
\text { Lwd. }\end{array}$ & $\begin{array}{l}\text { http://www.dorotheum.internationala } \\
\text { uctio- } \\
\text { neers.com/catalogues/LotDetail.asp } \\
\text { ?lang=deu\&LotID=414\&AuclD=6694 } \\
\text { (zuletzt aufgerufen: } 08.01 .2007 \text { ) }\end{array}$ \\
\hline 121 & $\begin{array}{l}\text { Elliger d. J., Ottmar } \\
(1666-1735)\end{array}$ & Tod der Dido & - & $\begin{array}{l}\text { Moskau } \\
\text { Puschkin-Museum }\end{array}$ & - & $\begin{array}{l}\text { http://www.ac-nancy- } \\
\text { metz.fr/enseign/lettres/LanguesAnci } \\
\text { ennes/Textes/Virgile/Didon.htm } \\
\text { (zuletzt aufgerufen: } 20.01 .2007 \text { ) }\end{array}$ \\
\hline 122 & $\begin{array}{l}\text { Errard, Charles } \\
(1607-1689)\end{array}$ & Porzia & - & unbekannt & - & $\begin{array}{l}\text { http://www.latribunedelart.com/Etud } \\
\text { es_2005/Errard_Porcia_16.JPG } \\
\text { (zuletzt aufgerufen: 08.01.2007) }\end{array}$ \\
\hline 123 & $\begin{array}{l}\text { Esperlin, Joseph } \\
(1707-\text { nach 1770) }\end{array}$ & $\begin{array}{l}\text { Tod der Kleo- } \\
\text { patra }\end{array}$ & 1759 & $\begin{array}{l}\text { Biberach } \\
\text { Städtische Sammlungen }\end{array}$ & $\begin{array}{l}72 \times 135 \\
\text { Lwd. }\end{array}$ & Hoffmann 1975, S. 53 \\
\hline 124 & $\begin{array}{l}\text { Ferrari, Luca } \\
(1605-1654)\end{array}$ & Sophonisbe & um 1640 & $\begin{array}{l}\text { Moskau } \\
\text { Puschkin-Museum }\end{array}$ & $\begin{array}{l}126 \times 106 \\
\text { Lwd. }\end{array}$ & [nicht mehr im Netz] \\
\hline
\end{tabular}


Bildkatalog

\begin{tabular}{|c|c|c|c|c|c|c|}
\hline 125 & $\begin{array}{l}\text { Fetti, Domenico } \\
(1588 / 89-1623)\end{array}$ & $\begin{array}{l}\text { Selbstmord der } \\
\text { Kleopatra }\end{array}$ & vor 1614 & $\begin{array}{l}\text { Rom } \\
\text { Slg. Fabrizio Lemme }\end{array}$ & $\begin{array}{l}95,2 \times 69,8 \\
\text { Lwd. }\end{array}$ & Safarik 1996, Kat.13 \\
\hline 126 & Fiammengo, Giusto? & $\begin{array}{l}\text { Tod des Sokra- } \\
\text { tes }\end{array}$ & - & $\begin{array}{l}\text { Berlin } \\
\text { Staatliche Museen } \\
\text { (seit } 1945 \text { verschollen) }\end{array}$ & Lwd. & $\begin{array}{l}\text { Danesi Squarzina 2001, S. } \\
119\end{array}$ \\
\hline 127 & $\begin{array}{l}\text { Fidani, Orazio } \\
(1606-1656)\end{array}$ & Tod der Dido & 1640 & $\begin{array}{l}\text { Mailand } \\
\text { Privatsammlung }\end{array}$ & $\begin{array}{l}206 \times 294 \\
\text { Lwd. }\end{array}$ & Mahon 1991, S. 291 \\
\hline 128 & $\begin{array}{l}\text { Fontana, Lavinia } \\
(1552-1614)\end{array}$ & Kleopatra & um 1580 & $\begin{array}{l}\text { Rom } \\
\text { Galleria Spada }\end{array}$ & Lwd. & Vicini, S:49 \\
\hline 129 & $\begin{array}{l}\text { Forabosco, Girolamo } \\
(1605-1679)\end{array}$ & Sophonisbe & - & $\begin{array}{l}\text { Cesena } \\
\text { Museum }\end{array}$ & $\begin{array}{l}98 \times 111 \\
\text { Lwd. }\end{array}$ & $\begin{array}{l}\text { http://www.comune.cesena.fc.it/pina } \\
\text { coteca/imm/Artemisia_beve_P.jpg } \\
\text { (zuletzt aufgerufen: 08.01.2007) }\end{array}$ \\
\hline 130 & $\begin{array}{l}\text { Fragonard, Jean-Honoré } \\
(1732-1806)\end{array}$ & $\begin{array}{l}\text { Koresus opfert } \\
\text { sich für Kallir- } \\
\text { hoe }\end{array}$ & - & $\begin{array}{l}\text { Paris } \\
\text { Louvre }\end{array}$ & $\begin{array}{l}309 \times 400 \\
\text { Lwd. }\end{array}$ & Compin, Bd. 3, S. 257 \\
\hline 131 & $\begin{array}{l}\text { Franz Caucig } \\
(1755-1828)\end{array}$ & Porzia & 1794 & $\begin{array}{l}\text { Graz } \\
\text { Joanneum }\end{array}$ & $\begin{array}{l}113 \times 84 \\
\text { Lwd. }\end{array}$ & Hagen, S. 90 (Abb. S. 47) \\
\hline
\end{tabular}




\section{Bildkatalog}

\begin{tabular}{|c|c|c|c|c|c|c|}
\hline 132 & $\begin{array}{l}\text { Franz Caucig } \\
(1755-1828)\end{array}$ & $\begin{array}{l}\text { Porzia sich ver- } \\
\text { letzend }\end{array}$ & - & $\begin{array}{l}\text { Wien } \\
\text { Akademie der bildenden } \\
\text { Künste }\end{array}$ & $\begin{array}{l}58 \times 44 \\
\text { Bister, Feder, } \\
\text { Pinsel }\end{array}$ & Hagen, S. 50 \\
\hline 133 & $\begin{array}{l}\text { Französisch } \\
\text { 17.Jh. }\end{array}$ & Tod der Porzia & - & $\begin{array}{l}\text { Leipzig } \\
\text { Museum der bildenden } \\
\text { Künste }\end{array}$ & $\begin{array}{l}41,2 \times 31,3 \\
\text { Lwd. }\end{array}$ & Sander, S. 59, Nr. 357 \\
\hline 134 & $\begin{array}{l}\text { Füger, Friedrich Heinrich } \\
(1751-1818)\end{array}$ & $\begin{array}{l}\text { Tod des Ge- } \\
\text { rmanicus }\end{array}$ & 1795 & $\begin{array}{l}\text { Wien } \\
\text { Akademie der bildenden } \\
\text { Künste }\end{array}$ & $\begin{array}{l}155 \times 235,5 \\
\text { Lwd. }\end{array}$ & Trnek 1989, S. 82 \\
\hline 135 & $\begin{array}{l}\text { Füger, Friedrich Heinrich } \\
(1751-1818)\end{array}$ & Tod der Virginia & - & $\begin{array}{l}\text { Wien } \\
\text { Akademie der bildenden } \\
\text { Künste }\end{array}$ & $\begin{array}{l}89,5 \times 103 \\
\text { Lwd. }\end{array}$ & Trnek 1989, S. 83 \\
\hline 136 & Füger, Heinrich Friedrich & $\begin{array}{l}\text { Sterbender Ge- } \\
\text { rmanicus }\end{array}$ & 1789 & $\begin{array}{l}\text { Wien } \\
\text { Österreichische Galerie } \\
\text { im Belvedere }\end{array}$ & $\begin{array}{l}71,5 \times 110 \\
\text { Lwd. }\end{array}$ & Mai 1987, Nr. 81 \\
\hline 137 & $\begin{array}{l}\text { Fungai, Bernardino } \\
\text { (um } 1460-1516 \text { ) }\end{array}$ & Sophonisbe & - & $\begin{array}{l}\text { St. Petersburg } \\
\text { Eremitage }\end{array}$ & $\begin{array}{l}\text { Hochzeits- } \\
\text { truhe }\end{array}$ & $\begin{array}{l}\text { Schubring, Tafel CXV, Nr. } 485 \\
\text { und } 486\end{array}$ \\
\hline
\end{tabular}




\section{Bildkatalog}

\begin{tabular}{|c|c|c|c|c|c|c|}
\hline 138 & $\begin{array}{l}\text { Füßli, Heinrich } \\
(1741-1825)\end{array}$ & $\begin{array}{l}\text { Dido auf dem } \\
\text { Scheiterhaufen }\end{array}$ & 1781 & $\begin{array}{l}\text { New York } \\
\text { Slg. L. und C. Feigen }\end{array}$ & $\begin{array}{l}183 \times 243 \\
\text { Lwd. }\end{array}$ & $\begin{array}{l}\text { http://www.ac-nancy- } \\
\text { metz.fr/enseign/lettres/LanguesAnci } \\
\text { ennes/Textes/Virgile/Didon.htm } \\
\text { (zuletzt aufgerufen: } 20.01 .2007 \text { ) }\end{array}$ \\
\hline 139 & $\begin{array}{l}\text { Gamelin, Jacques } \\
(1738-1803)\end{array}$ & $\begin{array}{l}\text { Tod des Sokra- } \\
\text { tes }\end{array}$ & - & $\begin{array}{l}\text { Bordeaux } \\
\text { Musée des Beaux-Arts }\end{array}$ & - & $\begin{array}{l}\text { Oberreuter-Kronabel 1986, } \\
\text { Abb.13 }\end{array}$ \\
\hline 140 & $\begin{array}{l}\text { Gamelin, Jacques } \\
(1738-1803)\end{array}$ & $\begin{array}{l}\text { Tod des Sokra- } \\
\text { tes }\end{array}$ & - & $\begin{array}{l}\text { Carcassone } \\
\text { Musée }\end{array}$ & - & $\begin{array}{l}\text { Oberreuter-Kronabel 1986, } \\
\text { Abb.14 }\end{array}$ \\
\hline 141 & $\begin{array}{l}\text { Gandolfi, Gaetano } \\
(1734-1802)\end{array}$ & $\begin{array}{l}\text { Selbstmord der } \\
\text { Lukretia }\end{array}$ & 1790 & $\begin{array}{l}\text { Bologna } \\
\text { Privatsammlung }\end{array}$ & $\begin{array}{l}87 \times 73 \\
\text { Lwd. }\end{array}$ & $\begin{array}{l}\text { Ebert-Schifferer 1988, Kat. D } \\
19\end{array}$ \\
\hline 142 & $\begin{array}{l}\text { Gandolfi, Gaetano } \\
(1734-1802)\end{array}$ & $\begin{array}{l}\text { Tod des Sokra- } \\
\text { tes }\end{array}$ & 1782 & $\begin{array}{l}\text { Bologna } \\
\text { Slg. Trenta }\end{array}$ & - & Oberreuter-Kronabel 1986, 17 \\
\hline 143 & $\begin{array}{l}\text { Gentileschi, Artemisia } \\
(1593-1653)\end{array}$ & Lukretia & um 1623 & $\begin{array}{l}\text { Mailand } \\
\text { Slg. Gerolamo Etro }\end{array}$ & $\begin{array}{l}100 \times 77 \\
\text { Lwd. }\end{array}$ & Christiansen / Mann, S. 363 \\
\hline 144 & $\begin{array}{l}\text { Gentileschi, Artemisia } \\
(1593-1653)\end{array}$ & Kleopatra & $\begin{array}{l}1610- \\
1612\end{array}$ & $\begin{array}{l}\text { Mailand } \\
\text { Slg. Amedeo Morandotti }\end{array}$ & $\begin{array}{l}118 \times 181 \\
\text { Lwd. }\end{array}$ & Christiansen / Mann, S. 99 \\
\hline 145 & $\begin{array}{l}\text { Gentileschi, Artemisia } \\
(1593-1653)\end{array}$ & Lukretia & - & $\begin{array}{l}\text { Potsdam } \\
\text { Neues Palais }\end{array}$ & - & Christiansen / Mann, S. 258 \\
\hline
\end{tabular}




\section{Bildkatalog}

\begin{tabular}{|c|c|c|c|c|c|c|}
\hline 146 & $\begin{array}{l}\text { Gentileschi, Artemisia } \\
(1593-1653)\end{array}$ & $\begin{array}{l}\text { David und Bath- } \\
\text { seba }\end{array}$ & - & $\begin{array}{l}\text { Potsdam } \\
\text { Neues Palais }\end{array}$ & - & Christiansen / Mann, S. 258 \\
\hline 147 & $\begin{array}{l}\text { Gentileschi, Artemisia } \\
(1593-1653)\end{array}$ & Kleopatra & 1633 & $\begin{array}{l}\text { Rom } \\
\text { Privatsammlung }\end{array}$ & $\begin{array}{l}117 \times 175,5 \\
\text { Lwd. }\end{array}$ & Christiansen / Mann, S. 403 \\
\hline 148 & $\begin{array}{l}\text { Gentileschi, Artemisia } \\
(1593-1653) \text { oder } \\
\text { Stanzione, Massimo } \\
(1590-1656)\end{array}$ & Lukretia & $1642-43$ & $\begin{array}{l}\text { Neapel } \\
\text { Museo di Capodimonte }\end{array}$ & Lwd. & Garrard, Farbabb. 22 \\
\hline 149 & $\begin{array}{l}\text { Gentileschi, Artemisia } \\
(1593-1653)\end{array}$ & Kleopatra & - & $\begin{array}{l}\text { Ferrara, } \\
\text { Fondazione Cavallini } \\
\text { Sgarbi }\end{array}$ & $\begin{array}{l}97 \times 71,5 \\
\text { Lwd. }\end{array}$ & $\begin{array}{l}\text { Spezzaferro / Calzavara, S. } \\
217\end{array}$ \\
\hline 150 & $\begin{array}{l}\text { Giampetrino, Giovanni } \\
\text { Pietro Rizzoli } \\
\text { (um 1485-1553) }\end{array}$ & $\begin{array}{l}\text { Selbstmord der } \\
\text { Kleopatra }\end{array}$ & - & $\begin{array}{l}\text { Paris } \\
\text { Louvre }\end{array}$ & $\begin{array}{l}73 \times 57 \\
\text { Holz }\end{array}$ & Compin, Bd. 2, S. 179 \\
\hline $150 a$ & $\begin{array}{l}\text { Giampetrino, Giovanni } \\
\text { Pietro Rizzoli } \\
\text { (um 1485-1553) }\end{array}$ & Dido & um 1520 & $\begin{array}{l}\text { Mailand / Isola Bella } \\
\text { Slg. Borromeo }\end{array}$ & $94,5 \times 71$ & Natale / Di Lorenzo, S. 170f \\
\hline
\end{tabular}




\section{Bildkatalog}

\begin{tabular}{|c|c|c|c|c|c|c|}
\hline $150 b$ & $\begin{array}{l}\text { Giampetrino, Giovanni } \\
\text { Pietro Rizzoli } \\
\text { (um 1485-1553) }\end{array}$ & Sophonisbe & $\begin{array}{l}\text { um } \\
1521 / 22\end{array}$ & $\begin{array}{l}\text { Mailand / Isola Bella } \\
\text { Slg. Borromeo }\end{array}$ & $94,5 \times 71$ & $\begin{array}{l}\text { Natale / Di Lorenzo, S. 170- } \\
179\end{array}$ \\
\hline $150 c$ & $\begin{array}{l}\text { Giampetrino, Giovanni } \\
\text { Pietro Rizzoli } \\
\text { (um 1485-1553) }\end{array}$ & Lukretia & 1525 & $\begin{array}{l}\text { Madison (Wisconsin) } \\
\text { Slg. Kress } \\
\text { Chazen Museum of Art }\end{array}$ & $95,9 \times 72,4$ & Natale / Di Lorenzo, S. 174 \\
\hline $150 d$ & $\begin{array}{l}\text { Giampetrino, Giovanni } \\
\text { Pietro Rizzoli } \\
\text { (um 1485-1553) }\end{array}$ & Kleopatra & 1525 & $\begin{array}{l}\text { Lewisburg (Pennsylvania) } \\
\text { Slg. Kress } \\
\text { Bucknell University }\end{array}$ & $94,3 \times 70,1$ & Natale / Di Lorenzo, S. 175 \\
\hline 151 & $\begin{array}{l}\text { Giolfino, Niccolò } \\
(1476-1555)\end{array}$ & Lukretia & um 1430 & $\begin{array}{l}\text { Berlin } \\
\text { Bode-Museum }\end{array}$ & $0,98 \times 0,77$ & Schubring, Tafel CLII, Nr. 695 \\
\hline 152 & $\begin{array}{l}\text { Giordano, Luca } \\
(1634-1705)\end{array}$ & $\begin{array}{l}\text { Selbstmord des } \\
\text { Cato }\end{array}$ & $1650-55$ & $\begin{array}{l}\text { Le Havre } \\
\text { Musée des Beaux-Arts }\end{array}$ & $\begin{array}{l}127 \times 100 \\
\text { Lwd. }\end{array}$ & Viatte, S. 188, Nr. 55 \\
\hline 153 & $\begin{array}{l}\text { Giordano, Luca } \\
(1634-1705)\end{array}$ & Tod des Seneca & - & $\begin{array}{l}\text { Ponce } \\
\text { Museo dell'Arte }\end{array}$ & - & $\begin{array}{l}\text { Oberreuter-Kronabel 1986, } \\
\text { Abb. } 54\end{array}$ \\
\hline 154 & $\begin{array}{l}\text { Giordano, Luca } \\
(1634-1705)\end{array}$ & Tod des Seneca & - & $\begin{array}{l}\text { Paris } \\
\text { Louvre }\end{array}$ & $\begin{array}{l}155 \times 188 \\
\text { Lwd. }\end{array}$ & Compin, Bd. 2, S. 180 \\
\hline
\end{tabular}


Bildkatalog

\begin{tabular}{|c|c|c|c|c|c|c|}
\hline 155 & $\begin{array}{l}\text { Giordano, Luca } \\
(1634-1705)\end{array}$ & $\begin{array}{l}\text { Selbstmord der } \\
\text { Porzia }\end{array}$ & um 1660 & $\begin{array}{l}\text { London } \\
\text { Trafalgar Galleries }\end{array}$ & $\begin{array}{l}122 \times 96,5 \\
\text { Lwd. }\end{array}$ & $\begin{array}{l}\text { Cassani / Sapio, Nr.51 } \\
\text { (S. 182/183) }\end{array}$ \\
\hline 156 & $\begin{array}{l}\text { Giordano, Luca } \\
(1634-1705)\end{array}$ & $\begin{array}{l}\text { Schwur des } \\
\text { Brutus }\end{array}$ & um 1685 & $\begin{array}{l}\text { Florenz } \\
\text { Casa Martelli }\end{array}$ & $\begin{array}{l}190 \times 187 \\
\text { Lwd. }\end{array}$ & $\begin{array}{l}\text { Cassani / Sapio, S. 288f., } \\
\text { Nr.90 }\end{array}$ \\
\hline 157 & $\begin{array}{l}\text { Giordano, Luca } \\
(1634-1705)\end{array}$ & $\begin{array}{l}\text { Tod der Kleopa- } \\
\text { tra }\end{array}$ & um 1700 & $\begin{array}{l}\text { Neapel } \\
\text { Privatsammlung }\end{array}$ & $\begin{array}{l}127 \times 100 \\
\text { Lwd. }\end{array}$ & $\begin{array}{l}\text { Cassani / Sapio, S. 352f., } \\
\text { Nr.125 }\end{array}$ \\
\hline 158 & $\begin{array}{l}\text { Giordano, Luca } \\
(1634-1705)\end{array}$ & $\begin{array}{l}\text { Lukretia und } \\
\text { Tarquinius }\end{array}$ & 1663 & $\begin{array}{l}\text { Neapel } \\
\text { Museo di Capodimonte }\end{array}$ & $\begin{array}{l}138 \times 187 \\
\text { Lwd. }\end{array}$ & Cassani / Sapio, S. 140 \\
\hline 159 & $\begin{array}{l}\text { Giordano, Luca } \\
(1634-1705)\end{array}$ & Tod Kleopatras & - & $\begin{array}{l}\text { Cosenza } \\
\text { Galleria Nazionale }\end{array}$ & $\begin{array}{l}162 \times 215 \\
\text { Lwd. }\end{array}$ & $\begin{array}{l}\text { http://www.sapere.it/tca/minisite/arte } \\
\text { /nonsolomostre/2003gall_cosenza/i } \\
\text { mages/gall_cosenza11.jpg } \\
\text { (zuletzt aufgerufen: 09.01.2007) }\end{array}$ \\
\hline 160 & [entfällt] & - & - & - & - & - \\
\hline 161 & $\begin{array}{l}\text { Girodet-Trioson, Anne- } \\
\text { Louis } \\
(1767-1824)\end{array}$ & $\begin{array}{l}\text { Horatius tötet } \\
\text { seine Schwester } \\
\text { Camilla }\end{array}$ & 1785 & $\begin{array}{l}\text { Montargis } \\
\text { Musée Girodet }\end{array}$ & $\begin{array}{l}111 \times 148 \\
\text { Lwd. }\end{array}$ & Mai 1987, Nr. 31 \\
\hline $161 a$ & $\begin{array}{l}\text { Gramatica, Antiveduto } \\
(1569-1626)\end{array}$ & Kleopatra & - & $\begin{array}{l}\text { Mailand } \\
\text { Slg. Koelliker }\end{array}$ & $\begin{array}{l}88 \times 70 \\
\text { Lwd. }\end{array}$ & Papi, S. 135 \\
\hline
\end{tabular}


Bildkatalog

\begin{tabular}{|c|c|c|c|c|c|c|}
\hline 162 & $\begin{array}{l}\text { Guarino, Francesco } \\
(1611-1654)\end{array}$ & Kleopatra & $\begin{array}{l}\text { nach } \\
1640\end{array}$ & $\begin{array}{l}\text { Genua } \\
\text { Palazzo Durazzo Palavic- } \\
\text { cini }\end{array}$ & $\begin{array}{l}122 \times 100 \\
\text { Lwd. }\end{array}$ & Cattaneo Adorno, S. 197 \\
\hline 163 & $\begin{array}{l}\text { Guercino, } \\
\text { Barbieri, Giovanni Fran- } \\
\text { cesco, gen. } \\
(1591-1666)\end{array}$ & $\begin{array}{l}\text { Tod der Kleo- } \\
\text { patra }\end{array}$ & $\begin{array}{l}\text { um } 1648 \\
\text { erworben }\end{array}$ & $\begin{array}{l}\text { Genua } \\
\text { Civica Galleria di Palazzo } \\
\text { Rosso }\end{array}$ & $\begin{array}{l}173 \times 238 \\
\text { Lwd. }\end{array}$ & Baumgärtel 1995, Kat.136 \\
\hline 164 & $\begin{array}{l}\text { Guercino, } \\
\text { Barbieri, Giovanni Fran- } \\
\text { cesco, gen. } \\
(1591-1666)\end{array}$ & Kleopatra & - & $\begin{array}{l}\text { Ferrara } \\
\text { Museo Civico }\end{array}$ & - & $\begin{array}{l}\text { Ebert-Schifferer 1988, S. } 499 \text {, } \\
\text { Abb. } 92\end{array}$ \\
\hline 165 & $\begin{array}{l}\text { Guercino, } \\
\text { Barbieri, Giovanni Fran- } \\
\text { cesco, gen. } \\
(1591-1666)\end{array}$ & Kleopatra & - & $\begin{array}{l}\text { Pasadena (California) } \\
\text { Norton Simon Foundation }\end{array}$ & - & $\begin{array}{l}\text { Ebert-Schifferer 1988. S. 505, } \\
\text { Abb. } 94\end{array}$ \\
\hline 166 & $\begin{array}{l}\text { Guercino, } \\
\text { Barbieri, Giovanni Fran- } \\
\text { cesco, gen. } \\
(1591-1666)\end{array}$ & Kleopatra & $1637-39$ & $\begin{array}{l}\text { Ferrara } \\
\text { Privatsammlung }\end{array}$ & $\begin{array}{l}116,5 \times 94,5 \\
\text { Lwd. }\end{array}$ & Mahon 1991, Kat. 83 \\
\hline
\end{tabular}




\section{Bildkatalog}

\begin{tabular}{|c|c|c|c|c|c|c|}
\hline 167 & $\begin{array}{l}\text { Guercino, } \\
\text { Barbieri, Giovanni Fran- } \\
\text { cesco, gen. } \\
(1591-1666)\end{array}$ & $\begin{array}{l}\text { Selbstmord des } \\
\text { Cato }\end{array}$ & 1641 & $\begin{array}{l}\text { Genua } \\
\text { Gallerie d'Arte del Com- } \\
\text { mune }\end{array}$ & $\begin{array}{l}96 \times 71 \\
\text { Lwd. }\end{array}$ & Mahon 1991, Kat. 87 \\
\hline 168 & $\begin{array}{l}\text { Guercino, } \\
\text { Barbieri, Giovanni Fran- } \\
\text { cesco, gen. } \\
(1591-1666)\end{array}$ & Lukretia & um 1644 & $\begin{array}{l}\text { Bologna } \\
\text { Credito Romagnolo }\end{array}$ & $\begin{array}{l}56 \times 51 \\
\text { Lwd. }\end{array}$ & Mahon 1991, Kat. 93 \\
\hline 169 & $\begin{array}{l}\text { Guercino, } \\
\text { Barbieri, Giovanni Fran- } \\
\text { cesco, gen. } \\
(1591-1666)\end{array}$ & Kleopatra & 1621 & $\begin{array}{l}\text { London } \\
\text { Thomas Agnew and Sons }\end{array}$ & $\begin{array}{l}116 \times 92,5 \\
\text { Lwd. }\end{array}$ & Mahon 1991, Kat.48 \\
\hline 170 & $\begin{array}{l}\text { Guercino, } \\
\text { Barbieri, Giovanni Fran- } \\
\text { cesco, gen. } \\
(1591-1666)\end{array}$ & Tod der Dido & 1631 & $\begin{array}{l}\text { Rom } \\
\text { Galleria Spada }\end{array}$ & Lwd. & Mahon 1991, S. 74 \\
\hline
\end{tabular}




\section{Bildkatalog}

\begin{tabular}{|c|c|c|c|c|c|c|}
\hline 171 & $\begin{array}{l}\text { Guercino, } \\
\text { Barbieri, Giovanni Fran- } \\
\text { cesco, gen. } \\
(1591-1666)\end{array}$ & Kleopatra & $\begin{array}{l}\text { späte } \\
\text { 1630er } \\
\text { Jahre }\end{array}$ & $\begin{array}{l}\text { London } \\
\text { British Museum }\end{array}$ & $\begin{array}{l}29,2 \times 21,5 \\
\text { Rötel }\end{array}$ & Walker / Higgs, S. 347 \\
\hline $171 a$ & $\begin{array}{l}\text { Guercino, } \\
\text { Barbieri, Giovanni Fran- } \\
\text { cesco, gen. } \\
(1591-1666)\end{array}$ & $\begin{array}{l}\text { Abschied des } \\
\text { Cato von Utica } \\
\text { von seinen } \\
\text { Söhnen }\end{array}$ & 1637 & $\begin{array}{l}\text { Marseille } \\
\text { Musée des Beaux-Arts }\end{array}$ & $\begin{array}{l}263 \times 267 \\
\text { Lwd. }\end{array}$ & Goldfarb, S. 333f. \\
\hline 172 & $\begin{array}{l}\text { Guérin, Pierre Narcisse } \\
(1774-1833)\end{array}$ & Tod des Cato & 1797 & $\begin{array}{l}\text { Paris } \\
\text { École des Beaux-Arts }\end{array}$ & - & $\begin{array}{l}\text { Oberreuter-Kronabel 1986, } \\
\text { Abb.60 }\end{array}$ \\
\hline 173 & $\begin{array}{l}\text { Günther, Matthias } \\
(1705-1788)\end{array}$ & Dido & 1756 & $\begin{array}{l}\text { Augsburg } \\
\text { Städtische Kunstsamm- } \\
\text { lungen }\end{array}$ & - & $\begin{array}{l}\text { http://www.ac-nancy- } \\
\text { metz.fr/enseign/lettres/LanguesAnci } \\
\text { ennes/Textes/Virgile/Didon.htm } \\
\text { (zuletzt aufgerufen: 20.01.2007) }\end{array}$ \\
\hline 174 & $\begin{array}{l}\text { Hackert, Jacob Philipp } \\
(1737-1807)\end{array}$ & $\begin{array}{l}\text { Aeneas und } \\
\text { Dido in der } \\
\text { Grotte }\end{array}$ & 1804 & $\begin{array}{l}\text { Hannover } \\
\text { Nieders. Landesmuseum }\end{array}$ & $\begin{array}{l}65 \times 88,5 \\
\text { Lwd. }\end{array}$ & Schreiner, S. 178 \\
\hline 175 & $\begin{array}{l}\text { Hallé, Noel } \\
(1711-1781)\end{array}$ & Tod des Seneca & 1750 & $\begin{array}{l}\text { Boston } \\
\text { Museum of Fine Arts }\end{array}$ & $\begin{array}{l}154 \times 122 \\
\text { Lwd. }\end{array}$ & Mai 1987, Nr. 36 \\
\hline
\end{tabular}




\section{Bildkatalog}

\begin{tabular}{|c|c|c|c|c|c|c|}
\hline 176 & $\begin{array}{l}\text { Hamilton, Gavin } \\
(1723-1797)\end{array}$ & Kleopatra & $\begin{array}{l}1767- \\
1769\end{array}$ & $\begin{array}{l}\text { Detroit } \\
\text { Detroit Institute of Arts }\end{array}$ & $\begin{array}{l}134 \times 98,1 \\
\text { Lwd. }\end{array}$ & Ritschard, S. 207 \\
\hline 177 & $\begin{array}{l}\text { Heiss, Johann } \\
(1640-1704)\end{array}$ & Tod der Dido & $1702 ?$ & $\begin{array}{l}\text { Braunschweig } \\
\text { Herzog Anton Ulrich- } \\
\text { Museum }\end{array}$ & $\begin{array}{l}116 \times 120 \\
\text { Lwd. }\end{array}$ & Jacoby, Kat. 1140 \\
\hline 178 & $\begin{array}{l}\text { Heyden, Jan van der } \\
(1637-1712)\end{array}$ & $\begin{array}{l}\text { Zimmerecke mit } \\
\text { Raritäten }\end{array}$ & 1712 & $\begin{array}{l}\text { Budapest } \\
\text { Szépmüvészeti Múzeum }\end{array}$ & $\begin{array}{l}75 \times 63,5 \\
\text { Lwd. }\end{array}$ & $\begin{array}{l}\text { Mai / Paarlberg / Weber, S. } \\
145\end{array}$ \\
\hline 179 & $\begin{array}{l}\text { Hirschvogel, Augustin } \\
(1503-1553)\end{array}$ & $\begin{array}{l}\text { Tod der Kleo- } \\
\text { patra }\end{array}$ & - & - & $\begin{array}{l}106 \times 150 \\
\text { Radierung }\end{array}$ & Bartsch 18,5 \\
\hline 180 & $\begin{array}{l}\text { Hoecke, Jan van den } \\
(1611-1651)\end{array}$ & $\begin{array}{l}\text { Hero beweint } \\
\text { den toten Lean- } \\
\text { der }\end{array}$ & $1635 / 37$ & $\begin{array}{l}\text { Wien } \\
\text { KHM }\end{array}$ & $\begin{array}{l}155 \times 215 \\
\text { Lwd. }\end{array}$ & Balis, S. 244 \\
\hline 181 & $\begin{array}{l}\text { Hoet, Gerard } \\
(1648-1733)\end{array}$ & $\begin{array}{l}\text { Tod der Kleo- } \\
\text { patra }\end{array}$ & - & $\begin{array}{l}\text { London } \\
\text { (im Handel: Christie's) }\end{array}$ & $\begin{array}{l}162 \times 215 \\
\text { Lwd. }\end{array}$ & [nicht mehr im Netz] \\
\hline 182 & $\begin{array}{l}\text { Hollanda, Francisco de } \\
\text { (um 1518-1584) }\end{array}$ & $\begin{array}{l}\text { Kleopatra / } \\
\text { Ariadne }\end{array}$ & $1538 / 39$ & $\begin{array}{l}\text { Madrid } \\
\text { Escorial }\end{array}$ & $\begin{array}{l}\text { Feder, } \\
\text { schwarze } \\
\text { Tinte }\end{array}$ & Brummer, S. 157, Abb. 136 \\
\hline
\end{tabular}




\section{Bildkatalog}

\begin{tabular}{|c|c|c|c|c|c|c|}
\hline 183 & $\begin{array}{l}\text { Italienische Schule } \\
\text { 17. Jahrhundert }\end{array}$ & $\begin{array}{l}\text { Tod der Kleo- } \\
\text { patra }\end{array}$ & - & $\begin{array}{l}\text { Tours } \\
\text { Musée des Beaux-Arts }\end{array}$ & $\begin{array}{l}119 \times 145 \\
\text { Lwd. }\end{array}$ & Fohr / Gilet, S. 243 \\
\hline 184 & $\begin{array}{l}\text { Jordaens, Jacob } \\
(1593-1678)\end{array}$ & $\begin{array}{l}\text { Tod der Kleo- } \\
\text { patra }\end{array}$ & 1653 & $\begin{array}{l}\text { Kassel } \\
\text { Staatliche Museen }\end{array}$ & $\begin{array}{l}171 \times 172 \\
\text { Lwd. }\end{array}$ & $\begin{array}{l}\text { Schnackenburg 1985, Tafel } \\
28 ; \text { Schnackenburg 1996, S. } \\
162\end{array}$ \\
\hline 185 & $\begin{array}{l}\text { Jordaens, Jacob } \\
(1593-1678)\end{array}$ & $\begin{array}{l}\text { Bankett der } \\
\text { Kleopatra }\end{array}$ & 1653 & $\begin{array}{l}\text { St. Petersburg } \\
\text { Eremitage }\end{array}$ & $\begin{array}{l}156,4 \times 149,3 \\
\text { Lwd. }\end{array}$ & $\begin{array}{l}\text { http://www.stylusart.com/noticias/fla } \\
\text { mencaerm/obra3.htm } \\
\text { (zuletzt aufgerufen: } 20.01 .2007 \text { ) }\end{array}$ \\
\hline 186 & [entfällt] & - & - & - & - & - \\
\hline 187 & $\begin{array}{l}\text { Kauffmann, Angelika } \\
(1741-1807)\end{array}$ & Tod der Alkeste & 1790 & $\begin{array}{l}\text { Bregenz } \\
\text { Vorarlberger Landesmu- } \\
\text { seum }\end{array}$ & $\begin{array}{l}114 \times 154 \\
\text { Lwd. }\end{array}$ & Baumgärtel 1998, S. 398 \\
\hline 188 & $\begin{array}{l}\text { Kauffmann, Angelika } \\
(1741-1807)\end{array}$ & $\begin{array}{l}\text { Maria Santacro- } \\
\text { ce als Lukretia }\end{array}$ & 1791 & $\begin{array}{l}\text { Warschau } \\
\text { Muzeum Narodowe w } \\
\text { Warzawie }\end{array}$ & Lwd. & Baumgärtel 1992, S. 39 \\
\hline 189 & $\begin{array}{l}\text { Kauffmann, Angelika } \\
(1741-1807)\end{array}$ & $\begin{array}{l}\text { Kleopatra } \\
\text { schmückt das } \\
\text { Grab des Mar- } \\
\text { cus Antonius }\end{array}$ & $1769 / 70$ & $\begin{array}{l}\text { Burghley } \\
\text { The Burghley House Col- } \\
\text { lection }\end{array}$ & $\begin{array}{l}125,5 \times 105 \\
\text { Lwd. }\end{array}$ & Walker / Higgs, S. 342 \\
\hline
\end{tabular}




\section{Bildkatalog}

\begin{tabular}{|c|c|c|c|c|c|c|}
\hline 190 & $\begin{array}{l}\text { Kauffmann, Angelika } \\
(1741-1807)\end{array}$ & $\begin{array}{l}\text { Augustus und } \\
\text { Kleopatra }\end{array}$ & 1883 & $\begin{array}{l}\text { Lawrence } \\
\text { University of Kansas, } \\
\text { Spencer Museum of Art }\end{array}$ & $\begin{array}{l}334 \mathrm{~mm} \\
\text { Tondo } \\
\text { Kupfer }\end{array}$ & Baumgärtel 1998, S. 351 \\
\hline 191 & $\begin{array}{l}\text { Kauffmann, Angelika } \\
(1741-1807)\end{array}$ & Dido & - & - & Lwd. & $\begin{array}{l}\text { http://www.ac-nancy- } \\
\text { metz.fr/enseign/lettres/LanguesAnci } \\
\text { ennes/Textes/Virgile/Didon.htm } \\
\text { (zuletzt aufgerufen: } 20.01 .2007 \text { ) }\end{array}$ \\
\hline 192 & $\begin{array}{l}\text { Knüpfer, Nikolaus } \\
(1603-1655)\end{array}$ & Tod der Lukretia & - & $\begin{array}{l}\text { Leipzig } \\
\text { Museum der bildenden } \\
\text { Künste }\end{array}$ & $\begin{array}{l}27,7 \times 21,5 \\
\text { Holz }\end{array}$ & Sander, 956 (S. 101) \\
\hline 193 & $\begin{array}{l}\text { Knüpfer, Nikolaus } \\
(1603-1655)\end{array}$ & Sophonisbe & - & $\begin{array}{l}\text { Leipzig } \\
\text { Museum der bildenden } \\
\text { Künste }\end{array}$ & $\begin{array}{l}53 \times 81,5 \\
\text { Holz }\end{array}$ & Sander, 1202 (S. 101) \\
\hline 194 & $\begin{array}{l}\text { Koninck, Salomon de } \\
(1609-1656)\end{array}$ & Sophonisbe & - & - & Lwd. & Forma et subtilitas, Abb. 100 \\
\hline 195 & $\begin{array}{l}\text { Lagrenée, Louis-Jean } \\
\text { Francois } \\
(1724-1805)\end{array}$ & $\begin{array}{l}\text { Tod der Kleo- } \\
\text { patra }\end{array}$ & $\begin{array}{l}\text { nach } \\
1774\end{array}$ & $\begin{array}{l}\text { Pau } \\
\text { Musée des Beaux-Arts }\end{array}$ & $\begin{array}{l}106 \times 139 \\
\text { Lwd. }\end{array}$ & Mai 1987, Nr. 40 \\
\hline
\end{tabular}




\section{Bildkatalog}

\begin{tabular}{|c|c|c|c|c|c|c|}
\hline 196 & $\begin{array}{l}\text { Lairesse, de Gérard ? } \\
(1641-1711)\end{array}$ & Tod des Pyrrhus & - & $\begin{array}{l}\text { Brüssel } \\
\text { Musées Royaux des } \\
\text { Beaux-Arts }\end{array}$ & $\begin{array}{l}138 \times 152 \\
\text { Lwd. }\end{array}$ & $\begin{array}{l}\text { Belgien, Musées, S. } 170 \\
\text { (und Roy: Lairesse, S. 495) }\end{array}$ \\
\hline 197 & $\begin{array}{l}\text { Lairesse, de Gérard } \\
(1641-1711)\end{array}$ & $\begin{array}{l}\text { Horatius Cocles } \\
\text { verteidigt den } \\
\text { Pons Sublicius }^{10}\end{array}$ & 1688 & $\begin{array}{l}\text { Den Haag } \\
\text { Binnenhof }\end{array}$ & & Lairesse, S. 349 \\
\hline 198 & $\begin{array}{l}\text { Lairesse, Gérard de } \\
(1640-1711)\end{array}$ & $\begin{array}{l}\text { Tod des Ge- } \\
\text { rmanicus }\end{array}$ & $\begin{array}{l}\text { um } \\
1675 / 80\end{array}$ & $\begin{array}{l}\text { Kassel } \\
\text { Staatliche Museen }\end{array}$ & $\begin{array}{l}74 \times 88,5 \\
\text { Lwd. }\end{array}$ & $\begin{array}{l}\text { Roy, P 95, Schnackenburg } \\
\text { 1996, S. } 166\end{array}$ \\
\hline 199 & $\begin{array}{l}\text { Lairesse, Gérard de } \\
(1640-1711)(?)\end{array}$ & Tod der Dido & - & $\begin{array}{l}\text { Lübeck } \\
\text { Museum für Kunst- und } \\
\text { Kulturgeschichte }\end{array}$ & $\begin{array}{l}88 \times 112 \\
\text { Lwd. }\end{array}$ & $\begin{array}{l}\text { Roy, P.R. } 28 \text { (Zuschreibung } \\
\text { abgelehnt) }\end{array}$ \\
\hline 200 & $\begin{array}{l}\text { Lairesse, Gérard de } \\
(1640-1711)\end{array}$ & Tod des Cato & - & $\begin{array}{l}\text { München } \\
\text { Bayerische Staatsgemäl- } \\
\text { desammlungen }\end{array}$ & $\begin{array}{l}216 \times 158 \\
\text { Lwd. }\end{array}$ & $\begin{array}{l}\text { Roy, P.R. } 33 \text { (Zuschreibung } \\
\text { abgelehnt) }\end{array}$ \\
\hline 201 & $\begin{array}{l}\text { Lairesse, Gérard de } \\
(1640-1711)\end{array}$ & $\begin{array}{l}\text { Bankett der } \\
\text { Kleopatra }\end{array}$ & $1675 / 80$ & $\begin{array}{l}\text { Amsterdam } \\
\text { Rijksmuseum }\end{array}$ & $\begin{array}{l}74 \times 95,5 \\
\text { Lwd. }\end{array}$ & Roy, S. 270 \\
\hline
\end{tabular}

\footnotetext{
${ }^{10}$ Stich nach Gemälde im »Lairessezaal« des Binnenhofs
} 


\section{Bildkatalog}

\begin{tabular}{|c|c|c|c|c|c|c|}
\hline 202 & $\begin{array}{l}\text { Lairesse, Gérard de } \\
(1640-1711)\end{array}$ & $\begin{array}{l}\text { Tod der Kleo- } \\
\text { patra }\end{array}$ & $\begin{array}{l}\text { um } \\
1675 / 80\end{array}$ & $\begin{array}{l}\text { Toronto } \\
\text { Art Gallery of Ontario }\end{array}$ & $\begin{array}{l}74,9 \times 95,6 \\
\text { Lwd. }\end{array}$ & Roy, S. 272 \\
\hline 203 & $\begin{array}{l}\text { Langetti, Giovanni Bat- } \\
\text { tista (nach) } \\
(1625-1676)\end{array}$ & Tod des Cato & - & $\begin{array}{l}\text { Paris } \\
\text { Louvre }\end{array}$ & $\begin{array}{l}\text { 96x80 } \\
\text { Lwd. }\end{array}$ & Compin, Bd. 2, S. 190 \\
\hline 204 & $\begin{array}{l}\text { Lastman, Pieter } \\
(1583-1633)\end{array}$ & Sophonisbe ${ }^{11}$ & - & $\begin{array}{l}\text { Bremen } \\
\text { Kunsthalle }\end{array}$ & & Tümpel 1986, Abb.99 \\
\hline 205 & $\begin{array}{l}\text { Laudin, Jacques II (zu- } \\
\text { geschrieben) } \\
\text { (um 1663-1729) }\end{array}$ & Porzia & 17. Jh. & $\begin{array}{l}\text { Dijon } \\
\text { Musée des Beaux-Arts }\end{array}$ & Emaille & $\begin{array}{l}\text { http://www.culture.gouv.fr/public/mist } \\
\text { ral_joconde_fr } \\
\text { (zuletzt aufgerufen: } 11.01 .2007 \text { ) }\end{array}$ \\
\hline 206 & $\begin{array}{l}\text { Lazzarini, Gregorio } \\
(1655-1730)\end{array}$ & Dido & - & $\begin{array}{l}\text { Macerata } \\
\text { Palazzo Buonaccorsi }\end{array}$ & - & $\begin{array}{l}\text { http://www.ac-nancy- } \\
\text { metz.fr/enseign/lettres/LanguesAnci } \\
\text { ennes/Textes/Virgile/Didon.htm } \\
\text { (zuletzt aufgerufen: 20.01.2007) }\end{array}$ \\
\hline 207 & $\begin{array}{l}\text { Le Brun, Charles } \\
(1619-1690)\end{array}$ & Tod des Cato & 1646 & $\begin{array}{l}\text { Arras } \\
\text { Musée d'Arras }\end{array}$ & $\begin{array}{l}99 \times 132 \\
\text { Lwd. }\end{array}$ & Mai 1987, Nr. 7 \\
\hline 208 & $\begin{array}{l}\text { Le Clerc } \\
\text { (Wirkerfamilie Brüssel) }\end{array}$ & $\begin{array}{l}\text { Kleopatra und } \\
\text { Antonius }\end{array}$ & - & - & Teppich & Walker / Higgs, S. 292 \\
\hline
\end{tabular}

\footnotetext{
${ }^{11}$ Zeichnung nach verlorenem Gemälde von François Venant
} 


\section{Bildkatalog}

\begin{tabular}{|c|c|c|c|c|c|c|}
\hline 209 & $\begin{array}{l}\text { Le Sueur, Eustache } \\
(1616-1655)\end{array}$ & $\begin{array}{l}\text { Camma und } \\
\text { Synorix im Dia- } \\
\text { na-Tempel }\end{array}$ & - & $\begin{array}{l}\text { Boston } \\
\text { Museum of Fine Arts }\end{array}$ & $\begin{array}{l}170 \times 125 \\
\text { Lwd. }\end{array}$ & Mérot 1987, Abb. PI. VI. \\
\hline 210 & $\begin{array}{l}\text { Le Sueur, Eustache } \\
(1616-1655)\end{array}$ & $\begin{array}{l}\text { Marcus Curtius } \\
\text { stürzt sich in die } \\
\text { Felsspalte }\end{array}$ & 1636 & $\begin{array}{l}\text { England } \\
\text { Slg. John Harris }\end{array}$ & $\begin{array}{l}110 \times 89 \\
\text { Lwd. }\end{array}$ & Mérot 1987, Abb.1 \\
\hline 211 & $\begin{array}{l}\text { Lethière, Guillaume Guil- } \\
\text { Ion } \\
(1760-1832)\end{array}$ & Tod des Cato & 1795 & $\begin{array}{l}\text { St. Petersburg } \\
\text { Eremitage }\end{array}$ & - & $\begin{array}{l}\text { Oberreuter-Kronabel 1986, } \\
\text { Abb.59 }\end{array}$ \\
\hline 212 & $\begin{array}{l}\text { Lippi, Filippino } \\
\text { (um 1457-1504) }\end{array}$ & Lucrezia & um 1482 & $\begin{array}{l}\text { Florenz } \\
\text { Palazzo Pitti }\end{array}$ & $\begin{array}{l}42 \times 126 \\
\text { Holz }\end{array}$ & Chiarini, S. 53 \\
\hline 213 & Liss, Johann & $\begin{array}{l}\text { Tod der Kleo- } \\
\text { patra }\end{array}$ & - & $\begin{array}{l}\text { München } \\
\text { Bayerische Staatsgemäl- } \\
\text { desammlungen }\end{array}$ & $\begin{array}{l}97,5 \times 85,5 \\
\text { Lwd. }\end{array}$ & $\begin{array}{l}\text { Augsburg / Cleveland, A 18, } \\
\text { Abb.18 }\end{array}$ \\
\hline 214 & $\begin{array}{l}\text { Lorrain, Claude } \\
\text { (um 1600-1682) }\end{array}$ & $\begin{array}{l}\text { Aeneas und } \\
\text { Dido in Kartha- } \\
\text { go }\end{array}$ & $1675 / 76$ & $\begin{array}{l}\text { Hamburg } \\
\text { Kunsthalle }\end{array}$ & $\begin{array}{l}120 \times 149,2 \\
\text { Lwd. }\end{array}$ & $\begin{array}{l}\text { Hamburg Kunsthalle 1966, S. } \\
94\end{array}$ \\
\hline 215 & $\begin{array}{l}\text { Loth, Johann Carl } \\
(1632-1698)\end{array}$ & Lukretia & - & $\begin{array}{l}\text { Karlsruhe } \\
\text { Kunsthalle }\end{array}$ & $\begin{array}{l}136,5 \times 116,5 \\
\text { Lwd. }\end{array}$ & $\begin{array}{l}\text { Staatliche Kunsthalle Karlsru- } \\
\text { he } 2005 \text {, Lg. } 666\end{array}$ \\
\hline
\end{tabular}




\section{Bildkatalog}

\begin{tabular}{|c|c|c|c|c|c|c|}
\hline 216 & $\begin{array}{l}\text { Loth, Johann Carl } \\
(1632-1698)\end{array}$ & Kleopatra & - & $\begin{array}{l}\text { Karlsruhe } \\
\text { Kunsthalle }\end{array}$ & $\begin{array}{l}135 \times 111,5 \\
\text { Lwd. }\end{array}$ & $\begin{array}{l}\text { Staatliche Kunsthalle Karlsru- } \\
\text { he 2005, Lg. } 667\end{array}$ \\
\hline 217 & $\begin{array}{l}\text { Lotto, Lorenzo } \\
(1480-\text { nach 1556) }\end{array}$ & $\begin{array}{l}\text { Damenporträt } \\
\text { mit Zeichnung } \\
\text { der Lukretia }\end{array}$ & $\begin{array}{l}1530- \\
1533\end{array}$ & $\begin{array}{l}\text { London } \\
\text { National Gallery }\end{array}$ & $\begin{array}{l}95,9 \times 110,5 \\
\text { Lwd. }\end{array}$ & Baker / Henry, S. 395 \\
\hline 218 & $\begin{array}{l}\text { Maître de Lecceto } \\
\text { (Anf. und Mitte 15. Jh.) }\end{array}$ & $\begin{array}{l}\text { Lukretia und } \\
\text { Collatinus }\end{array}$ & - & $\begin{array}{l}\text { Avignon } \\
\text { Petit Palais }\end{array}$ & $\begin{array}{l}31 \times 44 \\
\text { Holz }\end{array}$ & Laclotte / Mognetti, $137^{\text {bis }}$ \\
\hline 219 & $\begin{array}{l}\text { Maître de Lecceto } \\
\text { (Anf. und Mitte 15. Jh.) }\end{array}$ & Tod der Dido & - & $\begin{array}{l}\text { Avignon } \\
\text { Petit Palais }\end{array}$ & $\begin{array}{l}21 \times 20 \\
\text { Holz }\end{array}$ & Laclotte / Mognetti, $137^{\text {ter }}$ \\
\hline 220 & $\begin{array}{l}\text { Maître des héroines de } \\
\text { Chigi-Saracini }\end{array}$ & Kleopatra & um 1500 & $\begin{array}{l}\text { Siena } \\
\text { Slg. Chigi-Saraceni }\end{array}$ & $\begin{array}{l}77 \times 44 \\
\text { Holz }\end{array}$ & Ritschard, S. 38 \\
\hline 221 & $\begin{array}{l}\text { Maître des héroines de } \\
\text { Chigi-Saracini }\end{array}$ & Sophonisbe & um 1500 & $\begin{array}{l}\text { Siena } \\
\text { Slg. Chigi-Saraceni }\end{array}$ & $\begin{array}{l}77,1 \times 43,5 \\
\text { Holz }\end{array}$ & Ritschard, S. 38 \\
\hline 222 & $\begin{array}{l}\text { Maître des héroines de } \\
\text { Chigi-Saracini }\end{array}$ & $\begin{array}{l}\text { Sophonisbe } \\
\text { (Artemisia?) }\end{array}$ & um 1500 & Privatsammlung & - & Richard-Jamet 2003, S. 538 \\
\hline 223 & $\begin{array}{l}\text { Makart, Hans } \\
(1840-1884)\end{array}$ & $\begin{array}{l}\text { Tod der Kleo- } \\
\text { patra }\end{array}$ & 1875 & $\begin{array}{l}\text { Kassel } \\
\text { Staatliche Museen }\end{array}$ & $\begin{array}{l}191 \times 255 \\
\text { Lwd. }\end{array}$ & Frodl,S. 350, Nr. 253 \\
\hline
\end{tabular}




\section{Bildkatalog}

\begin{tabular}{|c|c|c|c|c|c|c|}
\hline 224 & $\begin{array}{l}\text { Makart, Hans } \\
(1840-1884)\end{array}$ & $\begin{array}{l}\text { Tod der Kleo- } \\
\text { patra }\end{array}$ & 1875 & $\begin{array}{l}\text { München-Gräfeling } \\
\text { Slg. Rauscher }\end{array}$ & $\begin{array}{l}\text { 122,x83 } \\
\text { Holz }\end{array}$ & Frodl, S. 350, Nr. 252 \\
\hline 225 & $\begin{array}{l}\text { Makart, Hans } \\
(1840-1884)\end{array}$ & $\begin{array}{l}\text { Nilfahrt der } \\
\text { Kleopatra }\end{array}$ & $1874 / 75$ & $\begin{array}{l}\text { Stuttgart } \\
\text { Staatsgalerie }\end{array}$ & $\begin{array}{l}189,5 \times 506 \\
\text { Lwd. }\end{array}$ & Frodl, S. 349, Nr. 251 \\
\hline 226 & $\begin{array}{l}\text { Manetti, Rutilio } \\
\text { (1571-1639) }\end{array}$ & $\begin{array}{l}\text { Massinissa und } \\
\text { Sophonisbe }\end{array}$ & $\begin{array}{l}\text { um 1623- } \\
1625\end{array}$ & $\begin{array}{l}\text { Florenz } \\
\text { Uffizien }\end{array}$ & $\begin{array}{l}168 \times 265 \\
\text { Lwd. }\end{array}$ & Gregori, Nr. 519 \\
\hline 227 & $\begin{array}{l}\text { Mantegna, Andrea } \\
\text { (um 1430-1506) }\end{array}$ & Sophonisbe & $\begin{array}{l}\text { um 1495- } \\
1506\end{array}$ & $\begin{array}{l}\text { London } \\
\text { National Gallery }\end{array}$ & $\begin{array}{l}71,2 \times 19,8 \\
\text { Tempera auf } \\
\text { Pappelholz }\end{array}$ & Baker, S. 407 \\
\hline 228 & $\begin{array}{l}\text { Mantegna, Andrea } \\
\text { (um 1430-1506) }\end{array}$ & Tuccia & $\begin{array}{l}\text { um 1495- } \\
1506\end{array}$ & $\begin{array}{l}\text { London } \\
\text { National Gallery }\end{array}$ & $\begin{array}{l}72,5 \times 23 \\
\text { Tempera auf } \\
\text { Pappelholz }\end{array}$ & Baker, S. 407 \\
\hline 229 & $\begin{array}{l}\text { Mantegna, Andrea } \\
\text { (um 1430-1506) }\end{array}$ & Dido & - & - & - & $\begin{array}{l}\text { http://www.ac-nancy- } \\
\text { metz.fr/enseign/lettres/LanguesAnc } \\
\text { ennes/Textes/Virgile/Didon.htm } \\
\text { (zuletzt aufgerufen: 20.01.2007) }\end{array}$ \\
\hline 230 & $\begin{array}{l}\text { Maratta, Carlo } \\
(1625-1713)\end{array}$ & Kleopatra & 1694 & $\begin{array}{l}\text { Rom } \\
\text { (ursprünglich für Frances- } \\
\text { co Montioni) }\end{array}$ & - & Richard-Jamet 2003, S. 538 \\
\hline
\end{tabular}




\section{Bildkatalog}

\begin{tabular}{|c|c|c|c|c|c|c|}
\hline 231 & $\begin{array}{l}\text { Maratta, Carlo } \\
(1625-1713)\end{array}$ & Lukretia & 1694 & $\begin{array}{l}\text { Rom } \\
\text { (ursprünglich für Frances- } \\
\text { co Montioni) }\end{array}$ & - & Richard-Jamet 2003, S. 538 \\
\hline $231 a$ & $\begin{array}{l}\text { Maron, Anton von } \\
(1733-1797)\end{array}$ & Tod der Dido & 1783 & $\begin{array}{l}\text { Rom } \\
\text { Villa Borghese }\end{array}$ & - & - \\
\hline 232 & $\begin{array}{l}\text { Martini, Biagio } \\
(1761-1840)\end{array}$ & $\begin{array}{l}\text { Tod des Sokra- } \\
\text { tes }\end{array}$ & 1791 & $\begin{array}{l}\text { Parma } \\
\text { Galleria Nazionale }\end{array}$ & - & $\begin{array}{l}\text { Oberreuter-Kronabel 1986, } \\
\text { Abb.15 }\end{array}$ \\
\hline 233 & $\begin{array}{l}\text { Matteis, Paolo de } \\
(1662-1728)\end{array}$ & Tod des Cato & - & $\begin{array}{l}\text { München } \\
\text { Bayerische Staatsgemäl- } \\
\text { desammlungen }\end{array}$ & $\begin{array}{l}260 \times 130,5 \\
\text { Lwd. }\end{array}$ & $\begin{array}{l}\text { Spinosa 1986, Nr. 138, Abb. } \\
155\end{array}$ \\
\hline 234 & $\begin{array}{l}\text { Maulbertsch, Franz An- } \\
\text { ton } \\
(1724-1796)\end{array}$ & Tod der Dido & - & $\begin{array}{l}\text { Wien } \\
\text { Österreichische Galerie } \\
\text { Barockmuseum }\end{array}$ & $\begin{array}{l}70,5 \times 54 \\
\text { Holz }\end{array}$ & $\begin{array}{l}\text { Kunstverein Wien 1974, Kat. } \\
100\end{array}$ \\
\hline 235 & $\begin{array}{l}\text { Mazzanti, Ludovico } \\
(1686-1775)\end{array}$ & Tod der Lukretia & $\begin{array}{l}\text { Ende der } \\
\text { 30er Jah- } \\
\text { re }\end{array}$ & $\begin{array}{l}\text { New York } \\
\text { (im Handel) }\end{array}$ & Lwd. & Spinosa 1987, Abb. 321 \\
\hline 236 & $\begin{array}{l}\text { Mazzoni, Sebastiano } \\
(1611-1678)\end{array}$ & Kleopatra & - & $\begin{array}{l}\text { Rovigo, } \\
\text { Accademia dei Concordi }\end{array}$ & - & Ottaviani Botteri, S. 132 \\
\hline
\end{tabular}




\section{Bildkatalog}

\begin{tabular}{|c|c|c|c|c|c|c|}
\hline 237 & $\begin{array}{l}\text { Meister der Halbfiguren } \\
\text { (Anf. 16. Jahrhundert) }\end{array}$ & Lukretia & $\begin{array}{l}\text { 1. H. } 16 . \\
\text { Jh. }\end{array}$ & $\begin{array}{l}\text { Rom } \\
\text { Galleria Colonna }\end{array}$ & $\begin{array}{l}43,9 \times 28,8 \\
\text { Holz }\end{array}$ & Safarik 1981, Nr.108 \\
\hline 238 & $\begin{array}{l}\text { Meister des Heiligen } \\
\text { Blutes }\end{array}$ & Lukretia & $\begin{array}{l}1520- \\
1525\end{array}$ & $\begin{array}{l}\text { Prag } \\
\text { Národní Galerie v Praze }\end{array}$ & $\begin{array}{l}56,5 \times 42,5 \\
\text { Eichenholz }\end{array}$ & Kotalivik, S. 111 \\
\hline 239 & Meister HTA & Kleopatra & $\begin{array}{l}\text { 2. H. } \\
\text { 16.Jh. }\end{array}$ & - & $\begin{array}{l}111 \times 167 \\
\text { Kupferstich }\end{array}$ & $\begin{array}{l}\text { Bartsch 14,199D, } \\
\text { Ritschard, S. } 83\end{array}$ \\
\hline 240 & Meister von 1515 & Kleopatra & - & - & $\begin{array}{l}101 \times 148 \\
\text { Kupferstich }\end{array}$ & Bartsch 25,2522(012) \\
\hline 241 & Meister von 1515 & Kleopatra & - & - & Kupferstich & Bartsch 25,2522 (013) \\
\hline 242 & $\begin{array}{l}\text { Mengs, Anton Raphael } \\
(1728-1779)\end{array}$ & $\begin{array}{l}\text { Augustus und } \\
\text { Kleopatra }\end{array}$ & um 1759 & $\begin{array}{l}\text { Augsburg } \\
\text { Städtische Kunstsamm- } \\
\text { lungen }\end{array}$ & $\begin{array}{l}59,5 \times 45 \\
\text { Lwd. }\end{array}$ & Baumgärtel 1998, S. 347 \\
\hline 243 & $\begin{array}{l}\text { Micheli, Andrea, gen. } \\
\text { Vicentino } \\
\text { (um 1542-1617) }\end{array}$ & Lukretia & $\begin{array}{l}1611- \\
1613\end{array}$ & $\begin{array}{l}\text { München } \\
\text { Residenz }\end{array}$ & - & Richard-Jamet 2003, S. 524 \\
\hline 244 & $\begin{array}{l}\text { Mignard, Pierre } \\
(1612-1695)\end{array}$ & Porzia & - & $\begin{array}{l}\text { Rennes } \\
\text { Musée des Beaux-Arts }\end{array}$ & $\begin{array}{l}101 \times 80 \\
\text { Lwd. }\end{array}$ & Baumgärtel 1995, Kat.165 \\
\hline
\end{tabular}




\section{Bildkatalog}

\begin{tabular}{|c|c|c|c|c|c|c|}
\hline 245 & $\begin{array}{l}\text { Mignard, Pierre } \\
(1612-1695) \\
\text { (zugeschrieben) }\end{array}$ & $\begin{array}{l}\text { Tod der Kleo- } \\
\text { patra }\end{array}$ & - & $\begin{array}{l}\text { England } \\
\text { Privatsammlung }\end{array}$ & $\begin{array}{l}99 \times 133 \\
\text { Lwd. }\end{array}$ & Mérot 1994, S. 120 \\
\hline 246 & $\begin{array}{l}\text { Mirys, Silvestre David } \\
(1742-1810)\end{array}$ & Lukretia & um 1810 & $\begin{array}{l}\text { München } \\
\text { Residenz (Inv.-Nr. 14d) }\end{array}$ & $\begin{array}{l}\text { Porzellan- } \\
\text { Teller }\end{array}$ & $\begin{array}{l}\text { http://www1.ku- } \\
\text { eich- } \\
\text { staett.de/SLF/Klassphil/grau/eichst.h } \\
\text { tm } \\
\text { (zuletzt aufgerufen:10.01.2007) }\end{array}$ \\
\hline 247 & $\begin{array}{l}\text { Mola, Pier Francesco } \\
(1612-1666)\end{array}$ & $\begin{array}{l}\text { Tod des Archi- } \\
\text { medes }\end{array}$ & $1655 ?$ & $\begin{array}{l}\text { Rom } \\
\text { Slg. Manca di Villahermo- } \\
\text { sa Busiri Vici }\end{array}$ & $\begin{array}{l}128 \times 97 \\
\text { Lwd. }\end{array}$ & Kahn-Rossi, Kat. I.34 \\
\hline 248 & Monogrammist I. F. & Kleopatra & - & - & $\begin{array}{l}283 \times 177 \\
\text { Kupferstich }\end{array}$ & Bartsch 1,5 \\
\hline 249 & $\begin{array}{l}\text { Moreau, Gustave } \\
(1826-1898)\end{array}$ & Kleopatra & 1887 & $\begin{array}{l}\text { Paris } \\
\text { Louvre }\end{array}$ & $\begin{array}{l}40 \times 25 \\
\text { Aquarell, Tin- } \\
\text { te, Gouache }\end{array}$ & Ritschard, S. 257 \\
\hline 250 & $\begin{array}{l}\text { Muller, Jan } \\
(1571-1628)\end{array}$ & Kleopatra & - & - & $\begin{array}{l}166 \times 225 \\
\text { Kupferstich }\end{array}$ & Bartsch 4,9 \\
\hline
\end{tabular}




\section{Bildkatalog}

\begin{tabular}{|c|c|c|c|c|c|c|}
\hline 251 & $\begin{array}{l}\text { Muller, Jan } \\
(1571-1628)\end{array}$ & Kleopatra & - & - & $\begin{array}{l}367 \times 250 \\
\text { Kupferstich }\end{array}$ & Bartsch 4,80 \\
\hline 252 & $\begin{array}{l}\text { Muratori, Domenico Ma- } \\
\text { ria } \\
\text { (um } 1661-1744 \text { ) }\end{array}$ & $\begin{array}{l}\text { Tod der Kleo- } \\
\text { patra }\end{array}$ & - & $\begin{array}{l}\text { Rom } \\
\text { Galleria Spada }\end{array}$ & Lwd. & $\begin{array}{l}\text { http://fototeca.iccd.beniculturali.it/O } \\
\text { GGFO- } \\
\text { TOINT/SDW?W\%3DMTRLEG\%3D1 } \\
7499 \\
\text { (zuletzt aufgerufen:10.01.2007) }\end{array}$ \\
\hline 253 & $\begin{array}{l}\text { Muratori, Domenico Ma- } \\
\text { ria } \\
\text { (um 1661-1744) }\end{array}$ & $\begin{array}{l}\text { Tod des Marc } \\
\text { Anton }\end{array}$ & - & $\begin{array}{l}\text { Rom } \\
\text { Galleria Spada }\end{array}$ & Lwd. & $\begin{array}{l}\text { http://fototeca.iccd.beniculturali.it/O } \\
\text { GGFO- } \\
\text { TOINT/SDW?W\%3DMTRLEG\%3D1 } \\
7499 \\
\text { (zuletzt aufgerufen:10.01.2007) }\end{array}$ \\
\hline 254 & $\begin{array}{l}\text { Natoire, Charles-Joseph } \\
(1700-1777)\end{array}$ & $\begin{array}{l}\text { Kleopatra und } \\
\text { Antonius }\end{array}$ & 1754 & $\begin{array}{l}\text { Nîmes } \\
\text { Musée des Beaux-Arts }\end{array}$ & $\begin{array}{l}335 \times 480 \\
\text { Lwd. }\end{array}$ & Ritschard, S. 211 \\
\hline 255 & $\begin{array}{l}\text { Natoire, Charles-Joseph } \\
(1700-1777)\end{array}$ & $\begin{array}{l}\text { Ankunft Kleopa- } \\
\text { tras in Tarsos }\end{array}$ & 1756 & $\begin{array}{l}\text { Nîmes } \\
\text { Musée des Beaux-Arts }\end{array}$ & $\begin{array}{l}335 \times 480 \\
\text { Lwd. }\end{array}$ & Ritschard, S. 211 \\
\hline 256 & $\begin{array}{l}\text { Nattier, Jean-Baptiste } \\
(1678-1726)\end{array}$ & Lukretia & 1712 & - & - & Richard-Jamet 2003, S. 535 \\
\hline 257 & $\begin{array}{l}\text { Nattier, Jean-Baptiste } \\
(1678-1726)\end{array}$ & Porzia & 1712 & - & - & Richard-Jamet 2003, S. 535 \\
\hline
\end{tabular}




\section{Bildkatalog}

\begin{tabular}{|c|c|c|c|c|c|c|}
\hline 258 & $\begin{array}{l}\text { Nattier, Jean-Baptiste } \\
(1678-1726)\end{array}$ & Kleopatra & 1712 & - & - & Richard-Jamet 2003, S. 535 \\
\hline 259 & $\begin{array}{l}\text { Neapolitanischer Meister } \\
\text { des 17.Jh. }\end{array}$ & $\begin{array}{l}\text { Selbstmord des } \\
\text { Cato }\end{array}$ & - & $\begin{array}{l}\text { Wien } \\
\text { Akademie der bildenden } \\
\text { Künste }\end{array}$ & $\begin{array}{l}134 \times 176 \\
\text { Lwd. }\end{array}$ & Trnek 1989, S. 166 \\
\hline 260 & $\begin{array}{l}\text { Neapolitanischer Meister } \\
\text { des 17.Jh. }\end{array}$ & Lukretia & - & $\begin{array}{l}\text { Wien } \\
\text { Akademie der bildenden } \\
\text { Künste }\end{array}$ & $\begin{array}{l}72 \times 912 \\
\text { Lwd. }\end{array}$ & Trnek 1989, S. 166 \\
\hline 261 & $\begin{array}{l}\text { Neroni, Bartolomeo } \\
\text { (um 1500-1571) }\end{array}$ & $\begin{array}{l}\text { Tod der Kleo- } \\
\text { patra }\end{array}$ & - & $\begin{array}{l}\text { London } \\
\text { British Museum }\end{array}$ & $40,5 \times 26,9^{12}$ & Walker / Higgs, S. 348 \\
\hline 262 & $\begin{array}{l}\text { Orley, Barend van } \\
\text { (um 1488-1541) }\end{array}$ & Porzia & $\begin{array}{l}\text { Anf. } 16 . \\
\text { Jh. }\end{array}$ & $\begin{array}{l}\text { Paris } \\
\text { Louvre }\end{array}$ & $\begin{array}{l}0,3 \times 0,428 \\
\text { Feder, Pinsel }\end{array}$ & $\begin{array}{l}\text { http://www.culture.gouv.fr/public/mist } \\
\text { ral_joconde_fr } \\
\text { (zuletzt aufgerufen: } 10.01 .2007 \text { ) }\end{array}$ \\
\hline 263 & $\begin{array}{l}\text { Palma il Giovane } \\
(1548-1628)\end{array}$ & $\begin{array}{l}\text { Tarquinius und } \\
\text { Lukretia }\end{array}$ & $\begin{array}{l}\text { Ende } 16 . \\
\text { Jh. }\end{array}$ & $\begin{array}{l}\text { Kassel } \\
\text { Staatliche Museen }\end{array}$ & $\begin{array}{l}119,5 \times 183,5 \\
\text { Lwd. }\end{array}$ & $\begin{array}{l}\text { Schnackenburg 1996, Tafel } \\
305\end{array}$ \\
\hline
\end{tabular}

\footnotetext{
${ }^{12}$ Feder, braune Tinte, Blaustift, schwarze Kreide.
} 


\section{Bildkatalog}

\begin{tabular}{|c|c|c|c|c|c|c|}
\hline 264 & $\begin{array}{l}\text { Palma il Vecchio, Jaco- } \\
\text { bo } \\
(1480-1528)\end{array}$ & Lukretia & - & $\begin{array}{l}\text { Rom } \\
\text { Villa Borghese }\end{array}$ & $\begin{array}{l}71 \times 59 \\
\text { Lwd. }\end{array}$ & - \\
\hline 265 & $\begin{array}{l}\text { Parker, John } \\
\text { (tätig um 1762) }\end{array}$ & $\begin{array}{l}\text { Tod der Kleo- } \\
\text { patra }\end{array}$ & $1748 / 49$ & $\begin{array}{l}\text { London } \\
\text { British Museum }\end{array}$ & $\begin{array}{l}21,6 \times 28,3 \\
\text { Öl auf Papier }\end{array}$ & Walker / Higgs, S. 364 \\
\hline 266 & $\begin{array}{l}\text { Pellegrini, Giannantonio } \\
(1675-1741)\end{array}$ & Sophonisbe & $\begin{array}{l}\text { nach } \\
1731(?)\end{array}$ & $\begin{array}{l}\text { Genua } \\
\text { Palazzo Durazzo Palavic- } \\
\text { cini }\end{array}$ & $\begin{array}{l}154 \times 149 \\
\text { Lwd. }\end{array}$ & Cattaneo Adorno, S. 159 \\
\hline 267 & $\begin{array}{l}\text { Pencz, Georg } \\
\text { (um 1500-1550) }\end{array}$ & Sophonisbe & um 1535 & - & $\begin{array}{l}189 \times 124 \\
\text { Kupferstich }\end{array}$ & Schlink / Sperlich, Tafel XLII \\
\hline 268 & $\begin{array}{l}\text { Pencz, Georg } \\
\text { (um 1500-1550) }\end{array}$ & Dido & - & - & $\begin{array}{l}94 \times 65 \\
\text { Kupferstich }\end{array}$ & Bartsch $16,85(344)$ \\
\hline 269 & $\begin{array}{l}\text { Perrin, Jean Charles } \\
\text { Nicaise } \\
(1754-1831)\end{array}$ & Tod des Seneca & 1789 & $\begin{array}{l}\text { Dijon } \\
\text { Musée des Beaux-Arts }\end{array}$ & - & $\begin{array}{l}\text { Oberreuter-Kronabel 1986, } \\
\text { Abb.50 }\end{array}$ \\
\hline 270 & $\begin{array}{l}\text { Peters, Johann Anton de } \\
(1725-1795)\end{array}$ & Tod des Seneca & - & $\begin{array}{l}\text { Köln } \\
\text { Wallraf-Richartz-Museum }\end{array}$ & $\begin{array}{l}97,5 \times 86,5 \\
\text { Lwd. }\end{array}$ & Heße, S. 252 \\
\hline
\end{tabular}




\section{Bildkatalog}

\begin{tabular}{|c|c|c|c|c|c|c|}
\hline 271 & $\begin{array}{l}\text { Peyron, Jean François } \\
\text { Pierre (1744-1814) }\end{array}$ & $\begin{array}{l}\text { Tod des Sokra- } \\
\text { tes }\end{array}$ & 1787 & $\begin{array}{l}\text { Kopenhagen } \\
\text { Statens Museum for } \\
\text { Kunst }\end{array}$ & - & $\begin{array}{l}\text { Oberreuter-Kronabel 1986, } \\
\text { Abb.26 }\end{array}$ \\
\hline 272 & $\begin{array}{l}\text { Pittoni, Giambattista } \\
(1687-1767)\end{array}$ & $\begin{array}{l}\text { Opferung der } \\
\text { Polyxena }\end{array}$ & $\begin{array}{l}\text { 40er Jah- } \\
\text { re des } \\
\text { 18.Jh. }\end{array}$ & $\begin{array}{l}\text { Stuttgart } \\
\text { Staatsgalerie }\end{array}$ & $\begin{array}{l}71,2 \times 49,9 \\
\text { Lwd. }\end{array}$ & Petermann, S. 299 \\
\hline 273 & $\begin{array}{l}\text { Pittoni, Giovanni Battista } \\
(1687-1767)\end{array}$ & $\begin{array}{l}\text { Opferung der } \\
\text { Polyxena }\end{array}$ & $\begin{array}{l}\text { frühe } \\
\text { 1730er } \\
\text { Jahre }\end{array}$ & $\begin{array}{l}\text { Malibu } \\
\text { J.Paul Getty Museum }\end{array}$ & $\begin{array}{l}128,3 \times 95,3 \\
\text { Lwd. }\end{array}$ & Martineau / Robinson, Abb.57 \\
\hline 274 & $\begin{array}{l}\text { Pittoni, Giovanni Battista } \\
(1687-1767)\end{array}$ & $\begin{array}{l}\text { Opferung der } \\
\text { Polyxena }\end{array}$ & $1735-37$ & $\begin{array}{l}\text { München } \\
\text { Alte Pinakothek }\end{array}$ & $\begin{array}{l}134 \times 160 \\
\text { Lwd. }\end{array}$ & Steingräber 1987, Kat.14 \\
\hline 275 & $\begin{array}{l}\text { Pittoni, Giovanni Battista } \\
(1687-1767)\end{array}$ & $\begin{array}{l}\text { Opferung der } \\
\text { Polyxena }\end{array}$ & $1730-40$ & $\begin{array}{l}\text { Madrid } \\
\text { Museo Thyssen Borne- } \\
\text { misza }\end{array}$ & $\begin{array}{l}72 \times 58 \\
\text { Lwd. }\end{array}$ & $\begin{array}{l}\text { Pita Andrade / del Mar Boro- } \\
\text { bia Guerrero, S. } 373\end{array}$ \\
\hline 276 & $\begin{array}{l}\text { Pittoni, Giovanni Battista } \\
(1687-1767)\end{array}$ & $\begin{array}{l}\text { Tod der Sopho- } \\
\text { nisbe }\end{array}$ & - & $\begin{array}{l}\text { Moskau } \\
\text { Puschkin-Museum }\end{array}$ & Lwd. & $\begin{array}{l}\text { http://upload.wikimedia.org./wikipedi } \\
\text { a/en/5/53/Deathofsofonisba.JPG } \\
\text { (zuletzt aufgerufen:10.01.2007) }\end{array}$ \\
\hline
\end{tabular}




\section{Bildkatalog}

\begin{tabular}{|c|c|c|c|c|c|c|}
\hline 277 & $\begin{array}{l}\text { Pittoni, Giovanni Battista } \\
(1687-1767)\end{array}$ & $\begin{array}{l}\text { Todestrunk der } \\
\text { Sophonisbe }\end{array}$ & - & $\begin{array}{l}\text { Im Handel } \\
\text { (Chateau La Borzeux } \\
\text { Stavelot September } \\
\text { 2004) }\end{array}$ & $\begin{array}{l}\text { 92x82 } \\
\text { Lwd. }\end{array}$ & Digitales Foto der Galerie \\
\hline 278 & $\begin{array}{l}\text { Poerson, Charles } \\
(1609-1667)\end{array}$ & $\begin{array}{l}\text { Camma und } \\
\text { Synorix trinken } \\
\text { den Giftbecher } \\
\text { im Diana- Tem- } \\
\text { pel }\end{array}$ & 1645 & $\begin{array}{l}\text { Metz } \\
\text { La Cour d'Or } \\
\text { Musées de Metz }\end{array}$ & $\begin{array}{l}128 \times 121 \\
\text { Lwd. }\end{array}$ & Baumgärtel 1995, Kat.88 \\
\hline 279 & $\begin{array}{l}\text { Poerson, Charles } \\
(1609-1667)\end{array}$ & Paulina & 1647 & $\begin{array}{l}\text { Paris } \\
\text { Hôtel de l'Arsenal }\end{array}$ & - & Richard-Jamet 2003, S. 534 \\
\hline 280 & $\begin{array}{l}\text { Poerson, Charles } \\
(1609-1667)\end{array}$ & Porzia & 1647 & $\begin{array}{l}\text { Paris } \\
\text { Hôtel de l'Arsenal }\end{array}$ & - & Richard-Jamet 2003, S. 534 \\
\hline 281 & $\begin{array}{l}\text { Poerson, Charles } \\
(1609-1667)\end{array}$ & Lukretia & 1647 & $\begin{array}{l}\text { Paris } \\
\text { Hôtel de l'Arsenal }\end{array}$ & - & Richard-Jamet 2003, S. 534 \\
\hline 282 & $\begin{array}{l}\text { Poussin, Nicolas } \\
(1594-1665)\end{array}$ & $\begin{array}{l}\text { Tod des Ge- } \\
\text { rmanicus }\end{array}$ & 1627 & $\begin{array}{l}\text { Minneapolis } \\
\text { The Minneapolis Institute } \\
\text { of Art }\end{array}$ & $\begin{array}{l}148 \times 198 \\
\text { Lwd. }\end{array}$ & Mai 1987, Nr. 8 \\
\hline
\end{tabular}




\section{Bildkatalog}

\begin{tabular}{|c|c|c|c|c|c|c|}
\hline 283 & $\begin{array}{l}\text { Preti, Mattia } \\
(1613-1699)\end{array}$ & $\begin{array}{l}\text { Sophonisbe mit } \\
\text { dem Giftbecher }\end{array}$ & $\begin{array}{l}\text { um 1660- } \\
1670\end{array}$ & $\begin{array}{l}\text { Lyon } \\
\text { Musée des Beaux-Arts }\end{array}$ & $\begin{array}{l}198 \times 174 \\
\text { Lwd. }\end{array}$ & Mai 1987, Nr. 73 \\
\hline 284 & $\begin{array}{l}\text { Preti, Mattia } \\
(1613-1699)\end{array}$ & Tod der Dido & $\begin{array}{l}\text { um 1660- } \\
1661\end{array}$ & $\begin{array}{l}\text { Chambery } \\
\text { Musée des Beaux-Arts }\end{array}$ & $\begin{array}{l}247 \times 209 \\
\text { Lwd. }\end{array}$ & Corace, Abb.42 (S. 97) \\
\hline 285 & $\begin{array}{l}\text { Preti, Mattia } \\
(1613-1699)\end{array}$ & Tod der Dido & $1656-60$ & $\begin{array}{l}\text { Braunschweig } \\
\text { Herzog-Anton-Ulrich- } \\
\text { Museum }\end{array}$ & $\begin{array}{l}204 \times 176,5 \\
\text { Lwd. }\end{array}$ & $\begin{array}{l}\text { Herzog Anton Ulrich-Museum, } \\
\text { Erwerbungen, Kat.13 }\end{array}$ \\
\hline 286 & $\begin{array}{l}\text { Preti, Mattia } \\
(1613-1699)\end{array}$ & Sophonisbe & - & $\begin{array}{l}\text { Melbourne } \\
\text { National Gallery of Victo- } \\
\text { ria }\end{array}$ & $\begin{array}{l}81,5 \times 110 \\
\text { Lwd. }\end{array}$ & Corace, Abb.83 (S. 119) \\
\hline 287 & $\begin{array}{l}\text { Preti, Mattia } \\
(1613-1699)\end{array}$ & Sophonisbe & - & $\begin{array}{l}\text { Lyon } \\
\text { Musée des Beaux-Arts }\end{array}$ & Lwd. & Spinosa 1984, Abb. 558147 \\
\hline 288 & $\begin{array}{l}\text { Prévost, Nicolas } \\
(1604-1670)\end{array}$ & Porzia & $1633-36$ & $\begin{array}{l}\text { Orléans } \\
\text { Musée des Beaux-Arts }\end{array}$ & $\begin{array}{l}218 \times 174 \\
\text { Lwd. }\end{array}$ & Goldfarb, S. 314f. \\
\hline 289 & $\begin{array}{l}\text { Prévost, Nicolas } \\
(1604-1670)\end{array}$ & Kleopatra & 1642 & $\begin{array}{l}\text { Montreuil-Belley } \\
\text { Privatsammlung }\end{array}$ & Lwd. & Ritschard, S. 42 \\
\hline 290 & $\begin{array}{l}\text { Prévost, Nicolas } \\
(1604-1670)\end{array}$ & Dido & 1642 & $\begin{array}{l}\text { Montreuil-Belley } \\
\text { Privatsammlung }\end{array}$ & Lwd. & Ritschard, S. 42 \\
\hline
\end{tabular}




\section{Bildkatalog}

\begin{tabular}{|c|c|c|c|c|c|c|}
\hline 291 & $\begin{array}{l}\text { Prévost, Nicolas } \\
(1604-1670)\end{array}$ & $\begin{array}{l}\text { Frau des Has- } \\
\text { drubal }\end{array}$ & 1642 & $\begin{array}{l}\text { Montreuil-Belley } \\
\text { Privatsammlung }\end{array}$ & Lwd. & Ritschard, S. 43 \\
\hline 292 & $\begin{array}{l}\text { Prévost, Nicolas } \\
(1604-1670)\end{array}$ & Sophonisbe & 1642 & $\begin{array}{l}\text { Montreuil-Belley } \\
\text { Privatsammlung }\end{array}$ & Lwd. & Ritschard, S. 43 \\
\hline 293 & $\begin{array}{l}\text { Puligo, Domenico } \\
(1492-1527)\end{array}$ & Tod Kleopatras & - & $\begin{array}{l}\text { Paris } \\
\text { Musee de l'Assistance } \\
\text { publique }\end{array}$ & $\begin{array}{l}59 \times 43 \\
\text { Holz }\end{array}$ & $\begin{array}{l}\text { http://www.viile- } \\
\text { ge.ch/musinfo/mahg/musee/presse/ } \\
\text { cleopatre/cleopatre3.htm } \\
\text { (zuletzt aufgerufen:10.01.2007) }\end{array}$ \\
\hline 294 & $\begin{array}{l}\text { Raimondi, Marcantonio } \\
\text { (um } 1480 \text { / um } \\
\text { 1527/1534) }\end{array}$ & Dido & - & - & $\begin{array}{l}159 \times 126 \\
\text { Kupferstich }\end{array}$ & Bartsch 26(187) \\
\hline 295 & $\begin{array}{l}\text { Raimondi, Marcantonio } \\
\text { (um } 1480 \text { / um } \\
\text { 1527/1534) }\end{array}$ & Lukretia & - & - & $\begin{array}{l}212 \times 130 \\
\text { Kupferstich }\end{array}$ & Bartsch 26(192) \\
\hline 296 & $\begin{array}{l}\text { Raimondi, Marcantonio } \\
\text { (um } 1480 \text { / um } \\
\text { 1527/1534) }\end{array}$ & $\begin{array}{l}\text { Neptun besänf- } \\
\text { tigt den Sturm }\end{array}$ & $1515 / 16$ & - & Kupferstich & $\begin{array}{l}\text { Bartsch 14,352 } \\
\text { Höper, S. } 205\end{array}$ \\
\hline
\end{tabular}




\section{Bildkatalog}

\begin{tabular}{|c|c|c|c|c|c|c|}
\hline 297 & $\begin{array}{l}\text { Raimondi, Marcantonio } \\
\text { (um } 1480 \text { / um } \\
1527 / 1534 \text { ) }\end{array}$ & Kleopatra & - & - & $\begin{array}{l}221 \times 135 \\
\text { Kupferstich }\end{array}$ & Bartsch 26,193 \\
\hline 298 & $\begin{array}{l}\text { Raimondi, Marcantonio } \\
\text { (um } 1480 \text { / um } \\
\text { 1527/1534) }\end{array}$ & Kleopatra & - & - & $\begin{array}{l}85 \times 131 \\
\text { Kupferstich }\end{array}$ & Bartsch 26,198 \\
\hline 299 & $\begin{array}{l}\text { Raimondi, Marcantonio } \\
\text { (um } 1480 \text { / um } \\
\text { 1527/1534) }\end{array}$ & Kleopatra & - & - & $\begin{array}{l}114 \times 168 \\
\text { Kupferstich }\end{array}$ & Bartsch 26,199 D \\
\hline 300 & $\begin{array}{l}\text { Recco, Gaetano } \\
\text { (17. Jh.) }\end{array}$ & Tod des Seneca & 1682 & $\begin{array}{l}\text { Neapel } \\
\text { Museo di Capodimonte }\end{array}$ & Lwd. & Spinosa 1984, Abb. 594 \\
\hline 301 & $\begin{array}{l}\text { Regnault, Jean-Baptiste } \\
(1754-1829)\end{array}$ & $\begin{array}{l}\text { Tod der Kleo- } \\
\text { patra }\end{array}$ & $1797 / 99$ & $\begin{array}{l}\text { Düsseldorf } \\
\text { Kunstmuseum }\end{array}$ & $\begin{array}{l}64 \times 80 \\
\text { Lwd. }\end{array}$ & Mai 1987, Nr. 49 \\
\hline 302 & $\begin{array}{l}\text { Régnier, Nicolas (Renie- } \\
\text { ri, Nicolò) } \\
(1591-1667)\end{array}$ & Sophonisbe & $\begin{array}{l}1655- \\
1665\end{array}$ & $\begin{array}{l}\text { Kassel } \\
\text { Staatliche Museen }\end{array}$ & $\begin{array}{l}128,3 \times 153 \\
\text { Lwd. }\end{array}$ & Baumgärtel 1995, Kat.170 \\
\hline $302 a$ & $\begin{array}{l}\text { Régnier, Nicolas (Renie- } \\
\text { ri, Nicolò) } \\
(1591-1667)\end{array}$ & Sophonisbe & - & $\begin{array}{l}\text { Padua } \\
\text { Musei Civici }\end{array}$ & $\begin{array}{l}101 \times 82 \\
\text { Lwd. }\end{array}$ & Banzato, Kat.18, S. 25 \\
\hline
\end{tabular}




\section{Bildkatalog}

\begin{tabular}{|c|c|c|c|c|c|c|}
\hline 303 & $\begin{array}{l}\text { Rehberg, Friedrich } \\
(1758-1835)\end{array}$ & Kleopatra & 1794 & - & Graphik $^{13}$ & Ittershagen, S. 102 \\
\hline 304 & $\begin{array}{l}\text { Rehberg, Friedrich } \\
(1758-1835)\end{array}$ & Sophonisbe & 1794 & - & Graphik $^{14}$ & Ittershagen, S. 90 \\
\hline 305 & $\begin{array}{l}\text { Rembrandt van Rijn } \\
(1606-1669)\end{array}$ & $\begin{array}{l}\text { Selbstmord der } \\
\text { Lukretia }\end{array}$ & 1664 & $\begin{array}{l}\text { Washington } \\
\text { National Gallery of Art }\end{array}$ & $\begin{array}{l}120 \times 101 \\
\text { Lwd. }\end{array}$ & Schwartz, Abb.382 \\
\hline 306 & $\begin{array}{l}\text { Rembrandt van Rijn } \\
(1606-1669)\end{array}$ & $\begin{array}{l}\text { Selbstmord der } \\
\text { Lukretia }\end{array}$ & 1666 & $\begin{array}{l}\text { Minneapolis } \\
\text { Institute of Arts }\end{array}$ & $\begin{array}{l}105,1 \times 92,3 \\
\text { Lwd. }\end{array}$ & Schwartz, Abb.383 \\
\hline 307 & $\begin{array}{l}\text { Rembrandt van Rijn } \\
(1606-1669)\end{array}$ & Sophonisbe & 1634 & $\begin{array}{l}\text { Madrid } \\
\text { Prado }\end{array}$ & $\begin{array}{l}223 \times 468 \\
\text { Lwd. }\end{array}$ & Bruyn 1986, S. 504 (A 94) \\
\hline 308 & $\begin{array}{l}\text { Reni, Guido } \\
(1575-1642)\end{array}$ & Lukretia & $1622 / 23$ & $\begin{array}{l}\text { Reggio Emilia } \\
\text { Privatsammlung }\end{array}$ & $\begin{array}{l}86 \times 76 \\
\text { Lwd. }\end{array}$ & $\begin{array}{l}\text { Ebert-Schifferer 1988, Kat. A } \\
9\end{array}$ \\
\hline 309 & $\begin{array}{l}\text { Reni, Guido } \\
(1575-1642)\end{array}$ & Lukretia & um 1625 & $\begin{array}{l}\text { Potsdam } \\
\text { Neues Palais }\end{array}$ & $\begin{array}{l}215 \times 151 \\
\text { Lwd. }\end{array}$ & $\begin{array}{l}\text { Ebert-Schifferer 1988, Kat. A } \\
15\end{array}$ \\
\hline 310 & $\begin{array}{l}\text { Reni, Guido } \\
\text { 1575-1642) }\end{array}$ & Kleopatra & um 1626 & $\begin{array}{l}\text { Potsdam } \\
\text { Sanssouci }\end{array}$ & $\begin{array}{l}124 \times 94 \\
\text { Lwd. }\end{array}$ & $\begin{array}{l}\text { Ebert-Schifferer 1988, Kat. A } \\
16\end{array}$ \\
\hline
\end{tabular}

\footnotetext{
${ }^{13}$ In Rom gestochen von Thomas Piroli.

14 In Rom gestochen von Thomas Piroli.
} 
Bildkatalog

\begin{tabular}{|c|c|c|c|c|c|c|}
\hline 311 & $\begin{array}{l}\text { Reni, Guido } \\
(1575-1642)\end{array}$ & Lukretia & $1626 / 27$ & $\begin{array}{l}\text { England } \\
\text { Privatsammlung }\end{array}$ & $\begin{array}{l}128 \times 99 \\
\text { Lwd. }\end{array}$ & $\begin{array}{l}\text { Ebert-Schifferer 1988, Kat. A } \\
17\end{array}$ \\
\hline 312 & $\begin{array}{l}\text { Reni, Guido } \\
(1575-1642)\end{array}$ & Lukretia & um 1632 & $\begin{array}{l}\text { Bologna } \\
\text { Slg. Lauro }\end{array}$ & $\begin{array}{l}69 \times 56 \text { (oval) } \\
\text { Lwd. }\end{array}$ & Ebert-Schifferer 1988, Kat. 26 \\
\hline 313 & $\begin{array}{l}\text { Reni, Guido } \\
(1575-1642)\end{array}$ & Kleopatra & $1639 / 40$ & $\begin{array}{l}\text { London } \\
\text { Slg. Sir Denis Mahon }\end{array}$ & $\begin{array}{l}77 \times 65 \\
\text { Lwd. }\end{array}$ & $\begin{array}{l}\text { Ebert-Schifferer 1988, Kat. A } \\
\text { 36; Cola / Salvagni / Scolaro / } \\
\text { Scolaro / Caroselli, Kat. } 72\end{array}$ \\
\hline 314 & $\begin{array}{l}\text { Reni, Guido } \\
(1575-1642)\end{array}$ & Lukretia & um 1639 & $\begin{array}{l}\text { Campione } \\
\text { Slg. Silvano Lodi }\end{array}$ & $\begin{array}{l}125,5 \times 93,5 \\
\text { Lwd. }\end{array}$ & Ebert-Schifferer 1988, Kat. 37 \\
\hline 315 & $\begin{array}{l}\text { Reni, Guido } \\
(1575-1642)\end{array}$ & $\begin{array}{l}\text { Selbstmord der } \\
\text { Kleopatra }\end{array}$ & $1620 ?$ & Privatsammlung & $\begin{array}{l}175 \times 102 \\
\text { Lwd. }\end{array}$ & $\begin{array}{l}\text { Cola / Salvagni / Scolaro / } \\
\text { Scolaro / Caroselli, Kat.46 }\end{array}$ \\
\hline 316 & $\begin{array}{l}\text { Reni, Guido } \\
(1575-1642)\end{array}$ & Kleopatra & $1640-42$ & $\begin{array}{l}\text { Rom } \\
\text { Galleria Capitolina }\end{array}$ & $\begin{array}{l}91,5 \times 72,5 \\
\text { Lwd. }\end{array}$ & Pepper, Abb. 190, Kat. 204 \\
\hline 317 & $\begin{array}{l}\text { Reni, Guido } \\
(1575-1642)\end{array}$ & Lukretia & $1625-26$ & $\begin{array}{l}\text { London } \\
\text { Kunstmarkt }\end{array}$ & $\begin{array}{l}128 \times 99 \\
\text { Lwd. }\end{array}$ & Pepper, Abb. IX, Kat.92 \\
\hline 318 & $\begin{array}{l}\text { Reni, Guido } \\
(1575-1642)\end{array}$ & Porzia & $1625-26$ & $\begin{array}{l}\text { Genua } \\
\text { Slg. Durazzo Pallavicini }\end{array}$ & $\begin{array}{l}120 \times 88 \\
\text { Lwd. }\end{array}$ & Pepper, Abb.88, Kat. 96 \\
\hline
\end{tabular}




\section{Bildkatalog}

\begin{tabular}{|c|c|c|c|c|c|c|}
\hline 319 & $\begin{array}{l}\text { Reni, Guido } \\
(1575-1642)\end{array}$ & Kleopatra & 1628 & $\begin{array}{l}\text { Hampton Court } \\
\text { Königliche Sammlungen }\end{array}$ & $\begin{array}{l}114 \times 95 \\
\text { Lwd. }\end{array}$ & Pepper, Abb.102, Kat. 111 \\
\hline 320 & $\begin{array}{l}\text { Reni, Guido } \\
(1575-1642)\end{array}$ & Lukretia & 1632 & $\begin{array}{l}\text { New York } \\
\text { Privatsammlung }\end{array}$ & $\begin{array}{l}98 \times 74 \\
\text { Lwd. }\end{array}$ & Pepper, Abb.125, Kat. 134 \\
\hline 321 & $\begin{array}{l}\text { Reni, Guido } \\
(1575-1642)\end{array}$ & Lukretia & 1638-39 & $\begin{array}{l}\text { Genua } \\
\text { Privatsammlung }\end{array}$ & $\begin{array}{l}\text { 96x71 (oval) } \\
\text { Lwd. }\end{array}$ & Pepper, Abb.159, Kat. 170 \\
\hline 322 & $\begin{array}{l}\text { Reni, Guido } \\
(1575-1642)\end{array}$ & $\begin{array}{l}\text { Artemisia } \\
\text { (Sophonisbe?) }\end{array}$ & $1638-39$ & $\begin{array}{l}\text { Genua } \\
\text { Privatsammlung }\end{array}$ & $\begin{array}{l}96 \times 71 \text { (oval) } \\
\text { Lwd. }\end{array}$ & Pepper, Abb. 159B, Kat. 170 \\
\hline 323 & $\begin{array}{l}\text { Reni, Guido } \\
(1575-1642)\end{array}$ & Kleopatra & $1638-39$ & $\begin{array}{l}\text { Florenz } \\
\text { Palazzo Pitti }\end{array}$ & $\begin{array}{l}122 \times 96 \\
\text { Lwd. }\end{array}$ & Pepper, Abb. 161, Kat. 173 \\
\hline 324 & $\begin{array}{l}\text { Reni, Guido } \\
(1575-1642)\end{array}$ & $\begin{array}{l}\text { Artemisia } \\
\text { (Sophonisbe?) }\end{array}$ & $1638-39$ & $\begin{array}{l}\text { Birmingham } \\
\text { City Art Gallery }\end{array}$ & $\begin{array}{l}74 \times 61 \\
\text { Lwd. }\end{array}$ & Pepper, Abb.162, Kat. 174 \\
\hline 325 & $\begin{array}{l}\text { Reni, Guido } \\
(1575-1642)\end{array}$ & Lukretia & $1640-42$ & $\begin{array}{l}\text { Rom } \\
\text { Pinacoteca Capitolina }\end{array}$ & $\begin{array}{l}91 \times 73 \\
\text { Lwd. }\end{array}$ & Pepper, Abb. 188, Kat. 202 \\
\hline 326 & $\begin{array}{l}\text { Reni, Guido } \\
(1575-1642)\end{array}$ & Lukretia & $1622-23$ & $\begin{array}{l}\text { Modena } \\
\text { Privatsammlung }\end{array}$ & $\begin{array}{l}85 \times 76 \\
\text { Lwd. }\end{array}$ & $\begin{array}{l}\text { Pepper, Abb.16 (Appendix), } \\
\text { Kat. N. } 22\end{array}$ \\
\hline 327 & $\begin{array}{l}\text { Reni, Guido } \\
(1575-1642)\end{array}$ & Lukretia & $1632-33$ & $\begin{array}{l}\text { Madrid } \\
\text { Prado }\end{array}$ & $\begin{array}{l}70 \times 57 \\
\text { Lwd. }\end{array}$ & $\begin{array}{l}\text { Pepper, Abb. } 23 \text { (Appendix), } \\
\text { Kat.N.33 }\end{array}$ \\
\hline
\end{tabular}




\section{Bildkatalog}

\begin{tabular}{|c|c|c|c|c|c|c|}
\hline 328 & $\begin{array}{l}\text { Reni, Guido } \\
(1575-1642)\end{array}$ & Lukretia & um 1635 & $\begin{array}{l}\text { Bologna } \\
\text { Slg. Lauro }\end{array}$ & $\begin{array}{l}69 \times 56 \text { (oval) } \\
\text { Lwd. }\end{array}$ & $\begin{array}{l}\text { Pepper, Abb. } 28 \text { (Appendix), } \\
\text { Kat. N } 39\end{array}$ \\
\hline 329 & $\begin{array}{l}\text { Reni, Guido } \\
\text { (1575-1642) }\end{array}$ & Lukretia & 1635 & $\begin{array}{l}\text { Campione d'Italia } \\
\text { Slg. Lodi }\end{array}$ & $\begin{array}{l}125,5 \times 93,5 \\
\text { Lwd. }\end{array}$ & $\begin{array}{l}\text { Pepper, Abb.29 (Appendix), } \\
\text { Kat. N } 41\end{array}$ \\
\hline 330 & $\begin{array}{l}\text { Reni, Guido } \\
(1575-1642))\end{array}$ & Kleopatra & $\begin{array}{l}1635- \\
1641\end{array}$ & $\begin{array}{l}\text { Madrid } \\
\text { Prado }\end{array}$ & $\begin{array}{l}110 \times 94 \\
\text { Lwd. }\end{array}$ & Rogelio Buendia, S. 196 \\
\hline 331 & $\begin{array}{l}\text { Reni, Guido } \\
(1575-1642)\end{array}$ & Porzia & 1625 & $\begin{array}{l}\text { Genua } \\
\text { Palazzo Durazzo Pallavi- } \\
\text { cini }\end{array}$ & $\begin{array}{l}102 \times 87 \\
\text { Lwd. }\end{array}$ & Cattaneo Adorno, S. 111 \\
\hline 332 & $\begin{array}{l}\text { Reni, Guido } \\
(1575-1642)\end{array}$ & $\begin{array}{l}\text { Sophonisbe } \\
\text { (Artemisia?) }\end{array}$ & $1640-42$ & $\begin{array}{l}\text { Minneapolis } \\
\text { Institute of Arts }\end{array}$ & $\begin{array}{l}57 \times 46 \\
\text { Lwd. }\end{array}$ & Pepper S. 302, Abb. 186 \\
\hline 333 & $\begin{array}{l}\text { Reni, Guido } \\
(1575-1642)\end{array}$ & Magdalena & 1635 & $\begin{array}{l}\text { Baltimore } \\
\text { Walters Art Gallery }\end{array}$ & $\begin{array}{l}90,5 \times 74 \\
\text { Lwd. }\end{array}$ & Pepper, Tafel XII \\
\hline 334 & $\begin{array}{l}\text { Reni, Guido } \\
(1575-1642)\end{array}$ & Tod Kleopatras & - & $\begin{array}{l}\text { Rom } \\
\text { Palazzo Barberini }\end{array}$ & - & $\begin{array}{l}\text { http://www.italica.rai.it/index.php?cat } \\
\text { egoria=arte\&scheda=mito_donna } \\
\text { (zuletzt aufgerufen:10.01.2007) }\end{array}$ \\
\hline 335 & siehe $\mathbf{3 0 2 a}$ & - & - & - & - & - \\
\hline
\end{tabular}


Bildkatalog

\begin{tabular}{|c|c|c|c|c|c|c|}
\hline 336 & $\begin{array}{l}\text { Reynolds, Joshua } \\
(1723-1792)\end{array}$ & Tod der Dido ${ }^{15}$ & 1781 & - & Lwd. & Penny, Abb. 123 \\
\hline 337 & $\begin{array}{l}\text { Reynolds, Joshua } \\
(1723-1792)\end{array}$ & $\begin{array}{l}\text { Miss Kitty Fisher } \\
\text { als Kleopatra }\end{array}$ & - & $\begin{array}{l}\text { Hampstead Heath (Lon- } \\
\text { don) } \\
\text { Kenwood House }\end{array}$ & $\begin{array}{l}76,2 \times 63,5 \\
\text { Lwd. }\end{array}$ & Penny, S. 99 \\
\hline 338 & $\begin{array}{l}\text { Ricchi, Pietro } \\
(1606-1675)\end{array}$ & Tod der Lukretia & - & $\begin{array}{l}\text { Braunschweig } \\
\text { Herzog Anton Ulrich- } \\
\text { Museum }\end{array}$ & $\begin{array}{l}127 \times 98 \\
\text { Lwd. }\end{array}$ & Jacob, S. $120 f$. \\
\hline 339 & $\begin{array}{l}\text { Ricchi, Pietro } \\
(1606-1675)\end{array}$ & $\begin{array}{l}\text { Josef und Poti- } \\
\text { phars Weib }\end{array}$ & - & $\begin{array}{l}\text { Braunschweig } \\
\text { Herzog Anton Ulrich- } \\
\text { Museum }\end{array}$ & $\begin{array}{l}127 \times 98 \\
\text { Lwd. }\end{array}$ & Jacob, S. $120 f$ \\
\hline 340 & $\begin{array}{l}\text { Ricchi, Pietro } \\
(1606-1675)\end{array}$ & $\begin{array}{l}\text { Lukretia und } \\
\text { Tarquinius }\end{array}$ & - & unbekannt & - & Ottaviani Botteri, S. 132 \\
\hline 341 & $\begin{array}{l}\text { Ricchi, Pietro } \\
(1606-1675)\end{array}$ & Lukretia & - & $\begin{array}{l}\text { Forlì } \\
\text { Istituto Prati }\end{array}$ & $130 \times 150$ & Ottaviani Botteri, S. 344 \\
\hline 342 & $\begin{array}{l}\text { Ricci, Sebastiano } \\
(1659-1734)\end{array}$ & Lukretia & $1680-84$ & $\begin{array}{l}\text { Parma } \\
\text { Ospedali Riuniti }\end{array}$ & $\begin{array}{l}134 \times 127 \\
\text { Lwd. }\end{array}$ & - \\
\hline
\end{tabular}

\footnotetext{
${ }^{15}$ Nur als Reproduktionsgraphik von Joseph Grozer erhalten.
} 


\section{Bildkatalog}

\begin{tabular}{|c|c|c|c|c|c|c|}
\hline 343 & $\begin{array}{l}\text { Ricci, Sebastiano } \\
(1659-1734)\end{array}$ & $\begin{array}{l}\text { Opferung der } \\
\text { Polyxena }\end{array}$ & $\begin{array}{l}1700- \\
1710\end{array}$ & $\begin{array}{l}\text { London } \\
\text { Königliche Sammlungen }\end{array}$ & $\begin{array}{l}76,8 \times 65,7 \\
\text { Lwd. }\end{array}$ & Rizzi, Kat.48 \\
\hline 344 & $\begin{array}{l}\text { Ricci, Sebastiano } \\
(1659-1734)\end{array}$ & Lukretia & - & $\begin{array}{l}\text { Dijon } \\
\text { Musée Magnin }\end{array}$ & $\begin{array}{l}148 \times 200 \\
\text { Lwd. }\end{array}$ & $\begin{array}{l}\text { Brejon de Lavergnée } 1980, \mathrm{~S} \\
94\end{array}$ \\
\hline 345 & $\begin{array}{l}\text { Ricci, Sebastiano } \\
(1659-1734)\end{array}$ & Sophonisbe & - & $\begin{array}{l}\text { London } \\
\text { (Sotheby Januar 2005) }\end{array}$ & $\begin{array}{l}\text { 66x85,7 } \\
\text { Lwd. }\end{array}$ & [nicht mehr im Netz] \\
\hline 346 & $\begin{array}{l}\text { Rieger, Johann (?) } \\
\text { oder Spillenberger, Jo- } \\
\text { hann } \\
(1628-1679)\end{array}$ & Sophonisbe & um 1700 & $\begin{array}{l}\text { Berlin } \\
\text { (im Handel bei Ploetz- } \\
\text { Peters 2006) }\end{array}$ & $\begin{array}{l}64,8 \times 81,6 \\
\text { Lwd. }\end{array}$ & [nicht mehr im Netz] \\
\hline 347 & $\begin{array}{l}\text { Rivalz, Antoine } \\
(1667-1735)\end{array}$ & $\begin{array}{l}\text { Tod der Kleo- } \\
\text { patra }\end{array}$ & - & $\begin{array}{l}\text { Toulouse } \\
\text { Musée des Augustins }\end{array}$ & $\begin{array}{l}123 \times 101 \\
\text { Lwd. }\end{array}$ & Ritschard, S. 202 \\
\hline 348 & $\begin{array}{l}\text { Rixens, Jean André } \\
(1846-1924)\end{array}$ & $\begin{array}{l}\text { Tod der Kleo- } \\
\text { patra }\end{array}$ & - & $\begin{array}{l}\text { Toulouse } \\
\text { Musée des Augustins }\end{array}$ & Lwd. & Walker / Higgs, S. 308 \\
\hline 349 & $\begin{array}{l}\text { Roberti, Ercole } \\
(1456-1496)\end{array}$ & Tod der Lukretia & um 1490 & $\begin{array}{l}\text { Modena } \\
\text { Galleria Estense }\end{array}$ & $0,46 \times 0,33$ & $\begin{array}{l}\text { Schubring, Tafel CXXIII, Nr. } \\
563\end{array}$ \\
\hline
\end{tabular}


Bildkatalog

\begin{tabular}{|c|c|c|c|c|c|c|}
\hline 350 & Roman d'Enèas & Äneas und Dido & 14.Jh. & $\begin{array}{l}\text { Paris } \\
\text { B. N. }\end{array}$ & - & $\begin{array}{l}\text { http://www.ac-nancy- } \\
\text { metz.fr/enseign/lettres/LanguesAnci } \\
\text { ennes/Textes/Virgile/Didon.htm } \\
\text { (zuletzt aufgerufen: } 20.01 .2007 \text { ) }\end{array}$ \\
\hline 351 & $\begin{array}{l}\text { Rottmayr, Johann Mi- } \\
\text { chael } \\
(1654-1730)\end{array}$ & Tod Senecas & vor 1695 & $\begin{array}{l}\text { Prag } \\
\text { Národní Galerie v Praze }\end{array}$ & $\begin{array}{l}127 \times 181 \\
\text { Lwd. }\end{array}$ & Kotalivik, S. 215 \\
\hline 352 & $\begin{array}{l}\text { Rubens, Peter Paul } \\
(1577-1640)\end{array}$ & $\begin{array}{l}\text { Hero und Lean- } \\
\text { der }\end{array}$ & $1604-05$ & $\begin{array}{l}\text { Yale } \\
\text { University Art Gallery }\end{array}$ & $\begin{array}{l}95,9 \times 127 \\
\text { Lwd. }\end{array}$ & $\begin{array}{l}\text { Antwerpen 1977, Antwerpen, } \\
\text { S. } 29\end{array}$ \\
\hline 353 & $\begin{array}{l}\text { Rubens, Peter Paul } \\
(1577-1640)\end{array}$ & $\begin{array}{l}\text { Tod des Decius } \\
\text { Mus }\end{array}$ & 1617 & $\begin{array}{l}\text { Vaduz / Wien } \\
\text { Sammlungen des Fürsten } \\
\text { von und zu Liechtenstein }\end{array}$ & $\begin{array}{l}288 \times 519 \\
\text { Lwd. }\end{array}$ & $\begin{array}{l}\text { Kräftner / Seipel / Trnek, S. } \\
\text { 164f. }\end{array}$ \\
\hline 354 & $\begin{array}{l}\text { Rubens, Peter Paul } \\
(1577-1640)\end{array}$ & $\begin{array}{l}\text { Sterbender Se- } \\
\text { neca }\end{array}$ & 1611 & $\begin{array}{l}\text { München } \\
\text { Alte Pinakothek }\end{array}$ & $\begin{array}{l}185 \times 154,7 \\
\text { Eichenholz }\end{array}$ & Steingräber 1983, 305 \\
\hline 355 & $\begin{array}{l}\text { Rubens, Peter Paul } \\
(1577-1640)\end{array}$ & Tod der Dido & $\begin{array}{l}\text { 2. Viertel } \\
\text { 17. Jh. }\end{array}$ & $\begin{array}{l}\text { Paris } \\
\text { Louvre }\end{array}$ & $\begin{array}{l}183 \times 117 \\
\text { Lwd. }\end{array}$ & $\begin{array}{l}\text { Brejon de Lavergnée / Foucart } \\
\text { / Reynaud, S. } 120\end{array}$ \\
\hline 356 & $\begin{array}{l}\text { Rubens, Peter Paul } \\
(1577-1640)\end{array}$ & $\begin{array}{l}\text { Tod der Kleo- } \\
\text { patra }\end{array}$ & um 1615 & $\begin{array}{l}\text { Potsdam } \\
\text { Neues Palais }\end{array}$ & - & - \\
\hline
\end{tabular}




\section{Bildkatalog}

\begin{tabular}{|c|c|c|c|c|c|c|}
\hline 357 & $\begin{array}{l}\text { Rubens, Peter Paul } \\
(1577-1640)\end{array}$ & Laurentius & 1615 & $\begin{array}{l}\text { München } \\
\text { Alte Pinakothek }\end{array}$ & $\begin{array}{l}244 \times 174 \\
\text { Lwd. }\end{array}$ & Steingräber 1983, S. 450f. \\
\hline 358 & $\begin{array}{l}\text { Rubens, Peter Paul } \\
(1577-1640)\end{array}$ & $\begin{array}{l}\text { Tarquinius und } \\
\text { Lukretia }\end{array}$ & $1610 / 11$ & $\begin{array}{l}\text { Potsdam } \\
\text { Schloss } \\
\text { (heute: St. Petersburg } \\
\text { Eremitage) }\end{array}$ & $\begin{array}{l}187 \times 214,5 \\
\text { Lwd. }\end{array}$ & $\begin{array}{l}\text { http://www.spsg.de/media/de/Ruben } \\
\text { s_Verlust_150 } \\
\text { (zuletzt aufgerufen:11.01.2007) }\end{array}$ \\
\hline 359 & $\begin{array}{l}\text { Rubens, Peter Paul } \\
(1577-1640)\end{array}$ & $\begin{array}{l}\text { Minerva und } \\
\text { Prudentia über- } \\
\text { geben Maria de } \\
\text { Medici die Herr- } \\
\text { schaft }\end{array}$ & $\begin{array}{l}\text { 1. Viertel } \\
\text { 17. Jh. }\end{array}$ & $\begin{array}{l}\text { Paris } \\
\text { Louvre }\end{array}$ & $394 \times 727$ & $\begin{array}{l}\text { http://www.culture.gouv.fr/public/mist } \\
\text { ral_joconde_fr } \\
\text { (zuletzt aufgerufen: } 11.01 .2007 \text { ) }\end{array}$ \\
\hline 360 & $\begin{array}{l}\text { Rustici, Francesco } \\
(1592-1626)\end{array}$ & $\begin{array}{l}\text { Selbstmord der } \\
\text { Lucretia }\end{array}$ & $\begin{array}{l}\text { um 1623- } \\
25\end{array}$ & $\begin{array}{l}\text { Florenz } \\
\text { Uffizien }\end{array}$ & $\begin{array}{l}175 \times 259,5 \\
\text { Lwd. }\end{array}$ & Gregori, Nr. 517 \\
\hline 361 & $\begin{array}{l}\text { Sacchi, Andrea } \\
(1599-1661)\end{array}$ & Tod der Dido & $1635-36$ & $\begin{array}{l}\text { Caen } \\
\text { Musée des Beaux-Arts }\end{array}$ & $\begin{array}{l}139,5 \times 148 \\
\text { Lwd. }\end{array}$ & Mai 1993, Kat.34 \\
\hline 362 & $\begin{array}{l}\text { Saint-Quentin, Joseph } \\
(1738-\text {-nach 1785) }\end{array}$ & $\begin{array}{l}\text { Tod des Sokra- } \\
\text { tes }\end{array}$ & 1762 & $\begin{array}{l}\text { Paris } \\
\text { École des Beaux-Arts }\end{array}$ & - & $\begin{array}{l}\text { Oberreuter-Kronabel 1986, } \\
\text { Abb. } 10\end{array}$ \\
\hline 363 & $\begin{array}{l}\text { Salamanca, Antonio } \\
(1500-1562)\end{array}$ & Sophonisbe & - & $\begin{array}{l}\text { Düsseldorf } \\
\text { Kunstmuseum }\end{array}$ & $\begin{array}{l}17 \times 13 \\
\text { Graphik }\end{array}$ & Baumgärtel 1995, S. 159 \\
\hline
\end{tabular}




\section{Bildkatalog}

\begin{tabular}{|c|c|c|c|c|c|c|}
\hline 364 & $\begin{array}{l}\text { Salamanca, Antonio } \\
(1500-1562)\end{array}$ & Porzia & - & $\begin{array}{l}\text { Düsseldorf } \\
\text { Kunstmuseum }\end{array}$ & $\begin{array}{l}17 \times 13 \\
\text { Graphik }\end{array}$ & Richard-Jamet 2003, S. 538 \\
\hline 365 & $\begin{array}{l}\text { Sandrart, Joachim von } \\
(1606-1688)\end{array}$ & Tod des Seneca & 1635 & $\begin{array}{l}\text { Berlin } \\
\text { (seit } 1945 \text { verschollen) }\end{array}$ & $\begin{array}{l}171 \times 215 \\
\text { Lwd. }\end{array}$ & $\begin{array}{l}\text { Danesi Squarzina 2001, S. } \\
118\end{array}$ \\
\hline 366 & $\begin{array}{l}\text { Sandrart, Joachim von } \\
(1606-1688)\end{array}$ & Tod des Cato & 1631 & $\begin{array}{l}\text { Padua } \\
\text { Museo Civico }\end{array}$ & $\begin{array}{l}140,4 \times 186,5 \\
\text { Lwd. }\end{array}$ & Klemm, S. 60 \\
\hline 367 & Schön, Erhard & Porzia & 1531 & - & Graphik $^{16}$ & Baumgärtel 1995, S. 162 \\
\hline 368 & Schön, Erhard & Lukretia & 1531 & - & Graphik $^{17}$ & Baumgärtel 1995, S. 162 \\
\hline 369 & $\begin{array}{l}\text { Scorel, Jan van } \\
(1495-1562)\end{array}$ & Kleopatra & $1520-25$ & $\begin{array}{l}\text { Amsterdam } \\
\text { Rijksmuseum }\end{array}$ & $\begin{array}{l}36 \times 61 \\
\text { Holz }\end{array}$ & $\begin{array}{l}\text { http://token.rijksmuseum.nl/screens/ } \\
\text { S-SK-A2843-00.jpg } \\
\text { (zuletzt aufgerufen: } 11.01 .2007 \text { ) }\end{array}$ \\
\hline 370 & $\begin{array}{l}\text { Sellaio, Jacopo } \\
(1441-1493)\end{array}$ & Porzia & $\begin{array}{l}\text { letztes } \\
\text { Drittel } 15 . \\
\text { Jh. }\end{array}$ & Hochzeitstruhe & - & Schubring, Nr. 365 \\
\hline 371 & $\begin{array}{l}\text { Sellaio, Jacopo } \\
(1441-1493)\end{array}$ & Tod des Brutus & - & $\begin{array}{l}\text { Florenz } \\
\text { Kunsthandel }\end{array}$ & - & Schubring, Nr. 931 \\
\hline
\end{tabular}

\footnotetext{
${ }^{16}$ Illustration zu: Hans Sachs: Der Ehrenspiegel der neun getrevsten heydnischen Fraven mit yhren vunder getreyen thaten. 
Bildkatalog

\begin{tabular}{|c|c|c|c|c|c|c|}
\hline 372 & $\begin{array}{l}\text { Sirani, Elisabetta } \\
(1638-1665)\end{array}$ & $\begin{array}{l}\text { Porzia, sich } \\
\text { selbst verlet- } \\
\text { zend }\end{array}$ & 1664 & $\begin{array}{l}\text { Rom } \\
\text { Galleria Borghese }\end{array}$ & Lwd. & $\begin{array}{l}\text { www.mystudios.com/women/pqrst/si } \\
\text { rani_tigh.html } \\
\text { (zuletzt aufgerufen:12.01.2007) }\end{array}$ \\
\hline 373 & $\begin{array}{l}\text { Sirani, Elisabetta } \\
(1638-1665)\end{array}$ & Dido & - & - & $\begin{array}{l}64 \times 87,5 \\
\text { Lwd. }\end{array}$ & $\begin{array}{l}\text { http://www.ac-nancy- } \\
\text { metz.fr/enseign/lettres/LanguesAnci } \\
\text { ennes/Textes/Virgile/Didon.htm } \\
\text { (zuletzt aufgerufen: 20.01.2007) }\end{array}$ \\
\hline 374 & $\begin{array}{l}\text { Sodoma, Giovanni An- } \\
\text { tonio Bazzi, gen. } \\
(1477-1549)\end{array}$ & Lukretia & - & $\begin{array}{l}\text { Hannover } \\
\text { Landesmuseum }\end{array}$ & $0,83 \times 047$ & $\begin{array}{l}\text { Schubring, Tafel CLVII, Nr. } \\
735\end{array}$ \\
\hline 375 & $\begin{array}{l}\text { Sodoma, Giovanni An- } \\
\text { tonio Bazzi, gen. } \\
(1477-1549)\end{array}$ & $\begin{array}{l}\text { Lukretia, Colla- } \\
\text { tinus und Lucre- } \\
\text { tius }\end{array}$ & 1513 & $\begin{array}{l}\text { Budapest } \\
\text { Szépmüvészeti Múzeum }\end{array}$ & - & $\begin{array}{l}\text { www.oceansbridge.com/paintings/ar } \\
\text { tists/s/Sodoma_Il/thumb_oil/Sodoma } \\
\text { _The_Death_of_Lucretia.jpg } \\
\text { (zuletzt aufgerufen:12.01.2007) }\end{array}$ \\
\hline 376 & $\begin{array}{l}\text { Solimena, Francesco } \\
(1657-1747)\end{array}$ & $\begin{array}{l}\text { Opferung der } \\
\text { Iphigenie }\end{array}$ & - & $\begin{array}{l}\text { New York } \\
\text { Antiquariatsmarkt }\end{array}$ & $\begin{array}{l}102,5 \times 128 \\
\text { Lwd. }\end{array}$ & Spinosa 1986, Nr. 71, Taf.16 \\
\hline 377 & $\begin{array}{l}\text { Solimena, Francesco } \\
(1657-1747)\end{array}$ & $\begin{array}{l}\text { Tod der Messa- } \\
\text { lina }\end{array}$ & - & $\begin{array}{l}\text { Malibu } \\
\text { The Paul Getty Museum }\end{array}$ & Lwd. & $\begin{array}{l}\text { Spinosa 1986, Nr. 26, Abb. } \\
31 \text {, S. } 31\end{array}$ \\
\hline 378 & $\begin{array}{l}\text { Solimena, Francesco } \\
(1657-1747)\end{array}$ & $\begin{array}{l}\text { Tod der Kleo- } \\
\text { patra }\end{array}$ & vor 1744 & $\begin{array}{l}\text { Florenz } \\
\text { Fondazione Longhi }\end{array}$ & $\begin{array}{l}75 \times 63 \\
\text { Lwd. }\end{array}$ & $\begin{array}{l}\text { Spinosa 1986, Nr. 69, Abb. } \\
\text { 77, S. } 22\end{array}$ \\
\hline
\end{tabular}




\section{Bildkatalog}

\begin{tabular}{|c|c|c|c|c|c|c|}
\hline 379 & $\begin{array}{l}\text { Solimena, Francesco } \\
(1657-1747)\end{array}$ & Tod der Lukretia & vor 1744 & $\begin{array}{l}\text { Florenz } \\
\text { Fondazione Longhi }\end{array}$ & $\begin{array}{l}75 \times 63 \\
\text { Lwd. }\end{array}$ & $\begin{array}{l}\text { Spinosa 1986, Nr. 69, Abb. } \\
78, \text { S. } 222\end{array}$ \\
\hline 380 & $\begin{array}{l}\text { Solimena, Francesco } \\
(1657-1747)\end{array}$ & Sophonisbe & 1705-09 & $\begin{array}{l}\text { Neapel } \\
\text { Privatsammlung }\end{array}$ & $\begin{array}{l}44 \times 55 \\
\text { Lwd. }\end{array}$ & $\begin{array}{l}\text { Settecento Napoletano, Nr. } \\
41, \text { S. } 214 \mathrm{f} \text {. }\end{array}$ \\
\hline 381 & $\begin{array}{l}\text { Solimena, Francesco } \\
(1657-1747)\end{array}$ & $\begin{array}{l}\text { Dido empfängt } \\
\text { Äneas und As- } \\
\text { canius }\end{array}$ & 1720 & $\begin{array}{l}\text { London } \\
\text { National Gallery }\end{array}$ & $\begin{array}{l}207,2 \times 310,2 \\
\text { Lwd. }\end{array}$ & Baker, S. 636 \\
\hline 382 & $\begin{array}{l}\text { Spillenberger, Johann } \\
\text { (1628-1679), (zuge- } \\
\text { schrieben) }\end{array}$ & $\begin{array}{l}\text { Opferung der } \\
\text { Polyxena }\end{array}$ & - & $\begin{array}{l}\text { Braunschweig } \\
\text { Herzog Anton Ulrich- } \\
\text { Museum }\end{array}$ & $\begin{array}{l}\text { 99x85 } \\
\text { Lwd. }\end{array}$ & Jacoby, Kat.1097 \\
\hline $382 a$ & $\begin{array}{l}\text { Spillenberger, Johann } \\
(1628-1679)\end{array}$ & siehe 346 & & & & \\
\hline 383 & $\begin{array}{l}\text { Stanzione, Massimo } \\
(1590-1656)\end{array}$ & $\begin{array}{l}\text { Selbstmord der } \\
\text { Lukretia }\end{array}$ & 1635 & $\begin{array}{l}\text { Rom } \\
\text { Privatsammlung }\end{array}$ & $\begin{array}{l}170 \times 180 \\
\text { Lwd. }\end{array}$ & $\begin{array}{l}\text { Ebert-Schifferer 1988, Kat. D } \\
45\end{array}$ \\
\hline 384 & $\begin{array}{l}\text { Stanzione, Massimo } \\
(1585-1656)\end{array}$ & Lukretia & $\begin{array}{l}\text { nach } \\
1640\end{array}$ & $\begin{array}{l}\text { Genua } \\
\text { Palazzo Durazzo Palavic- } \\
\text { cini }\end{array}$ & $\begin{array}{l}122 \times 100 \\
\text { Lwd. }\end{array}$ & Cattaneo Adorno, S. 196 \\
\hline
\end{tabular}




\section{Bildkatalog}

\begin{tabular}{|c|c|c|c|c|c|c|}
\hline 385 & $\begin{array}{l}\text { Stanzione, Massimo } \\
(1585-1656)\end{array}$ & $\begin{array}{l}\text { Tod der Kleo- } \\
\text { patra }\end{array}$ & um 1630 & $\begin{array}{l}\text { St. Petersburg } \\
\text { Eremitage }\end{array}$ & $\begin{array}{l}169 \times 99,5 \\
\text { Lwd. }\end{array}$ & $\begin{array}{l}\text { www.oceansbridge.com/paintings/ar } \\
\text { tists/s/Stanzione_Massimo/thumb_oi } \\
\text { l/cleopatra_1630s_XX_hermitag } \\
\text { (zuletzt aufgerufen:12.01.2007) }\end{array}$ \\
\hline 386 & $\begin{array}{l}\text { Stimmer, Tobias } \\
(1539-1584)\end{array}$ & $\begin{array}{l}\text { Sophonisbe vor } \\
\text { Massinissa }\end{array}$ & 1568 & - & $\begin{array}{l}72 \times 105 \\
\text { Holzschnitt }^{18}\end{array}$ & Bartsch 19,2(64.79 [348]) \\
\hline 387 & $\begin{array}{l}\text { Stimmer, Tobias } \\
(1539-1584)\end{array}$ & $\begin{array}{l}\text { Syphax wird zu } \\
\text { Scipio gebracht }\end{array}$ & 1568 & - & $\begin{array}{l}104 \times 146 \\
\text { Holzschnitt }^{19}\end{array}$ & Bartsch 19,2(64.80[348]) \\
\hline 388 & $\begin{array}{l}\text { Teniers, David der J. } \\
(1610-1690)\end{array}$ & $\begin{array}{l}\text { Tod des Lean- } \\
\text { der }\end{array}$ & 1658 & $\begin{array}{l}\text { Althorp } \\
\text { Slg. Earl Spencer }\end{array}$ & $\begin{array}{l}22,5 \times 52 \\
\text { Kupfer }\end{array}$ & $\begin{array}{l}\text { Musées royaux des Beaux- } \\
\text { Arts de Belgique 1965, S. } 259\end{array}$ \\
\hline 389 & $\begin{array}{l}\text { Tiepolo, Giambattista } \\
(1696-1770)\end{array}$ & $\begin{array}{l}\text { Tod der Sopho- } \\
\text { nisbe }\end{array}$ & $1755-60$ & $\begin{array}{l}\text { Madrid } \\
\text { Museo Thyssen- } \\
\text { Bornemsza }\end{array}$ & $\begin{array}{l}48,5 \times 438 \\
\text { Lwd. }\end{array}$ & $\begin{array}{l}\text { Pita Andrade / del Mar Boro- } \\
\text { bia Guerrero, S. } 379\end{array}$ \\
\hline 390 & $\begin{array}{l}\text { Tiepolo, Giambattista } \\
(1696-1770)\end{array}$ & Sophonisbe & $\begin{array}{l}\text { nach } \\
1731\end{array}$ & $\begin{array}{l}\text { Mailand } \\
\text { Palazzo Dugnani }\end{array}$ & $\begin{array}{l}520 \times 650 \\
\text { Fresko }^{20}\end{array}$ & Levey, S. 95 \\
\hline 391 & $\begin{array}{l}\text { Tiepolo, Giambattista } \\
(1696-1770)\end{array}$ & HI. Agathe & 1755 & $\begin{array}{l}\text { Berlin } \\
\text { Staatliche Museen }\end{array}$ & $\begin{array}{l}184 \times 131 \\
\text { Lwd. }\end{array}$ & Christiansen 1996, S. 235 \\
\hline
\end{tabular}

\footnotetext{
${ }^{18}$ Illustration einer Livius-Ausgabe.

${ }_{19}$ Illustration einer Livius-Ausgabe.

${ }^{20}$ Teilweise 1943 durch Bomben zerstört.
} 


\section{Bildkatalog}

\begin{tabular}{|c|c|c|c|c|c|c|}
\hline 392 & $\begin{array}{l}\text { Tiepolo, Giambattista } \\
(1696-1770)\end{array}$ & $\begin{array}{l}\text { Bankett der } \\
\text { Kleopatra }\end{array}$ & um 1740 & $\begin{array}{l}\text { London } \\
\text { National Gallery }\end{array}$ & $\begin{array}{l}46,3 \times 66,7 \\
\text { Lwd. }\end{array}$ & Walker / Higgs, S. 351 \\
\hline 393 & $\begin{array}{l}\text { Tiepolo, Giambattista } \\
(1696-1770)\end{array}$ & $\begin{array}{l}\text { Bankett der } \\
\text { Kleopatra }\end{array}$ & 1744 & $\begin{array}{l}\text { Melbourne } \\
\text { National Gallery of Victo- } \\
\text { ria }\end{array}$ & $\begin{array}{l}249 \times 346 \\
\text { Lwd. }\end{array}$ & Pallucchini 1990, Tafel XXX \\
\hline 394 & $\begin{array}{l}\text { Tiepolo, Giambattista } \\
(1696-1770)\end{array}$ & $\begin{array}{l}\text { Antonius und } \\
\text { Kleopatra }\end{array}$ & - & $\begin{array}{l}\text { Edinburgh } \\
\text { National Gallery of Scot- } \\
\text { land }\end{array}$ & $68 \times 38$ & Pallucchini 1990, Tafel XL \\
\hline 395 & $\begin{array}{l}\text { Tiepolo, Giambattista } \\
(1696-1770)\end{array}$ & $\begin{array}{l}\text { Ankunft und } \\
\text { Bankett }\end{array}$ & $\begin{array}{l}1747- \\
1750\end{array}$ & $\begin{array}{l}\text { Venedig } \\
\text { Palazzo Labia }\end{array}$ & $\begin{array}{l}650 \times 300 \\
\text { Fresken }\end{array}$ & Pallucchini 1990, S. 114 \\
\hline 396 & $\begin{array}{l}\text { Tintoretto, Jacopo } \\
(1518-1594)\end{array}$ & $\begin{array}{l}\text { Porträt eines } \\
\text { jungen Mannes } \\
\text { mit Skulptur der } \\
\text { Lukretia }\end{array}$ & 1555 & $\begin{array}{l}\text { München } \\
\text { Alte Pinakothek }\end{array}$ & $\begin{array}{l}113,5 \times 89,4 \\
\text { Lwd. }\end{array}$ & Steingräber 1983, 10447 \\
\hline 397 & $\begin{array}{l}\text { Tischbein, Johann Hein- } \\
\text { rich } \\
(1722-1789)\end{array}$ & $\begin{array}{l}\text { Sterbender An- } \\
\text { tonius vor Kleo- } \\
\text { patra }\end{array}$ & $\begin{array}{l}1767 \text { oder } \\
1769\end{array}$ & $\begin{array}{l}\text { Kassel } \\
\text { Staatliche Museen }\end{array}$ & $\begin{array}{l}34,7 \times 44,5 \\
\text { Lwd. }\end{array}$ & Ritschard, S. 224 \\
\hline
\end{tabular}




\section{Bildkatalog}

\begin{tabular}{|c|c|c|c|c|c|c|}
\hline 398 & $\begin{array}{l}\text { Tischbein, Johann Hein- } \\
\text { rich } \\
(1722-1789)\end{array}$ & $\begin{array}{l}\text { Augustus und } \\
\text { sterbende Kleo- } \\
\text { patra }\end{array}$ & 1769 & $\begin{array}{l}\text { Kassel } \\
\text { Staatliche Museen }\end{array}$ & $\begin{array}{l}34,7 \times 44,5 \\
\text { Lwd. }\end{array}$ & Ritschard, S. 224 \\
\hline 399 & $\begin{array}{l}\text { Tischbein, Johann Hein- } \\
\text { rich } \\
(1722-1789)\end{array}$ & Dido & 1775 & $\begin{array}{l}\text { Gotha } \\
\text { Schlossmuseum Fried- } \\
\text { richstein }\end{array}$ & Lwd. & $\begin{array}{l}\text { http://www.ac-nancy- } \\
\text { metz.fr/enseign/lettres/LanguesAnci } \\
\text { ennes/Textes/Virgile/Didon.htm } \\
\text { (zuletzt aufgerufen: } 20.01 .2007 \text { ) }\end{array}$ \\
\hline 400 & $\begin{array}{l}\text { Tiziano, Vecellio } \\
(1477-1576)\end{array}$ & $\begin{array}{l}\text { Tarquinius und } \\
\text { Lukretia }\end{array}$ & $1575-77$ & $\begin{array}{l}\text { Wien } \\
\text { Akademie der bildenden } \\
\text { Künste }\end{array}$ & $\begin{array}{l}114 \times 100 \\
\text { Lwd. }\end{array}$ & $\begin{array}{l}\text { Valcanover, S. } 363 \\
\text { Ferino-Pagden, S. 264-66 }\end{array}$ \\
\hline 401 & $\begin{array}{l}\text { Tiziano, Vecellio } \\
(1477-1576)\end{array}$ & $\begin{array}{l}\text { Lukretia und ihr } \\
\text { Gemahl }\end{array}$ & um 1515 & $\begin{array}{l}\text { Wien } \\
\text { KHM }\end{array}$ & $\begin{array}{l}82,5 \times 68,5 \\
\text { Holz }\end{array}$ & $\begin{array}{l}\text { Ferino-Pagden, Sylvia / Pro- } \\
\text { haska, Wolfgang / Schütz, } \\
\text { Tafel 41, S. } 123\end{array}$ \\
\hline 402 & $\begin{array}{l}\text { Tiziano, Vecellio } \\
(1477-1576)\end{array}$ & $\begin{array}{l}\text { Tarquinius und } \\
\text { Lukretia }\end{array}$ & - & $\begin{array}{l}\text { Cambridge UK } \\
\text { Fitzwilliam Museum }\end{array}$ & $\begin{array}{l}188,9 \times 145 \\
\text { Lwd. }\end{array}$ & Ferino-Pagden, S. 256-60 \\
\hline $402 a$ & $\begin{array}{l}\text { Tiziano, Vecellio } \\
(1477-1576\end{array}$ & $\begin{array}{l}\text { Tarquinius und } \\
\text { Lukretia }\end{array}$ & & Bordeaux & $\begin{array}{l}190 \times 143 \\
\text { Lwd. }\end{array}$ & Ferino-Pagden, S. 261-263 \\
\hline
\end{tabular}


Bildkatalog

\begin{tabular}{|c|c|c|c|c|c|c|}
\hline 403 & $\begin{array}{l}\text { Trevisani, Francesco } \\
(1656-1746)\end{array}$ & $\begin{array}{l}\text { Fest des Marc } \\
\text { Anton und der } \\
\text { Kleopatra }\end{array}$ & vor 1702 & $\begin{array}{l}\text { Rom } \\
\text { Galleria Spada }\end{array}$ & Lwd. & Vicini, S. 61 \\
\hline 404 & $\begin{array}{l}\text { Turchi, Alessandro } \\
(1578-1649)\end{array}$ & $\begin{array}{l}\text { Tod der Kleo- } \\
\text { patra }\end{array}$ & 1635 & $\begin{array}{l}\text { Paris } \\
\text { Louvre }\end{array}$ & $\begin{array}{l}255 \times 267 \\
\text { Lwd. }\end{array}$ & $\begin{array}{l}\text { Brejon de Lavergnée / Thié- } \\
\text { baut, S. } 249\end{array}$ \\
\hline 405 & $\begin{array}{l}\text { Turner, Joseph Mallord } \\
\text { William } \\
(1775-1851)\end{array}$ & $\begin{array}{l}\text { Dido baut Kar- } \\
\text { thago }\end{array}$ & 1815 & $\begin{array}{l}\text { London } \\
\text { National Gallery }\end{array}$ & $\begin{array}{l}155,6 \times 231,8 \\
\text { Lwd. }\end{array}$ & Baker S. 678 \\
\hline 406 & $\begin{array}{l}\text { Ubertini, Francesco, ge- } \\
\text { nannt: il Bachiacca } \\
(1494-1557)\end{array}$ & Tod der Lukretia & - & $\begin{array}{l}\text { Genua } \\
\text { Palazzo Durazzo Palavic- } \\
\text { cini }\end{array}$ & $\begin{array}{l}68 \times 48 \\
\text { Lwd. }\end{array}$ & Cattaneo Adorno, S. 288 \\
\hline 407 & Unbekannt & $\begin{array}{l}\text { Tod der Kleo- } \\
\text { patra }\end{array}$ & um 1405 & $\begin{array}{l}\text { London } \\
\text { British Library Royal }\end{array}$ & $\begin{array}{l}390 \times 270 \mathrm{~mm} \\
\text { Pergament }\end{array}$ & Walker / Higgs, S. 344 \\
\hline
\end{tabular}




\section{Bildkatalog}

\begin{tabular}{|c|c|c|c|c|c|c|}
\hline 408 & Unbekannt & $\begin{array}{l}\text { Sterben des } \\
\text { Antonius und } \\
\text { der Kleopatra }\end{array}$ & um 1480 & $\begin{array}{l}\text { London } \\
\text { British Library Royal }\end{array}$ & $\begin{array}{l}480 \times 345 \mathrm{~mm} \\
\text { Pergament }\end{array}$ & Walker / Higgs, S. 345 \\
\hline 409 & Unbekannt & $\begin{array}{l}\text { Bankett und Tod } \\
\text { der Kleopatra }\end{array}$ & 1473 & Holzschnitt $^{21}$ & $285 \times 193 \mathrm{~mm}$ & Walker / Higgs, S. 346 \\
\hline 410 & Unbekannt & $\begin{array}{l}\text { Haupt der Kleo- } \\
\text { patra }\end{array}$ & $\begin{array}{l}1533 \text { oder } \\
\text { später }\end{array}$ & $\begin{array}{l}\text { London } \\
\text { British Museum }\end{array}$ & $\begin{array}{l}24,6 \times 17 \\
\text { Schwarze } \\
\text { Kreide }\end{array}$ & Walker / Higgs, S. 355 \\
\hline 411 & Unbekannt & $\begin{array}{l}\text { Sophonisbe er- } \\
\text { hält den Mantel } \\
\text { des Syphax }\end{array}$ & um 1650 & $\begin{array}{l}\text { Manufaktur Heinrich Rey- } \\
\text { dacus, Brüssel }\end{array}$ & Teppich & Göbel, Nr. 285 \\
\hline 412 & Unbekannt & Porzia & 1473 & Holzschnitt" 22 & - & Bartsch $80,1473 / 363$ \\
\hline 413 & Unbekannt & Sophonisbe $^{23}$ & 1557 & - & Holzschnitt & $\begin{array}{l}\text { Schlink / Sperlich, Tafel XLII, } \\
96\end{array}$ \\
\hline 414 & Unbekannt & Dido & 1473 & - & Holzschnitt $^{24}$ & Bartsch $80,1473 / 334$ \\
\hline
\end{tabular}

${ }^{21}$ Illustration zu Boccaccios De mulieribus claris (Zainer, Ulm)

22 Illustration zu Boccaccios De mulieribus claris (Zainer, Ulm).

${ }^{23}$ Illustration zu Livius-Ausgabe Mainz 1557.

${ }^{24}$ Holzschnitt Illustration zu Boccaccios De mulieribus claris (Zainer, Ulm) 


\section{Bildkatalog}

\begin{tabular}{|c|c|c|c|c|c|c|}
\hline 415 & $\begin{array}{l}\text { Unbekannt } \\
\text { (nach Marcantonio Rai- } \\
\text { mondi) }\end{array}$ & Kleopatra & - & - & $\begin{array}{l}11,4 \times 18 \\
\text { Kupferstich }\end{array}$ & Höper, S. 199 \\
\hline 416 & $\begin{array}{l}\text { Valesio, Giovanni Luigi } \\
\text { (um 1583-1650) }\end{array}$ & Kleopatra & - & - & $\begin{array}{l}113 \times 63 \\
\text { Kupferstich }\end{array}$ & Bartsch 40,34 \\
\hline 417 & $\begin{array}{l}\text { Van den Eeckhout, } \\
\text { Gerbrand } \\
(1621-1674)\end{array}$ & Sophonisbe & 1664 & $\begin{array}{l}\text { Braunschweig } \\
\text { Herzog-Anton-Ulrich- } \\
\text { Museum }\end{array}$ & $\begin{array}{l}248 \times 197 \\
\text { Lwd. }\end{array}$ & Mai 1987, Nr. 58 \\
\hline 418 & $\begin{array}{l}\text { Vecchia, Pietro della } \\
(1603-1678)\end{array}$ & $\begin{array}{l}\text { Tod des Archi- } \\
\text { medes }\end{array}$ & - & $\begin{array}{l}\text { Bordeaux } \\
\text { Musée des Beaux-Arts }\end{array}$ & $\begin{array}{l}\text { oval, } 32 \times 45 \\
\text { Holz }\end{array}$ & Habert, 104 \\
\hline 419 & $\begin{array}{l}\text { Veneziano, Agostino } \\
\text { (um 1490-1540) }^{25}\end{array}$ & $\begin{array}{l}\text { Tarquinius und } \\
\text { Lukretia }\end{array}$ & 1523 & - & Stich & Höper, S. 57 \\
\hline 420 & $\begin{array}{l}\text { Veronese, Paolo } \\
(1528-1588)\end{array}$ & Lukretia & um 1583 & $\begin{array}{l}\text { Wien } \\
\text { KHM }\end{array}$ & $\begin{array}{l}109 \times 90,2 \\
\text { Lwd. }\end{array}$ & Romanelli / Strinati, S. $150 f$. \\
\hline 421 & $\begin{array}{l}\text { Vignon, Claude } \\
(1593-1670)\end{array}$ & Tod der Lukretia & um 1640 & $\begin{array}{l}\text { Blois } \\
\text { Château et Musées }\end{array}$ & $\begin{array}{l}138 \times 148 \\
\text { Lwd. }\end{array}$ & Baumgärtel 1995, Nr. 144 \\
\hline
\end{tabular}

${ }^{25} 1524$ übergangen von Enea Vico. 


\section{Bildkatalog}

\begin{tabular}{|c|c|c|c|c|c|c|}
\hline 422 & $\begin{array}{l}\text { Vignon, Claude } \\
(1593-1670)\end{array}$ & Tod des Seneca & 1633 & $\begin{array}{l}\text { Paris } \\
\text { Louvre }\end{array}$ & $\begin{array}{l}146 \times 126 \\
\text { Lwd. }\end{array}$ & Viatte, S. 134 \\
\hline 423 & $\begin{array}{l}\text { Vignon, Claude } \\
(1593-1670)\end{array}$ & Kleopatra & - & $\begin{array}{l}\text { Rennes, } \\
\text { Musée des Beaux-Arts }\end{array}$ & - & Ottaviani Botteri 1996, S.40 \\
\hline 424 & siehe $\mathbf{2 3 1 a}$ & - & - & - & - & - \\
\hline 425 & $\begin{array}{l}\text { Voorhout, Johannes } \\
(1647-1723)\end{array}$ & $\begin{array}{l}\text { Dido auf dem } \\
\text { Scheiterhaufen }\end{array}$ & 1684 & $\begin{array}{l}\text { Budapest } \\
\text { Szépmüvészeti Múzeum }\end{array}$ & $\begin{array}{l}109 \times 87 \\
\text { Lwd. }\end{array}$ & Mai 1987, Abb.44 \\
\hline 426 & $\begin{array}{l}\text { Vouet, Simon } \\
(1590-1649)\end{array}$ & Tod der Dido & 1642 & $\begin{array}{l}\text { Dôle } \\
\text { Musée municipal }\end{array}$ & $\begin{array}{l}215 \times 170 \\
\text { Lwd. }\end{array}$ & Baumgärtel 1995, Kat. 91 \\
\hline 427 & $\begin{array}{l}\text { Vouet, Simon } \\
(1590-1649)\end{array}$ & Sophonisbe & $\begin{array}{l}\text { um } \\
1622 / 24\end{array}$ & $\begin{array}{l}\text { Kassel } \\
\text { Staatliche Museen }\end{array}$ & $\begin{array}{l}128 \times 156 \\
\text { Lwd. }\end{array}$ & $\begin{array}{l}\text { Ebert-Schifferer 1988, Kat. D } \\
66\end{array}$ \\
\hline 428 & $\begin{array}{l}\text { Vouet, Simon } \\
(1590-1649)\end{array}$ & $\begin{array}{l}\text { Selbstmord der } \\
\text { Lukretia }\end{array}$ & $\begin{array}{l}\text { um } \\
1625 / 26\end{array}$ & $\begin{array}{l}\text { Prag } \\
\text { Národní Galerie v Praze }\end{array}$ & $\begin{array}{l}197 \times 148 \\
\text { Lwd. }\end{array}$ & $\begin{array}{l}\text { Ebert-Schifferer 1988, Kat. D } \\
\text { 67, und Christiansen / Mann } \\
\text { 2001, S. } 364\end{array}$ \\
\hline 429 & $\begin{array}{l}\text { Vouet, Simon } \\
(1590-1649)\end{array}$ & Tod der Lukretia & $\begin{array}{l}\text { um } \\
1624 / 25\end{array}$ & $\begin{array}{l}\text { Potsdam } \\
\text { Sanssouci }\end{array}$ & - & - \\
\hline 430 & $\begin{array}{l}\text { Vouet, Simon } \\
(1590-1649)\end{array}$ & $\begin{array}{l}\text { Tod der Sopho- } \\
\text { nisbe }\end{array}$ & - & $\begin{array}{l}\text { Potsdam } \\
\text { Sanssouci }\end{array}$ & & - \\
\hline
\end{tabular}


Bildkatalog

\begin{tabular}{|c|c|c|c|c|c|c|}
\hline 431 & $\begin{array}{l}\text { Vouet, Simon } \\
(1590-1649)\end{array}$ & Lukretia & $\begin{array}{l}1625- \\
1626\end{array}$ & $\begin{array}{l}\text { Prag } \\
\text { Národní Galerie v Praze }\end{array}$ & $\begin{array}{l}197 \times 148 \\
\text { Lwd. }\end{array}$ & Kotalivik, S. 229 \\
\hline 432 & $\begin{array}{l}\text { Vouet, Simon } \\
(1590-1649)\end{array}$ & $\begin{array}{l}\text { Artemisia lässt } \\
\text { das Mausoleum } \\
\text { bauen }\end{array}$ & um 1640 & $\begin{array}{l}\text { Stockholm } \\
\text { Nationalmuseum }\end{array}$ & $\begin{array}{l}161 \times 139 \\
\text { Lwd. }\end{array}$ & Baumgärtel 1995, S. 209 \\
\hline 433 & $\begin{array}{l}\text { Watteau, François Jo- } \\
\text { seph } \\
(1758-1823)\end{array}$ & $\begin{array}{l}\text { Tod des Sokra- } \\
\text { tes }\end{array}$ & 1780 & $\begin{array}{l}\text { Lille } \\
\text { Musée des Beaux-Arts }\end{array}$ & - & $\begin{array}{l}\text { Oberreuter-Kronabel 1986, } \\
\text { Abb.12 }\end{array}$ \\
\hline 434 & $\begin{array}{l}\text { Weber, Thoman } \\
\text { (um } 1535 \text { tätig) }\end{array}$ & $\begin{array}{l}\text { Tarquinius und } \\
\text { Lukretia }\end{array}$ & um 1535 & $\begin{array}{l}\text { Basel } \\
\text { Kunstmuseum }\end{array}$ & $\begin{array}{l}102 \times 69 \\
\text { Lwd. }\end{array}$ & $\begin{array}{l}\text { http://www.repro- } \\
\text { tab- } \\
\text { leaux.com/kunst/thoman_weber/tarq } \\
\text { uinius_bedroht_lukretia_lo.jpg } \\
\text { (zuletzt aufgerufen: } 12.01 .2007 \text { ) }\end{array}$ \\
\hline 435 & $\begin{array}{l}\text { Zick, Januarius } \\
(1730-1797)\end{array}$ & $\begin{array}{l}\text { Abschied des } \\
\text { Sokrates von } \\
\text { seiner Familie }\end{array}$ & 1794 & $\begin{array}{l}\text { Düsseldorf } \\
\text { Kunstmuseum }\end{array}$ & - & $\begin{array}{l}\text { Oberreuter-Kronabel 1986, } \\
\text { Abb. } 21\end{array}$ \\
\hline
\end{tabular}




\section{Künstler}

\section{Künstlerverzeichnis}

Aachen, Hans von 133

Albrechtsmeister 37

Alciat 170

Aldegrever, Heinrich 82, 133

Altdorfer, Albrecht 110, 125

Ammann, Jost 82

Arthur, Reginald 157, 165, 272

Aspertini, Amico 148, 149

Auvray, Felix 175, 176, 272

Balestra, Antonio 98

Beaufort, Jacques Antoine 136

Beccafumi, Domenico 81, 85, 163, 240, 241, 242, 243

Beham, Bartel 146

Beham, Hans Sebald 127, 146, 165

Bellange, Jacques 172

Benvenuto, Girolamo di 241, 243

Berthelot, Guillaume 249

Blanchard, Jacques 155

Böcklin, Arnold 160, 165, 272, 315

Bol, Ferdinand 112

Bosse, Abraham 163, 174, 256, 257

Botticelli, Sandro 124

Bourdon, Sébastien 113

Brescia, Giovanni Antonio da 109

Breu, Jörg der Ältere 125, 126

Bruegel 210

Burgkmair, Hans der Ältere 235, 256

Cagnacci, Guido 131, 132, 155, 159, 161, 162, 315

Cambiaso, Luca 161

Candid, Peter 128, 262, 264

Caravaggio 92, 158, 202, 203, 210, 229

Carenna, Jacomo-Antonio 162

Carneo, Antoneo 135

Caron, Antoine 249

Caroto, Giovanni Francesco 81

Castello 161

Caucig, Franz 175, 176, 264, 266, 272 
Cestaro, Jacopo 155

Champaigne, Philippe de 250, 251

Chauveau, Francois 163, 173, 255

Cifrondi, Antonio 135

Conca, Sebastiano 52, 53, 262, 303

Corona, Lionardo 263

Cort, Cornelis 133

Cortona, Pietro da 162, 250, 253

Cozza,Francesco 27, 155, 159

Cozzarelli, Guidoccio 124, 241, 243

Cranach, Lucas 126, 127, 128, 129,129, 262

Crespi, Giuseppe Maria 134

Crosato, Giovanni Battista 71, 85, 99

Curradi, Francesco 247

dal Sole,Giovan Gioseffo 87

David, Jacques-Louis 21, 22, 49, 295, 309, 310

Delacroix, Auguste 16, 160

della Bella, Stefano 144, 254

Dolce, Carlo 45, 86107, 210, 300

Dossi, Dosso 115

Dufresnoy, Charles-Alphonse 136, 313

Dupuis, Nicolas-Gabriel 261

Dürer, Albrecht 126, 128, 262, 263, 264

Dyck, Anthony van 155, 300

Eeckhout, Gerbrand van den 93, 94

Elliger der Ältere, Ottmar 114

Elliger, Ottmar der Jüngere 114, 155, 267, 268

Errard, Charles 174, 175

Esperlin, Joseph 155

Ferrari, Luca 87

Ferroni, Giulio 282

Feselen, Melchior 125

Fetti, Domenico 218, 229

Feuerbach, Anselm 18

Fiammengo, Giusto 203

Fidani, Orazio 53, 113

Flinck, Govert 313, 314

Forabosco, Girolamo 89

Füger, Heinrich Frieder 52, 175

Fungai, Bernardino 79

Füßli, Heinrich 116 


\section{Künstler}

Gandolfi, Gaetano 132, 135

Genga, Girolamo 241, 243

Gentileschi, Artemisia 23, 44, 125, 128, 132, 155, 156, 158, 255, 263, 264

Gherardi, Cristofano 245

Giampietrino, Giovanni Pietro Rizzoli, gen. 245

Gilfino, Niccolò 124

Gimignani, Giacinto 253

Giordano, Luca 134, 155, 159, 162, 174, 175

Giorgio, Francesco di 239

Giotto 24, 236, 237, 238

Giovanni, Apollonio di 109

Gramatica, Antiveduto 158

Gravelot, Hubert 21

Guarino

Guarino, Francesco 161, 263, 266

Guercino, Giovan Francesco Barbieri, gen. 111, 135, 147, 154, 155, 156, 162, 165, 250

Günther, Matthäus 114

Hackert, Jacob Philipp 111

Hamilton, Gavin 137

Heemskerck, Maarten van 256

Heiss, Johann 113

Heyden, Jan van der 232, 233

Hirschvogel, Augustin 147

Holbein, Hans, der Jüngere 34, 260

Hollanda, Francisco da 147, 149

Hopfer, Daniel 127

Jordaens, Jacob 146, 162, 254, 267, 268

Kauffmann, Angelika 116, 131, 133, 164, 272, 294, 296, 299, 300, 301

Kels, Hans der Ältere 83, 84

Ketel, Cornelis 260

Knüpfer, Nikolaus 91

Koninck, Salomon 89, 90, 93

Lairesse, Gerard de 26, 50, 99, 114, 146, 156, 260, 261, 267, 268

Landi, Neroccio de' 239

Langrenée, Louis 156

Lastman, Pieter 89, 90

Lazzarini, Gregorio 113

Le Brun, Charles 51, 88, 90, 282

Lippi, Filippino 124, 125

Liss, Johann 159

Lorrain, Claude 116 
Index

Loth, Johann Carl 263

Lotto, Lorenzo 129, 130, 232

Lucas, Richard Cockle 164

Maestri di Pandolfo Petrucci 163, 241

Maître de Griselda 239

Maître des héroïnes de Chigi-Saracini 80, 85,163, 241, 242, 256, 314

Makart, Hans 13, 14, 15, 16, 17, 18, 53, 141, 144, 165, 287, 315

Manet, Édouard 18, 19, 303

Manetti, Rutilio 85, 97, 194, 248

Mansion, Colard 43

Mantegna, Andrea 80, 110, 240, 250, 314

Maratta, Carlo 162, 250, 253

Massard, Johann Baptist Raphael Urbain 22

Matteo di Giovanni 239

Maulbertsch, Franz Anton 194

Mazzanti, Ludovico 263, 264

Mazzoni, Sebastiano 158

Meister HTA 147

Meister von 1515147

Meister von Lecceto 109

Meister H. G 42

Mengozzi, Gerolamo 161

Mengs, Anton Raphael 164

Michelangelo 38, 151

Mignard, Pierre 155, 156, 172

Millais, John Everett 15

Mosca, Padova, Gian Maria da, gen. il 171

Muller, Jan 146

Natoire, Charles-Joseph 146, 268

Nattier, Jean-Baptiste 253

Neroni, Bartolomeo 241

Orley, Barend van 170

Pacchiarotto, Giacomo 239

Pace, Valentino 33, 39, 41

Pacheco, Francisco 206

Padova, Gian Maria da, gen. il Mosca 171

Peiresc, Nicolas Claude Fabri de 249

Pellegrini, Antonio 98

Pellegrini, Gianantonio 96, 98

Pencz, Georg 82, 83, 84, 127

Perrier, Francois 203 


\section{Künstler}

Perugino, Pietro 81

Pinelli, Bartolomeo 301

Pinturicchio, Bernardino di Betto gen. 81

Piroli, Tommaso 297, 298

Pittoni, Francesco 264

Pittoni, Giovanni Battista 97, 310, 311

Poerson, Charles 253, 254

Pollaiuolo, Antonio 42

Poussin, Nicolas 136, 203, 250, 301

Preti, Mattia 94, 112, 158, 263, 264

Prévost, Nicolas 85, 144, 163, 173, 251, 252, 315

Puligo, Domenico 157

Raffael 48, 57, 86, 110, 126, 147, 217, 315

Raimondi, Marcantonio 110, 126, 127, 147

Régnier, Nicolas 57, 86, 101, 102, 267, 269, 270

Rehberg, Friedrich 294, 297, 314

Rembrandt 89, 91, 92, 93, 132, 221, 314

Reni, Guido 26, 55, 86, 87, 88, 126, 128, 130, 131, 132, 135, 147, 157, 158, 165, 172, 202, 204, $211,216,217,218,219,220,221,230,250,261,263,264,269,272,287,297,298,300,315$

Renieri, Niccolò 233, 262

Reynolds, Joshua 114, 165, 299, 300

Ricchi, Pietro 132, 134, 263, 264

Ricci, Sebastiano 96, 134

Rieger, Johann 99

Rivalz, Antoine 159

Rixens, Jean Andre 157, 165, 315

Romney, George 300

Rosselli, Matteo 247

Rousselet, Gilles 174, 256, 257

Rubens, Peter Paul 19, 22, 23, 24, 93, 113, 115, 133, 180, 183, 203, 210, 211, 212, 213, 214, 215 , 216, 230, 231, 249, 303

Rustici, Francesco 135, 248

Sacchi, Andrea 115

Sandrart, Joachim von 52, 91, 202

Scorel, Jan van 155,156

Seidler, Louise 296, 297

Sirani, Elisabetta 115, 175

Sodoma, Giovanni 135

Solimena, Francesco 95, 303

Spillenberger, Johann 99

Stanzione, Massimo 25, 128, 263, 266 
Index

Stimmer, Tobias 84

Stradanus, Johannes 247

Strozzi, Bernardo 50

Stuck, Franz von 165

Testa, Pietro 233

Tiepolo, Giambattista 95, 98, 99, 161, 211, 222, 223, 224, 225, 226, 304

Tiepolo, Giandomenico 222

Tintoretto, Jacopo 130, 209, 219, 232

Tischbein, Johann Heinrich, der Ältere 116

Tizian 53, 130, 132, 133, 135, 209, 213, 219

Trevisani Francesco, 164

Tucci, Biagio di Antonio 124

Tuccia 80, 241, 244, 246, 253

Tuck, Richard 185

Tümpel, Christian 84, 85, 90

Turchi, Alessandro 161, 162, 250

Turner, William 117

Valesio, Giovanni Luigi 146

van Cleve, Joos 129

van Obstal,Gérard 90

Vasari, Giorgio 45, 126, 236, 247

Velasquez, Viego Rodríguez de Silva y 261

Venant, Francois 89

Verona, Liberale da 109, 170

Veronese 209, 219, 263, 264

Vignon, Claude 25, 136, 159, 173, 252, 253, 256, 257

Villegas, Francisco de 107

Vicentino, Michieli, Andrea, gen. il 246

Vorstermann, Lucas 214

Vouet, Simon 23, 24, 91, 93, 111, 113, 128, 233, 249, 250, 251, 262, 263, 267, 269, 270, 314

Weber, Thoman 133

Zainer, Johannes 43, 78, 79, 109, 239 


\section{Personen}

\section{Personen}

Abigaïl 253

Abraham 256

Achilles 49, 237, 238

Adolfati, Andrea 275

Aelian 166

Aemilia 279

Aeneas 50, 64, 103, 104, 106, 107, 108, 109, 111, 114, 115, 116, 117, 142, 237, 244, 276, 277, $278,279,282$

Aeolos 277

Agathe (HI.) 94, 161, 222, 223, 224, 226

Agnesi-Pinottini, Maria Teresa 76

Aischylos 70

Alberti, Leon Battista 29, 45, 82

Albinoni, Tomaso 275, 278

Albrecht von Eyb 122

Aldofati, Andrea 278

Aldrovandi, Ulisse 149

Alexander 234, 246, 253

Alfieri, Vittorio 73,143

Alkuin 33

Ambrosius 195, 199, 258

Amor 277

Amymone 297

Andrea d'Ungheria 238

Andreini, Giovan Battista 218

Andreozzi, Gaetano 275

Andromache 169

Anfossi, Pasquale 275

Anna Amalia von Sachsen-Weimar 283

Anne d'Autriche 23, 25, 173, 250, 251, 252, 253, 254, 257

Anselm von Canterbury 37

Antiochus III. 253

Antiope 253

Antonini, Giovanni 286

Antonio Pierozzi de' Forciglioni 254

Antonius 76, 139, 140, 141, 142, 143, 145, 149, 154, 161, 164, 168, 194, 197, 267, 268, 288, 292

Appian 62, 63, 97, 166 
Index

Appius 52, 53

Aragón, Alvaro Cubillo de 108

Araia, Francesco 278

Archimedes 20

Ariadne 65, 147, 148, 154, 156, 273, 289, 291

Aristoteles 71, 304

Armenini, Giovanni Battista 313

Arne, Thomas Augustine 275

Arria 257, 297

Artemisia 23, 25, 53, 85, 86, 88, 91, 202, 239, 241, 243, 244, 246, 247, 249, 251, 253, 257, 263

Artus 234

Ascanius 277

Astarita, Gennaro 275

Attila 194

Attilius Regulus 278

Augustinus 27, 46, 119, 120, 179

Augustus 26, 65, 149, 154, 162, 164, 250, 253

Auletta, Pietro A. 275

Aurelius Victor 141

Aurisicchio, Antonio 275

Bach, Johann Christoph Friedrich 169

Bach, Johann Sebastian 30

Bandello, Matteo 68, 122

Barberini, Antonio 217

Barberini, Francesco 202

Bathseba 25, 263, 264

Batteux, Charles 269

Beethoven, Ludwig van 301

Bellarmin, Robert 218

Bellori, Giovanni Pietro 218, 253

Berenike 253

Berlioz, Hector 142, 287

Bernasconi, Andrea 275, 278

Bernhard von Clairvaux 39

Bertoni, Ferdinando 278

Biest, Hans van der 246

Boccaccio 24, 42, 43, 44, 62, 66, 67, 78, 79, 82, 83, 84, 100, 104, 105, 106, 107, 109, 110, 116, $121,122,125,140,145,167,169,170,181,235,236,239,240,244,314$

Bodin, Jean 181

Boétie, Etienne de la 181

Bonno, Giuseppe 278 


\section{Personen}

Borghese, Scipione 213

Boroni, Antonio 76, 275

Borromeo, Federico 209

Böttiger, Karl August 296, 301

Bouscal, Guerin du 168

Boyer, Claude 168, 171

Bracciolini, Poggio 181

Bretoni, Ferdinando 275

Brigitta (HI.) 235

Britten, Benjamin 123

Brivio, Giuseppe Ferdinando 278

Brun, Friederike 299

Brutus 52, 118, 121, 123, 125, 136, 166, 167, 168, 169, 170, 171, 174, 175, 176, 192, 256, 312

Busenello, Giovanni Francesco 275, 276, 277, 278, 279, 283

Caesar 65, 79, 139, 145, 151, 161, 166, 168, 170, 171, 192, 234, 237, 246

Caldara, Antonio 76

Calvin, Jean 178

Camilla 241, 243, 244

Camillus 250

Camma 257, 275

Campra, André 287

Capodiferro, Evangelista Maddaleni Fausto di 150, 151

Capua, Rinaldo da 278

Caputi, Antonio 278

Carenna, Jacomo-Antonio 162

Carretto, Galeotto del 69, 71

Casati, Conte 95

Cassandra 276, 277

Cassius 170

Cassius Dio 141

Castiglione, Baldassare 147, 150, 151, 152, 153, 154

Castro, Guillén de 107

Cato 20, 21, 22, 24, 50, 51, 128, 162, 166, 171, 174, 175, 192, 195, 199, 204, 207, 250, 256, 262, $264,278,279,285,312$

Cats, Jacob 75, 331

Cavalieri, Giovanni Battista de 148

Cavalli, Francesco 275, 276, 277, 278, 279

Caylus, Comte de 91

Celoniati, Ignazio 275

Celtis, Conrad 181

Charrière, Madame de 169 
Chateaubriand, François-René de 16

Chiarini, Pietro 275, 278

Chigi-Saraceni 85, 240, 241, 243

Christine de Pizan 106, 107, 116, 167

Ciampi, Vincenzo Legrenzio 275, 278

Cicero 20, 28, 179, 180, 182, 202, 203, 214, 306

Cicognini, Giacinto 273

Cinzio, Giovan Battista Giraldi 70, 107, 142

Claudia Quinta 239, 241, 244, 246

Clemens VII. (Papst) 152

Clemens VIII. (Papst) 209, 210

Cloelia 25, 125, 166, 245, 246, 257

Cocci, Gioacchino 76

Colla, Giuseppe 275

Collatinus 118, 120, 125, 135, 136

Colonna, Giovanni Paolo 150, 287

Coluccio Salutati 119, 121, 305

Coriolan 250

Corneille, Pierre 74, 143, 168, 169, 179, 196, 308, 379

Cornelia 83, 166, 241

Cornelia, Frau des Pompejus 144

Cornelius Nepos 235

Cosimo I. 246

Couperus, Louis 12, 13, 14, 15, 28, 273, 301

Creusa 276

Crispus 253

Cyprian 215

Cyrus 253, 256

d' India, Sigismondo 287

d'Arien, Bernhard Christoph 288

Dante Alighieri 120, 140

Danzi, Franz 275, 291

Daphne 43, 46, 47

David 234, 246, 256, 263

de' Medici, Carlo 202

de' Medici, Caterina 23, 73, 249, 254

de' Cesari, Cesare 142

de' Medici, Giovanni 126, 150, 151

de' Medici, Maria 23, 247, 249, 251, 254

Debora 24, 253, 256, 257

Deipyle 235 
Delamont, Francois Collin 287

Delfino, Giovanni 123

della Mirandola, Pico 148

Demokrit 214, 260, 261

Descartes, René 90

Desmarest, Henry 275

Deukalion 244

Diaghilew, Sergei 144

Diana 300

Diderot, Denis 21, 45, 93

Dinet, Francois 255

Dionysios von Halikarnassos 118

Dolce, Ludovico 45, 107

Douven, Jan Frans 212

Dryden, John 143

Du Bosc, Jacques 24, 25, 137, 163, 173, 234, 254, 255

Du Ryer, Pierre 123

Du Soucy Gerzan, Francois 255

Du Vair, Guillaume 185

Duni, Egidio Romualdo 275, 278

Eichendorff, Joseph von 300

Elektra 289

Eleonora von Toledo 247

Eliezer 301

Elisabeth (HI.) 235

Engel, Johann Jakob 299

Epiktet 190

Erasmus 180

Esther 25, 235, 239, 244, 246, 247, 248, 251, 253

Eunostos von Tanagra 239

Eurydike 32, 97, 264, 266, 273

Farnese, Rinuccio 68

Fauchet, Claude 181

Fausta 253

Félibien, André 45

Feo, Francesco Antonio 76

Ferdinando II. de' Medici 53, 247, 253

Ferradini, Antonio 275, 278

Filleuil, Nicolas 123

Fiorillo, Ignazio 76, 275, 278

Fioroni, Giovanni Andrea 275, 278 
Fischietti, Domenico 76

Fisher, Kitty 165, 299

Flaubert, Gustave 16

Florus 118

Fokin, Michail Michailowitsch 144

Fortuna 276

Francesco Barbaro 122

Francesco da Carrara 237

Franciscus von Assisi 39

Galathea 297

Galba 120

Galla Placidia 248

Galuppi, Baldassare 275, 278

Garnier, Robert 142, 168

Gataker, Thomas 185

Gautier, Théophile 144

Gazzaniga, Giuseppe 275

Gebel, Georg 76

Geibel, Emmanuel 73

Gemmingen, Heinrich von 293

Genlis, Stéphanie-Félicité de 296

Ghiberti, Lorenzo 237

Giacomelli, Geminiano 278

Gilbert, David 287

Gilbert, Gabriel 255

Giraldi, Lilius Gregorius 154

Giustiniani, Benedetto 202

Giustiniani, Vincenzo 52, 202, 203

Goethe, Johann Wolfgang 30, 31, 70, 74, 205, 290, 295, 296, 297

Gottfried von Bouillon 234

Goué, August Siegfried von 292

Goué, Siegfried von 108

Granvelle, Antoine Perrenot de 182

Graupner, Christoph 275

Grave, David Heinrich 283

Grenaille, Francois de 255

Grotius, Hugo 185

Gualdrada 247

Guglielmi, Pietro Allessandro 76

Hamilton, William 295, 297

Hamilton, Lady (Emma Hart) 78, 100, 164, 294, 295, 297, 298, 299, 300, 314 
Händel, Georg Friedrich 143, 278, 285, 286

Hannibal 50, 60, 76, 246

Hardy, Alexandre 107

Hasdrubal 25, 59, 61, 62, 66, 67, 86

Hasse, Johann Adolf 275, 278, 279

Haydn, Joseph 275

Hebe 300

Hegel, Georg Wilhelm Friedrich 45, 46, 47

Heinrich IV. 249

Heinrich von Veldeke 105

Hektor 169, 234, 237, 238

Hekuba 276, 277

Helena 125, 140, 235, 246, 250, 256

Helvidius 182

Hendel-Schütz, Henriette 297, 301

Hengelbrock, Thomas 278

Herakles 26, 112, 183

Heraklit 260, 261

Herder, Johann Gottfried 169, 274

Herkules 237, 246

Hermann der Lahme 37

Hermes 32

Hero 289

Hersilia 162, 245, 247, 250

Heywood, Thomas 123

Hieronymus 119, 167, 180

Hippo 241, 243

Hippolyte 235

Hirt, Alois 298

Hobbes, Thomas 185

Hoepfl, Simon 43, 79

Hoet, Gerard 269

Hoffmann, E.T.A. 78, 300

Holofernes 112, 303

Hompton, David 267

Horatius Cocles 26, 50, 246

Horaz 139, 141

Hoven, Monsieur van 269

Humboldt, Caroline von 299

Huydecoper, Joan 314

Hygeia 300 
Hymen 300

Hypnos 31

Hypsikratea 244

larbas 277

Ignatius von Antiochien 227

Insanguine, Giacomo 275

Iphigenie 289, 297

Iris $111,113,114,116,276$

Isabella d' Este 80, 240, 314

Isabella di Mantua 69

Isabella von Kastilien 257

Jacobaea von Baden 125

Jacobus de Voragine 41

Jacques de Longuyon 234

Jaël 25, 235, 246, 248, 253, 256

Jagemann, Karoline 297

Jeanne d'Arc 253, 257

Jehan Le Fèvre 234

Jenko, Davorin 275

Jodelle, Etienne 107, 142

Johann Wilhelm von der Pfalz 212, 213

Johanna von Österreich 247

Johannes 39

Johannes Chrystostomus 215

Jomelli, Nicola 278

Jommelli, Niccolò 76, 275

Joseph (HI.) 193, 256, 263, 264

Josua $24,234,256$

Judas Makkabäus 234, 246

Judith $25,80,81,85,112,156,163,204,235,239,241,242,244,246,248,251,253,256,257$, $261,263,264,303$

Julia 244

Julitta (HI.) 41

Julius II. (Papst) 38, 147, 148, 150, 151, 153, 154

Julius III. (Papst) 149

Junius, Samuel 123

Juno 72,277

Justinus 103, 105, 106, 108, 110, 115, 116

Kaisarion 139, 268

Kant, Immanuel 185

Karl der Große 234 


\section{Personen}

Karl VI. 26

Kassandra 297

Katharina (HI.) 42, 199

Keiser, Reinhard 123

Klein, Bernhard 275

Klopstock, Friedrich Gottlieb 169

Konstantin 26

Koželuh, Leopold 275

Krauss, Marianne 294

La Grange, Guillaume de 107

Laelius $61,67,77,79$

Lamartine, Alphonse de 16

Lampeto 235

Lampugnani, Giovan Battista 278

Landi, Giulio 142

Laokoon 32, 49, 88, 90, 92, 148, 149

Laurentius (HI.) 42, 212, 215

Le Métel de Boisrobert, François 107

Le Moyne, Pierre 24, 25, 137, 163, 234, 250, 252, 253, 255, 256, 257, 258, 259

Lee, Nathaniel 75

Lenoir-Laroche, Comtesse 310

Leo X. (Papst) 70, 126, 150, 151, 154, 181

Leonidas 309

Leopold Wilhelm, Erzherzog 119

Leopoldo di Toscana 202

Lessing, Gotthold Ephraim 30, 92, 231

Lipsius, Justus 179, 181, 182, 183, 184, 185, 186, 187, 188, 189, 190, 191, 192, 196, 199, 200 , $201,202,214,215,259,271,305,306$

Livia 65

Livius 26, 50, 52, 60, 61, 62, 63, 64, 65, 66, 67, 68, 76, 82, 83, 84, 85, 90, 97, 118, 122, 129, 137, $138,225,311$

Llamosas, Lorenzo de las 108

Lohenstein, Daniel Caspar von 3, 7, 75, 91,142, 179, 194,196, 197, 333, 361

Lomazzo, Giovanni Paolo 43

Lombardo della Seta 236

Lovato Lovati 180

Loyola, Ignatius von 204, 209

Lucretius 136

Ludwig X. 78

Ludwig XIII. 251

Ludwig XIV. 23, 250, 254 
Index

Luise von Hessen-Darmstadt 78

Lukan 140

Luti, Bartolomea 244

Lykurg 246

Macchiavelli, Niccolò 240

Machon, Louis 255

Magdalena (HI.) 210, 216, 218, 219, 220, 221, 230, 297

Mairet, Jean 74,143

Mander, Carel van 260

Manlius Torquatus 50, 246

Manna, Gennaro 278

Mansart, Francois 250

Manzoni, Alessandro 70

Marc Aurel 182

Marcello, Benedetto 285

Marcia 241

Marcus Antonius 250

Marcus Curtius 50, 246

Marcus Valerius Corvinus 246

Maria Magdalena von Österreich, Großherzogin der Toskana 135, 247, 248

Maria Stuart 253, 257

Mariamne 257

Mariette, Pierre-Jean 257

Marino, Giovanni Battista 25, 278

Marlowe, Christopher 107

Mars 65, 118, 140

Marschner, Heinrich 123

Marston, John 75

Martial 166

Massé, Victor 142

Massenet, Jules-Emile-Frédéric 142

Massinissa 59, 60, 61, 62, 63, 64, 65, 66, 67, 68, 69, 71, 72, 76, 77, 78, 79, 83, 84, 85, 89, 90, 92, $95,96,97,98,99,101,225,226,253,269,270,290,291$

Maupoint 142

Maximilian I. 26, 246

Maximilian II. 182

May, Thomas 143

Mazarin, Jules, Cardinal de 87, 202, 254

Mazzoni, Antonio 278

Medea 289

Mei, Eva 285 
Personen

Meilleraye, Duchesse de La 252, 257

Meißner, August Gottlieb 76, 78, 290, 291, 293

Menalippe 235

Merkur 183, 277

Mermet, Claude 73

Metastasio, Pietro 76, 108, 274, 276, 278, 279, 281, 282, 283

Minerva 23, 140, 183, 249, 300

Mirandola, Giovanni Francesco Pico della 154

Mirys, Silvestre David 99, 137

Mithridates 284

Molanus, Johannes 209

Monime 257

Montaigne, Michel de 181, 185

Montchrestien, Antoine de 73

Montéclair, Michel Pignolet de 287

Monteverdi, Claudio 218, 273, 276

Montfleury, Jacob 107

Montioni, Francesco 253

Montreux, Nicolas de 73, 142, 334

Morales, Cristóbal de 108

Moreto y Cabaña, Agustin 108

Moses 98, 246

Mucius Scaevola 51, 304

Muret, Marc Antoine 181

Musonius 182

Mussato, Albertino, 180

Naevius 103

Napoleon I. 16, 310

Narcissus 43, 46

Neefe, Christian Gottlob 76, 78, 291

Neptun 278

Neri, Filippo 64, 65, 120, 209

Nero 52, 53, 120, 182, 194, 213, 214

Nerval 16

Nervèze, Suzanne de 255

Neumann, Johann Leopold 288, 291

Niobe 88, 131, 153, 219, 289, 297

Niobiden 32, 153, 175, 218, 219

Octavia 139

Octavian 139, 142, 145, 164, 168, 171, 267, 268, 291, 292, 299

Oktavian 17, 141 
Ophelia 15

Orpheus 32, 97, 264, 266, 273

Osmida 279, 282

Ottheinrich, Pfalzgraf 235

Ovid 42, 46, 103, 119, 153

Pacheco, Francisco 206

Paer, Ferdinando 77, 273

Paleotti, Gabriele 209, 220

Pamphili, Benedetto 285, 286

Pamphili, Olympia 253

Panthea 253, 257

Paris 237

Pastor, Juan 108

Paul III. (Papst) 149

Paul V. (Papst) 149

Paulina 25, 52, 253, 257

Paulus 180, 210

Pazzi de' Medici 107

Pelagia (HI.) 192

Pels, Andries 114

Penelope 106, 116, 241, 244, 247

Penthesilea 235, 238, 246, 253

Perez, Davide 278

Pergolesi, Giovanni Battista 285

Pero 244

Petrali, Luigi 76

Petrarca 24, 58, 63, 64, 65, 66, 68, 82, 83, 84, 100, 120, 121, 180, 235, 237, 284

Petrucci, Borghese 240

Petrucci, Pandolfo 240

Petrucci, Sulpicia 240

Petrus 37, 210, 223

Piccinni, Nicola 275

Piccolomini 240

Pietrangeli, C. 147,149

Pistorelli, Celso 142

Platon 22, 258

Plinius d. Ä. 140, 304

Plinius der Jüngere 20, 235

Plutarch 73, 139, 142, 166, 167, 169, 255

Pluto 65

Poe, Edgar Allan 14 
Pollarol, Antonio 123

Polyxena 238, 252, 289

Pompeius 50, 53, 83, 279

Ponsard, Francois 123

Poppaea 144

Porpora, Nicola 76, 278

Porsenna 304

Proba Falconia 253

Properz 139, 141

Proserpina 65, 72, 290

Providentia 249

Prudentia 23, 183, 249, 251

Ptolemaios XIII. 139

Ptolemaios XIV. 139

Pückler-Muskau, Hermann von 16

Purcell, Henry 76, 108, 275

Pygmalion 289, 296

Pyramus 83

Pyrrha 244

Pythia 297

Quevedo, Francisco de 185

Quintilian 28

Quiricus (HI.) 41

Rebecca 301

Reifenstein, Johann Friedrich 294

Rhenanus, Beatus 181

Riccoboni, Luigi 76

Richard Löwenherz 37

Richardson, Samuel 231

Richelieu, Armand-Jean I. du Plessis, Cardinal de 173, 252

Robert von Anjou 236, 237

Robespierre 309

Robortello, Francesco 71

Rojas Zorrilla, Francisco de 108

Rollin, Charles 21

Romulus und Remus 250

Rosenberg, Jakob 127

Rossetti, Domenico 77

Rossini, Giachino 301

Rousseau, Jean Jacques 289

Rovere, Francesco Maria I. della 151 
Rovere, Giuliano della 151

Ruffo, Tommaso 131

Rutgers, Anthonie 269

Saba, Königin von 144, 238, 246

Sacchetti, Giulio Kardinal 202

Sachs, Hans 122, 123, 142

Salomon 238, 258

Salomone 256, 257

Salutati, Collucio 180, 302

Samson 237, 246

Santa Croce, Giorgio 68

Santacroce, Maria 133, 272, 299

Sappho 289

Sarpedon 31

Sarro, Domenico Natale 275, 276, 278, 285

Sarti, Giuseppe 278

Scaevola 246

Scalabrini, Paolo 278

Scamozzi, Vincenzo 70

Scarlatti, Alessandro 285

Scarlatti, Domenico 285

Scheibe, Johann Adolph 284

Schiassi, Gaetano Maria 278

Schönborn, Graf Lothar Franz von 98

Schoppe, Kaspar 185

Schütz, Karl-Friedrich Julius 297, 301

Schwanberg, Johann Gottfried 278

Schweitzelsperger, K.K. 123

Scipio 50, 59, 60, 61, 62, 63, 64, 65, 66, 67, 69, 71, 72, 76, 77, 79, 90, 92, 95, 197, 214, 225, 239, $243,246,253,273,303,308,310,311$

Scolari, Giuseppe 278

Scudéry, Georges de 107, 168, 255

Scudéry, Madeleine de 76, 123

Sebastian (HI.) 43, 199, 219

Seckendorff, Gustav Anton von 299

Segni, Bernardo 71

Selene 279

Semiramis 25, 140, 235, 247, 248, 253, 284

Seneca $20,21,22,50,52,53,70,178,179,180,181,182,183,184,185,186,189,190,192$, $194,200,201,202,211,213,214,215,216,227,230,262,264$

Sephora 248 


\section{Personen}

Serre, Jean Puget de la 255

Shaftesbury, Anthony Ashley Cooper Earl of 45

Shakespeare, William 122, 142, 168

Shaw, G.B. 141

Silvani, Fr. 76

Sinope 235

Six, Willem 262, 269

Sokrates 20, 21, 22, 50, 51, 58, 169, 178, 189, 190, 194, 199, 202, 203, 214

Solms, Gräfin 294

Solomon 237

Sophokles 70

Sophronia 192

Soucy, Francois de 75, 255

Sphinx 297

Steffani, Agostino 108

Stein, Charlotte von 108

Steinhöwel, Heinrich 78

Stepney, Lady 165

Stradella, Alessandro 285

Stratonike 253

Sulpicia 239, 244

Susanna 125, 246, 256

Sychaeus 104,115

Synorix 275

Syphax 59, 60, 61, 62, 63, 64, 66, 67, 69, 71, 72, 76, 77, 79, 84, 97, 290

Syre, Cornelia 130

Tacitus 52, 180, 181, 182, 183, 185, 194, 195, 213, 216

Tanaquil 241, 256

Tarquinius 26, 79, 118, 120, 121, 122, 124, 125, 133, 134, 136, 256, 285

Terradellas, Domenico 278

Tertullian 104, 119, 141, 180, 207

Teuta 235

Thanatos 31

Thermutis 253

Theseus 65

Thisbe 43,83

Thomson, James 75

Thomyris 85, 246, 251

Thrasea Paetus 182

Tiberius Gracchus 239

Timokleia 98 
Index

Tollens, Hendrik 123

Tomasi, Giovanni Battista 123

Tomasi, Guiseppe Maria 76

Tomyris 25, 235, 256

Traetta, Tommaso 76, 77, 78, 275, 278

Trajan 26, 148

Trissino, Gian Giorgio 70, 71, 72, 77, 98, 101

Trousset, Alexis 254, 256

Tuccia 80, 241, 244, 246, 253

Turnus 64

Valerius Maximus 24, 26, 65, 84, 119, 121, 166, 235, 244, 256, 304, 306, 311

Valier, Lucrezia 129

Van den Vondel, Joost 194

Van Mander, Karel 45

Vega, Gabriel Lobo Lassso de la 108

Velleius Paterculus 139

Venturi, Alessandro 244

Venturi, Palazzo 243

Venus $65,98,126,127,128,130,134,140,148,149,219,253,276$

Vergil $64,65,103,104,105,107,116,117,140,141,148,179,277,279$

Vesta 300

Veturia 235, 246

Vieillard, Pierre-Ange 287

Villegas, Francisco de 107

Vinci, Leonardo 276, 278, 281, 283

Virginia 52, 53, 125, 235, 246, 275, 297

Virués, Cristóbal de 108

Voltaire $74,75,168,228,344$

Vos, Jan 313

Vrillière,Louis Phélypeaux de la 162. 250

Vulkan 98

Walpole, Horace 297

Weise, Christian 204

Wetzel, Johann Carl 291

Wilhelm IV.,Herzog von Bayern 125, 235, 246

Wilhelm VIII. von Hessen-Kassel 233, 269

Winckelmann, Johann Joachim 44, 45, 148, 175

Wolter, Charlotte 16

Woverius, Johannes 182

Zanetti, Antonio Maria 76

Zenobia 257 
Personen

Zesen, Philipp von 75, 336

Zeuxis 243

Zipoli, Domenico 287 


\section{Forschung}

Abel, Günter 179, 181

Abert, Anna Amalie 273

Agosti, B. 202

Agosti, Giovanni 240

Alewyn, Richard 195

Alexander, Peter 122

Allen, Brian 296

Alt, Peter-André 75

Ameling, Walter 207

Andrae, August 69

Andreae, B. 147

Anton, Hans 258

Antonini, Giovanni 286

Appuhn, Horst 205, 206

Ariani, Marco 70, 71

Ariès, Philippe 36, 37, 194

Asch, Ronald 258, 287

Assmann, Aleida 261

Assmann, Jan 49, 306

Aurenhammer, Hans 205

Austin, John L. 289

Axelrad, Albert-José 73, 338

Bailey, C. 49

Baker, Christopher 80, 109

Baldriga, Irene 202, 203

Ballon, Hillary 252

Bamberg, Eduard von 283, 297

Barner, Wilfried 75, 179

Barocchi, Paola 210, 220

Barone, G. 41

Bartoli, Lorenzo 237

Bartsch, Adam 79, 127

Baskins, Cristelle 109

Bassani Pacht, Paola 249

Bastet, Frédéric 13

Baudouin, Frans 212 


\section{Forschung}

Baumgärtel, Bettina 23, 24, 25, 57, 116, 164, 235, 249, 250, 251, 254, 255, 265, 296, 300, 301

Bäumler, S. 235

Beer, Manuela 206

Belkin Lohse, Kristin 180, 203

Bellange, Jacques 172

Belting, Hans 206, 221, 231

Bénichou, Paul 179

Berhout, Marieke 58

Berliner, Rudolf 205

Bernier, Marc André 93

Bertling, Claudia 206

Beuth, Karl 184

Beyer, Andreas 71

Biadene, Susanna 213

Bialostocki, Jan 84

Bianchi, E. 64, 65

Bianconi, Lorenzo 274, 281

Bignamini, llaria 296

Bizoni, B. 202

Blank-Sangmeister, Ursula 26, 166

Blasiis, Giuseppe de 237

Bloch, Ernst 30, 44

Blumenberg, Hans 49, 307

Bode, Wilhelm von 123

Bohde, Daniela 53

Bonnefoy, Yves 142

Bonnet, Anne-Marie 247, 249

Borea, Evelina 219, 253

Borst, Arno 33, 36, 37

Bott, Gerhard 98

Bott, Katharina 98

Boudouin-Matuszek, Marie-Noëlle 249

Braham, Allan 80

Brambach, Joachim 141

Branca, Vittore 66, 105, 121, 167

Brandenburg, Gottfried Daniel 285

Brassat, Wolfgang 93

Bredius, Abraham 314

Breitenberg, Mark 122

Brejon de Lavergnée, Arnauld 310

Briesemeister, Dietrich 33 
Index

Brockhoff, E. 235

Brodersen, Kai 62

Brognoligo, Gioachino 68

Bronfen, Elisabeth 14

Broska, Matthias 78

Brummer, Hans Henrik 147, 148, 149, 150, 151, 154

Brunelli, Bruno 274, 279

Brunhölzl, Franz 82

Bruyn, J. 91

Brzoska, Matthias 77, 273

Buck, August 212

Budde, H. 16

Bull, Duncan 92

Burck, Erich 60, 342

Burckhardt, Jacob 47, 204, 221

Burdach, Konrad 180

Burdorf, Dieter 296

Burschel, Peter 177, 207, 224, 227

Busch, Werner 301

Butler, Judith 289

Büttner, Frank O. 206, 231

Büttner, Nils 213

Calzavara, Barbara 158

Campenhausen, Hans Freiherr von 227

Caroselli, Susan 217

Caroto, Giovanni Francesco 81

Casali Pedrielli, Cristina 221

Cavazzini, Patrizia 156

Chennevières, Ph. 257

Chesnutt, Michael 305

Chiamò, Maria 228

Christiansen, Keith 80, 156, 222, 223

Ciampolini, Ermanno 70

Clauss, Manfred 139, 141

Clemens VII. 152

Cola, Alberto 217

Cortenova, Giorgio 218

Courcelles, Pierre 179

Crépin-Leblond,Thierry 249

Curtius, Ernst Robert 312

Dahlhaus, Carl 77, 78, 274, 281, 290 
Daxelmüller, Christoph 28, 305

de Poorter, N. 162

Dédéyan, Charles 74

Dehio, Georg 205

Delumeau, Jean 228

Demmer, Sybille 289

Denzinger, Heinrich 208

Deswarte-Rosa, Sylvie 149

DeVoto, James 166

D'Hulst, Roger-Adolf 162, 267, 268

Dibbits, Taco 92

Diers, Michael 296

Dinzelbacher, P. 34

Distelberger, Rudolf 83

Donaldson, Ian 119

Doppler, Elke 16, 141

Dorsch, T. S. 168

Drach, Allard von 269

Dubois, Isabelle 250

Düchting, Reinhard 82

Ebert-Schifferer, S. 25, 86, 87, 88, 219

Egger, Irmgard 296

Eisen, Margret 285

Eisen, Walter 285

Eisenhut, W. 104

Elias, Norbert 185

Ellenius, Allan 258

Ember, Ildikó 233

Emich, Birgit 287

Emiliani, A. 25

Engel, Hans 284, 285

Erfen, I. 106

Erichsen, Johannes 128

Etter, Else-Lilly 180, 187

Evans, Robert C. 179

Evers, Hans Gerhard 214

Fajen, Robert 235

Farinella, Vicenzo 240

Fehrle, Rudolf 166

Feichtinger, Barbara 107

Feist, Dagmar 258, 287 
Feldmann, Dorothee 98

Fellsches, Josef 307

Ferrari Schiefer, Valeria 254

Ferroni, Giulio 282

Festa, Nicola 64,120

Feulner, A. 40

Fink, Hanns-Peter 200

Fleckner, Uwe 29, 43, 207

Fleischhauer, Günter 218

Flemming, J. 48

Floerke, Hanns 68, 260

Foerst-Crato, llse 299

Fögen, Marie Theres 52, 137

Follak, Jan 119, 120, 121, 122, 124, 126, 127, 130

Frappier, Jean 105

Freedberg, David 210

Frenzel, Elisabeth 58, 107

Frey, Hermann-Walther 247

Fricker, Harald 288, 361

Friedländer, Max 127, 205

Frodl, Gerbert 15, 16

Fuhrmann, Manfred 26

Fumaroli, Marc 208, 249, 307

Gaehtgens, Barbara 23, 29, 43, 249

Gaehtgens, Thomas W. 207

Gagnebin, Bernard 289

Galinsky, Hans 119, 120

Garrard, Mary D. 23, 44, 125, 127, 255

Gathercole, Patricia 109

Gavazza, E. 50

Geddo, Cristina 245

Gemin, Massimo 225

Georges, Karl Ernst 304

Gerhard, Anselm 274, 278, 279, 280

Giegling, Franz 285

Gier, Albert 273, 281

Goetz, Oswald 126

Golahny, Amy 91

Goldberg, Gisela 128, 263

Goldfarb, Hilliard 250

Gombrich, Ernst 148, 154 
Gomille, M. 261

Göpfert, Herbert 30, 93

Gottdang, Andrea 282

Götte, Johannes von 104

Göttler, Christine 215

Graesse, Th. 217

Graevenitz, G. von 33

Graziani, Françoise 249

Gregoli-Russo, Mauda 69, 70

Gregoli-Russo. Mauda

Gregory, Brad Stephen 207

Grimm, Claus 128

Grimm, Reinhold R. 105

Grunchec, Philippe 22

Guillaume, Jean 147

Gundel, H. 53

Günther, Erika 17

Günther, Heinz 86

Guthmüller, Bodo 122

Hagen, Bettina 175

Halbwachs, Maurice 304

Hamilton, C. A. 49

Hankamer, Paul 194

Hanley, Edwin 285

Hansmann, Martina 236, 238, 239

Harms, Wolfgang 93

Harris, Dale 144

Hartmann, Horst 122

Haskell, Francis 225

Haug, Walter 75, 305

Haverkamp, Anselm 312

Healy, Fiona 180, 203, 214

Heinen, Ulrich 93, 213, 214

Heinrich, Christoph 233

Heinz, Dora 161

Heinz, Günther 119

Heinz, Marianne 13

Held, Jutta 229

Hellwig, Karin 206

Henker, M. 235

Henning, A. 48, 57, 86, 217, 315 
Henry, Tom 80, 109

Herzog, Erich 269

Herzog, Reinhart 47

Hess, Günter 213, 214, 216

Heublein, Brigitte 193

Heyse, E. 33

Hibbard, H. 220

Higgs, Peter 142, 144, 165

Hirschfelder, Dagmar 221

Hofmann, Werner 18, 98

Holenstein-Weidmann, Pia 123

Höper, Corinna 110, 126, 147, 150

Hoppe, Ilaria 247, 248

Hortschansky, Klaus 77, 274, 278, 284

Hucke, Helmut 284

Hughes, Graham 124

Hughes-Hallett, Lucy 141

Imorde, Joseph 209, 210

Ittershagen, Ulrike 164, 296, 297, 298

Jacoby, Joachim 114

Jaffé, Michael 130

Jakoby, Richard 284, 285

Janitschek, Hubert 29, 150, 151

Janke, Pia 276

Jiránek, Jaroslav 294

Jolles, André 304

Jooss, Birgit 296, 301

Joost-Gaugier, Christiane 236, 237, 238

Jouin, Henry 90

Julhiet, C. 51

Jung, C. G. 312

Kaemmerling, E. 84

Kailuweit, Thomas 107

Kassel, Rudolf 216

Kaster, Gabriela 193

Kaufmann, Sylke 297

Kecks, Ronald 206

Kern, Manfred 216

Kerspern, Sylvain 174, 252

Kimbell, David 276

Kindler, Simone 15 
Kirchner, Thomas 90

Klein, Dorothee 205

Klein, J. 305

Klessmann, Rüdiger 234

Kliemann, Julian 243, 244

Knox, George 98

Knüpfer, Nikolaus 91

Koch, Heinrich Christoph 290

Koch, Klaus-Dietrich 273, 275, 278, 279

Kohl, Karl-Heinz 16

Kolsky, Stephen 106

Kord, Susanne 108

Koschatzky, Walter 78

Koselleck, R. 26, 28, 305, 306

Kris, E. 83

Krones, Hartmut 284

Kunze, Max 148

Kurz, Otto 220

Küster, Ulrike 288

Lachmann, Renate 308, 312

Laggner, Brigitte 61

Landfester, Rüdiger 305

Lang, Walther 94, 161, 204, 224, 228

Langen, August 296, 301

Lattuada, Riccardo 156

Laveissière, Sylvain 250

Le Foll, Joséphine 223, 225

Lebègue, R. 168

Lefèvre, Eckard 82

Lehmann, Jürgen 58, 269

Leithe-Jasper, Manfred 83

Lemaire, Gerard-George 16

Lentzen, M. 122

Leube, Eberhard 107

Levey, Michael 95

Lindinger, Michaela 141

Loraux, Nicole 137

Louvat, Bénédicte 74, 143

Luna, Juan J. 113

Maber, Richard G. 257

Maclean, Ian 251, 254, 255, 257, 258, 259 
Mai, Ekkehard 19, 50, 233, 269, 303

Mâle, Emile 210, 218, 227

Mann, Judith 156

Marquard, Odo 48

Martellotti, G. 64, 65

Martineau, Jane 80

Mathes, Melissa 137

Matsche, Franz 26

Maurens, Jacques 179

Maurer, Karl 70, 74, 75

Mayo, John S. M. 285

Mayr-Oehring, Erika 16, 141

Mazza, Angelo 230

McGrath, Elizabeth 215

Mégevand, M.-Ch. 51

Meid, Volker 75

Mérot, Alain 51

Mikuda-Hüttel, Barbara 193, 194

Millen, Ronald Forsyth 249

Miltner, Franz 166

Minges, Klaus 98, 260

Misciatell, Pieroi 243

Moiso-Diekamp, Cornelia 233, 259, 260, 261, 262, 267

Mojana, Marina 53

Mommsen, Theodor E. 237

Montagu, Jennifer 90

Montaiglon, A. 257

Moos, Peter von 26

Morehead, Allison 81, 143, 145, 238

Morford, Mark 183

Müller Hofstede, J. 130

Muller, Jeffrey M. 180, 203, 214

Müller, Th. 40

Muthmann, Fritz 294

Neri, F. 64, 65, 120

Neumann, Wolfgang 33

Neysters, Silvia 23, 57, 235

North, Michael 212

Oberreuter-Kronabel, Gabriele 20, 21, 22, 50, 51, 52

Oestreich, Gerhard 179, 181, 182, 183, 185

Olshausen, Eckart 82 


\section{Forschung}

Ost, Hans 130

Osthoff, Wolfgang 276

Ott, Norbert 234

Otto, Gertrud 217, 223

Paarlberg, Sander 233

Pacaud, Michel 169

Pace, Valentino 33, 39, 41

Pallucchini, Anna 95, 223, 225

Pallucchini, Rodolfo 98

Panofsky, Erwin 37, 38, 205

Patschovsky, Alexander 33

Paulsen, Friedrich 200

Pedrocco, Filippo 225

Pelling, Christopher 142

Pepper, Stephen 55, 86, 87, 88, 202, 216, 217, 218, 219, 263

Pestelli, Giorgio 274, 281

Petermann, Erwin 259

Petzold, Martin 30

Philipe, Julien 90

Pieri, Marzio 25

Pigler, Andor 52, 58, 83, 91, 109, 136, 160, 161, 170, 171

Piovene, Guido 95

Planiscig, L. 83

Plume, Cornelia 179

Prinz, Wolfram 236

Prohaska, Wolfgang 25, 303

Raffy, Jean-Louis 228

Ranke, Kurt 305

Rasch, Wolfdietrich 300

Raupp, Hans-Joachim 221

Rave, August 98

Raymond, Marcel 289

Regenbogen, Otto 180

Repp-Eckert, Anke 19, 50, 303

Restle, M. 36

Richard-Jamet, Céline 81, 85, 145, 162, 163, 235, 237, 238, 239, 240, 241, 242, 243, 246, 249, $250,251,252,253,254$

Richter, Karl 31

Richter, L. 230

Riedlbauer, Jörg 77

Riegl, Alois 88 
Rieks, Rudolf 82

Riffaud, Alain 74, 143

Ringbom, Sixten 205

Rippl, G. 261

Ritschard, Claude 81, 143, 145, 238

Roeck, Bernd 221

Rohlmann, Michael 243

Romanelli, Giandomenico 161

Ronconi, A. 20, 178, 195

Rosa, Alberto Asor 68, 69

Roscoe, William 126

Rosenberg, Jakob 127

Rosenblum, Robert 312

Rosenfeld, Hellmut 33, 34

Rossi, Luciano 65

Roux, Marie 168, 169

Roy, Alain 26, 50, 114, 267, 268

Ruf, Wolfgang 218

Sabatier, Gérard 258

Safarik, Eduard A. 218

Sainte Fare Garnot, Nicolas 249

Salvagni, Anna 217

Sandkühler, Hans Jörg 307

Santoro, Fiorella Sricchia 241

Sapegno, N. 64, 65

Saward, Susan 249

Scaglietti Kelescian, Daniela 161, 323

Scarlini, Attilia 303, 304

Schade, Karl 205

Schauer, Hans 169

Schawe, Martin 126, 127, 128, 262

Schellewald, Barbara 247, 249

Scherbaum, Anna 128

Schimpf, Wolfgang 288, 289, 292, 293

Schings, Hans-Jürgen 179

Schlaeger, Jürgen 231

Schleier, E. 26

Schlink, Wilhelm 84

Schloder, M. John E. 85

Schlumbohm, Christa 24

Schmidt, G. 53 
Schmidt, Peter Lebrecht 53

Schmidt, Paul Gerhard 107

Schmidt-Linsenhoff, Viktoria 131, 158

Schmieder, D. 290

Schmierer, Elisabeth 277, 279

Schmitt, Charles B. 148

Schmitt, P. 106

Schmitz, Eugen 284, 285, 289

Schnackenburg, Bernhard 162

Schnapper, A. 309

Schneede, Uwe 233

Schneemann, Peter Johannes 28

Schnell, Rüdiger 105

Schöler-Beinhauer, Monica 105

Schöne, Albrecht 84, 205

Schrammek, Bernhard 218

Schreiber, Ulrich 283

Schreiner, Klaus 36

Schröder, Klaus Albrecht 128

Schroeder, Horst 235

Schubring, Paul 83, 123, 124, 170

Schultze, Walther-Siegmund 285

Schulz, H.-J. 36

Schulze, Hendrik 277

Schumacher, Fritz 15

Schuster, Eva 35

Schwartz, G. 127, 314

Schwarz, Monika 78, 290

Schweickard, Wolfgang 296

Sciré, G. 50

Scolaro, Francesca 217

Scolaro, Michaela 217

Sedlacek, Ingrid 235

Seeger, Horst 273

Seidel, Martin 209, 219

Serbelj, Ferdinand 264

Settis, Salvatore 49

Siegmund, Bert 218

Sievernich, G. 16

Simson, Otto von 214

Skemp, Mary 107, 167 
Slenczka, Ruth 206

Smith, Lacey Baldwin 207

Solinas, Francesco 249

Sperlich, Martin 84

Spezzaferro, Luigi 158

Spies, Werner 130

Spinosa, Nicola 263

Sponza, Sandro 213

Squarr, Christel 223

Squarzina, Danesi Silvia 52, 202, 203

Stackelberg, Jürgen von 181

Stähelin 139

Stechow, Wolfgang 126

Steinemann, Holger 210

Steingräber, Erich 263

Stempel, W. 26, 305

Sternath, Marie Luise 128

Stieger, Franz 143, 274

Stierle, K. 33, 47, 48, 231, 305

Stillers, Rainer 71

Stone jr, Donald 73, 142

Strohm, Reinhard 281

Suida, Wilhelm 131

Sulzer, Johann Georg 45, 164

Sumowski, Werner 113

Suphan, Bernhard 169

Syndram, Karl Ulrich 16

Syre, Cornelia 130

Szarota, Elida Maria 194

Tasch, Stephanie Goda 300

Tauber, Christine 221

Terminello, G. 50

Thiébaut, Dominique 310

Thielemann, Andreas 93, 214

Thieme, U. / Becker, F. 15

Thuillier, Jacques 113, 249, 251

Thürlemann, Felix 261

Tischendorf, Konstantin von 36

Tönnesmann, Andreas 249

Trenaux, Jean-Claude 168

Trillhaas, Wolfgang 204 
Trnek, Renate 52

Tuck, Richard 185

Tümpel, Christian 84, 85, 90

Ubl, Ralph 217

Unverfehrt, Gerd 55

Uppenkamp, Bettina 124

Valentin, Jean-Marie 228

Van der Meulen, Marjon 213

Vandelli, Giuseppe 120

Vandenven, M. 162

Veh, Otto 62

Verspohl, Franz-Joachim 151

Viereck, Paul 166

Vlieghe, Hans 212

Vöhler, Martin 288

Volkmann, Hans 58, 59, 139

Vollmer, Hans 15, 18

Vuillermoz, Marc 74, 143

Wachinger, Burghart 305

Walker, Susan 142, 144, 165

Walthaus, Rina 107

Warning, Rainer 47, 48, 75, 231

Warnke, Martin 221

Weber, G. 48, 57, 86

Weber, Gregor 217, 233, 315

Weisbach, Werner 261

Weise, Georg 217, 223

Willems, Gottfried 79, 84

Wilton, Andrew 296

Wimböck, Gabriele 218

Winner, M. 147, 149

Wolf, Robert Erich 249

Wölfel, Kurt 93

Wolfzettel, Friedrich 16

Worstbrock, Franz 82

Zangheri, Luigi 247

Ziegler, Hendrik 250

Zimmer, F. 49

Zimmermann, Margarete 107, 167

Zschoch, Frieder 218 